$6.3 \quad-6$

(20):12. (n)

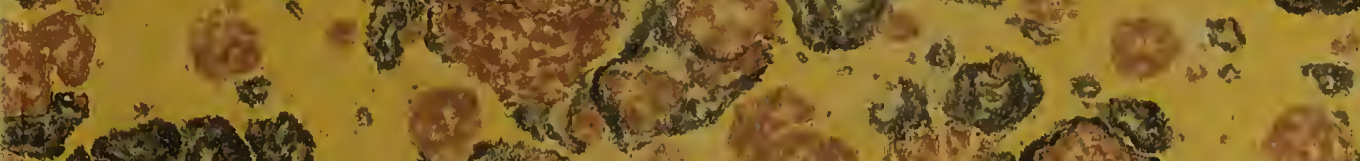

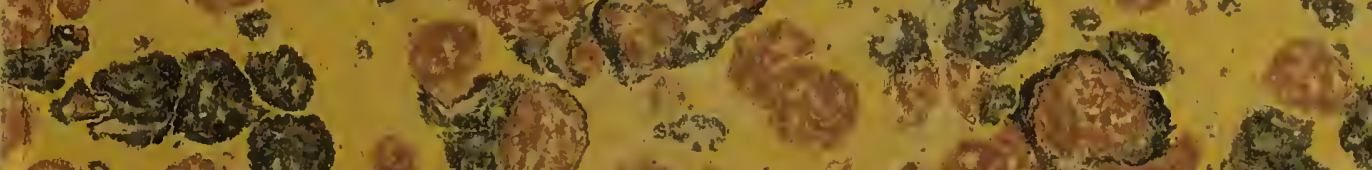

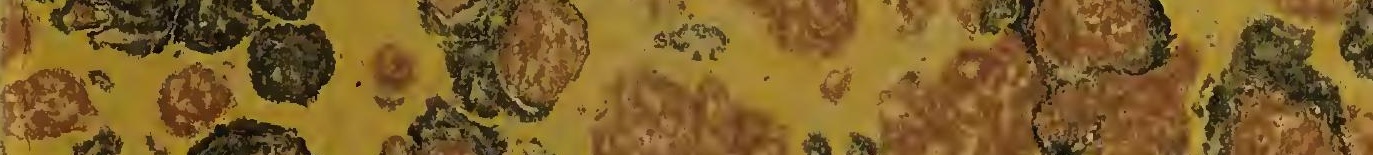

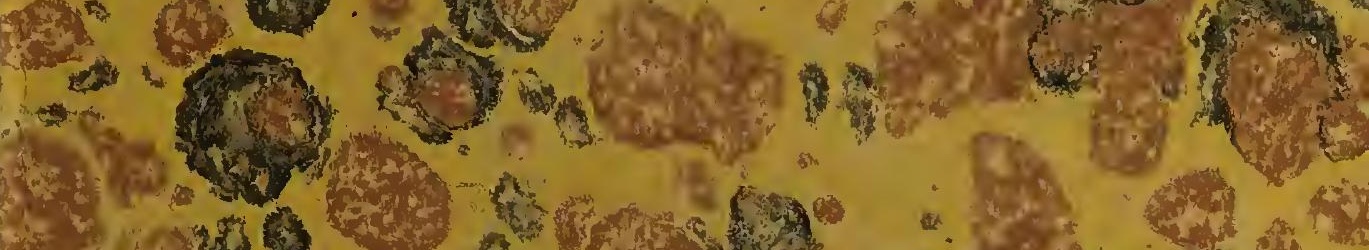

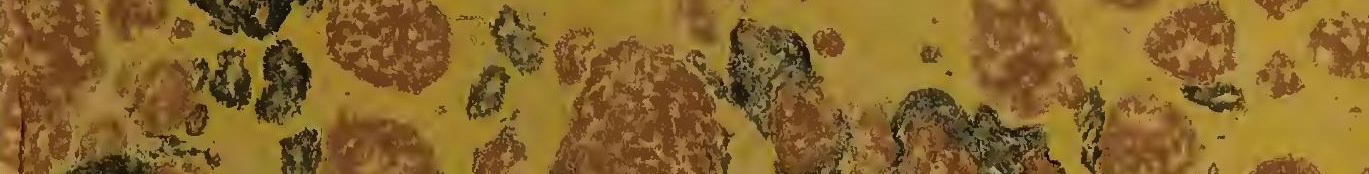

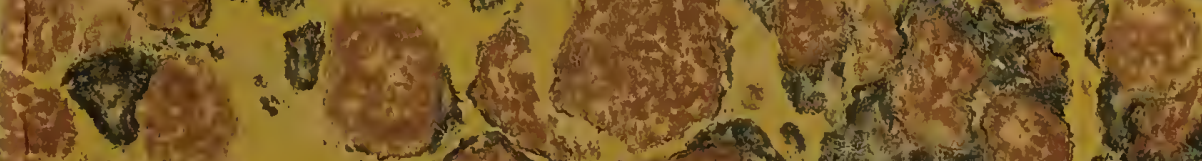
V.j.

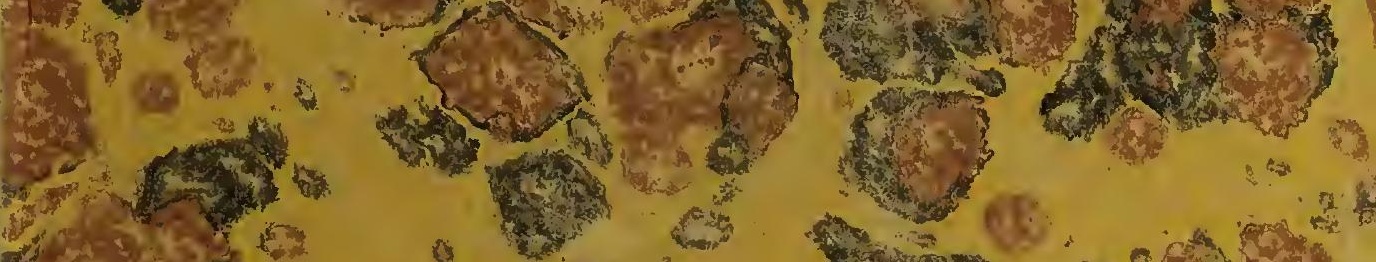

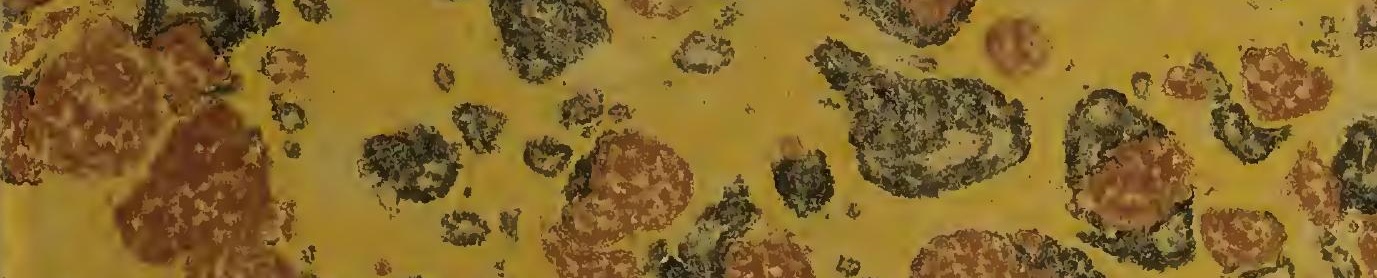
. 5 of a d ond as

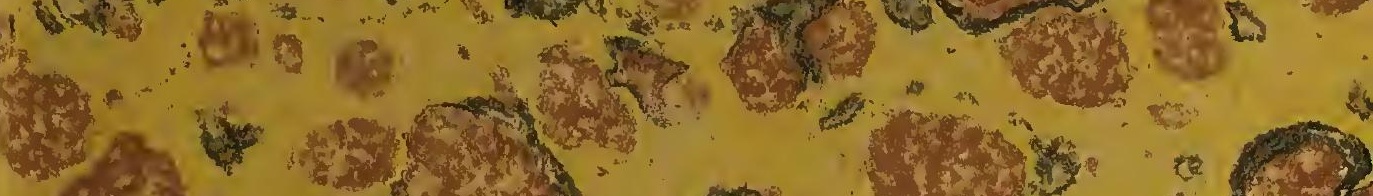

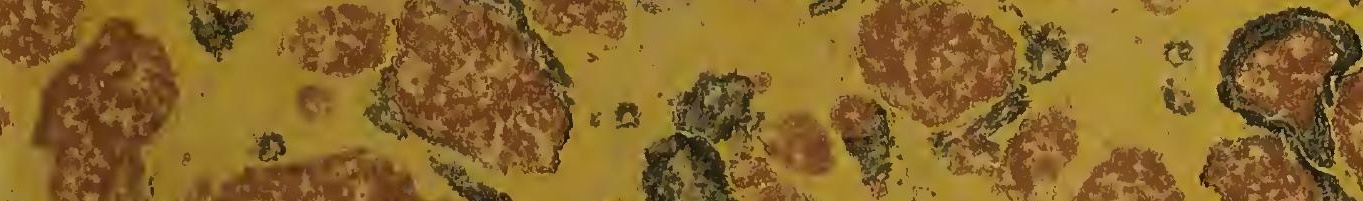

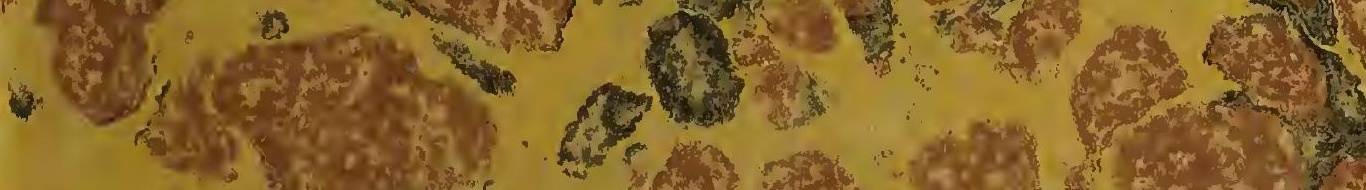
Q

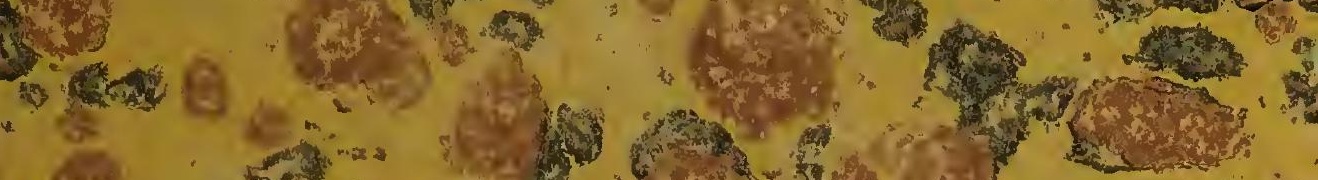
2.

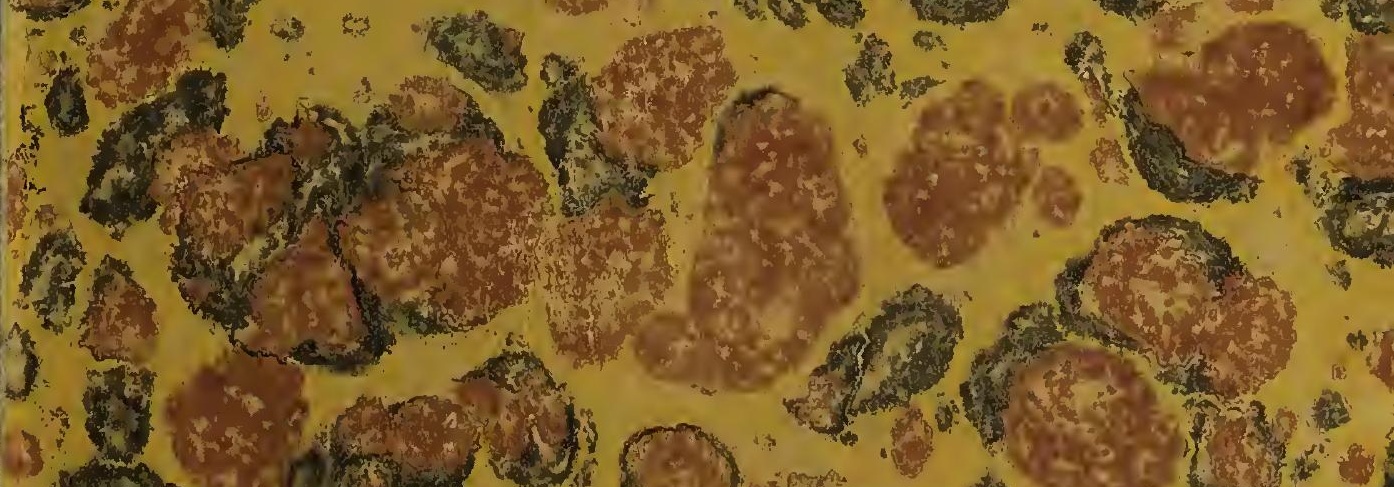

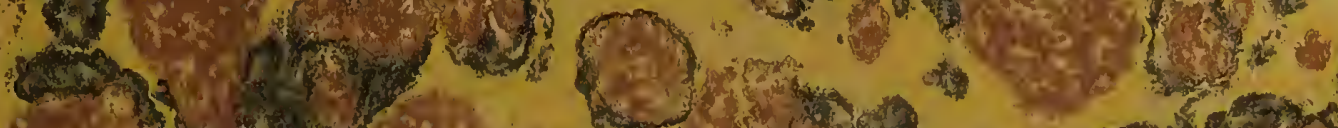

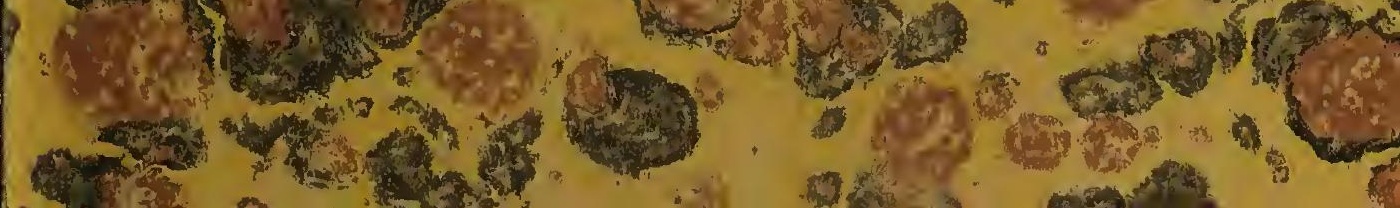


MICHAEL GRAVES-JOHNSTON Bookseller

P.O. Box 532, LONDON SW9 ODR 
等 






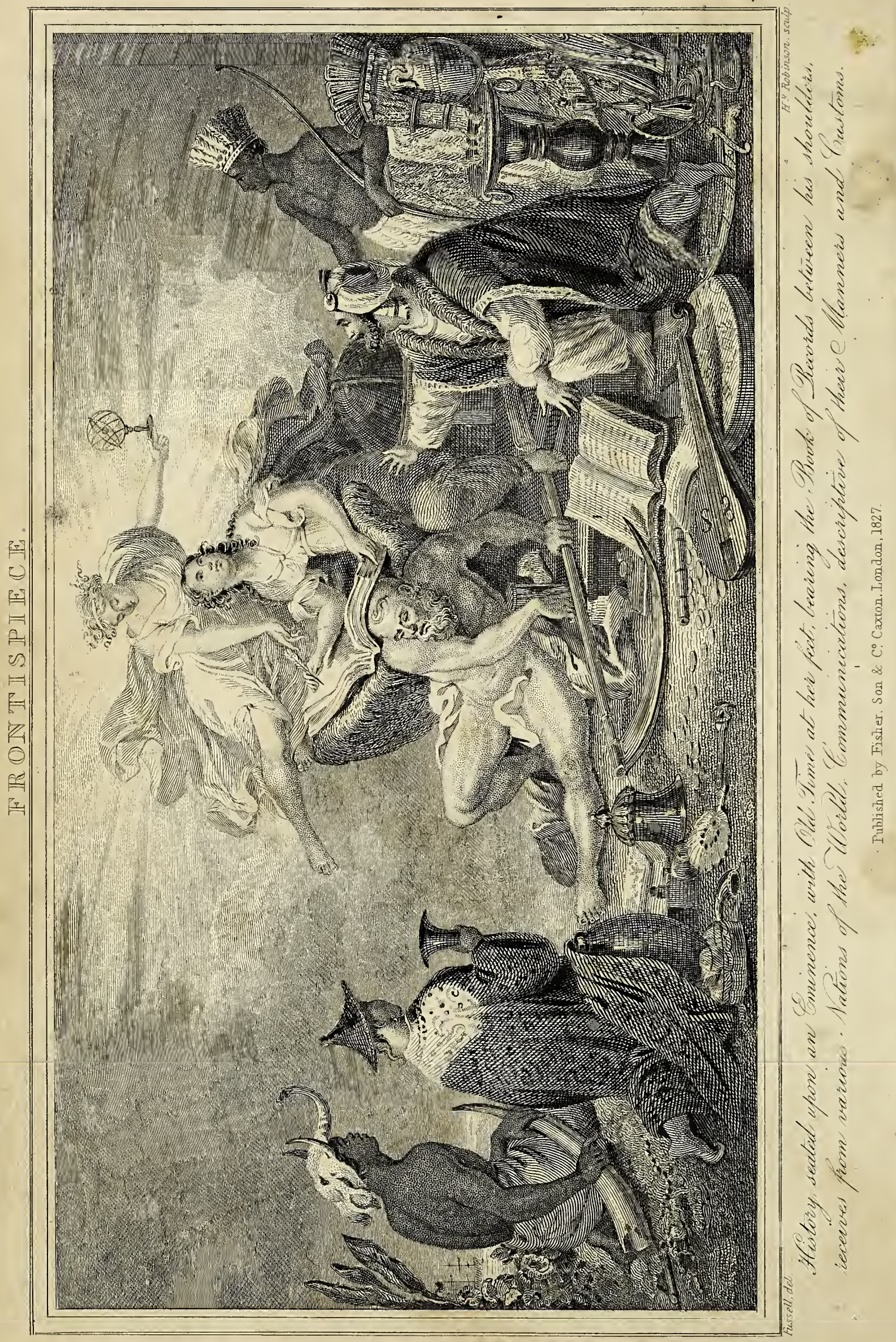




\section{MANNERS AND CUSTOMS}

OF

ALI NATIONS:

ALSO,

REMARKABLE BIOGRAPHIES, NOTABLE HISTORIES, ÉCCENTRIC SECTS, SINGULAR INVENTIONS,
NATURAL CURIOSITIES, MYSTICAL SCIENCES, EXTRAORDINARY BUILDINGS, WONDFRFUX ANIMALS, - -\&c.

BEING A

COMPENDIUM OF UNIVERSAL INFORMATION, Jellustrated with Eengrabings.

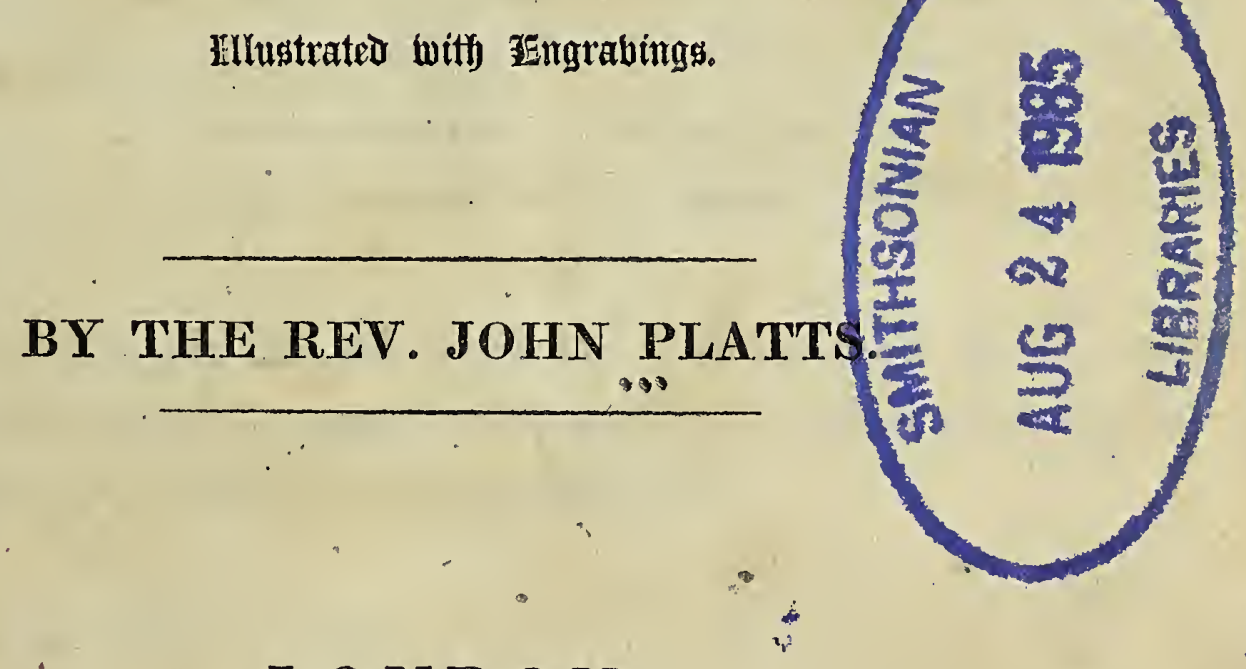

\section{O N D O N :}

PRINTED FOR HENRY FISHER, SON, AND CO. 38, NEWGATE-STREET. 


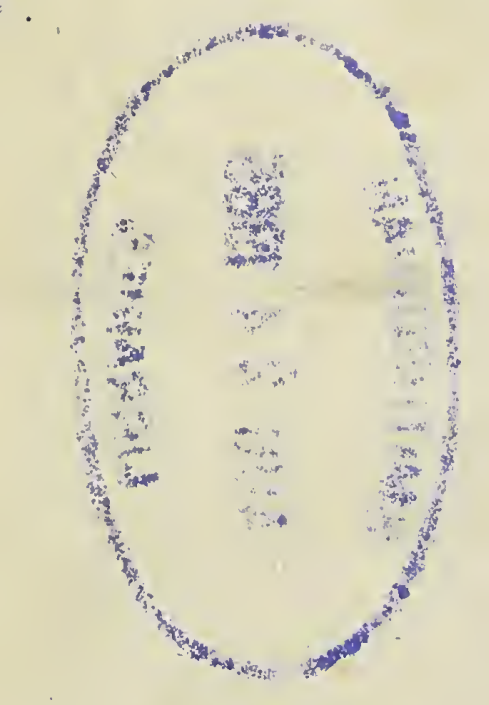


The writer presunes that the following work requires no apology; it claims a place in that class of publications, the value of which is indisputable, and on which the public has stamped its seal of approbation. The present volume, though complete in itself, may form a suirable companion to the writer's Book of Curiosities; it has been carefully compiled from standard books, and works of authority, and is also interspersed with shoice extracts from the periodical and fioat ing literature of the day. It is in truth a new compilation; though it is not improbable that some of the articles may be found among other collections; but on this point the author is incompetent to decide, having compiled for himself, without reference to the collections of others.

The writer has throughout the work endeavoured to maintain an originality in his extracts; on this account he has passed over many things which are generally included in works of this nature. In proof of these assertions, he need only refer the reader to the ": Remarkable Biographies," where he will find that the characters introduced are not generally those that have been exhibited under the term Eccentric Biography, but are principaliy a new selection.

The extracts in this volume are brought forward without any formality of disquisition, of which the writer did not see the necessity; but a sort of order is nevertheless observed in the arrangement of the whole, which, if it be not visibly marked, will be obvious to every judicious, abserver.

The compiler trusts that the work will fully answer to its title; and that it will not only be esteemed a Compendium of Information, but also of Amusement, by readers of every description.

Doncaster, May 18, 1827. 
PARt I. Manners and Customs of all Nations, .............. PAGE 9

.. II. Remarkable Biography, \&c.............................

.. III. Notable Histories, .............................459

.. IV. Eccentric Sects, \&c, ......................... . . . . . .

.. V. Singular Inventions, \&c. ...........................

.. VI. Natural Cúriosities, \&c. ........................ 595

.. VIr. Mystical Sciences, \&c. ........................665

.. VIII. Extraordinary Buildings, \&c......................692

.. IX. Wonderful Animals, Insects, Trees, \&c...................727

.. X. Miscellaneous Articles of Curiosity, ................... 784

\section{INDEX.}

ABARIS, the Hyperborean, 301

Aldals, Eastern saints, 562

Abiponians, a tribe of American Indians, 88 Abdalonymus, 302

Abjuration, an ancient English custom, 298 $\Lambda$ belard and Eloisa, the true story of, 496 Abstinence from food, 524 .

Abracadabra, a Syrian god, 539

Abyssinian least, 230

Acridophagi, or locust-eaters of Ethiopia, 159

Adam, legendary acconnt of, 439

Adams, Jack, the astrologer, 361

Adamites, a sect of ancient herefics, 549

Adoration of the Hindoos, mode of, 139

Adrian's wall, 703

Adultery, punisliments of, 298

Aerostation, history of, 448

Eina, a buruing mountain of Sicily, 635

Aitites, or eagle stone, $\mathbf{6 1 1}$

Agouti, an American animal, 736

Albinos, as described by the Portuguese, 112

Aleppo, climate, religion, and customs of, 93

Algerines, account of the, 45

Algonquins, a nation of N. America, 163

Alibamons, a tribe of Indians, 190

All-fools' day, 249

All-hallow even, or nut-crack niglst, 252

Alarof, the Mahometan partition wall, 554

Alme, or alına, dancing girls, 272

Alphabetical characters, combinations of, 799

Alps, a range of mountains, 624

Ale xand rian library, 708

A mazolis, an account of the, 146

Amboyna, custoins, religion, \&c. in, 56

Americans, customs, dress, \&c. of the, 76

Anerica, probable manner of first peopleing, 87

Amulots, 680

Angoy, a kingdom of Africa, 167

Anossi, a province of Madagascar, 189

Ansarians, a people of Syria, 144

Ansikans, inbabitants of Africa, 128

Anthropophagi, or man-eaters, 73
Antiquity of the world, 445

extravagant claims to, 445

Antipodes, 478

Anachorets, or anchorets, 541

Animal magnetisın, 685

Antiquities of Benevento iu I'taly, 694

, at Abydus in Egypt, 696

Ants' eggs, 766

bills, methods of destroying, 768

Aormas, a high rock in India, 622

Apparitions, remarks on, 682

Appellations, corrupted, 786

Arabians, manners and customs of the, 120

Arimanius, the evil god of the Persians, 53.5

Armenians, religion of the, $\mathbf{5 4 3}$

Aranjuez, palace of, 718

Ashantees, inanners and customs of the, 18

Asyla of altars and temples, 236

Asphyxia, or suspended animation, 515

Astronomical machine, Dr. Long's, 570

Assassins, a sect of Mahometans, 554

Astrology, 671

Athenian girls, description of, 44

Atooi, one of the Sandwich islands, 66

Avalanches, masses of snow, 662

Avars, a tribe of Sarmatian origin, 202

Ausenses, a people of Lybia, 115

Austerlitz, battle of, 514

Angury, 667

Babel, account of the city and tower of, 716

Bagdad, view of society in, 31

Babylonians, peculiar customs of the, 65

Barcans, of Africa, account of the, 32

Balinese, manners and customs of the, 99

Baptism of ships, 235

Bachelors, laws respecting, 291

Bakers, history of, 447

Balbec, ruins of, 806

Ballad-singers, English, 474

Barbarity in Virgieia, 466

Balloons, 448

Banian tree, 783

Battles, 500, 512, 514

Bangorian controversy, history of the, 563

Baltering-ram, and ancient arms, 572 
Bex?s, 574

Bebmen, Jacob, the Teutonic philosopher, 322

Bells, antiquity of, 253

- superstilious uses of, 256

Belamites, or thunder-bolts, 612

Beltan,superstitious custom in Scotland, 248

Beguins, a congregation of nuns, 546

Bacon fossil in Devonshire, 616

Bargarron noted for fine thread, 719

Ben-Nevis, a mountain of Scotland, 623

Belomancy, divination by arrows, 691

Bengal, extraordinary phenomenon in, 711

Biscayers, distinct people from the Spaniards, 69

Bissaons inhabitants of an African island, 163

Birth-day, 277

Bird-catching, Italian method of, 471

Blood, colonel, 353

Black-hole prison, Calcutta, catastrophe at, 498

Blenheim, battle of, 512

Blind lady, extraordinary case of a, 518

Blood, force of the, 585 transfinsion of, 586

Blood-hound, 742

Black hares, 739

Boat for ascending rapids in rirers, 579

Bockboldt, or Boccold, John, 306

Bog, a moving one in Irelasd, 605

Bombay, curiosities of, 697

Bonzes of China, 537

Bouk-worms, antidotes ayainst, 801 .

Boshies-men, a species of Hottentots, 128

Booshooanes, a tribe in the N. of Africa, 175

Bottle-conjuror, 465

Bourguignons, or Burgundians, 173

Bourignon, madam, $\mathbf{4 3 5}$

Brunk for correcting scolding women, 576

Brasilian flexible stone, 615

Brides, ancient customs respecting, 278

Bridgetins, a religious order, 562

Britton, T. the musical small-coal man, 367

Brossier, Martha, the demoniac, 434

Browny, 791

Brine-springs, 655

Bricks, ancient, 726

Bridges, natural, pendent, \&c. 721

Buckhars, manners, customs, $8 c$ of the 28

Bull-fighting, Roman, 218, Spanish, 219,

Burying alive, a punishment, 296

Buxton, Jedediah, 398

Bucephalus, the horse of Alexander, 447

Buchanites, a sect in Scotland, 568

Butter-tree (shea-tree) 788

Caledonia, New, inhabitants of, 135

Cantabrians, the enemies of the Romans, 76

California, inhabitants of, 195

Caffres aescribed, 202

Carbonari of taly, 34

Cardinal, origin and office of, $\mathbf{2 4 6}$

Calas, John, 403
Calcutta, history of the capture of, 498

Carthusians, 546

Cainites, a sect of heretics, 568

Calumet among the Indians, 583

Carmelites, a tribe of mendican t friars, 547

Cavern of Antiparos, 599

Caves in 8cotland and America, 60

Canal of Scotland, the great, 723

Canadian jerboa, 737

Castles, history of ancient English, 709

Celtiberians, a warlike nation, 162

Celestines, a religious order, 548

Celibacy and marriage, laws respecting, 297

Ceglonese, account of the, $\mathbf{1 5 4}$

Centipede worms, 757

Chaos, 591.

Charcoal, porousness and durability of, 591

Chatterton, Thomas, 423

Chinese, manners of the, 9

- customs peculiar to the, 10 - entertainments, 11

- tea.drinking among the, 13 religious sects among the, 16

Christening customs, 290

Christmas-keeping, 257 within doors in Germany, 263

Church bells, origin of, 254

Circassians, account of the, 209

Circulation of the blood, 584

Clans in Scotland, 530

Clemency, instances of, 467

Clocks, invention of, 577

Cleopatra's needle, and Pompey's pillar, 59:

Cochin-china, inhabitants of, 15

Coreans, account of the, 168

Cock-fighting, 215

Coffins, ancient customs respecting, 299

Congoese, an African nation, 171

Cossacks, account of the, 53

Corde, Clarlotte, the assassin of Marat, 436

Coroner's inquest, origin of the, 250

Cornaro, Lewis, the Venetian, 324.

Coryate, Thornas, 327,

Coral-fistery, 472

Coin of the realm, 479

Comet, 803

Commonweal th of Babina, in Poland, 501 .

Cork-jackets, 575

Colebrook Dale, in Shropshire, 661

Cock-crowing, 772

Crab, the land, 739

Cross, punishment by the, 244 superstitious acioration of the, 555

Cromwell, Oliver, the protector, 331

Cruden, Alex. author of the Concordance, 396

Crowns, ancient, 571

Crow, power of reason in a, 772

Cricket, the field, domestic and mole, 754

Currents in Norway, 660

Customs at weddings, 280

Cuerenbent, 'Theodore van, 315

Dahomans, inhabitants of Africa, 186 
Dances, ancient, 271

of the calumet, 272

Dancing girls in Egypt, 272

Dancers, a religious sect in Flander's, 565

Darien, inhabitants of, 201

Day, Thomas, 418

Dead sea, or lake of Asphaltites, 658

Deafness, and dumbness, 517

Dee, Joln , 316

Decoy for taking wild fowls, 725

Diamonds, extraordinary size and value of, 614

Dieu et mon dinit, 800

Dirnsdale, sir Harry, mavor of Garratt, 428

Doomsday or domesday book, 798

Dragooning the French, protestants, 556

Dutch, manners and character of the, 191

Dunstan, St. 303

Dwarfs, Lewis Hopkins and Joln Coan, 401 the Dutcb, Wyband Lolkes, 402

Earth, absorption of, and moving, 591 bread, 787

Egypt, state of female society in, 26

miser able state of the people of, 175

Egyptian darkness, 491

Dlectrical properties in animals, 745

Elephants, sagacity of, 727

Ellen Tate, 790

England, New, mauners and character of the citizens of, 160

Eonians, a fanatical sect, 555

Essenians, a ancient Jewish sect, 534

Ethiopians, modern manne's of the, 143 customs of the ancient, 277 funeral ceremonies of the, 294

Exposing of children, 276

Fairies, 789

Fakirs of India, 540

ralls of Foyers, 602

Families of children, numerous, 230

Famine in Bongal, 503

Female society in Egypt, 26

Fine fellows of two periods, 529

Fire, perpetual, 480

Fire and pestilence of tondon, 507

Flagellants, a sect of wild fanatics, 558

Flying Dutchman, 234

Force of men and horses, 788

Forore, a remarkable, 576

Forks for the table, $\mathbf{5 7 2}$

Formosans, account of the, 67

Free spirits, brethren and sisters of the, 559

Friendly Islands, inhabitants of the, 58

Funeral ceremonies, 64, 78, 110, 134, 156, $167,292,294,296$

Gabres, or Gaurs, a sect in Persia, 536

Galla, a natioǹ of Etliiopia, 182

Gareinia manyostana, a tree, 775

Garments, dress, \&ec. 24, 125, 133, 135,187

Gascoigne, Thos. a penurious character, 430

Georgia, inhabitants of, 96

Gilpin, Bernard, 308
Gladiators, an account of the, 205

Gladiator, the dying, 721

Glass, astonishing properties of, 78

Gnats, 765

Golden fish, 762

Goldsmith, Oliver, 414

Goiner a Gooding on St. Thomas's day, 234

Gordian knot, 487

Gog and Magog, 801 .

Granicus, battle of the, 511

Gratitude, instances of, 514

Greenland, account of the natives of $5 \mathrm{~L}$

Groaning tree, 778

Guiana, South A merica, natives of, 176

Guinea, history of the trade to, 491

humanity and civility of the vatives of, 101

Guy, Thos. the founder of Guy's Hospital, 369

Gymnotus, an electrical animal, 746

Gymnosophists, 537

Hagmena, a custom in Frncoria, 233

Hallow-even, the vigil of all saints day, 252

Halos, artificial, 583

Hand, 586, and Ambidexterity, 587

Handel, conunemoration of, 481

Hare, the mountain or alpine rabbit, 738

Harleian collection, $\mathbf{4 7 0}$

Harpoon gun, 580

Hatching, artificial, 592

Hattemists, a Dutch sect, 565

Hats, 581

Hawking, history of, 222

Hedgehog, 711

Heideggal, John James, 365

Henley, Joln, the Orator, 380

Heroic wnmen, 152

Hindoos, manners, customs, \&c, of the, 135

Hindoo suttee, 229

Hippopotamus or river borse, 729

Hogarth, William, the painter, 386

Holland, New, inliabitants of, 116

Hospitality, 79, 122

Hottentots, some account of the, 102 Labitations of the, 105 superstitions of the, 106

Houzouanas, a wandering nation of $A$ frica, 180

Howard, John, the philanthropist, 400

Humar horns, cases of, 521

Huaheine, one of the Society Islands, 131

Hunting among the Mexicans, 224. -in Lapland, 225

in the East Indies, 226

Hutton, Charlotte, 436

Jane of Flauders I. 433

Januarius, St. 302

Japanese, account of the, 12

Ice-hills in Russia, 664

Iceland, volcanoes and irruptions in, 650

Icelanders, account of the, 97

Ichneumon wasp, or savage, ros

Jenkins, Henry, 791 
Jerusalem, (with a view, 712

Jews of York, 485

Jezides, a sect in Turḱey and Persia, 542

Jidda, a port in Arabia, 706

Illuminati, history of the, 566

Imagination, power of the, 235

Improvement of the state of women, 300

Incombustible cloth, 575

Indians of America, manners and customs of the, 78

Idol of Owhyhee, 794

Insects, recently discovered, 766

Inscriptions on cliurch bells, 256

Tohn O'Groat's house, 720

Ischorti, inhabitants of Ingria, 133

Kabobiquas, a nation of South Africa, 184

Kalmucs, a tribe of Tartars, 187

Kamtschatka, inluabitants of, 22

Ketllewell, Lumley, esq. 432

Kubesha, a town in Egypt, 707

Labyrinths of Egypt and Crete, 597

Ladrone islands, inhabitants of the, 95

Lake Avernus, 657-Asphaltites, 658

Lapland, inliabitants of, 61

Law, John, the projector, 378

Lee-penny, or lee-stone, 614

Lieou-Kieou, inlabitants of, 89

Lilburne, Jolın, 350

Lilly, William, the astrologer, 342

Logan, or rocking-stone, 612

Lombards, account of the, 196

Londion, pestilence and fire of, 507

Longevity of the Antediluvians accounted for, 441

ancient and modern instances of, 443,790

Long hair, clerical zeal agaisst, 483

Loretta, chapel of, in Italy, 712

Lotteries, 472

Low-bell to take birds, 570

Madagascar, people of, 188

Magi, or Magians, of Persia, 385

Magliabechi, Antlony, 361

Mallicolla, in the Soutli-seas, 188

Manicheans, ancient heretics, 551

Man in the moon, 234

Marriage ceremonies, $63,65,31,109,123$ 198,279

Martinmas, 233

Massacre of St. Bartholomew, 509

Massianello, the fisherman of Naples, 355

Maternal affection in S. America, 468

Mathematicians, ancient, 472

Medina; mosque at, (with a view) 714

Menzikoff, Alexander, of Russia, 370

Mermaid or merman, 759

Michaelmas yoose, 232

Microscopic animals, 757

Mole-cricket, 756

Moon, superstition respecting the, 682

Morin, Simon, a French fanatic, 359

Morlacchi, in Dalmatia, 35

Moore, Anne, the fasting woman, 437
Moors, dress, customs, \&c. of the, 107 Mount St. Michael in France, 700

Mud-Iguana, 736

Murder, expiation of, 236

Mystics, a religious sect, 549

Nalural history; curious facts in, 773

Nayler, James, the Quaker, 346

Necromancy, 665

Negro slavery, origin of, 493

New-year's eve, 264,-day, 267

Nicobar islands, natives of the, 165

Nobility of Naples, 50

Noctilucus nereis, a kind of worm. 762

Nuba, a race of pagans, 169

Numerical figures, 501

Oak pucerons, 744 the royal, 776

Old times, prices of articles in, 242

Omens, with historical examples, 490

Ophites, a sect of heretics, 549

Ordeal, forms of trial by, 238

Organs, $\mathbf{5 7 3}$

Ustiacs, a people of Siberia, 158

Otaheite, inhabitants of, $\mathbf{1 5 5}$

Owhyhee (Hawaii) volcano in, 626 valley of Waipio, in, 660 inbabitants of, 164

Pagoda of Mavalipuran in India, 703

Pant\}eon at Rome, 692

Parias, or Perreas, a tribe of Hindoos, 43

Pairing of birds, 781

Palmyra, ruihs of, 704

Parisian or St. Bartholomew unassacre, 509

Parr, 0ld, 331

Parental despots in Russia, 198

Partridge, 773

Pastimes in Great Britain, 268

Patagonians of South America, 190

Pegu, inhabitants, religion, \&c. of, 94

Pelew islands, inhabitants of the, 92

Peopling of America, 87

Persia, people and oapital of, 193

Peru, inhabitants of, 72

Pestilence and fire of London, 507

Peter the wild boy, 390

Petrified ponds in Persia, 604

Phenomenon in Bengal, 711

Phenix, a fabulous bird, 786

Pholeys of Africa, 204

Plant, wonderful, of Sombrero, 729

Plants, propagation of, 780

Poets laureat, 483

Poison tree of Java, 774

Poland, iubabitants of, 193

Poligars, natives of Hindonstan, 173

Population of the world, 479

Porcupine man, 400

Portugal, inhabitants of, 205

Posts for the conveyance of letter's, 587

Potatoes, extraordinary increase of, 780

Prices of articles in old times, 242

Prison in Venice described, 698

Prisoners, Indian manner of treating, 83 
Psalm-singing, origin of, 251

Punisliments in Algiers, 46

Recluse, description of a, 562

Recreations, 111

Recovery of a female unjustly executed, 180

Religious fasting, 560

Rivers, disappearing of, 607

Rock of Aultgrande, in Scotland, 620

Romans at table, 230

Rosicrucians, bermetical philosophers, 564

Russia, the people of, described, 196

Salamander, 750

Salt-miues in Poland, 656

Saluration, modes of, 245

Samoieda, inhabitants of, 201

Sarcophagus, 617

Scylla and Charybdis, 619

Sea-dragon, 735

- serpent, 743 - ape, 773

Second-siglit, 687

Seeks, a religious sect in Persia, 541

Segalien, the island of, 16

Sego in Africa, Park s account of, 33

Selkirk, Alexander, 375

Senegaliens, of Senegar in Africa, 75

Seraglio of the emperor of Morocco, 47

Serpents, tricks performed with, 749

Sharp, Abralsam, the mathematician, 372

Shillook, inbabitants of Senmaar, 73

Siamese, account of the, 69

Sic ly, marriage customs in, 278

Sinai or Sina, mount, 618

Si-fans, or Tou-fans, of China, 71

Sixtus V. pope, 312

Six-nations of American Indians, 174

Snakes, a list of, found in Bengal, 697

Snake stones, or amınonilla, 610

Social customs, Asiatic, 298

Sorcery, or inagie, 678

Spain, inbabitants of, 191

Spanisls armada, history of the, 503

Spell, or charm, 682

Sphinx, 795.

Sponge, 768

Stukeley, Mr. the perpetual-motion seeker, 413

Stockings, and weavirg of, 582
Stones of various kinds, 610

Subterranean vaults of Maestricht, 598

lake of Burgundy, 610

Superstition of the N. Amer. Indians, 82

Hottentots, 106

Russians, 199

respecting the moon, 653

in Scotland, 248

ohserved in Bombay, 538

Suspended animation, 515

Suttee in Hindoostan, 229

Swift, a species of swallow, 769

Taylor, John, the water poet, 329

Temple of Jupiter, at Olympia, 695

Osiris in Egypt, 696,

Hiannen in China, 701

Theodore, Anthony, king of Corsica, 383

Tobacco, king James against, $78 \mathrm{~L}$

Tombs, alcient, 296

Tongues, confusion of, 487

Torpedo, 747

Trade to Guinea, history of, 491

Travelling, mode of, 25

Trees, age of, 777

Trenck, Frederiek von, 411

Trial, a singular, 211

Tarkey, iniabitants of, 192

Turkish bathing, $\mathbf{2 7 4}$

Turtle, 762

Valley of Waipio, in Owhylice, 660

Vegetable lanıb, 779

Venice, account of the prison in, 698

Vishnoo, a Hindoo deity, 569

Volcano of Owbybee, (Hawaii,) 626

Eina, 635

Icelaud, 650

Wars of the N. Amer. Indians, 84 .

Walnut tree, 778

Weather, clianges of the, 804

Weddings in Great Britain, 280

White bre hren, a popish sect, 559

Williamson, Peter, 403

Witchcraft, 676

Women, 26. 44, 48, 108, 140,146, 185 $209,300,443$

Writing, origin of the materials of, 589

Zend, or Zendavesta, 802

\section{LIST OF THE PLATES.}

Frontispiece, History upon an Emine ce, \&c....................page 1 w

Manuer of Travelling in Winter in Kamischatka, .................. 25

Canoes used by the Greenlanders, .......................... 51

Japlanders in their Winter Dress, .........................61

Men and Women of the Sandwich Islands, ...........................

A Man of New Caledonia throwing the Spear,........................ 185

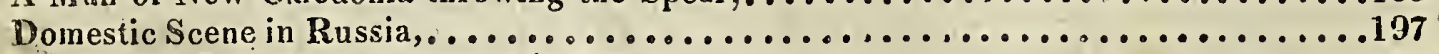

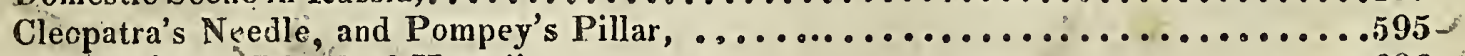

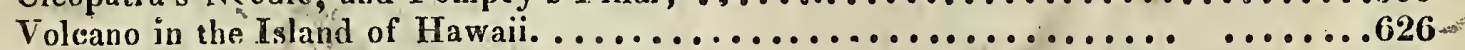

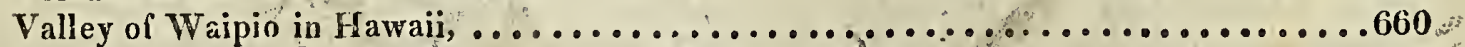

Prison is Venice, $698 \ldots \ldots \ldots \ldots \ldots$ Dansing Seppents, ................749

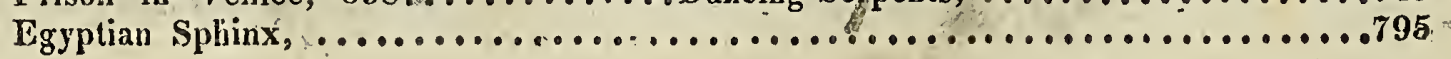




\section{MANNERS AND CUSTOMS,}

$$
\& c .
$$

\section{Part I.}

THE MANNERS AND CUSTOMS OF ALL NATIONS.

\section{Manners of the Chinese.}

THE manners of the Chinese bear little resemblance to those of any other nation; and, their historians say, they are the same now that they were 4000 years ago. The women are condemned to almost perpetual imprisonment within the precincts of their own houses. A woman is never seen, not even by her intended husband, before marriage. He knows nothing of her looks or person, but from the account of some female relation or confidant, who in these cases acts the part of match-maker; though when imposed upon, either with regard to her age or figure, he can have recourse to a divorce. The same matrons who negociate the marriage, also determine the sum which the intended husband must pay to the parents of the bride, for in China a father does not give a dowry to his daughter; it is a husband who gives a dowry to the wife.

When the day appointed arrives, the bride is placed in a palanquin, the key of which is committed to the care of a trusty domestic, who must deliver it to none but the husband. The latter, richly dressed, waits at his gates for the arrival of the procession. As soon as it approaches, the key is put into his hands; he eagerly opens the chair, and for the first time perceives his good or bad fortune. If he is contented with his new spouse, the bride descends and enters the house, where the marriage is celebrated by feasting and merriment as in other countries; but if the bridegroom is very much dis. appointed, he suddenly shuts the chair, and sends the bride home to her relations. To get rid of her in this manner, however, costs a sum equal to what he originally gave in dowry to obtain her." The Chinese women, even of the first rank, seldom quit their apartment, which is situated in the most retired part of the house, and in which they are secluded from all society but that of their domestics. 
The book of ceremonies requires that there should be two apartments in every house; the exterior one for the husband, and the interior for the wife. They must even be separated by a partition, the door of which is carefully guarded; nor is the husband at liberty to enter the wife's apartment, or she to quit it without good reason.

A widow of superior rank, who has children, seldom enters a second time into the marriage state, though those of the ordinary rank generally do. Poor widows are not at liberty to follow their inclinations, but are sold for the benefit of the parents of the deceased. As soon as the bargain is concluded, a couple of porters bring a chair, which is guarded by a number of trusty people. In this the widow is shut up, and thus conducted to her new husband.

Concubinage is tolerated in China, though not authorized by law: This privilege is granted only to the emperor, the princes of the blood, and mandarins; and none but the emperor is permitted to have more than one. But the people generally avail themselves of the toleration, and have two or three concubines, if they can afford to pay the customary sum to the parents, \&c. They, however, excuse themselves as well as they can to their wives in this respect, pretending only a desire of having many children, and a number of women to attend their wives; for the concubines and children must all be subject to the lawful wife. Others, desirous of having a niale child, which perhaps their lawful wife cannot have, take a concubine for this reason only, and dismiss her as soon as their wishes are accomplished; they then permit her to marry whom she pleases, and frequently even provide a husband for her themselves. These concubines are almost all procured from two cities, named Yang-Tcheou and Sou-Tcheou, where they are educated, and taught singing, dancing, music, and every accontplishment suitable to women of quality, or which can render them agreeable and pleasing. The greater part of them are purchased in other places, to be again disposed of in these cities. Unlawful intrigues are seldom heard of in China.

\section{Customs peculiar to the Chinese.}

ALL authors agree, that an absurd custom prevails throughout China, of coufining the feet of female infants in such a mauner, that they are never allowed to grow to near their full size. "Of most of the women we saw," says Sir G. Staunton, "even in the middle and inferior classes, the feet were unnaturally small, or rather truncated. They appear as if the forepart of the foot had been accidentally cut off, leaving the remainder of the usual size, and bandaged like the stump of an amputated limb. They undergo, indeed, much torment, and cripple themselves in a great measure, in imitation of ladies of higher rank, among whom it is the custom to stop by pressure the growth of the ankle as well as foot, from the earliest infancy; and leaving the great toe in its natural position; forcibly to bend the others, and retain them under the foot, till at length they adhere to, as if buried in the sole, and can no more be separated. It is said, indeed, that this practice is now less frequent than formerly, at least among the lower sort in the lower provinces." 
In China, every father of a family is responsible for his chldren, and even his domestics; all those faults being imputed to him which it was his duty to have prevented. Every father has the power of of selling his'son, "provided," says the law, "the son has a right of selling himself." This custom, liowewer, is barely tolerated among the middling and inferior ranks; and all are forbidden to sell them to comedians, or people of infamous character, or very mean stations. In China a son remains a minor during his father's life, and is even liable for the debis contracted by him, those from gaming only excepted. Adoption is authorized by law, and the adopted child immediately enters into all the rights of a lawful son; only the law gives a right to the father, of making a few dispositions in favour of his real children. The children, however, whether real or adopted, cannot succeed to the dignity of their father, though they may to his estate. The emperor alone can confer honours; and even then they must be resigned when the person atains the age of seventy; though this resignation is considered as an advice, rather than a law. The. will of a father cannot be set aside in China on account of any informality; nor can a mother make a will.

\section{Chinese Entertainments.}

Nothing can appear more irksome to an European, than the multitude of ceremonies used on all occasions by the Chinese. An invitation to an entertainment is not supposed to be given with sincerity, until it has been renewed three or four times in writing. $A$ card is sent the evening before the entertainment-a second on the morning of the appointed day - and a third when every thing is pre. pared. The master of the house introduces the guests into the hall, where he salutes them one after another. He then orders wiue to be brought him in a small cup, made of silver, porcelain, or precious wood, and placed on a small varnished salver. He lays hold of it witl both his hands, makes a bow to all the surrounding guests, and advances towards the fore part of the hall, where he raises his eyes and cup towards heaven; after which, he pours the wine on the ground. He afterwards pours some wine into the cup, makes a bow to the principal person in company, and then goes to place the cup on the table before him ; for in China every guest has a table to himself. The person for whom he intends this honour, however, generally saves him the trouble of placing the cup; calls for wine in his turn, and offers to place the cup on the master's table, who endeavours to prevent him, with a thousand apologies and compliments, according to Chinese politeness. A superior domestic conducts the principal guest to an elbow chair, covered with rich flowered silk, where the stranger again begins his compliments, and begs to be excused from sitting in such an honourable seat, which, however, he accepts of ; and all the rest of the guests do the same, otherwise the ceremonial must be gone through with each of them.

The entertainments of the Chinese are begun, not by eating, but by drinking; and the liquor they drink must always be pure wine. The intendant, or maitre de hotel, falling down on one knee, first 
invites the guests to take a glass; on which each of them lays hold, with both hands, of that which is placed before him, raising it as high as his forehead, then bringing it lower down than the table, and at last putting it to his mouth; they all drink together, and very slowly, taking three or four draughts. While they are drinking, the dishes on each of the tables are removed, and others brought in. Each of the guests has twenty-four set before him in succession; all fat, and in the form of ragouts. They never use knives in their repasts; and. two small-pointed sticks, ornamented with ivory or silver, serve them instead of forks. They never begin to eat, however, until they are invited by the maitre de hotel; and the same ceremony must be gone through every time they are going to take a cup of wine, or begin a new dish.

Some change has been made in the ceremonial of the Chinese by the Tartar conquest, and some new dishes have also been introduced, for the Tartars are much better cooks than the Chinese. All their dishes are highly seasoned ; and by various proportions of spiceries, they form a variety of dishes out of the same materials.

None of their viands, however, are more esteemed than stags' sinews, and the nest of a particular species of birds, which give a most agreeable relish to whatever is mixed with them. Other dishes are introduced at these repasts, which would be accounted very disagreeable with us; such as the flesh of wild horses, the paws of a bear, and the feet of several wild animals. The greater part of these provisions is brought preserved in salt from Siam, Camboya, and Tartary. Towards the mildle of the entertainment, the soup is brought in, accompanied with small loaves or pies. These they take up, with their small sticks, steep them in the soup, and eat them, without waiting for any signal, or being obliged to keep time with the rest of the guests. The entertainment, however, continues in other respects with the utmost formality, until tea is brought in; after which, they retire from table, and amuse themselves in another hall, or in the garden, for a short time, until the dessert is brought in. This, like the entertainment itself, consists of twenty-four dishes, made up of sweetmeats, fruits differently prepared, hains or salted ducks balied or dried in the sun, with shell and other kinds of fish. The same ceremonies which preceded the repast, are now renewed, and every one sits down at the same place he occupied before. Larger cups are then brouglit, and the master invites the guests to drink more freely. The entertainment is concluded by some theatrical representations, accompanied with the music of the country. A certain number of spectators are admitted to behold these theatrical representations; and even the women are allowed to view them through a wicket, so contrived that they may see them without being seen themselves. These entertainments never end till miduight. A small sum of money is given to the domestics; when each of the guests goes home in a chair preceded by several servants, who carry large lanterns of oiled paper, on which are inscribed the quality, and sometimes the name of the master. Without such an attendance, they, would be taken up by the guard; and the day following, they return a card of thanks to the officer. 


\section{Tea-Drining among the Cuinese.}

THE Chinese method of drinking tea is not like that of other nations. A small quantity of Bohea, sufficient to tinge the water and render it palatable, for they drink no green, is taken in the morning, and thrown into a vessel adapted to the number in the family. This stands till milk-warm; in which state it is kept the whole day, and a cup drank now and then without sugar or milk, to exhilarate their spirits when exhausted; and if a stranger call by accident; on a visit, or by appointment, the first thing presented is a small pipe, filled with tobacco of their own growth, and a cup of the tea, with sweatmeats, \&c. Tea is the daily beverage in China, and is drank by all ranks of people.

\section{Religious Sects among the Chinese.}

THE purity of the ancient Chinese religion has been long contaminated by many idolatrous and fanatical sects. That of Tao-Sse was founded by a philosopher called Lao-Kiun. His morality consists principally in banishing all vehement desires and passions. "According to him, the care of every wise man ought to be only to end eavour to live free from grief and pain, and to glide gently down the stream of life devoid of care and auxiety. To arrive at this happy state, he advises his followers to banish all thoughts of the past, and all anxiety for the future, arising from ambition, avarice, \&c. His disciples, however, found that a!l their endeavours to obtain a perfect tranquillity of mind were vain, so long as the thoughts of death intervened; they therefore declared it possible to discover a composition, from which a drink might be made, that would render mankind immortal. Hence they were led to the study of chemistry; and, like the western alchymists, wearied themselves in search of the philosopher's stone, until at last they gave themselves up to all the extravagancies of magic. The desire of avoiding death, together with the credulity natural to unenlightened minds, quickly prodiced a number of converts to the sect of Tao-Sse. Magical practices, the invocations of spirits,"and the art of foretelling events by divination, were quickly diffused over the empire, and the imbecility of the emperors contributed to propagate the folly. Temples consecrated to spirits were quickly reared; and two of the most celebrated of the sect were authorized to maintain public worship after the form which had been prescribed by their master. At the same time they made, and sold at a high price, images of those ideal spirits with which they had peopled the heavens and the earth. These were worshipped as so many deities independent of the supreme Being; and, in like manner, several of the ancient emperors are invoked as gods.

Being patronized by the eniperors of several dynasties, this sect became more and more powerful. At last they had the impudence to affix during the night to one of the gates of the imperial city, a book filled with mystic characters and magical figures. At daybreak, they informed the emperor of the sudden appearance of this 
book, and publicly declared that it was fallen from heaven. This trick casily imposed upon the weak prince. He immediately repaired with a nunıerous train to the spot where the sacred volıme appeared; and having taken it into his hands in a respectful manner, carried it in triumph to his palace, where he shut it up in a golden box. Another emperor carried lis reverence for the sect to such a height of impiety, as to order a celebrated Tao-Sse to be publicly worshipped, under the name of Chang-ti. The sect thus patronized by the princes, continued to gain ground, in spite of every opposition from the wiser part of the people, and is still very powerful in China. At present they offer up a hog, a fowl, and a fish, to a spirit whom they invoke. Various ceremonies, such as howlings, drawing fantastical figures upon paper, making a hideous noise with kettles, drums, \&c. are used in their incantations; and though for the most part unsuccessful, yet their credit is still kept up by those cases in which hey succeed by accident.

The chief Tao-Sse is invested with the dignity of grand mandarin : he resides in a sumptuous palace in a town of Kiang-si; and the superstitious confidence of the people attracts an immense number thither from all parts of the empire. Some come to be cured of diseases; others to get an insight into futurity. The impostor distributes to them small bits of paper filled with magical characters; and the ignorant wretches depart well satisfied, without grudging the expense of their journey, though ever so long.

A still more pernicious and more widely diffused sect is that of the idol Fo, which came originally from India. The Tao-Sse had promised to the brother of one of the emperor's of China, to introduce hin to a communication with spirits. The credulous prince having heard of a great spirit named Fo, who resided in India, prevailed on his brother to send an embassy thither. On the arrival of the ambassadors, however, they could only find two worshippers of this deity, both of whom they brought to China. Several images of Fo were also collected at the same time; and these, together with some canonical books of the Indians, were placed on a white horse; and carried in procession to the imperial city. This superstition was introduced into China about A. D. 65, and soon made vast progress.

One of the principal doctrines is that of the metempsychosis, or transmigration of suuls, of which. M. Grosier thinks he was the inventor, and that Pythagoras, who travelled into several parts of India, had borrowed the doctrine from him. The aecount given of him by the bonzes is, - that finding himself, at the age of 70; oppressed with infirmities, he called his disciples together; and told them he was unwilling to leave the world without communicating the sacred and hidden mysteries of his doctrine; which were, in short, that all things proceeded from nothing, and to that they must return. This doctrine produced a corresponding mode of action, or rather of inaction, in those who believed it.

The common doctrine; however, which admits of distinction between good and evil, finds more proselytes among those whose situation in life will not allow them to spend their time in idleness. They say that 
the god Fo came to save mankind, and to expiate their sins, and that he alone can procure them a happy regeneration in the life to come. Five precepts are inculcated on those who adopt this doctrine, 1. Not to kill any living creature; 2 . Not to take away the goods of another; 3. Not to pollute themselves by uncleanness : 4. Not to lie; and, 5. Not to drink wine. Above all, they recommend to them to perform acts of mercy and benevolence, to treat their bonzes well, build temples, \&c.

The doctrine of the metempsychosis has introduced into China an infinite number of idols, who are all worshipped, on the supposition that the spirit of Fo has transmigrated into the animals they represent. A colony of Jews was established in China about A. C. 206 ; but they are now reduced to a small number of families at Caisang, the capital of Ho-nan. The Mahometans have multiplied much more than the Jews. It is above 600 years since they entered the empire, where they have formed different establishments. They are become now so numerous, that, in the places where they reside, they exclude all who do not believe in their prophet, and frequent a mosque.

\section{The Ininatinats of Cochin China.}

THE inhabitants of Cochin China are well shaped; of a light brown complexion, with long hair, and thin beards. M. le Poure represents them as gentle, hospitable, frugal, and industrious. There is not a beggar in the country, and robbery and murder are absolutely unknown. A stranger may wander over the kingdom from one end to the other, the capital excepted, without meeting with the slightest insult. He will be every where received with the most eager curiosity, but at the same time with the greatest benerolence. A Cochin Chinese traveller, who has not money sufficient to defray his expenses at an inn, enters the first house of the town or village he arrives at, and, waiting the hour of dinner, takes part with the family, and goes away when he thinks proper, without speaking a word, or any person putting to him a single question. The people of this country bave a great affinity with those of Tonquin, with whom they have a common origin, and from whom they differ very little in their manners and customs, all of which they have in a great measure borrowed from the Chinese.

M. Grosier says, that a false report has gained ground in Europe, that when a trading vessel happens to run aground in Cochin China, or to be driven into any of its harbours by stress of weather, the king seizes the cargo, if the rudder be broken. He assures us, however, that so far from this being the case, a vessel in distress is much safer on the coast of Cochin China than almost any where else. Barks are immediately sent to the relief of the crew, and people employed to drag the sea with nets, to recover the goods that are lost. In short; neither labour nor expense is spared to put the ship in the best condition possible. As to religion, the Cochin Chinese believe in the metempsychosis. 
In A Bitants of the Island of Segalien, NeAr China.

LA Perouse, and M. Rollin the surgeon of his ship, both describe the natives of this island as a worthy and intelligent people. Of the presents which were made to them, they seemed to set a value only on such as were useful. Iron and stuffs prevailed over every thing; they understood metals as well as their guests, and for ornament preferred silver to copper, and copper to iron. They use looms, which though small are very complete, and by means of spindles they prepare thread of the hair of animals, of the bark of the willow, and of the great nettle, from which they make their stuffs. They are of a moderate size, squat, and strong-built, with the muscles of their bodies very exactly defined; their common height is five feet, and the greater does not exceed 5 feet 4 inches; but men of this size are uncommon. They have all a large head, and a broader and more rounded face than Europeans; their countenance is animated and agreeable, though destitute of that grace which we esteem essential to beauty; they have large cheeks, a short nose rounded at its extremity, with very broad nostrils; their eyes are lively, of a moderate size, for the most part black, though some are blue; their eye-brows are bushy, voice strong, lips rather thick, and of a dull red; in several the upper lip was tattoed, and tinged blue; these, as well as their eyes, are capable of every variety of expression; their teeth are white and even, their chin is rounded and a little advancing; their ears are small, they bore them, and wear in them glass ornaments or silver rings. The women are not so large as the men, and are of a more rounded and delicate figure, though there is little difference between their features. Their upper lip is tattoed all over of a blae colour, and they wear their hair long and flowing; their dress laardly differs from that of the men; the skin in both sexes is tawny, and their nails, which they suffer to grow to a great length, is a shade darker than that of Europeans. These islanders are very hairy, and have long beards, which give to the old men a venerable air, these last appear to be held in much respect. The hair of their head is black, smooth, and moderately strong; in some it is of a chesnut colour ; they all wear it round, about six inches long behind, and cut into a brush on the top of their heads, and over the temples. Their clothing consists of a kind of surtout, which wraps over before, where it is fastened by little buttons, strings, and a girdle placed above the haunches. This surtout is made of skin or quilted nankeen, a kind of stuff that they make of willow bark; it generally reaches to the calf of the leg, sometimes lower; some of them wear seal-skin boots, the feet of which, in form and workmanship, resemble the Chinese shoe, but the greater number go bare-footed and bare-headed; a few wear a bandage of bear-skin round the head, as an ornament. Like the Chinese, they all wear a girdle, to which they hang their knife as a defence against the bears, and several little pockets, into which they put their flint and steel, their pipe, and their box of tobacco; for they make a general practice of smoking.

Their huts are sufficient to defend them against the rain, but are very small in proportion to the inhabitants. The roof is formed 
of two inclined planes, which are from ten to twelve feet high at their junction, and three or four on the sides; the breadth of the roof is about fifteen feet, and its length eighteen. These cabins are constructed of frame-work, strongly put together, the sides being filled up with the bark of trees, and the top thatched with dry grass, in the same manner as our cottages are. On the inside of these houses is a square of earth, raised about six inches above the ground, and supported on the sides by strong planking. On this they make the fire; along the sides of the apartment are trenches 12 or 13 inches high, which they cover with mats, on which they sleep. The utensils which they employ in cooking their food consists of an iron pot, shells, vessels made of wood and birch bark, of various shapes and workmanship; and, like the Chinese, they take up their food with little sticks; they have generally two meals in the day, one at noon, and the other in the evening.

The habitations in the south part of the island are unch better built and furnished having for the most part planked floors; our author saw in them some vessels of Japan porcelain. They cultivate no kind of vegetables, live only on dried and smoked fish, and what little game they take by hunting. Each family lias its own canoe, and implements of fishing and hunting. Their arms are bows, javelitis, and a kind of spontoon, which they use principally in bear hunting. By the side of their houses are the magazines in which they lay up provisions for winter. These consist of dried fish, garlic, wild celery, angelica, a buibous root called apé, or the yellow lily of Kamptschatka, and fish oil, which they preserve in the stomachs of bears. These magazines are made of planks strongly put together, on stakes about four feet high.

Dogs are the only domestic animals; they are of a middling size, with shaggy hair, pricked ears, and a sharp long muzzle; their cry is loud, but not savage. These people, who are of a very mild and unsuspecting disposition; appear to have commercial intercourse with the Chinese by means of the Mantchou Tartars, with the Russians to the north of their island, and the Japanese to the south; but the articles of trade are of no great consequence, consisting only of a few furs and whale oil. This fish is caught only on the southern coast of the island. Their mode of extracting the oil is by no means economical ; they drag the whale on shore on a sloping ground, and, suffering it to putrefy, receive in a trench at the foot of the slope, the oil, which separates spontaneously. The islaind is well wooded and mountainous towards the centre, but is flat and level along the coast, the soil of which appears admirably adapted to agriculture. Vegetation is extremely vigorous; forests of pine, willow, and birch, covered nearly the whole surface.

The sea abounds with fish, as well as the rivers and brooks which abound in salmion and trout of an excellent quality. The weather is in general foggy and mild. All the inhabitants have an air of health and strength, which they retain even to extreme old age: nor did our author observe among them any instance of defective organization, or the least sign of contagious or eruptive disorder's prevailing among: them. 


\section{Manners and Customs of the Ashantees.}

Ashantee is a large and powerful negro state in Africa. The most authentic account which we have received respecting these people, is to be derived from the work of Mr. E. Bowdich, who was conductor of a mission from Cape Coast Castle to Ashantee; which was published in 1819. This gentleman, in describing the object and departure of his mission, states that Bosman and Barbot mention the Ashantees as first heard of by Europeans about the year 1706. Issert, a physician in the Danish service, who meditated a visit to Ashantee, writes - "This mighty king has a piece of gold as a charm, more than four men can carry; and innumerable slaves are constantly at work for him in the mountains, each of whom must collect or produce two ounces of gold per diem. In 1807 an Ashantee army reached the coast for the first time. In 1811 the Ashantees invaded Fantee, and again in 1816. These invasions inflicted the greatest miseries on the Fantees. Few were slain in battle, for they rarely dared to encounter the invaders; but the butcherings in cold blood were incredible, and thousands were dragged into the interior, to be sacrificed to the superstitions of the conquerors. The prolonged blockade of Cape Coast Castle in the last invasion, engendered so much distress and hazard, that the government having averted imminent danger by advancing a large sum of gold on account of the Fantees, earnestly desired the Committee to authorize and enable them to venture an embassy to deprecate these repeated calamities, to conciliate so powerful a monarch, and to propitiate an extension of commerce. In consequence of this application, in 1817 the African Committee forwarded liberal and suitable presents, and a mission was sent to Aspenlow, with proper instructions as to the observations they were to make. Under these instructions, the mission departed, accompanied by Mr. Bowdich; the result of whose observations has, as we have already stated, been published.

After describing the difficulties of his progress, and the country through which he passed, Mr. Bowdich proceeds as follows :-"We entered Coomassie at two o'clock, passing under a sacrifice of dead sheep, wrapped up in red silk, and suspended between two lofty poles. Upwards of five thousand people, the greater part warriors, met us, with awful bursts of martial music, discordant only in its mixture; for horns, drums, rattles, and gongs, were all exerted with a zeal bordering on frenzy, to subdue us by first impressions. The smoke which encircled us, from the incessant discharges of musketry, confined our glimpses to the fore-ground, and we were halied, whilst the captains performed their pyrrhic dance in the centre of the circle formed by the warriors, where a confusion of flags, English, Dutch, and Danish, were waved and flourished in all directions, the bearers plunging and springing from side to side with a passion of enthusiasm only equalled by the captains, who followed them, discharging their blunderbusses so close, that the flags were now and then in a blaze. The dress of the captains was a war cap, with gilded rams' 
horns projecting in front, the sides extend beyond all proporition by immense plumes of eagles' feathers, and fastened under the chin with bands of cowries. Their vests were of red cloth, covered with fetishes and saphies (scraps of Moorish writing as charms against evil) in gold and silver, and embroidered cases of almost every colour, which flapped against their bodies as they moved, intermixed with small brass bells, the horns and tails of animals, shells and knives; long leopards' tails hung down their backs, over a small bow covered with fetishes: they wore loose cotton trowsers, with immense boots of a dull red leather, coming half way up the thighs, and fastened by small chains to their waistbelt : a small quiver of poisoned arrows hung from their right wrist, and they held a long iron between their teeth, with a scrap of Moorish writing affixed at the end of it; a small spear was in their left hand, covered with red cloth and silk tassels : their black countenance's heightened the effect of this attire, and completed a figure scarcely human."

The author then proceeds to describe the iminense crowd of people by whom he was surrounded; he says,_- "The large open porches of the houses, like the fronts of stages in small theatres, were filled with the better sort of females and children, all impatient to behold white people for the first time:

"We were then squeezed up a long street to an open fronted house, where we were desired to wait the further invitation from the king. Here our attention was attracted to a most inhuman spectacle; it was a man whom they were tormenting previously to sacrifice : his hands were pinioned belind him, a knife was passed through his cheeks, to which his lips were noosed, like the figure of eight; one ear was cut off and carried before him, the other hung to his head by a small bit of skin; there were several gashes in his back; and a knife was thrust under each shoulder-blade; he was led, with a cord passed through his nose, by men disfigured with immense caps of shaggy black skins, and drums beat before him."

The author then proceeds to describe the extraordinary splendour which marked the retinue of the court, previously to his admission to the presence of the king.

6. The prolonged flourishes of the horns, and deafening tumult of drums, announced that we were approaching the king: we were already passing the principal officers of his household; the chamberlain, the gold-horn blower, the captain of the messengers, the captain for royal executions, the captain of the market, the keeper of the royal burial ground, and the master of the bands, sat surrounded by a retinue and splendour which bespoke the dignity and importance of their offices. The cook had a number of small services, covered with leopard's skin, held behind him, and a large quantity of massive silver plate was displayed before him, punchbowls, waiters, coffee-pots, tankards, and a very large vessel with clawed feet, which seemed to have been made to hold incense. The executioner, a man of an immense size, wore a massy gold hatchet on his_breast, and the execution stool was held before him, clotted in blood, and partly covered with a caul of fat. The king's four linguists were encircled by a splendour inferior to none, and their 
peculiar insignia, gold canes, were elevated in all directions, tied in bundles like fasces.

"A delay of some minutes, while we severally approached to receive the king's hand, afforded us a thorough view of him; his deportment first excited my attention; his manners were majestic, yet courteous, and he did not allow his surprise to beguile him for a moment of the composure of the monarch : he appeared to be about thirty-eight years of age, inclined to corpulence, and of a benevolent countenance."

In describing the customs of the Ashantees, Mr. Bowdich thus proceeds :-

"A general is appointed to the command of an army by receiving a gold-handled sword of the king's from his hand, (who strikes him gently with it three times on the head,) swearing to return it encrusted with the blood of his conquered enemies. One of the king's linguists always accompanies an army of any consequence, to whom all the politics of the war are intrusted. The Ashantees are superior in discipline as in courage to the people of the water side, though their discipline is limited to the following precautions. They never pursue when it is near sun-set; the general is always-in the rear; the secondary captains lead the soldiers on, whilst those in command, with a few chosen individuals, urge them forward with their heavy swords, and cut any man down who retreats until the case is desperate. The first object of the Ashantees in close fight, is to spring upon the throat of his enemy; to advance every time he fires, he feels to be imperative, if his commander thinks it possible; who would otherwise, if he escaped death in the action, inflict it on him directly it was over. The general has his umbrella spread in the rear, and besides his guard has several muskets ready loaded, for those soldier's who may be driven to him in case of reverse. His band plays all the time, and in his assumed contempt for the enemy, it is his etiquette to divert hiniself at some game, while the heads of the slain, of any rank in the hostile army, are sent to him to put his foot on. When the result of an important action is expected, the king is always seated, in public, with his golden worra before him, playing with some dignitary, and thus receives the news, in order to impress the people with confidence by his affected indifference to victory or defeat.

"Several of the hearts of the enemy are cut ont by the Fetish men who follow the army, and the blood and small pieces being mixed with various consecrated herbs, all those who had never killed an enemy before, eat a portion, for it is believed if they did not, their vigour and courage would be secretly wasted by the taunting spirit of the deceased. It was said that the king and all the dignitaries partook of the heart of any celebrated enemy.

"The army is prohibited during the active parts of the campaign from all food but meal; which each man carries in a small bag at his side, and mixes in his hand with the first water he comes to: this, they allege, is to prevent cooking-fires from betraying their position, or anticipating a surprise. Ashantee spies have been stationed two or three days in the high trees overlooking Cape Coast Castle, 
with no other supply than this meal and a little water, before the erieny has shewn himself. There is always a distinct body of recruits with the army, to despatch those with their knives whom the musket has only wounded, and they are all expected to return well armed from despoiling the enemy.

"It is the invariable policy of the Ashantees to make the contingents of the power last subrued, the revolters recently quelled, or the allies last accepted, the van of their army throughout the campaign, and very frequently there are no Ashantees but captains, with the army."

Speaking of the military forces, Mr. Bowdich says, "I can only calculate the population of the kingdom of Ashantee from its military force, which amounts to 204,000; this appears an extravagant force, until we recollect that it is probably one-fifth of the whole population. Barbot heard of the Ashantees losing 50,000 in two actions; an exaggeration which, nevertheless, serves to argue great military resources. Since the Ashantee invasion, their disposable force has been estimated by old residents, in public reports, at upwards of $150,000 . "$

In Mr. Hutchison's diary, which is quoted by Mr. Bowdich, the following statement is made :-

"When any public execution or sacrifice is to take place, the ivory horns of the king proclaim at the palace door, Wow! wow! wow! death! death! death! and as they cut off their heads, the bands play a peculiar, strain till the operation is finished.

"On a particular occasion a message was sent to one chief, to say that the king was going to his mother's house to talk a palaver; and shortly after, lis majesty arose and proceeded thither, ordering the attendants to conduct me out by another door.

"This sacrifice was in consequence of the $\mathrm{king}$ imagining that if he washed the bones of his mother and sisters, who died while he was on the throne, it would propitiate the Fetish, and make the war successful. - Those who had done any thing to displease the king, were then sent for in succession, and immolated as they entered, that their blood might water the graves.' The whole of the night the king's executioners traversed the streets, and dragged every one they found to the palace, where they were put in irons (which is often the case;) some one had disclosed the secret, and almost every one had fled, and the king was disappointed of most of his distinguished victims. The sacrifice was continued until the next Adai custom, seventeen days, at the end of which time the chiefs came from their concealment, and paraded the streets, rejoicing that they had escaped death, although a few days might put them in the same fear."

The power of the king of Ashantee is. liable to some check from the authority and infuence of his chiefs, and the prejudices and superstitions to which savages are always enslaved; he is highly despotic; and the indifference with which the lives of the subjects are sacrificed, merely for the gratification of his caprices, is such as is scarcely conceivable. Neither he nor any of his family can be put to death except by being drowned, in order that the royal blood may not be shed. He inherits all the gold in his dominions; and whatever is accidentally found is his perquisite, hence if his subjects 
pick up any thing in the street, they are punished with death, as guilty of lese majesty. These wise laws, however, they find means to evade by not'turning informers, and dispersing their gold among their relations before their decease, and not leaving it for his majesty to inherit.

The monarch has no less than 3333 wives; a mystic number, on which the salvation of the state is supposed to depend; but he is not bound to indulge them all with his company, and six only enjoyed that privilege when the British mission was at his capital. The rest were well secured and guarded; a precaution by no means superfuous in Ashantee, where the manners of the women are highly licentious. Owing to this cause, probably, the throne passes to the sister's son, as property does among the Nayrs on the coast of Malabar; and those fortunate dames, the king's sisters, are allowed to make choice of their spouses, - never failing, as Mr. Bowdich was told, to shew their taste by the personal charms of the hero they prefer

The wantonness with which the blood of the multitude is shed by their despotic master, is almost incredible; but it is at his funeral that the horrors of the merciless system are fully developed. All the members of the royal family burst forth, as if they were mad, and fire promiscuously amongst the crowd of unhappy slaves, who are driven forth by the chiefs to furnish marks for their superiors to aim at. The king's household slaves, to the number of a hundred or more, and women in abundance, are sacrificed upon his tomb. Besides this, all the funeral sacrifices made during his reign are repeated, "to amplify that for the death of the monarch," as Mr. Bowdich expresses it; and what such an "amplification" must amount to, we niay judge, when he tells us that 3000 victims were devoted to "water the grave" of the present king's mother. Something like this, on a smaller scale, is practised, several times in the year, at their public festivals, called "Customs," in the barbarous dialect of the English traders on the coast of Africa; and Mr. Bowdich witnessed the terror and consternation which the return of these fatal seasons occasioned.

The king has no power over the lives of the chiefs, (Cabeceiras,) but he can strip them of their property at his pleasure. The people appear to be in a state of wretched vassallage, exposed to all sorts of oppression and extortion from the great; and it is surprising to find them, under such disadvantages, so alert and industrious as they are.

\section{INHABITANTS OF KAMTSCHATKA.}

THE natives of Kamschatka are as wild as the country. Some have no fixed habitation, but wander from place to place with their reindeer; others have settled habitations, and reside upon the banks of rivers and the shore of the Parschinska sea, living upon fish and sea animals; and such herds as grow upon the shore; the former dwcll in huts covered with deer-skins, the latter in places dug out af the earth, though both in a very barbarous manner. Their disposition and tempers are rough ; and they are entirely ignorant of letters. The natives are divided into three different people, viz. the Kamtschatkans, Koi- 
aki, and Kuriles. The Kamtschatkans live on the south side of the promontory of Kamtschatka; the Korehi inhabit the north parts on the coast, of the Penschinska sea, and round the eastern ocean almost to the river Anadir, whose mouth lies in that ocean almost in $60^{\circ} \mathrm{N}$. lat. The Kuriles iuhabit the islands in that sea reaching as far as that of Japan.

The Kamtschatkans endeavour to give every thing a name in their language which may express the property of it; but if they do not understand the thing themselves, then they take a name from some foreign language, which perhaps has no relation to thing itself: $e . g$. they call a priest boghog, because probably they use the word boghog; God; bread they call brightatin augsh, that is, Russian root; and thus of several other words to which their language is a stranger.

It is supposed that the Kamtschatkans lived formerly in Mungalia, beyond the river Amur, and made one people with the Mungals; which is farther confirmed by the Kamtschatkans having several words common to the Mungal Chinese language, as their terminations in ong, ing, oang, chin, cha, ching, ksi, ksung. The Kamtschatkans and Mungals are both of a middling stature, and swarthy, have black hair, broad face, a sharp nose, with the eyes falling in, eye-brows small and thin, a hanging belly, slender legs and arms; they are both remarkable for cowardice, boasting, and slavishness to people who use them hardly, and for their obstinancy and contempt to those who use them with gentleness. The Kamtschatkans in outward appearance resemble the other inhabitants of Siberia, but differ in this, that their faces are not so long; their faces stand more out, their teeth are thick, their mouths large, their stature middling, and their shoulders broad, particularly those who inhabit the sea coast. Before the Russian conquest, they lived in perfect freedom, having no chief, being subject to no one, nor paying any taxes; the old men, or those remarkable for their bravery, bearing the particular authority in their villages, though none had any right to command and inflict punishment. Their manner of living is slovenly to the last degree; they never wash their hands or face, or cut their nails: they eat with the dogs out of the same dish, which they never wash; they never comb their heads, but both men and women plait their hair in two locks, binding the end with small ropes. When any starts out, then they sew it with threads to make it lie close, by which means they are swarming with lice. Those that have not natural hair sufficient, wear false locks sometimes as much as weigh 10lbs. They place their chief happiness in idleness, and satisfying their natural appetites, which incline them to singing, lancing, and relating of love stories; and they think it more eligible to die than to lead a disagreeable life, which of ten leads them to suicide. This was so common after the conquest, that the Russians had great difficulty to put a stop to it. They have no notion of fame, riches, or honour, therefore covetousness, ambition, and pride are not known among them. On the other hand, they are careless, lustful, and cruel ; these vices occasion frequent quarrels among them, sometimes with their neighbours, not with a desire of increasing power, but to carry off provisions, or their girls, which is often practised as the most summary method of procuring a wife. 
As to religion, they helieve that almost every place in heaven and earth is tilled with different spirits, and they offer them sacrifices. Some carry little idols about them, or have them placed in their dwellings ; but with regard to God, they not only neglect to worship him, but, in case of troubles and misfortunes, they curse and blaspheme him. They are so totally ignorant of arithmetic, that it is said they cannot reckon above twenty, and that with the help of their fingers and toes. They reckon ten months in the year, sone of which are longer and some shorter; for they do not divide them by the changes of the moon, but by the order of particular occurrences that happen in those regions. They commenly divide one year into two, so that winter is one year, and summer another; the summer year begins in May, and the winter in November. They do not distinguish the days by any particular names, nor form them into weeks or months. They mark their ejoch as from some remarkable event, as the arrival of the Russians, or their first expedition to Kantschatka.' They are, however, very ingenious in some arts. They are exceedingly fond of iron instruments, such as hatchets, knives, or needles, nay, at the first arrival of the Russians, a piece of broken iron was looked upon as a great present; and even yet they receive it with thankfulness, finding use for the least fragment, either to point their arrows or wake darts, which they do byhammering it out cold between two stones. As some of them delight in war, the Russian merchants are forbidden to sell them any warlike instruments; but they are ingenious enough to make spears and arrows out of the iron pots and kettles which they buy; and they are so dexterous when the eye of a needle breaks, as to make a new eye, which they will repeat until nothing remains but the point.

\section{Garments, Dresses, \&c.}

Their clothes for the most part are marle of skins of deer, dogs, sea and land animals, and even of the skins of birds, those of difierent animals being frequently joined in the same garment. They make the upper garments sometimes by cutting the skirts all of an equal length, and sometimes leaving them long behind, in the form of a train, with wide sleeves, of a length to come down below the knee, and a hood behind, which in bad weather they put over their heads below their caps ; the opening above is only large enough to let their heads pass; they sew the skins of dogs' legs round this opening, with which they cover their faces in bad weather; and round their shirts and sleeves they put a border of, white dog-skin. They commonly wear two coats, the under coat with the hairy side inwards, the other side being dyed with alder; and the upper with the hair outwards. Black, white, or speckled skins are much esteemed. Both men and women use these garments, their dress only differing in their under clothing, and in the covering of their feet and legs. The women have an under garment, which they commonly wear at home, consisting of a breeches and waistcoat sewed together. The breeches are wide like those of the Dutch shippers, and tie below the linee, the waistcoat is wide above, and drawn round with a string. The 



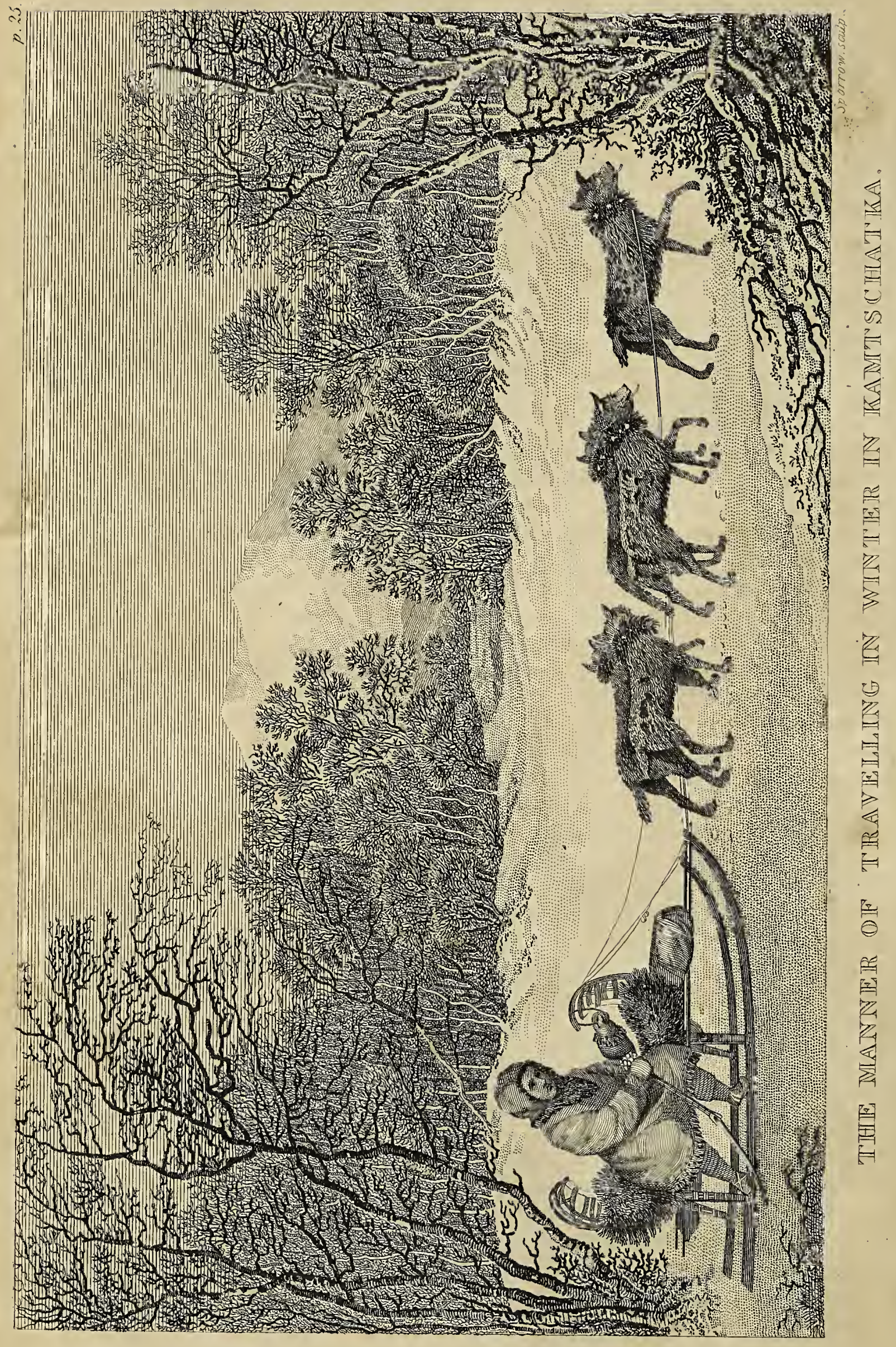


summer habits are made of dressed skins without hair; the winter garnents of deer or ram skins without hair. The Kantschatkans now wear linen shirts, which they buy from the Russians. The covering of their feet and legs is made of skins of different sorts. But the buskius, which both the Cossacks and Kamtschatkans use in the finest dress, is thus made: the sole is of fine seal skin, the upper part of fine white leather, the hinder quarters is of white dog-skin; what comes round the legs is of dressed leather, or dyed seal skin; the upper parts are embroidered. If a bachetor is observed to wear these, he is concluded to be upon a scheme of courtship. Thcy wear the same sort of caps as the people of Yakutski. In summer they rave a kind of hats of birch bark tied about their heads.

The Kuriles use in summer caps made of plaited grass. Around the Russ settlements, the women wear shirts, ruffes; waistcoats, caps, and ribands. The women do all their work in mittens; they formerly never washed their faces, but now they use both red and white paint; for white paint they make use of a rotten wood, and for red a sea plant, which they boil in seal's fat, and, rubbing their cheeks with it, make them very red. They dress most in the winter; especially when they visit. The common closhes for a Kanschatkan and his fanily will not cost him less than 100 rubles, for the coarsest worsted stockings, which cost in Russia twenty kopeeks, cannot be bought here for less than a ruble; and all other things in proportion. The Kuriles are more able to buy clothes than the Kamschatkans, for they can purchase for one sea-beaver as much as the Kamtschatkans can for twenty foxes; and one beaver costs the Kuriles no more trouble than five foxes do the Kanischatkans; for he must be a good hunter who catches more than ten foxes in a winter ; and a Kurile thinks himself unlucky if he does not catch three beavers in the season.

\section{Method of rovalling.}

The Kamtschatkans commonly travel in sledges drawn by dogs: the animals used for this purpose differ very little from the common house-dog; they are of a middling size, of various colours, though there seem to be more white, black, and gray than of any other. In travelling they make use of those that are castrated, and generally yoke four to a sledge. They drive ard direct their dogs with a crooked stick about four feet long, adorned with dififerent coloured thongs; this is looked upon as areat piece of fnery. They drive their sledge sitting upon their right side, with their feet hanging down; for it would be looked upon as a disgrace for a man to sit down at the bottom of the sledge, or to allow any person to drive him. It is very diffcult to travel in these sledges; for unless a man keeps the exactest balance, he is liable every moment, from the weight and narrowness of them, to be overturned. In a rugged road this would be very dangerous, as the dogs never stop till they come to some liouse, or are entangled by something upon the road, especially in going down steep hills, when they run with all their force, for which reason, in descending any great declivity, they unyoke all the dogs, except one, and lead them softly down. They likewise walk up hills, for it is as 
much as the dogs can do for to draw the sledge up empty. After a deep snow, before it has been hardened by a frost, there is no travelling with dogs, till a road be made, which is effected by a man going. before upon snow-shoes, whom they call brodor-skika.

The snow-shoes are made of two thin boards separated at the midAle, bound together at the ends, and with the fore parts bent a little upwards. The brodor-skika having one of these shoes upon each foot, leaves the dogs and sledge, and going oll, clears part of the road, then returning, leads forwards the dogs and sledge as far as the road is made; this he must continue till he comes to some dwelling house. This is very laborious, and it happens so often, that no driver ever sets out without his snow-shoes. When a storm of driven snow surprises them, they seek the shelter of some wood, and stay as long as the tempest lasts, which is sometimes a week. If they are a large company, they dig a place for themselves under the snow, and cover the entry with wood or brambles. Sometimes they hide themselves in caves or holes in the earth, wrapping themselves in their furs, and when thus covered they lie as warm as in their huts; they only require a breathing place, but their clothes must not be tight girt about them; for then the cold is insufferable. Another danger is, that in the severest frost several rivers are not frozen over; and as the roads for the most part lie close upon the rivers, the banks being: very steep, scarce a year passes without many being drowned. A disagreeable circumstance also, to those who travel in those parts, is, their having to pass through copses, when they run the risk of having their eyes scratched out, or their limbs broken; for the dogs always run most violently in the worst roads, and, to free themselves, very often overturn their drivers. The best travelling is in March or April, when the snow is become hard at the top; however, there is still this inconvenience attending it, that sometimes travellers are obliged to lodge two or three nights in desert places; and it is difficult to prevail upon the Kamtschatkans to make a fire, either for warming themselves or dressing their victuals, as they and their dogs eat dried fish, and find themselres so warm wrapped in their furs, that they need no other heat; nay, all the people of this climate bear cold so well, that they sleep in the open air as warm as others in a soft bed, and awake next morning perfectly refreshed and alert.

\section{State of Female Society in Egypt.}

\section{From Mrs. Belzoni's Account of the Women of Egypt, Nulia, and Syria.}

of HAving heard so much of Turks and Arabs, I took the opportunity while in Egypt, to observe the manners of the women in that country. On our arrival at Assouan, I went to visit the women of the aga of that place. I was met at the door by himself, his wife, his sister, her husband, two young children, three old women uglier than Macbeth's witches, and an old negro slave. I entered into a small yard, and a deal chair was brought me. The aga went out, and the women then stood round me, while the husband of the aga's sister made coffee and prepared a pipe, which lie presented me, not allowing 
the women to touch it. He durst not trust them with any thing, as he knew of their monkeyish tricks whenever he turned his back. He seemed to pride himself much on his great knowledge of the world; when he corrected the rough curinsity of the women, when they attempted to examine my dress too rudely.

$\because$ I made a sign I wished them to sit down, and in particular that the wife should take coffee with me; but he treated them very harshly; made me understand that coffee would be too good for them, and said water was good enough; at the same time he held the coffee-pot, pressing me to drink more: on my refusing, he locked it up in a small room, that the women might not drink it. By this time I had been so much among the women in Egypt, and compelled to smoke, that I could . easily finish my half pipe. After having smoked for some time, I laid it down; one of tle women took it up, and began to smoke: on seeing such a horrid profanation, the man took it from her with violence, and was going to beat her, which I naturally prevented. He filled it again, and offered it to me; but, as I did not wish to smoke any more, he went and carefully locked it up, making me understand, when I wanted it, it was at my service. I must confess, I felt hurt to see the distinction he made, but afterwards I saw the necessity of so doing.

"They always behaved to me not only with respect, but even with humility, so that their roughness seems not directed towards women in general; and I have often heard them remark to me, that if they treated these wornen as I was treated, they would become quite unruly: "A short time afterwards, the aga came in, and inquiring if they had served me with coffee and a pipe, he went to his treasury, and brought out some dirty bruised grapes, as a great treat, which he presented me, the poor women looking with wistful eyes towards the basket. In the impulse of the moment, I took it, and offered them to his wife, and then to the rest, who all refused; and though they did not dare to take any themselves, yet they pressed me to eat, and seemed astonished, when, on account of their dirt, I only took a small bunch. I kept the grapes in my hands for some time before I could muster resolution to eat them. I began at last, one by one, trying to wipe them in an handkerchief without their perceiving it; but I was mistaken, for their eyes was fixed upon me very closely. An old woman saw what I was doing, and ran and fetched me a burdock of water. I did not ask for water at first, as I was afraid to do any thing to offend them.

"I now gave my little present of beads and a looking glass, which contained a drawer; the beads pleased them, and the glass, being the largest they had ever seen, and made to stand by itself, was to. thein a matter of astonishment. To describe the tricks the women played with it, tearing it from each other, and setting it in any way but the right, would be thought a caricature. I at first atten pted to shew them the right way to use it, but there is no other metlood with those women than letting them have their own way; and I believe it is pretty well so in more civilized countries, or I anl much mistaken. When the wife perceived they had got the glass out of its frame, she put it in a little room, and locked it up with the beads. 
s. On the man coming in, they began to prepare to cook the dinner for the aga, which consisted of a dish of bamia boiled in mutton broth, pouxed over bread, with a little mutton and some minced meat, mixed up with rice into balls; what other ingredients might be mired, shall by me be nameless; the cleanliness of this preparation I have not eloquence to describe: the horror I felt at the idea that I should be obliged to eat of it, was more than my English stomach could reconcile' at that moment. They brought me all the dishes before they took then ont to the aga, and-Mr. B. was to dine with him: the first was the bamia, which 1 refused, but 1 took a piece of the boiled mutton, as being the cleanest, with some bread: that would not do, the wife took some of the minced meat and rice in her hands, and insisted on my eating it, making me understand it was the best. At last all was carried to the aga. I was then served with the customary coflee and pipe. The house, or rather stable, consisted of four wall, which had the sky for its ceiling, enclosing two small rooms, one in which the aga used to keep his treasure locked, such as coffee, coffee-cups, tobasco, \&c.; the other was the wife's, and contained all their great wardrobe, besides bread, onions, flour, dhourra, oil, and many other things of the kind. The furniture consisted of water-jars, sieves to clean the corn and sift the flour, a few earthen pots to cook in, some wooden bowls to eat, out of, an oven, and some burdocks for cooling water, a small coffee pot, and old mats to lie on. I took my leave, giving the children and women a small present of money, promising to call and see them on my return. Next morning, another wife of the aga sent me word that she should be glad to see me. I felt little inclination to go, but not wishing to make any distinction between them, I went, and found, to my surprise, a very pretty young woman. She lived next door to the other, who got upon the wall to see what passed between us. She had no cofiee to give me, but, instead, presented me with some dates and dhourra in grain. She seemed much afraid of the other wife. Though pretty in my eyes, she was not thought so by her own people; the other, though old, was considered the greatest beauty in Assouan, on account of her being so extremely fat. Their hair was plaited after the Nubian custom, adorned with a few gold ornaments, with plenty of stinking raw fat, and a certain bark of a tree beat in powder, to make it black besides, giving a horrid perfume, which they consider as a great improvement to their charms; it is not the same powder they use in blacking the eye-brows and cye-lids. I made her a present of some beads, which she tried to bide, aud I wished her farewell.

\section{Accoumt of the Bukinars, themr Houses, Customs, Marriage Ceremonies, and Religious Opinions.}

THE Bukhars are the inhabitants of Bukharia, a country on the borders of China. They are for the most part sun-burned, and black-haired; although some of them are very fair, handsome, and well made. They do not want politeness, and are addicted to commere, which they carry on with China, the Indies, Persia, and Russia : but they are ready to overreach those who deal with them. 
The habits of the men differ very little from those of the Tartars. Their girdles are like those of the Poles. The garments of the women differ in nothing from those of the men, and are commonly quilted with cotton. They wear bobs in their ears furteen inches long; part and twist their hair in tresses, which they lengthen with black ribbon embroidered with gold or silver, and with great tassels of silk and silver, which hang down to their heels; three other tufts of a smaller size cover their breasts. Both sexes carry about them prayers written by their priests, which they, licep in a small leathern purse by way of relies. The girls, and some of the women, tinge their nails red with the juice of an herb, called by them kena: they dry and pulverize it then mixing it with powdered alum, expose it in the air twenty-four hours before they uee it, and the colour lasts a long time. Both sexes wear close breeches, and boots of IRussia leather, very light, without heels, or rather soles; putting on galloches, or high-headed slippers, like the Turls, when they go abroad. They wear also the same sort of honets and covering for the head; only the women set of theirs with trinkets, smadl pieces of money, and Chinese pearls. Wives are distinguished from maids by a long piece of linen worn under their bonnets; which folding round the neck, they tie in a knot behind, so that one end of it hangs down to the waist.

The houses of the Bukhars are of stone, and pretty good; but their moveables consist chieny of Chinese trunks plated with iron. Upon these, in the day-time, they spread the quilts they made use of at night, and cover them with a cotton carpet of various colours. They have likewise a curtain sprigged with flowers and various figures; also assort of bedstead, half a yard high, and four yards long, which is lidden in the daytime with a carpet. They are very neat about their victuals; which are dressed in the master's chamber by his slaves, whom the Bukhars either take or buy from the Russians, Kalmucs, or other neighbonrs. For this purpose there are in the chamber, according to the largeness of the family, several iron pots, set in a.kind of range near a chinney. Some have little ovens made like the rest of the walls, with stifi clay or bricks. Their utensils consist of some plates and porringers made of Cagua wood or of China, and some copper vessels. A piece of coloured calico serves them instead of a table-cloth and napkins. They use neither chairs nor tables, knives nor forks, but sit cross-legged on the ground; and the meat being served up, they pull it to pieces with their fingers. Their spoons resemble our wooden ladles. Their usual food is minced meats, of which they make pies of the form of a half-moon; these serve for provisions when the Rukhars go long journeys, especially in winter. They carry them in a bag, having first exposed them to the frost; and when boiled in water, they make very good broth. Tea is their common drisk, of which they have a black sort prepared with milk, salt, and butter; eating bread with it, when they have anv.

The Bukhars buy their wives, paying for them more or less aceording to their handscmeness. The persons to be married must not see or speak to each other from the time of their contract, to the day of 
marriage. This is celebrated with three days' feasting, as they do great annual festivals. The evening before the wedding, a company of young girls meet at the bride's house, and divert themselves till midnight, playing, dancing, and singing. Next morning the guests assemble, and help her to prepare for the ceremony. Then, notice being given to the bridegroom, he arrives soon after, accompanied by ten or twelve of his relations. These are followed by some playing on "flutes; an Abus, a kind of priest, who sings, while he beats two little timbrels. The bridegroom then makes a horse race, which being ended, he distributes the prizes, six, eight, or twelve in number, according to his ability. They consist of damask, sables, fox-skins, calico, or the like. The parties do not see each other while the marriage ceremony is performing, but answer at a distance to the questions asked by the priest. As soon as it is over, the bridegroom returns home with his company ; and after dinner carries them to the bride's home, and obtains leave to speak to her. This done, he goes back, and returns again in the evening, when he finds her in bed; and in presence of the women, lays himself down by her in his clothes, but only for a moment. The same farce is acted for three days successively, but the third night he passes with her entirely, and the next day carries her home.

Although the prevailing religion throughout all Little Bukharia is the Mahometan, yet all others enjoy a perfect toleration. The Bukbars say that God first communicated the Koran to mankind by Moses and the prophets; and afterwards Mahomet explained and drew a moral from it, which they are obliged to receive and practise. They hold Christ to be a prophet, but have no notion of his sufferings. Yet they believe in the resurrection, but cannot be persuaded that any mortal should be eternally damned: on the contrary, they believe, that as the demons lead men into sin, so that the punishment will fall on them. They believe, moreover, that at the last day, every thing lout God will be annihilated; and, consequently, that all creatures, the devils, angels, and Christ himself, will die. Likewise, that after the resurrection, all men, excepting a few of the elect, will be purified or chastised by fire, every one according to his sius, which will be weighed in a balance. They say there will be eight different paradises for the good; and seven hells, where sinners are to be purified by fire; that they who will suffer most are liars, cheats, and others of that kind; thet the elect who do not feel the fire will be chosen from the good, viz. one ont of one hundred men, and one out of one thousand women; which little troop will be carried into one of the paradises, where they shall enjoy all manner of felicity, till it shall please God to create a new world. It is a sin, according to them, to say that God is in heaven. God, they say, is every where ; and therefore it derogates from his omnipresence to say that he is confined to any particular place.

They keep an annual feast of thirty days, from the middle of July to the middle of August, during which time they taste nothing all day; but eat twice in the night, at sun-set and midnight; nor do they drink any thing but tea, all strong liquors being forbidden. Whoever transgresses these ordinances is obliged to emancipate his 
most valuable slave, or to give an entertainment to sixty people; he is likewise to receive eighty-five strokes on the back with a leathern strap called dura. The common people, however, do not observe this fast exactly, and workmen are allowed to eat in the day-time. The Bukhars say prayers five times a day; before morning, towards noon, afternoon, at sun-set, and in the third hour of the night.

BAGDAD.

The following View of Society in Bagdad is taken from Sir R. Porter's Travels in Georgia, Persia, Babylonia, \&c.

THE wives of the higher classes in Bagdad are usually selected from the most beautiful girls that can be obtained from Georgia and Circassia; and, to their natural charms, in like manner with their captive sisters all over the East, they add the fancied embellishments of painted complexious, hands and feet dyed with henna, and their hair and eye-brows stained with rang, or prepared indigo-leaf. Chains of gold, and collars of pearls, with various ornaments of precious stones, decorate the upper part of their persons, while solid bracelets of gold, in shapes resembliug serpents, clasp their wrists and ancles. Silver and golden tissued muslins, not only form their turbans; but frequently their under-garments. In summer, the ample pelisse is made of most costly shawl, and in cold weather lined and bordered with the choicest firs. The dress is altogether very becoming ; by its easy folds, and glittering transparency, shewing a fine shape to advantage, without the immodest exposure of the open vest of the Persian ladies. The humbler females generally move abroad with faces totally unveiled, having a handkerchief rolled round their heads, from beneath which their hair hangs down over their shoulders, while another piece of linen passes under their chin, in the fashion of the Georgians. - Their garment is a gown of a shift form, reaching to their ankles, open before, and of a gray colour. Their feet are completely naked. Many of the very inferior classes stain their bosoms with the figures of circles, half-moons, stars, \&c. in a bluish stamp. In this barbaric eimbellishment, the poor damsel of Irak Arabi has one point of rarity resembling that of the ladies of Irak Ajem. The former frequently adds this frightful cadaverous hue to her lips; and, to conplete her savage appearance, thrusts a ring through the right nostril, pendent with a flat button-like ornament set round with blue or red stones.

But to return to the ladies of the higher circles, whom we left in some gay saloon of Bagdad. When all are assembled, the evening meal, or dinner, is soon served. The party, seated in rows, then prepare themselves for the entrance of the show; which, consisting of music and dancing, continues in noisy exhibition through the whole night, At twelve o'clock, supper is produced; when pilaus, kabobs, preserves, fruits, dried sweatmeats, and sherbets of ever fabric and flavour, engage the fair convives for some time. Between this second banquet and the preceding, the perfumed narquilly is never absent from their rosy lips; excepting when they sip cofree, or indulge a general shout of approbation, or a hearty peal of laughter, at the 
freaks of the dancers, or the subject of the singers' madri als. But no respite is given to the entertainer's; and, during so long a stretch of merriment, should any of the happy guests feel a sudden desire for temporary repose, without the least apology she lies down to sleep on the luxurious carpet that is her seat ; and thus she remains, sunk in as deep an oblivion as if the nummud were spread in her own chamber- Others speedily follow her example, sleeping as sound; notwithstanding the bawling of the singers, the horrid jangling of the guitars, the thumping on the jar-like double-drum, the ringing and loud clangour of the metal bells and castanets of the dancers, with an eternal talking in all keys, abrupt langhter, and vociferous expressions of gratification, maling in all a full concert of distracting sounds, suthcient, one might suppose, to awaken the dead. But the merry tumult and joyful strains of this conviviality gradually become fainter and fainter; first one and then another of the visitors (while even the performers are not spared by the soporific god) sink down under the drowsy influence; till, at length, the whole carpet is covered with the sleeping beauties, mixed indiscriminately with handmaids, dancers, and musicians, as fast asleep as themselves.

The business, however, is not thus quietly ended. "As soon as the sun begins to call forth the blushes of the morn, by lifting the veil that shades her slumbering eyelids," the faitluful slaves rub their own clear of any lurking drowsiness, and then tug their respective mistresses by the toe or the shoulder, to rouse them up to perform the devotional ablutions usual at the dawn of day. All start mechanically, as if touched by a spell; and then cominences the splashing of water, and the muttering of prayers; presenting a singular contrast to the vivacious scene of a few hours before. This duty over, the fair devotees shake their feathers like birds from a refreshing shower; and tripping lightly forward with garments, and perhaps looks, a little the worse for the wear of the preceding evening, plunge at once again into, all the depths of its amusements. Coffee, sweetmeats, kaliouns, as before, accompany every obstreperous repetition of the midnight song and dance; and adl being followed up by a plentiful breakfast of rice, meats, fruits, \&c., towards noon the party separate; after having spent between fifteen and sixteen hours in this riotous festivity.

\section{Batrcans.}

The Barcans are the natives of Barca, a country of Africa. The inhabitants of the mariime towns are more civilized than those that dwell in the inland parts. The first profess Mahometanism, and have imbibed some notions of humanity and justice; whilst the latter, who have no sign of worship among them, are altogether savage and brutish. They are a sort of Arabs, and, like them, live entirely upon plunder. By them, this tract, which before was a continued desart, was frst inhabited. At their first coming in, they settled in one of the best places of the country; but as they multiplied, and had frequent wars with one another, the strongest drove the weakest out of the best spots, and sent them to wander in the desart parts, 
where they live in the most miserable manner, their country hardly aftording one single necessary of life. Hence they are said to be the ugliest of all the Arabs, their bodies having scarcely any thing but skin and bone, their faces meagre, with fierce ravenous looks; their garments, which are commonly what they take from the passengers who go through those parts, tattered with long wearing; whilst the poorest of them have scarce a rag to cover their nakedness. They are most expert and resolute robbers; that being their chief employment and livelihood; but the travellers in these parts are so few, that the Barcans are often necessitated to make distant excursions into Numidia, Libya, and other southern countries. Those that fall into their. hands are made to drink plenty of warm milk, then they hang them up by the feet, and shake them, in order to make them vomit up any money they think they have swallowed; after which they strip them of all their. clothes, even to the last rag, but with all this inhumanity, they generally spare their lives, which is more than the other African robbers do. Yet notwithstanding every artifice they can use, the Barcans are so poor that they commonly let, pledge, or sell their children to the Sicilians and others, who supply them with corn, especially, before they set out on any long excursion.

\section{Mr. Mungo Park's Account of Sego in Africa.}

Mr. PARK informs us, that Sego contains about 30,000 inhabitants. The king of Bambarra constantly resides at Sego; he employs many slaves in conveying people over the rivers; and the money they receive, though the fare is only ten cowrie shells for each individual, furnishes a considerable revenue to the king in the course of a year. The canoes are of a singular construction, each of them being formed of the trunks of two large trees rendered concave, and joined together, not side by side, but endwise, the junction being exactly across the middle of the canoe; they are therefore very long, and disproportionably narrow, and have neither decks nor masts; they are, however, very roomy, for our author observed in one of them four horses, and several people, crossing over the river.

The river of this extensive city, the numerous canoes upon the river, the crowded population, and the cultivated state of the surrounding country, formed altogether a prospect of civilization and magnificence, which he little expected to find in the bosom of Africa. He met not, however, in Sego with that hospitality which he had experienced in some other African towns. The Moors, who abound in it, and whose bigotry renders them implacable enemies: of every white man suspected of being a Christian, persuaded the king that it was for no good purpose he had come into the territories of Bambarra. He was therefore ordered to take up his residence at a village a little distant, without being admitted into the royal presence. Even there, so strong was the prejudice that had been excited against him, that no person would admit him into his house. About sun-set, however, as he was preparing to pass the night in the top of a tree, that he might not be torn to pieces by wild beasts, a poor Negro woman conducted him to her hut, dressed a fine fish for his supper, and 
furnished him with a bed to sleep on. She then called to the female part of her family, who had stood gazing on him all the while with fixed astonishment, to resume their task of spinning cotton, in which they spent great part of the night. They lightened their labour by songs, one of which was composed extempore, for our author was hiniself the subject of it. It was sung by one of the young women, the rest joined in a sort of chorus. "The air was sweet and plaintive, and the words, literally translated, were these- "The winds roared, and the rains fell. The poor white man, faint and weary, came and sat underour tree. He has no mother to bring him milk; no wife to grind his corn."-Chorus. "Let us pity the white man; no mother has he," \&c. \&c. "Trifling (says Mr. Park) as this recital may appear to the reader, to a person in ny situation the circumstance was affecting in the highest degree."

Having remained three days in this village, he was dismissed on the fourth, after receiving from the king 5000 cowries, to enable him to purchase provisions in the eourse of his journey: Though this sum amounted only to one pound sterling, so cheap are the necessaries of life in Bambarra, that it was sufficient to purchase provisions for limself, and corn for his horse, for 50 days.

\section{The Carbonari.}

THE following description is given of this community by one of the initiated. The Carbonari of Italy owe their origin to Cardinal Ruffo, who in the year 1812, in conjunction with some Neapolitan emigrants formed a secret sect, known at first under the name of Calderari, for the purpose of restoring the ancient dynasty of privileges and pontifical influence. The Calderari consisted of a considerable nuniber of banditti and lazaroni, and their society fell into disrepute. Subsequently a grand or directoral lodge was organized; and this society took the name of Carbonajia, (the coal pit,) or rather a place where the coal is carbonized, and made into charcoal. The separate meetings were called barrache (markets,) and the members Carbonari (or coal burners). This society is at once political and religious. Its principles have their foundation in the purest maxims of the gospel, from which they derive eternal hatred to political and religious tyranny. They promise obedience to the law as far as it is founded on equity, and respect to those who do justice worthily. Ther hatred against tyranny and intolerance is so much the greater, because they consider $J$ esus Christ as the most illustrious victim of the arbitrary acis of governors and priests:

The Carbonari are distinguished by their ranks and the cross shines in all their symbolical signs." Their symbolical words are taken from the coal-trade, because their first chiefs lived, like coal-burners, in solitude, to withdraw themselves from tyranny. As to the words, the signs, and the secrets of the association, we must be silent. - The flag of the Carbonari is tricoloured; the colours are black, red, and blue. The black repiesents death, and the coal in its natural state-the red indicates liberty, glory, and blood ; that is to say, the battles, without which Italy could not hope to establish its 
liberty-blue is the emblem of constancy, without which every enterprise fails. The Neapolitan armies raised the fag of the Carbonari. It was also raised in Piedmont during the revolution. The object of the iustitution was to clear the Apennines of the ravening wolves which infest them. The Apennines signify all Italy; the ravening wolves are the foreign rulers, the oppressors of the people, and all the agents of power who gave into arbitrary proceedings against then. The efforts of the Carbonari consisted in spreading their principles, in enlightening the people, and in creating an Italian League, to recover the independence of the Italian states from foreign powers, and establish internal liberty. The Abruzzas, and even Calabrias, have witnessed the most astonishing conversions." The banditti, who infested the mountains, have changed the musket for. the hoe-so much have they been affected by pure and enthusiastic arlmonition.

The Carbonari is composed of all classes of the people. The noble and the peasant, the soldier and the priest, the sailor and the citizen, the judge and the lazaroni, are united in it.

\section{MORLACCHI.}

THESE are the inhabitants of Morlachia, in Dalmatia. They chiefly inhabit the pleasant valleys of Koter, along the rivers Kerha, Cetlina, Narenta, and among the inland mouniains of Dalmatia. They are by some said to be of Walachian extraction, as is indicated by their name: Morlachia being a contraction of MauroWalachia, that is, Black Walachia; and the Walachians are said to be descendants of the ancient Roman colonies planted in these countries. This, however, is denied by the Abbé Forits, who published a volume of travels in that country. He informs us, that the origin of the Morlacchi is involved in the darkness of barbarous ages, together with that of many other nations, resembling them so much in customs and language ; that they may be taken for one people, dispersed in the vast tracts from the Adriatic Sea to the Frozen ocean.

The emigrations of the various tribes of the Slavi, who, under the names of Scythians, Geti, Goths, Hunns, Slavini, Croats, Avari, and Vandals; invaded the Roman empire, and particularly the Ilyrian provinces, during he decline of the empire, must have strangely perplexed the genealogies of the nations which inhabited it, and which perhaps removed thither in the same manner as at more remote periods of time. The remainder of the Ardioei, Autariati, and the other Illyrian people anciently settled in Dalmatia, who would not reconcile themselves to a dependence on the Romans, might nevertheless form a union with foreign invaders, resenbling themselves in dialect and customs; and, according to our author, many families, driven out of Hungary by the Mogul Jenghiz Khan and his successors, might people the deserted valleys among the mountains of Dalmatia.

This conjecture is also somewhat confrmed by the traces of the Calmuk Tartars, still to be found in a part of that country called Zara. With regard to the etymology of the name, the Abbe observes, 
that the Morlacchi generally call themselves, in their own language, Vlassi; a national term, of which no vestige is found in the records of Dalmatia until the thirteenth century. It signifies powerful men, or men of authority : and the denomination of Moro Vlassi, now corrupted to Morlacchi, may perhaps point out the origin of the nation. This word may possibly signify the conquerors that came from the sea; Moor, in all the dialects of the Sclavonian language, signifying the sea.

The Morlacchi are so different from the inhabitants of the seacoast in dialect, dress, dispositions, and customs, that they seem clearly to be of a different origin, or at least the colonies must have settled at such distant periods from each other, that they have had time to alter in a great measure their national character. There is also a remarkable diversity among the Morlacchi themselves in different districts, probably on account of the different countries from whence they came. With regard to their character, they are much misrepresented by their maritime neighbours. The inhabitants of the sea coast of Dalmatia tell many frightiful stories of their avarice and cruelty; but these, in our author's opinion, are all either of an ancient date, or, if any have happened in later times, they ought rather to be ascribed to the corruption of a few individuals, than to the bad disposition of the nation in general; and though thievish tricks are frequent among them, he informs is that a stranger may travel securely through this country, where he is "faithfully escorted and hospitably treated.

The greatest danger is from the Haiducks, or banditti, of whom there are great numbers among the woods and caves of these dreadful mountains on the confines. There, says our author, a man ought to get himself escorted by a couple of these honest fellows : for they are not capable of betraying him, although a banditti; and their situation is commonly more apt to create compassion than diffidence. They live among the wolves, wandering from one precipice to another, exposed to the severity of the seasons, and often languish in want of the necessaries of life, in the most hideous and solitary caverus. Yet they very seldom disturb the tranquillity of others, and prove always faithful guides to travellers; the chief objects of their rapine being sheep and oxen, to supply them with food and shoes. Sometimes it happens, that, in their extreme necessity, the Haiducks go in parties to the shepherds' cottages, and rudely demand something to eat; which they immediately take by force, if any hesitation is made. It is seldom, indeed, that they meet with a refusal, or with resistance, as their resolution and fury is well known to be equal to the savage life they lead.

The Haiducks look upon it as a meritorious action to kill the Turks, being led to this, not only by their natural ferocity, but inflamed by a mistaken zeal for religion, and the discourses of their fanatic priests. But the Morlacchi are open and sincere to such a degree, that they would be taken for simpletons in any other country; and accordingly they have been : so often duped by the Italians, that the faith of an Italian, and the faith of a dog, are synonymous among them. They are very hospitable to strangers; and their hos- 
pitality is equally conspicuous among the rich and poor. The rich prepares a roasted lamb or sheep, and the poor with equal cordiality offer's whatever he has; nor is this generosity confined to strangers, but generally extends itself to all who are in want. When a Morlach is on a journey, and comes to lodge at a friend's huuse, the eldest daughter, or the new-married bride, if there happens to be one, receives and kisses him when he alights from his horse, or at the door of the house, but a foreigner is rarely favoured with these female civilities; on the contrary, the young women hide themselves, and keep out of the way.

The Morlacchi have little notion of domestic economy, and often consume in a week as much as would be sufficient for several months, whenever any occasion of merriment occurs. A marriage, the holyday of a saint, the arrival of relations or friends, or any other joyful incident, consumes ail the provisions in the house. Yet they are great economists of their.wearing apparel. Nothing but an absolute impossibility hinders a Morlach from being punctual, and if he cannot repay the money he borrowed at the appointed time, he carries a small present to his creditor, and requests a longer term. Thus, from term to term, and present to present, he often pays double what he owed.

Friendship is lasting among the Morlacchi. They have even made it a kind of religious point, and tie the sacred bond at the foot of the altar. The Sclavonian ritual contains a particular benediction for the solemn union' of two males or two females in presence of the congregation. The male friends thus united are called Pobratimi, and the female Posestreme, which means, half-brothers and half-sisters. Their duties are, to assist each other in every case of need or danger, to revenge mutual wrongs, and such like. The enthusiasm is often carried so far as to risk and lose lives for each other, although these savage friends are not celebrated like Pylades and Orestes. If discord happens to arise between two friends, it is talked of all over the country as a scandalous novelty; and there have been some recent examples of it, which the old Morlacchi attribute to their intercourse with the Italians. But as the friendships of the Morlacchi are strong, so their quarrels are unextinguishable. They pass from father to son; and the mothers put their children in mind of their duty to rerenge their father, if he has had the misfortune to be killed, and to shew them often the bloody shirt and arms of the dead.

A Morlach is naturally inclined to do good to his fellow-creatures, and is full of gratitude for the smallest benefit, but implacable if insulted or injured. A Morlach who has killed another of a powerful family, commonly saves himself by flight, and keeps out of the way for several years. If during that time he has been fortunate enough to' escape the search of his pursuers, and has got a small sum of money, he endeavours to obtain pardon and peace; and that he may treat about the conditions in person, he asks and obtains a safeconduct, which is faithfully maintained, though only verbally granted. Then he finds mediators, and on the appointed day the relations of the hostile families meet, and the criminal is introduced, dragging himself along on his hands and feet, the musket, pistol, or cutlass, with 
which he committed the murder, hung about his neck; and while he continues in that humble posture, one or more of his relations recites a panegyric on the dead, which sometimes rekindles the flame of revenge, and puts the poor prostrate in no small danger. It is the custom in some places for the offended party to threaten the criminal, holding all kinds of arms to his throat, and, after. much entreaty, to consent at last to accept of his ransom. These pacifications cost dear in Albania, but the Morlacchi nake up matters sometimes at a small expense; and every where the business is concluded with a feast at the offender's charge.

The Morlachs, whether they be of the Roman or Greek church, have very singular ideas about religion; and the ignorance of their teachers daily angment this evil. They are as firmly persuaded of the reality of witches, fairies, enchantnients, nocturnal apparitions, and sortileges, as if they had seen a thousand examples of them. Nor do they make the least doubt about the existence of vampyres; and attribute to them, as in Transylvania, the sucking the blood of infants. Therefore, when a man dies suspected of becoming a vampyre, or vukodlak, as they call it, they cut his hams, and prick his whole body with pins, pretending, that after this operation he cannot walk about. There are even instances of Morlacchi, who, imagining that they may possibly thirst for children's blood after death, intreat their heirs, and sometimes oblige them to promise to treat them as vampyres when they die. The boldest Haiduck would fly trembling from the apprehension of a spectre, ghost, or phantom, or such like goblius, as the heated imaginations of credulous and superstitious people lead them to think they see. The women are still more timorous, and some of them, by often hearing themselves called witches, actually believe they are so.

Great discord reigns in Morlachia between the Latin and Greek communions, which their respective priests fail not to foment, by telling a thousand little scandalous stories of each other. The churches of the Latins are poor, but clean; those of the Greeks are poor, but shamefully ill kept. Our author has seen the curate of a Morlach village sitting on the ground in the churchyard to hear the confession of women on their knees by his side : a strange posture indeed! but a proof of the innocent manners of those good people, who have the nost profound veneration for their spiritual pastors; who, on their part, frequently make use of a discipline rather military, and correct the bodies of their offending flock with the cudgel.

They also impose on the credulity of these poor mountaneers, by selling certain superstitious scrolls, called zapiz, on which they write sacred names, and sometimes add others very improperly joined. The virtues attributed to these zapiz are of the same nature as those which the Basilidians attributed to their monstrously cutstones. The Mollacchi carry them sewed in their caps, to cure or prevent diseases, and tie them to the horns of their oxen. The composers of the trumpery take every method to maintain the credit of their profitable trade, in spite of its absurdity, and the frequent proofs of its inutility. And so great has their success been, that not only the Morlacchi, but even the Turks near the borders, provide themselves plentifully with 
zapiz from the Christian priests, which not a little increases their income, as well as the reputation of the commodity.

The Morlacchi having also much devotion, and many of the ignorant people in Italy having little less, to certain copper and silver coins of the low empire, or to Venetian contemporary pieces, which pass among them for medals of St. Helen, they think they cure the epilepsy and such like. They are equally fond of an Hungarian coin called fretizza, which has the Virgin and Child on the reverse; and one of those is a most acceptable present to a Morlach.

The bordering Turks not only keep with devotion the superstitious zapiz, but frequently bring presents, and cause masses to be celebrated to the image of the Virgin, which is doubtless in contradiction to the Koran; yet when saluted in the usual manner in that country, by the name of Jesus, they do not answer. Hence, when the Morlacchi, or other travellers, meet them on the confines, they do-not say, Huaglian Issus, "Jesus be praised," but Huaglian Bog, "God be praised." Innocence, and the natural liberty of pastoral ages, are still preserved anong the Morlacchi. Pure cordiality of sentiinent is not there restrained by circumstances. A young handsome Morlach girl, who meets a man of her district on the road, kisses him affectionately, without the least immodest thought; and our author has seen all the women and girls, all the young men and old, kissing one another as they came into the church yard, on a holiday on the road, and at the fairs in the maritime towns. In times of feasting and merriment, however, amours often take their beginning, and frequently end: in marriage when the lovers are agreed. For it very rarely happens in places distant from the coast, that a Morlach often carries off a girl against her will, or dishonours her ; and were such attempts made, the young woman would be able to defend herself, the women in that country being little less robust than the men. But the custom is for the woman herself to appoint the time and place of being carried off, in order to extricate herself from other suitors from whom she may have received some token of love, as a brass ring, a little knife, or such like.

The dress of the unmarried women is the most complex and whimsical, in respect to the ornaments of the head; for when they are married; they are not allowed to wear any thing but a handkerchief tied about it. The girls use a scarlet cap, to which they commonly fasten a veil hanging down upon the shoulders, as a mark of virginity. The better sort adorn their caps with different sorts of silver coins, among which are frequently seen very ancient and valuable ones; they have also ear-rings of very curious workmanship, and liave small silver chains with the figures of half-moons fastered to the end of them. But the poor content themselves with plain caps; or, if they have any ornaments, they consist only of small exotic shells; small glass-beads, or bits of tin. The principal merit of these caps is to attract atten: tion by the noise they make on the least motion of their heads. Hence half-moons of silver or of tin, litlle chains and hearts, false stones and shells, together with all kind of splendid trumpery, are readily admitted into their hair-dress.

In some districts, they fix tufts of various colours, resembling two horns, on their caps ; in others, set artificial flowers; and in the 
variety of these capricious ornaments, sometimes a fancy not inelegant is displayed. Their. holiday shifts are embroidered with red silk and sometimes with gold, which they work while they attend their flocks, and this is executed very nicely. Both old and young women wear about their necks large strings of round glass beads, of various sizes and colours; and many rings of brass, tin, or silver, on their fingers. Their bracelets are of leather, covered with tin or silver; and they embroider their stomachers, or adorn them with beads or shells.' A broad wooden girdle surrounds their petticoat, which is commonly decked with shells, and of blue colour, called modrina. Their gown, called sadah, as well as petticoat, is of a kind of serge, and both reach near the ankle. They use no modrina in summer, and only wear the sadah without sleeves, over a linen petticoat or shift. The girls always wear red stockings, and their shoes are, like those of the men, called opanke. The sole is of undressed ox-hide, and the upper part of sheep-skin thongs knotted, which they call apute. These they fasten about the ankles like the ancient cothurnus. Even the richest unmarried women are not allowed to wear any other shoes, though after marriage they. may lay aside the opanke, and "Ise the Turkish slippers. The girls keep their hair tressed under their caps, but when married they let it fall dishevelled on the breast, or tie it under the chin; and always have medals, beads, or bored coins, in the Tartar or American mode, twisted amongst it. An unmarried woman who falls under the imputation of want of chastity, runs the risk of having her red cap torn off her head publicly by the curate; and her hair cut by some relation, in token of infamy. Hence, those who fall into an illicit amour, commonly lay aside the badge of virginity, and remove to some distance:

Nothing is more common among the Morlacchi than marriages concluded by the old people of the respective families, when the young parties live at a great distance, and neither see nor know each other; and the ordinary motive of these alliances is the ambition of being related to a numerous and powerful family, famous for having produced valiant men. The father of the future bridegroom, or some other relation of mature age, goes to ask the young man, or rather a young woman, of such a family, not having commonly any determinate choice. Upon this, all the girls of the house are shewn to him, and he chooses which he likes best, though he generally respects the right of seniority. A denial in such case is very rare, nor does the father of the maid inquire much into the circumstances of the family that asks her.

Sometimes a daughter of the master is given in marriage to the servant or tenant. On these occasions the Morlacchi girls enjoy a privilege which ours would wish to have, as in justice they certainly ought. For he who acts by proxy, having obtained his suit, is obliged to go and bring the bridegroom; and if, on seeing each other, the young couple are content, the marriage is concluded, but not otherwise. In some parts it is the custom for the bride to go to see the house and family of the proposed husband, before she gives a definitive answer; and if the place or persons are disagreeable to her, she is at liberty to cancel the contract. But if she is contented, she returns to her father's house, escorted by the bridegroom and nearest 
relations. There the marriage day is appointed; on which the bridegroom comes to the bride's house, atiended by all his friends of greatest note, who on this occasion are called svati, and are all armed, and on horseback, in their holiday clothes, with a peacock's feather in their caps, which is the distinctive ornament used by those who are invited to weddings. The company goes armed, to repulse any attack or ambush that might be intended to disturb the feast. The bride is conducted to a church veiled, and surrounded by the svati on horseback; and the sacred ceremony is performed amidst the noise of muskets, pistols, barbaric shouts, and acclamations, which continue till she return to her father's house, or to that of her husband, if not far off. Each of the svati has his particular inspection, as well during the cavalcade as at the marriage feast, which begins immediately on their return from church. The parvinaz precedes all the rest, singing such songs as he thinks suitable to the occasion.

Abbé Fortis describes a number of ridiculous ceremonies that follow, which are not worth quoting. The first day's entertainment is sometimes made at the bride's house, but generally at the bridegroom's, whither the svati hasten immediately after the nuptial benediction. The most extravagant abundance reigns in these feasts; and each of the svati contributes, by sending a share of provisions. All sorts of domestic fowls, kids, lambs, and sometimes venison, are heaped in prodigal quantities upon their tables; but the Morlacchi never eat veal.

This abhorrence to calves' flesh is very ancient among them. St. Jerome, against Jovinian, takes notice of it; and Torneo Marnavich, a Bosnian writer, who lived in the seventh century, says, that the Dalmatians, uncorrupted by the vices of strangers, abstain from eating calves' flesh, as an unclear food, even to his days. The women relations never dine at table with the men, but always by themselves. After dinner, they pass the rest of the day in dancing, singing ancient songs, and in games of dexterity, or of wit and fancy; and in the evening, at a convenient hour after supper, the three ritual healths having first gone round, viz. 1. The Saint Protector of the Family; 2. The Holy Faith; and 3. A certain sacred Name; the knum accompanies the bridegroom to the matrimonial apartment, which commonly is the cellar or the stable, whither the bride is also conducted by the diveri and the staches; but the three last are obliged to retire; and the knum remains alone with the new-married couple. If there happens to be any bed prepared better than the straw, he leads them to it; and having untied the bride's girdle, he causes them both to undress each other reciprocally. Next day the bride, without her veil and virginal cap, dines at table with the svati, and is forced to hear the coarse equivocal jests of her indelicate and sometimes intoxicated company. These nuptial feasts, called sdrave by the ancient Hunns, and by the Morlacchi sdravize, contain three, six, eight, or more days, according to the ability of the family. The new-married wife gets no inconsiderable profit in these days of joy, and it nearly amounts to much more than all the portion she brings with her, which often consists of nothing but a cow, and her clothes: nay; sometimes the parents, instead of giving money with their daughters, get some- 
thing from the bridegroom by way of price. The bride carries water every morning to wash the hands of her guests, as long as the feasting lasts; and every one throws a small piece of money into the bason after washing. The brides are also permitted to raise other little contributions among the svati, by hiding their shoes, caps, knives, or some other necessary part of their equipage, which they are obliged to ransom by a piece of money, according as the company rates it. And, besides all these voluntary and extorted contributions, each guest must give some present to the new-married wife at taking leave the last day of the sdravize, and then she also distributes some trifles in return, such as shirts, caps, handkerchiefs, and the 'like. The nuptials are almost precisely the same throughout all the vast country inhabited by the Morlacchi; and those in use among the peasants of Dalmatia, Istria, and the islands, differ but little from them.

Yet among these particular varieties, there is one, of the island Zarine, near Sebenico, remarkable enough ; for there the starisvat, whether drunk or sober, must, with his naked broad-sword, strike the bride's crown of flowers off her head, when she is ready to go to bed. And in the land of Pago, in the village of Novoglia, there is a custom more comical, and less dangerous, but equally savage. After the marriage contract is settled, and the bridegroom comes to conduct his bride to church, her father or mother, in delivering her over to him, makes an exaggeration of her ill qualities: "Know, since thou wilt lave her, that she is good for nothing, ill-natured, obstinate, \&c." On which the bridegroom, affecting an angry look, turns to the young woman, exclaiming, "Ah! since it is so, I will teach you to behave better;" and at the same time regales her with a blow or a kick, or some similar piece of gallantry, which is by no means figurative. And it seems in general, that the Morlach women, the inhabitants of the cities excepted, do not much dislike a beating either from their husbands or lovers.

Our author gives a most disgusting picture of the nastiness of the Morlacchi women after marriage; and says, that the mortifying manner in which they are treated by their husbands, is both the cause and effect of this neglect of their persons. He often lodged in Morlach houses, but observed that the female sex is universally treated with contempt. The pregnancy and births of those women would be thought very extraordinary anong us, where the ladies suffer so much, notwithstanding all the care and circumspection used before and after labour. But a Morlach woman neither changes her food nor interrupts her daily fatigue on account of her pregnancy; and is often delivered in the fields, or on the road, by herself; and takes the infant, washes it in the first water she finds, carries it home, and returns the day after to her usual labour, or to feed her flock. The infants, thus carelessly treated in their tenderest moments, are afterwards wrapped in miserable rags, where they remain three-or four months under the same ungentle management; after which they are set at liberty, and left to crawl about the cottage till they are able to walk upright by themselves; and at the same time acquire that singular degree of strength and health, with which the Morlacchi are 
enlowed; when, without the least inconvenience, they can expose their naked breasts to the severest frosts and snow. The infants are allowed to suck their mother's milk till she is with child again; though that should not happen for four, five, or six years. The length of the breasts of the Morlacchi women is extraordinary; for it is certain, that they can give the teat to their children over their: shoulders, or under their arms. They let the boys run about, without breeches, in a shirt which reaches only to the knee, till the age of thirteen or fourteen; following the custom of Bossina, subject to the Porte, where no capitation tax is paid for boys till they wear breeches, they being considered till then as children, not capable of earning their bread.

On the occasion of birth, and especially of the first, all the relations and friends send presents of meat to the woman in child-bed, or rather to the woman delivered; and the family makes a supper of all those presents together. The women do not enter the church till forty days after the child-birth. The Morlacchi pass their youth in the woods, attending their flocks and herds; and in that life of quiet and leisure, they often become dexterous in carving with a simple knife: they make wooden cups, and whistles adorned with fanciful bas reliefs, which are not void of merit, and shew the genius of the people.

Parias, or Perreas.

THIs is a tribe of Hindoos, so peculiarly degraded beyond all others, that they live by themselves in the outskirts of towns; and, in the country, build their houses apart from the villages, or rather have villages of their own, furnished with wells; for they dare not fetch water from those which other families make use of ; and, lest these latter should inadvertently go to one of theirs, they are obliged to scatter the bones of dead cattle about their. wells, that they may be known. They dare not in cities pass through the streets where the Bramins live; nor set foot in their villages where they dwell; nor enter a temple, either of their god Wissnow or Eswara; because they are held impure. They get their bread by sowing, digging, and building the walls of mud houses; most of those inhabited by the common people being raised by these Parias; who do all such kinds of dirty work, as other people will not meddle with. Nor is their diet much more cleanly; for they eat cows, horses, fowls, or other carrion, which die of themselves.

One would scarce imagine that contention for precedency should ever occur among a people who have renounced all cleanliness, and, like swine, wallow in filth, and who are held in such an utter contempt by the rest of the Hindoos; yet pride has divided the Parias into two classes : the first are simply called Parias, the other Seriperes. The employment of these last, is to go abroad selling leather, which they dress; also to make bridles ; and some of them serve for soldiers. The Parias, who reckon themselves the better fainily, will not eat in the houses of the Seriperes; who must pay them respect, by lifting their hands aloft; and standing upright before them. The Seriperes? 
when they marry, cannot set up a panaal, a kind of garland, before their doors, made with more than three stakes or trees; else the whole city would be in motion. They are, in fact, slaves; for when any person of authority dies; in the families of Komittis, Sittis, Palis, farriers or goldsmiths, and the relations incline to give some clothes to the Seriperes, their beards must be shaven; and when the corpse is carried out of town to be burned or interred, they must do that office; for which each receives a piece of silver worth three and a half sous. These Seriperes are called, at Surat, Kalalchors; that is, in the Persian language, eat-alls, or eaters at large. Nothing can offend an Hindoo more than to be called an Halalchor; yet these poor people submit to all this drudgery and contempt without repining.

They are very stupid and ignorant, and even vicious, from their wretched way of life; the Bramins and nobility shun them as if they had the plague, looking on the meeting of a Paria as the greatest misfortune. To conie near one of them is a sin,-to touch them a sacrilege. If a Paria were dying, it is infamy to visit him, or to give him the least assistance, even in the utmost distress. A Bramin, who touches a Paria, immediately washes himself from the impurity. Even their shadow and breath being reckoned contagious, they are obliged to live on the east side of their towns, thai the westerly winds which reign in their country may keep back their breath. And a Bramin may kill one of these unhappy creatures, if he does not avoid it by getting out of his way. In short, they think them reprobated by God, and believe the souls of the damned enter into the Parias, to be punished for their crimes. Yet the mission have found among these dregs of the people very active and zealous catechists, who by their labours have very much contributed to the conversion of their countrymen, particularly one Rajanaitzen, a Paria soldier, who, of all the inferior missionaries, has distinguished himself most by his labours and sifferings.

\section{Description of Athenian Girls. From Hughes's Travels in Greece.}

"Ovr hostess, Signora Vitali, introduced us to our next door neighbours', who consisted of her own sister, with three fair daughters, considered at this time the belles of Athens. They are known by the title of Consuline, their father having held the post of British vice-consul. One of these young ladies was supposed to be that - Maid of Athens' who is celebrated in some beautiful verses annexed to Childe Harolde : her countenance was extremely interesting, and her eye maintained much of its wonted brilliancy; but the roses had already deserted her cheek, and we observed the remains only of that loveliness which elicited such strains from an impassioned poet. So fading a flower is beauty in these climates, that a very few years see it rise to sparkle like a meteor and to vanish. A Grecian damsel of sixteen is frequently angelical; at twenty she becomes plain; and, in five years more, frightfully ugly. There is no transition, as with 
us, from the light beauty of the girl to the mature graces of the matron, and the venerable dignity of advanced age: the face of a sylph becomes almost at once transformed into a gorgon's head. In discussing this subject with Signor Lusieri, he assured me, that the fault lay not so much in the climate, as in the destructive habits of the Grecian females, more especially in the abuse of the bath, which they attend almost daily, remaining in its hot sudatories several hours at a time, where they discuss more scandal than circulates at an English tea-table in as many weeks : hence their colour vanishes, and their fibres are relaxed; hence they become languid, and unable to take wholesome exercise; soon after the age of twenty, wrinkles begin to appear, and they suffer all the inconveniences of premature delility. Though the Grecian females are not accomplished, yet they possess a considerable degree of elegance in their address and manners : their salutation is particularly graceful, consisting of a gentle inclination of the body, whilst the right hand is brought in contact with the waist : they are generally found by visitors reclining indolently on the sofas of the apartment, their silken robes bound round with a silver-clasped zone, their hair partly wreathed with flowers or adorned with pearls, and partly flowing in curls over their shoulders; their eye-brows carefully arranged, and tinged with surme, a powder of the blackest dye; their nails stainedwith henna, and their complexion too often aided by artificial lustre; exhibiting melancholy examples of the neglect of nature's choicest gifts, the substantial graces of the mind.

\section{Algerines.}

THE inhabitants of Algiers, a nation of pirates, who, in defiance of all the powers of Europe, have robbed and plundered the ships, and enslaved and murdered the subjects, of every Christian state in Europe and America, and for two centuries past, excepting only those of such as condescended to purchase their friendship or forbearance by presents. These pirates, all along the sea coasts, are a mixture of different nations; but chiefly Moors and Moriscoes, driven out of Catalonia, Arragon, and other parts of Spain. There are also great numbers of Turks among them, who come from the Levant to seek their fortunes, as well as multitudes of Jews and Christians taken at sea, and brought hither to be sold for slaves.

The inland inhabitants of Algiers, distinguished by the name of Berebers, are some of the most ancient inhabitants of the country; and are supposed to be descended from the ancient Sabians, that nation of robbers, who plundered the patriarch Job, and who are said to have come to Algiers from Arabia Felix, under the conduct of one of their princes. Others believe them to be descended from the Canaanites, who were driven out of Palestine by Joshua. They are dispersed all over Barbary, and divided into a multitude of tribes under their respective chiefs : most of them inhabit the mountainous parts; some range from place to place, and live in tênts, or portable huts; others in scattered villages, in which situation they have generally kept from intermixing with other nations. 
The Berebers are reckoned the richest of all the Algerines, go better clothed, and carry on a much larger traffic of cattle, hides, wax, honey, iron, and other commodities. They have also some artificers in iron, and some manufacturers in the weaving branch.-The name Bereber, is supposed to have been originally given them on account of their being first settled in some desart place. Upon their increasing in process of time, they divided themselves into five tribes, probably on account of religious differences, called the Zinhagiuns, Mascamedins, Zeneti, Houres, and Gornere; and these having produced 600 families, subdivided themselves into a great number of petty tribes. To these we may add the Zwowahs, by European authors called Azuagues, or Assuagues, who are likewise dispersed over most parts of Barbary and Numidia. Great numbers of these inhabit the moun tainous parts of Cuco, Labez, \&c. leading a wandering pastoral life. But the most numerous inhabitants are the Moors and Arabians. The former are very stout and warlike, and skilful hnrsemen; but so addicted to robbing, that one cannot safely travel along the country at a distance from the towns without a guard, or at least a marabout, or saint, for a safeguard. For as they look upon themselves to be the original proprietors of the country, and not only as dispossessed by the rest of the inhabitants, but reduced by them to the lowest state of poverty, they make no scruple to plunder all they can meet with, by way of reprisal.

The inhabitants in general have a pretty fair complexion, they are robust and well-proportioned. Penple of distinction wear their beards; they have rich clothes made of silk, embroidered with flowers of gold, and turbans enriched with jewels. The Turks, who compose the military force, have great privileges, pay no taxes, are never publicly punished, and rarely in private. The lowest soldier domineers over the most distinguished Moors at pleasure. If he finds them better mounted than himself, lie exchanges horses without ceremony. The Turks alone have the privilege of carrying fire-arms. Some good qualities, however, distinguish them, in spite of this excess of despotism. They never game for money, nor even for trifles ; and they never profane the name of the Deity. They soon forget their private quarrels ; and after the first paroxysm of resentment is over, it is infamy for a Turk to keep in remembrance the injuries he has received. In this respect, certainly, they are less barbarous than other nations that boast of their civilization.

\section{Punishments in Algiers.}

In this country it is not to be expected that justice will be administered with any degree of impartiality. The Mahometan soldiery, in particular, are so much favoured, that they are seldom put to death for any crime except rebellion; in which cases they are either strangled witl a bow-string, or hanged to an iron hook; in lesser offences they are fined, or their pay stopped, and if officers, they are reduced to the station of common soldiers, from whence they may gradually raise themselves to their former dignity. Women guilty of adultery have a halter tied about their necks, with the other end fastened to 
a pole, by which they are held under water till they are. suffocated. The bastinado is likewise inflicted for small offences: and is given either to the belly, back, or soles of the feet, according to the pleasure of the cadi, who also appoints the number of strokes. These sometimes amount to 200 or 300 , according to the indulgence the offender can obtain either by bribery or friends; and hence he often dies under this punishment for want of advocates sufficiently powerful. But the most horrible punishments are those inflicted upon the Jews or Christians who speak against Mahomet or his religion; in which cases they must either turn Mahometaris or be impaled a live. If they afterwards apostatize, they are burnt alive, or else thrown down from the top of the city walls, upon .iron hooks, where they are caught by different parts of their body, according as they happen to fall, and sometimes expire in the greatest torments, though by accident they may be put out of their pain at once. This terrible punishment, however, begins now to be disused.

\section{Seraglio or Harem of the Emperor of Morocco.}

THE following account of this seraglio is extracted from the interesting tour of $M$. Lempriere, who being a surgeon, was admitted into the harem to prescribe for some of the ladies who were indisposed, and was therefore enabled to give a full account of this female prison; and of the manners and behaviour of its inhabitants.

The harem forms a part of the palace. The apartments are verylofty, and four of them enclose a spacious square court, into which they open by means of large folding doors. In the centre of these courts, which are floored with blue and white chequered tiling, is a fountain, supplied by pipes from a large reservoir on the outside of the palace, which serves for the frequent ablutions recommended by the Mabometan religion. The whole of the harem consists of about twelve of these courts, communicating with each other by narrow passages, which afford a free access from one part to another, and of which all the women are allowed to avail themselves. The apartments are ornamented on the outside with beautiful carved wood. In the inside most of the rooms are hung with rich damask of various colours: the floors are covered with beautiful carpets, and there are mattresses disposed at different distances, for the purpose of sitting and sleeping The apartments are also furnished at each extremity with an elegant European mahogany bedstead, hung with damask, having on it several mattresses placed one over the other, which are covered with various coloured silks; but these berls are merely for ornament. In all the apartments the ceiling is wood carved and painted.

The principal ornaments were large and valuable looking-glasses, hung on various parts of the walls; clocks and watches of different sizes, in glass-cases were, disposed in the same inanner. The sultana Lalla Batoom, and another favourite, were indulged with a whole square to themselves; but the concubines were only each allowed a single room. Each female had a separate daily allowance from the emperor, proportioned to the estimation in which they were held by him. The late emperor's allowance was very trifling ; Lalla Douyan, the favourite 
sultana, had very little more than half-a-crown English a day, and the others less. He indeed made then occasional presents of money, dress, and trinkets, but this never could be sufficient to support the expenses they must incur. Their greatest dependence therefore was on the presents they received from those Europeans and Moors who visited the court, and who employed their influence in obtaining some particular favour from the emperor. This was the most successful mode that could be adopted.

When Mr. Lempriere was at Morocco, a Jew, desirous of obtaining a very advantageous favour from the einperor, for which he had been a long time unsuccessfully soliciting, sent to all the principal ladies of the harem presents of pearls to a very large amount; the consequence was, that they all went in a body to the emperor, and immediately obtained the wished-for concession. The ladies separately furnish their own rooms, hired their own domestics, and in fact do what they please in the harem, but are not permitted to go out without an express order from the emperor, who very seldom grants them that favour, except when they are to be removed from one palace to another. In that case, a party of soldiers is despatched a little distance before them, to disperse the male passengers, and prevent their being seen. This previous step being taken, a piece of linen cloth is tied round the lower part of the face, and afterwards these miserable females cover themselves entirely with their haicks, and either mount mules, which they ride like men, or, what is more usual, are put into a square carriage or litter constructed for this purpose, which by its lattice work allows them to see without being seen. In this manner they set off, under a guard of black eunuchs. This journey, and sometimes a walk within the bounds of the palace, is the only exercise they are permitted to take. The late emperor's harem consisted of between 60 and 100 females, besides their numerous domestics and slaves. Many of the concubines were Moorish women, several were European slaves, who had either been made captives, or purchased by the emperor; though some were negroes.

In this group, the Europeans, or their descendants, had by far the greatest claim to the character of handsome. There was one in par. ticular, who was a native of Spain, and taken into the harem at about the same age as Lalla Douyan, who was indeed a perfect beauty; and many others were almost equally handsome.

The eunuchs, who have the entire charge of the women, and who in fact live always among them, are the children of Negro slaves. They are generally either very short or fat, or else tall, deformed, and lame. Their voices have that particular tone which is observable in youths who are just arriving at manhood; and their persons together afford a disgusting image of weakness and effeminacy.

M. Lempriere gives a very curious account of the manners and ignorance of these immured females, from his own observation. Attended by an eunuch, says he, after passing the gate of the harem, which is always locked, and under the care of a guard of eunuchs, we entered a narrow and dark passage, which soon brought us to the court into which the women's chambers open. We here saw numbers of both black and white women and children, some concubines, 
and some slaves. Upon their observing the unusual figure of an European, the whole nultitude in a body surrounded me, and expressed the utmost astonishment at my dress and appearance, some stood motionless, with their hands lifted up, their eyes fixed, and their mouths open, in wonder and surprise. Some burst into fits of laughter; while others, with uncommon attention, eyed me from head to foot. The parts of my dress which seemed most to attract their notice, were my buckles, buttons, and stockings; for neither men nor women in this country wear any thing of the kind. With respect to the club of my hair, they seemed utterly at a loss in what view to consider it; but the powder they conceived to be employed for destroying vermin. Most of the children, when they saw me, ran away in consternation: and $I$ appeared as singular an animal, and $I$ dare say that $I$ had the honour of exciting as much curiosity and attention, as a lion or a man-tiger just imported from abroad, and introduced into a country town on a market-day. Every time I visited the harem, I was surrounded and laughed at by this curious mob, who, on my entering the gate, followed me close to the very chamber to which I was proceeding, and, on my return, universally escorted me out. The greatest. part of the women were uncommonly fat and unwieldy; had black and full eyes, round faces, with small noses. They were of different complexions; some very fair, some sallow, and others again perfect negresses.

"Ore of my new patients being ready to receive me, I was desired to walk within ber room; where, to my great surprise, I saw nothing but a curtain drawn quite across the apartment, similar to that of a theatre, which separates the stage from the audience. A female domestic brought a very low stool, placed it near the curtain, and told me I was to sit down there, and feel her mistress's pulse. 'The lady, who had by this time summoned up courage to speak, introduced her hand from the botton of the curtain, and desired me to inform her of all her complaints, which she conceived I might perfectly do by merely feeling the pulse. It was in vain to ask her where her pain was seated; the only answer I could procure was, a request to feel the pulse of the other hand. I was under the necessity of informing her, in positive terms, that to understand the disease, it was absolutely necessary to see the tongue, as well as to feel the pulse ; and that without it, I could do nothing for her. My eloquence, or that of rily Jewish interpreter, was, however, long exerted in vain, and she would have dismissed me without any further inquiry, had not her invention supplied her with a happy expedient. "She contrived to cut a hole in the curtain, through" which she extended her tongue, and thus complied with my injunction, but most effectually disappointed my curiosity. I was afterwards ordered to look at another of the prince's wives, who was affected with a scrofulous swelling in her neck. This lady was, in the same manner as the other, at first excluded from my sight; but as she was obliged to shew ne her complaint, I had an opportunity of seeing her face, and observed it to be very handsome."

It is curious to observe the childish notions of persons who have been totally secluded from the world. All the ladies of the harem expected that our author should have instantly discovered their com- 
plaints, upon feeling the pulse, and that he could cure every disease instantaneously. He found them proud and vain of their persons; and extremely ignorant.

"Among many ridiculous questions, they asked my interpreter," says $M$. Lempriere, "if I could read and write: upon being answered in the affirmative, they expressed the utmost surprise and admiration at the abilities of the Christians. There was not one among them who could do either; these rudiments of learning are, indeed, only the lot of a few of their men, who on that account are named Talbs, or explainers of the Mahometan law."

It is melancholy to reflect on the situation of these unfortunate women. Being considered as the mere instruments of pleasure, no attention is paid to the improvement of their minds. They have no employment to occupy their time. Their needle-work is performed by Jewesses; their food is dressed, and their chambers taken care of, by slaves and domestics. They have no amusement but a rude and barbarous kind of melancholy music, without melody, variety, or taste ; and conversation with one another, which must indeed be very confined, uniform, and inanimate, as they never see a new object. Fxcluded from the enjoyment of fresh air and exercise, so necessary for the support of health and life; deprived of all society but that of their fellow-sufferers, a society to which most of them would prefer solitude itself; they are only to be considered as the most abject of slaves - slaves to the vices and caprice of a licentious tyrant, who exacts, even from his wives themselves, a degree of submission and respect which borders upon idolatry, and which God never meant should be paid to a mortal.

\section{Nóbility of NaPLES.}

THE number of the high and low nobility is very great. "I an assured," says Dr. Moore, "that the king of Naples counts among his subjects one hundred persons with the title of prince, and a still greater number with that of duke. Six or seven of these have estates which produce from ten to twelve or thirteen thousand pounds a year; a considerable number have fortunes of about half that value; and the annual revenue of many is not above one or two thousand pounds. The inferior orders of the nobility are much poorer. Many. counts and marquisses have not above three or four hundred pounds a year of paternal estate; many have still less; and not a few enjoy the title without any estate whatever. These nobles, however, are exceedingly fond of splendour and show, which is seen in the brilliancy of their equipages, the number of their attendants; the richness of their dress, and the grandness of their titles. The finest carriages are painted, gilt, varnished, and lined, in a richer or more beautiful manner than has become fashionable either in England or France. They are often drawn by six, and sometimes eight horses. Before the carriage; it is the mode to have two running footmen, and, behind, three or four servants in the richest liveries. The ladies and gentlemen within the coaches glitter in all the brilliancy of lace, embroidery, and jewels. This finery is not confined to the persons within and with- 


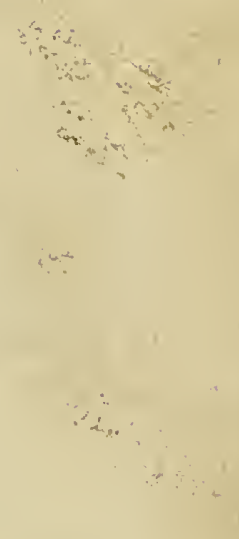




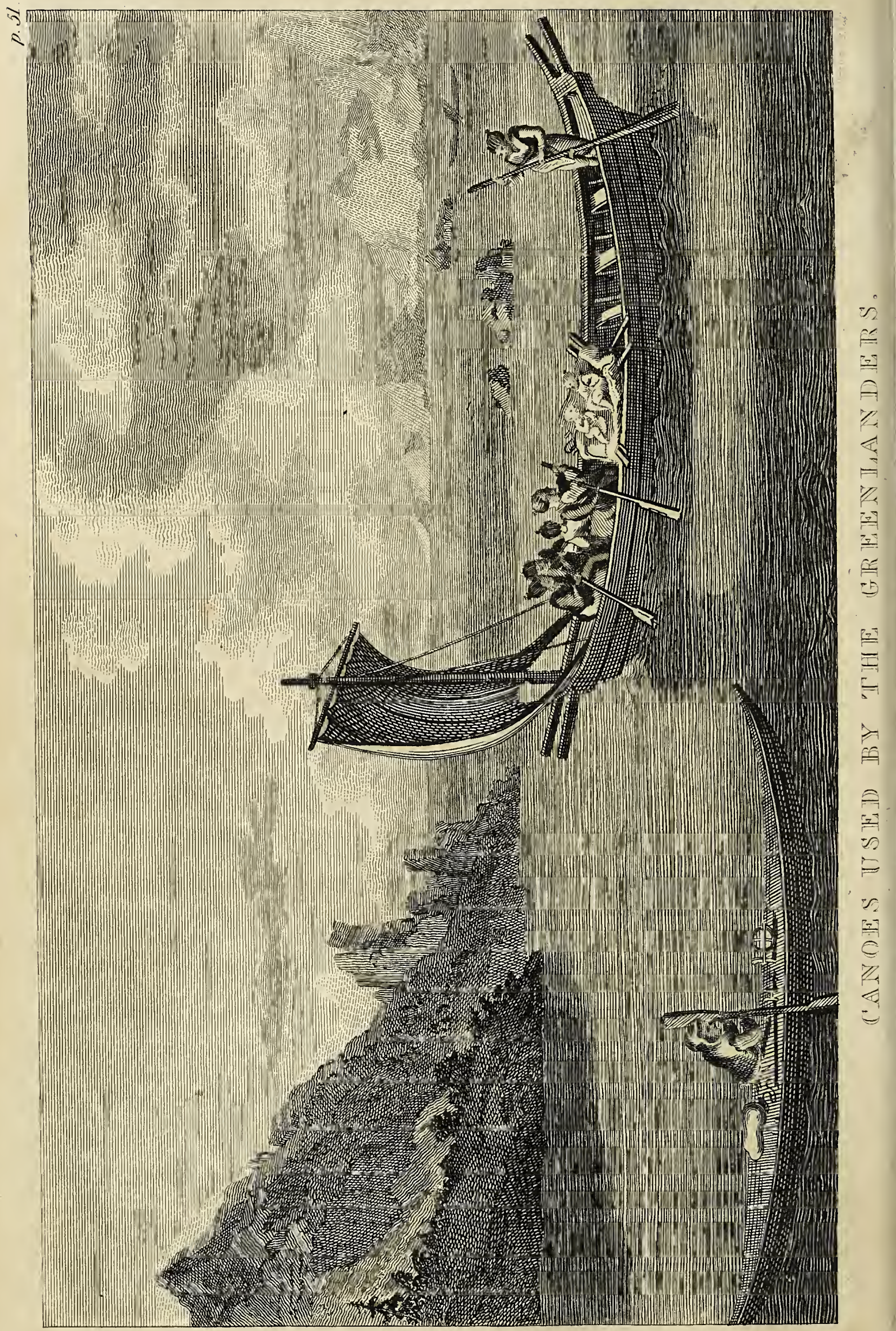


out of the coaches; it is extended to the lorses, whose heads, manes, and tails are ornamented with the rarest plumage, and set off with ribbons and artificial flowers."

The hereditary jurisdiction of the nobles over their vassals subsists in the fullest rigour of the feudal government. The peasants therefore are poor, and it depends entirely on the personal character of the master, whether their poverty be not the least of their grievances. As this power is too often abused, the importance of the nobility depends in a great measure on the favour of the king, who, under pretence of any offence, can confine them to their estates, or imprison them, at pleasure, and he has little to fear from their resentment.

\section{Manners, Character, and Customs of the Natives of Greenland.}

IN winter the people dwell in huts of stone or turf; on the sides are two windows, covered with the skins of seals or rein-deer. These huts are seldom more than two ells above the surface of the ground; the rest of them being sunk in the earth, for defence against wind and cold. Several families live in one of these houses, possessing each a separate apartment, before which is a hearth with a great lamp placed on a trevet, over whiclı hangs their kettle; above is a rack or shelf, on which their wet clothes are dried. They burn train oil in their lamps; and instead of wick, they use a kind of moss, which fully answers the purpose. These fires are not only sufficient to boil their victuals, but they likewise produce such a heat, that the whole house is like a bagnio. The door is very low, that as little cold air as possible may be admitted. The house within is lined with old skins, and surrounded with benches for the convenience of strangers. In summer they dwell in tents made of long poles fixed in a conical form, covered in the inside with deer-skins, and on the outside with seal-skins, dressed so that the rain cannot enter them.

In their dispositions, the Greenlanders are cold, phlegmatic, indolent, and slow of apprehension, but very quiet, orderly, and good natured. In natural affection they seem to equal the natives of the warmest climates. Two of them were carried off, and brought to Denmark, but though caressed by the king and court to the utmost, were quite unhappy, and one of them always wept upon seeing an infant in its mother's arms, whence it was concluded that he had left a wife and a young child in Greenland.

They live peaceably together, and have every thing in common, without strife, envy, or animosity. They are hospitable, but slovenly, to a degree almost beyond the Hottentots. They never wash themselves with water, but lick their paws like a cat, and then rub their faces witl them They eat after their dogs without washing their dishes, devour the vermin which devour them, and even lick the sweat which they scrape off their faces with their knives. The women wash themselves with what must not be named, which they imagine makes their hair grow ; and in winter go out immediately, to let the liquor freeze upon their skin. They often eat their victuals off the ground, and 
devour rotten flesh with avidity. In times of scarcity they will subsist on pieces of old skin, reeds, sea-weeds, and a weed called tugloronet, dressed with train oil and fat. The intestines of rein-deer, the entrails of partridges, and all sorts of offals, are counted dainties among these savages, and of the scrapings of seal skins they make pancakes. At first they could not taste the Danish provisions without abhorrence; but now they are becone extremely fond of bread and butter, though they still retain an aversion to tobacco and spirituous liquors; in which particular they differ from almost all savages on the earth.

The Greenlanders commonly content themselves with one wife; who is condemned, as among other savage nations, to do all the drudgery, and may be corrected and even divorced by the husband at pleasure. Heroes, however, and extraordinary personages, are indulged with a plurality of wives. These people never marry within the prohibited degrees of consanguinity, nor is it considered decent for a couple to marry who have bcen educated in the same family.

They have a number of ridiculous superstitious customs. While a woman is in labour, the gossips hold a chamber utensil over her head, as a charm to hasten the delivery; when the chiid is a year old, the mother licks and slabbers it all over, to render it, as she imagines, more strong and hardy. The Greenlanders are constantly employed either in fishing or lunting. At sea they pursue the whales, mooses, seals, fish for eating, and sea fowls. On shore they hunt the reindeer in different parts of the country. They drive these animals, which feed in large herds, into a narrow defile, where they kill them with arrows. Their bow is made of fir-tree, wound about with the twisted sinews of animals ; the string is of the same stuff, or of sealskin; the arrow is a full fathom in length, pointed with a bearded iron or a sharp bone; but those with which they kill birds are blunt, that they may not tear the flesh. Sea-fowls they kill with lances, which they throw to a great distance with surprising dexterity.

Their manner of catching whales is quite different from that practised by the Europeans. About fifty persons, men and women, set out in one long boat, which is called a kone-boat, from kone a women, because it is rowed by females only. When they find a whale, they strike him with harpoons, to which are fastened, with long lines, some seal-skins, blown up like bladders. These, by floating on the surface, not only discover the back of the whale, but hinder him from foundering under water for any length of time. They continue to pursue him until he loses strength, when they pierce him with spears and lances till he expires. On this occasion they are dressed in their spring coats, consisting of one piece, with gloves, boots, and caps of seal skin, so closely laced and sewed, that they keep out the water. Thus accoutred, they leap into the sea, and begin to slice off the fat, even under water, before the whale is dead.

They have many different ways of killing seals; namely, by striking them with a small harpoon, equipped also with an air-bag; by watching them when they come to breathe at the air-holes in the ice, and striking them with spears; by approaching them in the disguise of their own species, that is, covered with a seal skin, creeping upon 
the ice, and moving the head from side to side just as the seals are accustomed to do. By this stratagem the Greenlander moves towards the unsuspecting seal, and kills him with a spear.

The Greenlanders angle with lines made of whalebonè, cut very small, hy means of which they succeed wonderfully.

The Crreenland canoe, like that used in Nova Zembla and Hudson's Bay, is about three fathoms in length, pointed at both ends, and three-quarters of a yard in breadth. It is composed of thin rafts fastened together with the sinews of animals. It is covered with dressed seal-skins both above and below, in such a manner that only a circular hole is left in the middle, large enough to admit the body of one man. Into this the Greenlander thrusts himself up to the waist, and fastens the skin so tight about him, that no water can enter. Thus secured, and armed with a paddle broad at both ends, he will venture out to sea in the most stormy weather, to catch seals and sea-fowl; and if he is overset, he can easily raise himself by means of his paddle. A Greenlander, in one of these canoes, which was brought with him to Copenhagen; outstripped-a pinnace of sixteen oars, manned with choice mariners.

The kone-boat is made of the same materials, but more durable; and so large, that it will contain fifty persons with all their tackling, baggage, and provisions. She is fitted with a mast, with a triangular sail made of the membranes and entrails of seals, and is managed without the help of bracings and hawlings. The kones are flat-bottomed, and sometimes sixty feet in length. The men think it beneath them to take notice of them, and therefore they are left to the conduct of the women, who indeed are obliged to do all the drudgery, including even the building and repairing of their houses, while the men employ themselves wholly in preparing their hunting implements and fishing tackle.

Cossacks.

THIS is a name given the people inhabiting the banks of the rivers Duieper and Don, near the Black Sea, and borders of Turkey. The word implies irregular troops of horse. These people are divided into European and Asiatic Cossacks. The first consist of the Zaporogs, who dwell below the cataract of the Dnieper, some on the side next to Russia, and others on the opposite side of that river; the Upper and Lower Cossacks, the Bielgorod Cossacks, and a part of the Don Cossacks. The Asiatic Cossacks are composed of the rest of the Don Cossacks, the Grebin Cossacks, the Yaik Cossacks, and the Western Cossacks, who retiring from those that inhabited the south borders of Siberia, under Yaneki Khan, settled upon the Wolga, and are dependent upon Russia. The Cossacks have been known by that name ever since A. D. 948. They dwelt upon Mount Caucasus, in the place now called Cabardy; and were reduced to the Russian dominion by prince Mastiflau in the year 1021. Many Russians, Poles, and others, who could not live at home, have at different times been adnitted among the Cossacks; but the latter, abstracted from these fugitives, must hare been an ancient and well-governed nation. 
The Cossacks are tall and well made, generally hawk-nosed, and of good mien. They are hardy, vigorous, brave, and extremely jealous of what is most valuable in life, their liberty; fickle and wavering, but sociable, cheerful, and sprightly. They are a very powerful people, and their forces consist wholly of cavalry. Their dialect is a compound of the Polish and Russian language, but the latter is the most predominant. They were formerly Pagans or Mahometans; but upon their entering into the Polish service, they were baptized Christians of the Romish communion; and now that they belong to Russia, they profess themselves members of the Greek church.

Each of their towns, with the district belonging to it, is governed by an officer called cettoman, attamall, or hettman. The Cossacks in general are of great service to garrison towns by way of defence, or to pursue an enemy, but are not so good at regular attacks.

Don Cossacks, (so called from their residence on the banks of the Don.) - In 1599, when the czar, John Basilowitz, was emperor of Russia, they voluntarily put themselves under his protection, and are at this time on a pretty equal footing with the other Russian subjects. They have several towns and villages on the banks of the Don; but are prevented from extending farther up the country, by the scarcity of fresh water and wood in many places. Their chief support is grazing and agriculture, and occasionally robbing and plundering, for which they want neither capacity nor inclination. Every town is governed by a magistrate called tamann; and the tamanns, with their towns, are under the jurisdiction of two attamans, who reside at Tsherkasky. The troops of these Cossacks consist entirely of cavalry; and their manners in general resemble those of the Zaporog Cossacks. In this country all the towns and villages are fortified, and encompassed with palisades, to defend them against the incursions of the Calmucs and Kuban Tartars, with whom they are continually at war. The Heidamack or Seitsh Cossacks have their particular hettman. They inhabit the Russian, Polish, and Turkish dominions on the Dnieper.

The Yaik Cossacks, dwell on the south side of the river Yaik, and, upon the success of the Russian arms in the kingdom of Astracan, voluntarily submitted to them. In stature they greatly resemble the other Cossacks; though by their boorish manner of living, and intermarriages with the Tartars, they have not the shape and air peculiar to the rest of their countrymen. Their natural dispositions and customs are, however, nearly the same. Husbandry, fishing, and feeding of cattle are their principal employments ; and, like the other tribes they slip no opportunity of making depredations on their neighbours. Their continual war with the Kara Kalpacs, and the Kasal-Shaia-Horda, oblige them to keep their towns and villages in a state of defence. They are indeed subject to Russian waywodes, to whom they pay an annual tribute in corn, wax, honey, and cattle; but they have also their particular chiefs, who govern them according to their ancient customs. Though the generality of the Yaik Cossacks profess the Greek religion, yet a great many relics of Mahometanism and Paganism are still found among them.

Being naturally bold and hardy, they make excellent soldiers; and they are not so turbulent as the other Cossacks. They live entirely 
at peace with the Calmucs and their other neighbours, and even maintain a commercial intercourse with them. Zaporog Cossacks fixed their habitations on the spacious plains along the banks of the Dnieper, about the beginning of the sixteenth century. They had undergone considerable hardships from the incursions of the Tartars, for which they afterwards found means to revenge themselves in an ample manner. The Poles being sensible how serviceable the Cossacks might be in defending them from the ravages of the Tartars, and even of the Russians, proposed to them terms of alliance. In 1562 they solemnly took them under their protection, and engaged to pay them an annual subsidy ; in return for which, the Cossacks were to keep on foot a sufficient body of troops for the defence of the Polish dominions. With a view to bind them still more strongly by the ties of interest, the Poles gave them the whole country between the rivers Dneiper and Niester, and the borders of Tartary. The Cossacks applied themselves with great industry to the cultivation of this fertile spot; so that in a short time it was interspersed with large towns and handsome villages. Besides, they continually harassed the Turks, and did them great damage by their incursions; and in order to prevent the latter from pursuing them, or making reprisals, they possessed themselves of several small islands in the Dnieper, where theykept their magazines, \&c.

The hettman or general of the Cossacks was not in the least subordinate to the field-marshal of Poland, but acted in concert with him as an ally, and not as a subject of that republic. But this alliance, though of such manifest advantage to both parties, was not of long duration. The Poles, seeing the vast improvenients made by the Cossacks in the country they had given up to them, became envious of them, and actually made an attempt to bring them into subjection.

In 1648, the Cossacks gained great advantages over them, and the next year came to an accommodation, in which they notouly preserved their old communities, but obtained additional privileges. The result. of all was, that these Cossacks remained under the protection of Russia; and as their former territory was entirely laid waste in the late wars, they seitled in the Russian Ukraine, upon receiving formal assurances from the court of Russia, that no alteration should be made in their political constitution, and that no taxes whatever should be laid upon them. The Cossacks, on the other hand, were always to keep in readiness a good body of troops for the service of Russia; but in 1708, Mazetta, their hettman or chief, went over from the Russians to the Swedes, upon'which Peter II. resolved to prevent such revolts for the future. For this end, after the battle of Pultowa, he sent a strong detachment into the abovementioned little islands in the Dnieper, whither the Cossacks had fled with their wives and children and all their effects, and ordered them all to be put to the sword without distinction, and the plunder to be divided among his soldiers. He likewise sent a great number of men into their country, and caused several thousands of the Cossacks to be carried to the coasts of the Baltic, where they were put to all sorts of hard labour, by which means he in a manner extirpated the whole nation.

What distinguishes the Zaporog Cossacks from all other people is, that they never suffer any women in their settlements, as the Ama- 
zons are said not to have suffered any men among thern. The women of these Cossacks live in the-other islands of the Dnieper. They never marry, nor have any family; all their male children are enrolled as soldiers, and the females are left with their mothers. The brother often has children by his sister, and the father by his daughter. 'They know no laws but those which custom has introduced, founded on their natural wants, though they have among them some priests of the Greek persuasion. They serve in the army as irregulars; and wo to those who fall into their hands.

The country of these Cossacks, who are an assemblage of ancient Roxalans, Sarmatians, and Tartars, is called the Ocraine or Ukraine. It lies upon the borders of Russia and Poland, Little Tartary, and Turkey, and was anciently a part of Scythia. By the treaty between Russia and Polaud, in 1693 , the latter remained in possession of all that part of the Ukraine which is situated on the west side of the Dnieper, and is now but poorly cultivated. That on the east side, inhabited by the Cossacks, is in much better condition, and extends about two hundred and sixty miles in length, and as many in breadth. It is one continued fertile plain, watered by a great number of fine rivers, diversified with pleasant woods, and yields such plenty of all sorts of grain, pulse, tobacco, honey, and wax, as to supply a great part of the Russian empire with these commodities. "Its pastures are exceedingly rich, and its cattle very large, but the inhabitants are generally plagued with locusts, which infest this fine country. The houses in the Ukraine are, like those of the Russians, built mostly of timber.

\section{Customs, Religion, \&c. in Amboyna.}

THE men of Amboyna, one of the Malacca islands, wear large whiskers, but have little hair upon their chins, and have only a slight piece of stuff lapped round their middle. The women tie their hair in knots ; the maids are bought of their fathers before they are married; and if the wife proves barren, the marriage is dissolved. Sorne of the natives are Mahometans, and some Christians; but they are all said to be lazy, deceitful, and treacherous. They make war with small swift vessels, in shape like dragons with regard to the head and tail. Their houses are built of bamboo canes and sago-trees: Their weapons are bows and arrows, javelins, cimeters, and targets. Amboyna was first discovered by the Portuguese, who built a fort upon it, which was taken from them by the Dutch in 1605 .

They, did not, however, become masters of the whole island at once. The English had here five factories, the people of which lived under the protection of the Dutch castle, holding themselves safe, in respect to the friendship between the two nations. Great differences had arisen between the Dutch and English colonists in these parts of the world; till at last the East India company applying to king James, a treaty was concluded in 1619 , by which the concerns both of the English and Dutch were regulated, and certain measures agreed upon for preventing future disputes. This was an additional security to the English; and by virtue of the treaty, they continued 
twi years in Amboyna, trading with the Dutch. During this time, however, several disputes happened, which occasioning much discontent, the complaints were sent to Jacatra, in the island of Jara Major, to the council of deference of both nations then residing: but they not agreeing, a state of the matter was sent over to Europe, to be decided by the East India companies of both nations; or, in case they should not agree, by the king of England and the States of of Holland, according to an article in the the treaty of 1619.-But before these disputes could be decided in a legal way, the Dutch, in order to give the more specious colouring to the violent seizure which they meditated of the island of Ainboyna, made use of the pretext of a conspiracy being formed by the English and Japanese, to dispossess them of one of their forts in this place. The plot, it was alleged, had been confessed by a Japanese and Portuguese in the English service, who were most inhumanly tortured till they should answer in the affirmative such interrogatories as might favour the secret designs of these crue!-inquisitors. Upon the injurious evidence of this constrained declaration, they immediately accused the English factors of the pretended conspiracy. Some of them they imprisoned, and others they loaded with irons, and sent on board their ships; seizing at the same time all the English merchandise, with their writings.

These acts of violence were followed by a scene of horror unexampled in the punishment of the most atrocious offenders. Somé of the factors they tortured by compelling them to swallow water till their bodies were distended to the utmost pitch ; then taking the miserable victims down from the boards to which they had been fastened, and causing them to disgorge the water: if they did not "acknowledge the imputed guilt, the process of torture was repeated." Others of the English they tormented by burning them gradually from the feet upwards, in order to extort the confession of a conspiracy, which was only pretended by the infernal policy of those savage tormentors. Some had the nails of the fingers and toes torn off; and in some they made holes in their breasts, filling the cavities with inflammable materials, to which they afterwards set fire. Those who did not expire under the agonies of torture were consigned to the hands of the executioner.

The allegation of this pretended conspiracy was equally void of probability and truth. The Dutch had a garrison of three hundred men in the fort, besides the burghers in the town, and several other forts and garrisons in the island, while the English did not amount to twenty men; nor were even those provided with arms or ammunition; to effect such a design as that with which they were charged. There likewise was not one English vessel in the harbour, whereas the Dutch had eight ships ,riding near the town; neither, when the Dutch broke open the desks or trunks of the factors, was there found a single paper or letter which could be construed into a conspiracy. Add to all this, that such of the unhappy sufferers as could speak or be heard; declared, in the most solemn manner, their innocence of the plot with which they were charged. The whole of the transaction affords the most irrefragable testimony that it was 
founded only upon a political fiction of the Hollanders, who had formed the design of monopolizing the trade of the Spice Islands, for the accomplishment of which they perpetrated about the same time a similar tragedy at Pooleron, where they put to the torture one hundred and sixty-two of the natives, whom they likewise charged with a pretended conspiracy. It may justly be reckoned singular in the fortune of this commercial republic, that they have ever since been permitted to enjoy in peace those invaluable islands, which were originally obtained by such atrocious infringements of humanity and the laws of nations, as will stain the Dutch annals, to the latest ages, with indelible infamy.

But indeed we need not be surprised at any thing of this kind, while some of the powers of Europe pay so little attention to the dictates of humanity, as to permit the African slave-trade to be still carried on by their subjects, or suffer that nation of robbers, the Algerines, to continue their piracies umpunished.

Inmabitants oi the Frienduy Islands, in the Pacific Ocean.

THE natives of these islands seldom exceed the common stature, but are strong and well made. They are generally broad about the shoulders, and though the muscular appearance of the men rather conveys the idea of strength than of beauty, several of them are really handsome. Most of the women are well proportioned, and some are absolutely perfect models of beauty, both in features and figure. But the most remarkable distinction, is the uncommon smallness and delicacy of their fingers. The general colour is a cast deeper than the copper brown, but several have a true olive complexion, and some of the women are even a great deal fairer. Their countenances express their natural mildness, being entirely free from that savage keenness which marks most, nations in a barbarous style. They are frank, cheerful,-and good-natured. There are few natural deformities to be found among them. The most common is the tetter, or ringworm, which seems to affect almost one half of them, and, leaves serpentine marks behind it.

Captain Cook had the mortification to learn, that all the care he took when he first visited these islands, to prevent the venereal disease from being communicated to the inhabitants, had proved ineffectual. But they do not seem to regard it much. As there appeared few signs of its fatal effects, probably the climate, and their way of living, abate its virulence.

There are two other complaints frequent amongst them, one of which is an indolent firm swelling, that affects the legs and arms, and increases them to an extraordinary size in their whole length. The other is a tumor of the same sort, in the lower glands, which sometimes exceeds the size of the two fists. In other respects they seem uncommonly liealthy.

Their hair is in general straight, thick, and strong; though a few have it bushy, or frizzled. The natural colour is black, but the greatest part of the men, and some of the women, have it stained of a brown, purple, or orange colour. Some have it cut off on one side of the 
head only, others have it entirely cut off; except a single lock ; the wornen in gcneral wear it short. The men have their beards cut short; and both men and women pluck the hair from the arm-pits. The men are stained from about the middle of the belly to about half way down the thighs with a deep blue colour. The women have also a few small lines or spots, which they imprint on the inside of their hands.

The dress of both men and women is the same, and consists of a piece of cloth matting, about a yard wide, and $2 \frac{1}{2}$ long, so as to go once and a half round the waist, to which it is confined by a girdle. It is double before, and hangs down like a petticoat, as low as the middle of the leg. When unfolded, there is cloth sufficient to draw up, and lap round the shoulders. The inferior sort often wear nothing but a covering made of leaves, or the maro, which is a narrow piece of cloth like a sash, passed between the thighs, and, wrapped round the waist. The use of this is chiefly confined to the men.

The ornaments worn by both sexes are necklaces, made of the fruit of the pandanus, and various sweet-smelling flowers, which they name Kabulla. Others are composed of small shells, bones of birds, shark s teeth, \&c. all, which hang loose upon the breast; rings of tortoiseshells on the fingers; or joined together as bracelets on the wrists: The lobes on the ears, though most frequently only one, are perforated with two holes, in which they wear cylindrical bits of ivory about three inches long. They bathe in the ponds, being sensible that salt water hurts the skin; but when they bathe in the sea, they commonly have fresh water thrown upon them to wash it off. Those of superior rank use cocoa-nut oil, which, improves the appearance of the skin.

The manufacturing of their cloth is wholly consigned to the care of the women; as is also their mats, which are esteemed both for their texture and beauty, with many other articles of less note: as, combs, of which they make vast numbers, and little baskets with small beads, all finished with great neatness and taste. The employment of the men is more laborious and extensive. Agriculture, architecture, boat-building, fishing, and other things that relate to navigation, are the objects of their care. Roots and fruit being their principal support, they pay constant attention to agriculture, which they have brought to great perfection. In planting the plantains and yams they observe great exactness, and make the rows every way regular and complete. The cocoa nut and bread-fruit trees are scattered about without order, and give them no trouble after they have attained a certain height.

The houses of the lower people are poor huts, and very small; those of the higher ranks are larger and more comfortable. The dimensions of one of a middling size is 30 feet long, 20 broad, and 12 high. The house is, properly speaking, a thatched roof, supported by posts and rafters. The floor is raised with earth smoothed, covered with strong: thick matting, and kept very clean. A thick strong mat, about three feet broad, bent in a semicircle, and set upon its edge, in shape resembling a fender, encloses a space for the master and mistress to sleep in. The rest sleep upon the floor, the unmarried men and wo- 
men apart. If the family be large, there are small huts adjoining, to which the servants retire at night, so that privacy is much observed. The clothes they wear in the day serves for a covering at night. Their whole fortune consists of a bowl or two, in which they make kava, a few gourds, cocoa-nut shells, and some small wooden stools which serve them for pillows.

They display much ingenuity in building and navigating their canoes. The only tools that they use to construct them, which are very dexterously made, are hatchets, or rather thick adzes, of a smooth black stone that abounds at Toofoa, augers made of shark's teeth fixed on small handles, and rasps of a rough skin of a fish fastened on flat pieces of wood, thinner on one side, with handles. The cordage is made from the fibres of the cocoa-nut husk, which, though nine or ten inches long, they plait about the size of a quill, to any length, and roll it up in balls, from which the larger ropes are made by twisting several of these together. The lines that they fish with are as strong and even as the best cord we make.

Their weapons are clubs of different sorts, spears, and darts. They have also bows and arrows for shooting birds. The stools are about two feet long, but only four or five inches high, and four broad, bending downward in the middle, with four strong legs, and circular feet; the whole made of one piece of black or krown wood, neatly polished, and inlaid with bits of ivory. Yams, plantains, bread-fruit, and cocoa-nuts, compose the greatest part of their vegetable diet.

Of their animal food, the chief articles are hogs, fowl, fish, and shell-fish : the lower people eat rats. Their food is generally dressed by baking, and they have the art of making, from different kinds of fruit, several dishes, which Captain Cook's people esteemed very good. The women eat with the men, but there are certain ranks among them that can neither eat nor drink together. They seem to have no set time for meals. They go to bed as soon as it is dark, and rise with the dawn. Their diversions are chiefly singing, dancing, and music. The dancing of the men has a thousand different motions with the hands, performed with an ease and grace not to be described but by those who have seen them. Most of the men satisfy theirselves with one wife; the chiefs, however, have commonly several, though only one is looked upon as mistress of the family.

When any person of rank dies, his body is washed and decorated by women appointed for the occasion; who, by their customs, must not touch any-food with their hands for many months afterwards; and the length of the time that they are thus proscribed is the greater in proportion to the rank of the chief whom they had washed. The concern of these people for the dead is extraordinary. They beat their teeth with stones, strike a shark's tooth into the head until the blood flows in streams, and thrust spears into the inner part of the thigh, into their sides below the arm-pits, and through the cheeks into the mouth. But these painful operations are only practised to the dead nearly related. Their long and general mourning proves that they consider death as a very great evil, and this is confirmed by a very old custom which they practise to avert it. They suppose that the Deity will accept of the little finger, as a sort of sacrifice to 


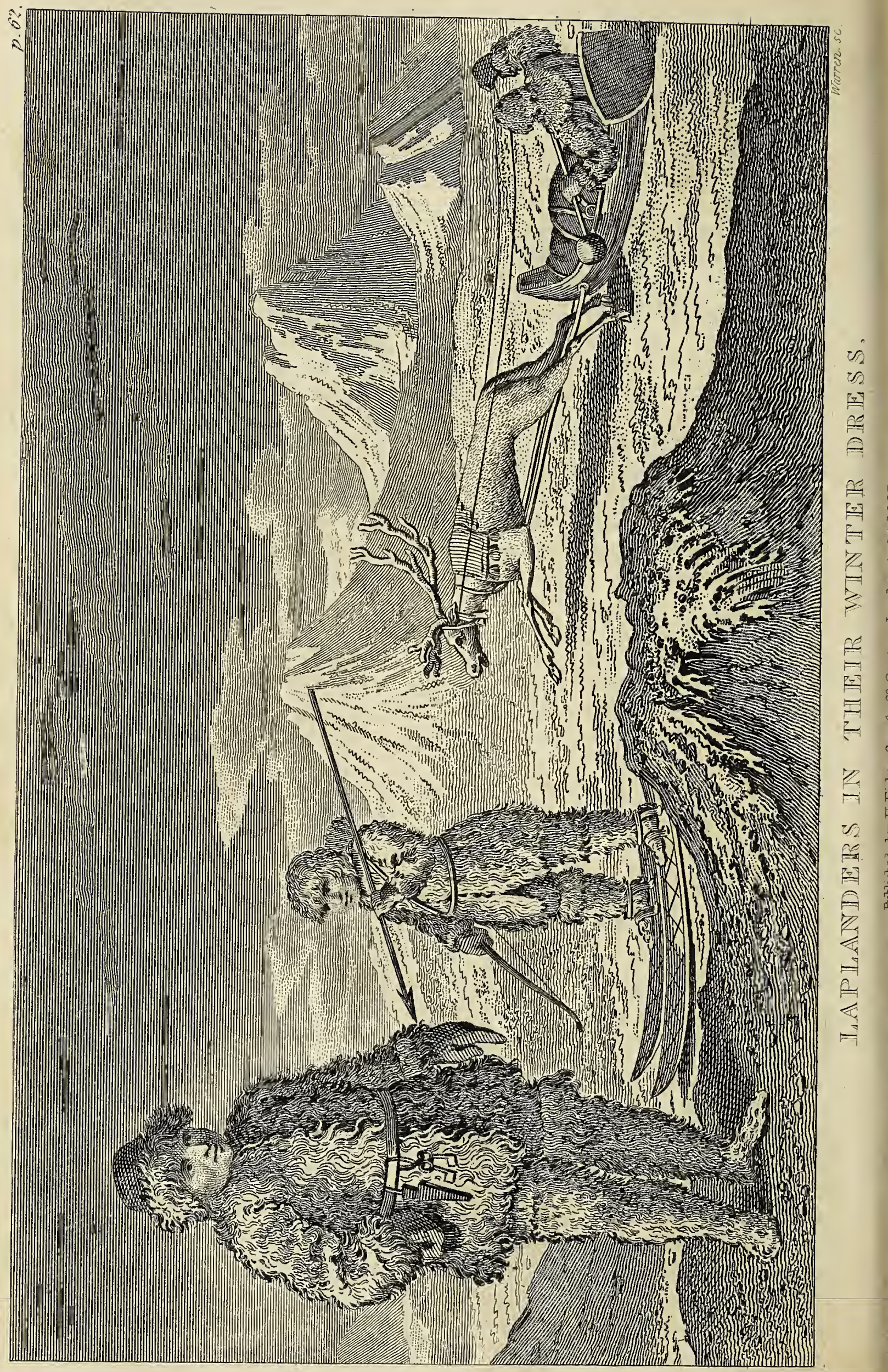


procure the recovery of their health. They cut it of with one of their stone hatchets. There was scarcely one in ten of them whowas not mutilated. The iuferior people also cut off a joiut of the little finger on account of the sickness of the chiefs to whom they lielong. They seem to have no ideas of future punisliment. They believe, howerer, that they are justly punished upon earth, and therefore use every method to render their divinities propitious. The supreme Author of all things they call Kallafoolonga, who, they say, is a female residing in the sky, and directing all the changes of the weather. They believe that when she is angry with them, the productions of the earth are blasted by lightning, \&c. and that they themselves are punished with sickness and death, as well as their hogs and other animals. They also admit a plurality of deities, though all inferior to Kallafoolonga. They call life, or the living principle, Otooa, i. e. a divinity, or invisible being.

The power of the king is unlimited, and the lives and properties of his subjects are at his disposal. The lower ranks of people have no property, nor safety for their persons, but are at the will of their chiefs. When any one wants to speak with the king, he advances, and sits down with his legs across; a posture to which they are so much accustomed, that any other position is disagreeable to them. To speak to the king standing, would be accounted a mark of rudeness. Though some of the chiefs may vie with the king in point of possessions, they fall very short in rank, and in certain marks of respect. It is a particular privilege annexed to his sovereignty, not to be punctured and circumeised as all his subjects are. Whenever he walks out, every one he meets must sit down, till he has passed. The person who is to pay obeisance, squats down before the chief, and boins his head to the sole of his foot, which, when he sits, is so placed that it cannot be easily come at; and having tapped or touched it with the under and upper side of the fingers of both liands, he retires: the hands, after th is application to the chief's foot, must not touch any kind of food until they be washed. While in this state they are called "taboo rema;" q. d. forbidden hands. Their great men are fond of having women sit beside them all night, or until they fall asleep, with some kind of music; after which they relax a little of their labour, unless they appear likely to awake, in which case they redouble their drumming until they are again fast asleep.

\section{IN HABITANTS OF LAPLAND.}

THE Laplanders are very low in stature, but have remarkably large heads. They are ill-shaped, and their features harsh. They are, however, strong, hardy, and robust, can bear incredible fatigue, and it is said that the stoutest Norwegian is not able to bend the bow of a Laplander. The women are much less homely than the men, and many of them have a delicate and forid complexion. These people are simple, hon est, hospitable, and timorous; their timidity, however, respects war alone, for to many other species of dangers they expose themselves with surprising intrepidity, whether in ascending and descending mountains and precipices with their snow-shoes and in 
sledges, or in venturing amidst whirlpools and cataracts in little slender boats made of thin fir boards, fastened together with thongs of leather, sinews of wild beasts, or tough and flexible I wigs of willow and osier. These boats are of dircent sizes, from two to six yards in length, managed witli oars, and calked with moss so tight as to keep out the water.

The Laplanders are partly settled, and partly roving, the latter live in tents made with coarse cloth; the former live in small villages near the lakes, and chiefly follow fishing. They build their cottages somewhat in the shape of a cone, by planting a circle of large trees or poles aslant in the earth, and close to each other, so that their tops meet, and form a small vent for the issue of the smoke; they cover the ground within with branches of trees. In spring their food consists principally of the eggs of water-fowl, which are extremely plentiful; in sumner and autumn, of the birds themselves, and of various others of the partridge tribe; and in winter, of the milk and flesh of the rein-deer and dried fish. They had till lately no bread, but used the inner rind of the pine-tree dried and ground, and dried fish reduced to powder. 'They make coufections and decoctions of berries, angelica, and sorrel, which they use as preservatives against the scurvy.

The Laplander enjoys almost uninterripted health, by temperance and exercise, which brace his nerves to a very unusual pitch of strength, and fortify his constitution in such a manner, that he often lives to the age of 100 without feeling any disease, or perceiving his vigour inpaired. It is not uncommon to see a Laplander in old age liunt ing, fowling, skaiting, and performing all the several exercises of youth with agility.

The summer garb of the men consists of a long coat of coarse cloth, reaching down to the middle of the $\mathrm{leg}$, and girded round the waist by a belt or girdle, from which hang a Norway knife, and a pouch containing fints, matches, tobacco, and other necessaries, the girdle itself being decorated with brass lings and chains. Their caps are made of the skin of the northern diver, with the feathers on; and their shoes of the rein-deer skin, with the hair outwards. They wear no linen, but the garments of the superior ranks are of a finer cloth, and they delight in various colours, of which red is the most agreeable. In winter they are totally cased up in coats, caps, boots, and gloves, made of rein-deer skins.

In the "Flora Laponica," Linnæus says, "Perhaps the curious reade $r$ will wonder how the people of Lapland, during the terrible cold that reigns there in winter, can preserve their lives; since almost all birds, and even some wild beasts, desert it at that time. The Laplander, not only in the day, but during the whole winter nights, is obliged to wander about in woods for his herds of rein-deer; for the rein-deer never come under cover, nor eat any kind of fodder but a particular kind of liverwort. On this account the herdsmen are under a necessity of living continually in the woods, to take care of their cattle, lest they should be devoured by the wild beasts. The Laplander easily does with little light, as the snow reflects the rays from - the stars, and as the Aurora Borealis illuminates the air every night, 
He guards himself against the cold in the following manner : he wears breeches made of rein-deer ckins with the hair on, and shoes made of the same materials, the hairy part turned outwards. He puts intc the shoes slender-eared broad-leaved cypress grass, that is cut in summer and dried. This he first combs, and rubs in his hands, and then places it in such a manner, that it not only covers his feet quite round, but his legs also; and being thus guarded, he is quite secured against the intense cold. With this grass he stuffis his gloves likewise, to preserve the hands. As this grass keeps out the cold in winter, so in summer it hinders the feet from sweating, and at the same time prevents them from being annoyed by striking against stones, \&c. for their shoes are very thin, being made not of tanned leather, but of raw hide. The women's apparel differs very little from that of the men; only their girdles are more ornamented with rings, chains, needle-cases, and toys that sometimes weigh $20 \mathrm{lb}$. In winter, both men and women lie in their furs; in summer they cover themselves entirely with coarse blankets, to defend themselves from the gnats.

\section{Marriage and Funeral Ceremonies.}

The manner in which the young Laplander chooses a wife is equally remarkable and ludicrous. When he has pitched upon a female, he employs some friends as mediators with the father; and these being provided with some bottles of brandy, the suitor accompanies them to the house of his future father-in-law, who invites the mediators to enter; but the lover is left without, till the liquor is drank, and the proposal discussed ; then he is called in, and entertained with such fare as the hut affords; yet without seeing his mistress, who retires, or goes out. Having obtained leave of her parents to make his addresses in person, he puts on his best apparel, and is admitted to the lady, whon he salutes with a kiss : then he presents her with the tongue of a rein-deer, a piece of beaver's flesh, or some other provision. She declines the offer, which is made in presence of her sisters and relations; but makes a signal to her lover to follow her into the fields, where she accepts the presents. When the lovers are agreed, the youth is permitted to visit his intended as often as he shall think proper; but every time he comes he must purchase this pleasure with a fresh bottle of brandy; a perquisite so agreeable to the father, that he often postpones the celebration of the nuptials for two or three years. At length the ceremony is performed at church by the priest of the parish. Even after this event the husband is obliged to serve his father-in-law a whole year, at the expiration of which time he retires to his own habitation with his wife and her patrimony of rein-deer, and receives presents from all his friends and relations. From this period he sequesters his wife from the company of all strangers, especially of the nale sex, and watches over her conduct with the most jealous vigilance. Many Lapland women are barren, and none of them are very fruitful.

A woman, immediately after delivery, swallows a draught of whale fat, the child is washed with snow or. cold water, and wrapped up in a hare-skin. The mother is seldom above five days in confine- 
ment, and in fourteen is generally quite recovercd; then she carries the child to church to be baptized. Before she can reach the residence of the priest, she is often obliged to traverse large forests, mountains, lakes, and wide-extended wastes of snow. The infant is fastened in a hollow piece of wood, stretched naked on a bed of fine moss, covered with the soft skin of a young rein-deer, and slung by two straps to the back of the mother, who always suckles her own child. At home this little cradle is hung to the roof of the hut, and the child lulled to sleep by swinging it from one side to the other.

The-boys from their infancy practise the bow, and they are not allowed to break their fast in the morning until they lave hit the mark. The female children are as early initiated in the business peculiar to their sey.

When a Laplander is supposed to be on his death-bed, his friends exhort him to die in the faith of Christ, and bear his sufferings with resignation, remembering the passion of our Saviour. They are not, however, very ready to attend him in his last moments, and, as soon as he expires, they quit the place with precipitation, apprehending some injury from his ghost, which they believe remains with the corpse, and takes all opportunities of doing mischief to the living. The deceased is wrapped up in woollen or linen, according to his circumstances, and deposited in a coffin by a persur selected for that purpose; but this office he will not perform, unless he is first secured from the ill offices of the manes by a consecrated brass ring fixed on his left arm. Together with the body, they put into the coffin an axe, a tlint, a steel, a flask of brandy, some dried fish, and venison. With the axe the deceased is supposed to hew down the bushes or boughs that may obstruct his passage in the other world; the steel and flint is designed for striking a light, should he find himself in the dark at the day of judgment; and on the provision they think he nay subsist during his journey. The Muscovite Laplanders observe other ceremonies, that bear an affinity to the superstitions of the Greek church. They provide him with money for the porter of paradise, and a certificate, signed by the priest, and directed to St. Peter, specifying that the bearer had lived like a good Christian, and ought to be admitted into heaven.

At the head of the coffin they place a little image of St. Nicholas, who is greatly reverenced as a friend to the dead. Before the interment, the friends of the deceased kindle a fire of fir boughs near the coffin, and express their sorrow in tears and lamentations. They walk in procession several times round the body, demanding, in a whining tone, the reason of his leaving them, with many other ridiculous questions. Meantime the priest sprinkles the corpse and the mourners alternately with holy water. The body is at last conveyed to the place of interment on a sledge drawn by rein-deer; which, with the clothes of the deceased, are left as the priest's perquisite. Three days after the burial, the kinsman and friends of the defunct are invited to an entertainment, where they eat the flesh of the reindeer which conveyed the corpse to the burying ground. This being a sacrifice to the manes, the bones are collected into a basket, and interred. Two-thirds of the effects of the deceased are inherited by 
his brothers, and the remainder divided among his sisters; but the lands, lakes, and rivers, are held in coparceny by all the children of both sexes, according to the division nade by Charles IX. of Sweden. when he assigned a certain tract of land to each family.

\section{Peculiar Customs of the Babylonians.}

WE shall first notice the peculiar and surprising construction of their boats of skins, in which they sailed along the river to Babylon. These boats were invented by the Armenians, whose country lay north from Babylonia. They made them with poles of willow, which they bent, and covered with skins; the bare side of the skins they put outward, and they made them so tight, that they resembled boards. The boats had neither prow nor stern, but were of a round form like a buckler. They put straw on the botiom. Two men, each with an oar, rowed them down the river, laden with different wares, but chiefly palm wines. Of these boats, some were very large, and some very small. The largest carried the weight of five hundred talents. There was room for an ass in their small boats; they put many into a large one. When they had unloaded after their arrival at Babylon, they sold the poles of their boats and the straw, and loading their asses with the skins, returned to Armenia, for they could not sail up the river, its current was so rapid. For this reason, they made their boats of skins instead of wood, and on their return to Armenia with their asses, they applied their skins to their former use.

As to their dress, they wore a linen shirt, which came down to their feet; over it they wore a woollen robe; their outer garment was a white vest. Their shoes resembled those of the Thebans. They let their hair grow. On their heads they wore a turban. They rubbed their bodies all over with fragrant liquors. Each man had a ring on his finger and an elegant cane in his hand, with an apple at the top, or a rose, a lily, or an eagle, or some other figure; for they were not suffered to use canes without devices.

When the Babylonians had become poor by the ruin of their metropolis, fathers used to prostitute their daughters for gain. There was one custom among the Babylonians worthy to be related. They brought their sick into the forum, to consult those who passed, on their diseases, for they had no physicians: they asked those who approached the sick, if they ever had the same distemper? if they knew any one who had it? and how it was cured? Hence, in this country, every one who saw a sick person was obliged to go to him and inquire into his distemper. They embalmed their dead with honey, and their mourning was like that of the Egyptians. There were three Babylonian tribes who lived only upon fish, which they prepared by drying them in the sun, and then beating them in a sort of mortar to a kind of four, which, after they had sifted through a linen sieve, they baked in rolls.

\section{Marriago Laws.}

When the girls were marriageable, they were ordered to meet in a certain place, where the young men likewise assembled. They were 
then sold by the public crier; but he first sold the most beantiful one. When he had sold her at an immense price, he put up others to sale, according to their degrees of beauty. The rich Babylor:ans were emulous to carry off the finest women, who were sold to the highest bidders. But as the young men who were poor could not aspire to have fine women, they were content to take the less handsome with the money which was given them; for when the crier had sold the handsomest, he ordered the ugliest of all the women to be brought, and asked if any one was willing to take her with a small sum of money. Thus she became the wife of him who was most easily satisfied; and thus the finest women were sold, and from the money which they sold for, small fortnues were given to the ugliest, and to those who had any bodily intirmity. A father could not give his danghter in marriage as he pleased; nor was he who bought her allowed to take her home, without giving security that he would marry her. But, after the sale, if the parties were not agreeable to each other, the law enjoined that the money should be restored. 'The inhabitants of any of their towns were allowed to marry wives at those auctions. Such were the early customs of the Babylonians. But they afterwards made a law, which prohibited the inhabitants to intermarry, by which husbands were punished for treating their wives ill.

\section{In Habitants of Atroor.}

ATOor is one of the Sandwich islands. The natives of this island are of the niddle size, and in general stoutly made. They are neither remarkable for a beautiful shape nor for striking features. Their visage, particularly that of the women, is sometimes round, but others have it long; nor can it justly be said that they are distinguished as a nation by any general cast of countenance. Their complexion is nearly of a nut-brown, but some individuals are of a darker hue. They are far from being ugly, and have to all appearance few natural deformities of any kind. Their skin is not very soft nor shining; but their eyes and teeth are for the most part pretty good. Their hair in general is straight; and though its natural colour is usually black, they stain it, as at the Friendly and other islands. They are active, vigorous, and most expert swimmers, leaving their canoes upon the most frivolous occasions, diving under them, and swimming to others, though at a considerable distance. Women with infants at the breast, when the surf was so high as to prevent their landing in the canoes, frequently leapt overboard and swam to the shore, without endangering their little ones. They appear to be of a frank cheerful disposition, and are equally free from the fickle levity which characterizes the inhabitants of Otalieite, and the sedate cast which is observable among many of those of Tongataboo. They seem to cultivate a sociable intercourse with each other; and, except the propensity to thieving which is as it were innate in most of the people in those seas, they appeared extremely friendly.

It was pleasing to observe with what affection the women managed their infants, and with what alacrity the men contributed their assistance in such a tender office; thus distinguishing themselves from 


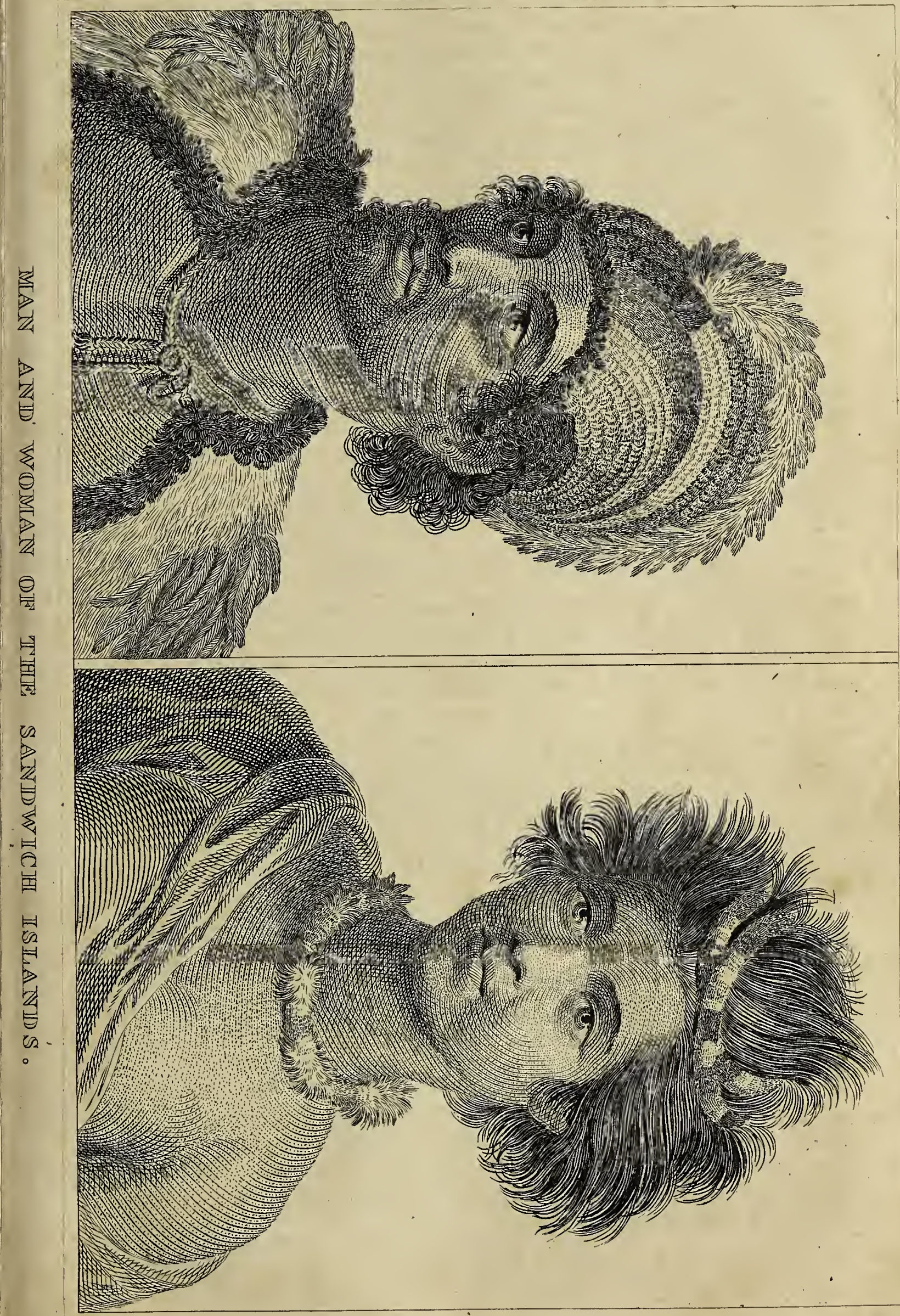



those savages who consider a wife and clild as things rather necessary, than desirable or worthy of their regard and esteen.

encom the numbers that were seen assembled at every village, in coasting along, it was conjectured that the inlabitants of this island are pretty numerous. Including the straggling louses, it was computed there might perhaps be, in the whole island, sixty such villages as that near which our ships anchored; and allowing five persons to each house, there would be in every village 500 , or 30,000 in all upon the island. This is by no means exaggerated; for there were sometimes 3000 people at least collected upon the beach, when it could not be supposed that above a tenth part of the natives were present.

\section{Formosans.}

THESE are the inhabitants of the island of Formosa. These Indians are distributed into forty-five villages, thirty-six of which lie to the north, and nine towards the south. The northern villages are very populous, and the houses almost after the Chinese manner. The habitations of the southern islanders are only heaps of huts, or cottages of earth. In these huts they have neither chairs, benches, tables, beds, nor any piece of furniture; the middle part is occupied by a kind of hearth or chimney raised two feet high, and constructed of earth, upon which they dress their victuals. Their ordinary food is rice, other small grain, and the game which they catch by coursing or kill with their arms. These islanders run with such surprising swiftness, that they can almost outstrip the fleetest greyhound. The Chinese attribute this agility to the precaution they take of confining their knees and reins by a close bandage, till the age of fourteen or fifteen.

Their favourite arms are lances, which they dart to the distance of sixty or eighty feet with the greatest dexterity and precision. They use bows and arrows, and can kill a pheasant on the wing with as much certainty as an European sportsman could with a fusee. They are very dirty in their manner of eating. They have neither plates, dishes, nor spoons, nor even small sticks as used in China. Whatever they dress is placed on a plain board or mat, and they use their fingers to convey it to their mouths. They eat flesh half raw; if it has been only presented to the fire, it appears to them excellent. Their beds are formed of fresh-gathered leaves. They go almost naked, and wear only a piece of cloth which hangs from their girdle to their knees. Those among them who have borne away the prize for agility in running, or dexterity in the chase, obtain the honourable privilege of marking on their skin, by a very painful operation, several fantastical figures of flowers, trees, and animals. All have a right of blackening their teeth, and of wearing ornaments of bracelets and crowns made of shells and crystals.

The islanders who inhabit the northern part, where the climate is something colder, clothe themselves with the skins of the stags which they kill in hunting. They make a kind of dress of them without sleeves, that pretty much resembles a dalmatic, or vestment worn at the altar by the Roman clergy. They wear on their heads caps in 
the form of a cylinder, made of palm leaves, and ornamented with several crowns placed one above another, on the top of which they fix plumes composed of the feathers of a cock or pheasant.

The marriage ceremonies of the Formosans approach near to the simple laws of nature. They neither purchase, as in China, the wonen whom they espouse, nor does interest preside over their unions. Fathers and mothers are scarcely ever consulted. If a young man has a mind to marry, and has fixed his affection on a young girl, he appears for several days foltowing near the place where she lives, with a musical instrument in his hand. If the young woman is satisfied with the figure of her gallant, she comes forth and joins him; they then agree, and settle the marriage contract. After this they give notice to their parents, who prepare a wedding dinuer, which is always given in the house where the young woman resides, and where the bridegroom remains, without returning again to his father. The young man afterwards considers the house of his fatherin-law as his own. He becomes the support of it, and has no farther connexion with that of his father; like married women in Europe, who generally quit their paternal home to live with their husbands. These islanders are therefore seldom anxious for male children; they prefei daughters, because they procure then sons-inlaw, who become the supports of their old age.

Although the Formosans are entirely subjected to the Chinese, they still preserve some remains of their ancient government. Each village chooses three or four old men from among those who have the greatest reputation for probity. By this choice they become rulers and judges of the rest. They have the power of finally determining all differences; and if any should refuse to abide by their judgment, he would be immediately banished from the village, without hopes of ever being able to re-enter it, and none of the inhabitants would afterwards receive him:

The natives pay in grain the tribute imposed upon them by the Chinese. To regulate every thing that concerns the laying on and collecting of this impost, government has established a Chinese in every village, who is obliged to learn the language, and act as interpreter to the mandarins. These interpreters are most cruel extortioners to the miserable people, whom they ought rather to protect; they are such insatiable leeches, that they can scarcely ever be satisfied. This daily and domestic tyranny, has caused the desertion of three villages in the southern part of the island, where formerly there were twelve. The inhabitants of these villages revolted, expelled their interpreters, refused to pay tribute any longer to the Chinese, and united themselves to the independent nations in the eastern part of the island.

It was in the island of Formosa, that John Struys affirms to have seen with his own eyes a man who had a tail more than a foot in length, covered with red hair, and greatly resembling that of an ox! This man with a tail said, that his deformity, if it was one, proceeded from the climate, and that all those of the southern part of the island were born with tails like his. But John Struys is the only anthor who attests the existence of this extraordinary race of men, no other 
writer who has spoken of Fornosa makes the least mention of this singular appendage.

\section{Biscayers.}

THESE are a people quite distinct from other Spaniards. Their language is counted aboriginal, and unmixed with Italian, French, or Spanish, and seems to be a dialect of the Celtic. It is so totally different from the Castilian, that we seldom meet with any of the peasants that understand one word of the Spanish. The Biscayers are stout, brave, and choleric to a proverb. The best sailors in Spain belong to the ports of Biscay, and its mountains produce a very valuable race of soldiers. Their privileges are very, extensive, and they watch over them with a jealous eye. They have no bishops in the province, and style the king only, lord of Biscay. The men are well-built and active, like all mountáneers.

The most singular thing in their dress is the covering of theirlegs ; they lap a piece of coarse grey or black woollen cloth round them, and fasten it on with many turus of tape. The women are tall, beautiful, light, and merry; their garb is neat and pastoral, their hair falis in long plaits down their backs; and a veil or handkerchief twisted round in a coquetish manner, serves them for a very becoming head-dress. On Sundays they generally wear white, covered with rose-coloured knots.

\section{SiAMESE.}

THESE are the inhabitants of Siam, a kingdom of Asia. The Siamese are of small stature, but well proportioned ; their complexions are swarthy; the faces of both sexes are broad, and their foreheads suddenly contracting, terminate in a point, as well as their chins. They have small black eyes, hollowed jaws, large mouths, and thick pale lips. Their teeth are dyed black, their noses are short and round at the end, and they have large ears, which they think beautiful. Their hair is thick and lank, and both sexes cut it so short that it reaches no lower than their ears; the women make it stand up on their foreheads, and the men shave their beards. People of distinction wear a piece of calico tied about their loins, that reaches down to their knees. The men bring up this cloth between their legs, and tuck it in their girdles, which gives it the appearance of a pair 0 ? breeches. They have also a muslin shirt without a collar, with wide sleeves; no wrist-bands, and the bosom open. In winter they wear a piece of stuff or painted linen over their shoulders like a mantle, and wind it about their arms.

The king of Siam is distinguished by wearing a vest of brocaded satin with straight sleeves that reach down to the waist, under such a shirt as above described; but no subject must wear this dress, unless he receives it from the king. They wear slippers with peaked toes turned up, but no stockings. All the retinue of the king, either in war or in bunting, are clotlied in red. The king wears a cap in the form of a sugar loaf, encompassed by a coronet of precious 
stones; those of his officers have a circle of gold, silver, or of vermilion gilt, to distinguish their quality; these caps are fastelled under the chin; they are only worn in the king's presence, or in courts of justice, and on other extraordinary occasions. They have also hats for travelling; but in general, few people cover their heads, notwithstanding the scorching heat of the sun.

The women also wrap a cloth about their middle, which hangs down to the calf of their legs. They cover their breasts with another cloth, the ends of which hang down over their shoulders. But they have no garment corresponding to a shift, nor any covering for their heads but their hair. The common people are almost naked, and wear neither shoes nor slippers. The women wear as many rings on the three last fingers of each hand as they can keep on, and bracelets upon their wrists and ancles, with pendants in their ears shaped like a pear. For an inferior to stand before a superior is deemed insolent; and therefore slaves and people of inferior rank sit upon their heels, with their head a little inclined, and their joined hands lifted up to their foreheads. In passing by a superior they bend their bodies, joining their hands and lifting them towards their heads. The highest part of the house is esteemed the most honourable. The Siamese, indeed, have but one story, but the rooms rise gradually, and the innermost, which are the highest, are always the most honourable.

The Siamese never permit such familiarities as are practised by gentlemen in Europe. Easiness of access, and affability to inferiors, is in that part of the world thought a sign of weakness; and yet they take no notice of some things which would be lnoked upon as ill breeding among us; such as belching in company, which no man endeavours to prevent, or to conceal, so much as to hold bis liand before his mouth.

They have an extraordinary respect for the head, and it is the greatest affront to stroke or touch that of another person ; nay, their cap mist not be used with too much familiarity. They are esteemed an ingenious people, and though rather indolent than active, they are not addicted to voluptuous vices, which often accompany a state of ease, being remarkably chaste and temperate. They are, however, insolent towards their inferiors, and equally obsequious to those above them. In general their behaviour is extremely modest, and they are averse from loquacity. Like the Chinese, they avoid speaking in the first person; and when they address a lady, it is always with some respectful epithet, insinuating accomplishments. No man learns any particular trade, but has a general knowledge of all that are commonly practised, and every one works six months for the king by rotation; at which time, if he should be found perfectly ignoraint o. the business he is set about, he is doomed to suffer tlie bastinado. The consequence of this burdensome service is, that no man endeavours to excel in his business, lest he should be obliged to practise it as long as he lives for the benefit of the crown.

The Siamese maintain the doctrine of transmigration, believing in a pre-existent state, and that they shall pass into other bodies till they are sufficiently purified to be received into paradise. They 
believe likewise that the soul is material but not subject to the touch; that it retains the human figure after quitting the body, and that when it appears to former acquaintances, which they suppose it to do, the wounds of one that has been murdered will then be visible. They are of opinion that no man will be eternally punished; that the good, after several transmigrations, will enjoy a perpetual happiness; but that those who are not reformed will be doomed to transmigration to all eternity. They believe in the existence of a Supreme Being; but the objects of their adoration are departed saints, whom they consider as mediators or intercessors for them; and to them both temples and images are erected.

The men are allowed a plurality of women; but excepting one, who is a wife by contract, the others are only concubines, and their children deemed incapable of any legal inheritance. Previous to every nuptial contract, an astrologer must be consulted, who calculates the nativity of the parties, and determines, whether their union is likely to prove fortunate or otherwise. When his prognostication is favourable, the lover is permitted to visit his mistress three times, at the last of which interviews the relations being present, the marriage portion is paid, when, without any religious ceremony performed, the nuptials are reckoned complete, and soon after consummated. A few days after, the talapoin visits the married couple, sprinkles them with water, and repeats a prayer for their prosperity. The Siamese were anciently famous for their skill in astronomy.

$$
\text { SI-FANS, or Tou-FANS. }
$$

THESE are a people inhabiting the country on the west of China. The Si-Fans are divided into two kinds of people; the one are called by the Chinese, black Si-Fans, the other yellow, from the different culours of their tents. The black are the most clownish and wretched; they live in small bodies, and are governed by petty chiefs, who all depend upon a greater. The yellow Si-fans are subject to a family, the oldest of which becomes a lama, and assumes the yellow dress. These lama princes, who command in their respective districts, have the power of trying causes and punishing criminals; but their government is by no means burdensome. Provided certain honours are paid them, and they receive punctually the dues of the god Fo, which amount to very little, they molest none of their subjects.

The greater part of the Si-fans live in tents; but some of them have houses built of earth, and even brick. Their habitations are not contiguous; they form at most but some small hamlets, consisting of five or six families. They feed a great number of flocks, and are in no want of the necessaries of life. The principal article of their trade is rhubarb, which their country produces in great abundance. Their horses are small, but they are well-shaped, lively, and robust. These people are proud, and of independent spirit, and acknowledge with reluctance the superiority of the Chinese government, to which they have been subjected. When they are summoned by the mandarins, they rarely appear; but the government, for political reasons, winks at this contempt, and endeavours to keep these intractable subjects 
under by mildness and moderation; it would besides be difficult by rigorous means to reduce them to perfect obedience; their wild and frightful mountains, the tops of which are always covered with snow, even in July, would afford them places of shelter, from which they conld never be driven by force.

The customs of these mountaineers are totally different from those of the Chinese. It is, for example, an act of great politeness among them to present a white handkerchief of taffeta or linen, when they accost any person whom they are desirous of honouring. All their religion consists in their adoration of the god Fo, to whom they have a singular attachment; their superstitious veneration extending; even to his ministers, on whom they have considered it as their duty to confer supreme honour and the goverument of the nation.

\section{Inhabitants of Peru.}

PERU is a country of South America, which abounds more in women than in men, and the women enjoy a better state of liealth, owing to the earlier intemperance of men. The Creoles are well made, of a proper stature, and of a lively and agreeable countenance. The Mestizos are also in general well made, often taller than the ordinary size, and very robust. The Indians are commonly low in stature, though strong and well-proportioned. Some are remarkably short. Their hair is thick and long, and worn loose; but the Indian women plait theirs behind with a ribbon, and cut that before, above the eye-brows. The greatest disgrace that can be offered to an Indian of either sex is to cut off their hair; any other punishment they bear witl patience, but this they never forgive. The colour of their hair is a deep black, lank, harsh, and coarse as that of a horse.

The male Mestizos, to distinguish themselves from the Indians, cut of their hair; but the females do not. The Mestizos wear a blue cloth, manufactured in Europe. The Mestizo women affect to dress in the same manner as the Spanish. The dress of the Indians consists of white cotton drawers down to the calf of the leg, loose, and edged with a lace. The shirt is supplied by a black cotton frock in the form of a sack, with three openings, one for the head and two others for the arms. Over this, is a serge cloak, and a hat. This is a general dress, which they never lay aside, even while they sleep.

The Indians who, have acquired some fortune, particularly the barbers and phlebotomists, distinguish themselves from the countrymen by the fineness of their drawers, and a shirt with lace four or five fingers broad, fastened round like a ruff or band. They wear silver or gold buckles in their shoes, though they wear no stockings; and have a cloak of fine cloth, often adorner with gold or silver lace. Rum and brandy are drank by persons of all ranks; but the excessive use of spirituous liquors chiefly prevails ariong the Mestizos. Another liquor much used in this cuuntry is made of an herb called Paraguay. Gaming is carried to an extravagant height. The conmon people and the Indians are greatly addicted to stealing, but highway robberies are seldom heard of. 


\section{Antiliopophagi or Men-Eaters.}

Garcilasso-DE-LA-VEGA mentions a people in Peru, who made eunuchs of their children by their female captives, in orler to fatten them for the table; and when the motliers could breed no more, they shared the same fate: and Herrera speaks of the markets in China, as being regularly supplied with human flesh, which was considered as a delicacy, and only fitted for the rich. The history of Milan furnishes an extraordinary instance of Anthropophagia. A woman was broken on the wheel, and burnt in that town, in the year 1519, whose crime was a long continued practice of enticing children into her house, whom she killed and sálted.

\section{SHILLOOK.}

Thrs is the name of the inhabitants of Sennaar, a country of Africa. This country, together with all the northern part of Africa, had been over-run by the Saracens during the rapid conquests of the Khalif's ; but instead of erecting any distinct principalities here, as in other parts, they had incorporated themselves with the original inhabitants called shepherds, whom they found at their arrival, and had converted them to their religion, and become one people with them. In 1504 the Shillook, a people before unknown, came from the western banks of the river Bahiar el Abiad, which runs into the Nile, and conquered the country, allowing the Arabs, however, to retain their possessions on condition of paying them a certain tribute. These founded the city of Sennaar, and have ever since continued to carry on a commercial intercourse with Egypt. At the establishment of their monarchy the whole nation were Pagans, but soon after became converts to Mahometanism, and took the name of Funge, an appellation signifying lords or conquerors, and likewise free citizens.

Mr. Bruce, who passed through this country in his return from Abyssinia, gives a list of twenty kings who have reigned in it since the conquest of the Shillook. "This country is inhabited by a people so barbarous and brutish, that no history of them can be expected. One of the most remarkable of their customs is, that the king ascends the throne with the expectation of being murdered whenever the gelleral council of the nation thinks proper. The dreadful office of executioner belongs to one single officer, styled, in the language of the country, Sid el Coom, and who is always a relation of the monaich himself. It was from his registers that Mr. Bruce took the list of the kings already mentioned, with the number of years they reigned, and which may therefore be received as authentic.

The Sid el Coom, in office at he time when Mr. Bruce visited this country; was named Achmet, and was one of his best friends. He had murdered the late king with three of his sons, one of whom was an infant at his mother's breast; he was also in daily expectation of performing the same office to the reigning sovereign. He was by no means reserved concerning the nature of his office. When asked by Mr. Bruce, why he murdered his young son in his father's presence? 
he answered, that he did it from a principle of duty to the king himself, who had a right to see his son killed in a lawful and regular manner, which was by cutting his throat with a sword, and not in a more painful or ignominious way, which the malice of his enemies might possibly have inflicted. The king, he said, was very little concerned at the sight of his son's death, but he was so very unwilling to die himself, that he often pressed the executioner to let him escape; but finding his entreaties ineffectual, he submitted at last without resistance. On being asked whether he was not afraid of coming into the presence of the king, considering the office he might possibly have to perform? he replied, that he was not in the least afraid, on this account - that it was his duty to be with the king every morning, and very late in the evening; that the king knew he had no hand in pro. noting his death; but that when the matter was absolutely determined, the rest was only an affair of decency; and it would undoubtedly be his own choice rather to fall by the hand of his own relation privately than by a hired assassin, an Arab, or a Christian slave, in the sight of the populace.

On the death of any sovereign of this country, his eldest son succeeds; on which as many of his brothers as can be found are apprehended, and put to death by the Sid el Coom. Women are excluded from the sovereignty here, as well as at Abyssinia. The princesses of Sennaar, however, are worse off than those of Abyssinia, having no settled income, nor are they treated in any degree better than the daughters of private persons. The king is obliged, once in his lifetime, to plough and sow a piece of ground, whence he is named Baady, " the countryman, or peasant," a title as common among the monarchs of Sennaar as Cæsar was among the Romans. When the royal family marry Arab women, the white colour of the mother is communicated to the child. This, we are told by $\mathrm{Mr}$. Bruce, is invariably the case when a negro man of Sennaar marries an Arab woman, and it holds equally good when an Arab man marries a negio woman; and he likewise informs us, that he never saw one black Arab all the time that he was at Sennaar.

The soil and climate of this country is extremely unfavourable both to man and beast. The men are strong, and remarkable for their size, but short-lived; and there is such a mortality among the children, that were it not for a constant importation of slaves, the metropolis would be depopulated. The shortness of their lives, however, may perhaps be accounted for, from their indulging themselves from their infancy in every kind of excess.

The dress of the people of Sennaar consists only of a long shirt of blue cloth, which wraps them up from the under part of the neck to the feet. The men sometimes have a sash tied about their middle; and both men and women go barefooted in the houses, whatever their rank may be. The floors of their apartments, especially those of the women, are covered with Persian carpets. Both men and women anoint themselves at least once a day with camel's grease mixed with civet, which they imagine softens their skin, and preserves it from cutaneous eruptions, of which they are so fearful, that they confine themselves to their houses, if they observe the smallest pimple on 
their skins. With the same view of preserving their skins, though they have a clean shirt every day, they sleep with a greased one at night, having no other covering but this. Their bed is a tanned bull's hide, which this constant greasing softens very much; it is also very conl, though it gives a smell to their bodies, from which they cannot be freed by any washing.

Our author gives a very curious description of the queen and ladies of the court of Sennaar. He had access to them as a physician, and was permitted to pay his visit alone. He was first shewn in to a large square apartment, where there were about fifty black women, all quite naked, except a very narrow piece of cotton rag about their waists. As he was musing whether these were all queens, one of them took him by the hand, and led him. into another apartment, nuch better lighted than the former. Here he saw three women sitting upon a bench or sofa, covered with blue Serat cloth, they themselves being clothed from the neck to the feet with cotton shirts of the same colour. These were three of the king's wives; his favourite, who was one of the number, appeared to be about six feet high, and so corpulent, that our traveller imagined her to be the largest creature he had seen, next to the elephant and rhinoceros. Her features perfectly resembled those of a negro; a ring of gold passed through her under lip, and weighed it down, till, like a flap, it covered her chin, leaving her teeth bare, which were small and very fine. The inside of her lip was made black with antimony. Her ears reached down to her shoulders, and had the appearance of wings; there was a gold ring in each of them about five inches in diameter, and somew hat smaller than a man's little finger, the weight of which had drawn down the hole, where her ear was pierced, so much, that three fingers might easily pass above the ring. She had a gold necklace of several rows, one below another, to which were hung rows of sequins pierced. She had two manacles of gold upon her ankles, larger than those used for chaining felons. Our author could not imagine how it was possible for her to walk with them, till he was informed that they were hollow: The others were dressed much in the same manner, only there was one who had chains coming from her ears to the outside of each nostril, where they were fastened. A ring was also put through the gristle of her nose, which hung down to the opening of her mouth, having altngether something of the appearance of a horse's bridle ; and Mr. Bruce thinks she must have breathed with difficulty.

\section{Senegalians.}

THESE are the inhabitants of the island of Senegal. The men are tall, and the women are accounted the handsomest negresses of all Africa. The Senegalians may be considered as the most courageous pcople in that part of the world, without even excepting the Moors. Their courage, however, is more nearly allied to temerity than to bravery. In the course of a voyage to Galam, they met the greatest dangers with gaiety and song. They dread neither musket nor canno, and are equally fearless of the cayman or crocodile. Should one of their companions be killed, and devoured by these aumals before their face, 
they ate not deterred from plunging into the water, if the working of the ship require it. These excellent qualifications, which distinguish them, do tot, however, preserve them from rapine. They are emulous to surpass one another in all the arts of over-reaching and fraud. The conduct of the Europeans has, no doubt, encouraged these vices, as much as the lessons of the Marabons, who inculcate the duty of plundering the Christians to the utmost of their power. The Yolof negroes of Senegal are either Christians or Mahometans, or, with more truth, neither; religion being a matter of indifference to them.

Cantabrians.

THE inhabitants of Cantabria are famous for their warlike character. In conjunction with the Asturians, they carried on desperate wars with the Romans, but were subdued by them about B. C. 25 . Impatient, however, of a foreign yoke, they soon revolted. Most of their youth had been taken prisoners by the Romans, and sold for slaves to the neighbouring nations; but having found means to break their chains, they cut the throats of their masters, and, returning to their own country, attacked the Roman garrisons with great fury. Agrippa marched against them with great expedition, but, on his arrival, met with so vigorous a resistance, that his soldiers began to despair of ever reducing them.

As the Cantabrians had waged war with Rome for upwards of 200 years, they were well acquainted with their manner of fighting, no way inferior to them in courage, and were become desperate, knowing that if they were conquered after having so often attempted to recover their liberty, they must expect the most severe usage. Animated by this reflection, they fell upon the Romans with a fury hardly to be imagined, routed them in several engagements, and defended themselves whien attacked with such intrepidity, that Agrippa afterwards owned he had never, either by sea or land, been engaged in a more dangerous enterprise. That brave commander used entreaties and menaces, and even branded some of his legionaries with ignominy, before he could bring them to enter the lists with such a formidable foe. But having at last prevailed upon them to try the chance of an engagement in the open field, he so animated them by his own example, that after a most obstinate dispute he gained a complete victory, which put an end to that destructive war. All the Cantabrians fit to bear arms were cut in pieces, their castles and strong holds taken and razed, and their women, children, and old men, none else being left alive, were obliged to abandon the mountainous parts, and settle in the plain.

Customs, Dress, \&c. of the Americans.

ALL the Indian nations take a peculiar pleasure in painting their bodies of a red colour with a certain species of earth. The mine of Guancavolica was formerly of no other use than to supply them with this material for dying their bodies; and the cinnabar extracted from it was applied entirely to this purpose. The tribes in Louisiana and 
Canada have the same passion; heuce minium is the commodity most in demand there. It may seem singular that these nations, whose natural colour is red, should affect the same colour as an artificial ornament. But it may be observed, that they do nothing in this respect but what corresponds to the practice of Europeans, who also study to heighten and display to advantage the natural red and white of their complexions.

The Indians of Peru have now indeed abandoned the custom of painting their bodies : but it was common among them before they were conquered by the Spaniards, and it still remains the custom of all those tribes who have preserved their liberty.

The northern nations of America, besides the red colour which is predominant, employ also black, white, blue, and green, in painting their bodies. The adjustment of these colours is a matter of as great consideration with the Indians of Louisiana, and the vast regions extending to the north, as the ornaments of dress amongst the most polished nations. The business itself was called maetacher, and they do not fail to apply all their talents and assiduity to accomplish it in the most polished manner. No lady of the greatest fashion ever consulted her mirror with more anxiety, than the Indians do while painting their bodies. The colours are applied with the utmost accuracy and address. Upon the eyelids, precisely at the root of the eyelashes, they draw two lines as fire as the smallest thread, the same upon the lips, the opening of the nostrils, the eye-brows, and the ears, of which last they even follow all the inflexions and sinuosities. Over the rest of the face, they distribute various figures, in all which the red predominates ; and the other colours are assorted so as to throw it out to the best advantage : a thick coat of vermilion commonly distinguishes the cheeks. The neck also receives its proper ornaments. Four or six hours are requisite for accomplishing all this with the nicety which they affect. As their first attempts do not always succeed to their wish, they efface them, and begin anew upon a better plan. No coquette is more fastidious in her choice of ornaments, none more vain when the important adjustment is finished. Their delight and self-satisfaction are then so great, that the mirror is hardly ever laid down. An Indian, maetached to his mind, is the vainest of all the human species. The other parts of the body are left in their natural state, and, excepting what is called a cachecul, they go entirely uaked.

Such as have made themserves eminent for bravery, or other qualifications, are distinguished by figures painted on their bodies. They introduce the colours by making punctures on their skin; and the extent of surface which this ornament covers, is proportioned to the exploits they have performéd. Some paint only their arms, others paint both their arms and legs, others again their thighs, while those who have attained the summit of warlike renown, have their bodies washed from the waist upwards. This is the heraldry of the Indians, the devices of which are probably more exactly adjusted to the merits of the persons who bear then, than those of more civilized countries. Besides these ornaments, the warriors also carry plumes of feathers on their heads, their arms, and ankles. These likewise are tokens of 
valour, and none but such as have been thus distinguished may wear them. The propensity to indolence is equal among ail the tribes of Indians.

The only employment of those who have preserved their independence is hunting and fishing. In some districts the women practise agriculture, in raising Indian corn and pompions, of which they form a species of aliment by bruising them together. They also prepare the ordinary beverage in use among them, taking care at the same time of the children, of whom the fathers take no charge. The female Indians of all regions of both North and South America, practise what is called the urea, a word which among them signifies elevation. It consists in throwing forward the hair from the crown of the head upon the brow, and cutting it round froin the ears to above the eye, so that the forehead and eyebrows are entirely covered. They tie. the rest of their hair behind. The males of the higher parts of Peru wear long and flowing hair, which they reckon a great ornament. In the lower parts they cut it short, on account of the heat of the climate. The inhabitants of Louisiana pluck out their hair by the zoots, from the crown of the head forwards, in order to obtain a large. forehead, denied them by nature. The rest of their hair is cut as sliort as possible, to prevent their enemies from seizing them by it in battle, and from easily getting their scalp, should they fall into their hands as prisoners. Among the North Americans, it is disgraceful to be hairy on the body, they say it likens them to hogs. - They therefore pluck it out as fast as it appears. Every nation has its customs.

"I have seen an Indian beau with a looking-glass in his hand," says Mr. Jefferson, "examining his face for hours together, and plucking out by the root every hair he could discover, with a kind of tweezer made by a piece of fine brass wire, that had been twisted round a stick, and which he used with great dexterity." The Indians of Sonth Ainerica distinguish themselves by modern dresses, in which they affect various tastes. Those of the high country, and of the valleys in Peru, dress inostly in the Spanish fashion. Instead of hats, they wear bonnets of coarse double cloth, the weight of which neither seems to incommode them when they go to warmer climates, nor does the accidental want of them seem to be felt in situations where the most piercing cold reigns. Their legs and feet are always bare, if we except a sort of sandals made of the skins of oxen.

\section{Funeral Rites.}

The force fo their friendship principally appears by the treatment of their dead. When any one of the society is cut off, he is lamented by the whole; on this occasion a thousand ceremonies is practised, denoting the most lively sorrow. No business is transacted, however pressing, till all the pious ceremonies due to the dead are performed. The body is washed, anointed, and painted; then the women lament the loss with hideous howlings, intermixed with songs which celebrate the great actions of the deceased and of his ancestors. The men mourn in a less extravagant manner. The whole village is present at the interment, and the corpse is habited in its most sumptuous ornaments Close to the body of the defunct are placed his 
bows and arrows, with whatever he valued most in his life, and a quantity of provision for his subsistence on the journey which he is supposed to take. This solemnity, like every other, is attended with feasting. The funeral beiug ended, the relations of the deceased confine themselves to their huts for a considerable time, to indulge their grief. After an interval of some weeks, they visit the grave, repeat their sorrow, new-clothe the remains of the body, and act over again all the solemnities of the funeral.

Among the various tokens of their regard for their deceased friends, the most remarkable is what they call the feast of the dead, or the feast of souls. The day for this ceremony is appointed in the council of their chiefs, who give orders for every thing which may enable them to celebrate it with pomp and magnificence; and the neighbouring nations are invited to partake of the entertainments. At the time, all who have died since the preceding feast of the kind, are taken out of their graves. Even those who have been interred at the greatest distance from the villages are diligently sought for, and conducted to this rendezvous of the dead, which exlibits a scene of horror beyond the power of description. When the feast is concluded, the bodies are dressed in the finest skins which can be procured, and after being exposed sone time in this pomp, are again committed to the earth with great solemnity, which is succeeded by funeral games.

\section{Hospitality.}

The Americans have certain rules which they observe on entering one another's villages. It is reckoned uncivil in travelling strangers to enter a village abruptly, without giving notice of their approach. Therefore as soon as they arrive within hearing, they stop and lialloo, remaining there till invited to enter. Two old men usually come out to them, and lead them in. There is in every village a vacant dwelling, called the stranger's house. Here they stay while the old men go round from hut to hut, acquainting the inhabitants that strangers are arrived, who are probably hungry and weary; and every one sends them what he can spare of victuals, and skins to repose on.

When the strangers are refreshed, pipes and tobacco are brought, and then, but not before, conversation begins, with inquiries who they are, whither bound, what news, \&c. and it usually ends with offers of service, if the strangers have occasion for guides, or other necessaries, for continuing their journey : and nothing is exacted for the entertainment. The same hospitality, esteemed among them as a principal virtue, is practised by private men, of which Conrad Wei. ser gave Dr. Franklin the following instance :-

"He had been naturalized among the Six Nations; and spoke well the Mohock language. In going through the Indian country, to carry a message from our governor to the council of Onondago, he called at the habitation of Canassetego, an old acquaintance, who embraced him, spread furs for him to sit on, placed before him some boiled beans and venison, and mixed some rum and water for his drink? When he was well refreshed, and had lit his pipe, Canassetego began to converse with him : asked him how he fared the many years since they had seen each other-whence then he came-and what had occasioned the journey, \&z. Conrad answered all his questions, and 
when his discourse began to flag, the Indian, to contiuue it, said" "Conrad, you have lived long among the white people, and know something of their customs; I have been sometimes in Albany, and have observed, that once in seven days they shut up their shops, and assemble all in the great house; tell me what it is for ?" "They meet there," said Conrad, " to hear and learn good things." "I do not doubt," says the Indian, "that they tell you so; they have told me the same; but I doubt the truth of what they say, and I will tell you my reasons. I went lately to Albany to sell my skins, and buy blankets, knives, powder, rum, \&c. You know I generally used to deal with Hans Hanson; but I was a little inclined this time to try some other merchant. However, 1 called first upon Hans, and asked him what he would give for beaver. He said he could not give more than $4 \mathrm{~s}$. a pound ; but, says he, I cannot talk on business now; this is the day when we meet together to learu good things, and I am going to the meeting. So I thought to myself, since I cannot do any business to-day, I may as well go to the meeting too; and I went with him. There stood up a man in black, and began to taik to the people very angrily. I did not understand what he said; but perceived that he looked much at me and at-Hanson. I imagined he was angry at seeing me there; so I went out, sat down near the house, struck fire, and lit my pipe, waiting till the meeting should break up. I thought too, that the man had mentioned something of beaver, and I suspected that it might be the subject of their meeting. So, when they came out, I accosted my merchant: "Well, Hans," says I, "I hope you have agreed to give more than 4s. a pound ?" "No", says he, "I cannot give so much," I cannot give more than 3s. 6d." I then spoke to several other dealers, but they all sung the same song, -three-and-sixpence, three-and-sixpence. This made it clear to me that my'suspicion was right; and that whatever they pretended of meeting to learn good things, the real purpose was to consult how to cheat poor Indians in the price of beaver. Consider but a little, Conrad, and you must be of my opinion. If they met so often to learn good things, they certainly would have learned some before this time. But they are still ignorant. You know our practice: If a white nan, in travelling through our country, enters one of our cabins, we all treat him as I treat you; we dry him if he is wet, we warm him if he is cold, and give him miat and drink to allay his thirst and hunger, and we spread soft furs for him to rest and sleep on ; we demand nothing, in return. But if I go into a white man's house at Albany, and ask for victuals and drink, they say, Where is your money? and if I have none, they say, Get out, you Indian dog: You see they have not yet learned those little good things that we need no meeting to be instructed in, because our mothers taught them to us when we were children; and therefore it is impossible their meetings - should be, as they say; for such purpose, or have any such effect; - they are only to contrive the cheating of Indians in the price of beaver."

\section{Ingenuity.}

The Indians are acquainted with letters, and their history is preserved in some few instances by hieroglyphic paintings, and sculpture, 
but principally in tradition. They often discover great ingenuity in communicating information to the absent. Of the following instance of hieroglyphic writing, Dr. Mitchel was an eye-witness. Tlie Dr. in company with several other gentlemen, as they were proceeding up the Onondago river to an Indian treaty, overtook several canoes of Seneka Indians, who encamped with them, near fort Brewington, and the next day proving rainy, they continued in company till the weather became so favourable as to permit them to cross the Oneida Lake. During the storm, one of the Indian canoes stove, and became unfit for service. The commissioners took the crew on board their boat, and carried them to a landing place, some distance up Wood Creek. Here one of them, before he forsook the water, took the following method to let his companions, who were left behind, know when and whither they liad proceeded. He took a piece of wood, and hewed it fat and smooth, and then raked his fire for a suitable coal, with which lie rudely delineated, on the slab, the figure of an Indian carrying his gun reversed upon his shoulder. In front of him he drew a crooked line, which reached to a man with a long coat and cocked hat, and holding a cane in his hand, and behind him a framed house. He then took a straight pole, and tied some weeds and grass upoin one end of it, and fixed the other in the earth, in such a manner, that in the position the sun then was, which was six oclock in the morning, it cast no shadow, or, in other words, he pointed it exactly towards the sun. The meaning of all this was "Susquewewah, (the name of the Indian,) left this place at six o'clock in the morning, or when the sun was in the place where the pole pointed, and has proceeded up wood Creek, (which is remakably crooked, to the settlement where the commissioners of the state of New York are assembled to hold"a treaty with the Indians." All these insignia were arranged so conspicuously on the margin of the creek, that his companions behind could scarcely avoid observing them as they passed.

\section{Marriages.}

Although the women generally bear the laborious part of domestic economy, their condition is far from being so slavish as it appears. On the contrary, the greatest respect is paid by the men to the female sex. The women even hold their councils, and have their share in all deliberations which concern the state. Polygamy is practised by some nations, but is not general. In wost they content thenselves with one wife, but divorce is admitted in case of adultery. No nation of the Anericans is without a regular marriage, in which there are many ceremonies, the principal of which is, the bride's presenting the bridegroom with a plate of their corn. The women, though before incontinent, are remarkable for chastity after marriage.

\section{Punishments.}

Controversies among the Indians are but few, and quickly decided. When any criminal matter is so flagrant as to become a national concern, it is brought under the jurisdiction of the great council ; but in ordinary cases the crime is either revenged or compromised by the parties concerned. If a murder be conmitted, the family 
which has lost a relation, prepares to retaliate on that of the offender. They often kill the murderer; and when this happens, the kindred of the last person slain, look upon themselves to be as much injured, and to have the same right to vengeance, as the other party. In general, however, the offender absents himself, and the friends send compliments of condolence to those of the person that has been murdered. The head of the family at length appears with a number of presents, the delivery of which he accompanies with a formal speech. The whole ends, as usual, in mutual feastings, songs, and dances. If the murder is committed by one of the same family or cabin, that cabin has the full right of judgment within itself, eitlier to punish the guilty with death, or to pardon him, or to give some recompense to the wife or children of the slain. Instances of such a crime, however, very seldom happens; for their attachment to those of the same family is remarkably strong, and is said to produce such friendship as may vie with the most celebrated in real or fabulous antiquity.

\section{Superstitions.}

The chief ingredient in the cliaracter of the Americans, is their propensity for war, which gives a strong bias to their religion. Arekoni, or the god of battle, is revered by them as the great god of the Indians. Him they constantly invoke before they go out into the field, and according as his disposition is more or less favourable to them, they conclude that they will be more or less successful. Some nations worship the sun and moon; among others there are numbers of traditions, relative to the creation of the world and the history of the gods, traditions which resemble the Grecian fables, but which are still more absurd and inconsistent. But religion is not the prevailing character of the Indians; and except when they have some immediate occasion for the assistance of their gods, they pay them no sort of worship.

Like all rude nations, however, they are strongly addicted to superstition. They believe in the existence of a great number of good and bad genii or spirits, who interfere in the affairs of mortals; and produce all their happiness or misery. It is from the evil genii in particular that our diseases proceed, and it is to the good genii we are indebted for a cure. The ministers of the genii are the jugglers, who are also the only phisicians among the savages. These jugglers are supposed to be inspired by the good genii, most commonly in their dreams, with the knowledge of future events; they are called in to the assistance of the sick, and are supposed to be informed by the genii whether they will get over the disease, and in what way they must be treated. But these spirits are extremely simple in their system of physic, and, in almost every disease, direct the juggler to the same remedy. The patient is enclosed in a narrow cabin, in the midst of which is a red stone pot; on this they throw water, until he is well soaked with the warm vapour and his own sweat. Then they hurry him from this bagnio, and plunge him suddenly into the next river. This coarse method, which costs many their lives, often performs very extraordinary cures. The jugglers have likewise the use of some specifics of wonderful efficacy; and all the savages are dexterous in curing wounds 
by the application of herbs. But the power of these remedies is always attributed to the magical ceremonies with which they are administered.

\section{Manner of Treating their Prisoners.}

United as the Americans are in small societies, connected within themselves by the firmest ties, their friendly affections, which glow with the most intense warmth within the walls of their own village, seldom extend beyond them. They feel nothing for the enemies of their nation, and their resentment is easily extended from the individual who has injured them, to all others of the same tribe. The prisoners, who have themselves the same feelings, know. the intentions of their conquerors, and are prepared for them. The person who has taken the captive, attends him to the cottage, where, according to the distribution made by the elders, he is to be delivered, to supply the loss of a citizen. If those who receive him have their family weakened by war or other accidents, they adopt the captive into the family, of which he becomes a member. But if they have no occasion for him, or their resentment for the loss of their friends be too high to endure the sight of any connected with those who were concerned in it, they sentence him to death. All those who have met with the same sentence being collected, the whole nation is assembled at the execution, as for some great solemnity. A scaffold is erected, and the prisoners are tied to the stake, where they commence their death-song, and prepare for the ensuing scene of cruelty with the most undaunted courage. Their enemies, on the other side, are determined to put it to the proof by the most refined and exquisite tortures.

They begin at the extremity of his body, and gradually approach the more vital parts : one plucks out his nails by the roots, another takes a finger into his mouth, and tears off the flesh with his teeth; a third thrusts the finger, mangled as it is, into the bowl of a pipe made red hot, which he smokes like tobacco; then they pound his toes and fingers to pieces between two stones; they cut circles about his joints, and gashes in the fleshy parts of his limbs, which they sear immediately with red-hot irons, cutting, burning, and pinching them alternately; they pull off the flesh, thus mangled and roasted, bit by bit, devouring it with greediness, and smearing ther faces with blood in an enthusiasm' of horror and fury. When they have thus torn off the flesh, they twist the bare nerves and tendons about an iron, tearing and snapping them, whilst others are employed in pulling and extending their limbs in every way that can increase the torment. This continues often five or six hours, and sometimes, such is the strength of the savages, days together Then they frequently unbind him, to give a breathing to their fury, to think what new torments they can inflict, and to refresh the strength of the sufferer, who, wearied out with such a variety of unheard-of torments, often falls into so profound a sleep, that they are obliged to apy'y the fire to awake him, and renew his sufferings. He is again fastened to the stake, and again they renew their cruelty : they stick him all over with small matches, or wood that easily takes fire, but burns slowly; they continually run sharp reeds into every part of his body; they drag out his teeth with pincers, and 
thrust out his eyes; and, lastly, after having burned his flesh from the bones with slow fires, and after having so mangled the body that it is all but one wound, after having mutilated his face in such a manner as to carry nothing human in it, after having peeled the skin from the head, and poured a heap of red-hot coals or boiling water on the naked skull, they once more unbind the wretch, who, blind and staggering with pain and weakness, assaulted and pelted on every side with clubs and stones, now up, liow down, falling into their fires at every step, runs hither and thither, till one of the chiefs, either out, of compassion or weary of cruelty, puts an end to his life with a club or dagger; the body is then put into a kettle, and this barbarous employment is succeeded by a feast as barbarous.

The women, forgetting tlie human as well as the female nature, and transformed into worse than furies, even outdo the men in this scene of lorror that has been described; while the principal persons of the country sit round the stake, smoking and looking on without the least emotion. What is most extraordinary, the sufferer himself, in the little interval of his torments, smokes too, appears unconcérned, alid converses with his torturers about indifferent matters. Indeed, during the whole time of his execution, there seems a contest which shall exceed-they in inflicting the most horrid pains, or he in enduring them with a firmness and constancy almost above human. Not a groan, not a sigh, not a distortion of countenance, escapes hin ; he possesses his mind entirely in the midst of his tornents; he recounts his exploits; he informs them what cruelties he has inflicted upon their combtrymen, and threatens them with the revenge that will attend his death; and though his reproaches exasperate them to a perfect madness of rage and fury, he continues his insults, even of their ignorance of the art of tormenting; and points out liniself more exquisite methods; and more sensible parts of the body to be afflicted.

The women have this part of courage as well as the men, and it is as rare for an Indian to be otherwise, as it would for an European to suffer as an Indian. Such is the worderful power of an early education, and a ferocious thirst of glory.' "I am brave and intrepid," exclaims the savage in the face of his tormentors. "I do not fear death nor any kind of tortures; those who fear them are cowards, they are less tlian women; life is nothing to those that have courage. May my enemies be confounded with despair and rage! Oh! that I conld devour them, and drink their blood to the last drop." But neither the intrepidity on the one side, nor the inflexibility on the other, is among themselves matters of astonishment, for vengeance and fortitude in the midst of torment are duties which they consider as sacred; they are the effects of their earliest education, and depend upon principles instilled into them from their infancy.

\section{Wars.}

War, if we except hunting, is the only employment of the men ; as to every other concern, including even the little agriculture they practise, it is left to the women. Their nost common motive for entering into war, when it does not arise from an accidental rencounter or inter- 
ference, is either to revenge themselves for the death of some losit friends, or to acquire prisoners who may assist them in their hunting, and whom they adopt into their society. These wars are either undertaken by some private adventurers, or at the instance of the whole company. In the latter case all the young men who are disposed to go out to battle, for no one is compelled contrary to his inclination; give a bit of wood to the chief, as a token of their design to accompany him; for every thing among these people is transacted with a great deal of ceremony. The chief who is to conduct them fasts several days, during which he converses with no one, and is particularly careful to observe his dreams, which the presumption natural to savages generally renders as favourable as he could desire. A variety of other superstitious ceremonies are observed. One of the most hideous is setting the war-kettle on the fire, as an emblem that they are going out to devour their enemies, which among some nations must formerly have been the case, since they still continue to express it in clear terms, and use an emblem significant to the ancient usage. Then they send a dish or large shell to their allies, inviting them to come along, and drink the blood of their enemies; for they think that those in their alliance must not only adopt their enmities, but have their resentment wound up to the same pitch with themselves. And, indeed, no other penple carry their friendships or resentments so far; and this is what should be expected from their peculiar circumstances-that principle in human nature which is the spring of the social affections, acts with so much the greater force, the more it is restrained.

The Americans, who live in small societies, who see few opjects and few persons, become wonderfully attached to those objects and persons, and cannot be deprived of them without feeling themselves miserable. Their ideas are too confined to enable them to entertain sentiments of universal benevolence. But this very circumstance, while it makes them cruel to an incredible degree towards those with whom they are at war, adds a new force to their particular frendships, and to the common tie, which unites the members of the same tribe, or of those different tribes which are in alliance with each other.

Without attending to this reflection, some facts we are going to relate would excite our wonder without informing our reason, and we should be bewildered in a number of particulars, seemingly opposite to one another, without being sensible of the general cause from which they proceed.

Having finished all the ceremonies previous to the war, and the day appointed for setting out on the expedition being arrived, they take leave of their friends, exchanging their clothes, or whatever moveables they have, in token of mutual friendship; after which they proceed from the town, their wives and female relations walking before, and attending them to some distance. The warriors march, all dressed in their finest apparel and most showy ornaments, without any order. The chief walks slowly before them, singing the war-song, while the rest observe the most profound silence. When they come up to their women, they deliver them all their finery, and, putting on their worst clothes, 
proceed on the expedition. Every nation has its peculiar ensign or standard, which is generally some beast, bird, or fish. Those anong the Five Nations are the bear, otter, wolf, tortoise, and eagle, and by these means the tribes are usually distinguished. They have the figures of those animals printed and painted on several parts of their bodies, and when they march through the woods, they commonly, at every encampment, cut the representation of their ensign on trees, especially after a successful campaign, marking at the same time the number of scalps or prisoners they have taken.

Their military dress is extremely singular. They cut off or pull off part of their hair, except a spot about the breadth of two English crowi-pieces, near the tops of their heads, and entirely destroy their eye-brows. The lock left upon their head is divided into several parcels, each of which is stiffened, and adorned with wampum beals, and feathers of various kinds, the whole being twisted into a form nuch resembling the modern pompoon. Their heads are painted red down to the eye-brows, and sprinkled over with white down. The gristles of their ears are split almost quite round, and distended with wires or splinters, so as to meet, and tie together on the nape of the neck. These are also hung with ornaments, and generally bear the representation of some bird or beast. Their noses are likewise broad and hung with trinkets of beads, and their faces painted with various colours so as to make an awful appearance. 'Their breasts are adorned with a gorget or medal of brass, copper, or some other metal; and that dreadful weapon, the scalping knife, hangs by a string from their neck.

The great qualities in an Indian warrior are vigilance and attention, to give and to avoid a surprise, and indeed in these they are superior to all the nations in the world. Accustomed to continual wandering in the forests, having their perceptions sharpened by keen necessity, and living in every respect according to nature, their external senses have a degree of acutenes which at first view appears incredible. They can trace out their enemies at an immense distance by the smoke of their fires which they smell, and by the tracks of their feet on the ground, imperceptible to an European eye, but which they can count and distinguish with the utmost facility. They can even distinguish the different nations with whom they are acquainted, and can determine the precise time when they passed, where an European could not, with his glasses, distinguish footsteps at all. These circumstances lowever, are of no small importance, because their enemies are equally acquainted with them. When they go out, therefore, they take care to avoid making use of any thing by which they might run the danger of a discovery. They light no fire to warm themselves or to prepare their victuals; they lie close to the ground all day, and travel only in the night; and marching along in lines, he that closes the rear diligently covers with leaves the tracks of his own feet and of those who preceded him. When they halt to refresh themselves, scouts are sent out to reconnoitre the country, and beat up every place where they suppose an enemy to be concealed. In this manner they enter unawares the villages of their foes; and while the flower of the nation are engaged in hunting, masacre all the women, children, and helpless 
old men, or make prisoners of as many as they can manage, or have strengtl enough to be useful to their nation.

But when the enemy is apprised of their design, and coming on in arms against them, they throw themselves flat on the ground amorig the withered herbs and leaves, which their faces are painted to resemble. Then they allow a part to pass unmolested, when, all at once with a tremendous shout rising from their ambush, they pour a storm of musket-bullets on their foes. The party attacked returns the same cry. "Every one shelters himself with a tree, and returns the fire of the adverse party, as soon as they can raise themselves from the ground to give a second fire. Thus does the battle continue until the one party is so much weakened as to be incapable of further resistance. But if the force on each side continues nearly equal, the fierce spirits of the savages, inflamed by the loss of their friends, can be no longer restrained. They abandon their distant war, to rush upon one another with clubs and hatchets in their hands, magnifying their own courage, and insulting their enemies with the bitterest reproaches. A cruel combat ensues; death appears in a thousand hideous forms, which would congeal the blood of civilized nations to behold, but which 'rouse the fury of savages. They trample; they they insult over the dead bodies, tearing the scalp from the head, wallowing in their blood like wild beasts, and sometimes devouring their flesh. The flame rages on till it meets with no resistance; then the prisoners are secured, those unhappy men whose fate is a thousand times more dreadful than those who die in the field. The conquerors set up a hideous howling, to lament the friends they have lost. They approach in a melancholy and severe gloom to their own villages; a messenger is sent to anounce their arrival; and the women with frightful shrieks come out to mourn their dead-brothers or their husbands; when they arrive, the chief relates in a low voice to the elders, a circumstantial account of every particular of the expedition. The orator proclaims aloud this account to the people; and as he mentions the names of those who have fallen, the shrieks of the women are redoubled. The men too join in these cries, according as each is most connected with the deceased by blood or friendship. The last ceremony is the proclamation of the victory; each individual then forgets his private misfortunes, and joins in the triumph of his nation; all tears are wiped from their eyes, and, by an unaccountable transition, they pass in a moment from the bitterest sorrow to an extravagance of joy. But the treatment of the prisoners, whose fate all this time remains undecided, is what chiefly characterizes the savages, and which has been already described.

\section{Probable Manner of first peopling America.}

Those who call in question the authority of the sacred writings, says Mr. Morse, pretend that the Americans are not descendants of Adam, that he was the father of the Asiatics only, and that God created otlier men to be patriarchs of the Europeans, Africans, and Americans. But this is contrary to the traditions of the Americans themselves, who, in their paintings and hymns, call themselves "the descendants of those who escaped from the general deluge." In answer to the ques- 
tion, therefore, how these descendants of Noah got over to America, we shall content ourselves by giving the opinion of the Abbe Clavigero, which appears to be the most probable of any we have met with. 1. "The men and animals of America," says the abbe, "passed there from the old continent. This is confirmed by the sacred writings: Moses, who declared Noah the common father of all who survived the deluge, says expressly; that in that general inundation of the earth, all its quadrupeds, birds, and reptiles, perished, except a few of the several species which were saved alive in the ark. The repeated ex. pressions which the sacred historian uses to signify its universality, does not permit us to doubt that all quadrupeds, birds, and reptiles, which are in the world, descended from those few individuals which were saved from the general inundation. II. The first inhabitants of America might pass there in vessels by sea, or travel by land or by ice. 1. They miglit either pass there in vessels designedly, if the distance by water, were but small, or be carried ipon it accidentally by winds. 2. They might pass by land, upon the supposition of the continents being united. 3. They might also make that passage over the ice of some frozen arm of the sea. III. The ancestors of the nations which peopled Anahuac, now New Spaii, might pass from the northern countries of Europe into the northern countries of America, or from the most eastern parts of Asia, to the most western parts of America. This conclusion is founded on the general tradition of those nations, that their aucestors came into Anahuac from the north and north-west. This tradition is confirmed by the remains of many ancient edifices, built by those people in their migrations." Here the abbe adduces different instances of these, and after refuting several absurd expositions, headds, "The probability is, that the quadrupeds, reptiles, \&c. of America, passed thither by land, and that the two continents were formerly united. This was the opinion of Acosta, Grotius, Buffon, and other great men. That this earth has experienced great changes since the deluge, will not admit of a doubt. Earthquakes have swallowed up great tracts of land in some places, subterraneous fres have thrown up others. The sea in some places has been forced to retreat many'miles from the shore ; in others it has made encroachments, and in many instances separated territories which were formerly united. Very considerable tracts of land have been also formed at the mouths of rivers. We have many examples of all these revolutions. Sicily was formerly united to the continent. The straits of Gibraltar as Diodorus, Strabo, and other ancient authors, affirm, were formed. by a violent irruption of the ocean upon the land, between the mountains Abyla and Calpe." The abbe adds many other instances, but these we think may suffice in proof of the general supposition that the two continents were once united.

\section{Abiponians.}

THESE are a tribe of American Indians, who formerly inhabited the district of Chak, iu Paraguay ; but the hostilities of the Spaniards have now obliged them to remove southward into the territory lying between Santa Fe, and St. Jago. The only account we have of them 
is that published by Mr. Dobrizhoffer in 1785. This gentleman, who lived seven years in their country, informs us that they are not numerous, the whole nation not much exceeding 5000 , for which he assigns as a reason an unuatural custom ámong their women, of sometimes destroying their own children from motives of jealousy, lest their husbands should take other mates during the long time they give suck, which is not less than two years. They are naturally white, but, by exposure to the air and smoke, become a brown colour. They are a strong and hardy race of people, which our author attributes to their marrying so late; an Abiponian seldom or never thinks of marrying till he is thirty years of age. They are greatly celebrated on account of their chastity and other virtues, thongh, according to our author, they have no knowledge of a Deity. They make frequent incursions into the territories of the Spaniards, mounted on horses which run wild in those parts. They have a kind of order of chivalry for theit warriors, and are so formidable, that 100 of their enemies will fly before ten of those horsemen. The hatred which these savages, whose manners, though rude and uncultivated, are in many respects pure and virtuous, bear to the Spaniards, is invincible.

"These pretended Christians," says our anthor, "who are the scum of the Spanish nation, practise every kind of fraud and villany among these poor barbarians; and their corrupt and vicions morals are so adapted to prejudice the Abiponians against the Christian religion, that the Jesuit missionaries have, by a severe law, prohibited any Spaniard from coming, without a formal permission, into any of their colonies."

From his account of the success of the Jesuits in converting them to Christianity, however, it does not appear that they have been able to do more than bribe them to a compliance with the ceremonies of the Popish superstition; so that in general they are quite ignorant and uncivilized; a most incredible instance of which is reported, viz. that in counting, they can go no farther than three, and that all the art of the Jesuits to teach them the simplest use and expression of numbers has proved unsticcessful!

In Habitants of LieOU-KIEOU, a King DOM IN AsIa, CONTAINING Thirty-six IsLands, subJeCt to China.

Father Gabal, a Jesuit, furnished some interesting details respecting these islanders, which he extracted from a chinese work, published in 1\%21, in 2 vols. by Sapao Koang, a learned Chinese doctor, who was sent ambassador by the emperor Koang-hi, in 1719, to the king of Lieou-kieou. Being on the spot, he examined, according to the emperor's orders, whatever he found interesting, relative to the number, situation; and productions of these isles, as well as the history, religion, manners, and customs of the natives.

These isles are situated between Corea, Formosa, and Japan. The natives pretend that the origin of their empire is lost in the remotest antiquity. They reckon up twenty-five successive dynasties, the duration of which forms a period of more than 18,000 years. It would be useless to point out the absurdity of these pretensions. It 
is certain that the existence of the country called Lieou-kieou was not known in China before the year 605 of the Christian era. In the course of that year, one of the emperors, of the dynasty of Soui, having heard of these isles, wished to know their situation. He first sent some Chinese for this purpose ; but their expedition proved fruitless, for want of interpreters. They, however, brought some of the islanders with them to Sig-nan, the capital of Chen-si, and the usual residence of the emperors of that dynasty. An ambassador of the king of Japan being then at court, he and his attendants knew the strangers to be natives of Lieou-kieou; but they described these isles as a wretched country, the inhabitants of which had never been civilized. The emperor of China afterwards learned that the principal island lay east of the city of Fou-tcheou, the capital of Fo-kien; and that in a passage of five days one might reach the island where the king kept his court.

On this information, the emperor Yan-ki sent a party, with interpreters, to summon the prince to do homage to the emperor of China, and to pay him tribute. The king of Lieou-kieou sent back the Chinese, telling them sternly, that he acknowledged no prince to be his superior. This answer irritated the 'emperor, who caused a fleet to be immediately equipped at Fo-kien, in which he embarked 10,000 men. This fleet arrived in safety at the port of Napa-kiang. The army, in spite of every effort made by the natives, landed in the island; and the king, who had put himself at the head of his troops, having fallen in battle, the Chinese pillaged, sacked, and burnt the royal city, made more than 5000 slaves, and returned to China. The emperor of the dynasties of Tuang, and those of the dynasties of Song, made no attempts to render these isles tributary.

In 1291, Chi-tsou, emperor of the dynasty of $\mathrm{Yu}$-len, wished to revive the pretensions of his predecessors. He fitted out a fleet to subdue these. islands, but the schemes of conquest had become disagreeable to the Chinese, since the disaster that befell their army in an expedition against Japan. The fleet of Chi-tsou went no farther than the isles of Pong-heu, and the west coast of Formosa, when they returned to Fo-kien. But in 1372, in the reign of Hong-vou, founder of the dynasty of Mino, these islands submitted voluntarily to the Chinese government. Hong-vou had sent one of his grandees to the court of Tsay-tou, when reigning at Lieou-kieou, to inform him of his accession to the throne The Chinese ambassador acquitted himself of his commission with all the address of an able minister. In a private aurlience he exhorted Tsay-tou to own himself a tributary of the empire, and laid before him various advantages he would derive from this step. His reasoning made so much impression on Tsay-tou, that he sent immediately to the emperor to demand the investiture of his states. Hong-vou received his envoys in a magnificent manner, and loaded them with presents. He solemnly declared Tsay-tou a vassal of the empire, and after having received his first tribute, consisting of horses, aromatic wood, sulphur, copper, tin, \&c.'he sent to this prince a golden seal, and confirmed the choice he had made of one of his sons for successor. Hong-vori sent thirty-six families, almost all from Fo-kien, to Lieou-kieou. Tsay-tou assigned them lands 
near Napa-kiang, and appointed certain revenues for their use, at the same time that Hong-vou made them considerable remittances. These families first introduced into Lieon-kieou the learned language of the Chimese, the use of their characters, and the ceremonies practised in China in honour of Confucius. On the other hand, the sons of several of the grandees of the court of Tsay-kou were sent to Nan-king, to study in the imperial college, where they were treated with distinction, and maintained at the emperor's expense.

The isles of Lieou-kieou having neither iron nor porcelain, Hongvou carried a great number of utensils and instruments of iron to be made, which he sent thither with a quantity of porcelain vessels. Commerce, navigation, and the arts, soon flourished. These islanders learned to cast bells for their temples, to manufacture paper and the finest stuffs, and to make porcelain.

The celebrated revolution which placed the Tartars on the imperial throne of China, produced no change in the conduct of the kings of Lieou-kieou. Chang-tche, who was then reigning, sent ambassadors to acknowledge Chim-tchi, and received a seal from him, on which were engraven sorine Tartar characters. It was then settled, that the king of Lieou-kieou should pay his tribute only every two years, and that the number of persons in the train of his envoys should not exceed 150 .

The emperor Kang-hi paid more attention to these isles than any of his predecessors. He caused a superb palace to be erected in honour of Confucius, and a college, where he maintained masters to teach the sciences of the Chinese characters. He also instituted examinations for the different degrees of the literari; he ordained that the king of Lieou-kieou should send in tribute nothing but the productions of the country, particularly a fixed quantity of sulphur, copper, tin, shells, and mother-of-pearl, which is remarkably pretty in these islands; besides house-furniture, pistol-cases, \&c. which these islanders manufacture with great taste and neatness.

It is above 900 years since the bonzes of China introduced, at Lieoukieou, the principal books belonging to their sect, with the worship of Fo, which is now the established religion. There is in the royal city a magnificent temple, erected in honour of another idol of the Chinese, named Tien-fey, which signifies celestial queen. These islanders do not make promises, or sweal before their idols, but burn perfumes present fruits, and stand respectfully before some stone, which they call to witness the solenmity of their engagements. Numbers of stones are to be seen in the courts of their temples, in most public places, and upon their mountains, appropriated to this purpose. They have also women consecrated to the worship of spirits, who are supposed to have great influence over those beings. "They visit the sick, distribute medicines, and pray for their recovery.

They respect the dead as much as the Chinese, and are no less ceremonious in learning, but their funerals are neither so pompous, nor attended with so much expense. Their coffins, which are of an hexagonal or octagonal figure, are three or four feet high. They burn the bodies of their dead, but preserve the bones. They never offer provisions to them, but place lamps around them, and burn perfumes. Families are distinguished in Lieou-kieou by surnames, but 
a man and a woman of the same surname cannot marry. The king is uot permitted to marry but into three grand families, which always enjoy the highest privileges. There is a fourth, of equal distinction with the three former; but neither the king nor the princes contract any alliances with this family, for it is doubtful whether it is not sprung from the same stem as the royal line.

Young men and women enjoy the liberty of seeing one another, and of conversing together, and their union is always in consequence of their own choice. The women are very reserved, they collect their hair on the top of their heads in the form of a curl, and fix it by long pins made of gold and silver.

Besides his vast domains, the king receives the produce of the sulphur, copper, and tin mines, and of the salt-pits, together with what arises from taxes. From these revenues he pays the salaries of the mandarins, and officers of his court. These salaries ars estimated at a certain number of sacks of rice. There are nine orders of mandarins, distinguished by the colour of their caps, or by their girdles and cushions. The greatest parts of the titles of these mandarins are hereditary, but some are only acquired by merit. In the royal city there are tribunals established for nanaging the revenues and affairs of all the islands. There are also particular tribunals for civil and criminal matters, and for regulating the affairs of religion, the public granaries, revenues, duties, commerce, manufactures, ceremonies, navigation, public edifices, literature, and war. The vessels built in this country are greatly valued by the people of China and Japan. In these the natives go to China, Tong-king, Cochin-China, Corea, Nangazaki, Salzuma, the neighbouring isles, and Formosa, where they dispose of their silk, cotton, paper, arms, copper utensils, mother-of-pearl, tortoise and other sliells, coral, and whet-stones, \&c. which are in great request both in China and Japan.

\section{Inhabitants or the Pelew Istandos.}

THEY are all of a deep copper colour, going perfectly naked. They are of a middling stature, very straight, muscular, and well-formed, but their legs, from a little above their ankles to the middle of their thighs, are tattooed so very thick, as to appear dyed of a far deeper colour than the rest of their skin. Their hair is of a fine black, long, and rolled up behind, in a simple manner, close to the back of their heads, which appear both neat and becoming; but few of them have beards, it being the general custon to pluck out the hairs by the roots.

The island of Coorooraa, of which Pelew is the capital, produces plantains, bananas, Seville oranges, and lemons $s_{2}$ but neither of them in any considerable quantity. None of the islands which the English visited had any kind of grain. As to birds, they had plenty of common cocks and hens, which, though not domesticated, kept running about near their houses and plantations; and what appears extremely singular is, that the natives had never made any use of them, till our people told them they were excellent eating. Pigeons they account a great dainty ; but none except those of a certain dignity were permitted 
to eat of them. The country is very mountainous, but the valleys are extensive and beantiful, affording many delightful prospects.

The houses are raised about eight feet from the ground, upon stones which appear as if hewn from the quarry. The interior part of them is without any division, the whole forming one great room, which rises in a ridge like our barns, the outside being thatched thick and close with bamboos and palm leaves. All their implements, utensils, weapons of war, and canoes, are much of the same kind with those in the South Sea islands. In their marriages they allow a plurality of wives, though in general not more than two.

\section{Climate, Reirgion, anti Customs of Alepro.}

THE air of Aleppo is very dry and piercing, but at the same time very-salubrious for all who are not troubled with asthmatic complaints. The city, however, and the environs, are subject to a singular endemial disorder, which is called the ring-worm, or pimple, of Aleppo. It is, in fact, a piniple which is at first inflammatory, and at length becomes an ulcer of the size of a finger nail. The usual duration of this ulcer is one year: it usually fixes on the face, and leaves a scar, which disfigures almost all the inhabitants. It is alleged that every stranger who resides there three months is attacked with it; and experience has taught them that the best mode of treatment is to make use of no remedy. No reason is assigned for this malady: but M. Volney suspects it proceeds from the quality of the water, as it is likewise frequent in the neighbouring villages, in some parts of Diarbekar, and even in certain districts near Damascus, when the soil and the water have the same appearances.

Of the Christian inhabitants, the greater number are Greeks, next to them the Armenians, then the Syrians, and lastly the Maronites, each of whom have a church in the city, called Judida; in which quarter, and the parts adjacent, mosi of them reside. The common language is the vulgar Arabic, but the Curlss of condition use the Turkish. Most of the Armenians can speak the Armenian, some few Syrians understand Syriac, and many of the Jews Hebrew ; but scarcely one of the Greeks understand a word of Greek. The people in general are of a middle stature, and tolerably well proportioned; but they seem neither vigorous nor active. Both sexes are handsome when young; but the beard soon disfigures the men, and the women, as they come early to maturity, very soon fade; females are generally married from fourteen to eighteen years of age, and many under fourteen. The people of rank here are polite and affable, making allowances for that superiority which the Mahometan religion instructs its votaries to assume over all who hold a different faith.

Their hread is generally of wheat flour made into thin cakes, but very ill prepared, and is generally eaten as soon as it comes out of the oven. The principal people have small loaves of a finer flour, which are well fermented and baked. Besides this, there a variety of biscuits, most of which are strewed on the top with some kinds of seeds. The Europeans liave very good bread, balied and 
prepared in the French manuer. All the inhabitants, of loth sexes, smoke tobacco to a great excess; even the very servants have constantly a pipe in their mouths. Coaches or carriages are not used here; therefore persons of quality ride on horseback in the city, with a number of servants walking before them, according to their rank. Ladies of the first distinction are even compelled to walk on foot in the city, or to any place at a moderate distance; in longer jonrneys they are carried by mules, in a kind of couch closely covered up. There are a number of public bagnios in this city; which are used by people of all ranks, except those of the highest distinction, who commonly have baths and every other convenience in their own houses.

Inilabitants, Customs, Manners, and Religion of Pegu.

PEgU is a very considerable kingdom of Asia. The inhabitants are of an olive, or rather a tawny complexion. The women are branded by some travellers as having shook off all modesty. The Peguers may be ranked among the most superstitious of all mankind. They maintain and worship crocodiles, and will drink nothing but the waters of the ditches where those monstrous animals harbour, and by whom they are often devoured. They have five principal festivals in the year, called sapans, which they celebrate with extraordinary magnificence. In one of them the king and queen make a pilgrimage about twelve leagues from the city, riding on a triumphal car, sorichly adorned with jewels, that it may be said they carry about with them the value of a kingdom. This prince is extremely rich, and has in the chapel of his palace idols of inestimable value, some of them being of massy gold and silver, and adorned with all sorts of precious stones.

The talapoins and priests have no possessions, but such is the respect paid them by the penple, that they are never known to want. They preach to them every Monday, not to commit nurder, to take from no person any thing belonging to him, to do no hurt, to give no offence, to avoid impurity and superstition, but above all not to worship the devil ; but these discourses have no effect in the last respect. The people, attached to Manicheism, believe that all good comes from God, that the devil is the author of all the eril that happens to men, and that therefore they ought to worship him, that he may not affict them. This is a common notion among the Indian idolaters.

The inhabitants of Pegu are accused by some authors of being slovenly it their houses, and nasty in their diet, on account of their seasoning their victuals with sidol, a composition made of stinking fish, reduced to a consistency like mustard, so nauseous and offensive, that none but themselves can endure the smell of it. Balbo says, he could sooner bear the scent of stinking carrion; and yet with this they season their rice and soups, instead of oil or butter.

As they have no wheat in their country, their bread is rice made into cakes. Their common drink is water, or a liquor distilled from cocoa-water. They are a spirited and warlike people, open, generous, and hospitable, and have neither the indolence nor jealousy of most 
other eastern nations. The men here, as in most eastern countries, buy their wives, or pay their parents a dowry for them. Fhes: marriages for a time, are well regilated, and often prove very beneficial to the occasional husband. Most of the foreigners who trade hither, marry a wife for the time of their stay. In case of a separation, the fatler is obliged to take care of the boys, and the mother of the girls. No woman is looked upon the worse, but rather the better, for having had several European husbands. In Pegu, the inheritance of all land is in the king; he is likewise the heir of all his subjects who die without issue, but in case they have children, two-thirds go to them, and the rest to the king.

The religion of the Peguers is the same, in the main, with that which prevails over the rest of India and Thibet, only according to the humour or interest of the priest. They hold the existence of one supreme God, of whom they make no image; but they have many inferior created gods, whose images are set up in the temples, ror the laity to worship.

When a person falls sick, we are told that they generally make a vow to the devil, from whom they believe all evil comes. Then a scaffold is built, and victuals are spread on the top of it, to solace Old Nick, and render him propitious. This feast is accompanied with lighted candles and music, and the whole is managed by an undertaker called the devil's father.

\section{IN HABITANTS OF THE LADRONE ISLANDS.}

WHEN these islands were first discovered, the natives were totally unacquainted with any other country except their own, and having no account of their own origin, supposed that the author of their race was formed of a piece of the rock of Furna, one of their smallest islands. Many things looked upon by us as absolutely necessary to our existence, were utterly unknown to them. They had no animals, but one species of birds, resembling turtle doves, which they never killed, but only tamed them; and taught them to speak. They were much astonished on seeing a horse which a Spanish captain left among them, in 1673. But what is most incredible is, that they were utterly unacquainted with fire, till Magellan, provoked by their repeated thefts, burnt one of their villages. When they saw their wooden houses blazing, they thought that the fire was a beast which fed upon the wood; and some of them who came too near, being burnt, the rest stood at a distance, lest they should be devoured, or poisoned by the breathings of that terrible animal.

The inhabitants are olive-coloured, but not of such a deep dye as those of the Philippines; their stature is good, and their limbs wellproportioned. Though their food consists entirely of fish, fruits, and roots, yet they are so fat, that to strangers they appear swelled, but this does not render them less nimble and active. They often live to one hundred years or more, yet retain the health and vigour of men of fifty. The men go stark naked, but the women are covered. They are not ill-looking, and take great care of their beauty, though their, ideas on that subject are very different from ours. They admire 
black teeth and white hair. Hence one of their principal occupations is to keep their teeth olack by the help of certain lierbs, und to whiten the hair by sprinikling upon it a certain water. The women have their hair very long; but the men generally shave it close, except a single lock on the crown of the head, after the Japanese malner.

\section{InHabitants of Georgia.}

"The inhabitants of Georgia," says Sir George Chardin, "are robust, valiant, and of a jovial temper; great loyers of wine, and esteemed very trusty and faithful ; endowed with good rational parts, but, for waint of education, very vicious. The women are so fair and comely, that the wives and concubines of the king of Persia and his court are for the most part Georgian women. Nature has adorned them with graces no where else to be met with; it is impossible to see them without loving them ; they are of a good size, clean limbed, and well shaped." Another traveller, however, of no mean character, thus expresses himself with respect to these women. "As to the Georgian women, they did not at all surprise us, for we expected to find them perfect beauties. They are indeed no way disagreeable, and may be counted beauties, if conpared with the Curdes. 'They have an air of health that is pleasing enough,-but, after all, they are neitler so handsome nor so well shaped as is reported. Those who live in the towns have nothing extraordinary more than the others, so that I may, I think, venture to contradict the accounts that have been given of them by most travellers."

The other inhabitants of Georgia are Tartars, Ossi, and Armenians, called in the Georgian language, Somakhi. These last are found all over Georgia, sometimes mixed with the natives, and sometimes in villages of their own. They speak among themselves their own language, but all understand and can talk the Georgian. Their religion is partly the Armenian, and partly the Roman Catholic. They are the most oppressed of the inliabitants, but are still distinguished by that instinctive industry which every where characterizes these nations.

Besides these, there are in Georgia considerable numbers of Jew's, called in the language of the country, Uria. Some have villages of their own, and others are mixed with the Georgian, Armenian, and Tartar inhabitants, bit never with the Ossi. They pay a small tribute above that of the natives. The Georgians are Christians of the Greek communion. Their dress nearly resembles that of the Cossacks, but men of rank frequently wear the habit of Persia. - They usually dye their hair, beards, and nails with red. The Georgian women employ the same colour to stain the palms of their hands. On their heads they wear a cap or fillet, under which their black hair falls on their forehead ; behind, it is braided into several tresses. Their eye-brows are painted black, so as to form one entire line, and their faces are perfectly coated with white and red. Their robe is open to the girdle, so that they are compelled to conceal the breasts with their hands. Their air and manners are extremely voluptuous. Being generally educated in convents, they can all read and write, a qualifi- 
cation which is very unusual among the men even of the highest rank. Girls are betrothed as soon as possible, often at three or four years of age.

In the streets the women of rank are always veiled, and then it is indecent in any man to accost them. It is likewise uncivil in conversation to inquire after the wives of any of the company. These, however, are not ancieut customs, but consequences of the violences committed by the Persians under Shah Nadir. Travellers accuse the Georgians of drunkenness, superstition, and cruelty, sloth, avarice, and cowardice, vices which are every where common to slaves and tyrants, and are by no means peculiar to the natives of this country. The descendants of the colonists carried off by Shah Abbas, and settled in Persia near Ispahan and in Masanderan, have changed their character with their, government; and the Georgian troops, empioyed in Persia against the Afighans, were advantageously distinguished by their docility, their discipline, and their courage.

\section{ICELANDERS.}

THE modern Icelanders are middle-sized and well made, though not very strong; and the women are in general ill-featured. Vices are much less common among them, than in any other parts, where luxury and riches have corrupted the morals of the people. Though their poverty disables them from imitating the hospitality of their an-" cestors in all respects, yet they continue to shew their inclination to it they cheerfully give away the little they have to spare, and express the utmost satisfaction if strangers are pleased with their gifts. They are uncommonly obliging and faithful, and extremely attached to government. They are very religious, and thankful for the Divine protection, when they escape any dangers. They have an inexpressible attachment to their native country, and therefore rarely settle in $\mathrm{Co}$ penhagen, though the most advantageous termis should be offered. On the other hand, they do not display much ingenuity. They work on in the way to which they have been accustomed, without thinking of improvements. They are, in conversation, simple and credulous, but have no aversion to a bottle, when they have opportusity.

Their chief pastime consists in reading their history. The master of the house begins, and the rest continue in their turn when he is tired. Some of them have these stories by heart, others have them in print, and others in writing. They are also great players at chess and cards for anusement, but never for money. They have made little alteration in their dress from what was formerly in use. The men wear linen shirts, with short jackets and wide breeches. When they travel, another short coat is put over all : the whole is made of coarse black cloth, called wadmal, but some wear white cloaks. On the head they wear large three-cornered hats, and on their fect Iceland shoes and worsted stockings. Some of them indeed have shoes from Copenhagen, but they generally make their own shoes, sometimes of the hides of oxen, but oftener of sheep's leather. They make them by cutting a square piece of leather, rather wider than the length of the foot; this they sew up at the toes and behind at the heels, and tie 
it on with leather thongs. These shoes are convenient where the country is level, but it would be difficult to walk with them among rocks and stones, as the Icelanders do.

The women are also dressed in black wadmal. They wear a bodice over their shifts, which is sewed up at the bosom; and above this a jacket laced before with long narrow sleeves reaching down to the wrists. In the opening of the sleeve, they have, buttons of chased silver, with a plate fixed to each button, on which the lover, when he brings them to present to his mistress, gets his name engraved along with hers. At the top of the jacket a little black collar is fixed, three inches broad, of velvet or silk, and only trimmed with gold cord. The petticoat is likewise of wadmal, and reaches down to the ankles. Round the top of it is a girdle of silver, over some other metal, to which they fasten an apron of wadmal, ornamented at the top with chased silver buttons. Over this they wear an upper dress, resembling that of the Swedish peasants, but wider at bottom; this is close at the neck and wrists, and a handbreadth shorter than the petticoat. On their fingers they wear gold, silver, or brass rings. The head-dress consists of several cloths wrapped round the head, almost as high again as the face. It is tied last with a handkerchief, and serves more for warmth than ornament. Girls are not allowed to wear this head-dress till they are marriageable.

At their weddings they are adorned in a very particular manner. The bride wears, close to the face, round her head-dress, a crown of silver, gilt; and two chains round her neck, one of which hangs very low before, and the other rests on her shoulders. She has also a lesser chain, from which generally hangs a little heart, which may be opened to put perfume in it. This dress is worn by all the Icelandic women without exception, only the poor have it of coarse wadmal, with ornaments of brass.

The Icelanders breed numbers of cattle, but on the coasts the men employ themselves in fishing both summer and winter. On their return home, when they have cleaned their fish, they give them to their wives, whose care it is to dry them. In winter, when the inclemency. of the weather prevents them from fishing, they are obliged to take care of their cattle and spin wool. In summer they mow the grass, provide fuel, go in search of strayed sheep and goats, and kill cattle. They prepare barks with the spiraca ulnaria, instead of bark. Some few work in gold and silver, and others in mechanics, in which they are tolerable proficients. The women prepare the fish, take care of the cattle, manage the milk and wool, sew, spin, and gather eggs and down. When they work in the evening, they use, instead of an hourglass, a lamp with a wick made of epilobium dipped in train oil, which is contrived to burn four, six, or eight hours.

Among the common people, time is not reckoned by the course of the sun, but by the work they have done, which is prescribed by law. A man is to mow in one day as much hay as grows on thirty fathoms of manured soil, or forty fathoms of land which has not been manured, or he is to dig roo pieces of turf eight feet long and three broud. If as much snow falls as reaches to the horses' bellies, a man is required to clear a piece of ground sufficient for 100 sheep. A woman is to 
rake together as much hay as three men can mow, or to weave three yards of wadmal a day. A man's wages are fourdollars and twelve yards of wadmal, those of a woman tivo dollars and five yards of wadmal. When men are sent a fishing out of the country, there is allowed to each man, by law, from the 25 th of Sept. to the 14 th of May, six pounds of butter, and eighteen pounds of dried fish, every week. When they are at home, and can get butter, every man receives only five pounds of dried fish, and three-quarters of a pound of butter a week.

\section{Manners and Customs of the Balrnese.}

THE Balinese are the natives of the island of Bali, sometimes called Little Java. In disposition the Balinese are represented as mild and inoffensive, and neither prone to anger nor revenge. They readily associate with strangers, and are altogether divested of those bigoted prejudices of caste, nation; and religion; with which the people of continental Asia are so deeply imbued. It has been remarked of the Balinese, that they are the only people of this archipelago who possess either courage or tractability sufficient for receiving the regulat discipline of European troops. Their use of poisoned arrows, however; is a relic of barbarism, which still connects them with the savages of the neighbouring islands, and is not easily reconciled with the other parts of their character, or the progress they have made in the path of civilization. 'Prisoners of war are either associated with the conquerors, or sold for slaves, but never put to death.

The diet of the people is not confined to vegetables, as animal food seems to be very common. This consists principally of the flesh of hogs and buffaloes; and ships touching at Bali are readily supplied with this sort of provisions, as hogs are generally very numerous, Nor is the use of spirituous liquors or opium unknown? both of which have been introduced by Europeans. Their houses are built upon the ground, as in Java, and not raised upon posts like those of the Malays, and other inliabitants on the borders of rivers and marshy, sea coasts. This is an evidence of the dryness and salubrity of the climate.

The Palimese are generally clothed in cotton of their own manufacture, which is of a better fabric than those of the Javanese, though they is not so well clad as the inhabitants of the larger islands. The females, indeed, go nearly naked till they are married, when the bridegroon laps a selendang or cloth round the bosom of the bride. They also manufacture cotton cloths for exportation, which may be considered as a decisive proof of the advanced state of society.

The women, as among the Javanese, are the sole manufacturers. The art of printing their cottons does not appear to be known; as they are either white, or striped with other colours in the loom. They also manufacture their own weapons, even including fire-arms; and though the locks of these are clumsy, much taste is displayed in inlaying the barrels. : The people of this archipelago are placed under circumstances so similar, that where their efforts are not counteracted by differing causes, they must tend to produce a strik- 
ing uniformity. The Balinese are, however, honourably distinguished from their neighbours the Javanese, by fidelity, and decorum of intercourse between the sexes. Marriage is not contracted till the parties arrive at muturity, and then not merely as a temporary contract between persons of similar ages, but in general as an indissoluble union for life.

Their religion is that of Budh, and they are not divided into castes, though the priesthood seems hereditary. Their priests are called Brahmins, and live in separate societies, generally in some seclnded spot among the mountains, and have lands assigned for the support of themselves and their temples; but these they cultivate with their own hands. Though the Balinese do not manifest any hostility towards people of other religious sects, they have steadily resisted the doctrines of Mahomedanism, and very few converts have ever been made in the islands. Such as have embraced the faith of Islam are treated like the proscribed castes in India. Law and religion are blended together, as in other countries of the East; but here the administration of justice is not in the hands of the priests, but is executed by distinct magistrates, who expound the law from written authorities, and pay much attention to the distribution of justice; which is a decided proof that civilization has had a powerful influence even upon the body of the people.

Bali is under the government of several independent princes, each of whom is absolute in his own dominions; though their despotism seems of a much milder character than among the native governments of Java. The right of private property in the soil is said to be established, and the claims of the prince to be restricted to a small proportion of the rice-crop alone. Though the common people are not burdened with forced or feudal services, difference of rank is sufficiently palpable, as the language presents the degrading distinction of one class of words for the privileged orders, and another for the people in general. An obligation of feudal service in war is still maintained; but slavery is unknown among them, though they sometimes sell the prisoners of war as slaves to other nations.

As the Balinese are habituated to the peaceful pursuits of agriculture, and but little inclined to follow war as a favourite occupation, they present none of that ferocious and hardy character exhibited by the savage warriors of some of the other islands. Their mode of warfare is desultory; they never engage in large bodies, but dispersed in small parties of forty or fifty together. Bali is divided in to seven states, which are frequently in either open or secret hostility to each other.

In countries where industry has become at all conspicuous, commerce and agriculture go hand in hand, each supplying a stimulus to. the prosecution of the other, and both contributing to the comfort and advancement of society. Though the Balinese are perhaps more engaged in preparing the materials of trade than actively engaged in its transactions, yet it has a strong influence upon the state of thè island.

The chief articles of export are cotton cloths, as well as raw cotton, the latter of which is often sent to Java in considerable quantities, and which, from its superior quality, and the facility with which 
it is raised, might in some constitute a valuable article of trarle to Europe. Besides these, kossumbo flowers and mangksla roots for dying, rice, nutmegs, cloves, slaves, and some other articles, are ali exported. The Chinese who reside on the coasts are the principal merchants, especially as dealers in slaves. Rice is sent to all the surrounding conntries as far as Bencoolen and the straits of Malacca; and of late it is said to have been imported in considerable quantities into the Moluccas. The nutmegs are of the long kind, and are supposed to be produced in the recesses of the island in a wild state, as they are sent to Java in great abundance, where they are called the Bali nutmegs, and are to be obtained at a very cheap rate.

Gold is also found in this island; a mine of this metal is worked at a place called Pejen, on the eastern coast, but the quantity of its produce is not known. The imports of the Balinese are chiefly Indiain chintz and other piece goods, opium, iron, and china-ware. Iron is in general demand, both in this and the other islands of the Oricntal archipelago, and few articles appear to promise so much advantage, either to the importer or consumer, as none seems to be elsewhere manufactured, and so nuch both of the advancement and comfort of society depends on its use.

A brief historical sketch of this people would have been interesting; as developing the means by which they have raised themselves above the other islanders of the same group, in most of the arts of life, but, for this the materials are wanting, unless any documents should exist in the native language. The inlabitants are supposed to have been converted to Budhism about 1740 years ago, when the priests of that sect were expelled from India by the superior influence of the Brallmins. Sir Francis Drake, according to Valentyu, visited Bali in 1597; and the Dutch, who constantly traversed these seas, undoubtedly often landed on the shores of Bali, but they do not appear ever to have acquired much influence, or to have formed any establislinent on the islands: The latitude of the eastern peak is $8^{\circ} 24^{\prime}$. S. and its .oligitude $115^{\circ} 24^{\prime} \mathrm{E}$.

\section{Humanity and Civility of tire Natives of Guinea.}

Mr. Adanson, speaking of the appearance of Senegal and Gambia, and of the disposition of the people, says, "Which way soever I turned my eyes, on this pleasant spot, I beheld a perfect inage of pure nature; - an agreeable solitude, bounded on every side by charning landscapes, the rural situation of cottages in the midst of trees, alid the ease and indolence of the negroes, reclined under the shades of their spreading foliage, together with the simplicity of their mantiers, revived in my mind the idea of our first parenis, aind I seemed to contemplate the world in its primitive siate. They are, generally speaking, very good natured, sociable, and obliging. I was not a little pleased with this my first reception; it convinced me there ought to be a considerable abatement made in the accounts I had read every where of the savage character of the Africans. I observed, both in the negroes and Moors, great humanity and sociableness, which gave me strong hopes that I should be very safe amongst them, and neet 
with the success I desired, in my inquiries after the curiosities of the country."

He was agreeably amused with the conversation of the negroes. Speaking of the remarks which the negroes made to him, of the stars and planets, he says, "it is amazing that such a rude and illiterate people should reason so pertinently in regard to those heavenly bodies; there is no manner of doubt, that, with proper instruments, that they would become excellent astronomers."

\section{HoTTENTOTS.}

MANY accounts have been published concerning the filthy customs of the Hottentots ; but from the observations of late travellers it appears that these have either been exaggerated, or that the Hottentots have in some measure laid aside their former manners. Dr. Sparman describes them in much less disgustful terms, and M. Vaillant seems to have been charmed with their innocence and simplicity. According to the Doctor, these people are as tall as the generality of Europeans, though more slender in their persons, which he ascribes to their scanty supply of food, and not accustoming themselves to hard labour. One characteristic of the nation, however, and which he thinks has not been observed by any one before, is, that they have small hands and feet in proportion to the other parts of their body. The distance between the eyes appears greater than in Europeans, by reason of the root of the nose being very low. The tip is pretty flat, and the iris of the eye has generally a dark-brown cast, sometimes approaching to black. Their skin is of a yellowish brown, something like that of an European who has the jaundice in a high degree; though this colour does not in the least appear in the whites of the eyes. Their lips are thinner than those of their neighbours, the Negroes, Caffres, or Mozambiques. The hair of the head is black and frizzled, though not very close, and appears like wool, but is harsher. They seldom have any beards, or hair upon other parts of their bodies; and when any thing of this nature is visible it is very slight.

The Hottentots besmear all their bodies with fat mixed up with a little soot. "This," says Dr. Sparman, "is never wiped off"; on the contrary, I never saw them use any thing to clean'their skins, except that, in greasing their waggons, when their hands were besmeared with tar and pitch, they used to get it off very easily with cow-dung, at the same time rubbing their arms up to the shoulders with this cosmetic.

"The Hottentots perfume their bodies by daubing them all over with the powder of a herb, the smell of which is at once rank and aromatic, approaching to that of the poppy mixed with spices. For this purpose, they use various species of the diosma, called by them bucku, and which they imagine to be very efficacious in the cure of disorders. 'One species of this plant growing about Goud's river, is said to be so valuable, that no more than a thimble-full of its powder is given in exchange for a lamb. By the ointment of soot and grease, stuck full of the powder of bucku, a paste is formed, which defends the bodies of the Hottentots in a great measure from the action 
of the air ; so that they require very few clothes, and in fact go almost quite naked. The only covering of the men consists of two leather straps, which generally hang down the back from the chine to the thighs, each of them in the form of an isosceles triangle, their points uppermost, and fastened to a belt which goes round their waist, their bases not being above three fingers broad; so that the covering they form is extremely trifling. These straps. have very little dressing bestowed upon them, so that they make a rattling: noise as the Hottentot runs along; and Omanthor supposes that they may produce an agreeable coolness by fanning him. Besides this, the men have a bag or flap made of skin, which hangs down before, and is fastened to the belt already mentioned. They call this pusse by the Dutch name of jackal, it being almost always prepared of the skin of that animal, with the hairy side turned outwards.

The wonen cover themselves much more scrupulously than the men, having always two and sometimes three coverings like aprons, though these seem to be abundantly small for what we should term decency in this country. The outermost of these, which is the largest, measures only from six inches to a foot in breadth. All of them are made of a skin well prepared and greased, the outermost being adorned with glass beads strung in different figures. The outermost reaches about half way down the thighs; the middle about a third, or one half less; and the third scarcely exceeds the breadth of the hand. The first is said to be designed for ornament, the second as a defence for modesty, and the third to be useful on certain occasions.

The other garments of the. Hottentots are formed of a sheep's skin, with the woolly side turned inwards, this forming a kind of cloak, which is tied forwards over the breast; though sométimes, instead of a sheep's skin, some smaller kind of fur is used as a material. In warm weather they let this cloak hang carelessly over their shoulders, so that it reaches down to the calves of their legs, leaving the lower part of the breast, stomach, and fore part of the legs and thighs, bare; but in cold weather they wrap it round them, so that the fore part of the body is pretty well covered by it as far as the knees; but as one sheep-skin is not sufficient for their purpose, they sew a piece on the top of each side with a thong or cat-gut. In warm weather they sometimes wear the woolly side outwards, but more frequently take off the cloak altogether, and carry it under their arm. This cloak, or krosse, serves them not only for clothes, but for bedding also; and in this they lie on the bare ground, drawing up their bodies so close, that the cloak is abundantly sufficient to cover them. The cloaks used by the women differ little from those already described, excepting only that they have a long peak on them, which they turn up; forming with it a little hood or pouch, with the hairy side inwards. In this they carry their young children, to which their mothers' breasts are now and then thrown over their shoulders; a custom among other nations, where the breasts of females, from want of support, grow to an enormous length. The women commonly wear no covering on their heads, though our author says he has seen one or two who wore a greasy night-cap, made of skin, with the hair taken off. 
Those who live nearest the colonists have taken a liking to the European hats, and wear them slouched all round, or only with one side turned up. The women also frequently go bare-headed; though they sometimes wear a cap made in the shape of a short truncated cone. This appears to be the section of some animal's stomach, and is perfectly blacked by sont and fat mixed up together. These caps are frequently prepared in such a manner as to look shaggy; others have the appearance of velvet, and in our author's opinion are not inelegant. Over this they sometimes wear an oval wreath, or kind of crown, made of a buffalo's hide, with the hair outermost. It is about four fingers' breadth in height, and surrounds the head so as to go a little way down upon the forehead, and the same depth on the neck behind, without covering the upper part of the cap above described. The edges of this wreath, both upper and under, are always smooth and even, each of them set with a row of shells of the cyprea kind, to the number of more than thirty, in such a manner, that, being placed close to one another, their beautiful white enamel, together with their mouths, are turned outwards. Between two rows of these shells run two others parallel, or else waved and indented in various ways. The Hottentots never adorn their ears or noses, as other savages do; though the latter are sometimes marked with a black streak of soot; at others, though more rarely, with a large spot of red lead; of which last, on festivals and holidays, they likewise put a little on their cheeks.

The necks of the men are bare, but those of the women are ornamented with a thong of undressed leather, upon which are strung eight or ten shells. These shells are sold at an enormous price, no less than a sheep for each, as it is said that they come from the distant coast of Caffraria.

Both men and women are very fond of European beads, particularly the blue and white ones, of the size of a pea; of which they tie several rows round the middle, and next to the girdles which hold the coverings above mentioned. Besides these ornaments, they use rings on their arms and legs, most of them made of thick leather straps, generally cut in a circular shape; which, by being beat, and held over the fire, are rendered tough enough to retain the curvature that is given them.

From these rings it has been almost universally believed that the Hottentots wrap guts about their legs, in order to eat them occa. sionally. The men, wear from one to five or six of these rings on their arms, just above their wrists, but seldom on their legs. The matrons of a higher rank have frequently a considerable number of them both on their arms and legs, especially on the latter, so that they are covered with them from the feet to the knees. These rings are of various thicknesses, from that of a goose-quill to two or three times that size. Sometimes they are made of pieces of leather forming one entire ring; so that the arms and feet must be put through them when the bearer wishes to put them on. They are strung upon the legs, small and great, without any nicety; but are so large, that they shake and get twisted, when the person walks. Rings of iron or copper, but especially of brass, of the size of a goose-quill, are 
considered as more genteel than those of leather. However, they are sometimes worn along with the latter, to the number of six or eight at a time, particularly on the arms. The girls are not allowed to use any rings till they are marriageable.

The Hottentots seldom wear any shoes, but such as they do make use of, are of the same form as those worn by the African peasants, by the Esthonians and Livonians, as well as by some Finlanders; so that it is impossible to say whether they are the invention of the Dutch or the Hottentots themselves. They are made of undressed leather, with the hairy side outward, without any other preparation than that of being beat or moistened.

\section{Habitations.}

The huts of the Hottentots are built exactly alike, and are done in a style of architecture which not a little contributes to keep envy from coming under their roofs. Some of them are circular, others of an oblong shape, resembling a bee-hive; the ground plot being from eighteen to twenty-four feet in diameter. The highest are so low, that it is scarce possible for a middle-sized man to stand upright even in the centre of the arch ; but, says our author, neither the lowness thereof, nor that of the door, which is just three feet high, can be considered as any inconvenience to a Hottentot, who finds no difficulty in stooping and crawling upon all fours, and is at any time more inclined to lie down than to stand. The fire-place is in the middle of each hut, by which means the walls are not so much exposed to danger from fire. From this situation of the fire-place, also, the Hottentots derive this additional advantage, that they can all sit or lie in a circle round it, equally enjoying the warmth. The door, low as it is, alone lets in day-light, and lets out the smoke; and so much are these people accustomed to live in such smoky hovels, that their eyes are never affected by it, nor their health by the mephitic vapour of the fuel, which to Europeans would be certain death.

The frame of the arched roof is composed of slender rods or sprays of trees. These being previously bent into a proper form, are laid, eithez whole or pierced, some parallel, others crosswise; afterwards they are strengthened by binding others round them in a circular form with withes. All these are taken principally from the Cliffortia conoides, which grows plentifully near the rivers. Large mats are then placed very neatly over this lattice work, so as perfectly to cover the whole. The aperture which is left for the door is closed occasionally, by a skin or piece of matting. These mats are made of a kind of reed, and are ingeniously constructed in the following manner. The reeds being laid parallel to one another, are fastened together: with sinews, or some kind of catgut which they have an opportunity of getting from the Europeans, so that they have it in their power to make them as long as they please, and as broad as the length of the reeds, which is from six to ten feet. The colonists use the same kind of matting next the tilts of their waggons, to prevent the sailcloth from being worn, and to keep out the rain. - In a kraal, or Hottentot village, the huts are most commonly disposed in a circle; with the doors inwards; by which means a kind of court-yard is 
formed, where the catile are kept at nights. The milk, as soon as taken from the cow, is put to other milk which is curdled, and kept in a leather sack, with the liairy side inwards, as being the more cleanly, so that thus the milk is never drunk sweet. In some northern districts, where the land is dry and parched, both Hottentots and colonist, are shepherds. When a Hottentot intends to shift his dwelling, he lays all the rods, skins, and mats, of which it is com. posed, on the backs of his cattle, which to a stranger makes a monstrous unwieldy and even ridiculous appearance.

\section{Superstitions.}

The Hottentots have very crude notions of religion. They have the most firm belief in the powers of magic; fron whence it might be inferred that they believe in an evil being analogous to the devil; but they pay no religious worship to him, though from this source they derive all the evil that happens; and among these they reckon coid, rain, and thunder. So great is their ignorance, that many of the colonists assured Dr. Sparrman that their Boshiesmen would abuse the thunder with many opprobrious epithets, and threaten to assault the flashes of lightning with old shoes, or any thing that first came to hand. Even the most intelligent among them could not. be convinced, by all the arguments our author could use, that rain was not always an evil, and that it would be an unhappy circumstance were-it never to rain. "A maxim," says he, "from a race of men in other respects really endowed with good sense, and frequently with no sinall degree of penetration and cunning, which ought methinks to be considered as an indelible religious or superstitious notion, entertained by them from their infancy."

As the Hottentots have so strong a belief in the power of magic, it is no wonder that they have abundance of witches and conjurers among them. Many of the Hottentots believe that all disorders incident to the human body are cured by magic. The wizards encourage this idea, but at the same time take care to employ both external and internal remedies. These conjurers seem to be possessed of a considerable slight of hand. The superstition of the Hottentots never operates in making them afraid in the dark. They seem, however, to have some idea of a future state, as they reproach their friends, when dead, with leaving them so soon, at the same admonishing them from henceforth to demean themselves properly, by which they mean that their deceased friends should not come back again and haunt them, nor allow themselves to be made use of by wizards to bring: any mischief on those that survive them.

There is a genus of insects which, it has been generally thought, the Hottentots worship; but our author says, that so far from this, they have more than once caught several for him, and assisted him in sticking pins through them. "There is, however," he adds, "a diminutive species of this insect, which some think it would be a crime, as well as very dangerous, to do any harm too; but this we have no more reason to look upon as any kind of religious worship, than we have to consider in the same light a certain superstitions notion prevalent among many of the more simple people in our own country; 
Sweden, who imagine that their sins will be forgiven them, if they set a cockchafer on its feet, that has happened to fall on its back. The moon, according to Kolben, receives a kind of adoration from the Hottentots; but the fact is, that they merely take the opportunity of her beams, and at the same time of the coolness of the night, to am use themselves with dancing; and consequently have no more thoughts of worshipping her than the christian colonists, who are seen at that time strolling in great numbers about the streets, and parading on the stone steps with which their houses are usually encircled. The conjurers themselves are generally freethinkers, who have neither religion nor superstition of any kind.

\section{Dress, Customs \&c. of the Moors.}

THE Moors of the plains wear nothing but their woollen stuff, they have neitheir shirts nor drawers. Linen among these people is a luxury, known only to those of the court or the city. The whole wardiobe of a country Moor in easy circumstances consists of a haick for winter, another for summer, a red cap, a hood, and a pair of slippers. The common people, both in the country and in towns, wear a kind of tunic of woollen cloth, white, gray, or striped, which reaches to the middle of the leg, with great sleeves, and a hood, resembling the habit of the Carthusians. The women's dress in the country is likewise confined to a haick, which covers the neck and the shoulders, and is fastened with a silver clasp. The ornaments they are the fondest of are, ear-rings, which are either in the form of rings or crescents, made of silver, and bracelets, with rings for the small of the leg. They wear these trinkets at their most ordinary occupations, less out of vanity, than because they are unacquainted with the use of caskets or cabinets for keeping them. They also wear necklaces made of coloured glass beads, or cloves strung on a cord of silk.

The women, to add to their beauty, imprint on their face, neck, breast, and almost every part of their body, representations of flowers and other figures. The impressions are made with a piece of wood stuck full of needles, with the points of which they gently puncture the skin, and then lay it over with a blue-colonred substance, or gunpowder pulverized, and the marks never wear out. This custom, which is very ancient, and which has been practised by a variety of nations, in Wurkey, all over Asia, in the southern parts of Europe, and perhaps over the whole globe, is, however, not general among the Moorish tribes.

The Moors consider their wives as slaves destined to labour. Except in the business of tillage, they are employed in every servile operation; nay, to the disgrace of humanity, in some of the poorer quarters a woman is often scen yoked in a plough along with a mule, an ass, or some other animal. When the Moors remove their doulars, all the men seat themselves in a circle on the ground, and, with their elbow resting on their knees, pass the time in conversation, while the women strike the tents, fold them up into bundles, and place them on the backs of their camels or oxen. The old women are then each 
loaded with a parcel, and the young carry the children on their shoul. ders, suspended in a cloth girt round their bodies.

In the more southern parts, the women are likewise employed in the care of the horses, in saddling and bridling them ; the husband is always a despot, issues his orders, and must be obeyed. The women travel without being veiled; they are accordingly sun-burnt, and have but small pretensions to beauty. There are, however, some quarters in which they put on a little rouge; they every where stain their feet, and the ends of their fingers, with a small herb called henna, which gives them a deep saffron colour, a custom that must be very ancient amoug the people of Asia. Abu Becr dyed his eye-brows and beard with the same colour, and many of his successors imiiated him.

\section{Moorish Women.}

The Moorish women, when settled, seldom leave the house, and when they do, are always veiled. The old very carefully hide their faces, but the young and handsome are somewhat more indulgent, at least towards foreigners, for they are extremely cautious with the Moors. Being veiled, their husbands do not know them in the street, and it is even unpolite to endeavour to see the faces of the women who pass. There are some very fine women among the Moors, especially up the country. As females in warm countries sooner arrive at maturity, they are also sooner old.

The women of the south are in general the handsomest, and are so reserved, or so guarded, that their very relations do not enter their houses. Yet, so contradictory is their customs, that there are tribes in these provinces, among whom it is held to be an act of hospitality to present a woman to a traveller. The Moorish women who live in cities are more addicted to dress than those of the country; but as they generally leave the house only one day in the week, they seldom dress themselves.

Not being allowed to receive male visitors, they remain in their houses employed by their families, and so totally in dishabille, that they often wear only a shift, with a coarser one over it, tied round their waist, with their hair plaited, and often without a cap. When dressed, they wear a fine linen shift, the bosom embroidered with gold; a rich caftan of cloth, stuff, or velvet, worked in gold; and one or two folds of gauze, streaked with gold and silk, round the head, and tied behind, so that the fringes, intermingled with their tresses, descend as low as the waist; to which some add a ribbon of about two inches broad, worked in gold or pearls, that encircles the forehead in form of a diadem. Their caftan is bound round their waist by a crimson velvet girdle, embroidered in gold, with a buckle of gold or silver, or a girdle of tamboured stuff manufactured at Fez. The women have yellow slippers, and a kind of stockings of fine cloth, tied below the knee, and at the ankle, over which it falls in folds. These stockings are less calculated to shew what we call a handsome leg, than to make it appear thick, for to be fat is one of the rules of beauty among the Moorish women. To obtain this quality they take infinite pains; feed, when they become thin, on a diet somewhat like forced-meat balls, a certain quantity of which 
is given them daily; and, in fine, the same care is taken among the Moors to fatten young women, as in Europe to fatten fowls. The season of a custom like this may be found in the nature of the climate and quality of the aliments, which make the people naturally meagre.

The Moors present their wives with jewels of gold, silver, or pearls, but very few wear precious stones. They have rings in silver or gold ; also ear-rings in the form of a crescent, five inches in circumference, and as thick as the end of the little finger. They first pierce their ears, and introduce a small roll of paper, which they daily increase in thickness, till at length they insert the kernel of the date, which is equal in size to the ear-ring. They wear bracelets in gold and solid silver, and silver rings at the bottom of the legs, some of them considerably heavy. The use of white paint is unknown among the Moorish women, and that of red but little. It is much more common to see them dye their eye-brows and eye-lashes, which dye does not add to the beauty of the countenance, but considerably to the fire of the eyes. On their visiting-days they wrap themselves in a clean fine haick, which comes over the head, and surrounds the face, se as to let them see without being seen. When they travel, they wear straw hats to keep off the sun; and in some parts of the empire the women wear hats on their visits, which is peculiar to the tribes coming from the south, who have preserved their customs; for the Moors do not change modes which they have once adopted.

\section{Marriages.}

The Moors marry very young, many of their females not being more than twelve years of age at their nuptials. As Mahometans, their religion admits of polygamy to the extent of four wives, and as many concubines as they please; but if we except the very opulent, the people seldom avail themselves of this indulgence, as it entails upon them a vast additional expense in housekeeping, and in providing for a large family. In contracting marriages, the parents of both parties are the only agents, and the intended bride and bridegroom never see each other till the ceremony is performed. The marriage ceremonies are made before the cadi, and then the friends of the bride produce her portion; or, if not, the husband agrees to settle a certain sum upon her in case he should die, or divorce her on account of barrenness, or any other cause.

The children of the wives have all an equal claim to the effects of the father and mother, but those of the concubines can each only claim half a share.

When the marriage is finally agreed upon, the bride is kept at home eight days, to receive her female friends, who pay congratulatory visits every day. At the same time a priest attends upon her, to converse with her relative to the solemn engagement on which she is about to enter, and he accompanies his admonitions with singing a pious hymn, adapted to the solemnity. The bridegroom receives visits from his male friends in the morning, and in the evening rides through the town accompanied by them, some playing on hautboys and drums, others firing volleys of musketry. In all 
their festivals, the discharge of musketry, indeed, forms a principal part of the entertainment. Contrary to the European mode, which aims at firing with exactness, the Moors discharge their pieces as irregularly as possible, so as to have a continual succession of reports for a few minutes.

On the marriage-day, the bride in the evening is put into a square or octagonal cage, about twelve feet in circumference, which is covered with fine white linen, and sometimes with gauzes and silks of different colours. In this vehicle, which is placed on a mule, she is paraded round the streets, accompanied by her relations and friends, some carrying lighted torches, others playing on hautboys, and others firing volleys. In this manner she is carried to the house of the bridegroom, who returns about the same time from performing similar ceremonies. On he: arrival, she is placed in an apartment by herself, and her husband is introduced to her alone for the first time, who finds her sitting upon a silk or velvet cushion, with a small table before her, upon which are placed two wax candles lighted. Her shift or shirt hangs down like a train behind her, and over it is a silk or velvet robe with close sleeves, which at the breast and sleeves is embroidered with gold; this dress reaches somewhat lower than the calf of the leg. Round her head is tied a black silk scarf, which hangs behind as low as the ground. Thus attired, she sits with her hands over her eyes, when her husband appears, and receives her as his wife without any further ceremony; for the agreement made before the cadi is the only specific contract thought necessary. If the husband has any reason to suspect that his wife has not been strictly virtuous, he may divorce her, and take another; and the wife may divorce her husband, if he does not provide her proper subsistence.

For some time after marriage, the family and the friends are engaged in much feasting, and a variety of amusements. It is very customary for the man to remain at home eight days, and the woman eight months, after they are first married. If he curses her, he must pay her for the first offence eight ducats, for the second a rich dress of still greater value, and the third time she may leave him entirely. He is then at liberty to marry again in two months. Women suffer little inconvenience in their country from child-bearing; they are frequently up the next day, and go through all the business of the house with the infant upon their back.

\section{Funeral Rites.}

When any person dies, a certain number of women are hired for the purpose of lamentation; in the performance of which, nothing can be more grating to the ear, or more unpleasant, than their frightful moans, or rather howlings; at the same time these mercenary mourners beat their heads and breasts, and tear their cheeks with their nails. The bodies are usually buried a few hours after death. Previous to interment, the corpse is washed very clean, and sewed up in a shroud with the right hand under the head, which is pointed towards Mecca; it is carried on a bier supported on men's shoulders to the burying place, which is always with great propriety on the 
outside of the town, for they never bury their dead in the mosques, or within the bounds of an inhabited place. The bier is accompanied by numbers of people, two abreast, who walk very fast, calling upon Ged and Mahomet, and singing hymns adapted to the occasion. 'The grave is made very wide at the bottom, and narrow at the top, and the body is deposited without any other ceremony than singing and praying, in the same nanner as on their way to the grave. They have no tombs in this country, but long and plain stones: and it is frequently customary for the female friends of the departed to weep over their graves for several days after the funeral.

\section{Recreations.}

The Moors have in general but few amusements; the sedentary life they lead in cities is little varied, except by the care they take of their gardens, which are rather kept for profit than for pleasure. Most of these are planted with orange and lemon trees, and cedars in rows, in such great quantities that the appearance is rather that of a forest than a garden. The Moors sometimes, though rarely, have music in these retreats; but a state of slavery ill agrees with the love of pleasure. The people of $\mathrm{Fez}$, alone, either from a difference of education, or because their organs and sensibilities are more delicate, make music a part of their amusements.

There are not in Morocco, as in Turkey, public coffee-houses, where people meet to inquire the news of the day; to obtain this, the Moors go to the barbers' shops, which in all countries seems to be a rendezvous of newsmongers. These shops are surrounded by benches, on which the customer, the inquisitive, the idle, seat themselves; and when there are no places vacant, they crouch themselves on the ground like monkeys. Showmen and dancers come often in to the towns; round whom the people assemble, and partake of the amusement for a trifle. There are also a kind of wandering historiaus. - The vulgar, who cannot read, and who every where are eager to hear, are the most assiduous in attending these narrators, but want of more extensive information prevents the tale-teller from remaining above a week in a place.

A common diversion in the towns where there are soldiers, as well as in the country, is what the Moors call the game of gunpowder, a kind of military exercise, that is the more pleasing to the people, as, by the nature of their government, they all are, or are liable to become, soldiers, therefore all have arms and horses. By explosions of powder, too, they manifest their festivity on their holidays. Their game of gunpowder consists in two bodies of horse, each at a distance from one another, galloping in successive parties of four and four, and discharging their pieces charged with powder. Their chief art is in galloping up to the opposite detachment, firing their muskets, facing about, charging, and returning to the attack; all which manœuvres are also performed by their opponents. The Moors take great pleasure in this amusement, which is only an imitation of their military evolutions.

The common topics for conversation among the Moors are the occurrences of the place, their religion, their women, but, above all, 
their horses. This last topic appears to occupy by far the greatest portion of their attention. These animals are seldom kept in stables in Morocco. They are watered and fed only once a day, the former at one o'clock at noon, and the latter at sun-set : the only mode they use for cleaning them is by washing them all over in a river two or three times a week, and suffering them to dry of themselves. Notwithstanding the attachment which the Moors shew to their horses, they most certaily use them with great cruelty. Their highest pleasure, and one of their first accomplishments, is, by means of long and sharp spurs, to make the horse go full speed, and then to stop him instantaneously, and in this they certainly manifest uncommon dexterity. The iron work of their bridles is so constructed, that by its pressure on the horse's tongue and lower jaw with the least exertion of the rider, it fills his mouth full of blood, and, if not used with the utmost caution, throws him inevitably on his back. The bridle has only a single rein, which is so very long, that it serves the purpose of both whip and curb. The Moorish saddle is in some degree similar to the Spanish, but the pommel is still higher and more peaked. The stirrups, in which they ride very short, are so formed as to cover the whole of the foot. They either plate or gild them, according to the dignity, opulence, or fancy of the possessor. Their saddles, which are covered with red woollen cloth, or, if belonging to a person of consequence, with red satin or damask, are fastened with a strong girt round the body, in the European style, and another round the shoulders. The Moors frequently amuse themselves by riding with the utmost apparent violence against a wall; and a straliger would conceive it impossible for them to avoid being dashed to pieces, when, just as the horse's head touches the wall, they stop him with the utmost accuracy.

\section{Albinos.}

The white Moors are thus denominated by the Portuguese. The Albinos are looked upon by the negroes as monsters. At a distance they might be taken for Europeans; but, upon a near inspection, their white colour appears like that of a person affected with leprosy. -In Saussure's "Voyages dans les Alpes," is the following account of two boys, in Chamouni, who have been called Albinos. "The elder, who was, at the end of the year 1785, about twenty or one-andtwenty years of age, had a dull look, with lips somewhat thick, but nothing else in his features to distinguish him from other people. 'The other, who is two years younger, is rather a more agreeable figure; he is gay and sprightly, and seems not to want wit. But their eyes are not blue; the iris is of a very distinct rose colour; the pupil too, when viewed in the light, seems decidedly red; which seems to demonstrate that the interior membranes are deprived of the uvea, and of that black mucous matter which should line them. Their hair, their eye-brows, and eye-lashes, the down upon their skin, were all, in their infancy, of the most perfect milk-white colour, and very fine : but their hair is now of a reddish cast, and has grown pretty strong. Their sight too is somewhat strengthened, though they exaggerate to strangers their aversion for the light, and half shut their eye-lids, to give them- 
selves a more extraordinary appearance. But those who, like me, have seen them in their infancy, before they were tutored to this deceit, and when too few people came to Chamounito make their affectation profitable to them, can attest that then they were not much offended with the light of day. At that time they were so little desirous of exciting: the curiosity of strangers, that they hid themselves to avoid such, and it was necessary to do a sort of violence to them, before they could be prevailed upon to allow themselves to be inspected. It is also well known at Chamouni, that when they were of a proper age, they were unable to tend the cattle like the other children at the same age, and that one of their uncles maintained them out of charity, at a time of life when they were capable of gaining a subsistence by their labour. I am therefore of opinion that we may consider these two lads as true Albinos, for if they had not the thick lips and flat noses of the white negroes, it is because they are Albinos of Europe, not of Africa. This infirmity affects the eyes, the complexion, and the colour of the hair; it even diminishes the strength, but does not alter the conformation of the features. Besides, there are certainly in this malady various degrees; some may have less strength, and be less able to endure the light, but these circumstances in those of Chamouni are marked with characters sufficiently strong to entitle them to the unhappy advantage of being classed with that variety of the human species denominated Albinos.

"When nature," continues this author, " presents the same appearance often, and with circumstances varied, we may at last discover some general law, or some relation which that appearance has with known causes; but when a fact is so singular and so rare as that' of those Albinos, it gives but little scope to conjectures, and it is very difficult to verify those by which we at first attempt to explain it. I at first imagined that this disease might be referred to a particular sort of organic debility; that a relaxation of the lymphatic vessels within the eye might suffer the globules of the blood to enter too abundantly into the iris, the uvea, and even into the retina, which might occasion the redness of the iris and of the pupil. The same debility seemed also to account for the intolerance of the light, and for the whiteness of the hair. But a learned physiologist, Mr. Blumenbach, professor in the university at Gottingen, who has made many profound observations on the organs of sight, and has considered with great attention the Albinos of Chamouni, attributes their infirmity to a different cause. The study of comparative anatony has furnished him with frequent opportunities of observing this phenomenon; he has found it in birds, in white dogs, and in owls ; he says it is gellerally to be seen in the warm-blooded animals, but that he has never met with it in those with cold blood. From his observations, he is of opinion that the redness of the iris, and of the other internal parts of the eye, as well as the extreme sensibility that accompanies this redness, is owing to the total privation of that brown or blackish mucus, that, about the fifth week after conception, covers all the internal parts of the eye in its sound state. He observes, that Simon Pontius, in his treatise de Coloribus Oculorum, long ago remarked, that in blue eyes the interior membranes were less abundantly pro- 
vided with this black mucus, and were therefore more sensible to the action of light. This sensibility of blue eyes agrees very well, says M. Blumenbach, with northern people, during their long twilight; while, on the contrary, the deep black in the eyes of negroes enables them to support the splendour of the sun's beams in the torrid zone. As to the connexion between this red colour of the eyes and the whiteness of the skin and hair, the same learned physician says that it is owing to a similiarity of structure-consenses ex similitudin efabricæ. He asserts, that this black mucus is formed only in the delicate cellular substance, which has numerous blond-vessels contiguous to it, but contains no fat, like the inside of the eye, the skin of negroes, the spotted palate of several domestic animals, \&c. And, lastly, he says, that the colour of the hair generally corresponds with that of the iris."

At the very time that $M$. Blumenbach was reading this memoir to the Royal Society of Gottingen, M. Buzzi, surgeon to the hospital of Milan, an elevé of the celebrated anatomist Moscati, published in the "Opusculi Scelti de Milan," 1784, xviii. p. 11. a very interesting memoir, in which he demonstrates by dissection what Blumenbach had only supposed. - A peasant of about forty years of age died at the hospital of Milan of a pulmonary disorder. His body being exposed to view, was exceedingly remarkable by the uncommon whiteness of the skin, of the hair, of the beard, and of all other covered parts of the body. M. Buzzi, who had long desired an opportunity of dissecting such a subject, immediately seized upon this. He found the iris of the eyes perfectly white, and the pupil of a rose-colour. The eyes were dissected with the greatest possible care, and were found entirely destitute of that black membrane which anatomists call the uvea; it was not to be seen either bebind the iris, or under the retina. Within the eye there was only found the choroid coat extremely thin, and tinged of a pale red colour by vessels filled with discoloured blood. What was more extraordinary, the skin, when detached from different parts of the body, seemed also entirely divested of the rete mucosum : maceration did not discover the least vestige of this, not even in the wrinkles of the noblamen, where it is most abundant and most visible. M. Buzzi likewise accounts for the whiteness of the skin and of the hair, from the absence of the rete mucosum, which, according to him, gives the colour to the cuticle, and to the bars that are scattered over it. Among other proofs of this opinion, he alleges a known fact, that that if the skin of the blackest horse be accidentally destroyed in any part of the body, the hairs that afterwards grow on that part are always white, because the rete mucosum, which tinges those hairs, is never regenerated from the skin. The proximate cause of the whiteness of Albinos, and the colour of their eyes, seem therefore pretty evidently to depend on the absence of the rete mucosum. But what is the remote cause? In the first place, it seems probable that men affected by this infirmity form no distinct species, for they are produced from parents that have dark skins and black eyes. What is it then that destroys the rete mucosum in such persons? M. Buzzi relates a singular fact, which seems to throw some light on this subject.- 
A woman of Milan, named Calcagni, had seven sons. The two elder had brown hair and black eyes; the three next had white skins, white hair, and red eyes; the two last resembled the two elder. It was said that this woman, during the three pregnancies that produced the Albinos, had a continual and immoderate appetite for milk, which she took in great quantities; but that when she was with child of the other four children, she had no such desire. It is not, however, ascertained that this preternatural appetite was not itself the effect of a certain heat or internal disease, which destroyed the rete mucosum in the children before they were born. The Albinos of Chamouni are also the offspring of parents with dark skins and blue eyes. They have three sisters by the same father and mother, who are also brunettes. One of them, that I saw, had the eyes of a dark brown, and the hair alnost black. They are said, however, to be all afflicted with a weakness of sight. Should they have offspring, it would be curious to observe how the eyes of the children will be formed. The experiment would be particularly decicive, if they were married to men like themselves. But this faulty conformation seems to be more rare among women than among men; for the four of Milan, the Chamouni, the one described by Maupertuis, the one by Helvetius, and almost all the instances of these singular productions, have been of the male sex. It is known, however, that there are races of men and women affected by this disease, and that these races perpetuate themselves, in Guinea, in Java, at Panama, \&c. Upon the whole, this degeneration does not seem to be owing to the air of the mountains, for though I have traversed the greatest part of the Alps and the other mountains of Europe, these are the only individuals of the kind that ever I met with."

\section{Ausenses.}

THE Ausenses were a people of Libya, described by Herodotus, book iv. 180. They dwelt round the lake Tritonis, and were separated from the Machlyes by the river Triton. They were distinguished from their neighbours by the fashion of their hair, the Machlyes nourishing it behind, the Ausenses in front. One of their remarkable customs was, a festival celebrated annually to Minerva, whom they called a native goddess. On this anniversary the young girls divided themselves into two opposite parties, and fought with sticks and stones so desperately, that some of them often died of their wounds: such, however, as did so were deemed unchaste. Before this skirmish, they dressed the most beautiful of their girls in Grecian armour, and drew her round the lake in a chariot. They stated that the Minerva whom they worshipped was the daughter of Neptune and the lake Tritonis; and that, having had some quarrel with her father Neptune, she gave herself up to Jupiter, who adopted her. Their women were in common. The men had a general meeting every three months, at which the adults were introduced; and as each resembled any particular man, he claimed that individual as his father. 
Inhabitants of New Holiand.

THE natives of this vast region are by all accounts reckoned the most miserable race of mortals, perhaps, on the face of the earth. They go entirely naked; and though pleased at first with some ornaments which were given them, they soon threw them away as useless. It does not appear, however, that they are insensible of the benefits of clothing, or of some of the conveniences which their new neighbours possess. Some of them, whom the colonists partly clothed, seemed to be pleased with the comfortable warmth they derived from it; and they all expressed a great desire for the iron tools which they saw their neighbours make use of. Their colour, in the opinion of Captain Cook, is rather a deep chocolate than a full black; but the filth with which their skins are covered, prevents their true colour from appearing. At some of their interviews with the colonists, several droll instances happened of their mistaking the negroes among the colonists for their own countrymen.

Notwithstanding their disregard for European finery, they are fond of adorning, or rather deforming, their bodies with scars; so that some of them cut the most hideous figures that can be imagined. The scars themselves have an uncommon appearance; sometimes the flesh is raised considerably above the skin, and they appear as if filled with wind; and all these seem to be reckoned marks of honour. Some of them perforate the cartilage of the nose, and thrust a large bone through it. This hideous kind of ornament was humorously called by the sailors their spritsail-yard. Their hair is generally so clotted with red gum, that their heads resemble a mop. They also paint their bodies of various colours, and sometimes ornament themselves with beads and shells, but make no use of the beautiful feathers of their native birds.

Most of the men want one of the fore-teeth in the upper jaw; a circumstance mentioned by Dampier and other navigators; and this also appears to be a badge of manhood and of honour among them. It is very common among the women to cut off the two lower joints of the little finger; which, considering the clumsiness of the amputating instruments they possess, must certainly be a very painful operation. This was at first supposed to be peculiar to the married women, or those who had born children; but some of the oldest women were withont this distinction, while it was observed in others who were very young.

The New Hollanders appear extremely deficient in the useful arts. Of the cultivation of the ground they had no notion; nor could they at first be prevailed upon to eat bread or dressed meat. Hence they depended entirely for subsistence on the fruits and roots they could gather, and the tish they could catch. Grovernor Phillip also mentions their frequently setting fire to the grass, in order to drive out the opossums and other aninals from their retreats; and they also used decoys for quails. As all these resources, however must be at best precarious, it is no wonder that they were frequently distressed for provisions. Thus, in summer, they would eat neither the shark nor 
sting-ray, but in winter any thing was acceptable. A young whale being driven ashore, was quickly cut in pieces and carried off. They broiled it only long enough to scorch the outside; and in this, raw state they eat all their fish. They broil also the fern root, and another whose species is unknown.

Among the fruit used by them, is a kind of wild fig, and the kernels of a fruit resembling the pine-apple. The principal part of their subsistence, however, is fish; and when these happened to be scarce, they often watch an opportunity when the colonists haul the seine, and seize on such as fall within their reach. They sometimes strike the fish from their canoes with their spears, sometimes catch them with their hooks and nets, contrary to the assertion of Dr. Hawkesworth, who says that none of these are to be met with among them. Their nets are generally made of the fibres of the flax plant, with very little preparation, and are strong and heavy; the lines of which they are composed are twisted like whipcord. Some of them, however, appear to be made of the fur of animals, and others of cotton. The meshes of their nets are made of very large loops, artificially inserted in each other, but without knots. Their hooks are made of the inside of a shell, very much resembling motherof-pearl. The canoes in which they fish are only large pieces of bark tied up at each end with vines; and considering the slight texture of these vessels, the dexterity with which they are nuanaged is admirable, as well as the boldness with which they venture in them out to sea. They generally carry fire along with them in these canoes, in order to dress their fish when caught. When fishing with the hook, if the fish appears too strong to be drawn on board with the line, the canoe is paddled to the shore, and while one man gently draws the fish along, anotler stands ready to strike it with a spear, in which he generally succeeds. There is no reason for supposing them to be cannibals, though they always eat animal substances raw, or next to it. Some of their vegetables are poisonous when raw, but deprived of this property when boiled. A convict unhappily experienced this, by eating some in an unprepared state, in consequence of which he died in twenty-four hours. They dislike European provisions. If bread be given them, they chew it, and spit it out again, seldom choosing to swallow it. They like saltbeef, and pork rather better; but they originally could never be brought to taste spirits a second time, though this aversion is now overcome.

The huts of these savages are formed in the most rude and barbarous manner imaginable. They consist only of pieces of bark laid together in the form of an oven, open at one end, and very low, though long enough for a man to lie at full length. There is no reason, however, to believe that they depend more on them for shelter than on the caverns with which the rocks abound.

We must not imagine that the custom of going naked inures them so to the climate as to rilake them insensible to the injuries of the weather. The colonists had repeated opportunities of observing this, by seeing them shivering with cold in winter, or huddling together in heaps in their huts, or in caverns, till a fire could be kindled to warm them. 
It is probable, however, notwithstanding their extreme barbarity, that some knowledge of the arts will soon be introduced among them as some have been seen attentively considering the utensils and conveniences of the Europeans, with a view, seemingly, of making similar improvements of their own. It has also been observed, that in some things they possess a very great power of imitation. They can imitate the songs and language of the Europeans almost instantaneously, much better than the latter can imitate theirs by long practice. Their talent for imitation is also discernible in their sculptures, representing men and other aninals, every where met with on the rocks; which, though rude, are very surprising for a people who have not the knowledge even of constructing habitations in the least comfortable for themselves, or even clothes to preserve them from the cold.

In their persons they are active, vigorous, and stout, though generally lean. Dampier asserts that they have a dimness of vision; though later navigators have determined this to be a mistake, ascribing to them, on the contrary, a quick and piercing sight. Their sense of smelling also is very acute. One of them having touched a piece of pork, held out his finger for his companion to smeli, with strong marks of disgust. The only kind of food they eagerly accept of is fish.

The New Hollanders generally display great personal bravery, on the appearance of any danger. An old man, whom governor Philip had treated with some familiarity, took occasion to steal a spade; but being taken in the fact, the governor gave him a few slight slaps on the shoulder; on which the old man caught hold of a spear, and, coming up to him, seemed for some time determined to strike, though, had he done so, it would have been impossible for him to have escaped, being then surrounded with officers and soldiers. No encounters between parties of the natives themselves have been observed, though from some circumstances it appears that wars are carried on among them. They have more than once been assembled, as if bent on some expedition.

An officer once met fourteen of them marching along in a regular Indian file through the woods, each man having a spear in one hand and a stone in the other. A chief appeared at their head, who was distinguished from the rest by being painted. They passed on peaceably, though greatly superior in number to our people. On another occasion, they offered no hostilities, when assembled to the number of even two or three hundred, though meeting the governor attended only by a small party. With all their courage, however, they are much afraid of a musket, and almost equally so of a red coat, which they know to be the martial dress of the colonists.

Though these savages allow their beards to grow to a considerable length, it does not appear that they look upon them to be any ornament, but rather the contrary, as appears from the following instance. Some young gentlemen, belonging to the Sirius, one day met with an old man in the woods with a beard of considerable length. This, his new acquaintance let him know they would rid him of, stroking their chins, and shewing him the smoothness of them at the same time. At length the old fellow consented, and one of the youngsters, 
taking a penknife from his pocket, and making the best substitute for lather he could, performed the operation with such success, that the Indian seemed highly delighted. In a few days he paddled alongside of the Sirius again, pointing to his beard, but could not by any means be prevailed upon to enter the ship. On this, a barber was sent down to him, who again freed him from his beard, at which he expressed the utmost satisfaction. It has, however, been impossible to form any kind of permanent intercourse with the natives, though many attempts liave been made for that purpose; but in his letter, above quoted, governor Philip declares he has not the least apprehension of their doing any damage to the colony.

At first the colonists imagined the spears of the New Hollander's to be very trivial weapons, but it now appears they are capable of inflicting very grievous and mortal wounds. They are sometimes pointed with a sharp piece of the same reed of which the shafts are made, but more frequently with the small bone of the sting-ray. They certainly burn their dead, which perhaps has given rise to the report of their being cannibals. Governor Philip, observing the ground to be raised in several places, caused all these tumuli to be opened, in which were found a jaw-bone half consumed, and some ashes. From the manner in which the ashes are deposited, it appears that the body has been, laid at length, raised from the ground a little space, and consumed in that posture, being afterwards lightly covered with mould.

They seem very little given to thieving, in comparison with the inhabitants of most of the South Sea islands, and are very honest among themselves, leaving their spears and other implements open upon the beach, in full and perfect security of their remaining untouched. They are very expert at throwing a javelin, and will hit a mark with great certainty at a considerable distance; and it seems that sometimes they kill the kangaroo with this weapon, as a long splinter of a spear was taken out of the thigh of one of those animals, the flesh having closed over it completely. The people are more numerous than was at first imagined, though still the number of inhabitants must be accounted small in comparison to the extent of the country; and there is reason to believe that the interior parts are uninhabited.

They produce fire with great facility according to Captain Cook, but with difficulty according to later accounts, and spread it in a wonderful manner. To produce it, they take two pieces of dry soft wood; one is a stick of about eight or nine inches long, the other is flat. The stick they shape into an obtuse point, at one end; and pressing it upon the other, turn it simply by holding it between both their hands, as we do a chocolate mill; often shifting their hands up, and then moving them down upon it, to increase the pressure as much as possible. By this method they get fire in less than two minutes; and from the smallest spark, they increase it with great speed and dexterity. "We have often seen," says Captain Cook, " one of their men along the shore, to all appearance, with nothing in his hand, who stooping down for a moment at the distance of every fifty or one hundred yards, left fire behind him, as we could plainly see, first by the smoke, and then by the flame among the drift-wood and other litter, 
which was scattered along the place. We had the curiosity to examine one of these planters of fire when he set off, and we saw him wrap up small sparks in dry grass, which when he had run a little way, having been fanned by the air that his motion produced, began to blaze; he then laid it down in a place convenient for his purpuse, enclosing a spark of it in another quantity of grass, and so continued his course."

It ought to be observed, that the preceding account chiefly relates to the dispositions and manners of the natives when they were first visited by the European nations. Since that period their characters have been more fully developed, though not much to their advantage. Their improvement in useful knowledge is very slow, but they have given proofs that they are capable of moral culture, and of civil refinement.

\section{Manners and Customs of the Arabians.}

Tre settled natives of Arabia are of a middle stature, thin and sallow; having black eyes and hair, and thin wiry beards. They are very abstemious. Their common food consists of thin cakes of wheaten or durrah bread, and pillau, which is made of fowl or mutton boiled in rice; their beverage is water and coffee, or kisher, a preparation from the husks of coffee-beans, which is almost the only luxury they indulge in. They seldom transgress the laws of Mahomet by drinking any fermented liquors, and never do it in public. The use of tobacco is universal ; and they often make up for the want of intoxicating liquors, by smoking hemp-leaves freely. (See De Sacys Chrestonathie Arabe, ii. 120.) At dinner-time they sit round on the floor of the room, spread a cloth or piece of leather before them, place the dishes upon it, and helping themselves with their fingers, for they have no knives and forks, they finish their meal very quickly. This is the custom among the rich and great, as well as among the poor.

Their religion requires frequent ablutions, and they are naturally cleanly, so that this use of their hands in eating is not so filthy as might be supposed. Their temperance is probably the chief cause of the constant health they usually enjoy. Tedious illnesses are uncommon among them, and the worst disorder to which they are liable is the leprosy, the prevalence of which is in a great measure owing to the ignorance of their physicians. They are extremely fond of anointing themselves; even the poorest people do it on holidays. Those who are in good circumstances are fond of burning incense, and sprinkling their clothes with sweet-scented waters; and both are done when a stranger comes in, as is usual in most Mahometan countries. The Arabs are fond of society, and great frequenters of the coffeehouses. The women, as must always be the case where the laws of Mahomet are observed, are kept in great seclusion. They have the care of all the children in their earliest years; but the boys, after a certain age, (five or six years;) are removed from the harem, and kept entirely with their male relations. In wealthy families they are placed under the care of a tutor. They are extremely careful, in mar- 
niages, to ascertain that their wife virginity is unspotted; and if the contrary proves to be the fact, they either require a compensation in money from her father, or return her upon his hands.

The hospitality of the Auabs is almost proverbial; they are also civil to strangers, and were not, when the Danish travellers visited their country, inclined to look upon Christians with that abhorrence which characterizes so many of the followers of Mahomet. They did not seem anxious to make proselytes. The Arabs have been accused of being crafty and revengeful: the former charge does not at all apply to that part of the nation of which we are now speaking; the latter does to a certain extent, since they are sometimes provoked by very gross insults to commit murder, and even to revenge themselver on the relations of the offender; but it must be remembered, that the law of retaliation is prescribed by the Koran, and that a disposition to revenge is therefore almost enjoined on Mussulmans.

The dress of the Arabs is very simple; large white trowsers, a blue and white striped shirt with very wide sleeves, a leathern girdle, a short jacket without sleeves, a capot thrown over the shoulders; and a turban, consisting of a cap with a shawl twisted round it, together with a pair of slippers, constitute the whole of their attire. A short crooked knife or dagger is stuck in to their girdle, and it is there that the poor carry their purses, smoking utensils, \&c. A coarse shirt hanging down to the knees, and girded round the loins, is all the clothing the labourers wear. The women's dress is much like that of the men, but nose and ear-rings, together with bracelets and rings round their ankles, are worn only by them. They also stain their nails red with henna, Lawsonia inermis, and their eye-lids with stibium.

This nation is divided into two distinct classes of men, who differ materially in their habits and manners; the inhabitants of the towns, and those of the desart: the latter are always encamped, and continually changing their place of abode; the former, settled in cities and villages, are those of whom we now intend to speak. Their character appeared in a very favourable light to the Danish travellers, in 1762 and 1763 , but it may be feared that the wars in which the Wahhabis have involved most parts of Arabia, in these latter times, have had a mischievous effect upon the habits of that people. The traders and public officers in the city, are indeed, often crafty and fraudulent, and sometimes oppressive and rapacious, but the inhabitants of the villages are simple, inoffensive, and industrious; and surprisingly free from that fanaticism which is the genuine offspring of the Koran. They are often much oppressed by the exactions of their rulers, for the imperfections of Mahomet's system pervade every Mussulman government, and are felt under the unostentatious courts of Yemen; as 'well as under the splendid ones of Constantinople or Delhi.

The education of the Arabs, as Niebuhr observes, (Besch. v. Arab. p. 27,) is so different from ours, that it must produce a vast difference of hebits and character. Their children are removed from the harem, as we have before remarked, when they are five or six years old, and from that time are accustomed to sit for hours together $w$ ith their fathers. Familiar intercourse with the other sex, and such amusements as nusic and dancing, are also considered as unlawful by the 
Arabians, they therefore acquire habits of seriousness from a very early age. But they do not dislike society; the coffee-houses are much frequented, and they delight in acute and pointed discourse. They are not quarrelsome, though noisy in their disputes. They have not so many terms of abuse as most European nations.

Hospitality is prescribed by the Koran: the traveller is peculiarly the object of the charitable, and the good effects of this benevolent precept are felt in Arabia, as well as other Mahometan countries. Fountains and caravanseras are as common in Yemen as in other parts of Asia; and though nothing but house-room is provided by the one, or water by the other, the abstemiousness and simple habits of the Arabians render every thing beyond that superfluous. The heroes of all their romances are celebrated for their liberality as well as their bravery, and those virtues were fostered by the doctrines of Mahomet. His uncle Abdallah was one of the three, concerning whom some Arabs had been disputing the point of liberality; when each determined 10 go to the one whom he preferred, to ask his assistance. Abdallah was just mounting his camel for a long journey: "Son of the uncle of the Apostle of God," said the man who wished to try his liberality, "I am a traveller in distress." Abdallah, immediately alighting, gave him the camel with all her trappings, only requiring. him not to dispose of a sword, slung from the saddle, because it had belonged to Ali.' The camel carried, besides robes of silk, 4000 pieces of gold, but the sword was still more valuable.-The second of the disputants went to Kais, the next of the three about whom they had been debating, and learned from a servant that his master was asleep; "Take, however," said he, "these 7000 pieces of gold; it is all we have in the house, and shew th is token to my master's camel-driver; he will provide you with a camel and a slave for your journey home."Arabah, the third of these generous men, was leaning on two slaves, for his eye-sight failed him, and on his way to the mosque, when he met the man who wished to put his liberality to the test. No sooner had he heard the request, than, clapping his hands together, and lamenting his misfortune in having no money, he desired him to take the two slaves; which the other refused, till Arabah declared that he would liberate them if he did not, and, dismissing his slaves, went onward, feeling his way by the wall. The palm for liberality was given, as may be supposed, in favour of Arabah. (Sale's Prelim. Disc to Koran, p. 29.)

The Arabs are extremely courteous; inferiors in rank or age always kiss, or attempt to kiss, the hand of their superiors. Equals embrace each other, putting cheek to cheek. They use, when addressing Mussulmans, the common salutation, Es-salam Alei-kum which properly signifies, "God save you!" and that explains why Mahometans are unwilling to give it to Christians ; the latter also dislike to use it, as being connected with the faith of Mahomet. They have a great deal of etiquette in the form of their visits, and it appears from Niebuhr's plate of his audience at Sanaa, that subjects are not allowed to sic down in presence of the imam. They sit cross-legged, as most of the other Asiatics do; and inferiors may be said to sit upon their heels when in the presence of their superiors, a most uncomfortable posture. 
Their houses are not luxurious; even those of the great have few conveniences, while the habitations of the lower orders are miserable hovels. When those who have no separate apartments for the wowomen carry a stranger home, they detain him at the door, till they have gone in, and cried, Tarik, i.e. Away! away! which sends all the women out of sight immédiately. - It may reasonably be doubted whether the seclusion of the women in the East is really considered as a hardship by them. It is not improbable that the exposure of their persons without a veil, would shock them to such a degree as to render European society highly irksome. Concealment and retirement are as essential in the eyes of Mahometan women, as decent clothing in those of a Christian.

\section{Marriages.}

The Europeans are mistaken in thinking the state of marriage so different among the Mussulmans from what it is with Christian nations. The women of Arabia seem to be as free and happy as those of Europe can possibly be. Polygamy is permitted, indeed, among the Mahometans, and the delicacy of our ladies is shocked at this idea; but the Arabians rarely avail themselves of the privilege of marrying four lawful wives, and entertaining at the same time any number of female slaves. None but rich men and voluptuaries marry so many wives, and their conduct is blamed by all sober persons. Men of sense, indeed, think this privilege rather troublesome than convenient. A husband is by law obliged to treat his wives suitably to their condition, and to dispense his favours among them with perfect equality : but these are duties not a little disagreeable to most Mussuimans; and such modes of luxury are too expensive to the Arabians, who are seldom in easy circumstances. I must, however, except one case; for it sometimes happens that a man marries a number of wives in the way of a commercial speculation. I knew an Arab, in a town near the Euphrates, who had married four wives, and was supported by the profits of their labour.

Divorce, the idea of which is also regarded as horrid by the fair sex in Europe, is not nearly so common in the East, as is imagined. The Arabians never exercise the right of repudiating a wife, unless urged by the strongest reasons; because this is considered a dishonourable step by persons who value their reputation, and throws disgrace on the woman and her relations. Wives are entitled to demand a divorce when they think themselves ill used by their husbands. Only profligate and imprudent men, who have married without consideration, divorce their wives for slight causes. An Arabian, in moderate circumstances, seldom marries more than one wife. 'And even men who are in a condition to maintain as many wives as they please, have often confessed to me, that although they had begun to live with several wives, they had at last found that they could be happy only with one. The Arabian women enjoy a great deal of liberty, and even a great deal of power, in their families. They continue mistresses of their dowries, and of the annual income which these afford, during their marriage; and, in the case of divorce, all their own property is reserved to them. Hence it happens, that 
when a man in narrow circumstances marries a woman of fortune, be is entirely dependent on his wife, and dares not divorce her:

It is absurd to say, as some travellers have said, that the Mahometan wives are all slaves, entirely the property of their husbands; that they are even inherited by his heirs. In this representation, slaves purchased with money have been confounded with women of free estate, who dispose of themselves in the East just as in Europe. This opinion, respecting women in Arabia, seems to have arisen from the mistaken notion, that fathers there sell their daughters to the highest bidder. It many times happens, no doubt, that a poor man, who has a handsome daughter, is pleased to match her with a rich man, from whom he may receive occasional presents. And rich voluptuaries, wlo clioose to marry more wives than one, are obliged to take young women of low condition, who are compelled by interested parents, or seduced by splendour, to accept a husband, who associates them with other wives, and at length divorces them. Iustead of selling his daughter; every man, in tolerably easy circumstances, strives to give her a dowry, which may continue her own property. The marriage is made out before the cadi, and signed in his presence, and in it, not only is her dowry secured to the wife, but also a separate maintenance, in case of a divorce. The rich often give their daughters, in preference, to poor mell, and consider their children more likely to be happy, when thus settled, than if they were married to lich men. The wife is then mistress of all the property, and even of the house of her husband, and is not in danger of being sent away.

Many superstitious observances, respecting marriage, still prevails in Arabia. The Arabs still believe in the virtue of enchantments, and in the tying and untying the knots of fate. The miserable victim of this diabolical art addresses some plysician, or some old wonan ; for the old women are always skilled in sorcery. The Christians of the East have a still more certain remedy against the effects of witchcraft. They say masses for the persons afflicted; and when, at last, the imagination of the poor victim has had time to recover, the honour of the cure is always ascribed to the powerful influence of the masses!

\section{THE JAPANESE.}

THE inhabitants of Japan are well-grown, agile, active, and stoutlimbed, though they do not equal in strength the northern inhabitants of Europe. Their complexion is yellow, sometimes varying to brown, and sometimes to white. The inferior classes, who during their work in sunimer have often the upper part of the body naked, are sunburnt, and browner ; women of distinction, who never go uncovered into the open air, are perfectly white: The Japanese are said to be intelligent, prudent, frank, obedient, polite, good-natured, industrious; economićal, sober, hardy, cleanly, faithful, brave, and iuviucible; yet; with all these virtues, they are accused of being suspicious, superstitious, haughty, and vindictive-as indeed they shewed themselves to the unfortunate Portuguese. But in all its transactions, the nation 
shews great intelligence, and can on no account be numbered among the uncivilized portion of mankind. Here there are no appearances of that vanity so common. admong the Asiatics and Africans, of adorning themselves with shells, glass-beadis, metal-plates, \&c.. neither are: they fond of the European ornaments of gold and silver lace, jewels, \&c: but provide thenselves: from the productions of their own country. with tea clothes, well-tasted food, and good weapons. Their curiosity is excessive. Nothing imported by the Europeans escapes it. They inquire concerning every article, aud thein questions continue till they becone wearisome. Ecollomy is a virtue practised in the emperor's palace as well as, in the meanest cottage, Here scarcity and famine are unknown, and handly a person in necessity, or a beggar; is to be found.

The principal funiture of the Japanese consists of straw mats, which serves for seats and beds : a small table for eating is the ouly moveable. The Japanese sit always upontheir hams. Before dinner begins, they make a profound bow, and "drink to the health of the guests. The women eat by themselves. During the courses, they drink a glass of sakki, a kind of beer made of rue, kept constantly warm; and they drink at each new morsel. Tea and sakki are the most favourite drink of this people; wine and spirits are never used, nor even accepted when offered by the Dutch. Sakki is as clear as wine, and of an agreeable taste; taken in great quantity, it intoxicates, and causes headach. Tobacco is in universal vogue; and smoked continually by both sexes. The gardens about their houses are adorned with a variety of flowers, trees, verdure, baths, terraces, and other embellishments.

The furniture and decorations of persons of distinetion consist in japan work of various colours, curious paintings, beds, couches, skreens, cabinets, tables, a variety of porcelain jars, vases, tea equipages, \&c. together with swords, guns, scymeters, and other arms. Their retinues are more or less splendid: according to their rank, but there are few of the lords who have less than fifty or sixty men richly clad and armed, some on foot, but most on: horseback. Their petty. kings and princes are seldom seen without 200 or 300 such attendants, when they either wait on the emperor, which they do one half of the year, or attend him abroad.

The garments of the Japanese deserve, more than that of any othen people, the name of uational, as they not only differ from other-men's, but are also of the same form in all ranks, from the monarch to the meanest subject, as well as in both sexes; and what exceeds all credibility, they have not been altered for at least 2460 years. 'They universally consist of night-gowns, made long and wide, of which several are worn at once by all ranks and ages. The more distinguished, and the rich; liave-then of the finest silk; the poorer sort, of cotton. Those of the women reach dowi to the ground, and sometimes have a train; in the man, they reach down to the heels; travellers, soldiers, and labouners, either tuck them up, or only wear them down to the knees. The habit of the men in general is of one colour ; the rest is variegated, and frequently interwoven with flowers of gold. The men seldom wear a great number, but the women thirty, fifty, or 
more, all so thin, that they scarcely together amount to 5lbs. The undermost serves for a shirt, and is therefore either white or blue, and for the most part thin and transparent. All these gowns are fastened round the waist with a belt, which in the men are about an handbreadth, in the women about a foot, of such a length that they go twice round the waist, and afterwards are tied in a knot with many ends and bows. The knot, particularly among the fair sex, is very conspicuous, and immediately informs the spectator whether they are married. The unmarried have it behind on their back, the married before.

In this belt the men fix their sabres, fans, pipes, tobacco, and medicine boxes. In the neck, the gowns are always cut round, without a collar; these, therefore, leave the neck bare, nor is it covered with cravat, cloth, or any thing else. The sleeves are always very wide at the opening before, they are half sewed up, so that they form a sack, in which the hands can be put in cold weather; they also serve for pockets. Girls have their sleeves so long, that they reach to the ground. Such is the simplicity of their habit, that they are soon dressed; and to undress, they need only open their girdle, and draw in their arms. As the gowns, from their length, keep the thighs and legs warm, there is no occasion for stockings, nor do they use them in all the empire. Among poorer persons on a journey, and among soldiers, who have not such long gowns, buskins of cotton are used. Shoes, or more properly slippers, are, of all that is worn by the Japanese, the simplest and meanest, though in general use among high and low, rich and poor. They are made of interwoven rice straw, and sometimes, for persons of distinction, of reeds split very thin. They consist only of a sole, without upper-leathers or quarters. Before, runs Iransversely a bow of linen, of a finger's breadth; from the point of the shoe to this bow goes a thin round band, which running within the great toe, serves to keep the shoe fixed to the foot. The shoe being without quarters, slides in walking like a slipper. Travellers have three bands of twisted straw, by which they fasten the band to the foot and leg. The Japanese never enter their houses in shoes, but put them off in the entrance, on account of their neat carpets.

During the time of the Dutch reside in Japan, as they have occasion to pay the natives visits in their houses, and as they have their own apartments at the factory covered with the same sort of carpets, they do not wear the European shoes, but have in their stead red, green, or black slippers, which can easily be put off at entering in. They, however, wear stockings, with shoes of cotton, fastened by buckles. These shoes are made in Japan, and may be washed whenever they become dirty.

The method of dressing the hair is not less peculiar to this people, nor less universally prevalent than the use of their long gowns. The men shave the hearl from the forehead to the neck; and the hair remaining on the temples, and in the napes, is well besmeared with oil, turned upwards, and then tied wich a white thread, wrapped round several times. The ends of the hair beyond the head are cut crosswise, about a finger's length being left. This part, after 
being passed together with oil, is bent in such a manner that the point is bronght to the crown of the head; in which situation it is fixed by passing the same thread round it once. Women, except such as are separated from their husbands, shave no part of their heads. The head is never covered with hat or bonnet, in winter or in summer, except when they are on a journey, and then they use a conical hat made of a sort of grass, and fixed with a riband. Some travelling women have a bonnet, like a shaving bason inverted, on the head, made of cloth interwoven with gold. On other occasions their naked heads are preserved both from rain and the sun by umbrellas. Travellers have a sort of riding-coat made of thick paper oiled; they are worn by the upper servants of princes, and the suite of other travellers. Dr. Thunberg and his fellow-travellers, during their journey to court, were obliged to provide such for their attendants, when they passed through the place where they are made. A Japanese always has his arms painted on one or more of his garments, especially on the long and short gowns, on the sleeves, or between the shoulders; so that nobody can steal them, which otherwise might easily happen in a country where the clothes are so much alike in stuff, shape, and size.

The family names of the Japanese are never changed, yet they seldom use them, except when they sign some writing; to which they also for the most part affix their seals. There is also this peculiarity, that the surname is always placed first. The prenomen is always used in addressing a person; and it is changed several times in the course of a life. A child receives at birth from its parents a name, which is retained until it has itself a son arrived at maturity. A person again changes his name when he is invested with any office, and when advanced to a higher trust; emperors and princes acquire a new name after death. The names of women are less variable; they are in general borrowed from the most beautiful flowers.

The wife, after marriage, is confined to her own apartment, from whence she hardly ever stirs, except to the funeral rites of her family; not is she permitted to see any man, except some very near relation, and that as seldom as can be. The wives bring no portions, but are rather bought by the husbands, of their parents and relations. The bridegroom most commonly first sees his bride upon her being brought to his house from the place of the nuptial ceremony, for in the temple, where it is performed, she is covered over with a veil which reaches from the head to the feet. A husband can put his wives to a more or less severe death, if they give him the least cause of jealousy, by being seen barely to converse with another man, or suffering one to come in to their apartment.

When a prince or great man dies, there are commonly about ten, twenty, or more youths of lis household, and such as were his greatest favourites, who put themselves to a voluntary death, at the place where the body is buried or burned. As soon as the pile, consisting of odoriferous woods, gums, spices, oils, and other ingredients, is set on fire, the relations and friends of the deceased throw their presents into it, such 'as clothes, arms, victuals, money, sweet herbs, flowers, and other things, which they imagine will be of use 
to them in the other world. Those of the middle or lower rauk commonly bury their dead, without any other burning that that of odoriferous woods, gums, \&c. The sepulchres, into which the bones and ashes of persons of rank are deposited, are generally magnificent, and situated at some distance from the towis.

\section{Ansicans.}

THE Ansicans are the inhabitants of Ansiko, a kingdom of Africa; they are neatly made, well-proportioned, and strong: wandering about from place to place, and living on the bounties of nature, without either sowing or reaping. They are dreaded for their extreme britality, and with them the Europeans never trade. They are equal to the Giagas in fierceness and barbarity, and are so accustomed to the eating of human fesh, that it is cosserted they have markets where it is publicly sold. They try the courage of their prisoners of war by shooting at them as at marks, directing their arrows above or around their heads; and whoever discovers the least sign of fear, is immediately devoured; without mercy. Those who appear intrepid and resolute, have their noses and ears bored, and two fore-teeth of the upper jaw drawil. They are then improved in barbarity, by accustoming them to the most borrid cruelties. The language of the Ansicans is barbarons, and difficult to be learned, even by the inhabitants of Congo.

The most distinguished among them wear red and black caps, of Portuguese velvet; the lowest ranks go naked from the waist upwards, and, to preserve their health, anoint their bodies with a composition of pounded white sandal wood and palm oil. Their arms are battle-axes, and small but very strong bows, adorned with serpent skius. Their strings are made of supple and tender shoots of trees, that will not easily break, and their arrows of hard and light wood. These people, who kill birds fying, shoot with such surprising swiftness, that they can discharge twenty-eight arrows from the bow, before the first falls to the ground. With equal dexterity they manage their battle-axe; one end of which is sharpened, and cuts like a wedge; the other is flattened like a mallet, with a liandle set between, about half the length of the iron, rounded at the end like an apple, and covered with the skin of a serpent.

The current money among them is a kind of shell, which is fished for, and passes among several African nations. They worship the sun as their chief deity; whom they represent as the figure of a man, and the moon by that of a woman. They have also an immense number of inferior deities; each individual having a parti. cular idol, whom he addresses on certain occasions.

\section{BOSHIES-MEN.}

THEsE are a species of Hottentots, so called, according to Dr. Sparrman, from their dwelling in woody mountainous places. They are sworn enemies to a pastoral life, live on hunting and plunder, and never keep any animal alive for the space of one night. By this 
means they render themselves odious to the rest of the inhabitants of the Cape, and are pursued and exterminated like the wild beasts whose manners they have assumed. Others are kept alive, and made slaves of. Their weapons are poisoned arrows, which, shot out of a small bow, will fly 200 paces, and hit a mark, with a tolerable degree of certainty, at the distance of 30 or even 100 paces. From this distance they call convey death to the game they hunt for food, as well as to their foes, and even to so large and tremendous a beast as the lion. The Hottentot, in the mean time, safe in his ambush, is certain of the operation of his poison, which is always of the most virulent kind, and it is said he has only to wait a few minutes to see the beast languish and die.

The dwelling of these foes to a pastoral life are generally not more agreeable than their manners. Like the wild beasts, bishes and clefts in rocks serve them for houses, and they are even said to be much worse than beasts in some of their domestic concerns. A great many of them are entirely naked, but such has have been able to procure the skin of any sort of animal, great or small, cover their borlies with it, from the shoulders downwards as far as it will reach, wearing it till it falls off their backs in rags.

Ignorant of agriculture, they wander over hills and dales after wild roots, berries, and plants, which they eat raw, to sustain a life that this miserable food would soon extinguish, were they used to better fare. Their table, however, is sometimes composed of several other dishes, such as the larvæ of insects, caterpillars, white ants, the termes, grasshoppers, snakes, and some sorts of spiders. The Boshies-man is nevertheless frequently in want, and famished to such a degree, as to waste almost to a shadow. "It was with nu small astonishment," says Dr. Sparrman, "that, for the first time, I saw in Lang Kloof a lad belonging to this race of men, with his face, arms, legs, and body, so monstrously small and withered, that I could not have been induced to suppose but that he had been brought to this state by the fever which was epidemic in those parts, had I not seen him at the same time run like a lapwing. It required but a few weeks to bring one of those starvelings to a thriving state, and even make him fat; their stomachs being strong enough to digest the great quantity of food with which they are crammed, as they may be rather said to bolt than eat."

The capture of slaves from among this race of men is by no means difficult; and is effected, Dr. Sparrman informs us, in the following manner : "Several farmers join together, and take a journey to that part of the country where the Boshies-men live. They, as well as their Lego-Hottentots, or else such Boshies-men as have been caught some time before, and have been trained up to fidelity in their service, endeavour to spy out where the wild Boshies-men have their haunts. This is best discovered by the smoke of their fires. They are found in societies from 10 to 100 , reckoning great and small. Notwithstanding this, the farmers will venture, in a dark night, to set upon them with only six or eight people, which they contrive to do by pieviously stationing themselves at some distance round the kraal.' 'They then give the alarm by firing a gun or two. By this means there is such a 
consternation spread among these savages, that it is only the boluest anoug them that have the courage to break through the circle. These the captors are glad enough to get rid of at so easy a rate, heing better pleased with those that are stupid, timorous, and struck with amazement, and who consequently allow themselves to be taken and carried into bondage : they are, however, at first treated by gentle methods ; that is, the victors intermix the finest promises with their threats, and endea. vour, if possible, to shoot some of the larger kinds of game for their prisoners, such as buffaloes, sea-cows, and the like. Such agreeable baits, together with a little tobacco, soon induce them, continually cockered and feasted as they are, to go with a tolerable degree of cheerfulness to the colonists' place of abode. There this luxurious junketing upon meat and fat is exchanged for moderate portions, consisting for the most part of buttermilk, frumenty, and hasty pudding. This diet, nevertheless, makes the Boshies-man fat in a few weeks. However, he soon finds his good living imbittered by the maundering and grumbling of his master and mistress. The words t'guzeri, and t'gaunatsi, which perhaps are best translated by those of "young sorceror" and "imp," are expressions which he must frequently put up with, and sometimes a few curses and blows into the bargain ; and this for neglect, remissness, or idleness - which last failure, if it cannot be said to be born with him, is, however, in a nanner, naturalized in him : so that, by nature and custom, detesting all manner of labour, and now from his greater corpulency become. still more slothful, and having besides been used to a wandering life, subject to no control, he most sensibly feels the want of his liberty. No wonder then that he generally endeavours to regain it by making his escape ; but what is really a subject for wonder is, that when one of these poor wretches runs away from his service, or more properly bondage, lie never takes with him any thing that does not belong to him. This is an instance of moderation in these savages towards their tyrants which is universally attested, and at the same time praised and admired, by the colonists themselves, though I cannot easily reconcile it with what I have learned of the human heart. Is it in consequence of their fearing to meet with harder usage, in case they should be retaken? This much however, is certain, that none of this species of Hottentots are inuch given to violence or revenge. Free from many wants and desires that torment the rest of mankind, they are little, if at all, addicted to thieving, if we except brandy, yictuals, and tobacco. It is not improbable likewise, that the advantages arising from a theft may be overlooked by them, when their thonghts are taken up with regaining their liberty, the greatest of all treasures.

It is necesssary to observe here, that some of the Hottentots or $\mathrm{Bo}$ shies-men, who are thus forced into the service of the colonists, live in small societies peaceably and quietly in desart tracts, where the colonists cannot easily come at them, and are sometimes in possession of a few cows. Those people originate from Boshies-mer who have run away from the colonists' service. I must confess that the Boshies-men in some husbandmen's service are treated in the gentlest manner, and perhaps, without ever having a harsh word given them, live very well with regard to provisions, are well clad, relatively to 
their condition in life ; and are very comfortably lodged in comparison of what others are, in their own straw cottages. The chief of their business, perhaps, consists in tending a herd of cattle or tlock of sheep during the heat of the day, when they have an opportunity of getting into a gentle state of intoxication by smoking tobacco; a state which excites in them sensations of as agreeable a nature, as the frenzy produced by spirituous liquors and opium seems to afiord to many others, who are never at ease but when they can procure to themselves this delicious but pernicious pleasure. And yet, though they may thus agreeably pass away the otherwise tedious hours of their lives in smoking and sleep, they nevertheless run away.' The colonists wonder at this, as a procedure entirely devoid of reason; without perceiving, that in so doing they suppose the Hottentots not endued with a desire, which has its immediate foundation in nature, and which is corrmon to the human race, and even to most brute animals, viz. an earnest longing after their birth-place and families, and more especially after their liberty.

The slave business, that violent outrage to the natural rights of mànkind, always in itself a crime, and which leads to all manner of abominations and wickedness, is exercised by the colonists in general with a cruelty towards the nation of Boshies-men, which merits the ablorrence of every man; though I have been told that they pique themselves upon it, and that not only are the captors of those Hottentots considered merely as a party of pleasure, but in cold blood they destroy the bands which nature has knit between husbands and their wives and children. Not content, for instance, with having torn an unhappy woman from the embraces of her husband, her only protection and comfort, they also endeavour all they can, and that chiefly at night; to deprive her of her infants; for it has been observed; that the mothers can seldom persuade themselves to flee from their tender offspring. The amiable tenderness of the mother, which perhaps glows with a more lively flame in the breast of this poor heathen than in that of her Christian tylants, is the very circumstance laid hold on by her persecutors to rivet the chains of this wretched female so much the faster. - There are some mothers, however, that set themselves free, when they have lost all hopes of saving their children; but having made their escape, they keep secretly about the neighbourhoed, in hopes of some opportunity of recovering their infants again.

\section{INHABITANTS OF HUAIEINE, ONE OF THE SoCIETY ISLANDS.}

THEY are nearly as fair as the Europeans, and bolder than the inhabitants of the other Society Islands. They are stout and well made, some of the tallest being six feet three inches in height; they are extremely indolent, and seem to have as little curiosity as fear. The dogs are in great favour with all the women, "who couid not have caressed them," says Mr. Forster, "with a nore ridiculous affection, if they had been European ladies of fashion. Here was seen a middle-aged woman, whose breasts were full of milk, offering then to a little puppy which had bcen trained up to suck then. 
The sight disgusted those who saw it so much, that they could not forbeas expressing their dislike to it; but the woman siniled, and told them slie allowed young pigs to do the same It appeared afterwards that this woman had lost her child. Some of the gentlemen were present at a dramatic entertainment on this island; the piece represented a girl running away from her pareuts, and seemed to be levelled at a female passenger, who had come in Captain Cook's ship from Utaheite, and who happened to be present at the entertainment. It nuade such an impression upon the girl, that the gentlemen could scarcely prevail on her to see the piece out, or to refrain from tears while it was acting. It concluded with the reception she was supposed to meet with from her friends, which was made out not to be a very agreeable one. These people introduce extempore pieces, upon occasion; and it is most probable that this was meant as a satire upon the girl above mentioned, and to discourage others from acting in the same manner."

In maitants, Ranks, Customs, Superstitions, \&c. of Anossi.

Anossi is a province of the island of Madagascar; it is inhabited by three different sorts of whites, and four sorts of negroes. The whites a're discriminated by the names of Rohandrians, Anacandrians, and Ondzatsi; and all these are distinguished from the negroes by the general name of Zaforamini, or Rahmini, but the Rohandrians are honoured above the other whites. When they proceed to an election of a sovereign, whom they call Ompiandria, he is chosen from the Rohandrian race. Next to him, the others hold the rank of princes, and are honoured as such by all the rest of the subjects. The Anacandrians are descended of the chiefs, but have degenerated, and are accomited the bastards of princes, or those who are descended from a Rohandrian and any inferior white or black women. These are likewise called by the name of Ontempassemca, or people from sandy parts of Mecca, from whence, they say, came the Rohandrians. Botl the Rohandrians and Anacandrians wear long hair, which hang down in curls; and enjoy the privilege of killing beasts. The Ondzatsi, or lowest class of whites, are descended from the bastards of the Anacandrians. These are all fishermen, and are allowed to kill no land-animal, except a chicken. The four classes of negroes are named Voadziri, Lohavohits, Ontsoa, and Ondevenes. The Voadziri, the inost powerful and the richest, are masters of several villages, and descended from the original lords of the country. They enjoy the privilege of killing beasts, when at a distance from the whites, and no Rohandrian or Anacandrian is in the village.

The Lohavohits are descended from the Voadziri and also lords; but with this difference, that the one commands a whole district, and the jurisdiction of the other extends only to their own family and village. They are also permitted to kill those beasts they intend to eat, when at a distance from the whites. Ontsoa are next to the Lohavohits, and are their near relations. The Ondevenes are the lowest of all, being originally slaves both by father and mother. The Voadziri, 
Lohavohits, and Ontsoa, enjoy the privilege of submitting themselves, on the death of their lord or king, to any chief they please. In peturn for such homage, the new lord makes them a present, in consequence of which he becomes heir of all their possessions; hence the lower classes, both of whites and blacks, when death approaches, are under the greatest anguish of mind, knowing that their lords will not fail to deprive their children of every thing they possess. The Ondevenes have not the same liberty with the otliers, but, in times of famine, the chiefs are obliged to supply them with necessaries, which, if they fail to do, they have the liberty of submitting themselves to new masters.

The inhabitants of this province have no temples, and very little appearance of religion, only they keep up a custon of immolating beasts upon particular occasions, as in sickness, planting yams and rice, on assemblies, \&c. They offer the first-born beast to the Devil, and to God, naming the Devil first, in this manner, Diaubilis Aminhauhabere, or, Lord Devil and God.

\section{Ischorti, or Ischortzi.}

THESE are the inhabitants of the flat country of Ingria. When Peter the Great wrested this province from the Swedes, which was confirmed to him by the treaty of Nystadt in 1721, the inhabitants were a Finnish people, but little different from the Finns of Carelia, as to their language and manners; but they are not allowed to retain their ancient Swedish privileges. Peter made a present of part of the Ischortzi to several Russian nobles, who, on their side, were obliged to people the less cultivated cantons of Ingria with colonies of Pus sians from their estates, and hence we often see a village of Russians surrounded by villages of Finns. The Ischortzi have long foliowed agriculture : their economy is an ill chosen mean between that of the Russians and that of the Finns. They assemble in small villages, of five or ten farms each, and live miserably in small dirty huts. Their household furniture indicates the greatest penury; and their manner of living is disgusting. Notwithstanding the land that each family occupies is of tolerable extent, their agriculture and cattle are equally poor. Their inclination to idleness and drinking leads them often to sell their stock, and even the corn they have saved for sowing their fields. The money thus obtained they'soon squander, and are thus reduced to the most deplorable indigence. In this state they behold their cattle die of hunger and cold, with indifference. Some of them, however, imitate the Russian villagers, who, being better managers, are in better circumstances. The Ingrians are a stupid, suspicious, thievish race, and dangerous from their pilfering habits. Those who live along the road to Riga, resemble the gypsies, wander about like them, calculate nativities, and tell fortunes.

The dress of the men is like that of the Finn boors, but that of the women betrays a variety, which, considering their poverty, and the tyranny which their husbands and fathers exercise over them, may pass for luxury. The lower part of their dress resembles that of the Finn country women. Their shifts reach down to their kuees, having 
close wristbands, both pinked. The sleeves are large, and whimsically made. The body of the shift is large, and puffed with numberless plaits ; and the making of it is usually four weeks' work. Instead of a petticoat, the Ingrian women tie on each side a linen apron without gathers, These aprons are sometimes of cloth, and sometimes of linen, wrought with different colours. Those behind come over one another, but before they are at some distance; the open part of the petticoat, then left, is concealed by a smaller apron, adorned with glass beads and little shells. Several strings of these beads are worn round the neck, and fall upon the breasts. They carry, rather than wear, heavy ear-rings - with the addition, generally, of strings of beads. 'The girls wear their hair loose and uncovered; the married women conceal their hair with a piece of linen full four yards long, folded into a kind of cap; while its extremities fall on the back, and are supported by the girdle, so that the whole makes a kind of spread sail over the shoulders.- When they dress to go to town, they put on a I'uss cap, ornamented with a peak in front, lined with fur, and laced round the edges; with this they wear a long gown, made of coarse stuff, and fastened down the breast with buttons. Before the Russians conquered this country, the Ingrians had Lutheran ministers in every canton, but numbers of them have since been converted to the faitls of the Greek cliurch.

They have many absurd notions and pagan superstitions, which they mix with the ceremonials of Christianity. They consider the figures of saints as idols to be adored. They carry them into the woods in procession, and pay them a formal homage. - When a man is inclined to marry, he buys a girl, and celebrates his nuptials. All the way to church they are accompanied by two women in veils, who sing a senseless kind of ballad. No sooner is the marriage ceremony performed, than the husband begins to treat his wife with severity, and thenceforward keeps her under a discipline answerable to this unseasonable specimen.

The dead are buried by the priest of the profession to which they belong; but these superstitious people, it is said, retirn to the grave under cover of the night, and having taken up the sod, deirosit eatables for their departed friend, which they renew every fortnight or three weeks. Dogs and other animals scratch up these victuals, and devour them ; while these simple people believe they were consumed by the deceased. They think that they continue to live in the subterranean world as they did on the earth, and that the grave is little else than a change of liabitation, they therefore bring then money for their use in the other world. They speak to their deceased friends, and go to their graves, for that purpose; but at the same time are nuch afraid of them. Among their holy places there is one on the road from St. Petersburg to Riga. It is bounded by a large lime-tree, whose branches are interwoven with those of the forest nearest to it, and form a delightful bower. On the festival of St. John, at night, the Ischortzi assemble round this tree, and remain till morning, singing and dancing round a great fire; concluding their orgies with burning a white cock, and making the most absurd gesticulations and grimaces. 
Manners, Dinesses, and Manuage Cenemonies, of the HiN Doos.

In ordinary life, the Hindoos are lively, fond of conversation and a musements, and particularly dancing. They do not, however, learn or practise dancing themselves, but have women taught for the purpose, and in viewing these they will spend whole nights. They disapprove of many parts of the education of European Iadies, as supposing that they engage the attention too much, and draw away a woman's attention from her husband and children. Hence there are few women in Hindoostan who can either read or write. In general they are finely shaped, gentle in their manners, and have soft and even musical voices. The women of Kashmere, according to Mr. Forster, have a bright olive complexion, fine features, and delicate shape; a pleasing freedom in their manners, but without any tendency to imimodesty.

The dress of the modest women in Hindoostan consists of a close jacket, which covers their breast, but perfectly shews their form. The sleeves are tight, and reach half way to the elbows, with a narrow border painted or embroidered round the edges. Instead of a petticoat, they have a piece of white cotton cloth wrapped round their loins, and reaching near the ankle on the one side, but not quite so low on the other. A wide piece of muslin is thrown over their right shonlder, which, passing under the left arm, is crossed round the middle, and hangs down to the feet. The hair is usually rolled up into a knot or bunch towards the back of the head; and some have curls hanging before and behind the ears. They wear bracelets on their arms, rings in their ears, and on their fingers, toes, and ankles, with sometimes a small one in the nostril. The dress of the dancing. women, who are deemed votaries of Venus, is very various. Sometimes they wear a jaina, or long robe, of wrought muslin, or gold and silver tissue; the hair plaited, and hanging down behind, with spiral curls on each side of the face. They are taught every accomplishment which can be supposed to captivate the other sex, form a class entirely different from the rest of the people, and live by their own rules. Their clothes, jewels, and lodging, are considered as implements of their trade, and must be allowed them in case of confiscation for debt; they may drink spirituous liquors, and eat any kind of meat except beef ; their dances are said to resemble those of the ancient Bacchanalians, represented in some of the old paintings and basreliefs. In some of their dances they attach gold and silver bells to the rings, of the same metal they wear on their ankles. The men generally shave their heads and beards, leaving only a pair of small whiskers, and a lock on the back of their heads, which they take great care to preserve.

In Kashmere and some other places they let their beards grow to the length of two inches. They wear turbans on their heads, but the brahmins, who officiate in the temples, commonly go with their heads uncovered, and the upper part of their body naked. Round their shoulders they hang the sacred string called Zemar, made of a kind of perennial cotton, and composed of a number of threads of a de- 
ternined length. composed of fewer threads, but the Sooderas are not allowed to wear any string the other dress of the brahnins consist of a piece of white cotton cloth wrapped about the loins, descending below the knee, but lower on the left than on the right side In cold weather they sometimes put a red cap on their heads, and wrap a shawl round their bodies. The Khatries, and most other inhabitants of this coun try, wear also pieces of cotton cloth wrapped round them, hut which cover the upper as well the lower part of the body Ear-rings and bracelets are worn by the men as well as the women; and they are fond of ornamenting themselves with diamonds, rubies, and other precious stones, when they can procure them. They wear slippers on their feet of fine woollen cloth or velvet, frequently embroidered with gold and silver; those of princes being sometimes adorned with precious stones. The lower classes wear sandals or slippers of coarse woollen cloth or leather: these slippers are always put off on going into any apartment; being left at the donr, or given to an attendant; nevertheless, the Hindoos make no complaints of the Europeans, for not pulling off their shoes when they come into their houses, which must certainly appear very uncouth to them.

Hindoo families are always governed by the eldest male, to whom great respect is shewn. Filial veneration is carried to such a height. among them, that a son will not sit down in the presence of his father until ordered and Mr. Forster observes, that during the whole time of his residence in India, he never saw a direct instauce of undutifulness to parents; and the same is related by oflier writers.

Among the Hindoos, marriage is considered as a religious duty: and parents are strictly commanded to marry their children by the time they arive at eleven years of age at farthest. Polygamy is allowed; but this license is seldom made use of, unless there should be no children by the first wife. In case the second wife also proves, barren, they commonly adopt a son from among their relations The Hindoos receive no dower with their wives, but, on the contrary, the intended husband makes a present to the father of his bride Nevertheless, in many cases a rich man will choose a poor relation for his daughter; in which case the bride's father is at the expense of the wedding, receives his son-in-law into his house, or gives him a part of his fortune. The bridegroom then quits the dwelling of his parents, with certain ceremonies, and lives with his father-in-law. Nany formalities take place between the parties, even after the match is agreed upon, and the celebration of the marriage is attended with much expense: magnificent processions are made, the bride and bridegroom sitting in the same palanquin, attended by their friends and relations; some riding in palanquins, some on horses, and others on elephants. So great is their vanity on these occasions, that they will borrow or hire numbers of these expensive animals to do honour to the ceremony. The rejoicings last several days; dining the evenings of which, fire-works and illuminations are displayed, and dalicing women perform their feats; the whole concludes with balms to the poor, and presents to the brahmins and principal 
guests, generally consisting of shawls, pieces of muslin, and oiher,

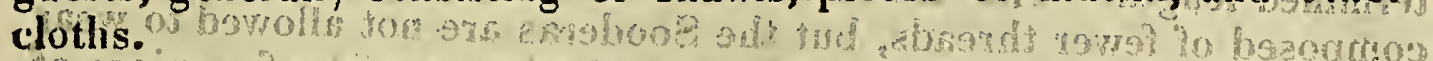

A number of ceremonies are performed when the parties are of age, and cohabit together the same are repeated when the young wife becomes pregnant - when she passes the seventh month without any accident - and when she is delivered of her child. The relations assemble at the tenth day after the birth, to assist at the ceremony of naming the child ; but if the brahmins be of opinion that the aspect of the planets is at that time unfavourable, the ceremony is delayed, and prayers are offered up to avert the misfortune. When the lucky. moment is discovered, they fill as many pots with water as there are planets, and offer a sacrifice to them; afterwards they sprinkle the head of the child with water, and the brahmin gives it such a name as he thinks best adapted to the time and circumstances; and the ceremony concludes with prayers, presents to the brahmins, and alms to. the poor.

Mothers are obliged to suckle their own children; nor can this duty be dispensed with, except in cases of sickness. More cerer monies, with presents to the brahmins, take place, when a boy comes of age to receive the string, which the three first casts wear round their waist.

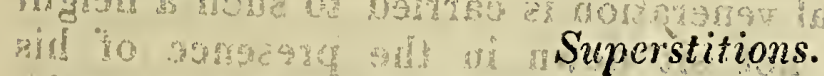

Great numbers of devotees are to be met with every where throughout Hindoostan. Every cast is allowed to assume this way of life, except the Chandalahs. Those held most in esteem are named Scinasses and Yogeys. The former are allowed no other clothing but what will cover their nakedness, nor have they any woridly goods besides a pitcher and a staff; but though they are strictly enjoined to meditate on the truths contained in the sacred writings, they are expressly forbidden to argue about them. They nust eat but once a day, very sparingly, of rice or other vegetables; they must also shew the most perfect indifference about hunger, thirst, leat, cold, or any thing relating to this world, looking forward with continual desire to the separation of the soul from the body. Should any one of tiem fail in this self-denial, he is rendered so much more criminal by the attempt, as he neglected the duties of ordinary life for those of another which he is not able to accomplish.

The Yogeys are bound to much the same rules, and both subject themselves to most extravagant penances. Some keep their arms stretched over their heads till they become withered, and incapable of motion; others keep them crossed over their breast during life; while others, keeping their hands constantly shut, have them quite pierced through by the growth of their nails. Some chain themselves to trees, or particular spots of ground, which they never quit; others resolve never to lie down, but sleep leaning against a tree; but the most curious penance perhaps on record is that of a Yogey, who measured the distance between Benares and Juggernaut with the length of his body, lying down and rising alternately. Many of these enthusiasts throw themselves into the way of the chariots of Vishrou or Sheevah, when brought forth to celebrate the feast of a temple, and 
drawn by several hundreds of men. Thus the wretched devotees are instantly crushed to death. Others devote themselves to the flames, to shew their regard to some of their idols, or to appease the wrath of one whom they thought to be offended.

A certain set of devotees are nained Pandarants; and another, on the coast of Coromandel, are named Cary Patra Pandarains: the former rub themselves all over with cow-dung, running about the country singing the praises of the god Sheevah; whom they worship; the latter go about asking charity, by striking their hands together, for they never speak. They accept of nothing but rice, and when they have got as much as will satisfy their hunger, never give themselves any trouble about more, but pass the rest of the day in the shade, in a state of such supine indolence as scaicely to look at any object whatever. The Tadinuns are another sort of mendicants, who sing the incantations of Vishnou. They have hollow brass rings round their ankles, which they fill with pebbles, so that they make a considerable noise when they walk; they beat likewise a kind of tabor.

The Transactions of the Literary Society of Bombay contain a paper by Sir John Malcolm, on the Hindoo festival of Dusrah, the ceremonies of which were formerly attended by a mystery of great wickedness. It was not uncommon on these cccasions to immolate hitman victims at the altar of one of their goddesses; and upon inquiring of a brahmin as to the truth of the report, Sir John Malcolm was assured that his infurmation was perfectly correct; and, moreover, that the unhappy persons who were selected as sin-offerings to the sanguinary divinity, were usually closely connected with the individual whose hands deprived them of life. The particulars relative to this horrible sacrifice were communicated to Sir John Malcolm nearly as follows. The brahmins of the tribe of Kurradee were formerly accustomed to immolate yearly a young lbrahmin to Kula Dewary, an infernal goddess; this deity is supposed to delight in human blood, and is usually represented with three fiery eyes, and covered with red flowers; holding in one hand a sword, and in the other a battle-axe. The prayers of her votaries are offered to her during the first nine days of the Dusrah feast; and in the evening of the tenth day a grand repast is prepared, to which the whole family is invited. An intoxicating drug is secretly mixed with the food of the intended victim, who in many cases is a stranger, whom the master of the liouse has for several months, perhaps years, treated with the greatest kindness and attention; and sometimes, to lull suspicion, gives him his daughter in marriage. As soon as the poisonous and intoxicating drug operates, the master of the house, unattended, takes the devoted person into the temple, leads him three times round the idol, and, on his prostrating himself before it, takes this opportunity to cut his throat. He collects with the greatest care the blood in a small bowl, which he first applies to the lips of the ferocious goddess, and then sprinkles it over her body; and a hole having been dug at the feet of the idol, he deposits the corpse in it with the greatest care, in order to prevent discovery. After the perpetration of this horrid act, the Kurradee brahmin returns to his family, and spends 
the night in mirth and revely; convinced that by this praiseworthy act he has propitiated the favour of the blocdthirsty deity for twelve years. On the norning of the following day, the corpse is taken from the hole into which it had been thrown; and the idol is laid aside till the next Dusrah, when a similar sacrifice is made. The discontinuance of this barbarous superstition was occasioned by the knowledge of a very revolting case having been conveyed to the peishwa of the district, some time before Poona was added to the British dominions; who suppressed immediately this order of the brahmins, or at least forbade the exercise of ther detestable rites within the limits of his government.

\section{Adoration.}

Mr." Ward, one of the Baptist missionaries at Serampore, in a work on the History and Literature of the Hindoos, has given the following curious account of the modes of adoration, which they call $F$ o $j a$. "Previously to entering on this act of idolatry" says he, "the person bathes; returning home, he washes his feet, spreads a blanlict or some other proper thing to sit upon, and then sits down before the idol, having the articles necessary for worship before him; a kosha or metal basin, and a koshee or smaller one, a small wooden stand, a metal plate, an iron stand to hold five lamps, a censer, a brass stand with a small shell placed on it, a metal plate on which to place flowers, a metal bowl into which the water and flowers are thrown after they have been presented to the idol, a metal jug for holding water, a metal plate to be used as a bell, a shell or sacred conch which sounds like a horn, with a number of dishes, cups, and other utensils for holding rice, paint, incense, betel, water, millk, butter, curds, sweatmeats, flowers, clarified lutter, \&c. Having all these articles ready, the worshipper takes water from the kosha with the koshee, and, letting it fall into his hand, drinks it; he then takes a drop more, then another, repeating incantations. After this, with the finger and thumb of his right hand, he touches his mouth, nose, eyes, ears, navel, breast, shoulders, and the crown of his head, repeating certain forms. He then washes his hands, makes a number of motions with his fingers, and strikes the earth with his left heel three times, repeating incantations. When this is done, he flirts the first finger and thumb of his right hand, waving his hand toward the ten divisions of the earth, closes, his eyes, and repeats iucantations to purify his mind, his body, the place where he sits, as well as the offerings about to be presented, which it is supposed may have become unclean by having been seen or touched by a cat, a dog, a shackal, a shoodru, or a Mussulman. Next, he takes a flower, which he lays on his left hand, and, putting his right hand upon it, resolves in his nind the form of the god he is worshipping. He then lays the fower on his head, and joining his hands, together, closes his eyes; thinks upon the form - that he has a nose, eyes, four arms, four heads, \&c. - and then recites the outward forms of worship in his mind. He now presents the offerings: first, a square piece of gold or silver, as a seal for the god, inviting him to come and sit down, or visit him; and then asking the god if he be hamb, repeats for him, "Very 
happy." After this he presents water to was the feet; takes up water with the koshee, and pours it into the metal bowl; and presents at once ricê, a vilivu leaf, eight blades of Doorva grass, paint, and water, with incantations. He then presents water to wash the môth, curds, sugar, honey ; then water to wash the mouth agair, and water to bathe in, with prayers; then cloth, jewels, gold, silver, ornaments, bedsteads, curtains, a bed, pillow, cloth, printed cloth"; clothes for men, women, or children; shoes, brass drinking cups, candlesticks, and whatever would be proper presents to the brahmins.

It must not be supposed that all these articles are presented daily by the Hindoos. This account describes what is performed at festivals. In the daily worship, flowers, leaves, sacred grass, a little rice, \&c., are presented. After this, paint, either red or white, is presented on a flower; then eight or ten flowers; leaves of the vilivu tree; a necklace of flowers ; incense of three kinds, and a lighted lamp, with incantations. A fter the bloody sacrifices, the offerings are presented, comprising rice, split-peas, different kinds of peas, shaddocks, pomegranates, pine-apples, netted custard-apples, another species of custard-apples, bread-fruit or jakus, mangoes, water-melons, cucumbers, plantains, oranges, ginger, cocoa-nuts, almonds, raisins, guavas, dates, jambus, jujubes, wood-apples, melons, sugar-canes, radishes, sweet-potatoes, kesooru, water, milk, curds, cream, butter, sour milk, clârıfied butter, sugar, sugarcandy, \&c. \&c.

After presenting the offerings, the person repeats the name of a god for some time, and then prostrates himself, the spectators doing the same; putting the cloth round his neck, and joining his hainds, he offers praise to the god, and prostrates himself again. The dinner follows, consisting of fried greens, and several other dishes made up of kidney-beans, varttakee, cocoa-nuts, \&c., fried together; splitpeas, and several kinds of fried herbs or fruits; four kinds of fish; boiled and fried goat's flesh, venison, and turtle; different fruits prepared with treacle; rice and milk boiled with sugar; things prepared with pounded rice; curds, sweetmeats, \&c. The fish, flesh, fried greens, and every thing of this kind, is eaten with boiled rice. A dish called kekooree, consisting of rice; split-peas, clarified butter, turmeric, and spices, boiled together, is also presented; and then water to drink. With every article of food a separate prayer is offered. Water is next presented to wash the mouth, and a straw to pick the teeth, with prayers; then the burnt-offering is made; and a present of money given. At last the person prostrates himself before the object of worship, and then retires to feast on the offerings with other brahmins. This is a detail of the form of worship on a large scale, at which time it occupies the officiating brahmin two hours." Vol. ii. p. 64, et seq. 8vo.

The same gentleman has given the following interesting account, in a letter to a lady in this country. Addressing his female friend, he says :-

There are, in Hindoostan, seventy-five millions of your sex who can neither read nor write, and thirty millions of these are British subjects. In every country not ameliorated by Christianity, the state of woman has alwas been most deplorable; but the Hindoo legislators 
have absolutely made their acquisition of the knowledge of letters a curse, and they are by a positive prohibition denied all access to their scriptures. Being thus degraded, even by their sacred writings, women in India are in a state of ignorance and superstition, which has no parallel in the history of tribes the most savage and barbarous.

"A female is despised as soon as she is born : she comes into the world amidst the frowns of her parents and friends, disappointed that the child is not a boy. Every mother among the tribe of Rajpoots puts her female child to death as soon as born. While 1 was in Bengal, I was informed of the case of a Rajpoot who had spared one of his daughters, and she lived till she attained the age when India girls are marriageable. A girl in the house of a Rajpoot was, however, so extraordinary a circumstance, that no parent chose to permit his son to marry her. The father then became alarmed for her chastity and the honour of his family, and he therefore took her aside one day, and with a hatchet cut her to pieces!-These are the circumstances into which your sex enter into life in British India.

"In childhood and youth they have no education, no cultivation of any kind whatever. There is not a sing le girl's school in all India; and the mother being herself entirely unlettered, and being the devoted victim of a dark and cruel superstition, is utterly incapable of improving her child. The first days of the girl are therefore spent in an inanity which prepares her for a life doomed to be spent in superstition and vice.

"In the age of comparative childhood she is united in marriage, without any knowledge of, or having ever seen, her husband: when they meet together for the first time, they are bound together for life. Thousands who are thus married in a state of childhood, lose their husbands without having ever lived with them, and are doomed to a life of widowhood, for the law forbids them to re-marry. Parents in some cases marry fifty or sixty daughters to one brahmin, that the family may be raised to honour by a marriage-relation to this mau. These females never live with the husband, but in the houses of their own parents, or they leave the houses in which they have been thus sacrificed for the supposed honour of the family, and enter the abodes of infamy and ruin.

"Supposing the female, however, to have been united to a person who really becomes attached to her, - what a mother! Without the knowledge of the alphabet; wholly unacquainted with mankind, and with all the employments of females in a civilized country; unable either to make, to mend, or to wash the clothes of her household! She never sits to eat with her husband, but prepares his food, waits upon him, and partakes of what he leaves. If a friend of the other sex calls upon her husband, she retires. She is veiled, or goes in a covered palanquin, if she leaves the house. She never mixes in public companies. She derives no knowledge from the other sex, except from the stories to which she may listen from the mouth of a religious mendicant. She is, in fact, a mere animal, kept for burden or for slaughter, in the house of her husband. A case, lately occurred in Calcutta, of $a$ girl being burnt alive on the funeral pile nitl the dead 
body of the youth with whom she was that day to have been married. You will be prepared now, Ladies, to expect that such a system of mental darkness will have rendered the sex, in India, the devoted victims of idolatry; and such victims no other country, however savage, however benighted, can boast. - What must be the state of the female mind when mothers are found throwing the children of their vows into the sea! when a guard of Hindoo soldiers are necessary, to prevent mothers throwing their living children into the jaws of the alligators! these mothers standing and watching the animal while it crushes the bones, tears the flesh, and drinks the blood, of their own ofispring! how deplorable the condition of your sex, when superstition thus extinguishes every sensibility of the female, and every feeling of the inother, and makes her more savage than the tiger which howls in the forest, but which always spares and cherishes its own offspring.

"At the calls of superstition, many females immolate themselves by a voluntary death in the sacred rivers of India. A friend of mine, at the junction of the Jumna and the Ganges at Allahabad, in one morning saw from his own window sixteen females, with pans of water fastened to their sides; sink themselves in the river; a few bubbles of air rising only to the surface of the water, after they were gone down. The drowning of so many kittens in England would excite more horror here, than the drowning, on system, of your own sex in India.

"But horrors still deeper are connected with the state of female society in India. The Euglish magistrates in the presidency of Bengal, in their annual official returus to the Calcutia government, state that in the year $181 \%$, seven hundred and six widows were either burnt alive, or buried alive, with the dead bodies of their husbands, in that part of British India. Is there any thing like this in the whole records of time! have fires like these, and so numerous, ever been kindled any where else on earth -or graves like these ever been opened?-Two females roasted alive every day in one part of British India alone! At noon-day, and in the presence of numerous spectators, the poor widow, ensnared and drawn to the funeral pile, is tied to the dead body, pressed down on the faggats by strong levers, and burnt alive, her screams amidst the flames being drowned by shouts and music. Amidst the spectators is her own son, her first-born, who, (tremendous idea) has set fire to the pile; and watches the progress of the flames which are to cansume the living mother to ashes; the mother wha fed him from hei breast, and dandled him on her knees, and who once looked up to him as the support of the declining days of herself and his father!

"I have seen yhree widows thus burnt alive, and could have witnessed many more such spectacles, had they not been too much for my feelings. Other widows are buried alive : here the female takes the dead body upon her knees, as she sits in the centre of a deep grave, and her children and relations, who have prepared the grave, throw in the earth around her; two of these descend into the grave, and trample the earth with their feet around the body of the widow. She sits an unremonstrating spectator of the process't the earth rises higher and higher around her; at length it reacles the bead, when 
the remaining earth is thrown with haste upon her, and these children and relations mount the grave, and trample upon the head of the expiring victim !"

"O ye British mothers! ye British widows! to whom shall these desolate beings look? In whose ears shall these thousands of orphans cry, losiing father and mother in one day,-if not to you? Where shall we go? In what corner of this miserable world, full of the habitations of cruelty, shall we find female society like this-widows and orphans like these? Seventy-five millions in this state of ignorance! Say, how long, ye who never saw a tear, but ye wiped it away-a wound, but ye attempted to healit-a human sufferer, but ye poured consolation into his heart-- how long shall these fires burn-these graves be opened? The appeal, my fair countrywomen; is to you-to every female in Britain. Government may do much to put an end to these immolations; but without the communication of knowledge, these fires can never be wholly quenched, nor can your sex in India ever rise to that state to which Divine Providence has destined them.

"Don't despai"- the victims are numerous; but on that account shall the life-boat not venture to leave the shore? There can hardly be a misery connected with human existence, which the piety and the zeal of British fémales, under the blessing of Providence, is not able to remove, and if this dreadful case be properly felt in every town of the united kingdom, these immolations must shortly cease for ever.

alis Scliools must be commenced - knowledge must be communicated ; and then the Hindoo female will be behind none of her sex in the charms which adorn the female character, in no mental elevation to which the highest rank of British females have attained. Other triumph of humanity may have been gained by our Howards, our Clarksons, our Wilberforces; but this emancipation of the females and widows of British India must be the work of the British fair."

\section{Modern MaNNers of the ETHIOPIANS.}

MR. BRUCE gives an ample description of the manners of the Abyssinians, whe in some respects are barbarous beyond measure. The continual state of war in which they are engaged, no doubt, contributes to confirm them in their barbarity. That again, according to Mr. Bruce, arises from an error in their regulations concerning the regal succession. The crown was indeed hereditary in the time of Solomon, but it now depends on the minister to choose the particular person who is to enjoy it; and as it is always his inclination to have the government in his own hands, he never fails to choose an infant, who is seldom suffered to live after he comes to the years of maturity. Thus perpetual wars and commotions take place.

All authors indeed agree that the devastations committed by the armies of this country are excessive, insomuch, that after a long encampment is removed, nothing is to be seen, all around the place where it was, but bare earth. When an army marches through the country, says Mr. Bruce," "an inconceivable number of birds and beasts of prey, especially the former, follow it from the first day of its march to its return ; increasing always in proportion as it advances 
into the country. An army there leaves nothing living behind it, not evel the vestige of a habitation; but the fire and the sword reduce every thing to a wilderness and solitude. The beasts and birds, unmolested; have the country to themselves, and increase beyond all possible conception. The slovenly manner of this savage people, who after a battle bury neither friends nor enemies; the beasts of burden that die perpetually under loads of baggage, and a variety of mis: management ; the quantity of offal, and half-eat'en carcases of cows, goats, and sheep, which they consume in their march for sustenance; all furnish a stock of carrion suficient to occasion contagious distempers, were there not such a number of voracious attendants to consume them before putrefaction. There is no giving the reader any idea of their number, unless by comparing them to the sands of the sea. While the army is in motion, they are a black canopy, which extends over it for leagues; when encamped, the ground is discoloured with them beyond the sight of the eye, and also the trees are loaded with them.

The prodigious number of criminals executed for high treason, whose bodies are cut in pieces and thrown about the streets, invite the hyenas into the capital. The method of keeping off these voracious animals is thus described by Mr. Bruce : "An officer called Serach Maffery, with a long whip, begins cracking and making a noise worse than twenty French postilions, at the door of the palace, before the dawn of day. This chases away the hyenas and other wild beasts ; this too is the signal for the king's rising, who sits in judgment every morning fasting; and after that, about eight o'clock, he goes to breakfast." From these and other circunistances, we should be apt to imagine that the Abyssinians, instead of becoming more civilized, were daily improving in barbarity... The king is anointed at his election with plain oil of olives, "which, (says Mr. Bruce,) being poured upon crown of the head, he rubs into his long hair indecently enough with both his hands, pretty much as his soldiers do with theirs when they get plenty of butter." In former times, however, matters seem to be conducted with more decency. Socinios, the greatest monarch that ever sat on the Abyssinian throne, was crowned, after having gained a great victory over the Gallas, in a very different manner with the ceremonies which were used among the ancient kings of Tigré; and which Mr. Bruce describes at large. These, however, are now given over, on account of their enormous expense. Our author was informed by Tecla Kaimanuut, that when he was obliged to retire into Tigré, Ras Michael proposed to have him crowned, in contempt of his enemies ; but, by the most moderate calculation, it would have cost twenty thousand ounces of gold, about eiglity thousand pounds sterling; on which account all thoughts of it were laid aside.

\section{Origin, Religion, \&c. of the Ansarians.}

THese were a people of Syria, so called in that country, but styled in Delisle's maps, Ensarians, and in those of Danville, Nassaris. The territory occupied by these Ansarians is that chain of moun. tains which extends fiom An takia to the rivulet called Nahr-el-Kahir, 
on the Great River. Tlie following account is taken from the Bibliotheque Orientale of Assemani, $a$ writer who has ldrawn his matevials from the best authorities.

ofls In the year of the Greeks, 1202, A. D. 891, there lived at the village of Nasar, or in the environs of Kousa, an old man, who, from his fastings, his continual prayers, and his poverty, passed for a saint. Several of the common people declaring themselves his partisans, he selected from amoing them twelve disciples, to propagate his doctrine : but the commiandant of the place, alarmed at his proceedings, seized the old inan, and confined him in prison. In this situation he excited the pity of a girl, who was a slave to the jailer: she determined to give him his liberty, and an opportunity soon offered to effect her design. One day, when the jailer was gone to bed intoxicated, and in a profound sleep, she gently took the keys from under his pillow, and after opening the door to the old man, returned them to their place unperceived by her master : the next day, when the jailer went to visit his prisoner; he was extremely astonished at finding he had made his escape, as he could perceive no marks of violence. He therefore concluded he had been delivered by an angel, and spread the report, to a void the reprehension he merited the old nan, on the other hand, asserted the same thing to his disciples, and preached his doctrines with more earnestness than ever. He even wrote a book, in which, among other things, she says, (x) $I$, (such a one) of the village of Nasar, have seen Christ, who is the Word of God, who is Ahmad, son of Mahonimed, son of Hanasa of the race of Ali; who also is Gabriel: and he said to me, Thou art Te who readeth with understanding, thou art the man who speaketh truth; thou art the camel which preserveth the faithful from wrath; thou art the beast which carrieth their burden; thou art the Holy Spirit, and John the son of Zachary! Go, and preach to men, that they make four genuflections in praying - two before the rising of the sun, and two before its setting-turning their faces towards Jerusalem; and let them say three times, God Almighty! God Most High! God Most Great! Let them observe the second and third festiVal ; let them fast but two days annually: let them not wash the prepuce; nor dripk beer, but as much wine as they think proper, and lastly, let them abstain from the flesh of carnivorous animals. This old man passing into Syria, propagated his opinions among the lower orders of the country, numbers of whom believed in him: and after a fêw years he went away, and nobody ever hnew what became of him.

Worom this account, the founder of the Ansarians appears to have been either a deliberate impostor, like Mahomet, or more probauly a crazy enthusiast, like Richard Brothers, who took the dreams of a warm imagination for realities. We cannot be surprised that these ignorant peasants should have believed in this enthusiast, when we so lately found that many persons of our own enlightened age and Wation gave credit to the equally absurd reveries of Richard!

- The Ansarians are divided into several tribes or sects ; among which are distinguished the Shamsia, or adorers of the sun the 
Kelbia, or worshippers of the dog. Many of the Ansarians believe in the inetempsychosis; others reject the immortality of the soul; and in general, in that civil and religious anarchy, that ignorance and rudeness, which prevail among them, those peasants adopt what opinions they think proper, following the sect they like best, and frequently attaching themselves to none.

* Their country is divided into three principal districts, formed by the chiefs called Mokadannim. Their tribute is paid to the pacha of Tripoli; from whom they annually receive their title. Their mountains are in general not so steep as those in Lebanon, and consequently are better adapted to cultivation; but they are also more exposed to the Turks, and hence doubtless it happens, that with greater plenty of corn, tobacco, wines, and olives, they are more thinly ishabited than those of their neighbours the Maronites and the Druses:

\section{Amazons.}

THEse were an ancient nation of female warriors, who are said to have founded an empire in Asia Minor, upon the river Thermodoon, along the coasts of the Black Sea, and to have formed a state from which men were excluded. What commerce they had with that sex, was only with strangers: they killed all their male children; and they cut off the right breasts of their female ones, to make them more fit for the combat. From which last circumstance it is, that they are supposed to take their name. But Dr. Bryant, in his AnaJysis of Ancient Mythology, explodes this account as fabulous; and observes, that they were in general Cuthite colonies, from Egypt and Syria, who formed settlements in different countries, and that they derived their name from zon, the sun, which was the national object of worship. It has, indeed, been controverted, even among ancient writers, whether there really ever were such a nation as that of the Amazons. Strabo, Palæphatus, and others, deny it. On the contrary, Herodotus, Pausanias, Diodorus Siculus, Trogus Pompeius, Justin, Pliny, Mela, Plutarch, \&c. expressly assert it.

The Amazons are mentioned by the most ancient Greek writers. In the third book of the Iliad, Homer represents Priam speaking as having been present in a battle with the Amazons; and some of them, afterwards, came to the assistance of that prince during the siege of Troy.

The Amazons are particularly mentioned by Herodotus, who informs us that the Grecians fought a battle with the Amazons, on the river Thermodoon, and defeated them. After this victory, they carried off all the Amazons they could take alive, in three ships. But, whilst they were out at sea, these Amazons conspired against the men, and killed them all. Having, however, no knowledge of navigation, nor any skill in the use of the rudder, sails, or oars, they were driven by, wind and tide till they arrived at the precipices of the lake Mootis, in the territories of the Scythians. Here they went ashore, and seized the first horses they met with, and began to plunder the inhabitants. The Scythians at 
length took them to be men; but after they had taken some prisoners, they discovered them to be women. They were then unwilling to carry on hostilities against them; and by degrees, a number of the young Scythians formed connexions with them, and were desirous that these gentle dames should live with them as wives, and be.incorporated with the rest of the Scythians. The Amazons agreed to continue their connexions with their Scythian husbands, but refused to associate with the rest of the inhabitants of the country, and especially with the women of it. They prevailed upon their husbands to retire to Sarmatia, where they settled. Hence; says Herodotus, the wives of the Sarmatians still continue their ancient way of living: They hunt on horseback in the company of their husbands, and sometimes alone. They march with their armies, and wear the same dress with the men. The Sarniatians use the Scythian language, "but corrupted from the beginning, because the Amazons never learned to speak correctly: Their marriages are attended with this circumstance, that no virgin is permitted 10 marry till she has killed an enemy in the field, so that some always grow old before they can qualify themselves as the law requires.

Diodorus Siculus says, that there was formerly a nation who dwelt near the Thermodoon, which was subjected to the government of women, and in which the women managed all the military affairs, like men. Among these female warriors was one who excelled the rest in strength and valour; she assembled an army of women, whom she trained up in military discipline, and subdued some of the neighbouring nations. Afterwards, having by her valour increased her fame, she led her army against the rest, and, being successful, she -was so puffed up, that she styled herself the daughter of Mars, and ordered the men to spin wool, and do the work of the women within doors. "She also made laws, by which the women were to go to the wars, and the men to be kept at home in a servile state, and employed in the meanest offices. Having become eminent for her skill in military affairs, she at length built a large city at the mouth of the Thermodoon, and adorned it with a magnificent palace. In her enterprises she enforced military discipline and good order, and added to her entpire all the adjoining nations, even to the river Tanais. She at last ended her days like a heroine, falling in a battle, in which she had fought courageously.

She was succeeded in the kingdom by her daugher, who imitated the valour of her mother, and in some exploits excelled her. She caused the girls from their infancy to be exercised in hunting, and trained up in military exercises. She instituted solemn sacrifices and festivals to Mars and Diana, which were named Tauropoli. She afterwards carried her arms beyond the Tanais, and subdued all the people of those regions, even in Thrace. Returning with a great quantity of spoil into her own lingdom, she caused magnificent temples to be erected to the deities before mentioned, and gained the love of her subjects by her mild and generous government. She afterwards undertook an expedition against those who were on the other side of the river, and subjected to her dominion a great part of Asia, extend ing their arms as far as Syria. 
Diodorus also mentions another race of Amazons, who dwelt ia Africa, and whom he speaks of as being of greater antiquity than those who lived near the Thernisdoon. In the western parts of Libya, says he, upon the borders of those tracts that are habitable, therewas anciently a nation under the government of women, whose manners and mode of living were altogether different from ours. It was the custom for these women to manage all military affairs, and for a certain time, during which they preserved their virginity, they went out as soldiers into the field. After some years employed in this manner, when the time appointed for this purpose was expired, they associated themselves with men, in order to obtain children; but all public offices, they kept entirely in their own hands. The men, as the women are with us, are employed in household duties, submitting themselves wholly to the authority of their wives. They are not permitted to take any part in military affairs, or to have any public authority, which might tend to encourage then to cast off the yoke of their wives. As soon as any child was born, it was delivered to the father, to be fed with milk, or such other food as was suitable to its age. If females were born, they seared their breasts, \&z.

Justin represents the Amazonian republic to have been in Scythia.The Scythians had a great part of Asia under their dominion upwards of 400 years, till they were conquered by Ninus, the founder of the Assyrian empire. After his death, which happened B.C. 1150, and that of Sermiramis and their son Ninias, Ilinus and Scolopites, princes of the blood royal of Scythia, were driven from their country by other princes, who, like them, aspired to the crown. They departed with their wives, children, and friends; and being accompanied by a great number of young people of both sexes, they passed into Asiatic Sar-z matia, beyond mount Caucasus, where they formed an establishment, supplying themselves with the riches they wanted, by making excursions into the countries bordering on the Euxine sea. The people of these countries, exasperated by the incursions of their new neighbours, united, surprised, and massacred the men. The women then determining to revenge their death, and at the same time, to provide for their own security, resolved to form a new kind of government, to choose a queen, enact laws, and maintain themselves, without men, and even against the men themselves. This design was not so very surprising as at first sight appears; for the greatest number of girls among the Scythians had been inured to the same exercises as the boys-to draw the bow, to throw the javelin, and to manage other arms, to riding, hunting, and even the painful labours that seem reserved for men; and many of them, as among the Sarmatians, accompanied the men in war. Hence they had no sooner formed their resolution, than they prepared to execute it; and exercised themselves in all military operations. They soon secured the peaceable possession of the country; and not content with shewing their neighbours that all their efforts to drive them thence, or subdue them, were ineffectual, they made war upon them, and extended their own frontiers.

They had hitherto made use of the assistance of a few men that remained in the country; but finding at length that they could stand 
theirground, and aggrandize themselves without then, they killed a! whom flight or chance had saved from the fury of the Sarmatians, and for ever renounced marriage, which they now considered as an insulyortable slavery. But as they could only secure the duration of their new kinglom by propagation, they made a law to go every year to the frontiers, to invite the men to come to them. To bocrs bas

All those whom age rendered fit for propagation, and were willing to serve the state by breeding girls, did not go at the same lime in search of men: for Hippocrates mentions it as a law among the Amazons, that in order to obtain a right to promote the nultiplication of the species, a young Amazon must first have contributed to its destruction; nor was she tliought worthy of giving birth to children, till sle had killed three men. If from this commerce they brought forth girls, they educated them; but with respect to boys, if we may believe Justin, they strangled them at their birth:

According to Diodorus Siculus, they twisted their legs and arms, so as to render them unfit for military exercises; but Quintus Curtius Philostratus, and Jordarus, say that the less savage sent them to their fathers. It is probable that at first, when their fury against the men was carried to the greatest height; they killed their boys; that when their fury abated, and most of the mothers were filled with horror at depriving the little creatures of the lives they had first received from. them, they fulfilled the first duties of a mother, but, to prevent their causing a revolution in the state, maimed them in such a manner as to render them incapable of war, and employed them in the mean offices which these warlike women thought beneath them; in short, that when their conquests had confirmed their power, their ferocity subsiding, they entered into political engagements with their neighbours, and the number of males they had preserved becoming burdensome, they, at the desire of those who rendered them pregnant, sent them the boys, and continued still to keep the girls.

As soon as the age of the girls permitted, they took off the right breasts, that they might draw the bow with the greater force. The common opinion is, that they burnt that breast, by applying to it, at eight years of age, a hot brazen instrument, which insensibly dried up the fibres and glands. Some think, that when the part was formed, they got rid of it by amputation; some again, with greater probablity, assert that they employed no violent measures; but, by a conti-y nual compression of that part from infancy, prevented its grow th, at least so far as to hinder its ever being incommodious in war. Plutarch, treating of the Amazons, in his Life of Theseus, considers the accounts concerning them as partly fabulous and partly true. He gives accounts of a battle which had been fought between the Athenians and the Amazons at Athens; and relates some particulars which had been recorded by an ancient writer named Clidemus. He says that the left wing of the Amazons moved towards the place which is yetcalled Amazonium, and the right to that place called Pryre, near Charyssa, upon which the Athenians, issuing from bebind the temple of the Muses, fell upon them; and that this is true, the graves of those that were slain, to be seen in the streets that lead to the gate Piraica, by the temple of the hero Chalcodne, was a sufficient proof: 
Here the Athenians were routed, and shamefully turned their backs to women, as far as the temple of the Furies. But fresh supplies coming in from Palladium, Ardettus, and Lyceum, charged their right wing, and beat them back into their tents; in which action, a greatnumber of the Amazons were slain.

In another place he says, "It appears that the passage of the Amazons through Thessaly was not without opposition; for there are yet to be seen many of their sepulchres near Scrotusæa and Cynocephalæ." And in his Life of Pompey, he says, "They inhabit those parts of Mount Caucasus that look toward the Hyrcanian sea, not bordering upon the Albanians, for the territories of the Getæe and the Leges lie betwixt; and these people do they yearly, for two months only, company with, near the river Thermodoon. After that, they retire to their own habitations, and live alone all the rest of the year."

Quintus Curtius says, "The nation of the Amazons is sitnated upon the borders of Hyrcania, inhabiting the plains of Thermiscyra, near the river Thermodoon. Their queen was named Thalestris, and she had under her subjection all the country that lies betiveen mount Caucasus and the river Phasis. This queen came out of her dominions in consequence of an ardent desire she had conceived to see Alexander;' and "being advanced near the 'place where he was, she previously sent messengers to acquaint him, that the queen was come to have the satisfaction of seeing and conversing with him. Having obtained permission to visit him, she advanced with three hundred of the Amazons, leaving the rest of her troops behind. As soon as she came within sight of the king, she leaped from her horse, holding two javelins in her right hand.

The apparel of the Amazons does not cover all the body; for the left side is naked down to the stomach, nor do the skirts of their garments, which they tie up in a knot, reach below their knees. They preserve their left breast entire, that they may be able to suckle their female ofispring; and they cut off and sear their right, that they may draw their bows and cast their darts with the greater ease.

Thalestris looked at the king with an undaunted countenance, and narrowly examined his person; which did not, according to her ideas, come up to the fame of his great exploits; for the barbarians have great veneration for a majestic person, esteeming those only to be capable of performing great actions, on whom nature has conferred a dignified appearance. The king having asked her whether she had any thing to desire of hini, she replied without scruple or hesitation, that she was come with a view to bring him heirs to his dominions. Their oftspring, if of the female sex, she would retain herself; and if of the male sex, it should be delivered to Alexander. He then asked her: whether she would accompany him in his wars? But this she declined, alleging that she had left no one to take care of her kingdom. Justin also repeatedly mentions this visit of Thalestris to Alexander, and it one place he says, that she had a march of twenty-five days in order to obtain this meeting with him. The interview between Alexander and Thalestris is likewise mentioned by Diodorus Siculus. The learned Goroppius, as quoted by Dr. Petit, laments the hard fate of Thales. 
tris, who was obliged to travel so many miles, and encounter so many hardships, to procure this interview with the Macedonian prince, and, from the circunstances, is led to consider the whole account as incredible. But Dr. Petit, with equal erudition, and superior force of reasoning, at length determines that her journey was not founded upou irrational principles, and that full credit is due to those historians by whom this account has been related.

The Amazons are represented as being armed with bows and arrows, with javelins, and also with an axe of a particular construction, which was denominated the axe of the Amazons. According to the elder Pliny, this axe was invented by Penthesilea, their queen, who went to the Trojan war. On many of the ancient medals are representations of the Amazons armed with these axes. They are also said to have had bucklers in the shape of a half-moon. The Amazons are mentioned by many other ancient authors beside those which have been enumerated; and if any credit be due to the accounts concerning them, they subsisted through several ages.

That at any period there should have been women, who, without the assistance of men, built cities and governed them, raised armies and commanded them, administered public affairs, and extended their doninions by arms, is undoubtedly so contrary to all that we have seen and known in public affairs, as to appear in a very great degree incredible; but that women may have existed sufficiently robust, and sufficiently courageous, to engage in warlike enterprises, and even to have been successful in them, is certainly not impossible, however contrary to the usual course of things. In support of this side of the question, it may be urged, that women who have been early trained to warlike exercises, to hunting, and to a hard and laborious node of living, may be rendered more strong, and capable of more vigorous exertions, than men who have led indolent and luxurious lives, and who have seldom been exposed even to the inclemencies of the weather. The limbs of women, as well as of men, are strengthened and rendered more robust by frequent and laborious exercise. $A$ nation of women, therefore, brought up and disciplined as the ancient Amazons are represented to have been, would be superior to an equal number of effeminate men, though they might be much inferior to an equal number of hardy men, trained up and disciplined in the sáme manner.

That much of what is said of the Amazons is false, there can be no reasonable doubt; but it does not follow that the whole is without foundation. The ancient medals and monuments on which they are represented are very numerous, as are also the testimonies of the ancient writers. It seems not rational to suppose that all this originated in fiction, though it may be much blended with it. The Abbe Guyon speaks of the history of the Amazons as having been regarded by many persons as fabulous, "rather from prejudice than from any real and solid examination ;": and it must be acknowledged, that the arguments in favour of their existence, from ancient history and from ancient monuments, are extremely powerful. The fact seems to be, that truth and fiction have been blended in the narrations concerning these ancient heroines. 
Instances of heroism in women have occasiunally occurred in modern times, somewhat resembling that of the ancient Amazons. The times and the manners of chivalry in particular, by bringing great enterprises, bold adventures, and extravagant heroism, into fashion, inspired the women with the same taste. The women, in consequence of the prevailing passion, were accordingly seen in the midst of camps and of armies. They quitted the soft and tender inclinations, and the delicate offices, of their own sex, for the toilsome occupations of ours. During the crusades, animated by the double enthusiasm of religion and of valour, they often performed the most manly exploits, obtained indulgences on the field of battle, and died with arms in their hands, by the side of their lovers or of their husbands. In Europe, the women defended and attacked fortifications, princesses commanded their armies, and obtained victories. Such was the celebrated Join de Montfort disputing for her duchy of Bretagne, and fighting for it herself. Such was that still more celebrated Margaret of Anjou, an ingenious and intrepid general and soldier, whose genius and spirit supported for a long time a feeble husband, taught him to conquer, placed him upon the throne, twice relieved him from prison, and, oppressed by fortune and by rebels, did not bend till after she had decided in person twelve battles.

The warlike spirit among the women, consistent with ages of barbarism, when every thing is impetuous, because nothing is fixed, and when all excess is the excess of force, continued in Europe upwards of 400 years, shewing itself from time to time, and always in the middle of convulsions, or on the eve of great revolutions. But there are aras and countries in which that spirit appeared with particular lustre. Such were the displays it made in the 15 th and 16th centuries in Hungary, and in the islands of the Archipelago and the Mediterranean, when they were invaded by the Turks.

Among the striking instances of Amazonian conduct in modern ladies, may be mentioned that of Jane of Belleville, widow of Mons. de Clisson, who was beheaded in the year 1353, on a suspicion of carrying on a correspondence with Eugland and the Count de Montfort This lady, filled with grief for the death of her husband, and exasperated at the ill treatment which she considered him as having received, sent off herson secretly to London, and, when her apprehensions were removed with respect to him, sold her jewels, fitted out three ships, and put to sea, to revenge the death of her husband upon all the rrench with whom she should meet. This female corsair made several descents upon Normandy, where she storméd castles: and the inhabitants of that province were spectators more than once, whilst their villages were all in a blaze, of one of the finest women in Europe, with a sword in one hand and a torch in the other, urging: the carnage, and eyeing with pleasure all the horrors of war." Mezeray says, that during the crusade, in 1147, "many women did not content themselves with taking the cross; but also took up arms to defend it, and composed squadrous of females, which rendered credible all that has been said of the prowess of the Amazons."

In 1590, the League party obtained some troops from the king of Spain. Upon the news of their being disembarked, Barri de St. Aunez, 
Henry the Fourth's governor at Leucate, ventured to attack them, but unfortunately fell into their hands. They were persuaded, that by thus having the governor in their power, the gates of that place would be inmediately opened to them, or at least would not hold out 1ong. But Constantia de Ceselli, his wife, after having assembled the garrison, put herseif so resolutely at their head, pike in hand, that she inspired the weakest with courage; and the besiegers were repulsed wherever they presented themselves. Shame, and their. great loss, having rendered them desperate, they sent a message to the courageous woman, acquainting her, that if she continued to defend herself, they would hang her husband. She replied with tears in her eyes, "I have riches in abundance: I have offered theu, and I still do offer them, for his ransom; but I would not ignominiously purchase a life which he would reproach me with, and which he would be ashamed to enjoy. I will not dishonour him by treason against my ling and country." The besiegers having made a fresh attack withont success, put her husband to death, and raised the siege. Henry the Fourth afterwards sent to this lady the brevet of governess of Leucate, with the reversion of it to her son. ...

The famous maid of Orleans is a shining example of female courage and patriotism, well known to every reader; and her fate is an everlasting disgrace to the tyrant who murdered her. In the end of the 18th century, the enthusiasm of French liberty and equality excited many females of that nation to commence Amazons, and to follow their husbands, brothers, and lovers, to victory or death. The Abbé Arnaud, in his memoirs, speaks of a countess of St. Balmont, who used to take the field with her husband, and fight by his side. She sent several Spanish prisoners of her taking to marshal Feuquirs; and what is not a little extraordinary, this Amazon, at home, was all sweetness and good nature, and gave herself up to reading and acts of piety. John de los Sanetos, a Portuguese author, in his description of Ethiopia, speaks of a nation of Amazons existing in Africa, and \#neas Sylvins gives a very particular account of a nation of real Amazons in Bohemia, which lasted seven years, founded by a courageous maid named Valasca.

Dr. Petit, a French physician, published a Latin dissertation in 1685 , to prove that there was really a nation of Amazons; it contains abundance of curious inquiries relating to their habits, their arms, the cities built by them, \&c. Others of the moderns also maintain that their existence is sufficiently proved by the testimolly of such historians of antiquity as are most worthy of credit, by the monuments which many of them have mentioned, and by medals, some of which are still remaining : and there is not the least room to believe that what is said of them is fabulous.

Dr. Johnson seems to have given some credit to the accounts which have been transmitted to us concerning the ancient Amazons, and he has endeavoured to shew, that we ought not hastily to rejeet ancient historical narrations, because they contan facts repugnant to modern manners, and exhibit scenes to which nothing now occurring bears a resemblance.- "Of what we know not," says he, "we can only judge by what we know. Every novelty appears more 
wonderfül, as it is more remote from any thing with which experience or testimony has hitherto acquainted us, and if it passes farther, beyond the notions that we have been accustomed to form, it becomes at last incredible. We seldom consider, that human knowledge is very narrow-that national manners are formed by chance that uncommon conjunctures of causes produce rare effects - or that what is impossible at one time or place, may yet happen in another. It is always easier to deny than to inquire. To refuse credit, confers for a moment, an appearance of superiority, which every little mind is tempted to assume, when it may be gained so cheaply as by withdrawing attention from evidence, and declined the fatigue of comparing probabilities. Many relations of travellers have been slighted as fabulous, till more frequent voyages have confirmed their veracity; and it may reasonably be imagined, that many ancient historians are unjustly suspected of falsehood, because our own times afford nothing that resembles what they tell. Few narratives will, either to men or women, appear more incredible, than the histories of the Amazons; of female nations, of whose constitution it was the essential and fundamental law, to exclude men from all participation either of public or domestic business ; where female armies marched under female captains; female farmers gathered the harvests; female partners danced together, and female wits diverted one another. Yet several ages of antiquity have transmitted accounts of the Amazons of Caucasus, and of the Amazons of America, who had given their name to the greatest river of the world. Condamine lately found such memorials, as can be expected among erratic and unlettered nations, where events are recorded only by tradition, and new swarms, settling in the country from time to time, confuse and efface all traces of former times.

Rousseau says, "The empire of woman is an empire of softness, of address, of complacency. Her commands are caresses, her menaces are tears. But the empire of the Amazons was certainly an empire of a very different kind. Upon the whole, we may conclude with Dr. Johnson, "The character of the ancient Amazons was rather terrible than lovely. The hand could not be very delicate that was only employed in drawing the bow and brandishing the battle-axe. Their power was maintained by cruelty, their courage was deformed by ferocity; and their examples only shews, that men and women live best together."

\section{Ceylonese.}

THE inlabitants of the island of Ceylon in the East Indies. The aborigines of Ceylon consist of two classes of people, the Cingalese and the Vaddhs. The latter are still in the rudest stage of social life, they live embosomed in the woods, or in the hollows of the mountains, nunting is their sole employment, and providing for the day their only care. Some of them acknowledge the authority of the king of Candy, and exchange with the Cingalese elephants' teeth, and deer's Mesh, for arrows, cloths, \&c.; but this trafic is not general, for two- 
thirds of them hold no communication with the Cingalese, and have an utter antipathy to strangers.

They worship a particular god, and their religious doctrine seems to consist of some indistinct notions of the fundamental principles of the brahninical faith. "In some places they have erected temples; but for the most part they perform their worship at an altar constructed of banboos, under the shade of a banyan tree. 'The Cingalese are the subjects of the king of Candy, and appear to have lieen, from time immemorial, a race of Hindoos, instructed in all the arts of civil life, nearly in as high a degree as the nations of the neighbouring continent. They are a quiet inoffensive people ; very grave, temperate, and frugal. Their bodies partake of the ease of their minds, and it is with reluctance they are roused to any active exertion. Wheir, however, necessity obliges them to apply to any work, such as cultivating the land, they can undergo a great deal of labour.

They use boats, hollowed out of the trunks of trees, about twelve or fourteen feet long, but only as many inches broad within. The tree part in the bottom is much larger; but when the boat, on account of the size of the tree, is too small, they make a trough on the top of it, square at both ends. Some boats, however, are much larger, being built between two trees, and with these they coast along the sliore; the others are for fishermen.

They are pagans, and though they acknowledge a supreme God, they worship none but the inferior sort, among whom they reckon the sun and moon. In their temples are images well executed, though their figures are monstrous; some are of silver, copper, \&c. The different gods have various priests, who have all some privileges. The houses are small and low, with walls made of hurdles, smoothly covered with clay, and roofs thatched. They have lio chimneys, and their furniture is only a few earthen vessels, with two copper basons, and two or three stools, none but the king being allowed to sit in a chair. Even the most affluent have no other clothes than cuarse linen wrapped about them. Their food is generally rice and salt, and their common drink water, which they pour into their mouths out of a vessel like a tea-pot, through the spout, never touching it with their lips.

\section{INHABITANTS OF OTAHEITE.}

THE inhabitants of Otaheite are a stout, well-made, active, and comely people. The stature of the men in general is from five feet seven to five feet ten inches: the tallest men seen by Captain Wallis measured six feet three and a half inches; and Captain Cook, in his second voyage, describes $\mathrm{O}$-Too, the king of Otalieite, to be of that height. They are of a pale brown complexion ; in general, their hair is black, and finely frizzled; they have black eyes, flat noses, large mouths, and fine white teeth; the men wear their beards in many fashions, but all of them pluck out a great quantity of it; they have prominent bellies. The women, in genèral, are much smâller, especially. tho es of the lower ranks.

Their skin is most delicately smooth and soft; they have no colour 
in their cheeks ; their nose is generally somewhat flat, but their eyes are full of expression, and their teetli beautifully even and white. "The women," says MV. de Bougainville, "have features not less agreeable than the generality of Europeans; and a symmetry of body, and beatiful proportion of limbs, which might vie with any of them? Somelhave their hair brown, red, or flaxen, in which they are exceptions to all the nations of Asia, Africa, and America, who have their hair black universally; here, in the children of both sexes, it is genejally flaxen. The strongest expression is painted in the countenances of these people; their walk is graceful, and all their motions are performed with great vigour and ease. The men of consequence on the island wear their nails long, as a badge of distinction. "The women always cut their hair short round their heads. Both sexes have a cus. tom of staining their bodies, which they call tattowing, and both men and women have the hinder part of their thighs and loins marled very thick with black lines, in various forms. These marks are made by striking the teeth of an instrument, somewhat like a comb, just through the skin, and rubbing into the punctures a kind of paste, made of soot and oil, which leaves an indelible stain. Both sexes are gracefully clothed, in a white cloth made of the bark of a shrub. Their dress consists of two pieces of this cloth; one of them, having a hole in the middle to put the licad through, hangs from the shoulders to the middle leg, before and behind; another piece, between four and fie yards long, and about one broad, they wrap round the body; this cloth is made, like paper, of the macerated fibres of the inner bark, spread out and beaten together. "Their ornaments are feathers, flowers, pieces of shell, wid pearls; the pearls a re worn chiefly by the women. In wet weather they wear matting of different kinds, as their cloth will not bear wetting:

\section{Funeral Ceremonies in Otaheite.}

Captain Cook has given the following account of these ceremonies, "When one of them died, they placed the corpse in the open air till the bones were quite dry; a shed was erected close by the house where the deceased had resided; it was about fifteen feet long and eleven broad: one end was left quite open ; the other, and the two sides, were partly enclosed with a sort of wicker-work. The bier was a frame of wood, like that on which the sea-beds, called cots, are placel, with a matted bottom, supported with four posts, at the height of about four feet from the ground. The body was covered first with a mat, and then with white cloth; by the side of it lay a wooden mace, one of their, weapons of war; and near the head of it, which lay next to the close end of the shed; lay two cocoa-nut shells; at the other end a bunch of green leaves, with some dried twigs, all tied together, were stuck in the ground, by which lay a stone as big as a cocoa-nut? Near these lay one of the young plantain leaves that are used for enblems of peace, and close by it a stone axe. At the other end of the shed also hung, in several strings, a great number of palm-nuts, and without the shed /was stuck up in the ground a stem of a plaitain tree, about six fent high, upon the top of which was placed a cocoa-mut- 
shell full of fresh water Against the side of one of the posts hung a small bag, containing a few pieces of bread-fruit ready roasted. The food so placed by the corpse was designed as an offering to their gods. They cast in near the body, small pieces of cloth, on which the tears and blood of the mourners have been shed; for in their pas roxysm it was an universal custom to wound themselves with a shark's tooth. The chief mourner must always be a man, and be dressed in a very singular habit. When the bodies are stripped of their fleshy and becomedry, they are buried.

As soou as a native of Otaheite is dead, the house is filled with relations, who deplore his loss; some by loud lamentations, some by less clamorous, but more genuine expressions of grief Those who are in the nearest degree of kindred, and are affected by the event, are silent; the rest are one moment utiering passionate exclat inations in chorus, and the next laughing and talking without the lease appearance of concern. 'In this manner the renainder of the day on which they assemble is spent, and all the succeeding nighton on the next day the body is shrouded in a cloth, and conveyed to the sea-side on a bier, which the bearers support upon their shoulders, attended by the priest, who, having prayed over the body, repeats his sentences during the procession. When it arrives at the water's edge, it is set down upon the beach; the priest renews, his prayers, and, taking: up some of the water in his hands, sprinkles it towards the body, but not upon it. It is then carried back forty or fifty yards, and soon after brought again to the beach, where the prayers and sprinkling are repeated. It is thus removed backwards and forwards several times; and while these ceremonies have been performing, a house has been built, and a small space of ground railed in. In the centre of this house, or tupapow, posts are set up to support the bier, which is at length conveyed thither, and placed upon it; and here the body remains to putrefy till the flesh is wasted off the bones.

As soon as the body is deposited in the tupapow, the women assemble, and are led to the door by the nearest relation, who strikes a shark's tooth several times into the crown of the chief mourner's head; the blood copiously flows, and it is carefully received upon the pieces of linen, which are thrown under the bier. The rest of the women follow this example: and the ceremony is repeated at the interval of two or three days, as long as the zeal and sorrow of the parties hold out. The tears also, which are shed upon these occasions, are received upon pieces of cloth, and offered as oblations to the dead.

Whilst these ceremonies are carrying on by the women, the ments seem to be wholly insensible of their loss; but two or three days after, they also begin to perform a part. The nearest relations talse it in turn to assume the dress, and perform the offices. The chief nourner carries in his hand a long flat stick, the edge of which is set with shark's teeth, and in his frenzy, which his grief is supposed to have inspired, he runs at all he sees, and if any of them happen to be over taken, he strikes them most unmercifully with his indented cudgel, d which cannot fail to wound them in a dangerous manner. The prodle cession continues at certain intervals for five moons; but are less and less frequent, by a gradual diminution, as the end of that time ap 
proaches. The mourning, which is worn here, is a head-dress of feathers, the colour of which is consecrated to Death, and a veil over the face. The whole nation is said to appear this on the death of their king. The mourning for fathers is very long. The women mourn for their husbands, but not the husbarid for their wives.

Of late years, since their more frequent intercourse with Europeans, the manners and customs of these islanders have undergone a considerable change. The introduction of Christianity among them has also wrought an essential change in their character. The preceding accounts must therefore be understood to refer to the Otaheiteans as they appeared when Captain Cook first visited their shores.

\section{Ostiacks.}

THese are a people of Asia, in Siberia. They live upon the banks of the Oby and Jenisay, and some other rivers which fall into these. They are poor and very lazy, and in summer live mostly upon fish. They are of a middle size, with broad faces and noses, and yellowish or red hair. All their garments, from top to toe, are made of fish skins, for they have neither linen nor woollen, and indeed they might almost as well go naked, Their greatest diversion is hunting, and they go together in crowds, with a weapon, like a large knife, fastened in a stick. In summer they take and dry the fish which serve them in winter; and when this season begins, they go into the woods with their bows and arrows, their dogs and nets, to kill sables, ermine, bears, reindeer, eliss, martens, and foxes. Part of the furs of these is paid as a tax to the emperor of Russia, and the rest sold at a stated price to the Russian governors, but sometimes they are allowed to dispose of them to private persons. They chiefly live, through the year, upon venison, wild fowls, fish, and roots ; for they have neither rice nor bread." They drink for the most part water, and it is said they can very well relish a draught of train oil. They are immoderately fond of tobacco, and of swallowing the smoke, which intoxicates them.

In winter they build their huts in woods and forests, where they find the greatest plenty of game, and dig deep in the earth to secure themselves from cold, laying a roof of bark or rushes over their huts, which are soon covered with snow. In summer they build above ground, on the banks of the rivers, to enjoy the convenience of fishing, and make no difficulty of forsaking their habitations.

They have a sort of princes among them, in one of whose houses some European travellers found four wives. One of these had a red cloth coat on, and was set off with all sorts of beads. They may have as many wives as they please, and make no scruple of marrying their nearest relations. They purchase a wife of her relations for three or four reindeer, returning her again if they do not like her, only losing what they gave for the purchase. Upon the birth of their children, some give them the name of the first thing they happen to see afterwards; others call their childien according to the order of their birth, as First, Second, Third, \& $c$ c. 
They have no other furniture than cradles and chests, joined together with the bark of trees. Their beds consist of wood shavings, almost as soft as feathers, and their chilaren lie naked upon them in cradles. They can neither read nor write, nor do they cultivate the land; and they seem totally ignorant of times past. Their boats are also made of the bark of trees sewed together, and their religion is pagan. They have some little brazen idols, tolerably well cast, representing men and animals, made of wood and earth, all of which are dressed in silks, in the manner of Russian ladies. To these they sometimes offer a beast or fish in sacrifice, and are persuaded that the saint or hero, represented by the image, always attends their sacrifices, and, when over, returns to his abode in the air. The Ostiacks are obliged to take an oath of fidelity, or rather inprecation, to the Russian government.

\section{ACRIDOPHAGI.}

THIS word signifies Locust-eater, and was used to distinguish an ancient people of Ethiopia, who inhabited near the deserts and fed on locusts. Diodorys Siculus describes these people as being short of stature, meagre, and extremely black. "They were so short-lived, that their lives never exceeded forty years, and they generally died a wretched death. In their old age, winged insects of different forms bred in their bodies, beginining in the breast and belly, and soon spreading through the whole frame. The patient at first felt an itching, and the agreeable sensation produced by scratching occasioned these vermin, forcing their way ont, to be accompanied by effusions of corrupt blood, with excruciating pains in the skin. The sufferer, with lamentable cries, was industrious himself to make passages for them with his nails. At length he expired, covered with numberless ulcers. In spring, when the warm west winds drive swarms of locusts among the Acridophagi, they set fire to wood and other combustibles, in a steep and large valley, when in their flight locusts passing oyer it, were suffocated by the smoke. They are immediately cullected in heaps, and salted for use."

Pliny represents the Parthians as feeding on locusts. Elian says, they were sold in Egypt for food, which is corroborated by the testimony of yarious Greek authors Hasselquist, who vsited Syria and Egypt in the year 1752 , with a view to improve natural history, informs us that he asked some Franks, and many others who had lived long in these countries, whether they had ever heard that the inhabitants of Arabia, Ethiopia \&c. used locusts as food? They answered in the affirmative. To the same questions, the Armenians, Copts, and Syrians, who lived in Arabia, and had travelled in Syria, and near the Red sea, gave a similar answer. A learned scheik at Cairo, who had lived six years in Mecca, mentioned, that a famine frequently rages at Mecca, when there is a scarcity of corn in Egypt, which obliges the inhabitants to live upon coarser food than ordinary, and that when corn is scarce, the Arabians grind the locusts in handmills, or stone mortars, and bake them into calies, and use these in place of bread. 
Sparrman informs us, that locusts afford a high treat to the remote hordes of the Hottentots; when, as sometimes happens, after an interval of eight, ten, fifteen, or twenty years, they make their appearance in incredible numbers. At these times they come from the north, migrating to the southward, and do not suffer thenselves to be impeded by any obstacles, but fly boldly on, and are drowned in the sea, whenever they come to it. The females of this race of insects, which are most apt to migrate, and are chiefly eaten, are sail not to be able to fly ; partly by reason of the shortness of their wings, and partly on account of their being heavy and distended witheggs; and shortly after they have laid these in the sand, they are said to die. It is particularly of these, that the Hottentots make a brown coffee-coloured soup, which at the same time acquires from the eggs a fat and greasy appearance. The Hottentots are highly rejoiced at the arrival of these locusts, though they are sure 1o destroy every bit of verdure on the ground; but they make ample amends for this loss, by falling foul upon the animals thenselves, eating them in such quantities, as, in the space of a few days, to get visibly fatter, and in better condition than before.

Dr. Shaw observes, that the Jew's were allowed to eat them, and that when they are sprinkled with salt, and fried, their taste resembles that of onr fresh-water crayfish; and Russcll says, the Arabs salt and eat them as a delicacy. These accounts sufficiently explaiu the scriptural statement respecting the food of John the Baptist in the wilderness, Matt. iii. 4. Some, indeed, naintain that the original , word signifies the tops of certain herbs, or the fruits of certain trees; others have supposed that it means quails; but Shaw contends that it is applied to the locust on account of its appetite for such food. The word is used by Aristotle and other historians in the same sense; and therefore the literal interpretation of the word may be received. In addition to the authors cited above, consult Strabo, lib. xvi.-Agathareides Perip. de Rubro Mari.-Athenzens, lib. xlix.Plin. Nat. Hist. lib. vi. and xi.-Hieronysis' Opera, tom. iv.-Niebuhr's Descrip. de l'Arabie._-Barrow's Travels, vol. i. - Drake's Voyages.-Buffon's Nat. Hist. vol. vi.-Bryant on the Plagnes of Egypt, art. Locusts.-Harmer's Observations, vol. ii.-Calmet's Dictionary.

Manners and Cinaracter of the Citizens of New-England.

THE New-Englanders are generally tall, stout, and well built. They glory, and with justice, in possessing that spirit of freedom which induced their ancestors to leave their native country, and to brave the dangers of the ocean, and the hardships of settling in a wilderness. Their education, laws, and situation, serve to inspire them with high notions of liberty. Their jealousy is awakened at the first appearance of an invasion of their rights. A law, respecting the descent of estates, which are generally held in fee simple, which for substance is the same in all the New England states, is the chief foundation and protection of this liberty. By this law, the possessions of the father are to be equally divided among all the children, excepting the eldest 
som who has a double portion In this way is preserved that happy nediocrity among the people, which, by inducing economy and industry removes from them temptations to luxury, and forms them tor habits of sobriety and temperance At the same time, their industry and frugality exempt them from want, and from the necessity of submitting to any encroachment on their liberties.

10 In New England, knowledge is more generally diffused among all ranks of people than in almost any other part of the globe, arising from the extensive establishment of schools in every township. Another source of information is the newspapers, of which no less than thity chousand are printed every week in New England, and circulated in almost every town and village in the country. A person of mature age, who cannot both read and write, is rarely to be found $\mathrm{By}$ means of this general establishment of schools, the extensive circulation of newspapers, and the consequent universality of information, every township throu hout the country is furnished with men capable of conducting the affairs of their town with judgment and discretion. These men are the channels of political information to the lower class of people, if such a class may be said to exist in New England, where every man thinks himself at least as good as his neighbour, and believesi that all mankind are, or at least ought to be, equal The citizens from their childhood form habits of canvassing public affairs, and commence politicians, which naturally leads them to be very inquisitive. This desire of knowledge in a greater on less degree prevails throughout all classes of people in New England and from their various modes of expressing it, some of which are blunt and familiar, bordering on impertinence, strangers have been induced to mention impertinent inquisitiveness as a distinguishing characteristic of the people.

gd Each man also has his independent systern of polities, and each assumes a dictatorial office. Hence originates that restless, litigious, complaining spirit, which forms a dark shade in the character of New-Englaudmen. Before the American war, which introduced into New England a flood of corruptions with many improvements, the sabbath was observed with great strictness ; no unnecessary travelling, no secular business, no visiting nor diversions, were permitted on that sacred day. But since the war, a catholic tolerant spirit, occasioned by a more enlarged intercourse with mankind, has greatly increased, and is becoming universal.

- There is one distinguishing characteristic in this people,-the custom of annually celebrating fasts and thanksgivings. The people of New England generally obtain their estates by hard and persevering labour; they of consequence know their value, and spend with frugality. Yet in no country do the indigent and unfortunate fare better. Their laws oblige every town to provide a competent maintenance for their poor; and the necessitous stranger is protected and relieved' by their humane institutions. In no part of the world are the people happier, better furnished with the necessaries and conveniencies of life, or more independent, than the farmers in New Eugland. As the great boidyl of the people are hard independent freeholders, their manners are congenial to their employments, plain, simple, and unpolished, 
Strangers are received and entertained among them with a great dea. of artless sincerity, and friendly, unformal hospitality, and remark with pleasure the honest and decent respect that is paid them by the children, as they pass through the country.

Many of the women in New England are handsome. They gene-rally have fair, fresh, and healthful countenances, mingled with much female softness and delicacy. Those who have had the advantages of a good education, and they are very numerous, are genteel, easy, and agreeable in their manners, and are sprightly and sensible in conversation. They are easily taught to manage domestic concerus with neatness and economy. Ladies of the first fortune make it a part of their daily business to superintend the affairs of their family. To be employed at the needle, in cookery, and at the spinning wheel, with them is honourable: idleness, even in those of independent fortunes, is universally disreputable. The women in the country, manufacture the greatest part of the clothing of their families.- Their linen and woollen cloths are strong and decent. Their butter and cheese is not inferior to any in the world. "Dancing is the principal and favourite amusement in New England. Gaming is practised by none but those who cannot, or will not, find a reputable employment. The gamester, the horse-jockey, and the knave, are equally despised, and their company is avoided by all who would sustain fair characters.

The odious and inhuman practice of duelling, gouging, cockfighting, and horse-racing, are scarcely known. The athletic and healthy diversions of cricket, football, quoits, wrestling, jumping, foot-races, $\& c$. are universally practised in the country, and some of them in the most populous places, and by people of almost all ranks. Squirrelhunting is a noted diversion in country places, where this game is plentiful. Some divert themselves with fox-hunting, and others with the more profitable sports of fishing and duck-hunting; and in the frontier settlements, where deer and game abound, the inhabitants make a lucrative sport of hunting them. In winter, when the ground is covered with snow, which is commonly two or three months; sleighing is the general diversion. A great part of the families throughout the country are furnished with horses and sleighs.

\section{Celtiberians.}

THE inhabitants of Celtiberia were very brave and warlike; their cavalry in particular was excellent. They wore a black rough cloak, the shag of which was like goats' hair. Some of them had light bucklers, like the Gauls ; others hollow and round ones, like those of other nations. They all wore boots made of hair, and iron helmets adorned with crests of a purple colour. They used swords which cut on both sides, and poniards of a foot long. Their arms were of an admirable temper, and are said to have been prepared in the following manner; they buried plates of iron under ground, where they let them remain till the rust had eaten the weakest part of the metal, and the rest was consequently hard and firm. Of this excellent iron they made their swords, which were so strong and well-tempered, that there was neither buckler nor helmet that conld resist their edge. The 
Celtiberians, were very cruel towards their enemies and malefactors, but shewed the greatest humanity to their guests They not only cheerfully granted their hospitality to strangers who travelled in their country, but were desirous that they should seek protection under theirroof.

\section{agnand the}

These are the inhabitants of Bissao, an African island. The men of Pissao wear only a skil fixed to the girdle, before and behind. The dress of the married women consists of a cotton petticoat; but virgins go entirely naked, wearing only bracelets of different kinds on their arms and legs. If they are of high quality, their bodies are painted with various, hideous forms of snakes, \&c. which, as their colour is jet black, gives their skins somewhat the appearance of a flowered satin. Even the princess-royal herself, the eldest daughter of the emperor, is only distinguished from the other women by the elegance of those paintings, and the richness of her bracelets.

One very extraordinary ornament is a large iron ring with a flat round surface on the outside, instead of a stone, npon which they ring changes, with a bit of iron, in such a manner as to converse with the greatest facility by means of the different sounds produced; but this kind of language is used only among the polite and great.

(All the Bissaons are idolaters, nor has commerce introduced the smallest change in their manners; but their ideas of religion are exceedingly confused. Their chief idol is a little image called China, of which the worshippers give very absurd accounts; but besides this, every man invents a god for himself; trees are held sacred, and if not adored as gods, are worshipped as the residence of sume divinity.

The government is despotic, the will of the emperor being a law to his people. Of this we have an instance in Bissao, not to be matched in any other country whatever. Any subject may make a present of the estate of his neighbour to the emperor; and as such presents are generally accepted, the proprietor dares not resist, but immediately sets about building another house; though even this he cannot do without the prince's leave, and if this should not be readily granted, he must live with his family in the open air, till permission to build a new house can be obtained.

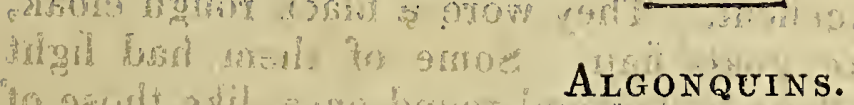

A NATION in North America, who formerly possessed great tracts of laud along the north shore of the river St. Lawrence. For a long time they had no rivals as hunters and warriors, and were in alliance with the Iroquois, whom they agreed to protect from all invaders, and to give them a share of their venison. The Iroquois, on the other hand, paid a tribute to their allies out of the culture of the earth, and verformed for them all the menial services of slaying the game, curing the fish, and dressing the skins. By degrees however. the Iroquois associated in the hunting matches and warlike expedi 
tions of the Algonquins; so that they soon began to fancy themselves as well qualified, either for war or hunting, as their neighbours The Algonquins having murdered a hunting party of the Iroquois out of jealousy at their success, the latter, after trying their prowess on other inferior nations, attacked the Algonquins with such diabolical fury, as shewed that they could be satisfied with nothing less than the extermination of the whole race; which, had it not been for the interposition of the French, they would have accomplished. The few Algonquin nations that are now to be seen, seem entirely ignorant of agriculture, and subsist by fishing and hunting. They have a plurality of wives; notwithstanding which, they daily decrease in population, few or none of their communities containing above six thousand souls, and many of them not two thousand.

\section{Inhabitants of Oinhyiez.}

THe men are above the middle size, stout, well-made, and fleshy but not fat. Their colour is brown olive. The women are in general inasculine, but there are some exceptions. The features of both sexes are good, and some of the females are really fine women. They are very healthy, and some live to a gieat age. They are all thieves, without exception. (The custom of tattowing prevails greatly among them, but the men have a much larger share of it than the women. Both men and women are very cleanly in their persons; the latter wash their bodies twice, and sometimes three times, a day. Their clothing consists of cloth of different kinds : that worn by the men, which is called marro, is about half a yard wide and four yards long, and that of the women, three-quarters of a yard wide, and of the same length as the men's; this they called pah-o-ouwa; they both wear it round the middle, but the men pass it between their legs. This is the general dress of both sexes; but the better sort sometimes throw a large piece loosely over their shoulders. Besides the marro, they have several other kinds of cloth; all, however, are made from the Chinese paper-mulberry tree. The principal of these is the cappa, which is about ten or twelve feet long, and nearly as many wide, and is thick and warm; they wrap themselves up in this when they retire to sleep. They have another kind, which is white, and much thinner; it is sometimes twenty or thirty yards long, and wide in proportion. The marro and pah-o-ouwa are curiously painted, of various patterns; but the others are generally white, or dyed red, black, and yellow. The principal ornaments of the men are feather caps and cloaks. They have also a kind of fly cap, made of a bunch of feathers, fixed to the end of a thin piece of polished wood; the handle is very frequently made of the bones of the arm or leg of those whom they have killed in battle, curiously inlaid with tortoise-shell : these they deem very valuable, and will not part with them under a great price. This ornament is common to the superiors of both sexes.

The ornament which the women value most, is the orai. This is a kind of ruff or necklace, made of red, green, black, and yellow feathers, curiously put together, and in most elegant patteris. Others 
are composed of small variegated shells, and some consist of several rows of twisted hair, with a piece of carved wood or bone, highly polished, the bottom part forming a curve. They have also the joo-remah, or bracelet; the most valuable of which are of boar's tusks, fastened together side by side with a piece of string, by means of a hole drilled through the middle.

Such, at least, was the character, dress, and manners of these islailders, before the missionaries of late years settled among then; since which time, they have made rapid advances in civilization, and have adopted many European customs.

\section{Natives of the Nicobar Islands.}

THESE islands lie in Asia, at the entrance of the gulf of Bengal. The natives are low in stature, but well-made, active, and strong; they are copper-coloured, and their features have a cast of the Malay, quite the reverse of elegant. The women are extremely ugly. The men cut their hair short, and the women haye their heads shaved quite bare, and wear no covering but a short petticoat, made of a sort of rush, or dry grass, which reaches half way down the thigh. This grass is not interwoven, but hangs round the person, sometimes like the thatching of a house. Such of them as have received presents of cloth petticoats from the ships, commonly tie them round immediately under the arms. The men wear nothing but a narrow slip of cloth about the middle. The ears of both sexes are pierced when very young, and by thrusting into the holes large plugs of wood, or hanging heavy shells, they render them wide, and disagreeable to look at. They are naturally goodhumoured, and fond of siting at table with Europeans, where they eat every thing that is set befure them, most enormously. They do not care for wine, but will drink bumpers of arak as long as they can see. A great part of their time is spent in feasting and dancing.

When a feast is held in any village, every one that chooses goes uninvited. At those feasts they eat immense quantities of pork, which is their favourite, food. Their hogs are remarkably fat, being fed upon cocoa-nut kernels and sea water, as indeed all their domestic animals, fowls, dogs, \&c. are. They have also plenty of snall sea-fish, which they strike very dexterously with lances, wading into the sea about knee-deep. They are sure of killing a very small fish at ten or twelve yards' distance. They eat the pork almost raw, giving it only a liasty grilling over a quick fire. They roast a fowl by running a piece of wood through it by way of a spit, and holding it over a brisk fire until the feathers are burnt off, when it is ready for eating, in their taste. They, never drink water, only cocoa-nut milk, and a liquor called soura, which oozes from the cocoa-nut tree after cutting off the young sprouts or flowers. This they suffer to ferment before it is used, and then it is intoxicating; to which quality they add much, in their method of drinking, it, by sucking it through a small straw. 
After eating, the young men and women, who are fancifully dressed with leaves, go to dancing, and the old people surround them, smoking tobacco, and drinking soura. The dancers, while performing, sing some of their tunes, which are far from wanting harmony, and to which they keep exact time. Of musical instruments, they have only one kind, namely, a hollow bamboo, about two and a half feet long, and three inches in diameter, along the outside of which is stretched, from end to end, a single string, made of the threads of a split cane; and the place under the string is hollowed a little, to prevent it from touching. This instrument is played upon in the same manner as the guitar. It is capable of producing few notes; but the performer makes it speak harmoniously, and generally accompanies it with the voice.

Their habitations are generally built upon the beach, in villages of fifteen or twenty houses, each house containing a family of about twenty persons. They are raised upon wooden pillars, about ten feet from the ground; they are round, have no windows, but appear like bee-hives covered with thatch. The entrance is through a trapdoor below, where the family mounts by a ladder, which is drawn up. at night. This manner of building is intended to secure the houses from snakes and rats, and for that purpose the pillars are bound round with a smooth kind of leaf, which prevents animals from mounting, and each pillar has a broad round flat piece of wood near the top of it, the projecting of which prevents the further progress of such vermin as have passed the leaf. The flooring is made of thin slips of bamboos, laid at sucl distances as to leave free admission for light and air ; and the inside is neatly furnished and decorated with fishing-lances, nets, \&c. The art of making cloth is unknown to the inhabitants; but from the ships that come to trade in cocoa-nuts, they purchase a much larger quantity of cloth than is consumed upon their own island. This is intended for the Choury narket.

Choury is a small island south of theirs, to which a large fleet of their bo ats sail every year about November, to exchange clothes for canoes, ior they cannot make these themselves. This voyage they perform by the sun and stars. They have two remarkable qualities: one is, their entire neglect of compliment and ceremony; and the other, their aversion to dishonesty. A Nicobarian travelling to a distant village, upon business or amusement, passes through many towns in his way, without speaking to any one. If he is hungry or tired, he goes into the nearest house, and helps himself to what he wants, and sits till he is rested, without taking the smallest notice of any of the family, unless he has business or news to communicate.

Theft or robbery is so very uncommon a mong them, that a man going out, never takes away his ladder, or shuts his door, but leaves it open to any body to enter that pleases, without the least apprehension of having any thing stolen. Their intercourse with strangers is so frequent, that they have acquired in general the barbarous Portuguese so common all over India; their language has a sound quite different from all others, their words being pronounced with a kind of stop or catch in the throat, at every syllable.

It is said by Mr. Hamilton, that they have no notion of a God, but 
believe firmly in the devil, and worship him from fear. In every village there is a high pole erected, with long strings of ground rattans hanging from it, which, it is said, has the virtue to keep him at a distance. When they see any signs of an approaching storm, they 1magine that the devil intends them a visit, upon which many superstitious ceremonies are performed. The people of every village march round their own boundaries, and fix up at different distances smali sticks split at the top, into which slit they put a piece of cocoa-riut, a whisp of tobacco, and the leaf of a certain plant, either as a peaceoffering to the devil, or a scarecrow to frighten him away. When a man dies, all his live-stock, cloth, hatchets; fishing-lances, and every moveable he possessed, is buried with him, and his death is nourned by the whole village. In one view, this is an excellent custom, as it prevents all disputes about the property of the deceased. His wife must conform to custom, by having a joint cut off from one of her fingers; and if she refuses this, she must have a deep notch cut in one of the pillars of her house.

"I was once present," says Mr. Hamilton, "at the funeral of an old woman. When we went into the house, which had belonged to the deceased, we found it full of her female relations; some of whom were employed in wrapping up the corpse in leaves and cloth, and others tearing to pieces all the cloth which had belonged to her. In another house hard by, the men of the village, with others from the neighbouring towns, were sitting drinking soura, and smoking tobacco. In the mean time, two stout young fellows were busy digging a grave in the sand, near the house. When the women had done with the corpse, they set up a most hideous howl, "upon which the people began to assembe round the grave, and four men went up into the house to bring down the body; in doing this, they were much interrupted by a young man, son to the deceased, who endeavoured with all his might to prevent them, but finding it in vain, he clung round the body, and was carried to the grave along with it: there, after a violent struggle, he was turned away, and conducted back to the house. The corpse being now put into the grave, and the lashings, which bound the legs and arms, cut, all the live-stock which had been the property of the deceased, consisting of about six hogs and six fowls, were killed, and flung in above it: a man then approached with a bunch of leaves stuck to the end of a pole, which he swept two or three times gently along the corpse, and then the grave was filled up. During the ceremony, the women continued to make the most horrible vocal concert imaginable; the men said nothing. A few days afterwards, a kind of monument was erected over the grave, with a pole upon it, to which long stripes of cloth of different colours are hung.

Customs, Religion, \&c., of the Natives of Angoy, a King DOM OF AfRica.

THE natives of Angoy allow polygamy, and the best beloved wife has the command of the rest; but is no less liable to be turned out, if she proves unfaithful. The ladies of the royal blood, however, 
have the privilege of choosing their husbands out of any, even the meanest rank, and have even the power of life and death over then, as over their paramours, if any of them are caught tripping: but the husbands are by no means entitled to expect the same fidelity from their royal ladies. Women of the lowest rank are allowed, when they receive strangers, to admit them to disgusting familiarities. This obliged the missionaries who travelled through this country, to give notice, on their approach to any of their heuses, that none of the fenale sex might enter within their doors.

Their religion consists chiefly in a variety of superstitious customs, such as powdering their public and domestic idols with the dust of a kind of red wood, on the first day of the moon, and paying a kind of worship to that planet. If on that night it happens to shine clear and bright, they cry out, "Thus may I renew my life as thou dost;" but if the night is cloudy, they imagine the moon has lost her virtue, and pay her no respect. We do not hear of their offering any sacrifices to their idols, though they commonly consult them about the success of their enterprises, thefts, or the like. The king of Congo still styles himself sovereign of Angoy; but the king of this little state pays neither tribute nor honour to any foreign power.

\section{Comeans.}

THESE are the natives of Corea, a country near China. The Coreans are well made, ingenious, brave, and tractable, are fond of dancing, and shew great docility in acquiring the sciences, to which they apply with great ardour, and honour in a particular manner. The northern Coreans are larger-sized and more robust than those of the south, have a taste for arms, and become excellent soldiers. Their arms are cross-bows and long sabres. Men of learning are distinguished from other classes of people by two plumes of feathers in their caps; and when merchants present the Coreans with any books for sale, they dress thenselves in their richest attire, and burn perfumes, before they treat concerning the price. 'The Coreans mourn three years, as in China, for a father or a mother, but for a brother only three months. The dead are not interred until three years after their decease, and when the ceremony is performed, they place around the tomb the clothes, chariots, and horses of the deceased, with whatever else he shewed the greatest fondness for while alive, all which they leave to be carried off by the assistants. Their houses consist only of one story, and are very ill built-in the country being composed of earth, and in cities generally of brick, but all thatched with straw. The walls of their cities are constructed after the Chinese manner, with square turrets, battlements, and arched gates. Their writing, dress, religious ceremonies, and creed, as well as the greatest part of their customs, are borrowed from the Chinese. Their women, however, are less confined, and have the liberty of appearing in public with the other sex, for which they are often ridiculed by their neighbours. They differ from the Chinese also in their ceremonies of marriage, and in the manner of contracting it; the parties in this country taking the liberty to choose for themselves, without consult- 
ing the inclinations of their parents, or suffering them to throw any obstacle in the way.

NuBA.

THIS is the name of a race of black pagans in the neighbourhood of Sennaar. Mr. Bruce passed a day or two among them, in his way from Abyssinia; and he tells us that they are all soldiers of the Mek, or king, of Sennaar, cantoned in villages, which to the distance of four or five miles surround the capital. They are the aborigines of that part of Africa, but " are either purchased or taken from Fazulco, and the provinces to the south, upon the mountains Dyre and Tegle." Though the slaves of a cruel and treacherous master, Mr. Bruce represents them as a gentle, honest, and hospitable people; and he says that, on a journey, he had seldom passed a more comfortable night, than one in which he took refuge from a storm in a village of these Nuba. He had a good supper, and a clean neat hut to sleep in, while some of the Nuba watched for him all night, and took care of his beasts and his baggage. Having settlements and provisions given them by the government of Sennaar, as also arms put into their hands, they never wish to desert, but live a very domestic and sober life, and are a much gentler sort of negroes than their masters. Though the established religion of Sennaar is that of Mahomet, the government has never attempted to convert the Nuba. On the contrary, a certain number of pagan priests is maintained for them in every village, who have soldiers in pay to assist them in the affairs of their religion. This is a very singular instance of toleration among Mahometans, and what we should little have expected from such barbarous and sanguinary twretches as those who have the supreme power in Sennaar. ensthe idolatry of the Nuba is described as a mixture of Sabiism and idol-worship; but it is singular that their worship is chiefly paid. to the moon, while they pay no attention to the sun, rising or setting, advancing to the meridian or receding from it. They worship likewise a tree and a stone; but our author could never discover what tree or stone, only he learned that neither of them exists in Sennaar, but in the country where the Nuba are born. Such of them as are natives of the villages where he saw them, became, like their masters, nominal Mahometans; the rest practise the idolatrous worship of their ancestors, and are much under the influence of their priests, from fear rather than from affection. They are immoderately fond of swine's flesh, and maintain great herds of small hogs, marked with black and white spots. Few of the Nuba advance higher than to be soldiers and officers in their own corps; and the Mek maintains about twelve thousand of them near Sennaar, to keep the Arabs in subjec. tion. In a climate so hot as that which they inhabit, there is very little need of fuel; and it is happy for them that such is the case, for in the whole country there is not a single tree, nor turf, nor any thing resembling it. They do not, however, eat their meat raw like the Abyssinians; but with the stalk of the dora or millet, and the dung of camels, they make ovens under ground, in which they roast their hogs whole, in a very cleanly manner, keeping the skins on till they are perfectly baked." 


\section{Houzouanas.}

Tils is the name of a wandering nation of -Africa. When M. Vaillant was at the Cape, he was informed that this people formerly inhabited the country of Camdebo, the Snowy Mountains, and the district between them and Caffraria, and that they lived on peaceable and friendly terms with the European planters, till a set of lawless banditti, sent from Holland, subjected them to bondage, repaid their most laborious services with harsh treatment, and, when the Houzouanas fled to the mountains for refuge, pursued and massacred them like wild beasts; that on this they removed to the land which they now possess, but, enraged at their tyranny, swore in their own name to be revenged on these European monsters. "And thus," adds he, "if tradition says true, was a peaceful and industrious nation rendered warlike, vindictive, and ferocions;" and their hatred to the planters is perpetuated. Their courage and predatory habits rendered them the dread of the surrounding tribes: yet a Hottentot, who had lived many years among them, assured M. Vaillant, "that they are by no means murderers by profession; that they take up arms only to make just reprisals; that they live entirely by hunting; and that though they sometimes rob when provisions fail, they never kill except in retaliation."

On the whole, they appear in many respects to resemble the Arabs, being, like them, brave, and addicted to rapine, but so unalterably faithful to their engagements, that they will defend to the last drop of their blood the traveller who purchases their service, and puts his confidence in them for protection. In M. Vaillant's opinion, " if it be at all practicable to travel from south to north through Africa, it can only be under the conduct of the Houzouanas;" and he thinks tifty men of their brave, temperate, and indefatigable nation, will be sufficient to protect an enterprising European through that long and hazardous journey. "He describes these people as so superior to the other natives of South Africa, that, though of low stature, (a persen five feet four inches high being among them counted very tall,) yet in their well-proportioned little bodies are united surprising strength and agility, with a certain art of assurance, boldness, and haugitiness, which awes the belıolder. Of all the savage races, M. Vaillant saw - none that appeared endowed with a mind so active, and a constitution so hardy. He also celebrates them as affectionate parents and husbands. As to their persons, their heads, though they resemble those of the Hottentots, are rounder towards the chin. They are not so black, but have rather the leai-coloured complexion of the Malays. Their hair is more woolly, and very short. Their noses are flatter, which makes their faces have a bad profle; although their eyes are so large and lively, and their features so expressive, that their countenances are on the whole agreeable.

The clinate being hot, they go almost entirely naked all the year, except that they have a piece of jackal skin fastened round the loins. They often sleep on the bare ground, they sometimes stop in fertile places, and erect a kraal, or temporary village, in which case they have no private property, but enjoy all things in common. 
When two of their hordes meet, the reception is friendly on both sides, and they treat each other as brethren, though they have never seen each other before. When they emigrate from these kraals, they leave their huts standing, that other tribes who travel that way may make use of them. Active and nimble, they climb the highest mountains and most dangerous rocks. They conducted $M$. Vaillant, with his servants and cattle, over precipices, which he and his Hottentots Without their aid would have reckoned absolutely impassable. Their only arms are bows and arrows, which they use with great expertness. Nocturnal fires are a kind of telegraph, which they have brought to great perfection, and, by varying the number and form of which, they announce to their distant friends a victory or defeat, an arrival or departure, a successful expedition, or the want of assistance.

Among their physical peculiarities, M." Vaillant describes "an enormous natural rump of the women, which distinguishes them from all other people." But this rump we suspect not to be natural, any more than the little feet of the Chinese women, but the effect of art; for he adds, that when the women have children too young to follow them, they place them on this rump, and that he has seen one of these women run with a child of three years old, that stood erect on its feet at her back, like a foot-boy behind a carriage." The utility, therefore of such an artificial pad, to women who travel without clothing, is self-evident, and accounts for its formation and continuance.

Character, Complexion, Manners, and Religion of the CONGOESE.

Congo is a country of Africa. There is scarcely a nation on earth that have a higher opinion of themselves or their country, than the Congoese, or that is more hardened against all conviction to the contrary, from reason, experience, or comparison with other countries in Europe and $\mathbb{A}$ sia. Indeed, it is impossible they should think otherwise, when it is one of the fundamentals of their belief, that the rest of the world was the work of angels, but that the kingdom of Congo, in its full and ancient extent, was the handiwork of the Supreme Architect; and of course has vast prerogatives and advantages over all others. When told of the magnificence of the European and Asiatic courts, their immense revenues, the grandeur of their palaces and edifices, the riches and happiness of their subjects, the great progress they have made in the arts and sciences, to which their country is wholly a stranger, - they coolly answer, that all this comes vastly short of the dignity and splendour of the kings and kingdom of Congo; and that there can but be one Congo in the world, to the happiness of whose monarch and people all the rest were created to contribute, and to whose treasury the sea and rivers pay their constant tribute of shells, which are their current coin; whilst other princes must condescend to enrich themselves by digging through rocks and mountains, to come, at the excrements of the earth,-so they style gold and silver, which are in such great request 
among other nations. Accordingly, they imagine that the natives who come to traffic with them, are forced to that servile employment by their poverty, and the badiess of their own country, whilst they themselves can indulge their natural indolence, though attended with the most pinching poverty, rather than disgrace their blood by the least effort of industry, which, how laudable and beneficial soever, is looked upon by them as only a lesser degree of slavery.

But though they generally esteem it below their dignity to apply to auy useful work, they think it no disgrace to beg or steal. With respect to the first, they are said to be the most shameless and importunate beggars in the world: they will take no denial, spare no crouching, lying, or prayers, to obtain what they want; nor curses and ill language, when sent away without it. With regard to the last, it is rather robbery than theft, for they deem no abstraction of property unlawful or scandalons, except it be committed in a private manner, without the knowledge of the person wronged. It is esteemed a piece of bravery and gallantry to wrench any thing from another by violence; and this is so common, not only among the vulgar, but also among the great ones, that they make no scruple, in their travels from place to place, to seize not only upon the provisions they meet with in villages and towns, but upon every thing else that falls in their way. These violences oblige the poor people to conceal the few valuables they have, in some secret places, out of the knowledge of those harpies; and they think themselves well off if they escape a severe bastinading, to make them discover the place of their concealment.

The complexion of the natives is black, though some are of a much deeper black than others. Their bair is black, and finely curled; some have it also of a dark sandy colour; their eves are mostly of a fine lively black, but some of a dark sea-colour. They have neither flat noses nor thick lips, like the other negroes. Their stature is mostly of the middle size, and, excepting their black complexion, in their persons they much resemble the Portuguese. In temper they are mistrustful, envious, jealous, and treacherous; and where they once take an afront, will spare no pains, nor stick at any means however base, to be avenged of, and crush their enemy under their feet. "They are said to be destitute of natural affection. A husband, if a heathen, may take as many wives as he pleases; and if a Christian, may have a number of concubines, whom he may divorce at pleasure, or even sell them, though with child. So little regard have they for their children, that there is scarcely one among them who will not sell a son or a daughter, or perhaps both, for a piece of cloth, a collar or girdle of coral or beads, and often for a bottle of wine or brandy.

The Congoese, like most of the other African Indians, are extremely indolent. To this is to be ascribed the little produce they reap from their lands; while the Portuguese, settled among them, who are at more pains in the cultivation of theirs, enjoy all manner of plenty. The natives, however, had rather run the risk of the most terrible famines, than be at the tenth part of the labour they see the Portuguese take. They seem to think it below them to use any other exercises than those of dancing, leaping, hunting, shooting, dac.; the rest of their time they spend in smoking, and downight idleness, com- 
mitting the laborious part of their household affairs to their slaves, or, in want of them, to their wives. Nothing is more common than to see these poor creatures toiling in the fields and woods, with a child tied to their backs, and fainting under their excessive burdens and heavy Jabour, or, which is still worse, hunger and thirst. What is yet more urprisingly shameful is, that though they have plenty of domestic animals, which they might easily make use of for laborious services, and though they see the Portuguese do it every day to great advantage, yet they will rather see their tender females sink under their toil and labour, than take the trouble of breeding up any of those useful creatures to their assistance.

The religion of the Congoese in many parts is downright idolatry, accompanied with the most ridiculous supersitions, and the most absurd and detestable rites, invented by their gaugas or priests ; and even in those parts where Christianity is professed, it is exceedingly darkened by superstitions of one kind or another.

\section{BourguIgNoNS, OR BURGUNDIANS.}

THESE are a northern nation, which, with others, overran the Roman empire, and settled in Gaul. They were of great stature, and very warlike, for which reason the emperor Valentinian the Great engaged them in his service against the Germans. They lived in tents close to each other, that they might the more readily unite on any unforeseen attack. These conjunctions of tents they called burghs, and they served them for towns. Sidonius Apollinarius tells us, that they wore long hair, took great pleasure in singing, and were fond of praise for their vocal talents. He adds, that they were great gluttons; and anointed their hair with butter, deeming that unction very ornamental. Their crown was at first elective, and the authority of their kings depended on their success. They were answerable not only for their own misconduct, but likewise for the calamities of nature and fortune. They were deposed if they lost a battle, if they succeeded ill in any enterprise, or if, in short, any great event had not correponded with the hopes of the people. They were not more favourabiy treated in case of a bad harvest or vintage, or if any epidemical distemper ravaged the state. At first they were governed by many kings, and Hendin was the title of the royal dignity: but in later times they were subjected to one sovereign; and on the introduction of Christianity, they grew bumane and civilized. Before that epocha, their religion was much the same with that of the other northern nations. They had many priests, the chief of whom was entitled Sinistrus : he was perpetual, and they paid him great respect.

\section{Polygars.}

The Polygars are natives of Hindoostan: they inhabit almost impenetrable woods, and are under the absolute direction of their own chieftains. In times of peace they are professionally robbers, but in times of war are the guardians of the country. The general name of 
these people is Polygar. Their original institutions, for they live in distinct clans, is not very well understood. It probably took its rise from the municipal regulations relative to the destruction of tigers and other ferocious beasts. Certain tracts of woodland were indisputably allotted as rewards to those who should slay a certain number of those animals; and those lands approximating, probably laid the foundation of the several conferleracies of Polygars. The pollams, or woods, from which is derived the word Polygar, lying in profusion through all the southern parts of Hindoostan, the ravages committed in the open countries by these adventurous clans, are both frequent and destructive. Cattle and grain are the constant booty of the Polygars. They often despoil travellers of their property, and sometimes murder, if they meet with opposition; yet these very Polygars are the hands into which the aged and infirm, the wives, children, and treasure of both Hindoos and others, are entrusted, when the circumjacent country unfortunately happens to be the seat of war. The protection they afford is paid for; but the price is inconsiderable, when the helpless situation of those who fly to them for shelter is considered, and especially when their own very peculiar character is properly attended to. The native governments of Hindostan are under the necessity of tolerating these honourable banditti. Many of them are so formidable as to be able to bring 15,000 or 20,000 men into the field. There are actually laws among the Hindoos, regulating the shares of these robbers. Mr. Sullivan supposes that the toleration of these robbers is continued by the Hindoolegislature, for the purpose of suppressing the destructive civil wars and depredations, that were apt to take place among the various clans under the rajahs and zemindars.

\section{The Six Nations.}

These are Indians who live on the banks of the Niagara. The following information was communicated to the Royal Society of London by Mr. Richard M'Causland, surgeon to the eighth regiment of foot, who, writing from the best authority, informs us, that each nation is divided into three tribes, of which the principal are called the Turtle-tribe, the Wolf-tribe, and the Bear-tribe. Each tribe has two or more chiefs, called Sachems : and this distinction is always hereditary in the family, but descends along the female line; for instance, if a chief dies, one of his sister's sons, or one of his own brothers, will be appointed to succeed him. Among these, no preference is given to proximity or promogeniture; but the sachem, during his life-time, pitches upon one whom he supposes to have more abilities than the rest; and in this choice he frequently consults the principal men of the tribe. If the successor happens to be a child, the offices of the post are performed by some of his friends until he is of sufficient age to act for himself. Each of these posts of sachem has a name peculiar to it, and which never changes, as it is always adopted by the successor; nor does the order of the precedency of each of these names or titles ever vary. Nevertheless, any sachem, by abilities and activity, may acquire greater power and influence in the nation than those who rank before him in point of precedency; but this is merely tem- 
porary, and dies with him. Each tribe has one or two chief warriors, which dignity is also hereditary, and has a peculiar name attached to it. These are the only titles of distinction which are permanent in the nation, for although any Indian may, by superior talents either as a counsellor, or as a warrior, acquire infuence in the nation, yet it is not in his power to transmit this to his family. The Indians have also their great women, as well as their great men, to whose appearance they pay great deference; and this distinction is also hereditary in families. They do not sit in council with the sachem, but have separate ones of their own. When war is declared, the sachems and great women generally give up the management of public affairs to the hands of other warriors: but a sachem may at the same time be also a chief warrior.

\section{Miserable State of the Peorle of Egypt.}

THE ordinary dress of the Egyptians consists of a shirt of coarse blue linen, and a clumsy black cloak, with a sort of black bonnet over their heads ; and over all they wear a red woollen hand kerchief. Their arms, legs, and breasts are naked, and most of them do not even wear drawers. They live in mud-walled huts of the most miserable construction, where they are exposed to the inconveniences of smoke, heat, and unwholesome air; to all which are to be added the continual fear they live in of being robbed by the Arabs, oppressed by the Mamelukes, or some other grievous calamity. The only conversation is concerning the intestine troubles and misery of the country, murders, bastinadoes, and executions. Here sentence of death is executed without the least delay, or even form of trial. The officers who go the rounds in the streets, either by night or day, are attended by executioners, who carry along with them the leathern bags for receiving the heads they cut off in their expeditions. Even the appearance of guilt is not necessary to infer a capital punishment, for frequently nothing more is requisite than their possession of wealth, or being supposed to possess it. In this case the unfortunate person is summoned before some bey; and "when he makes his appearance, a sum. of money is demanded of him. If he denies that lie possesses it, he is thrown on his back, and receives two or three hundred blows on the soles of his feet; nay, perhaps is put to death without any ceremony. The only security, therefore, of those who possess any wealth, in this country, is to preserve as great an appearance of poverty as possible.

\section{Booshooanas.}

THESE are a tribe in the northern part of Africa; the capital of which, Leetahoo, contains, according to the estinate of commissioners who visited it in 1781, between two and three thousand houses, and from ten to fifteen thousand people. They live almost upon vegetables and milk, notwithstanding which, they are tall and athletic, and are principally shepherds: the women divide their time between agriculture and their family. "The skins of the beasts they kill in hunting, are made up into shoes and cloaks. Their houses are cir- 
cular, about ten feet in diameter; the lower part, for nearly fourfeet, is formed of stone bedded in clay, with wooden spars at certain distances; on the east side a fourth part of each house is left open ; the building is finished with a round pointed rocf, well thatched with long reeds; from the centre to the back, a round apartment is formed, with a narrow top, and in this the head of the family takes his rest, while the others sleep in the front, or between the two circles in the inside. Every house is enclosed with palisales, and in the space formed between the house and railing, their grain and pulse are stored in large vessels, made of baked clay in the form of oil jars, and these are set on tripods, raised about nine inches from the ground, made of the same materials; they are also covered with a round straw roof, supported by poles, and of such a height as to admit a ready entrance to the jars, the tops of which are five or six feet from the ground.

\section{Natives of Gurana, rn Soutu America.}

TEEY are divided into different tribes, more or less enlightened and polished, as they are more or less remote from the settlements of the Europeans. They allow polygamy, and have no division of lands. The men go to war, hunt, and fish, and the women look after domestic concerns, spin, weave in their fashion, plant cassava, and manure the other plants which are cultivated by the natives. Their arms are bows and arrows, sharp-pointed arrows blown through a reed, which they use in hunting, and clubs made of a heavy wood called Irox-wond. They eat the dead bodies of the slain, and sell for slaves those whom they take prisoners, their wars being chiefly undertaken to furnish the European plantations. All the different tribes go naked. On particular occasions they wear caps of feathers, but, as cold is wholly unknown, they cover no part but that which distinguishes the sex.

They are cheerful, humane, and friendly, but timid, except when heated by liquor, and drunkenness is a very common vice among then. Their houses consist of four stakes set up in a quadrangular form, with cross poles bound together by slit wihes, and covered with a particular kind of large leaves. Their life is ambulatory, and their houses, which are put up and taken down in a few bours, are all they have to carry with them. When they remove from place to place, as they inhabit the banks of rivers, they go by water, in small canoes; a few vessels of clay made by the women, a flat stone on which they baise their bread, and a rough stone on which they grate the roots of the cassava, a hammock, and a hatchet-are all their furniture and utensils: most of them, however, have a bit of lookingglass framed in paper, and a comb. Their poisoned arrows are made of splinters of a hard heavy wood called cacario; they are about twelve inches long, and somewhat thicker than a coarse knitting-needle : one end is formed into a sharp point; round the other is wound some cotton, to make it fit the bore of the reed through which it is to be blown. They will blow these arrows forty yards with absolute certainty of hitting the mark, and with force enough to draw blood, which is certain and immediate death. Against this poison no antidote is known. The Indians never use these poisoned arrows in war, 
but in hunting only, and chiefly against the monkeys. The flesh of the animal thus killed may be safely eaten, and even the poison itself swallowed with impunity.

\section{KALMUCS.}

THESE are a tribe of Tartars. They are in general, says professor Pallas, of a middle size, and it is even rare to see among them a person that is tall; the women especially are of low stature, and have very agreeable reatures. Their limbs are neatly turned, and very few liave any defects contracted in infancy. Their education being left solely to nature, procures for them a well-formed body and sound constitution. Their skin is pretty fair, especially when young; but the lower sort allow their male young children to go quite naked, both in the heat of the sun, and in the smoky atmosphere of their felt huts; the men, too, sleep naked, covered unly with their drawers; and thus they acquire that yellowish brown colour which characterizes them. The women, on the contrary, have a very delicate complexion; among those of a certain rank are found some of the most beautiful faces, the whiteness of which is set off by the fine hlack of their hair; and in this, as well as in the features, they perfectly resemble the figures in Chinese paintings. The physiognomy of the Kalmues is peculiar. Strangers are made to believe that it is frightfully deformed; and though there are indeed very ugly men to be found, yet in general their countenances have an openness that bespeaks a mild, frank, and social disposition. In many it is of a roundish shape, and exceedingly agreeable; among the women, some would be thought beauties, even in those European cities where the taste is most scrupulous. The characteristic features of a Kalmuc or Monoul countenance are the following : The interior angle of the eye is placed obliquely downwards towards the nose, and is acute and fleshy; the eye-brows are black, narrow, and much arched; the nose is of a structure quite singular, being generally flat and broken towards the forchead; the cheek-bone is high, the head and face very round; the eye is dark, the lip thick and fleshy, the chin short, and the teeth exceedingly white, continuing so to old age; the ears are of an enormous size, standing out from the head. These characters are more or less visible in each individual; but the person that possesses them all in the highest degree is considered as the most beautifully formed. Among all the Mongul nations, the men have much less beard than in our European countries, and anong the Tartars it apppears much later. The Kalmucs have most of it, and yet even with them the beard is very scanty and thin; and few have much hair on any other part of the body. They enjoy the bodily senses in the greatest perfection. They find the subtilty of their sense of smell very useful in their military expeditions: by it they perceive at a great distance the smoke of a fire or the smell of a camp; many of them can tell, by applying the nose to the hole of a fox or any other quadruped, if the animal be within or not. They hear at a great distance the trampling of horses, the noise of an enemy, or strayed cattle; they have only to stretch themselves on the ground, and to apply their ear close to the turf. But notbing is more aston- 
ishing than the acuteness of their sight, and the extraordinary dis. lance at which they often perceive very minute objects, such as the dist raised by cattle or horses, and this from places very little elevated, in immense level deserts, though the particular inequalities of the surface, and the vapours which in fine weather are seen to undulate over the soil in great heats, considerably increase the dificulty. They are also accustomed to trace the print of a foot in these deserts by the sight alone. The Kalmucs possess many good qualities, which give them a very great superiority over the wandering wartars. A certain natural sagacity, a social disposition, hospitality, eagerness to oblige, fidelity to their chiefs, much curiosity, and a certain vivacity accompanied with good-humour, which hardly ever forsakes even the most wretched amorg them, form the fair side of their character. On the other hand, they are careless, superficial, and want true courage; they are credulous, and yet cunning and distrustful, and they have a great inclination, authorized by custom, for drunkenness and debauchery. They are less indolent than any other Asiatics. Those who exercise any trade, or who lend themselves to the Russians for labour or for fishing, are very assiduous and indefatigable. They sleep but little, going to rest late, and rising with the sun. But their extreme dirtiness can neither be disguised nor justified : this, however, proceeds chiefly from their education. With regard to their intellectual faculties, notwithstanding their want of instruction and information, they possess good natural parts, an excellent memory, and a strong desire to learn. They acquire the Russian language with facility, and pronounce it well, in which last article they very much surpass the Chinese. Though generally of a sanguine and choleric temperament, they live more amicably together than could be expected in a people that lead so independent a life. They seldom come to blows even over their cups, and their quarrels are hardly ever bloody. A murder very rarely happens, though their anger has something in it exceedingly fierce. The Kalmucs are very affable, and of so social a disposition that they will go many miles to salute a traveller, and to inquire into the object of his journey. When a troop of Kalmucs perceive any person at a distance, it is customary for them to detach one of their number to the next eminence, from whence he makes a sigual with his cap for the person to draw near. If this signal is not obeyed, the person is considered as an enemy or a robber, and is often pursued as such. They enter willingly into friendships, but these connexions are not quite disinterested, for to give and to receive presents are with them essential articles. A mere trife, however, is sufficient to induce them to do you all manner of service, and they are never ungrateful as far as they are able. Adversity cannot alter their courage, nor deprive them of good-humour. A Kalmuc will never beg, were he in the extremest misery, but rather endeavour to acquire a subsistence by labour, or even by robbery. But they are very hospitable. A Kalmuc provided with a horse, arms, and equipage, may ramble through the country for months together, without taking with him either money or provisions. Wherever he comes lie finds friends, from whom be meets with the kindest reception, and is entertained in the best man- 
ner circumstances afford. His wants are supplied with the most affectionate cordiality. Every stranger, of whatseever nation, is well received by a Kalmue, and he may depend upon having his efrects secure, the moment he puts bimself under his protection, for to rob a guest is considered by the Kalmues as the worst of crimes. When the master of the house sits down to meat with others of inferior rank, he begins indeed by serving himself and his family; but whatever remains, is distributed among all present. When any one receives, a preseat of meat or drink, he divides it faithfully with his companions, even though of inferior rank. But they are much more niggardly even of their other effects, and especially of their cattle, and do not willingly give these away, unless a friend has accidentally suffered the loss of his flocks, when he is sure to be most willingly assisted. Perhaps too it may be related as an article of their hospitality, that they abandon their wives to their friends with the greatest facility, and in general they are very little inclined to jealousy. Their robberies are never cominitted upon their equals, and even the greater part of the rapine exercised on other tribes is founded on hatred or national quarrels; neither do they attempt this by open force, but prefer the machinations of cunning.

yon must also be confessed that it is only those that live with princes, and in camps where those hold their courts, or their priests, that are most addicted to these practices; while the common people, satisfied with the pleasures of a pastoral life, spend their days in innocent simplicity, and never attack the property of another, till forced by necessity, or led by their superiors who set them the example. The Kalmues are very faithful to their princes, and endure every sort of oppression, and are with dificulty induced to revolt; but if they belong to a prince who has not become so by right of succession, they easily rebel. They honour old age : when young men travel with such as are older than themselves, they take upon them the whole care of the cattle, as well as of the feast. They are exceedingly prudent in matters that relate to their sovereign or their nation, or which are recommended to their care by their priests, to whom they yield an unreserved obedience. The moveable habitations of the Kalmucs are those felt huts, with a conical roof, in use among all the roaming Asiatics. The truly ingenious invention of these tents was undoubtedly conceived in the eastern parts of Asia, and most probably by the Mongul nations. As they can be easily taken to pieces, and folded into a small compass, they are very useful, and perfectly agree with the migratory life of those people, who are ignorant of the use of carriages. The frame of these huts, and the felt they are covered with, though made as light as possible, yet are a sufficient load for a camel, or two oxen. But the capacity of these huts, their warmth in winter, their streugth in resisting tempests and excluding rain, abundantly compensate for this inconvenience. The wood endures many years, and though the felt begins to break into holes in the second year, yet as they do not consider it disgraceful to have them patched, they make them serve a good deal longer: The huts are in general use from the prince down to the meanest Kalmuc, differing only in size, and in the embellishments within. In winter they are warm, even when heated 
with the driest excrements of their cattle, to which they are ofen obliged to have recourse, for want of other kinds of fuel, in many places of the deserts which are destitute of wood. In summer they remove the felt, to enjoy the fresh air. The master of the lent has his bed placed opposite to the door, behind the fire-place. The bedsteads are low, and made of wood. The rich adorn their beds with curtains, and spread carpets of felt upon the ground. When a Kalmuc possesses an idol, he places it near the head of his bed, and sets before it several small consecrated cups, full of water, milk, ov other food. On festivals the idols are decorated, the lamps are lighted, and perfumes are burnt before it. The riches of the Kalmucs, and their whole means of subsistence, depends on their flocks, which many of them reckon by hundreds, and even by thousands. A man is thought capable of living on his possessions, when he is master of ten cows with a bull, and eight mares with a stallion. The aninals they have in great abuidance are horses, horned cattle, and sheep. Camels, which require time and pains to rear, cannot multiply fast with them; they are besides too delicate, and it is only the rich or the priests who possess any of them. 'Their horses are small, too weak for the draught, and too wild; but they are very swift, and support with ease the weight of a man. They may be made to gallop several hours without injury, and can pass two days without drinking. They have a litile hoof, but very hard, and may be used at all times without being shod. They perpetuate their species without any assistance from man. The Kalmucs castrate the greater pait of their male foals, and slit their noses, that they may breathe more freely when they run. The stallions are never separated from the mares, that there may always be plenty of milk. Their horned cattle are of a beautiful shape. They keep more bulls than are necessary for the cows, and employ a great number of them as beasts of burden, for carrying their honses and furniture from place to place. They think a buil equally to ffty cows. Their sheep have large tails, exceedingly fat, and furnish a suct as soft as butter. They have also large pendent ears, and their heads are much arched. Their wool is coarse, and they seldom have liorns. One ram is suficient for one hundred ewes. The wool is only fit to make felt for tents. Many sheep die during winter, and a greater number still of the early laniss, the skins of which are wrought into those fine furs so mucli esteemed in Russia and foreign parts. The rich Kalmucs only have eamels; for they are very dear, multiply slowly, and are subjected to many disenses. They are guarded with more care in winter, yet many of them die of consumption and diarrha, occasioned probably by the moisture of their pasture. No animal is so tormented with insects, and they often die in summer of those they swallow in eating the leaves of the oak and birch. The meloe prescarabrus, which covers all the plants in many places where they feed, is generally fatal to them. In spring, when they cast their hair, and which falls at once from every part of their body; they are exposed to the bite of the spider scorpion, whose wound is so venomous, that the camel dies of it at the end of eight days, sometimes in three. Camel's milk is tlick, unctuous, and of a saltish taste, and this last property makes the 
Kalmues fond of it to tea. They use the hair for stufting cushions, and for making ropes, packthread, felts, and very beantiful camlets. The camels with two bunches afford a very uneasy seat to the person who rides them ; their trot is so heavy, and even their walk so rude, that he receives the most violent shocks at every step.

When a Kalmuc horde intends to seek a fresh pasture, which in summer happens every six or eight days, people are sent to reconnoitre the best place for the khan or prince, for the lama, and for the hut containing the idols. These begin the march, and are followed by the whole troop, on these days the women paint and dress themselves in their best clothes. The Kalmues are supplied by their flocks with milk, cheese, butter, and flesh, which are their chief articles of food. They also eat the roots and stalks of many wild plants, such as the bulbous chervil, dandelion, \&c. Their ordinary drink is the mill of mares or cows. The former when fresh has a disagrceable taste of garlic; but it takes, as it grows sour, a very agreeable vinous flavour; it meither yields cream nor curd, but furnishes a very wholesone refreshing beverage, which inebriates when taken to excess. They never use new milk, nor milk or water that has not been boiled. The ir milk is boiled as soon as it is taken from the animal; when cold, it is poured into a large leathern bag, where there remains as much of the old milk as is sufficient to turn the new sour. This comminuni. cates to the milk a vinous fermentation. As often as the Kalmucs procure much milk from the flocks, they intoxicate themselves with the spiritnous liquor which they distil from it. Mare's milk is the most spirituous; and the quantity meant to be distilled remains twenty-four hours in summer, and three or four days in winter, in those corrupted bags, to prepare it for the operation. Cow's milk vields one-thirtieth part, and mare's milk one-fifteenth of spirit. This liquor is limpid and very watery, and consequently does not take fire, but is capable of being long kept in glass bottles. The rich Kalmucs increase its strength by a second distillation.

These people are exceedingly fond of tea and tobacco. As it comes to them from China by the way of Russia, that the poor neople supply its place with various wild plants, such as liquorice, the seed of the sharp-leafed dock, Tartarian maple, the roots of wild angelica, \&c. The Kalnues are excellent horsenen. Their arms are lances, bows and arrows, poniards, and crooked sabres; the rich have fire-arms. They wear, when at war, coats of mail, and their helmets are gilt at top. Falcony and hunting are their chief amusements. Their passion for play, especially cards, is carried to as great excess as in any nation. The greater part of their time is spent in diversions; and however miserable their manner of life may seem to us, they are quite happy with it. They cannot endure for any time the air of a close room, and think our custom of living in houses insupportable. The greatest part of them arrive at a vigorous old age, their discases being neither frequent nor dangerous. Men of eighty or one hundred years old are not uncommon, and at that age they can still endure the exercise of riding. Simple food, free air, a hardy constitution, continual exercise, and a mind free from care, are the causes of their health and longevity. It is remarkable that a nigratory people, whose 
life seems so congruous to the natural history of mankind, should have been subjected from time immemorial to the unlimited anthority of an absolute sovereign. Neither written records nor traditions bave preserved any trace of their ever having enjoyed a state of independence: On the contrary, they say they have always been sub. ject to khans; whose authority has been transmitted to them by succession, and is considered as a right perfectly safe and divine.

\section{GALLA.}

Tuis is the name of a nation of Ehiopia, originally dwelling, as Br. Bruce supposes, under the Line, and exercising the profession of shepherds, which they still continue to do. For many years, he says, they have been constantly migrating northward, though the cause of this migration is not known. At first they had no horses; the reason of which was, that the country they came from did not allow the animals to breed; but as they proceeded northwards, and conquered some of the Abyssinian provinces, they soon farnished themselves with snch numbers, that they are now almost entirely cavalry, and make little account of infantry in their armies. On arlvancing to the frontiers of Abyssinia, the multitude divided, and part directed their course towards the Indian ocean; after which, having made a setilement in the castern part of the continent, they turned southward into the countries of Bali and Dawar, which they entirely conquered, and settled there in 153\%. Anolher division having taken a westerly conrse, spread themselves in a senicircle along the banks of the Nile, surrounding the country of Gojam, and passing eastward behind the country of the Agows, extended their possessions as far as the territories of the Gongas and Gasats. Since that time the Nile has been the boundary of their possessions; though they have frequently plundered, and sometimes conquered, the Abyssinian provinces on the other side of the river, but have never made any permanent settlement in these parts. A third division has settled to the south of the low commry of Shoa, which the governor of that province has permitted, in order to form a barrier betwixt him and the territories of the emperor, on which he scarcely acknowledges any dependence. The Galla are of a brown complexion, and have long black hair; but some of them, who live in the valleys, are entirely black. At first their common food was milk and butter; but since their intercourse with the Abyssinians, they have learned to plough and sow their lands, and to make bread. They seem to have a predilection for the number seven, as each of the three divisions above mentioned are subdivided into seven tribes. In their behavionr theyare extremely barbarcus, and live in continual war with the Abyssinians, whom they murder without mercy as often as they fall into their hands. Yet notwithstanding their excessive cruelty abroad, they live under the strictest descipline at home, and every broil or quarrel is instantly punished according to the nature of the offence. Wach of the three divisions of the Galla has a king of its own; and they have also a kind of nobility, from among whom the sovereign can only be chosen; however, the commonalty are not excluded 
from rising to the rank of nobles, if they distinguish themselves very much in battle. None of the nobility can be elected till upwards of forty years of age, unless he has with his own hand killed such a number of enemies, as, added to his own age, make forty. There is a council of each of the seven tribes, which meets separately in its own district, to resolve how many are to be left behind to settle and govern the territory, and other matters of importance. These nations have all a great veneration for a tree which grows plentifully in their country, called wanzey, and which these superstitious people are even said to adore as a god. Their assemblies for the choice of a king are held under one of these trees; and when the sovereign is chosen, they put a bludgeon of this wood into his hand by way of sceptre, and a garland of the flowers upon his head.

The Galla are reported to be very good soldiers, especially in cases of surprise; but, like most other barbarians, have no constancy nor perseverance after the first attack. They will, however, perform extraordinary marches, swimming rivers, holding by the horses tails, and are thus enabled to do very great mischief by the rapidity of their movements. They are excellent light-horse for a regular army in a hostile conntry, but are very indifferently amed, on account of the scarcity of iron among them. rheir principal ams are lances made of wood, sharpened at the end and hardened in the fire; and their shields are composed of one single fold of bull's hide, so that they are extremely apt to warp by heat, or to become too soft in wet weather. They are exceedingly cruel, and make a shill and horrid noise at the beginning of every engagement, which greatly terrifies the horses, and very often the babarous riders who oppose them. The Galla are somewhat below the middle size, but extremely light and nimble. The women are frutful, and sufer solittle in childbearing, that they do not even confue themselves for a single day after cielivery. They plough, sow, and reap the com, which is trodden out by the cattle, but the men have all the charge of the cattlo in the fields. In their customs, they are filhy to the last degree, plaiting thei hair with the guts of oxen, which they likewise twist round their midule, and which by the quick putrefaction occasion an abominable strnch. Whey anoint their leads and their whole bodies with grease, in which, is well as in other respects, they greatly resemble the Hotentots. It has been supposed that they have no religion whatever, but Mr. Bruce is of opinion that this is a mistake. The wanzey, he says, is undoubtedly worsipped by all the three nations as $a^{\prime}$ god; and they have hicewise certain stones which are worshiped as gods. They worsh the moon and also some stars, when in certain positions, and at some particular seasons of the year. They all believe in a resurection, and have some fant notions of a state of happiness, but no idea of future punishment. "Some of them to the south profess the Makometan religion, but those of the east and west are generally pagans. They all internary with each other, but will notallow strangers to live among: them, thongh the Moors have found out a method of safely rading with them... The commodities they dea! in are blue Surat cloths, myrrh, and salt, the last being the most valuable article. Whe marriages among the Galla are celebrated 
with some of the disgusting customs of the Hottentots, and after these ceremonies the bridegroom promises to give the bride meat and drink while she lives, and bury her when dead. Polygamy is not only allowed among them, but the women even solicit their husbands to take others to their embraces, that they may have numerons families of children, who may be capable of defeuding them against their enemies, as the Galla, according to Mr. Bruce, always fight in families, whether against foreign enemies or with one another.

\section{KABOBIQUAS.}

THIs is the name of a nation of South Africa, who had never seen a white man till 1935, when M. Vaillant visited them. Having received previous intimation of his approach from the adjacent tribes, theil curiosity was wound up to the highest pitch, and, upon the first appearance of his company, the whole horde quitted their kraal, and ran out to meet him. Hardly able to believe their eyes, they felt his hail, his hands, his feet, and almost every part of his body. His beard astonished them, and, believing him to be all over hairy, they half unbuttoned his clothes, before they could be satisfied to the contrary. The children were dreadfully frightened, but were soon reconciled to him by presents of sugarcandy. Their chief shewed him every mark of respect. He was a majestic figure, advanced in life, and wore a long mantle made of four jackals' skins.

The Kabobiquas have neither the flat nose nor the plump cheeks of the Hottentots. They are as tall and as black as the Caffres. Their hair is very short, much curled, and ornamented with small copper buttons. They go alnost entirely naked during the hot weather, wearing only a small round piece of leather over the pudenda; yet their manners are uncommonly chaste, and no females can be more reserved than their women, whose aprons only reach half way down the thigh. They wear a long mantle, made of skins with the hair on. Their only ornaments are glass beads, which they wear as bracelets. M. Vaillant gave them a number of glass bottles, which they greatly admired, and called solid water-having seen ice, and having no idea that any other solid substance could be formed transparent. They supposed that M. Vaillant prevented them from melting before their fires by magic. He says he "never saw a nation so disinterested. 'They vied with each other in generosity. Every night they brought to his camp a considerable quantity of milk; and they never came to spend the evening with his people without bringing some sheep to regale them. Many of them gave away gratuitously; and without receiving any thing in return, part of their herds and flocks." With all this benevolence, they have also a courageous and martial character. Their weapons are poisoned arrows, and lances with long points. Their defensive arms are bucklers of two different sizes, made of skins, very thick, and impenetrable by arrows. Their courage is equally displayed against their enemies and against wild beasts. Yet with all their boldness, they are extremely obedient to their chief, whose will is a law. They believe in a supreme Being, who exists fal beyond the stars, and who made and governs all things. 


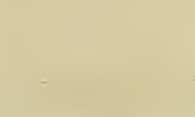

.
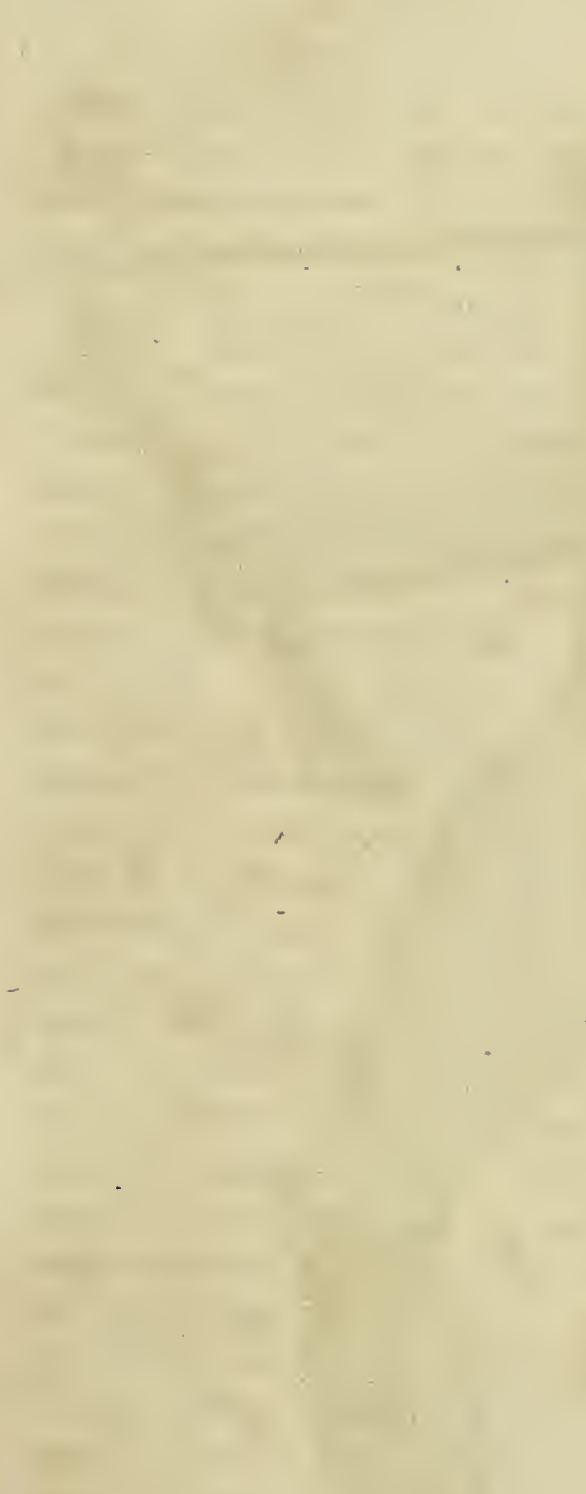
p. 185

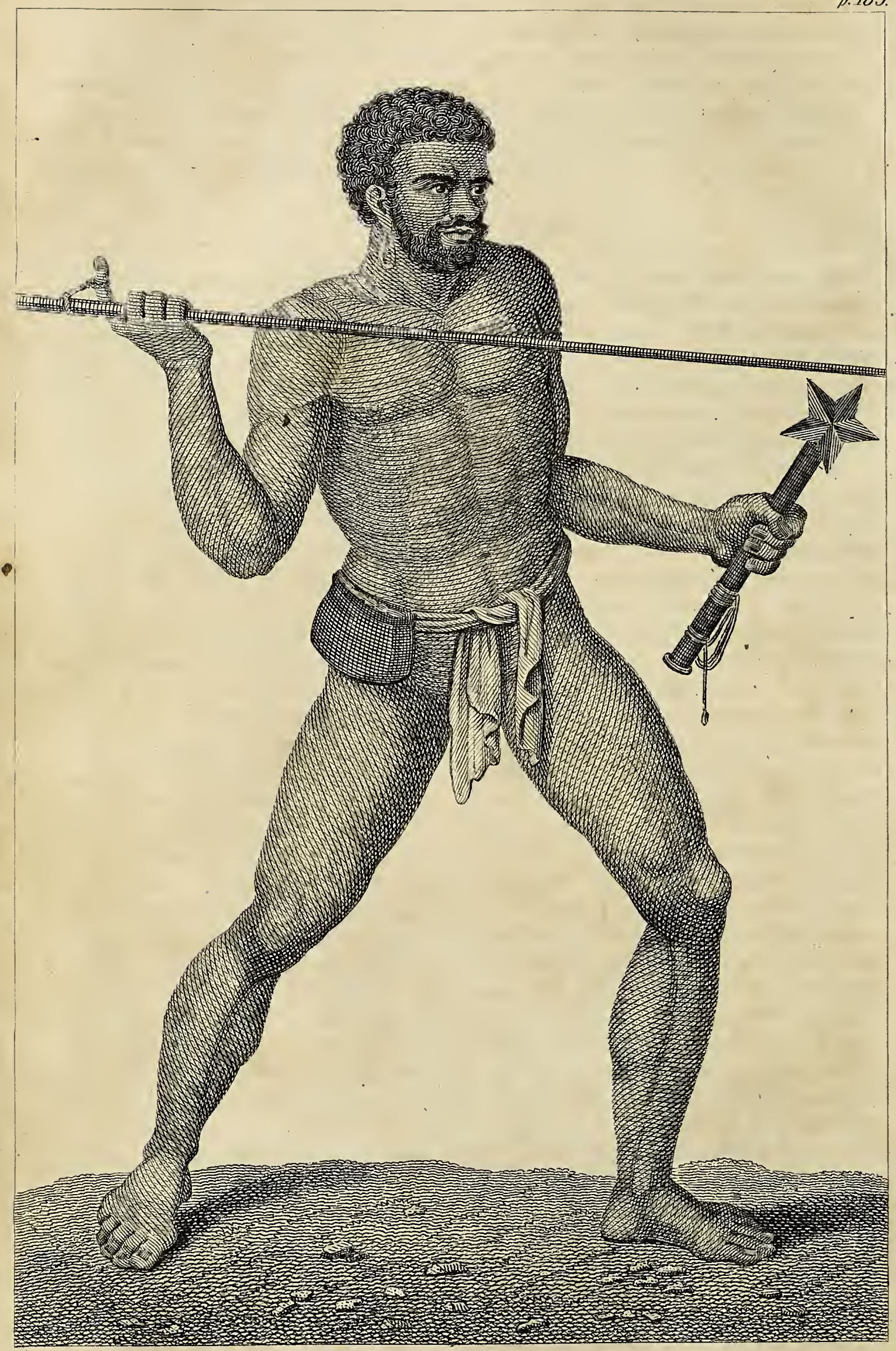

A MAN OF NIEW CALEDONIA, IHIROWILNG THE SPIAR. 
Yet, if we may believe M. Vaillant, they have no conception of future existence, or rewards and punishments; and they have neither worship? sacrifices, ceremonies, nor priests."

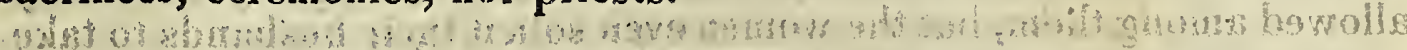

\section{Inmabitants, Customs, \&c, of New CaLEDonia, an Island IN THE SOUTH SE $\Lambda$.}

THE inhabitants are in general very tall, stout, and well proportioned; their features mild; their beards and hair black, and strongly frizzled, so as to be somewhat woolly; in some individuals their colour is a dark chestnut brown. A few measured six feet four inches. They are remarkably courteous, not at all addicted to pilfering; in which feature of characer they are singular, all the other nations in the South Sea being remarkably thievish: Some wear their hair long, and tie it up to the crown of their heads; others suffer only a large lock to grow on each side, which they tie up in clubs ; nany others, as well as the women, wear it cropt short. They all use a kind of comb made of sticks of hard wood, from seven to ten inches long, and about the thickness of knitting-needles. These combs they also wear in their hair on one side of the head. Some have a kind of concave cylindrical stiff black cap, which appears to be a great ornament among them, and was supposed to be worn only by the chiefs and warriors. The men go naked; only tying a string round their middle, and another round their neck. A little piece of brown cloth, made of the bark of a fig-tree, sometimes tucked up to the belt, and sometimes pendulous, scarcely deserves the name of a covering, nor indeed does it seem intended for it. This piece of cloth is sometimes of such a length, that the extremity is fastened to the string round the neck; to this string they sometimes hang small round beads, of a pale nephritic stone. They had also coarse garments made of a sort of matting; but they seemed never to wear them, except in their canoes, and unemployed.

The women seemed to be in a servile state; they were the only persons, who had any employment, and several of them brought bundles of sticks and fuel on their backs; those who had children carried them on their backs in a kind of satchel. The women also dig up the earth, to plant it. They are in general of a dark chestnut, but sometimes of a mahogany brown; their stature middle-sized, though some are tall, and their whole form stout, and somewhat clumsy. Their dress is a short petticoat or fringe, consisting of filaments or little cords, about eight inches long, fastened to a very long string, which they tie several times round their waist. These filaments lie above each other in several layers all round the body, but do not near cover the thigh; they were sometimes dyed black, but frequently of a dirty gray. There was not a single instance, during the ship's stay at this island, of the women permitting any indecent familiarities with an European. The general ornaments of both sexes are ear-rings, necklaces, amulets, and bracelets made of shells, stones, \&c. Notwithstanding the inoffensive disposition of the inhabitants of New Caledonia, they were all pravided with offensive weapons, as clubs, spears, darts, and slings. Their clubs are about two and a half 
feet long, and variously formed,-some like a scythe, others like a pickaxe; some with a head like a hawk, others with round heads; but all are neatly made, and ornamented with carvings. The slings are simple, but they form the stones into a shape somewhat like an egg. They drive the dart by the assistance of short cords knotted at one end and looped at the other, called by the seamen, beckets. These contain a quantity of red wool, taken from the great Indian bat. Bows and arrows are wholly unknown among them. Their language bears no affinity to that spoken in the other South Sea islands, the word arrekee, and one or two more, excepted. This is the more extraordinary, as different dialects of one language were spoken not only in the easterly islands, but at New Zealand. Their only musical instrument is a kind of whistle--a little polished piece of brown wood about two inches long, shaped like a bell, though apparently solid, with a rope fixed at the small end; two holes are made in it near the base, and another near the insertion of the rope, all which communicate with each other, and by blowing in the uppermost a shrill sound like whistling is produced. Many of these people were observed to have prodigiously thick arms and legs, which seem to be affected with a kind of leprosy; the swelling was extremely hard, but. the skin was not alike harsh and scaly in all those that were afflicted with the disorder. The preternatural expansion of the arm or leg did not appear to be a great inconvenience to them, and they very rarely felt any pain in it; but after some time the disorder began to form blotches, which are marks of a great degree of virulence. They bury their dead in the ground. The grave of a chief who had been slain in battle resembled a large mole-hill, and was decorated with spears, darts, paddles, \&c., all stuck upright in the ground about it. Lieutenant Pickersgill was shewn a chief whom they called Teabeoma, and styled their arrekee, or king; but nothing farther is known of their government, and nothing at all of their religion. They have no idea of goats, hogs, dogs, or cats.

\section{Dahomans.}

THEsE are the inhabitants of Dahomy, a kingdom of Africa. The religion of the Dahomans is vague and uncertain in its principles, and rather consists in its performance of some traditionary ceremonies, than in any fixed system of belief, or of moral conduct. They believe more firmly in their amulets and fetiches, than in the Deity; their national fetiche is the tiger, and their houses or huts are decorated with ugly images, tinged with blood, stuck with feathers, besmeared with palm oil, and bedaubed with eggs. The government is perhaps the most perfect despotism upon earth. The policy of the country admits of no intermediate degree of subordination between the king and slave, at least in the royal presence, where the prime minister is obliged to prostrate himself with as much abject submission as the meanest subject, all acknowledging the unlimited power of the sovereign. A minister of state crawls towards the apartment of audience on his hands and knees, till he arrives in the royal presence, where he lays himself flat on his belly, rubbing his head in the dust; and 
uttering the most humiliating expressions. Being desired to advance, he receives the king's commands, or communicates any particular business, still continuing in a recumbent posture, for no person is permitted to sit, even on the floor, in the royal presence, except the women; and even they must kiss the earth when they receive or deliver the king's message.-The king of Dahomy maintains a considerable standing arny, commanded by an agaow, or general, with several other subordinate military officers, who must hold themselves in readiness to take the field upon all occasions, at the conımand of the sovereign. The payment of this troop chiefly depends on the success of the expeditions in which they are engaged. On extraordinary occasions, all the males able to bear arms are obliged to repair to the general's standard, every caboceer marching at the head of his own people. Sometimes the king takes the field at the head of his troops, and, on very great emergencies, at the head of his women.

Within the walls of the different royal palaces in Dahomy are immured not less than three thousand women; several hundreds of these are trained to arms under a female general, and subordinate officers appointed by the king, in the same manner as those under the agaow. These Amazons are regularly exercised, and go through their evolutions with as much expertness as the male soldiers. They have their large umbrellas, their flags, their drums, trumpets, flutes, and other musical instruments. In short, the singularity of this institution never fails to attract the particular attention of Europeans, when, among other uncommon exhibitions, they are presented with the curious spectacle of a review of female troops.

The dress of the men in Dahomy consists of a pair of striped or white cotton drawers, of the manufacture of the country; over which they wear a large square cloth of the same, or of European manufacture. This cloth is about the size of a common counterpane for the middling class, but much larger for the grandees. It is wrapped about the loins, and tied on the left side by two of the corners, the others hanging down, and sometimes trailing on the ground. A piece of silk or velvet, of sixteen or eighteen yards, makes a cloth for a grandee. The head is easily covered with a beaver or felt hat, according to the quality of the wearer. The king, as well as some of his ministers, often wears a gold or silver laced hat and feather. The arms and the upper part of the body remain naked, unless when the party travels, or performs certain pieces of work, when the large cloth is laid aside, and the body is covered with a sort of frock or tunic without sleeves. The feet are always bare, none but the sovereign having a right to wear sandals.

The dress of the women, though simple, consists of a greater number of articles than that of the men. They use several cloths or handlerchiefs, some to wrap round their loins, and others to cover occasionally the breasts and upper part of the body. The neck, arms, and ankles, are adorned with beads and cowries; and rings of silver, or baser metal, encircle the fingers. The ears are so pierced as to admit the little finger, and a coral bead of that size stuck in each, if the party be able to afford it ; otherwise a portion 
of red sealing wax, or a piece of oyster-shell polished, is applied in the same manner. Girls before the age of maturity wear nothing but a string of beads or shells round their loins, and young women usually expose the breasts to view. The general character of the Daliomans is marked by a mixture of ferocity and politeness. The former appears in the treatment of their enemies; the latter they possess far above the African nations with whom we hitherto had any intercourse, this being the country where strangers are least exposed to insult, and where it is easy to reside in security and tranquillity.

\section{Natives of Mali.icollo.}

THESE people are described as the most ugly, ill-proportioned people imaginable, and in every respect different from the other islanders in the South Sea. They are of a very dark colour, and diminutive size; with long heads, flat faces, and monkey countenances; their hair is in general black or brown, short and curly, but not so soft and woolly as that of a negro. Their beards are very strong, crisp, and bushy, and generally black and short. But what serves to increase their natural deformity is, a custom which they have of wearing a belt or cord round their waist; this rope is as thick as a mar's finger, and is tied so tight round their belly, that it would be fatal to a person unaccustomed from infancy to such an unnatural ligature ; for it cuts such a deep notch across the navel, that the belly seerns in a manner divided, one part above and the other below the rope.

The men go quite naked, except a piece of eloth or leaf used as a wrapper. Most other nations invent some kind of covering from motives of shame; but here a roll of cloth, fastened to the belt, rather displays what should be concealed. Besides having the flat broad nose and projecting cheek-bones of a negro, and a very short forehead, many increase their natural ugliness by painting their faces and breasts black. Some few had a small cap on the head made of matted work. They wear bracelets of white and black shells, which press the upper arm so closely, that they seem to have been put on when the wearer was very young; this tends, as well as the belt, to reduce the Mallicollese to that slender shape which characterizes them. The depression of their foreheads is supposed to be artificial, as the heads of infants may be squeezed into any kind of form.

\section{Manners and Charactzr of tile People of Madagascar.}

TriesE people are civil and good-natured, hut easily provoked, and apt to shew their resentment when they think themselves injured. Another characteristic is, the very high notions they entertain of their ling, who resides in a town buil, with mud, about twelve miles up from St. Augustine's bay. Their physiognomy displays the appearance of frankness and satisfaction; they are desirous only of learning stich things as may administer to their necessities; that species of knowledge which demands reflection, is indifferent to them; sober, agile, active, they spend the greatest part of their time in amusements. 
In fine, according to the Abbé Rochon, they are devoid of vice and of virtue; the gratifications of the present moment solely occupy their reflections; they possess no kind of foresight, and have no idea that there are men in the world who trouble themselves about the evils of futurity. But such a description of any human beings is hardly credible. All the women of Madagascar, excepting the very poorest, wear a covering over their breasts and shoulders, ornamented with glass beads, and none go without a cloth about their loins. They commonly walk with a long slender rod or stick. The men marry as many women as they can support.

The Abbé gives the following description of the people in the south division of the island. "That part of Madagascar in which Fort Dauphin is situated, is very populous. When the chiefs go abroad, they are always provided with a musket, and a stick armed with iron, adorned at the extremity with a little tuft of cow's hair. They wear a bonnet of red wool. It is chiefly by the colour of their bonnet that they are distinguished from their subjects. Their authority is extremely limited: however, in the province of Carcanossi, the lands by custom belong to their chiefs, who distribute them anong their subjects for the purpose of cultivation; they exact a trifing quitrent in return, which in their language is called jaensa. The people of Carcanossi are not altogether ignorant of the art of writing; they even possess some historical works in the Madagascar tongue, but their learned men, whom they term Ombiasses, use the Arabic characters alone. They have ireatises on medicine, geomancy, and judicial astrology; the most renowned live in the province of Matatane; in that district magic still remains in all its glory, and the Matatanes are actually dreaded by all the other Madagasses on account of their excellence in this delusive art. The Ombiasses have public schools, in which they teach geomancy and astrology. The natives have undoubtedly learned the ari of writing from the Arabians, who made a conquest of this island about three hundred years since.

"The people of Anossi, near Fort Dauphin, are lively, gay, sensible, and grateinl; they are passionately fond of women, are never melancholy in their company, and their principal occupation is to please the sex; indeed, whenever they meet their wives, they begin to sing and dance. The women, from being happy, are always in good humour. Their lively and cheerful character is extremely pleasing to the Europeans. 1 have often been present at their assemblies, where affairs of importance have been agitated; I have observed their dances, their sports, and their amusements, and I have found them free from those excesses which are too common among polished nations."- "If the people of Nadagascar," adds the Abbé, "have availed themselves of treachery, they have been forced to it by the tyranny of the Europeans. The weak have no other arms against the strong. They are uninformed and helpless, and we availourselves of their weakness to make them submit to our covetousness and caprice. They receive the most cruel and oppressive treatment, in return for the hospitality which they generously bestow on us; and we call them traitors and cowards, when we force them to break the yoke with which we load them." 


\section{Alibamons.}

ThIs is one of the native tribes of Americans on the river Alibama in Georgia. This tribe is remarkable for their hospitality and frankness. They believe in a future state of existence, resembling the sensual paradise of Mahomet. Their dead are buried in a sitting posture, with a pipe and tobacco; but the bodies of suicides, who are considered as cowards, are thrown into the rivers. As they marry only one wife, they are exceedingly jealous of their honour, though their young women are allowed to trifle with their chastity. This spirit of jealousy induces them to set out on their hunting parties with their families, in canoes, about the end of October; and after travelling through a distance of eighty or a hundred leagues, they return at their seed-time, in March, loaded with skins and dried flesh. Their diet consists chiefly of toasted maize cooked with flesh, which they call sagamiti. The Alibamons have their magicians and little deities or manitus, and pretend to heal diseases by magical incantations.

\section{Patagonians.}

These are the inhabitants of Patagonia, in South America. From the accounts of Commodore Byron and his crew, and the testimonies of other navigators, some of the Patagonians are of a gigantic stature, and clothed with skins; others. go almost quite naked, notwithstanding the inclemency of the climate. Some of them also who live about the streights, are perfect savages; but those with whom Byron and his people conversed, were gentle and humane. They live on fish and game, and what the earth produces spontaneously. A vast deal has been said respecting the stature of the Patagonians, by people of diferent nations, and on various occasions. Mr. Charles Clarke, who was on board Byrou's ship in 1764, says that some of them are certainly nine feet, if they do not exceed it. Captain Wallis, on the other hand, who went out to the Straits of Magellan after Byron's return, found that the tallest man among them measured only six feet seven inches high; several were within an inch or two as tall; but the ordinary size was from five feet ten inches to six feet. All agree, however, that the hair is black, and harsh like bristles; that they are of a dark copper colour; that their features are rather handsome than ugly; that they clotlie themselves with skins; that they paint themselves variously, and there is reason to suspect that by that variety they distinguished their tribes. One remarkable observation made by our vogagers is, that the Patagonians could repeat whole sentences after our men, more distinctly than almost any European foreigner, of what nation soever. Another very remarkable particular is, that they had none of the characters of a ferocious people, there were no ofiensive weapons among then, except the scymeter, and a kind of sling which they use in hunting, consisting of two round stones of about a pound weight each, connected together by a thong. These stones were fastened to the extremities of the thong; and when they threw them, they held one stone in the hand, and swung the other about the head. 


\section{Inhabitants of Spain.}

THE Spaniards want neither inclination nor capacity for the sciences, but have hardly any opportunity of acquiring any true learning or knowledge, at least in their schools and universities. They are admired for their secrecy, constancy, gravity, patience in adversity, and loyalty. They are also said to be true to their word, great enemies to lying, and so nice and jealous in point of honour, that they will stick at nothing to wipe off any stain that is cast upon it. Among their vices and defects are reckoned their pride, and contempt of foreigners, their indolence, laziness, lust, bigotry, and credulity in believing the feigned miracles and legends of their monks. They are also extremely passionate, jealous, and vindictive, and are noted, above any other European nation, for despising and neglecting agriculture, arts, and manufactures.

\section{Manners and Character of the Dutch.}

THE Dutch boors or husbandmen are very industrious, but heavy and slow of understanding. The seamen are a plain, blunt, but rough, surly, and ill-mannered sort of people. Their tradesnien are something sharper, and make use of all their skill to take advantage of those they deal with. Every class of men is extremely frugal. All appetites and passions run lower and cooler than in other conntries, avarice excepted. Quarrels are very rare, revenge is seldom beard of, and jealousy scarcely ever known. It is very uncommon for any of the men to be really in love, or even to pretend to it; nor do the women seem to care whether they are or not. People converse pretty much upon a level here, nor is it easy to distinguish the man from the master, or the maid from the mistress; such liberties do they allow their servants, or rather are obliged to allow them, for they may not be struck or corrected, but the dispute must be referred to the magistrate.

The Dutch are tall and strong built, but both men and women have the grossest shapes that are to be met with any where. Their garb, except among the officers of the army and some few others, is exceedingly plain, and the fashions change as seldom as in Spain. The men are addicted to drinking, which some think necessary to this foggy air, both for their health, and the impovement of their understanding. Among their diversions, that of skating in winter is one of the chief. It is amazing to see the crowds in a hard frost upon the ice, and their dexterity in skating; both men and women darting along with inconceivable velocity. The Dutch are remarkable for their cleanliness; nothing can exceed the neatness of their houses; towns, and villages. Many of them have distinguished themselves by their learning, and some even by their: wit and ingenuity; witness Eras mus, Grotius, \&c. The Dutch excel also in painting and engraving, particularly the former; and some of them have been no contemptible statuaries. 


\section{DRESS CHARACTER, AND MANNERS OF NIE IN HABITANTS OF TURKEY.}

The Turks are generally robust and well-shaped, of a good mien, and patient of hardships, which renders them fit for war. They shave their heads, but wear their beards long, except the military and those in the seraglio, who wear only whiskers. They cover their heads with a white linen turban of an enormous size, and never put it off but when they sleep. None but Turks must presume to wear a white turban. Their breeches or drawers are of a piece with the stockings; and they have slippers instead of shoes, which they pull off when they enter a temple or bouse. They wear shirts with wide sleeves, not gathered at the wrists, and over them a vest tied with a sash; their upper garment being a loose gown, something shorter than the rest. The women's dress much resembles that of the men; only they have a stiffened cap. with horns, something like a mitre, on their leads instead of a turban, and wear their hair flowing down. When they go abroad, they are so wrapped up that their faces cannot be seen. The rurks sit, eat, and sleep, accurding to the custom of the East, on sophas and cushions, mattresses and carpets. Rice is their most general food, and coffee their common drink. Their most usual salutation is to bow their heads a little, laying their right hand upon their breasts; but to persons of rank, they stoop so low as to touch the border of their vest. The women are kept under a rigorous confinement. They have generally delicate skins, regular features, black hair and eyes, with an admirable chest. Many of them are complete beauties. Their cleanliness is extraordinary; for they bathe twice a week, and sufer not the smallest hair or least soil to be upon their bodies. As to the qualities of their minds, they are said to wan neither wit, vivacity, uor tenderuess, and to be exceedingly amorous. It is no doubt for this reason that the men never suffer their wives' faces to be seen, not even by the dearest friend they have in the world. There is no need of much, wit to behave one's self well here; for a good mien and gravity supply the place of merit in the East, and much gaiety would spoil all. Not that the lurks want wit, but they speak little, and pride themselves in sincerity and modesty, more than eloquence. The Turks use no unnecessary words, whereas the Greeks talk incessantly. Though these two nations are born under one climate, their tempers are more difierent than if they lived in the most distant countries. The Turks make profession of candour and faithfulness, and are charitable good-natured people, jealousy excepted, and very sober. On the other hand, they are extremely proud, insolent and indolent, superstitious and covetous. They are also much addicted to unnatural lusts; and despise all other nations in general, especially those which are not of their own religion. The common appellation they give to Christians is that of - dogs.

An uniformity runs through all the actions of the Turks, and they never change their manner of living. They seem to have no kind of genius for the improvement of the arts and sciences, though they live under the influence of the same heaven, and possess the same 
countries, as the ancient Grecians did. They generally loiter away their time, either among the women in the harem, or in smoking, or in taking opium; and though they herd together, you will observe as little conversation among them as among so many horses in a stable. They seldom travel, or use any exercise or rural sports, and discover little or no curiosity to be informed of the state of their own or any other country: but Turkey, after all, is not without men of parts, probity, and honour; nor without benevolent, liberal, conver. sible, and ingenious people. They behave very commendably to their slaves and servants, and frequently better than the Christians do to theirs. There are no hereditary governments, or titles of nobility, in Turkey; and indeed the commonalty there enjoy the greatest liberty.

\section{Inhabitantis of Poland.}

When Poland was an independent kingdom or republic, the inhabitants consisted of nobles, citizens, and peasants. The first possessed great privileges, which they enjoyed, partly by the indulgence of their kings, and partly by ancient custom and prescription. Some of them had the title of prince, count, or baron, but no superiority or pre-eminence on that account over the rest, which was only to be obtained by some public post or dignity. They had the power of life and death over their vassals ; paid no taxes ; were siibject to none but the king; had a right to all mines and salt-works on their estates; to all offices and employments, civil, military, and ecclesiastic; could not be cited or tried out of the kingdom; might choose whom they would for a king, and lay him under what restraints they pleased; and none but they and the burghers of particular towns could purchase lands. In short, they were almost entirely independent, enjoying many other privileges and prerogatives besides those we have specified; but if they engaged in trade, they forfeited their nobility.

The Poles are personable, and have good complexions. They are esteemed a brave, honest people, without dissimulation, and exceedingly hospitable. They clothe themselves in furs in winter, and over all they throw a short cloak. No people keep grander equipages than the gentry: they consider themselves as so many sovereign princes; and have their guards, bands of music, and openhouses; but the lower sort of the people were, and we fear still are, in the lowest state of slavery. The exercises of the gentry are hunting, riding, dancing, vaulting, \&c. They reside mostly upon their estates in the country; and maintain themselves and families by agriculture, breeding of bees, and grazing.

\section{Manners of the People of Persia.}

THE ancient Persians are known to have been exceedingly voluptuous and effeminate. After the conquest of the empire by Alexander, the Greek discipline and martial spirit being in part cominunicated to them, they became much moje formidable; and hence the Parthians 
were a match, not only for the Syro-Macedonian princes, but even for the Romans. Of their marners we know little or nothing, but that to their valour and military skill they joined in a surprising degree all the luxury and dissipation of the ancient Persians. The modern Persians, like the Turks, plundering all the adjacent nations for beautiful females, are men of a good stature, shape, and complexion, but the Gawres, or ancient Persians, are homely, ill-shaped, and clumsy, with a rough skin and olive complexions. In some provinces not only the complexions, but the constituitions of the inhabitants, suffer greatly by the extreme heat of the climate. The Persian women are generally handsone and well-shaped, but much inferior to those of Georgia and Circassia. The men wear large turbans on their heads, some of them very rich, interwoven with gold and silver; a vest girt with a sash, and over it a loose garment, something shorter, with sandals or slippers on their feet. When they ride, which they do every day, they wear pliant boots of yeilow leather; the furniture of their horses is extremely rich, and the stirrups are generally of silver; whether on horseback or on foot, they wear a broadsword, and a dagger in their sash. The dress of the women does not differ much from that of the men, only their vests are longer, and they wear stifiened caps on their heads, and their hair down. With respect to outward behaviour, says an intelligent traveller, " the Persians differ from the nations of the East. Whilst a rude and insolent demeanour peculiarly marks the character of the Turkish nation towards foreigners and Christians, the behaviour of the Persians would, on the contrary, do honour to the most civilized nations; they are kind, courteous, civil, and obliging. Their usual drink is water and sherbet, as in other Mahometan countries, wine being prohibited; but of all Mahometan nations, they pay the least regard to this prohibition. Many of them drink wine publicly, and almost all of them in private, excepting those who have performed the pilgrimage to Mecca, and men of religion; they are also very liable to be quarrelsome when inebriated, which is often attended with fatal consequences. They eat opium, but in much less quantities than the Turks; and indeed in every thing they say or do, eat or drink, they make a point to be as different from this nation as possible, whom they detest beyond measure, esteeming Jews and Christians superior to them, and much nearer to salvation. They are of the sect of Ali, whom they venerate to a high degree of blasphemy, and exalt even above the Alnighty himself."

\section{The Schah of Persia.}

An officer in the service of Persia gives, in one of his letters, the following details respecting the Schah of Persia, and the town of Teheran, the residence of the court :-

"The present Schah, Feth Ali, is about fifty-five years of age. He is of high stature. His demeanour is full of majesty; his countenance pale, and shining like marble; but when he speaks on subjects which animate him, a glowing red mantles in his cheeks. His eyes are black and brilliant; his eye-brows full, and finely arched. His long beard, of the finest black, comes down to his waist: (a long beard has for ages back been the distinguishing mark of the royalty 
of the Persian sovereigns.) His physiognomy, in general expresses sweetness, and his smile is at once noble and gracious. His moral qualities are not inferior to his physical advantages. He is benevolent, generous, and one of the most learned men in Persia. He knows, and perfectly appreciates, European customs, having been almost always surrounded by European officers, both French and English. His policy is not narrow, like that of the Turks. A single instance will suffice to shew how much the policy of the court of Persia differs from that of the Porte. Whilst at Constantinople the princes of the imperial family are iniprisoned all their lives in an old seraglio, it is the custom at Teheran to confide the important provinces of Persia exclusively to the princes of the royal blood.

"The Persian army is composed, first, of the guards of the king and princes; secondly, of the troops furnished by the Nomadic tribes; thirdly, of the provincial militia, who do no regular nor permanent duty; fourthly, of various corps of infantry, cavalry, and artillery, exercised and clothed nearly the same as European soldiers, without reckoning a corps of bad artillery, called Zemboureh.

The number of guards is ................. 4,000

That of the Nomadic troops ............... 80,000

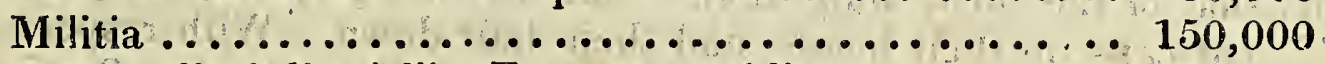

Troops disciplined like European soldiers $\ldots \ldots \ldots \ldots, \mathbf{2 0 , 0 0 0}$

Total.............. 20,000

"In time of war, the number of Nomadic troops and militia may easily be doubled.

"Tehraun, (falsely called Teheran;) the capital of the enpire, is situated in a plain at the foot of the mountains of Elborz. It is surrounded by deep moats, towers, and a wall which embraces an extent of four miles. The streets are narrow and dirty, like those of all the towns of Persia. When a khan or great personage goes out to take an airing, or for any other purpose, he is rarely seen on foot; he mounts a horse, and is followed by thirty or forty domestics on foot. One of these carries his master's pipe; the others are required to make up his suite. The narrators of national histories, surrounded by a group of listeners, are often met with in the streets. They relate, with animated gestures, and changing their tone or voice as the subjects require, sometimes the loves of $K$ hosroo and Shirenee; at others, the exploits of Rustaum, their favourite hero; or sing some verses of Ferdousi, the Homer of their country. Every body takes delight in these amusements, from the peasant to the prince. The Schah, as well as the prince-governors, have each their history-narrator, and they send for them when they are affected, with a moment's melancholy. They represent at once, the bards of ancient times, -- the troubadours of more modern days,-and the Italian improvisatori of our own age."

In Habitants OF California.

The Californians are well made, and very strong. They are said to be extremely pusillanimous, inconstant, stupid, and even insensible. Before the Europeans penetrated into California, the natives had no 
form of religion. The missionaries, indeed, tell us many tales concerning them, but they evidently bear the marks of forgery. Each nation was then an assembly of cottagers more or less numerous, all confederated by alliances, but without any chief. They were stranger's even to filial obedience. No kind of dress was used by the men, but the women made use of some coverings, and were even fond of ornamenting themselves with pearls, and such trinkets as the country afforded. What mostly displayed their ingenuity was the construction of their fishing-nets, which are said by the Jesuits to have even exceeded in goodness those made in Europe. They were made by the women, of a coarse kind of flax, procured from some plants which grow there. Their houses are built of branches and leaves of trees, nay, many of them were only enclosures of earth and stone, raised half a yard high, without any covering; and even these were so small that they could not stretch themselves at length in them. In winter they dwelt in caves under ground.

\section{LOMBARDS.}

THE Lombards were at first a cruel and barbarous nation, but their natural fierceness gradually wore off, especially after they embraced the Christian religion, and they governed with such equity and moderation, that most other nations envied the happiness of those who lived under them. Under the government of the Lombards, says Paulus Diaconus, no violence was committed, no one unjustly dispossessed of his property, none oppressed with taxes; thefts, robberies, murder, and adultery were seldom heard of ; every one went without apprehension wherever he pleased. Their laws were so just and equitable, that they were retainec in Italy, and observed there some ages after their kingdom was at an end. Their dress was loose, and for the most part linen, such as the Anglo-Saxons wore, being interwoven with various colours; their shees were open to the end of the foot, and they used to button or lace them. From some ancient paintings, it appears that they shaved the back part of their heads, but that their hair was long before, their locks being parted; and laid on each side their foreheads.

\section{Manners, Character, and Customs of the People of Russia.}

THE native Russians are stigmatized by their neighbours as ignorant and brutal, totally resigned to sloth, and addicted to drunkenness, even to the most beastly excess, nay, they are accused of being arbitrary, perfidious, inhuman, and destitute of every social virtue. There is not in their language a phrase analogous to ours--" the manners or the sentiments of a gentleman," nor does gentleman with them express any thing moral; they have no such distinction. Gaming is professed and gloried in by all; and the nobleman who is detected telling a lie is vexed, but not in the least ashamed. In the whole regiment of the marine by Peter the Great, there is not one word addressed to the honour, or even to the probity, of his officers. Hopes of reward, and the constant fear of detection and punishment, are the 


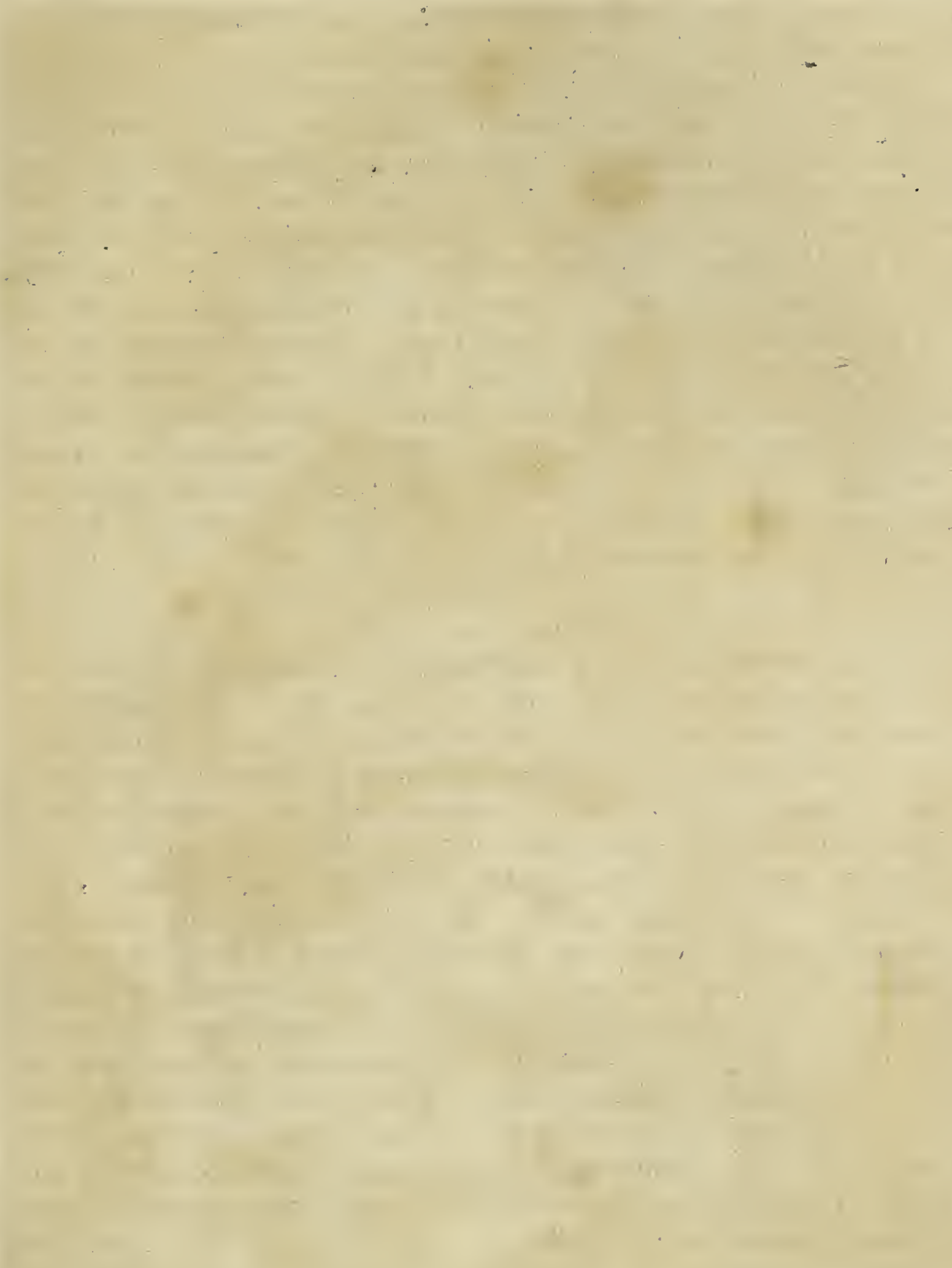




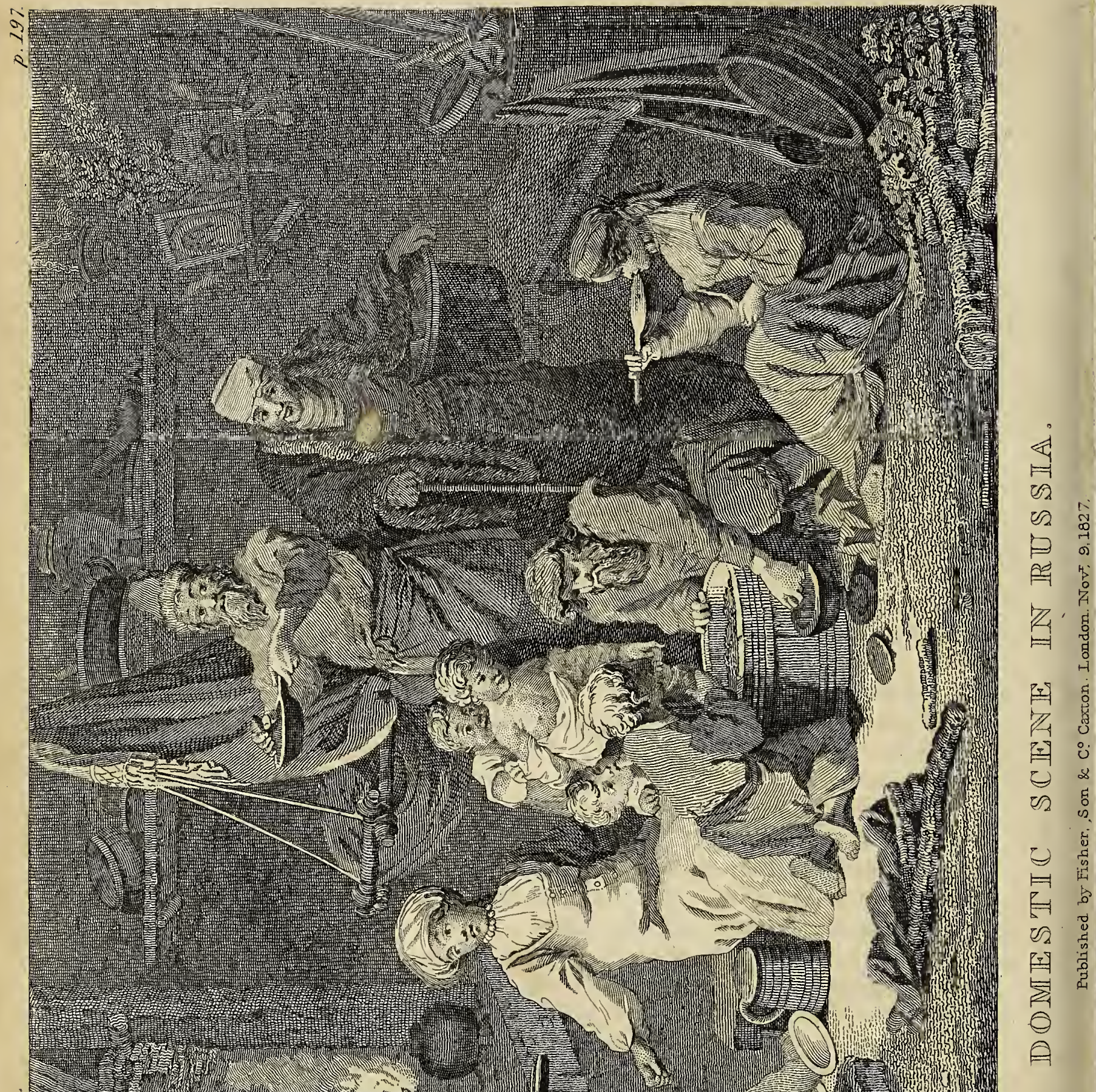


only motives touched ou. In every ship of war, and in every regiment, there is a fiscal or authorized spy, a man of respectable rank, whose letters must not be opened; but at the risk of the great knout; and he is required by express statute to give monthly reports of the behaviour of the officers and privates. Such regulations we cannot think well adapted to improve the morals of the people, yet we believe they have been improved by the care, assiluity, and example of some of their late sovereigns. Certain it is, the vice of drunkenness was so universally prevalent among them, that Peter. I. was obliged to restrain it by very severe edicts, which; however, have not produced nuch effect. There. were in the city of Moscow no fewer than 4000 brandy shops, in which the inhabitants used to sot away their time in drinking strong liquors and smoking tobacco. This last practice became so dangerous among persons in the most beastly state of intoxication, that a very severe law was made to prevent the pernicions consequences, otherwise the whole city might have been consumed by fire. The nobility were heretofore very powerful, each commanding a great number of vassals, whom they ruled with the most despotic and barbarous authority; but their possessions have been gradually circumscribed, and their power transferred in a great measure to the czar, on whom they are now wholly dependent. The Russian nobles formerly wore long beards, and long robes with straight sleeves dangling down to their ankles; their collars and shirts were generally wrought with silk of different colours; in lieu of hats, they covered their heads with furred caps; and, instead of shoes, wore red or yellow leathern buskins.

The dress of the women nearly resembled that of the other sex; with this difference, that their garments were more loose, their caps fantastical, and their shirt-sleeves three or four ells in length, gathered ip ii folds from the sloulder to the fore-arm. But now the French fashions prevail among the superior ranks throughout all Muscovy. The common people in this country are generally tall, healthy, and robust, patient of cold and hunger, inured to hardships, and remarkably capable of bearing the most sudden transitions from the extremes of hot or cold weather. Nothing is more customary than to see a Russian, who is over-lieated, and sweating at every pore, strip himself naked, and plunge into a river; nay, when their pores are all opened in the hot bath, to which they have daily recourse, they either practise this immersion, or subject themselves to a discharge of some pailfuls of cold water. This is the custom of both men and women, who enter the baths promiscuously, and appear uncovered to each other without scruple or hesitation. A Russian will subsist for many days upon a little oatmeal and water, and even raw roots; an onion is a regale; but the food they generally use in their journeys is a kind of rye bread cut into small square pieces, and dried again in the oven; these, whel they are hungry, they soak in water, and eat as a very comfortable repast. Both sexes are remarkably healthy and robust, and accustom themselves to sleep every day after dinner. The Russian women are remarkably fair, comely, strong, and well shaped, obedient to their lordly husbands, and patient under discipline. 


\section{Parental Despotism.}

Such is the slavery in which the Muscovites of both sexes are kept by their parents, their patrons, and the eimperor, that they are not allowed to disfiute any match that nay be provided for them by these directors, however disagreeable or odious it may le: Officers of the greatest rank in the army, both natives and foreigners, have been saddled with wives by the sovereign in this arbitrary manner.

A great general, some time ago deceased, who was a native of Britain, having been pressed by the late empress to wed one of her ladies, saved himself from a very disagreeable marriage, by pretending his constitution was so unsound that the lady would be irreparably injured by his compliance. In Russia, the authority of parents over their children is alnost as great as it was among the ancient Romans, and is often exercised with equal severity. Should a father, in punishing his son for a fault, be the immediate cause of his death, he could not be called to account for his conduct; he would have done nothing but what the law authorized him to do. Nor does this legal tyranny cease with the minority of children; it continues while they remain in their father's family, and is of ten exerted in the most indecent manner. It is not incommon, even in St. Petersburg, to see a lady of the highest rank, and in all the poinp and pride of youthful beauty, standing in the court-yard with her back bare, exposed to the whip of her father's servants. And so little disgrace is attached to this punishment, that the same lady will sit down at table with her father and his guests immediately after she has received her flogging, provided its severity has not confined lier to bed.

\section{Marriage Ceremonies.}

On the wedding day, the bride presents the bridegroom with a whip of her own making, in token of submission; and this he fails not to employ as the instrument of his authority. Very little ceremony is here used in match-making, which is the work of the parents. The bridegroom seldom sees the woman till he is joined to her for life. The marriage being proposed and agreed to, the lady is minutely examined by a certain body of her female relations; and if they find any bodily defect, they endeavour to cure it by their own skill. The bride, on her wedding day, is crowned with a garland of wormwood, implying the bitteriess that often attends the married state. When the priest has tied the nuptial linot at the altal, his clerk or sexton throws upon her head a handful of hops, wishing that she may prove as fruitful as the plant thus scattered. She is muffled up, and led home by a certain number of old women, the parish priest carrying the cross before; while one of his subalterns, in a rough goat-skin, prays all the way that she may bear as many children as there are hairs on his garment. The new-married couple, being seated ấ table, are presented "with bread and salt; and a chorus of boys and girls sing the epithalamium, which is always grossly obscene. The bride and bridegroom are then conducted to their own chamber by an old woman, who exhorts the wife to obey her husband, and retires. Then the bridegroom desires the lady to 
pull off one of his buskins, giving her to understand, that in one of them there is contained a whip, and in the other a jewel or a purse of money. She takes, her choice; and if she finds the purse, interprets it into a good omen; whereas, should she light on the whip, she construes it into an unhappy presage, and instantly receives a lash, as a specimen of what she has to expect.

The Muscovite husbands are the most barbarous, even to a proverb; they not only administer frequent and severe corrections to their wives, but sometimes torture them to death, without being sub. ject to any punishment for the nurder. He that marries a second wife, the first being alive, is not admitted farther than the church door; whoever espouses a third, is excomnunicated; so that, though polygamy is tolerated, they count it infamous. If a woman is barreu, the husband generally persuades her to retire into a convent; if fair means will not succeed, he may whip her into compliance.

\section{Religions and Superstitions.}

The Russians were converted to the Christian religion about the end of the tenth century. Since that period they have professed the articles of the Greek church, ningled with many superstitious ceremonies of their own. They do not believe in the pope's infallibility or supremacy; they hold no communion with the see of Rome; they use auricular confession, communicate in both kinds, adopt the Athanasiain creed, and adhere to the established liturgy of St. Basil. They worship the Virgin Mary and other saints, and adore crosses and relics. They observe four great fasts in the year, during which they never taste fish, flesh, nor any animal food; they will not drink after a malı who has eaten flesh, nor use a knife that has cut meat, in less than twenty-four hours after it has been used; nor will they, even though their health is at stake, touch any thing in which liartshorn or any animal substance has been infused. While this kind of Lent con tinues, they subsist upon cabbages, cucumbers, and rye-bread, drinking nothing stronger than a sort of small beer called quassi. They likewise fast every Weduesday and Friday. Their most common penance is to abstain from every species of food and drink, but bread, salt, cucumbers, and water. They bend their bodies, and continue in that painful posture, and between whiles strike their head against an image. The Muscovites reject as impure, horseflesh, elk, veal, hare, rabbit, ass's milk, mare's milk, and Venice treacle, because the flesh of vipers is an ingredient, also every thing that contains even the smallest quantity of musk, civet, and castor; yet they have no aversion to swine's flesh, and the country produces excellent bacon.

They celebrate fifteen grand festivals in the year. On Paln Sunday there is a magnificent procession, at which the czar assists in person and on foot. He is dressed in cloth of gold, his train is carried by the prine nobility, and he is attencled by his whole court. $\mathrm{He}$ is ininediately.preceded by the officers of his household, one of whom carries his handkerchief on his arm, lying upon another of the lichest embroidery He halts at a sort of platform of free-stone, where, 
turning to the east, and bending his body almost double, he pronownces a short prayer ; then he proceeds to the church of Jerusalem, where he renews his devotion. This exercise being performed, he returis to his palace, the bridle of the patriarch's horse resting upon his arm. The horse's head being covered with white linen, is held by sone noblemen, while the patriarch, sitting sidewise, and holding a cross in his hand, distributes benedictions as he moves along : on his head he wears a cap edged with ermine, adorned with loops and buttons of goll, and precious stones; before him are displayed banners of consecrated stufi, in a variety of colours. Above 500 priests walk in the procession; those who are near the patriarch, bearing pictures of the Virgin Mary, richly ornamented with gold, jewels, and pearls, with crosses, relics, and religious books, including a copy of the Gospels, which they reckon of inestimable value. In the midst of this procession is born a triumphal arch, and on the top an apple-tree covered with fruit, which several little boys enclosed in the machine endeavour to gather. The lords and laity carry branches of willow; the guards and the spectators throw themselves on the ground, while the procession haits, and after the ceremony, the patriarch presents a purse of 100 rubles to the czar, who perhaps invites him to dine at his table during the season of Easter; the whole empire is filled with myrth and rejoicing, which, however, never fails to degenerate into heat and debauchery; even the ladies may indulge thenselves with strong liquor's to intoxication without scandal. During these carnivals, a great number of people, in reeling home drunk, fall down and perish among the snow. It is even dangerous to relieve a person thus overtaken, for should he die, the person who endeavoured to assist him is called before the judge, and generally pays dear for his charity. The Muscovite priests use exorcisms at the administration of baptism. They plunge the child three times over head and ears in water, and give it the sacrament of the Lord's supper in one kind, until it hath attained the age of seven, aiter which the child is indulged with it in both kinds. They likewise administer the sacrament to dying persons, together with extreme unction; and if this be neglected, the body is denied Christian burial. Soon as the person expires, the body is deposited in a coffin, with a lunchion of bread, a pair of shoes, some few pieces of money, and a certificate sigued by the parish priest, and directed to St. Nicholas, who is one of their great patrons. They likewise hold St. Andrew in great veneration, and pretend they were converted by him to Christianity. But next to St. Nicholas, they adore St. Anthony of Padina, who is supposed to have sailed upon a mill-stone through the Mediterranean and Atlantic, and over the lakes Ladoga, and Onega, as far as Novogorod. Every house is furnished with an image of St. Nicholas, carved in the most rude and fantastic manner; and when it becomes old and worm-eaten, the owner either throws it into a river with a few pieces of coin, saying, Adien, brother, or returns it to the maker, who accommodates him with a new image.

The women are very careful in adorning their private St. Nicholases with rich clothes and jewels; but on emergency, these are resumed, and the saint left as naked as he came from the hand of 
the carpenter. There are monasteries in Russia ; but neither the monks nor the nuns are subjected to severe restrictions. The friars are either horse-jockeys, or trade in hops, wheat, and other conmodities; the sisters are at liberty to go abroad when they please, and indulge themselves in all manner of freedoms. Heretofore liberty af conscience was denied, and every convicted heretic was cominitted to the flames; but since the reign of Peter, all religions and sects are tolerated throughout the empire. Roman Catholics, Lutherans, Calvinists, Armenians, Jews, and Mahometans, enjoy the free exercise of their respective forms of worship; though it was not without great difficulty, and by dint of extraordinary solicitation from different powers, that the Rumish religion was allowed. Peter, knowing the dangerous tenets of a religion that might set the spiritual power of the pope at variance with the temporal power of the emperor, and being well acquainted with the meddling genius of its professors, held out for some time against the intercession of Germany, France, and Poland: and though at length he yielded to their joint interposition, he would by no means suffer any Jesuits to enter his dominions.

\section{INHABITANTS OF SAMOIEDA.}

THEse people are so rude, that they can hardly pretend to humanity, except in face and figure, they have little understanding, and in many things resemble brutes, for they will eat carrion of every kind. They travel on the snow on sledges, drawn with an animal like a rein-deer, but with the horns of a stag. Travellers affirm, that no people on the earth make such shocking figures : their stature is short; their shoulders and faces are broad, with-flat broad noses, great blubber lips, and staring eyes; their complexion is dark, and their hair long, and as black as pitch, and they have very little beards, and the Samoiede women have black nipples. If they have any religion at all, it is idolatry, though some attempts have been made of late to convert them.

Their huts are made of birch bark sewed together, which is laid upon stakes set in the ground, and at the top is a hole to let out the snoke; the fire is made in the middle, and both men and women lie naked round it all night. They have little regard to the nearness of kin, and take as many wives as they can keep; their only employment is hunting and fishing.

\section{Inhabitants of Darien.}

THE aboriginal natives of the isthmus or province of Darien, have several peculiar customs. Although they go naked, like most of the other American Indians, yet they wear nose-jewels. The men have silver plates in the form of a crescent, fastened to their noses, and hanging over their mouths. The women have rings passing through their noses, and hanging down in the same manner. They also have several chains, composed of teeth, shells, beads, \&c., hanging down from the neck to the pit of the stomach. 
Their houses are scattered by the sides of rivers, and have plantations around them. They are built with small posts set upright, about seven feet high, hurdled with sticks, and daubed over with earth. The men clear the plantations, and the women cultivate them. The girls pick and spin cotton,'which the women weave into cloth for their hammocks. The men make baskets very neatly with canes, reeds, and palmetto leaves, dyed of different colours. Each man has several wives, who live together in great harmony. They dance to the sound of a pipe or drim, and are expert at tumbling. When they go a hunting, the women carry baskets full of plantains, bananas, yams, potatoes, and cassava roots, ready roasted. Rivers are no interruption to their expeditions, men, women, and children being equally expert at swimming. They have no distinction of weeks, but reckon their time by the course of the moon.

\section{CAFrRES.}

THESE are the natives of Caffraria, whom Mr.Walker thus describes : "The Caffies are tall, active, and strong, and evince great courage in attacking lions, and other beasts of prey. Their complexions are black : their clothing consists of hides of oxen, which are as pliant as cloth." Perhaps this kind of clothing has led voyagers to confound them with the Hottentots. "Industry is the leading trait in the character of the Caffres. The men employ much of their time in hunting, the women in cultivating the land. They also make earthenware, and curious baskets. They have, a high opinion of the supreme Being, and of his power; believe in a future state of rewards and punishments; and think that the world had no beginning, and will be everlasting. They have no form of prayers nor priests, yet undergo, at nine years of age, the initiatory rite of the Hebrews. Their government is limited monarchy, and their ling is of ten poorer than his subjects. He is allowed a plurality of wives."

\section{Avars.}

THESE were a tribe of Sarmatian origin, deriving their name which signifies far distant, from their remote easteru situation with regard to Europe. Their name and their nation were unknown to the civilized world, till in the sixth century they revealed their existence to it by the terrors they inspired, and connected their history with its revolutions and its downfall. Driven before a tribe more fierce and powerful than themselves, they emerged from their primeval wilds, and appeared on the confines of the Eastern empire in the reign of Justinian. Their pride was not tamed by their defeats, nor their confidence dismayed by the appearance of a civilized and powerful state. Their ambassadors having gained admittance to the Roman emperor, represented their nation as the most powerful and most warlike people on the earth, as invincible when attacked, or irresistible when aggressors. Upon the faith of this character, they offered their services to the empire, and demanded gifts and riches as their reward. Instead of endeavouring to dispel this cloud of bar- 
barians, the timid monarch who then sat on the throne of the Cesars, courted their alliance, and purchased their protection. He sent an ambassador to their camp at the foot of mount Caucasus, to assure them of his friendship, and to point the line of their invading hordes to the country of his enemies.

Their camps were soon pitched on the Danube and the Elbe; and their savage fury either swept from the earth, or rendered tributary to their dominion, many tribes of Hungary, Poland, and Gernany. Their king still retained an attachment to the emperor, who on his side appeared not averse to continue the alliance, till his friendship was claimed by a more powerful horde, who effected to treat the Avars as slaves and fugitives. The Turks had pursued them from their native wilds to the Wolga, to Mount Caucasus, and the Euxine, and they now appeared in the presence of the emperor requiring him to withdraw his countenance from apeople whom they had followed so far as runaway subjects, and whom they now claimed a right to subdue or extirpate. The timid emperor yielded to this demand, and renounced the alliance of his friends the Avars. "Their ambassadors, who came to renew the coalition, and to represent the advantages that might result from it, were dismissed without presents or promises, and their remonstrances or threats treated with haughty defiance. The king, called Chagan, and his tribe, were either awed by the power of the empire, or dissembled their resentment till a more convenient opportunity should occur for gratifying it, and retired into Germany, where they met in dreadful conflict with the fierce and powerful nation of the Franks. They were obliged to withdraw from the neighbourhood of the Franks, after repeated defeats, and might, like many other hordes of those barbarous ages, have been totally extinguished in their retreat to their native wilds, had they not had the good fortune to have formed a league with the Lombards, in conjunction.with whom they destroyed the tribe of Gepida, and succeeded to their dominions. Their new allies directing their views to Italy, left them in possession of their extensive territories, which stretched from the Euxine to Germany and Prussia. They were now in a condition to repay the insults offered them by the Romans, and the most glorious of their kings, Baion, was not backward to display the power of his arms, and to extend the terror of his name. He made repeated inroads upon the empire, and demanded presents as the price of his retreat. Submission and exactions only increased arrogance, and the value of the presents bestowed only encouraged future demands. The emperor Maurice found he must either become a tributary to a barbarian, or repel his incursions by meeting him in the field. In five battles his general was victorious, 60,000 of the barbarians, with four of the king's sons, were killed in battle, and nearly $\mathbf{2 0 , 0 0 0}$ prisoners were taken. The Avars, however, were not finally subdued, and seizing the opportunity when the eastern parts of the empire were pressed with all the weight of hostility by the Persian kings, they renewed their dreadful inroads with augmented forces and more atrocious cruelties. Blood and rapine every where marked their progress, the most fruitful violations of nature and humanity every where distinguished their conduct. : Their captives were either 
killed in cold blood or reduced to slavery, and virgins of the highest rank were abaindoned to their brutal lusts.

Heraclius, the emperor of the east, having in vain endeavoured to purchase their retreat, was almost surprised by the barbarian king in an interview which the latter solicited, as preparatory to a mutual reconciliation. Having joined his forces with the Persians, the chagon invested Constantinople, and after endangering the safety of the city, by repeated assaults, was driven from it by the ancestors of the race that now possess it. After this period the fortune of the Avars began to decline, and we find them, in r95, surrendering themselves to the arms of Charlemagne, and offering to embrace his religion as well as to submit to his sway.

\section{Pholeys.}

The Pholeys are the inhabitants of Pholey, a kingdom of Africa, and a people of very peculiar manners. Mr. More, however, says, that the Pholeys live in clans, build towns and are in every kingdom and country on each side the river, yet are not subject to any kings of the country, though they live in their territories, for if they are used ill in one nation, they break up their towns and remove to another. They are rather of a low stature, but have a genteel and easy shape, with an air peculiarly delicate and agreeable. Though they are strangers in the country, they are the greatest planters in it. They are extremely industrions and frugal, and raise much more corn and cotton than they consume, which they sell at reasonable rates, and are so remarkable for their hospitality, that the natives esteem it a blessing to have a Pholey town in their neighbourhood, and their behaviour has gained them such reputation, that it is esteemed infamous for any one to treat them in an inhospitable manner. Their humanity extends to all, but they are doubly kind to people of their own race. They are, however, as brave as any people of Africa, and very expert in the use of their arms, which are javelins, cutlasses, bows and arrows, and occasionally guns. They usually settle near some Mantingo town, there being scarce any of note up the river that has not a Pholey town near it. Most of them speak Arabic, which is taught in their schools, and they are able to read the Koran in that language, thongh they have a vulgar tongue called Pholey.

Their houses are built in a very regular manner, they being round structures, placed in rows at a distance from each other to avoid fire, and each of them has a thatched roof, somewhat resembling a high crowned hat. They are also great huntsmen, and not only kill lions, tigers, and other wild beasts, but frequently go twenty or thirty in a company, to hunt clephants, whose teeth they sell, and whose flesh they smoke-dry and eat, keeping it for several months together. They are almost the only people who make butter, and sell cattle at some distance up the river. They are very particular in their dress, and never wear any other clothes but long robes of white cotton, which they make themselves. They are always very clean, especially the women, who keep their houses exceedingly neat. 


\section{InHabitants of Portugád.}

The Portuguese are represented as inferior to the Spaniards, both in person and genius; as extremely treacherous, and crafty in thein dealings; much given to avarice and usury; and vindictive, malicious, and cruel. The meaner sort are said to be addicted to thieving; yet they have shewn themselves on many occasions a brave and warlike people. They are justly famed for their skill in navigation; and for their many discoveries both in the East and West Indies. The women are not so prolific as in colder climes; but they are very beautiful whilst young, though their complexion is somewhat upon the olive. Their eyes are very black and sparkling, and retain their brilliancy after all their other charms are gone. The ladies spoil and disfigure their skins and complexions with paints and washes; but, though lively and witty, they have a nice sense of female honour. Both men and women make great use of spectacles: not so much to aid their sight, as to give them the appearance of wislom and gravity. Their dress, like that of the Spaniards, never used to vary, especially among the men; but of late years, both sexes have given much into the French modes.

\section{Gladiators.}

THESE were persons who fought for the amusement of the public in the arenas of amphitheatres in the city of Rome, and of other places under the dominion of the Romans. The term is derived from their use of the gladius, or sword; and the origin of this horrid custom is said to have been the practice of sacrificing captives to the manes of chiefs killed in battle. It seems, however, more probable that it arose from the funeral games of antiquity, when the friends of the deceased fought in honour of his memory; an instance of which occurs in the twenty-third book of the Iliad, at the burning of the budy of Patroclus: Achilles having ordained every solemn rite usual upon those occasions, Homer adds,

\section{"The prizes next are order'd to the field,} For the bold champions who the crestus wield."

The leather which composed the crestus being loaded with lead, enabled the combatants to give each other mortal blows, though the hands only were used. Epeus, of gigantic stature, challenged the whole of the Grecian chiefs, who were terrified at his bulk, and Euryolus alone accepted his defiance.

" Him great Tydides urges to contend,

Warm with the hopes of conquest for his friend;

Officious with the cincture girds him round,

And to his wrist the gloves of death are bound."

The captives slain on this occasion were not commanded to fight; they had been led to the pile, and died with the sheep, oxen, coursers, 
and dogs, that the bodies might be burnt by the flames which con sumed that of Patroclus:

\section{"'Then last of all, and horrible to tell,}

Sad sacrifice! twelve Trojan captains fell."

The above quotations positively prove that the Romans deviated from their predecessors in the practice of this barbarous custom. The Greeks appear to have destroyed their prisoners on a revengeful principle, and despatched them immediately; but the former delighted in cruelty, and would rather purchase captives, or destroy the lives of ill-disposed slaves, than send the ashes of their friends to the urn bloodless, or the spectators of the obsequies home, without the gratification of witnessing wretches cutting each other to death, though not under the influence of previous anger.

According to Valerius Maximus, and Lampridius in Heliogabalus, gladiators were first introduced at Rome by $\mathbf{M}$. and $\mathrm{D}$. Brutus, at the funeral of their father, in the consulship of Ap. Claudius and M. Fulvius. The examples of great men, however detestable, ever produce imitators. Hence, though the brothers may have acted from motives of family vanity only, other great personages, perceiving that the people delighted in the sight of blood, determined to gratify them by adopting the custom; which was afterwards extended to public exhibitions given by the priests in the Ludi Sacerdotales, and managed solely for the amusement of the populace, or perhaps to confirm them in an habitual contempt for wounds and military death.

Thus the family alluded to, introducing perhaps three pairs of gladiators to the citizens of Rome, was the means of multiplying their number to an amount which is shocking to humanity, for the subsequent emperors appeared to have attempted to excel each other in assembling them at their birth-day celebrations, at triumphs, the consecration of edifices, at their periodical games, and at the rejoicings after great victories.

As the disposition of several of the chief magistrates who are recorded as having exhibited gladiators was mild and merciful, it is but fair to suppose that Julius Cassar, who produced three hundred and twenty pairs in his edileship, Titus, Trajan, and others, submitted to the custom in compliance with the temper of the people, rather than from any predilection to it in themselves. But there are few pernicious practices which do not carry their punishment with them. The prevailing frenzy had at length arrived to such an excess, that the gladiators became sufficiently numerous to threaten the safety of the state, for, when the Catiline conspiracy raged, an order was issued to disperse the gladiators in different garrisons, that they might not join the disaffected party; yet although the fears of the government were excited, it does not appear that any steps were taken to lessen their number, as the emperor Otho had it in his power, long afterwards, to enlist two thousand of them to serve him against Vitellius.

The people tlius cut off from society, and rendered murderers per force, were fully justified in considering the whole Roman state their enemy; nor was it surprising that they were sometimes willing to revenge themselves upon their oppressors. Spartacus, a gladiator, 
gave a bold but unavailing example to his brethren, by rushing ont of an amphitheatre at Verona, at the head of those collected there for public exhibition, declaring war against the Romans, and assembling so great a force as to make the citizens of Rome tremble. Similar apprehensions were entertained at intervals by enlightened people ; and Cicero observed, "The shows of gladiators may possibly to some persons seem barbarous and inhuman ; and indeed, as the case now stands, I cannot say that the censure is unjust. But in those times when only guilty persons composed the number of combatants; - the ear perhaps might receive many better instructions, but it is impossible that any thing which affects our eyes should fortify us with more success against the assaults of grief and death." Still he had the good sense to propose a law prohibiting all candidates for offices from exhibiting gladiators within two years before they became such. Julius Cresar limited their number in Rome. Augustus ordained that not more than sixty pairs of combatants should fight at one exhibition, and that there should only be two of the latter in a year. During the reign of Tiberius it was decreed that gladiators were not to be brought before the public by persons worth less than 400,000 sesterces. Constantine the Great had the humanity and courage to abolish the custom, after it had prevailed near six hundred years; but it revived under Constantius, Theodosius, and Valentinian, and was finally suppressed by the emperor Honorius.

The guilty persons alluded to by Cicero must apply to those slaves whose masters sold them, for disobedience or nalpractices, to the Lanistre, who, instructing them in the arts of attack and defence, hired them to any rich man disposed to exhibit them. Had they been entirely confined to this class of people, we might have been less inclined to censure the custom; but when we reflect that honest and courageous soldiers were condemned to undergo the lash of their captors, and afterwards perish by the swords of slaves, or each other, we cannot fail of being astonished that the high-spirited Roman should expose himself to their vengeance, by voluntarily entering the arena. with them, there to meet almost certain death. Strange, however, as it appears; freemen fought for hire under the term of Auctorati; and even knights, nobles, and senctors, who had wasted their property by extravagance, have deigned to become gladiators. Augustus, offended at their conduct, forbade the senatorian order and knights to enter the lists as such; but preceding princes, less influenced by a sense of honour, permitted them to act as they pleased. The contagion at length extended to the females of Rome; and, lastly, dwarfs were taught the use of the sword, and, fighting with the women or each other, furnished a new description of diversion. Kennet classes the various sorts of Gladiators under the terms of Retiarii, the Secutores, the Myrmillones, the Thracians, the Samnites, the Essedarii, and the Andabatæ; the Gladiatores Meridiani fought in the afternoon; the Gladiatores Fiscales were paid from the emperor's private treasury; the Gladiatores Postulatiti were men of consummate art in the profession; the Gladiatores Catervarii fought in small companies; and the Gladiatores Ordinarii were not particularly distinguished, but fought in a common way. 
The dress of the Retiarius was a short habit, and a bat tied under the chin. His means of offence were a weapon called a fuscina, and a net. With the latter in his right hand, he endeavoured to entangle his adversary; and, with the fuscina in the left, he aimed mortal blows at him; but as this description of gladiator was invariably opposed to Secutor, armed with a scymeter, a buckler, and a helmet, the Retiarius had no means of escape, if he failed in casting his net, except by fight round the arena, during which he adjusted it for a new trial. The best gladiators were Thracians; these men, with their falchion and small round shiclds, possessed more deternined ferocity and cruelty than any of their opponents. Kenuet says, "The origin of the Samnite gladiators is given by. Livy. The Campanians," says he, "bearing a great hatred to the: Samnites, they armed a part of their gladiators after the fashion of that country, and called them Sanunites. They wore a shield, broad at top, to defend the breast and shoulders, and growing more narrow towards the bottom, that it might be moved with the greater convenience. 'They had a sort of belt coming over their breasts, a greave on their left foot, and a crested helmet on their heads." The Epidarii sometimes engage from chariots, and at others on foot; and the Andabata mounted. The exhibition of gladiotors was announced to the public by bills fixed in the public places, sometimes accompanied by paintings of the intended combat, or tlie must celebrated combatants; and when the time mentioned had arrived, and the pcople assembled, the gladiators marched slowly round the arena; they were then matched, by persons appointed for that purpose, as equally as possible, and they prepared for the contest by fencing with blunted swords, \&c.; after which the trumpets were sounded, and the battles began in serious earnest. When a severe wound was given, the gladiator who inflicted it, and the people, exclaimed, "He has it." If that proved decisive, the vanquished person resigned his weapon, and acknowledged himself conquered. But this submission was not alone sufficient to save his life; the people were to decide his fate. He therefore turned to them, and supplicated mercy, which was granted, or refused, according to their opinion of his skill and courage. Several learned authors have differed as to the exact manner in which the hands and fingers were placed, to express praise or disapprobation on those occasions. According to Juvenal, the bending of the thumbs backwards authorized the conqueror to kill his adversary as a coward. The emperor might, however, intérfere, if he was present, and save the gladiator; it is supposed, besides, that his entrance at the instant of defeat was favourable to the vanquished party, as far as his life was concerned.

The rewards of the victors consisted of money collected from the spectators; and when they happened to be slaves, they received the pileus, or cap, denoting that from that moment they became free; or the rudis, or wand, which signified that their services as gladiators were thenceforth dispensed with, whether slaves or freemen. It was customary for the persons thus situated either to become Lanista, or to suspend their arms in the temple of Hercules.

There are few nations which have not imitated this strange custom, 
in a greater or less degree, at different periods of their history ; and, less than a century past, we had gladiators in London, who fought and bled, but never killed each other. Malcolm's Anecdotes of the Manrers and Customs of this great Metropolis, contains numerous particulars relating to those modern swordsmen; whose exertions were rivalled by several females, in the art of boxing and cutting. One of their challenges, from the publication alluded to, will be a proper conclusion to this article. "In Islington Road, on Monday, beingthe 17th of July, 1727, will be performed a trial of skill by the following combatants. We, Robert Baker and Mary Welsh, from Ireland, having often contaminated our swords in the abdominous corporations of such antagonists as have had the insolence to dispute our skill; do find ourselves once more necessitated to challenge, defy, and invite Mr. Stokes, and his bold Anızonian virago, to meet us on the stage ; where we hope to give a satisfaction to the lonourable lord of oui nation, who has laid a wager of twenty guineas on our heads. They that give the most cuts to have the whole money, and the benefit of the house. And if swords, daggers, quarter-staff, fury, rage, and resolution, will prevail, our friends-shall not meet with a disapointment."-_We, James and Elizabeth Stokes, of the city of London, having already gained an universal approbation by our agility of body, dexterous hands, and courageous hearts, need not preambulate on this occasion, but rather choose to exercise the sword to their sorrow, and corroborate the general opinion of the town, than to follow the custom of our repartee antagonists. This will be the last time of Mrs. Stokes performing on the stage. There will be a door on purpose for the reception of the gentlemen, where coaches may drive up to it, and the company come in without being crowded. Attendance will be given at three, and the combatants mount at six. They all fight in the same dresses as before."

\section{Circassians.}

THE inlabitants of Circassia, a conntry in Asia. The Circassian women are extremely well-shaped, with exceeding fine features, smooth clear complexions, and beautiful black eyes, which with their black hair, hanging in two tresses, one on each side the face, give them the most lovely appearance ; they wear a black coif on their heads, covered with a fine white cloth, tied under the chin. During summer they all wear only a chemise of divers colours, and that far too open to afford modest and becoming concealment; thus with their beautiful faces, always uncovered, contrary to the customs of many of the other provinces in these parts, their good humour and lively freedom in conversation, altogether l'ender them very attracting; notwithstanding this, they have the reputation of being very chaste, though much exposed to temptation; for; according to the accounts of a late traveller, it is an established point of good mauners among them, that as soon as any person comes in to speak to the wife, the husband goes out of the house : but whether this continency of theirs proceeds from their own generosity, to recompense their husbands for the confidence they place in them, or has its foundation only in fame, he pretends not to 
defermine. Their language they have in common with the other neighbouring Tartars, although the chief people among them are not ignorant of the Russian; their ancient and native religion is Paganism, for notwithstanding the use of circumcision, they have neither priest, koran, nor mosque, like the Mahometans. Every person offers his own sacrifice at pleasure; for which, however, they have certain days, established rather by custom than auy positive command; their most solemil sacrifices are offered at the death of their nearest friends; upon which occasion both men and women meet in the field to be present at the offering, which is a he-goat; and having killed, they flay it, and stretch the skin, with the head and horns on, upon a cross at the top of a long pole, placed commonly in a quickset edge, to keep the cattle from it; and near this place the sacrifice is offered, by boiling and roasting the flesh, which they afterwards eat. When the feast is over, the men rise, and having paid their adoration to the skin, and muttered over some prayers, the womell withdraw, and the men conclude the ceremony with drinking a great quantity of aqua-vita, and this generally ends in a quarrel before they part. In summer the Circassians quit the towns, and encamp in the fields like the neighbouring Tartars, occasionally shifting their stations along with their focks and herds. Besides game, in which the country greatly abounds, the Circassians eat beef and mutton, but that which they prefer to all others is the flesh of a young horse. Their bread consists of thin cakes of barley-meal, baked upon the hearth, which they always eat new ; and their usual drink is water, or mare's milk, from the latter of which they distil a spirit, as most of the Tartar nations do. They allot no fixed hours for the refreshments of the table or sleep, which they indulge irregularly, as inclination or conscience dictates. When the men make excursions into an enemy's country, they will pass several days and nights successively without sleeping, but at their return devote as much time to repose, as the space in which they had before abstained from that gratification. When they eat, they sit cross-legged on the floor, the skin of some animal serving them instead of a carpet. In removing from one part of the country to another, the women and children are carried in waggons, which are a kind of travelling houses, and drawn by oxen or camels, as they never use horses for draught. 'Their breed of the latter, however, is reckoned exceeding good; and they are accustomed to swim along any river on horseback. The wonien and children smoke tobacco as well as men; and this is the most acceptable commodity which a traveller can carry with him into the Tartar countries. The principal branch of their traffic is their own children, especially their daughters, whom they sell for the use of the seraglios in Turkey and Persia, where they frequently marry to great advantage, and make the fortune of their families. The merchants who come from Constantinople to purchase those girls, are generally Jews, who, as well as the mothers, are said to be extremely careful of preserving the chastity of the young women, knowing the very high value that is set by the Turks upon virgin purity. The greater part of the Circassians are Christians of the Greek church; but there are also both Mahometans and Pagans amongst them. 


\section{Singular Trial.}

An Historical Account of Joseph Lesurques, who, through a judicial error, was condemned and executed on the 30th of October, 1796.From the "Drapeau Blanc."

Joseph LESURQues was born at Donai in 1763, of an honest and respectable family. He received a good education, which inspired him with a taste for the arts. After having served some time in the regiment of Auvergne, he returned to his country, and was admitted as principal in the bureaux of the administration of the district. His conduct in this situation merited and obtained the suffrages of all who knew him, and he continued to enjoy the reputation of a worthy man. A marriage which he contracted with a young lady of good family increased his fortune, and put him in possession of an annual income of ten thousand francs, - a considerable fortune this, in a provincial town. The father of a family, he determined at the age of thirty-three, to settle at Paris, in order that he might himself conduct the education of his children. He had three; two girls, and a boy. He took lodgings in the house of M. Moruet, a notary, and amused himself with rendering them convenient and agreeable.Fortune till then had smiled upon him, but; alas! she now prepared for lim the most fatal reverses.

It is is well known that people who come to Paris from the provinces are almost lost, in so large a town, from their first connexions with persons of their own country. M. Lesurques knew Le Sieur Guesno, who kept a waggon-office at Donai, and to whom he had lent two thousand francs. Le Sieur Guesno came to see him--returned the two thousand francs, and invited him to breakfast. Guesno lodged at the house of one Richard, born, as well as himself, at Donai, but a man of a dissipated character. Richard was conuected with an individual named Courriol, who was a perfect stranger to Lesurques. Richard was present at breakfast; Courriol came in unexpectedly, and remained. This meeting took place four days after an event which still occupies the whole capital. The courier of Lyons had been stopped; robbed, and assassinated on the road from Paris to Melun.- Search was making for the assassins. Courriol was one, and consequently not free from terror and anxiety. Guesno was gone to Chateal.Thierry on business; Courriol followed, and took lodgings in the same house as Guesno. He was arrested; all his papers, those belonging to Guesno, and even those of Golier the landlord, were seized. The two latter presented themseives at the police office, appeared free from all suspicion, and were discharged; Courriol alone was detained,-Guesno received permission to return for his papers. Unhappily Guesno met Lesurques just as he was entering the central office of the police; he asked him to accompany him; Lesurques consented; each entering with that unsuspecting confidence which the peace of a good conscience inspires. Here commence all the misfortunes of Lesurques.

M. Daubauton, officer of the judicial police, was taking depositions against the assassins of the courier of Lyons. The antechamber of 
his cabinet was filled with persons ready to swear. Among these persons were two women from the environs of the place where the crime had been committed. For some time they fixed their eyes on Guesno and Lesurques, who were waiting for admission. They requested soon after that they might be shewn into the cabinet of M. Daubauton; they were admitted, and assured M. D. that they had just recognized in the antechamber two men who had beell concerned in the assassination of the courier. The judge exhorted them not to yield to false conjectures, and represented to them the improbability of their declaration ; but they still persisted in it. It was indeed difficult to believe that two culprits should thus of their own accord throw themselves into the hands of justice. Nothing, however, could induce these women to desist. The magistrate therefore saw himself necessitated to arrest two honest men, who were entirely unconscious of the danger which threatened them. The deposition of these women against Guesno was inexcusable, for he did not resemble any of the real culprits; but it may be justified in the case of Lesurques, for, by a terrible fatality, he bore a great resemblance to one of the robbers described as the principal agent, or one of the accomplices, in the assassination. Recourse was had to the description of the person: it was found exact. Lesurques was asked for his carte de surete. He could only produce one belonging to his father, who bore the same name as himself. So many circumstances appearedoverwhelming. The judicial officer began to entertain suspicions, and Lesurques and Guesno were accused with Courriol, whom we have already mentioned; Bcrnard, who furnished the assassins with horses ; Richard, at whose house a part of the stolen goods were deposited, in order to undergo examination; and a Sieur Bruer, whom an innkeeper of Lieursaint thought he recognized, was quickly declared innocent.

At the moment that Lesurques underwent this afflicting trial, he had just finished the furnishing and decorating of lis lodgings. On the ill-fated day of his arrest he had left them gaily; he had only slept there one night, and he was never to enter them again. Information was sought after with all that ardour which animated the magistrates in those times, when the roads were infested with robbers, when the couriers were frequently stopped, and the money of the state taken by force.

As soon as the arrest of Lesurques was made public, the consternation and grief of his family, his friends, and all the town of Donai, were extreme. All were impatient to give him some marks of the lively interest they took in his fate. The least reflection was sufficient to convince the mind, that a man who possessed a fortune of 10,000 francs, who till the present moment had enjoyed the most honourable reputation, who cane to settle at Paris with his wife and children, who hired lodgings at the house of M. Motuet, a well-kilown notary, and occupied himself in furnishing them, never could have left his country to come and assassinate the Courier of Lyons on the road of Melun. The sum stolen from the Courier was 14,000 francs in cash, and 7 millions in assignats, which, in 1796, might be equal to from 5 to 6000 francs. The number of culprits marked out for justice were six, including the man who furnished the horses. It was then 
supposed that a rich and honourable man, in order to obtain three thousand francs, transformed himself suddenly into an assassin on the high road. In such a case, all concerned should have proceeded with extreme circumspection, and, above all, have been on their guard against prejudice. Quite the contrary. When called to the trial, the two women were obstinate in their declaration. Guesno made their deposition void by proving his alibi by evidence. Of what weight then was the testimony of these women? Bruer, recognized by an innkeeper of Lieursaint, proved, with the same success, that he neither had nor could have had any part in the crime for which the law pursued him. Lesurques thought himself equally sure of demonstrating his innocence.

He called two distinguished artists of Paris, who gave evidence that they had dined with him the day the assassination took place, and had not left him till eleven o'clock at vight. Their depositions were fortified by many important and satisfactory proofs. One of them recollected, too, that that very day he had mounted the guard, and the registers of the national guard confirmed his testimony. Two jewellers of the Palais Royal attested that he had been at one of their shops, bought a ladle, and changed some ear-rings. The tribunal required that the books should be produced. Here, by a new fatality, the register was misdated!

Separate this particular circumstance from Lesurques situation, and it scarcely merits attention. It happens every day that mistakes are made in the dates of the month, and easily corrected. There is no merchant's daily journal which does not furnish some example of this; but such was the seriousness of the circumstances, and the disposition of the tribunal, that this incident filled the judges with the strongest conviction. They would hear nothing more. All the depositions which they had received were looked upon only as so many acts of conspiracy; still, however, their real authority was not lessened. The unfortunate condition of Lesurques arose from an excess of confidence; if he had not been desirous of multiplying the proofs of his innocence, if he had been satisfied with calling the two artists whom we have mentioned, and the workmen who were employed in furnishing his lodgings, his alibi would have been proved. Nearly forty witnesses bore testimony to his probity; most of them came from Donai at their own expense, in order to support and declare his innocence and virtue. None of these considerations could weaken or dispel the prejudices of the tribunal, or perhaps of the jurymen. They saw only the book of the jeweller, which was misdated. A single presumption destroyed the most decisive testimonies.

They shewed the accused a plaited spur found on the road, and the woman who had declared that she recognized Lesurques, said to him, I saw you mend it; I lent you thread to tie the links which were broken." Lesurques had nothing to oppose to the many charges which seemed to overwhelm him, but the undisturbed countenance and proud tranquillity of an honourable man. Courriol and his accomplices denied the crime most obstinately. The decision of the public accuser was such as might have been expected from a magistrate known for his severity, and prejudiced by a multitude of circumstances 
which the malice of fortune scemed to have wrought together for the express purpose of crushing an unfortunate but guiltless man. Courriol, Lesurques, and Bernard, were condemned to death, and Richard to imprisonment in irons. Neither Richard nor Bernard had taken an active part in the assassination. The former had only received a part of the stolen goods, and the latter lent horses to the assassins. The condemned sued for a repeal, but their application was rejected. As soon as Courriel saw that death was inevitable, he was impatient to bear testimony to innocence; he declared before his judges that he had never been in any way connected with Lesurques; that this unfortunate man had taken no part in the crime; that in sentencing; him to death they were immolating a victim unjustly; he pointed out all his accomplices, and particularly described Dubosq, whose figure and features bore such a fatal resemblance to Lesurques; in short, he fortified his declaration with so many evidences, that the Directory thought it their duty to address a message to the Council of Five Hundred, in favour of the unfortunate Lesurques. Must then (said the Directory) the innocent perish for the guilty?

The Council of Five Hundred ordered a delay, and named a commission to bring them a prompt account. Alas! the same prejudices which had induced the judges to pass sentence on Lesurques, assailed the commission. It was supposed that Courriol might have been persuaded by the offer of money to make his tardy confessions; that the details which he had given of the assassination might be all a falsehood, concerted between him and his accomplice; that the culprits whom he pointed out might be imaginary beings only, and that the proofs which were brought to fortify the declaration of Courriol might be only the work of Lesurques' friends. And thus their decision rested on a simple probability. A second message from the Directory had no more effect than the first; they added to the above-mentioned probabilities, the respect due to the decisions of the jury, and the inviolability of its judgments. Lesurques, Bernard, and Courriol were condemned to die. To the last moment Courriol proclaimed the innocence of Lesurques, and continued to desire that they would search for the men he had described. Lesurques died forgiving the jurges, and all those any way concerned in his death. One of the artists who had given evidence in his favour, traced with his pencil his last adieu to his fanily. The murderer, and the man of worth and honour, were buried in the same tomb.

The day when all was to be discovered was not very distant. Four months had scarcely passed away, when they arrested one of the culprits pointed out by Courriol ; he made confession of his crime, confirmed all the evidence of Courriol, and, like him, protested that Lesurques was innocent. Two other assassins were pursued and taken. One of them was that Dubosq, whom Courriol had described as resembling Lesurques in a singular manner. This fact was confirmed when he appeared before his judges. The astonished witnesses were struck with terror and renorse when they beheld him; and the woman, who had so obstinately persisted in her accusation of Lesurques, asked Heaven's pardon for her error. The judges themselves were dismayed. All France heard of this skocking event, 
and shuddered. Dubosq was a villain who had been condemned to the galleys, from whence he had escaped; arrested at Versailles, he again escaped from prison: he was again taken, when they found in his possession two boxes full of false keys, and other iustruments necessary for the commission of crimes. He was condemned to death, and suffered with a man named Victal, whom Courriol had also marked out, and who was overwhelmed by the most conclusive evidence. All the researches of justice had been able to mark out only five individuals as parties concerned in the assassination. Four, not including Lesurques and Bernard, had been executed; the fifth still remained unpunished: he had taken shelter in Spain, and they discovered him. When examined, he at first denied the crime with which he was charged; condemned to die, and seeing no prospect of a reprieve, he desired his confessor to declare that he died justly, and that Lesurques was innocent of the crime imputed to him.

At length the important proof had been given; justice, considering Bernard as an accomplice, had only six culprits to punish; she had punished seven. Of these seven, who was the innocent one? Lesurques, or Dubosq? The first was a respectable man, acquitted even by the authors of the crime. The second was a villain, and known to be such; he was charged by all those concerned in the assassination; it was he who had mended and lost the spur presented at the trial; the other, which he had thrown into a ditch, was afterwards found. The division of the money-stolen, took place at his house. Can there remain the least doubt as to the innocence of the unfortunate Lesurques?

As soon as all the circumstances of this dieadful tragedy were known, the memory of Lesurques was justified in public opinion, in the opinion of all the respectable part of society, in that of all the citizens of Donai, and in that of the whole of the department in which he so honourably performed all the duties of society. It was so fully cleared in the minds and hearts of all the deputies of this department, that since the restoration they readily came forward, and were all impatient to support a petition presented by his unhappy family: We must give honour to M. Daubauion, who, penetrated with grief for the error of the judges, collected himself the proofs of Lesurques' innocence, and neglected nothing to obtain the reversal of his sentence. He died with grief at not being able to succeed. But, however honourable those testimonies of interest and public opinion may be for Lesurques, his death demanded a more solemn reparation. For twenty-five years his family claimed, but could not obtain it. It is that reparation which has recently been solicited with fresh ardour, and, above all, with a certain persuasion that the voice of oppressed innocence, and the prayer of the unfortunate, will not be turned from that throne where justice and pity dwell with the most virtuous and enlightened of monarchs.

COCK-FIGHTING.

THIs is a mode of diversion so cruel and inhuman, that it is astonishing that not only the ancients, barbarians, Greeks, and Romans, should have adopted it, but that it should be continued by Christians 
of all sorts, and even pursued in those more humane and enlightened times. The ancient Greeks and Romans were wont to call all the nations in the world barbarians; yet certainly, if we consider the many instances of cruelty practised among them, there was very little reason for the distinction. Human sacrifices were common both to them and the barbarians; and the combats of men and wild beasts, and of men in the gladiatorial scenes, were spectacles of delight and festivily. The islanders of Delos were great lovers of cock-fighting, and Tanagra, a city in Bootia, the isle of Rhodes, Chalcis in Euboa, and the country of Media, were famous for their generous and magnanimous race of cocks. From Persia this kind of poultry was first brought into Greece; and if one may judge of the rest from the fowls of Khodes and Media, the excellency of the broods, at that time, consisted in their weight and largeness, as the fowls of those countries were heavy and bulky, and of the nature of what our sportsmen call shakebags, or turn-pokes. The Greeks had some method of preparing the birds for battle by feeding, as may be collected from the Columella. At first cock-fighting was partly a religious and partly a political institution at Athens, and was there continued for improving the seeds of valour in their youth; but afterwards perverted, both there and in other parts of Greece, to a common pastime, without any political or religious institution, as is now practised among us. The Romans were prone to imitate the Greeks. They did not, however, adopt this practice very early. It may be gathered from Columella, that the Romans did not use the sport in his time. This author styles cock-fighting a Grecian diversion; and speaks of it in terms of ignominy, as an expensive amusement, unbecoming the frugal householder, and often attended with the ruin of the parties that followed it; as still happens too often in England. The Romans at last adopted the custom, although not till the decline of the empire. The first cause of contention between the two brothers, Bassianus and Geta, sons of the emperor Septimus Severus, happened, according to Herodian, in their youth, about the fighting of their cocks. Cocks and quails, fitted for engaging one another to the last gasp, are compared with much propriety to gladiators. Consequently, one-would expect that when the scenes of the amphitheatre were discarded, on the establishment of the Christian religion, (the shedding of man's blood in sport, being of too cruel a nature to be patronized under an institution so merciful as the Christian,) cock-fighting would also have been abandoned. The fathers of the church continually inveighed against the spectacles of the arena, and upbraided their adversaries with them. These indeed were more unnatural and shocking than a main of cocks; but this, however, had a tendency towards infusing the like ferocity and implacability into the breasts and dispositions of men. The cock is not only an useful animal, but stately in his figure, and magnificent in his plumage. His tenderness towards his brood is such, that, contrary to the custom of many other males, he will scratch and provide for them with an assiduity almost equal to that of the hen; and his generosity is so great, that, on finding a hoard of meat, he will chuckle the hens together, and, without touching one bit himself, will relinquish the whole. He was highly esteemed in some 
countries, and in others was even held sacred. One cannot but regret therefore that a creature so useful and noble should be so enormously abused by us. It is true the massacre of Shrove Tuesday is now in a declining way, and in a few years, it is to be hoped, will be totally disused; but the cock-pit still continues a reproach to the humanity of Englishmen, and to their religion-the purest, the tenderest, and most compassionate of all religions, not excepting even the Brahmanic. It is not known when the pitch-battle first entered England, but it was probably brought hither by the Romans. The bird was brought here before Casar's arrival, but no notice of his fighting occurs earlier than the time of William Fitz-Stephen, who wrote the life of archbishop Becket in the reign of Henry II. and describes the cocking as a sport of school-boys on Shrove Tuesday. From this time, the diversion, however absurd, and even impious, was continued among us. It was followed, though disapproved and prohibited in 39 Edward III., also in the reign of Henry VIII., and A. D. 1596. It has by some been called regal diversion; and the cock-pit at Whitehall was erected by a crowned head, for the more magnificent celebration of it. There was another pit in Drury-lane, and another in Javin-street. It was prohibited, however, by one of Oliver's acts, March 31, 1654. What aggravates the reproach and disgrace upon Englishmen are those species of fighting which are called the battle-royal and the Welsh main, known no where else in the world, neither in China, Persia, Malacca, nor among the savage tribes in America. In the battle-royal, an unlimited number of fowls are pitted, and when they have slaughtered one another for the diversion of the otherwise generous and humane Englishmen, the single surviving bird is to be esteemed the victor, and carries away the prize.

The Welsh main consists, we will suppose, of sixteen pair of cocks; of these, the sixteen conquerors are pitted a second time, the eight conquerors of these are pitted a third time, the four conquerors the fourth time, and lastly the two conquerors of these are fitted the fifth time; so that, incredible barbarity! thirty-one cocks must be inhumanly murdered for the sport and pleasure, the noise and nonsense, the profane cursing and swearing, of those who have the effrontery to call themselves, with all these bloody doings, and with all this impiety about them; Christians! nay, what with many is a superior and distinct character, men of benevolence and morality! But let the morality and benevolence of such be appreciated from the following instance.-The following melancholy fact is recorded as authentic, in the obituary of the Gentleman's Magazine for April 1789, "Died, April 4, at Tottenham, John Ardesoif, Esq. a young man of large fortune, and in the splendour of his carriages and horses rivalled by few country gentlemen: His table was that of hospitality, where it may be said he sacrificed too much to conviviality; but if he had his foibles, he had his merits also, that far outweighed them. Mr. Ardesoif was very fond of cock-fighting, and had a favourite cock, upon which he lad won many profitable matches. The last bet that he laid upon this cock he lost, which so enraged him, that he had the bird tied to a spit, and roasted alive before a large fire. The screams of the miserable 
anmai were so affecting, that some gentiemen who were present attempted to interfere; which so enraged Mr. Ardesoif, that he seized a poker, and with the most furious vehemence declared, that he would kill the first man who interfered; but in the midst of his passionate asseverations, he fell dead upon the spot. Such, we are assured, were the circumstances which attended the death of this great pillar of humanity."

\section{Ronan Bull-figiting.}

THE following account of a bull-feast in the Coliseum at Rome, in 1332, extracted from Muratori by Mr. Gibbon, may give some ideas of the pomp, the ceremonies, and the danger which attend these exhibitions. "A general proclamation, as far as Rimini and Ravenua, invited the nobles to exercise their skill and courage in this perilous adventure. The Roman ladies were marshalled in three squadrons, and seated in three balconies, which on this day, the 3rd of September, were lined with scarlet cloth. The fair Jacova di Rovere led the matrons from beyond the Tiber; a pure and native race, who still represent the features and character of antiquity: the remainder of the city was divided between the Colonna and the Ursini families. The two factions were proud of the number and beauty of their female bands: the charms of Savella Ursini are mentioned with praise, and the Colonna regretted the absence of the youngest of their house, who had sprained her ankle in the garden of Nero's tower. The lots of the champions were drawn by a respectable citizen; and they descended into the arena or pit, to encounter the wild bulls, on foot as it should seem, with a single spear.

"Amidst the crowd our annalist has selected the names, colours, and -devices of twenty of the most conspicuous knights. Several of the names are the most illustrious of Rome and the Ecclesiastical State; Malatesta, Polenta, Della Valle, Cafarello, Savelli, Cappoecio, Conti, Annabaldi, Altieri, Corsi. The colours were adapted to their taste and situation; and the devices, expressive of hope or despair, breathed the spirit of gallantry and arms. "I am alone, like the youngest of the Horatii," the confidence of an intrepid stranger: "I live disconsolate," a weeping widower : "I burn under the ashes," a discreet lover: "I adore Lavinia or Lucretia," the ambiguous declaration of a modern passion: "My faith is as pure," the motto of a white livery: "Who is stronger than myself?" of a lion's hide: "If I am drowned in blood, what a pleasant death!" the wish of ferocious courage. The pride or prudence of the Ursini restrained them from the field, which was occupied by three of their hereditary rivals, whose inscriptions denoted the lofty greatness of the Colonna name : "Though sad, I am strong:" "Strong as I am great :" "If I fall," addressing himself to the spectators, "you fall with me :" intimating, says, the writer, that while the other families were the subjects of the Vatican, they alone were the supporters of the Capitol. The combats of the amphitheatre were very dangerous and bloody. Every champion successively encountered a wild bull; and the victory may be ascribed to the quadrupeds, since no more than eleven were left 
on the field, with the loss of nine wounded and eighteen killed on the side of their adversaries. Sonie of the noblest families might mourn; but the pomp of the funerals, in the churches of St. John Lateran, and St. Maria Maggiore, afforded a second holiday to the people. It was not in such conflicts that the blood of Romans should have been shed; yet in blaming their rashness, we are compelled to applaud their gallantry; and the volunteers who display their magnificence and risk their lives under the balconies of the fair, excite a more generous sympathy than the thousands of captives and malefactors who were reluctantly dragged to the scene of slaughter."

\section{Spanish Bull-Fighting.}

A STRIKING relic of barbarity in the Spanish manners is the excessive attachment of that nation to bull-fights, a spectacle which shocks the delicacy of every other nation in Europe. Many Spaniards consider this practice as the sure means of preserving that energy by which they are characterized, and of habituating them to violent emotions, which are terrible only to timid minds. But it seems diffcult to comprehend what relation there is between bravery, and a -spectacle where the assistants now run no danger; where the actors prove, by the few accidents which befall them, that theirs has nothing in it very interesting; and where the unhappy victims meet only with certain death, as the reward of their vigour and courage. The bullfights are very expensive, but they bring great gain to the undertakers. The worst places cost two or four rials, according as they are in the sun or in the shade: the price of the highest is a dollar. When the price of the horses and bulls, and the wages of the torreadores, have been paid out of the money, the rest is generally appropriated to pious foundations; at Madrid it forms one of the principal funds of the hospital. It is only during summer that these combats are exhibited, because the season then permits the spectators to sit in the open air, and because the bulls are then most vigorons. Those which are of the best breed are condemned to this hind of sacrifice; and connoisseurs are so well acquainted with their distinguishing marks, that so soon as the bull appears upon the arena, they can mention the place where he was reared. This arena is a liud of circus surrounded by about a dozen seats, rising one above another; the highest of which only is covered. The boxes occupy the lower part of the edifice. In cities which have no place particularly set apart for these-combats, the principal square is converted in to a theatre. The balconies of the houses are widened, so as to project ove the streets which end there. The spectacle commences by a kind of procession round the square, in which appear, on horseback and on foot, the combatants who are to attack the fierce animal; after which two alguazils, dressed in perukes and black robes, advance with great gravity on horseback; who ask from the president of the entertainment an order for it to commence. A signal is immediately given, and the animal, which was before shut up in a kind of hovel with a door opening into the square, soon makes its 
appearance. The alguazils hasten to retire, and their fight is a prelude to the criel pleasure which the spectators are about to enjoy. The bull is received with loud shouts, and almost stunned with the noisy expressions of their joy. He has to contend first against the picadores, combatants on horseback, who, dressed according to the ancient Spanish manner, and as it were fixed to their saddles, wait for him, each being armed with a long lance. This exercise, which requires strength, courage, and dexterity, is not considered as disgraceful. Formerly the greatest lords did not disciain to practise it; even at present the hidalgos solicit the honour of fighting the bull on horseback. The picadores open the scene.

It often happens, that the bull, without being provolsed, darts upon them, and every person entertains a favourable opinion of his courage. If, notwithstanding the sharp-pointed weapon which defends his attack, he returns immediately to the charge, their shouts are redoubled, as their joy is converted into enthusiasm ; but if the bull, struck with terror, appears pacific, and avoids his persecutors by walking round the square in a timid manner, he is hooted at and hissed by the whole spectators, and all those near whom he passes load him with blows and reproaches. If nothing can awaken his courage, he is judged unworthy of being tormented by men ; the cry of " Perros, perros," brings forth new enemies against him, and large dogs are let loose upon hin, which seize him by the neck and ears in a furious manner. The animal then finds the use of those weapons with which nature has furnished him; he tosses the dogs into the air, who fall down stunned, and sometimes mangled; they often recover, renew the combat, and generally finish by overcoming their adversary, who thus perishes ignobly. If, on the other hand, he presents himself with a good grace, he runs a longer and nobler, but nuch nore painful career. The first act of the tragedy belongs to the combatants on horseback ; this is the most bloody of all the scenes, and the most disgusting. The irritated animal braves the pointed steel which makes deep wounds in his neck, attacks with fury the innocent horse who carries his enemy, rips up his sides and overturns him together with his rider. The latter, then dismounted and disarmed, would be exposed to inminent danger, did not combatants on foot, called Chulos, come, to divert the bull's attention, and to provoke him by shaking before him different pieces of cloth of various colours. It is, however, at their own risk that they thus save the dismounted horseman; for the bull sometimes pursues them, and they have need then for all their agility. They often escape from him by letting fall the piece of stuff which was their only arms, and against which the deceived animal expends all his fury. Sometimes the combatant has no other resource but to throw himself speedily over a barrier six feet high, which encloses the interior part of the arena. In some places this barrier is double, and the intermediate space forms a kind of circular gallery, behind which the pursued torreadore is in safety. But when the barrier is single, the bull attempts to jump over it, and often succeeds; the nearest of the relations are then in the greatest consternation; their haste to get out of their way, and to crowd to the upper benches, becomes often more fatal to them than even the fury of the 
bull, who, stumbling at every step, thinks rather of his own safety than of revenge, and besides, soon falls under the blows given him from all quarters. Except in such cases, which are very rare, be inimediately returns. His arlversary has now had time to get up; he immediately remounts his horse, provided he is not killed or rendered unfit for service, and the attack commences; but he is often obliged to change his horse several times. Expressions cannot then be found to celebrate these acts of prowess, which, for several days, become the farourite topic of conversation. The horses are very affecting models of patience, courage, and docility, and may be seen treading under their feet their own bloody entrails; which drop from their sides half torn open, and yet obeying, for some time after, the hand which conducts them to new tortures. Spectators of delicacy are then filled with disgust, which converts their pleasure into pain. A new act, however, is preparing, which reconciles them to the entertainment. As soon as the bull has been sufficiently tormented by the combatants on horseback, they retire, and leave him to be irritated by some on foot. The latter, which are called banderilleros, go before the animal; and the moment he darts upon them, they plunge into his neck, two by two, a kind of dart called banderillas, the points of which are hooked, and which are ornamented with small streamers nade of coloured paper.

The fury of the bull is now redoubled; he roars and tosses his head, while his vain efforts serve only to increase the pain of his wounds. This last scene calls forth all the agility of his adversaries. The spectators at first tremble for them, when they behold them braving so near the horns of this formidable animal; but their hands, well exercised, aim their blows so skilfully, and they avoid the danger so nimbly, that after having seen them a few times, one neither pities nor admires them, and their address and dexterity seem only to be a small episode of the tragedy. When the vigour of the bull appears to be almost exhausted by the blood running from his neck and sides, and when the people, tired of one object, demand another victim, the president of the entertainment gives the signal of death, which is announced by the sound of trumpets. The matador then advances, and all the rest quit the arena ; with one hand he holds a long dagger, and with the other a kind of flag, which he waves backwards and forwards before his adversary. They both stop and gaze at one another, and while the agility of the matador deceives the impetuosity of the bull, the pleasure of the spectators, which was for some time suspended, is now awakened into life.-Dometimes the bull remains motionless, throws up the earth with his feet, and appears as if meditating revenge. The bull in this condition, and the matador who calculates his motions and divines his projects, form a group which an able pencil might not disdain to delineate. The matador, at length gives the mortal blow ; and if the animal immediately falls, a thousand voices proclaim with loud shouts the triumph of the conqueror; but if the blow is not decisive, if the bull survives, and seeks still to brave the fatal steel, murmurs succeed to applause, and the inatador, whose glory was about to be raised to the skies, is considered only as an unskilful butcher. He endeavours to be soon 
revenged, and to disarm his judges of their severity. His zeal sometimes degenerates into blind fury, and his partisans trenble for the conscguences of his imprudence He at length directs his blow better. The animal staggers and falls, while his conqueror is intoxicated with the applauses of the people.

Three mules, oriamented with bells and streamers, come to terminate the tragedy. A rope is tied about the horns of the bull which has displayed his valour, and the brave animal is dragged ignominiously from the arena which he has lionoured, and leaves only the traces of his blood, and the remembrance of his exploits, which are soon effaced on the appearance of his successor. On each of the days set apart for these entertainments, six are thus sacrificed in the morning, and twelve in the afternoon, at least at Madrid. The three last are given exclusively to the matador, who, without the assistance of the picadores, exerts his ingenuity to vary the pleasure of the spectators. Sometimes he causes them to be combated by some intrepid stranger, who attacks them, mounted on the back of another bull, and sometimes he matches them with a bear; this last method is generally destined for the pleasure of the populace. The points of the bull's horus are concealed by something wrapped round them, which breaks their force. The animal, which in this state is called embolado, has power neither to pierce nor to tear his antagonist. The amateurs then descend in great nunibers to torment him, each after his own manner, aud often expiate his cruel pleasure by violent contusions; but the bull always falls at length under the stroke of the matador.

\section{History OF HAWKING.}

HAWKING was anciently a favourite amusement in Britain; and to carry a hawk, was esteemed a distinction of a man of rank. The Welsh had a saying, that you may know a gentleman by his hawk, horse, or greyhound. In those days a person of rank seldom went without a hawk in his hand. Even the ladies were not without them, for in an ancient sculpture in the church of Milton Abbey, in Dorsetshire, appears the consort of king Athelstan, with a falcon on her royal fist, tearing a bird. There are only two countries, however, in the world, where we have evidence that the exercise of hawking was very anciently in vogue; these are Thrace and Britain. In the former, Pliny tells us, it was merely the diversion of a particular district. But the primeval Britons had a peculiar taste for hawking, and every chief amoing them maintained a considerable number of these birds for their sport. It appears also from a passage in Ossian, that it was fashionable in Scotland. He tells us that a peace was endeavoured to be gained by the proffer of one hundred managed steeds, one hundred foreign captives, and one hundred hawks with fluttering wings, that fly across the sky." To the Romans this diversion was scarce known in the days of Vespasian : yet it was introduced soon after. Probably they adopted it from the Britons ; first they greatly improved it by the introduction of spaniels into the island. In this state it appears among the Roman Britons in the sixth century. Gildas in his first epistle, speaking of Maglocunus, on his relinquishing ambition and taking refuge in a monastery, com 
pares him to a dove, that with various turnings and twinings takes her flight from the talons of the hawk? In after times, hawking was the principal amusement of the English; a person of rank scarce stirred about without a hawk on his hand, which in old paintings is the criterion of nobility. Harold, afterwards king of England, when he went on an embassy into Normandy, is represented embarking with a bird on his fist, and a dog under his arn : and in an ancient picture of the nuptials of Henry VI. a nobleman is represented in the same manner; for in those days, it was thought sufficient for noblemen to wind their lorn, and to carry their hawk fair, and to leave study and learning to the children of poor people! In short, this diversion was, among the ancient English, the pride of the rich, and the privilege of the poor; no man seems to have been excluded the amusement: we learn from the book of St. Albans, that every degree had its peculiar hawk, from the emperor down to the holywater clerk. Vast was the expense that sometimes attended this sport. In the reign of James $\mathbf{I}$. Sir Thomas Monion is said to have given one thousand pounds for a cast of hawks; we are not then to wonder at the rigour of the laws made to preserve a sport that was carried to such an extravagant pitch. In the 34 th of Edward III. it was made felony to steal a hawk; to take its eggs, even in a person's own ground, was punishable with an imprisonment for a year and a day, besides a fine at the king's pleasure ; in queen Elizabeth's reign, the imprisonment was reduced to three months, but the offender was to find security for seven years, or lie in prison till he did. Such was the state of Old England : during the whole day, the gentry were addicted to hawking or hunting; in the evening they celebrated their exploits with the most abandoned and brutish sottishness; while the inferior rank of people, by the most unjust and arbitrary laws, were liable to capital punishments, fines, and loss of liberty, for destroying the most noxious of the feathered tribe.

According to Olearius, the diversion of hawking is more followed by the Persians and Tartars than ever it was in Europe: "Il n'y avoit point de buter," says he, "qui n'eust son aigle ou son fálcon." The falcons or hawks that were in use in these kingdoms, are now found to breed in Wales, in North Britain, and its isles. The penguin falcon inhabits the rocks of Caernarvonshire. The same species, and the gyrfalcon, the gentil, and the goshawk, are found in Scolland, and the lanner in Ireland. The Norwegian breed was, in old times, in high esteem in England, they were thought bribes worthy of a king. Geoffrey Fitzpierre gave two good Norway hawks to king John, to obtain for his friend, Walter de Madena, one hundred weight of cheese; and Nicholas, the Dane, was to give the king a hawk every time he came into England, that he might have free liberty to traffic throughout the king's dominions. They were also made the tenures by which some nobles held their estates from the crown. Thus Sir John Stanley had a grant of the Isle of Man from Henry IV., to be held of the ling, his heirs and successors, by homage, and the service of two falcons on the day of his or their coronation. And Philip de Hasting held his manor of Combertown, in Cambridgeshire, by the service of keeping the king's falcons. 
THE Mexicans were very dexterous in hunting; they used bows and arrows, darts, nets, snares, and a kind of tubes called carbottane, through which they shot by blowing out little balls at birds. Those which the kings and great men made use of were curiously carved and painted, and likewise adorned with gold and silver. Besides the exercise of the chase, which private individuals took either for amusement or to provide food, there were general hunting matches, sometimes appointed by the king, at others to provide victims for sacrifices. A large wood, generally that of Zacatapec, near the capital, was pitched upon as the scene of these grand hunting matches. Here they chose the place best adapted for setting a number of snares and nets. The wood was enclosed by some thousands of hunters, forming a circle of six, seven, or eight miles, according to the number of animals they intended to take. Fire was then set to the grass in several places, and a noise made with drums, horns, shouting, and whistling." The hunters gradually contracted their circle, continuing the noise till the game was enclosed in a very small space. They were then killed, taken in snares, or with the hands of the hunters. The number of animals taken or destroyed on these occasions was so great, that the first Spanish viceroy of Mexico would not believe it, without making the experiment himself. The place chosen for his hunting-match was a great plain in the country of the Otomies, lying between the villages of Xilotepec and S. Giovanuidel Rio, the Indians being ordered to proceed according to their usual customs. The viceroy, attended by: a vast retinue of Spaniards, repaired to the place appointed, where acconmodations were prepared for them in houses of wood erected for the purpose. A circle of more than fifteen miles was formed by eleven thousand Otomies, who started such a quantity of game on the plain, that the viceroy was quite astonished, and commanded the greater part of them to be set at liberty, which was accordingly done. 'The number retained was still incredibly great, were it not attested by a witness of the highest credit; on this occasion, upwards of six hundred deer and wild goats, one hundred cajotes, with a surprising number of hares, rabbits, and other smaller animals. The plain still retains the Spanish name of Cazadero, which signifies the place of the chase. The Mexicans had also particular contrivances for catching certain animals. Thus, to catch young asses, they made a small fire in the woods, putting among the burning coals a particular kind of stone named cacalott, i. e. raven of black stone, which bursts with a loud noise when lieated. The fire was covered with earth, and a little maize laid around it. The asses quickly assembled with their young, in order to feed upon the maize; but while they were thus employed, the stone burst, and frightened away the old ones by the explosion, while the young, unable to fly, were carried off by the hunters. Serpents were taken with the hands, seizing them intrepidly by the neck with one hand, and sewing up their mouths with the other: this method is still practised. They shewed the greatest dexterity in tracing the steps of wild beasts even 
when an European could not have discovered the smallest print of their feet. The Indian method, however, was by observing sometimes the herbs or leaves broken down by their feet, sometimes the drops of blood which fell from them when wounded. It is said that some of the American Indians shew still greater dexterity in disco. vering the tracks of their enemies, which to an European would be altogether imperceptible.

\section{Methods of Hunting: In Lapland.}

THE Laplanders make surprising excursions upon the snow in their hunting expeditions. They provide themselves each with a pair of skates, or snow-shoes, which are fir boards covered with the rough skin of the rein-deer, turned in such a manner that the hair rises against the snow, otherwise they would be too slippery. One of these shoes is usually as long as the person who wears it the other is about a foot shorter. The feet stand in the middle, and to then the shoes are fastened by thongs or withes. The Laplander, thus equipped, wields a long pole in his hand, near the end of which there is a round ball of wood, to prevent its piercing too deep in the snow; and with this he stops himself occasionally. By means of these accoutrements, he will travel at the rate of sixty miles per day, without being fatigued; ascending steep mountains, and sliding down again with amazing swiftness. The Laplander not only travels on foot, but is provided with a carriage drawn by the rein-deer, in which he journeys with still greater rapidity. The sledge, called pulka, is made in the forn of a small boat, with a convex bottom, that it may slide the more easily over the snow; the prow is sharp and pointed, but the sledge is flat behind. The traveller is swathed in this carriage like an infant in a cradle, with a stick in his hand to steer the vessel, and disengage it from pieces of rock, or stumps of trees, that may chance to encounter it in the route. He must balance the sledge with his body, otherwise he will be in danger of being overturned. The traces by which this carriage is fastened to the rein-deer, are fixed to a collar about the animal's neck, and run down over the breast between the fore and hind legs, to be connected with the prow of the sledge; the reins managed by the traveller, are tied to the horns; and the trappings are furnished with little bells, the sound of which is agreeable to the animal. With this draught at his tail, the rein-deer, if pressed, will travel ten or twelve Swedish miles, (seventy or eighty English,) in a day ; but by such hard driving he is generally destroyed. It, however, frequently happens that he will persevere in his journey fifty miles without intermission, and withont refreshment, except occasionally moistening his mouth with the snow. Before he sets out, the Laplander whispers in his ear the way he is to go, and the place at which he is to halt, firmly persuaded that the beast understands his meaning. In the beginning of winter, the laplanders mark the most frequented roads, by strewing them with fir boughs; which being frequently covered with new snow, and alternately beaten by the carriage, consolidates them into a kind of canseway, which is the harder if the surface has felt a partial thaw, and is crusted by a subsequent frost. It requires great caution to follow these tracks, fo: 
if the carriage deviates to the right or left, the traveller is plunged into an abyss of snow. In less frequented parts, where there is no such beaten road, the Laplander directs his course by certain marks made on the trees. Hunting being the clief occupation of the Iaplanders, they perform it in various ways. In summer they hunt the wild beasts with small dogs trained to the diversion. In winter they pursue them by their tracks upon the snow, skating with so great a velocity, that they often run down the prey. They catch ermines in traps, and sometimes with dogs. They kill squirrels, martens, and sables with blunt darts, to avoid wounding the skin. Foxes and beavers are slain with sharp-pointed darts and arrows; in shooting which, they are accounted the best marksmen in the world. The larger beasts, such as bears, wolves, elks, and wild rein-deer, they either kill with fire-arms purchased in Sweden and Norway, or take in snares and pits.

Their game laws are observed with great punctuality. The beast becomes the property of the man in whose snare or pit he is caught; and he who discovers a bear's den, has the exclusive privilege of hunting him to death. The conquest of a bear is the most honourable achievement that a Laplander can perform, and his flesh is esteemed the greatest delicacy. The bear is despatched with a fusil, sometimes laid as a snare, ready cocked and primed; but more frequently by the hunter, who runs the mostimminent risk of his life, should he miss his aim. The death of a bear is celebrated by the Laplander as a signal victory. The carcase is drawn to the cabin or hut of the victor by a reill-deer, which is kept sacred frum any other work for a whole year, for this service. The bear is surrounded by a great number of men and women, reciting a song of triunph; then they express their acknowledginent to God, that he has created beasts for the use of men, and endued mankind with strength and courage to overcome and attack the fiercest of them. The hero is saluted by the women, who spit cheived elder bark in his face: He is feasted three days successively, and his cap is decorated with an additional figure wrought in tin wire.

\section{East Indian Methods of Hunting.}

Hunting was a favourite diversion of the bloody conqueror Jenghiz Khan, if indeed the word diversion can be applied to a molister whose mind was set upon the destruction of his own species, and who only endeavoured to make the murder of brutes subservient to that of mell, by keeping his soldiers in a state of warfare with the beasts, when they had no human enemies to contend with. His expeditions were conducted on a plan similar to that of the Mexicans already mentioned; and were, no doubt, attended with still greater success, as his numerous arny could enclose a much greater space than all the Indians the Spanish viceroy could muster. The East Indian princes still shew the same inclination to the chase, and Mr. Blanc, who attended the hunting excursions of Asoph UI Dowah, vizier of the Mogul empire, and nabob of Oude, in 1785 and 1786, gives the following account of the method practised on this occasion. 
The tine is alout the beginning of December, and the diversion is continued till the heats, which commence about the beginning of March, oblige them to stop. During this period, a circuit of between five and six hundred miles is generally made, the hunters bending thei course towards the skirts of the northern mountains, where the country is wild and uncultivated. The vizier takes alongwith him not only his court and seraglio, but a great part of the inhabitants of his capital. His immediate attendants amount to two thousand, but he is also followed by five or six hundred horse, and several battalions of regular seapoys with their field-pieces; four or five hundred elephants also accompany him, of which some are used for riding, others for fighting, and somenfor clearing the jungles and forests of the game. About as many beautiful sumpter-horses, of the beautiful Persian and Arabian breeds, are taken with him. A great number of wheeled carriages, drawn bybullocks, likewise attend, which are used chiefly for the convenience of the women. Sometimes he has an English chaise or two, and sometines a chariot, but all these are merely for show, the vizier himself never using any other conveyance than an elephant, or sometimes, when fatigued and indisposed, a palanquin. The animals used in the sport are principally about three hundred gres hounds, two handred hawk, and a few trained leopards for hunting decr. There is a great number of marksmen, whose profession it is to shoot deer, with many fowlers, who provide game; as none of the natives of India know how to shoot game with small shot, or to hunt with slow hounds. A vast number of matchlocks are carried along with the company, with many English pieces of various kinds, forty or fifty pairs of pistols, bows and arrows, besides swords, daggers, and sabres without number. There are also nets of various kinds, some for quails, and others very Jarge for fishing, which are carried along with him upon elephants, atteuded by fishermen, so as to be always ready for throwing into any river or lake that may be met with. Every article that can contribute to pleasure or luxury is carried along with the army.

A great number of carts are loaded with the Ganges water, and even ice is transported for cooling the drink. The fruits of the season, and vegetables, are daily sent to him by bearers stationed at every ten miles, by which means each article is conveyed day and night at the rate of four miles an hour. There are also fighting antelopes, buffaloes, and rams in great numbers, several hundied pigeons, some fighting-coclis, with a great variety of parrots, nightingales, \&c. To complete the magnificence or extravagance of this expedition, there is always a large bazar, or moving town, which attends the camp, consisting of shopkeepers and artificers of all kinds, mon $y$-changers, and dancing women; so that, on the most moderate calculation, the whole number of people in his camp cannot be computed at less than twenty thousand. The nabob himself, and all the gentlemen of his camp, are provided with double sets of tents and equipage, which are always sent on the day before to the place to which he intends to go, and this is generally eight or ten miles in whatever direction game is expected; so that by the time he has finished his sport in the morning, he finds his tent ready pitched for 
his reception. The nabob, with the attending gentlemen, proceed in a regilar moving court or durbar, and thus they keep conversing togetlier, and looking out for gane. Many foxes, hares, jackals, and sometimes deer, are picked up as they pass along; the hawks are carried immediately before the elephants, and let fly at whatever game has sprung, which is generally bustards, partridges, and different kinds of herons; these last afford excellent sport with the falcons. Wild boars are sometimes started, and are either shot, or run down by the dogs and horsemen. Hunting the tiger, however, is looked upion as the principal diversion, and the discovery of one of these animals is accounted a matter' of great joy. The covert in which he is found is long grass or reeds, in such a height as frequently to reach above the elephants; and it is dificult to find him in such a place, as he commonly endeavours either to steal off, or lie so close to the ground, that he cannot be roused, until the clephants are almost upon him. He then roars and skulks away, but is shot as soon as he can be seen; it being generally contrived that the nabob shall have the compliment of firing first. If he be not disabled, he continues to skulk along, followed by the elephants; the nabobil and others shooting as often as ha can be seen, till he falls. The elephants themselves are very much afraid of this terrible animal, and discover their apprehensions as soon as they begin to smell him, or hear hin growl; generally attempting to turn away from the place where he is. When the tiger can be traced to a particular spot, the elephants are disposed of in a circle round him; in which case he will make a desperate attack, springing upon the elephant that is nearest, and alcmpting to tear him with his teeth or claws. Some, but very few, of the elephants can be brought to attack the tiger, and this they do by curling up their trunks under their mouths, and then attempting to toss or otherwise destroy him with their tusks, or to crush him with his feet or knees. It is considered as good sport to kill one tiger in a day; though sometimes, when a female is met with her young ones, two or three will be killed. The other objects of pursuit in these excursions, are wild elephants, buffaloes, and rhinoceroses.

Our author was present at the hunting of a wild elephant of vast size and strength. An attempt was first made to take him alive by surrounding him with tame elephants, while he was kept at bay by crackers and other fire-works; but he constantly eluded every effort of thiskind. Sometimes the drivers of the tame elephants got so near him, that they threw strong ropes over his head, and endeavoured to detain him by fastening them round trees; but he constantly snapped the ropes like packthread, and pursued his way to the forest: Some of the strongest and most furious of the fighting elephants were then brought out, to engage him; but he attacked them with such fury, that they were obliged to desist. In his struggles with one of them, he broke one of his tusks, and the broken piece, which was upwards of two inches in diameter, of solidivory, Hew up into the air several yards above their heads. Orders were now given to kill him, as it appeared impossible to take him alive; but even this was not accomplished without the greatest difficulty. 
He twice turned, and attacked the party who pursued him, and in one of these attacks struck obliquely the elephantion which the prince rode, threw him upon his side, but then passed on without offering farther injury. At last he fell dead, after having received, as was supposed upwards of one thousand balls in his body.

\section{HINDOO SuTTEE.}

THE following interesting account of one of these dreadful sacrifices, extracted from the letter of an English officer who superintended the ceremony, places the influence of fanaticism, in supporting this horrid custom, in its proper light :- "In my present situation, it falls to my lot to preside over the executions of criminals, and also over those horrible exhibitions peculiar to this country, of a widow burning herself on the funeral pile of her dead husband : and as the authentic account of such a scene may be interesting, I send you a short description of a suttee, at which I was lately present in my. new character of presiding officer. The day before it took place, (as is customary;) a report came from the police, of the widow's intention to burn herself, if the magistrate gave his permission. On the principle of religious toleration, this is always given the magistrate is allowed to argue, and to endeavour to dissuade the woman from her purpose, but cannot absolutely forbid it, unless under certain circumstances, such as when it is not perfectly voluntary on her part. Myself and several friends went to her house, and did all we could to turn her from her design; but she answered only by quoting her bible, in which she observed, it is written, 'The widow who burns herself with her husband's body enjoys happiness with him in heaven.' Having thus failed in our entreaties, which are indeed usually to no purpose, we ordered a guard to watch, and take care that she had no opium or intoxicating drugs given her, and that she went to her death in her senses, at least as much so as she could be under the influence of such extraordinary fanaticism. The next morning, at daybreak, we proceeded to the ground appropriated to the ceremony, where the woman had just arrived in a rude sort of car, carried on men's shoulders, and accompanied by the barbarous music of her country. She seemed quite unconcerned at the preparations for the horrid sacrifice she was about to perform. For my part, when I looked at the pile on which lay her husband's dead body, the faggots, her nearest relations with fire-brands lighting the pile, the victim dressed and adorned with flowers, - the whole scene appea red to me as a frightful vision : I could hardly persuade myself of its reality. I spoke to her once more, f being a high-caste woman, she spoke the Hindoostanee language,) and represented to her the horrible death she was about to suffer, and the long time she must continue in the most dreadful agony. I urged to her, that it was no sudden or easy death by which she was to reach paradise, but a protracted course of torture She heard me out with calmness, thanked me for my intentions, which she admitted were good, but again repeated her intention so decidedly as to preclude any hope of saving her. I felt her pulse, and it was far calmer than my own at the moment I am writing. Mrs. E, of 
whom thave often made honourable mention, thinking herpersuasions, as one of her own sex, might avail, then went up to the wretched victim, and in the most earnest manner tried to dissuade her. She offered her a pension for life, and an honourable asylum in the company's territories. Among other inducements, intending it probably as an appeal to female vanity, Mrs. E. said that she should be made a lady of, and have a palanquin to ride in : she immediately answered, pointing to the pile, 'Ce humera palkee hy -that is my palanquin?' The-victim then performed various ceremonies, and prepared herself to jump on the pile, which was blazing to receive her. The flames had arisen to a great height, and they were feeding them with tar and faggots. I then addressed her for the last time: told her no force slould be used to keep her in the fire, but conjured her, if her resolution failed, to jump out, and run to me; that I was surrounded by my police-men, and that $I$ would bear her away from her cruel relations to a place of safety, where they should never see her more. Her resolution was immoveable. She then distributed flowers and sweet-meats gave me a piece of her dress, and, having danced three times round the pile, threw herself in. $\Lambda$ that moment the people shouted, the drums and native music struck up, and, if she nttered any cries, I heard them not. She resolutely sat in the fire, apparently alive, for two or three minutes, but moved only her hands occasionally. Such is the description of a dreadful act that takes place every day ? ?

\section{The Romans at Table.}

The Roman manner of disposing themselves at table was this :- A low round table was placed in the cœnaculum, or dining-room, and about this usually three, sometimes only two, beds or couches, according to the number of which it was called biclinium, or triclinium, These were covered with a sort of bed-clothes, richer or plainer according to the quality of the person, and furnished with quilts and pillows, that the guests might be the better accommodated. There were three persons on each bed; to crowd more, was esteemed sordid. In eating, they lay down on their left sides, with their heads resting on their elbows. The first lay at the head of the bed, with his feet extended behind the back of the second; the second lay with the back of his head extended towards the middle of tlie first, only separated by a pillow, his feet behind the back of the third; and so of the third and fourth. The middle place was esteemed the most honourable. Before they cane to table, they changed their clothes, putting on what they call conatoria vestis, the dining-garment, and pulled off their shoes, to prevent soiling the bed.

\section{Abysinian Feast.}

Mr. BRUCE gives the following account of an Abyssinian feast.- In the capital, where one is safe from surprise at all times, or in the country or villages, when the rains are become so constant that the valleys will not bear a horse to pass them, or that men cannot venture from home through fear of being surrounded and swept away by 
temporary torrents, occasioned by sudden showers on the mountains; in a word, when a man can say he is safe at home, and the spear and shield are huing up in the hall; a number of people of the best fashion in the villages, of both sexes, courtiers in the palace or citizens in the town, meet together to dine, between twelve and one o'clock. A long table is set in the middle of a large room, and benches besides it, for a number of guests who are invited. Tables and benches, the Portuguese introrluced among them; but bull hides spread upon the ground served them before, as they do in the camp and country now. A cow or a bull, one or more, according to the number, is brought close to the door, and his feet strongly tied. The skin that lrangs down under his chin and throat, which I think we call the dewlap in England, is cut only so deep as to arrive at the fat, of which it totally consists; and by the separation of a few small bloodvessels, six or seven drops of blood only fall upon the ground. There is no stone, bench, or altar, upon which this cruel assassin lays the animal's head in this operation. I should beg his pardon indeed for calling him an assassin, as he is not so merciful as to aim at the life, but, on the contrary, to keep the beast alive till he is totally eaten up. Having satisfied the Mosaical law, according to his conception, by pouring these six or seven drops upon the ground, two or more of them fall to work on the back of the beast; and on each side of the spine they cut skin-deep; then putting their fingers between the flesh and the skin, they begin to strip the hide of the animal half way down his ribs, and so on to the buttock, cutting the rikin wherever it hinders them commodiously stripping the poor animal bare. All the flesh of the buttocks is then cut off, in solid square pieces, without bones or much effusion of blood; and the prodigious noise the animal makes is a signal for the company to sit down to table.

"There are then laid before every guest, instead of plates, round cakes, if I may so call them, about twice as big as a pancake, and something thicker and tougher. It is unleavened bread, of a sourish taste, far from being disagreeable, and very easily digested, made of a grain called teff. It is of different colours, from black to the colour of the whitest wheat bread. Three or four of these cakes are generally put uppermost, for the food of the person opposite to whose seat they are placed. Beneath these are four or five of ordinary bread, and of a blackish kind. These serve the master to wipe his fingers upon, and afterwards tlie servant for bread to his dinner.

s'Two or three servants then come, each with a square piece of beef in their bare hands, laying it upon the cakes of teff, placed like dishes down the table, without cloth or any thing else beneath them. By this time all the guests have knives in their hands, and the men have the large crooked ones, which they put to all sorts of uses during the time of war. The women have small clasped knives, such as the worst of the kind made at Birmingham, and sold for a penny each.

"The company are so ranged, that one man sits between two women; the man, with his long knife, cuts a thin piece, which would be thought a good beef-steak in England, while you see the motion of the fibres yet perfectly distinct aud alive in the flesh. No man in Abyssinia, of any fashion whatever, feeds himself, or touches his own 
meat. The women take the steak, and cut it lengthwise like strings, about the thickness of your little finger, then crosswise into square pieces, something smaller than dice. This they lay upon a piece of the teff-bread, strongly powdered with black pepper, or Cayenne pepper, and fossil salt; they then wrap it up in the teff-bread like a cartridge.

"In the mean time, the man having put down his lnife, with each hand resting upon his neighbour's knee, his body stooping, his head low and forward, and mouth open very like an idiot, turns to the one whose cartridge is first ready, who stuffs the whole of it into his mouth, which is so full that he is in constant danger of being choked. This is a mark of grandeur. The greater a man would seem to be, the larger a piece he takes into his mouth; and the more noise he makes in chewing it, the more polite he is thought to be. They have indeed a proverb that says, "Beggars and thieves only eat snall pieces, or without making a noise.' Having despatched this morsel, which he does very expeditiously, his next female neighbour holds forth another cartridge, which goes the same way; and so on till he is satisfied. He never drinks till he has finished eating; and before he begins, in gratitude to the fair ones that feed him, he makes up two small rolls of the same kind and form; each of his neighbours open their mouths at the same time, while with each hand he puts their portion into their mouths. He then falls to drinking out of a large handsome horn; the ladies eat till they are satisfied, and then all drink together, 'Vive le joye et la jeunesse!' A great deal of joke and mirth go round, very seldom with any mixture of acrimony or ill-humour.

"At this time the unfortunate victim at the door is bleeding indeed, but bleeding little. As long as they can cut off flesh from his bones, they do not meddle with the thighs, or the parts were the great arteries are. At last they fall upon the thighs likewise, and soon after, the animal bleeding to death becomes so tough, that the cannibals who have the rest of it to eat, find very hard work to separate the thesh from the bones with their teeth, like dogs."

\section{Michaelmas Goos̀e.}

Michaelmas was formerly a season of great celebrity: at present, all that we do in honour of it, is to eat a goose. The origin of this custom is referred to Queen Elizabeth, who was eating gocse on Micliaelmas-day, when she heard of the destruction of the Spanish Arniada. Geese are not, in general, of such famous repute in France as they are here, and seldom make their appearance upon the tables of Parisian epicures. The flesh they condemn as coarse and unwholesome; and the apple-sauce, when mentioned, never fails to elicit flashes of astonishment, subsiding into peals of laughter. But the livers and thighs of geese learnedly made into pies, and properly trufled," (patés de foies gras,) are reckoned a most delicate article; yet they have killed nearly as many gastronomers as the small-pox and scarlet fever have destroyed children. The department of Perigord, with Tonlouse and Bayonne, used, notwithstanding, to cook anmually, for the rest of the world, about one hundred and twenty thousand of these lethiferous 
pies. Large droves of geese were anciently led from Picardy to Italy, waddling over the Alps, and constantly stooping, according to their prudent custom, under the lofty triumplial arclies which they happened to pass in their way. Yet geese are not so stupid as they are generally supposed to be. The fanous chemist, Lemery, asserts, that he saw a goose tuming the spit on which a turkey was roasting: unconscious, we hope, that some friend would soon accept the office for her. "Alas! we are all turnspits in this world," adds the gastrographer who relates the fact; "and, when we roast a friend, let us beware that many stand ready to return the compliment."

\section{Martinmas.}

FormerLY a custom prevailed every where amongst us, though generally confined at present to country villages, of killing cows, oxen, swine, \&c. at this season, which were cured for the winter, when fresh provisions were seldom or never to he had. Two or more of the poorer sort of rustic families still join to purcliase a cow, \&c. for slaughter at this time, called always in Norlumberland, a Mart; the entrails of which, after having been filled with a kind of pudding-meat, consisting of blood, suet, groats, \&c. are formed into little sausagelinks, boiled, and sent about as presents they are called black-puddings from their colour. The author of the Convivial Antiquities tells us, that in Germany there was in his time a kind of entertainment called the "Feast of Sausages, or Gut-puddings," which was wont to be celebrated with great joy and festivity. The learned Moresin refers the great doings on this occasion, which he says were common to almost all Europe in his time, to an ancient Athenian festival, observed in honour of Bacchus, upon the eleventh, twelfit, and thirteenth days of the month Anthesterion, corresponding with our November. J. Boemus Aubanus seems to confirm this conjecture, though there is no mention of the slaughter of any animal, in the description of the rites of the Grecian festival. The eleventh month had a name from the ceremony of tapping their barrels on it; when it was customary to make merry. Dr. Stukeley, in his Itinerary, speaking of Martinsal-hill, observes: I take the name of this hill to come from the merriments among the northern people, called Martinalia, or drinking healths to the memory of St. Martin, practised by our Saxon and Danish ancestors. I doubt not but upon St. Martin's day, or Martinmas, all the young people in the neighbourhood assembled here, as they do now upon the adjacent St. Anne's-hill, upon St. Anne's day. A note adds, 'St. Martin's day, in the Norway calendar, is marked with a goose; for on that day they always feasted with a roasted goose : they say, St. Martin, being elected to a bishopic, hid himself, (noluit episcopari, but was discovered by that animal. We have transferred the ceremony to Michaelmas.

\section{HAGMEN A.}

J. BoEMUs AUBANUs tells us that in Franconia, on the three Thursday nights preceding the Nativity of our Lord, it is customary 
for the youth of both sexes to go from house to house, knocking at the doors, singing Christmas carols, and wishing a happy new year. They get, in return, at the houses they stop at, pears, apples, nuts, and even money. Little troops of boys and girls still go about in this very manner at Newcastle-upon-Tyne, and other places in the north of England, some few nights before, on the night of the eve of Christmas-day, and on that of the day itself. The Hagmena is still preserved among them, and they always conclude their begging song with wishing a merry Christmas and a happy new year. The very observable word "Hagmena," used on this occasion, is by some supposed of an antiquity prior to the introduction of the Christian faith. Others deduce it from three French words run together, and signifying "the man is born." Others again derive it from two Greek words signifying the "holy month."

\section{The Man in the Moon.}

The ancient superstition of "The Man in the Moon" is supposed to have taken rise from the passage in the book of Numbers; (xv. 32.) where a man is related to have been punished with death for gathering sticks on the Sabbath.

Going a-Gooding on ST. Thomas's DaY.

"I FIND some faint traces of a custom of going a-Gooding (as it is called) on St. Thomas's Day, which 'seems to have been done by women only, who, in return for the alms they reccived, appear to have presented their benefactors with sprigs of evergreens, probably to deck their houses with at the ensuing festival. Perhaps this is only another name for the northern custom of going about and crying, Hagmeña."-Brand's Popular Antiquities.

\section{The Flying Dutchman.}

THE following extract is from a work entitled, "Researches into Atmospheric Phæuoniena," by Thomas Forster, Esq. -Among the superstition s referable to atmospheric phænomena, may be mentioned the story of the Flying Dutchman, a ship, said by mariners to be seen about the Cape of Good Hope in blowing weather, unde the following extraordinary circumstances:- "She is never known to get into port, and is seen at uncertain periods sailing at an immense rate before the wind, under full press of canvass, in the most violent gales. The story attached to this appearance is, that she was a merchant ship from Holland, and that the captain having sworn a tremendous oath, in consequence of not leing able to make the port, he was condemned, as a punishment, together with all the rest of the crew, to beat about the sea till the day of judgment. From the corroborated account of many navigators, there seems to be no doubt but that something is seen, which they take for a distant sailing vessel ; but the nost intelligent naval officers, with whom I have conversed, seem to regard it as some waterspout, or else a cloud reflected in the 
mist, or some other atmospherical phantom, which the superstitious imaginations of the sailors have converted into a ship, and attached thereto the above fable, as well as many other remarkable histories. These peculiar refractions, whereby the hulks of distant vessels appear elongated, are well known, as is the elevation of the coast seen from the sea, and the Fata Morgana.

\section{Power of Imagination.}

DR. DARW IN relates the following instance of the power of superstition on the mind, which, two centuries ago, would have been accounted witchery:-_ $A$ young Warwickshire farmer, finding his hedge broken and robbed during a severe winter, determined to watch for the thief. He chose a moonlight night, and lay many hours beneath the shade and shelter of a haystack. He suffered much from the cold, and at midnight was about to retire; but at the moment appeared a decrepit old woman, in appearance much corresponding with the popular notion of a witch : she hastily collected a bundle of sticks from the hedge, and was about to carry them off; the farmer sprang from his concealment, and seized the old woman, as the nightly thief of his property. After some struggling, the old woman, who displayed great personal strength and deterinination, suddenly knelt down upon her bundle of sticks, and, after silently raising her withered arms to the moon, then at the full, she thus addressed the already half-frozen farmer : "Heaven grant thou mayest never again enjoy the blessings of warmth!' The terrified farmer left her, and and made his way home; under the full effect of the cold spell: He complained of extreme cold the following day; wore an extra upper coat-then another-and at length, in despair, took to his bed, which was continually heaped with blankets, which covered even his face-and in which he actually lay until his death, which did not happen until twenty years afterwards."

\section{Baptism of SHips.}

THIs is a burlesque ceremony on board merchant ships, practised both on vessels and persons who pass the tropic or line for the first time. The baptizing a vessel is simple, and consists only in washing it throughout with sea water; that of the passengers is more mysterious. The oldest of the crew that has passed the tropic or line, comes with his face blackened, a grotesque cap on his head, and some sea-book in his hand, followed by the rest of the seamen dressed like himself, each having a kitchen utensil in his hand, with drums beating; "he places himself on a seat on the deck, at the foot of the main-mast. At the tribunal of this mock magistrate, each passenger, not yet initiated, swears he will take care the same cerenony be observed whenever he is in the like circumstances. Then," by giving a little money by way of gratuity, he is discharged with a sprinkling of water; otherwise he is heartily drenched. The ship-boys are enclosed in a cage, and ducked at discretion:-The seamen, on baptizing the ship at this time, pretend to a right of cutting off the beak or 
head, unless redeemed by the captain. It is also customary, at the launching of new ships, to baptize the vessel, by breaking a bottle of wine or other liquor upon her, just as she is going off the stocks.

\section{ASYLA.}

TIE Asyla of altars and temples were very ancient; and likewise those of tombs, statues, and other monuments of considerable personages. Thus the temple of Diana at Ephesus was a refuge for debtors; the tomb of Theseus, for slaves. Among the Romans, a celebrated Asylum was opened by Romulus between the mounts Palatine and Capitoline, in order to people Rome, for all sorts of people indiscriminately worshipped the god Asylaus.

The Jews had their Asyla ; the most remarkable of which were the six cities of refuge, the temple, and the altar of burnt-offerings; which protected those who had incurred the lash of the law, but not for any deliberate crime. But it was customary among the Heathens to allow refuge and impunity even to the vilest and most flagrant offenders ; some out of superstition, and others for the sake of peopling their cities. They had an idea that a criminal who fled to the temple or altar, submitted his crime to the punishment of the gods, and that it would be impicty in man to take vengeance out of their hands. It was by this means and with such inhabitants, that Thebes, Athens, and Rome were first stocked. We even read of Asyla at Lyons and Vienna, among the ancient Gauls; and there are some cities in Germany, which still preserve the ancient right of Asylum. The emperors Honorius and Theodosius granting the like immunities to churches, the bishops and monks laid hold of a certain tract or territory, without which they fixed the bounds of their secular juris. diction; and so well did they manage their privileges, that converts in a little time became next akin to fortresses, where the most notorious villains were in safety, and braved the power of the magistrate. These privileges at length were extended, not only to the churches and church-yards, but also to the bishops' houses; whence the criminal could not be removed without a legal assurance of life, and an entire remission of the crime. The reason of this extension was, that they might not be obliged to live together in the churches, \&c. where several of the occasions of life could not be decently performed. But at last these Asyla were stripped of most of their immunities, because they served to make guilt more daring. In Britain particularly, they were entirely abolished, as protecting criminals, although there still remained some privileged places of refuge for debtors; such was the abbey of the Holy Rood House, near Edinburgh, and its precincts.

\section{ExPIATION OF MURDER.}

IN conformity with the Jewish and eastern opinions on this subject, if the crime of blood lay on any member of a family, he or she was said to have begotten or brought forth an Erynnis to the house.

But although the blood-avenger underwent incalculable difficulties, and spent an incredible time in hunting down his victim, a commu. 
tation or compensation for murder was, not unfrequently, adjusted between the parties. Moswiah, after the slaughter of his brother Said Ben Beker, expiated the crime by camels :-we read indeed of an instance, where one hundred camels have been accepted for blood, which we know became usual afterwarls, among the Koreish and sone other tribes. Among the Arabs of the desart, ten were formerly the usual number; and whenever such a compensation is admitled, it is classed under the term Divat. In the Shahnamen, Kai Khosin, agreeably to this received custom, pursues Afrasiab through many regions, to revenge the murder of his father: and a singular instance occurs in Hamilton's abridged translation of Antar. "Now there was blood-revenge betweel Gheidac and Antar, because Antar had killed his father, and he had been brought up an orphan; but when he grew up, he became a valiant horseman; and destroyed his opponents; and he was a blazing thunderbolt, and overthrew knights and slew warriors. And when his name was spread abroad among the tribes, they gave him supreme command, and he sat in the place of his father. He became proud, and behaved baughtily to his people. Now there was a man in the tribe called Gaalhaah, and he hated Gheidac. $O$. Gheidac, said he one day, thou art a marked man; it does not become thee to behave so haughtily towards the horsemen, when thqu hast not yet revenged the murder of thy father: how canst thou presume to boast over the brave and the valiant? And Gheidac said, Who is the stout king on whom I am to be avenged? Thy revenge is on Antar the son of Shedad, said he. Then the light became darkness in his eyes, and he cried out to the horsemen of his tribe, and he ordered them to prepare for an expedition to attack the tribe of $\mathrm{Abs}$, and he swore he would slay Antar, and make him drink the cup of perdition, and destroy the whole tribe of Abs and Adnan," Another instance, which exemplifies the opinions on mulcts for blood, occurs in vol. 3. p. 299 ; it relates to the murder of Sou by Thalany: "King Zoheir was highly incensed, his eye-balls started into the crown of his head. O tribe of Antar, cried he, I demand: from you one of three conditions. First, that you return me my son, as he was; but if you cannot effect that, fill then my outer cloak with the constellations of heaven; and if you cannot effect that, I demand of you the whole tribe of Ghani, that I may sacrifice all theirchildren and their parents. O my lord, said they, verily you insult and outrage us, and demand of us inpossibilities; for he who requests what no human being can perform, oppresses and tyrannizes. But we will pay you ten times the price of blood, and we beg of you to set at liberty our women and our daughters. Thus the tribe continued, till king Zoheir was duped, and relented. Consulting with Rehia about the abandonment of retaliation, and their return howe, $O \mathrm{king}$, said. Rebia, what is this you say? How can we raise our heads among the Arabs, if we permit the blood of Shas to pass unrevenged. And unsheathing his sword, To arms! to arms! he exclaimed, and rushed with his drawn sabre among the tribe of Ammir, whilst the sons of king Zoheir also, joining in a similar shont, extended their spears, and plied their scimeters among them," \&c. \&c.

In the Orestes of Euripides, water is described as possessing pecu. 
liar qualities in cases of blood-shedding; and the scholiast on the Ajax of Sophocles avers, that ablution of the hands was accounted effectual. Pausanias, in Corinth. informs us that Orestes expiated the murder of Clytemnestra in the waters of Hippocrene; and we may remark the same notion in Virgil's $2 d$ Fneid. Thoas, in the Iphigenia in Tauris of Euripedes, delivers the doctrine as a canon, that Apollo in the Alcestis (v. 5.) declares his degradation during the time that he served Admetus, to have been considered as atonement for the murder of the Cyclops; and whether there be any distant allusion to the Goel, in the fable of Orcus drinking the blood of the victims at the tombs of the dead, we cannot determine. When the fine for blood was accepted or the purification perfected, doubtless some visible token of security, like the mark on Cain, was granted to the offender: thus when the injury is compromised among the Arabs, a mantle of security is given to the delinquent by the reconciled party.

\section{OrDEAL.}

Tils was an ancient form of trial. There were two sorts of it more common than the rest in Europe, by fire, and by water :- the former was confined to persons of higher rank, the latter to the common people. Both these might be performed by deputy; but the principal was to answer for the success of the trial, the deputy only venturing some corporeal pain, for hire, or perhaps for friendship. The Fire Urdeal was performed either by taking up in hand, unhurt, a piece of red-hot iron, one, two, or three pounds weight; or also by walking, barefoot and blindfold, over nine red-hot ploughshares, laid lengthwise at unequal distances : and if the party escaped being hurt, he was adjudged innocent, but if it happened otherwise, as without collusion it usually did, he was then condemned as guilty. Water Ordeal was performed either by plunging the bare arm up to the elbow in boiling water, and escaping unhurt thereby, or by casting the person suspected into a river or pond of cold water; and if he floated therein, without any action of swimming, it was a decided evidence of his guilt; but if he sunk, he was acquitted. It is easy to trace out the traditional relics of this water ordeal, in the ignorant barbarity still practised in many countries to discover witches, by casting them into a pool of water, and drowning them, to prove their innocence. In the eastern empire the fire-ordeal was used for the same purpose by the emperor. Theodore Lascasis, who, attributing his sickness to magic, caused all those whom he suspected to handle the hot iron ; thus joining, as has been well remarked, to the most dubious crime in the world, the most dubious proof of innocence. Besides these methods of trial, there were some others common in Europe; the principal of which were, the judicial combat, and the ordeal of the cross:-The judicial combat was well suited to the genius and spirit of fierce and warlike nations, and was one of the most ancient and universal modes of trial. It was exceedingly common in Germany in very remote ages. It was also used in some countries on the continent at pretty early'periods ; it is not, however, mentioned 
III any of the Anglo Saxon laws; and it does not appeac to have been much used in England til! after the Conquest. There are, however, two remarkable instances of it recorded in Dr. Henry's History of Great Britain, to which we shall refer the inquisitive reader. We need scarcely add, that this detestable form of trial was the foundation of the no less detestable crime of duelling, which still disgraces our age and nation.--It was so much the custom in the middle ages of Christianity, to respect the cross even to superstition, that it would have been indeed wonderful if the same ignorant bigotry had not converted it into an ordeal; accordingly, we find it used for this purpose in so many different ways as almost to preclude description. Dr. Henry gives the following account of it. In criminal trials the judg:ment of the cross was thus conducted. When the prisoner had declared his innocence upou oath, and appealed to the judgment or the cross, two sticks were prepared, exactly like one another : the figure of the cross was cut on one of these sticks, and nothing on the other ; each of them was then wrapped up in a quantity of fine white wool, and laid on the altar, or on the relics of the saints; after which a solemn prayer was put up to God, that he would be pleased to discover, by evident signs, whether the prisoner was innocent or guilty. These solemnities being finished, a priest approached the altar, and took up one of these sticks, which was uncovered with much anxiety. If it was the stick marked with the cross, the prisoner was pronounced innocent; if was the other, he was declared guilty. When the judgment of the cross was appealed to in civil causes, the trial was coiducted in this manner, The judges, parties, and all concerned, being assembled in a church, each of the parties chose a priest, the youngest and stoutest that he could find, to be his representative in the trial. These representatives were then placed one on each side of some famous crucifix; and at a signal given they both at once stretched their arms at full length, so as to form a cross with their body. In this painful posture they continued to stand while divine service was performing; and the party whose representatives dropped his arms first, lost his cause. These and the like relics of supertition and barbarism were abolished in England, as had been done in Denmark above a century before; by act of parliament, 3 Hen. III. according to Sir Edward Coke, or rather by an order of the king in council.

Ordeal seems to have been carried to a greater height among the Hindoos than ever it has been in any nation or among any people, however rude or barbarous; for in a paper of the Asiatic Researches, communicated by the celebrated Warren. Hastings, Esq., we find that the trial by ordeal among them is conducted in nine different ways: viz. 1. by the balance; 2 . by fire; 3 . by hot oil; 4 . by images; 5 . by poison ; 6. by red-hot iron; 7 . by rice; 8 . by the Cosha; 9 . by water-Ordeal by balance is thus performed: The beam having been previously adjusted, the cord fixed, and both scales made perfectly even, the person accused, and a Pandit, fast a whole day; then, after the accused has been bathed in sacred water, the homa or oblation presented to fire, and the deities worshipped, he is carefully weighed; and, when he is taken out of the scale, the Pandits pros- 
trate themselves before it; pronounce a certain mentra oriticantation, agreeably to the Sastra, and, having iv ritten the substance of the accusation on a piece of paper, bind it on his head. Six minutes after, they place him again in the scale, and if he weighs more than before, he is held guiliy; if less, innocent; if exactly the same, he must be weighed a third time, when, as it is written in the Mitac shera, there will certainly be a difference in his weight. Should the balance, though well fixed, break down, this would be considered a s a pronf of his guilt.-Ordeal by fire: In this, ain excavation, nine hands long, two spans broad, and one span deep, is malle in the ground, and filled with fire of a peculair wood; inte this the person accused must. walk barefooted; and if his feet be whurt, they hold him blameless; if burnt, guilty._-Ordeal by hot oil, is very simple, but preceded by certain superstitious ceremonies. It is thus performed : The ground appointed for the trial is cleared, and rubbed with cow-dung; and the next day at sun-rise the Pandit worships Ganesa, or the Hindoo Janus, presents his oblations, and pays adorar cion to other deities, conformably to the Sastra; then, having read the incantation prescribed, he places a round pan of gold, silver, copper, iron, or clay, with a diameter of sixteen fingers, and four fingers deep ; and throws into it one ser, or eighty sicca weight, of clarified butter, or oil of sesamum. After this, a ring of gold, silver, or iron, is cleaned and washed with water, and cast into the oil ; which they pruceed to heat, and when it is very hot, pour into it a fresh leaf of hippala, or of beleva; when the leaf is burned, the oil is known to be sufficiently hot: then, having pronounced a mentra, they order the party accused to take the ring out of the pan; and if he takes it ont without being burned, or without a blister on his hand, his innocence is considered as proved; if not, his guilt-Ordeal by images : To perform the ordeal by dharmarch, which is the Hindoo name appropriated to this mode of trial, either an inage, named Dharma, or the genius of justice, is made of silver, and another, called Adharma, of clay or iron, both of which are thrown into a large earthen jar and the accused, having thrust his hand into it, is acquitted if he brings out the silver image, but condemned if be draws forth the iron. Or, the figure of a deity is painted on white cloth, and another on black; the first of which they name Dharma, and the second Adharma; these are severally rolled up in cow-dung, and thrown into a large jar, without ever havirg been shown to the accused; who must put his hand icto the jar, and is acquitted or convicted as he draws out the figure on white or on black cloth. Ordeal by poison: There are two sorts of trial by poison; first, the Pandits having performed their homa, and the person accused his ablution, two rettis and a half, or seven barley-corns, of vishanaga, a-poisonous root, or of sancliga, that is, white arsenic, are mixed in eight mashas, or sixty-four rettis, of clarified butter, which the accused must eat from the hand of a braliman : if the poison produces no visible effects, he is acquitted; otherwise condemned. Secondly, the hooded snake, called naga, is thrown into a deep earthen pot, into which is dropped a ring, seal, or coin this the person accused is ordered to take out with his hand; and, if the ser- 
pent bite him, he is pronounced guilty ; if not, innocent.-Ordeal by red-hot iron: In this trial they make an iron ball, or the head of a lance, red-hot, and place it in the hands of the person accused: who, if it burn him not, is judged guiltless.-Ordeal by rice : When several persons are suspected of theft, some dry rice is weighed with the sacred stone called salgram, or certain slocas are read over it; after which the suspected persons are ordered to chew a quantity of it; they are to throw it on some leaves of pippal, or, if none be at hand, on some b'hurja patra, or the bark of a tree from Nepaul or Cashmir. The man from whose mouth the rice comes dry, or stained with blood, is held guilty; the rest are acquitted.-Ordeal by the Cosha is as follows: The accused is made to drink three draughts of the water in which the images of the sun, of Devi, and other deities, have been washed for that purpose; and if within fourteen days he has any sickness or indisposition, his crime is considered as proved. Ordeal by water, is performed by causing the person accused to stand in a sufficient depth of water, either flowing or stagnant, to reach his navel; but care should be taken, that no ravenous beast be in it, and that it be not moved by much air; a brahman is then directed to go into the water, holding a stafi in his hand, and a soldier shoots three arrows on dry ground from a bow of cane; a man is then despatched to bring the arrow that has been shot farthest; and, after he has taken it up, another is ordered to run from the edge of the water, at which instant the person accused is told to grasp the foot or the staff of the brahman who stands near him in the water, and immediately to dive into it. He must remain under the water till the two men who went to fetch the arrows are returned; for if he raise his head or body above the surface before the arrows are brought back, his guilt is considered as fully proved. In the villages near Benares, it is the practice for the person who is to be tried by this kind of ordeal, to stand in water up to his navel, and then, holding the foot of a brahman, to dive under it as long as a man can walk fifty paces very gently; if before the man has walked thus far, the accused rise above the water, he is condemned; if not, acquitted.... A very peculiar species of water ordeal is said to be prevalent among the Indians on the coast of Malabar. A person accused of an enormous crime is obliged to swim over a large river abounding with crocodiles; and if he escapes unhurt, he is esteemed innocent. At Searin, besides the usual methods of fire and water ordeal, both parties are sometimes exposed to the fury of a tiger let loose for that purpose : and if the beast spares either, that person is accounted innocent; if neither, both are held to be guilty; but if he spares both; the trial is incomplete, and they proceed to a more certain criterion. There were various tricks by which persons escaped in ordeal. Upon this subject, Dr. Henry has the following remarks : "If we suppose that few or none escaped conviction who exposed themselves to those fiery trials, we shall be very much mistaken. For the histories of those times contain innumerable examples of persons plunging their nalsed arms into boiling water, handling red-hot balls of iron, and walking upon burning ploughshares, without receiving the least injury. Many learned men have been much puzzled to 
account for this, and disposed to think that Providence graciously interposed, in a miraculous manner, for the preservation of injured innocence. But if we examine every circumstance of these fiery ordeals with due attention, we shall see sufficient reason to suspect that the whole was a gross imposition on the credulity of mankind.

The accused person was committed wholly to the priest, who was to perform the ceremony three days before the trial, in which he had time enough to bargain with him for his deliverance, and to give him instructions low to act his part. On the day of trial, no person was permitted to enter the church but the priest and the accused, till after the iron was heated, when twelve friends of the accuser, and twelve of the accused, and no more, were admitted, and ranged along the wall on each side of the church, at a respectful distance. After the iron was taken out of the fire, several prayers were said, the accused drank a cup of holy water, and sprinkled his hand with it, which might take a considerable time, if the priest was indulgent. The space of nine feet was measured by the accused himself with his own feet, and he would probably give but scanty measure. He was obliged only to touch one of the marks with the toe of his right foot, and allowed to stretch the other foot as far towards the other mark as he could, so that the conveyance was almost instantaneous. His hand was not immediately examined, but wrapped in a cloth prepared for that purpose three days. May we not then, from all these precalltions, suspect that these priests were in possession of some secret, that secured the hand from the impressions of such a momentary touch of hot iron, or removed all appearances of these impressions in three days, and that they made use of this secret when they saw reason? Such readers as are curious in matters of this kind, may find two different directions for making ointments that will have this effect, in a work here quoted. Du Cange, Gloss.tom. iii. p. 397. What greatly strengthens these suspicions is, that we meet with no example of any champion in the church who suffered the least injury from the touch of hot iron in this ordeal; but when any one was so simple as to appeal to it, or to that of lot water, with a view to deprive the church of any of her possessions, he never failed to burn or scald his fingers, and lose his cause.

\section{OLD TIMES. - (FROM THE BERKELEY MSS.)}

"In the time of Edward I. and II. they set beans by the hand, and leazed the seed wheat from the ear itself.

"Prices of articles in the time of Edward I. \&c. - Wheat per quarter $2 \mathrm{~s}, 2 \mathrm{~s} 4 \mathrm{~d}, 3 \mathrm{~s} 4 \mathrm{~d}, 5 \mathrm{~s}$.- maslyn (wheat and rye mixed) per quarter, $2 \mathrm{~s}, 2 \mathrm{~s} 4 \mathrm{~d}, 3 \mathrm{~s} 4 \mathrm{~d}$.- - barley per quarter, $20 \mathrm{~d}, 2 \mathrm{~s}-8 \mathrm{~d}, 3 \mathrm{~s}, 3 \mathrm{~s} 4 \mathrm{~d}, 4 \mathrm{~s}$. beans per quarter, $2 \mathrm{~s}, 2 \mathrm{~s} 8 \mathrm{~d}$. $3 \mathrm{~s}, 3 \mathrm{~s} 4 \mathrm{~d}$, $4 \mathrm{~s}$.-Oats per quarter, $20 \mathrm{~d}$, $2 \mathrm{~s}, 2 \mathrm{~s} 4 \mathrm{~d}$.-pill corne; from the mill, per quarter, $3 \mathrm{~s}$, or $3 \mathrm{~s} 8 \mathrm{~d} .-$-an oxe, $10 \mathrm{~s}, 11 \mathrm{~s}, 12 \mathrm{~s}$. - cow and calf, 9s, 10s. - bacon hog, $5 \mathrm{~s}, 5 \mathrm{~s} 6 \mathrm{~d} .-$ fat porket, 2s, 2s $2 \mathrm{~d}$.- fat sheepe, 17d, 18d, 20d, 2s.-lambe, 10d or 12d.-goose, 3d.-capon, $2 \mathrm{~d}$.- $-\mathrm{a}$ hen, 1 $1 \frac{1}{2} \mathrm{~d} .-\mathrm{a}$ duck, 1d.-four pigeons, 1d.-twenty eggs, 1. 
15th Edward II. - Wheat per quarter, 4s,-malt ditto, 3s.-barley ditto, 3s.-beans ditto, 3s.-oats ditto, 2s.-fetches $20 \mathrm{~d}$ - malt (of wheat,) $6 \mathrm{~s}$; of barley, $4 \mathrm{~s}$; of oats, $2 \mathrm{~s} 2 \mathrm{~d}$.-apples, quarter of, $10 \mathrm{~d}$.

" 19th Edward II. - A sturgeon, 26s 8d.--an oxe, 20s.-an oxehide, $2 \mathrm{~s} 6 \mathrm{~d}$.- cow and calf, 12s, 13s, 15s.-sheepe between $17 \mathrm{~d}$ and $2 \mathrm{~s}$. - sheep-skin according to growth, 4d, 5d, 6d.-lambe, 12d. goat-skin, $4 \frac{1}{2} \mathrm{~d}$.-goose, $3 \mathrm{~d}$.-duck, $1 \frac{1}{2}$ - the rest as before.-wages of a day labourer, $\frac{3}{4} \mathrm{~d}-\mathrm{a}$ yeoman's board-wages by the day, $1 \frac{1}{2} \mathrm{~d},-\mathrm{a}$ groom or page's, $1 l$. And by proclamation, 8 Edward II. the maximum of wine was $3 d$ the gallon.

"Latter" end of Edward III.-Wheat per quarter, $5 \mathrm{~s} 4 \mathrm{~d}$ to $10 \mathrm{~s}$. barley ditto, $4 \mathrm{~s}$ to $5 \mathrm{~s} 4 \mathrm{~d}$.- - beans ditto, $4 \mathrm{~s}$.- oats ditto, $2 \mathrm{~s} 8 \mathrm{~d}$, to $3 \mathrm{~s} 4 \mathrm{~d}$.- bay-salt ditto, $18 \mathrm{~d}$.- an oxe, $14 \mathrm{~s}$ to $24 \mathrm{~s}$. - sowe and six pigs, 5s.-boare, 4s.-calfe, 2 s.-store pigg or shote, $12 d$-pigeons, per dozen, $3 d$ to $4 \mathrm{~d}$.- -haggard falcon, 20s.--In the residue, little variation.

"And in the reign of Richard II. for 22 years of his reign, the prices of graine, cattle, and poultry, were rather cheaper than dearer: but the difference in effect that was, was in the temperance and season of the yeare. A weight of woll, being 21 pound, called pondus, $5 \mathrm{~s}$ - - a sacke of woll, $6 \mathrm{~s} 8 \mathrm{~d}$. - onyons, a bushell, $8 \mathrm{~d}$.- - eggs 20 for a penny, which neither rose nor fell for 160 years.

wa And at this day when I write, A. D. 1622, the common prices of the like commodities are generally thus: Wheat per quarter, $36 \mathrm{~s}$ maltyn ditto, $26 \mathrm{~s}$ 8d.--barley ditto, $20 \mathrm{~s}$. - barley malt, 24s.- - beans, 20 s.- - a draught oxe, $5 l$.-cow and calf, $2 l 10$ s.-sheepe, 6 s.-eggs, five for $1 d$.

"And for horses, in those active old ages of the three Edwards. and Richard 11., the lord Berkeleys have paid for horses of service in the warres, and for sadle and draught, as deere as now in our daies. $100 l, 100$ marks, 50l, 30l, 20l, 10l, 20 nobles, \&c.

The household and standing domesticall family of this lord, lodged in house, consisted of 200 persons and upwards, ranked into their degrees of servants, nilites, armigeri, valetti, garciones et pagetti, knights, esquires, yeomen, gromes, and pages, besides husbandmen, hindes, and such other of low condition. The wages of one of his esquires was iij $\frac{1}{2} \mathrm{~d}$ a day, and a horse in his stables or pastures; or $\mathrm{ij} \frac{1}{2} \mathrm{~d}$ for him instead, and two sutes by the yeare furred (duas robas cum furruris,) or xxiijs iiijd; and for a garcion or boy to attend him $1 \frac{1}{2} \mathrm{~d}$ a day; which, besydes diet in his house, came to xxiijl iiijs $i \frac{1}{2}$ by the yeare. The wages of a knight, more; of an inferrior attendant, less.

"This lord was the first who used marle as a manure. Joan, lady of lord Thornas, though forty years a wife, never travelled ten miles from the house of her husband in the counties of Gloucester and Somerset.

cTithes, why willingly paid.-A Hebrew proverb was in use: "Pay tithes justly, that thou mayst be rich."? 


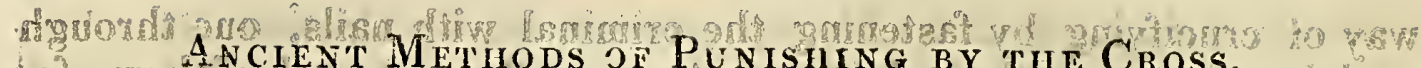

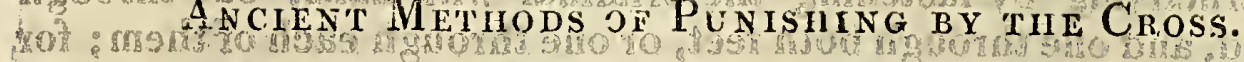

Che cross was made with two pieces of wood placed crosswise, either erossing at right angles at the top with $\mathrm{T}$, or in the middle of their length like an $\mathrm{X}$. The cross to which our Saviour was fastened, and on which he died, was of the former kind; being thus represénted by old monuments, coins, and crosses; and St. Jerome conpares it to a bird flying, a man surviving, or praying with his arms extended. The punishment of the cross was common among the Syrians, Egyptians, Persians, Africans, Greeks, Romans, and Jews. It was the most dreadful of all others, both for the shame and pain of it; and so scandalous, that it was inflicted as the last mark of detestation upon the vilest of people. It was the punishment of robbers and murderers, provided that they were slaves too; but if they were free, and had the privilege of the city of Rome, it was thonght too infamous a punishment for such a one, let his crimes be what they would. The Mosaic law ordained that the bodies of persons executed should not he left upon the tree after sun-set, Deut. xxi. 22. The Jews believe that the souls of those who remain upon the gibbet, and without burial, enjoy no peace, but wander up alld down till their bodies are buried; which agrees with the notions that Greeks and Romans had. The body of the criminal was fastened to the upright piece by nailing the feet to it, and on the other transverse piece, generally by nailing the hands on each side. Now, bccause these parts of the body, being the instruments of action aid motion, are provided by nature with a much greater quantity of Nerves than others have occasion for ; and because all sensation is performed by the spirit contained in these nerves; it will follow, that wherever they abound, the sense of pain in proportion must be more quick and tender. The Jews confess that they crucified people in their country, but deny that they inflicted this punishment upon any one alive. Before the crucifixion the criminal was generally scourged with cords; sometimes pieces of bones were tied to these scourges, that the condemned peison might suffer more severely. It was also a custom, that he who was to be crucified, should bear his own cross to the place of execution. In this manner Christ was compelled to bear his own cross, and as he sunk under the burden, Simon the Cyrenian was constrained to bear it after him and with him. But whereas it is generally supposed that our Lord bore the whole cross, i. e. both the long and transverse part, this seems to be a thing impossible; and therefore Lipsius, in his treatise De Supplicio Crucis, has set the matter in a true light, when he tells us that Jesus only carried the transverse beam, because the long beam, or the body of the cross; was either fixed in the ground before, or made ready to be set up as soon as the prisoner came; and from hence he observes, that the painters are very much mistaken in representing our Saviour carrying the whole cross. There are several ways of crucifying; sometimes the criminal was fastened with cords to a tree, sometimes he was crucified with his head downwards. This way St. Peter chose, out of respect to his master Jesus Christ, not thinking himself worthy to be crucified like him; though the common 
way of crucifying by fastening the criminal with nails, one through each hand, and one through both feet, or one through each of them; for this was not always performed in the same manner. The ancients sometimes represent Jesus Christ crucified with fournails, and some, times with three. The criminal was fixed to the cross quite naked; and in all probability the Saviour of the world was not used with any greater tenderness than others upon whom this punishment was inflicted. The soldiers divided his clothes among, them, and cast lots for his tunic, which is an under garment worn over the skin like a shirt. The text of the gospel shews clearly that Jesus Christ was fastened to the cross with nails; and the Psalmist, xxii. 16, had foretold long before, that they should pierce his hands and his feet; but there are great disputes concerning the number of these nails. The Greeks represent our Saviour as fastened to the cross jwith four nails, (in which Gregory of Tours agrees with them, ) one at each hand and foot. But several are of opinion that our Saviour's hands and feet were pierced with three nails only; viz, one at each hand, and one through both his feet; and the custom of the Latins is rather for this last opinion, for the generality of the old crucifixes made in the Latin churches have only three nails.

1 Norinus thinks that our Saviour's arms were besides bound fast to the cross with chains; and St. Hilary speaks of the cords wherewith he was tied to it. Sometimes they who were fastened upon the cross lived a long while in that condition. St. Andrew is said to have continued three days alive upon it Eusebius speaks of certain martyrs in Egypt who were kept upon the cross till they were starved to death. Pilate was amazed at Jesus Christ's dying so soon; because naturally he must have lived longer, if it had not been in his power to lay down his life, and take it up again. The thighs of the two thieves who were crucified with our Saviour, were broken, to hasten their death, that their bodies might not remain upon the cross on the sabbathday, and to comply with the law of Moses, which forbids the bodies to be left there after sun-set. But among other nations, they were suffered to remain upon the cross a long time. Sometimes they were devoured alive by birds and beasts of prey. Guards were appointed to observe that none of their friends or relations should take them down and bury them. The Roman soldiers who had crucified Jesus Christ and the two thieves, continued near the crosses till the bodies were taken down and buried.

\section{Modes of Salutation in various Countries.}

GREENLA DERS have none, and laugh at the idea of one person being inferior to another.

Islanders near the Philippines take a person's hand or foot, and rub it over their face.

Laplanders apply their noses strongly against the person they salute.

In New Guinea they place leaves upon the head of those they salute.

In the Straits of the Sound they raise the left foot of the person they salute, passing it gently over the right leg, and thence over the face. 
The inhabitaits of the Philippines bend very low, placing their hands on their cheeks, and raise one foot in the air with the knee beit.

An Ethiopian takes the robe of another and ties it about him, so as to leave his friend almost naked.

Two female Otaheitans placed themselves in a state of nudity before Sir Joseph Banks.

The Japanese take off a slipper, and the people of Arracan their sandals, in the street, and their stockings in the house, when they salute.

The Negro kings. on the coast of Africa salute by snapping their middle finger three times.

The inhabitants of Caranania, when they would shew a particular attachment, open a vein, and present the blood to their friend as a beverage.

If the Chinese meet after a long separation, they fall on their knees, bend thcir face to the earth two or three times, and use many other affected modes. The Chinese have also a kind of ritual, or formulary, of compliments, by which they regulate the number of bows, genuflections, and words, to be used on any occasion. Ambassadors practise forty days these ceremonies before they appear at court.

In Otaheite they rub their noses together in saluting.

The Dutch, who are considered as great eaters, have a morning salutation, which is common amongst all ranks : "Snaalkelyk eeten;" - " May you eat a hearty dinner." Another universal salutation among this people is, "Hoe vaart awe ?"-How do you sáil ?" adopted, no doubt, in the early periods of the republic, when they were all navigators and fishermen.

The usual salutation at Cairo is, "How do you sweat?" a dry hot skin being a sure indication of a destructive ephemeral fever.

I think some author has observed, in contrasting the haughty Spaniard with the frivolous Frencliman, that the proud steady gait and inflexible solemnity of the former were expressed in his mode of salu-' tation: "Come esta?"- "How do you stand?" Whilst the "Comment vous portez vous ?"- How do you carry yourself?" was expressive of the gay motion and incessant action of the latter.

The common salutation in the southern provinces of China, amongst the lower orders, is, "Ya fan ?"- "Have you eaten your rice?"

Parke says, in his Travels in Africa, "A young woman (his intended bride) brought a little water in a calabash, and kneeling down before him, desired him to wash his hands; when he had done this, the girl, with the tear of joy sparkling in her eyes, drank the water; this being considered as the greatest proof she could give of her fidelity and attachment."

\section{Account of the Origin and OfFice of Cardinal.}

A CARDINAL is one of the chief governors of the Romish church. The cardinals compose the pope's council or senate; in the Vatican is a constitution of pope John, which regulates the rights and titles of the cardinals; and which declares, that as the pope represents Mo- 
ses, so the cardinals represent the 70 elders, who, under the pontifical authority, decide private differences. Cardinals, in their tirst institution,-were only the principal priests of the parishes of Rome. In the primitive church, the chief priest of a parish, next the bishop, was called presbyter cardinalis, to distinguish him from the other petty priests, who had no church. The term was first applied to them in A. D. 150; others say, 300. Under pope Gregory, cardinal priests and deacons were only such as had a church or chapel under their care ; and thus was the original use of the word. Leo IV. in the couneil of Rome, held in 353 , calls them presbyteros sui cardinis ; and their churches, parochias cardinales. The cardinals continued on this footing till the eleventh century; but as the grandeur of his holiness became exceedingly augmented, he would have his councils of cardinals make a better figure than the ancient priests had done. It was a good while, however, before they had the precedence over bishops, or got the election of the pope into their hands; but they soon after got the red hat and purple, and became at length superior to the bishops, by the sole quality of being cardinals.

Du Cange observes, that originally there were three kinds of churches: the first, or genuine churches, were properly called parishes; the second, deaconries, which were chapels joined to hospitals, and served by deacons; the third, oratories, where private masses were said, and were discharged by local and resident chaplains. He adds, that to distinguish the principal churches from the chapels and oratories, the name cardinales was given them. Accordingly, parish churches gave titles to cardinal priests; and some chapels also, at length, gave the titles to cardinal deacons. Others are of opinion, that the title was given not only to priests, but likewise to such bishops and deacons as were attached to certain churches, to distinguish them from those who only served them en passant, and by commission. Titular churches, or benefices, were a kind of parishes, i. e. churches assigned each to a cardinal priest, with some stated district, and a font for administering baptism, in cases where the bishop himself could not do it. These cardinals were subordinate to the bishops; and accordingly, in conncils, particularly that held at Rome in 868 , subscribed after them. It was not, however, only at Rome, that priests bore this title, for there were cardinal priests in France; thus the curate of the parish of St. John de Vignes is called in old charters the cardinal priest of that parish. The title is also given to some bishops, -quatenus bishops, e. $\mathrm{g}$. to those of Mentz and Milan; the archbishop of Bourges is also, in ancient writings, called cardinal. The sacred college consists of seventy cardinals, divided into three classes, viz. bishops, priests, and deacons. The cardinal bishops, who are the pope's vicars, bear the titles of the bishoprics assigned to them; the rest take such titles as are given them; the number of cardinal bishops has been fixed, but that of cardinal priests and deacons, and consequently the sacred college itself, has often fluctuated. Till 1125, the college only consisted of fifty-two or fifty-three; the council of Constance reduced them to twenty-four; but Sixtus IV, about 1480 , raised them again to fifty-three, and Leo $X$. to sixty-five. Thus, as 
the number of cardinal priests were anciently fixed to twenty-eight, new titles were to be established, in proportion as new cardinals were created. The cardinal deacons were originally no more than seventeen, for the fourteen quarters of Rome; but they were afterwards increased to nineteen, and after that were again diminished. Pope Pius IV. enacted, in 1562, that the pope should be chosen only by the senate of cardinals, exclusive of the clergy, in the time of Alexander III. in 1160. Others go higher still, and say, that Nicholas II. having been elected at Sienna, in 1058, by the cardinals alone, occasioned the right of election to be taken from the clergy and people of Rome ; only leaving them that of confirming him by their consent, which was at length likewise taken from them. At the creation of a new cardinal, the pope performs the ceremony of opening and shutting his mouth; which is done in a private consistory. The shutting his mouth implies the depriving him of the liberty of giving his opinion in congregations ; and the opening his mouth, which is performed fifteen days after, signifies the taking off this restraint. If the pope happens to die during the time a cardinal's mouth is shut, he can neither give his voice in the election of a new pope, nor be himself advanced to that dignity.

The dress of a cardinal is a red soutanne, a rocket, a short purple mantle, and a red hat. The cardinals began to wear the red hat at the council of Lyons, in 1243. The decree of pope Urban Vili. where by it is appointed, that the cardinals be addressed under the title of Eninence, is dated 1630 ; till then, they were called Illustrussimi. When cardinals are sent to the courts of princes, it is in quality of legates-a-latere: and when they are appointed governors of towns, their goverument is called by the name of legation.

\section{Beltan, or Beliteir.}

THIS is the name of a superstitions custom observed in the Highlands of Scotland. "It is," says Mr. Pennant, in his Tour, "a kind of rural sacrifice perfornied by the herdsnen of every village on the 1st of May. They cut a square trench in the ground, leaving the turf in the middle; on that they make a fire of wood, on which they diess a large sandell of eggs, butter, oatmeal, and milk; and bring, besides the ingredients of the çaudle, plenty of beer and whisky, for each of the company must contribute something. The rites begin with spilling some of the caudle on the ground, by way of libation; on that, every one takes a cake of oatmeal, upon which are raised nine square knobs, each dedicated to some particular being, the supposed preserver of their floeks and herds, or to some particular animal, the real destroyer of them : each person then turns his face to the fire, breaks off a knob, and, flingirig it over his shoulder, says, This I give to thee, preserve thou my horses; this to thee, preserve thou my sheep; and soon. After that they use the same cerenony to the noxious animal. This I give to thee, $O$ fox, spare thou my lambs; this to thee, $O$ hooded crow, this to thee, $O$ eagle! When the ceremony is over, they dine upon the caudle, and after the feast is finished, what is left, is had by two persons for that 
purpose, but on the next Sunday they reassemble, and finish the relics of the first entertainment. - Dr. James Robertson, minister of Callander, gives a very different and seemingly more credible, account of this festival, in Sir John Sint clair's Stat. Acc. vol. ii. 620. "Upon the first day of May," says the Dr. "which is called Beltan, or Baltein day, all the boys in a township or hamlet meet in the moors. They cut a table in the green sod, of a round figure, by casting a trench in the ground, of such circumference as to hold the whole company." After dressing the caudle, as above mentioned, they knead a cake of oatmeal, which is toasted at the embers, against a stone. After the custard is eaten up, they divide the cake into so many portions, similar as possible to one another in size and shape, as there are persons in the company. They daub one of these portions all over with charcoal, until it is perfectly black. They put all the bits of the cake into a bonnet. Every one, blindfold, drawsout a portion : he who holds the bonnet, is entitled to the last bit. Whoever draws the black bit; is the devoted person who is to be sacrificed to Baal, whose favour they mean to implore, in reildering the year productive of the sustenance of man and beast. There is little doubt of those inhuman sacrifices having been once offered in this country, as well as in the east, although they now pass from the act of sacrificing, and only compel the devoted person to leap three times through the flames; with which the ceremonies of this festival are closed. The Dr. in a note traces the origin of this and otlier superstitions from our ancient Druidism. Balstein, signifies the fire of Baal : Batal, or Ball, is the only word in Gaelic for a globe. This festival was probably in honour of the sun, whose return, in his apparent annual course, they celebrated, on account of his having such a visible influence, by his genial warmth, on the productions of the earth. That the Caledonians paid a superstitious respect to the sun, as was the practice among many other nations, is evident not only by the sacrifice of Baltein, but upon many other occasions. When a Highlander goes to bathe, or to drink waters out of a consecrated fountain, he must always approach by going round the place from east to west on the south side, in imitation of the apparenit diurnal motion of the sun. When the dead are laid in the earth, the grave is approached by going round in the same manner. The bride is conducted to her future spouse in the presence of the minister, and the glass goes round a company, in the course of the sun. This is called in Gaelic, going round the right, or the lucky, way. The opposite course is the wrong, or the unlucky, way.

\section{All Fools' Dä-(First of April.)}

MAURICE, in his "Indian Antiquities," vol. vi. p. 71, speaking of "the First of April, or the ancient feast of the vernal equinox, equally observed in India and Britain," tells us : "The first of April was anciently observed in Britain a a high and general festival, in which an unbounded hilarity, reigned through every order of its inhabitants; for the sun, at that period of the year, entering into the sign Aries, the new year, and with it the season of rural sports and vernal 
delight, was then supposed to have commenced. On both continents, some very remarkable traits of the jocundity which then reigned, remain even to these distant times. Of those preserved in Britain, none of the least remarkable or ludicrous is that relic of its pristine pleasantry, the general practice of making April fools, as it is called, on the first day of the month; but this, Colonel Pearce (Asiatic Researches, vol. ii. p. 334,) proves to have been an immemorial custom among the Hindoos, at a celebrated festival holden about the same period in India, which is cal!ed the Huli festival. "During the Huli, when mirth and festivity reign among the Hindoos of every class, one sulyject of diversion is, to send people on errands and expeditions that are to end in disappointment, and raise a laugh at the expense of the person sent. The Huli is always in March, and the last day is the general holiday. I have never yet heard any acconnt of the origin of this English custom; but it is unquestionably very ancieut, and is still kept up even in great towns, though less in thein than in the country. With us, it is chiefly confined to the lower class of people: but in India, high and low join in it and the late Suraja Doulah, I am told, was rery foud of making Huli fools, thongh he was a Mussulman of the highest rank. They carry the joke here so far, as to send letters, making appointments in the name of persons who, it is known, must be absent from their house at the time fixed upon; and the laugh is always in proportion to the trouble given." The least inquiry in to the ancient customs of Persia, or the minutest. acquaintance with the general astronomical mythology of A sia, would have taught Colonel Pearce that the boundless hilarity and jocuind sports prevalent on the first day of April in England, and during the Huli festival of India, have their origin in the ancient practice of celebrating with festival rites the period of the vernal equinox, or the day when the new year of Persia anciently began.

\section{ORIGIN OF THE CORONER'S INQUEST.}

A GENTLEWOMAN of London, after having buried six husbands? found a gentleman hardy enough to make her a wife once more. For several months their happiness was mutual; a circumstance which seemed to pay no great compliment to the former partners of her bed, who, as she said, had disgusted her by their sottishness and infidelity. In the view of knowing the real character of his amorous mate, the gentleman began frequently to absent himself, to return at late hours, and, when he did return, to appear as if intoxicated. At first, reproaches, but afterwards menaces, were the consequence of this conduct. The gentleman persisted, aud seemed every day to become more addicted to his bottle: one evening, when she imagined him to be dead drunk, she unsewed a leaden weight from one of the sleeves of her gown, aind, having melted it, she approached her husband, who pretended still to be sound asleep, in order to put it into his ear with a pipe. Convinced of her wickedness, the gentlemen started up, and seized ber; when, having procured assistance, he secured her till the morning, and conducted her before a magistrate, who conducted her to prison. The bodies of her six husbands were dug up, and, as marks 
of violence were still discernible upon each of them, the proof of her guilt appeared so strong upon her trial, that she was condemined and executed. To this circumstance is England indebted for that useful regulation, by which no corpse can be interred in the kingdom withont a legal inspection.

\section{Origin of Psalm Singing.}

THERE is in "D'Israeli's Curiosities of Literature" an amusing account of the origin of psalm-singing. It appears that the first book of psalms in verse was written by Marot, a Frenchman, the favoured bard of Francis the First-that "prince of poets," and that "poet of princes," as he was quaintly but expressively designated by his contemporaries. It was published at Paris, and contained fifty psalns, written in a variety of measures, with "the same style he had done his ballads and rondeaux." This "holy song-book" was dedicated to the king of France; and being a gay novelty, no book was ever more eagerly received by all classes than "Marot's Psalms :" they sold faster than the printers could take them off their presses; but as they were understood to be songs, and were unaccompanied by music, every one set them to favourite tunes, commonly those of popular ballads.

The universal reception of "Marot's Psalms" induced Theodore Beza to conclude the collection, and ten thousand copies were immediately dispersed. These, however, had the advantage of being set to music, for we were told tley were "admirably fitted to the violin, and other musical instruments;" and we learn with surprise that it was to Calvin, the "gloomy and ascetic Calvin," they were indebted for the simple and beautiful airs with which they were accompanied. Taking arvantage of the public feeling, he had engaged the first inusical composers to aid, by the power of melody, the spread of his opinions. "At first this was not discovered, and Catholics, as well as Huguenots, were solacing themselves on all occasions with this new music. But when Calvin appointed these psalms to be sung at his meetings, and Marot's forned an appendix to the catechism of Geneva, this put an end to all psaim-singing for the poor Catholics! Marot himself was forced to fly to Geneva from the fulminations of the Sorbonne, and psalm-singing became an open declaration of what the French termed "Lutheranism."

In our island, its history is soon told. Sternhold, an enthusiast for the Reformation, undertook to be our Marot-without his genius. His psalms were practised by the Puritans in the reign of Elizabeth; and more particularly during the protectorate of Cromwell.

Psalms were now sung at lord mayors' dinners and cily feasts: soldiers sang them on the march, and at parade; and few houses, which had windows fronting the street, but had their cvening psalms.

The following lines, which conclude the dedication, well describe the feeling and enthusiasm of their author:-

Thrice happy they, who may belold,

And listen, in that age of golu! 


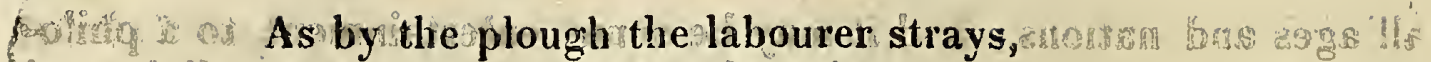

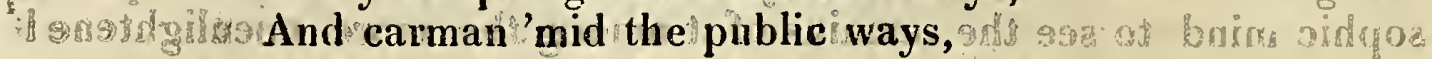
And tradesman in his shop shall swell

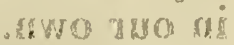

thom

af From woods shall come a sweeter strain!

8xp95e. Shepherd and shepherdess shall vie

a

And the Creator's name prolong,

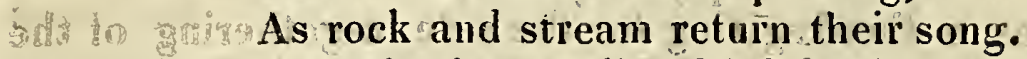

hagyeged of Begin then, ladies fair! begin

thogr The age renew'd that knows no sin!

And with light heart, that wants no wing,

and 198 Sing ! from this holy song-book sing!

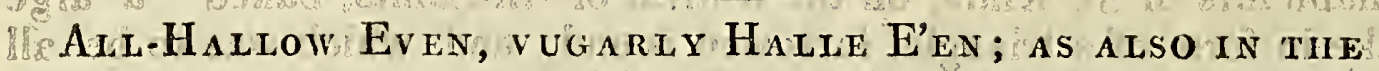

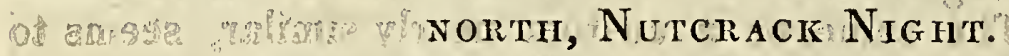

Hallow Even is the rigil of All Saints day, which is on the first of November. It is customary on this night with young people in the north of England to dive for apples, or catch at them, when stuck ipon one end of a kind of hanging beam, at the other extremity of which is fixed a lighted candle, and that with their mouths only, their hands being tied behind their backs.

Nuts and apples chiefly compose the entertainment, and from the custom of flinging the former into the fire, or cracking them with their teeth, it has doubtless had its vulgar name of "Nutcrack night."

87 The catching at the apple and candle may be called playing at something like the ancient English game of the quintain, which is now almost totally forgotten, but of which there is the following description in Stow's Survey of London: "I have seen (says he) a quinten set up on Cornehill, by the Leaden Hall, where the attendants on the lords of merry disports have runne and made greate pastime; for he that hit not the broad end of the quinten was of all men laughed to scorne; and he that hit it full, if he rid not the faster, had a sound blow in his necke with a bag full of sand hanged on the other end."

Mr. Pennant tells us, in his Tour in Scotland, that the young women there determine the figure and size of their husbands by "drawing cabbages blindfold" on All-hallow Even, and, like the English, "fling nuts into the fire."

bris last custom is beautifully described by Gay in his "Spell."

"Two hazel nuts I threw into the flame,

And to each nut I gave a sweetheart's name,

This with the loudest bounce me sore amazd,

That in a flame of brightest colour blaz'd;

As blaz'd the fat, so may thy passion grow,

For t'was thy nut that did so brightly glow!"

"The passion of prying into futurity," says Mr. Burns " striking part of the history of human nature, in its rude state, in all 
all ages and nations; and it may be some entertainment to a philosophic mind to see the remains of it among the more unenlightene 1 in our owil."

This ingenious author gives therefore the principal charms and spells of this night; so big with prophecy to the ptasantry in the west of Scotland.

The rev. Mr. Shaw, in the History of the Province of Moray, seems to consider the festivity of this night as a kind of harvest-home rejoicing: "A solemnity was kept," says he, "on the eve of the first of November, as a thanksgiving for the safe in-gathering of the produce of the fields. This, I am told, but have not seen it, is observed in Buchan and other counties, by having "Hallow-Eve fire kindled on some rising ground."

Different places adopt different ceremonies : Martin tells us that the inhabitants of St. Kilda, on the festival of All-Saints, baked " a large cake in form of a triangle, furrowed round, and which was to be all eaten that night." The same, or a custom nearly similar, seems to have prevailed in different parts of England.

The same writer, speaking of the isle of Lewis, says : "The inhabitants of this island had an ancient custom to sacrifice to a seagod, called Shony, at Hallow tide, in the manner following: The inhabitants round the island came to the church of St. Mulvay, having each man his provision along with him; every family furnished a peck of malt, and this was brewed into ale : one of their number was picked out, to wade into the sea up to the middle, and, carrying a cup of ale in his hand, standiug still in that posture, cried out with a loud voice, saying, 'Shony, I give you this cup of ale, hoping that you'll be so kind as to send us plenty of sea-ware, for enriching our ground the ensuing year; and so threw the cup of ale into the sea.' This was performed in the night-time. At his return to land, they all went to church, where there was a candle burning upon the altar; and then standing silent for a little time, one of them gave a signal, at which the candle was put out, and immediately all of them went to the fields, where they fell a drinking their ale, and spent the remainder of the night in dancing and singing, \&c." He adds, "The ministers in Lewis told me they spent several years before they could persuade the vulgar natives to abandon this ridiculous piece of superstition.

\section{Antiquity of Bells.}

THE use of bells is very ancient, as well as extensive. We find them among Jews, Greeks, Romans, Christians, and Heathens, variously applied, as, on the necks of men, beasts, birds, horses, and sheep, but chiefly being in buildings, either religious, as in churches, temples, and monasteries ; or civil, as in houses, markets, and baths; or military, as in camps and frontier towns. Among the Jews it was ordained, that the lower part of the blue tunic, which the high priest wore when he performed religious ceremonies, should be adorned with pomegranates and gold bells, intermixed equally, and at equal distances. As to the number of the bells worn by the high priests, 
the scripture is silent, and athors are not agreed; but the sacred historian mentions the use and intent of them, ia Exod. xxviii. 3335. The kings of Persia are said to have had the hems of their robes adorned, like the Jewish high-priests, with pomegranates and gold bells. In the opinion of Calmet, the high priest wore little bells on the hem of his robe, as a kind of public notice that he was going to the sanctuary; for, as in the king of Persia's court no one was allowed to enter the royal apartments without giving notice thereof by the sound of something; so the high priest, out of respect to the divine presence, did, by the sound of little bells fastened to the botfom of his robe, desire, as it were, permission to enter, that the sound of the bells might be heard, and he not punished with deatli for intrusion. The figure of these bells is not known to us. The prophet Zachariah xiv. 20. speaks of bells hung to war-horses. Among the Greeks, those who went the nightly rounds in the camps or garrisons, carried with them a little bell, which they rang at each sentry box, to see that the soldiers on watch were awake. A codonophorus, or bell-man, also walked in funeral processions, at a distance before the corpse, not only to keep off the crowd, but to advertise "flamen dialis" to keep out of the way, for fear of being polluted by the sight, or by the funeral music. The priest of Proserpine at Athens, called Hierophant us, runga bell to call the people to sacrifice! There were also belis in the houses of great men, to call up the servants each morning. Zonaras assures us, that bells were hung with whips on the triumphal chariots of their victorious generals, to put them in mind that they were still liable to public justice. Bells were put on the necks of criminals going to execution, that persons might be warned by the sound to get out of the way of so ill an omen as the sight of the hangman or the condenined criminal who was going to be sacrificed to the "dii manes." Of bells hung on the necks of brutes, express mention is made in Phœdrus; "Celso cervice eminens, clarumque collo jactans tintinabulum." Taking these bells away, was construed by the civil law, theft ; and if the beast was lost by this means? the person who took away the bells was to make satisfaction.

ON THE ORIGIN OF CHURCII BELLS.

ON the origin of Church bells Mr. Whitaker, in his History of Manchester, observes, that, bells being used, among other purposes, by the Romans to signify the times of bathing, were naturally applied by the Christians of Italy to denote the hours of devotion, and summon the people to church. The first application to this purpose is, by Polydore Vired and others, ascribed to Pauluris bishop of Nola, a city of Campania, about the year 4000. Hence it is said the names Nola and Campanica were given them; the one referring to the city, the other to the country. Though others say they took the latter of these names, not from their being invented in Campania, but because it was bere the manner of hanging and balancing them now in use, was first practised; at least, they were hung on tlie model of a sort of balance invented or used in Campania; for in Latin writers we find Campane statera, for a steel-yard ; and ponderare, to weigh. In Britain, bells were used in churches before the conclusion of the 
seventh century, in the monastic societies of Northumbria, and as early as the sixth, even in those of Caledonia. And they were therefore lised from the first erection of parish churches among us. Ihose of France and England appear to have been furnished with several bells. In the time of Clothair II. king of France, A. D. 610, the army of that king was frighted from the siege of Sens by ringing the bells of St Stephen's church. The second excerption of Egbert about A.D. 750 , which is adopted in a French Capitulary of 801, commands rvery priest, at the proper hours, to sound the bells of his church, and then to go through the offices sacred to God. And the council of Ercham, in 1011, requires all the mulcts for sins to be expendediu the renaration of the church, clothing and feeding the minister of God, and the purchase of church vestments, church books, and churuh bells. These were sometimes composed of iron in France; and in England, as formerly at Rome, were frequently made of brass. And as enly as the ninth century, there were many cast of large size and deep note. Ingulphus mentions, that Turketulus, abbot of Croyland, who died about 870 , gave a great bell to the church of that abiey, named Guthlac; and afterwards six others, viz. two which he called Bartholomew and Betelin, two called rurkettul and Taturin; and two named Pega and Bega, all which rang together; the same author says, Non erat tunc tanta consonantia campanarum in tota Anglia." Not long after, Kinfeus, archbishop of York, gave two great bells to the church of St.John at Beverley, and at the same time provided that other churches in his diocese should be furnished with bells. Mention is made by St. Aldheim and William of Malmsbury, of bells given by St. Dunstan to the churches in the west. The number of bells in every church gave occasion to the curious and singular piece of architecture in the campanile or bell-tower; an addition which is more susceptible of the grander beauties of architecture than any other part of the edifice; and is generally therefore the principle or rudiment of it. It was the constant appendage to every parish church of the Saxons, and is actually mentioned as such in the laws of Athelstan. The Greek Christians are usually said to have been unacquainted with bells till the ninth century, when their construction was first taught them by a Venetian: but it is not true that the use of bells was unknown in the ancient eastern churches, and that they called the people to church, as at present, with wooden mallets. Leo Allatius, in his dissertation on the Greek temples, proves the contrary from several ancient writers. He says, bells first began to be disused among them after the taking of Constantinople by the Turks, who, it seems, prohibited them, lest their sound should disturb the repose of souls, which, according to them, wander in the air. He adds, that they still retain the use of bells in places remote from the intercourse of the Turks; particularly very ancient ones, in Mount Athos. F. Simon thinks the Turks prohibited the Christians the use of bells rather from political than religious reasons; as the ringing of bells might serve as a signal for the execution of revolts against their authority. 


\section{Inscriptions on Church Bells.}

WeEver, in his Funeral Monuments, mentions that-Bells had frequently these inscriptions on them:

Funera plango, Fulgura frango,

Sabbata pango ;

Excito !entos, dissipo ventos, Paco cruentos.

In this little sanctuary at Westminster, king Edward III. erected a clochier, and placed therein three bells for the use of St. Stephen's chapel, about the biggest of them were cast in the metal these words :

King Edward made mee

thirtie thousand weight and three.

Take mee down and weigh mee, and more you shall fynd me.

But these bells being to be taken down in the reign of Henry VIII, one writes underneath with a coal:

\section{But Henry the eight}

Will bait me of my weight.

This last distich alludes to a fact mentioned by Stow in his Survey of London, ward of Farringdon Within, to wit, that near St. Paul's school stood a clochier, in which were four bells called Jesus's bells; the greatest in all England, against which Sir Miles Partridge staked one hundred pound, and won them of Henry VIII. at a cast of dice. Abroad, however, there are bells of greater magnitude. In the steeple of the great church at Roan in Normandy, there is a bell, unless it has been melted and turned into cannon, as others have been during the great revolutionary war, with the following inscription:

Je suis George de Ambois,

Qui trente cinque mille pois ;

Mei lui quii me pesera,

Trente six mille me trouversa.

I am George of Ambois,

Thirtie five thousand in pois:

But he that shall weigh me,

Thirty six thousand shall find me.

And it is a common tradition that the bells of King's-college chapel, in the university of Cambridge, were taken by Henry $V$. from some church in France, after the battle of Agincourt. They were taken down some years ago, and sold to Phelps the bell-founder in WhiteChapel, who melted them.

\section{SUPERSTITIOUS USES OF BELLS.}

Matthew Paris observes, that anciently the use of bells was prohibited in time of mourning, though at present they make one of the principal ceremonies of mourning. Mabillon adds, that it was 
an ancient custom to ring the bells for persons about to cxpire, to advertise the people to pray for them; whence our passing-bells. The passing-bell was anciently rung for two purposes : one, to bespeak the prayers of all good Christians for a soul just departing; the of her, to drive away the evil spirits, who stand at the bed's foot, and about the house, ready to seize the prey, or at least to molest and terrify the soul in his passage : but by the ringing of that bell, for (Durandus informs us, evil spirits are much afraid of bells, they were kept aloof: and the soul, like a hunted hare, gained the start, or had what is by sportsmen called law. Hence, perhaps, of the additional labour, was occasioned the high price demanded for tolling the greatest bell of the church, for that being louder, the evil spirits must go farther off to be clear of its sound, by which the poor soul got so much the more start of them : besides, being heard farther off, it would likewise" procure the dying man a greater number of prayers." This dislike of spirits to bells is mentioned in the Golden Legend, by W. de Worde. "It is said the evil spiryts had been in the regijon of thayre, doubte moch when they here the belles rongen, and this is the cause why the belles ben rongen whan it thondreth, and whan grete tempeste and outrages of wether happen, to the end that the fiends and wicked spirytes should be abashed and flee, and cease of the movynge of tempeste." Lobineau observes, that the custom of ringing bells at the approach of thunder, was to call the people to church, to pray that the parish may be preserved from that terrible metor. The use of bells were summed up in the following distich, as well as that first above mentioned:

Laudo Deum verum, plobem voco,
Defunctos ploro, pestem, fugo, festa
decoro.

\section{Christuas-KeEPing.}

\section{(From the New Monthly Magazine.)}

"Now Hospitality, to cheer the gloom

Of winter, invitation sends abroad:

The rural housewife lays the annual block

Of Christmas on tlie hearth; and bids a blaze

Of tenfold brightness glad its sable spot;

Then sprucely decks the window with fresh sprigs

Of evergreens, triumphant o' the storms

of fading time, while ever social mirth

And rival kindness load the smoking board;

And boistrous sport and heavy dance resound."-The Year.

AMIDsT the wintry desolation of the munth of December, remembrance of a season once anticipated in joyous hope by all ranks of people, recurs to the lovers of "Auld lang syne" - to those who remember with what pleasure they once welcomed its chill atmosphere and snow storms with the vivid raptures of youth. Even in London, the memory of its festivities is not yet wholly extinguished; but in the 
remote part of the island, it is still hailed as the period of enjoymentit is still marked by genial appearances ; and round the social hearth of Christmas-eve, the less artificial inhabitants of the country will be found as Burns describes, them :-

The lasses feat, an' clonely neat,

More braw than when they "re fine,

Their faces blythe, fu' sweetly kythe,

Hearts leal, an' warm, an' kin',

The lads sae trig, wi' wocer-babs,

Well knotted on their garten,

Some unco blate, an' some wi' gabs,

Gar lasses' hearts gang startin,

Whiles fast at night.

Christmas is supposed by some to be founded on the Saturnalia of the Romans, and was distinguished a century or two ago by its "festival of fools." The mummeries practised at that season were performed in disguises made with the skins of animals; and the lower orders, who could not afford masks and dresses, daubed their faces with soot, the sexes changing clothes. The Saturnalia were celebrated in a similar manner. Such resemblance, and the obvious policy of transmitting the heathen festivities into rejoicings of some kind, after the introduction of Christianity, that the people might not be deprived of their customary pleasures, give a plausible ground for supposing that the early Christians availed themselves of the opportunity to establish a fetê in honour of the hirth of their Founder. But this can only be conjecture, like a thousand other opinions we read of the same nature, and must for ever remain so. The decision of the question, indeed, might gratify curiosity, but could be of no utility to the interests of mankind., It is a most pleasing occupation to dwell upon the celebration of Christmas at later periods among ourselves, to go over ground that is interesting from its proximity to our own, and to realize the agreeable feeling always excited in the human bosom at the contemplation of every thing, however insignificant, which is tinged with the gray melancholy of age.

In London, as in all great cities, particularly in those which are commercial, where strangers continually arrive, and new customs are daily introduced, observances of a nature similar to those formerly kept at Christmas must soon be lost. That season is accordingly marked here by few of the pleasantries and enjoyments with which it is even now characterized in the country. The merchant and shopkeeper are absorbed in tratfic, and the closing up of their accounts ; and but a short space is devoted to that drunkenness and gluttony among the lower orders, which are the besetting sin of the time. The genuine cockney, however, though on the verge of bankruptcy, considers it a moral duty to spend his creditors guinea for a fat turkey on Christmas-day; which with a plenary potation of some kind of liquor, a minute fraction within the quantity necessary to produce ebriety among the more sober citizens, and a fraction beyond it among those less concerned as to outward deportment, completes the annual memorial of the time. The canaille may be seen; 
as usual when rejoicing, in all the stye-grovelling stupidity of the most inexcusable sensuality, reeling from lamp-post to lamp-post. The gin-shops overflow with ragged visitants, and the bloated porterdrinkers, saturating thenselves with doses of coculus indicus, and divers adulterating narcotics which muddle the brain and clog the circulation, fill the pot-houses. Intoxicated draymen, dustmen, and butcher's' attendants, hie to the suburbs to fight their dogs, and finally to fight among themselves. St. Giles's vomits forth its mass of vice and contamination, mingled with the filth and vociferations of drunken Irish barrow-women, wretched, squalid, and hectic from dram-drinking.

Such is a London Christmas-keeping.--Among viands once common there at this season plum-puddings, and mince-pies are still found, and most probably will long remain, on the score of their intrinsic value to gastronomists. Pantomimic representations are proffered at that time in theatrical entertainments, to attract such little children and their parents as can afford to laugh at them but once a year. In London, no yule-log now blazes in the contracted chimneys, as in days of yore on its once ample hearths; no yule-songs are sung; and the wassail-bowl, as in most parts of the country, is quite forgotten. The hearty but natural and simple merriment of the rustic, has no parallel in such over-grown congregations of men; and the festive activity of the Christmas hall-dance, where

Jest, and youth ful jollity,

Quips, and cracks, and wanton wiles,

Nods, and becks, and wreathed smiles,

once abounded, has taken its flight, and left nothing half so heartcheering behind. Thus mortal customs perish like those who were observers of them, but only with a little less rapidity.

But the celebration of Christmas in London was formerly marked with

pomp, and feast, and revelry,

With mask and antic pageantry.

The Lord of Misrule, a personage whose origin is lost in the obscurity of years, superiutended the sports in every nobleman's and gentleman's house. Each parish had also a ruler of sports with the same title. The lord mayor of London and the sherifts were not behind-hand in jocularities, and, besides a fool, they had each a sovereign of mummeries on their establishment. His reign began on All-hallow-eve. Even royal authority afterwards sanctioned the use of these officers, whose post always continued until the eve of the Purification. During the entire period of his sway, Stow says, there were "fine and subtle disguisings, masks, and mummeries."

King Edward the Sixth appointed one George Ferres to hold the office. This man was a "poet, lawyer, and historian," and was the first styled "Lord of the Pastimes." Even the grave lawyers of Lincolı's Inn doffed their sober habils at Christmas; they, too, had a King of Christmas-day, with his attendants, who presided in their hall; and so earnest were they in these matters, that on Childermas-day they elected another officer, who presided with attendants 
in a sinilar manner, and was styled "King of the Cockneys." The gentlemen of the gown thus kept a canival in the very court of gravity itself How edifying would it now be for the augmented number of students in the profession, to witness the be-wigged judges. and benchers relaxing from that stiff solemnity of physiognomy, which so often passes current in the profession for wisdom - to sheep-tails and periwigs, flling the atmosphere of the legal arena with showers of perfumed clust-dissipating the labours of Danby and other eininent wig-architects, by the shaling of their curls at the munineries of the Zany and his followers decked with fools caps and bels: and, the keeper of the king's conscience himself "loolding both his sides" at the sight of Robin Goodfellow and the bear-skin man, formerly called a Wodehouse, forgetting even chancery suits and fees, for a moment, in the indulgence of unrestrainable laughter.

The Middle-temple lawyers, not to be outdone by their "learned brethren" of Lincoln's. Inn, elected a Prince of Christmas so late as the ycar 1635. This personage dined with them in their hall, having eight attendants: He was seated under a cloth of state, and served with great attention. To complete this climax of foolery, this Zany was afterwards introduced at court, and actually kniglited at Whitehall, and was most probably not the first of his character who received that honour, as the prssent generation can testify he was not the last.

But, as later periods have also sliewn, the lawyers were far outdone by the clergy in matters appertaining to feasting and revelry. The former soon relapsed into their wonted habits, the departure from which had been momentary; for very few cliancellors besides Sir Thomas More would have admitted, even in ancient days, that they were good throwers at cocks : Sir Thomas does not say he practised it after he came to the lord-chancellorship.-The clergy, however, seem to have had no scruples, and to have shared largely in Christmas sports and revels of all sorts. Even at the universities they elected a "King of the Bean" on Christmas-day. In cathedral churches there was an "Archbishop or Bishop of Fools" elected, and in Catholic times a "Pope of Fools." The office of "King of Fools," (Rex Stultorum) was abolished in 1731, perhaps as being derogatory to the dignity of kingship. These mummers attended divine service in pantomimical dresses, and were followed by crowds of the laity in masks of different forms. Abroad, some assumed the habits of females, and displayed the most wanton gestures. One ceremony consisted in shaving a "Precentor of Fools" before the church-door, in presence of the populace, who where amused by a vulgar sermon. In England a Boy-Bishop was regularly elected in the churches at Christmas, who mimicked the service and ofice of bishop; and the clergy even cnjoined the children of St. Paul's school to attend at the cathedral, and give the Boy-Bishop a penny each!

This mockery was abolished at the Reformation, in the thirty-third year of Henry the VIII.; and though revived by Mary, it ceased entirely at her death.

The exercise of quintin was anciently much practised in London at Christmas : a quintin was set up at that season in Cornhill, near 
Leadenhall. Plays were also exhibited at court, but they only consisted of pantomime and buffoonery, until the reign of Edward III. The clergy in the reign of Edward II. possessed the exclusive right of getting up Christmas plays from scripture subjects; and in that reign a petition was presented to the crown by the scholars of St. Paul's, complaining that secular actors infringed on this right. Cards were forbidden to apprentices in London, except at Christmas; and at that season the servant-girls and others danced every evening before their masters' doors. Honest Stow laments the decay of the manner. of keeping festivities in his time, which seems to have become unwarlike. and effeminate. "Oh," says he, "what a wonderful change is this! Our wrestling at arms is turned into wallowing in ladies'laps, our courage to cowardice, our running in to royot, our bowes into bowles, and our darts into dishes."

The English, according to Polydore Virgil, "celebrated the feast. of Christmas with plays, masks, and magnificent spectacles, together with games and dancing, not common with other nations." Camden says, that "few men played at cards in England, but at Christmas." But it is to the country at present, that we mu'st look for what remains of the customs practised by our ancestors at that season. The relics of old and ridiculous observances, deprived of all their objectionable parts by the improving spirit of successive years, are hallowed in our memories, and always recall the vernal season of life, and its regretted pleasures. In the north they have yet their "fools' plough," and in Cornwall their goose-dancers. The latter still exhibit an old hunchbacked man, called the "King of Christmas," and sometimes the "Father:" like customs may be traced in other counties. The yule$\log$ still blazes in the chimney of the rustic at Christmas-eve, under the different appellations of Christmas-stock, log-block, \&c. 'The wassail was regularly carried from door to door in Cornwall forty or fifty years ago; and even now a measure of flip, ale, porter, and sugar, or some beverage, is handed round while the yule-log is burning,-or stock, as denominated in the western counties. The wassail bowl is of Saxon origin, and merits notice on an historical account. Vortigern, prince of the Silures, fell in love with Rowena, the niece of Hengist, the Saxon warrior. She presented the prince with a bowl of spiced wine, saying in Saxon, "Waes Heal Hlaford Cyning," which signified "Be of health, lord king." Vortigern married her, and thus his kingdom fell to the Saxons. Robert of Gloucester notices this incident :-

"Kuteshire and sitte hire adoune, and glad drink hire heil,

And that was in this land the Verst, 'Was hail,'

As in the language of Saxyone that we might evere iwite,

And so well he paieth the fole about, that he is not Yet vorgute."

Waes-heil thus became the name of the drinking cup of the AngloSaxons; and those cups were afterwards constantly used at public entertainments.

In parts of the country remote from the metropolis, the singing of Christmas carols yet ushers in the mornings.-After breakfast the busy housewife prepares her plum-puddings, mince-pies, and confectionary, which she decorates with the emblems of the time:-a scratch 
in the dough in the shape of a hay-rack, denoting the nanger of the infant Saviour, is one of those emblems most commonly in use. The younger part of the lousehold hunt the garden for evergreens to decorate the interior of the apartments and the wonds are sought to bring home the misletoe, which is to be suspended in the room where the pleasures of the evening are to take place, and beneath which the "sighing lips," as Moore calls them, of many a lovely girl still contimues to be pressed, despite of that coy resistance and those blushes, that so much heighten the charms of beauty. - They also paint candles of different colours, to be lighted up in the evening; a custom perhaps borrowed from ancient Roman practice; though some imagine that lighting up houses formed a part of the worship of the Teutonic god Thor, being one of the ceromonies observed at Jul-tide, or the feast of Thor, from which it was introduced into the Christian feast of Christmas. Thus, if some parts of our Christian ceremonies was derived from the Saturnalia, another was evidently of northern origin. The misletoe was a plant held sacred by the Druids. The Christmas-carols also, were, it is probable, Junl or Ule songs first sung in honour of the heathen deity; and the evergreens may be ascribed to the same origin. In the evening, the Ule-log, or Christmas stock, as at present denominated, is placed on the fire in the principal apartment of the house. The company seat themselves round it, and the cheerful cup is yet handed alout, which often contains nothing more than ale, in the cottages of the peasantry.

What remains to the modern times of Christmas gambols then coinmences, and ancient Christian plays are even still plainly to be traced among them. Blindman's buff, hunt the slipper, the game of the goose, snap-dragon, push-pin, and dancing, form the amusements of the younger parts of the assemblage, and cards the elder; though among the more substantial people, as they are denominated in the language of the country-folks, the simpler amusements begin to lose their value. But their very simplicity recalls the memory of past times: they have a certain charm about them, worth all that is artificial, and they would not be bereft of attraction to minds of sensibility, if they were wholly abandoned to the lowly: for they have that in them which is far more endearing than the sordid heartlessness of fashionable entertainments, and the formality of high life. Bereft of superstition, Christmas is then a season of innocent mirth-a pleasing interlude, to lighten and beguile the horrors of our inclement winters.

It affords a period for the exhibition of hospitable greetings, and the pleasing interchange of good offices, of which, in the country, opportunities are rare. How many innocent hearts rejoice there at anticipating the season and its festivities, whose feelings have never been chilled by the artificial, and circulating, and calculating, civilities of Metropolitan intercourse. But the humbler ranks have been accused of superstition, because the stocking is still thrown, the pod with nine peas hid over the door, and all the little ceremonies so admirably depicted by Burns in his Hallowe'en, still practised. These, however, are now generally looked upon as a diversion, and few have faitli in their efficacy; for in our days the poor have as good common sense as their superiors.-These diversions come to them but once a 
year, and it is to be hoped that they may long continue to practise them.

"Let the rich deride, the proud distain,

The simple pleasures of the lowly train ;

To me more dear, congenial to my heart,

One native charm than all the gloss of art.

Before concluding, it may not be irrelevant to observe, that Christmas is still kept as a festival in some parts of America, together with many of the old English usages, which are no more seen in the mother country.

This affords an illustration of what time may one day effect respecting the language and literature of Britain, which America is in all probability destined to preserve in full bloom, when our greatness of population and wealth, by the vicissitudes of time, is no more; and our rich fields and fertile meadows are again returned to the primitive wildness, covered with heath, and changed into a waste-howling wilderness.

Christmas within-doons-in Germany.

OF Christmas, as it is lept in the north of Germany, we have a pleasing description by $\mathrm{Mr}$. Coleridge, in his very entertaining collection of Essays, called "The Friend" of which a new edition was lately published in three pocket volumes. Writing from Ratzeburg, Mr. Coleridge says, "There is a Christmas custom here, which pleased and interested me." The children make little presents to their parents, and to each other; and the parents to the children. For three or four months before Christmas, the girls are all busy, and the boys save up their pocket-money, to make or purchase these presents. What the present is to be, is cautiously kept secret, and the girls have a world of contrivances to conceal it - such as working when they are out on visits, and the others are not with them; getting up in the morning before day-light, \&c. Then on the evening before Christmas. day one of the parlours is lighted up by the children, into which the parents must not go: a great yew bough is fastened on the table at a little distance from the wall; a multitude of little tapers are fastered in the bough, but not so as to burn it, till they are nearly burnt out, and coloured paper, \&c. hangs and flutters from the twigs. Under this bough the children lay out in great order the presents they mean for their parents, still concealing in their pockets what they intend for each other. Then the parents are introduced, and each presents his little gift: they then bring out the rest one-by one from their pockets, and present them with kisses and embraces. Where I witnessed the scene, there were eight or nine children, and the eldest daughter and the mother wept aloud for joy and tenderness, and the tears ran down the face of the father, and he clasped all his children so tight to his breast, it seemed as if he did it to stitle the sob that was rising within him. I was very much affected. The shadow of the bough and its appendages on the wall, and arching over on the ceiling, made a pretty picture; and then the raptures of the very little 
ones, when at last the twigs and their needles began to take fire and snap-O, it was a delight for them !-On the next day, in the great parlour, the parents laid out on the table the presents for the childrent: a scene of more sober joy succeeds, as on this day, after an old custom, the mother says privately to each of her daugliters, and the father to his sons, that which he has observed most praiseworthy, and that which was most faulty, in their conduct. Formerly, and still in all the smaller towns and villages throughout North Germany, these presents were sent by all the parents to some one fellow, who, in high buskins, a white robe, a mask, and an enormous flaxen wig, personates Knecht Rupert, i. e. the servant Rupert. On Christmas nighthe goes round to every house, and says, ' that Jesus Christ, his Master, sent him thither." The parents and their children receive him with great pomp of reverence, while the little ones are most terribly frightened. He then inquires for the children, and, according to the character which he hears from the parent, he gives them the intended present, as if they came out of heaven."

\section{NEw Year's ErE.}

THERE was an ancient custom, which is yet retained in many places, on New Year's Eve: Young women went about with a wassail bowl of spiced ale, with some sort of verses, that were sung by them as they went from door to door. Wassail is derived from the Anglo-Saxon, Waes hael, (be in health.) It were unnecessary to add, that they accepted little presents on the occasion, from the houses at which they stopped to pay this annual congratulation.

In the Antiquarian Repertory, is a wood-cut of a large oak beam, the ancient support of a chimney-piece, on which is carved a large bowl, with this inscription on one side, 'Wass-heil.'

The ingenious remarker on this representation, observes, that it is the figure of the Old Wassel Bowl, so much the delight of our hardy ancestors, who on the vigil of the New Year never failed to assemble round the glowing hearth with their cheerful neighbours, and then in the spicy Wassel Bowl (which testified the goodness of their hearts) drowned every former animosity, an example worthy modern imitation. Wassel was the word, - Wassel every guest returned, as he took the circling goblet from his friend, whilst song and civil mirth brought in the infant year.

A writer in the Gentleman's Magazine, (vol. 65, for May, 1784, p. 347) tells us, that "The drinking the Wassel Bowl or Cup, was, in all probability, owing to keeping Christmas in the same manner they had before the Feast of Yule.' One custom more should be remembered; and this is, that it was usual, some years ago, in Christmas time, for the poorer people to go from door to door with a Wassail Cup, adorned with ribbons, and a golden apple at the top, singing, and begging money for it; the design of which was, that they also might procure lamb's-wool to fill it; and regale themselves as well as the rich.

The following Carol for a Wassel Bowl, to be sung to the tune of " Gallants, come away;' is from a collection of 'New Christmas Ca- 
rols, in the curious study of that ever to-be-respected antiquary, Mr. Anthony Wood, in the Ashmolean Museum.

A jolly Wassel bowl,

A Wassel of good ale,

Well fare the butler's soul,

what setteth this to sale;

Our jolly Wassel.

Good Dame, here at your door Our Wassel we begin,

We are all maidens poor,

We pray now let us in, With our Wassel.

Our Wassel we do fill

With apples and with spice,

Then grant us your good will

To taste here once or twice

Of our good Wassel.

If any maidens be

Here dwelling in this house,

They kindly will agree

To take a full carouse

Of our Wassel.

But here they let us stand

All freezing in the cold:

Good master, give command,

To enter and be bold,

With our Wassel.
Much joy into this hall are

With us is enter'd ing whe

Our master first of alt,

We hope will now begin,

of our Wassel :

And after his good wife

Our spiced bowl will try,

The Lard prolong your "life:

Good fortune we espy,

For our Wassel.

Some bounty from your hands,

Our Wassel to maintain :

We'll buy no house nor lands With that which we do gain With our Wassel.

This is our merry night

Of choosing King and Queen,

Then be it your delingt

That something may be seen

In our Wassel.

It is a noble part

To bear a liberal mind,

God bless our master's heart

For here we comfort find

Wilh our Wassel.

And now we must be gone,

To seek out more good cheer;

Where bounty will be shown,

As we have found it here,

With our Wassel.

In the Collection of Ordinances for the Royal Household, published by the Society of Antiquaries, we have some account of the ceremony of Wasseling, as it was practised at court, on Twelfth Night, in the reign of Henry the Seventh. From these we learn that the ancient custom of pledging each other out of the same cup, had now given place to the more elegant practice of each person having his cup, and that "When the steward came in at the doore with the Wassel, he was to crie three tymes, Wassel, Wassel, Wassel, and then the chappell (the chaplain) was to answere with a songe.'

The subsequent Wassailers song on New Year's Eve, is still sung in Gloucestershire. The Wassailers bring with them a great bow?, dressed up with garlands and ribbons.

Wassail ! Wassail all over the town,

Our toast it is white, our ale it is brown.

Our bowl it is made of a maplin tree,

We be good fellows all; I drink to thee. 
Here's to — God send our maister a happy New Year; A liappy New Year as e'er he did seeWith my Wassailing Bowi I drink to thee.

Come, butler, bring us a bowl of the best:

I hope your soul in heaven will rest:

But if you do bring us a bowl of the small, Then down fall butler, bowl, and all.

* The name of some horse.

\section{Conclusion of the Year.}

"Dost thou know the price of a day, an hour, or a minute? Didst thou ever examine the value of time? If thou hadst, thou wouldst employ it better, and not spend so many happy opportunities upon trifles; and so casily and so insensibly part with so inestimable a treasure. What is become of thy past hours? Have they made thee a promise to come again when thou callest for them? or canst thou shew me which way they went? No, no; they are gone without recovery; and in their flight, methinks, TIme seems to turn his head, and laugh over his shoulder in derision at those that made no better use of him, when they had him. Dost thou know that all the minutes of our life are but as so many links of a chain that has death at the extremity; and every moment brings thee nearer thy expected dissolution? Perchance while the word is speaking, it may be at thy very door. How stupid is he who dies while he lives, for fear of dying! How insensible is he that lives as if he should never die, and only fears death when he comes to feel it!-QuEveno, Vision 5th.

To-morrow you wili live, you always cry;

In what far country does this morrow lie,

That tis so mighty long ere it arrive?

Beyond the Indies does this morrow live?

Tis so far fetch'd this morrow, that I fear

'Twill be both very old and very dear.

To-morrow I will live, the fool does say;

To-day itself's too late,--the wise lived yesterday!

Martial, by Cowley, lib. v. 48.

6very year we behold proofs and symptoms of decay. All things around is are subject to dissolution, and are actually dissolving. The mountain oak, which flourished for ages, now stands a bligh ted trunk, inspiring melancholy. Places renowned of old for beauty and defence, are known to us now only by their names. Of Jerusalem and Mount Sion, of which such glorious things are said, there is not one stone left upon another. Babylon, the nighty Babylon, is fallen - is fallen. Families, and states, and empires, have their rise, and glory, and decline. The earth itself is waxing old. The sun, and stars, and elements, shall at last dissolve. YEARs, as they pass, speak us of the consummation of all things. Listen to their parting voice. In still, but solemn language, they speak of the Angel who shall lift up his hand to heaven, and swear by him that liveth for ever and everThere shall be T'IME no more." 


\section{R65 NEW-YEAR'S DAY.}

BIsHop Stillingfleet observes, that among the Saxons of the morthern nations, the feast of the new-year was observed with more than ordinary festivity. Thence, as Olaus Wormius observes, they reckoned their age by so many Tolas. The poet Naogeorgus is cited by Hospinian, as telling us, that it was usual in his time for friends to present each other with a new-year's gift; for the husband to give one to his wife; parents to their children; and masters to their servants, \&c.; a custom derived to the Christian world from the times of Gentilism. The superstition condemned in this by the ancient fathers, lay in the idea of these gifts being considered as onens of success for the ensuing year. In this sense, also, and in this sense alone, could they have censured the benevolent compliment of "wishing a merry Christmas, and a happy new-year." The latter has been adopted by the modern Jews, who on the first day of the nionth $T$ isri have a splendid entertainment, and wish each other a happy new-year.

The Romans were great observers of the custom of new-year's gifts, even when their year consisted only of ten months, of thirty-six days each, and began in March; also when January and February were arded by Numa to the ten others, the calends or first of January were the time on which they made presents : and even Romulus and Tatius made an order that every year vervain should be offered to them with other gifts, as tokens of good fortune for the new-year. Tacitus makes mention of an order of Tiberius, forbidding the giving or demanding of new-year's gifts, unless it were on the calends of January; at which time, as well the senators as the linights, and other great men, brought gifts to the emperor, and, in his absence, to the capitol. The ancient Druids, with great ceremonies, used to scrape off from the outside of oaks the misleden, which they consecrated to their great Tutates, and then distributed it to people through the Gauls, on account of the great virtues which they attributed to it; from whence new-year's gifts are still called in some parts of France, Guy l'an neuf. Our English nobility, every newyear's tide, still send to the king a purse with gold in it. Reason may be joined to custom to justify the practice; for as presages are drawn from the first things which are met on the beginning of a day, week, or year, none can be more pleasing than of those things that are given us. We rejoice with our friends after having escaped the dangers that attend every year ; and congratulate each other for the future by presents and wishes for the happy continuance of that course, which the ancients called Strenarum Commercium. And as formerly men used to renew their hospitalities by presents, called Xenia, a name proper enough for our new-year's gifts, they inay be said to serve to renew friendship, which is one of the greatest gifts imparted by Heaven to men.

In Sir John Sinclair's Statistical Account of Scotland, Edinburgh, 1794,8 vo, vol. xi. p. 458 , the minister of Kirkmichael, in the county of Banf, under the head of Superstitions, \&c. tells us : "On the first night of January, they observe, with anxious attention, the disposi- 
tion of the atmosphere. As it is calm or boisterous-as the wind How from the south or the north-from the east or the west-they prognosticate the nature of the weather till the conclusion of the year. The first night of the new year, when the wind blows from the west, they call lor-na-coille, the night of the fecundation of the trees; and from this circunstance has been derived the name of that, night in the Gaelic language. Their faith in the above signs is couched in verse, (ibus trauslated:) "The wind of the south will be productive of leat and fertility; the wind of the west, of milk and fish; the wind from the north, of cold and storm; the wind from the east, of fruit on the trees.'"

Eastern Magi.

OF these Magi, or sages. (commonly called the three kings of Colen, the first, named Melchior, an aged man, offered gold : the second, Jasper, a beardless youth, offered frankincense : the third, Balthazar, a black or Moor, ofiered myrrh: according to this distich:-

Tres Reges Regi Regum tria dona ferebant

Myrrham Homini, Uncto aurum, thura dedere Deo.

\section{PASTIMES.}

Pastimes of some kind seem to be absolutely necessary, and to none more than to the man of study; for the most vigorous mind cannot bear to be always bent. Constant application to one pursuit, if it deeply engage the attention, is apt to unhinge the mind, and generate madness; of which Don Quixote of Cervantes, and the Astronomer of Johnson, are two admirably conceived instances; confirmed by too many facts in real life. But though pastime is necessary to relieve the mind, it indicates great frivolity when made the business of life; and yet the rich and the great, who are not obliged to labour for the means of subsistence, too ofien rove from pastime with as constant assiduity as the mechanic toils for his family, or as the philosopher devotes himself to science. When those pastimes give elasticity to the mind, or strength to the body, such conduct is not only allowable, but praise-worthy; but when they produce effects the reverse of these, it is both hurtful and criminal. The gamingtable, the masquerade, the midnight assembly of any sort, must of necessity enfeeble both the body and the mind; and yet such are the fashionable amusements of the present day, to which many a belle and many a beau sacrifice their beauty, their health, their quiet, and their virtue. Far different were the pastimes of our wiser ancestors; remote from efieminacy, they were innocent, manly, and generous exercises.

From ancient records, it appears, that the sports, amusements, pleasures, and reereations, of our ancestors, as described by FitzStephen, added strength and agility to the wheels of state mechanism, while they had a direct tendency towards utility. For most of these ancient recreations are resolvable into the public defence of the state against the attacks of a foreign enemy. The play at ball derived 
from the Romans, is first introduced by this author as the common exercise of every school-boy. The performance was in a field, where the resort of the most substantial and considerable citizens, to give encouragement and countenance to this feat of agility, was splendid and numerous. The intention of this amusement was to make the juvenile race active, nimble, and vigorous; which qualities were requisite whenever their assistance should be wanted in the protection of their country.

Another species of mauly exercise was truiy martial, and intended to qualify the adventurers for martial discipline. It is related by Fitz-Stephen thus : "Every Friday in Lent, a company of young men enter the field on horseback, attended and conducted by the best horsemen : then march forth the sons of the citizens, and other young men, with aimed lances and shields; and there practise feats of war. Many courtiers likewise, when the king is near the spot; and attendants upon noblemen, repair to these exercises; and while the hopes of victory inflame their minds, they shew by good proof how serviceable they would be in martial affairs." This evidently is of Roman descent, and immediately brings to our recollection the Ludus Trojæ, supposed to be the invention, as it was the common exercise, of Ascanius. The common people, in that age of masculine manners, made every amusement where strength was exerted, the subject matter of instruction and improvement.

In the vacant intervals of industry and labour, commonly called the holidays, indolence and inactivity, which now mark this portion of time, were found only in those who were distempered witli age of infirmity. Fitz-Stephen says, "In Easter holidays they fight battles upon the water. A shield is hanged upon a pole, fixed in the middle of the stream. A boat is prepared without oars, to be born along by the violence of the water; and in the forepart thereof standeth a young man, ready to give charge upon the shield with his lance. If so be that he break his lance against the shield, and doth not fall, he is thought to have performed a worthy deed. If without breaking his lance he runs strongly against the shield, down the falleth into the water; for the boat is violently forced with the tide : but on each side of the shield ride two boats, furnished with young men, who recover him who falleth soon as they, may. In the liolidays, all the summer, the youths are exercised in leaping, dancing, shooting, wrestling, casting the stone, and practising their shields; and the maidens trip with their timbrels and dance as long as they can well see. In winter, every holiday, before dinner the boars prepared for brawn are set to fight, or else bulls or bears are baited." Such were the pursuits to which leisure was dovoted by our forefathers, so far back as $\mathbf{1 1 3 0}$.

Their immediate successors breathed the same, spirit. In 1222, the 6th year of Henry III. certain masters in exercises of this kind made a public profession of their instructions and discipline, which they imparted to those who were desirous of attaining excellence and victory in these honourable achievements.

About this period, persons of rank and family introduced the play of temis, and erected courts or ablong edifices for the performance of 
it About 1253, the 38th of Henry III, the quintin was a sport much in fashion in almost every part of the kingdom. This contrivance, consisted of an upright post firmly fixed in the ground, upon the top of which was a cross piece of wood, moveable upon a spindle; one end of which was broad like the flat part of an halberd, while at the other end was hung a bag of sand. The exercise was performed on horseback. The masterly performance was, when, upon the broad part being struck with a lance, which sometimes broke it, the assailant rode so swiftly on as to a void being struck on the back by the bag of sand, which turned round instantly upon the stroke given, with a very swift motion. He who executed this feat in the most dexterous manner was declared victor, and the prize to which he became entitled was a peacock. But if, upon the aim taken, the contender miscarried in striking at the broadside, his impotency of skill became the ridicule and contempt of the spectators. Dr. Plott, in his Natural History of Oxfordshire, tells us, that this pastime was in practice in his time at Deddington. $\mathrm{He}$ and Matthew Paris give sinilar accounts.

But all the manly pastimes seem to have given place to one, indeed no less manly, which was Archery. This had a continuance to the reign of Charles I. It appears from 33 Hen. VIII. that by the intru. sion of other perricious games, a rchery had been for a long time disused; to revive which, a statute was made.

Towards the beginning of James I.'s reign,-military prowess seems to have sounded a retreat. He, to gratify the importunity of the common people, and at the same time to obviate his own fears upon a refusal, publisherl a book of sports, in which the women had been some time before indulged on Sunday evenings, but which had been lately prohibited. These sports consisted of dancing, singing, wrestling, church ales, and other profanations of that day. Charles I, his successor, wisely, in the very entrance of his reign, abolished these sports, which was no doubt proper, and shewed the distinguished piety of this unfortunate monarch. But in this age likewise ended the manly sports of Britons, and nothing was introduced that could compensate for the loss.

In the Satistical Account of Scotland, parish of Monquhitter, under - Amusements,' we are told, 'People who are not regularly and profitably employed, rejoice in a holiday, as the means of throwing off that languor which oppresses the mind, and of exerting their active powers. So it was with our fathers. 'They frequently met to exert their strength in wrestling, in casting the hammer, and in throwing the stone, their agility at foot-ball, and their dexterity at coits and penny-stone:

Hot-cockles. - This sport is deseribed as follows by Gay:

"As at Hot Cockles once I laid me down,

I felt the weighty hand of many a clown;

Buxoma gave a gentle tap, and I

Quick rose, and read soft mischief in her eye."

Races.-Misson, in his Travels in England, translated by Ozell, says : The English nobility take great delight in horse-races. The most famous "are usually at Newmarket: and there you are sure to 
see a great many persons of the first quality; and almost all the gentlemen of the neighbourhood. It is pretty common for them to lay Wagers of two thousand pounds sterling upon one race. I lave seen a horse, that after liaving run twenty miles in fifty-five minutes, upon ground less even than that where the races are run at Newmarket. and won the wager for his master, would have been able to run aliew without taking breath, if he that had lost durst have ventured again:"Grose mentions anong the Sports of Sailors, the following:

Ambassador" A trick to duck some ignorant fellow, or landsman, frequently played on board ships in the warm latitudes. It is thus nianaged: A large tub is filled with water, and two stools placed on each side of it. Over the whole is thrown a tarpawlin, or old sail; this is kept tight by two persons, who are to represent the King and Queen of a foreign country, and are seated on the stools. The person intended to be ducked plays the Ambassador, and after repeating a ridiculous speech dictated to him, is led in great form up to the throne, and seated between the King and Queen; who rising suddenly as soon as he is seated, he falls backward into the tub of water.' - He inotices another game in the subsequent words:

Arthur, King Arthur: A game used at sea, when near the Line, or in a hot latitude. - It is performed thus : A man who is to represent King Arthur, ridiculonsly dressed, having a large wig, made out of oakum, or same old swabs, is seated on the side, or over a large ves sel of water. Every person is to be ceremoniously introduced to him, and to pour a bucket of water over him, crying, Hail, King Arthur! If, during this ceremony, the person introduced laughs or smiles, (to which his majesty endeavours to excite him by all sorts of ridiculous gesticulations, ) he changes place with, and then becomes King Arthur, till relieved by some brother tar who has as little com. mand over his muscles as himself?

Ancient Dances.

THE origin of dancing among the Greeks was doubtless the same as among all other nations; but as they proceeded a certain length in civilization, their dances were of consequence more regular and agreeable than those of the more barbarous nations. They reduced dancing into a kind of regular system, and had dances proper for exciting, by means of sympathy, any passion whatever in the minds of the behold. ers. In this way they are said to have proceeded very great lengths, to us absolutely incredible. At Athens it is said, that the dance of the Eumenides, or Furies, on the theatre, had so expressive a character, as to strike the spectators with irresistible terror: men grown old in the profession of arms trembled; the multitude ran out; women with child miscarried; and people imagined they saw in earnest those terrible deities commissioned with the vengeance of heaven to pursue and punish crimes upon earth. The Greeks had martial dances, which they reckoned to be very useful for keeping up the warlike spirit of their youth; but the Romans, though equally warlike with the Greeks, never had any thing of the kind. This probably maybe owing to the want of that romantic turn, for which the Greeks were so remarkable. 
The Romans had no heroes among them such as Hercules, Achilles, or Ajax; nor does the whole Roman history furnish an exanple of a general who made war after the manner of Alexander the Great. Though their soldiers were as valiant as those of the Greeks, the object with them was the honour of the republic, and not their owupersonal praise. Hence there was less fury, and much more cool deliberate valour, exercised by the Romans, than any other nation whatever. The passions of pride, resentment, obstinacy, \&c. were excited in them, not by the mechanical means of music aud dancing, but by being taught that it was their chief honour to fight for the republic.It does not, however, appear that the Romans were at all less capable of being affected in this mechanical manner than the Greeks. When dancing was once introduced, it had the very same effects at Rome as at Athens.

\section{Dance of the Calumet.}

THis is a solemn rite among the Indians on varions occasions. They dare not wash themselves in a river in the beginning of sunmer, nor taste of the new fruits, without performing it; and the same ceremony always confirms a peace, or precedes a war. It is performed in winter in their cabins, and in summer in the open fields. For this purpose they choose a spot among trees, to shade them from the heat of the sun, and lay in the middle a large mat, as a carpet, setting upon it the god of the chief of the company. On the right hand of this image they place the calumet, as their great deity, with their arms erected round it. The hour of the dancing being come, those who are the most honourable take their seats under the shade of the trees. The company is then ranged round; every one, before he sits down, saluting the inonitor, which is done by blowing upon it the smoke of tobacco Each person next receives the calumet in rotation, and holding it with both hands, dances to the cadence of the vocal music, which is accompanied with the beating of a sort of drum. During this exercise, he gives a sigual to one of his warriors; who takes a bow, arrow, and axe, from the trophies already mentioned; and fights him; the former defending himself with the calumet only, and both of them dancing all the while. This mock engagement being over, he who holds the calumet makes a speech, in which he gives an account of all the battles he has fought, and the prisoners he has taken, and then receives a cloak, or some other present, from the chief of the ball. He then resigns the calumet to another, who, having acted a similar part, delivers it to a third, and he to a fourth, \&ec tifl at last the instrument returns to the person who began the ceremony, and who presents it to the nation invited to the feast, as a mark of their friendship, and a confirmation of their alliance.

Alm ol Alma.

ThIs name is given to the singing and dancing girls in Egypt, who, like the Italian Improvisatori, can occasionally pour forth unpre- 
meditated verse. They are called Almê, from having received a better education than other women. They form a celebrated society in their country. To be received into it, according to Savary, it is necessary to have a good voice, to know the language well, to understand the rules of poetry, and be able to compose and sing couplets ou the spot, adapted to present circumstances. The Almé know by heart all the new songs. Their memory, is furnished with the most beautiful tales. There is no festival without them; no entertainment of which they do not constitute the ornament. They are placed in a rostrum, from whence they sing during the repast. They then descend into the saloon, and form dances, which have no resemblance to ours; they are pantomime ballads, in which they usually represent the occurrences of life. The mysteries of love, too, furnish them with scenes. The suppleness of their bodies is inconceivable. Orie is astonished at the mobility of their features, to which they give at pleasure the impression suitable to the characters they play. The indecency of their attitude is often carried to excess. Their looks, their gestures, every thing speaks, but in so expressive a maniler, that it is impossible to mistake them. At the beginning of the dance they lay aside with their veils the modesty of their sex. A long robe of very fine silk goes down to their heels, which is slightly fastened with a rich girdle. Long black hair, plaited and perfumed, lies on their shoulders. A shift, transparent as gauze, scarcely hides their bosom. As they put themselves in motion, the shapes, the contours of their bodies, seem to develop themselves successively. Their steps are regulated by the sound of the flute, of castanets, the tainbour de lasque, and cymbals, which accelerates or retards the measure. They are still fartler animated by words adapted to such scenes. They appearin a state of intoxication. They are the bacchantes, in a delirium. It is when they are at this point, throwing off all reserve, they abandon themselves wholly to the disorder of their senses; it is then that a people, far from delicate, and who like nothing hidden, redouble their applauses.

These Almé are sent for into all the harems. They teach the women the new airs, amuse them with amorous tales, and recite in their presence poems, which are so much the more interesting, as they furnish a lively picture of their manners. They initiate them into the mysteries of their art, and teach them to contrive lascivious dances. These girls, who have a cultivated understanding, are very agreeable in conversation. They speak their language with purity. The habit of dedicating themselves to poetry, renders the softest and most sonorous expressions familiar to them. They repeat with a great deal of grace. In singing, nature is their only guide. Sometimes two of them sing together, but always with the same voice. It is the 'same with an orchestra, where all the instruments playing in unison execute the same part. The Almé assist at the marriage ceremonies, and march before the bride, playing on instruments. They make a figure likewise at funerals, and accompany the procession, singing sorrowful airs. They break forth into groans and lamentations, and give every sign of grief and despair. These women are paid very high, and seldom appear but among the grandees. The common people have 
also their Almé. These are girls of the second class, who try to imitate the former; but they have neither their elegance, their graces, nor their knowledge. They are every where to be met with. The public places and the walks about Grand Cairo are full of them. As the populace require allusions still more strongly marked, decency will not permit the relation of the pitch to which these carry the licentiousness of their gestures and attitudes.

\section{TURKISI BATHING.}

IN modern Turkey, as well as among the ancients, bathing makes a part of their luxuries, so that in every town and even village there is a public bath. Indeed, the necessity of cleanliness, in a climate where one perspires so copiously, has rendered bathing indispensable ; the comfort it produces, preserves the use of it ; and Mahomet, who knew its utility, reduced it to a precept. Of these baths; and the maniler of bathing, particularly at Cairo, the following account is given by M. Savary, in his letters on Egypt.

: The first apartment one finds on going to the bath, is a large hall, which rises in the form of a rotunda. It is open at the top, to give a free circulation to the air. A spacious estrade, or raised floor, covered with a carpet, and divided into compartments, goes around it, on which one lays one's clothes. In the middle of the building, a jet-d'eau spouts out from a bason, and agreeably entertains the eye. When you are undressed, you tie a napkin round your loilis, take a pair of sandals, and enter into a narrow passage, where you begin to be sensible of the heat. The door shuts to, and, at twenty paces off, you open a second, and go along a passage, which forms a right angle with the former. Here the heat increases. They who are afraid of suddenly exposing themselves to a stronger degree of it, stop in a marble hall, in the way to the bath properly so called. The bath is a spacious and vaulted apartnent, paved and lined with marble, along which there are four closets. The vapour, incessantly rising from a fountain and cistern of hot water, mixes itself with the burning perfumes; these, however, are never burnt, except the persons who are in the bath desire it: they inix with the stean of the water, and produce a most agreeable effect. The bathers are not imprisoned here, as in Europe, in a tub, where one is never at one's ease. Extended on a cloth spread out, the head supported by a small cushion, they stretch themselves freely in every posture, whilst they are lapped up in a cloud of odoriferous vapours, which penetrates into all their pores. After reposing there some time, until there is a gentle moisture over the whole body, a servant comes, presses you gently, turns you over, and when the limbs are become supple and flexible, he makes all the joints crack, without difficulty. He masses, i. e. touches delicately, and seems to knead the flesh, without making you feel the smallest pain. This operation finished, he puts on a stuff glove, and rubs you a long time. During this operation he detaches from the body of the patient, which is running with sweat, a sort of small scales, and removes even the imperceptible dirt that stops the pores. The skin becomes soft and smooth like satin. He 
then conducts you into a closet, pours the lather of perfumed soap upon your head, and withdraws.

The ancients did more honour to their guests, and treated them in a more voluptuous manner. Whilst Telemachus was at the court of Nestor, the beautiful Polycaster, the handsomest of the daughters of the king of Pylos, led the son of Ulysses to the bath, washed him with her own hands, and after anointing his body with precious oils, covered him with rich habits and a splendid cloak. Pisistratus and Telemachus were not worse treated in the palace of Menelaus. When they had admired its beauties, they were conducted to basons of marble, where a bath was prepared; beautiful female slaves washed them: and, after anointing them with oil, covered them with rich tunics and superb pelices.

The closet to which one is conducted is furnished with a cistern and two cocks, one for cold and another for hot water. There you wash yourself. Soon after, the servant returns with a depilatory pomatum, which in an instant makes the hair fall off the places it is applied to. Both men and women make general use of it in Egypt. It is composed of a mineral called rusma, which is of a deep brown. The Egyptians burn it lightly, knead it with water, mixing it with balf the quantity of slaked lime. This grayish paste, applied to the hair, makes it fall off in two or three minutes, without giving the slightest pain. After being well washed and purified, you are wrapped up in hot linen, and follow the guide through the windings that lead to the outer apartment. This insensible transition from heat to cold prevents one from suffering any inconvenience from it. On arriving at the estrade, you find a bed prepared for you; and scarcely are you laid down, before a child comes to press every part of your body with its delicate fingers, in order to dry you thoroughly. You change linen a second time, and the child gently grates the callosity of your feet with pumice-stone. He then brings you a pipe, and Moka coffee.

Coming out of a stove where one was surrounded by a hot and moist fog, where the sweat issues from every pore, and transported into a spacious apartment open to the external air, the breast dilates, and one breathes with voluptuousness. Perfectly massed, and as it were regenerated, one experiences an universal comfort. The blood circulates with freedom, and one feels as if disengaged from an enormous weight, together with a suppleness and lightness to which one has been hitherto a stranger. A lively sentiment of existence diffuses itself to every extremity of the body; whilst it is lost in delicate sensations, the soul sympathizing, with the delight, enjoys the most agreeable ideas. The imagination, wandering over the universe, which it embellishes, sees on every side the most enchanting pictures, every where the image of happiness. If life be nothing but the succession of our ideas, the rapidity with which, they then lecur to the memory, the vigour with which the mind runs over the chain of them, would induce a belief that in the two hours of that delicious calm that succeeds the bath, one has lived a number of years.

Such are the baths, the use of which were so strongly recommended by the ancients, and which are still the delight of the Egyptians. It is by 
means of them that they cure rheumatisms, catarris, and such cutaneous disorders as are produced by want of perspiration. By the Aame resource they get rid of that uncomfortable feeling so common to all nations who do not pay atiention to the cleanlitiess of their bodies.

Mr. Tournefort, indeed, who had used steam-baths at Constantinople, where there is less refinement in them than at Cairo, is of opinion that they injure the breast : but, according to $\mathrm{Mr}$. Savary, this is an error which further experience would have corrected. There are no people who make more frequent use of them than the Egyptians, and there is no country where there are fewer asthmatic people: the asthma is hardly known there. The women are fond of these baths, frequent them once a week, and take with them slaves properly qualified to assist them. More luxurious than the men, after undergoing the usual preparations, they wash their bodies, and, above all, their heads, with rose-water. It is there that female headdressers form their long black hair into tresses, which they mix with precious essences, instead of powder and pomatum. It is there that they blacken the edge of their eye-lids, and lengthen their eye-brows with cohel, a preparation of tar burnt with gall-nuts; it is there they stain the finger and toe nails with henne, a shrub common in Europe, and which gives them a golden colour. The liien and clothing they make use of, are passed through the sweet steam of the wood of aloes; and when the work of the toilet is at an end, they remain in the outer apartment, and pass the day in entertainments. Their women entertain them with voluptuous songs and dances, or tell them tales of love.

\section{Exposing of CHILdREN.}

THIs was a barbarous custom practised by most ancient nations, excepting the Thebans, who had an express law, whereby it was made capital to expose children, and ordained that such as were not in condition to educate them should bring them to the magistrates, to be brought up at the public expense. Among the other Greeks, when a child was born, it was laid on the ground; and if the father designed to educate his child, he immediateiy touk it up; but if he forbore to do this, the child was carried away and exposed. The Lacedemonians indeed had a different custom; for with them all new-born children were brought before some of the gravest men in their own tribes, by wlion the infants were carefully viewed; and if they were found lusty and well-favoured, they gave orders for their education, and allotted a certain proportion of land for their maintenance ; but if weakly or deformed, they ordered them to be cast into a deep cavern near mount Taygenus, thinking it neither for the good of the children themselves, nor for the public interest, that such should be brought up Many exposed their children only because they were not in a condition to educate them, having no intention that they should perish. It was the unhappy fate of daughters especially to be thus treated, as requiring more to educate and settle them the world than sons. 
The parents chiefly tied jeweis and rings to the children they exposed, or any other thing whereby they might afterwards discover them, if Providence should preserve them, as well as to encourage such as found them to nourish and educate them if alive, or to give them human burial if dead. The places where it was usual to expose children were those most frequented, that they might be found, and taken up by compassionate persons, who were able to be at the expense of their education. Thus the Egyptians and Romans chose the banks of rivers, and the Greeks the highways.

\section{CUSTOMS OF THE ANCIENT ETHIOPIANS.}

THESE ancient Ethiopians, says Diodorus, were of a dry adust temperament; their nails in length resembled claws; they were ignorant of the arts which polish the mind; their language was hardly articulate, their voices were shrill and piercing. As they did not endeavour to render life commodious and agreeable, their manners and customs were very different from those of other nations. When they went to battle, some were armed with bucklers of ox's hide, and little javelins in their hands; others carried crooked darts; others used the bow; and others fought with clubs. They took their wives with them to war, whom they obliged to enter upon military service at a certain age. The women wore rings of copper at their lips. Some of these people went without clothing. Sometimes they threw about them what they happened to find, to shelter them from the burning rays of the sun. Some lived upon a certain fruit, which grew spontaneously in marshy places; some ate the tenderest shoots of trees, which were defended by the large branches from the heat of the sun; and others sowed Indian corn and lotos. Some of them lived only on the roots of reeds. Many spent a great part of their time in shooting birds, and, as they were excellent archers, their bows supplied them with plenty; but the greater part of this people were sustained by the flesh of their flocks.

\section{BIRTH-DAY.}

THE ancients placed a good deal of religion in the celebration of their birth-days, and took omens from thence of the felicity of the coming year. The manner of celebrating birth-days was by a peculiar dress, wearing a sort of rings appropriated to that day, offering sacrifices, the men to their Genius, of wine and frankincense, the women to Juno, giving suppers, and treating their friends and clients, who in return made them presents, wrote and sung their panegyrics, and offered good wishes for the frequent happy returns of the same day. The birth-days of emperors were also celebrated with public sports? feasts, vows, and medals struck on the occasion.

But the ancients, it is to be observed, had other sorts of birth-days besides the day on which they were born. The day of their adoption was always reputed as a birth-day, and celebrated accordingly. The emperor Adrian, we are told, observed three birth-days, viz. the day of his nativity, of his adoption, and of his inauguration. In those 
times it was held, that men were not born only on those days when they first came into the world, but on those also when they arrived at the chief honours and commands in the commonwealth; e. gr. the consulate. Hence that of Cicero, in his oration at duirites, after his return from exile: "A parentibus, id quod necesse erat, parvus sum procreatus ; a vobis natus sum consularis."

\section{Ancient Customs respecting Brides.}

AMONG the ancient Greeks, it was customary for the bride to be conducted from her father's house to her husband's in a chariot, the evening being chosen for that purpose. She was placed in the middle, her husband sitting on one side, and one of her intimate friends on the otlier; torches were carried before her, and she was entertained in the passage with a song suitable to the occasion. When they arrived at the end of their journey, the axle-tree of the coach they rode in was burnt, to signify that the bride was never to return to her father's house. Among the Romans, the bride was to seem to be taken by force from her motler, in memory of the rape of the Sabines under Romulus; she was to be carried home in the night to the bridegroom's house, accompanied by three boys, one of whom carried a torch, and the other two led the bride, a spindle and distaff being carried with her. She brought three pieces of money, called asses, in her hand to the bridegroom, whose doors on this occasion were adorned with flowers, and branches of trees; being here interrogated who she was, she was to answer, Caia, in memory of Caia Cecilia, wife of Tarquin the elder, who was an excellent spinstress; for the like reason, besides her entrance, she lined the door-posts with wool, and smeared them with grease. Fire and water being set on the threshold, she touched both; but starting back from the door, refused to enter, till at length she passed the threshold, being careful to step over, without tolching it; here the keys were given her, a nuptial supper was prepared for her, and minstrels to divert her; she was seated on the figure of a Priapus, and here the attendant boys resigned her to the females, who brought her into the nuptial chamber, and put her to bed. This office was to be performed by matrons only, who had been married, to denote that the marriage was to be for perpetuity.

\section{Marriage Customs in Sicily.}

ThE Sicilians till lately retained a great many foolish and superstitious customs, but particularly in their marriage and funeral ceremonies: it would be tedious to give but an account of all these; some of them are still practised in the wild and mountainous parts of the island. As soon as the marriage ceremony is performed, two of the attendants are ready to cram a spoonful of honey into the mouths of the bride and bridegroom; pronouncing it emblematical of their love and union, which they hope will ever continue as sweet to their souls as that honey is to their palates. They then begin to throw haudfuls of wheat upon them, which is continued all the way to 
the house of the bridegroom. This is probably the remains of some ancient rite to Ceres, their favourite divinity, and they think it cannot fail of procuring them a numerous progeny :-however, the Sicilian women have no occasion for any charm to promote this, as, in general, they are abundantly prolific even without it. Fazello gives an account of women having frequently upwards of forty children; and Carera mentions one who had forty-seven.

The young couple are not allowed to taste of the marriage feast; this, they pretend, is to teach them patience and temperance; but when dinner is finished, a great bone is presented to the bridegroom by the bride's father, or one of her nearest relations, who pronounces these words, "Rodi tu quest osso, \&c. Pick you this bone, for you have now taken in hand to pick one, which you will find much harder and of more difficult digestion." Perhaps this may have given rise to the common saying, when one has undertaken any thing arduous or difficult, that "He has got a bone to pick."

The Sicilians like most other nations in Europe, carefully avoid marrying in the month of May, and look upon such marriages as extremely inauspicious. This piece of superstition is as old, perhaps older, than the time of the Romans, by whose authors it is frequently mentioned, and by whom it has been transmitted to almost every nation in Europe. It is somewhat unaccountable that so ridiculous an idea, which can have no foundation in nature, should have stood its ground for so many ages. There are indeed otber customs still more trivial, that are not less universal : that of making April fools on the first day of that month ; the ceremony of the cake on Twelfthnight; and some others that will occur to the reader, of which, no than this, have we ever been able to learn the origin.

The marriages of the Sicilian nobility are celebrated with great magnificence; and the number of elegant carriages produced on these occasions is astonishing. I wanted to discover when this great luxury in carriages had taken rise; and have found an account of the marriage of the daughter of one of their viceroys to the $\mathrm{Duke}$ of $\mathrm{Bi}$ vona, in the year 1551. It is described by one Clenco, who was a spectator of the ceremony. He says, the ladies as well as the gentlemen were all mounted on fine horses, sumptuously caparisoned, and preceded by pages ; that there were only three carriages in the city, which were used by invalids who were not able to ride on horseback. These he calls carette, which now signifies a little cart.

The Sicilian ladies marry very young, and frequently live to see the fifth or sixth generation. You will expect, no doubt, that I should say something of their beauty :- In general, they are sprightly and agreeable; and in niost parts of Italy they would be esteemed handsome. A Neapolitan or a Roman would surely pronounce them so: but a Piedmontese would declare them very ordinary; so indeed, would most Englishmen. Nothing is so vague as our ideas of female beauty; they change in every climate, and the criterion is no where to be found.

Ask where's the North? - at York, 'tis on the Tweed, In Scotland at the Orcades; and there, At Nova Zembla, or the Lord knows where. 
Jivinations at Weddings. - Divinations at marriages were practised in times of the remotest antiquity. Valiancy tells $u s$, that in the. memoirs of the Etruscan academy of Cortona is the drawing of a picture found in Herculaneum, representing a marriage. In the front is a sorceress casting the five stones. - The writer of the memoir. justly thinks she is divining. The figure exactly corresponds with the first and principal cast of Irish purin: all five are cast up, and the first cast is on the back of the hand.--He has copied the drawing : on the back of the hand stands one, and the remaining four on the ground. Opposite the sorceress is the matron, attentive to the success of the cast. No marriage ceremony was performed without consulting the druidess and her purin :

"Auspices solebant nuptis interesse."

In the St. Janies's Chronicle, from April 16th to April 18th, 1799, are the following lines on the bride-cake.

"Enlivening source of hymeneal myrth,

All-hail the blest receipt that gave thee birth !

Tho' Flora culls the fairest of her bowers,

And strews the path of Hymen with her flowers,

Not half the raptures give her scattered sweets;

The cake for kinder gratulation meets.

The Bride-maid's eyes with sparkling glances beam,

She views the cake, and greets the promis'd dream.

For, when endowed with necromantic spell,

She knows what wondrous things the cake will tell.

When from the altar comes the pensive Bride,

With downcast looks, her partner at her side;

Soon from the ground these thoughtful looks arise,

To meet the calse that gayer thoughts supplies.

With her own hand she charms each destin'd slice,

And thro' the ring repeats the trebled thrice.

The hallow'd ring infusing magic pow'r,

Bids Hymen's visions wait the midnight hour;

The mystic treasure, plac'd beneath her head,

Will tell the fair if haply she may wed.

These mysteries protentous lie concealed,

Till Morpheus calls, and bids them stand reveal'd;

The future husband that night's dream will bring,

Whether a sailor, soldier, beggar, king,

As partner of her life the fair must take,

Irrevocable doom of Bridal Cake."

Skarfs, Points, and Bride-laces at Weddings.

Skarfs, now confined to funerals, were anciently given at marriages, as noticed in Ben Jonson's Silent Woman. In the same author's Tale of a Tub, Turf is introduced as saying on this occasion, We shall all ha' bride-laces or points, I zee." -

Among the lots presented to Queen Elizabeth in Davison's Rhapsody, the two following occur, in a list of Prizes for Ladies :- 
"You are in every point a Lover true, ant to esmis an

And therefore Fortune gives the Points to you?

\section{A Skarfe.}

"Take you this Scarfe, bind Cupid hande and fcote,

So Love must aske you leave before he shoote." het bon salt

Herric, in his Hesperides, in the Epithalamie on Sir Clipseby Crew and his Lady, this cautions the bridegroom's men against offending the delicacy of the new-married lady:

"We charge ye that no strife

(Farther than gentleness tends) get place

Among ye, striving for her Lace."

At the marriage ceremony of John Newchombe, the weal thy clothier of Newbury, cited by Strutt, his bride was led to church between two sweet boys, with bride-laces and rosemary tied about their silken leaves.

Bride Knives. - Strange as it may appear, it is however certain that knives were formerly part of the accoutrements of a bride. 'This perhaps will not be difficult to account for, if we consider that it, anciently formed part of the dress for women to wear a knife or kuives sheathed and suspended from their girdles a finer or more ornamented pair of which would very naturally be either purchased or presented on the occasion of a marriage In that most rare play, the Witch of Edmonton, Somerton says, "But see the bridegroom and bride comes: the new pair of Sheffield knives fitted to one sheath."-In 'Well-met, Gossip ;' or, 'Tis Merry when Gossips meet; the Widow says, -

"For this you know, that all the wooing season,

Suitors with gifts continual seek to gain

Their mistress' love, \&c."

The wife answers:-

"That's very true

In conscience I had twenty pair of gloves,

When I was maid, given to that effect;

Garters, knives, purses, girdles, store of rings,

And many a thousand dainty, pretty things."

Thus to another part of the dress, in the old play of the Witch of Edmonton, old Carter tells his daughter and her sweetheart, "Your marriage money shall be received before your wedding shoes can be pulled on. Blessing on you both."

We find the following passage in "a Treatise wherein Dicing, Dauncing, Vaine Plays, or Enterluds, with other idle Pastimes, \&c. commonly used on the Sabbath-day, are proved by the authoritie of the Word of God, and antient writers, by Jolin Northbrook, minister and preacher of the word of God.-In olde time (we reade) that there was usually carried before the Mayde, when she shoulde be married, and came to dwell in hir husbande's house, a distaffe, 
charged with flaxe, and a spyndle hanging at it, to the intente shee might bee myndeful to lyve by hir labour."

Chaucer's Miller of Trumpinton is represented as wearing a Sheffield knife :

"A Shefeld thwitel bare he in his hose."

And it is observable that all the portraits of Chaucer give him a linife hanging at his breast.

Among the women's trinkets, A. D. 1560, in the four P's of John Heywood, occur :-

"Silkers, swathbands, riband, and sleave laces,

Girdles, knives, purses, and pin cases."

"An olde merchant had hanging at his girdle, a pouch, a spectacle-case a punniard, a pen and inckhorne, and a handkertcher, with many other trinkets besides : which a merry companion seeing, said, it was a habberdasher's shop of small wares."

Strewing Herbs, Flowers, or Rushes before the Bridegroom and Bride in their way to Church: as also the wearing Nosegays on the occasion.

There was anciently a custom at marriages, of strewing berbs and flowers, as also rushes, from the house or houses where persons betrothed resided, to the church.

Every one will call to mind the passage in Shakspeare to this purpose :-

"Our bridal flowers serve for a buried corse."

Armin's "History of the Two Maids of Morelacke," 4 to. 1609, opens thus, preparatory to a wedding, "Enter a maid strewing flowers, and a serving man perfuming the door. The maid says, 'Strew, strew ;'-the man, "The Muscadine stays for the bride at church."

"It is worthy of remark that something like the ancient custom of strewing the threshold of a new-married couple with flowers and greens, is, at this day, practised in Holland. Among the festoons and foliage, the laurel was always conspicuous: this denoted, no doubt, that the wedding-day is a day of triumph."

The bell-ringing, \&c, used on these occasions are thus introduced:

"Lo! where the hamlet's ivy'd gothic tow'

With merry peals salutes th' auspicious hour,

With sounds that thro' the cheerful village bear

The happy union of some wedded pair."

In Hasket's "Marriage Present," the author introduces among flowers used on the occasion, primroses, maiden's-blushes, and violets.

The strewing herbs and flowers on marriage occasions, as mentioned in a note upon the old play of Ram Alley, to have been practised formerly, is still kept up in Kent and many other parts of England. With regard to nosegays, called by the vulgar in the north of England "Posies" Stephens has a remarkable passage in , his character of "A plaine Country Bridegroom :" "He shows," says he, " neere affinity betwixt marriage and hanging: and to that purpose he 
provides a great nosegay, and shakes hands with every one he meets, as if he were now preparing for a condemned man's voyage." Nosegays occur in the poem of the Collier's wedding :--

"Now all prepared and ready stand

With fans and posies in their hands."

Rosemary and Bays at Weddings.-Rosemary, which was anciently thought to strengthen the memory, was not only carried at funerals, but also worn at weddings.

In a curious wedding sermon, by Roger Hacket, D. D., 4to. Lonron, 1607, entitled, "A Marriage Present," he thus expatiates on the use of rosemary at this time: "The last of the flowers is rosemary, (rosmarinus, the rosemary, is for married men,) the which by name, nature, and contisued use, man challengeth as properly belonging to himselfe. It overtoppeth all the flowers in the garden, boasting man's rule. It helpeth the braine, strengtheneth the memorie, and is very medicinable for the head. Another property of the rosemary is, it affects the heart. Let this rosmarinus, this flower of men, ensigne of your wisdome, love, and loyaitie, be carried not only in your hands, but in your heads and hearts." Both rosemary and bays appear to have been gilded on these occasions. The rosemary used at weddings was previously dipped, it should seem, in scented water.

We gather from the old play of Ben Jonson, entitled, the Tale of a Tub, that it was customary for the maidens, i. e. the bridemaids, on the bridegroom's first appearance in the morning, to present him with a bunch of rosemary bound with ribbons. So late as the year 1698 , the old country use appears to have been kept up, of decking the bridal bed with sprigs of rosemary; it is not, however, mentioned as being general.

The Marriage Ceremony, or part of it, performed anciently in the Church Porch, or before the Door of the Church.-

Can this custom have had its rise in the times of Gentilism! Vallancy informs us that "the ancient Etruscans always were married in the streets, before the door of the house, which was thrown open at the conclusion of the ceremony." All the ancient Missals mention, at the beginning of the nuptial ceremony, the placing of the man and woman before the door of the church, and direct, towards the conclusion, that here they shall enter the church as far as the step of the altar. Selden, in his Uxor Hebraica, asserts, that no where else but before the face, and at the door, of the church, could the marriage dower have been lawfilly assigned.

By the parliamentary reformation of marriage and other rites under ling Edward the Sixth, the man and woman were first permitted to come into the body or middle of the church, standing no longer, as formerly, at the door : yet, by the following from Herrick's Hesperides, one would be tempted to think that this custom had survived the reformation :- 
- The Entertainment, or Porch Verse, at the Marriage of Mr. Henry Northy and the nost witty Mrs. Letlice Yard.

"Welcome ! but yet no entrance till we blesse First you, then you, and both for white successe: Profane no porch, young man and maid, for fear Ye wrong the threshold god that keeps peace here; Please him, and then all good luck will betide. You the brisk bridegroom, you the dainty bride."

Drinking Wine in the Church at Marriages-This custom is enjoined in the Hereford Missal. By the Sarum Missal it is directed that the sops immersed in this wine, as well as the liquor itself and the cup that contained it, should be blessed by the priest. The beverage used on this occasion was to be drunk by the bride and bridegroom, and the rest of the company.-In Mr. Lyson's Environs of London, in his account of Wilsdon parish, in Middlesex, he tells us of an "Inventory of the goods and ornaments belonging to Wilsdon Church about A. D. 1547," in which occur " two Massers that were appointed to remayne in the church for to drynk yn at Brideales." The pieces of cake, or wafers, that appear to have been inmersed in the wine on this occasion, were properly called sops, and doubtless gave name to the flower termed "Sops in wine.".

The allusions to this custom in our old plays are very numerous. In Ben Jonson's Magnetic Lady, the wine drank on this occasion is called "a Kuitting Cup." The Jews have a custom at this day, when a couple are married, to break the glass in which the bride and bridegroom have druik, to admonish them of mortality. This custom of nuptial drinking appears to have prevailed in the Greek Clurch.

The Nuptial.Kiss in the Church.-The Nuptial Kiss in the church is enjoined both by the York Missal,* and the Sarum Manual ; + it is expressly mentioned in the following line from the old play of the Insatiate Countess, by Marston :

"The Kisse thou gav'st me in the church here take."

Care Cloth.-Among the Anglo-Saxons, the nuptial benediction was performed under a veil, or square piece of cloth, held at eacli corner by a tall man, over the bridegroom and bride, to conceal her virgin blushes; but if the bride was a widow, the veil was esteemed useless. According to the use of the church of Sarum, when there was a marriage before mass, the parties kneeled together, and had a

* Thus the York Missal, "Accipiat Sponsus pacem," (the Pax) "a Sacerdote, et ferat Sponsæ, osculans eam, et neminem alium, nec ipse, nec ipsa."

+ 4to. Par., 1553, Rubrick, fol. 69, "Surgant ambo, Sponsus, et Sponsa, et accipiat Sponsus pacem a Sacerdote, et ferat Sponsæ, osculans eam, et neminem alium, nec ipse, nec ipsa."

t Taughan, in his Golden Grove, says, "Among the Romans, the future couple sent certain pledges one to another, which most commonly they themselves, afterwards being present, would confirm with a religious kiss." 
fine linen cloth (called the Care-cloth) laid over their heads during the time of mass, till they received the benediction, and then were dismissed.

Bride-ale, called also Bride-bush, Bride-stake, Bidding, and Bridewain.-Bride-ale, bride-bush, and bride-stake, are nearly synonymous terms, and all derived from the circumstance of the bride's selling ale on the wedding day, for which she received, by way of contribution, whatever handsome price the friends assembled on the occasion chose to pay her for it. A bush at the end of a pole or stake was the ancient badge of a country ale-house. Around this bride-stake, the guests are wont to dance as about a may-pole. The bride-ale appears to have been called in some places a bidding, from the circumstance of the bride and bridegroom's bidding, or inviting, the guests. In Cumberiand it had the appellation of a bride-wain, a term which will be best explained by the following extract from the Glossary to Douglas's Virgil :- - There was a custom in the Highlands and north of Scotland, where new-married persons, who had no great stock, or others low in their fortune, brought carts and horses with them to the houses of their relations and friends, and received from them corm, meal, wool, or whatever else they could get."

Winning the Kail; in Scotland termed Broose, in Westmoreland called Riding for the Ribbon. The Glossary to Burns Scottish Poems describes "Broose" (a word which has the same meaning with "Kail") to be "a race at country weddings, who shall first reach the bridegroom's house on returning from church." The meaning of the words is every where strangely corrupted. "Broose" was originally; I take it for granted, the name of the prize on the above occasion; and not of the race itself : for whoever first reaches the house to bring home the good news, wins the "Kail," i.e., a smoking prize of spice broth, which stands ready prepared to reward the victor in this singular kind of race. This same kind of contest is called in Westmoreland "riding for the Ribbon."

Torches used at Weddings.-At Rom ethe manner was, that two children should lead the bride, and a third bear before her a torch of white-thorn, in honour of Ceres. We have seen foreign prints of marriages, where torches are represented as carried in the procession? We know not whether this custom ever obtained in England, though from the following lines in Herrick's Hesperides, one might be tempted to think that it had:-

Upon a Maid that dyed the day she was marryed.

Q9at That morne which saw me made a bride,

The ev'ning witnest that I dy'd.

Those holy lights, wherewith they guide

Unto the bed the bashful bride,

3* In a sinall book entitled the Westmoreland Dialect, we are told that, "The ceremony being over, awe raaid haim fearfu' wele, an the youngans raaid for th ribban, me cusin Betty banged awth lads, an gat it, for sure." ... 
Serv'd but as tapers for to burne, And light my reliques to their urne. This epitaph, which here you see, Supplied the epithalamie."

Music at Weddings. - At the marriages of the Anglo-Saxons, the parties were attended to church by music. In the old history of John Newcombe, the wealthy chothier of Newbury, cited by Strutt, speaking of his marriage and the bride's going to church, the writer observes, "There was a noise of musicians that played all the way before her."

Dame Sibil Turfe, a character in Ben Jonson's play of the Tale of a Tub, is introduced reproaching her husband as follows; "A clod you shall be called, to let no music go afore your child to church, to chear her heart up!" and Scriben, seconding the good old dame's rebuke, adds, "She's ith' right, sir : for your wedding dinner is starved without music." The rejoicing by ringing of bells at marriages of any consequence, is every where common. On the fifth bell at the church of Kendal, in Westmoreland, is the following inscription alluding to this usage :

"In wedlock bands,

All ye who join with hands,

Your hearts unite;

So shall our tunefull tongues combine.

To laud the nuptial rite." $\$$

Bride Favours. - A knot, among the ancient northern nations seems to have been the symbol of love, faitl, and friendship, pointing out the indissoluble tie of affection and duty. Thus the ancient Runic inscriptions, as we gather from Hicks's Thesaurus, are in the form of a knot. Hence among the northern English and Scots, who still retain in a great measure the language and manners of the ancient Danes, that curious kind of knot, a mutual present between the lover and his mistress, which, being considered as the emblem of plighted fidelity, is therefore called a true-love knot; a name which is not derived, as one would naturally suppose it to be, from the words "true" and "love," but formed from the Danish verb, "Trulofa fidem do, I plight my troth or faith. Thus we read, in the Islandic Gospel, the following passage in the first chapter of St. Mattlew; which

$\S$ In Swinburne's account of the gypsies, in his Journey through Calabria, is the following remark: "At their weddings they carry torches, and have paranymphs to give the bride away, with many other unusual rites." Lamps and flambeaux are in use at present at Japanese weddings. "The nuptial torch," (says the author of Hymen, \&c, an account of marriage ceremonies of different nations,) "used by the Greeks and Romans, has a striking conformity to the flambeaux of the Japanese. The most considerable difference is, that, amongst the Romans, this torch was carried before the bride by one of her virgin attendants; and among the Greeks, that office was performed by the bride's mother. In the Greek church, the bridegroom and bride enter the church with lighted wax tapers in their hands.". 
confirms beyond a doubt, the sense here given - "til ein rar Meyar er trulofad var einum Manne," \&c., i. e. to a Virgin espoused, that is, who was promised, or had engaged herself, to a man, \&c.

Hence evidently the bride-favours or the top-knots at marriages, which had been considered as emblems of the ties of duty and affection between the bride and her spouse, have been derived.

Bride-favours appear to have been worn by the peasantry of France, on similar occasions, on the arm. In England, these knots of ribbons were distributed in great abundance formerly, even at the marriages of persons of the first distinction. They were worn on the hat, (the gentleman's, we suppose,) and consisted of ribbons of various colours. If we mistake not, white ribbons are the only ones used at present. To this variety of colours in the bride-favours used formerly, the following passage, wherein lady Haughty addresses Morose, in Jonson's play of the Silent Woman, evidently alludes:

Let us know your bride's colours and your's at least."

The bride-favours have not been omitted in the northern provincial poem of "The Collier's Wedding."

"The blithsome, buxom, country maids,

With knots of ribands at their heads,

And pinners flutt'ring in the wind,

That fan before and toss behind, \&c."

And, speaking of the youth, with the bridegroom, it says,-

"Like streamers in the painted sky,

At every breast the favours fly."

Bride Maids.-The use of bride-maids at weddings appears as old as the time of the Anglo-Saxons; among whom, as Strutt informs us, " the bride was led by a matron, who was called the bride's womain, followed by a company of young maidens, who were called the bride's maids.".

The bride-maids and bridegroom men are both mentioned by the author of the Convivial Antiquities, in his description of rites at marriages in his country and time.

In later times it was among the offices of the bride-maids to lead the bridegroom to church, as it was the duty of the bridegroom men to conduct the bride thither.

This has not been overlooked in the provincial poem of the Collier's Wedding :-

"Two lusty lads, well drest and strong,

Stepp'd out to lead the bride along:

And two young maids, of equal size, As soon the bridegroom's hand surprise."

Bridegroom Men. - These appear anciently to have had the title of Bride Knights. Those who led the bride to church were always bachelors : but she was to be conducted home by two married persons. Polydore Virgil, who wrote in the time of Henry the Eighth, informs us that a third married man, in coming home from church, preceded the bride, bearing, instead of a torch, a vessel of silver or 
gold. Moresin relates, that to the bachelors and married men who led the bride to and from the church, she was wont to present gloves for that service during the time of dinner.

In a curious old book called, "The Fifteen Comforts of Marriage," a conference is introduced at p. 44, 46, and 48 , concerning bridal colours in dressing up the bridal-bed, by bridemaids :-Not (say they) with yellow ribbands, these are the emblems of jealousy-nor with feuillemort, which signifies fading love; but with true blue, that signifies constancy, as green denotes youth: put them both together, and there's youthful constancy.-Ore proposed blue and black, which signifies constancy till death; but that was objected to, as these colours will never match.-Violet was proposed, as signifying religion; this was objected to as being too grave ; and at last they concluded to mingle gold tissue with grass green, which latter signifies youthful jolity.-For the bride's favour, (top-knots and garters,) the bride proposed blue, gold colour, popinjay green, lemon colour ; but they objected to gold colour, as signifying a varice, and to popinjay green, as indicating wantonness. The younger bride-maid proposed mixture, flame-colour, willow, and milh white. The second objected to it, as willow signifies forsaken. It was settled that red signities justice, and sea-green inconstancy. The milliner at last fixed the colours: for the Favours, blue, red, peach-colour, and orange-tawny for the young ladies' Top-knots, grass-green and milk-white; and for the garters, a perfect yellow, signifying honour and joy.

Garlands at Weddings :-Nuptial garlands are of the most remote antiquity. They appear to have been equally used by the Jews and the Heathens.

Among the Anglo-Saxons, after the benediction in the church, both the bride and bridegroom were adorned with crowns of flowers, kept in the church for that purpose.

In the Eastern church, the chaplets used on these occasions appear to have been blessed.

The nuptial garlands were sometimes made of myrtle.

In England, in the time of Henry the Eighth, the bride wore a garland of corn-ears, sometimes one of flowers.

Gloves at Weddings :-The giving of gloves at marriages is a custom of remote antiquity.

The following notice of them occurs in a letter to Mr. Winwood from Sir Dudley Carleton, dated London, 1604, concerning the manner of celebrating the marriage between Sir Philip Herbert and the Lady Susan: "No ceremony was omitted of bride-cakes, points, garters, and gloves.":

In Ben Jonson's play of the Silent Woman, Lady Haughty observes to Morose, "We see no ensigns of a wedding here, no character of a bridale ; where be our skarves and our gloves?"

The custom of giving away gloves at weddings occurs in the old play of "The Miseries of inforced Marriage." White gloves still continue to be presented to the guests on this occasion. The following is an extract of the late Rev. Dr. Lort's : At Wrexham in Flintshire, on occasion of the marriage of the surgeon and apothecary of the 
place, August 1785, I saw at the doors of his own and neiglibours houses, throughout the street where he lived, large boughis and posts of trees, that had been cut down and fixed there, filled with white paper, cht in the shape of women's gloves and of white ribbons."

The following is in Parkinson's Garden of Flowers : The bayleaves are necessary both for civil uses and for physic, yea, both for the sick and for the sound, both for the living and the dead. It serveth to adorn the house of God as well as man-to crown or encircle, as with a garland, the heads of the living, and to sticke and decke forth the bodies of the dead : so that from the cradle to the grave we have still use of it, we have still need of it." Ibid. - "Rosemary is almost of as great use as bayes, as well for civil as physical purposes : for civil uses, as all doe know, at weddings, funerals, \&c. to bestow among friends."

It should seem, by the following passage in Clavell's Recantation of an Ill-led Life, that anciently this present was made by such prisoners as received pardon after condemnation. It occurs in his Dedication "To the impartial Judges of his Majesties Bench, my Lord Chief Justice and his other three honourable Assistants."

"Those pardon'd men, who taste their prince's loves

(As married to new life) do give you gloves," \&c.

Clavell was a highwayman, who had just received the king's pardon. He dates from the King's Bench Prison, Octobér, 162\%.-Fuller in his "Mixt Contemplations on these Times," says, "It passeth for a general report of what was customary in former times, that the sheriff: of the county used to present the judge with a pair of white gloves, at those which we call mayden assizes, viz. when no malefactor is put to death theréin."

Can the custom of dropping or sending the glove, as the signal of a challenge, have been derived from the circumstance of its being the cover of the hand, and therefore put for the hand itself? - The giving of the hand, is well known to intimate that the person who does so will not deceive; but stand to his agreement.-To "shake hands upon it," would "not, it should seem, be very delicate in an agreement to fight, and therefore gloves may, possibly, have been deputed as substitutes -We may, perhaps, trace the same idea in wedding gloves.

Wedding Ring.-Among the customs used at marriages, those of the ring and bride-cake seem of the most remote antiquity. Confarreation and the ring were used anciently as binding ceremonies by the heathen, in making agreements, grants, \&zc., whence they have doubtless been derived to the most solemn of our engagements. The supposed heathen origin of our marriage ring had well nigh caused the abolition of it during the time of the commonwealth.

The wedding ring is worn on the fourth finger of the left hand, because it was anciently believed, though the opinion has been justly exploded by the anatomists of modern times, that a small artery ran

In the north of England, a custom still prevails, at maiden assizes, i.e. when no prisoner is capitally convicted, to present the judges, \&c. with white gloves. 
from this finger to the heart. Wheatley, on the authority of the Missals, calls it a vein : "It is," says he, "secause from thence there proceeds a particular vein to the heart. This, indeed, (he alds, is now contradicted by experience; but several eminent authors, as well Gentiles as Christians, as well physicians as divines, were formerly of this opinion, and therefore they thought this finger the properest to bear the pledge of love, that from thence it might be conveyed, as it were, to the heart."

Rings appear to have been given away formerly at weddings. In Wood's Athena Oxonienses, vol. i. p. 280, we read, in the account of the famous philosopher of queen Elizabeth's days, Edivard Kelley, "Kelley, who was openly profuse beyond the nodest limits of a sober philosopher, did give away in gold wire rings, (or lings twisted with three gold wires,) at the marriage of one of his maid-servants, to the value of $40001 . "$ r'h is was in 1589 , at Trebona..

Christening Customs. -The learned Dr. Moresin informs us of a remarkable custom, which he himself was an eye-witness of in Scotland: They take, says he, on their return from church, the newly baptized infant, and vibrate it three or four times gently over a flame, saying, and repeating it thrice, "Let the flame consume thee now or never."-Grose tells us there is a superstition that a child who does not cry in baptism will not live. He has added,another idea equally well founded, that children prematurely wise are not long lived, that is, rarely reach maturity; a notion which we find quoted by Shakspeare, and put into the mouth of Richard the Third.-It appears to have been anciently the custom at christening entertainments, for the guests not only to eat as much as they pleased, but also, for the ladies at least, to carry away as much as they liked in their pockets. Hutchinson, in his History of Northumberland, tells us that children in that country, when first sent abroad in the arms of the nurse, to visit a neighbour, are presented with an egg, salt, and fine bread. It was anciently the custom for the sponsors at Christenings to offer gilt spoons as presents to the child ; these spoon were called Apostle Spoons, because the figures of the twelve apostles were chased or carved on the tops of the handles. Opulent sponsors gave the whole twelve; those in middling circumstances gave four ; and the poorer sort contented themselves with the gift of one, exhibiting the figure of auy saint, in honour of whom the child received its name. - Brand's Popular Antiquities.

\section{NUMEROUS FAMILIES OF CHILDREN.}

In the genealogical history of Tuscany, written by Gamarini, mention is made of a nobleman of Sieuna, named Pichi, who by three wives had had one hundred and fifty children ; and that, being sent ambassador to the pope and the emperor, he had forty-eight of his sons in his retinue. In a monument in the church-yard of St. Innocent, at Paris, erected to a woman who died at eighty-eight years of age, it is recorded that she might have seen 288 children directly issued from her. But children here evidently includes grand-children, \&c. \&c. Hakewell relates of Mrs. Honeywood, a gentlewoman of Kent, who 
was born in $152 \%$; married at sixteen to her only husband, $R$. Honey wood of Charing, Esq. who died in her ninety-third year; that she had sixteen clildren of her own body: of whom three died young, and a fourth had no issue; yet her grand-children amounted to one liundred and fourteen; her great grand-children to two hundred and twenty-eight; and her grand-children's grand-children to nine, before she died. The whole number she might have seen in her life-time, being $367 ! 16+$ $114+228+9=367$ - But the faithful mother of the Dalburg family saw her offspring of the sixth generation; as recorded in the following distich :

Mater (1), ait natre (2), dic nata (3), filia natam (4),

Ut moneat, natre (5) plangere filiolan! (6):

That is, "The mother (1), says to her daughter (2), Daughter, go lell your daughter (3), to advise her daughter (4), to chastise her daughter's (5) litt!e daughter." (6).

LAws of SPARTARESPECING CELIBACY AND MARRiage.

CELIBACY in men was infamous, and punished in a most extraordinary manuer; for the bachelor was constrained to walk naked in the depth of winter, through the market place: while he did this, he was obliged to sing a song in disparagement of himself; and he had none of the honours paid him which otherwise belonged to old age, it being held umeasonable that the youth should venerate him who was resolved to have none of his progeny behind him, to revere them when they grew old in their turn. The time of marriage was also fixed; and if a man did not marry when he was at full age, be was diable to an action; as. were such also as married above or below themselves. Such as had three children had great immunities: such as had four were free from all taxes whatsoever. Virgins were married without portions; because neither want should hinder a man, nor viches induce him, to marry contrary to inclinations.

\section{LAWS RESPECTING BACHELoRs.}

THE Roman censors frequently imposed fines on old bachelors Dion. Halicarnassus mentions an old law, by which all persons of full age were obliged to marry. But the most celebrated law of the kind was that made under Augustus, called the "Lex Julia de maritandis ordinibus;" by which bachelors were made incapable of legacies or inheritances by will, unless from their near relations. This brought many to marry, according to Plutarch's observations, not so much tor the sake of raising heirs to their own estates, as to make themselves capable of inheriting those of others.

The rabbius maintain, that by the laws of Moses, every body, except some few particulars, is obliged in conscience to marry, at twenty years of age : this makes one of their 613 precepts. Hence those maxins so frequent among their casuists, that he who does jot take the necessary measures to leave heirs behind him, is not a man, 
but ought to be reputed a homicide. Lycurgus was not more favour able : by his laws, bachelors are branded with infamy, excluded from all offices civil and military, and even from the shows and public sports. At certain feasts they were forced to appear, to be exposed to the public derision, and led round the market-place.s At one of their feasts, the women led them in this condition to the altars, where they were obliged to make the amende honourable to nature, accompanied with a number of blows and lashes with a rod, at discretion. To complete the affront, they forced them to sing certain songs composed in their own derision.

The Christian religion has been supposed to be more indulgent to the bachelor state, because the aposile Paul has recommended it as preferable, as it certainly was during the early ages of Christianity, when a man was in danger of suffering, not only in his own person or property, but in those of his nearest and dearest counexions, for the sake of religion, which rendered such persecutions much more dreadful and severe upon the married than the unmarried. The alleient church, overlooking this principle, upon which the apostle's advice is evidently founded, recommended the bachelor state, as well as that of perpetual virginity in the other sex, as not only more perfect than the married state, but even as highly meritorious, and thus gave birth to the absurd system of monasteries, nunneries, and the celibacy of the clergy, which for so many ages has burdened Europe with thousands of idle drones of both sexes. In the canon law, we find injunctions on bachelors, when arrived at puberty; either to marry, or to turn monks, and profess chastity in earnest. In England there was a tax on bachelors, after twenty-five years of age, (12l.10s. for a duke, a common person, 1s.) by 7 Wil. III. 1695. In Britain, at present, they are taxed by an extra duty on their servants. Every man of the age of 21 years and upwards, never having been married, who shall keep one male servant or more, shall pay 11 . 5s. for each, above, or in addition to, the ordinary duties leviable for servants. Every man of the age of twenty-one years and upwards; never having been married, keeping one female servant, shall pay 2 s. $6 \mathrm{~d}$. in addition to the former $2 \mathrm{~s} .6 \mathrm{~d}$.; $5 \mathrm{~s}$. in addition for each, if he has two female servants; and $10 \mathrm{~s}$. in addition for each, for three or more female servants.

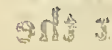

\section{CUSTOMS AT FuNERALS:}

isolsowing the colpse to the grave, carrying evergreens on that occasion in the hand, together with the use of psalmody.--Bourne tells us, that the heathens followed the corpse to the grave, becaiss it presented to them what would shortly follow, how they themselves should be so carried out to be deposited in the grave. Christians, he adds, observe the custom for the very same reason. And he further remarks, that this form of procession is an emblem of our dying shortly after our friend; so the carrying in our hands of ivy, sprigs of Jaurel, rosemary, or other evergreens, is an emblem of the soul's immortality. The Romans and other heatlens, upon this occasion; made use of cypress, which being once cut, will never flourish nor grow again, as an emblem of their dying for ever; but instead of 
that, the ancient Christians used the things before mentioned, and deposited them under the corpse in the grave, to signify that they who die in Christ do not cease to live; for though, as to the body, they die to the world; yet, as to their souls, they live and revive to God? And as the carrying these evergreen's is an emblem of the soul's immortality, so it is also of the resurrection of the body: for as these lherbs are not entirely plucked up, but only cut down, and will, at the returning season, revive and spring up again : so the body, like then, is but cut down for a while, and will rise and shoot up again at the resurrection : for, in the language of the evangelical prophet, "rev bones shall flourish like'an herb?" Bourne cites Gregory, c. 26 , as observing that it was customary among the ancient Jews, as they returned from the grave, to plick up the grass two or three times, and then throw it behind them, saying these words of the psalnist, SThey shall flourish out of the city like grass upon the earth', which they did, to shew, that the body though dead, should swring up as the grass Various are the profofs of the ancient custom of carrying out the dead with psalmody in the primitive church; in imitation of which it is still customary, in many parts of this nation, to carry out the dead with singing of psalms and hymis of triumph; to shew that they have ended their spiritual warfare, that they have finished their course with joy, and become conquerors. This exultation, as it were, for the conquest of their deceased friend over hell, sin, and death, was the great ceremony used in all funeral processions among the ancient Christians. In poems by the Rev. John Black, minister of Burley, in Suffolk, 8vo. Ipsw. 1799, p. 10, in "An elegy on the Author's Mother, who was buried in the church-yard of Dunichen in Scotland? is the following stanza:

10 Ob, how my soul was grievd, when I let fall.

The string that dropt her silent in the grave!

Yet thought I then, I heard her spirit call :

'Safe I have passed through death' overwhelming wave.

On the second line the author has this note:

- In Scotland, it is the custom of the relations of the deceased them selves to let down the corpse into the grave, by mourning cords fastened to the handles of the coffin; the chief moumer standing at the head, and the rest of the relations arranged according to their propinquity. When the coffin is let down and adjusted in the grave, the mourners first, and then all the surrounding multitude, uncover their heads : there is no funeral service read; but that solemn pause for about the space of ten minutes, when every one is supposed to be meditating on death and immortality, always struek my heart in the most awful manner, and on one interesting occasion with peculiar solembity. The sound of the cord, when it fell on the coffin, still seems to vibrate oniniy ear.?

Torches and Lights at Funerals. - The custom of using torches and lights at funerals, or in funeral processions, appears to have been of long standing. The learned Gregory tells us that " the funeral tapers, lowever thought of by some, are of harmlesse import Their meaning is to shew that the departed soules are not quite put ont, but, having 
walled here as the children of light, are now gone to walk before God in the light of the living.- Strutt tells is, the burning of torches was very honourable. To have a great many, was a special mark of esteem in the person who made the funeral to the deceased. Moilsieur Jorevin, describing a lord's burial uear Shrewsbury, says, "After the burial service, the clergyman, having his bough in his hand like the rest of the congregation, threw it on the dead body when it was put into the grave, as did all the relations, extinguishing their flambeaux in the earth with which the corpse was to be covered. This finislied, every one retired to his home without further ceremony.

\section{Ancient Funeral Ceremonies of the Ethiopians.}

THE Ethiopians had very particular ceremonies in their funerals. According to Ctesias, after having salted the bodies, they put them into a hollow statue of gold, which resembled the deceased, and was placed in a niche, on a pillar set up for that purpose. The remains of the richest Ethiopians were thus honoured. The bodies of those of the next class were contained in silver statues ; the poor were enshrined in statues of earthenware. Herodotus informs us, that the nearest relations of the dead kept the body a year in their houses; and offered sacrifices and fruits during that time to their deceased friend; and at the end of the year they fixed the niche in a place set apart for the purpose near their town. The inhabitants of the country of Meroe had various methods of paying respect to their deceased friends. Some threw their bodies into the river, thinking that the most honourable sepulchre. Other's kept them in their houses in niches, thinking that their children would be stimulated to virtuous deeds by the sight of their ancestors; and that grown people, by the same object, would retain their parents in their memories. Others put their dead bodies into coffins of earthenware, and buried them near their temples. To swear with their hand laid upon a corpse, was their most sacred and inviolable oath.

\section{Ancient Customs Respecting Coffins.}

THE sepulchral honours paid to the manes of departed friends, in ancient times, are curious, and worthy of attention, Being put into a coffin, was considered a mark of the highest distinction. With us, the poorest people have their coffins. If the relations cannot afford them, the parish is at the expense. On the contrary, in the east they are not at all made use of in our times. Turks and Christians, as Thevenot assures us, agree in this. The ancient Jews seem to have buried their dead in the same manner; neither was the body of our Lord, it should seem, put into a coffin: nor that of Elisha, whose bones were touched by the corpse that was let down a little after into his sepulchre. However, that they were anciently made use of in Egypt, all agree; and antique coffius of stone and sycamore wood are still to be seen in that eountry, not to mention those said to be made of a kind of pasteboard, formed by folding or glueing cloth together a good many times, curiously plastered, and then painted with hieroglyphics. 
Its being an ancient Egyptian custom, and not practised in the neighbouring countries, was doubtless the cause that the sacred his. turian expressiy observes of Joseph, that he was not only embalmed, but put into a coffin too, both these being practices peculiar to the Egyptians. Bishop Patrick, in his commentary on this passage, takes notice of these Egyptian coffins of sycamore wood and of pasteboard; but he does not mention the contrary usage in the neighbouring countries, which was requisite, one might suppose, in order fully to illus. trate the passage; but even this perhaps would not have conveyed the whole idea of the sacred author. Maillet apprehends that all were not enclosed in coffins who were laid in the Egyptian repositories of the dead; but that it was an honour appropriated to persous of figure. Hence, after having given an account of several niches found in those chambers of death, he proceeds, "But it must not be imagined that the bodies deposited in these gloomy apartments were all enclosed in chests, and placed in niches. The greatest part were simply embalned and swathed after that manner which every one has some notion of ; after which they laid them one by the side of another without any ceremony. Some were even laid in these tombs without any embalming at all; or such a slight one, that there remains nothing of them in the linen in which they were wrapped, but the bones, and those half rotten. It is probable that each considerable family had one of these burial places, that the niches were designed for the bodies of the heads of the families; and that those of their domestics or slaves had no other care taken of them, than the laying them on the ground, after having been embalmed, or without that, which without doubt was all that was done even to the heads of families of less distinction." After this, he gives an account of a way of burial, practised anciently in that country, which had been but lately discovered, and which consisted in placing the bodies, after they were swathed, upon a layer of charcoal, and covering them with a mat, under a depth of sand of seven or eight feet.

That coffins then were not universally used in Egypt, is undoubtedly proved from those accounts, and probably they were only persons of distinction who were buried in them. It is also reasonable to believe, that in times so remote as that of Joseph, they night not be less common than afterwards; and consequently that Joseph's being put in a coffin in Egypt, might be mentioned with a design to express the great honours which the Egyptians did him at his death, as well as in life, he being interred after the most sumptuous manner of the Egyptians, - embalmed, and put into a coffin. Agreeable to this, the Septuagint version, which was made for Egyptians, seems to represent coffins as a mark of grandeur.

It is no objection to this account, that the widow of Nain is represented as carried forth to be buried on a bier, for the present inhabitants of the Levant, who are well known to lay their dead bodies on the earth unenclosed, carry them frequently out to burial in a kind of coffin. So Dr. Russel, in particular, describes the bier used for the Turks at Aleppo, as a kind of coffin much in the form of ours, only that the lid rises with a ledge in the middle. Christians indeed, he tells us, are carried to the grave on an open bier; but as the most common 
kind of bier resembles our cofins, that used by the people of Nain might possibly be of the same kind.

\section{Funeral Rites anong tie a nCien't Jews.}

WHEN any person was dead, his relations and friends rent their clothes, which custom is but faintly imitated by the modern Jews, who only cut off a bit of their garment, in token of affection. It was usual to bend the dead person's thumb into the hand, and fasten it in that posture with a string; because the thumb then having the figure of the name of God, they thought the devil would not dare to approach it. . When they came to the burying-place, they made a speech to the dead, in the following terms: "Blessed be God, who had formed thee, fed thee, and maintained thee, and taken away thy life. $O$ dead the knows your numbers, and shall one day restore your life, \&c. Then they spake the eulogium or funeral oration of the deceased, after which they said a prayer, called " the righteousness of judgment;" then turning the face of the deceased towards heaven, they called out, "Go in peace."

\section{BURYING ALIVE.}

THIs was the punishment of a vestal who had violated her vow of virginity. The unhappy priestess was let down into a deep pit, with bread, water, milk, oil, a lamp burning, and a bed to lie on. "But this was only for show; for, the moment she was let down, they began to cast in the earth upon her till the pit was filled up. Some midrle-age writers seem to make burying alive the punishment of a woman-thief: This barbarous custom has even been used in Scotland under the feudal tyranny. Mr. Matheson, minister of Kilmuir Easter, in Rossshire, mentions, that, in the year $\mathbf{1 7 5 1}$, as labourers were digging a bank of earth near Miln-town, they found a human skeleton sitting in an erect posture, on a seat seemingly made for that purpose. Many credible per'sons authenticate this as a fact known to themselves. Tradition says, that several persons have been buried alive, in this and the neighbouring parish, by the direction of a cruel and arbitrary landlord, who was proprietor of these lands in the beginning of the last century." Lord Bacon gives instances of the resurrection of persons who have been buried alive. The famous Duns Scotus is of the number, who having been seized by a catalepsis, was thought dead, and laid to sleep aniong his fathers, but raised again by his servants, in whose absence he had been buried. 'Bartholin gives an account of a woman, who, on recovering from an apoplexy, could not beliève but that she was dead, and solicited so long and so earnestly to be buried, that they were forced to comply, and performed the ceremony at least in appearance. The famous emperor Charles V. after his abdication, took it into his head to have his burial celebrated in his lifetime, and assisted at it.

\section{Ancient Tombs.}

IN many nations it has been customary to burn the bodies of the dead, and to collect the ashes with pious care into an urn, which was 
deposited in a tomb or sepulchie. Anong many nations it has also been the practice to lay the dead body in a tomb without consuming. it, after having wrapped it up decently, and sometimes placed it in a coffin. The tombs of the Jews were generally hollow places hewh out of a solid rock. The Egyptians also buried their dead in caves, called catacombs. The pyramids, as some think, were also employed for the same purpose. Sometimes also, after embalming their dead, they placed them in niches in some magnificent apartment in their houses.

\section{Persian Tombs.}

A tomb of the Persians is a circular building, open at top, about fifty-five feet in diameter, and twenty-five feet in height, filled to within tive feet of the top, except a well of 15 feet in the centre. The part so filled is terraced, with a slight declivity toward the well. "Two clicular grooves, three inches deep, are raised roind the well, the first at the distance of four, the second at ten feet from it. Grooves of the like depth or height, and four feet distant from each other at the outer part of the outer circle, are carried straight from the wall to the well, communicating with the circular ones, for the purpose of carrying off the water, \&c. The tomb is thus divided into three circles of partitions; the outer, about seven feet by four ; the middle six by three; the inner, four by two; the outer for the men, the middle for the women, the inner for the children; in which the bodies are lespectively placed, wrapped loosely in a cloth, and left to be devoured by the vultures, which is very soon done. The friends of the deceased come at the proper time, and throw the bones into the well. The entrance is closed by an iron door, four feet square, on the eastern side, as high up as the terrace, to which a road is raised. Upon the wall, above the door, an aditional wall is raised, to prevent people from looking into the tomb, which the Persees are particularly careful to prevent. A Persian inscription is on a stone inserted over the door. From the bottom of the wall subterraneous passages are conducted," in order to receive the bones, \&zc. and prevent the well from filling.

Russian Tombs.

Of the ancient sepulchres found in Russia and Siberia, some are perfect tumuli, raised to an enormous height, while others are almost level with the ground. Some of them are encompassed with a square wall of large quarry stones placed in an erect position; others are covered only with a small heap of stones, or they are tumuli adorned with stones at top. Some are walled with brick within, and vaulted over; others are no more than pits or common graves. In some the earth is excavated several fathoms deep; others, and especially those which are topped by a lofty tumulus, are only dug of a sufficient depth for covering the carcase. Urns are never met with here; but sometimes what remained of the bodies after the combustion, and even whole carcases, are found wrapped up. in thin plates of gold.

\section{Turkish and Moorish Tombs.}

The Moors hold it an irreverent thing to bury their dead in mosques. The buitial grounds of all Mahometans are mostly without the city, 
and they inter the dead at the hour set apart for prayer. Their tombs are exceedingly simple, and have no pretensions to architectural elegance. Among the northern nations, it was customary to bury their dead under heaps of stones called cairns, of under barrows. The inhabitants of Thibet, it is said, neither bury nor burn their dead, but expose them on the tops of the mountains.

xig

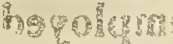

Socia L Custom.

Colonel GaEnBER ascribes the following custom to the subjects of an Asiatic prince. "Whenever the prince has a son, he is carried round from village to village, and alternately suckled by every womar. who has a child at her breast, until he is weaned. This custom, by establishing a kind of brotherhond between the prince and his subjects, singularly endears them to each other."

\section{ABJURATION.}

IN the ancient English customs, abjuration is an oath taken by a person guilty of felony; who, having thed to a place of sanctuary, engages to leave the kingdom for ever. The following passage will furnish a curious illustration of this subject. "This heare thou Sir Coroner, that $I, M$. of $H$. am a robber of sheep or any other beast, and a nurderer of one or of none, and a fellow of our lord the king of England, and because I have done many such euilles or robberies in his land, I I do abjure the land of our lord Edward king of England, and I shall haste me towards the port of (such a place), which thou hast given me, and that I shall not go out of the high way, and if I doe, I will that I be taken as a robber and a felon of our lorde the king. And that at such a place I will diligently seeke for passage, and I will tarrie there but one flood and ebbe, if I can have passage; and unlesse I can have it in such a place, I will goe every day into the sea up to my knees, assaying to pass over, and unlesse I can do this within fortie days, I will put myselfe again into the church, as a robber and a felon of our lord the king: so God me helpe and his holy judgment, \&c." Rastall's Collect. of Stat. p. 2.

$\operatorname{brg} 6 e^{\circ}$

Punishants of Adutery.

THIs crime has been punished in many ages and nations, though with different degrees of severity. In many it has been capital, in others venial, and only attended with slight pecuniary mulcts. Some of the penalties are serious, and even cruel; others of a jocose and humorous kind. Even contrary laws have been enacted as punishments for adultery. By some, the criminals were forbid marrying, in case they became single; by others, they were forbid to marry any besides each other; by some, they have been incapacitated from ever comnitting the like crime again. Among the Egyptians, adultery in the man was punished by one thousand lashes with rods, and in the woman by the loss of her nose. Among the rich $G$ reeks, adulterers were allowed to redeem themselves bv a pecuniary fine; the woman's 
father in such cases returned the dower he had received from her husband, which some think was refunded by the adulterc. Another punishment among those people was, putting out the eyes of the adulterers. At Gortyn in Crete, adulterers were covered with wool, an emblem of the softness and effeminacy of their disposition, and in that dress carried through the city to the magistrate's house, who sentenced them to ignominy, whereby they were deprived of all their privileges, and their share in administering the laws, or being employed in any public business.

There are various conjectures concerning the ancient punishment of adultery among the Romans. Some will have it to have been made capital by a law of the Romans, and again by the twelve tables. Others, that it was made capital by Augustus ; and others, not before the emperor Constantine. The truth is, the punishments in early ages were very various, much being left to the discretion of the husband and partners of the adulterous wife; who exercised it differently, rather: with the silence and countenance of the magistrate, than by any formal authority from him. Thus we are told, the wife's father was allowed to kill both parties when caught in the fact, provided he did it inmediately, killed both together, and as it were with one blow. The same power ordinarily was not indulged the husband, except the crime was committed with some mean and infamous person; though in other cases, if his rage carried hin to put them to death, he was not punished as a nurderer. On many occasions, however, revenge was not carried so far, but mutilating, cutting off the ears, nose, \&c. served the turn.

whe punishment allotted by the Lex Julia, was not, as many have imagined, death, but rather banishment, or being interdicted fire and water, though Octavius appears, in several instances, to have gone beyond his own law, and to have put adulterers to death. Under Mauricus, many were burnt at a stake. Constantine first by law made the crime capital. Under Constantius and Constans, adulterers were burnt, or sewed in sacks and thrown into the sea. Under Leo and Marcian, the penalty was abated to perpetual banishment, of cutting of the nose. Under Justinian, a farther mitigation was granted. at least in favour of the wife, who was only to be scourged, lose her dower, and be shut up in a monastery.: After two years, the husband was at liberty to take her back again; if he refused, she was shaven, and made a uun for life; but it still remained death for the husband. The reason alleged for this difference was, that the woinan is the weaker vessel. Mathreus declaims against the empress Theodora. Who is supposed to have been the cause of this law, as well as of others procured in favour of that sex from the emperor.

By the Jewish law, adultery was punished by death in both parties where either the woman was married, or both. The Jews had a particular method of trying an adulteress, or a woman suspected of the crime, by making her drink the bitter waters of jealousy, which, if she was guilty, made her swell. In Spain they punished adultery in men by amputation of the offending member.

The Saxons formerly burnt the adulteress and over he erected a gibbet, whereon the adulterer was lianged, In this kingdorn 
likewise, adultery, dy the ancient laws, was severely punished. King Edmund ordered adultery to be punished in the same manner as homicide; and Canute ordered that a man who committed adultery should be banished, and that the woman should have her nose and ears cut off In the time of Henry I. it was punished with the loss of eyes, and mutilation. Among the Mingrelians, according to Char. din, adultery is punished with the forfeiture of a hog, which is usually eaten in good friendship between the gallant, the adulteress, and the injured party.

Among the Japanese, and divers other nations, adultery is only penal in the woman. Among the Abyssinians, the crime of the husband is said to be only punished on the innocent wife. In the Marian islands, on the contrary, the woman is not punishable for adultery, but if the man go astray, he pays severely : the wife and her relations waste his lands, turn him out of his house, \&cc. Among the Chinese, there is reason to conclude that adultery is not capital, for it is said that fond parents will make a contract for their daughter's future husband to allow them this indulgence.

In Britain, adultery is reckoned a spiritual offence, and is cognizable by the spiritual courts, where it is punished by fine and penance. The common law takes no farther notice of it, than to allow the party aggrieved an action and damages. This practice is often censured by foreigners, as making too light of a crime, the bad consequences of which, public as well as private, are very great. It has been answered, that perhaps this penalty, by civil actions, is more wisely calculated to prevent the frequency of the offence, which ought to be the end of all laws, than a severer punishment. He that by a judgment of law is, according to circumstances, stripped of a great part of his fortune, thrown into prison till he can pay it, or forced to fy his country, will, no doubt, in most cases, own that he pays dearly for his crime.

\section{IMPROVEMENT OF THE STATE OF WOMEN.}

For the presentimproved state of the fair sex, and, in consequence thereof, of society in general, modern Europeans are indebted to our Gothic ancestors. Women, among the ancient Greeks and Romans, seem to have been considered merely as objects of sensuality, or of domestic conveniency; they were devoted to a state of seclusion and obscurity, had few attentions paid them, and were permitted to take as little share in the conversation, as in the general commerce of life. But the northern nations, who paid a kind of devotion to the softer sex, even in their native forests, had no sooner settled themselves in the provinces of the Roman empire, than the female character began to assume new consequence. Those fierce barbarians, who seem to hare thirsted only for blood, always forbore to offer any violence to the women. They brought along with them the respectful gallantry of the north, which had power to restrain their savage ferocity; and they introduced into the west of Europe a generosity of sentiment, and a complaisance towards the ladies, to which the most polished nations of antiquity were strangers. These sentiments of generous gallantry were fostered by the institution of chivalry, which lifted women yet 
higher in the scale of tife. Instead of being nobody in society, she became its primum mobile. "Every knight devotiug himself to danger, declared bimself the humble servant of some lady, who was often the object of his love. Her honour was supposed to be intimately connected with his, and her smile was the reward of his valour; for her he attacked, for her he defended, and for her he shed his blood. Courage animated by so powerful a motive, lost sight of every thing but enterprize; incredible toils were cheerfully endu red, incredible actions were performed, and adventures seemingly fabulous were realized. The effect was reciprocal. Women, proud of their influence, became worthy of the heroism which they had inspired; they were not to be approached but by the high-minded and the brave; and men then could only be admitted to the bosom of the chaste fair, after proving their fidelity and affection by years of perseverance and of peril.

biAgain, as to the change which took place in the operations of war, it may be observed, that the perfect hero of antiquity was superior to fear, but he made use of every artifice to annoy his enemy; impelled by animosity and hostile passion, like the savage in the American woods, he was only anxious of attaining his end, without regarding whether fraud or force were the means. But the true knight, or modern hero of the middle ages, who seems in all his rencounters to have had his eye on the judicial combat, or judgment of God, had an equal contempt for stratagem and danger. He disdained to take advantage of his enemy, he desired only to see him, and to combat him on equal terms, trusting that Heaven would declare in behalf of the just; and as be professed to vindicate the cause of religion, of injured beauty, or oppressed innocence, he was further confirmed in his enthusiastic opinion by his own heated imagination. Strongly persuaded that the decision must be in his favour, he fought as if rather under the influence of divine inspiration, than of military ardour. Thus the system of chivalry, by a singular combination of manners, blended the heroic and sanctified characters, united devotion and valour, zeal and gallantry, and reconciled the love of God and of the ladies.

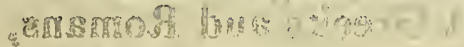

Abaris, tIE HYPERBorean.

Trirs person was a celebrated sage of antiquity, of whom a great number of fabulous stories are told; such as, that he got a present of a miraculous arrow from Apollo, with which he travelled without taking food; that he could foretell earthquakes, allay tempests, drive away the pestilence, \&c. \&c. Harpocratian tells us that the whole earth being infected with a dreadful plague, A pollo ordered that the Athenians should offer up prayers in behalf of all other nations; upon which, ambassadors were sent to Athens, from different countries. Among these was Abaris, who during this journey renewed the alliance between his countrynen, and the inhabitants of the isle of Delos. He also went to Lacedemon, where he built a temple to Proserpine the Salutary. The history and travels of Abaris have given occasion 
for much learned discussion. Mr. Toland makes it appear not improbable that he was a Scotchman. "If, says he", ro the Hebrides, or Western Isles of Scotland, were the Hypeiboreans of Diodorus, then the cele. buted Abaris was of that country, and likewise a druid, having been the priest of Apollo." Suidas and some others make him a Scythian, though Diodorus has fixed his country in all island, and not on the continent. All agree, however, that he travelled over Greece, and thence into Italy; and that he conversed familiarly with Pythagoras, who favoured him beyond all his other disciples. Hirnerius, the Sophist, who applauds him for speaking pure Greek, describes his person accurately, and gives him a good character. "He came, says he, "to Athens, holding a bow in his hand, having a quiver hanging over his shoulders, his body wrapt up in a plaid, girt about the loins with a gilded belt, and wearing trowsers reaching from his waist downwards." By this is evident, says Mr. Toland, that he was not habited like the Scythians, who were always covered with skins, but in the native garb of an aboriginal Scot. "Hirnerius adds, that he was affable, discreet, industrious, quick-sighted, circumspect, a searcher after wisdom, desirous of friendship, trusting little to fortune, and braving every thing trusted to him for his prudence." Suidas reports, that he wrote several books, viz. Apollo's Arrival in the Country of the Hyperboreans; the Nuptials of the River Hebrus ; the Generation of the Gods; a Collection of Oracles, \&c.

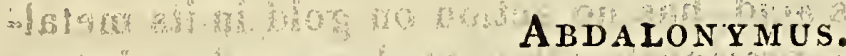

Turs was a person of the royal line of Sidon, who, though descended from king Cyniras, was contented to live in obscurity, and get his subsistence by cultivating a garden, while Strato was in possession of the crown of Sidon. Alexander the Great having deposed Strato, inquired whether any of the race of Cyniras was living, that he might set him on the throne. It was generally thought that the whole race was extinct; but at last Abdalonymus was thonght of, and mentioned to Alexander, who immediately urdered some of his soldiers to fetch hin. They found the good man at work, happy in his poverty, and entirely a stranger to the noise of arms, with which all Asia was at that time disturbed; and they could scarcely persuade him they were in earnest. Alexander was convinced of his high descent by the dignity that appeared in his person, but was desirous of learning from him in what manner he bore his poverty. "I wish," said Abdalonymus, "I may bear my new condition as well. These hands have supplied my necessities; I have had nothing, and I have wanted nothing." This answer pleased Alexander so much, that besides giving him all that was Strato's, he augmented his dominions, and gave him a large present out of the Persian spoils.

\section{ST. JANUARIUS.}

THIs is the patron saint of Naples, where his head is occasionally carried in procession, in order to stop the eruptions of Vesuvius.The liquefaction of his blood is a famous miracle at Naples. The saint suffered martyrdom about the end of the third century. 2 When 
he was beheaded, a pious lady of Naples caught about one ounce of his blood, which, tradition says, has been carefully preserved in a bottle ever since, without ever having lost a single grain of its weight? This, of itself, were it demonstrable, might be considered as a gieater miracle than the circumstance on which the Neapolitans lay the whole stress, viz. that the blood, which bas congealed, and acquired a solid form by age, is no sooner brought near the head of the saint, than, as a mark of veneration, it liquefies. This experiment is made thrice a year, and is esteemed by the Neapolitans as a miracle of the first magnitude. The substance in the bottle, which is exhibited for the blood of the saint, is supposed to be something naturally solid, but which melts with a small degree of heat. When first broight out of the cold chapel, it is in its solid state; but when brought before the saint by the priest, and rubbed between his warm hands, and breathed upon for some tine, it melts; and this is the whole mystery. The head and blood of the saint are kept in a kind of press, with folding doors of silver, in the chapel of St. Januarius, belonging to the cathedral church. The real head is probably not so fresh and well preserved as the blood; on that account it is not exposed to the eyes of the public, but is enclosed in a large silver bust, gilt and enriched with jewels of high value This being what is visible to the people, their ideas of the saint's fentures and cumplexion are taken entirely from the bust. The blood is kept in a small repository by itself. The chemical process for performing this pretended miracle is by muriatic acid. Though this acid has no action on gold in its metallic state, yet if the metal is previously attenuated or reduced to a calx, either by precipitation from aqua regia, or by calcination in mixture with calcinable netals, this acid will perfectly dissolve it, and keep it in solution. This solution is of a yellow colour, gives a purple stain to the skin, bones, and other solid parts of aninals, and strikes a red colour with tin. In distillation, the nitrous acid arises and the muriatic acid remains, combined with the gold, in a blood-red mass, soluble in spirit of wine. If towards the end of the distillation the fire is hastily raised, part of the gold distils in a high saffroncoloured liquor, and part sublimes into the neck of the retort, in clusters of long slender crystals of a deep red colour, fusible in a swall heat, deliquating in the air, and easily soluble in water. By repetitions of this process, the whole of the gold nay be elevated, excepta small quantity of white powder, whose nature is unknown. This red sublimate of gold being easily fusible by the heat of one's hand, is exhibited by the priest for St. Januarius's blood. The French are said, in their first invasion of Naples, during the revolutionary furor, to have thrown the bottle into the bay ; but it found its way a gain to the priests, and the French no longer disputed the reality of the miracle, because they derived advantage from the continuance of the popular delusion.

\section{ST. DUNSTAN.}

THIs was a famous archbishop of Canterbury, of whom the monkish historians give us the following acconnt. He was descended from 
noble family in Wessex, and educated in the abbey of Glastonbury. Here he studied so hard, that it threw him into a violent fever, which brought him to the very point of death. When the whole family were standing about his bed, dissolved in tears, and expecting every moment to see him expire, an angel came from heaven in a very dreadful storm, and gave him a medicine, which restored him to perfect health in a moment. Dunstan immediately started from his bed, and ran with all his speed towards the church, to return thanks for his recovery: but the devil met him by the way, surrounded him by a great multitude of black dogs, and endeavoured to obstruct his passage. This would have frightened some boys; but it had no such effect upon Dunstan; who, pronouncing a sacred name, and brandishing his stick, put the devil and all his dogs to flight. The church-doors being shut, an angel took him in his arms, conveyed him through an opening in the roof, and set him softly down on the floor, where he performed his devotions. After his recovery he pursued his studies with the greatest ardour, and soon became a perfect master in philosophy, divinity, music, painting, writing, sculpture, working in gold, silver, brass, and iron, \&c. When he was still very young, he entered into holy orders, and was introduced by his uncle Athelm, archbishop of Canterbury, to king Athelstan, who, charmed with his person and accomplishments, retained him in his court, and employed him in many great affairs. At leisure hours he used to entertain the king and his courtiers with playing on his harp, or some other musical instrument; and now and then he wrought a miracle, which gained him great admiration.

His old enemy the devil was much offended at this, and prompted some envious courtiers to persuade the king that his favourite was a magician, which that prince too readily believed. Dunstan discovering by the king's countenance that he had lost his favour, and resolving to resign rather than be turned out, retired from court to another uncle, who was bishop of Winchester. This good prelate prevailed upon his nephew to forsake the world, and become a monk; after which he retired to a little cell built against the church-wall of Glastonbury. Here,he slept, studied, prayed, meditated, and sometimes amused hinself with forging several useful things in brass and iron.

One evening, as he was working very busily at his forge, the devil, putting on the appearance of a man, thrust his head in at the window. of his cell, and asked him to make something for him. Dunstan was so intent upon his work, that he nade no answer; on which the devil began to swear and talk obscenely, which betrayed the lurking fiend. The holy blacksmith, putting up a secret ejaculation, pulled his tongs, which were red-hot, nut of the fire, seized the devil with them by the nose, and squeezed him with all his strength, which made his infernal majesty roar and scold at such a rate, that he awakened and terrified all the people for many miles around! Thus far the legend.

Ridiculous as were these fictions, they served, in those times of ignorance, to procure Dunstan a high degree of reputation. It appears that this extraordinary person was recalled to court by king Edward, A. D. 941, who bestowed upon him the rich abbey of Glastonbury, which for his sake he honoured with many peculiar privileges. He 
enjoyed the favour of this prince during his short reign of six years, but he stood much higher in the favour of his brother and successor, ling Edred, to whom he was confessor, chief confidant, and prine ninister. He employed all his influence during this period of court favour, in promoting the interest of the monks of the Benedictine order, to which he belonged, and of which he was a most active and zealous patron. Having the treasures of these two princes, especially of the last, very much at his command, he lavished them away in building and endowing monasteries for these monks, because almost all the monasteries were in possession of secular canons. He persuaded Edred to bestow such immense treasures on the churches and monasteries by his last will, that the crown was stripped of its most valuable possessions, and left in a state of indigence. This conduct of Dinstan rendered him very odious to Edwi; who succeeded his uncle Edred, A. D. 955; and his rude behaviour to himself, and his beloved queen Elgiva, raised the resentment of that prince so high, that he deprived him of all his preferments, and drove him into exile. The banishment of Dunstan was a severe lilow to the nonks, who were expelled from several monasteries; but their sufierings were not of long continuance, for Edgar, the younger brother of Elwi, having raised a successful rebellion against his unhappy brother, and usurped all his dominions on the north side of the Thames, recalled Dunstan, and gave him the bishopric of Worcester, A. D. 95\%. From this time he was the chief confidant and prime minister of king. Edgar, who became sole monarch of England, A. D. 959, by the death of Edwi.

In 960, Dunstan was raised to be archbishop of Canterbury, and being this possessed of the primacy, and assured of the royal support and assistance, he prepared to execute the grand design which he had long meditated, of compelling the secular canons to put away their wives and become monks, or of driving them ont, and introducing Benedictine monks in their room. With this view he procured the promotion of Oswald to the see of Worcester, and of Ethelwald to that of Winchester; two prelates who were monks themselves, and animated with the most ardent zeal for the advanccment of their own order. This triumvirate, by their arts and intrigues, in the course of a very few years filled no fewer than forty-eight monasteries with Benedictines. But on the death of Edgar, in 975, they received a check. The sufferings of the persecuted canons had excited much compassion; and many of the nobility, who had been overawed by the power and zeal of the late king, now espoused their cause, and promoted their restoration. "Elfric duke of Mercia drove the monks by force out of all the monasteries in that extensive province, and brought back the canons, with their wives and children ; while Elfwin duke of East Anglia, and Brithnot duke of Essex, raised their troops to protect the monks in these countries. To allay these commotions, several councils were held ; in which Dunstan was so hard pushed by the secular canons and their friends, that he was obliged to practise some of his holy stratagems; and finally, by dint of miracles; he overcame all opposition. St. Dunstan died A. D. 988, in the sixty-fourth of his age, having held the bishopric of London, together with the archbishopric of Canterbury, about 27 years. 
As this prelate was the great restorer and promoter of the monastic institutions, the grateful monks, who were almost the oniy historians of those dark ages, have loaded him with the most extravagant praises, and represented lim as the greatest wonder-worker, and highest favourite of heaven, that ever lived. To say nothing of his many conflicts with the devil, in which he often belaboured that enemy of mankind most severely, the following short story, which is told with great exultation by his biographer Osborn, will give the reader some idea of the astonishing impudence and impiety of those monks, and of the no less astonishing blindness and credulity of the people.

" The most admirable, the most in estimable Father Dunstan," says, that author, "whose perfections exceed all human imagination, was admitted to behold the Mother of God and his own mother in eternal glory ; for before his death he was carried up into heaven, to be presented at the nuptials of his own mother with the Eternal King, which were celebrated by the angels with the most sweet and joyous songs. When the angels reproached him for his silence on this great occasion, so honourable to his mother, he excused himself on account of his being unacquainted with those sweet and heavenly strains ; but being a little instructed by the angels, he broke out into this melodious song, O King and Ruler of nations, \&c."

It is unnecessary to make any comment on this most shocking story. The violent and too successful zeal of Dunstan and his associates, in promoting the building and endowing so great a number of houses for the entertainment of useless monks and nuns, was very fatal to their country; for a spirit of irrational, unmanly superstition was thus diffused amongst the people, which debased their minds, and diverted them from nobler pursuits; and a great proportion of the lands of England having been put into hands wh.o contributed nothing to its defence, rendered it an easy prey, first to the insulting Danes, and afterwards to the victorious Normans.

\section{JOHN BOCKHOLDT, OR BOCCOLD.}

This person, a memorable example of the force of fanaticism, was a journeyman tailor of Leyden, in the early part of the sixteenth century. Joiuing with Jutin Matthias, a baker of Haerlem, who, like himself, assumed the character of a prophet among the sect of Anabaptists, they fixed their residence at Munster, an imperial city in Westphalia, and einployed themselves with great zeal in propagating their opinions. Their proselytes at length became numerous enough to enable them to make themselves masters of the city, in which they established a new form of government, directed by Matthias as its head, with the uncontrolled power of a prophet inspired by Heaven. This was in 1534; and Matthias sent emissaries to all the sect, inviting them to repair to Munster, as the Mount Sion of true believers, whence they were to proceed to reduce the whole earth to their obedience. Meantime the bishop of Munster, assembling an army, laid siege to the town, and Matthias, in a frantic sally, was slain. Boccold succeeded him in the prophetic authority, and, being a more cautious man in action, be contented himself with carrying on 
a defensive war. He was, however, still more of an enthusiast than his predecessor, as he soon proved by extraordinary proceedings. He marched naked through tle streets, proclaiming that the kingdom of God was at hand, when whatever was highest on earth should be brought low, and whatever was lowest should be exalted. In consequence, he commanded the churches, as well as the highest buildings in the city, to be levelled with the ground; and he deprived Cuiperdoling, the most considerable proselyte, of the consulship to which he had been raised, and even made him perform the office of common executioner.

Following the abrogated obligation of the Jewish legislature, he appointed twelve judges, in analogy to the twelve tribes of Israel, reserving to himself the divine authority of the Moses of this new legislature. Not content, however, with this degree of supremacy, he producedia prophet, to declare it to be the will of God that John Boccold should be the king of Sion, and sit on the throne of David; and he was installed in this new dignity with the greatest pompand solemnity. As he was amply furnished with the warmth of constitution ordinarily accompanying fanaticism, his next step was to direct the teachers of the sect to preach up a plurality of wives, as one of the privileges of the saints; and he soon brought it to practice by marrying three wives at once, one of them the beautiful widow of Matthias, whom alone he permitted to share with him the h.onours of royalty. As his passions became more ardent by indulgence, he increased the number of his wives to fourteen; and the example of his licentiousness being readily adopted, the most unbounded profligacy in this respect immediately; took place, so that every female who could by any latitude be deemed marriageable in Munster, was obliged to submit to a fugitive union.

She siege, in the mean time, was drawn closer about the town, no succours arrived, and scarcity began to be sensibly felt. Yet such was the ascendency Boccold had acquired over the mind of his followers, by his confident promises and predictions, that the multitude retained their expectations of deliverance, and never admitted the idea of surrender. Indeed, any token of an inclination of this kind was punished with instant death ; and no one used the sword of allthority with more rigour than the king of Munster. One of his wives having presumed to utter some doubts concerning his divine mission, he assembled the whole flock of them, and, causing the heretic to kneel down in the midst, he struck of her head with his own hands, while the rest danced in frantic joy round the bleeding corpse of their companion. At"length, all the horrors of famine pressed on the unfortunate people of Munster, who still refused to capitulate. But a deserter having pointed out a weak place in the walls, they were scaled by a party, and the rest of the army was admitted. The Ana: baptists defended themselves in the market-place with desperate valour till most of them were killed. Boccold was taken alive; and it was thought proper treatment to carry him loaded with irons from town to town, by way of spectacle, exposing him to all the insults of the populace. He bore those indignities with an unbroken spirir, and sill adhered to all the tenets of his sect. He was brought back 
to Munster, and there put to death under the most exquisite torments, which he endured with astonishing fortitude. He finished his extraordinary course when only twenty-six years of age. adt haseg way

$=925 \sin$

BERNARD GrLPIN.

THIs excellent parish priest was distinguished among his contemporaries by the title of, the Apostle of the North. He was descended from an ancient and honourable family in Westmoreland, and horn in 1517. Being bred in the Roman Catholic religion, he for some time defended it, and held a disputation with Hooper, afterwards bishop of Worcester, and martyr for the Protestant faith; but was foiled in another dispute, with Peter Martyr, and began seriously to examine the contested points. "Being presented to the vicarage of Norton in Durham, he resigned it, and went abroad to consult eminent professors on both sides; and after three years' absence, returned a little before the death of queen Mary, satisfied in the doctrines of the Reformation. He was kindly received by his uncle, Dr. Tonstal, bishop of Durham; who soon after gave him the archileaconry of Durham, and rectory of Effington. Though the persecution was then at its height, he boldly preached against the vices, errors, and corruptions of the times, especially in the clergy, on which a charge, consisting of thirteen articles, was drawn up against him, and presented to the bishop. But Dr. Tonstal dismissed the cause in such a manner as to protect his nephew without endangering himself, and soon after presented him to the rich living of Houghton-le-Spring. He was again accused to the bishop, and again protected; "when his enemies, enraged at this second defeat, laid their complaint before Dr. Bonner, bishop of London, who immediately gave orders to apprehend him. Upon which; Mr. Gilpin bravely prepared for martyrdom, and ordering his steward to provide him a long garment, that he might make a decent appearance at the stake, set out for London. Luckily, however, he broke his leg on the journey, which protracted his arrival until the queen's death.

Being immediately set at liberty, he returlied to Houghton, where he was received by his parishioners with the sincerest joy. Upon the deprivation of the Popish bishops, he was offered the see of Carlisle, which he declined; and confining his attention to his rectory, discharged all the duties of his function in the most exemplary manner. He was not satisfied with the advice he gave in public, but used to instruct in private, and made his parishioners come to him with their difficulties. He had a most engaging manner towards those whom he thought well disposed. His very reproof was so conducted, that he seldom gave offence; the becoming gentleness with which it was urged; making it always appear as the effect of friendship. By these means, in a few years he made a great change in his neighbourlood, and gave evidence what reformation a single man may effect, when he has it at lieart. He was particularly anxious to improve the minds of the younger part of his flock; pressing them to mix religion with their labours, and, anidst the cares of this life, to have a constant eye upon the next. He attended to every thing that might be 
of service to his parishioners, and was very assiduous in preventing lawsuits. His hall was said to have been often thronged with people, who came to him about their differences. Though little acquainted with law, he decided equitably, and that satisfied; nor could the royal conmission have given him more weight than his own character had given him. His hospitable manner of living was the admiration of the whole country. He spent in his family every fortnight forty bushels of corn, twenty bushels of malt, and a whole ox, besides a proportionable quantity of other provisions. Strangers and travellers found a cheerful reception. All were welcome that came, and even their beasts had so much care taken of them, that it was said, "If a horse was turned loose in any part of the country, it would immediately make its way to the rector of Houghton." Every Sunday from Michaelmas to Easter was a public day to him. During this season he wished to see all his parishioners and their families. For this reception he had three tables well covered ; the first for gentlemen, the second for husbandmen, and the third for day-labourers. This piece of hospitality he never omitted, even when loss, or scarcity of provisions, made its continuance rather difficult. When he was absent from home, no alteration was made in his family expenses; the poor were fed, and his neighbours entertained, as usual.

Notwithstanding the extent of his parish, Mr. Gilpin thought the sphere of his benevolence too confined. It grieved him to see every where in the parishes around him so great a degree of ignorance and superstition, occasioned by the negligence of the clergy in those parts. To supply, as far as he could, what was wanting in others, every yea he regularly visited the most neglected parishes in Northumberland Yorkshire, Cheshire, Westmoreland, and Cumberland; and that his own parish in the mean time might not suffer, he was at the expense of a constant assistant. In each place he stayed two or three days, called the people around him, and laid before them the danger of leading wicked or careless lives, instructing them in the duties they "owed to God, their neighbour, and themselves; and shewing them how greatly a moral and religious conduct would contribute to their present as well as future happiness. As he had all the warnith of an enthusiast, though under a very calm judgment, he never wanted an audience, even in the wildest parts; where he roused many to a sense of religion, who had contracted the nost inveterate habits of inattention to every thing serious. And wherever he came, he used to visit all the gaols, few in the kingdom having then an appointed minister. By his labours, and affectionate manner of behaving, he is said to have reformed many of the most abandoned persons in those places. He employed his interest likewise for criminals, whose cases he thought attended with any hard circumstances, and often procured pardons for them.

There are two tracts upon the borders of Northumberland, called Redesdale, and Tyuedale, of all barbarous places in the north, at that time the most barbarous. Before the union, these places were called the Debatable land, subject by turns to England and Scotland, and the common theatre where the two nations acted their bloody scenes. They were inhabited by a kind of desperate banditti, rendered 
fierce and active by constant alarms; who lived by theft on both sides of the barrier; and what they plundered on one side, they exposed to sale on the other, thus escaping justice on both sides. In this dreadful country, where no man would even travel who could avoid it, Mr. Gilpin never failed to spend some part of every year. He generally chose the Christmas holidays, because he found the people at that time most disengaged, and most easily assembled. He had set places for preaching, which were as regularly attended as the assize towns of a circuit. If he came where there was a church, lie made use of it; if not, of barns or any other large buildings, where great crowds of people were sure to attend him, some for his instructions, and others for his charity. This was a very difficult and laborious employment. The country was so poor, that what provisions he could get, extreme hunger would make palatable. The inclemency of the weatlier, and the badness of the roads through a mountainous country, and at that time covered with snow, exposed him likewise often to great hardships. Sometimes lie was overlaken by the night, the country being in many places desolate for several miles together, and obliged to lodge out in the cold. At such times be made his servant ride about with his horses, whilst he himself on foot used as much exercise as his age, and the fatigues of the preceding day, would permit. All this he cheerfully underwent, esteeming such services well compensated by the advantages which he hoped might accrue from them to his uninstructed fellow-creatures. The disinterested pains he took among this barbarous people, and the good offices he was always ready to do them, drew from them the warmest and sincerest expressions of gratitude. Indeed, he was little less than adored among them, and might have brought the whole country almost to do what he pleased. One instance is related, that shews how greatly le was revered.

"By the carelessness of his servants, his horses were one day stolen. The news was quickly propagated, and every one expressed the highest indignation at the theft. The thief was rejoicing over his prize, when, by the report of the country, he discovered whose horses he had taken. Terrified at what he had done, he instantly came trembling back, confessed the fact, returned the horses, and declared he believed the devil would have seized him directly, had he carried them off, knowing them to have been Mr Gilpin's."

The value of Mr. Gilpin's rectory was about 4001 . a year' an income indeed at that time considerable, but yet in appearance very disproportionate to the generous things he did. Indeed, he could not have done them, unless his frugality had been equal to his generosity. His friends, therefore, could not but wonder to find him, amidst his great and continual expenses, purpose to build and endow a grammar school; a design, however, which his exact economy soon enabled him to accomplish, though the expense of it amounted to upwards of 5001. His school was no sooner opened than it began to flourish, and there was so great a resort of young people to it, that the town was soon not able to accommodate them. He put himself then to the inconvenience of fitting up a part of his own house for that purpose, where he seldom had fewer than twenty or thirty children. Some of 
these were the sons of persons of distinction, whom he boarded at 9 easy rates; but the greater part were poor children, whom ${ }^{3}$ not only educated, but clothed and maintained. $H e^{\text {was }}$ at the expense likewise of boarding iil the town many other poor children. He used to bring several every year from the different places where he preached, particularly Redesdale and Tynedale. As to his school, he not only placed able masters in it, whom he procured from Oxford, but himself likewise constantly inspected it. To encourage and quicken the application of his boys, he always took particular notice of the most forward; he called them his own scholars, and sent for them often into his study, to instruct them himself. When he met a por boy upon the road, he made trial of his capacity by a few questions; and if the answers pleased him, he provided for his education. Besides those whom he sent from his own school to the universities, and there wholly maintained, he likewise gave to others, who were in circumstances to do something for themselves, what farther assistance they needed. By these means he induced many parents to allow their children a liberal education, who otherwise would not have done it.

Nor did he think it enough to afford the means only of an academical education to these young people, but endeavoured to make it as beneficial to them as he could. With this view he held a punctual correspondence with the tutors; and made the youths frequently write to him, and give him an account of their studies. And once every other year he made a journey to the university, to inspect their behaviour. This uncommon care was not fruitless; for many of his scholar's became ornaments to the church, and exemplary instances of piety. Every Thursday throughout the year, a very large quantity of meat was dressed, wholly for the poor, and every day they had what quantity of broth they wanted. Twenty-four of the poorest were his constant pensioners. Four times in the year a dinner was prepared for them ; when they received from his stew. ard a certain quantity of corn and a sum of money, and at Christmas they had always an ox divided among them. In his walks abroad, he often brought home with him poor people, and sent them away clothed as well as fed. He took great pains to inform hinself of the circumstances of his neighbours, that the nodesty of the sufferer might not prevent his relief.

But the money best laid out was, in his opinion, that which encouraged industry. It was one of his greatest pleasures to make up the loss of his laborious neighbours, and prevent their sinking under them. If a poor man had lost a beast, he would send him another; if a farmer had a bad year, he would make him an abatement in his tithes. Thus, as far as he was able, he took the misfortunes of his parish upon himself, and, like a true shepherd, exposed himself for his flock. But he was most forward to assist those who had large families; such never failed to meet with his bounty, when they wanted to settle their children in the world. In the distant parishes where he preached, as well as in his own neighbourhood, his generosity and benevolence were continually exercised, particularly in the desolate parts of Northumberland. 
"When he began his journey,"says ain old Ms. life of him, "he would have 10l. in his purse; and at his coming liome, lie would be 20 nobles in debt, which he would always pay within a fortuight after." In the gaols he visited, he was not only careful to give the prisoners proper instructions, bit used to purchase for them likewise what necessaries they wanted. Even upon the public road, he hever let slip an opportunity of doing good. He has often been known to take off his cloak, and give it to a half-naked traveller; and when he had scarcely noney enough in his pocket to provide himself a dinner, yet would he give away part of that little, or the whole, if he found any one who seemed to stand in need of it. One day, returning home, he saw in a field several people crowding together; and judging sonething nore than ordinary had happened, he rode up, and found that one of the horses of a team had sudilenly dropped down dead. The owner of it declaring how grievous a loss it would be to him, Mr. Gilpin bade him not be dislieartened: "lll let roi have," said he, "honest man, that horse of mine," pointing to his servant's. - "Ah ! master," replied the countryman," my pocket will not reach such a beast as that." "Come, come," said Mr. Gilpin, "take him ; and when I demand my money, then thou shalt pay ne." This excellent divine, who deservedly obtained the glorious titles of the Father of the Poor, and the Apostle of the North, died in 1583, in the 60 th year of his age.

\section{Pope Srxtus V.}

Tis singular character was born 13 th of December, 1521 , in La Marca, a village in the seigniory of Montalto. His father, Francis Pereth, was a gardener, and his mother-a servant maid. He was their eldest child, and was called Felix. At the age of nine he was hired out to an inhabitant of the village, to keep sheep; but disobliging his master, he was degraded to the keeper of the hogs. He was engaged in this employment, when F. Michael Angelo Selleri, a Franciscan friar, asked the road to Ascoli, where he was going to preach. Young Felix conducted him thither, and struck the father so much with his eagerness for knowledge, that he recommended him to the fraternity to which he had come. Accordingly he was invested with the habit of a lay brother, and placed under the sacristan, to assist in sweeping the church, lighting the candles, and the like, for which he was to be taught the responses, and rudiments of grammar. His progress in learning was so surprising, that at the age of fourteen he was qualified to begin lis noviciate, and was admitted at fifteen to make his profession. He pursued his studies with unwearied assiduity, and was ordained priest in 1545, when he assumed the name of Father Montalto ; soon after, he took his doctor's degree, and was appointed professor of theology at Sienna; where he so effectually recommended himself to cardinal de Carpi, and his secretary Bossins, that they ever remained his steady friends. "Meanwhile the severity and obstinacy of his temper incessantly engaged him in disputes with the monastic brethren. His reputation for eloquence, which was now. spread over Italy, about this time gained him some new friends. 
Among these were the Colouna family, and F. Ghisilieri, by whose recommendation be was appointed inquisitor general at $\mathrm{Y}$ enice, but he exercised that office with so much severity, that he was obliged to flee precipitately from that city. Upon this he went to liome, where he was made procuratol general of his order, and soon after accompanied cardinal Buon. Compagnon into Spain, as a claplain and consultor to the inquisition; where he was treated with great respect.

Pius IV. dying, Father Ghisilieri, or cardinal Alexandrino, succeed d him, under the name of Pius V; and Montalto was immediately invested by the pontiff with new dignities. He was made general of his order, bishop of St. Agatha, raised to the dignity of cardinal, and received a pension. About this time he was employed by the Pope to draw up the bill of excommunication against queen Elizabeth. He began now to look towards the papacy; and, to obtain it, formed and executed a plan of hypocrisy with unparalleled constancy and success. He became humble, patient, and afiable. He changed his dress, his words, and his actions, so completely that his most intimate friends declared him a new man. Never was there such an absolute victory gained over the passions; never was a fictitions character so well maintained, nor the foibles of human nature so artully con. eealed. He had formerly treated his relations with the greatest tenderness, but he now changed his behaviour to them entirely.

When Pius V. died in 1572 , he entered the conclave with the other cardinals, but seemed altogether indifferent about the election, and never left his apartnent, except to his devotion. When cardinal Buon. Compagnon, or Gregory XIII. was elected, Montalto flattered him; but the new pope treated him with the greatest contempt, and deprived him of his pension. He now assumed all the infirmities of old age; his head hung down upon his shoulders; he tottered as he walked, and supported himself on a staff. His voice became feeble, and was often interrupted by a cough, so excedingly severe, that it seemed every moment to threaten his dissolution. He interfered in no public transactions, but spent his whole time in acts of devotion and benevolence. Meantime he constantly employed the ablest spies, who brought him in telligence of every particular.

When Gregory XIII died in 1585 , he entered the conclave with reluctance, and appeared perfectly inilifferent about the event of the election. He joined no party, yet flattered all. He knew that there would be divisions in the conclave, and that when the leaders of the different parties were disappointed in their own views, they often agreed upon the election of some old and infirm cardinal, the brevity of whose life would soon oceasion a new vacaucy. Three cardinals, the leaders of opposite factions being unable to procure the election which each of them wished, unanimously agreed to make choice of Montalto. When they came to acquaint him with their intention, he fell into a violent fit of cough ing, and told him that his reign would last but a few days, and conjured them to take the whole weight of afiairs upon their awn shoulders. The cardinals swallowed the bait, and Montalto was elected. He now pulled off the mask which he had worn for fourteen years. No sooner was his election secured, than he started from his seat, and appeared almost a foot taller than he had done for several years. 
His former complaisance and humility disappeared together with his infirmities, and he now treated all around him with reserve and haughtiness.

The tirst care of Sixtis V. was to correct the abuses, and put a stop to the enormities, daily commited in the Ecclesiastical State. The lenity of Gregory's government had introduced a general licen. tiousness of manners. It had been usual with former popes to release delinquents on the day of their coronation, who therefore voluntarily surrendered themselves prisoners after the election of the pupe. When the governor of Rome and the keeper of St. Angelo waited on his holiness, to know his intention in this particular, he replied, "We have too long seen the prodigious degree of wickedness that reigns in the state, to think of granting pardons. Let the prisoners be brought to a speedy trial, and punished as they deserve, to shew the world that divine Providence has called us to the chairof St. Peter, to reward the good and chastise the wiclied; that we bear not the sword in vain, but are the ministers of God, and a revenger to execute wrath on those that do evil." Accordingly he appointed commissioners to inspect the conduct of judges, displacerl those who were inclined to lenity, and put others of severer dispositions in their room. He offered rewards to any person who could convict them of corruption or partiality. He ordered the syndics of all the towns and signiories to make out a complete list of the disorderly persons within their districts. The syndic of Albano was scourged in the market-place, because he had left his nephew, an incorrigible-hibertine, out of his list. He made laws equally severe and just against robbers and assassins. Adulterers when discovered suffered death; and they who willingly submitted to the prostitution of their wives, a custom then common in Rome, received the same punishment. He was particularly careful of the purity of the female sex, and never forgave those who attempted to debauch them. His execution of justice wás as prompt as his edicts were rigorous.

A Swiss happening to give a Spanish gentleman a blow with his halberd, was struck by him so rudely with a pilgrim's staff, that he expired on the spot. Sixtus inforned the governor of Rome that he was to dine early, and that justice must be executed on the criminal before lie sat down to table. The Spanish ambassador and four cardinals entreated him not to disgrace the gentleman by sufiering him to die on a gibbet, but to order him to be beheaded. "He shall be hanged," replied Sixtus, " but I will alleviate his disgrace by doing him the honour to assist personally at his death." He ordered a gibbet to be erected before his own windows, where he continued sitting during the whole execution.

When Sixtus assended the throne, the whole Ecclesiastical State was infested with bands of robbers, who from their numbers and outrages, were exceedingly formidable; but by his vigorous conduct, he soon extirpated the whole of his banditti. Nor was the vigour of his conduct less conspicuous in his transactions with foreign nations. Before he had been pope two nonths, he quarrelled with Philip II of Spain, Henry III. of France, and Henry king of Navarre. "His intrigues indeed in some measure influenced all the councils of Europe. 
After his accession to the pontificate, he sent for his family to Rome, with orders that they slould ajpear in a decent and modest manner. Accordingly his sister Camilla came thither, accompanied by her daughter and two grand-children. Some cardinals, to pay court to the pope, went out to meet her, and introduced her in a magnificent dress. Sixtus pretended not to know her, and asked two or three times who she was. Her conductors at last found it necessary to carry her to an inu, and strip her of her tinery. When Camilla was again introduced, Sixtus embraced her tenderly, and said, "Now we know indeed it is our sister; nobody shall make a princess of you but'ourselves." He stipulated with lis sister, that she should neither ask any favour in matters of government, nor intercede for criminals, nor interfere in the administration of justice, declaring that such request should meet with a certain refusal. These terms being agreed to, and punctually observed, he made the most ample provision, not only for Camilla, but for all his relations.

This great man was also an encourager of learning. He caused an Italian translation of the Bible to be published, which raised a good deal of discoutent among the Catbolics. When some cardinals reproached him for his conduct in this respect, he replied, "It was published for the benefit of you cardinals who cannot read Latin." He died twenty-seventh of August, 1500, after a reign of little more than five years.

To the indulgence of a disposition naturally severe, all the defects of this wonderful man are to be ascribed. Clemency was a stranger to his bosom; his punishments were often too cruel, and seemed sometimes to border on revenge. But though the conduct of Sixtus seldon excites love, it generally commands our esteem, and sonetimes our admiration. He strenuously defended the cause of the poor, the widlow, and the orphan; he never refused audience to the injured; however wretched or forlorn. He never forgave those magistrates who were convicted of partiality or corruption; nor suffered crimes to pass unpunished, whether committed by the rich or the poor. He was frugal, temperate, sober, and never neglected to reward the smallest favour which had been confered on him before his exaltation. When he mounted the throne, the treasury was not only exhausted, but in debt; at his death it contained five millions of gold. Rome was indebted to him for several of her greatest embellishments, particularly the Vatican library; it was by him, too, that trade was first introduced into the Ecclesiastical State. And he allotted 3000 crowns a year for the redemption of Christian slaves from the Turks.

\section{Theodore Van Cuerenhert.}

THIS very extraordinary man was born at Amsterdam, in 1522. Early in life he travelled into Spain and Portugal. He was a man of science, an engraver, and a good poet. These sister arts he first considered as an amusement only; but in the end he was obliged to have recourse to engraving alone for his support. And though the different studies in which he employed his time, prevented his attachment to his profession from being so close as it ought to have been, 
yet marks of genius appear in his works. They are slight, and executed with the graver alone; but in an open careless style, so as greatly to resemble designs made with a pen. He was established at Haarlem, and there pursuing his favourite studies in liceriture, he learned Latin, and was made secretary to that town, from whence he was sent several times as ambassador to the prince of Orange, to whon he addressed a famons manifesto, which that prince published in 1566. Had he stopped here, it had been well, but he undertook an argument as dangerous as it was absurd. He maintained that al! religions communions were corrupted; and that, without a supernatural mission, accompanied with miracles, no peison had a right to administer in any religious office. He therefore pronounced that man to be unworthy the llame of a Christian, who would enter any place of public worship. He shewed the sincerity of his belief by his practice, for he would not communicate with either Protestant or Papist. His works were published in three vols. folio, in 1630; and though several times imprisoned, and at last sentenced to banishment, yet he did not alter his sentiment. He died at Dergonde in 1590, aged 68. He worked conjointly with the Galles and other artists, from the designs of Martin Hemskirck? The subjects are from the Old and New Testament, and consist chiefly of middling-sized plates lengthwise. He also engraved several subjects from Francis Floris.

\section{JOHN DEE.}

TuIs singular characte: was a great mathematician, and greater enthusiast; the son of Rowland Dee, gentleman sewer to Henry VIII. and grandson to Bedo Dee, standard-bearer to lord de Ferrars at the battle of Tournay : he was born at London, July 13, 1527; and after some time spent at school there, and at Chelmsford in Essex, was sent to John's coliege in Cambridge, where he informs us of his progress in the following words: "Anno 1542 , I was sent by my father, Rowland Dee, to the university of Cambridge, there to begin with logic, and so to proceed in the learning of the good arts and sciences; for I had before been meetly well furnished with understanding in the Latin tongue, I being then somewhat above fifieen years old. In the years $1543,1544,1545$, I was so veliemently bent to study, that for those years I did inviolably keep this order, -only to sleep four hours every night; to allow to meat and drink, and some refreshing after, two hours every day; and of the other eighteen hours, all, except the time of going to and being at divine service, was spent in my studies and learning."

In 1547 he went into the Low Countries, on purpose to converse with Frisius, Mercator, \&c. and other learned men, particularly nıthematicians; and in about eight months after, returned to Cambridge, where, upon the founding of Trinity college by Henry VIII. he was chosen one of the fellows, but his bias was to the study of mathematics and astronomy. He brought over with him from the Low Countries several instruments made by the direction of Frisius, together with a pair of large globes, made by Mercator: and his reputation was very high. His assiduity, however, in making astronomical observations, (in those days always understood to be connected with 
the desire of penetrating into futurity), brought some suspicion upon him; which was so far increased by a very singular act that befell him, as to draw upon him the imputation of a necromancer, which he deserved afterwards more, than now. This afiair happened soon after his removal from St. John's College, and his being chosen one of the fellows of 'Trinity, where he was assigned to be the under reader of the Greek tongue, Mr. Pember being the chief Greek reader then in Trinity college. "Hereupon," says he, "I did set forth, and it was seen of the university, a Greek comedy of Aristophanes, named in Latin, Pax; with the performance of the scarabæus, or beetle; his flying up to Jupiter's palace, witl a man, and a basket of victuals on his back; whereat was great wondering, and many vain reports spread abroad of the means how that was effected.'

Disturbed with these reports, he left England again in 1548 , and went to the university of Louvain; where be distinguished himself so much, that he was visited by the duke of Mantua, by don Lewis de la Cerda, afterwards duke of Medina, and other persons of great rank. While he remained there, Sir William Pickering, who was afterwards a favourite with queen Elizabeth was his pupil; and in the university it is probable, though not certain, that he had the degree of LL.D. conferred upon him. July 1550, he went from thence to Paris, where, in the college of Rheims, he read lectures upon Euclid's Elements with uncommon applause; and very great offers were made him, if he would accept of a professorship in that university. In 1551 he returned to England, was well received by Sir John Cheke, introduced to secretary Cecil, and even to king Edward himself, from whom he received a pension of one hundred crowns a year, which was in 1558 exchanged for a grant of the rectories of Upton upon Severn, and Long Lednam, Lincolnshire.

In the reign of queen Mary, he was for some time very kindly treated; but afterwards came into great trouble, and even in danger of his life. At the very beginning of it, Dee entered into a correspondence with several of the lady Elizabeth's principal servants, while she was at Woodstock and at Milton; which being observed, and the nature of it not known, two informers charged him with practising agaiust the queen's life by enchantments. Upon this he was seized and confined; but being, after several trials, discharged of treason, he was turued over to bishop Bonner, to see if any heresy could be found in him. After a tedious persecution, on August 19, 1555, he was, by order of council, set at liberty, and thought his credit so little hurt by what had happened, that, January 15, 1556, he presented a supplication to queen Mary, for the recovery of ancient writers and monuments. The design was certainly good, and would have been attended with good consequences, had it taken effect; its failure cannot be too deeply regretted, as there was then an opportunity of recovering many of the contents of the monastic libraries dispersed in Edward's time. Dee also appears to have had both the zeal and knowlenge for this undertaking. The original of his supplication, which has often been printed, is still extant in the Cotton library; and we learn from it, that Cicero's famous work, De Republica, was once extant in this kingdom, and perished at Canterbury. 
Upon the accession of queen Elizabeth, at the desire of Lord Robert Didley, afterwards earl of Leicester, he delivered somewhat upon the principles of the ancient astrologers, about the choice of a fit day for the coronation of the queen, from whom he received many promises; nevertheless, his credit at court was not sufficient to overcome the public orlium against him, on the score of magical incantations, which was the true cause of his missing several preferments. He was by this time become an author; but, as we are told, a little unluckily, for his books were such as scarcely any pretended to understand, written upon mysterious subjects, in a very mysterious manner. In the spring of 1564 he went abroad again, to present the book which he dedicated to the then emperor Maximilian, and returned to England the same summer. In 1568, he engaged the earl of Pembroke to present the queen with his Propredumata Aphoristica; and two years after Sir Henry Billingsley's translation of Euclid appeared, with Dee's preface and notes; which did him more honour than all his performances, as furnishing incontestable proofs of a more than ordinary skill in the mathematics.

In 1571 we find him in Lorrain, where, falling dangerously sick, the queen was pleased to send hin two physicians. After his return to England, he settled himself in his house at Mortlake; where he prosecuted his studies with great diligence, and collected a noble library, consisting of four thousand volumes, of which above a fourth part were Mss. a great number of mechanical and mathematical instruments, a collection of seals, and many other curiosities. His books only were valued at 2000 . It was upon his leaving the kingdom in 1583, that the populace, who always believed him to be one who dealt with the devil, broke into his house at Mortlale; where they tore and destroyed many things, and dispersed the rest in such a manner that the greater part of them were irrecoverable.

In 1572 a new star appeared in Cassiopeia's chair, which gave Dee an opportunity of distinguishing himself in his own way. March 1575, queen Elizabeth went to his house, to see his library; but having buried his wife only a few lours before, he could not entertain her in the manner he would have done, nor indeed did she enter the house; but he brought out to her majesty a glass of his, which laad occasioned much discourse, shewed her the properties of it, and explained the causes, in order to wipe off the aspersion under which he had so long laboured, of being a magician. In 1577 a comet appearing, the queen sent for him to Windsor, to consult him upon it, and was pleased with his conversation, and pronised him her royal protection, notwithstanding the vulgar reports to his prejudice. The year after, her majesty being greatly indisposed, Dee was sent abroad to confer with the German physicians upon the nature of her com. planit. The queen, hinting her desire to be thoroughly informed as to her title to conntries discovered in different parts of the globe by subjects of England, Dee applied himself to the task with great vigour, so much so, that October 3,1580 , which was not three weeks after, he presented to the queen, in her garden at Richmond, two large rolls, in which those conntries were geographically described and historically explained; with the addition of all the testimonies and 
authorities necessary to support them, from records, and other authentic vouchers. These she very graciously received and, after dinner, the same day conferred with Dee about thein, in the presence of some of her privy council, and of the lord treasurer Burleigh especially. His next employment, of consequence enough to be remembered, was the reformation of the calendar, which, though it never took effect until the reign of George II. was one of his best performances, and did him great credit.

We cone now to that period of his life by which he has been nost known, though for reasons which have justly relidered him least regarded. He was certainly a man of uncommon parts, learning, and application, and might have distinguished himself in the scientific world, if he had been possessed of solid judgment, but he was very credulous, superstitions, extremely vain, and, we suspect, a litlle roguish ; but we are told that it was his ambition to surpass all men in knowledge, which carried him at length to a desire of knowing beyond the bounds of human faculties. In short, he suffered himself to be deluded into an opinion, that by certain invocations, an intercourse or communication with spirits might be obtained, from whence he promised bimself an insight into the occult sciences. He found a young man, one Edward Kelly, a native of Worcestershire, who was already either rogue or fool enough for his purpose, and readily undertook to assist him, for which he was to pay him fifty pounds per annum. Dec. 2, 1581, they began their incantations, in consequence of which, Kelly was, by the inspection of a certain table, consecrated for that purpose with many superstitions ceremonies, enabled to acquaint Dee with what the spirit thonght fit to show and discorer. These conferences were contiused for about two years, and the subjects of them were committed to writing, but never published, though still preseried in Ashmole's museum.

In the mean time, there came ovcr hither a Polish lord, one Albert Laski, palatine of Siradia, a man of greát parts and learning and, as a late writer observes, of large fortune too, or he would not have answered their purpose. This nobleman was introduced by the earl of Leicester to Dee, and became his constant visitant. Having himself a bias to those superstitious arts, he was, after much entreaty, received by Dee into their conspany, aid into a participation of their secrets. Within a short time, the palatine of Siradia, returning to his own country, prevailed with Dee and Kelly to accompany him, upon the assurance of an ample provision there; and accordingly they went all privately from Mortlake, in order to embark for Holland, from whence they travelled by land through Germany into Poland, where, Feb. 3, 1584, they arived at the principal castle belonging to Albert Laski. When Laski liad been sufficiently amused with their fanatical pretences to a conversation with spirits, and was perfectly satisfied that they were impostors, he contrived to send them to the emperor Rodolpli II. who, being quickly disgnsted with their impertinence, declined all farther interviews. Upon this, Dee applied himself to Laski, to introduce him to Stephen, king of Poland; which accordingly he did at Cracow, April, 1585. But that prince soon detecting his delusions, and treating him with contempt, he returned to the 
emperor's court at Prague, from whose dominious he was soon banished at the instigation of the pope's nuncio, who gave the emperor to understand how scandalous it appeared to the Christian world, that he should entertain two such magicians as Dee and Kelly; At this time, and while these confederates were reduced to the greatest distress, a young noblenan of great power and fortune in Bohemia, and one of his pupils, gave them shelter in the castle of Trebona; where they not only remained in safety, but lived in splendour, Kelly, having in his possession, as is reported, that philosophical powder of projection, by which they were furnished with money very profusely.: Some jealousies and heart-burnings afterwards happened between Dee and Kelly, that brought on at length an absolute rupture. Kelly, however, who was a younger man than Dee, seems to have acted a much wiser part; since it appears, 'from an entry in Dee's diary, that he was so far intimidated, as to deliver up to Kelly, January, 1589, the powder, about which, it is said, he had learned from the German chemists many secrets which he had not communicated to Dee.

The noise their adventures made in Europe, induced queen Elizabeth to invite Dee home, who in May 1589 set out from Trebona towards England. He travelled with great pomp and solemnity, was attended by a guard of horse, and, besides waggons for his goods, had no less than three coaches for the use of his family; for he had married a second wife, and had several children. He landed at Gavesend Nov. 23 : and Dec. 9; presented himself at Richmond to the queen, who received him very graciously. He then retired to his house at Mortlake; and collecting the remains of his library, which had been toru to pieces and scattered in his absence, he sat down to study. He had great friends, received many presents ; yet nothing, it seenis, could keep him from want. The queen had quickly notice of this, as well as of the vexations he suffered from the common people, who persecuted him as a conjurer, which at that time was not a title equivalent to an impostor. The queen, who certainly listened of tener to him than might have been expected from her good sense, sent him muney from time to time; but all would not do.

At length he resolved to apply in such a manner as to procure some settled subsistence; and accordingly, Nov. 9, 1592, he sent a memorial to her majesty by the countess of Warwick, in which he very earnestly pressed her, that commissioners might be appointed to hear. his pretensions, and to examine into the justness of his wants and claims. This had a good effect, for on the $22 n d$, two commissioners, Sir Thomas Gorge, kuight. and Mr. Secretary Wolley, were actually sent to Mortake, where Dee exhibited a book containing a distinct account of all the memorable transactions of his life, those which occurred in his last journey abroad only excepted; and as he read this historical narration, he produced all the letters, grants, and other evidences, requisite to confirm them, and, where these were wanting, named living.winesses. The title of this work, the original of which still remains in the Cotton library, and a transcript of it among Dr. Smith's written collections, runs thus: "The compendious rehearsal of John Dee, his ditiful declaration and proof of the course and race of his studious life for the space of half an hundred years, 
now by God's favour and help fully'spent; and of the very great injul ries, damages, and indignities, which for these last nine years he fiath in England sustained, contrary to her majesty's very gracious will and express conmandment, made unto the two honourable commis sioners by her most excellent majesty thereto assigned, according to the intent of the most humble supplication of the said John, exhibited to her nost gracious majesty at Hampton-court, ann. 1592, Nov. 9.?

Upon the report made by the commissioners to the queen, he received a present, and promises of preferment " but the promises ending like the former, (in nothing, he engaged his patroness the countess of Warwick, to present another short Latin petition to the queen, but with what success does not appear. In Dccember, 1594, however, he obtained a grant to the chancellorship of St. Paul's. But this did not answer his end: upon which he applied hinself next to Whitgift, archbishop of Canterbury, by a letter, in which he inserted a large account of all the books he had either published or written? and in consequence of this letter, together with other applications, he obtained a grant of the wardenship of Manchester college. Febuary. 1596, he arrived with his wife and family in that town, and was in stalled in his new charge. He continued flere about seven years; which he is said to have spent in a very troblesome and unquie uanner.

June 1604, he presented a petition to king James, earnestly desiring him that he night be brought to a trial; that, by a formal and judicial sentence, he might be delivered from those suspicions and surmises which had created him so much uneasiness for upwards of fifty years. But the king, although he at first patronized him, being better informed of the nature of his studies, refused hin any maik of royal countenance and favour; which must have affected a man of that vain and ambitious spirit, which all his misfortunes could never alter or amend. November the same year, he quitted Manchester with his family, in order to return to his house at Mortlake, where he remained but a short time, being now very old, infirm, and destitute of friends and patrons, who had generally forsaken him. We find him at Mortlake in 1607 ; where he had recourse to his former invocations, and so came to deal again, as he fancied, with spirits. One Hickman served him now, as Kelly had done formerly. Their transactions were continued to Sept. $7,160 \%$, which is the last date of that journat published by Casaubon, whose title at large runs thus :

"A true and fathful relation of what passed for many years be tween Mr. John Dee, a mathematician of great fame in queen Elizabeth and king James their reigns, and some Spirits, tending, had it succeeded, to a general alteration of most states and kingdoms in the world: His private conference with Rodolph, emperor of Gernany, Stephen king of Poland, and divers other princes, about it: The particulars of his cause, as it was agitated in the enperor's court by the pope's intervention: His banishment, and restoration in part; as also the letters of sundry great men and princes, some of whom were present at some of those conferences and apparitions of spirits to the said $\mathrm{Dr}$. Dee : out of the original copy written with Dr. Dee's own hand, kept in the library of Sir Thomas Cotton, knt. baronet, with a 
preface confirming the reality, as to the point of spirits, of lisis relation, and shewing the several good uses that a sober Christian may make of all By Meric Casaubon, D. D. I.ond. 1659," fol.

This book made a great noise upon its first publication; and many years after, the credit of it was revived by one of the ablest mathematicians and philosophers of his time, the celebrated Dr. Hooke, who believed that not only Casaubon, but archbishop Usher, and other learned men, were entirely nistaken in their notions about this book; and that, in reality, our author, Dee, never fell under any such delusions, but being a man of great art and intrigue, made use of this strange method of writing, to conceal things of a political nature, and, instead of a pretended enthusiast, was a real spy. - But there are several reasons which will not suffer us to suppose this. One is, that Dee began these actions in: England; for which, if we suppose the whole treatise to be written in cipher, there is no account can be given, any more than for pursuing the same practices in king James's time, who cannot be imagined to have used him as a spy. Another, that lie admitted foreigners, such as Laski, Rosenberg, \&c. to be present at these consultations witl spirits; which is not reconcileable with the notion of his being intrusted with political secrets. Lastly, upon the return of Dee from Bohemia, Kelly did actually send an account to the queen, of practices against her life; but then this was in a plain and open method, which would never have been taken, if there had been any such mysterious correspondence between Dee and her ministers, as Hooke suggests. In the latter end of his life lie became miserably poor. It is highly probable that he remained under these delusions to his death; for he was actually providing for a new journey into Germany, when, worn out by age and distemper, he died in 1608, aged eighty, and was buried at Mortlake.

\section{Jacob Beirnen, called the Teutonic Philosopiner.}

The person was the founder of a sect called Behmists, and was born of poor parents at a village near Gorlitz, in Upper Lusatia, in 1575. At the age of ten he was sent to school, where he learned to read and write, after which he was put apprentice to a shoemaker, and in 1594, he became a master, and entered into the state of marriage. In the year 1600 he is said to have fallen into a spiritual trance, or ecstasy, for seven days, during which he was not only drawn nearer to God, but had wonderful things revealed to him. In 1610 he fell into another trance of the like kind; and that the remembrance of what had been disclosed to him might not be lost, he wrote, in 1612, a book called Aurora, the style of which is exceedingly dark and obscure. Gregorius Richter, a clergyman at Gorlitz, having seen this work, resolved to get it suppressed, and accused Behmen before the council, who ordered the book, though not yet completed, to be seized and shut up in the town-house. Paulus Scipio, however, one of the burgomasters, sent a copy of it to George von Pflug, marshal of the household to the elector of Saxony, who transmitted it to Amsterdam to be printed. In 1619 he wrote another book, on the Three $P_{r i n-}$ ciples, to which in the course of a few years he added several others. 
In 1624 he travelled to Dresden, where he was interrogated by some divines, who declared, as is said, that they found nothing reprehensible in his character. He died the same year, after receiving the sacrament from the hands of Elias Dietrich, and, according to the account of his biographer, was honourably interred at Gorlitz.

His other works are, Of the Threefold Life of Man; Of the Iucarnation of Christ, his sufferings, death, and resurrection; A Book on the Six Points; On Celestial and 'Terrestrial Mysteries; De Scriptura Rerum; On the Four Complexions; On True Repentance; On True Resignation; On the Second Birth; Mysterium magnum; On the First Bools of Moses; On Spiritual Life, \&c. These appeared at first separately, 'but were afterwards collected and printed together. The best edition is said to be that published in German at Amsterdam. Sonje have bestowed great praise on this mystic, on account of the wislom which they pretend is contained in his writing; but their principal merit seems to consist in a certain obscurity, which excites wonder in weak minds, and induces them to believe that it is owing to want of capacity, if they do not comprehend what they read. Others have accused him of the most dangerous errors, and have written volumes in opposition to his doctrines; among whom may be mentioned one Gilbert, who published an admonition against his works, which was answered by Theodore von Tscheusch, a Silesian noblenan, and this produced a reply from Gilbert. After this, Gerrard Antagnossus, who called himself a Catholic, published the defence of Von Tscheusch, with a refutation of it in Latin, under the title of "Ne Sutor ultra crepidam," in which he endeavoured to shew that Behmen entertained the same opinions as the Manichaeans and the Gnostics." Tobias Wagner also wrote a book to refute Beheman's doctrines, entitled Judicum Propempticon; but it appears that he confounded Behmen's Aurora with another book, called the Aurora of Wisdom, written by Paul Felgenhauer.

Some have endeavoured to prove from Behmen's writings, that he did not acknowledge a Deity; and particularly Von Muller, a work enticled The Fanatic Atheist, and various authors, have at different times appeared for or against him ; but he acquired many followers, especially among the alchymists and makers of gold.

His life, which is printed along with most of the editions of his works, was written by a Silesian nobleman, named Von Frankenburg. Tiedeman, in his Spirit of Speculative Philosophy, speaking of Behmen says, "We are not informed by history from what source he derived his idea. Some have suspected that he only lent his name to another enthusiast; but others entertain the most probable opinion, that he had read the works of Paracelsus, because some expressions of that phýsician are to be found in his writings. Be this as it may, he cannot have been the author of the whole, for the chemical words of art, and many Latin words relating to the sciences, which he uses, are not to be expected from an illiterate shoemaker. He makes no quotations but from the scriptures, and repeatedly affirms, in the most solemn manner, that he obtained his deep knowledge by a particular revelation. However, without too much lessening the esteem in which he is by some held, one may on good grounds assert, that imagination 
and his vanity, flattered by the' supposed intercourse with the Deity, have led him into error. His language and doctrines betray him beyond all dispute, and prove him to have been a man who formed his ideas from books on chemistry and the Platonic mysteries. He is most intelligible in this Aurora, so that he will be easily understood by those acquainted with the Alexendrian philosophy, except where he introduces in a spiritual sense many words borrowed from chemistry and alchymy, and so corrupts his style, that no one can discover his real meaning."

Among Behmen's numerous followers, no one rendered himself more conspicuous than John Pordage, a physician and naturalist, who pretended to divine revelation, and declared that by these means he had been convinced of the truth of Behmen's doctrines. That he might, therefore, throw more light upon them, he published a book, entitled Divine and True Metaphysics, with some other works of the same kind; which being soon spread through Germany, became, together with Behmen's writings, the standard books of all en thısiasts." Behmen has had admirers even in this country; the most distinguished of whom is the famous Mr. William Law, author of Christian Perfection, who gave ain English edition of his works, in two volumes quarto.

10ure wat

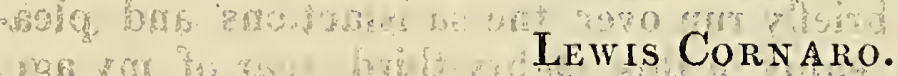

2.5TH was a Venetian, of noble extraction, memorable for having lived to an extreme age : he was ninety-eight years old at the time of his death, which happened at Padua, April 26, 1566, his birth being fixed in 146\%. Amongst other little performances, he left behind him a piece entitled, "De Vita Sobrire Commodis," i, e. "Of the Advantages of a Temperate Life." He was moved, it seems, to compose this little piece at the request and for the benefit of some young men, for whom he had a regard; who having long since lost their parents, and seeing him then eighty-one years of age, in a florid state of health, were desirous to know by what means he contrived to preserve a sound mind in a sound body to so exireme an age. In answer, he tells them, that when he was young he was very intemperate:; that this intemperance had brought upon him many and grievous disorders; that from the thirty-fifth to the fortieth year of his age, he spent his days and nights in the utmost anxiety and pain; and that in short, his life was grown a burden to him. The physicians, however, as he relates, notwithstanding all the rain and fruitless efforts which they made to restore him, told him, that there was one rnedicine still remaining, which had never been tried, but if be could prevail with himself to use with perseverance, might free him in time from all his complaints; namely, a regular and temperate way of living, but, - that unless he resolved to apply instantly to it, his case would soon become desperate. Upon this, he immediately prepared himself for his new regimen, and now began to eat and drink nothing but what was proper for one in his weak habit of body. But this at first was very disagreeable to him : he wanted to live again in his old manner; and he did indulge himself in a freedom of diet some- 
tines, without the knowledge of his physicians indeed, although much to his own uneasiness and detriment. Driven in the mean time by necessity, and exenting resolutely all the powers of his understanding, he grew at last confirmed in settled and uninterrupted course of temperance, by virtue of which, all his disorders had left him in less than a year, and he had been a firm and healthy man from that time to his giving this account.

18 To shew what a security a life of temperance is against the ill effects of hurts and disasters, he relates an accident which befell him when he was very old. One day being, overturned in his chariot, he was dragged by the horses a considerable way upon the ground. His head, his arms, his whole body, were very much bruised, and one of his ankles was put out of joint. He was carried home, and the physicians, seeing how much he was injured, concluded it was impossible he should live three days; but, by bleeding and evacuating medicines, he presently recovered his health and strength. Some sensualists, as it appears, had objected to his manner of living; and in order to evince the reasonableness of their own, had urged, that it was not worth while to mortify one's appetite at such a rate, for the sake of being old ; since all that was life, after the age of sixty-five, could not properly be called "vita viva, sed vita mortua ;" not a living life, but. a dead life. "Now," says he, "to shew these gentlemen how much they are mistaken, I will briefly run over the satisfactions and pleasures which I myself now enjoy in this eighty-third year of my age. In the first place, $I$ am always well, and so active withal, that 1 can with ease mount a horse upon a flat, and walk to the tops of high nountains. In the next place, I am always cheerful, pleasant, perfectly contented, and free from all perturbation, and every uneasy thought. I have none of that fastidium vitze, that satiety of life, so often to be met with in persons of my age. I frequently converse with men of parts and learning, and spend much of my time in reading and writing. These things $I$ do, just as opportunity serves, $n$ my humour invites me, and all in ny own house here at Padua; which, I may say, is as commodious and elegant a seat as any perhaps this a ge can shew, built by me according to the exact proportions of architecture, and so contrived as to be an equal shelter against heat and cold. I enjoy at proper intervals my gardens, of which thave many. whose borders are refreshed with streams of running water. $I$ spend some months in the year at those Euganean hills, where $I$ have another conmodious house, with gardens and fountains ; and I visit also a seat I have in the valley, which abounds in beauties, from the many: structures, woods, and rivulets that encompass it. I frequently make excursions to some of the neighbouring cities, for the sake of seeing my friends, and conversing with the adepts in all arts and sciences: architects; painters, statuaries, musicians, and even husbandmen. o contemplate their works, compare them with the ancients, and am: always learning something which it is agreeable to know. I take a view of palaces, gardens, antiquities, public buildings, temples, fortifications ; and uothing escapes me, which can afford the least amusement to a rational mind. Nor are these pleasures at all blunted by the usual imperfections of great age, for I enjoy all my senses in per- 
fect vigour; my taste so very acute, that have a better relish for the plainest food now, than $I$ had for the choicest delicacies, when formerly immersed in a life of luxury. Nay, to let you see what a portion of fire and spirit I have still left within me, know, that I have this very year written a comedy, full of innocent mirth and pleasantry; and, if a Greek poet was thought so very healthy and happy, for writing a tragedy at the age of seventy-three, why should not $I$ be thought as healthy and as happy, who have written a comedy when I am ten years older? In short, that no pleasure whatever may be wanting to my old age, I please myself daily with contemplating that immortality, which $\mathbb{I}$ think I see in the succession of my posterity.? For every time I return home, I meet eleven grand children, all the offspring of one father and mother; all in fine health; all, as far as I can discern, apt to learn, and of good behaviour. I am often amused by their singing, nay, 1 ofter sing with them, because my roice is louder and clearer now than ever it was in my life before. These are the delights and comforts of my old age; from which, I presume, it appears, that the life I spend is not a dead, morose, and melancholy life, but a living, active, pleasant life, which I would not change with the robustest of those youths who indulge and riot in all the luxury of the senses, because I know them to be exposed to a thousand diseases and a thousand kinds of deaths. I, on the contrary, am free from all such apprehensions, - from the apprehension of disease, because I have nothing for disease to feed upon; from the apprehension of death, because I have spent a life of reason. Besides, death, I am persuaded, is not yet near me. I know that, barring accidents, no violent disease can touch me. I must be dissolved by a gentle and gradual decay, when the radical humour is consumed like oil in a lamp, which affords no longer life to the dying taper. But such a death as this cannot happen of a sudden. To become unable to walk and reason, to become blind, deaf, and bent to the earth, from all which evils am far enough at present, must take a considerable portion of time: and I verily believe, that this immoral soul, which still inhabits my body with so much hamony and complacency, will not easily depart from it yet. I verily believe that I have many years to live, many years to enjoy the world, and all the good that is in it-by virtue of that strict sobriety and temperance, which I have so long and so religiously observed ; friend as $\overline{1}$ am to reason, but foe to sense."

His wife, who survived him, lived also to nearly the same age. Sir Joln Sinclair, in his "Code of Health and Longevity," mentions the edition of 1779 as the best English translation of Cornaro's works. There are four discourses on one subject, penned at different times : the first, already mentioned; which he wrote at the age of eighty-three, in which he declares war against every kind of intemperance. The second was composed three vears after, and contains directions for repairing a bad constitution. "The third he wote when he was ninetyone, entitled "An earnest Exhortation to a Sober Life ;" and the last is a letter to Barbaro, patriarch of Aquileia, written when was ninety-five, which contains a lively description of the liealth, vigour, and perfect use of his faculties, which he had the happiness of enjoying at that advanced period of life. 


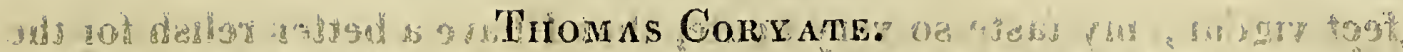

THIS rvas an extraerdinaryperson, who made himself famous by his whims and extravagancies. He was the son of a clergyman, and born at Odcombe in 1577. He was first educated at Westminster school, and became a commoner of Gloucester hall, Oxford, in 1596; where continuing about three years, he attained, by mere dint of memory, some skill in logic, and more in the Greek and Latin languages. After he had been taken home for a time, he went to London, and was received into the family of Henry prince of Wales, either as a domestic, or, according to some, as a fool, an office which in former days was filled by a person hired for the purpose. In this situation he was exposed to the wit of the court, who finding in him a strange mixture of sense and folly, narle lim their whetstone; and so, says Wood, he became too much known all over the world. In 1608 he took a journey to France, Italy, Germany, \&c. which lasted five months, during which time he had travelled 1975 miles,-more than half upon one pair of shoes, which were only once mended, and on. his return were hung up in the church of Odcombe. He published his travels under this title, "Crudities hastily gobbled up in five months" travels in France, Savoy, Italy, Rhetia, Helvetia, some parts of High Germany, and the Netherlands.". This work was ushered into the world by an Odcombian banquet, consisting of near sixty copies of verses, made by the best poets of that time, which, if they did not make Coryate pass with the world for a man of great parts and learning, contributed not a little to the sale of his book. These verses were reprinted in the same year, 1611, detached from the Crudities, with this title, "The Odcombian Banquet dished forth by Thomas the Coriat, and served in a number of Noble Wits, in praise of his Crudities, and Crambe too-Asinus portans mysteria-" ant with a prose advertisement at the conclusion, of which is the following transcript, which may serve as a specimen of Coryate's strange and whimsical style.

"Noverint mniversi, \&c. "Know, gentle reader, that the book in praise whereof all these precediug verses were written, is purposely committed for their and thy purses' good; partly for the greatness of the volume, containing 654 pages, each page thirty-six lines, each line forty-eight letters ; besides panegyrics, poems, epistles, prefaces, letters, orations, fragments, posthumes, with the commas, colons, fullpoints, and other things hereunto appertaining; which being printed of a character legible without spectacles, would have caused the book much to exceed that price whereat men in those witty days value such stuffe as that; and partly for that one,

Whose learning, judgment, wit, and braine,

Are weight with Ton's just to a graine ;"

"Having read the book with an intent to epitomize it, could he but have melted out of the whole lumpe so much matter worthy of reading as would have filled four pages ; but, finding his labour lost, and his hope therein fallen short, is resolved to defer it till the author of the "Crudities" has finished lis second travels; which being intended for a place far more remote; is likely to produce a book of farre 
greater bulk, both which being diawn into an exact compenel, as Munster, Baronius, the Magdeburgians, and other famous chronologers, have been, may perhaps afford something either worthy thy reading, or supply thy need in such cases of extremitie, as nature and costume oftentimes enforce men unto. Vale!"

Among those poets who were concerned in the Odcombian Banquet were Ben Jonson, Sir John Harrington, Inigo Jones the architect, Chapman, Domne, Drayton, \&c. In the same year he published Coryate's Crambe, or his "Colewort twice sodden; and now served in with other Macarenic dishes, as the second course of his Crudities," 4to. In 1612, after he had taken leave of his countrymen by an oration spoken at the cross in Odcombe, he took a large and long journey, witl intention not to return till he had spent ten years in travelling. The first place he went to was to Constantinople, where he made his usual desultory observations; and took from thenee opportunities of viewing divers parts of Greece. In the Hellespont he took notice of the two castles Sestos and Abydos, which Musaus has made famous in his poem of Hero and Leander. He saw Smyrna, from whence he found a passage to Alexandria inEgypt; and afterwards he observed the pyramids near Grand Cairo. From thence he went to Jerusalem; and soon to the Dead Sea, to Aleppo in Syria, to Babylon in Chaldea, to the kingdom of Persia, and to Ispahan, where the king usually resided; to Suras, anciently called Shushan; to Candahar, the first province north-east under the subjection of the great mogul, and so to Lahore, the chief city but one belonging to that empire. From Lahore he went to Agra; where being well received by the English factory, he made a halt. He staid there till he had learned the Turkish and Morisco or Arabian languages; in which study he was also very apt, and had some knowlerlge in the Persian and Indostan tongues, all of which were of great use to him in his travelling up and down the great mogul's dominions. In the Persian tongue he afterwards made an oration to the great mogul; and in the Indostan he had so great a command, that we are gravely told, he actually silenced a boundarywoman belonging to the English ambassador in that country, who used to scold all the day long. After he had visited several places in that part of the world, he went to Surat in East India, where he was seized with a diarrhœa, of which he died in 1617 .

This strange man, it is evirlent, had an insatiable desire to view distant and unknown parts of the world, which has never been reckoned a symptom of folly; nor indeed would Coryate have been so much despised, if he had not unluckily fallen into the hands of wits, who, by way of diverting themselves, imposed upon his weakness and extreme vanity, and nothing vexed him more than to have his vanity checked. Thus, when one Steel, a merchant, and servant to the East India company, came to Sir Thomas Roe, the English ambassador at Mandoa, where the mogul then resided, he told Coryate, that he had been in England since he saw him, and that king James had inquired about him; and that upon telling his majesty that he had met him in his travels, the king replied, "Is that fool living?"

Our traveller was equally hurt at another time, when, upon his departure from Mandoa, Sir Thomas Roe gave him a letter, and in that 
a bill to receive 101 at Aleppo. The letter was directed to Mr. Chapman, consul there at that time; and the passage that concerned Coryate was this : Mr. Chapman, when you shall handle theseleters; I desire you to receive the bearer of them, Mr. Thomas Coryate, with courtsee, for you will find hitn a very honest poor wretch," \&c. This expression troubled Coryate extremely, and therefore it was altered to his mind. He was very jealous of his reputation abroad; for he gave out, that there were great expectances in England of the large accounts he should give of his travels at his return home.

What became of the notes and observations he made in his long peregrinations, is unknown. The following only; which he sent to his friends in England, were printed in his absence :-Letters from Asmere, the court of the great mogul, to several persons of quality in England, concerning the emperor and his country of East Iudia, in the title of which is onr author's picture, riding upon a elephaut: A letter to his mother Gertrude, dated from Agra in East India, containing the speech that he delivered to the great mogul in the Persian lan guage: Certain observations from the mogul's court, and East India: Travels to, and observations in, Constantinople, and other places in the way thither, and in his journey thence to Aleppo, Damascus, and Jerusalem : His oration, Purus Putus Coryatus, (quintessence of Coryate;) spoken extempore, when Mr. Rugg dubbed him a knight on the ruins of Troy, by the name of Thomas Coryate, the first English knight of Troy: Observations on Constantinople, abridged : all these are to be fuund in the Pilgrimages of Sam. Purchas: Divers Latin and Greek epistles to learned men beyond the seas; some of which are in his Crudities.-Among his persecutors was Taylor the Water-poet, who frequently endeavours to raise a laugh at his expeuse. To Coryate's works may be added a copy of verses, in the Somersetstire dialect, printed in Guidott's "Collection of Treatises on the Bath Waters," 1725, 8vo.

\section{John Taylon, the Water Poet.}

Thrs person, usually called the Water Poet, from his being a water man as well as a poet, and certainly more of the former than the latter, was born in Gloucestershire about 1580 . Wood says he was born in the eity of Gloucester, and went to school there; but he does not seem to have learned more than his audience, as appears by some lines of his own. From this school he was brought to London, and bound apprentice to a waterman, whence he was either pressed or went voluntarily into the naval service, for he was at the taking of Cadiz, under the earl of Essex, in 1596, when only sixteen years old, and was afterwards in Germany, Boheinia, and Scotland, as may be collected from various passages in his works. At home he was many years collector, for the lieutenant of the Tower, of the wines which were his fee, from all ships which brought them up the Thames; but was at last discharged, because he would not purchase the place at more than it was worth.

He calls himself the "King's Water Poet," and the "Queen's Wa$2 \mathrm{~T}$ 
lerman," and wore the badge of the royal arms. While a waterman, he very naturally had a great hatred to coaches; and besides writing a satire against them, he fancied that the watemen were starving for want of employment, and presented a petition to James I. which was referred to certain commissioners, of whom Sir Francis Bacon was one, to obtain prohibition of all playhouses except those on the bank-side, that the greater part of the inhabitants of London, who were desirous of seeing plays, might be compelled to go by water. Taylor himself is said to have undertaken to support this singular petition, and was prepared to oppose before the commissioners the arguments of the players, but the commission was dissolved before it came to a hearing.

When the rebellion commenced in 1642, Taylor left London, and retired to Oxford, where he was much noticed and esteemed for his facetious turu. He.kept a common victualling liouse there, and wrote pasquinades against the round-heads; by which he thought, and Wood too seems to think, that he did great service to the royal cause. After the garrison at Oxford had surrendered, he retired to Westminster, kept a public-house in Phonix-alley, near Longacre, and continued constant in his loyalty to the ling, after whose death, he set up a sigu over his door, of a mourning crown; but that proving offensive, he pulled it down, and hung up his own picture with these verses under it:

"There's many a head stands for a sign,

Then, gentle reader, why not mine?"-

And on the other side,

" Though I deserve not, I desire

The laurel wreath, the poet's hire."

He died in 1654, aged seventy-four, as Wood was informed by his nephew, a painter of Oxford, who gave his portrait to the picture gallery there in 1655. This nephew's own portrait, also by himself, is on the staircase. His works were published under the title of "All the Workes of John Taylor the Water Poet, being sixty and three in number, and collected into one volume by the author, with sundry new additions: corrected, revised, and newly imprinted." 1630, folio." These pieces, which are not destitute of natural humour, abound with low jingling wit, which pleased and prevailed in the reign of James $I$. though it too often bordered upon bombast and nousense. He was countenanced by a few persons of rank and ingenuity, but was the darling and admiration of numbers of the rabble. He was himself the father of some cant words, and he has adopted others, which were only in the mouths of the lowest vulgar. From the date of this volume it is evident that it does not contain those "pasquins" and satires which Wood says he wrote at Oxford, and which perhaps it might have been unsafe to avow or republish, as he did not survive the times of the usurpation. Five articles, however, whose titles nay be seen in the "Bibliotheca Anglo-Poetica;" were published between 1637 and 1641. One of them is the life of Old Parr, printed in 1635, when Parr is said to have been living, at the age of 152 . 


\section{OLDPARR.}

Turs person lived to the vast age of 152 years. But as his life is publicly known, we shall only state in this place the following lines respecting him, from Taylor the Water Poet:

Good wholesome labour was his exercise,

Down with the lamb, and with the lark would rise;

In mire and toiling sweat he spent the day,

And to his team he whistled time away;

The cock his night-clock, and till day was done,

His watch and chief sun-dial was the sun.

He was of old Pythagoras opinion,

That green cheese was most wholesome with an onion;

Coarse mesliul bread, and for his daily swig,

Milk, butter-milk, and water, whey and whig:

Sometimes metheglin, and, by fortune happy,

He sometimes sipp'd a cup of ale most nappy,

Cider or perry, when he did repair

T" a Whitsun-ale wake, wedding, or a fair ;

Or when in Christmas-time he was a guest

At his good landlord's house amongst the rest ;

Else he had little leisure-time to waste;

Or at the ale-house huff-cap ale to taste. -

His physic was good butter, which the soil

Of Salop yields, more sweet than Candy oil:

And garlic he esteem'd above the rate

Ôf Venice treacle, or best mithridate.

He entertain'd no gout, no ache he felt,

The air was good and temperate where he dwelt;

While mavisses and sweet-tongued nightingales

Did chant him roundelays and madrigals.

Thus living within bounds of nature's laws.

Of his long lasting life may be some cause.

And the same writer describes him in the two following lines:

From head to heel, his body had all over

A quick-set, thick-set, natural hairy cover.

\section{Oliver Cromwell.}

OnIver Cromwell is well known as being the Lord Protector of the Commonwealth of England, and one of the most extraordinary persons mentioned in history. He was born at Huntingdon, April 25, 1599 , and received the name of Oliver, from his uncle Sir Oliver Cromwell, who was his godfather. His father, Robert Cromwell, esq. second son of Sir Henry Cromwell, knight, enjoyed an estate in or near Huntingdon, of about three hundred pounds a year; and to ease the expenses incident to a numerous progeny, carried on, besides, an extensive trade in the brewery; and being fond of a private and domestic life, he lived and died in that town. 
No presages of the future greatness of our hero marked his birth ; at least none lave been handed down to us. An incident that threatened to put an early perior to that existence which teemed with so much fingled glory and infamy, must not, however, be omitted. While he was vet an infant, being at Hinchenbrook, the residence of his grandfather Sir Henry Cromwell, a monkey, which was suffered to go lonse, took him fron the cradle, and ran with him to the leads of the house, where he stood exhibiting all the imitative tricks of his species. The family, greatly alarmed for the safety of the child, ran with beds, blankets, \&c. to the spot on which he was expected to tumble from the arms of his inexperienced nurse, in order to break the fall; but the sagacious animal, to the great joy of the anxious beholders, brought young Oliver down, with the same care and circumspection that he had conveyed lim to the dangerous eminence. Whether this instance may be construed into an ominous token of his future exaltation, and of the manifold anxieties and hazards that preeminence was attended with, is left to the opinion of the reader; as likewise are the following traditions, which are said not to want credible authentications.

Hinchenbrook, at that time the seat of Sir Oliver Cromwell, as being near Huntingdon, was generally one of the resting places of any excursions of the royal family into the north. When Charles I. then duke of York, was on his journey from Scotland to Loudon, in the year 1604, he called at that place. The knight, to divert the young prince, sent for his nephew Oliver, that he, in addition to his own sons, might play with his royal highness. But they had not been long together, before Charles and Oliver disagreed; and the former being weakly, and the latter strong, the royal visitant was worsted. Even at this early age, Oliver so litile regarded dignity, that he made the blood fow in copious streams from the prince's nose. When the civil wars afterwards commenced, and Oliver began to grow conspicuous, this circumstance was considered as no very favourable presage for the king.

Oliver likewise used to aver, that as he lay one night awake, a gigantic figure opened the curtains of his bed, and told him that he should be the greatest person in the kingdom. The word "king" was not mentioned; but from a part of the subsequent conduct and expectation of Uliver, it may be supposed that he concluded the expression made use of to convey that idea. Upon his repeating it in the morning, he was severely chastised by his schoolmaster, at the particular reguest of his father. And though he was told it was traitorons to relate it, yet he could not be prevented from frequently repeating it, and often, after he had arrived at the height of his glory, he spoke of it as a fact, and noticed the accomplishment of it But to return.

Oliver's fatier, who appears to have been a gentleman of good sense and competent learning, placed him at the free grammar school of Huntingdon, where the proficiency he made in his scholastic studies has been a matter of dispute: by some it is said to have been very considerable; by others it has been no less decried; but from his speeches, and from other instances where he had occasion to exhibit proofs of his learning, nothing more than mediocrity is observable? In 
his studies he was very eccentric and inconsistent, now applying himself with unremitting assiduity for a few weeks, then becoming indolent for as many months. Traits of his character would also at this time break out. When he was at the grammar school, it was a custom for the scholars to perform a play once a year. Upon one of these occasions the comedy of Lingua, or The Combat of the Tongue and the Five Senses for the Superiority, was tixed upon. The plan of this play, which was printed in 1607 , is, - Lingua gives a crown and royal robe to be contested for by the Senses. Tactus, one of the principal persons of the piece, having stumbled over the crown and robe as they lay on the ground, it gives rise to the following soliloquy, which so accorded with the sentiments of Oliver, even at this early period of his life, that he could not conceal the pleasure he received from it and nothing would satisfy him but his being permitted to personate the character of Tactus. As this speech gives such a striking picture of the first development of an ambitious nind, the whole of it is here transcribed:

\section{Scene VI. A Soliloquy.}

TACTUS.

Tactus, thy sneering somewhat did portend;

Was ever man so fortunate as $\mathrm{I}$,

To break my shins at such a stumbling block?

Roses and bays, back hence, - this crown and robe,

My brows and body circles and invests!

How gallantly it fits me! Sure the slave

Measured my head, that wrought this coronet.

They lie, who say complexious cannot change;

My blood's ennobled, and I am transformed.

Under the sacred temper of a King,

Methinks I hear my noble parasites

Styling me Coesar, or Great Alexander;

Licking $m y$ feet, and wondering where I got

This precious ointment. How my pace is mended!

How rincely do I speak! How sharp I threaten!

Peasants, I'll curb your head - strong impudence,

And make you tremble when the lion roars.

Ye earth-bred worms! Oh, for a looking glass!

Poets will write whole volimes of this change!

Where's my attendants? Come hither, sirrah, quickly, Or by the wings of Hermes-

From Huntingdon grammar-school, Oliver was removed, about the beginning of the year 1616, to Sydney Sussex College in Cambridge, -where, his genius being little fitted for the calm and elegant occupations of learning, he made no great progress in his studies. His course of life, on the contrary, was dissolute; and he became more famous, while at college, for foot-ball, cricket, wrestling, cudgelling, and other gymnastic amusements, than for his application to the instruction of his tutors. He did not, however, totally neglect his studies; he obtained a tolerable knowledge of the Latin language, and likewise of the Greek and Roman histories; and as he was afterwards 
in possession of a valuable and well-chosen library, ever patronized men of learning and science, and through $h$ is whole life retained a regard for the university of Cambridge, we are not to suppose that he was averse to learning, or without a competent share of it.

Upon the death of his father, which happened about a year after he had been placed at Cambridge, he left the university, by the directions of his mother, who appears to have been a prudent sensible woman. Mrs. Cromwell was probably induced to take this step, from a knowledge of his irregularities there, which must have reached her ears : and it is not less probable that ler injunctions were obeyed without reluctance by her son, as one reason of his returning home was to take possession of the family estate. He now fell into the usual dissipations of a young heir ; and unheedful of the affectionate entreaties of a tender mother, gave himself up to all the levities and vices of ungovernable youth. Oliver did not continue long at home. He soon after set out for London, in order to study the law; and he became a student at Lincoln's inn, where he remained about two or three years. But as the metropolis was not a place wherein his dissolute propensities were likely to find restraint, women of easy virtue engrossed more of his time than Coke upon Littleton, and the chief places of his residence were taverns and brothels. His companions were of the lowest rank, his manners and behaviour being so boisterous and overbearing, that no persons of respectability would be seen with him. So notorious was he at length become, that it was not uncomnion for the tavern-keepers, when they saw him coming, to say, "Here comes young Cromwell! shut up the door." In short, at this period he seems to have had no control over his actions, but to have gratified his inclinations without respect to time, person, or place.

These dissolute propensities, however, do not appear to have supported their dominion over the mind of young Cromwell for any considerable length of time. He had scarcely completed his twenty-first year, before the impropriety of his conduct forcibly struck him; and he began to listen to the admonitions of a fond and venerable mother. He became sensible of the folly of having lavished away much of his property; a conpunction for the crimes which had attended this prodigality took possession of his mind; and he formed the resolution, not only of parting with his foibles, but of correcting his manners. He did so, and this amendment of his conduct procured him many and great friends. His relations, the Hampdens and the Barringtons, now interested themselves in his fortunes; and by their influence he obtained an alliance with a lady of the name of Bourchier, who compensated, by the fortune she brought him, and her virtue and good sense, for the want of personal attractions. How difficult is it in the concerns of life to obtain that happy medium, which ensures internal satisfaction, and at the same time the approbation of the world!

From a debauched way of living, Oliver fell by degrees into the other extreme. His sudden transition from vice to virtue, with the preciseness of manners he had since adopted, having recommended him to the notice of the nonconformists, particularly to some of their preachers, they weaned him from the established church, and instilled into his head all the enthusiastic notions of their own sect. His 
course of life grew stricter; his mind seemed wholly bent upon religious subjects; and he not only exerted himself in behalf of his new brethren, but his house became the retreat of their persecuted ministers.

The nation at large being at this time extremely dissatisfied with the court, he obtained through this mode of procedure a seat for the borough of Huntingdon, as a champion of the people. Whether he was at this or any former period concerued in the brewing business, as his father had been, is difficult to ascertain ; but several lampoons, containing inferences of that kind, were published by his enemies during his life. Huntingdon after some time becoining disagreeable to him, on account of the loyalty of its corporation, and of his uncle Sir Oliver Cromwell, he sold his estates there, and took a farm at Si. Ives, in the same county. But his new residence does not appear to have been long agreeable to him. The occupation he had entered into was not suited to his turn of mind. Indeed, it did not turn out so advantageous as he expected; which might partly be attributed to his want of knowledge in the grazing business, to which the farm was appropriated, and partly from his employing too much of his own and his servants time in prayer and other religious duties.

A more pleasing revolution in his affairs, however, soon took place: for, upon the death of his maternal uncle, Sir Thomas Steward, who died in the year 1635, without issue, he became possessed of very considerable estates in and near Ely; to wlich he removed; after having resided about five or six years at St: Ives. Here those seeds of ambition which were implanted by nature in the breast of Oliver, began to distend themselves; and he seems to have neglected no opportunity of increasing his popularity. For, in the year 1638, we find him strenuously opposing the scheme for draining the fens in Lincolnshire and the Isle of Ely, which had been undertaken by the earl of Bedford and others, under the royal sanction. Notwithstanding the undertaking must have proved extrenely beneficial to the country, and had been recommended by his father, yet as it was very unpopular, particularly among the common people, because they had a custom of commoning and fishing in dry times, Oliver set his face against it; and by his plausibility, activity, and interest, at a meeting of the propietors held in Huntingdon, he obliged them to drop their intention. By doing this, he gained a great number of frieids, and it likewise procured him the title of "lord of the fens." By such" gradual steps did that popularity expand itself, which at length was the means of raising him to the most elevated situations. But discontent for the present clouded his mind, and rendered him dissatisfied with his native country:

Having opposed by every means in his power the arbitrary proceedings of the court, and finding that nothing would alter the system which Charles and his ministers had determined to pursue, he resolved to leave England, in order to enjoy that liberty of conscience which was denied him here. With this design he went to London; and embarked with many other gentlemen of fashion, several of whom were of far better fortune than himself, particularly his, cousin Hampden, on board some ships bound for $\mathrm{New}$ England, in North America, which 
was then the retreat of the disaffected and persecuted nonconformists, where they fond a shelter from archbishop Laud's impolitic and cruel severity.

Bui his intention of leaving the kingdom was prevented by government, which, jealous of so many opulent subjects transplanting themselves, issued a proclamation, forbidding any person, to leave the lingdon witlout a royal license. This was followed by an order of: council for stopping the ship in which Mr. Cromwell and his family. had embarked; and likewise many other vessels bound on the same expedition.

Disappointed in this plan, which would have frustrated the more Hattering one that was imperceptibly carrying on, he retired again to. Ely; where, his mina being now disengaged from every thing but religious melancholy, heightened by dissatisfaction, both with the religious and civil establishments of the kingdom; constantly reflecting upon some disappointment in his fortunes, which were never, through a want of economy, in a flourishing state; and magnifying, by the force of his imagination, the foibles of his youth into the greatest of crimes; he became sour and gloomy in the extreme. Such was his prejudice against the established church and liturgy; especially agaiust the cathedral service, that he once entered the collegiate church of Ely during the performance of it, and being attended by some soldiers and rabble, put a stop to it, and drove away the: congregation.

In 1640 king Charles summoned a parliament, in order to obtain pecuniary assistance from them; but the commons rather wishing to procure redress for many real, and some supposed grievances, the mistaken monarch dissolved them, in hopes of getting money some other way than contending with an angry assembly. But scarcely were they dismissed, than he found himself obliged to call another parliament. In both of these, Oliver obtained a seat as member for. Cambridge, where his opposition to the draining scheme, before mentioned, had rendered him very popular. Thus did Oliver get seated in the long parliament, to the proceedings of which he afterwards put a stop by his own authority.

Let us now take a view of the personal and mental qualifications of this celebrated man, in order to examine how far he might be supposed capable of making a shining figure in so august an assembly, and likewise what prospect is exhibited thereby of his future exaltation. He was now arrived at the middle age of life, which undoubtedly is the most proper for deliberation, and his judgment and capacity were certainly great : but in these qualifications he was only on a par with very many in the house at that time, consequently there could be but little prospect of his attaining a pre-eminence. In the next place, his estate, even at the best of times, was too inconsiderable for-a man to set himself up; on the strength of it, as the leader of a party in a great nation, and, when compared to what the generality of his fellow. nembers enjoyed, it might be considered as a mere bagatelle.

In his advantages as a gentleman, there appears to have been a still greater disproportion between him and most of the members of the house of commons. Instead of being versed in the dead and 
Fiving languages, his learning, as already observed, extended only to a moderate acquirement of the Latin: so far from being acquainted with the jarring interests of foreign courts, and the dispositions of the different princes on the continent, he had never been out of the kingdom; and as to a knowledge of the arrangements of the Euglish court, and the characters of the leading men either of that or the country party, it must have been very confined, as he had resided but a short time in the capital, and had sat in parliament but a few months. His person, though manly, did not possess any of those elegancies which captivate regard or command respect, and which are only to be acquired by a long and familiar acquaintance with persons of the first rank. And as for his ciress, it was far from attracting respect. He rather engaged the attention of the house by a slovenly habit. His clothes were ill made, entirely out of the fashion, the work of an ordinary country tailor, and no part of them of the best materials. Sir Philip Warwick, a gentleman, the exactness of whose description may be relied on, gives the following account of Oliver's appearanee when he was first called to sit in the Inng parliament.

"The first time," says the knight, "that ever I took notice of him, was in the beginning of the parliament held in November 1640. I came one morning into the honse, and perceived a gentleman spealsing; whom I knew not, very ordinarily apparelled; for il was a plain cloth suit, which seemed to have been made by a bad country tailor, his linen was plain, and not very clean; and I remember a speck or two of blood upon his little band, which was not much larger than his collar; his hat was without a band; his stature was of good size; his sword stuck close to his side; his countenance swollen and reddish; his voice harsh and untunable; and his eloquence full of fervour."

With all these disadvantages of mind and body, was it ever to be expected that Oliver would become a principal person in the senate, and much less its future sovereign? It is, howerer, no less strange than true, that this very man, within a few years, was not only noticed in the house for the boldness of his speeches, and the solidity of his arguments, but that he studied both grace in his gesture, and neatness and gentility in his dress. "And I lived to see," continues Sir Philip Warwick, "this very gentleman, who out of no ill will I thus describe; by multiplied good successes, and by real but usurped power, having had a better tailor, and more converse among good company, in my own age, when for six weeks together I was a prisoner in his sergeant's hands, and daily waited at White hall, appear of a great and majestic deportment, and comely presence."

From the foregoing observations we see, that though Oliver's speeches were delivered at first without grace, eloquence, or even perspicuity, yet he soon commanded the attention of the house by the depth of his arguments; and overcame all his disadvantages, by his pelletration, unwearied diligence, courage, and perseverance; by his accommodating himself to the dispositions of the different persons of his own party, and discovering the tempers of all; and by even not neglecting to copy the dress and behaviour of the most graceful and refined. 
A man of his deep penetration could not but perceive that the national liberty was deeply wounded. His gloomy turn of mind might induce him to consider it as absolutely destroyed. And as he was undoubtedly, in his religious sentiments, a flaming puritanical bigot, he was as violent against the decent cerenonies of the church, as archbishop Laud was anxious to graft upon them many of the superstitions of the church of Rome.

Probably, even at this early period, he foresaw that a civil war must decide between prerogative and liberty; and had already determined what part he should take. But if he had formed any aspiring views, they must have been very confined; the most towering flights of his ambition could never have suggested a hope of attaining the command of an arny, much less that of the whole kingdom.

The ill-fated year 1642 witnessed the commencement of the fatal quarrel between king Charles and his parliament; which took its rise from the insincerity of both. Upon this occasion, Oliver, through the interest of his relation Mr. Hampden, obtained a commission from the latter to raise a troop of horse, which he found no difficulty in doing in his own county of Huntingdon; and as his recruits chiefly consisted of freeholders' sons, they did not a little contribute, by their firmness and discipline, to his success and elevation.

He first served under Sir Philip Stapleton, and was in the batlle of Eilgehill, where the dawning of his bravery first shone forth. The following year, 1643 , he obtained a colonel's commission; and almost immediately after, for the services he had performed, was appointed lieutenant-general to the earl of Manchester. Such was the rapidity with which he rose in the army, notwithstanding he was totally unacquainted with arms before the fatal rupture commenced. But it was the at relief of Gainsborough, during this year, where, with the brave troop of his countrymen, he exhibited the great proofs of his courage, that laid the foundation of his future greatness.

Oliver's antipathy was so determined and undisguised, that he would enlist none but those who would resolve to go any lengths with him agairst the king. And this enmity was so well known to archbishop Williams, that he advised his majesty to secure him by some signal favour, or to take him off by violence. Though Charles at the time only smiled at the bishop's proposal, yet he was afterwards heard to say, "I would that some would do me the service to bring Cromwell to ine, alive or dead."

Under Fairfax, he was the grand movement of a victorious army, from which, in the end, the kingdom must receive its laws. Now it was that his contracted principles of religion, together with his ostensible patriotism, began to give way to his ambition. Of the former, if we may judge by the tenor of his conduct, little more than the mask remained. And when honours and great emoluments conrted his acceptance, to a mind aspiring as his, it was impossible to sit down again as a private gentleman. His ambition, however, at this time, might have had its limits. He had probably set a certain mark to his desires, the arriving at which would entirely have satisfied him; and in return, he would, no doubt, have been as firm a friend to the ruined monarch, as he had been a formidable foe. His 
utmost wish, it is said, was at one time to have been created earl of Essex, honoured with the garter, made first captain of the guards, and declared vicar-general of the kingdom. It is true, these demands have the appearance of being very extravagant; and yet when his consequence in the state, at the time the demand was made, is considered, and that his namesake and relation, Sir Thomas Cromwell, from the meanest situation had been invested with greater honours and revenues than these by so haughty a monarch as Henry VIII., it will not be thought that he was so unreasonable in his proposals. The parliament, who had much less to fear or hope from him than the king, when the propositions for peace were under consideration of the house, voted that he should be created a baron, and have two thousand five hundred pounds a year settled upon him. The unfortunate Charles, whose mind was unsettled, wavering, distrustful, and insincere, instead of closing with terms which alone could save his crown, his life, and the constitution, endeavoured by artifice, first to amuse, and then to ruin him

But Cromwell, to whom nothing, how secret soever, was unknown, excelled the king as much in policy as he did in real power; and he now agreed, though with some reluctance at first, to secure his own life, by the sacritice of that of his sovereign. At this time he could have formed no idea of attaining the eminence he afterward did. On the contrary, there is every reason to believe, that he would have been happy to have closed with his majesty, had he found him sincere, and could have done it with safety to himself, by not risking the hatred of the army ; for it appears that they were so jealous of him, that he durst not be seen with, or permit any one to come to him from the king. Olivey, however, is known to have averred, that "it must be expected; he would perish for his sake."

But it was not till after this that Oliver met with a fuil confirmation of Charles's insincerity, in a letter from him to the queen, wherein he says, "that he was courted by both parties, but would close with that which offered him the best terms;" a declaration highly ungenerous, as he had at that time pledged his honour to the army. The king even went farther: in another letter he informed her majesty, "that it would be easier for him to take off Cromwell when he had agreed with the parliament, than now he was at the head of his army." Oliver, who was perfectly acquainted with every step taken by the king; acquired a knowledge of the contents of these letters; and probably it was upon this occasion that he said, "If it must be my head or the king's, can I hesitate which to choose?"

Though these deceptions may seem to render Oliver's unremitted enmity to the king in some degree warrantable, yet his hypocrisy to the public, and jocularity throughout the dreadful tragedy of his majesty's trial and execution, will not admit of the least palliation. A great part of the latter indeed was affected, and only a cover to hide the perturbation of his mind.

The first principle of nature, self-defence, might be pleaded in his justification, or at least as an extenuation, in putting the king to death; but to indulge a vein of mirth and pleasantry in the misfortune of any one, particularly a person of so high a dignity, and who stood in so 
sacred a relation to him as that of his sovereign, cannot be excused. During the last scenes of the king's life, he talked jestingly, and acted buffoonery; and this, ton, when he was confessing himself guided by Providence, and with a hypocritical countenance lamented the situation of him whose miserable fate he was fixing.

While the trial of the king was carying on, he laughed and jeered in the court of wards; and éven in the solemn act of signing the warrant for his majesty's execution, he marked the face of one of his companions with his pen, - who returned the compliment.

It is likewise a well-known fact, that he went to feast his eyes upor the nutdered king; and it is said that he put his finger to the neck, to feel if the head was entirely severed. On viewing the inside of the body, he observed how sound it was, and how well made for longevity. And yet, notwithstanding these unequivocal marks of satisfaction at the tragical steps that had been taken, he mocked his $\mathrm{Ma}$ ker, both before and during the trial and execution, with hypocritical prayers in his sovereign's behalf, and was often seen to shed tears for his untappy situation and death. The artful manner by which, after Charles's catastrophe, he drove his masters and employers (the parliament) fron the sovereignty; and stepped into it himself, is ton well known to need a repetition here. He accomplished the latter with the same consummate art and resolution with which he had brought about the former; and on the 120th of December, 1653, he was elected the supreme head of the British empire, by the style and title of Eord Protector.

His fist inauguration into the protectorate took place in the court of chancery at Westminster, on the 16 th of the same month, in the 1)esence of the lords commissioners of the great seal of England, the barons of the exchequer, and the judges, the council of the commonwealth, the lord mayor, aldermen, and recorder of the city of London, and many of the chief officers of the army. And a few days after, a second and more solemn investiture was performed in Westminster-hall, where scaftoldings were erected for the purpose, and at the upper end of which a chair and canopy of state were set. As a part of the ceremony, Oliver was presented by the speakers, in the name of the parliament, with a robe of purple veivet, a bible, a sceptre, and a sword; and the oath being taken, the heralds, by sound of trumpet, proclaimed his highness, Protector of England, Scotland, and Ireland, together with the dominions thereunto belonging, requiring all persons to yield him due obedience.

That he governed the nation, for the few years he was at the head of it, with an ability that wanted only legality to entitle it to the highest encomiums, must be allowed even by those who are most prejudiced against him. He not only procured the British name honour throughout the world, but in his domestic administration ruled with as much disinterestedness as was consistent with his own safety and the temper of the times.

The methods made use of both by the king of France and the king of Spain, to win the friendship of Cromwell, were beyond description humiliating. His very name was terrible to them. It is said, that he obliged the haughty Lewis XIV. on executing a treaty, to sign his name afte: his. He would not receive the tille of Cousin from that 
King, but expected that of Brother. He obliged all nations to pay his ambassadors the sane honours they had paid to similar representatives when these realms were governed by kings. All Europe trembled at his nane. Cardinal Mazarine declared "that he was more afraid of him than of the devil." The pope ordered processions to avert the thunder of his cannon from reaching Rome. The duke of Savoy was commanded to put a stop to the massacre of his protestant subjects; and no sooner was the mandate received, than he obeyed. The Dutch were all submission to him. Sweden took uncommon pains to obtain his alliance. He treated Denmark and Portugal with an excess of haughtiness. All Italy, with the states of Africa, stood in awe of him, after he had severely punished them for the depredations they had committed on the British ships. So that; though the means by which he obtained the sovereign power were highly unwarrantable, yet his use of that power was as highly commendable and advantageous to the llation.

This prosperous consummation of his ambitious wishes was not, however, attended with that happiness which alone could make it desirable; for, worn out by excessive fatigue both of mind and body, by grief arising from many domestic misfortunes, among which the loss of a favourite daughter was not the least; and likewise by financial difficulties; he paid the debt of nature at his palace of Whitehall, Sept. 3,1658 ; a day that in several instances of his life had been pregnant with great events to him.

His body, after being embalmed, and wrapped in a sheet of lead, was removed on the 26th from the palace of Whitehall, his usual residence, to Somerset-house, where it lay in state; and on the 23d of November was interred with great funeral pomp, in a vault purposely prepared for it, in Henry the Seventh's chapel, in Westminster abbey.

But no sooner was the restoration brought about, than a humiliating reverse took place. The body of the Protector, with those of Ireton and Bradshaw, having been taken from the places of their interment, were, on the 29th of January, 1660 , the anniversary of king Charles's death, conveyed upon sledges to Tyburn, where they hung till sun-set. They were then beheaded; and their trunks being thrown into a hole under the gallows, their heads were set upon poles, and placed on the top of Westminster-hall.

Such were the indignities with which the corpse of this great man, (for, as the most victorious general and the greatest sovereign of the age in which he lived, such he must be allowed to be, was treated by his enemies. With regard to his general character, whether he was a saint or a hypocrite, whether "he deserved a halter or a crown," has been, and still is, matter of dispute.

The character which was drawn of him by Smollet, who, as he was known to have no small attachment to "high prerogative," we may suppose not to be partial to him, comes, probably nearest to the truth. It runs thus,- "Oliver Cromwell was of a robust make and constitution, and his aspect manly, though clownish. His education extended no farther than a superficial knowledge of the Latin tongue: but he inherited great talents from nature, though they were such as 
be could not have exerted to advantage at ally juncture but that of a civil war, inflamed by religious contests. His character was formed from an amazing conjunction of enthusiasm, hypocrisy, and anbition. He was possessed of courage and resolution, that overlooked all dangers and saw no difficulties. He dived into the characters of mankind with wonderful sagacity, whilst he concealed his own purposes under the impenetrable shield of dissimulation. He reconciled the most atrocious crimes to the most rigid notions of religious obligations. From the severest exercises of devotion, he relaxed into the most ludicrous and idle buffoonery. He preserved the dignity and distance of his character in the midst of the coarsest familiarity. He was cruel and tyrannical from policy, just and temperate from inclination, perplexed and despicable in his discourse, clear and consummate in his designs, ridiculous in his reveries, respectable in his conduct ; in a word, the strangest compound of villany and virtue, base. nesss and magnanimity, absurdity and good sense, that we find upon record in the annals of mankind."

The Protector married, August 22, 1620, at St. Giles's church, Cripplegate, London, Elizabeth, daughter of Sir James Bourchier, of Felsted, in Essex, knight, who, notwithstanding she has been greatly traduced by the enemies of her hushand, appears to have been a virtuous and deserving woman. In her person she was certainly very ordinary, and was usually denomiuated by the royalists, on account of the plainness of her person, Joan Cromwell. Slie bore him niue children, five sons and four daughters, most of whom were very amiable characters, particularly Elizabeth, the second and favourite child of Oliver, who was married to John Claypole, esq. and died a siort time before her father; and Henry, who was appointed by Oliver, lord lieutenant of Ireland; where he, not only by the wisdom and equity of his administration soon procured the love of the Irish, so. that they regarded hin as a blessing, but was constantly treated with every mark of esteem even by the cavaliers of both kingdoms. What is remarkable in Oliver's children is, that most of them disapproved of the violent steps their father was taking, and were warm partisans for Charles 1 . as well as for his son, whose restoration they greatly. approved of, and lived quietly under his government.

Besides the foregoing children by his wife, Oliver is supposed to have had several illegitimate children; for though a great devotee, and affecting an outward sanctity of manners, he is known to have indulged himself, after he arrived at power, with the company of ladies, and that not in the most innocent manner.

\section{WiLLIAM LILLY.}

Some account of this man has been given in many publications; but he was altogether so remarkable a character, that a general outline of his history, in this place, may not be unacceptable to the curious reader:

He was born at Diseworth in Leicestershire, in 1692, and was put to school at Ashby-de-la-Zouch in the same county; but his father not being in circumstances to give him a liberal education, as he 
intended, at Cambridge, he was obliged to quit the school after leaining writing and arithmetic. Being then, as his biographers inform us, of a forward temper, and endued with shrewd wit, he resolved to push liis fortune in London, where he arrived in 1620, and where his immediate necessities obliged him to article himself as a servant to a mantua-maker, in the parish of St. Clement Danes. In 1624 he was assistant to a tradesman in the Strard; who not being able to write, employed hin, among other donestic offices, as his book-keeper." He had not been above three years in this place, when, his master dying, he addressed and married his mistress, with a fortune of 10001. In 1632 he turned his mind to astrology, and applied to one Evals, a worthless Welsh clergyman, who, after practising that craft many years in Leicestershire, had come to London, and at this time resided in Gunpowder-alley. Here Lilly became his pupil, and made such a quick progress, that he understood, in the cant of his brethren, how "to set a figure" perfectly in seven or eight weeks; and, continuing his application with the utmost assiduity, gave the public a specinen of his attainments and skill, by intimating that the king had chosen an unlucky horoscope for the coronation in Scotland, 1633.

In 1634, having procured a manuscript, with some alterations, of the "Ars Notoria" of Cornelius Agrippa, he became so infatuated by the doctrine of the magical circle, and the invocation of spirits, as not only to malie use of a form of prayer prescribed there to the angel Salmonæus, and to Lanoy himself, a favourite of great power and interest with that uncreaten phantom, but even to claim a knowledge of, and a faniliar acquaintance with, particular guardian angels of England, Salmaland Malchidael. After this he treated the nore common mystery of recovering stolen goods, \&c. with great contempt, claiming a supernatural sight, and the gift of prophetical predictions, and seems to have known well how to profit by the credulity of the times. Such indeed was lis fame, as to produce the following notable story.

When one Ramsay, the king's clock-maker, being informed that there was a great treasure buried in the cloister of Westminster Abbey, obtained the dean's (Dr. Williams, bishop of Lincoln) leave to search for it with the divining or Mosaical rods; he applied to Lilly for his assistance. Lilly, with one Scot, who pretended to the use of the said rods, attended by Ramsay and above thirty persons more, went into the cloister by night, and observing the rods to tumble over one another on the west side of the cloister, concluded the treasure lay hid under that spot; but the ground being dug to the depth of six feet, and nothing found but a coffin, which was not heavy enough for their purpose, they proceeded, without opening it, into the Abbey. Here they were alarmed by a storm, which suddenly arose, and increased to such a height, that they were afraid the west end of the church would have been blown down upon them : the rods moving not at all; and the candles and torches, all but one, being extinguished, or burning very dimly. Scot was amazed, looked pale, and knew not what to think or do ; until Lilly gave directions to dismiss the daemons, which when done, all was quiet again, and each man returned home. Lilly, however, took care not to expose his skill again in this manner, though 
he was cunning enough to ascribe the miscarriage, not to any defect in the art itself, but to the number of people who were present at the operation, and divided it; shrewdly laying it down for a rule, that secrecy and intelligent operators, with strong confidence and knowledge of what they are doing, are necessary requisites to succeed in this work.

In the mean tine he buried his first wife, purchased a moiety of thirfeen houses in the Strand, and married a second wife, who, joilling to an extravagant temper a termagant spirit, which all his art could not lay, made him both poor and miserable. With this lady he was obliged to retire in $\mathbf{1 6 3 7}$, to Horsham, in Surrey, where he continued till September, 1641 ; and now seeing a prospect of advantage from the growing confusion of the times, and the prevalence of enthusiasm and credulity of all kinds, he returned to London. Here having purchased several curious books in his art, which were found on pulling down the house of another astrologer, he perused them with incessant diligence, and, in 1644, published his "Mertinus Anglicus Junior," and several other astrological books. He had contracted an intimacy, the preceding year, with Bulstrode Whitelocke esq., who was afterwards his friend and patron; and, in 1645, devoted himself entirely to the interests of the parliament after the battle of $\mathrm{Naseby}$, though he had before rather inclined to the king's party.

In 16.47, upon the breaking out of the quarrel between the parliament and army, whose head-quarters were at Windsor, he was sent for, together with Booker, another astrologer, by Fairfax the general, who addressed them in these terms : "That God had blessed the army with many signal victories, and yet their work was not finished; that he hoped God would go along with them until the work was done; that they sought not themselves, but the welfare and tranquillity of the good people, and the whole nation, and for that end were resolved to sacrifice both themselves and their fortunes; that they hoped the art which they, Lilly and Booker, studied, was lawful, and agreeable to God's word, and that he understood it not, but did not doubt they both feared God, and therefore had a good opinion of them."

To this speech Lilly returned the following answer:" "My lord, I am glad to see you here at this time; certainly, both the people of God, and all others of this nation, are very sensible of God's mercy, love, and favour unto them, in directing the parliament to nominate and elect you general of their armies, a person so religious, so valiant. The several unexpected victories obtained under your excellency's conduct will eternize the same unto posterity. We are confident of God's going along with you and your army, until the great work, for which he ordained you both, is fully perfected; which will be the conquering and subversion of yours and the parliament's enemies, and then a quiet settlement and firm peace over all the nation, unto God's glory, and full satisfaction of tender consciences. Sir, as for ourselves, we trust in God, and as Christians believe in him; we do not study any art but what is lawful, and consonant to the scriptures, fathers, and antiquity; which we humbly desire you to believe."

This audience, in November, seems to have been occasioned by a suspicion of his attachment to the royal party, of which he had 
afforded some ground by receiving an application from the king, then in custody of the army at Hampton-court; for in the August preceding, when his majesty had framed thoughts of escaping from the soldiery, and hiding himself somewhere near the city, he sent, as Lilly tells us, Mrs. Whorwood, to know in what quarter of the nation he might be safely concealed, till he thought proper to discover' himself. Lilly, having erected a figure, said the king might be safely concealed in some part of Essex, about twenty miles from London, where the lady happened to have a house fit for his majesty's reception, and went away next morning to acquaint him with it. But the king was gone away in the night westward, aud surrendered himself at length to Hammond, in the Isle of Wight; and thus the project was rendered abortive.

He was again applied to by the same lady in 1648 , for the same purpose, while the-king was at Carisbrook castle; whence having' laid a design to escape by sawing the iron bars of his chamber window, Mrs. Whorwood came to our author, and acquainted him with it. Lilly procured a proper saw, made by one Farmer, an ingenious locksinith, in Bow-lane, Cheapside, and furnished her with aquafortis besides, by which means his majesty had nearly succeeded; but his heart failing; he proceeded no farther. About September, the same lady came a third time to Lilly on the same errand. The parliament commissioners were now appointed to treat with his majesty; on which our astrologer, after perusing his figure, told the lady the commissioners would be there on such a day, appointed the day and hour when to receive them, and directed, as soon as the propositions were read, to sign then, and make haste with all speed to come up with the commissioners to London, the army being then far distant from London, and the city enraged stoutly against them. The king is said to have promised he would do so, but was diverted from it by lord Say.

All this while our astrologer continued true to his own interest, by serving that of the parliament party, from whom he received this year, 1648, fifty pounds in cash, and an order from the council of state for a pension of 100l. per ann. which was granted to him for furnishing them with a perfect knowledge of the chief concernments in France. This he obtained by means of a secular priest, with whom he had been formerly acquainted, and who now was confessor to one of the French secretaries. Lilly received the pension 'two years, when he threw it up, with the employment, on some account or other. He read public lectures upon astrology in 1648 and 1649 , for the improvement of young students in that art, and succeeded so well, both as a practitioner and teacher, that we find him, in 1651 and 1652, laying out near 2000l. in a house and lands at Horsham. During the siege of Colchester, he and Booker were sent thither to encourage the soldiers, which they did by assuring them that the town would soon be taken, which proved true, and was perhaps not difficult to be foreseen. In 1650 he published that the parliament should not continue, but a new government arise, agreeably thereto; and in the almanack for 1653 , he also asserted that the parliament stood upon a ticklish foundation, and that the commonalty would join together against them. On this he was called before the committee of plundered ministers, but 
receiving nothing; before the arrival of the messenger, he applied to speaker Lenthal, always his friend, who pointed out the offensive passages, which he immediately altered; and attended the committee next morning with six copies printed, which six alone he acknowledged to be his. By this trick he escaped, after having been only detained thirteen days in custody of the sergeant at arms. This year he was engaged in a dispute witl Mr. Thomas Gataker, and, before the expiration of the year, he lost his second wife, to his great joy, and married a third in October following. In 1655 he was indicted at Hicks'shall, for giving judgment upon stolen goods, but acquitted; and, in 1659, he received, from the king of Sweden, a present of a gold chain and medal, worth above 50l. on account of his having mentioned that monarch with great respect in his almanacks of 1657 and 1658 .

After the restoration, in 1660, being taken into custody, and examined by a conmittee of the house of commons, touching the execution of Charles I., he declared, that Robert Spairn, then secretary to Cromwell, dining with him soon after the fact, assured him it was done by cornet Joyce. This year he sued out his pardon under the great seal of England, and continued in London till 1665; when, on the appearance of the plague, he retired to his estate at Horsham. Here he applied himself to the study of physic, laving, by means of his friend Elias Ashmole, procured from archbishop Sheldon a license to practise it; and from October 1670, he exercised botl the faculties of physic and astrology till his deatl, which was occasioned by a paralytic stroke, in 1681, at Horsham. He was interred in the chancel of the church at Walton, and a black marble stone, with a Latin inscription, was paced over his grave, soon after, by Mr. Aslimole, at whose request also, Dr. Smabridge, bishop of Bristol, then a schiolar at Westminster-school, wrote a Latiu and English elegy on his death, both which are annexed to the history of our author's life and times, from which this nemoir is extracted.

Lilly, a little before his death, adopted one Henry Coley, a tailor, for his son, by the riame of Merlin Junior, and made him a present of the copyright, or good will, of his almanack, which had been printed six-and-thirty years successively; and Coley carried it on for some time. Lilly bequeathed his estate at Horsham to one of the sons of his friend and patron Bulstrode Whitelock; and his magical utensils came into the hands of Dr. Case, his successor, of facetious memory.-Lilly was author of many works.

\section{JAMES NAYLER,}

AN English Quaker in the seventeenth century, was remarkable both on account of the extravagance of the delusions which for some time possessed him and his followers, and the excessive severity of the punishment which was inflicted upon him. He was the soll of an industrious little farmer, who supported his family by the cultivation of his own estate; and was born in the parish of Ardsley, near Wakefield in Yorkshire, about the year 1616. He had a good natural capacity, and was taught to read and write his native tongue with correctness. About the age of twenty-two he married, and removed 
into the parish of Wakefield, where he continued till the breaking out of the civil wars in 1641. He then entered into the parliament army, and served as a soldier eight or nine years, at first under lord Fairfax, and afterwards as quarter-master in major-general Lambert's troop in Scotland; till, being disabled by sickness, he returned home about the year 1649. At this time he was a member of the Independent party, and continued so till the year 1651, when the preaching of George Fox made him a convert to the communion of the Quakers, as they are called. Among them he soon commenced preacher, and, according to their judgment, acquitted himself both well in speaking and writing.

In the beginning of the following year he imagined he heard a voice, calling upon him to renounce his kindred and his father's louse; and go into the west, promising that God would be with hin. In obedience to this voice, which he believed to be the voice of God, he went about preaching from place to, place, and greatly increased the numbers of the new sect. Towards the close of the year 1654, or early in 1655, he came to London, where he found a meeting of Friends which had been established by Edward Burrough and Francis Howgill, among whom be so greatly distinguished himself by his preaching, that many began to draw invidious comparisons between him and his brethren, which created uneasiness and differences in the society. To such a length did these proceed, that some women, admirers of Nayler, assumed the liberty of interrupting and disputing with Howgill and Burrougnin the midst of their preachings, and thus disturbed the peace of the meetings. For this conduct they were reproved by these preachers; upon which they complained so loudly and passionately to Nayler, that he was weak enough to take their part, and was so intoxicated with their flattering praises, that he became estranged from his best friends, who strongly disapproved of and lamented his conduct. In the year 1656 we find him in Devonshire, where he was committed to Exeter jail for propagating his opinions. Here he received letters from some of his female admirers and others, written in the most extravagant strains, calling hin the everlasting Son of righteousness - the Prince of peace-the only begotton Son of Godthe fairest among ten thousand, \&c.; and some of his followers kneeled before him in the prison, and kissed his feet. Before he could suffer such language to be applied to him, the intoxication of his brain must have arisen to frenzy, of which he soon afforded additional evidence. While he continued in this prison, George Fox called upon him, and reproved him for his defection and lofty pretensions; but without effect. At parting, Nayler would have kissed Fox ; but the latter told him, that since lie had turned against the power of God, he could not receive his show of kindness. And it is but justice to the Quakers in general to mention, that they had now disowned Nayler and his adherents.

Soon afterwards Nayler was released from imprisonment; and intended to return to London, but, taking Bristol in his way, as he passed through Glastonbury and Wells, his deluded attendants strewed their garments before him. . When they came to Bedminster, about a mile from Bristol, they carried their extravagance to the highest pitch ; 
for they formed a procession in imitation of our Saviour's entrance into Jerusalem, in which a man walked bare-headed before Nayler, and a woman led his horse, while other women spread their scarfs and handkerchiefs in the road, and the company sung, Holy, holy, holy, is the Lord God of hosts ; Hosanna in the highest! holy, holy, is the Lord God of Israel! In this manner these mad people made their entrance into Bristol, marching though the mire and dirt, to the amazement of some; and the diversion of others; but the nagistrates thought proper to interfere, and, after an examination into what had passed, committed them to prison. Soon afterwards they were sent to London, and a committee was appointed by parliament to examine witnesses against Nayler, upon a charge of blasphemy, for admitting religious worship to be paid to him, and for assuming the names and incommunicable titles and attributes of our blessed Saviour. Before the committee, he did not deny what was alleged concerning the extraordinary proceedings in Exeter jail, and at his entrance into Bristo.; while he defended himself, by maintaining that the honours which he-received were not shewn to him, but to Christ who dwelt within him; and that if they were offered to any other than to Christ, he disowned them.

However, the committee having made a report to the house on the tifth of December, declaring the charge well founded, on the following day he was sent for, and heard at the bar; and on the eighth they resolved that James Nayler is guilty of horrid blaspliemy, and that he is a grand impostor, and a great seducer of the people. The next business to be determined on was, the nature of the punishment to be inflicted on him; which occupied the debate of the house, both on forenoons and afternoons, till the sixteenth of December, many members being for putting him to death, (and losing their vote, as secretary Thurloe, informs us, only by fourteen voices,) while many other members totally disapproved of the severity which was used against him. At length, on the following day, after a considerable debate, the majority came to the resolution, "That James Nayler be set on the pillory! in the Palace-yard, Westminster, during the space of two hours, on Thursday next; and be whipt by the hangman through the streets from Westminster to the Old Exchange, and there likewise to be set with his head in the pillory, for the space of two hours, between the hours of eleven and one on Saturday next; in each place wearing a paper, containing an inscription of his crimes: And that, at the Old Exchange, his tongue be bored through with a hot iron; and that he be there also stigmatized in the forehead with the letter B: That he be afterwards sent to Bristol, and be conveyed into and through the said city on horseback, with his face backward, and there also publicly whipt the next market-day after he comes thither: And that from thence lie be committed to prison in Bridewell, London, and there restrained from the society of all people, and there to labour hard till lie be released by parliament; and, during that time, be debarred the use of pen, ink, and paper, and shall have no relief but what he earns by his daily labour.

This sentence was repugnant to humanity, equity, and wisdom; for, though the religious extravagancies of Nayler might reasonably 
shock pious and sober minds, yet his criminality ought to liave been estinated, not by the greatness of the titles and claims which he assumed, or were given him, but by the delusion and frenzy which had seized his brain. On this ground he was an object of pity, not of indignation, and he should have been assigned over to the physician for a cure of his madness, and not to the executioner of public justice to be punished. In its cruelty this sentence bears a great resemblance to that passed on Dr. Leighton by the infamous court of star-chamber ; and it vied with it in illegality, for the house of commons is no court of judicature, nor lias any power to inflict a punishment beyond imprisonment during its session. To the honour of humanity, however, it ought to be mentioned, that several persons had offered petitions to parliament on his behalf; but it was resolved not to read them till sentence had been passed.

On the eighteenth of December, the first part of it was carried into execution with the greatest rigour; but he was brought into a state of such extreme weakness by his cruel whipping, that, upon repeated applications to the parliament, his punishment was respited for one week. During this interval, many persons, looking upon him rather as a madman than guilty of wilful blasphemy, again interposed in his favour by a petition to parliament that the remainder of his punishment might be wholly remitted: but intolerance and vindictiveness resisted those solicitations. The Protector was then addressed, and wrote a letter to the house, which, though it occasioned sonie debate, obtained no resolution in favour of the prisoner. On this the petitioners presented a second address to Cromwell; but, it is said, the influence of the ministers prevented its effect. Five of these reverend gentlemen, Caryl Manton, Nye, Greffith, and Reynolds, went to Nayler, in order to bring him to an acknowledgnent of his ofience: but though in many respects excellent characters, they did not manage this interview in a manner worthy of themselves, or honourable to their memory; for they would admit no friends of his, nor any neutral or impartial person, into the room, although requested so to do. When Nayler insisted that what had passed should be put to writing, and a copy be left with him or the jailer, they consented; but on remarking, in the course of the conversation, when he thought that they were desirous of wresting his words, "How soon have you forgot the works of the bishop, who are now found in the same, seeking to ensnare the innocent!' they rose up with some warmth, burnt what they had committed to paper, and so left him, as he said, "with some bemoaning expressions."

On the twenty-seventh of December, the remainder of Nayler's sentence was executed at the Old Exchange. Afterwards he was sent to Bristol, where he was publicly whipt, from the middle of Thomasstreet, over the bridge to Broad-street; which punishment, we are told, he bore with wonderful patience, as he had done the former. From Bristol, he was brought back to Bridewell, London, where he was confined about two years; during which his mind recovered from the frenzy which had governed it, and he felt deep humiliation and sincere repentance on account of his past conduct. Having also, notwithstanding the prohibition in his sentence, found means to procure 
pen, ink, and paper, he wrote letters to the parliament, the magistrates of Bristol, and his friends, in which he acknowledged and condemned his extravagant behaviour, and asked forgiveness of all to whom he had given offence. He likewise wrote several small books, in which he retracted his past errors, and other pieces that are particularly mentioned by Sewell.

After the protector's death, Nayler was released from prison, and went to Bristol, where, in a public meeting, he made confession of his offence and fall, in a manner so affecting as to draw tears from most of those who were present, and having afforded satisfactory evidence of his unfeigned contrition, was again received into the communion of his friends. "Because God," says Sewell, "forgiveth the transgressions of the penitent, and blotteth them out, and remembereth them no more, so could James Nayler's friends do no other than forgive his crime, and thus take back that lost sheep into their society."

Nayler did not long survive his enlargement, for having left London in October 1660, with the intention of going home to his wife and children at Wakefield, he was taken ill in Huntingdonshire, where, it is said, he was robbed, and left bound in a field. Whether he received any personal injury is not known, but being found towards evening by a countryman, he was carried to a friend's house at Holm near King's Rippon, where he expired in the month of December, when about forty-four years of age. The expressions uttered by him about two hours before his death, both in justice to his name, which is so conspicuous in the history of the reveries of human imagination, and on account of their own excellence, ought not to be omitted in the memoirs of his life.

"There is a spirit which I feel," said he, "that delights to do no evil, nor to revenge any wrong, but delights to endure all things, in hopes to enjoy its own in the end. Its hope is to outlive all wrath and contention, and to weary out all exaltation and cruelty, or whatever is of a nature contrary to itself. It sees to the end of all temptation : as it bears no evil in itself, so it conceives none in thoughts to any other. If it be betrayed, it bears it, for its ground and spring is the mercies and forgiveness of God. Its crown is meetsess, its life is everlasting love unfeigned, and takes its kingdom with entreaty and not with contention, and keeps it by lowliness of mind. In God alone it can rejoice, though none else regard it, or can own its life. It is conceived in sorrow, and brought forth without any pity to it; nor doth it murmur at grief and oppression. It never rejoiceth but through sufferings; for with the world's joy it is murdered. I found it alone, being forsaken; I have fellowship therein with them who lived in dens, and-desolate places in the earth, who through death obtained this resurrection and eternal holy life." His writings were collected together, and published in an octavo volume in $\mathbf{1 7 1 6 .}$

\section{JoHn LILBURNe.}

THis remarkable character in the republican party, during the time of Charles. I. and Cromwell, was born in 1618, of an ancient family in the county of Durham. Being a younger son, he was sent at an early 
age, and with very little education, to an apprenticeship with an eminent wholesale clothier in London. He appears to have imbibed fiom his family those principles of opposition to what were thought illegal exertions of power in church and state, which then began to prevail: and he also inherited a bold, unquiet, and forward temper, which involved him in that perpetual series of contention and suffering by which his life was distinguished. He gave an early specimen of his disposition by a complaint before the city chamberlain against his master for ill-usage; and having carried his point, he was enabled to indulge his propensity for reading, which was turned to the religious systems and controversies at that time so much studied by the puritanical party. 'The book of Martyrs, in paricular, inspired him with an enthusiastic passion for encountering all dangers and sufferings in the canse of truth. He soon began to be taken notice of by those of similar sentiments; and was introduced by his pastor in 1636 , to Dr. Bastwick, then a star-chamber prisoner on account of sedition.

Contracting an intimacy-with this person, he was entrusted to carry over to Holland one of his anti-episcopal writings, in order to get it printed. On his return, he employed himself in similar occupations, till, being betrayed by an associate, he was apprehended, and found guilty, in the star-chamber court, of printing and publishing libels and seditious books. At his examinations he refused to answer interrogatories, and stood up so firmly for the privileges of Englishmen, that he acquired the appellation of Freeborn John. His sentence was to receive five hundred lashes at the cart's tail, and then to be set in the pillory, which was executed in April, 1638, with great severity; but his spirit was so far from being subdued by this treatment, that upon the pillory he uttered many invectives against the bishops, and threw pamphlets from his pockets among the crowd. For this contumacy he was remanded to prison, and kept double-ironed in one of the worst wards; yet here he contrived to get another libel printed and published. Such was the opinion of his desperate resolution, that a fire having taken place near his cell, he was thought to have caused it for his deliverance, and the other prisoners and neighbours joined in an application for his removal to a more airy situation.

On the meeting of the long parliament in 1640 , an order was made, in consequence of his petition to the house of commons, that he should have the liberties of the Fleet and a better apartment. In consequence of this indulgence, he was enabled to appear as one of the ringleaders of an armed mob which assembled at Westminster, and cried out for justice against the earl of Strafford ; for which he was brought to the bar of the house of lords on a charge of treason, but was dismissed.

In May, 1641, a vote passed the house of commons, "That the sentence of the star-chamber against Mr. Lilburne was illegal, barbarous, bloody, and tyrannical, and that reparations ought to be given him for his imprisonment, sufferings, and losses." When an army was raised by the parliament, Lilburne entered into it as a volunteer, and at the battle of Edgehill acted as a captain of infantry. He behaved with distinguished bravery at the affair of Brentford, where he was made prisoner, and carried to Oxford. He was there arraigned 
of high treason, but was saved by a declaration of parliament, threatening reprisals, and soon after was exchanged. He was received with triumph by his party, and rewarded with a purse of three hun: dred pounds.

When his general, the earl of Essex, began to urge the Scotch covenant in the army, Lilburie, who was attached to the principles of the Independents, left him, and obtained the commission of major of foot in the forces raised by the earl of Mauchester. 'The regiment in which he served was sent to garrison Boston in Lincolnshire, and he was diligent in putting the place in a good state of defence. Having quarrelled here with his colonel, the earl of Manchester made him lieutenant colonel to his own regiment of dragoons, in which situation he behaved with great bravery at the battle of Marston-moor, in 1644. Cromwell and Fairfax would willingly have given him a good post in the army, as new-modelled in 1645 ; but Lilburne's dislike to Presbyterian church government would not permit him to serve the party then in power, and he laid down his sword. This, however, was only to take up his other weapon, the pen, which he employed against Prynne, Lenthal, and other persons. He was in consequence conmitted to Newgate on a charge of seditious practices; but no bill being found against him, he was discharged without trial.

It would be a waste of the reader's time to enter into all the events of this man's turbulent life, which are detailed with extraordinary minuteness in the Biographia Britannica. A few incidents, most important to his character and that of the times, will suffice for the remainder of the article. Having thrown out some reflections against the earl of Manchester, for which he was brought before the house of lords, he treated the jurisdiction of that house with so much contempt, that he was committed first to Newgate, and then to the Tower. So much was he regarded by the people as the champion of liberty, that a remonstrance, signed by many thousand names, was presented to the house of commons in his behaif. This failing of effect, he continued to publish pamphlets, in which he displayed his grievances in such bold and virulent language, that he rendered the leading men of all parties his enemies.

Finding himself abandoned by the parliament, he endeavoured to engage the army in his favour; and as he conceived that his wishes were thwarted by Cromwell, he did not scruple to charge that powerful man with a design of usurping the sovereignty. He even brought a charge of high treason against Cromwell and Ireton, on account of which he was ordered to be tried for seditious and scandalous practices against the state. In conclusion, however, so active and numerous were his friends among the people, that the house of commons, in 1648, thought fit to discharge him from imprisonment, and make an order for giving lim satisfaction for his sufferings.

At the time of the king's death, Lilburne was extremely busy in plans for settling a new mode of government. Finding the army-leaders resolved to keep the power in their own hands, he opposed them with his usual intrepidity, and boldly maintained the right of the people to form a constitution for themselves. So dangerous did he aspear to Cromwell and his council, that he was again committed to the Tower, 
and brought to his trial for high treason, before a special commission, but was fully acquitted by the jury, to the great joy of the populace: Upon this occasion, a medal of his head was struck, with the following iinscription :- "John Lilburne, saved by the power of Grod and the integrity of his jury, who are judges of law as well as of fact.". The names of the jurymen are on the reverse. A new offence which he gave to the parliament, caused that body to pass a sentence of heavy fine and punishment against him, upon which he retired to Holland. Here he remained till the dissolution of the long parliament, when he used all his interest to obtain a passport for his return to England; but not succeeding, he ventured, in June 1653, to return without one. Being. apprehended and committed to Newgate, lie defended himself on the plea of illegality in his sentence of banishment; and this served him so well at his trial at the Old Bailey, that he was again acquitted by the jury. He was, however, ordered, to be re-transported; but giving security for his future quiet behaviour, he was suffered to remain. He now settled at Elham in.Kent, and having. apparently spent the contentious fir of his disposition, but retained his enthusiasm, he joined the Quakers, and preached at their meetings in Woolwich and other adjacent places, till his death, in $165 \%$, at the age of thirty-nine. He had a wife, who seems to have possessed the undaunted spirit of her husband, and was his faithful and affectionate helpmate in all his suffering's.

John Lilburne was certainly, according to Anthony Wood's expression, " a great trouble-world," in all the varieties of government. This may partly be ascribed to his natural disposition, which was such, that it is said, "If. there were no more living but him, John would be against Lilburne, and Lilburne against John." Yet it would be unjust not to grant him a pure and disinterested zeal for what he conceived to be justice and the public good; which he pursued against all parties, with an invincible spirit, through a life of persecution. As a writer, he was extremely vulgar and virulent, but not without acuteness and a show of reason. He was a firm supporter of the laws of his country, which in return often supported him, and proved effectual barriers against arbitrary violence.

\section{COLONEL BLOOD.}

Thomas BLOOD, commonly called Colonel Blood, was a disbanded officer of Oliver Cromwell, famous for his daring crimes and his good fortune. He was first distinguished by engaging in a conspiracy to surprise the castle of Dublin; which was defeated by the vigilance of the duke of Ormond, and some of his accomplices were executed. Escaping to England, he meditated revenge against Ormond; and actually seized him one night in his coach at'St. James's street, where he might have finished his purpose, if he had not studied refinement in his vengeance. He bound him behind one of his associates, resolving: to hang him at Tyburn, with a paper pinned to his breast; but when they got into the fields, the duke threw, himself, and the assassin to whom he was fastened, to the ground, and while they were struggling in the mire, he was rescued by his servants, but the authors of this attempt were not then discovered. 
After living a considerable time among the malcontents in Ireland, he went to Holland; where he became intimate with some of the principals of the republic, particularly the famous De Ruyter. He returned thence to England, with recommendations to the republican party; whence he went to Scotland, where he contributed much to the breaking out of the insurrection, and was present in the action of Pentland hills, Nov. 27, 1666; in which the insurgents were killed. He returned to England, where he rescued his friend Captain Mason from a party of soldiers who were conducting him to trial.

In 1671 Blood formed a design of carrying off the crown and regalia from the Tower: a design to which he was prompted, as well by the surprising boldness of the enterprise, as by views of profit; and was very near succeeding. He had bound and wounded Edwards the keeper of the jewel-office, and had got out of the Tower with his prey, but was overtaken and seized, with some of his associates. One of them was known to have been concerned in the attempt upon Ormond; and Blood was immediately concluded to be the ringleader: when questioned, he frankly avowed the enterprise, but refused to discover his acconiplices : "The fear of death," he said, "should never engage him to deny an offence, or betray a friend." All these extraordinary circumstances made him the subject of conversation, and the king was moved with an idle curiosity to see and speak with a person so noted for his courage and his crimes. Blood wanted not address to improve this opportunity of obtaining a pardon. He told Charles that he had been engaged, with others, in a design to kill him with a carabine about Battersea, where his majesty often went to bathe; that the cause of this resolution was the severity exercised over the collsciences of the godly, in restraining the liberty of their religious assemblies; that when he had taken his stand among the reeds, full of these bloody resolutions, he found his heart checked with an awe of majesty, and he not only relented himself, but diverted his associates from their purpose; and that he had long ago bronght himself to an entire indifference about life, which he now gave up for lost, yet he could not forbear warning the king of the dangers which might attend his execution; that his associates had bound themselves by the strictest oaths to revenge the deaths of any of their confederacy, and that no precaution nor power could secure ally one from the effects of their desperate resolutions. Whether these considerations excited fear or admiration in the king, they confirmed his resolution of granting a pardon to Blood; but he thought it a point of decency first to obtain the duke of Ormond's consent. Addington came to Ormond in the king's name, and desired that he would not prosecute Blood, for rean sons which he was commanded to give him. The duke replied, that his majesty's commands was the only reason that could be given; and being sufficient, he might therefore spare the rest. Charles carried his kindness to Blood still farther, and granted him an estate of five hundred a year in Ireland; he encouraged his attendance about his person, shewed him great countenance, and many applied to him for promoting their pretensions at court. And while old Edwards, who had been wounded in defending the crown and regalia, was neg lected, this man, who deserved to be hanged, became a favourite. 
Blood enjoyed his pension about ten years, till, being charged with fixing an imputation of a scandalous nature on the duke of Buckingham, he was thrown into prison; yet though the damages were laid at ten thousand pounds, Blood found bail. He died, however, soon after, on the 24th of August, 1680. But the public had now got such a notion of the restless spirit of Blood, than they did not believe he could rest even in his grave. Nor did they indeed permit him to do so ; for a story being circulated that lis death and burial were only a trick preparatory to some extravagant exploit, it gained credit to such a degree, that the body was obliged to be taken up, and the coroner's inquest to sit upon it, and to call witnesses to prove the identity of the colonel's corpse, before the public could be fully persuaded that so extraordinary a genius was actually dead.

\section{Tirumas Massianello.}

'THIs person was the son of a fisherman of Naples, and is remarkable for being the author of a temporary revolution in that state. In 1623 , when this man was born, Naples was subject to the house of Austria, and governed by a viceroy. The Neapolitans had supported the government in this house with great loyalty and liberality, and submitted themselves to many voluntary impositions and burdellsome taxes in support of it.' But in 1646, the necessities of the king requiring it, a new donation was projected, and a design was formed to lay a fresh tax upon fruits, comprehending all sorts, dry or green; as far as mulberries, grapes, figs, apples, pears, \&c. The people, being thus deprived of their ordinary subsistence, took a resolution to disburden themselves, not only of this, but of all other insupportable exactions formerly imposed. They made their grievances known to the viceroy by the public cries and lamentations of women and children as he passed through the market-place, and petitioned him, by means of the cardinal Feilomarino, the archbishop, and others, to take off the said tax. He promised to redress the grievance, and convened proper persons to find out some method to take off the tax on fruits. But the farmers, because it was prejudicial to their interest, found some secret mealls to frustrate his endeavours, and dissuaded him from performing his promise to the people; representing to him, that all the clamour was made only by a wretched rabble, not worth regarding.

Thomas Anello, or Massianello, now in his 24th year, dwelt in a corner of the great market-place at Naples. He was stout, of a good countenance, and a middle stature. He wore linen slops, a blue waistcoat, and went barefoot with a mariner's cap. His profession was to angle for little fish with a cane, hook, and line, as also to buy fish, and to retail them. This man, having observed the murmurings up and down the city, went one day very angry towards his house, and net with the famous banditto Perrone and his companion, as he passed by a church where they had fled for refuge. They asked him what ailed him? He answered in great" wrath, "I will be bound to be hanged, but I will right this city." They laughed at his words, saying, "A proper squire to right the city of Naples!". Massianello replied, 
replied, Do not laugh, I swear by God, if I had two or three of my humour, you should see what could do. Will you join with me?" They answered, "Yes," "Plight me then your faith ;"'which they having done, he departed. A little after, when his fish was taken from him by the court, because he had not paid the tax, he resolved to avail himself of the murmurings of the people against the tax on fruit. He went among the fruit shops that were in that quarter, advising them that the next day they should come all united to market, with a resolution to tell the country fruiterers that they would buy no more taxed fruit.

A number of boys used to assemble in the market place, to pick up such fruit as fell. Massianello got among these, taught them some cries and clamours suited to his purpose, and enrolled such a number of them between sixteen and seventeen years of age, thit they came to be 500 , and at last 2000 . Of this militia he made himself general, giving into the hands of every one of them a little weak cane. The shop-keepers observing his iustructions, there happened the next day a great tumult between them and the fruiterers, which the regent of the city set Anaclerio, the prefect of the city, to quell. Among the fruiterers was a cousin of Massianello's, who, according to the instructions given him, began more than any to inflame the people. He saw that he could sell his fruit but at a low price, which, when the tax was paid, would not quit cost. He pretended to fall in to a great rage, threw two large baskets on the ground, and cried out, "God gives plenty, and the bad government a dearth. I care not a straw for this fruit, let every one take of it." While the boys eagerly ran to gather and eat the fruit, Massianello rushed in among them, crying, "No tax! no tax!" and when Anaclerio threatened him with whipping and the galleys, not only the fruiterers, but all the people, threw figs, apples, and other fruits, with great fury in his face. Massianello hit him on the breast with a stone, and encouraged his militia of boys to do the same, which obliged Anaclerio to save his life by flight.

Upon this success, the people flocked in great numbers to the market place, exclaiming aloud against the intolerable grierances under which they gioaned, and protesting their resolution to submit no longer to them. 'The fury still increasing, Massianello leaped upon the highest table that was among the fruiterers, and liarangued the crowd; comparing himself to Moses, who delivered the Israelites from the rod of Pharoah; to Peter, who was a fisherman as well as himself, yet rescued Rome from the slavery of Satan; promising them a like deliverance from their oppressions by his means, and protesting his rea. diness to lay down his life in such a glorious cause. Massaniello repeated these and such like words until he had inflamed the minds of the people, who were soon disposed to co-operate with him for this purpose.

To begin the work, fire was put to the house next to the toll-house for fruit, both which were burnt to the ground, with all the books and accounts, goods and furniture. This done, every one shut up his shop, and, the numbers increasing, many thousand people uniting themselves, went to other parts of the city, where all the other tollhouses were; them they plundered of all their writings and books, great quantities of money, with many rich moveables; all which they 
threw into a great fire of straw, and burnt to ashes in the streets. The people meeting with no resistance, assumed more boldness, and made towards the palace of the viceroy. The first militia of the Massianello, consisting of 2000 boys, marched on, every one lifting up his cane with a piece of black cloth on the top, and with loud cries excited the compassion, and entreated the assistance, of their fellow-citizens.' Being come before the palace; they cried out that they would not be freed of the fruit tax only, but of all others, especially that of corn. At last they entered the palace, and rifled it, notwithstanding the resistance of the guards, whom they disarmed.

The viceroy got into his coach, to secure himself within the church of St. Lewis; but the people, spying him, stopped the coach, and, with naked swords on each side of it, threatened him, unless he would take off the taxes. With fair promises, and assurances of redress, and by throwing money among the multitude, which they were greedy to pick up, he got at last safely into the church, and ordered the doors to be shut. The people applied to the prince of Basignano, who was much beloved by them, to be their defender and intercessor. He promised to obtain what they desired; but finding himself unable, after much labour and fatigue, to restrain their licentiousness, or quell their fury, he took the first opportunity of retiring from the popular tumult.

After the retirement of the prince, the people, finding themselves without a head, called out for Massianello to be their leader and conductor, which charge he accepted. They appointed Genoino, a priest of approved knowledge, temper, and abilities, to attend his person; and to him they added for a companion the famous banditto Perrone. Massaniello, by his spirit, good sense, and bravery, won the hearts of all the people, insomuch that they became willing to transfer unto him solemnly the supreme command, and to obey him accordingly. A stage was erected in the middle of the market-place, where, clothed in white like a mariner, he with his counsellors gave public audience, received petitions, and gave sentence in all cases, both civil and criminal. He had no less than one hundred and fifty thousand men under his command. An incredible number of women also appeared with arms of various sorts, like so many Amazons. A list was made of about sixty persons, who had farmed the taxes, or been some way concerned in the custom houses; and, as it was said they enriched themselves with the blood of the people, and ought to be made examples to future ages, an order was issued, that their houses and goods should be burnt, which was executed accordingly, and with so much regularity, that no one was suffered to carry away the smallest article. Many, for stealing mere trifles from the flames, were hanged by the public executioner, in the market-place, by the command of Massianello.

While these horrid tragedies were acting, the viceroy thought of every method to appease the people, and bring them to an accommodation. He applied to the archbishop, of whose attachment to the government he was well assured, and of whose paternal care and affection for them the people had no doubt. He gave him the original charter of Charles V., which exempted them from all taxes, 
and upon which they had all along insisted, confined by lawful au thority, and likewise an indulgence or pardon for all offences whatever committed. The bishop found means to induce Massianello to convoke all the captains and chief commanders of the people together, and great hopes were conceived that a happy accommodation would ensue.

In the mean time 500 banditti, all armed on horseback, entered the city, under pretence that they came for the service of the people, but in reality to destroy Massianello, as it appeared afterwards, for they discharged several shots at him, some of which very narrowly missed him. This put a stop to the whole business, and it ivas suspected that the viceroy had some hand in the conspiracy. The streets were immediately barricaded, and orders were given that the aqueduct leading to the castle, in which were the viceroy and family and all the principal officers of state, should be cut off, and that no provisions, except some few roots and herbs, should be carried thither. The viceroy applied again to the archbishop, to assure the people of his sincere good intentions towards them, bis abhorrence of the designs of the banditti, and his resolution to use all his authority to bring them to due punishment. Thus the treaty was again renewed; and soon completed; which being done, it was thought proper that Massianello should go to the palace, to visit the viceroy. He gave orders that all the streets leading to it should be clean swept, and that all masters of families should hang their balconies and windows with their richest silks and tapestries. He threw off his mariner's habit, and dressed himself in cloth of silver, with a fine plume of feathers il his hat, and, mounted upon a prancing steed, with a drawn sword in his hand, went, attended by fifty-thousand of the people. While he was in conference with the viceroy in a balcony, he gave surprising proofs of the ready obedience of the people. Whatever cry he gave out, it was immediately echoed; when he put his finger upon his mouth, there was sucli a profound universal silence, that scarce a man was heard to breathe. At last he ordered that they should all retire, which was punctually and presently obeyed, as if they had all vanished away.

On the Sunday following the capitulations were signed, and solemnly sworn to, in the cathedral church, to be observed for ever. Massianello declared, that now having accomplished his honest designs, he would return again to his former occupation. If he had kept this resolution, he might have been ranked among the benefactors of his country; but either through the instigation of his wife and kindred, through fear, or allured by the tasted sweets of rule and power, he still continued his authority, and exercised it in such a capricious and tyrannical manner, that his best friends began to be afraid of him.

He seems to have fallen into a frenzy, which might naturally enough be occasioned by his sudden elevation, his care and vigilance, for lie seldom either ate or slept during the whole transaction, and by his immoderate drinking of strong wine, whicl excess he gave into, on the happy event. - Four persons took an opportunity of assassinating him. As he fell, he only cried out, "Ungrateful traitors!" His head was thrown into one ditch, and his body into another. The tumult, 
however, did not subside until the Neapolitans were entirely freed

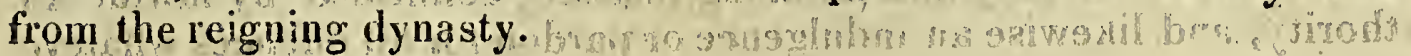

\section{Sruon Morrin.}

THis person was a celebrated French fanatic, who excited much attention at Paris in the seventeenth century : he was born about the year 1623, at Richmont, near Aumale in Normandy, of obscure pa. rents, who found means to procure him instruction in reading and writing, but they were not able to obtain a situation for him, in which he might earn his maintenance. He therefore went to try his fortune at Paris, where his good penmanship recommended him to the place of clerk in the office of M. Charron, extraordinary treasuier at war. Here he soon betrayed symploms of a deranged imagination, and indulged so much in his visionary contemplations, that his business was neglected, and he was dismissed from his employnent. He had now nothing to depend upon but his skill as a copyist, and having much leisure time, he spent it in a manner that increased the disorder of his mind, by listening to the reveries of the Illuminés, who were then numerous in Paris. In company with persons of this description, he was one day arrested, and committed to the prison belonging to the bishop's court; where his behaviour was in general so decent and inoffensive, that he was soon liberated. Having taken an apartment at the house of a woman who sold fruit and other refreshments to the frequenters of an adjoining tennis-court, he seduced the daughter of his hostess, whom he was obliged to marry. This adventure, however, did not produce any diminution of his religious enthusiasm, and he formed an acquaintance with several of the fives-players, who were weak enough to attend to his rambling harangues, and to be persuaded that he saw visions, and had supernatural divine communications. His apartment was soon found to be too small for the numbers who came to hear him, upon which he hired a much larger room in a neighbouring house. The police, however, being informed of those meetings, thought proper to arrest him a second time in 1664, and to immure him within the walls of the Bastille, where he was confined twenty-one months. At the expiration of that time he was again set at liberty, when his fanaticism appeared to have acquired fresh vigour during his hours of solitude, and he immediately set about composing his book: of Thoughts, designed to explain and to propagate more widely his, opinions. Manuscript copies of this piece were received with eager-, ness by his deluded followers; but the demand for it became so great, that in 1647 he caused it to be privately printed, with this title, "In the name of the Father, and of the Son, and of the Holy Spirit: The Thoughts of Morin, dedicated to the King," \&c. octavo. This work is a tissue of arrogance, wild fanaticism, and ignorance, and maintains some of the notions afterwards condemned in the Quietists, only that Morin carried them to a greater length of absurdity, mixed. with mad presumption : for he affirms, that there would quickly be a reformation in the church, and that all nations should be converted to the true faith. He pretends that this renovation was to be accomplished by the second coming of Jesus Christ, in his state of glory, 
incorporated in Morin himself; and that for the execution of the events to which he was destined, he was to be attended with a great number of perfect souls, and such as participated in the glorious state of Jesus Christ, whom he therefore called the champion of glory.

For this publication Morin was denounced to the lieutenant of the police, and thought proper to withdraw into concealment. Notwithstanding all his precautions, lowever, the place of his retreat. was discovered, and he was a second time imprisoned in the Bastile, where he continued till the beginning of the year 1649 . He then purchased his deliverance by a solemn abjuration of his errors, which he published the same year; and followed it by a printed declaration, some months afterwards, to the same purport, and professed unreserved submission to the dogmas of the church. It was not long after this that he retracted his abjuration, and again attempted to make converts to his opinions by private persuasions, and the writings of one of his disciples, published in 1650 and 1651, which were attributed to his own pen. Upon this the parliament of Paris gave directions for his arrest, and sentenced him by an arret to spend the remainder of his days in a house of confinement for lunatics. This sentence was revoked in 1656, upon his making a second abjuration; and he was again set at liberty. Still the frenzy of his mind was unsubdued, and he continued in secret to propagate his former opinions. He also composed, in 1661, with the design of its being circulated among his adherents through the instrumentality of Marets, a piece entitled, A Proof of the Second Advent on the Son of Man, and the Son of God in him. This agreement was so very satisfactory to our visionary, that he placed his entire confidence in Des Marets, and communicated to him all his secret opinions; conferring upon him at the same time, as a mark of special favour, the offer of his forerunner, calling him a true John the Baptist risen again.

Having thus obtained the evidence which he wanted, Des Marets basely impeached Morin of dangerous heresy; in consequence of which, he was taken into custody, just as he had put the finishing hand to a discourse which he was desirous of presenting to the king, beginning with these words:- "The Son of Man to the King of France." He was now again committed prisoner to the Bastile, whence he was afterwards brought to the Chatelet for trial, and there, on the deposition of Des Marets, was pronounced guilty of the charge preferred against him, and condemned to be burnt alive. Against this cruel sentence he appealed to the parliament, but without success; and it was carried into execution in 1663, when he was about forty years of age. It would have reflected greater honour on the justice and humanity of the parliament, if they had sent him once more to bedlam instead of the stake. At his execution his accomplices were condemned to be present, and then to be sent to the galleys for life, having been first whipped by the hangman, and branded with fleurs de-lis on the right and !eft shoulders. In this number there were two priests, and others of education superior to that of the vulgar. Those who have any curiosity to meet with further particulars concerning this fanatic; may be gratified by 
reading, it Moreri, an extract from a curious paper on the sub. ject, inserted in the twenty-seventh volume of father Niceroir $y$ Memoirs.

\section{Jack Adams, the Astrologer.}

Turs person lived in the reign of Charles II., and styled himself "Professor of the Celestial Sciences." He was very singular in his dress, and affected to cast his horoscopes with extraordinary gravity. When his predictions failed, he asserted that the' heavenly bodies did not absolutely compel, but only powerfully incline; and threw the blame upon wayward and perverse fate!

There is a portrait of this personage existing, in which he is thus designated: $-\infty$

"Magnifico Smokentissimo Custardissimo Astrologissimo, Cunningmanissimo, Rabbinissimo Vero.JACKo ADAMS, de Clarkenwell Greeno, hanc lovelissiman sui Picturam. Hobbedeboody, pinxit et stratchabat."

The following curious description accompanies the portrait :-

View here the wonder of Astrologers,

How solemnly he with himself confers:

Sure by his leaning posture we may guess

Some serious things his noddle doth possess.

The drum, tops, whips, and rattles, by his head

He seems to slight, whilst fortune he doth read.

Unto which purpose, with what earnestness,

See how the gallant doth his counsel press:

So earnestly as not to be denied,

Longing to have a Princess for his bride.

Joan, Queen of Sluts, as earnest doth importune

His worship would be pleased to tell her fortune;

Whilst he looks down with an intentive look,

On the twelve houses and poor Robin's book.

The medal which before him hangs on pin,

Is that which the Great Turk did send to him.

Nought else remaineth, that we should describe,

But horn-book and napkin by his side;

His pipe's at girdle, which he calls his gun;

His inkhorn a porridge pot: and so we have done.

\section{Anthony MaGLiabechi.}

This extraordinary man was born at Florence, October 28 or 29 , 1633. His parents, who were of low rank, are said to have been satisfied when they got him into the service of a man who 'sold fruit and herbs: He had never learned to read, and yet was perpetually poring over the leaves of old books, that were used as waste paper in his master's shop. A bookseller who lived in the neighbourhood, and who had often observed this, and knew the boy could not read, asked him "what he meant by staring so much on printed paper?" He said " that he did not know how it was, but that he loved it; and 
that he was very uneasy in his business, and should be the happiest: creature in the world, if he could live with him, who had always so many books behind him." The bookseller, pleased with his answer, consented to take him, if his master was willing to part with him. Young Magliabechi thanked him with tears in his eyes, and having obtained his master's leave, went directly to his new employment, which he had not followed long, before he could find any book that was asked for as readily as the bookseller himself.

This account of his early life, which Mr. Spence received from a gentleman of Florence who was well acquainted with Magliabechi and his family, differs considerably from that given by Nueron, Firaboschi, and Fabroni. From the latter, indeed, we learn that he was placed as an apprentice to a goldsmith, after he had been taught the principles of drawing, and he had a brother that was educated for the law, and made a considerable figure in his profession. His father died while he was an infant, but rabroni makes no mention of his poverty. It seens agreed, however, that after he had learned to read, that became his sole employment, but he never applied himself to any particular study. He read every book almost indifierently, as it happened to come to his hands, with a surprising quickness; and yet such was his prodigious memory, that he not only retained the sense of what he read, but often all the words, and the very manner of spelling them, if there was any thing peculiar of that kind in any author.

His extraordinary application and talents soon recommended him to Ermini, librarian to the cardinal de Medicis, and to Marmi, the grand duke's librarian, who introduced him into the company of the literati, and made him known at court. Every where he began to be looked upon as a prodigy, particularly for his vast and unbounded memory, of which many remarkable anecdotes have been given. A gentleman at Florence, who had written a piece that was to be printed, lent the manuscript to Magliabechi, and sonie time after it had been returned with thanks, came to him again with the story of a preteuded accident by which he had lost his manuscript. The author seemed inconsolable, and intreated Magliabechi, whose character for remembering what he had read was already very great, to try to recollect as much of it as he possibly could, and write it down for him against his next visit. Magliabechi assured him he would, and wrote down the whole Ms. without missing a word, or even varying any where from the spelling. Whatever our readers may think of this trial of his memory, it is certain that by treasuring up at least the subject and the principal part of all the books he ran over, his head became at last, as one of his acquaintance expresses it to Mr. Spence, "an universal index both of titles and matter."

By these means Magliabechi became so famous for the vast extent of his reading, and his amazing retention of what he had read, that he was frequently consulted by the learned, when meditating a work on any subject. For example, (and a curious example it is,) if a priest was going to compose a panegyric on any saint, and came to consult Magliabechi, he would immediately tell him who had said any thing of that saint, and in what part of their work. and that sometimes to the 
number of about a hundred authors. He would tell not only who had treated of the subject designedly, but point out such. as had touclred upon it only incidentally; both which he did with the greatest exactness, naming the anthor, the book, and often the very number of the page in which they were inserted. All this he did so often, so readily, and so exactly, that he came at last to be looked upon as an oracle, on account of the ready and full answers that he gave to all questions that were proposed to him, in any science or faculty whatever.

The same talent inducel the grand duke Cosno III. to appoint him his librarian; and no man, perhaps, was ever better qualified for the situation, or happy to accept it. He was also very conversant with the books in the Laurentian library, and the keeping of those of Leopold and Francis Maria, the two cardinals of Tuscany. Yet all this, it is said, did not appease his voracious appetite, he was thought to have read all the books printed before his time, and all in it. Doubtless this range, although very extensive, must be understood of Italian literature only or principally. Crescemberi paid him the highest compliment on this. Sperking of a dispute whether a certain poem had ever been printed or not, he concluded it had not, because Magliabechi had never seen it. We learn farther, that it was a general custom for authors and printers to present him with a copy of whatever they printed, which must have been a considerable help towards the very large collection of books which he himself made. His mode of reading in his latter days is said to have been this. When a book first came into his hands, he would look over the title-page, then dip here and there in the preface, dedication, and advertisements, if there were any, and then cast his eye on each of its divisions, the different sections or chapters, and then he would be able to retain the contents of that volume in his memory, and produce them if wanted. Soon after he had adopted this method, of what Mr. Spence calls "foreshortening his reading," a priest who had composed a panegyric on one of his favourite saints, brought it to Magliabechi as a present. He read it over in his new way, the title-page and heads of the chapters, \&c. and "then thanked the priest very kindly "for his excellent treatise." The anthor, in some pain, asked him "whether that was all that he intended to read of his book?" Magliabechi coolly answered, "Yes, for , I know very well every thing that is in it." This anecdote, however, nay be explained otherwise than upon the principles of memory. Magliabechi knew all that the writers before had said of this saint, and he knew this priest's turn and character, and thence judged what he would choose out of them, and what he would omit.

Magliabechi had even a local memory of the place where every book stood, as in his master's shop at first, and in the Pitti and several other libraries afterwards; and seems to have carried this farther than in relation to the collection of books with which he was personally acquainted. One day the grand duke sent for him after he was his librarian, to ask him whether he could get him a book that was particularly scarce. "No, sir," answered Magliabechi ; "for there is but one in the world, and that is in the grand signior's library at Constantinople, and is the seventh book on the second shelf on the right hand as you go in." 
Though this extráordinary man must have lived a sedentary life, with the most intense and alnost perpetual application to books, yet ye arrived to a good old age. He died in his eighty-first year, July 14, 1714. By his will, he left a very fine library of his own collection for the use of the public, with a fund to maintain it; and whatever should remain over, to the poor. By the funds which he left, by the addition of several other collections, and the bounty of some of the grand dukes, his library was so much augmented as to vie with some of the most considerable in Europe. Of this collection, a catalogue and description of the works printed in the fifteenth century were published by Fossi, under the title " Catalogus Codicum Saculo XV. impressorum in Bibliotheca Magliabechiana, Florentix adversantur," Florence, 3 vols. fol. 1793-1795.

Of the domestic habits of Magliabechi, we have many accounts that represent him as an incorrigible sloven. His attention was so entirely absorbed by his books and studies, that he totally neglected all the decencies of form and ceremony, and often forgot the most urgent wants of human nature. His employment under the grand duke did not at all change his manner of life: the philosopher still continued negligent in his dress, and simple in his manners. An old cloak served him for a gown in the day, and for bed-clothes at night. He had one straw chair for his table, and another for his bed; in which he generally continued fixed among his books till he was overpowered by sleep. The duke provided a commodious apartment in his palace ; of which Magliabechi was with much difficulty persuaded to take possession, and which he quitted in four months, returning to his house on various pretences, against all the remionstrances of his friends.

He was, however, characterized by an extraordinary modesty, and by a sincere and beneficent disposition, which his friends often experienced in their wants. He was a great patron of learned men, and had the highest pleasure in assisting them with his advice and information, in furnishing them with all necessary books and manuscripts. Cardinal Noris used to call him his Macenas; and writing to him one day, he told him, he thought himself more obliged to him for direction in his studies, than to the pope for raising him to the purple. He had the utmost aversion to any thing that looked like constraint. The grand duke knew his disposition, and therefore always dispensed with his personal attendance upon him; and when he had any orders to give him, sent him them in writing. The pope and the emperor would gladly have drawn him into their service, but he constantly refused their most honourable and advantageous offers. The regimen he observed contributed not a little to preserve his health to old age. He always kept his head warmly covered, and took at certain times treacle, which he esteemed an excellent preservative against noxious vapours. He loved strong wine, but drank it in small quantities. He lived upon the plainest and most ordinary food. Three hard eggs and a draught of water was his usual repast. He took tobacco, to which he was a slave to excess, but was absolute master of himself in every other article.

He died in the midst of public applause, after enjoying, during all the latter part of his life, such an affluence as very few persons have 
ever procured by their knowledge or learning, and which, as he had acquired honourably, he bestowed liberally.

Though he never composed any work himself, yet the commonwealth of learning is greatly obliged to him for several, the publication of which was owing to him, such as the Latin poems of Henry de Settimello, the Hodaporicon of Ambrose Camaldula, the Dialogue of Benedict Aretin, and many others. A collection of letters, addressed to him by literary men, was printed at Florence in 1725 , but it is said to be incomplete.

\section{JoIIN JAMES HEIDEGGAR.}

THIs very singular adveuturer was the son of a clergyman, and a native of Zurich in Switzerland, where he married, but left his country in consequence of an intrigue. Having had an opportunity of visiting the principal cities in Europe, he acquired a taste for elegant and refined pleasures, which by degrees qualified him for the management of public amusements. In 1708, when he was nearly 50 years old, he came to England on a negociation, from the Swiss at Zurich; but failing in hís embassy, he was entered as a private in the guards, for protection. By his sprightly engaging conversation and insinuating address, he soon became a favourite with our young people of fashion, from whom he obtained the appellation of the Swiss count, by which name he is noticed in the Tatler. He had the address to procure a subscription, with which, in 1709 , he was enabled to furnish out the opera of Thomyris, which was written in English, and perforned in the Queen's theatre in the Haymarket with such success, that he gained, by this performance alone, five hundred guineas. The judicious remarks he made on several defects in the conduct of our operas in general, and the hints he threw out for improving those entertainınents, soon established his character as a theatrical critic. Appeals were made to his judgment; and some very magnificent and elegant decorations, introduced upon the stage in consequence of his advice, gave such satisfaction to George II: who was fond of operas, that his majesty was pleased from that time to countenance him, and he soon obtained the chief management of the opera-house, in the Haymarket. He then undertook to improve another species of diversion, not less agreeable to the king, the masquerades; and over these he always presided at the King's theatre. He was likewise appointed master of the revels. The nobility low caressed him so much, and had such an opinion of his taste, that all splendid and elegant entertainments, given by them upon particular occasions, and all private assemblies by sulscription, were submitted to his direction, for which: he was liberally rewarded.

From the emoluments of these several employments, he gained a regular and considerable income : amounting, it is said, in some years to five thousand pounds, which he spent with much liberality, particularly in the maintenance of perhaps too luxurious a table; so that it may be said he raised an income, but never a fortune. His charity was so great, that after a successful masquerade, he has been known to give away several hundred pounds at a time. "You know poor 
objects better than I do, he would frequently say to the father of the gentleman who published this aneedote, "Be so kind as to give away this money for me." This well-known liberality, perhaps, contributed much to his carrying on that diversion with so little opposition as he met with.

That he was a good judge of music, appears from his opera; but this is all that is known of his mental abilities, unless it may be added, in honour of his memory, that he walked from Chairing-cross to Teniple-bar, and back again, and when he came home, wrote down every sign on each sile of the Strand.

As to his person, though he was tall and well made, it was not very pleasing, from an unusual hardness of features. But he was the first to joke upon his own ugliness ; and he once laid a wager with the earl of Chesterfield, that within a certain given time his lordship would not be able to produce so hideous a face in all London. After a strict search, a woman was found whose features were at first sight thought stronger than Heideggar's, but upon clapping her head-dress upon himself, he was universally allowed to have won the wager.

Jolly, a well-known tailor, carrying his bill to a noble duke; his grace, for evasion, said, "I never will pay you till you bring me an uglier fellow than yourself." Jolly bowed and retired, wrote a letter, and sent it by a servant to Heideggar, saying, "his grace wished to see him the next morning on particular business." Heideggar attended, and Jolly was there to meet him; and in consequence, as soon as Heideggar's visit was over, Jolly received the cash.

The late facetious duke of Montagu, the memorable contriver of the bottle-conjurer at the theatre in the Hay-Market, gave an entertainment at the Devil Tavern, Temple-bar, to several of the nobility and gentry, to whom he imparted his plot. Heideggar was invited, and, a few hours after dinner, was made drunk, and laid insensible upon a bed. A profound sleep ensued; when the late Mrs. Salmon's danghter was introduced, who took a mould from his face in plaster of Paris. From this a mask was made, and a few days before the next masquerade, at which the king promised to be present with the countess of Yarmouth, the duke made application to Heideggar's valet de chambre, to know what suit of clothes he was likely to wear, and then procuring a similar dress, and a person of the same stature, he gave him his instructions. On the evening of the masquerade, as soon as his majesty was seated, who was always known by the conductor of the entertainment and the officers of the court, though concealed by his dress from the company, Heideggar, as usual, ordered the music to play "God save the King ;" but his back was no sooner turned, than the false Heideggar ordered them to strike up " Charly over the Water." The whole company were instantly thunderstruck, and all the courtiers, not in the plot, were thrown into a stupid consternation. Heideggar flew to the music gallery, stamped and raved, and accused the musicians of drunkenness, or of being set on by some secret enemy to ruin him. The king and the countess laughed so immoderately, that they hazarded a discovery. While Heideggar stayed in the gallery, "God save the King" was the tune; but when, 
after setting matters to rights, he retired to one of the dancing rooms, to observe if lecorum was kept by the company, the counterfeit stepping forward, and placing himself upon the floor of the theatre, just in front of the music gallery, called out in a most audible voice, imitating Heideggar, and asked if he had not just told them to play "Charly over the Water ?" A pause ensued; the musicians, who knew his character, in their turn either thought him drunk or mad; hut, as he continued his vociferation, "Charly" was played again. At. this repetition of the supposed affront, some of the ofticers of the guards, who always attended upon these occasions, were for ascending the gallery, and kicking the musicians out; but the late duke of Cumberland, who could hardly contain himself, interposed. The company were thrown into great confusioll. Shame! shame! resounded from all parts, and Heideggar once more flew in a violent rage to that part of the theatre facing the gallery. Here the duke of Montagu artfully addressing himself to him, told him the king was in a violent passion, that his best way was to go instantly and make an apology, for certainly the musicians were mad, and afterwards to discharge them. Almost at the same instant he ordered the false Heideggar to do the same. The scene now became truly comic in the circle before the king. Heideggar had no sooner made a genteel apology for the insolence of his musicians, but the false Heideggar advanced, and in a plaintive tone cried out, "Indeed, sire, it was not my fault, but that devil's, in my likeness." Poor Heideggar turned round, stared, staggered, grew pale, and could not utter a word. The duke then humanely whispered in his ear the sum of his plot, and the counterfeit was ordered to take off his mask. Here ended the frolic; but Heideggar swore he would never attend any public amusement, if that witch, the waxwork woman, did not break the mould, and melt down the mask before his face.

Being once at supper with a large party, when a question was debated, which nation of Europe had the greatest ingenuity; to the surprise of all present, he claimed that character for the Swiss, and appealed to himself for the truth of it. "I was born a Swiss," said he, crand came to England without a farthing, where I have found means to gain five thousand a year, and to spend it. Now I defy the most able Englishman to go to Switzerland, and either to gain that income, or to spend it there." He died, September 4 th, 1749 , at the advanced age of ninety years, at his house' at lachmond, in Surrey, where he was buried. He left behind him one natural daughter, Miss Pappet, who was married, September 2, 1750, to captain, afterwards admiral Sir Peter Denis. Part of this lady's fortune was a house at the north-west corner of Queen-square, Ormond-street, which Sir Peter afterwards sold to the late Dr. Campbell, and purchased a seat in Kent, pleasantly situated near Westram, then called Valence, but now by its present preprietor, the earl of Hilborough, Hill Park.

\section{THOMAS DRITTON.}

THIs man, who is worthy of record for the singularity of his character and attainments in a humble condition, was born about 
the middle of the 17 th century, at or near Higham Ferrars, in Northamptonshire. He served as an apprentice to a small-coal man in London, and set up in the same trade in Clerkenwell. It was his business to go about the streets of London with his sack on his back, calling "Small Coals ;" but with this occupation, than which none can be meaner, he was a chemist, a collector of curious books, and, above all, a musical amateur. His taste for chemistry he imbibed from his neighbour, Dr. Garencieres ; and his ingenuity enabled him to contrive a moving laboratory, built by himself at a small expense, with which he performed many curious experiments. Of the nature of these we are not informed; but as many of the books he had picked up, related to the Rosicrucian philosophy, it is not improbable that he might waste some of his suall-coal in search after the grand secret. His daily rounds through a part of the town abounding in book-stalls, probably first made him a collector of curiosities in that way, and eventually introduced him to those acquaintances which so inuch distinguished him in his sphere of life.

About the commencement of the eighteenth century, a passion prevailed among several persons of distinction, for collecting old books and MSS.; and it was their Saturday's amusement during winter, to ramble through various quarters of the town, in pursuit of those treasures. The earls of Oxford, Pembroke, Sunderland, and Winchelsea, and the duke of Devoushire, were of this party, and Mr. Bagford and other-collectors assisted them in their researclies. Britton appears to have been employed by them; and as he was a very modest, decent, and unpresuming man, he was a sharer in their conversation, when they met after their morning's walk at a bookseller's shop in Ave-Maria-lane. Britton used to pitch his coal-sack on a bulk at the door, and, drest in his blue frock, to step in and spend an hour with the company.

But it was not only by a few bookish lords that his acquaintance was cultivated: his liumble roof was frequented by assemblies of the flash and gay; and this small-coal man has the singular honour of having set the first example in this country of that elegant and rational amusement, the musical concert. His fondness for music caused him. to be known to many amateurs and performers, who formed themselves into a club at his house, where capital pieces were played by some of the first professional artists and other practitioners. Dr. Pepusch, and even Handel, hare here displayed their powers on a harpsichord, and here Dubourg played his first solo on the violin. Britton's house was an old mean building, of which the ground-floor was a repository for coals; over this was the concert-room, long, low, and narrow, and ascended to by a pair of stairs from the outside, scarcely to be mounted without crawling. Yet some of the fairest ladies of the land were seen to trip up this awkward ascent without airs or hesitation.

This musical meeting commenced in $\mathbf{1 6 7 8}$, and it was affirmed that it was absolutely gratuitous; but in process of time, probably after Britton had taken a more convenient room in the next house, a subscription was made of ten shillings a year each, for which, however, he provided musical instruments. He had also a very good collection of ancient and modern music by the best authors. $\mathrm{Mr}$. 
John Hughes, the poet, who was a performer at. Britton's concert, has commemorated him in the following lines, inscribed beneath his engraved portrait:

Though mean thy rank, yet in thy humble cell

Did gentle Peace, and Arts unpurchased dwell.

Well pleas'd Apollo thither led his train,

And music warbled in her sweetest strain.

Cyllenius, so fable tells, and Jove,

Came willing guests to poor Philemon's grove,

Let useless Pomp behold, and blush to find

So low a station-such a liberal mind.

The singularity of Britton's mode of life, and the contrast between his station and his connexions, caused a variety of opinions to prevail concerning him and his meetings. He was taken for an atheist, a Jesuit, a sectary, and a conjurer, and his concerts were thought to be meetings for seditious or magical purposes. He was, however, a piain honest man, of an ingenious countenance and cheerful temper, and a sincere votary of the arts and studies in which he engaged. He appears rather to have been a general virtuoso, than a real proficient in any other branch, yet he played upon the viol-de-gamba at his own concerts; and the noted antiquary, Thomas Hearne, has attested his real skill in rare books and old manuscripts. He sold a large collection of these some years before his death, the printed catalogue of which, Hearne says, he has often looked over with wonder; and another collection of books and music, being the chief property he left behind him, was sold by his widow.

The circumstances of his death were as extraordinary as those of his life, if the story may be credited. A ventriloquist was introduced into his company by an acquaintance, who was lord of mischievous jests. This man, in a voice apparently coming from a distance, announced to poor Britton his approaching end, and bid him prepare for it by repeating the Lord's Prayer on his knees. Britton, whose mystical and magical books had probably made him credulous, obeyed the injunction, went home, took to his bed, and actually died in a few days. This was in September, 1714. He was buried, with a very respectful attendance, in Clerkenwell church-yard.

\section{Thomas Gux.}

THIS person, the founder of Guy's Hospital, was the son of Thomas Guy, lighterman and coal-dealer in Horseleydown, Sonthwark. He was put apprentice, in 1650, to a bookseller in the porch of Mercers' chapel, and set up trade with a stock of 2001 . in the house that forms the angle between Coruhill and Lombard-street. The English Bible being at that time very badly printed, Mr. Guy engaged with others in a scherre for printing them in Holland, and importing them; but this being put a stop to, he contracted with the university of Oxford for their privilege of printing them, and carried on a great Bible trade many years to considerable advantage. Thus he began to accumulate noney, and his gains rested on his hands; for, being a single man 
and very penurious, his expenses were very trifing. His custom was to dine on his shop-counter, with no other table-cloth than an old newspaper; he was also as little nice in regard to his apparel. The bulk of his fortune, however, was acquired by the less reputable purchase of seamen's tickets during queen Anne's wars, and by Southsea stock in the memorable year 1720 .

To shew what great events spring from-trivial causes, it may be observed, that the public are indebted to a most trifling accident for the greatest part of his fortunes being applied to charitable uses. Guy had a maid-servant, whom he agreed to marry ; and preparatory to his nuptials, he had ordered the pavement before his door to be mended, so far as to a particular stone which he marked. The maid, while her master was out, innocently looking on the paviers at work, saw a broken place they had not repaired, and mentioned it to them; but they told her that Mr. Guy had directed them not to go so far. "Well," says she, "do you mend it: tell him I bade you, and I know he will not be angry." It happened, however, that the poor girl presumed too much on her influence over her wary lover, with whom the charge of a few shillings extraordinary turned the scale entirely against her; for Guy, enraged to find his orders exceeded, renounced. the matrimonial scheme, and built hospitals in his old age.

In $\mathbf{1 7 0 \%}$ he built and furnished three wards, on the north side of the outer court of St. Thomas's hospital in Southwark, and gave 1001. to it annually for eleven years preceding the erection of his own hospital. Some time before his death he erected the stately iron gate, with the large houses on each side, at the expense of about 30001 . He was seventy-six years of age when he formed the design of build. ing the hospital near St. Thomas's, which bears his name. The charge of erecting this vast pile amounted to 18,7931 . besides 219,4991 . which he left to endow it: and he just lived to see it roofed in. He erected an almshouse, with a library, at Tamworth in Staffordshire, the place of his mother's nativity, (and which he represented in par'liament,) for fourteen poor men and women; and for their pensions, as well as for the putting out of poor children apprentices, bequeathed 125l. a year. To Christ's hospital he gave 4001 . a year for ever ; and the residue of his estate, amounting to about 80,000l. among those who could prove themselves in any degree related to him.

He died December 17, 1724, in the eighty-first year of his age, after having dedicated to charitable purposes more money than any one private man upon record in this kingdom.

\section{Alexander Menzikoff.}

THIs was a prince of the Russian empire, deeply concerned in the politics of his time. The general opinion of the origin of Menzikoff is, that his father was a peasant, who had placed him at Moscow with a pastry-cook, and that he carried little pies about the streets singing as he went. In this situation he was seen by the emperor Peter, who, pleased with the wit and liveliness, which on examination he found in him, took him about his person, and thus opened the way to his fortune. Others, however, say that his father was an officer 
in the service of the czar Alexis Michaelowitz, and that, as it was not extraordinary for gentlemen to serve in the stables of the czar, Menzikoff was there employed as one of the head-grooms, and that in this situation his talents were noticed by the czar, and his advancement begun.

Whatever may in this respect be true, it is certain, that when he had begun to attend the emperor, he soon made himself agreeable, and finally necessary, to that prince, whose projects he seconded with great address; and, having studied several languages, was able to be useful in various situations. Being appointed to the government of Ingria, his services in that situation obtained him the title of prince, with the rank of major-general in the army. He signalized himself in 1708 and 1709 ; but in 1713 he was accused of peculation, and condemned to pay a fine of three hundred thousand crowns. The czar, however, remitted the fine, and having received him again into his favour, sent him with a command into the Ukraine in 1719, and ambassador to Poland in 1722. When the czar died in 1725, Menzikoff had already contrived the means of continuing and increasing his power. He was aware of the designs of Peter to give his throne to the empress Catherine, and therefore, to secure her gratitude, Menzikoff prepared all parties to acquiese in this arrangement. Catherine was not insensible of her obligations to him, and agreed that her son, afterwards Peter II. should marry the daughter of Menzikoff, which she made an article in her will. At her death in $172 \%$, the prince being then under twelve years of age, Menzikoff was also one of the regency appointed by her will, and the most active member in it.

Snon after the accession of Peter II. that prince was affianced publicly to the daughter of Menzikoff, who then thought himself almost at the summit of happiness and elevation; he was made generalissimo by sea and land, duke of Cozel, and had the chief appointment in the household of the czar. Intoxicated at length with this extraordinary elevation, he behaved with-haughtiness towards the young czar, and with an imprudent ostentation in himself, which gave his enemies, particularly the princess Dolgomchi, the means of supplanting him in the affections of the prince, and compassing his final overthrow. His disgraces now followed fast upon each other.

The emperor removed from the palace of Menzikoff, whither he had hitherto resided, and he was ordered to quit Petersburgh, and pass the remainder of his days at Oranienburgh, a petty town on the borders of the Ukraine, which he had built and partly fortified. On his departure, he added to his other imprudences, that of setting out in great pomp; but on his journey he was overtaken by an order to seal up all his effects, and leave him nothing but necessaries. Many complaints being now preferred against him, he was condemned to live altogether, for the rest of his life, at Beresowa, situated on the most distant frontiers of Siberia. His wife, grown blind with weeping, died upon the jonrney. His three children fell sick of the small-pox, and one of them, a daughter, died of it. Menzikoff bore his nisfortunes with more firmness than might have been expected. He even recovered his health for a time, which had been injured by a grossness of habit, and, bcing allowed ten roubles a day, he not only found them suffin 
rient for his wants, but saved enough to build a small church, at which he worked himself. Yet he did not long survive his disgrace, for he died Nov. 2, 1729; and, it is said, of a plethora, there being no person at Beresowa skilful enough to open a vein. Some time after his death, the Dolgomkis being in their turn disgraced, his surviving son and daughter were recalled by the czarina Anne: the son marde an officer in the guards, with a restoration of the fifth part of his father's fortune; and the daughter had the appointment of maid of honour to the enipress, and soon after married advantageously.

Menzikoff had a very strong attachment to Peter I. and to his maxims for civilizing the Russian nation: He was afiable and polite towards strangers, that is, to all who were submissive, and not ambitious of eclipsing him in wit or other talents. His inferiors, in general, he treated with gentleness, and never forgot a service rendered to him. His courage was incontestable, and proved on many trying occasions. His friendship, when once fixed, was steady and zealous. On the other hand, his ambition was boundless; he could not bear a superior or an equal, much less a rival, in any quality or advantage. He was not destitute of wit, but for want of an early polish it was rather coarse. His avarice was insatiable, and led hin into several difficulties, even with his indulgent master Peter I; and when he was disgraced, he was found to possess the value of three millions of roubles, in jewels, plate, and money, besides his vast estates. There are many features of resemblance between Menzikoff and Wolsey, not only in his rise from a low origin, but more particularly in the imprudence, haughtiness, and ostentation, which accelerated his fall.

\section{Abrafian Suarp.}

THss eminent mathematician, mechanist, and astronomer, was descended from an ancient family at Little. Horton, near Bradford, in the West Riding of Yorkshire, where he was born about 1651. After completing his school education, he was put apprentice to a merchant at Manchester ; but having a strong attachment to mathematics, he quitted the mercantile business, and removed to Liverpool. Here he applied with great diligence to his favonrite study, but particularly to those branches which relate to astronomy; and to procure subsistence, he opened a school, where he taught writing and accounts.

Happening to meet with a merchant or tradesman, in whose house at London Mr. Flamsteed the astronomer then lodged, he engaged with him as clerk, that he might have an opportunity of becoming acquainted with that eminent man. He therefore left Liverpool, anc on his arrival at the capital soon made himself known to Mr. Flamsteed, by whose interest and recommendation he obtained a more profitable employment in the dock-yard at Clatham, where he remained till his friend and patron, convinced of his great merit in astronomy and mechanics, invited him to be his assistant in fitting up the apparatus in the royal observatory at Greenwich, which had been erected about the year 1676. In this situation Mr. Sharp continued to make observations, and had a considerable share in forming a catalogue of 3000 fixed stars, with their longitudes and magnitudes: 
their right ascension and polar distance, and the variations of the same while they change their longitude by one degree.

Being, howerer, of a weakly constitution, the fatigue of continually observing the stars at right, in a cold dense air, injured his health; and for the recovery of it he returned to his house at Horton, where, as soon as he found himself in a state of convalescence, he fitted up an observatory of his own, having first made an elegant and curious engine for tuming all kinds of work in wood or brass, and even irregular figures, as ovals, wreathed pillars, \&c. He constructed also most of the tools used by joiners, clock-makers, opticians, and mathematical instrument-makers. The limbs or ares of his large equatorial instrument, sextant, quatrant, \&c. he graduated with the nicest accuracy, by diagonal divisions, into degrees and minutes. The telescopes he used were all of his own making, and the lenses were ground and adjusted with his own hands.

At this time he assisted Mr. Flamsteed in calculating most of the tables in the second volume of his Historia Celestis, and made curious drawings of the constellations, which were sent to Amsterdam to be engraved; and though executed by a masterly hand, the originals are said to have exceeded the engravings in beauty. In the year 1689, Mr. Flamsteed completed his mural arc at Greenwich, and in the Prolegomena to his Historia Celestis, he acknowledges, in a most ample manner, the valuable assistance he received from Mr. Sharp, whom in the month of August, 1688, he had brought into the observatory as his amanuensis. As he was not only a skilful mathematician, but expert in mechanical operations, he employed him chiefly in the construction of the mural arc, which, in the course of fourteen months, he finished so much to Mr. Flamsteed's satisfaction, that he speaks of him in the highest terms of praise.

The ingenious Mr. Smeaton, in a paper published in the Philosophical Transactions for the year 1786 , says, that this mural arc may be considered as the first good and valid instrument of the kind, and that Mr. Sharp was the first person who cut accurate and delicate divisions upon astronomical instruments. The delicacy of Mr. Sharp's hand will permanently appear from the copper plates of a quarto book, published in the year 1\%18, entitled, Geometry improved by A. Sharp; or rather, $171 \%$, by $A$. S. Philomath, in which not only the geometrical lines on the plates, but the whole engraving of the letters and figures, were done by himself. At the same time this elaborate work affords an honourable proof of the author's great abilities as a mathematician, and contains things well worth attention: 1. A large and accurate table of Segments of Circles, with the method of its construction, and various uses in the solution of several difficult problems. 2. A concise treatise of Polyedra, or sulid bodies of many bases, both the regular ones and others; to which are added twelve new ones, with various methods of forming them, and their exact dimensions in surds or species, and in numbers. The models of these polyedra he cut out in box-wood with astonishing neatness and accuracy. Few or none of the mathematical instrument-makers, indeed, could exceed him in exactly graduating or neatly engraving any mathematical or astronomical instrument. In short, he possessed a remarkably 
clear head for contriving, and an extraordinary hand for executing, any thing, not only in mechanics, but in drawing, writing, and making the most exact schemes or figures in all his calculations and geometrical constructions.

In the year 1699 he undertook for his own private amusement the quadrature of the circle, deduced from two different series, by which the truth of it was proved to seventy-two places of figures, as may be seen in the introduction of Sherwin's tables of logarithms, where may be seen also his ingenious improvements on the making of logarithms, and the construction of the natural sines, tangents, and secauts. Mr. Sharp maintained an epistolary correspondence with most of the eminent mathematicians and astronomers of his time, as Mr. Flamsteed, Sir Isaac Newton, Dr. Halley, Dr.Wallis, Mr. Hodgson, Mr. Sherwin, \&c. and on the backs of his letters he received, wrote copies of his answers to them, in a short-hand of his own contrivance. It appears from a great variety of letters, which remained after his death, written by these and other celebrated mathematicians, that he spared neither pains nor time to promote real science. Being one of the most accurate and indefatigable computers that ever existed, he was for many years the common resource for Mr. Flamsteed, Sir Jonas Moore, Dr. Halley, and others, in all troublesome and delicate calculations.

On quitting Mr. Flamsteed, he retired to the village of Little Horton, in Yorkshire, where he spent the remainder of his days. He continued all his life a bachelor, and passed his time as recluse as a hermit. He was of a middling stature, but exceedingly thin, and being of a weakly constitution, fell into a state of great feebleness during the last three or four years of his life. He died on the 18th of July, 1742, in the 91st. year of his age. In his retirement at Little Horton, he employed four or five rooms or apartments for different purposes, and in these none of the family were ever suffered to enter without his permission. He had few visitors, except two gentlemen at Bradford, one a mathematician, and the other an ingenious apothecary. When he chose to be visible, these were admitted on making a signal, by rubbing a stone against a certain part of the outside wall of the house.

Every Sunday he regularly attended the dissenting chapel at Bradford, of which he was a member, and he always took care to be provided with plenty of halfpence, which he very charitably suffered to be taken singly out of his hand, held behind him during his walk to the chapel, by a number of poor people who followed him, without his ever looking back or asking a single question. He was remarkably sparing of his diet, and very irregular in his meals, which he frequently took in the following singular manner:

A small square hole or wicket formed a communication between the room where he was usually employed in his calculations, and another chamber or room to which his servant had access. This hole was closed by a sliding board, which he could remove at pleasure, and the servant always placed his victuals before the hole, without speaking or making the least noise. As soon as he had a little leisure, he visited his cupboard, to see what it afforded to satisfy his hunger or thirst: but it frequently happened that the breakfast, dinner, and supper were found untouched when the servant went to remove what 
had been left, so much had his thoughts been ellgaged in his calculations.-Cavities, it is said, might easily be perceived in an old English oak table, at which he was accustomed to write, occasioned by the continual rubbing and wearing of his elbows. By his epitaph, it appears that he was related to archbishop Sharp. Mr. Sharp the eminent surgeon was his nephew; aud another nephew was the father of Mr. Ramsden, the celebrated instrument-maker, who used to say, that his grand-uncle, the subject of this article, had been, some time in his younger days, an excise-man, but quitted that occupation on coming to a patrimonial estate of about 200 per annum.

\section{Alexander Selkirk.}

Thrs person, whose adventures gave rise to a well-known historical romance, Robinson Crusoe, was born at Largo, in Fife, in 1676, and was bred a seaman. He went from England in 1703, in the capacity of a sailing master of a small vessel, called the Cinque-Ports, Charles Pickering, captain, burden ninety tons, with twenty-six guns and sixty-eight men; and in September, the same year, sailed from Cork, in company with another ship of twenty-six guns and one hundred and twenty men, called the St. George, commanded by that famous navigator William Dampier, intending to cruise. against the Spaniards in the South Sea, ou the coast of Brazil. Pickering died, and was succeeded in his command by his lieutenant, Thomas Stradling. They proceeded on their voyage round Cape Horn to the island of Juan Fernandez, whence they were driven by the appearance of two French ships, of thirty-six guns each, and left five of Stradling's men there on shore, who were taken off by the French. Hence they sailed to the coast of America, where Dampier and Stradling quarrelled, and separated by agreement, on the nineteenth of May, 1704. In September following, Stradling came again to the island of Juan Fernandez, where Selkirk and his captain had a difference, which with the circumstance of the ship's being leaky and in very bad condition, induced him to determine on staying there alone; but when his companions were about to depart, his resolution was shaken, and he desired to be taken on board again. The captain, however, refused to admit him, and he was obliged to remain, having nothing but his clothes, bedding, a gun, and a small quantity of powder and ball; a hatchet, knife, and kettle; his books, and mathematical and nautical instruments. He kept up his spirits tolerably till he saw the vessel put off, when, as he afterwards related, his heart yearned within him, and melted at parting with his comrades and all human society at once. Such is the rooted love we bear mankind, ruffians as too many of them are.

Thus left sole monarch of the island, with plenty of the necessaries of life, he found himself in a situation hardly supportable. He had fish, goats, flesh, with turnips and other vegetables; yet he grew dejected, languid, and melancholy, to such a degree as to be scarcely able to refrail from doing violence to himself. Eighteen months passed before he could, by reasoning, reading his bible, and study, be thoroughly reconciled to his condition. At length he grew happy, em- 
ploying humself in decoratung his huts, chasing the goats, which he equalled in speed, and scarcely ever failed of catching. He also tamed young kids, and kept a guard of tame cats round him, to defend him when asleep from the rats, which were very troublesonie. When his clothes were worn out, he made others of goat-skins, but could not succeed in making shoes, with the use of which, however, habit in time enabled him to dispense. His only liquor was water. He computed that he had caught 1000 goats during his abode in this island; of which he had let go 500, after marking them by slitting their ears. Commodore Anson's people, who were there about thirty years after, found the first goat they shot upon the. island was thus marked, and, as it appeared to be very. old, concluded that it had been under the power of Selkirk. He made companions of his tame goats and cats, often dancing and singing with them; but he dreaded nothing so much as the thoughts of being eaten by his cats when he should be dead.

Though he constantly performed his devotion at stated hours, and read aloud; yet when he was taken off the island, his language, from disuse of conversation, was become scarcely intelligible. In this solitude he continued four years and forr months; during which time only two incidents happened which he thought worth relating, the occurrences of every day being in his circumstances nearly similar. The one was, that pursuing a goat eagerly, he cáught it just on the edge of a precipice, which was covered with bushes, so that he did not perceive it, and he fell over to the bottom, where he lay, according to Capt. Roger's account, twenty-four hours senseless; but, as he related it to $\mathbf{R}$. Steele, he computed, by the alteration of the moon, that he had lain three days. When he came to himself, he found the goat lying under him dead. It was with great difficulty that he could crawl to his habitation, whence he was unable to stir for ten days, and did not recover of lis bruises for a long time. The other event was the arrival of a ship, which was at first supposed to be French ; and such is the natural love of society in the human mind, that he was eager to abandon his. solitary felicity, and surrender himself to them, although enemies; but upon their landing, he found them to be Spaniards, of whom he had too great a dread to trust himself in their hands : they were by this time so near, that it required all his agility to escape, which he effected by climbing into a thick tree, being shot at several times as he ran off. Fortunately, the Spaniards did not discover him, though they stayed some time under the tree where he was hid, and killed some goats just by.

In this solitude Selkirk remained until the second of February 1909, when he saw two ships come into the bay, and knew them to be English. He immediately lighted a fire as a signal, and on their coming on shore, found they were the Duke, captain Rogers, and the Duchess, captan Courtnay, two privateers from Bristol. He gave them the best entertainment he could afford; and as they had been a long time at sea without fresh provisions, his goats were highly acceptable. His habitation, consisting of two huts, one to sleep in, the other to dress his food in, was so obscurely situated, and so difficult of access, that only one of the ship's officers would accompany him to it. Dam- 
pier, who was pilot on board the Duke, and knew Selkurk very well, told Captain Rogers, that, when on board the Cinque Ports, he was the best seaman on board of that vessel: upon which captain Rogers appointed him niaster's mate of the Duke.

After a fortnight's stay at Juan Fernandez, the ships proceeded on their cruise against the Spaniards; plundered a town on the coast of Peru; took a Manilla ship off California, and returned by way of the East Indies to Eugland, where they arrived the first of October, 1711; Selkirk having been absent eight years, more than half of which he had spent in the island.

The public curiosity being excited respecting hım, he was induced to put his papers into the hands of Daniel Defoe, to arrange and form them into a regular narrative. These papers must have been drawn up after he had left Juan Fernandez, as he had no means of recording his transactions there. Captain Cook remarks, as an extraordinary circumstance, that he had contrived to keep an account of the days of the week and month; but this might be done, as Defoe makes Robinson Crusoe do, by cutting notches in a post, or many other methods. From this account of Selkirk, Defoe took the idea of writing a more extensive work, the Romance of Robinson Crusoe, and very dishonestly defrauded the original propristor of his share of the profits.

Of the time, place, or manner, of this extraordinary man's death, we have received no account; but in $\mathbf{1 7 9 2}$ the chest and musket whi :h Selkırk had with him on the island, were in the possession of his grand-nephew, John Selkirk, weaver, in Largo.

Robinson Crusoe, the favourite of the learned and unlearned, of the youth and the adult, the book that was to constitute the library of Rousseau's Emilius, owes its secret charm to its being a new representation of human nature, yet drawn from an existing state; this picture of self-education, self-inquiry, self-happimess, is scarcely a fiction, although it includes all the magic of romance; and is not a mere narrative of truth, since it displays all the forcible genius of one of the most original minds our literature can boast. The history of the work is therefore interesting. It was treated in the author's time as a mere idle romance, for the philosophy was not discovered in the story: after his death it was supposed to have been pillaged from the papers of Alexander Selkirk, confided to the author; and the honour, as well as the genius, of De Foe, were alike questioned.

The entire history of this work of genius may now be traced from the first hints to the mature state, to which only the genius of De Foe could have wrought it.

In this artless narrative we may discover more than the embryo of Robinson Crusoe.-The first appearance of Selkirk, 'a man clothed in goat's skins, who looked more wild than the first owners of them ;' the two huts he had built, the one to dress his victuals, and the other to sleep in; his contrivance to get fire, by rubbing two pieces of pimento wood together; his distress for the want of bread and salt, till he came to relish his meat without either; his wearing out his shoes, till he grew so accusiomed to be without them, that he could not for a long time afterwards, on his return lome, use them withou 
inconvenience; his bedstead of his own contriving, and his bed of goat-skins; when his gunpowder failed, his teaching himself by continual exercise to run as swiftly as the goats; his falling from a precipice in catching hold of a goat, stunned and bruised, till, coming to his senses, he found the goat dead under him; his taming kids to divert himself, by dalling with them and his cats; his converting a nail into a needle; his sewing goat-skins with little thongs of the same, and when his knife was worn to the back, contriving to make blades out of some iron hoops; his solacing himself in this solitude by singing psalms, and preserving a social feeling in his fervent prayers; and the habitation which Selkirk had raised, to reach which, they followed him "with difficulty climbing up and creeping down many rocks, till they came at last to a pleasant spot of ground, full of grass and of trees, where stood his two huts, and his numerous tame goats shewed his solitary retreat;' and finally, his indifference to return to world, from which his feelings had beell so perfectly weaned:- such were the first rude materials of a new situation in human nature; an European in a primeval state, with the habits or mind of a savage.

The year after this account was published, Selkirk and his adventures attracted the notice of Steele; who was not likely to pass nnobserved, a man and a story so strange and so new. In his paper of "The Englishman," Dec. 1713, he communicates further particulars of Selkirk. When Steele became acquainted with him, he says he could discern that he had been much separated from conpany from his aspect and gesture. There was a strong but cheerful seriousness in his looks, and a certain disregard to the ordinary things about him, as if he had been sunk in thought. The mall frequently bewailed his return to the world, which could not, he said, with all its enjoyments, restore him to the tranquillity of his solitude." Steele adds another curious change in this wild man, which occurred some time after he had seen him. "Though I had frequently conversed with him after a few months' absence, he net me in the street, and though he spoke to me, I could not recollect that I had seen him. Familiar converse in this town had taken off the loneliness of his aspect, and quite altered the air of his face.' De Foe could not fail of being struck by these interesting particulars of the character of Selkirk; but probably it was another observation of Steele, which threw the germ of Robinson Crusoe into the mind of De Foe.

\section{John Law.}

TuIs person is usually known by the name of the Projector, and was the eldest son of a goldsmith, in Edinburgh, by Elizabeth Campbell, heiress of Laurieston, near that city, and born about 1681. He was bred to no business, but possessed great abilities, and a very fertile invention. He had the address, when but a very young man, to recommend himself to the king's ministers in Scotland, to arrange the revenue accounts, which were in great disorder at the time of settling: the equivalent before the union. He also laid before the Scots parliament a scheme for supplying the kingdom with money, by establishing a bank, which should issue paper to the value of the whole landed property in the kingdom; but his plan being thought too wild was rejected. 
His father dying about 1904, Law succecled to the small estate of Laurieston; but the rents being insufficient for his expense, he had recourse to gaming. He was tall and graceful in his person, and much addicted to gallantry; and giving a sort of ton at Edinburgh, he welt commonly by the name of Beau Law. He was forced to ty his country, however, in the midst of his career, in consequence of his having fought a duel, and lilled his antagonist. He escaped to Holland, thence proceeded to Venice, and wanderesl over Italy, studying the nature of banks, and making himself an adept in the mysteries of exchanges and re-exchanges.

At the close of the reign of Lewis XIV. when the French finances: were in great disorder, Law having obtained an audience, the bank:rupt king was delighted by his projects : but the minister Desmarest menacing him with the Bastile, obliged him to fly from Paris. He next applied to Victor Amadeus, Duke of Savoy, who told him he was not rich enough to ruin himself.

At the death of Lewis XIV. the regent Duke of Orleans, in despair; called in our numerical quack. By an arret of the second of March, 1716, a bank was established by authority, in favour of Law and his associates : 200,000 shares were instituted, of 1000 livies each; and Law deposited in it to the value of two or three thousand crowns, which he had accumulated in Italy by gaming. Many persons had at first little confidence in this bank; but when it was found that the payments were made with quickness and punctuality, they began to prefer its notes to ready money. In consequence of this, shares rose to more than twenty times their original value; and in 1719 , their valuation was more than eighty times the amount of all the current specie in the kingdom. Law was created Count Tankerville, and his native city humbly presented him with her freedom, in which appeas these remarkable expressions: "The city of Edinburgh presents its. freedom to John Law, count of Tankerville, \&c. \&c. a most accomplished gentleman, the first of all bankers in Europe, the fortunate inventor of sources of commerce in all parts of the remote world, and one who has so well deserved of his nation." Law was idolized ; the proudest courtiers were reptiles before this mighty man, and dukes and duchesses patiently waited in his ante-chamber. But in 1720, this mighty commercial meteor burst, and his immense fabric of false credit fell to the ground, and almost overthrew the French government, ruining some thousands of families; and it is remarkable, that the same game was played by the South Sea directors in England in the same fatal year 1720 .

Law being exiled as soon as the credit of his projects began to fail, retired to Venice, where he died in 1729 .

Montesquieu, who saw him there, says, "He is still the same man, his mind ever busied in financial schemes; his head is full of figures; of agios, and of banks. Of all his more than princely revenue, he has only saved a large white diamond, which, when he has no money, he pawns."

The principles upon which Law's original scheme of finance was founded, are explained by himself in "A Discourse concerning Money and Trade," which he pullished in Scotland. 


\section{JoHN HENLEY.}

This singular character is better known by the appellation of Orator Henley. He has furnished the world with memorials of himself, in a book entitled Oratory Transactions, which are in some respects worth preserving. He was born at Melton Mowbray, Leicestershire, Aug. 3, 1692. His father, the Rev. Simon Henley, and his grandfather by his mother's side, John Dowel, M.A. were both vicars of that parish. His grandfather by his father's side, John Henley, M.A. was likewise a clergyman, rector of Salmonby and Thetford in Lincolnshire. He was educated among the dissenters, and conformed at the Restoration.

Orator Henley was brought up first in the free-school of Melton, under Mr. Daffy, a diligent and expert grammarian. From this school he was removed to that of Okeham in Rutland, under Mr. Wright, eminent for his knowledge of the Latin, Greek, and Hebrew languages. About 1709, he entered of St. John's college, Cambridge, where, on his examination by Dr. Gower, then master, Dr. Lambert, Dr. Edmundson, and others, he was, he tells us, particularly approved. While an undergraduate at St. John's, he wrote a letter to the Spectator, dated from that college, Feb. 3, 1712, signed Peter de Quir, abounding with quaintness and local wit. He began here to be very soon uneasy; he was more inclined to dispute than to assent to any points of doctrine, and already fancied himself able to reform the whole system of acadenical education.

After he had commenced bachelor of arts, he was desired, by the trustees in the school in Melton, to assist in, and then to take the direction of, that school ; which he increased, and raised from a declining to a flourishing condition. He established here, he tells us, a practice of improving elocution, by the public speaking of passages in the classics, morning and afternoon, as well as orations, \&c. Here he was invited, by a letter from the Rev. Dr. Newcome, to be candidate for a fellowship in St. John's ; but as he had long been absent, and therefore lessened his personal interest, he declined appearing for it. Here likewise he began his Universal Grammar, and furnished ten languages, with dissertations prefixed, as the most ready introduction to any tongue whatever.

In the beginning of this interval he wrote a poem on Esther, which was approved by the town, and well received, as indeed it amply deserved. It is preceded by a learned preface, in which he discovers an intimate knowledge of Oriental studies, and some learned etymologies from the Persic, Hebrew, and Greek, concerning the name and person of Ahasuerus, whom he makes to be Xerxes. On the occasion of his grammars, Dr. Hutchinson wrote him a complimentary letter. He was ordained a deacon by Dr. Wake, then bishop of Lincoln; and after having taken his degree of M.A. was admitted to priest's order's by Dr. Gibson, his successor in that see. He did not long consent to rest in the country, but, impatient to obtain wealth and fame in London, resigned his offices of master and curate, and entered upon his new career.

In town, he produced several publications, as, a Translation of 
Pliny's Epistles, of several works of abbé Vertot, of Montfaucou's Italian Travels, in folio, and many other books. His principal patron was the earl of Macclesfield, who gave him a benefice in the country, the value of which, to a resident, would have been above eighty pounds a year; he had likewise a lecture, in the city ; and, according to his ow account, preached more charity sermons about town, was more numerously followed, and raised more for the poor children, than any other. preacher, however dignified or distinguished.

This popularity, with his enterprising spirit, and introducing regular action into the pulpit, were the true causes, he says, why some obstructed his rising in town, from envy, jealousy, and a disrelish of those who are not qualified to be complete spaniels:-for there was no objection to his being tossed into a country benefice "by the way of the sea, as far as Galilee of the Gentiles," like a pendulum, swinging one way as far as the other. Not being able to obtain preferment in London, and not choosing to return into the country, he struck out the plan of his Lectures or Orations, which he puffed with an aston:ishing vulgarity of arrogance, as usay be seen in the following specimen :

"That he should have the assurance to frame a plan which no mortal ever thought of; that he slould singly execute what would sprain a dozen of moderu doctors, of the tribe of lssachar; that he should have success against all opposition; challenge his adversaries to fair disputations, without any offering to dispute with him ; write, read, and study twelve hours a day, and yet appear as untouched by the yoke as if he never wore it; compose. three dissertations each week, on all subjects, however uncommon, treated in all lights and manners, by himself, without assistance; as some would detract from him; teach in one year, what schools and universities teach in five; offer to learn-to speak-and to read; not be terrified by cabals, or menaces, or insults, or the grave nonsense of one, or the frothy satire of another ; that he should still proceed, and mature this bold scheme, and put the church, and all that, in danger!-This man nust be a-a-a- \&c."

Henley, lectured on Sundays upon theological matters, and on Wednesdays upon all other sciences. He declaimed some years against the greatest persons, and occasionally, says Warburton," did Pope that honour." The poet retorts upon him in the well-known lines:

But where each science lifts its modern type,

History her pot, Divinity his pipe,

While proud Plilosophy repines to shew,

Dishonest sight! his breeches rent below;

Imbrown'd with native bronze, lo, Henley stands,

Tuning his voice and balancing his hands.

How fluent nonsense trickles from his tongue

How sweet the periods, neither said nor sung!

Still break the benches, Henley with his strain,

While Kennet, Hare, and Gibson preach in vain.

$O$ great restorer, of the good old stage,

Preacher at once and zany of thy age. 
This strange man struck medals, which he dispersed as tickets to his subscribers: A star rising to the meridian, with this motto, "Ad summa ;" and below , Inveniam viam, aut faciam." Each auditor paid one shilling. His audience was generally composed of the lowest ranks ; and it is well known, that he once collected a vast number of shoenakers, by announcing that he could teach them a speedy mode of operation in their business; which proved only to be, the making of shoes by cutting off the tops of ready-made boots! His motto on this occasion was "Omne majus continet in se minus." He was author of a weekly paper of unintelligible nonsense, called The Hyp-Doctor, for which secret service he had one hundred a year given him, and which was intended to counteract the effect of The Craftsman; a proof how little his patron, Sir Robert Walpole, knew of literary assistance. Henley used, every Saturday, to print an advertisement in the Daily Advertiser, containing an account of the subjects on which he intended to discourse on the ensuing evening, at his oratory near Lincoln's-InnFields. The advertisement had a sort of motto before it, which was generally a sneer at some public transaction of the preceding week.

Dr. Cobden, one of George II.'s chaplains, having, in 1748, preached a sermon at St. James's from these words: "Take away the wicked from before the king, and his throne shall be established in righteousiless ;" it gave so much displeasure, that the doctor was struck out of the list of chaplains; and the next Saturday, the following parody of his text appeared as a motto to Henley's advertisement:

\section{"Away with the wicked before the king, And away with the wicked behind him; \\ His throne it will bless. \\ With righteouswess, And we shall know where to find him."}

Henley died October 14th, 1756. In his account of himself, he assumes the credit of considerable learning, and a strong zeal for knowledge, which at one time certainly was the case; but his talents became miserably perverted, if we may judge from the specimens we have seen of his compositions. Both his style and his thoughts are low; vanity and censoriousness are the most conspicuous qualities, and his manners, become gross and ferocious, corresponded with his writings.

Orator Henley is a principal figure in two very humorous plates of Hogarth; in one of which he is christening a child: in the other, called the Oratory, he is represented on a scaffold; a monkey, over whom is written "Amen," by his side : a box of pills, and the Hyp-Doctor, lying beside him. Uver his head, The Oratory: "Inveniam viam, aut faciam." Over the door; "Ingredere at proficias." A parson receiving the money for admission. Under him, the Treasury. A butcher stands as porter. On the left hand, Modesty in a cloud; Folly, in a coach; and a gibbet prepared for Merit; people laughing. One marked "The Scout," introducing a puritan divine.

Henley, says a late judicious reviewer of his life, was a scholar of great acquirements, and of no mean genius; hardy and inventive, eloquent and witty, he might have been an oruament to literature, 
which he made ridiculous; and the pride of the pulpit, which he so egregiously disgraced; but having blunted and worn out that interior feeling, which is the instinct of the good man, and the wisdon of the wise, there was no balance in his passions, and the decorum of life was sacrificed to its selfishness. He condescended to live on the follies of the people; and his sordid nature had changed him; till he crept along, licking the dust with the serpent.

\section{Theodore Anthony I., King of Corsica.}

THIs personage, baron Niewhoff, grandee of Spain, baron of England, peer of France, baron of the holy empire, prince of the papal throne, (for this he styled himself, "a man whose chain to royalty," says lord Orford, "was as indisputable, as the most able titles to any monarchy can pretend to be," was born at Metz, about 1696. The particulars of his eventful history are thus related.

In March, 1736, while the Corsican malcontents were sitting in council, an English vessel from Tunis, with a passport from our consul there, arrived at a port then in possession of the malcontents. A stranger on board this vessel, who had the appearance of a person of distinction, no sooner went on shore, but was received with singular honours by the principal persons, who saluted him with the titles of excellency, and viceroy of Corsica. His attendants consisted of two officers, a secretary, a chaplain, a few domestic and Morocco slaves. He was conducted to the bishop's palace; called himself lord Theodore, whilst the chiefs knew more about him than they thought convenient to declare. From the vessel that brought him were debarked ten pieces of cannon, four thousand firelocks, three thousand pair of shoes, a great quantity of provisions, and coin to the amount of twenty thousand ducats. Two pieces of cannon were placed before his door, and he had four thousand soldiers posted for his guard. He created officers, twenty-four companies of soldiers, distributed among the malcontents the arms and shoes he had brought with him, conferred knighthood on one of his chiefs, appointed another his treasurer, and professed the Roman Catholic religion. Various conjectures were formed in different courts concerning him. The eldest son of the pretender, prince Ragotski, the duke de Ripperda, comte de Bonneval, were each in their turns supposed to be this stranger; all Europe was puzzled : but the country of this stranger was soon discovered; he was, in fact, a Prussian, well known by the name of Theodore Anthony, baron of Niewhoff.

Theodore was a knight of the Teutonic order, had successively been in the service of several German princes, had seen Holland, England, France, and Portugal; gained the confidence of the great at Lisbon, and passed there for a chargé-des-affairés from the emperor. This extraordinary man, with an agreeable person, had resolution, strong natural paris, and was capable of any enterprise. He was about fifty years of age. Upon his first landing, the chiefs of the Corsicans publicly declared to the people, that it was to him they were to be indebted for their liberties, and that be had arrived in order to deliver the island from the tyrannical oppressions of the Genoese. The 
general assembly offered him the crown, not as any sudden act, in to which they had been surprised, but with all the precaution that people could take to secure their freedom and happiness under it. "Theodore, however, contented himself with the title of governor-general. In this quality he assembled the people, and administered an oath for preserving eternal peace among themselves; and severely did he exact oljedience 10 this law.

He was again offered the title of king: he accepted it the 15 th of April, 1736, was crowned king of Corsica, and received the oath of fidelity from his principal subjects, and the acclamations of all the people. The Genoese, alarmed at these proceedings, publicly declared him and his adherents guilty of high treason; caused it to be reported, that he governed in the most despotic manner, even to the putting: to death many principal inhabitants merely because they were Genoese; than which nothing could be more false, as appears from the manifesto in answer to the edict. Theodore, however, having got together twenty-five thousand men, found 'himself master of a country where the Genoese durst not appear. He carried Porto Vecchio, and, May the third, blocked up the city of Bastia, but was soon obliged to retire. He then separated his force, was successful in his conquests, and came again before Bastia, which scon submitted to him. His court grew brilliant, and he conferred titles of nobility upon his principal courtiers.

Towards July, murmurs were spread of great dissatisfaction, arising from the want of Theodore's promised succours: on the other hand, a considerable armament sailed from Barcelona, as was supposed, in his favour; at the same time France and England strictly forbade their subjects in any way to assist the malcontents. September the second Theodore presided at a general assembly, and assured his subjects anew of the speedy arrival of the so much wanted succours. Debates ran high; and Theodore was given to understand, that before the end of October he must resign the sovereign authority, or make good his promise. He received in the mean time large sums, but nobody knew whence they came; he armed some barks, and chased those of the Genoese which lay near the lsland. He now instituted the order of Deliverance, in memory of his delivering the country from the dominion of the Genoese. The moneys he had received, he caused to be new coined; and his affairs seemed to have a promising aspect, but the scene presently changed.

In the beginning of November, he assembled the chiefs, and declared that he would not keejp them longer in a state of uncertainty, their fidelity and confidence demanding of him the utmost efforts in their favour, and that he had determined to find out in person the succours he had so long expected. The chiefs assured him of their determined adherence to his interests. He named the principal among them to take the government in his absence, made all the necessary provisions, and recommended to them union in the strongest terms. The chiefs, to the number of forty-seven, attended lim in the utmost respect, on the day of his departure, to the water-side, and even on board his vesse! ; where, after affectionately embracing them, he took bis leave, and they returned on shore, and went immediately to the 
respective posts which he had assigned them; a demonstrative proof this, that he was not forced out of the island, did not quit in disgust, or leave it in a manner inconsistent with his royal character.

Thus ended the reign of Theodore, who arrived in a few days, in the disguise of an abbé, at Livonia, and thence, after a short stay, conveyed himself nobody knew whither. The next year, however, he appeared at Paris ; was ordered to quit the kingdom in forty-eight hours ; precipitately embarked at Rouen, and arrived at Amsterdam, attended by four Italian domestics; took up his quarters at an inn, and there two citizens arrested him, on a claim of sixteen thousand florins. But he soon obtained a protection, and found some merchants, who engaged to furnish him with a great quantity of ammunition for his faithful islanders. He accordingly went on board a frigate of fifty-two guns, and one hundred and fifty men; but was suon afterwards seized at Napies, in the house of the Dutch consul, and sent prisoner to the fortress of Ceuta. This unhappy king, whose courage had raised him to a throne, not by a succession of bloody acts, but by the free choice of an oppressed nation, for many years struggled with fortune, and left no means untried which policy could attempt, to recover his crown. At length he chose England for the place of his retirement, where he might enjoy that liberty which he had so vainly attempted to give to his Corsicans; but his situation here by degrees grew wretched, and he was reduced so low as to be, several years before his death, a prisoner for debt in the King's Bench.

To the honour of some private persons, a charitable contribution was set on foot for him in 1753; and in $175 \%$, at the expense of the late lord Orford, a marble monument was erected to his memory, in the church yard of St. Anne's, Westminster, with the following inscription

Near this place is interred

Theodore King of Corsica,

who died in this parish December 11, 1756,

immediately after leaving the

King's-bench prison,

by the benefit of the Act of Insolvency ;

in consequence of which,

He registered his kingdom of Corsica, for the use of his Creditors.

The grave, great teacher, to a level brings

Heroes and beggars, galley-slaves and kings.

But Theodore this moral learn'd ere dead,-

Fate poured its lesson on his living head;

Bestowed a kingdom, and denied him bread.

Theodore had a son, known by the name of Colonel Frederic, who, after following his father into England, entered into the army in foreign service; but he appears to have been disappointed in his hopes of rising, or acquiring even a competence, and after sustaining many distresses, without timely relief, put an end to his life by a pistol, near the gate of Westminster Abbey, $x^{7} \mathrm{eb} .1,179 \%$ He was a man 
of gentlemanlike manners and accomplishments, and much regretted: by those who knew him intimately. He was interred in the churchyard of St. Anne's, Soho, by the side of his father. He published, in 1768, Nemoirs pour servir a l'Histoire de Corse, 12mo, of which there is an English translation; and A Description of Corsica, with an account of its temporary union to the crown of Great Britain, dec. 8vo.

\section{William Hogarti.}

THIs truly great and original genius, is said by $\mathrm{Dr}$. Burn to have been the descendant of a family originally from Kirby. Thore, in Westmorland. His grandfather, a plain yeoman, possessed a small tenement in the vale of Bampton, a village about fifteen miles north of Kendal in that county, and had three sons, the eldest of whon assisted his father in farming, and succeeded to his little freehold. The second settled in Troutbecks, a village eight miles north-west of $\mathrm{Ken}$ dal, and was remarkable for his talent at provincial poetry. The third, Richard, educated at St. Bees, and who had been a schoolmaster in the same county, went early to London, where he was employed as corrector of the press, and appears to have been a man of some learning; a dictionary in Latin and English, which he composed for the use of schools, being still extant in manuscript. He married in London, and kept a school in Ship-court in the Old Bailey: the subject of the present article, and his sisters Mary and Anne, are believed to have been the only product of the marriage.

William Hogarth was born in 1697, or 1698, in the parish of St. Martin, Ludgate. The outset of his life, however, was unpromising. "He was bound," says Mr. Walpole, "to a mean engraver of arms on plate:" Hogarth probably chose this occupation, as it required some skill in drawing, to which his genius was particularly turned, and which he contrived assiduously to cultivate. His master, it since appears, was Mr. Ellis Gamble, a silversmith of eminence, who resided in Cranbournstreet, Leicester fields. In this profession it is not unusal to bind apprentices to the single branch of engraving arms and ciphers on every species of metal, andin that particular department of the business young Hogarth was placed; but before his time expired, he felt the impulse of genius, and that directed him to painting."

During his apprenticeship, he set nut one Sunday, with two or three companions, on an excursion to Highgate : the weather being hot, they went into a public-house, where they had not bean long, befure a quarrel arose between some persons in the same room. One of the disputants struck the other on the head with a quart pot, and cut him very much. The blood running down the man's face, together with the agony of the wound, which had distorted his features into a most hideous grim, presented Hogarth, who shewed himself thus early "apprised of the mode nature intended he should pursue," with too laughable a subject to be overlooked. He drew out his pencil, and produced on the spot one of the most ludicrous figures that ever was seen. What rendered this piece the more valuable was, that it exhibited an exact likeness of the man, with the portrait of his 
antagonist, and the figures in caricature of the principal persons gathered round him.

How long he continued in obscurity we cannot exactly learu ; but the frst thing in which he distinguished himself as a painter, is sup joised to have been a representation of Wanstead Assembly. The igures in it, we are told, are drawn from the life, and without any circumstances of burlesque. The faces are said to have been extremely like, and the colouring rather better than some of his later and more highly finished performances. From the date of the first plate that can be ascertained to be the work of Hogarth, it may be presumed that he began business, on his own account, at least as early as 1720.

His first employment seems to have been the engraving of arms and shop-bills. The next step was to design and furnish plates for booksellers, and here we are fortunately supplied with dates. Thirteen folio prints, with his name to each, appeared in Aubry de la Mobraye's Golden Ass, in 1725; fifteen head-pieces to Beaver's Military Punishments of the Ancients; five frontispieces for the translation of Cassandra, in five volumes, 12mo. 1925 ; seventeen cuts for a duolecimo edition of Hudibras, with Butler's head, in 1726 ; two for Perseus and Andromeda, in 1730; two for Milton, the date uncertain; and a variety of others, between 1726 and 1733. Mr. Bowles, at the Black Horse in Cornhill, was one of his earliest patrons, but paid him very low prices. His next friend, in the same business, was Mr. Philip Overton, who rewarded him somewhat better for his labour and ingenuity.

There are still many family pictures by Hogarth existing, in the style of serious conversation-pieces. What the prices of his portraits were, Mr. Nichols strove in vain to discover; but he suspected that they were originally very low, as the persons who were best acquainted with them chose to be silent on the subject. At Rivenhall, in Essex, the seat of Mr. Western, is a family picture by Hogarth, of Mr. Western and his mother, chancellor Hoadley, archdeacon Charles Plumptre, the Rev. Mr. Cole of Milton near Cambridge, and Mr. Henry Taylor, curate there, 1736. In the gallery of Mr Cole, of Milton, was also a whole length picture of Mr. Western by Hogarth, a striking resemblance. He is drawn sitting in his fellow-commoner's habit, and square cap with a gold tassel, in his chamber at Clare-hall, over the arch towards the river; and the artist, as the chimney could not be expressed, has drawn a cat sitting near it, agreeable to his humour, to shew the situation. Mr. Western's mother, whose portrait is in the conversation-piece at Rivenlall, was a daughter of Sir Anthony Shirley.

It was Hogarth's custom to sketch out on the spot any remarkable face which particularly struck him, and of which he wished to preserve the remembrance. A gentleman informed his biographer, thas being once with him at the Bedford coffee-house, he observed him drawing something with a pencil on his nail. Inquiring what had been his employment, he was shewn a whimsical countenance of a person who was then at a small distance.

It happened in the early part of Hogarth's life, that a noman, who was uncommonly ugly and deformed, cane to sit to him for his 
picture. It was executed with a skill that did honour to the artists ability; but the likeness was rigidly observed, without even theneces. sary attention to compliment or flattery. The peer, disgusted at this counterpart of his dear self, never once thought of paying for a reflector, that would only insult him with bis deformities. Some time was suffered to elapse before the artist applied for his money; but afterwards many applications were made by him (who had then no need of a banker) for payment, but without success. The painter, however, at last hit upon an expedient which he knew must alarm the nobleman's pride, and by that means answer his purpose. It was couched in the following card. "Mr. Hogarth's dutiful respects to lord and finding that he does not mean to have the picture which was drawn for him, is informed again of Mr. H.'s necessity for the money if, therefore, his lordship does not send for it in three days, it will be disposed of, with the addition of a tail, and some other little appen. dages, to Mr. Hare, the famous wild-beast man; Mr. H. having given that gentleman a conditional promise of it for an exhibition picture, on his lordship's refusal." This intimation had the desired effect: The picture was sent home, and committed to the flames:

Mr. Walpole has remarked, that if our artist indulged his spirit of ridicule in personalities, it never proceeded beyond sketches and drawings, and "that he never, with intention, produced caricatures of the very features of any identical person." But this elegant writer, who may be said to have received his education in a court, had perhaps few opportunities of acquaintance among the low popular characters with which Hogarih occasionally peopled his scenes. The friend who contributed this remark, was assured by an ancient gentleman of unquestionable veracity and acuteness of remark, that almost all the personages who attended the "Levee of the Rake" were undoubted portraits ; and that in "Southwark Fair," and the "Modern Midnight Conversation," as many more were discoverable. on the former plate be pointed out Essex the dancing-master; and in the latter, as well as in the second plate to the "Rake's Progress," Fig, the prize-fighter. He mentioned several others by name, from his immediate knowledge both of the painter's design anil the characters represented; but the rest of the particulars by which he supported his assertions, have escaped the memory of our informant. 10 While Hogarth was painting the "Rake's Progress"" he had a summer residence at Isleworth, and never failed to question the company who came to see these pictures, if they knew for whom one or another figure was designed. When they guessed wrongly, he set them right. The duke of Lecds has an original scene in the Beggar's Opera, painted by Hogarth. It is that in which Lucy and Polly are on their knees before their respective fathers, to intercede for the life of the hero of the piece. All the figures are either known, or supposed to be portraits. If we are not misinformed, the late Sir Thomas Robinson, better known perhaps by the name of Long $\operatorname{Sir}$ Thomas, is standing in one of the side-boxes. Macheath, unlike his spruce representative on our present stage, is a slouching bully. and Polly appears happily disencumbered of such a hoop as the daughter of Peachum, within the reach of younger memories, has worn $T$ The 
duke gave thirty-five pounds for this jicture at Mr. Rich's auction. Another copy of the same scene was bought by the late Sir Willitin Saunderson, and is now in the possession of Sir Harry Gougli. Mr. Walpole has a picture of a scene in the same piece, where Macheath. is going to execution In this, also, the likenesses of Walker and Miss Fenton, afterwards duchess, of Bolion, the original Macheath, and Polly are preserved.

In the year 1726, when the aftair of Mary Tofts, the rabbit-breeder, of Godalmin, engaged the public attention, a few of the principal surgeons suliscribed their guinea apiece to Hogarth for an engraving from a ludicrous sketch he had made on that very popular subject. This plate, amongst other portraits, contains that of St. Andre, then anatomist to the royal household, and in high credit as a surgeon. In 1727, Hogarth agreed with Morris, an upholsterer, to furnish him with a design on canvass, representing the element of earth as a pattern for tapestry. The work not being performed to the satisfaction of Morris, he refused to pay for it, but the artist by a suit at law recovered the money.

In 1730, Hogarti married the only daughter of Sir James Whornhill, by whom he bad no child. This union, indeed, was a stolen one, and probably without the approbation of Sir James, who, considering the youth of his danghter, then barely eighteen, and the slender finances of her husband, as yet an obscure artist, was not easily reconciled to the match. Soon after this period, however, he began his "Harlot's Progress," and was advised by lady Thornhill to have some of the scenes in it placed in the way of his father-in-law. Accordingly, one morning early, Mrs. Hogarth undertook to convey several of them into his dining-room. When they arose, he inquired whence they came, and being told by whom they were introduced, he cried out, "Very well! the man who can furnish representations like these, can also maintain a wife without a portion." He designed this remark as an excuse for having kept his purse-strings close; but soon after became both reconciled and generous to the young couple.

An allegorical ceiling by Sir James Thornhill is at the house of the late Mr. Huggins, at Headly-park, Hants. The subject of it is a story of Zephyrus and Flora; and the figure of a satyr and some others were painted by Hogarth. In 1732, he ventured to attack Mr. Pope, in a plate called, "The Man of Taste," containing a view of the gate of Burlington-house, with Pope white-washing it, and bespattering the duke of Chandos's coach. This plate was intended as a satire on the Translation of Homer, Mr. Kent the architect, and the earl of Burlington. It was fortunate for Hogarth that he escaped the lash of the first. Either Hogarth's obscurity at that time was his protection, or the bard was too prudent to exasperate a painter who had already given such proof of his abilities for satire. What must he have felt, who could complain of the pictured shape prefixedoto "Gulliveriana," "Pope Alexander's Supremacy and Infallibility exanined," by Ducket, and other pieces, had such an artist as Hogarth undertaken to express a certain transaction recorded by Cibber: urge Soon afier his marriage, Hogarth had summer lodgings at SouthLambeth; and, being intimate with Mr. Tyers, contributed to the 
improrement of the Spring Gardens at Valixhall, by the hint of embellishing them with paintings, some of which were tlie suggestions of his own truly comic pencil. For his assistance, Mr. Tyers gratefully presented him with a gold ticket of admission for himself and his friends, inscribed, "In Perpetuam Beneficii Menoriam." This ticket remained in possession of his widow, and was by her occasionally employed.

In 1733 his genius became conspicuously known. The third scene of his "Harlot's Progress" introduced him to the notice of the great. At a board of treasury, which was held a day or two after the appearance of that print, a copy of it was shewn by one of the lords, as containing, among other excellencies, a striking likeness of Sir John Gonson. It gave universal satisfaction: from the treasury each lord repaired to the print-shop for a copy of it, and Hogarth rose completely into fame.

The ingenious abbe $\mathrm{Du}$ Bos has often complained, that no historical painter of his time went through a series of actions, and thus, like an historian, painted the successive fortunes of a hero from the cradle to the grave. What $\mathrm{Du}$ Bos wished to see done, Hogarth performed. He launches out his young adventurer, a simple girl, upon the town, and conducts her through all her vicissitudes of wretchedness to a premature death. This was painting to the understanding and to the heart; none had ever before made the pencil subservient to the purposes of morality and instruction; a book like this is fitted to every observer, and he that runs may read.

Nor was the success of Hogarth confined to his figures. One of his excellencies consisted in what may be termed the furniture of his pieces; for as in sublime and historical representations the more seldom trivial circumstances are permitted to divide the spectator's attention from the principal figures, the greater is their force ; so in a series copied from familiar life, a proper yariety of little domestic images contributes to throw a degree of verisimilitude on the whole. "The rake's levee room," says Mr.Walpole, "the nobleman's diningroom, the apartments of the husband and wife in Marriage-à-la-Mode, the alderman's parlour, the bed-chamber, and many others, are the history of the manners of the age."

The novelty and excellence of Hogarth's performances soon tempted the needy artist and print-dealer to avail themselves of his designs, and rob him of advantages to which he was entitled from them. This was particularly the case with the "Midnight Conversation," the "Harlot's" and "Rake's" Progresses, and others of his early works. To put a stop to depredations like these on the property of himseif and others, and to secure the emoluments resulting from his own labours, as Mr. Walpole observes, he applied to the legislature, and obtained an act of parliament, 8 Geo. II. cap. 38. to vest an exclusive right in designers and engravers, and to restrain the nultiplying of copies of their works, without the consent of the artist. This statute was drawn by his friend Mr. Huggins, who took for his model the eighth of queen Anne, in favour of literary property; which was so accurately executed as entirely to remedy the evil; for, in a cause founded on it, which cane before Lord Hardwicke in chancery, that 
excellent lawyer determined, that no assignee, claiming under an assignment from the original inventor, could take any benefit by it.

Hogarth, immediately after the passing of the act, published a small print with emblematical devices, and an inscription expressing his gratitude to the three branches of the legislature. Small copies of the "Rake's Progress" were published by his permission. In 1745, finding that, however great the success of the prints might be, the public were not inclined to take his pictures off his hands, he was induced to offer some of them, and those of the best he had then produced, for disposal by way of auction; but after a plan of his own, viz. by keeping open a book to receive biddings, from the first day of February to the last day of the same month, at twelve o'clock. The ticket of admission to his sale was his print of "The Battle of the Pictures," a humorous production, in which he ingeniously upheld his assertions concerning the preference so unfairly given to old pictures; and the tricks of the dealers in them. The pictures thus disposed of were :

f. s. d.

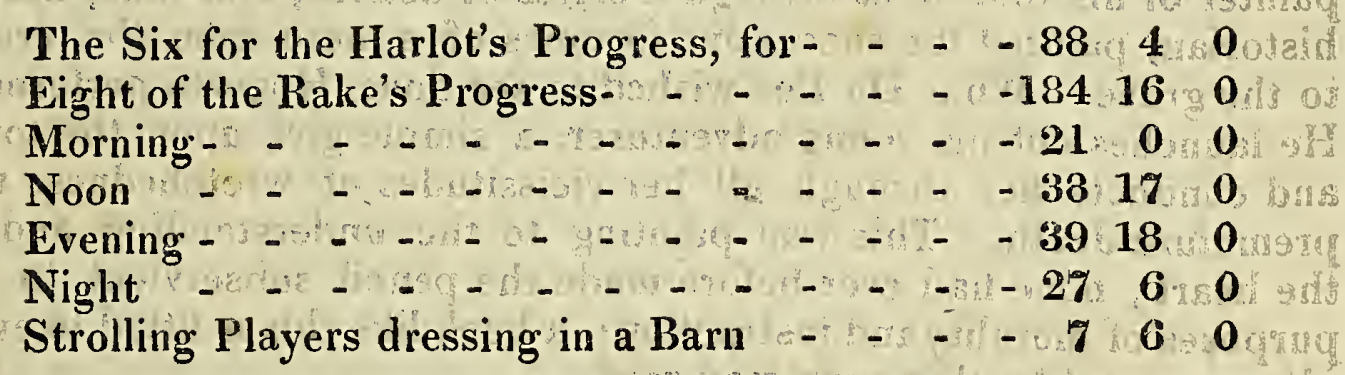

In the same year he acquired additional reputation by the six prints of "Marriage-a-la-Mode, which may be regarded as the groundwork of novel called "The Marriage Act," by Dr. Shebbeare, and of "The Clandestine Marriage."

Hogarth had projected a "Happy Marriage," by way of counterpart to his "Marriage-à-la-Mode." A design for the first of his intended six plates he had sketched out in colours, and the following is as accurate an account of it as conld be furnished by a gentleman who long ago only enjoyed a few minute's sight of so great a curiosity. The time supposed was immediately after the return of the parties from church. The scene lay in a hall of an antiquated country man. sion On one side the marriage couple were represented, sitting. Behind thern was a group of their young friends of both sexes, in the act of breaking bridecake over their heads. In front appeared the father of a young lady, grasping a bumper, and drinking with a seeming roar of exultation, to the future happiness of her and her husband, By his side was a table covered with refreshments. Jollity rather than politeness was the designation of his character. Under the screen of the hall, several rustic musicians, in grotesque attitudes, together with servants, tenants \&c. were arranged. Through the arch by which the room was entered, the eye was led along a passage into the kitchen, which afforded a glimpse of sacerdotal luxury. Before the dripping-pan stood a well-fed divine, in his gown and cassock, with his watch in his hand, giving directions to a cook, dressed all in white, who was employed in basting a haunch of venison. Among the faces of the principal figures, no one but that of the young lady 
was completely finished. Hogarth had been often reproached for his inability to impart grace and dignity to his heroines. "The Bride" was therefore meant to vindicate his pencil from so degrading an imputation. The effort, however, was unsuccessful. The girl was certainly pretty; but her features, if we may use the term, were uneducated. She might have attracted notice as a chambermaid, but would have failed to extort applause as a woman of fashion, The clergyman and his culinary associates were more laboured than any other parts of the picture. It is natural for us to dwell longest on that division of a subject which is more congenial to our private feelings. The painter sat down with a resolution to delineate beauty improved by. art; but he seems, as 'usual, to have deviated into neanness, or he could not help neglecting his original purpose, to lixuriate in such ideas as his situation in early life had fitted himself to express. He found himself, in short, out of his element in the parlour, and therefore hastened, in quest of ease and amusement, to the kitchen-fire. Churchill, with more force than delicacy, once observed of him, that he only painted the uncomeliness of Nature. It must be allowed, that such an artist, however excellent in his walk, was better qualified to represent the low-born parent than the royal preserver of a foundling.

Soon after the peace of Aix-la-Chapelle, he went over to France, and was taken into custody at Calais, while drawing the Gates of that town, a circumstance which he has recorded in his picture entitled "Oh! the Roast Beef of Old England!" published March 26, 1749. He was actually carried before the governor as a spy, and, after a very strict examination, committed a prisoner to Gransire his landlord, on his promise that Hogarth should not go out of his house till he was embarked for England.

Soon after this period he purchased a small house at Chiswick, where he usually passed the greater part of the summer seasou, yet not without occasional visits to his house in Leicester-fields. In 1953 he appeared to the world in the character of an author; and published a fourth volume, entitled "The Analysis of Beanty" written with a view to correct fluctuating ideas of taste. In this performance he shews, by a variety of examples, that a curve is a line of beauty, and that ronnd swelling figures are pleasing to the eye; and the truth of his opinion has been countenanced by subsequent writers on the subject. In this work, the leading idea of which was hieroglyphically thrown out in a frontispiece to his work in 1745, he acknowledges himself indebted to his friends for assistance, and particularly to one gentleman, for his correction and amendment of at least a third part of the wording. This friend was Dr. Benjamin Hoadley the physician, who carsied on the work to about the third part, chap. ix., and then, through indisposition, declined the friendly office with regret. Mr. Hogarth applied to his neighbour, Mr. Ralph; but it was impossible for two such persons to agree, both alike vain and positive. He proceeded no further than about a sheet, and they then parted friends, and seem to have continued such. The kind office of finishing the work, and superintending publication, was lastly taken up by Dr. Norrell, who went through the remainder of the book. The preface was in like manner 
corrected by the Rev. Mr. Townley. The family of Hogarth rejoiced when the last sheet of the "Analysis" was printed off; as the frequent disputes he had with his coadjutors in the progress of the work, did not much harmonize his disposition. This work was translated into German by Mr. Mylius, when in England, under the anthor's inspection; and the translation was printed in London, price five dollars. A hew and correct edition was in $\mathbf{1 7 5 4}$ proposed for publication at Berlin, by Ch. Fr. Vok, with an explanation of Mr. Hogarth's satirical prints, translated from the French; and an Italian tianslation was published at Legliorn in 1761 .

Hogarth had one failing, in common with most people who attain wealth and.eminence without the aid of a liberal education. He affected to despise every kind of knowledge which he did not possess. Having established his fame with little or no obligations to literature, he either conceived it to be needless, or denied it because it was out of his reach. His sentiments, in short, resembled those of Jack Cade, who pronounced sentence on the clerk of Chathain because he could read and. write. Till, in evil hour, this celebrated artist commenced author, and was obliged to employ the friends already mentioned to correct his "Analysis of Beauty," he did not seem to have discovered that even spelling was a necessary qualification; and yet he had ventured to ridicule the late Mr. Rich's deficiency as to this particular, in a note which lies before the "Rake," whose play is refused while he renains in confinement for debt.

Before the time of which we are now speaking, one of our artist's conimon topics of declamation, was the uselessness of books to a man of his profession. In "Beer-street," among other volumes consigned by him to the pastry-cook, we find "Turnbull on Ancient Painting," a treatise which Hogarth should have been able ta understand before he ventured to condemn. When his Sigismunda appeared, it. was condemned, and he was irritated; whereas a word in its favour might have commanded a proof print, or forced an original sketch, out of our artist's hands. The person who supplied this remark owed one of Hogarth's scarcest performances to the success of a compliment, which might have seemed extravagant even to sir Godfrey Kneller.

The following well-authenticated story will also serve to shew how much more easy it is to detect ill-placed or hyperbolical adulation respecting others, than when applied to ourselves: Hogarth being at dinner with the celebrated Cheselden, and some other company, was told that Mr. John Freke, surgeon of St. Bartholomew's hospital, a few evenings before, at Dick's coffee-house, had asserted that Greene was as eminent in composition as Handel. "That fellow Freke," replied Hogarth, "is always shooting his bolt absurdly one way or another. Handel is a giant in music, Greene only a light Forence kind of composer:"- "Ay," said the informant, "but at the same time Mr. Freke declared you were as good a portrait painter as. Vandyke."-_"There he was in the right," added Hogarth " "and so I am-give me my time, and let me choose my. subject."

Hogarth was the most absent of men. At table he would sometimes turn round his chair as if he had finished eating, and as suddenly would return it, and commence his neal again. He once directed a 
letter to Dr. Hoadley, thus; "To the Doctor at Chelsea." This epistle, however, by goodluck, did not miscarry; and was preserved by the late chancellor of Winchester, as a precious memorial of his friend's extraordinary inattention. Another remarkable instance of Hogarth's absence was related by one of his intimate friends. Soon after he set up his carriage, he had occasion to pay a visit to the lord mayor, Mr. Beckford. When he went, the weather was fine, but business detained him till a violent shower of rain came on." He was let out of the mansion-house by a different door from that which he entered: and, sceing the rain, began immediately to call for a hackney-coach. Not one was to be met with on any of the neighbouring stands; and the artist sallied forth to brave the storm, and actually reached Leicester-fields, without ever bestowing a thought on his own carriage, till Mrs. Hogarth, surprised to see him so wet and splashed, asked him where he had left it.

A specimen of Hogarth's propensity to merriment on the most trivial occasions, is observable in one of his cards, requesting the company of Dr. Arnold King to dine with him at the Mitre. Within a circle, to which a knife and fork are the supporters, the written part is contained. In the centre is drawn a pie, with a mitre on the top of $i$ it; and the invitation concludes with the following sport on three of the Greek letters-to Eta Beta $\mathbb{P}$. The rest of the inscription is not very accuralely spelt.

A quibble by Hogarth is surely as remarkable as a conundrum by Swift. In one of the carly exhibitions at Spring-gardeus, a very pleasing small picture by Hogarth made its first appearance. It was painted for the earl of Charlemont, in whose collection it renains, and was entitled "Picquet, or Virtue in Danger," and shews us a young lady, who, during a tête-a-tête, had just lost all her money and jewels to a handsome officer of her own age. He is represented in the act of offering her the contents of his hat, in which are bank-notes, jewels, and trinkets, with the ỉopes of exchanging them for a more delicate plunder. On the chimney-piece is a watch-case, and a figure of Time over it, with this motto-"Nunc." Hogarth has caught his heroine during this moment of hesitation, this struggle with herself, and has marked her feelings with uncommon success.

In the "Miser's Feast," Mr. Hogarth thought proper to pillory Sir Isaac Shard, a gentleman proverbially avaricious. Hearing this, the son of sir Isaac, the late Isaac P. Shard, esq. a young man of spirit, just returned from his travels, called at the painter's to see the picture; among the rest, asking the Cicerone "whether that odd figure was intended for any particular person :" on his replying, "that it was thought to be very like one Sir Isaac Shard," he immediately drew his sword, and slashed the canvass. Hogarth appeared instantly in great wrath; to whom Mr. Shard calmly justified what he had done, saying that this was a very unwarrantable license, that he was the injured party's son, and that he was ready to defend any suit at law ;" which, however, was never instituted.

About $175 \%$ his brother-in-law Mr. Thornhill resigned the place of king's sergeant painter in favour of Mr. Hogarth. "The last memorable event in our artist's life," as Mr. Walpole observes, "was his 
quarrel with Mr. Wilkes; and though he did not commence direct hostilities on the latter, he at least obliquely gave the first offence, by an attack on the friends and party of that gentieman. This conduct was the more surprising, as he had all his life avoided dipping his pencil in political contests, and had early refused a very lucrative ofier that was made, to engage him in a set of prints against the head of a court party. Without entering into the merits of the cause, I shall only state the fact. In September 1\%63, Mr. Hogarth published his print of "The Times." It was answered by Mr. Wilkes a severe paper in the 'North Briton.' On this the painter exhibited the caricature of the writer. Mr. Churchill, the poet, then engaged in the war, and wrote his 'Epistle to Hogarth,' not the brightest of his works, and in which the severest strokes fell on a defect that the painter had neither caused, nor could amend, namely, his age, which however, was neither remarkable nor decrepit, much less had it impaired his talents, as appeared by his having composed, but six months before, one of his most capital works, the satire on the Methodists. In revenge for his epistle, Hogarth caricatured Churchill, under the form of a canonical bear, with a club and a pot of porter, \&zc. (vitulâ tu dignus et hic,)-never did two angry men, of their abilities, throw mud with less dexterity.

"When Mr. Wilkes was the second time brought from the Tower. to Westmiuster-hall, Mr. Hogarth skulked behind in a corner of the gallery of the Court of Common Pleas; and while the chief justice Prati, with the eloquence and courage of old. Rome, was enforcing the great principles of Magna Charta and the English constitution; while every breast from him caught the holy flame of liberty; the painter was wholly employed in caricaturing the person of the man, while all the rest of his fellow-citizens were auimated in his cause, for they knew it to be their own cause, that of their country, and of its laws. It was declared to be so a few hours after by the unanimous sentence of the judges of that court, who were all present. "The print of Mr. Wilkes," says a writer of that day, was soon after published, "drawn from the life by William Hogarth." It must be allowed to be an excellent compound caricature, or a caricature of what nature had already caricatured. I know but one short apology that can be made for this gentleman, or, to speak more properly, for the person of Mr. Wilkes. It is, that he did not make himself, and I never heard that he once hung over the glassy stream, like another Narcissus, admiring the image in it, nor that he cver stole an amorous look at his counterfeit in a side-mirror. His form, such as it was, ought to give him no pain, because it was capable of giving pleasure to others. I fancy he found himself tolerably happy in the clay-cottage to which he was tenant for life, because he had learnt to keep it in good order. While the share of health and animal spirits, which heaven had given him held out, I can scarcely imagine he was one moment peevish about the outside of so precarious, so. temporary, a habitation, or was ever brought to own, that his earthly taberuacle was too homely for his dignity.

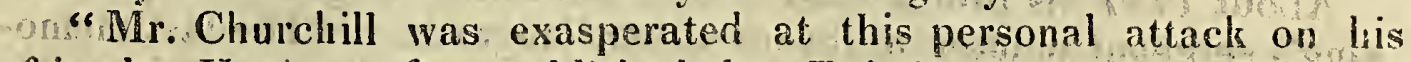
friend. He soon after published the 'Epistle to William Hogarth' 
and took for the motto, "Ut pictura poesis." Mr Hogartl's revenge against the poet terminated in vamping up old print of $a_{1} \mathrm{Pg}$ $\operatorname{dog}$ and a Bear, which he published under the title of "The Bruiser: C. Churchill, in the character of a Russian Hercules," \&c.

At the time when these hostilities were carrying on in a manner so virulent and disgraceful to all the parties, Hogarth was visibly declining in his health. In 1762 he complained of an inward pain, which coutinuing, brought on a general decay that proved incurable. This last year of his life he employed in retouching his plates, with the assistance of several engravers, whom he took with him to Chiswick. Oct. 25, 1764, he was conveyed from thence to Leicester-fields in a very weak condition, yet remarkably cheerful; and receiving an agreeable letter from the American Dr. Franklin, he drew up a rough draught of an answer to it; but going to bed, he was seized with a vomiting, upon which he rang the bell with such violence that he broke it, and expired about two hours afterwards. His disorder was an aneurism; and his-remains were interred in the church-yard of Chiswick, where a monument is erected to his memory, with an inscription by his friend Mr. Garrick.

It may be truly observed of Hogarth, that all his powers of delighting. were restrained to his pencil. Having rarely been permitted into polite circles, none of his sharp corners had been rubbed off; so that he continued to the last a gross uncultivated man. The slightest contradiction transported him into rage. To some confidence in himself he was certainly entitled, for as a comic painter, he could have claimed no honour that would not most readily have been allowed him; but he was at once unprincipled and variable in his political conduct and attachments. He is also said to have beheld the rising eminence and popularity of Sir Joshua Reynolds with a degree of envy; and if we are not misinformed, frequently spoke with asperity both of him and his performances. Justice, however, obliges us to add, that our artist was liberal, hospitable, and the most punctual of paymasters; so that in spite of the emoluments his works had procured to him, he left but an inconsiderable fortune to his widow.

\section{Alexander CRUDEN.}

TuIs gentleman was an author, whose literary labours will ever entitle him to the gratitude of all who wish to study the scriptures. He was the son of Mr. William Cruden, a merchant of Aberdeen. He was born in 1701, and educated in the grammar-school of that city: along with George Keith, earl marischal, and the celebrated fieldmarischal James Keith. He studied divinity at the marischal college, and intended to follow that profession, had he not been prevented by a misfortune, to which kings and beggars have been equally subjected, and to which men of uncommon genius are peculiarly liable, if we may credit the poet, that

Great wit to madness oft is near allied,

And thin partitions do the bounds divide."

The cause of his insanity has been variously accounted for, but the most probable reason assigned, appears to have been disappointment 
in love; to which, with the vexation of repeated refusals, was arded the horror of hearing that the object of his affection was with child by her own brother. Being a clergyman's daugliter, she was sent out of the country. Mr. Cruden never after mentioned her name, but with the most tender compassion and the bitterest grief. "He was confilled for some time after in an asylum at Aberdeen. Being released, he went to London in 1722, as a private tutor; in which employment he also spent some years in the Isle of Man. About 1732, he returned to London, and acted as a bookseller, and corrector of the press. His shop was under the Royal Exchange.

One day, a gentleman from Aberdeen calied upon him, and expressing a wish to serve him, offered to introduce him to a frieid, who was a merchant near the Exchange. Upon their calling, the door was opened by the unfortunate young lady above mentioned, who, unknown to Mr. Cruden's friend, resided here, the merchant being her brother. Mr. Crudell started back with strong signs of surprise and agony, and, grasping his friend's hand, exclaimed wildly, "Ah, she has still her fine black eyes!" Mr. Cruden neither then, nor ever after, entered the house, or courted the owner's acquaintance.

In $\mathbf{1 7 3 3}$ he began to compile that important work, which he had long meditated, "A complete Concordance of the Holy Scriptures of the Old and New Testament." If the merit of labour only be allowed, it must be acknowledged that he bestowed labour to which no addition can be made, accompanied by a perseverance with hardly any interval. But he had the additional merit of both forming the plan arid executing it. The work was dedicated to Queen Caroline, who had given him reasons to expect a graluity on presenting it. But a few days before its publication, Cruden lost his royal patroness by the queen's death. His affairs were now embarrassed; his hopes were gone; and in such circumstances, it is not surprising that he should have had a return of his mental disorder, which rendered it necessary again to confine him. Upon his release, he avenged himself on his keepers, by publishing a pamphlet entitled, o The London Citizen exceedingly injured, giving an account of his adventures during his fever, and his long campaign at Bethnal Green for nine weeks and six days," \&c. After this, he lived chiefly by correcting the press, particularly of the Greek and Roman classics, which were published under his inspection with great accuracy. In this occupation he spent several years, with the strictest attention and fidelity to the booksellers who employed him, till a third attack of his disorder obliged his friends to confine him once more. When released, he published his case, under the whimsical title of "The Adventures of Alexander the Corrector." This work exhibited a faithful picture of a wild mind ; various, whimsical, serious, and jocose. $\mathrm{He}$ announced in it, that he was commissioned by Heaven to reform the manners of the age. He endeavoured to persuade his sister and other friends, who had confined him, to submit to be imprisoned in Newgate, as a compensation for the injuries they had done him.

At the general election in 1745 , he resolved to stand candidate for the city of London, and not only prevailed on Mr. Sheriff Chitty 
to put him in nomination, at the Common Hall, but had actually several hands held up for him.

In 1961, he was corrector of the Public Advertiser to the late Mr. Woodfall, when he published a second edition of his Concordance, to which he har made great additions. Anxious at all times to do good, a singulor and extraordinary opportunity occured; in 1762, to call forth his utmost exertions. One Richard Potter, a sailor, was tried and capitally condemned for utiering a scaman's will, knowing it to be forged. It appeared upon evidence that Potter was a poor illiterate creature, the tool of annther, and ignorant of the nature of the crime. Mr. Cruden, who happened to be iu court, was so convinced of this, that he resolved to make application for the royal mercy; and however improbable his success appeared, he, by his repeated applications and representations, actually succeeded, and Potter's sentence was changed to transportation.

Numberless other instances of Mr. Cruden's bencvolence might be given, if room permitted. One man, depressed by poverty, he saved from suicide, and made comfortable and happy with his family by an immiediate pecuniary supply, as well as by his best religious advice; both of which he was equally ready to bestow upon all suitable occasions; and when he met with proper objects, often gave away more money than he retained for his own use. In private life he was courleous and affable, in religious sentiments a strict Calrinist, but by no means intolerant. In $1 \% 69$ he revisited Aberdeen, where he spent about a year; after which he returned to London, and on the first of Nov. 17\%0, was found dead on his knees, in the posture of praying. He had for some time before been troubled with an asthma.

\section{JeDEDIAH Buxton.}

Thus was a prodigy with respect to skill in numbers. His father, William Buxton, was schoolmaster of the parish where he was born in 1704 : vet Jedediah's education was so much veglected, that he was never tanght to write, and, with respect co any other knowledge but that of numbers, seemed always as iguorant as a boy of ten years of age. How he came first to know the relative proportions of numbers, and their progressive denominations, he did not remember, but to this he applied the whole force of bis mind, and upon this his attention was constantly fixed, so that he frequently took cognizance of external objects only with respect to their numbers. If any space of time was mentioned, he would soon after say it was so many minutes; and if any distance of way was stated, he would assign the number of hairbreadths without any question being asked, or any calculation expected by the company.

When he once understood a question, he began to work it with amazing facility, after his owi method, without the use of a pell, pencil, or chalk, or even understanding the common rules of arithmetic as taught in the schools. He would stride over a piece of land or a field, and tell the contents of it almost as extict as if one har measured it with the cliain. In this manner he measured the whole 
lordship of Elmton, of some thousand acres, belonging to Sir John Rhodes, and brought him the contents, not only in acres, roods, and perches, but even in square inches. After this, for his own amusement, be reduced them into square hairbreadths, computing 48 to each side of the inch. His memory was so great, that while resolving a question, he could leave off, and resume the occupation again where he left off, the next morning, or at a week, a month, or at the end of several months, and proceed regularly till it was completed. His memory would doubtless have been equally retentive with respect to other objects, if he had attended to them with equal diligence; but his perpetual application to figures prevented the smallest acquisition of any other knowledge.

He was sometimes asked, on his return from church, whether he remembered the text or any part of the sermon, but it never appeared that he brought away one sentence, his mind, upon closer examination, being found to liave been busied, even during divine service, in this favourite operation, either dividing some time or some space into the smallest known parts, or resolving some question that had been given him as a test of his abilities. As this extraordinary person lived in poverty, his life was uniform and obscure. Time, with respect to him, changed nothing but his age; nor did the seasons vary his employment, except that in winter he used a fail, and in summer a ling-hook.

In $\mathbf{1 7 5 4}$ he came to London, where he was introduced to the Royal Society, who, in order to prove his abilities, asked him several questions in arithmetic, and he gave, them such satisfaction, that they dismissed him with a handsome gratuity. In this visit to the metropolis, the only object of his curiosity, except figures, was to see the king and royal family; but they being at Kensington, Jedediah was disappointed. During his residence in London, he was taken to see king Richard III. performed at Drury-lane play-house, and it was expected either that the novelty and splendour of the show would have fixed him in astonishment, and kept his imagination in a continual hurry, or that his passions would in some degree have been touched by the power of action, if he had not perfectly understood the dialogue. But Jedediah's mind was employed in the play-house just as it was employed in every other place. During the dance he fixed his attention upon the number of steps; and declared, after a fine piece of music, that the innumerable sounds produced by the instruments had perplexed him beyond measure, and he attended even to Mr. Garrick only to count the words he uttered, in which he said he perfectly succeeded.

Jedediah returned to the place of his birth, where, if his enjoyments were few, his wishes did not seem to be greater. He applied to his labour with cheerfulness; he regretied nothing that he left behind him in London; and it continued to be his opinion, that a slice of musty bacon afforded the most delicions repast.

Peter tue WiLd Boy.

This was a savage, found in the woods near Hamelen, a town in the electorate of Hanover, when King George I. with a party of 
friends, was hunting in the forest of Hertswold. He was supposed to be then about twelve years of age, and had subsisted in those woods upon leaves, berries, wild plants, bark of treès, \&c. from his infancy. How long he had been in that state is not known. In 1726 he was brought over to England, and put under the care of Dr. Arbuthnot, with proper teachers. But though there appeared no natural defect in his organs of speech, he could never be brought to articulate a single syllable distinctly. He was afterwards committed to the care of different persons, but never acquired any degree of improvement. He died $22 \mathrm{~d}$ of February, 1785, when he was supposed to be seventy-two years old. He was well-made; middle sized; had no appearance of an idiot, nor any thing particular in his form, except two of his fingers nnited by a web up to the middle joint. He was delighted with music, and learnt to hum a tune. He had a foreknowledge of bad weather. Lord Mouboddo gives a particular deseription of him, as an instance of his favourite hypothesis, that " man in a state of nature is a mere aninal."

\section{Porcupine Man.}

This is the name by which one Edward Lambert, who had a distempered skin, went by in London. The following account of him is given in the Philos. 'Trans, for 1755 , by Mr. Henry Bakers, F.R. S. "He is now," says he, "forty years of age, and it is twenty four years since he was first shewn to the Society. The skin of this man, except on his head and face, the palms of his hands, and the soles of his feet, is covered with excrescences that resemble an innumerable company of warts, of a brown colour and cylindrical figure; all rising to an equal height, which is about an inch, and growing as close as possible to each other at their bases; but so stiff and clastic as to make a rustling noise when the hand is drawn over them. These excrescences are annually shed and renewed in some of the autumn or winter months. The new ones, which are of paler colour, gradually rise up from beneath, as the old ones fall off ; and at this time it has been found necessary for him to lose a little blood, to prevent a slight sickuess which he had been used to suffer before this precaution was taken. He has had the small-pox, and has been twice salivated, in hopes to get rid of this disagreeable covering; but though just when the pustules of the small-pox had scaled off, and immediately after his salivations, his skin appeared white and smooth, yet the excrescences soon returned to a gradual increase, and his slin became as it was before.

"His health, during his whole life, has been remarkably good : but there is one particular of this case more extraordinary than all the rest; this man lias had six children, all of whom had the sanie rugged covering as himself, which came on, like his own, about nine weeks after their birth, Of these children only one is now living, a pretty oboy, who was shewn with his father. It appears, therefore, as Mr. Baker remarks, that a race of people might be propagated by this man, as diferent from other men as an African is from an Englisl:man; and that if this should have happened in any former age, and 
the accidental original have been forgotten, tnere would be the same objections agairist their being, derived from the same common stock with others. It must therefore be admitted possible, that the differences now subsisting between one part of mankind and another may have been produced by some such accidental cause, long after the earth had been peopled by one common progenitor."

\section{Lewis Hopkins, and John Coan, DWares.}

THE following account of Hopkins is contained in a letter from John Browning, Esq. of Barton-hill, near Bristol, to Mr. Henry Baker, F.R.S. dated September 12, 1751. "I am just returued," says the writer, "from Bristol, where I have seen an extraordinary young man, whose case is very surprising: he is shewn publicly for money, and therefore I send you the printed bill which is given about to bring company, and also a true copy of a certificate from the minister of the parish where he was baptized, together with the attestation of several of the neighbours, of great credit and veracity, some of whom are personally known to me; to these I have likewise added my own observations, as necessary to clear up the case. The certificate is as follows :-

"This is to certify, that Lewis. Hopkins, the bearer hereof, is a man of a very honest character, and has six children. His second son, Hopkins, whom you see now with him, is, in the filteenth year of his age, not exceeding two feet seven inches in height, and about twelve or thirteen pounds weight; wonderful to the sight of all beholders: the said little man was baptized the 29 th of January, 1796 , by me,-R. Harris, Vicar of Llantrissent, Glanorganshiro",

"The above is signed also by eight geutlemen of figure and fortune in the county of Glamorgan.

agal I went myself," says Mr. Browning, sto view and examine this very extraordinary, and surprising but melancholy, subject: a lad entering the fifteenth year of his age, whose stature is no more than two feet seven inches, and weight thirteen pounds, labouring under all the miseries and calamities of old age, being weak and emaciated, his eyes dim, his hearing very bad, his countenance fallen, his voice very low and hollow; his head hanging down before, so that his chin touches his breast, consequently his shoulders are raised, and his back rounded not unlike a hump-back; he is so weak, that he cannot stand without support.

"His father and mother both told me that he was naturally sprightly though weak, and, until he was seven years old, would attempt to sing and play about, and then weighed nineteen pounds, and was as tall, if not taller, than at present, naturally straight, well-grown, and in due proportion; but from that period he had gradually declined and grown weaker, losing his teeth by degrees, and is now reduced to the unhappy state I have just been describing. The mother is a very jolly healthy woman, in the prime of life; the father enjoys the same blessing."

Another dwarf is thus described in the same work by William Arderon, F.R.S. John Coan, a dwarf, was born at Twitshall in 
PIorfolk, in 1728, and has been shewn in this city for some weeks past. I weighed hin myself, April 3, 1750, and his weight with all his clothes was no more than thirty-four pounds. 1 likewise neasured him, and found his height, with his hat, shoes, and wig on, to be ility-eight inches. His limbs are no bigger than a child of three or four years old; his body is perfectly straight, the lineaments of his face answerable to his age, and his hrow has some wrinkles in it when he looks attentively at any thing. He has a good complexion, is of a sprightly temper, discourses readily and pertinently considering his education, and reads and writes English well. His speech is a little hollow, though not disagreeable ; he can sing tolerably, and amuses the company that come to see him, with mimicking a cock's crowing, which he imitates very exactly. In 1744 he was thirty-six inches ligh, and weighed twenty-seven pounds and a half ; his father says, when about a year old he was as large as children of that age usually arc, but grew very little and slowly afterwards.

\section{Wyband Lolkes, the Dutch Dwarf.}

TuIs personage was born at. Jelst in West Friesland, in the year 1730. His parents were in low circumstances; his father being fishermail, and having eight children to support. The parents were of ordinary stature, and so were seven of the children, but Wybrand was a mere dwarf. This little creature at an early age exhibited proofs of a faste for mechanism; and when he arrived at a proper age, was bound apprentice to an eminent watch and clock maker in Amsterdam: he worked for this master four years after the expiration of his apprenticeship, and removed from thence to Rotterdam, where he began business for himself, and where he first became connected with, and afterwards married, the person who accompanied him to Engiand.

His trade of a watch-maker, however, failing, he came to the resolution of exhibiting his person publicly as a show, and by attending the several Dutch fairs obtained a handsome conspetency. Impelled by curiosity, and in hopes of gain, he came to England, and was risited at Harwich (where he first landed) by crowds of people: encouraged by this early success, he proceeded to London, and on applying to the late Mr. Philip Astley, obtained an engagement at a weekly salary of five guineas. He first appeared at the Amphitheatre, Westminster Road, on Easter Monday, 1790, and continued to exlibit every evening during the whole season. He always was accompanied by his wife, who came on the stage with him hand in hand ; but though he elevated his arm, she was compelled to stoop considerably to meet the proferred honour.

Mynheer Lolkes was a foud husband; he well knew the value of his partmer, and repaid her care of him with the most fervent affection; for he was not one of those men, who

Are April when they woo,

December when they wed.

He had by his wife three children, one of whom, a son, lived to the age of twenty-three, and was five feet seven inches in height.-This little man, notwithstanding his clumsy and awkward appearance, 
ance, was remarkably agile, and possessed uncommon strength; he could with the greatest ease spring from the ground into a chair of ordinary heiglit. He was rather of a morose temper, and extremely vain of himself, and, while discoursing in broken English, was extremely (as he imagined) dignified. He continued in England but one season, and, through the help of a good benefit, returned to his native country with his pockets better furnished than when he left it.

\section{JohN CaLAS.}

This was a most unfortunate French Protestant at Thoulouse, inhumanly butchered under form of law, cruelly sacrificed to gratify: the sanguine impulse of ignorant Popish zeal. He had lived forty years at Thoulouse. His wife was an English woman of French extraction; they had five sons, one of them, Lewis, had turned Catholic, through the persuasion of a Catholic maid, who had lived thirty years in the family. In October, 1761, the family consisted of Calas his wife, Mark Anthony their son, Peter their second son, and this maid. Anthony was educated for the bar, but, being of a melancolly turn, was continually dwelling on passages from authors on the subject of suicide, and one night in that month hanged himself on a bar laid across two folding doors in their shop. The crowd collected, from the confusion of the house on so shocking a discovery, took it into their hears that he had been strangled by the family to prevent his changing his religion, and that this was a common practice among Protestants.

The officers of justice adopted the popular tale, and were supplied by the mob with what they accepted as evidence of the fact. The fraternity of White Penitents got the body, buried it with great ceremony, and performed a solemn service for him as a martyr; the Franciscans did the same; and after these formalities no one doubted the guilt of the devoted heretical family. They were all condemned to the torture, to bring them to a confession; they appealed to the parliament, who, as weak and as wicked as the subordinate magistrates, sentenced the father to the torture, ordinary and extraordinary, to be broken upon the wheel, and then to be burnt to ashes. A diabolical decree! which, to the disgrace of humanity, was actually carried into execution. Peter Calas, the other son, was banished for life; and the rest were acquitted. The distracted widow found some friends; among the rest M. Voltaire, who laid her case before the council of state at Versailles, and the parliament of Thoulouse were ordered to transmit the proceedings. These the king and council unanimously agreed to annul: the capetoul, or chief magistrate, of Toulouse was degraded and fined; old Calas was declared to have been innocent; and every imputation of guilt was removed from the family, who also received from the king and clergy considerable gratuities.

\section{PeTER Wiluiamson.}

an $T$ is person was born at a village a few miles from $\Lambda$ berdeen, in scotland. He afterwards was sent to reside with an aunt at Aberdecn. 
When he was but eight years of age, while playing on the quay wrik: others of his companions, he was kiduapped, and taken on board a vessel, which shortly after sailed for America.

On their arrival at Philadelphia, Peter was sold, with his other companions, at about $16 l$. per head: what became of his fellowsin misfortune, he never knew, but it was his chance to be sold for a term of seven years to a North Briton, who had in his youth undergone the same fate as Peter, having been kidnapped from St. John's Town in Scotland.

This new master having no children of his own, and commiserating the condition of his fellow-countryman, took great care of him till he was fit for business: in this service he continued till he was seven. teen years old, when his master died, and as a reward for Peter's faitliful services, left him about two hundred pounds currency, his best horse; saddle, and all his wearing apparel.

Being now his own master, and possessed of money as well as other necessaries, he employed himself in jobbing about the neighbouring plantations, for nearly seven years; when, considering himself sufficiently enriched to follow some better way of life, he carried into execution his resolution to settle, and married the daughter of a substantial planter. His fother-in-law, in order to establish Peter and his wife in an easy, if not in an afluent manner, presented him with a tract of land on the borders of the forest of Delaware, of about two hundred acres. The situation pleased Peter so well, that he inmmediately settled on it: but his felicity was not of long duration; for in 1754, the Indians in the French interest, who had for a long time before ravaged and destroyed other parts of America, began to be very troublesome to the Pennsylvanians. On the second of October 1754, his wife being then from home, Peter was sitting up later than usual, waiting her return; when about eleven o'clock at night he heard the dismal war-wboop of the savages, and soon found that his house was attacked; he asked the Indians what they wanted, and they told him, if he would come out and surrender, they would not kill him. He accordingly went out with his gun in his hand: they immediately. rushed on him, disarmed him, and bound him to a tree; they then went into the house, plundered and destroyed every thing that was in it, carrying of what moveables they could; they then set fire to the house and the barn, which with the cattle were all destroyed.

Having conpleted the object of their ravages, they untied him, and caused him to carry a great load, under which he travelled all night; at daybreak, he was ordered to lay down his load, and was again tied so close round a tree with a small cord, as to force the blood from his fingers' ends. They next kindled a fire, and for some time danced round him, whooping, hallooing, and crying in a frightful tone: they then proceeded in a more tragical manner, taking the flaming sticks, and brandishing them near his face, head, hands; and feet, with seeming ferocious pleasure and satisfaction, at the same time threatening to burn him entirely, if he made the least noise, or cried out : thus tortured almost to distraction, he suffered their brutal pleasure without being allowed to express any anguish otherwise than by shedding tears, which the savages observing, they again took flaming sticks, 
and, placing them near his eyes, told him his face was wet, and they would dry it, at length they sat down, and roasted their meat, of which they had robbed Willianson's dwelling having satisfied their hunger, they offered some to their unfortunate captive, which he pretended to cat. After having finished their repast, they proceeded onward to their winter habitations, and on their journey committed the most cruel outrages, till they reached Alamingo, where the severity of the cold increasing, they stripped him of his cloak for their own use, and gave him such as they usually wore themselves, being a piece of blanketing, and a pair of mogares, or shoes, with a yard of coarse cloth to put round him instead of breeches. Thus, for nearly two months, naked as he nearly was, did he endure the inclemency of the weather, which rendered his limbs in a manner quite stiff, and unsusceptible of motion : he contrived, however, to erect a little wigwam with the bark of the trees, covering the same with earth, which made it resemble a cave : and to prevent the ill efrects of the cold which penetrated into it, he always kept a good fire near. the entrance.

At length, the time arrived when the Indians were preparing for $a$ new expedition, and the snow being quite gone, so that no traces of theirfootsteps could be perceived, they set forth on their journey towards the provinces of Penusylvania. One night, the Indiaus being much fatigued with their day's excursion they feli so soundly asleeps that Williamson, trusting to Divine providence for protection, effected his liberty ; and after very narrow escapes of being refaken he arrived, on the fifth day, at the louse of Jchn Bell, an ond acquaintance, who kindly received him: here he remained some tume, and on January 4, $1 \% 55$, arrived at his father-in-law's house in Chester county, when scarcely one of the family would believe their eyes, thinking he had fallen a prey to the merciless cruelty of the Indians.

Shortly after his arrival at home, his wife having been dead two months before, he enlisted into Colonel Shirley's regiment, which was intended for the frontiers, to destroy the French ports : in this desultory kind of warfare, he continued till Oswego was captured by the French in August 1756, when the French, and the Indians in their in terest, committed the most heart-rending barbarities and excesses.

Williamson was one of the persons taken prisoners at Oswego, and was, in November $\mathbf{1 7 5 6}$, brought from America to Plymouth under a flag of truce; where, in about four months subsequent to his arrival, he was discharged as incapable of further service, occasioned by a wound in his left hand. He then published a narrative of his sufferings, in a tract, entitled "French and Indian Cruelty displayed in the Life and Adventures of Peter Williamson:" Neither the strange vicissitudes of his own fortune, chequered with uncomnon calamities, nor the good intention of his narrative, could protect him from the resentment of some merchants of Aberdeen, where he went in quest of his relations; because, in the introduction to his narrative, he had noticed the manner in which he had been illegally kidnapped on board ship, and sold for a slave. For that publication he was im prisoned, and three hundred and fifty copies of his book, the only means he had of obtaining his livelihood, were taken from him, and 
his enlargement granted him only on condition of his signing a paper disclaiming two or three pages fo his book. However, as he soon after found a few of his relatives, he got the attestations of some, and the aflidavits of others, proving that he was the person taken away, as mentioned in the narrative.

\section{John Howard, EsQ.}

THIs was a man of singular and transcendent humanity. He was born at Hackney, in 1726 ; and was put apprentice to Mr. N. Newman, grocer, in Watling-street. His father died in 1742, leaving only this son and a.daughter, to both of whom he bequeathed handsome fortunes; but by his will directed that his son should not be considered of age till he was twenty-five. His constitution being very weak, the remaining time of his apprenticeship was bought up, and he applied himself to the study of medicine and nateral philosophy. Falling into a nervous fever, while he lodged with a widow lady, named Sarah Lardeau, a worthy woman, but an invalid, he was nursed with so much care and attention, that he resolved to marry her out of gratitude. In vain she expostulated with him on the extravagance of such a proceeding, he being about twenty-eight and she about fiftyone years of age; but nothing could alter his resolution, and they. were privately married about 1752. She was possessed of a small fortune, which he presented to her sister.

During his residence at Newington, Ms. Howard, who was bred a dissenter, and steadfastly athered to that profession all his life, gave fifty pounds to purchase the lease of a homse near the meeting-house, and to appropriate it as a parsonage house for the minister. His wite died Nov. 10, 1755, aged 54, and he was a sincere mourner for her death. About this time he was elected F. R.S. In 1756 he experienced some of those evils which he made it his business to redress. He embarked that year in a Lisbon packet to make the tour of Portugal, when the vessel was taken by a French privateer.

"Before we reached Brest," says he, in lis treatise on Prisons, p. 11. "I suffered the extremity of thirst, not having, for above forty hours, one drop of water, nor hardly a morsel of food. In the castle of Brest I lay six nights upon straw, and observing how crielly my countrymen were used here and at Morlaix, whither 1 was carried next,-during the two months I was at Carhaix upon parole, I corresponded with the English prisoners a Brest, Morlaix, and Diman; at the last of these towns were several of our ship's crew, and my servant. I had sufficient evidence of their being treated with such barbarity that many hundreds had perished, and that thirty-six were buried in a hole at Diman in one day. When I came to England, still on parole, I made known to the commissioners of sick and wounded seamen the sundry particulars, which gained their attention and thanks. Remonstrance was made to the French court: our sailors had redress; and those that were in the three prisons mentioned above, were brought home in the first cartel-ships. Perhaps (adds Mr. Howard) what I suffered on this occasion, increased my sympathy with the unhappy people whose case is the subject of this book 
He afterwards made the tour of Italy, and at his return settled at Brokenhurst, a pleasant village in the New Forest, near Lymington in Hanipshire, having, April 25, 1785, married a daughter of Edward Leeds, Esq. of Croxton, Cambridgshire, king's sergeant. This lady died in $\mathbf{1 7 6 5}$ in child-bed, of her only child, a son, who unfortunately became a lunatic. After her death Mr. Howard left Lymington, and purchased at estate at Cardington near Bedford. "While he lived here in retirement," says Mr. Palmer in his funeral sermon, "his neat but humble mansion was hospitable to a few select friends, but was never the scene of luxurious banqueting. Though polite to all, he neither sought nor admitted the company of the profligate, however distinguished by rank or fortune. His charity had no bounds, except those of prudence; and was not more commendable for the extent of it, than for the manner in which it was exercised. He gare not his bounty to countenance vice and idleness, but to encourage virtue and industry. He was singularly useful in furnishing employment for the labouring poor of both sexes, when a scarcity of work rendered their situation nost compassionable. And at other times, though never inattentive to the tale of woe, he was not easily imposed upon by it, but nade himself acquainted with the case. He. had indeed a general acquaintance with the cases and characters around him, and made it his business to visit the abodes of affliction. In circuinstances of bodily disorder, he often acted the part of a physician as well as a friend.

But his kindness was not confined to the bodies of his fellow-creatures; it extended to their spiritual and immortal part. He used his advice, his admonitions, his influence, to discountenance immorality of all kinds, and to promote the knowledge and practice of religion. He provided for the instruction of poor children, by erecting and supporting schools. In short, he was an universal blessing to the village where he resided, in every part of which are to be seen the pleasing monuments of his magnificence and taste. His liberality also extended to adjacent places, nor was it confined to persons of his own religious persuasion, but comprehended the necessitous and deserving of all parties : while he was particularly useful in serving the interests of the Christian society to which he belonged. What won ler if such a man were universally beloved? Was it possible he should have an enemy? One, however, he had, and I never heard of more; an idle and dissolute wretch who had often been reproached by him for his vices, formed the desperate resolution to murder him as he was going to public worship, which he almost always did on foot. But Providence remarkably interposed to preserve so valuable a life, by inclining him that morning to go on horseback a different road.

"But the sphere in which he had hitherto moved, was too narrow for his enlarged mind. Being appointed, in 1773, sheriff of Bedfordshire, this office brought the distress of the pitsoners more immediately under his notice. He personally visited the county jail, where he observed such abuses, and such scenes of calamity, as he had before no conception of. He inspected the prisons in some neigh? bouring counties, and finding in them equal room for complaint, he determined to visit the principal prisons in England. The farther he 
proceeded, the more shocking were the scenes he discovered, which induced him to exert himself to the utmost, for a general reform in these horrid places of confinement; considering it as of the highest importance, not only to the wretched objects themselves, but to the community at large. Upon this subject he was examined in the house of commons in March, 1774; when he had the honour of their thanks. This encouraged him to proceed. He visited all the prisons in the kingdom, together with the principal houses of correction. In 1775, he enlarged his circuit by going into Wales, Scotland, and Ireland, where he found the same need of reformation. One of his grandest objects was, to put a stop to that shocking distemper called the jailfever, which raged so dreadfully in many of the prisons, as to render them to the last degree dangerous; a distemper by which more had been taken off than by the hands of the executioner, and which in several instances had been conmunicated from the prisoners to the courts of justice, and had proved fatal to the magistrates and judges, and to multitudes of persons who atlended the trials, as well as to the families of the discharged felons and lebtors.

Another end he proposed was, to procure the immediate release of prisoners, who, upon trial; were acquitted, but who often continued long to be unjustly detained, for not being able to pay the accustomed fees; also to abolish many other absurd and cruel usages, which had long prevailed. "But the greatest object was, to introduce a thorough reform of morals into our prisons, where he had found the most flagrant vices to prevail in such a degree, that they were become seminaries of wickedness and villany, and the most formidab!e nuisances to the community, in consequence of the promiscuous intercourse of prisoners of both sexes, and of all ages and descriptions; whereby the young and less experienced were initiated; by old and hardened sinners, into all the arts of villany, and the mysteries of iniquity; so that, instead of being reformed by their coufinement, which should be the chief end and design of punishment, those that were discharged became more injurious to society than before. For the attainment of these great objects, Mr. Howard spared neither paihs nor expense, and cheerfully exposed himself to much iuconvenience and hazard; particularly from that malignant distemper, of which he saw many dying in the most loathsome dungeons, into which none who were not obliged (besides himself) would venture.

He "I have frequently," says Mr. Howard, "been asked what precautions I use, to preserve myself from infection in the prisons and hospitals which I visit; and have made answer, "Next to the free goodness and mercy of the Author of my being, temperance and cleanliness are my only preservatives. Trusting in divine Providence, and believing myself in the way of duty, I visit the most noxious cells ; and while thus employed, I fear no evil. I never enter a hospital or prison before Breakfast ; and in an offensive room I never draw my breath deeply."

His laudable endeavours, he had the pleasure to see, in some instances crowned with success ; particularly in regard to the healthiness of prisons, some of which were rebuilt under his inspection. Better provision was also made for the instruction of prisoners, by the introduction of Bibles and other pious books into their cells, and 
a more constant attendance of clergymen. The jailors, likewise, have by act of parliament been rendered incapable of selling: strong liquors, which had been the source of much diunkenness and disorder. But for a minute detail of particulars, the reader is referred to $\mathrm{Mr}$. Howard's publications; which shew that much is yet wanting.

With a view to a more general and happy regulation; and the reformation of criminals, he resolved to visit other countries, in hopes of collecting some information which might be useful in his own. For this purpose he travelled into France, Flanders, Holland, Germany, Switzerland, Prussia, and Austria, and visited Copenhagen, Stockholm, Petersburg, Warsaw, and some cities in Portugal and Spain: In all these expensive and hazardous journeys, he denied himself the usual gratifications of travellers, and declined the honours offered him by persons of the first distinction, applying himself solely to his grand object. To him the inspection of a jail or hospital was more grateful than all the entertainments of a palace. With what astonishment and gratitude he was received by their miserable inhabitants, might be easily imagined, since, while he made observations on their situations, he meditated their relief; and many distressed prisoners abroad, as well as at home; partook of his bounty; and some were liberated by it; for he considered all, of every nation, and people, and tongue, as brethren. Nor was he sparing of advice, or of reproof, as he saw occasion, to persons of rank and influence, whereby the miseries of their countrymen might be relieved. As he courted the favour of none, neither did he fear the frowns of any; but, with a manly freedom, and a Christian fortitude, spoke his mind to crowned heads, particularly to the emperor Joseph II. in a manner to which they were not accustomed; which, however, in a person of disinterested views; procured him esteem, and in some instances proved effectual in relieving the miserable and oppressed.

On his return, he published in 1777, "The State of Prisons in England and Wales, with Preliminary Observations, and an Account of some Foreign Prisons," Ato.; and in 1778, he took a third journey through the Prussian and Austrian dominions, and the free cities of Germany and Italy. The observations made in this tour were published in 1780, with remarks respecting the management of prisoners of war, and the hulks on the Thames. In 1781 he again revisited Holland, some cities in Germany, and the capitals of Denmark, Sweden, Russia, and Poland; and in 1733 some cities in Portugal and Spain, and returned through France, Flanders, and Holland. The substance of all these travels were afterwards thrown into one narrative, published in 1784. He also published a curious account of the nfamous Bastile, 8vo. (so soon afterwards levelled to the ground.) He next visited the lazarettos of $F$ rance and Italy, to obtain information concerning the best methods to prevent the spreading of the plague $\mathrm{He}$ then proceeded to Smyrna and Constantinople, where that most dreadful of human distempers prevailed, pleasing himself with the idea of not only learning, but being able to communicate, somewhat to the inhabitants of those distant regions. In the execution of this design, though he was so much exposed to danger, and actually caught the plague, "that merciful Providence," heremarks, "which had hitherto preserved 
him, was pleased to extend his protection to him in this journey also, and to bring him home once more in safety."

In his return, he revisited the chief prisons and hospitals in the countries through which he passed, and afterwards went again to Scotland; and thence to Ircland, where he inspected the Protestant charter-schools, in some of which he had observed shameful abuses, which he had reported to a committee of the Irish house of commons. In this town he took a particular account of what he observed amiss in the conduct of this noble charity, with a view to a reform,-and not without success. In the course of these journeys, various cities and communities paid him proper respect. At Dublin he was created LLD. by the university. At Glasgow and Liverpool he was enrolled among their honorary nembers. Upon his return, having again inspected the prisons in England, and the hulks on the Thames, to see what alterations had been made, he published the result of his last laborious investigations, in "An account of the principal Lazarettos in Europe, with various papers relative to the Plague; together with further observations on some Foreign Prisons and Hospitals, and additional remarks on the Present State of those in Great Britain and Ireland," with a number of curious plates. The work likewise contained observations on Penitentiary Houses, for the correction and reformation of criminals, of which he and Dr. Fothergill had been nominated by the king to be superiutendants. He also published the Grand Duke of Tuscany's "New Code of Criminal Law, with an English Translation;" and of all his publications he gave a vast number of copies among his acquaintance.

His laying open the horrors of despotism in France, had nearly exposed him to suffer them; and had it not been for the timely notice of our ambassador, he had been immured in the Bastile. He concluded his Account of Lazarettos with announcing his intention again to guit his country, revisit Russia, Turkey, \&c. and extend his tour in the East. "I am not insensible," says he, "of the dangers that must attend such a journey. 'Trusting, however, in the protection of that lind Providence which has hitherto preserved me, I calmly and cheerfully commit unyself to the disposal of unerring Wisdom: Should it please God to cut off my life in the prosecution of this rlesign, let not my conduct be imputed to rashness or enthusiasm, but to a serious deliberate conviction that I am pursuing the path of duty, and to a sincere desire of being made an instrument of more extensive usefulness to ny fellow-creatures than could be expected in the narrower circle of a retired life."

Accordingly, in the summer of 1789 he set out on this hazardous enterprise, the principal object of which was to administer James's Powder, a medicine in high repute in malignant fevers, under a strong persuasion that it would be equally efficacious in the plague. In this second tour in the East, having spent some time at Cherson, a Russian settlement on the Dnieper, he caught, in visiting the Russian hospital, or, as some say, a young lady who was ill of it, a malignant fever, which carried him off January 20 , after an illness of about twelve days. He was buried, as he desired, in the garden of a villa belonging to a French gentleman, from whom he had received great civi- 
lities, by his faithful servant, who had attended him in his former journeyings.

While absent in his first tom to Turkey, \&c. his character for active benevolence had so much attracted the public attention, that a subscription was set on foot to erect a statue to his honour, and in no long space fifteen hundred pounds was subscribed for that purpose. But in consequence of two letters from Mr. Howard himself to the subscribers, inserted in the Gent. Mag. vol. lvii. p. 101, the design was laid aside. It has, however, been resumed since his death; and surely, of all the monuments ever erected by public gratitude to illustrious characters, none was ever erected in honour of worth so admirable as his-who devoted his time, his strength, his fortune, and finally sacrificed his life, in the pursuits of humanity: who, to arlopt the expressive words of Burke, visited all Europe and the East, not to survey the sumptuousness of palaces, or the statehiness of temples, not to make accurate measurements of the remains of ancient grandeur, nor to form a scale of the curiosity of modern art; not to collect medals or collate Mss. ; but to dive into the depths of dungeons, to plunge into the infections of hospitals; to survey the mansions of sorrow and of pain; to take the gauge and dimensions of misery, depression, and contempt; to remember the forgotten, to attend to the neglected, to visit the forsaken, and to compare and collate the distresses of all men in all countries. His plan is original, and it is as full of genius as it is of humanity. It is a voyage of philanthropy, a circumnavigation of charity; and already the benefit of his labour is felt more or less in every country."

\section{Frederick Baron Von Trenck.}

This person celebrated by his adventures, and the romantic account he has given of his life, was descended from a noble Prussian family, and born at Konigsberg in 1726. His father, a major general in the army, pursued, as he says, the best means, and took the greatest care, to render him a happy man, and, among other things, exercised him in swimming; but too much indulgence on the one hand, and on the other too much neglect of the most essential rules, produced a quite contrary effect. At the age of twelve he was placed as a boarder with a schoolmaster named Kowalewsky; but his father dying some months after, and his mother having again married and quitted Prussia, Mr. Von Derschau, his maternal grandfather, who held an official situation at Konigsberg, took him under his care, and gave him instructions hinself. He, however, always allowed. him more money than was necessary, and this mistaken kindness only served to give an additional stimulus to the impetuosity of his character, as soon appeared by his fighting a duel with a count Wellenrodt. The rector of the university, at the request of his worthy friend Kowalewsky, punished him by some hours confinement; but his grandfather, delighted with this mark of spirit in his grandson, withdrew him from the care of Kowalewsky, and placed him in another seminary under Professor Christiana, where he maintained theses with great approbation. 
In 1742 he entered into the Prussian guards, which at that time formed only one squadron, and were quartered at Potsdam. Next year, when the guards quitted the capital, to accompany as far as Stettin the sister of Frederick II. who had married the king of Swedeu, Trenck's figure made a strong impression upon a lady whom he does not name, but who, from the manner in which he speaks of her, could be no other than a princess of the royal family. In 1744, on the commencement of the second Silesian war, he attended the king as an aid-de-camp ; but suspicions being excited by some intercepted letters, that he maintained a traitorous correspondence with this cousin, who was chief of the Austrian Pandours, he was accordingly arrested, and confined in the fortress of Glat $z$, the commander of which at that time was General Fouquet. Trenck attempted to escape, but was caught on the ramparts, and subjected to still harsher treatment. He, however, found means to bribe some of the officers, and, quitting the fortress with a person named Schnell, got safe to Bohemia, whence he proceeded to Elbing, in Polish Prussia, where he arrived in the month of March 1747. He then went to Vienna and Nuremberg, and entering the Russian service, after various adventures reached Moscow, at which the empress then resided with her court, and where he gained the good graces of the lady of the chancellor Bestuchef, the favourite of Elizabeth. From Moscow he travelled to Petersburg? and having visited Stockholn, Copenhagen, and Holland, returned again to Vienna, with a view to recover the property of his cousin Baron Trenck, which was contested with him.

Dissatisfied with the treatment he received from the Austrian court, he set out once more for Russia; but while passing through Dantzic, he was arrested at the request of the Prussian resident, and conducted to Magdeburg, where he suffered a rigorous imprisonment of ten years. During this tedious confinement, the instructions he had received from Kowalewsky and Christiana served him as a resource to begnile the time, and he amused himself with writing verses. Being set at liberty after the war of 1763 , he published the poems he had composed in his prison at Frankfort on the Mayne. He afterwards published some other works at Aix-la-Chapelle, where he became editor of a Gazette, which was conducted for some time with considerable success, and where he married a lady of respectable character and connexions, descended from a Dutch family.

The office of gazette-writing becoming tiresome or less lucrative, Trenck began business as a wine merchant; and, according to Denina, was assisted in his undertaking by the liberality of a Prussian minister at Aix-la-Chapelle, who enabled him to extend his commercial speculations to England. But the wine trade did not succeed as expected; and Trenck, about the year 1783, disappeared. Of his subsequent history little is known. In 1792 he was editor of a journal published at Hamburgh and Altona, from the latter of which he went the year following to France, where, like many other adventurers, he lost his life by the guillotine in the month of July, 1794 .

Trenck's Memoirs of his own life appeared, at Berlin in 1787, in two parts, 8vo. "It was not," says Denina, "till after the death of Frederick II. that his name began to make a noise in Germany, and to 
excite fanaticism in France. The public, entirely ignorant of the events mentioned by Trenck in his Memoirs, believed him on his word, and felt an interest for him, as is natural for an extraordinary man supposed to be unjustly persecuted. He was, however, soon unmasked, much more effectually than he pretended to unmask the Macedonian Hero, Frederick II. For my part, I cannot help subscribing to what is said of him in the fifth volume of Mirabeau's Prussian Monarchy, especially as it accords with the opinion of the most enlightened persons at Berlin, and the account given of him by various German writers:"- Trenck published several works in prose and verse, which it is not necessary to enumerate. His Life, translated into French by himself, was published at Paris. A new edition of his Macedonian Hero was printed in Frankfort and Leipsic.

Mr. Stukely, the Perpetual-Motion Seeker.

THE following account is extracted from the Percy Anecdotes. Mr. Stukeley was a gentleman of fortune, bred to the law, but gave up the profession, and retired into the country, filled with the project of discovering the perpetual motion. During a period of thirty years he never went abroad but once, which was when he wasliged to take the oath of allegiance to King George the First; this was also the only time he changed his shirt and clothes during the whole course of his retirement.

Mr. Stukeley was at once the dirtiest and the cleanliest man ; washing his hands twenty times a day, but his hands only. His family consisted of two female servants; one lived in the house, and the other out of it. He never had his bed made. After he had relinquished the project of the perpetual motion, he devoted himself to observing the works and economy of ants; and stocked the town so plentifully with that insect, that the fruits in the gardens were devoured by them.

During the reign of Queen Anne, whenever the duke of Marlborough opened the trenches against a city in Flanders, he broke ground at the extremity of a floor in his house, made with lime and sand, according to the custom of that country, and advanced in his approaches regularly with his pickaxe, gaining work after work, chalked out on the ground according to the intelligence in the $\mathrm{ga-}$ zette; by which he took the town in the middle of the floor at Biddeford, the same day the duke was master of it in Flanders : thus every city cost him a new floor.

Sterne, no doubt, had Mr. Stukeley in his eye, when he drew the character' of my uncle Toby.

Mr. Stukeley never sat on a chair, and when he chose to warm hinf self, he made a pit before the fire, into which he leapt, and thus sat on the floor. He suffered no one to see him but the heirs to his estate, his brother and sister : the first never but when he sent for him, and that very rarely; the other sometimes once a year, and sometimes seldomer, when he was cheerful, talkative, and a lover of the tittle-tattle of the town. Notwithstanding his apparent avarice, he was by no means a lover of money, for, during his seclusion, he never received nor asked for any rent from any of his tenants; those who brought 
him money, he would often keep at an inn more than a week, and then pay all their expenses, and dismiss them without receiving a shilling. He lived well in his house, frequently gave to the poor, always ate from large joints of meat, never saw any thing twice at table; and at Christmas divided a certain sum of money among the necessitous of the town. He seemed to be afraid of two things only, one, being killed for his riches, the other, being infected with disease; for which reasons he would send his naid sometimes to borrow half-acrown from his neighbours, to hint he was poor; and always received the money which was paid him in a bason of water, to prevent taking infection from those who paid him. He did not lseep his money locked up, but piled it on the shelves before the plates in his kitchen. In his cliamber, which no servant had entered during the time of his remaining at home, he had two thousand guineas on the top of a low chest of drawers, covered with dust, and five hundred on the foor, where it lay five and twenty years; this last sum a child had thrown down, which he was fond of playing with, by oversetting a table that stood upon one foot; the table continued in the same situation also: through this money he had made two paths, by kicking the pieces on one side, one of which led from the door to the window, the other from the window to the bed. When he quitted the Temple in London, he left an old portmanteau over the portal of the antechamber, where it had continued many years, during which time the chambers had passed through several hands : at length a gentleman who possessed them ordered his servant to pull it down; it broke, being rotten, and out fell four or five hundred pieces of gold, which were found to belong to him, from the papers enclosed. It was generally supposed at his death, that he had put large sums in the hands of a banker, or lent it to some tradesman in London, without taking any memorandum ; all which was lost to his heirs, as he would never say to whom he lent it, through fear, perliaps, lest he should hear it was lost; which some minds can bear to suspect, though not to know positively. After more than thirty years living a recluse, he was at last found dead in his bed, covered with vermin. Thus ended the life of this whimsical being, at the age of seventy.

The gentleman who accompanied him to the town-hall, when he went to take the oath of allegiance, talked with him on every subject he could recollect, without discovering in him the least tincture of madness. He rallied himself on the perpetual motion, laughed at the folly of confining himself in-doors, and said he believed he should come abroad again like other men. He was always esteemed a person of good understanding before his shutting himself up. At the time of his death, he was building a house, the walls of which were seven feet thick.

\section{Oliver Goldsmith.}

THIs celebrated writer was born at Roscommon in Ireland, in 1729. His father, who possessed a small estate in that county, had nine sons, of whom Oliver was the third. After being well instructed in the classics, he was, with his brother the Rev. Henry Goldsmith, placed in Trinity 
College, Dublin, about the end of 1749. In this seminary he took the degree of B. D. but his brother not being able to obtain preferment, Oliver turned to the study of physic, and after attending some courses of anatomy in Dublin, proceeded to Edinburgh in 1751, where he studied medicine under the professors of that university. His benevolent disposition soon involved him in difficnlties; and he was obliged precipitately to leave Scotland; in consequence of having engaged to pay a considerable sun for a fellow student. A few days after, about the beginning of 1754, he arrived in Sunderland, near Newcastle, where he was arrested, at the suit of a tailor in Edinburgh, to whom he had given security for his friend. By the good offices of Lachlan Maclaire, Esq. and Dr. Sleigh, then in the college, he was delivered out of the hands of the bailiff, and took his passage on board a Dutch ship to Rotterdam, where, after a short stay, he proceeded to Brussels. He then visited great part of Flanders, and, after passing some time at Strasburg and Louvain, where he took the degree of M. B., he accompanied an English gentleman to Bern and Geneva. He travelled on foot most part of his tour, having left England with very little money. Being of a philosophical turn, capable of sustaining fatigue, and not easily terrified at danger, he became enthusiastically fond of seeing different countries. He had some knowledge of French and of music, and played tolerably well on the German flute; which, from an amusement, became the means of subsistence. His learning procured him a hospitable reception at most of the religiou's houses; and his music made him welcome to the peasants of Flanders and Germany.

"Whenever I approached," he used to say, "a peasant's house towards night-fall, I played one of my most merry tunes; and that procured me not only a lodging, but subsistence for the next day; but in truth, I must own, whenever I attempted to entertain persons of a higher rank, they always thought niy performance odious, and never made me any return for my endeavours to please them."

On his arrival at Geneva, he was recommended as a travelling tutor to a young man, who had inherited a considerable sum of money by his uncle, a pawnbroker near Holborn. This youth, who had been articled to an attorney, on receipt of his fortune, determined to see the world; and on engaging with his preceptor, made a proviso, that he should be permitted to govern himself; and Goldsmith soon found his pupil understood the art of directing in money concerns extremely well, as avarice was his prevailing passion. Such curiosities on the way as could be seen for nothing he was ready to look at; but if the sight of them was to be paid for, he usually asserted, that he had been told they were not worth seeing. He never paid a bill without observing how amazingly expensive travelling was and all this, though he was not yet 21 !

During Goldsmith's continuance in Switzerland, he assiduously cultivated his poeticaletalent, of which he gave some proofs while at Edinburgh. From this place he sent the first sketch of his delightful poem called The Traveller, to his brother the clergyman in Ireland, who lived with an amiable wife on an income of only 401 , a year. Erom Geneva Mr. Goldsmith and his pupil visited the south of France, 
where the young man, upon a disagreement with his preceptor, pand him the small part of his salary which was due, and embarked at Marseilles for England.

Our wanderer was now left once more upon the world at large, and passed through various difficulties in traversing the greatest part of France. At length, his curiosity being satisfied, he bent his course towards England, and arrived at Dover the beginning of winter, 1758. When he came to London, his cash did not amount to two livres. Being an entire stranger, his mind was filled with the most gloomy reflections. With difficulty he discovered that part of the town where his old acquaintance Dr. Sleigh resided. This gentlentan received him with the warmest affection, and liberally invited him to share his purse till some establishment could be procured for him.

Goldsmith, unwilling to be a burden to his friend, eagerly embraced an offer which was made him soon after, to assist the late Rev. Dr. Milner in the academy at Peckham, and acquitted himself greatly to the doctor's satisfaction: but having obtained some reputation by the criticisms he had written in the Monthly Review, Mr. Griffith, the proprietor, engaged him in the compilation of it; and resolving to pursue the profession of an author, he returned to London, as the mart where abilities of every kind meet distinction and reward.

As his finances were not in a good state, he adopted a plan of the strictest economy, and took lodgings in an obscure court in the Old Bailey, where he wrote several ingenious pieces: The late $\mathrm{Mr}$. Newbery, who gave great encouragement to men of literary abilities, became a patron to him, and introduced him as one of the writers in the Public Ledger, in which his Citizen of the World originally appeared, under the title of Chınese Letters. His fortune now began to improve. The siniplicity of his character, the integrity of his heart, and the merit of his productions, made his company very acceptable to a number of respectable families; and he emerged from his shabby apartments in the Old Bailey to the polite air of the Temple, where he took handsome chambers, and lived in a genteel style. The publication of his Traveller, and his Vicar of Wakefield, was followed by the performance of his comedy of the Good-natured Man at Covent Garden theatre, and placed him in the first rank of the poets of the 18th century.

Among many other persons of distinction who were desirous to know him, was the duke of Northumberland; and a circumstance, that attended his introduction to that nobleman, shews a striking trait of his character. "I was invited," said the Doctor, "by my friend $\mathrm{Mr}$." Piercy, to wait upon the duke, in consequence of the satisfaction he had received from the perusal of one of my productions. I dressed myself in the best manner I could; and, after studying some compliments I thought necessary on such an occasion, proceeded to Northumberland house, and acquainted the servants that I had particular business with his grace : they shewed me into an antechamber, where; after waiting some time, a gentleman very genteelly dressed made his: appearance. Taking him for the duke, I delivered all the fine things 1 had composed, in order to compliment him on the honour he had done me; when, to my: great astonishment, he told me I had mis-. 
taken him for his master, who would see me immediately. At this instant, the duke came into the apartment; and I was so confused on the occasion, that I wanted words barely sufficient to express the sense I entertained of the duke's politeness, and went away extremely chagrined at the blunder I had committed."

Another anecdote exhibits the strict integrity of his character. Previous to the publication of his Deserted Village, the bookseller had given him a note for one hundred guineas for the copy, which the Doctor mentioned a few hours after to one of his friends, who observed, that it was a very great sum for so short a performance: "In truth," replied Goldsmith, "I think so too; I have not been easy since I received it; therefore I will go back and return him his note:" which he absolutely did, and left it entirely to the bookseller to pay him according to the profits produced by the sale of the piece; which, however, turned out very considerable.

During the last rehearsal of his comedy, entitled She Stoops to Conquer, which Mr. Coleman had no opinion would succed; on the Dr.'s objecting to one of Tony Lumpkin's speeches, being apprehensive it might injure the play; the manager, with great keenness, replied, "Psha, ny dear Dr.; do not be fearful of squibs, when you have been sitting almost these two hours on a barrel of gunpowder." This piece, however, was received with uncommon applause by the audience; and the severity of Coleman's observation put an end to the Doctor's regard for him. Notwithstanding the great success of his pieces, by some of which he cleared 8001. in one year, his circumstauces were not in a prosperous situation; partly owing to the liberality of his disposition, and partly to an unfortunate habit of gaming, the arts of which he knew very little of, and thus became the prey of those who took advantage of his simplicity.

Beforehis death he published the prospectus of an Universal Dictionary of Artsand Sciences; and as his literary friends, Sir Joshua Reynolds, Dr.Johnson, Mr. Beauclerc, Mr. Garrick, and others, had undertaken to furnish him with articles on different subjects, he entertained the most sanguine expectations from it The undertaking however, did not meet with that encouragement from the booksellers, which he imained it would receive; and he lamented this circumstance almost to the last hour of his life. He had been for some years afflicted at different times with a violent straingury, which contributed to imbitter the latter part of his life; and which, united with the vexations which he suffered upon other occasions, brought on a kind of habitual despondency. In this unhappy condition he was attacked by a nervous fever, which terminated in his death on the 4th of April 1774. His character is justly expressed in Mr. Pope's line;

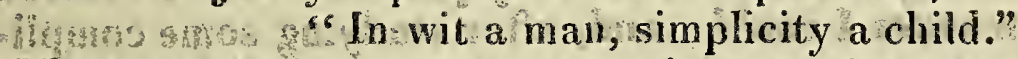

The learned leisure he loved to enjoy was ofteninterrupted by distress which arose from the irritability of his temper, which sometimes threw him into violent fits of passion ; but this impetuosity was corrected upon reflection, and his servants have been known, upon these occasions, purposely to throw themselves in his way, that they might profit by it immediately after, for he who had the good fortune to be reproved, was certain of being rewarded for it. The universal esteem in which his 
poems were held, and the repeated pleasure they gave in the perusal, is a striking test of their merit. He was a studious and correct observer of nature; happy in the selection of his images, in the choice of his subjects, and in the harmony of his versification; and though his embarrassed situation prevented him from putting the last hand to many of his productions, his Hermit, his Traveller, and his Deserted Village, claim a place among the most finished pieces in the English language.

\section{Thomas Day.}

This poetical and miscellaneous writer, of an eccentric character, was born in Well-close square, London, June 22, 1748. His father was an officer in the custom-house, and had been twice married. This son was the issue of his second marriage, to Miss Jane Bonham, the only daughter of Samuel Bonhim, esq. a merchant in the city. His father died when he was littl: more than a year old, leaving him a fortune of $1200 \mathrm{l}$. a year, including $300 \mathrm{l}$. as a jointure to his mother, who in a few years married Thomas Phillips, esq. another officer in the custom-house. To this gentleman, who died in 1782, young Day behaved with decent respect, but felt no great attachment. His mother, however, chiefly superintended his education, and accustomed him early, we are told, to bodily exertions, on which he afterwards set so high a value. He was first put to a child's school at StokeNewington, and when admissible, was sent to the Charter-house, where he resided in the house, and under the instructions, of Dr. Crusius, until his sixteenth year. He now entered as a gentleman-commoner of Corpus Christi College, Oxford, where he remained three years, but left it without taking a degree.

As soon as he came of age, his property and conduct devolved upon himself. At an early period of life, we are told, be manifested a particular fondness for scrutinizing the human character; and as if such knowledge could not be acquired at home, he took a journey in 1766 from Oxford to Wales, that he might contemplate that class of men, who, as still treading the unimproved paths of nature, might be presumed to have the qualities of the mind pure and unsophisticated by art. What of this description he found in Wales, we are not informed; but in pursuit of the same investigation of men and manners, he determined to go abroad; and accordingly spent one winter at Paris, another at Avignon, and a third at Lyons, a summer in the Austrian Netherlands, and another in Holland. At Lyons, as every where else, he was distinguished by his humanity and generosity, which made his departure from those places to be sincerely regretted, and at Lyons it produced an effect singularly characteristic of the class of people on whom he bestowed his bounty. A large body of them assembled at his departure, and very justly considering that they would now be in a worse condition than if he had never relieved them, requested that he would leave a sum of money behind for their future wants. It is probable that these returns for his imprudent liberality had a considerable share in producing the misanthropy which appeared in his future conduct.

He had already formed some very absurd notions of the state of 
society in England, and had accustomed himself to mistake the reveries of Rousseau for the result of experience. He had been early rejected by a young lady to whom he paid his addresses, and, considering her as a fair sample of her sex, despaired of finding among them a wife such as he would chuse; one that should have a taste for literature and science, for moral and patriotic philosophy; fond of retirement from the infectious taint of human society; simple as a mountain girl, in her dress, hel diet, and her manners; and fearless and intrepid as the Spartan wives and Roman heroines. Observation soon taugh him that there was no such creature ready made, and he must therefore mould some infant into the being his fancy had imaged.

From a comparison of dates, it appears to have been in 1769 , when he came of age, that he formed this curious project. Accompanied by a Mr. Bicknell, a barrister, rather older than himself, he went to Shrewsbury to explore the Foundling Hospital, and from these children, Mr. Day, in the presence of Mr. Bicknell, selected two girls, of twelve years each, both beautiful; one fair, with flaxen locks and light eyes, whom he called Lucretia; the other, a clear auburn brunette, with darker eyes, more glowing bloom, and chesnut tresses, he called Sabrina. These girls were obtained on written conditions, for the performance of which Mr. Bicknell was guarantee. They were to this effect: that Day should, within the twelvemonth after taling them, resign one into the protection of some respectable tradeswoman, giving one hundred pounds to bind her apprentice; maintaining her, if she behaved well, till she married, or began business for herself. Upon either of these events, he promised to advance four hundred pounds more. He avowed his intention of educating the girl he should retain, with a view to make her his future wife; solemnly engaged never to violate her innocence; and, if she should renounce his plan, to maintain her decently in some creditable family till she married, when he promised to give her five hundred pounds as her wedding portion. It would, probably, be quite untiecessary to make any appeal to the feelings of parents, or to offer any remarks on the conduct of the governors of this hospital, respecting this strange bargain, for the particulars of which we are indebted to Miss Seward.

The narrative goes on to inform us that Mr. Day went instantly into France with these girls, not taking an English servant, that they might receive no ideas except those which himself might chuse to impart, and which he soon found were not very acceptable. His pupils teazed and perplexed him ; they quarrelled; they sickened of the smallpox; they chained him to their bed-side, by crying if they were ever left alone with any person who could speak English. Hence he was obliged to sit up with them many nights, and to perform for them the lowest offices of assistance. They lost no beauty, however, by their disease, and came back with $\mathrm{Mr}$. Day, in eight months, when Sabrina was become the favourite. He placed Lucretia with a chamber milliner, and she afterwards became the wife of a linen draper in London.

With Sabrina he actually proceeded, during some years, in the execution of his favourite project; but none of his experiments had the success he wished. Her spirit could not be armed against the dread of pain and the appearance of danger ; a species of courage, which, 
with him was a sine qua non in the character of a wife. When he dropped melted sealing wax upon her arms, she did not endure it heroically; nor when he fired a pistol at her petticoats, which she believed charged with ball, could she help starting aside, or wholly suppress her screams. When he tried her fidelity in secret-keeping, by telling her well-invented tales, in which great danger would result from its being discovered, he once or twice detected her having imparted them to the servants and to her play-fellows. He persisted, however, in these foolish experiments, and sustained considerable disappointment during a whole year's residence in the vicinity of Litchtield. The difficulty seemed to be, in giving her a motive to selfexertion, self-denial, and heroism. It was against his plan to draw it from the usual sources, - pecuniary reward, luxury, ambition, or vanity. His watchful cares had precluded all knowledge of the value of money, the reputation of beauty, and its concomitant desire of ornamented dress. The only inducement, therefore, which this girl could have to combat and subdue the natural preference in youth, of ease to pain, and of vacant sport to the labour of thinking, was the desire of pleasing her protector, though she knew not how or why he became such, and in that desire fear had greatly the ascendant of affection. At length, however, he renounced all hopes of moulding Sabrina into the being which his disordered imagination had formed; and, ceasing now to behold her as his future wife, placed her at a boarding-school at Sutton Coldfield, Warwickshire, where during three years she gained the esteen of her instructress, grew feminine, elegant, and amiable, adorning the situation in which she was placed.

After this Mr. Day paid his addresses to two sisters in succession, both of whom rejected him. His appearance and manners were indeed not much calculated to charm; and the austere singularities of his sentiments, and the caprices of his temper, all which were parts of the system of happiness he had formed to himself, were tolerable, even by his friends, for a very short period. With the second of these ladies, indeed, he was so enamoured as to tell her that he would endeavour to acquire external refinements; but, finding the progress he made insufficient to aba te her dislike, he returned to his accustomed plainness and neglect of his person. But notwithstanding these disadvantages, he found a lady, a Miss Milnes of Yorkshire, then residing in London, to whom, after a singular courtship, he was united in 1798. The best part of his conduct in this affair was, his settling her whole fortune, which was as large as his own, upon herself, totally out of his present or future control.

What follows is of a less amiable complexion. They retired, soon after their marriage, first to Stapleford Abbots, in Essex, and afterwards to Anningsley, near Chertsey, in Surrey. Here they had no carriage, no appointed servant about Mis. Day's own person, nor luxury of any sort. Music, in which she was a distinguished proficient, was deemed trivial. She banished her harpsichord and music books. Frequent experiments upon her temper and her attachment were made by him, whom she lived but to obey and love. Over these, we are told, she often fret, but never repined; and no wife, bound in the strictest fetters, as to the incapacity of claiming a scparate mainte. 
nance, ever made more absolute sacrifices to the most imperious masters, than did this lady, whose independence had been secured. She is even said to have died broken-hearted for his loss, about two years after his departure.

The whole of their residence at Anningsley, however, was not passed in inflicting or tolerating caprice. Some of Mr. Day's experiments were of a more praiseworthy kind. His neighbours of the lowest class, being as rough and as wild as the commons on which they dwelt, he tried if by mutual attrition he could not polish; and though the event fell short of his expectation, he was not wholly unsuccessful. Many of the peasants he took to work on his farm, and in his selection of them it was always his object to accommodate those who could not find employment, elsewhere, until they could meet with some fresh job: but so fond were they of their new master, that they wanted frequently to be reminded that their stay was only temporary. During the winter season they were so numerons, that it was scarcely in the power of a farm of more than two hundred acres, of a family on the spot, and of the contiguous neighbourhoorl, to raise for thein a shadow of employment from day to day. Mr. Day, whenever he walked out, usually conversed with them in the fields, and questioned them concerning their families. To most of them, in their turn, he sent blankets, corn, and butcher's meat. He gave advice and medicine io the sick, and occasionally brought them into his kitchen, to have their meals for a few weeks among the servants. Once or twice he took them into his service in the house, on the sole account of their bad health, a circumstance which by many would have been deemed ample cause for dismission. Mrs. Day aided the benevolent exertions of her husband by employing the neighbouring poor in knitting stockings, which were occasionally distributed amongst the labourers.

Mr. Day's modes and habits of life were such as the monotony of a rural retirement naturally brings upon a man of ingenuity and literary taste. To his farm he gave personal attention, from the fondness which he had for agriculture, and from its being a source to him of health and amusement. It was an additional pleasure to him, that hence was derived employment for the poor. He had so high an opinion of the salutary effects of taking exercise on horseback, that he erected a riding-house, for the purpose of using that exercise in the roughest weather. Though he commonly resided in the country during the whole of the winter season, and was fond of shooting as an art, he for many years totally abstained from field-sports, apprehending them to be cruel; but at last, from the same motive of humanity, he resumed the gun.

He rose about eight, and walked out in his grounds soon after breakfast, but much of the morning, and still more of the afternoon, were usually spent at his studies, or in literary conversations when he was visited by his friends. At length, Mr. Day, who suffered no species of control to interfere with what he fancied or undertook, fell a victim to a part of his own system. He thought highly of the gratitude, generosity, and sensibility of horses; and that whenever they were disobedient, unruly, or vicious, it was owing to previous 
ill-usage from men. Upon his own plan, therefore, he reared, fer?, and tamed, a favourite foal, and, when it was time it should become serviceable, disdaining to employ a horse-breaker, he would use it to the bit and the burden himself. The animal, however, disliking his new situation, heeded not the soothing voice to which he had been accustomed, but plunged, threw his master, and instantly killed him with a kick. This melancholy accident happened on September 28, 1739 , as he was returning from Anningsley to his, mother's house at Barehill, where he had left Mrs. Day. He was interred at Wargrave, in Berkshire, in a vault which had been built for the family.

In the very flattering, and by no means just or discriminative character of Mr Day, given in the Biographia Britannica, his life is represented to have been one continued exertion in the cause of humanity. He thought nothing mispent or ill-bestowed which contributed in any degree to the general sum of happiness. In the pursuit of knowledge, though he deemed it highly valuable as a private and personal acquisition, he had a particular view to the application of it to the purposes of philanthropy. It was to be able to do good to others, as well as to gratify the ardent curiosity and activity of his own mind, that he became an ingenious mechanic, a well-informed chemist, a learned theoretical physician, and an expert constitutional lawyer. But though his comprehensive genius embraced almost the whole range of literature, the subjects to which he was the most attached, and which he regarded as the most eminently useful, were those that are comprehended in historical and ethical science. Indeed, every thing was important in his eyes, not merely as it tended to advance the individual, but in proportion to its ability in disclosing the powers, and improving the general interests, of the human species."

On this high character, after the facts we have exhibited, it wiil not be necessary to offer any remarks. As the epithet "constitutional lawyer" is here employed, it remains to be mentioned, that he was admitted to the Middle Temple in 1765, and called to the bar in 1979. Much of this time, we have seen, elapsed in his travels, and pursuits of another kind; ror, although his name remained on the book of the society, did he ever enter seriously into the business of the profession. In politics he attached himself to no party, properly so called; he was neitlier whig nor tory, but joined many of the popular associations about the close of the American war, to which lie was a decided opponeut, and wrote some political pamphlets,-on peace, reform of parliament, and other topics which agitated the nation at that period.

His poetical talents, if not of the first rate, evinced considerable taste and elegance, but were not always equally usefully enployed. His first publication, The Dying Negro, published in 1793 , sone part of which was written by his friend Mr. Bicknell, contributed its share to create that general abhorrence of the slave-trade, which ended at length in the abolition of a traffic so disgraceful to the nation. His other poems, The Devoted Legions, and the Desolation of America, were both of a political cast. His prose effusions on national affairs consists of the Letters of Marius, or Reflection upon the Peace, the East India Bill, and the Present Crisis; the Fragment of a Letter on the Slavery of the Negroes, expressing his regret that the friends of freedom in America 
had not learned to share that blessing with their slaves; A Dialogue between a Justice of Peace and a Farmer; and a Letter to Arthur Young, Esq. on the bill then depending in parliament to prevent the Exportation of Wool.

The only works, however, which Mr. Day publislied, that are likely to prolong his name, are those upon education. This was a subject in which, we have already seen, he tried some bold and ridiculous experiments. His notions, however, became at last more moderate, and his schemes a little more practicable. He had a particular dislike to the fashionable modes of education that prevail in this country. Youth, he thought, should be inspired with a hardy spirit, both of passive and active virtue, and led to form such habits of industry and fortitude as would produce a manly independence of character, and a mind superior to the enticements of luxurious indulgence; with this view, he wrote the history of Sandford and Merton, a work intended for the use of children; the first volume of which appeared in 1783, the second in 1786, and the third in 1789. These soon acquired great popularity, which is now much decayed. They are harmless at least, and amusing, though ill accommodated to the actual state of manners. He published also The History of Little Jack; a story, the moral of which is this simple truth, that it is of very little consequence how a inan comes into the world, provided he behaves himself well, and discharges his duty when he is in it.

Thomas Chatéterton.

THE early and extraordinary talents, and tragical end, of this youth, have rendered him an object of much interest and curiosity. He was the posthumous son of a person in humble life at Bristol, in which city he was born in November, 1752. He was slow in attaining the first rudiments of education, and it was not till he had been delighted with the illuminated capitals of an old manuscript, that he took to learning his letters. This circumstance, and his being taught to read out of a black-letter bible, will doubtless be thought, by the partisans of the theory of association, to have had a great share in the peculiar turn to the imitation of antiquities which he afterwards displayed. All the scholastic education he received was at a charity school, where no language was taught but the mother-tongue. Here he remained some time undistinguished, except that a pensive gravity of demeanour assimilated him rather to the man than the boy. About his tenth year a taste for reading disclosed itself, which thenceforth became a kind of ruling passion. He hired and borrowed books as he had opportunity, and between his eleventh and twelfth year diew up a catalogue of those he had read, amounting to seventy, which chiefly consisted of history and divinity. It is not absolntely certain how soon he began to write verses, but he had certainly composed -some at twelve years of age; and he now began to shew that ardour of mind and versatility of parts by which he was afterwards so strongly characterized.

In his fifteenth year he left school, and was articled to a scrivener at Bristol, in the lowest form of apprenticeship. Though in this situsation lie underwent much confinement, yet his leisure was great, and 
he employed a large portion of it in literary pursuits. It was in the year 1678 that he first began to attract notice from the fruits of his studies; but on this subject it is necessary to enter into some preliminary explanations.

In the church of St. Mary Radcliffe, Bristol, whick was founded or rebuilt by W. Canynge, an eminent merchant of Bristol, in the reign of Edward IV. in the fifteenth century, there is a room in which were deposited six or seven chests, one of which was called Mr. Canynge's coffer. This chest had formerly been secured by six keys, entrusted to different persons; but in process of time the keys were lost; and when, about 1727 , in consequence of a notion that the chest contained some title-deeds, an order was made for its examination by an attorney, the locks were broken open. The deeds found in it were taken away; but a number of other manuscripts were left exposed to casual depredation. Many of them were carried off; but the father of Chatterton, whose uncle was sexton to the church, was insatiable in his plunder, and removed baskets full of parchment, of which, however, he made no better use than as covers to books. Young Chatterton is said, soon after the commencement of his clerkship, to have been accidentally struck with one of these parchments, converted into his mother's thread-paper, and, on inquiry, to have obtained a remaining hoard of them yet unused. Whatever was the fact of his first knowledge of them, he appears early to have formed the design of converting the circumstance into a system of literary forgery. In the variety of his studies, antiquities had occupied a favourite place. He dabbled in heraldry, and made collections of old English words from glossaries.

Upon the opening of the new bridge at Bristol, in October, 1768, a paper appeared in Farley's Bristol Journal, intitled, A Description of the Fryars first passing over the Old Bridge, taken from an Old Manuscript. This was traced to Chatterton; and on being interrogated about its origin, after some variation of account, he at length asserted that it came from the chest above mentioned in Radcliffe church. He next propagated a rumour, that certain ancient pieces of poetry had been found in the same place, the authors of which were Thomas Canynge, and an intimate friend of his, one Thomas Rowley, a priest. Mr. Catcott, an inhabitant of Bristol, of an inquiring turn, hearing of this report, was directed to Cliatterton, from whom he readily obtained, without reward, various poetical pieces, under the name of Rowley. These were communicaterl to Mr. Barret, surgeon, who was writing a history of Bristol. They met with credit, and acquired for Chatterton the patronage of Barret and Catcott. These pieces were all written upon small pieces of vellum, and passed for the original Mss. Chatterton was occasionally gratified with money for his presents, and books were lent him for the prosecution of his studies, which began to be very multifarious. About this time his intimate companions observed in him extraordinary fits of poetic enthusiasm, particularly when walking in the meadows near Radcliffe, and talking about, or reading, the pretended productions of Rowley. No doubt, he was then labouring with that inspiration of the muse, which is scarcely a fiction in the breast of real genius.

In 1769 he made a still bolder effort to raise himself to public 
notice. He wrote a letter to the honourable Horace Walpole, well known for his curious researches in literature and the arts, offering to furnish him with some accounts of a scries of eminent painters who had flourished at Bristol; at the same time mentioning the discovery of the old poems, and enclosing two small pieces as a specimen. To a very polite reply, requesting further information, Chatterton returued an answer stating his condition in life, and hinting a wish to be freed from an irksome and servile profession, and placed in a situation more favourable to the pursuit of elegant studies. Mr. Walpole communicated the papers to Gray and Mason, who, without hesitation, pronounced them forgeries. This occasioned a cold and monitory letter from him to Chatterton, which so offended the high-spirited youth, that he immediately demanded back the manuscripts, alleging that they were the property of another. Walpole, then about to depart for Paris, neglected to send them back; and on his return found a very resentful letter from Chatterton, peremptorily requiring the papers, and telling Walpole, "that he had not dared to use him so, had he lot been acquainted with the narrowness of his circumstances." Walpole then ericlosed them in a blank cover, and thus the correspondence ended.

Walpole's conduct on this occasion has subjected him to much oblo-. quy, and he has been charged with suffering this flower of genius to be blighted by neglect, and even has been made remotely arcessary to Chatterton's unhappy end. But to this he has very properly replied, that Chatterton could appear to him in no other light than that of a young man disgusted with his proper profession, and attempting to obtain his notice by passing a forgery upon him. Whatever were the merits of the pieces, as he himself imputed them to another, they implied no singular abilities in him. The neglect of returning them. was, however, a fault, though one apparently of no very great consequence.

Chatterton had before this time commenced a correspondence with the Town and Country Magazille; and various communications from him were printed in the numbers for that work in 1769 , consisting of matters relating to antiquity, of extracts from the pretended Rowley, and of pieces entitled Saxon Poems, written in the style of Ossian. He also became a very prolific writer in satire, particularly of the political kind. In March, 17\%0, he composed a satirical poem of 1300 lines, eltitled, Kew Gardens, the object of which was to abuse the princess dowager of Wales and lord Bute, together with the principal partisans of the ministry, in Bristol; nor did he spare some of his own friends and patrons. His character, indeed, upon developing himself, did not appear in the most favourable light. His confidence in his powers rendered him proud and imperious; and some of his productions shew great laxity of principle, though it is affirmed that his conduct was sufficiently regular. He had openly renounced his belief in the Christian religion, one effect of which.was to render the idea of suicide no longer a horror to him. A declared intention of this kind was the immediate cause of his leaving the service of Mr. Lambert, the person to whom he was apprenticed.: Upon his desk was found a paper, entitled, "The last Will and Testament of 
Thomas Chatterton," in which he avowed his determination to put an end to his life on the following day, which was Easter Sunday, 1770. Un discovering it, Mr. Lambert immediately dismissed him from lis house and service, in which he had lived upwards of two years and nine months. $\Lambda$ s he did not then put his threat into execution, it is probable that it was an artifice to obtain his dismission; especially as he had before territied Mr. Lambert's mother and the servants with similar intimations. He had acquired so little law in this situation, that he was unable to draw up a legal discharge from his apprenticeship.

London was now the great object of his views, as the only proper mart for his abilities, and an intimate friend of Chatterton has furnished us with his own account of his plans for the metropolis. "My firstattempt," said be, "shall be in the literary way: the promises I have received are sufficient to dispel doubt; but should I, contrary to expectation, find myself deceived, I will in that case turn Methodist preacher. Credulity is as potent a deity as ever, and a new sect may easily be devised. But if that too should fail me, my last and final resource is a pistol." This is certainly not the language of a simple ingenuous youth, smit with the love of sacred song-a Beattie's minstrel, as some of Chatterton's sentimental admirers have chosen to paint him.

On his arrival in London, he applied to the booksellers, his former correspondents, and immediately engaged in a variety of literary labours, which required equal industry and versatility of parts. A history of England, a history of London, a magazine, essays in the daily papers, and songs for the public gardens, were among his actual or projected tasks. Above all, party politics were his darling pursuit. He connected himself as intimately as he could with the patriots of the day; and was extravagantly elated with an introduction to the celebrated city magistrate, Mr. Beckford. Soon finding, however, that money was scarce on the opposition side, he observed to a friend, that he was a poor author who could not write on both sides; and he was not long in adopting this prudential maxim. For a time, it appears, that he indulged himself in the most sanguine hopes of attaining distinction and affluence by the exertions of his pen; and his letters to his friends were filled with visionary prospects of this sort, partially excusable in a youth not eighteen. It is right to mention, as a proof of the tenderness of his social affections, that the prospect of being able to assist his family, and raise them from their humble sphere, appears to have given him peculiar pleasure; nor did he omit to send them little presents out of his first gains.

His taste for dissipation, however, kept pace with his hopes; and he asserted, that to frequent places of public amusement was as necessary to him as food." Yet it would seem, that with respect to the grosser pleasures of sense, he still preserved a temperate restriction. What occasioned the very sudden change in lis expectations, does not clearly appear. He probably found that he had nothing to hope from the pationage of the great, and that he must henceforth depend upon the booksellers for a scanty and hard-earned subsistence. This severely mortified his pride, and seems to have disgusted him with his literary labours. He even wished to quit the scene of his disap- 
pointment, and made an unsuccessful attempt to abstain the very undesirable post of surgeon's mate to the coast of Africa. The remainder of his history is short and melancholy.

Falling into a state of indigence, which is not easily accounted for, supposing him to have continued his exertions even in a moderate degree, he was reduced to the want of necessary food. Yet such was his pride, that he refused, as a sort of insult, an invitation to a dinner with his hostess, on the day preceding his death, assuring her he was not hungry. This was on August 24, 1770, and he soon after swallowed arsenic in water, the consequences of which proved fatal on the ensuing day. He was then in lodgings in Brook-street, Holborn. His remains were interled in the burying ground of Shoe-lane workhouse. Thus, a prey to all the horrors of despair, friendless and forlorn, poor Chatterton terminated a life which he had not enjoyed eighteen complete years.

To enter in to more minute particulars concerning the moral character of Chatterton, seems unnecessary, but the character of his genius demands a further discussion. It seems agreed that its measure should be taken from the poems published under the name of Rowley: for that they are really the product of the age and person to whom he attributed them, is a supposition now abandoned by all who pretend to literary discernment. Their authenticity, it is true, was at first defended by great names, especially of the antiquarian class, who too often have proved the dupes to their fondness for the wonder's of antiquity. But, exclusive of strong external marks of suspicion, internal evidence is abundantly sufficient to decide the question. That an unknown writer, of the fifteenth century should, in productions never heard of, but made to be locked up in a chest, so far surpass the taste and attainments of his age, as to wite pieces of uniform correctness, free from all vulgarity and puerility, requiring nothing but a change of spelling to becone harmonious to a modern ear, and even containing measures peculiar to the present age of English poetry, may safely be pronounced a moral impossibility; that such could be produced by a boy of fifteen or sixteen, is only extraordinary.

Rowley's Poems were first collected in an octavo volume by Mr: Tyrwhit, and afterwards splendidly published in quarto by Dean Milles, president of the society of antiquarians. They cousist of pieces of all the principal classes of poetical composition ; tragedies; lyric and heroic poems, pastorals, epistles; ballads, \&c. Many of them abound in sublimity and beauty, and display wonderful powers of imagination, and facility of composition; yet there is also much of the common-place flatness and extravagance, that might be expected from a juvenile writer, whose fertility was greater than his judgment, and who had fed his mind upon stores collected with more avidity than choice. The spelling is designedly uncouth, and plain words are copiously besprinkled, which good judges say were never the diction of any one age of English literature, but are culled from glossaries. There is no doubt that these peculiarities have thrown a veil over the defects of the poems, and have aggrandized their beauties, by referring the imagination, even of those who were disbelievers of their genuineness, to a remote age, when they would have 
been really wonders. Yet they must ever be looked upon as very extraordinary productions of a boy, and will perpetuate the name of Chatterton among those of the most remarkable examples of premature genius.

Of his avowed writings, a miscellaneous volume was published in 1778 , followed by a supplement in 1786 . These, though upon the whole inferior to his Rowley, display the same versatility and quickness of parts, and are not without some passages of striking merit.

It has been concluded by many of the warm admirers of Chatterton, that had he been born under happier auspices, and lived to the maturity of his faculties, he would have risen to the very first rank of English poetry. But this may be a mistaken opinion. The history of literature affords many instances of the promise of youth remaining unfulfilled in mature years; and it is not unlikely that his imagination would early have exhausted itself, without being succeeded by any other quality of the mind in an equal measure.-His disposition appears likely to have been too volatile to have allowed him steadily to pursue perfection in any one walk. - The uncommon talents and melancholy fate of Chatterton have caused many tributes to be paid to his memory, some of them in strains highly animated and pathetic. That in these poetical commemorations his merit should have been exaggerated, his faults extenuated, and his catastrophe represented rather as a stain upon his countrymen than himself, is perhaps excu. sable; but a deviation from truth in the sober narration of a biographer admits of no apology.

Sir Harry Dimsdale, Miyor of Garratt.

THE origin of electing a mayor of Garrat is involved in some obscurity; but it is generally believed to have taken its rise from a frolic which was practised towards the close of the seventeenth century, when some watermen, during an election, determined on passing a merry day at Garratt, a district in the parish of Wandsworth in Surrey, took in to their heads to choose one of their company representative of that place. Ever since, at a general election, the custom has been kept up,--when a cripple or an idiot is usually elected mayor. A great crowd generally attend on these occasions, and there is a sort of fair on the day of election. On one occasion, Sir Harry Dimsdale, as he was called, was elected to the office.

Sir Harry, who was a complete idiot, was born in Shug-lane, Haymarket, in the year 1758. Of his early pursuits little is known; but we find him, in 1788, receiving parochial relief from St. Martin's parish: his trade at that time was vending "bobbins, thread, and staylaces, for the ladies :" he next commenced muffin dealer, by which he made himself very conspicuous about the streets of London. His harmless behaviour gained him many customers, and life rolled on gaily and smoothly, till ambition fired his soul, and he aspired to the honour of representing the borough of Garrat, on the death of that celebrated character Sir Jeffrey Dunstan; and in which he was successtul. Sir Harry was elected to fill the important station of Mayor of Garratt, during four parliaments ; though not without experiencing violent opposition in the persons of Squire Jobson the - bill-sticker, 
Lord Goring the ministerial barber, and others. The following is a copy of his address to his constituents at the goneral election, 1807.

"To the worthy, free, and independent Electors of the ancient borough of Garratt.

"Gentlemen-Once more you are called upon to exercise your invaluable right, the elective franchise, for your ancient and honourable borough; and once more your faithful representative, for the three last parliaments, offers himself a candidate.

"Gentlemen, as All the Talents were lately dismissed disgracefully, it is requisite I should declare to you, I held no place under thein. I am, gentlemen, no milk-and-water patriot-I am no summer insect. I have always been a champion for the rights and privileges of my constituents; - and as we have now an entire change of men, I hope, as they are called by many All the Blocks, they will see the necessity of calling to their aid and assistance men who have long been hid in obscurity-men, whose virtue and integrity may shine at this awful crisis-and, Gentlemen, should they at length see their interest so clear, as to call into action my abilities, I declare I am ready to accept any place under them; but $I$ am determined to act on independent principles, as my worthy colleague, Lord Cochrane, so loudly and so often swore on the hustings at Covent Garden.

"Gentlemen, I congratulate you on the defeat of Sixpenny Jack, [John E-t, Esq.] he was obliged to hop off, and leave the laurel of victory to Sir Francis Burdett and my worthy colleague Lord Cochrane; and should any quixotic candidate be hardy enough to contest with me the high honour of representing your ancient borough, I have no doubt, by your manly exertions, you will completely triumph over my opponent. In times past you have had confidence in my wisdom and integrity-you have looked up to me as your guardian angeland I hope you have not been deceived; for, believe me, when I repeat what I so often have done, I am ready to sacrifice life, health, and fortune, in defence of the invaluable rights, privileges, and inımunities of your ancient and honourable borough.
"I am \&c.
Sir Harry Dimsdale,

From my attic chamber, the dirty end of Monmouth-street, June 10, $180 \%$.

In this contest Sir Harry was again successful, and his procession to Garrat-lane exceeded any thing of this kind ever seen in London. He was placed, or rather tied, on an eminence in a carriage, somewhat resembling a triumphal car, drawn by four horses, which were profusely decorated with dyed wood-shavings-a substitute for ribands. The dress of Sir Harry was perfectly en suite, and the tout ensemble a rare display of eccentric magnificence. Solomon, in all his glory, was not arrayed like the mayor of Garratt, on this memorable day.

And now, for a short time, all was sunshine with Sir Harry; yet he found something was wanting to complete his happiness, and he resolved on taking to his bosom a wife. A suitable object presenting herself in the person of an iumate of St. Anne's workhouse; in a few wecks after the consummation of their nuptials, his rib, with the utmost 
good-nature, presented him with a son and heir, of which he was very proud.

In addition to his office of mayor, he was nominated as a proper person to be opposed to the then all-powerful Buonaparte, whereupon he was elected emperor. His garb now assumed all the show of royalty ; but, unlike most monarchs, he carried his crown in his havd, it not being correct, he said, for him to wear it till he had ousted his more powerful rival. In this character, Sir Harry levied pretty handsome contributions on the good people of London : but the novelty of his person at length lost most of its attractions; he became neglected, illness seized him, and he died in the year 1811, in the fifty-third year of his age.

\section{Mr. Thomas Gascoigne.}

THIs was a very penurious character, who was resident at East Retford, in the county of Nottingham. He was a native of Derby, and was born on the 24th of June, 1738, being the same month and year as that in which his late majesty was born. At an early period of his life, Mr. Gascoigne's parents removed from Derby to Ordsall, a village near Retford: when arrived at a proper age, he was bound apprentice to a shoemaker of Retford, who was a burgess of that place; and at the close of his apprenticeship, Mr. G. was consequently entitled to the privilege of a freeman, and at his death he was the oldest burgess upon the list. Some time after the expiration of his apprenticeship, he obtained a situation in the excise, and was ap. pointed to fulfil the duties of his office at Derby, which he did to the satisfaction of his superior officers, as also those whom it was his duty to survey, till an accident obliged him to retire on a pension when about the age of forty.

About this time an uncle of Mr. G.'s died, who left him the owner of several houses, situate in Derby, one of which is the Crown Inn; he now returned to Retford, and again followed his vocation as a shoemaker, which he continued to do till within the last ten years preceding his death. During the whole of his long life he was never known to employ a doctor, and was generally his own tonsor, except upou particular occasions, such as the dinners of the freemen, which were about twice a year, and which he regularly attended, when he repaired to the hair-dresser's to be fillished, having himself previously applied the scissors and razor, and taken off the greatest part, purposely with a view to save expense. He regularly went once a year to Derby to receive his rents, on which occasion he put on his best coat and boots, and cocked lat, each of which had been in use more than forty years. It was his practice always to walk, carrying with him a pair of old saddle-bags, hung over his shoulders, containing provisions necessary for his whole journey. On his way thither, as also on his return, he generally reposed during the night on Nottingham forest, thinking himself and his property more safe there than sleeping in a public-house; and being ton penurious to pay for a bed, or to call at an inn for refreshment. His saddle-bags, on these occasions, were not only used for the purpose of carrying the provisions 
necessary for his journey, but were also a subservient receptacle for potatoes, and every orher eatable which might chance to fall in his way, and which he did not fail to carry home with him.

During his absence on one of his tours to Derby, about five years before his death, his house was broken open, and robbed of bills and cash to the amount of 500l. which was but a small sum compared with what was secreted in the louse, and that escaped the scrutinizing search of the robbers. His punctuality as a paymaster for his rent, and that which necessity compelled him to purchase, was very. strict, as was also his accuracy as a bouk-keeper; for at the time of the robbery, he had carefully booked the number of every note, the name of the person who signed and entered them, and the date; he likewise kept an account of his expenditure, many weeks in which appeared to be only a penny and twopence, as he chiefly subsisted on what he picked up in the streets, particularly on market days, by which means he became well known to all who fiequented the market, as he always wore a long coat, whicl, with his stockings, could not be said to contain a particle of the original, they being so patched and darned with worsted. A ton of coals would serve him seven years, in the use of which he was very sparing and economical; for in making his fire he first put a few sticks and coals, then a tier of stones, next a few more coals, and at top another tier of stones, which in time became red hot; but it was only to bake his bread that he made a fire, at which times he also roasted potatoes sufficient to serve him till he again baked. His house was a miserable abode, and had more the appearance of a receptacle of filth, than the residence of a human being; it was indeed unfit for "mortal ken," the walls not having" been whitewashed, nor the floor washed, for more than twenty years. In one corner lay a heap of stones for his fire; in another, hundreds of pieces of leather, such as old soles, which he had gathered for the purpose of mending his own.

Many other instances of his parsimonious disposition might be named, but they would occupy too much of our space. The principal part of his furniture consisted of an old clock, a table, bed, and several old chairs, all of which had been the property of his father; none of them appeared to have been cleaned for a number of years, or even removed from their situation, being covered and surrounded with dust to a great thickness. Mr. Gascoigne lived and died a bachelor: the full amount of his property is not known, but supposed to be some thousands, the whole of which went to his two nephews. Mr. G's. patched coat, an ancient saddle which he used when in the excise, and several other antiquities of the same description, it was said, would make a valuable addition to the curiosities in the British Museum. In an electioneering squib, printed in 1802, are the following lines, which shew the state of the coat at that time, and of a truth he continued to wear it ever after:-

"Had I been this fam'd poet, I'd have wrote

'Bout Gascoigue's bald old hat, or worsted coat :

No man dare undertake to count the stitches, Or take the grease in nine days from his breeches." 


\section{Lumley Kettheweli, Esq.}

TiIs gentleman was a resident of Clementhorpe, near York, and was noted for eccentricity of character. He died in the year 1819, in the seventieth year of his age. His education and fortune had fitted him for the enjoyment of life; but from some mysterious bias of mind, he renounced the comforts, pleasures, and honours of the world, and adopted the life of a hermit. In his person he was delicate, rather below mediocrity, and capable of great exertion. He possessed a very acute and intelligent countenance. His dress was mean, squalid, tattered, and composed of the most opposite and incongruous garments ; sometimes a fur cap with a ball-room coat, bought at an old clothes shop, and hussar-boots; at another tume a high-crowned London hat, with a coat or jacket of oil-skin, finished off with the torn remains of black silk stockings, and so forth. His manners were polished, soft and gentlemanly, like those of a courtier of the middle of the last century.

Early in life he shone in the sports of the field; and he kept bloodhorses and game dogs to the last; but the former he invariably starved to death, or put such rough, crude, and strange provender before them, that they gradualiy declined into so low a condition, that the ensuing winter never failed to terminate their career, and their places were as regularly supplied by a fresh stud. The dogs also were in such a plight, that they were scarcely able to go about in search of food in the shambles or on the dunghills. A fox was usually one of his inmates, and he had Muscovy ducks, and a brown Maltese ass, of an uncommon size, which shared the fate of his horses, dying for want of proper food and warmth. All these animals inhabited the same house with himself, and they were his only companions there; for no human being was allowed to enter that mysterious mansion. The front door was strongly barricadoed within, and he always entered by the garden, which communicated with Clementhorpe fields, and thence climbed up by a ladder into a small aperture that had once been a window.

He did not sleep in a bed, but in a potter's crate filled with hay, into which he crept about three or four o'clock in the morning, and came out again about noon the following day. His money used to be laid about in his window seats, and on his tables; and from the grease they had contracted by transient lodgment in his breeches pockets, the bank-notes were once or twice devoured by rats. His own aliment was most strange and uninviting : vinegar and water was his beverage; cocks' heads with their wattles and combs, baked on a pudding of bran and treacle, formed his most dainty dish, and occasionally lie treated himself with rabbits' feet: he liked tea and coffee, but these were indulgences too great for every day. He read and wrote at all hours not occupied with the care of the aforesaid numerous domestic animals, and with what he called the sports of the field. His integrity was spotless; his word at all times being equal to other men's bonds.

His religion is what is commonly understood by the "religion of 
nature;" he attended no place of worship; nor would he without great effort and much reluctance, vote at the city and county elections. But when he did, it was always in support of the candidate most favourable to the cause and rights of the people.

"Never vote for the ministerial members," he used to say, " the king and the great men will always take care of themselves." He used to carry about with him a large sponge, and on long walks and rides he would now and then stop, dip the sponge in water, and soak the top of his head with it, saying it refreshed him far more than food or wine. He admitted no visitor whatever at his own house; but sometimes went himself to see any person of whose genius or eccentricity he had conceived an interesting opinion; and he liked; on these visits, to be treated with a cup of tea or coffee, books, and a pen and ink; he then sat down close to the fire, rested his elbow on one kuee, and, almost in a double posture, would read till morning, or make extracts of passages peculiarly striking to him. His favourite subjects were the pedigree of blood-horses, the writings of freethinkers, chemistry, and natural history.

\section{J ANE OF FLANDERS I.}

THis remarkable lady, who seems to have possessed all the best qualities of both sexes, was the wife of John de Mountfort, a competitor for the dukedom of Brittany upon the death of John III. This duke dying without issue, left his domininns to his niece Jane, wife of Charles de Blois, nephew to the king of France; but John de Mountfort, brother to the late duke, but by a second marriage, claimed the duchy, and was received as successor by the people of Nantes. The greatest part of the nobility swore fealty to Charles de Blois, thinking him best supported. This dispute occasioned a civil war, in the course of which John was taken prisoner, and sent to Paris. This misfortune would have ruined his party, had not his interest been supported by the extraordinary abilities of his wife Jane. Bold, daring, and intrepid, she fought like a warrior in the field; shrewd, sensible, and sagacious, she spoke like a politician in the council; and endowed with the most amiable manners and winning address, she was able to move the minds of her subjects by the force of her eloquence, and mould them to her pleasure.

She was at Rennes when she received the news of her husband's captivity; but that disaster served only to rouse her native courage and fortitude. She fortliwith assembled the citizens; and, having in her arms her infant son, recommended him to their care and protection in the most pathetic terms, as the male heir of their ancient dukes, who had always governed them with lenity and indulgence, and to whon they had always professed the most zealous attachment. She declared herself willing to run all hazards with them in such a just cause; pointed out their resources in the alliance of England; earnestly beseeching them to make one vigorous effort against an usurper, who being forced upon them by the intrigues of France, would, as a mark of his gratitude, sacrifice the liberties of Brittany to his protector. The people moved by the affecting appearance, and animated 
by the noble conduct of the princess, vowed to live and die with her in defending the rights of her family; and their example was followed by almost all the Britons. The countess went from place to place, encouraging the garrisons of the several fortresses, and providing them with every thing necessary for their subsistence; aftel which she shut herself up with her son in Hennebon, where she resolved to wait for the succours which Edward III. had promised to send to her assistance.

Charles de Blois, accompanied by the dukes of Burgundy and Bourbon, and many other noblemen, took the field with a numerons army, and having reduced Rennes, laid siege to Hennebon, which was defended by the countess in person. This heroine repulsed the assailants in all their attacks with the most undaunted courage, and observing one day, that their whole army had left the camp to join in a general storm, she rushed forth at a postern gate with three hundred horse, set fire to their tents and baggage, killed their sutlers and servants, and raised such a terror and consternation through all their quarters, that the enemy gave over their assault, and, getting betwixt her and the walls, endeavoured to cut off her retreat in to the city. Thus intercepted, she put spurs to her horse, and, without halting, galloped directly to Brest, which lay at the distance of twenty-two miles from the scene of action. There being supplied with a body of five hundred horse, she immediately returned, and, fighting her way through part of the French camp, was received into Hennebon amidst the acclamations of the inhabitants. Soon after this, the English succours arrived, and obliged the enemy to raise the siege.

Martha Brossier,

A FrENCH woman, who made no small noise about the end of the sixteenth century, by pretending to be possessed by the devil, and counterfeiting convulsive fits. M. de Thou and other historians have given a particular account of her. Her father was a weaver at Romorentin, but found he could gain more, in that credulous age, by exhibiting his daughter as a demoniac, than by following his honest and useful profession. She was first detected at Orleaus in 1593; and afterwaids at Angers, where the bishop, inviting Martha to dinner, not only proved that her demon could not distinguish between common and holy water, but that he was such an ignorant devil, that he did not know the difference between the Book of Exorcisms, and Virgil's $\mathbb{E}$ Eneid! Notwithstanding these detections, the credulity of the public was such; and some of the priests acquired so much reputation by exorcising the evil spirit, that Henry IV. enjoined the parliament of Paris to take cognizance of the affair, who, after a consultation of physicians, ordered the father and daughter to be confined to Romorentin; under pain of corporeal punishment. The priests; however, carried the business and the parties before the court of Rome; but the pope being forewarned by the court of Paris, did nothing contrary to the decision of parliament. Some of the French priests lost their benefices by their villanous zeal; and the preteuded demoniac and her father died in deserved contempt in a hospital at Rome. 
THIS remarkable character in the tribe of self-inspired fanatics was born at Lisle in 1616. Early impressed with a notion of the decay of pure Christianity among all sects and churches, she fancied herself destined to revive it by a particular interference of Providence. Her family, which was opulent, wished her to enter into the marriage state, but such was her aversion to it, that she eloped to avoid their persecution, and underwent a variety of adventures. Her fortune and her enthusiastic turn rendered her the object of much hypocritical artifice; but she seems to have been far from deficient in care of herself and property. Her temper appears to have been extremely unamiable, involving herself in perpetual quarrels with the persons connected with her, and making her a tyrant over her servants and dependants; nor is any thing of the gentleness or simplicity of the gospel to be discovered in her conduct. She was the governess of a hospital at Lisle, and took the order and habit of St. Augustin; but such were the disturbances in the hospital, that the magistrates interfered, and she thought fit to withdraw to Ghent.

About this time she made a convert of Christian Bartholomew de Cordt, a Jansenist, and priest of the oratory at Mechlin, who had made the purchase of part of an island gained from the sea in Holstein, called Noordtstrandt. Madam Bourignon bought of him an estate there, meaning to settle upon it with her disciples, and in the mean while resided a considerable while at Amsterdam, where she was much noticed by fanatics of various kinds. She wrote several books there, particularly one entitled, "Of the Light of the World," in which her leading principles are explained, as far as her mystical and incoherent ideas are capable of explanation. The fundamental doctrine is, that the christian religion neither consists in knowledge nor in practice, but in a certain internal feeling and divine impulse, that arises immediately from communion with the Deity.

De Cordt died, and made her his heiress, and she left Holland in 1671 to go to Noordstrandt. She became disgusted with many of the disciples who wished to join her, fearing lest their intention was to live at her cost. She set up a printing-press in her house, and wrote books, with prodigious facility, in French, Dutch, and German. Her opinions and disposition subjected her to a variety of persecutions, which drove her from place to place, and made her life very uneasy. At length she retired to East Friesland, where she had the direction of a hospital; but though she was willing to devote her time to the poor, she was always averse to bestowing her money upon them,-never, as she said, being able to find any whose conduct was deserving of encouragement. 'She ended her turbulent life at Franeker in 1680 . Though the number of her personal followers was almost dwindled to nothing, her writings gained a considerable number of proselytes after her death.

One Peter Poiret, a man of ability, and a great Cartesian, dressed up in artful colours, and reduced to a kind of system, the vagaries of Madam Bourignon, in a large work, entitled L'Oeconomie Divine, or Systeme Universel, published at Amsterdam. Her notions also were 
warmly acuopted by several persons in Scotland, which occasioned a controversy there, in which Dr. Cockburn distinguislied himself as the opponents of the Bourignonists. It is scarcely necessary to add, that their disputes have long since sunk into oblivion.

\section{Charlotte Corde.}

Thrs lady, a celebrated heroine during the French revolution, was born in 1768, of a good family, near Seez in Normandy, and lived chiefly at Caen, where she was greatly admired for her beauty and spirit. She is described by J. Baptist Lonuel as " a stout, handsome young woman, of a most engaging air, gentle yet noble, modest and beautiful; in her face and carriage, which were those of a fine and pretty woman, there was a mixture of gentleness and majesty, which indicated her sublime way of thinking."

Among the many officers who were massacred by the soldiery at the instigation of Marat, there was one Besunce, a major, for whom Charlotte Corde had a particular regard, and the melancholy fate of this man animated her with vengeance against the miscreant, whom she considered as the chief cause of all the bloodshed and anarchy that then distracted her country. Regardless of her own life, and determined to revenge the death of her lover, and rid the nation of a tyrant, she hastened to Paris, got herself introduced into the presence of Marat, to whom she presented a paper to read, and while he was thus employed, she stabbed him to the heart with a dagger, July 12, 1793. Far from attemptiug to escape, she confessed the action; and from the conclusion of a letter which she wrote to her father on the occasion, "Crime begets disgrace, and not the scaffold," she secms to have considered it no crime nor disgrace. She was guillotined July 16, 1793; manifesting at her execution, as she had also done at her trial, the most undaunted courage.

The extraordinary conduct of this woman was accompanied with conduct not less extraordinary, for as she was conveyed to the scaffold, a deputy of the city of Mayence, named Adam Lux, a young man, was so transported with admiration of her beauty, that he hastened to the tribunal, and demanded to suffer death under the same instrument, and he was accordingly condemned and executed.

\section{Charlotte Hutton.}

THIs most extraordinary genius was the youngest daughter of the late Dr. Charles Hutton of Woolwich. She was born in 17\%8, and was only 16 years of age, when she died of a rupture of a vessel in her lungs, Dec. 24, 1794. Yet in that short period she had acquired more learning and knowledge than many persons do who live to fourscore. She knew several languages, and almost all sciences in a considerable degree, and had acquired a knowledge of arithmetic, algebra, geography, astronomy, music, drawing, poetry, history, botany, gardening, besides all the usual female accomplishments in a superior degree and style. Most of these acquisitions were chiefly made by her own talents and energy of mind, with little or no assistance 
from others. It was sufficient for her once to see or hear any thing done, she soon made it her own, She was her father's amanuensis and assistant upon all occasions; she wrote for him, and read to him in all languages and sciences; she made drawings for him of all kinds, astronomical, mathematical, mechanical, \&c. She arranged and managed his library, and knew so well where all his books stood, that she could find them even in the dark. She was author of several ingenious compositions and calculations. She extracted the square-roots of most of the second 1000 numbers, to twelve places of decimals, and proved the truth of them by means of differences; arranging the whole in a table fit for publication. She drew elegant geographical maps, and, only the second day before she died, began and completed the whole hemisphere of the earth. In composition, whether epistolary or scientific, her style was excellent.

In the midst of all these literary acquisitions, she was so active in family affairs, that sle was no less useful to her mother in her domestic concerus, than to her father in his scientilic business. 'To all these qualifications, she added uncommon goodness, affability, cheerfulness, and sweetness of disposition, which made her as much beloved, as her extraordinary talents and acquirements made her admired.

\section{Anne Moore, of Tutbury.}

THIs woman was an impostor, who professed to live without taking any food. She was a native of Royston, near Ashborn, in Derbyshire, where she was born in 1761. Her maiden name was Peg, and her parents were persons of low and mean extraction. At the age of twenty-seven, Anne was married to James Moore, a labouring man. She soon separated from her husband, went again to service, and had two children by her master.

About the beginning of the year 180\%, Anne Moore was resident at Tutbury, a village in Staffordshire. It was then that she first excited the attention of the public, by making an open declaration that she could exist without food, offering to prove the truth of her declaration by submitting to be watched for such a period as should place the matter beyond all doubt.

In order that there might be no appearance of deception, she suffered herself to be removed from her own dwelling to the house of $\mathrm{Mr}$. Jackson, grocer, of the same village, and all the inhabitants were solicited to unite in watching her conduct. Mr. Taylor, a surgeon, was superintendant of the watch, which continued sixteen days, during which time she took no sustenance, except a little water on the three first days. At the conclusion of the watch, she was removed to her own home, and Mr. Taylor published an account, declaring that she had lived for thirteen days without taking any food, liquid or solid. This account, so attested, was believed by numbers, who flocked to see ber, and few visited her without leaving her some proof of their credulity or piry. By this means she collected about $\mathfrak{E 2 5 0}_{25}$

Though the declaration of the persons who formerly watched her had obtained considerable credit, yet there were many who thought her an impostor, and demanded that she should be again watched. 
A committee was formed of the neighbouring clergymen and magis. trates, who met on Tuesday, the 20 th of April, 1813 ; and the time it was determined she should be watched was fixed at one month, to which she at last was obliged to assent.

Her bed was filled with chaff, and the clothes examined in the presence of the committee. The watch entered on their office at two o'clock on Wednesday. She received the watch with as much good manners as she was capable of, though she had been crying bitterly before they came. The first watch, which continued four hours, was begun by Sir Oswald Mosley and the Rev. Legh Richmond, and followed by several other gentlemen. At the end of seven days, the public was informed that she had during that time taken no food whatever. - Great confidence was now expressed by her advocates that she would endure the ordeal with credit. But when the machine for weighing her,was put under the bed, it was found that she lost weight rapidly. At last, on the ninth day, she insisted upon the watches quitting the room, declaring that she was very ill, and that her daughter must be sent for. She was now greatly reduced, and the watches who attended her were much alarmed lest she should expire, and, apprehensive of being implicated in the charge of murder, they quitted the room, and admitted the daughter, who administered what she thought proper, when the mother began to recover.

One remarkable circumstance was, that on Friday, the thirtieth of April, after the watch broke up, she desired to take a solemn oath that she had not, during the time she was watched, taken any food whatever; which oath was administered unto her. This she did in hope, notwithstanding all, still to impose upon the public. But as her clothes gave evidence against her, to her utter confusion, she was brought at last to make the following confession :

"I, Anne Moore, of Tutbury, humbly asking pardon of all persons whon I have attempted to deceive and impose upon, and, above all, with the most unfeigned sorrow and contrition, imploring the divine mercy and forgiveness of that God whom I have greatly offended, do most solemnly declare, that I have occasionally taken sustenance for the last six years.

"Witness my hand, this fourth day of May, 1813.

$$
\text { The mark of ANNE MOORE." }
$$

"The above declaration of Anne Moore, was made before me, one of his Majesty's justices of the peace for the county of Stafford, "THOMAs Lister."

"Witness of the above declaration and signature of my mother Anne
"Moore,-

This impostor was committed to prison, February 1816, for falsely collecting money under the pretence of charity. After her liberation, she left Tutbury, and is since dead. 


\section{PART III}

\section{NOTABLE HISTORIES.}

\section{Legendary Accounts of Adam.}

AcCording to the Talmudists, when Adam was created, his body was of immense magnitude. When he sinned, his stature was reduced to 100 ells, according to some; to 900 cubits, according to others, who think this was done at the request of the angels, who were afraid of so gigantic a creature. In the island of Ceylon is a mountain, called the Peak or Mountain of Adam, from its being, according to the tradition of the country, the residence of our first parent. Here the print of his footsteps, above two palms in length, are still pointed out.

By the same writers, things equally extravagant are ascribed to Adam's understanding. Several Christians, indeed, seem to be little behind the Jews in the degree of knowledge he was supposed to possess; nothing being hidden from him, according to some, except contingent events relating to futurity. One writer indeed, Pinedo, excepts politics; but a Carthusian friar, having exhausted, in favour of Aristotle, every image and comparison he could think of, at last asserted that Aristotle's knowledge was as extensive as that of Adam.

In consequence of this surprising knowledge with which Adam was endued, he is supposed to have been a considerable author. The Jews pretend that he wrote a book on the creation, and another on the Deity. Some rabbins ascribe the ninety-second psalm to Adam; and in some manuscripts the Chaldee title of this psalın expressly declares that this is the song of praise which the first man repeated for the sabbath-day. Strange stories are told concerning Adam's children. The Mahometans tells us, that our first parents having been thrown headlong from the celestial regions, Adam fell upon the isle of Serendib, or Ceylon, in the East Indies, and Eve on Jodda, a port of the Red Sea, not far from Mecca: After a separation of upwards of 200 years, they met in Ceylon, where they multiplied; according to some, Eve had twenty, according to others, only eight deliveries, bringing forth at each time twins, a male and a female, who afterwards married. The rabbins imagine that Eve brought forth Cain and Abel at a birth; that Adam wept for Abel 100 years, in the valley of tears near Hebron. The inhabitants of Ceylun affirm that the salt lake on the mountain of Columbo consists wholly of the tears which Eve for one hundred years together shed because of Abel's death.

Some of the Arabians tell us, that Adam was buried near Mecca, on Mount Abukobeis ; others, that Noah, having laid his body in the ark, caused it to be carried after the deluge to Jerusalem by Melchisedec the son of Shem; of this opinion are the Eastern Christians ; but the Persians affirm that he was interred in the isle of Serendib; where his corpse was guarded by lions, at the time the giants warred upon one another. St Jerome imagined that Adam was buried at 
Hebron; others on Mount Calvary. Some are of opinion that he died un the very spot were Jerusalem was afterwards built, and was buried on the place where Christ suffered, so that his bones might be sprinkled with the Saviour's blood!!!

It would be endless to relate all the whims that have been written on this subject, but we cannot omit the relations of Madam Bourignon, concerning Adam, which are peculiarly marvellous. According to this lady, Adam, before his fall, possessed in himself the principles of both sexes, and she affirms that he actually did produce a son before the creation of Eve, a perfect being like himself, and that this perfect being was, after the fall, associated with the Deity, and became the human nature of our Saviour!

She even imagined, that, in an ecstasy, she saw the figure of Adam before he fell, with the manner how, by himself, he was capable of procreating other men. "God," says she, "represented to my mind the beauty of the first world, and the manner how he had drawn it from the chaos; every thing was bright, transparent, and darted forth light and ineffable glory. The body of Adam was purer and more transparent than crystal, and vastly fleet; through this body was seen vessels and rivulets of light, which penetrated from the inward to the outward parts, through all his pores. In some vessels ran fluids of all kinds and colours, vastly bright, and quite diaphanous. The most ravishing harmony arose from every motion; and uothing resisted or could annoy him. His stature was taller than the present race of men; his hair was short, curled, and of a colour inclining to black; his upper lip covered with short hair, and he was fashioned as our bodies will be in the life eternal, which I know not whether I dare reveal. In that region, the nose was formed after the manner of a face, which diffused the most delicious fragrancy and perfumes, whence also men were to issue; all which principles were inherent in him.

"Woman was formed by taking out of Adam's sides the vessels that contained the above principles, which she still possesses, as is discovered by anatomists."

After retailing so many incredible stories and whimsical fancies, respecting our first progenitor, no reader of sensibility will be displeased, that we add a few lines respecting the probable cause of his fall. Of ail the conjectures that have been formed, with regard to the motives that influenced him to partake of the forbidden fruit, none appears more probable than that of Milton, when he supposes that it proceeded from his excessive love for his wife, which made him willing to embrace certain death along with her, mather than live, even in paradise, without her. Indeed, it is hardly to be accounted for tipon any other principle, that a being, in a state of innocence and perfection, who had received prohibition personally from his Creator, and who had such frequent and immediate communication, with the Deity, could have been prevailed on to disobey a command so express, and incur a punishment so great as was threatened, if he had not been under the irresistible impulse of an extreme degree of the purest and best of human passions, accompanied with the distracting thought of for ever losing the beloved object of his affections, by death and annihilation. 
LONGEVITY of THE ANTEDILUVIANS ACCOUNTED For.

ONE of the most extraordinary circumstances which occurs in the antediluvian history, is the vast length of human lives in those first ages, in comparison with our own. Few persons now arrive at eighty. or one hundred years; whereas, before the flood, they frequently lived to nearly 1000 , a disproportion almost incredible, though supported by the joint testimonies of sacred and profane writers. Some, to reconcile the matter with probability, have imagined that the age of those first men might possibly be computed, nct by solar years, but months, an expedient which reduces the length of their lives rather to a shorter period than our own. But for this, there is not the least foundation, besides the many absurdities that would there follow, such as their begetting children at about six years of age, as some of them in that case must have done, and the contraction of the whole interval between the creation and the deluge to considerably less than two hundred years, even according to the larger computation of the Septuagint.

Josephus, and some Christian divines, are of opinion, that before the flood, and some time after, mankind in general did not live to such a remarkable age, but only a few beloved by God, such as the patriarchs mentioned by Moses. They reason in this manner: Though the historian records the names of some men, whose longevity was singular, yet that is no proof that the rest of mankind attained to the same period of life, more than that every man was of a gigantic stature, because he says in those days there were giants upon the earth. Besides, had the whole of the Antediluvians lived so very long, and increased in numbers in proportion to their age, before the flood of Noah, the earth could not have contained its inhabitants, even supposing no part of it had been sea. Hence they conclude, that God extended only the lives of the patriarchs, to such an extraordinary length. But most writers maintain the longevity of mankind in general in the early world, not only upon the authority of sacred, but likewise of profane history. And for such a constitution, the moral reasons are abundantly obvious.

When the world was wholly unpeopled, except by one pair, it was necessary to endow men with a stronger frame, and to allow them a longer continuance upon earth for peopling it with inhabitants. In the infant state of every mechanical art, relating to tillage, building, clothing, \&c. it would require many years' experience to invent proper tools and instruments to ease men of their labour, and by multiplying essays and experinents to bring their inventions to any degree of maturity and perfection. Every part of their work must have been exceedingly arduous, from such a penury and coarseness of tools, and must have required longer time, and niore strength of body, than afterwards, when mechanical knowledge was introduced into the world. If parents at this period had not continued long with their children, to have taught them the art of providing for themselves, and have defended themselves from the attacks of wild beasts, and other injuries to which they were exposed, many families would have been totally extinguished. 
But one of the best and most valuable ends which longevity would answer was, the transmitting of knowledge to mankind. And thus, before writing was invented, or any such easy and durable mode of conveyance was found out, a very few men served for many generations to instruct their posterity, who thus would not be at a loss to consult living and authentic records.

The natural causes of this longevity are variously assigned. Some have imputed it to the sobriety of the Antediluvians, and the simplicity of their diet; alleging, that they had none of those provocatives to gluttony, which art and vice have since invented. Temperance might undoubtedly have some effect, but not psssibly to such a degree. There have been many temperate and abstemious persons in later ages, who yet seldom have exceeded the usual period. Others have thought, that the long lives of the inhabitants of the old world proceeded from the strength of their stamina, or first principles of their bodily constitution : which might indeed be a concurrent, but not the sole and adequate cause of their longevity; for Shem, who was born before the deluge, and had all the virtues of the antediluvian constitution, fell three hundred years short of the age of his forefathers, because the greatest part of his life was passed after the flood. Others have imputed the longevity of the Antediluvians to the excellency of their fruits, and some peculiar virtue in the herbs and plants of those days. But to this supposition it has been objected, that, as the earth was cursed immediately after the fall, its productions, we may suppose, gradually decreased in their virtue and goodness, till the flood; and yet we do not see the length of men's lives decreased considerably, if at all, during that interval. Waving this objection, as the import of the curse is variously interpreted, it appears certain that the productions of the earth were at first, and probably continued till after the deluge, of a different nature from what they were in future times.

Buffon supposes their difference may have continued gradually to diminish for many ages subsequent to that catastrophe. The surface of the globe, according to his theory, was, in the first ages of the world, less solid and compact, because gravity having acted only for a short time, terrestrial bodies had not acquired their present density and consistence.' 'The produce of the earth, therefore, must have been analogous to its condition. The surface being more loose and moist, its productions must, of course, be more ductile and capable of extension. Their growth, therefore, and that of the human body, must require a longer time to be completed. The softness and ductility of the bones, muscles, \&c. would probably remain for a longer period, because every species of food was more soft and succulent. Hence, the full expansion of the human body, or when it was capable of generating, must have required one hundred and twenty, or one hundred and thirty years; and the duration of life would be in proportion to the time of growth, as is uniformly the case at present; for if we suppose the age of puberty, among the first races of men, to have been one hundred and thirty years, as they now arrive at that age in fourteen years, the age of the Antedilivians will be in exact proportion to that of the present race:; since by multiplying these 
two numbers by seven, for example, the age of the present race will be ninety-eight, and that of the Antediluvians nine hundred and ten. The period of man's existence therefore may have gradually diminished in proportion as the surface of the earth acquired more solidity by the constant action of gravity: and it is probable that the period from the creation to the days of David was sufficient to give the earth all the density it was capable of receiving from the influence of gravitation; and consequently, that the surface of the earth has ever since remained in the same state, and the terms of growth in the productions of the earth, as well as the duration of life, have been invariably fixed from that period.

It has been further supposed, that a principal cause of the longevity under consideration was, the wholesome constitution of the antediluvian air, which, after the deluge, became corrupted and unwholesome, breaking, by degrees, the pristine crasis of the body, and shortening human life in a few ages, to near the present standard. The temperature of the air and seasons, before that catastrophe, are, upon very probable grounds, supposed to have been constantly uniform and mild: the burning heats of summer, and the severities of the winter colds, were not then come forth, but spring and autumn reigned perpetually together; and indeed, the circumstance, above all others most conducive to the prolongation of human life, in the postdiluvian world, appears to be an equal and benign temperature of climate, whence it seems reasonable to infer, that the same cause might have produced the same effect in the antediluvian world.

\section{Ancient and Modern Instances of Longevity.}

THAT the common duration of men's ages has been the same in all periods since the general deluge, is plain both from sacred and profane history. Yet instances of lives greatly exceeding the common extreme, are not only to be found in the history of all ages and countries, but even in our island and in the present age. Mr. Whitehurst, in his Inquiry in to the Origin, and Strata of the Earth, has given a list, since enlarged by Dr. Fothergill, of thirty-two persons who died between 1635 and 1681 , all of whom had lived above a century, most of them considerably longer, and one, who was living in 1780, had attained the astonishing age of 175 .

Lord Bacon assures us, from the most incontestable evidence, that in A. D. 76, when a general taxation was made over the Roman empire by Vespasian, there were found living in Italy, between the Appenines arid the $\mathrm{Po}$, no fewer than one hundred and twenty-four persons, aged one hundred and upwards. Of these, fifty-four were one hundred years old; fifty-seven were one hundred and ten ; two, one hundred and twenty-five ; four, one hundred and thirty; four, one hundred and thirty-six; and three, one hundred and forty years old, each : besides nineteen others in Placentia, Faventia, Rimini, \&c. of whom six were one hundred and ten years old; seven, one hundred and twenty; one, one hundred and twenty-five; two, one hundred and thirty; one, one hundred and thirty-one; one, one hundred and thirtytwo; and one, one hundred and fifty ; and in our own age and country, 
Sir John Sinclair's statistical account affords numerous and authentic evidences, that longevity is far from being uncommon. In proof of this, we might, if room permitted, give quotations from abore four hundred of the nine hundred and thirty-eight parochial accounts in that work, but we shall content ourselves with only one from that of Crossmichael in Galloway:- "Within these twenty years," says the Rev. J. Johnstone, "at least twelve persons have died in the lower parts of Galloway, from one-hundred to one hundred and fifteen years. old. William Marshal, a tinker in this place, is now one hundred and eighteen. He might pass for sixty: his faculties are unimpaired, and he walks through the country with ease."

From the various instances of longevity given by $\mathrm{Mr}$. Whitehurst and others, we shall only select a few of the most remarkable :

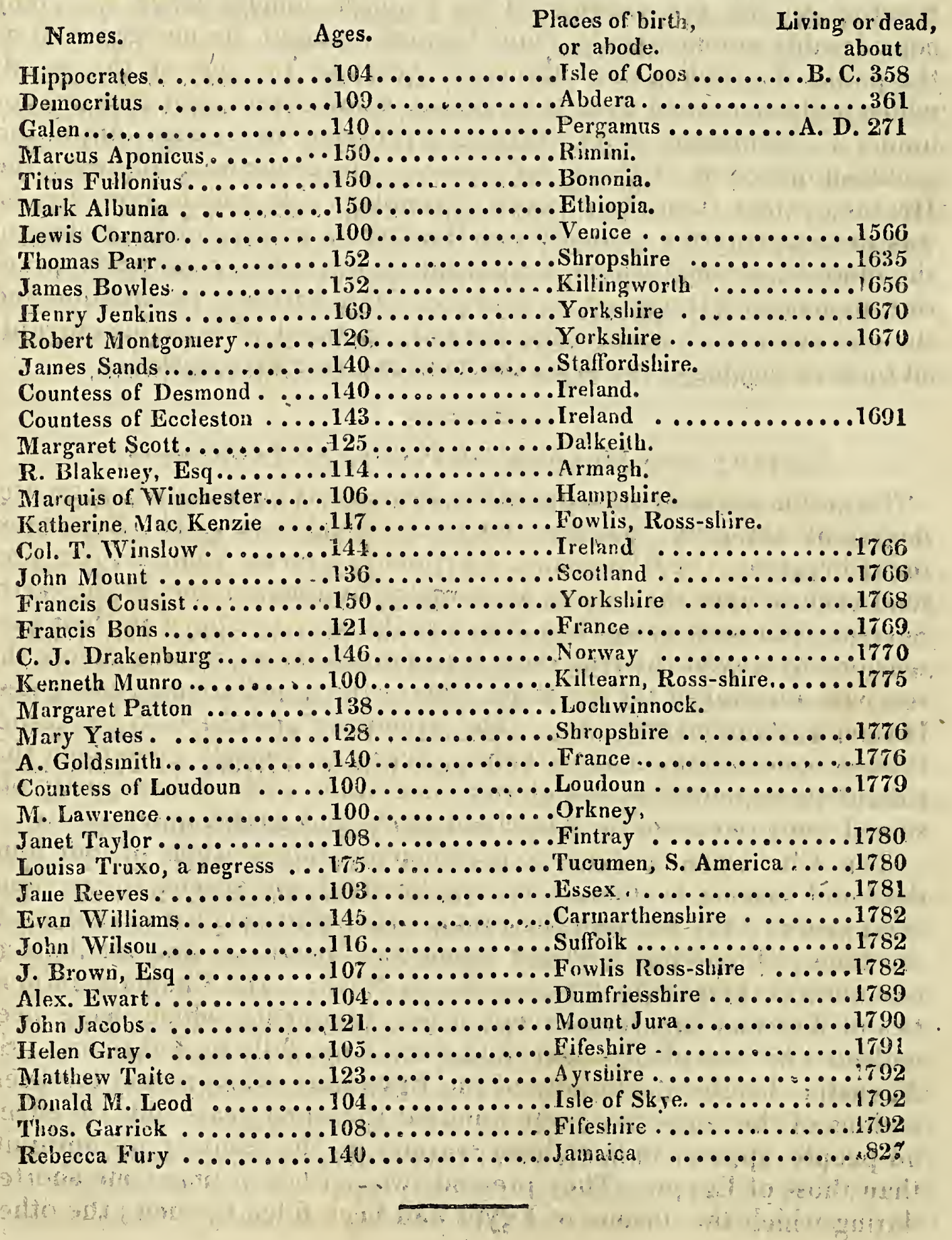




\section{Antiquity of the World.}

THERE have been great disputes concerning the antiquity of the world. Aristotle carried it back even to eternity. Parmenides, $\mathbf{P y}$ thagoras, and the Chaldeans, were of the same opinion; and there are not wanting philosophers of the present age, who have adopted the same idea. Dr. Thompson has published two treatises on this subject; the one entitled the Eternity of the World, and the other the Eternity of the Universe.' But the generality of philosophers, as well as divines and historians, have always held an origin of it; though where to fix that origin is the difficulty. The different systems of the chronology of the Greeks, the Egyptians, the Jews, the Hebrew text, and the Septuagint version, of Scaliger, of Pezron, of Sir Isaac Newton, \&c. to say nothing of the Chinese annals, leave the point considerably embarrassed. Dion Pezron thought he merited well of the public by adding two thousand years to the age of the world, which had been taken from it by Scaliger and others; but this did not hinder F. Montianay from entering a prosecution against him in the archbishop's court, of Paris, for heresy. His crime was, following the Heathen rather than the: Hebrew chronology; in which, however, he was preceded by the generality of the fathers and primitive writers of the church; among whom it appears to have been a common practice, to make five thousand five hundred years between the creation and the incarnation. In reality, the Jews are charged with having corrupted their chronology, by which the moderns have been misled.

\section{Extravagant Claims of Nations to Antiquity.}

THERE is scarcely a nation under heaven but lays claim to a greater degree of antiquity than the rest of its neighbours. The Scythians, the Phrygians, the Chaldeans, Egyptians, Greeks, Chinese, \&c. pretend each to have the honour of being the first inhabitants of the earth. Several of these nations, lest they should be outstripped in their pretensions by any of the rest, have traced up their origin long before the. received account of the creation. Hence the appellations, Aborigines, Indigena, Antebunares, \&c. The Athenians pretended to be Autocthones; and, what is remarkable, Socrates himself gave them this ridiculous appellation ; which, as some other philosophers justly observed, only put them on a level with ants and grasshoppers.

The Chaldeans pretend to astronomical observations of four hundred and seventy thousand, or four hundred and seventy-three thousand years; they mention the precise king who reigned over them at the time of the deluge; whose name was Xisuthrus, and attribute to him several things which we ascribe to Noah. The Chaldaic antiquities of Berosus are lost, except. a few fragments which have been collected by Joseph Scaliger, and since more fully by Fabricius. St. Augustine laughs at the folly of the Egyptians, who pretend to observations of the stars above one hundred thousand years old ; in effect, no people appear to have been warmer in the contest for antiquity. than those of Egypt. - They pretend two periods of time; ; one shorter; during which the throne of Egypt had been filled by men; the other; 
almost infinite, wherein gods and demi-gods had worn the crown. From Isis and Osiris to Alexander they reckon a space of twenty-three thousand years; the time before that, while the gods reigned, made forty-two thousand nine hundred and eighty-four years more ; the whole duration, from the beginning of the monarchy, amounting to sixty-five thousand nine hundred and eighty-four. The computation of their dynasties, as given by Manetho, extends to five thousand five hundred and fifty years before Alexander's time; and the Egyptian chronicle, cited by Syncellus, goes farther, reckoning 36,525 years ! Diogenes Laertius makes no less than 48,863 years from the reign of Vulcan! Yet the Scythians, the Phrygians, Ethiopians, and some others, still insisted on their priority to the Egyptians. It is no wonder their catalogues should be ridiculously incredible, when the Egyptians made their first kings reign 1200 years apiece, and the Assyrians theirs about 4000 .

But the Chinese pretend to the most ancient monarchy in the universe, having cultivated the sciences from the earliest ages, and subsisted at least these four thousand years, with the same laws, manners, and usages. Some indeed have called in question the authenticity of the Chinese annals; yet we find them confirmed, at least as high as 660 years before Christ, by the annals of Japan. Dr. Chambers argues, that, "at worst, the Chinese antiquities stand on as good a footing as those of either Greece or Rome. Their annalists, he adds, both for order and chronology, are not inferior to any of those ancients so much admired among us, but far surpass them in point of antiquity, and have a better title to be credited, as having been written by public authority, which can be said of few Greek or Roman pieces, except perhaps the Capitoline marbles, which are not properly a history."

But here we cannot help differing from the Doctor : for public authority is by no means the best of guardians for historical truth, especially in a country where this authority is placed in the hands of an absolute monarch, and where learning in monopolized by the priests. But the whole of the Chinese chronology has been successfully attacked by Mr. Costar.

The British have also laid claim to very high antiquity; but before Casar's invasion their history is utterly dubions, not to say fabulous. Old chronicles speak of Samothes, the son of Japhet, as the founder of the British monarchy. Albion, a descendant of Cham, invaded it three hundred years after; and about six hundred years after this, Brute, the son of Æneas, came and took possession of the island in the year of the world 2880 , giving it the name which it still retains, and which it had wlien Cæesar made his first attempt. This is Geoffrey of Monmouth's system of the antiquity of the British nation. It has been defended by A. Thomson of Queen's college, in the preface to his English translation of that writer.

It must not be forgotten that the Irish also pretend to be the most ancient of all nations; they trace their origin without interruption up to Japhet! And our ancient Scots historians have not been much behind-hand with them, as they trace their origin from an elder branch of the Scythians, the first of men, and from a mixture of : Scythians, Greeks, Jews, and Egyptians, who emigrated under the command of 
Gathelus the son of Cecrops, lsing of Athens, who married Scota, the daughter of Pharaoh, king of Egypt in the time of Moses.

\section{Bucephalus.}

THIs was the name of the horse of Alexander the Great, which was killed in the action with Porus, after crossing that river. Others say, this horse died of age, thirty years old; and not in the battle, but some time after. Hesychius says, his being marked on the buttock with the head of a horse, gave rise to his name. This animal, which had so long shared the toils and dangers of his master, had formerly received signal marks of royal regard. Having disappeared in the county of Uxii, Alexander issued a proclamation, commanding his horse to be restored, otherwise he would ravage the whole country with fire and sword. This command was immediately obeyed." "So dear," says Arrian, "was Bucephalus to Alexander, and so terrible was Alexander to the barbarians."

\section{History OF Bakers.}

ThE learned are in great doubt about the time when bakers were first introduced, and baking became a particular profession. It is, however, generally agreed that they had their rise in the East, and passed from Greece to Italy, after the war with Pyrrhus, about the year of Rome 558. Till then, every housewife was her own baker; for the word pistor, which we find in Roman authors before that time, signified a person who ground or pounded the grain in a mill or mortar, to prepare it for baking, as Varro observes. According to Athenæus, the Cappadocians were the most applauded bakers, after them the Lydians, then the Phonicians.

To the foreign bakers brought into Rome were added a number of freedmen, who were incorporated into a body, or, as they called it, a college, from which neither they nor their children were allowed to withdraw. They held their effects in common, and could not dispose of any part of them. Each bakehouse had a patroness, who had the superintendency ; and these patroni elected one out of their number each year, who had superintended once over all the rest, and who had the care of the college. Out of the body of the bakers, now and then one was admitted among the senators. To preserve honour and honesty in the college of bakers, they were expressly prohibited all alliance with comedians and gladiators : each had his shop or bakehouse, and they were distributed into fourteen regions of the city. They were excused from guardianship and other offices, which might divert them from their employment.

By statute 22 Hen. VIII. c. 13, bakers are declared not to be handicrafts. No man, for using the mysteries or sciences of baking, brewing, surgery, or writing, shall be interpreted an handicraft. The bakers were a brotherhood in England before 1155, in the reign of king Henry II. though the white bakers were not incorporated till 1307 by king Edward III. and the brown bakers not till 1621, in king James I.'s time. The bakers of London make the nineteenth com- 
pany, and consists of a warden, four masters, thirty assistants, and one hundred and forty men on the livery, besides the commonalty.

The French had formerly a great baker, called grand panetier de France, who had the superintendence of all the bakers of Paris. Since the beginning of this century, they were first under the jnrisdiction of the lieutenant-general de police. In some provinces the lord was the only baker in his seigneury, and kept a public oven, to which all the tellants were obliged to bring their bread! This right was called furmagium, or furmaticum, though, it rather merited the title of furtum, and made part of the bannalite.

\section{Aerostation.}

In the modern application of the term, aerostation signifies the art of navigating througl the air, both in its principles and practice. Hence also the machines which are employed for this purpose are called aërostats, or aërostatic machines; and, on account of their round figure, air-balloons. In 1729 Bartholomew Grisman, a Jesuit of Lisbon, caused an aërostatic machine, in the form of a bird, to be constructed; and made it to ascend by means of a fire kindled under it, in the presence of the king, queen, and a great concourse of spectators. Unfortunately, in rising, it struck a gainst a cornice, was torn, and fell to the ground. The inventor proposed renewing his experiment; but the people had denounced him to the inquisition as a sorcerer, and he withdrew into Spain, where he died in a hospital. In 1766 the honourable Henry Cavendish discovered that inflammable air, (hydrogen gas) was at least seven times as light as the common air. It soon afterwards occurred to the celebrated Dr. Black, that if a thin bag were filled with this gaseous substance, it would, according to the established laws of specific gravity, rise in the common atmosphere; but he did not pursue the inquiry. The same idea was next conceived by $\mathrm{Mr}$. Cavallo, to whom is generally ascribed the honour of commencing the experiments on this subject. $\mathrm{He}$ had made but little progress, however, in these experiments, when the discovery of Stephen and John Montgolfier, paper-manufacturers of France, was announced in 1782, and engaged the attention of the pliilosophical world. Observing the natural ascent of smoke and clouds in the atmosphere, these artists were led to suppose that heated air, if enclosed in a suitable covering, would prove buoyant. Accordingly, after several smaller experiments, by which this idea was fully confirmed, they inflated a large balloon with rarefied air, on June $5,1 \% 83$, which immediately and rapidly rose to the height of six thousand feet, and answered their most sanguine expectations.

Mr. Montgolfier repeated an experiment with a machine of his construction, before the commissaries of the Academy of Sciences, on the eleventh and twelfth of September. This machine was forty-seven feet high, and about forty-three feet in diameter. When distended, it appeared spheroidical. It was made of canvass, covered witl paper both within and without, and it weighed one thousand pounds The operation of filling it with rarefied air, produced by means of the combustion of fifty pounds of dry straw and twelve pounds of chopped 
wool, was performed in about nine minutes; and its force of ascension, when inflated, was so great, that it raised eight men, who held it, some feet from the ground. This machine was so much damaged by the rain, that it was found necessary to prepare another for exhibition, before the king and royal family, on the nineteenth. This new: machine consisted of cloth, made of linen and cotton thread, and was painted with water colours both within and without. Its height was nearly sixty feet, and its diameter about 13 feet. Having made the necessary preparations for inflating it, the operation was begun about one o'clock on the nineteenth of September, before the king and queen, the court, and all the Parisians who could procure a conveyance to. Versailles. In eleven minutes it was sufficiently distended, and the ropes being cut, it ascended, bearing up with it a wicker cage, in which were a sheep, a cock, and a duck. Its power of ascension, or the weight by which it was lighter than an equal bulk of common air, allowing for the cage and animals, was 696 pounds. This balloon rose to about $\mathbf{1 4 4 0}$ feet; and being driven by the wind, it descended gradually, and fell gently in a wood, at the distance of 10,200 , feet from Versailles, after remaining in the atmosphere eight minutes. The animals in the cage were safely landed. The sheep was found feeding ; the cock had received some hurt on one of his wings, probably from a kick of the sheep; the duck was perfectly well.

The success of this experiment induced M. Pilatre de Rozier, with a philosophical intrepidity which will be recorded with applause in the history of aerostation, to offer himself as the first adventurer in this aërial navigation. Mr. Montgolfier constructed a new machine for this purpose in a garden in the Fauxbourg St. Antoine. Its shape was oval; its diameter being about forty-eight feet, and its height about seventy-four feet. To the aperture at the bottom was annexed a wicker gallery, about three feet broad, with a ballustrade about three feet high. From the middle of the aperture was suspended by chains, which came down from the sides of the machine, an iron grate or brazier, in which a fire was lighted for inflating the machine; and port-holes were opened in the gallery, towards the aperture, through which any person, who should venture to ascend, might feed the fire on the grate with fuel, and regulate the dilatation of the enclosed air of the machine at pleasure. The weight of the aerrostat was upwards of 1600 pounds. On the 15 th of October, the fire being lighted, and the machine inflated, M. Pilatre de Rozier placedhimself in the gallery, and ascended, to the astonishment of an immense number of spectators, to the height of eighty-four feet from the ground, and kept the machine afloat above four minutes, by repeatedly throwing straw and wool into the fire : the machine then descended gradually and gently, through a medium of increasing density, to the ground; and the intrepid aëronaut assured the spectators he had not experienced the least inconvenience in this aërial excursion. This experiment was repeated on the seventeenth and the nineteenth, when $M$. P. de Rozier, in his descent, and in order to avoid danger, by reascending, evinced to a multitude of observers, that the machine might be made to ascend and descend at the pleasure of the aeronaut, by increasing or diminishing the fire in the grate. 
The balloon having been hauled down, M. Grande de Villiette placed himself in the gallery opposite to M. Rozier, and being suffered to ascend, it hovered for nine minutes over Paris, in the sight of all its inhabitants, at the height of about three hundred and thirty feet.

In another experiment, the Marquis d'Ariandes, ascended with M. Rozier much in the same manner. In consequence of the report of the preceding experiment, signed by the commissaries of the Academy of Sciences, it was ordered that the anmual pension of six luundred livres should be given to Messrs. Montgolfier for the year 1783. In the experiments above recited, the machine was secured by ropes; but they were soon succeeded by unconfined aërial navigation. Accordingly, the balloon of seventy-four feet in height, above mentioned, was removed to a royal palace in the Bois de Boulogne, and all things being ready, on the twenty-first of December, M. Pilatier de Rozier and the Marquis de Arlandes took their respective posts in the car, and at fifty-four minutes after one the machine was absolutely abandoned to the element, and ascended calmly and majestically in the atmosphere. The aëronants having reached the height of about two hundred and eighty feet, waved their hats to the astonished multitude; but they soon rose too high to be distinguished, and were thought to have soared to an elevation of about three thousand feet. They were at first driven by a north-west wind horizontally over the river Seine and over Paris, taking care to clear the steeples, and high buildings by increasing the fire, and an rising met with a current of air, which carried them southward. Having passed the Boulevard, and desisting from supplying the fire with fuel, they descended very gently in a field beyond the New Boulevard, about nine thousand yards distant from the palace, having been in the air twenty-five minutes. The weight of the whole apparatus, including that of the two travellers, was between sixteen hundred and seventeen hundred pounds.

Notwithstanding the rapid progress of aërostation in France, we have no account of any aërostatic experiments having been performed in other countries till about the close of the year 1783. The first experiment of this kind publicly exhibited in our own country was performed in London on the twenty-fifth of November by count Zambeccari, an ingenious Italian, with a balloon of oiled silk, ten feet it: diameter, and weighing eleven pounds; It was gilt in order to render it more beautiful, and more impermeable to the gas. This balloon, three-fourths of which were filled with inflammable air, was launched from the Artillery Ground in the presence of a vast concourse of spectators, at one o'clock in the afternoon, and at half past three was taken up near Petworth in. Sussex, forty-eight miles distant from London; so that it travelled at the rate of nearly twenty miles an honr. Its descent was occasioned by a rent, which must have been the effect of the rarefaction of the inflammable air, when the balloon ascended to the lighter parts of the atmosphere.

Aerostatic experiments and aërial voyages became so frequent in the course of the year 1784, that the limits of this article will not allow our particularly recording them. We shall, therefore, merely mention those which were attended with any peculiar circumstances. 
Messrs. de Molveau and Bertrand ascended from Dijon in April, to the height of about thirteen thousand feet, with an inflammable air-: balloon; the thermometer was observed to stand at twenty-five degrees. They were in the air during an hour and twenty-five minutes, and went to the distance of about eighteen miles. The clouds floated beneath them, and secluded them from the earth; and they jointly repeated the motto inscribed on their aërostat:-_ "Surgit nunc gallus ad æethera." In May, four ladies and two gentlemen ascended with a montgolfier at Paris above the highest buildings: the machine was confined by ropes; it was seventy-four feet high, and seventy-two in diameter.

In a second voyage, performed by $M$. Blanchard from Rouen, in May, it was observed that his wings and oars could not carry him in any other direction than that of the wind. The mercury in the barometer descended as low as 20.57 inches ; but on the earth, before he ascended, it stood at 30.16. On the twenty-third of June, a large aërostat; on the principle of rarefied air, ninety-one and a half feet high; and seventy-nine in diameter, was elevated by Moutgolfier at Versailles; in the presence of the royal family and the king of Sweden. M. Pilatier de Rozier, and M. Pruust ascended with it, and continued for twentyeight minntes at the height of eleven thousand seven hundred and thirty-two feet, and observed the clouds below them, that reflected the rays of the sun to the region which they occupied; the temperature of the air being five degrees below the freezing point; and in three-quarters of an hour they travelled to the distance of thirty-six miles. In consequence of this experiment, the king granted to $M$. Rozier a pension of two thousand livres.

Un the twenty-fifth of July, the Duke of Chartres, the two brothers, Roberts, and another person, ascended with an inflammable air-balloon of an oblong form, fifty-five and a half feet long, and thirty-four feet in diameter, from the park of St. Cloud : the machine remained in the atmosphere about forty-five minutes. This machine contained an interior small balloon, filled with common air, by which means it was proposed to make it ascend or descend without any loss of inflammable air or ballast. The boat was furnished with a helm and oars, intended for guiding it. At the place of departure the barometer stood at 30.12 inches. Three minutes after ascending, the balloon was lost in the clours, and involved in a dense vapour. An agitation of the wind, resembling a whirlwind, alarmed the aërial voyagers, and occasioned several shocks, which prevented their using any of the instruments and contrivances prepared for the direction of the balloon. Other circumstances concurred to increase their danger; and when the mercury, standing in the barometer at 24.36 inches, indicated their height to be about five thousand one hundred feet, they found it necessary to make holes in the bottom for discharging the inflammable air ; and having, made a vent of between seven and eight feet; they descended very rapidly, and at last came safely to the ground.

The longest and most interesting voyage, which was performed about this time, was that of Messrs. Roberts and M. Collin Hullini, at Paris, on the nineteenth of September. This aërostat was filled with inflammable air. Its diameter was twenty-seven feet and three-quarters, 
and its length forty-six feet and three-quarters, and it was made to Hoat with its longest part parallel to the horizon, with a boat of nearly seventeen feet long attached to a net that went over it as far as its middle. To the boat were annexed wings or oars, in the form of an umbrella. At twelve o'clock they ascended with four hundred and fifty pounds of ballast, and after various mancuvres descended at forty minutes past six o'clock at Arras in Artois, having still two hundred pounds of their ballast remaining in the boat. Having risen about fourteen hundred feet, they perceived stormy clouds, which they endeavoured to avoid; but the current of the air was uniform, from the height of six hundred to four thousand two hundred feet. The barometer on the coast of the sea was 29.61 inches, and sunk to 23.64 inches. They found that by working with their oars, they accelerated their course. In the prosecution of their voyage, which was one hundred and fifty-miles, they heard two claps of thunder, and the cold, occasioned by the approach of stormy clouds, made the thermometer fall from seventy-seven to fifty-nine degrees, and condensed the inflammable air in the balloon, so as to make it descend very low. From some experiments, they concluded that they were able, by the use of two oars, to deviate from the direction of the wind about twenty-two degrees. But this experiment was not sufficient to ascertain the effect here ascribed to oars.

The second aërial voyage in England was performed by M. Blanchard, and Mr. Sheldon, professor of anatomy in the Royal Academy, the first Englishman who ascended with an aërostatic machine. 'This experiment was performed at Chelsea, on the sixteenth of October. The wings used on this occasion seemed to have produced no deviation in the machine's track from the direction of the wind. M. Blanchard having landed his friend about the distance of fourteen miles from Chelsea, proceeded alone with different currents, and ascended so high as to experience great difficulty of breathing: a pigeon also, which flew away from the boat, laboured for some time with its wings, in order to sustain itself in the rarefied air, and, after wanderiug for a good while, returned, and rested on one side of the boat. M. Blanchard perceiving the sea before him, descended near Rumsey, about seventy-five miles from London, having travelled at the rate of near twenty miles an hour.

On the twelfth of October, Mr. Sadler, of Oxford, made a voyage of fourteen miles from that place in seventeen minutes, with an inflammable air-balloon of his own contrivance and construction.

The fate of M. P. de Rozier, the first aërial navigator, and of his companion M. Romain, has been much lamented. They ascended at Boulogne, on the fifteenth of June, with an intention of crossing the channel to England. Their machine consisted of a spherical balloon, thirty-seven feet in diameter, filled with infiamniable air, and under this balloon was suspended a small montgolfier, or fire-balloon; ten feet in diameter. This montgolfier was designed for rarefying the atmospheric air, and thus diminishing the specific gravity of the whole apparatus. - For the first twenty minutes they seemed to pursue the proper course, but the balloon appeared to be much inflated, and the aerronauts seemed anxious to descend. Soon, however, when they 
were at the height of about three-quarters of a mile, the whole apparatus was in flames, and the unfortunate adventures fell to the ground, and were killed on the spot.

On the nineteenth of July, Mr. Crosbie ascended at Dublin, with a view of crossing the channel to England. To a wicker basket of a circular form, which he had substituted for the boat, he had affixed a number of bladders, for the purpose of rendering his gallery buoyant in case of a disaster at sea. The height to.which he ascended at one time was such, that by the intense cold his ink was frozen, and the mercury sunk into the ball of the thermometer. He himself was sick, and he felt a strong impression on the tympanum of his ears. At his utmost elevation be thought himself stationary, but on discharging some gas he descended to a very rough current of air, blowing to the north. He then entered a dense cloud, and experienced strong blasts of wind, with thunder and lightning, which brought him with rapidity towards the surface of the water. The water soon entered his car; the force of the wind plunged him into the ocean, and it was with difficulty that he put on his cork jacket. The bladders which he had prepared were now found of great use. The water, added to his own weight, served as ballast; and the balloon maintaining its poise, answered the purpose of a sailing-boat. He was at length overtaken by some vessels that were crowding sail after him, and conveyed to Dunleary with the balloon.

On the 22nd of July, Major Money, who ascended at Norwich, was driven out to sea, and, after haviug been blown about for two hours, he dropped into the water. After much exertion for preserving his life, and when he was almost despairing of relief, hewas taken up by a revenue cutter, in a state of extreme weakness; having been struggling to keep himself above water for about seren hours.

The longest journey that had been hitherto made was performed by M. Blanchard towards the end of August. He ascended at Lisle, accompanied by the Chevalier de L'Epinard, and traversed a distance of three hundred miles before they descended. On this, as well as on other occasions, Mr. Blanchard made trial of a parachute in the form of a large umbrella, which he contrived for breaking his fall in case of any accident. With this machine he let down a dog, which came to the ground gently and unhurt. On the 8th of September, Mr. Baldwin ascended from the city of Chester, and performed an aerial voyage of twenty-five miles in two hours and a quarter. His greatest elevation was about a mile and a half, and he supposes that the velocity of his motion was sometimes at the rate of twenty miles an hour. He has published a circumstantial account of his voyage, described the appearances of the clouds as he passed through them, and annexel a variety of observations relating to aerostation.

We shall next proceed to give an account of some aërostatic experiments performed in England by M. Garnerin, a French aëronaut. The first of these is remarkable for the very great velocity of its motion; the second, for the exhibition of a mode of leaving the balloon, and of descending with safety to the ground.

On the 30 th of Jume, 1802 , the wind being strong, though not impetuous, M. Garnerin and another gentleman ascended, with an in- 
fammable air, or hydrogen gas balloon, from Ranalegh gardens, on the south-west of London, between four and five o clock in the afternoon; and in exactly three-quarters of an hour they descended near the sea, at the distance of four miles from-Colchester. The distance of that place from Ranelagh is sixty miles, therefore they travelled at the astonishing rate of eighty miles per hour. It seems that the balloon had power to keep them up four or five hours longer, in which time they might have gone safely to the continent; but prudence induced them to descend when they discovered the sea not far off.

The singular experiment of ascending into the atmosphere with a balloon, and of descending with a machine called a parachute, was performed by M. Garnerin on the 21st of September 1802. He ascended from St. George's parade, North Andley-street, and descended safely in a field near the Small-pox Hospital at Pancras. The balloor was of the usual sort, viz, of oiled silk, with a net, from which ropes proceeded, that terminated in, or were joined to, a single rope at a few feet below the balloon. To this rope the parachute was fastened in the following manner. The reader may easily form to himself an idea of this parachute, by imagining a large umbrella of canvass, of thirty feet in diameter, but destitute of the ribs and handle. Several ropes, of about thirty feet in length; which proceeded from the edge of the parachute, terminated in a common joining, from which shorter ropes proceeded, to the extremities of which a circular basket was fastened, and in this basket M. Garnerin placed himself. The single rope passed through a hole in the centre of the parachute; also through certain tin tubes, which were placed one after the other in the place of the handle or stick of an umbrella, and was lastly fastened to the basket, so that when the balloon was in the air, by cutting the end of the rope next to the basket, the parachute with the basket would be separated from the balloon, and in falling downwards would be naturally opened by the resistance of the air. The use of the tin tubes was to let the ropes slip off with greater certainty, and to prevent its being entangled with any of the other ropes, as also to keep the parachute at a distance from the basket. The balloon began to be filled about two o'clock. There were thirty-six casks filled with iron filings and diluted sulphuric acid, for the production of the hydrogen gas. These communicated with three other casks, or general receivers, to each of which was fixed a tube that emptied itself into the main tube attached to the balloon. At six, the balloon being quite foll of gas, and the parachute, \&c. being attached to it, M. Garnerin placed himself in the basket, and ascended majestically amidst the acclamations of innumerable spectators. The weather was the clearest and pleasantest imaginable; the wind was gentle, and about west-by-south; in consequence of which M. Garnerin went in the direction of nearly east-by-north. In about eight minutes the balloon and parachute had ascended to an immense height, and M. Garnerin in the basket could scarcely be perceived. While every spectator was contemplating this grand sight before them, M. Garnerin cut the rope, and in an instant he was separated from the balloon, trusting his safety to the parachute. At first, viz. before the paracliute opened, he fell with great velocity, but as soon as the parachute was 
expanded, which took place in a few moments after, the descent became, very gentle, and gradual. A remarkable circumstance was observed; namely, that the parachute, with the appendage of cords and basket, soon began to vibrate like the pendulum of a clock, and the vibrations were so great, that more than once the parachute, and the basket with M. Garnerin, seemed to be on the same level, or quite horizontal; however, the extent of the vibrations diminished as he descended. On coming to the earth, Mr. Garnerin experienced some pretty strong shocks, but he soon recovered his spirits, and remained without any material hurt. As soon as the parachute was separated from the balloon, the latter ascended with great rapidity, and being of an oval form, turned itself with its longer axis in an horizontal position.

The voyages which we have hitherto detailed were undertaken merely as matters of curiosity, and little of scientific research had yet been attempted by them. Philosophers, however, now became anxious to turn them to a more useful purpose, and to determine, by the means which they afforded, what circumstances attended the magnetic and electric actions in the upper regions of the atmosphere; as also the proportions of the component parts of the air in places remote from the surface of the earth.

The first aërial voyage which can be said to have been made with the above views, was undertaken by Mr. Robertson and Lhoest, from Hamburgh, about the middle of July, 1803. The ascent having been accomplished, the aëronauts hovered for some time over the city: when, after throwing out some ballast, they rose to such a height, that the elasticity of the gas distended the balloon so much, that they. were under the necessity of opening the valve, and suffering some of the gas to escape, which issued from its confinement with a loud noise. The tension of the balloon being thus considerably lessened, they threw out more ballast, and ascended to such a height, that it was almost impossible to eudure the cold that they experienced. Their teeth chattered, and M. Robertson's veins swelled, and the blood issued from his nose. His companion was otherwise affected, his head having swelled so much, that he could not keep on his hat: they also both experienced a great numbness, which inclined them to sleep. Not being able any longer to endure this temperature they descended slowly for about half an hour, and approached the earth over Badenburg, near. Winsen on the Luke, where they intended to have alighted; but the inhabitants, taking them for spectres, fled with the utmost consternation, taking with them their cattle. The aeronauts, fearing that this terror might be attended with serious consequences to them, after throwing out part of their ballast, again ascended, and continued their voyage, ultimately arriving at Wich tenbeck, on the road to Zell.

Where the balloon first rose, the atmosphere below was very serene, but it was cloudy above; they observed, that as they ascended, the heat decreased very sensibly, and that they could look at the sun without being dazzled. The barometer, which before the ascent stood at twenty-seven inches, fell to four teen, where it appeared to become stationary; and the thermometer sunk to $4 \frac{1}{2}$ below zero. Having, while thus 
situated, taken some refreshment, they ascended higher, viz. till the barometer fell to $12 \frac{1}{2}$ inches : and at that height the cold out of the car was insupportable, although the thermometer was now only one degree below the freezing point. Here our adventurers were obliged to respire very rapidly, and their pulsations became very quick. In this region, while the balloon was invisible to the earth, Mr. Robertson made the following experiments :

1. Having let a drop of ether fall on a piece of glass, it evaporated in four seconds.

2. He electrified by friction, glass and sealing wax; but those substances gave no signs of the accumulation of electric fluid, that could be communicated to other bodies. The Voltaic pile, which, when the balloon was set free from the earth, acted with its full force, gave only one-tenth part of the electricity.

3. The dipping needle seemed to have lost its magnetic virtue, and could not be brought to that direction which it had at the surface of the eartl.

4. He struck with a hammer, oxygenated muriate of potash. The explosion occasioned a sliarp noise, which, though not very strong; was insufferable to the ear. It is also to be observed, that though the aëronauts spoke very loudly, they could only with great difficulty hear each other.

5. At this lieight Mr. Robertson was not able to extract any electricity from the atmospheric electrimeter and condenser.

6. In consequence of a suggestion from Profesśor Helmbstadt, of Berlin, Mr. Robertson carried with him two birds. The rarefaction. of the air killed one of them, and the other was unable to fly; it lay extended on its back, but fluttered with its wings.

\%. Water began to boil by means of a moderate degree of heat maintained with quick lime.

8. According to observations made, it appeared that the clouds never rise above 2000 toises; and it was only in ascending and descending through clouds, that Mr. Robertson was able to obtain positive electricity.

The greatest height attained in this voyage is estimated at $\mathbf{2 6 0 0}$ toises.

Mr. Robertson afterwards, viz. on the thirtieth of June, 1804, ascended from Petersburg with the academician Sacharof; the aëronauts, taking with them, for the purpose of making the different experiments proposed by the academy, twelve exhausted flasks, a barometer, an attaclied thermometer, two electrometers, sealing wax, and sulphur, a compass and magnetic needle, a seconds watch, a bell; a speaking trumpet, a prism of crystal, and unslaked lime, and a few other apparatus for chemical and philosophical experiments.

In order to ascertain, with some precision, over what part of the earth the balloon at any time was hovering, the two following methods were employed.

In an aperture made in the bottom of the car, there was fixed, perpendicularly, an achromatic telescope, which shewed very distinctly those terrestrial objects over which the balloon happened to be, and to which side it directed its course. In the next place, two shects of 
black paper werefixed together at right angles, and suspended from the car with a piece of thread, which was intended to indicate any variation in the direction of the balloon, and was therefure called the way-wiser; it answered its purpose much better than had been anticipated. At about a quarter past seven in the evening, when the barometer stood at thirty inches, and the centigrade thermometer at $19^{\circ}$, the machine ascended, and at thirty-one minutes past seven the barometer had sunk to twenty-nine inches, and the thermometer to $18^{\circ}$ : the first cask was now filled with air, and, six minutes after, when the barometer had fallen another inch, the second cask was opened and filled. At this time, as the towns and villages were obscured by a fog; the paper way-wiser was thrown out, which indicated any variation in the direction of the balloon, as also its sinking and rising; for as soon as the machine fell, the way-wiser, as it was much lighter than the balloon, and found more resistance in falling, appeared to fly up; and when the balloon rose, it sunk to the full length, of its thread; at other times it was found to hold a diagonal direction, and in short it pointed out with considerable accuracy, with the assistance of the compass needle, not only any variation in the motion, but the actual direction of the whole machine.

Having at twenty-five minutes past eight, ascended to such a height that the barometer stood at twenty-six inches, another cask was filled with air; and soon after another, when the barometer was at twenty-five inches; and the same was done for every inch of descent of the mercury. At about thirty ninutes past nine, the barometer indicated twenty-two inchess and the thermometer $4 \frac{1}{2}^{\circ}$; at which time the voyagers saw the sun; it was about half obscured, either by a fog or by the horizon, but they could not distinguish which., At this period they commenced the following series of experiments and observations. A piece of sealing wax, rubbed with cloth, put in motion Bennet's electrometer. The magnetic needle, which was taken for the purpose of examining the inclination, had been damaged; but in order to ascertain whether the magnetic power still remained the same as at the earth's surface, Mr. Sacharof placed a common magnetic needle on a pin, and was surprised to find the north end rise, and consequently the south descend, considerably, making an angle of ten or twelve degrees. This experinent being repeated several times both by this gentleman and Mr. Robertson, the result was constantly the same :-after descending, and at present, (Mr. Sacharof observes,) the same needle assumes a horizontal position. At this height the aëronauts did not experience the slightest inconvenience, except that their ears were benumbed with the cold. "My pulse," says Mr. Sacharof, "beat as on the earth, that is, eighty-two times in a minute, and I breathed twenty-two times in the same interval, as is usual with me. In a word, I was exceedingly tranquil and cheerful, and experienced no change or uneasiness." At that time there were white clouds a great way above the balloon, but the heavens in general were clear and bright, nntwithstanding which, however, they could observe no stars. Mr. Sacharof at this time proposed to continue their voyage all night, in order that they might see the sun rise, and have time to make other experiments; but being ignorant of the country over 
which they were then floating, and the almost total consumption of their ballast, and the continual though gradual and slow sinking of the balloon, induced Mr. Robertson to reject this proposal.-As the aeronauts were now floating over some towns or villages, Mr. Sacharof took his speaking trumpet, and directing it towards the earth, called, as loud as he was able, when, contrary to his expectations, he heard his own words after a considerable interval, clearly and distinctly repeated by an echo; he called out again several limes, and each time the echo repeated his words in about ten seconds: at this time the barometer was removed, for the purpose of descending, so that he could make no observation upon it; but computing by the supposed velocity of sound, he must then have been about five thousand seven hundred feet from the earth.

In order that the descent might be made as safely as possible, and, for the sake of security, all the instruments and warm clothing were tied up in a bundle, and let down, together with an anchor, by a rope. The balloon, which was driven by the wind with considerable force, and fell with great rapidity, was, notwithstanding, so light, that when the bundle reached the earth, and the machine was in part divested. of this load, it had a tendency to rise; in the mean time, however, Mr. Robertson suffering the gas to escape, the descent was ultimately effected in the gentlest and pleasantest manner possible, at about forty-five minutes past ten, on the estate of Counsellor Demidof; but it unfortunately happened, by the bundle being drawn for a considerable distance along the ground, that most of the instruments were destroyed, and only four of the eight casks that had been charged, were in a state proper for experiment.

We have given the detail of the two preceding ascents, not in consequence of the importance of the observations or experiments that were performed in them, but because they seem to have been the first aërial excursions made purely with a view to philosophical research, and, moreover, because in some respects the inferences to be drawn from them are at variance with the deductions formed from the experiments performed in the two following ascents; the first by Biot and Gay Lussac, and the second by the latter philosopher alone.

M. Biot, and Gay Lussac ascended from the Conservatoire des Arts, on the 24th of August, 1804, their principal object being to examine whether the magnetic power experienced any appreciate diminution as we ascend from the terrestrial surface. It seems from the account given by Messrs. Sacharof and Robertson, that there was at least a change in the dipping power ; and Saussure, from experiments marle on the Col du Geant, at the height of three thousand four hundred and thirty-five metres above the level of the sea, thought he could perceive a very sensible decrease of magnetic virtue, which he estimated at one-fifth. It had even been asserted by some aëronants, that the magnetic energy vanishes entire!y at a certain height; and it appeared important to many members of the institute to ascertain the truth or fallacy of these assertions ; and Saussure, in particular, was anxious that his observations might be repeated in isolated situatious, remote from any effect of local attractions.

Besides the usual provisions of barometers, thermometers, hygro- 
meters, and electrometers, M.M. Biot and Gay Lussac took with them two compasses and a dipping needle, with another fine needle, carefully magnetized, and suspended by a very delicate white thread, for ascertaining by its vibration the force of the magnetic attractions in the upper regions of the atmosphere; and to examine the electricity of the different strata of this medium, they carried several metallic wires, from sixty to three hundred feet in length, and a small electrophorus slightly charged. For galvanic experiments, they had procured a few discs of zinc and copper, with some frogs, to which were also added some insects and birds.

It was also proposed to bring back air collected at as great a height as possible; for which purpose they had an exhausted glass ball closely shut; so that to fill it with air at any place, it was only necessary to open it, and then to stop it again with care and security.

Thus prepared, the philosophers took their departure at ten o'clock in the morning of the day above stated: the barometer standing at 23 inches 3 lines, or 30.13 inches, English ; Reaumur's thermometer at $13^{\circ} .2$, and the hygrometer at $80^{\circ} .8$, consequently very, near to the greatest degree of humidity.

The ascent was extremely pleasant and gradual, and the novelty, beauty, and magnificence of the spectacle, which now for the first time burst upon them, engaged all the attention of our philosophers, whilst the indistinct buz of distant gratulations from innumerable spectators gently met their ear. These first moments being past, they entered into the regions of the clouds, which seemed like a thin fog, and gave them a slight sensation of humidity. The balloon now had become quite inflated, and they were obliged to let part of the gas escape by opening the upper valve, at the same time throwing out some ballast to gain a greater elevation; and in a few minutes they had risen completely above the clouds, which they did not enter again till their return. These clouds had in this situation a blueish tint, similar to that which they exhibit from the surface of the earth; while their upper surface, full of small eminences and undulations, presented to the aemronauts the appearance of a vast plain covered with snow. At this time their altitude, computed according to Laplace's barometrical formula, was two thousand metres, or about six thousand five hundred English feet, and here their observations and experiments first commenced.

The balloon ascended to the enormous height of four English miles and one-third; from this stupendous height; M. Gay Lussac still saw clouds at a considerable height above, but none below, although the atmosphere had a dull misty appearance, which destroyed its transparent quality: the limit, therefore, fixed by M. Sacharof for the greatest height of the clouds, is obviously erroneous.

While occupied with experiments at this enormous elevation, $\mathbf{M}$. Gay Lussac, though well clothed, began to suffer from excessive cold; and his hands, by continual exposure, grew benumbed. He felt likewise a difficulty in breathing, and his pulse and respiration were much quickened. His throat became so parched, that lie could scarcely swallow a morsel of bread, but he experienced no other direct inconvenience from his situation. He had, indeed, been affected through 
the whole day with a slight headach, brought on by preceding fatigues and want of sleep, but though it continued without abatement, it was increased by his ascent.

The ballast being now reduced to thirty-three pounds, and the balloon completely distended, it began to drop; and M. Gay Lussac; therefore, only sought to regulate its descent. It subsided very gently at the rate of about a mile in eight minutes, and in little more than half an hour the anchor touched the ground, and instantly secured the car. The voyager alighted with great ease near the hamlet of St. Gourgon, about sixteen miles north-west of Rouell. As soon as he reached Paris, he hastened to the laboratory of the Polytechnic school with his Aasks containing the air of the higher regions, and proceeded to analyze it in the presence of Thenard and Gresset. When opened under water, the fluid rushed into the vessels, and apparently half filled their capacity. The transported air was found, by a very delicate analysis, to contain exactly the same proportion as that collected near the surface of the earth, every 1000 part holding 215 of oxygen. From concurring observations, therefore, we may conclude that the atmosphere is essentially the same in all situations.

On the seventh of April, 1806, M. Mosment, an experienced aëronaut, uudertook an aërial voyage from Lisle; he ascended at noon; waving a flag decorated with the imperial eagle, amid the shouts of the assembled spectators. The commencement of his career was so rapid as to carry him in a very short time beyond the vision of the crowd. During his ascent he dropped a dog, attached to a parachute, which came safely to the ground. About one o'clock something was observed slowly descending through the atmosphere, which proved, on its fall, to be the flag which M. Mosment had carried with him. Very soon afterwards a murmur circulated through the crowd that the unfortunate adventurer was discovered in one of the fosses of the city, lifeless, and covered with blood; which proved but too correct. The balloon reached the ground on the same day, at the distance of twenty-five leagues from Lisle. The car contained nothing except an unloaded, pistol, a little bread, and a piece of meat. M. Garnerin ascribes this melancholy disaster to the extreme shallowness of the car, and the too great distance between the cords which attached it to the balloon; and is of opinion that M. Mosment, in leaning over the car to drop the animal, had lost his balance, and was thus precipitated to the earth.

Another interesting voyage was that undertaken by M. Garnerin at eleven o'clock in the evening of the fourth of August, 1807. He ascended from Tivoli at Paris, under the Russian flag, as a token of the peace that subsisted at that time between France and Russia. His balloon was illuminated by twenty lamps, and, to obviate all danger of communication between those and the hydrogen gas which it might be necessary to discharge in the course of the voyage, the nearest of the lamps was fourteen feet distant from the balloon, and conductors were provided to carry the gas away in an opposite direction. After his ascent, rockets which were let off at Tivoli, seemed to him scarcely to rise above the earth, and Paris with all its lamps appeared a plane studded with luminous spots. In forty minutes he found hin- 
self at the elevation of 13,200 feet; when, in consequence of the distention of the balloon, he was under the necessity of discharging a part of the inflammable air.

About twelve o'clock, when 3600 feet from the earth, he heard the barking of dogs; about two o'clock in the morning he saw several meteors flying about him, but none of them so near as to create apprehension; at half past three he beheld the sun emerging in brilliant majesty above an ocean of clouds, and the gas being thereby expanded, the balloon soon rose 15,000 feet above the earth, where he felt the cold extremely intense. In seven hours and a half from his departure, Mr. Garnerin descended near Loges, forty-five leagues distant from Paris.

On the twenty-first of September, 180\%, the same intrepid aëronaut undertook a second nocturnal voyage, in the course of which he was exposed to the most imminent danger. M. Garnerin, prognosticating an approaching storm from the state of the atmosphere, refused to be accompanied by a second person, who earnestly requested it.- $\mathrm{He}$ ascended, therefore, alone from Tivoli, and was carried up, with - unexampled rapidity, to an immense height above the clouds: the balloon was there dilated to an alarming degree, and M. Garnerin; having been prevented, by the impatience of the mob before his ascent, from regulating those parts of the apparatus which were meant to conduct the gas away from the lamps on its escape, was totally unable to manage the balloon; he had no alternative left, therefore, but with one hand to make an opening two feet in diameter, through which the inflammable air was discharged in great quantities, and with the other to extinguish as many of the lamps as he could possibly reach. The adventurer was now without a regulating valve, and the balloon, subject to every caprice of the whirlwind, was tossed about from current to current. When the storm impelled him downwards, he was obliged to cast out his ballast, to restore the ascending tendency; and, at length, every resource being exhausted, no expedient was left him, to provide against future exigencies. In this forlorn condition, the balloon rose through thick clouds, but afterwards sunk, and the car having struck against the ground-with a violent impulse, rebounded from it to a considerable altitude. The fury of the storm dashed him against the mountains, and, after many rude agitations and severe shocks, he was reduced to a state of temporary insensibility. On recovering from this perilous situation, he reached Mount Tonnere in a storm of thunder. A very short time after, his anchor hooked in a tree, and in seven hours and a half after his departure, he landed at the distance of three hundred miles from Paris, which is at the rate of forty miles per hour, supposing his course to have been straight. This is only about half the velocity with which this gentleman, in one of his excursions in this country, was conveyed from London to Colchester, a distance of sixty miles, which he passed over in three-quarters of an hour.

We shall next give an account of an aërial excursion by our intrepid countryman, Sadler, who undertook the perilous task of passing from Dublin to Liverpool, on the first of October, 1813. He ascended from Belvidere House, about one o'clock on the above day, with 
the wind at south-west, and in thirty-five minutes had sight of the mountains in Wales: he continued in the same direction till three o'clock, when, being nearly over the Isle of Man, the wind blowing fresh, he found himself rapidly approaching the Welsh coast, and at four o'clock had a distinct view of the Skerry light-house, with the prospect of consummating his ardent hopes of a speedy arrival in Liverpool. The wind now shifting, he was driven off, and lost sight of land; when, after hovering about a long time, he discovered five vessels beating down the channel; and in hopes of their assistance, he determined to descend with all possible expedition, and precipitated himself into the sea. In this most critical situation he had the mortification to find that the vessels took no notice of him. Obliged therefore to reascend, he now threw out a quantity of ballast, and quickly regained his lofty situation, to look for more friendly aid.- It was a length of time before he had the satisfaction of discovering any, but he now observed a vessel, which gave him to understand, by signals, that she intended to assist him. Two others also, at this time, appeared in sight, and one of them, tacking about, hoisted the Manx colours. Night coming on, he was determined to avail himself of their proffered kindness, and accordingly once more descended to the sea. Here the wind, acting upon the balloon as it lay on the water, drove the car with so much velocity, that the vessel could not overtake it, and notwithstanding he used his utmost efforts, and finally tied his clothes to the grappling iron, and sunk them, to keep him steady, still the balloon was carried away so fast, that he was under the necessity of expelling his gas, upon which the car actually sunk, and he had now nothing but the netting to cling to. His perilous situation, and the fear of getting entangled, deterred the men from coming near him, until, in danger of being drowned, Mr. Sadler begged that they would run their bowsprit through the balloon, and expel the remaining gas. Having done this, and thrown out a line which he wound round his arm, he was dragged a considerable way, but fortunately at length got on board, nearly exhausted.

We shall close this narrative of aërial voyages with that of another Englishman, Mr. Green, who ascended from the Green Park in honour of his majesty's coronation. 'The following is Mr. Green's own account of his voyage.

"The balloon with which I ascended was thirty-one feet in diameter, as near the size as possible of the one in which Lunardi first made an ascent in England. It was inflated with about one thousand two hundred cubic feet of carbonated hydrogen gas, supplied from the main pipes of the original chartered gas company, and I am much indebted to the gentlemen of the committee for their kind assistance during the operation of filling. I had no doubt of being able to ascend with gas, for since the period when I first conceived the idea that common gas would answer the purpose of aërostation, I made frequent experiments, all of which completely succeeded; nor was my ardour damped when I knew that, even within an hour of my ascension, persons of great experience in aërostation expressed their opinion that I should not be able to ascend.

"About five minutes before one o'clock, the ropes were divided, 
and, having taken my seat in the car, the balloon rose in a most majestic manner, nearly perpendicular. The almost deafening shouts of the populace, and the roar of cannon that took place, when I had ascended a considerable distance from the earth, agitated the balloon. I felt the effect of it most sensibly. The moment the discharge of cannon took place, I knew it was the signal to be given when the crown was set upon the head of my most gracious sovereign; and I drew the cork of a botttle of brandy, and having poured out a full glass, I drank "Health, long life, and a glorious reign to his majesty." The effect of the air upon the brandy is worthy of notice : when I drew the cork, a report took place, which $I$ attribute to the rarefaction of the air, similar to that produced by drawing a cork out of a bottle of soda water. When the balloon travelled at its greatest rapidity, I felt not the least motion; it appeared as if the car in which I sat was stationary, and the earth was receding from me. The balloon took a north-east direction at first; and on my looking down upon the vast assemblage of persons in Westminster, the delight $I$ felt is out of my power to describe. The view presented one entire living mass of more than a million of human beings. Having ascended as high as I could without throwing out ballast, I determined, as the weather was so fine, to keep in sight as long as possible. I threw out two bags of sand of ten pounds weight each, and immediately the balloon rose with astonishing rapidity almost perpendicularly, according to my wish. Whell the balloon arrived at its utmost altitude, which, in my opinion, (I could not be certain, in consequence of the oscillation of the quicksilver in the barometer,) was about eleven thousand feet from the earth, I found that I had entered a current of air, conveying me directly eastward towards the Nore. The cold was extreme. I put on a cloak which $I$ took up with me, and on looking at my glass I found that it was below 30. - two degrees below the freezing point. I was fearful of being carried to sea, and immediately opening the valve, the gas issued in considerable quantities; and I found, by the increase of the size of objects below me to my optics, that I was descending very rapidly. The largest fields, which a few minutes before appeared to be not more than six inches square, increased in size greatly; and I very soon saw the sea, and a number of vessels, most distinctly. The balloon had a rotatory motion, and turned about four times in a minute.

"Still fearing that I should fall in to the sea, I opened the valve to its utmost extremity, and having descended so as to be able to recognize small objects distinctly on the earth, with great delight I found that the balloon had entered another current of air, which was conveying me from the sea: I was then travelling north-west. I sat down and ate some sandwiches with a good appetite, and saw the clouds rolling beneath me, apparently on the ground. About twenty minutes before two o'clock, I descended in a field belonging to a farmer, named Lamkins, which is situated about four miles beyond Barnet, in the parish of South Mims. I was not aware that I had descended so rapidly; before 1 had time to draw myself up to the hoop, the car struck the earth with great force, and I was thrown out of it on my back; I was nearly stunned from the effects of a blow which I 
received. I still held the hoop of the balloon; and the grappling' iron, which I had thrown out when about a quarter of a mile from the earth, not taking firm hold, I was dragged on my back along the ground a considerable distance. The balloon was eventually secured, with the assistance of a gentleman named Waugh, and conveyed to a place of safety in his park, and I was afterwards most hospitably entertained at his mansion; to him my gratitude is due, and, but for his kind exertions, I have no doubt the balloon would have suffered considerable injury from the great crowd of persons that assembled on my descent. I believe, from the best calculation I can make, that I travelled altogether, in various, directions, upwards of fifty miles."

The same gentleman made a second ascent shortly after, in the same balloon, from the Belvidere Tea Gardens, Pentonville. An immense concourse of people were assembled to witness the spectacle. The ascent took place about half-past three, and Mr. Green gives the following account of his voyage:- "Having fastened the mooring ropes which held the balloon to the earth, I mounted the car, and standing upright therein, with a flag in each hand, I gave the signal for ascending; and, having made my obeisance to the ladies and gentlemen who were around me, the balloon then ascended to the atmosphere in the most majestic manner. The delight felt by thousands who witnessed the grand spectacle, was manifested by the most tremendous shouts of applause, clapping of hands, and waving of hankerchiefs. The balloon took at first a north-easterly direction. It passed over Hoxton, Hackney, and made towards the Essex coast. Precisely seven minutes after the balloon left the Belvidere-gardens, it entered a very dense cloud, and immediately the earth was obscured completely from my view, though I still heard the shouts of the people at Hackney and in the neighbourhood. On the balloon entering the cloud, it was twentythree minutes to four o'clock, and the barometer stood at 24. 2-10ths. I understand the balloon remained in the sight of the spectators at the Belvidere precisely seven minutes. A.t a quarter to four, having risen very rapidly after going through the cloud, the gas stood at 21-10ths. This was the utmost height the balloon reached, and the light and heat were quite oppressive to me, the former more than the latter; and although the clouds were rolling beneath me, representing to my view a sea of white down, yet above me the sun slione with extreme brilliancy. At fifteen minutes before four o'clock I opened the valve to its utmost extremity, and descended most rapidly; having passed through the clouds, I heard the shouts of persons on the earth, and saw some riding, and others running in the direction which the balloon was taking. At ten minutes before four o'clock the balloon descended (having been tiventy ninutes precisely on its voyage, in which period of time it had travelled about fourteen miles) in a six-acre field belonging to Mr. Grout, a farmer, at Tanyard Farm, Barking-side, two miles from Ilford, in Essex." Mr. Green took a carrier pigeon with him, and the moment he dêscended, he wrote on a paper- "Ten milutes to four, descended quite safe near Barking, Essex." This note he tied to the foot of the bird, and it arrived in the City-road before six o'clock, and the gratifying intelligence was communicated to Mr. Green's wife, family, and friends, 
A number of gentlemen paid Mr. Green the most polite attention on his descent.

\section{The Bottle-Conjurer.}

A BouT the middle of January, 1749 , a humorous incident happened, which greatly diverted the attention of the people, and was ascribed to a contrivance of the facetious Duke of Montagu, to ridicule the public credulity. The following advertisement appeared in the newspapers:

"At the New Theatre in the Haymarket, on Monday next, the 16th inst. to be seen, a person who performs the several most surprising feats, viz. - First, he takes a common walking-cane from any of the spectators, and thereon plays the music of every instrument now in use, and likewise sings to surprising perfection.-Secondly, he presents you with a common wine-bottle, which any of the spectators may first examine: this bottle is placed on a table in the middle of the stage, and he (without any equivocation) goes into it in sight of all the spectators, and sings in it; during his stay in the bottle, any person may handle it, and see plainly that it does not exceed a common tavern bottle. Those on the stage, or in the boxes; may come in masked habits, if agreeable to them, and the performer (if desired) will inform them who they are.

"Stage, 7s. 6--Pit. 3s.-Gallery, 2s.

c To begin at half an hour after six o'clock. - Tickets to be had in the Theatre.

6* The performance continues about two hours and a half.

“N. B. If any gentlemen or ladies, after the above performances, (either singly or in company, in or out of mask, are desirous of seeing the representation of any deceased person, such as husband or wife, sister or brother, or any intimate friend of either sex, (upon making: a gratuity to the performer, they shall be gratified by seeing and conversing with them for some minutes, as if alive." Likewise, if desired, he will tell you your most secret thoughts in your past life, and give you a full view of persons who have injured you, whether dead or alire. For those gentlemen or ladies who are desirous of seeing this last part, there is a private room provided. These performances have been seen by most of the crowned heads of Asia; Africa, and Europe, and never appeared public any where but once. He will wait on any persons at their houses, and perform as above, for five pounds each time."

In burlesque to this manifest imposition on the credulity of the public, the next day produced the following advertisement:-

'Lately arrived from Italy, Sig. Capitello Jampedo, a surprising dwarf, no taller than a common tobacco-pipe; who can perform many wonderful equilibres on the slack or tight rope; likewise, he'll transform his body into above ten thousand different shapes and postures: and after he has diverted the spectators two hours and a half, he will open his mouth wide, and jump down his own throat. He being the most wonderfullest wonder of wonders that ever the world wondered at, would be willing to join in performance with that surprising musi- 
cian on Monday next in the Haymarket. He is to be spoken with at the Black Raven, in Golden-lane, every day from seven to twelve, and from twelve all day long."

Although it might be supposed morally impossible that mankind could be so egregiously imposed on, yet the scheme took, and, on the evening of exhibition, the house was crowded with nobility-and gentry of both sexes. About seven o'clock the house was lighted; and the audience sat a considerable time without even the amusement of a single fiddle. Their patience being at length exhausted, a chorus of catcalls ensued, hastened by loud vociferations and beating of sticks; when a man came from behind the curtain, and, bowing, said, that if the performer did not appear, the muney should be returned. At the same time some person in the pit called out, that "If the ladies and gentlemen would give him double prices, the conjurer would get into a pint bottle." Soon after this, a young gentleman in one of the boxes, took a lighted candle, and threw it on the stage, which alarming the greater part of the audience, they made the best of their way out of the theatre, some losing their cloaks and hats, and others their wigs and swords. A party, however, staid in the house to demolish the inside, when the mob breaking in, they tore up the benches, broke the scenes, pulled down the boxes, and entirely demolished the theatre.

\section{BARBARITY.}

A PLANTER in Virginia, who was owner of a considerable number of slaves, instead of regarding them as human creatures, and of the same species with himself, used them with the utmost cruelty, whipping and torturing them for the slightest faults. One of these, thiniing any change preferable to slavery under such a barbarian, attempted to make his escape among the mountain Indians, but unfortunately. was taken and brought back to his master. Poor Arthur, this being his name, was immediately ordered to receive three hundred lashes. These were to be given him by his fellow slaves, among whom there happened to be a negro which the plantei had purchased on the preceding day. This slave, the moment he saw the unhappy wretch destined to the lashes, rushed forward, clasped him in his arms, and embraced him witl the greatest tenderness; the other returned his transports, and nothing could be more moving than their mutual bemoaning each other's misfortunes. Their master was soon given to understand that they were countrymen and intimate friends; and that Arthur had formerly, in a battle with a neighbouring nation, saved the life of his friend at the expense of his own. The newly purchased negro threw himself at the planter's feet with tears, beseeching him, in the most moving manner, to spare his friend, or; at least, to let him undergo the punishment in his stead, protesting that he would rather die ten thousand deaths, than lift his hand against him. But the haughty planter, looking on this as an affront to the absolute power he pretended over them, ordered Arthur to be immediately tied to a tree, and his friend to give him the lashes; telling him, that for every lash not well laid on, he should himself receive a score. The negro, 
amazed at the barbarity so unbecoming a human creature, with a generous disdain refused to obey him, at the same time upbraiding him with his cruelty; upon which the planter turning all his rage on him, ordered him to be immediately stripped, and commanded Arthur, to whom he promised forgiveness, to give his countryman the lashes which he had been destined to receive. This proposal he heard with scorn, protesting he would rather suffer the most dreadful torture than injure his friend. This generous conflict, which must have raised the strongest feelings in a breast susceptible of pity, did but more inflame the monster, who now determined they should both be made examples of, and, to satiate his revenge, was preparing to begin with Arthur, when the negro drew a knife from his pocket, stabbed the planter to the heart, and at the same time struck it to his own, rejoicing with his last breath, that he had avenged his friend and the world of such a monster.

\section{Instances of Clemency.}

Two patricians having conspired against Titus Vespasian, the Roman emperor, were discovered, convicted, and sentenced to death by the senate; but that excellent prirce sent for them, and admonished them that in vain they aspired to the empire, which was given him by destiny, exhorting them to be satisfied with the rank in which by Providence they had been placed, and offering them any thing else which was in his power to grant. At the same time he despatched a messenger to the mother of one of them, who was then at a great distance, and under deep concern about the fate of her son, to assure her that her son was not only alive, but forgiven.-Licinius having raised a numerous army, (Zosimus says, thirteen thousand men,) attempted to wrest the government out of the hands of his brother-in law Constantine the emperor. But his army being defeated, Licinius fled, with what forces he could rally, to Nicomedia; whither Constantine pursued him, and immediately invested the place; but on the second day of the siege, the emperor's sister entreating him to forgive her husband, and grant him at least his life, he granted her request, and the next day Licinius, throwing himself at his feet, delivered up the purple and the other ensigns of sovereignty. Constantine received him in a very friendly manner, entertained him at his table, and afterwards sent him to Thessalonica, assuring him that he should live unmolested, so long as he raised nu new disturbances.

Clemency seems to be rather a personal tlian national virtue; yet $\mathrm{Mr}$. Rollin, after narrating the revolution in Athens by the expulsion of the thirty tyrants, and the general amnesty that took place upon the motion of the excellent Thrasybulus, speaks of it as one of the finest events in ancient history, worthy the Athenian clemency and benevolence, and which has served as a model to successive ages in all good governments.

Never had tyranny been more cruel and bloody, than that which the Athenians had at this time thrown off. Every house was in mourning, every family bewailed the loss of some relation; it had been a series of public robbery and rapine, in which impunity had autlorized 
all manner of crimes. The people appeared to have a right to demand the blood of all accomplices in such notorious malversations, and even the interest of the state seemed to authorize such a claim, that, by exemplary severities, such enormous crimes might be prevented for the future. But Thrasybulus, rising above those sentiments, from the superiority of his more extensive genius, and the views of a more discerning and profound policy, foresaw, that by punishing the guilty, eternal seeds of discord and enmity would remain, to weaken the public by intestine divisions, when it was necessary to unite against the common enemy; and would also occasion the loss, to the state, of many citizens, which might render important services, from. the view of making amends for past misbehaviour.

Cardinal Mazarine observed to Don Lewis de Haro, prime minister of Spain, that "the gentle and humane conduct in the government of France had prevented the troubles and revolts of that kingdom from having any fatal consequences, and that the king had not lost a foot of ground by them to that day; whereas the inflexible severity of the Spaniards was the occasion that the subjects of that monarchy, whenever they threw off the mask, never returned to their obedience but by the force of arms; which sufficiently appears, added he, in the example of the Hollanders, who are in the peaceable possession of many provinces, that not an age ago were the patrimony of the king of Spain."

Leonidas, the heroic king of Sparta, with only three hundred men, disputed the pass of Thermopyla against the whole army of Xerxes; and being killed in the engagement, Xerxes, by the advice of Mardonius, one of his generals, caused his dead body to be hung upon a gallows, making thereby the intended dishonour of his enemy his own immortal shame. But some time after, Xerxes being defeated, and Mardonius slain, one of the principal citizens of $\mathbb{E}$ gina came and addressed himself to Pausanias, desiring him to avenge the indignity that Mardonius and Xerxes had shewn to Leonidas, by treating Mardonius's body after the same manner. He added, that by satisfying the manes of those who were killed at Thermopyla, he would be sure to immortalize his own name throughout Greece, and make his memory precious to the latest posterity. "Carry thy base counsels elsewhere," replied Pausanias; "thou must have a very wrong notion of true glory, to imagine that the way for me to acquire it is to resemble the barbarians. If the esteem of the people of $\mathbb{E}$ gina is not to be purchased. but by such a proceeding, I shall be content with preserving that of the Lacedrmonians only, amongst whom the base and ungenerous pleasure of revenge is never put in competition with that of shewing clemency and moderation to their enemies, especially after their death. As for the souls of my departed countrymen, they are sufficiently avenged by the death of many thousands of the Persians slain upon the spot, in the last engagement."

Maternal Affection.

(From M. de Humbold's Travels.

IN 1797, the missionary of San Fernando had led his Indians to the banks of the Rio Guaviare, on one of those hostile incursions, 
which are prohibited alike by religion and the Spanish laws. They found in an Indian hut a Guahiba mother, with three children, two of whom were still infants. They were occupied in preparing the flour of cassava. Resistance was impossible; the father was gone to fish, and the mother tried in vain to flee with her children. . Scarcely had slic reached the savanna, when she was seized by the Iudians of the mission, who go to hunt men, as the whites hunt the negroes in Africa. The mother and her children were bound, and dragied to the bauk of the river. The mouk, seated in his boat, waited the issue of an expedition, of which he partook 'not the danger. Had: the mother made too violent a resistance, the Indians would have killed her, for every thing is permitted when they go to the conquest of souls, ( $a$ lu conquista espiritual), and it is children in particular they seek to capture, in order to treat them in the mission as poitos, or slaves of the Christians. The prisoners were carried to San Fernando, in the hope that the mother would be unable to find her way back to her home by land. Far from those children who had accompanied their father on the day in which she had been carried off, this unhappy woman shewed signs of the deepest despair. She aitempted to take back to her family the children who had been snatched away by the missionary, and fied with them repeatedly from the village of San Fernando: but the Indians never failed to seize her anew; and the missionary, after having caused her to be mercilessly beaten, took the cruel resolution of separating the mother from the two children who had been carried off with her. She was conveyed alone toward the missions of the Rio Negro, going up the Atabapo. Slightly bound, she was seated at the bow of the boat, ignorant of the fate that awaited her; but she judged, by the direction of the sun, that she was removing farther and farther from her hut and her native country. She succeeded in breaking her bonds, threw herself into the water, and swam to the left bank of the Atabapo. The current carried her: to a shelf or rock, which bears her name to this day. She landed, and took shelter in the woods, but the president of the missions ordered the Indians to row to the shore, and follow the traces of the Guahiba. In the evening she was brought back. Stretched upon the rock (la Piedra de la Madre, a cruel punishment was inflicted on her with those straps of manatee leather, which serve for whips in that country, and with which the alcades are always furnished. This unhappy woman, her hands tied behind her back with strong stalks of maracure, was then dragged to the mission of Javita.

She was thrown into one of the caravanseras that are called Cassa del Rey: It was the rainy season, and the night was profoundly dark. Forests, till then believed to be impenetrable, separated the nission of Javita from that of San Fernando, which was twenty-five leagues distant in a straight line. No other path is known than that of the rivers; no man ever attempted to go by land from one village to another, were they only a few leagues apart. But such difficulties do not stop a mother who is separated from her children. The Guahiba was carelessly guarded in the caravansera; her arms being wounded, the Indians of Javita had loosened her bonds, unknown to the missionary and the alcades: she succeded, by the help of her 
teeth, in breaking them entirely; disappeared during the night; and at the fourth rising sun was seen at the mission of San Fernando, hovering around the hut where her children were confined. "What that woman performed," added the missionary who gave us this sad narrative, " the most robust Indian would not have ventured to undertake. She traversed the woods at a season when the sky is constantly filled with clouds, and the sun during whole days appeared but for a few minutes. Did the course of the waters direct her way? The inundations of the rivers forced her to go far from the banks of the main stream, through the midst of woods, where the movement of the waters is almost imperceptible. How often must she have been stopped by the thorny lianas, that form a network round the trunks they entwine! How often must she have swum across the rivulets that run iuto the Atabapo! This unfortunate woman was asked how she had sustained herself during four days; she said that, exhausted with fatigue, she could find no other nourishment than those great black ants called vachacos, which climb the trees in long bands, to suspend on them their resinous nests." We pressed the missionary to tell us whether the Guahiba had peacefully enjoyed the happiness of remaining with her children; and if any repentance had followed the excess of cruelty. He would not satisfy our curiosity; but at our return from the Rio Negro, we learnt that the Indian mother was not allowed time to cure her wounds, but was again separated from her childien, and sent to one of the missions of the Upper Oroonoko. There she died, refusing all kind of nourishment, as the savages do in great calamities.

\section{Harleian Collection.}

Turs is a most valuable collection of curious manuscripts, begun near the end of the 17th century, by R. Harley Esq. of Brampton Bryan, afterwards earl of Oxford, and conducted upon the plan of the great Sir Robert Cotton. In August, 1705, he published his first considerable collection, and in less than ten years he got together nearly two thousand five hundred rare and curious manuscripts. Soon after this, the celebrated Dr. George Hicks, Mr. Anstis, garter king at arms, bishop Nicolson, and many other eminent antiquaries, not only offered him their assistance in procuring manuscripts, but presented him with several that were very valuable. Being encouraged to perseverauce by his success, he kept many persons employed in purchasing manuscripts for him abroad, giving them written instructions for their conduct. Thus the manuscript library was, in 1721 , increased to near six thousand books, fourteen thousand original charters, and five hundred rolls. His son Edward, earl of Oxford, still farther enlarged the collection; so that when he died, June 16,1741, it consisted of eight thousand volumes, several of them containing distinct and independent treatises, besides many loose papers, which have since been sorted, and bound up in volumes; and above forty thousand original rolls, charters, letters patent, grants, and other deeds and instruments of great antiquity. The principal design of making this collection was the establishment of a manuscript English historical 
library, and the securing from destruction such national records as had eluded the vigilance of preceding collectors; but Lord Oxford's plan was more extensive, for his collection abounds also with curious manuscripts in every science. This collection is now in the British Museum; and an enumeration of its contents may be seen in the Annual Register, vol. vi. p. $140, \& c$.

\section{Italian Method of Bird-Catching.}

THE following method of catching wild pigeons is eagerly pursued as a diversion in different parts of Italy, particularly by the inhabitants of Cava, in the Hither Principate, and is thus described by Mr. Swinburne.

The people assemble in parties, and should any stranger chance to stray to their rendezvous, they give him a most cordial welcome amongst them. I am not in the least surprised at their passionate fondness for this sport, as I found it extremely bewitching, keeping the attention constantly alive, and the springs of the mind pleasingly agitated by expectation; the situations where the toils are spread are incomparably beautiful, the air is pure and balsamic, and every thing around breathes health and satisfaction.

When the stock-doves, in their periodical flight, return from the northern and western parts of Europe, to gain warmer regions for their winter abode, the fowler repairs to the mountain, and spreads his net across the intermediate passes, through which the birds direct their course, to avoid unnecessary elevation in their flight. These nets are hung upon a row of large trees planted for the purpose. The branches being very thick and close at the top, and the whole very lofty and bare, a great opening is left below for the toils, which reach to the ground, and by means of pulleys fall in a heap with the least effort. Sometimes they are extended upon poles that exceed the height of the trees. At a small distance is a lofty circular turret, like a column with a little capital or cap, upon which a man is stationed to watch the approach of the game. As he commands a free view over all the country, and practice has made his sight as acute as that of the lynx, he descries the birds at a wonderful distance. The doves advance with great velocity; but the alert watchman is prepared for them, and, just as they approach his post, hurls a stone above them with a sling: upon which the whole fock, fearing birds of prey, and supposing the stone to be an enemy of that kind ready to pounce on them, dart down like lightning, to avoid the blow by passing under the trees; but there they rush into the jaws of death, by dashing against the net, which instantly drops, and so entangles them that not one can escape the active hands of the fowler. These birds are sometimes taken by dozens at one fall, and are accounted fine eating. The dexterity with which the slingers manage their weapon is very remarkable; they throw the stone to a great height without any violent effort, and even without whirling the sling round before they discharge the pellet. In the Pyrenean mountains, where the same diversion is followed, the watchmen use bows and arrows trinmed with the feathers of a hawk. 
IT seems that the first English Lottery was drawn in 1569. It con sisted of forty thousand lots, at ten shillings each lot. The prizes were plate, and the profits were intended for the repair of the havens of the kingdom. It was drawn at the west door of St. Paul's Cathedral.-In $1612 \mathrm{King}$ James, for the special encouragement of the plantation of English colonies in Virginia, granted a lottery, to be held at the west end of the Park; the prizes seem again to have consisted of plate. Lotteries were suppressed as nuisances to the public in the reign of Queen Anne; but they were revived under that of her successor George I.

\section{Coral Fishery.}

THE manner of fishing is nearly the same wherever coral is found. The method used at the bastion of France, under the direction of the company established at Marseilles, is to send out seven or eight men in a boat, and when the net is thrown by the caster, the rest work the vessel, and help to draw the net in. The net is composed of two rafters of wood tied crosswise, with leads fixed to them; to these they fasten a quantity of hemp, tied loosely round, and intermingled with some large netting. This instrument is let down where they think there is coral, and pulled up again when the coral is strongly entangled in the hemp and netting. For this purpose six boats are sometimes required, and if, in hauling in, the rope happens to break, the fishermen run the hazard of being lost. Before they go to sea, they agree for the price of the coral, at so much per pound; and they engage, on pain of corporal punishment, that neither they nor their crew shall embezzle any, but deliver the whole to the proprietors. When this is accomplished, which amounts, one year with another, to twenty-five quintals for each boat, it is divided into thirteen parts; of which the proprietors have four, the casters two, and the other six men one each, the thirteenth is claimed by the company to whom the boat belongs.

\section{Ancient Mathematicians.}

THE first who cultivated mathematics after the flood were the Assyrians and Chaldeans; from whom Jusephus says the science was carried by Abraham to the Egyptians; who proved such notable proficients, that Aristotle fixes the first rise of mathematics among them. From Egypt they passed into Greece, through the hands of Thales, A. A. C. 584 ; who having learned geometry of the Egyptian priests, taught it in his own country. After Thales, Pythagoras, among. other mathematical arts, paid a particular regard to arithmetic, fetching the greatest part of his philosophy from numbers: he was the first, as Laertius tells us, who abstracted geometry from matter; and to him we owe the doctrine of incommensurable magnitude, and the five regular bodies, besides the first principles of music and astronomy. Pythagoras was seconded by Anaxagoras, Enopides, Briso, 
Antipho, and Hyppocrates of Scio; who all applied particularly to the quadrupture of the circle, the duplicature of the cube, \&c. but the last with most success; this last is also mentioned by Proclus, as the first who compiled elements of mathematics. Democritus excelled in mathematics as well as physics, though none of his works in eitler kind is extant, the destruction of which some authors lay at the door of Aristotle.

The next in order is Plato, who not only improved geometry, but introduced it into physics, and so laid the foundation of a solid philosophy. Out of his school proceeded a crowd of mathematicians. Proclus mentions thirteen of note, among whom was Leodamus, who improved the analysis first invented by Plato; 'Theatelus, who wrote elements; and Archiates, who was the first that applied mathematics to use in life. These were succeeded by Neocles and Theon, the last of whom contributed to the elements. Eudoxus excelled in arithmetic and geometry, and was the first founder of a system of astronomy. Menachunus invented the conic sections, and Therodius and Hermotimus improved the elements. Aristotle's works are so stored with mathematics, that Blancanus compiled a whole book of them. Out of his school came Eurlemus and Theophrastus; the first of whom wrote of numbers, geometry, and invisible lines; the latter, a mathematical history. To Aristeus, Isidorus, and Hypsicles, we owe the books of solids; which, with the other books of elements, were inproved, collected, and methodized by Euclid, who died in the year A.A. C. 284.

A century after Euclid, came Eratosthenes and Archimedes. Con. temporary with the latter was Conon, a geometrician and astronomer. Soon after appeared Apollonius Pergaus, whose conics are still extant. To hin are likewise ascribed the fourteenth and fifteenth books of Euclid, which are said to have been contracted by Hypsicles. Hip. parclius and Menelaus wrote on the subtenses in a circle, the latter also on spherical triangles. Theodosius's three books of spherics are still extant. All these, with the exception of Menelaus, lived before the Christian era.

Ptolemy of Alexandria, the prince of ancient astronomers, and no mean geometrician, was born A. D. \%o. He was succeeded by the philosopher Plutarch, of whom we have still extant some mathematical problems. After him flourished Eutocius, who commented on Archimedes, and occasionally mentions the inventions of Philo, Diocles, Nicomedes, Sporus, and Heron, on the duplicature of the cube: to Clesibius of Alexandria, we owe pumps; and Geminus, who appeared soon after, is preferred by Proclus to Euclid himself. Diophantus of Alexandria was a great master of numbers, and the first inventor of algebra; Nicomachus is celebrated for his arithmetical, geometrical, and musical works; Serenus, for his books on the sections of the cylinder; Proclus, for his comments on Euclid; and Theon has the credit, among some, of being the author of the books of elements ascribed to Euclid. The last among the ancient mathematicians; is Pappus of Alexandria, who flourished A. D. 400, and is celebrated for his books of mathematical collections, still extant. 
THE minstrels were once a great and flourishing body in Eurgland; but their dignity being interwoven with the illusory splendours of feudal institutions, declined in proportion to the advance of moral cultivation : they became in time vulgar mountebanks and jugglers, and in tlie reign of Elizabeth-the reign of robust intellect-they were absolutely suppressed as rogues and vagabonds. Banished from the streets and highways, they fled to alehouses, and followed the trades of fiddlers and pipers : minstrelsy was no longer known in England. The instruments so long in use by this order of musicians would now astonish by their number, and the rudeness of their plan and fabric. There has not been for an age any trace of this peculiar order, if we except the instance of a man well known in Derbyshire, who appeared at the close of the last century in the streets of the metropolis with the canister and string, singing the fine old ballad of Lord Thomas and Fair Eleanour. From the earliest times songs were chanted in our streets; but before the reign of Elizabeth they were invariably accompanied by the sound of some musical instrument.

The suppression of the minstrel order was followed by the rise of the ballad-singers-a race that relied for success exclusively on the merits of their voices. This revolution, though a curious part of knowledge, is scarcely distinguished, or not alleged with sufficient stress, in most of our histories of literature. The subjects of many of the songs handed down by the minstrels, were still held in honour by the ballad-singers. The feats of Clym of the Clough, Randle of Chester, and Sir Topaz, grown faded under the keeping of the minstrels, were now refreshed, and brought more boldly before the sense, in the new version. Robin Hood had his honours enlarged under the new dynasty - more maidens, more heroes than ever, wept at and were inspired by the history of his fortunes. Drayton's allusion to the propagation of Robin's fame may give an idea of the diffusion of the ballad-singers.

"In this our spacious isle 1 think there is not one, But he hath heard some talk of him and little John; And to the end of time the tales shall ne'er be done, Uf Scarlock, George-a-Green, and Muck the Miller's son."

The new race-the ballad singers - started with a full tide of popularity: they had the glory of being opposed by, and triumphing over, the unanimous hostility of the votaries of the Muses, from the highest to the least worthy. The poets of the first rank confessed their uneasiness at the success of the innovators. Of this fact we have abundant evidence in Spenser's Tears of the Muses-and even the supreme Shakespeare himself would bring their calling into contempt. It is worth while to attend to the grounds of difference between the minstrels and their more simple successors. The former were the creatures of feudal vanity, and adopted some very degrading notions of government, both domestic and politic:- the ballad-singers addressed themselves to the people; they courted no obligation from the rich - they wore no livery of the great-they moved in independ- 
ence-the members of a pure democratic institution. The times had passed away when the wonted phrase of subserviency at the beginning of each song, "Fair lordyages and ladies all, \&c." was to be heard.

But the ballad-singers did not enjoy alone empty popularity, as may be understood from the perseverance of the old singers, and the number of carididates that yearly sought refuge in the profession, from the risks of a more uncertain state of life. One of the most popular singers of this early time was a boy, who, from the character of his voice and manner, is distinguished by the name of Outroaring Dick; an epithet as honestly bestowed as any descriptive compound on any hero in Greek or Latin story. He was bred to a mechanical employment; but he had a voice, the possession of which would teach a less enterprising spirit to aspire above all the gross toils of handicraft. His success was as permanent in the end, as it was steady in its growth. He first renounced the mechanical life; in time his prosperity enabled him to confine his journeys of business to the adjacent counties - the home circuit-and the decline of his life was spent in the dignified repose of an amateur. His earnings, according to $\mathrm{Mr}$. Warton, amounted to about tél shillings a day: he was well known throughout Essex, and was not missed for many years from the great fair of Braintree. But Cheeke, for such was his real name, was haunted in the midst of his glory by a rival. Will Wimbars had a voice quite of as much compass and flexibility, but not of as much pathos, as Dick. Dick was the more popular man of the two; he consulted times and tastes, and had a greater variety of songs : Wimbars had a select list, from which he never departed. Cheeke was free and easy, and had a turn for the humorous; his rival was all for doleful tragedies. The former was sought as a companion; the latter pleased best in the public exercise of his talents.

But the most universally esteemed ballad-singer of his age was Mat Nash, a man from the "North Countrie," the officina of ballad-singers, as it had been formerly of the minstrels. Nash had a masculine vehement style ; all the border ballads he had nearly made his own, by the force and enthusiasm of his manner of singing them. His "Hunts-up," a song which obtained for the author so much favour in a former reign, was one of his most celebrated efforts. But undoubtedly his forte was the famous old ballad of Chevy Chase, then called the Hunting of Cheviot. This was the song which Sir Philip Sidney declared, moved his heart more than a trumpet. If instead of tlie "Blind Crowder, with no rougher voice than rude style," to whom he alludes, he had heard Nash accompany the words with the liveliest dramatic action-had he seen him fall suddenly on his knees, and move about cutting and thrusting on all sides, as if to realize the description of Witherington fighting on his stumps-it is easy to suppose what would have been the result in favour of Nash. However, it so happened that the date of Nash's fortune was fixed at a later period; for the great secretary Cecil was once so captivated with his singing, that he soon enabled him to retire from the profession.

The accident that led to this fortunate reconnoitre is not impertinent to our subject :-in the time of a dearth, which was severely felt in the city, the famous ballad-maker Delone composed a song reflect- 
ing on her majesty. The ballad-singer and the publisher were both committed to the Compter; but the poet defied the government from his retreat. In a letter to the lord mayor, he avowed the ballad, justified his satire, and concluded with these lines from the Mirror of Magistrates, descriptive of the duties of a true poet. They were composed by one Collingbourne, put to death in the reige of Richard III. for making a foolish rhyme.

"Things that import, hemust be quick to pen,

Reproving ices sharply now and then;

He must be swift, when touched tyrants chafe,

To gallop thence to keep his carcase safe."

Nash, in the nean time, in an interview with the secretary, fully established his innocence, and laid the foundation of his future prosperity.

The gipsies furnished a number of female ballad-singers about this time. The laws, and the prejudices of society in that age, concurred in denouncing this race. But how just is nature! the most esteemed and the best received ballad-singers of their time beloug to the outlawed tribe. Alice Boyce, for instance, with the bronzed face, dark eyes and hair, of her nation, came to London from Cumberland. She sang her way to the metropolis, and, when there, very quickly gained the ears of the great. She was even appointed to sing, "O the broom," and "Lady Greenleaves," before the queen.

The reigns of King James I. and his successor were remarkable for nothing connected with our purpose, except that the taste of the population, for nature and simplicity, kept up the profession of balladsinging. The poets of the day, in the mean time, became so learned, that they were searcely to be understood, eren by the great: Henceforward ballad-singing maintained a prosperous and respectable course. The singers had no state enemies to contend with. Their employment was too lucrative, and custom had ton firmly sanctioned it, to permit the persecutions of parish fiends. But, better than all, the law as yet furnished no pretext for stopping the free circulation of the lower ranks throughout the country. The government, and still more frequently the corporation of London, had been alarmed at the influx of humble strangers into the metropolis. There were issued bulls of penal annunciation, street proclamations, circumstantial and minute, embracing the professors of all manner of arts and employments, whether for use or amusement; yet not a word of ballad singers. Fiddlers put the whole council into consternation; minstrels (such as they were) had a price set upon their bodies; but there was no vice assumed of the members of the vocal throng. Cromwell was disturbed by the presence of low visitors to the metropolis; he again excommunicated minstrels and fiddlers, but left ballad-singers to pursue their business unmolested. And yet the Protector found not in that order a friendly or even a neutral power. They sang of bold cavaliers and ladies bright, themes that did not fail to keep the nemory of past times "green in the souls of men." But as soon as the Restoration removed all restraint from the ballad-singers, the streets re-echoed to the strains either of thanksgiving for the return of the monarch, or in ridicule of the fallen power. The song begin- 
ning with the words, "Rebellion hath broken up house" was very celebrated at the time. However, the taste of the public, in the course of a short time, was divided between political and amatory poetry: the circumstances of the times recommended the first species; and the spirit that produced the Sedleys, Etheridges, and Rochesters, brought in the latter. Many of the celebrated poets of the day wrote for the streets and villages: but there never was an era when the ballad-singers answered more faithfully to the public feeling. 'They were a fearful check on the acts of a despotic monarch: when the charter was withdrawn from the city of London, a storm of ballads assailed the court, and, was heard with dismay in the council. The agitated period that immediately went before the Revolution permitted scarcely any but political ballads to be sung. Lord Wharton, the author of a song, boasted that he had rhymed king James out of his dominions; and the testimony of the gravest writers of the time, sliew that there was no exaggeration in the boast. The tide of popular favour and ballad-singing flowed on the side of the newly established dynasty. The queen absolutely patronized the balladsingers; she did not hesitate to avow, even on state occasions, a preference. for the simple ballads that charmed her early years, to the elaborate compositions of the most esteemed masters of the time.

We are to look upon the ballad-singers from this time forth in the light of a corporation. Custom had established yearly festivals for them in the classic regions of St. Giles's, which were much frequented by some of the wits of the day-Swift, Gay, Bolingbroke, Steele, \&c. From these high followers of the muses, yearly contingents of ballads were cxpected. Swift contracted to furnished the humorous songs: Gay, who, as Goldsmith observes of him, had a liappy strain of ballad-thinking, was set down for the pathetic ones; those of a miscellaneous character were divided amongst a number of amateur bards. No importunities, even of his friends, could induce Pope to attend any of these assemblies. He was, however, prevailed on to write an epitaph for a young creature whom he had several times seen and heard, and who was known to her companions under the title of Clarinda. Sthe was much favoured by some of the great, and, but for her attachment to the life of a ballad-singer, might with her beauty and accomplishments have risen to fortune.

Gay and Swift had naturally a relish for low society, and were hailed by the fraternity and sisterhood as the most precious sources of profit. Amongst other songs which Swift sent into the world through the medium of ballad-singers, was a severe satire on the Duke of Marlborough, beginning, "Our Johnny is come from the wars." The song drew much attention in the streets, and excited the. strongest resentment against the author, in the breast of the accomplished duchess. She remained implacable, until the publication of Gulliver, when she offered her friendship to Swift, through his friend Gay. The Beggar's Opera was originally written (we have it on Gay's own authority) to celebrate the marriage of James Chanter and Moll Lay.

There was a young creature among tlie ballad-singers, now known to the world by no other title than Clara, who drew much attention 
at this time by the sweetness and pathos of her tones. She was the original singer of Black-eyed Susan, and one or two songs which were afterwards introduced into the Beggar's Opera. But her recommendation to particular notice was the circumstance of her for many years being the object of Lord Bolingbroke's enthusiastic affection. The poor girl strayed for some time, during which his lordship had not seen her: and it was after that interval, that, having met her, he addressed to her the tender lines, beginning,

" Dear thoughtless Clara, to my verśe attend,

Believe for once the lover and the friend."

And concluding thus,

"To virtue thus; and to thyself restored,

By all admired, by one alone adored;

Be to thy Harry ever kind and true,

And live for him who more than died for you.

A series of calamities totally ruined her vocal powers, and she afterwards subsisted by the sale of oranges at the Court of Requests.

The profession did not continue to maintain its rank. The disap:pointed author in Roderic Random, who set about writing for the ballad-singers, was introduced into one of their assemblies. His testimony establishes the deepest degeneracy in the members of the order. Indeed, the history of ballad-singing, during the remainder of the last century, affords but an unsatisfactory subject of reflection to the lovers of song.

\section{Antipodes.}

THE Antipodes are those people who, living on the other side of the globe, have their feet directly opposite to ours. Plato is esteemed the first who thought it possible that Antipodes existed, and is looked upon as the inventor of the word. As this philosopher apprehended the earth to be spherical, he had only one step to make, to conclude the existence of Antipodes. The ancients, in general, treated this opinion with the highest contempt. Lactantius and Augustine laughed at the notion of Antipodes; the latter of these fathers was perplexed to think how men should hang pendulous in the air, with their feet uppermost, as he thonght they must do in the other hemisphere; and Boniface, archbishop of Mentz, and legate of pope Zachary in the eighth century, declared a bishop of that time, called Vigilius, a heretic, for maintaining that there were such beings as Antipodes.

But the Christian fathers were not the only persons who disputed the truth of the Antipodes. Lucretius had done it before them, at the end of his first book, v. 1063, \&c. See also Plutarch, lib. De facie in orbe Lucinæ; and Pliny, who refutes the opinion, lib. ii. cap. 5. They never reflected that these terms upwards' and downwards are merely relative; and signify only nearer to, or farther from, the centre of the earth, the common centre to which all heavy bodies gravitate; and that, therefore, our Antipodes have not their feet upwards and heads downwards, any more than ourselves; for they, as well as we, have their feet nearest the centre of the earth, and their heads farthest 
from it. To have the head downwards, and feet upwards, is to place the bony in a direction of gravity tending from the feet to the head: but this cannot be supposed with regard to the Antipodes; for they, as well as we, tend toward the centre of the earth, in a direction from head to foot.

\section{Population of the World.}

AcCording to a Statistical Chart published in a Neapolitan Journal, the universal population of the Globe is 632 millions, thus subdivided:-172 millions in Europe; 330 millions in Asia; 70 millions in Africa; 40 millions in America; and 20 millions in the other parts.

Estimate by approximation.-In Europe: Births, per annum, $6,271,370$; per diem, 17,453; hour, 727 ; minute, 62 ; second 1 .

Deaths per annum, $5,058,822$; per diem, 13,860 ; hour, 577 ; minute, 66 ; second, 1.

In the entire universe-Births, per annum, 23,407,407; per diem, 64,130 ; hour, 2,692 ; ninute, 148 ; second, 8 .

Deaths per annun, 18,588,235; per diem, 50,927; hour, 2,122; minute, 125 ; second, 7 .

Persons arrived at the age of one lundred.-In 1800, according to Larrey, there were at Cairo 35 individuals who had attained to the age of 100 and upwards. In Spain, in the last age, were to be seen at St. Jean de Page, a town in Galicia, 13 old persons, the youngest of whom was 110 , and the oldest 127 ; their ages together made 1499 years. England is generally accounted to contain 3100 individuals of 100 years old. At the commencement of the present century, there were in Ireland 41 individuals from the age of 95 to 104 , in a population of only 47,000 souls. In Russia, amongst 892,642 dead, in 1814 , there were 3531 individuals of from 100 to 132 years of age. In Hungary, the family of Jean Rovin has furnished the example of the most extraordinary longevity. The father lived 192 years, his wife 164 years; they were married for 142 years, and the youngest of their children was 115.

Daniel Bernauli calculated that the inoculation of the small-pox has been the means of prolonging human life by three years, and the new observations of Duvillard gave the same result from vaccination.

\section{CoIN of THE ReALM}

The Pound, called sterling, was first ordered by William the Conqueror, in 1073 , to be considered as the measure of value, and all sums to be multiples, or parts of the pound.-The money was then silver.

Gold was first coined by Edw. III. in 1345, and consisted of Florins, which were $13 \mathrm{~s}$. $4 \mathrm{~d}$. or two-thirds of the pound.

In 1395 , gold Nobles, worth $6 \mathrm{~s}$. $8 \mathrm{~d}$., or one-third of the pound, were coined.

In 1423, gold Reals, worth $10 \mathrm{~s}$. or half the pound, were struck.

In 1510, gold Sovereigns, worth 22s. were coined; and in 1550, 
gold Sovereigns of 20 s., or one pound; but in 1553 , the same was ordered to pass for 30 s.

In 1632, Guineas first coined, value 20 shillings; and in 171\%, when Sir Isaac Newton was master of the mint, they were made to pass for 21 shillings, to prevent them being milled down.

In 1978, the light gold called in, amounted to $15,563,3931$, which was recoined at the expense of $700,000 \mathrm{l}$. At that period the Bank of England notes amounted to 10,500,000l, in all 26,000,000l.

Gold Seven-shilling pieces were issued the $2 d$ of December, 1697; and silver tokens the 1st of January, 1798.

The amount of sovereigns issued since the above period is about eight millions; and bank-paper about twenty-two millions; which is only four millions more than in 1.798, when the guineas and banknotes amounted to twenty-six millions. As our exports and imports are trebled, and our taxes quadrupled, and the value of most articles increased, we cannot be said to have, proportionally, more than half the circulating money that we had in 1998.

At no time during the late war had we much more than we have now, but the country bank-notes were what made the difference; then they were in great quantities, but now the issue is much diminished. The universal use of bankers paying in chécks, and the daily practice anongst the bankers themselves, of settling accounts by means of mutual demands, so far as they go, and only requiring money for the balances, all make a less quantity necessary.

\section{Perpetual Fire.}

IN the Peninsula of Abeheron, in the province of Schirwan, formerly belonging to Persia, but now to Russia, there is found a perpetual, or, as it is there called, an eternal fire. It rises, or has risen from time immemorial, from an irregular orifice of about twelve feet in depth, with a constant flame. The flame rises from the height of six to eight feet, but unattended with smoke, and yields no smell. The aperture, which is about 120 feet in width, consists of a mass of rock, ever retaining the same solidity and the same depth. The finest turf grows about the borders, and at the distance of two toises are two springs of water. The neighbouring inhabitants have a sort of veneration for this fire, and celebrate it with religious ceremonies.

\section{Singular Recovery of a Female unjustly executed.}

THE following account of the case of a poor girl who was unjustly executed in 1766, is given by a celebrated French author, as an instance of the injustice which was often committed by the equivocal mode of trial used in France:---

"About seventeen years since, a young peasant girl, possessed of a very agreeable figure, was placed at Paris, in the service of a man depraved by all the vices consequent on the corruption of great cities. Smitten with her charms, he tried every method to seduce her; but she was virtuous, and resisted. The prudence of his girl only irritated the passion of her master, who, not being able to make her submit to 
his desires, detemined on the most black and horrible revenge. He secretly conveyed into her box many things belonging to him, marked with his name. He then exclaimed that he was robbed, called in a conmissarie, (a ministerial officer of justice), and made his deposition. The girl's box was searched, the things discovered, and the unhappy servant was imprisoned. She defended herself only by her tears; she had no evidence to prove that she did not put the property into her box, and her only answer to the interrogations was, that she was innocent. The judges had no suspicion of the depravity of the accuser, whose station was respectable, and they administered the law in all its rigour; a rigour undoubtedly excessive, which ought to disappear from our code, to give place to a simple but certain penalty, which leaves fewer crimes unpunished. The innocent girl was condemned to be hanged. 'The dreadful office was inefiectually performed, as it was the first attempt of the son of the old cxecutioner. A surgeon had purchased the body for dissection, and it was conveyed to his house. On that evening, being abont to open the head, he perceived a gentle warmth about the body. The dissecting knife fell from his hand, and he placed in his bed her whom he was about to dissect. His efforts to restore her to life were effectual; and at the same time he sent for a priest, on whose discretion and experience he could depend, in order to consult with him on this strange event, as well as to have him for a witness to his conduct. The moment the unfortunate girl opened her eyes, she believed herself in the other world: perceiring the figure of the priest, who had a marked and majestic conntenance (for I know him, and it is from him that I have this fact,) she joined her hands trembling, and exclaimed-" Eternal Father, you know my innocence-have pity on me !" In this manner she continued to invoke the ecclesiastic, believing, in her simplicity, that she beheld her God. They were long in persuading her that she was not dead-so much had the idea of the punishment and of death possessed her imagination. Nothing could be more touching and more expres sive than the cry of an innocent being, who thus approached towards him whom she regarded as her supreme Judge; and, independently of her affecting beauty, this single spectacle was sufficient to create the most lively interest in the "breast of an observing and sensible man.-What a scene for a painter! What a moral for a philosopher! What a lesson for a legislator!"

\section{COMMEMORATION OF HaNDEL。}

THIs was a musical exhibition instituted in 1784 , a century after the death of Handel, the eminent musical master and composer. This exhibition was the grandest of the kind ever attempted in any nation. Of the rise and progress of the design, together with the manner in which the first celebration was executed, an accurate and authentic detail is given by Dr. Burney, in the fourth volume of his History of Music.

"Few circumstances," says the Doctor, "will more astonish veteran musicians, than to be informed that there was but one general rehearsal for each day's performance, an indisputable proof of the 
high state of cultivation, to which practical music has at present arrived in this country; for if good performers had not been found ready made, a dozen rehearsals would not have been sufficient to make them so. At this general rehearsal, above five hundred persons found means to obtain admission, in spite of every endeavour to shut out all but the performers, for fear of interruption, and perhaps of failure in the first attempts at incorporating and consolidating such a numerous band, consisting not only of all the regulars, both native and foreign, that the capital could furnish, but of all the irregulars, that is, dilettanti, and provincial musicians of character, who could he mustered, many of whom had never seen or heard each other before. This intrusion suggested the idea of turning the eagerness of the public to some profitable account for the charity, by fixing the price of admission to half-a-guinea for each person.

"The public did not manifest great eagerness in securing tickets till after this rehearsal, Friday, May 21, which astonished even the performers themselves by its correctness and effect. But so interesting did the undertaking become by this favourable rumour, that from the great demand of tickets it was necessary to close the subscription. Many families, as well as individuals, were attracted to the capital by its celebrity; and it was never remembered to have been so.full, except at the coronation of his late majesty George III. Many performers came, unsolicited, from the remotest parts of the kingdom, at their own expense ; some of them however were afterwards reimbursed, and had a small gratuity, in consideration of the time they had been kept from their families by the two unexpected additional performances.

"Foreigners, particularly the French, must be most astonished at so numerous a band moving in such exact measure, without the assistance of a coryphreus to beat the time, either with a roll of paper, a noisy baton, or a truncheon. Rousseau says, that the more time is beaten, the less it is kept; and it is certain that when the measure is broken, the fury of the musical general increasing with the disobedience and confusion of his troops, he becomes more violent, and his strokes and gesticulations more ridiculous, in proportion to their disorder. As this commemoration is not only the first instance of a band of such magnitude being assembled together, but of any band, at all numerous, performing in a similar situation, without the assistance of a manuductor to regulate the measure, the performances in Westminster Abbey may be safely pronounced no less remarkable for the multiplicity of voices and instruments employed, than for accuracy and precision. When all the wheels of that huge machine, the orchestra, were in motion, the effect resembled clock-work in every thing, with the addition of feeling and expression. And as the power and gravity of attraction in bodies is proportioned to their mass and density, so it seemed as if the magnitude of this band had commanded and impelled adhesion and obedience, beyond that of any other of inferior force. The pulsations in every limb, and ramifications in every vein and artery, in an animal, could not be more reciprocally isochronous, and under the regulation of the heart, than the members of this body of musicians were under that of the conductor and leader. The totality of sound seemed to proceed from one voice and one instrument, 
and its power's produced not only new and exquisite sensations in judges and lovers of the art, but were felt by those who never received pleasure from music before. The effect ran the risk of being doubted by all who heard the report; and the present description will probably be pronounced fabulous, if it should survive the present generation."

\section{Poets Laureat.}

THE custom of crowning poets is as ancient as poetry itself; it has indeed frequently varied; it existed, however, as late as the reign of Theodosius, when it was abolished as a relic of paganism.

When the barbarians overspread Europe, few appeared to merit thishonour, and fewer who could have read their works. It was about the time of Petrarch that poetry resumed its ancient lustre; he was publicly honoured with the laurel crown. It was in this century (the thirteenth) that the establishment of Bachelor and Doctor was fixed in the universities. Those who were found worthy of the honour obtained the laurel of Bachelor, or the laurel of Doctor; Laurea Baccalarreatus; Laurea Doctoratus. At their reception they not only assumed this title, but they also had a crown of laurel placed on their heads.

To this ceremony the ingenious writer attributes the revival of the custom. The poets were not slow in putting in their claims to what they had most a right; and their patrons sought to encourage them by these honourable distinctions.

In Italy these honours did not long flourish; although Tasso dignified the laurel crown by his acceptance of it.

In Germany the laureat honours flourished under the reign of Maximilian the First. He founded in 1504 a poetical college at Vienna: reserving to himself and the regent the power of bestowing the laurel. But the institution, notwithstanding this well-concerted scheme, fell into disrepute, owing to a crowd of claimants who were fired with the rage of versifying, and who, though destitute of poetic talents, had the laurel bestowed on them.

The French never had a Poet Laureat, though they had Regal Poets; for none were ever solemnly crowned. The Spanish nation, always desirous of titles of honour, seem to have known the Laureat; but little information concerning it can be gathered from their authors.

Respecting our own country, little can be said but what is mentioned by Selden. John Kay, who dedicated a History of Rhodes to Edward the Fourth, takes the title of his humble Poet Laureat. Gower and Chaucer were Laureats; so was likewise the rhyming Skelton to Henry the Eighth. In the Acts of Rymer, there is a charter of Henry the Seventh, with the title of Pro Poeta Laureato.

It does not appear that our poets were ever solemnly crowned as in other countries.

Clerical Zeat against wearing Long Hatr.

POPE ANICETus is said to have been the first who forbade the ulergy to wear long hair: but the prohibition is of an older date in the 
churehes of the East; and the latter, in which that decree is written, is thich later than that pope. The clerical tonsure is related by Isido. rus Hispalenus as an apostolic institution. Long hair was ancientiy held so odious, that there is a canon still extant, of 1096, importing that "such as wore long hair sliould be excluded coming into church while living, and not be prayed for when dead." Luitprand made a furious declamation against the emperor Phocas, for wearing long hair. The French historians have been very exact in describing the hair of their kings. Chanlemagne wore it very short; his sons shorter. Charles II." had nove at all. Under Hugh Capet it began to appear again, but the priests excommunicated all who let their hair grow. Peter Lombard expostulated so warmly with Charles VI. that he cut off his hair; and his successors for some generations wore it very short.

A professor of Utrecht, in 1650 , wrote expressly on the question, whether it be lawful for men to wear long hair; and concluded with the negative. Another divine, named Reves, who wrote for the afirmative, answered him. The clergy, both secular and regular, were obliged to shave the crowns of their heads, and keep their hair short, which distinguished them from the laity; and several canons were madc against their concealing their tonsure, or allowing their hair to grow long. The shape of this clerical tonsure was the subject of long and violent debates between the English clergy on the one hand, and those of the Scots and Picts on the other; that of the former being circular, and that of the latter only semicircular.

Long flowing hair was universally esteemed a great ornament; and the tonsure of the clergy was considered as an act of mortification and self-denial, to which many of them submitted with 'reluctance, and endeavoured to conceal as much as possible. Some, who pretended to superior sanctity, inveighed with great bitterness against the long hair of the laity, and laboured to cut it short, in imitation of the clergy. Thus St. Wulstan, bishop of Worcester, declaimed with great vehemence against luxury of all kinds, but chiefly against long hair, as most criminal and most universal. "When any of those vain people who were proud of their long hair," says William of Malmesbury, "bowed their hears to receive his blessing, before he gave it, he cut a lock of their hair with a little knife, which he carried about with him for that purpose, and commanded them, by way of penance for their sins, to cut all the rest of their hair in the same inaner. If any of them refused to comply with this command, he denounced the most dreadful judgments against them, reproached them for their effeminacy, and foretold, that as they imitated women in the length of their hair, they would imitate them in cowardice, when their country was invaded; which was accomplished at the landing of the Normaus."

This continued to be long a topic of declamation with the clergy, who even represented it as one of the greatest crimes, and most certain marks of reprobation. Anselm, archbishop of Canterbury, went so far as to pronounce the then terrible sentence of excommunication a'gainst all who wore long hair ; for which pious zeal he is very much commended. Seilo, a Norman bishop, acquired great honour by a sermon which he preached before Henry 
curled hair, with which the king and his courtiers were so much affected, that they consented to resign their flowing ringlets, of which they had been so vain. The prudent prelate gave them no time to change their minds, but immediately pulled a pair of shears out of his sleeve, and performed the operation with his own hand. Another incident happened about twenty-five years after, which gave a temporary check to the prevailing fondness for long hair.

"An event happened, A. D. 1129, says a contemporary historian, which seems very wonderful to our young gallants; who, forgetting that they were men, had transformed themselves into women by the length of their hair. A certain knight, who was very proud of his long luxuriant hair, dreamed that a person sufiocated him with his curls. As soon as he awoke, he cut his hair to a decent length. The report of this spread all over England, and almost all the knights reduced their hair to the proper standard. But this reformation was not of long continuance, for all who wished to appear fashionable returned to their former wickedness, and contended with the ladies in length of hair. Those to whom nature had denied that ornament, supplied the defect by art."

\section{The Jews of York.}

WIIEN Richard the First ascended the throne, 1189, the Jews, to conciliate the royal protection, brought their tributes. Many had hastened from remote parts of England, and appearing at Westminter, the court and the mob imagined that they had leagued to bewitch his majesty: An edict was issued to forbid their presence at the coronation; but several, whose curiosity was greater than their prudence, conceiving that they night pass unobserved among the crowd, ventured to insinuate themselves into the Abbey. Probably their voice and their visage alike betrayed them, for they were soon discovered; they flew diversely il great consternation, while many were dragged out with little remains of life.

A rumour spread rapidly through the city, that in honour of the festival, the Jews were to be massacred. The populace, at once eager of royalty and riot, pillaged and burnt their houses, and murdered the Jews. Benedict, a Jew of York, to save his life, received baptism; and returning to that city, with his friend Jocenus; the most opulent of the Jews, died of his wounds. Jocenus and his servants related the late tragic circumstances to their neighbours; but where they hoped to move sympathy, they excited rage. The people at York soon gathered, to imitate the people at London, and their first assault was on the house of the late Benedict; which having some strength and magnitude, contained his family and friend's, who found their graves in its ruins. The alarmed Jews hastened to Jocenus, who conducted them to the governor of York castle, and prevailed on him. to afford them an asylum for their persons and effects. In the mean while their habitations were levelled, and the owners murdered; except a few unresisting beings, who, unmanly in sustaining honour, were adapted to receive baptism.

The castle had sufficient strength for their defence; but a suspicion 
arising that the governor, who often went out, intended to betray them, they one day refused him entrance. He complained to the sheriff of the county, who, being deeply indebted to the Jews, united with him, and orders were issued to attack the castle. The cruel multitude, acting with the soldiery, felt such a desire of slaughtering those they intended to despoil, that the sheriff, repenting of the order, revoked it, but in vain ; fanaticism and robbery, once let loose, will satiate their appetency for blood and plunder. They solicited the aid of the superior citizens, who, perhaps, not owing quite so much money to the Jews, humanely refused it ; but having addressed the clergy, (the barbarous clergy of those days,) were by them animated, conducted, and blessed.

The leader of this rabble was a canon regular, whose zeal was so fervent that he stood by them in his surplice, which he considered as a coat of mail, and reiteratedly exclaimed, "Destroy the enemies of Jesus." This spiritual laconism invigorated the arm of men, who perhaps wanted no other stimulative than the hope of obtaining the immense property of the besieged. It is related of this canon, that every morning before he went to assist in battering the walls, he swallowed a consecrated wafer. One day having approached too near, defended as he conceived by his surplice, this church militant was crushed by a heavy fragment of the wall, rolled from the battlement.

But the avidity of certain plunder prevailed over any reflection, which, on another occasion, the loss of so pious a leader might have raised.

Their attacks continued; till at length the Jews perceived they could hold out no longer, and a council was called, to consider what remained to be done in the extremity of danger.

Among the Jews, their elder rabbin was most respected. It has been customary with this people to invite for this place some foreiguer renowned among them for the depth of his learning and the sanctity of his manners. At this time the Haham, or elder rabbin, was a foreigner, who had been sent over to instruct them in their laws, and was a person, as we shall observe, of no ordinary qualifications. When the Jewish council was assembled, the Haham rose, and addressed them in this manner-

"Men of Israel! the God of our ancestors is omniscient, and there is no one who can say, Why doest thou this? This day he commands us to die for his law; for that law, which we have cherished from the first hour it was given, which we have preserved pure throughout our captivity in all nations, and which, for the many consolations it has given us, and the eternal hope it communicates, can we do less than die? Posterity shall behold this book of truth, sealed with our blood; and our death, while it displays our sincerity, shall impart confidence to the wanderer of Israel. Death is before our eyes; and we have only to choose an honourable and easy one. If we fall into the hands of our enemies, which you know we cannot escape, our death will be ignominious and cruel; for these Christians, who picture the Spirit of God in a dove, and confide in the meek Jesus, are athirst for our blood, and prowl around the castle like wolves. It is, therefore, my advice that we elude their tortures; that we ourselves should be our own 
executioner's ; and that we voluntarily surrender our lives to our Creator. We trace the invisible Jehovah in his acts; God seems to call for us, but let us not be unworthy of that call. Suicide, on occasions like the present, is both rational and lawful : many examples are not wanting among our forefathers; as I advise, men of Israel, they have acted on similar occasions. Having said this, the old man sat down and wept.

The assembly were divided in their opinions. Men of fortitude applauded its wisdom, but the pusillanimous murmured that it was a dreadful counsel.

Again the rabbin rose, and spoke these few words in a firm and decisive tone : 'My children! since we are not unanimous in our opinions, let those who do not approve of my advice depart from this assembly !-Some departed, but the greater number attached themselves to their venerable priest. They now employed themselves in consuming their valuables by fire; and every man, fearful of trusting to the timid and irresolute hand of the women, first destroyed his wife and children, and then himself. Jocenus and the rabbin alone remained. Their life was protracted to the last, that they might see every thing performed according to their orders. Jocenus being the chief Jew, was distinguished by the last mark of human respect, in receiving his death from the consecrated hand of the aged rabbin, who immediately after performed the melancholy duty on himself.

All this was transacted in the dead of the night. In the morning, the walls of the castle were seen wrapt in flames, and only a few miserable and pusillanimous beings, unworthy of the sword, were viewed on the battlements, pointing to their extinct brethren. When they opened the gates of the castle, these men verified the prediction of their late rabbin; for the multitude, bursting through the solitary courts, found themselves defrauded of their hopes, and in a moment avenged themselves on the feeble wretclies who knew not to die with hónour.

Such is the narrative of the Jews of York, of whom the historian can only cursorily observe, - that five hundred destroyed themselves.

\section{Gordian KNOT.}

This was a knot made by K. Gordian, in one of the cords of his yoke, or, as some have it, in the leathers of his chariot-harness; which was so very intricately twisted, that it was impossible to discover where it began or ended. The oracle of Apollo having declared, that whoever should untie this knot should be master of all Asia, many attempted it, but without success ; till at last Alexander the Great, after likewise attempting in vain to untie it, cut it asunder with his sword, and thus either eluded or fulfilled the prediction.

\section{Confusion of Tongues.}

Is the history of mankind, this is a memorable event, which happened in the year 101 according to the Hebrew chronology, and 401 by the Samaritan, after the flood, at the overthrow of Babel, and 
which was providentially brought about, to facilitate the dispersion of mankind and the population of the earth. Until this period there had been one common langnage, which formed a bond of union that prevented the separation of mankind into distinct nations, and some have supposed that the tower of Babel was erected as a lind of fortress, by which the people intended to defend themselves against the separation which Noah had projected. There has been a considerable difference of opinion as to the nature of this confusion, and the manner in which it was effected.

Some learned men, prepossessed with the notion that all the different idioms now in the world, did at first arise from one original language to which they may be reduced, and that the variety among them is no more than must naturally have happened, in a long course of time, by the mere separation of the builders of Babel, have maintained, that there were no new languages formed at the confusion, but that this event was accomplished by creating a misunderstanding and variance among the builders, without any immediate infuence on their langunge. But this opinion, advanced by Le Clerc, \&c. seems to be directly contrary to the obvious meaning of the word shapha, lip, used by the sacred historian.

Others have imagined that this was brought about by a temporary confusion of their speech, or rather of their apprehensions, causing them, whilst they continued together and spoke the same language, to understand the words differently. Scaliger is of this opinion. Others, again, account for this event by the privation of all language, and by supposing that mankind was under a necessity of associating together, and of imposing new names on things by common consent.

Another opinion ascribes the confusion to such an indistinct remembrance of the original language which they spoke before, as made them speak it very differently, so that by the various inflections, terminations, and pronunciations of divers dialects, they could no more understand one another, than they who understand Latin can understand those who speak French, Italian, or Spanish, though all these languages have arisen nut of it. This opinion is adopted by Casaubon, and by bishop Patrick in his Commentary in loco, and is certainly much more probable than either of the former. And $\mathrm{Mr}$. Shuckford maintains, that the confusion arose from small beginnings, by the invention of new words in each of the three families of Shem, Ham, and Japheth, which might contribute to separate them from one another, and that in each family new differences of speech might gradually arise, so that each of those families went on to divide and subdivide aniong themselves.

Mr.Joseph Mede, Dr. Wotton \&c. not satisfied with any of the foregoing methods of accounting for the diversity of languages among: mankind, have recourse to an extraordinary interposition of divine power, by which new languages were framed, and communicated to different families by a supernatural infusion or inspiration; which languages have been the roots and originals from which the several dialects, that are or have been spoken, have arisen, and to which they may with ease be reduced.

As to the number of languages thus introduced, many opinions 
have been adopted. If there were no more than nations or heads of nations, then the number would be seven for Japhet, four for Ham, and five for Shem; but if there were as many as there were families, which is the more probable opinion, their number cannot be certainly assigned. However, the Hebrews fancy there were seventy, because the descendants from the sons of Noah, enumerated Genesis x. were just so many. Allowing, then, the languages of the chief families to have been fundamentally different from each other, the sub-languages and dialects within each branch would probably have had a mutual affinity, greater or less, as they settled nearer or farther from each other. But whichever of these hypotheses is adopted, the primary object of the confusion at Babel was the separation and dispersion of mankind.

As none of these, however, give a complete or satisfactory idea, either of the immediate cause or of the nature of this important event, others have been led to consider it in a different point of view. Agreeing with the observation, that the meaning of the Hebrew word slsaphan, is lip, and comparing various passages of sacred writ where the phrase is used, they understand it as signifying religious service or confession; distinct from leshan, which denotes tongue or language. Keeping this in view, Shem, Ham, and Japheth, and their descendants at that time, confessed the same truth, and worshipped the same God in the same manner that Noah had done; and we are toll, that as they journeyed from the east; they found a plain, and dwelt there. It is said the word here translated plain, should have been rendered oak or grove, and that, when compared with the plain or oak mentioned in the $6 \mathrm{th}$ verse of the following chapier, the 1 st of the eighteenth chapter, and 4 th and $8 \mathrm{th}$ of the $35 \mathrm{th}$ chapter of Genesis, as well as with Judges vi. 12. and ix. 6, the oak or grove appears to have been a place where the presence of Jehovah was visible with his people. The reproofs of the propliets, also, seem to refer to a cormption of these places of patriarchal worship, when the people are spoken of as worshipping under every green tree.

In building this tower, then, in the plain of Shinar, the builders made light of the oak or grove, and of him who appeared there; for it was to be dedicated to the heavens, $i$. $e$. the heavenly bodies. This was the origin of all the ancient worship of Baal. It is further observeo, that if the intention of the builders was simply to erect a tower, the height of which was to be its chief excellency, they would never have chosen a plain for its foundation; but considering them in this view, as joined together in apostacy from the God of heaven, we see why their speech was confounded, and their building stopped, and why they were scattered abroad through the earth. Their dispersion was doubtless a part of the Divine plan; for, upon the site of this tower, ancient Babylon, the figurative scene of much confusion and idolatry, was founded by one race; another race was distinguished for the purpose of founding Jerusalem, the figurative scene of order and peace ; and at Jerusalem, on the day of Pentecost, Acts it this curse of the confusion of speech was remarkably counteracted when the apostles were heard by men of every nation, speaking in their own tongue the wonderful works of God; but the full effects of this 
counteracting will be further displayed when the Lord will give to his people a pure language, that they may call on his name, and serve him with one consent.

\section{On Omens, - with Historical Examples.}

A MOST singular chain of uncommon circumstances preceded the assassination of that excellent monarch, Henry IV. of France, in the morning of the day on which he was murdered by Ravaillac, (viz. Friday, May 14, 1680.) His majesty was exceedingly pensive. In the hope of composing his spirits, he threw himself on his bed, but was unable to rest. Thrice he rose, and thrice he fell on his knees in prayer. Soon after, repairing to the presence-chamber, his attendants endeavoured to divert the melancholy which preyed so deeply on his mind. Being naturally amiable and cheerful, he tried to fall into the well-meant pleasantry of his nobles, and attempted to smile, but concluded thus:- "We have laughed enough for Friday, there will be weeping on Sunday."

His queen (Mary de Medicis) had been crowned but the day before his murder. One La Brosse, a physician, is by some reported to have said to the Duke de Vendome, in the evening of that day, "If the king survives a mischief which threatens him at present, he will live these thirty years." The duke - entreated the king to grant this physician an audience, and repeated what the old gentleman had been saying. His majesty, with unusual asperity and hastiness, rephed, "He is an ola fool for telling you such things, and you are a young fool if you believe him."-[It is proper to apprise the reader, that Bayle has endeavoured to shake the credit of this whole story about La Brosse and the Duke de Vendome. See his third volume under the article of Henry IV.] - The duke's rejoinder was firm, respectful, and sensible:- "Sire, one ought not to believe such things, but one may fear them."

The same day, as the king stopped to speak with some body present, the queen stopping at the same time, he said to her, as by a spirit of involuntary prophecy, Passez, passez, Madame la regente; i. e. Go on, go on, Madame the regent.

$A$ few nights before the catastrophe, the queen dreamed that all the jewels in her crown were changed into pearls, and that she was told pearls were significative of tears. Another night she started, and cried out in ber sleep, and waked the king, who asking her what was the matter, she answered, "I have had a frightful dream; but I know that dreams are mere illusions." "I was always of the same opinion," replied Henry ; "however, tell me what your dream was."-"I dreamed," continued she, "that you were stabbed with a knife under the short-ribs."- "Thank God," rejoined the king, "it was but a dream."

On the morning of the fatal day, his majesty was unusually chagrined, and he said more than once to those about him, "Something or other hangs heavy on my heart." Before he went to his coach, he took leave of the queen no fewer than three times; and on stepping into his carriage, he had not passsed through many streets, ere Ravaillac 
gave him that fatal stab, which deprived France of one of the most generous and humane sovereigns she ever had.

When Charles I. of England opened the civil war by erecting his standard on Nottingham castle, it was soon blown down by a high wind, and the weather continued so boisterous, that the standard could not be refixed for several days. Some years after, while the same unfortunate prince was taking his trial before what was called the high court of justice, the silver head fell off from his cane, nor did the head of its owner remain many days longer upon his shoutder's.

\section{Egyptian DarkNess.}

ONE of the most terrible sorts of darkness was that which, at the command of Moses, came upon Egypt, as a plague to the inliabitants of it. The Septuagint, our translation of the bible, and indeed most others, in explaining Moses' account of this darkness, render it "a darkness which may be felt;" and the Vulgate has it "a palpable darkness," consisting of black vapours and exhaltations so condensed that they might be perceived by the organs of seeing or fecling: but some commentators think that this is carrying the sense too far, since in such a medium as this, mankind could not live an hour, much less for the space of three days, as the Egyptians are said to have done, during the time this darkness lasted; and therefore they imagine that instead of a darkness that might be felt, the Hebrew plirase may signify a darkness wherein men went groping and feeling about for every thing they wanted. Le Clerc is of this opinion, and thinks that Philo, in his life of Moses, understood the passage in its right sense. "For in this darkness," says he, "whoever were in bed durst not get up; and such as their natural occasions compelled to get up, went about by the walls, or any thing they could lay hold on, as if they had been blind." What it was that occasioned this darkness, whether it was in the air or in the eyes,-whether it was a suspension of light from the sun in that country, or a black thick vapour which totally intercepted it, -it would be in vain to conjecture.

\section{History of the Trade to Guinea.}

THE most ancient account we have of this country, particularly that part situated on and between the Senegal and Gambia, is from the writings of two ancient authors, one an Arabian, and the other a Moor. The first wrote in Arabic about the twelfth century. His works, printed in that language at Rome, were afterwards into Latin, and printed at Paris, under the patronage of the famous Thuanus, chancellor of France, with the title of Geograplia Nubiensis, containing an account of all the nations lying on the Senegal and Gambia. The other was written by John Leo, a Moor, born at Grenada in Spain, before the Moors were totally expelled from that kingdom. He resided in Africa, but being on a voyage from Tripoli to Tunis, was taken by some Italian corsairs, who, finding him possessed of several Arabian books, besides his own Mss. concluded him 
to be a man of learning, and as such presented him to pope Leo X. This pope encouraging him, he embraced the Romish religion, and his description of A frica was published in Italian.

From these writings we learn, that after the Mahometan religion had extended to Morocco, some of the promoters of it crossing the sandy deserts of Numidia, which separate that country from Guinea, found it inhabited by men, who, under no regular government, and destitute of that knowledge the Arabians were favoured with, lived in content and peace. The first author particularly remarks that they never made war, or travelled abroad, but employed themselves in tending their herds, or labouring in the ground. Leo says, (p. 65.) that "they lived in common, having no property in land, no tyrant or superior lord, but supported themselves in an equal state, upon the natural produce of the country, which afforded plenty of roots, game, and honey; that anbition or avarice never drove them into foreign countries, to cheat or subdue their neighbours. Thus they lived without toil or superfuity.

"The ancient inhabitants of Morocco, who wore coats of mail, and swords and spears headed with iron, coming among these naked and harmless people, soon brought them under subjection, and divided that part of Guinea wbich lies on the Senegal and Gambia into fifteen parts; those were the fifteen kingdoms of the negroes, over which the Moors presided, and the conmon people were negroes. These Moors taught the negroes the Mahometan religion, and arts of life, particularly the use of iron, before unknown to them.

"About the fourteenth century, a native negro, called Heli Ischia, expelled the Moorish conquerors; but though the negroes threw of the yolse of a foreign nation, they only changed a Libyan for a negro master. Heli Ischia, himself becoming king, led the negroes on to foreign wars, and established himself in power over a very large extent of country."

Since Leo's time, the Europeans have had very little knowledge of those parts of Africa, nor do they know what became of this great empire. It is probable that it fell in pieces, and that the natives resumed many of their ancient customs; for in the account published by Monre, in his Travels on the Gambia, we find a mixture of the Moorish and Mahometan customs, joined with the original simplicity of the negroes.

It appears by accounts of ancient voyages, collected by Hackluit, Purchas, and others, that it was about fifty years before the discovery of America, that the Portuguese attempted to sail round Cape Bojador, which lies between their country and Guinea: this, after divers repulses, occasioned by the violent currents, they effected; when, landing on the west coasts of Africa, they soon began to make incursions into the country, and to seize and carry off the natives.

As early as 14:34, Alonzo Gonzales, the first who is recorded to have met with the ratives, being on that coast, pursued and attacked a number of them, when some were-wounded, as was also one of the Portuguese; which the author records as the first blood spit by Christians in these parts. Six years after, Gonzales again attacked the natives, and look twelve prisoners, with whom he returned to his 
vessels; he afterwards put a woman on shore, to induce the natives to redieem the prisoners, but the next day one hundred and fifty of the inhabitants appeared on horses and camels, provoking the Portuguese to land; which they not daring to venture, the natives discharged a volley of stones at them, and went off. After this, the Portuguese continued to send vessels on the coast of Africa, particularly we read of their falling on a village, whence the inhabitants fled, and being pussued, twenty-five of them were taken; "he that ran best," says the author, "taking the nost." In their way home they killed some of the natives, and took fifty-five more prisoners. Afterwards Digama landed his crew on the island Arguin, where they took fifty-four Moors, then running along the coast eighty leagues farther, they at several times took fifty slaves; but here seven of the Portuguese were killed. Then being joined by several other vessels, Digama proposed to destroy the island, to revenge the loss of the seven Portuguese; of which the Moors being apprised, fled, so that no more than twelve were found, whereof only four could be taken, the rest being killed, as also one of the Portuguese." Many more captures of this kind on the coast of Barbary and Guinea are reported to have been made in those early times by the Portuguese, who, in 1481, erected their first fort at D'Elmina on that coast, from whence they soon opened a trade for slaves with the inland parts of Guinea.

From the foregoing accounts, it is undoubted that the practice of making slaves of the negroes owes its origin to the early incursions of the Portuguese, solely from an inordinate desire of gain. This is clear from their own historians, particularly from Cada Mosti, about 1455, who writes, "that before the trade was settled for purchasing slaves from the Moors at Arguin, sometimes four and sometimes nore Portuguese vessels were used to come to that gulf, well armed, and, landing by uight, would surprise some fishermen's villages; that they even entered into the country, and carried off Arabs of both sexes, whom they sold in Portugal." And also, that the Portiguese and Spaniards, settled on four of the Canary islands, would go to the other islands, by night, and seize some of the natives of both sexes, whom they sent to be sold in Spain."

After the settlement of America, those devastations, and the capture of the miserable Africans, greatly increased. Anderson, in his History of Trade and Commerce, p. 336, speaking of what passed in 1508, writes, that "the Spaniards had by this time found that the miserable Indian natives, whom they had made to work in their mines and fields, were not so robust, and proper for those purposes, as negroes brought from Africa; wherefore they, about that time, began to import negroes for that end into Hispaniola, from the Portuguese settlements on the Guinea coasts; and also afterwards for their sugar works.

About 1551, towards the end of Edward VI.'s reign, some London merchants sent out the first English ship to the coast of Guinea. This was soon followed by several others; but the English not having then any plantations in the West Indies, and consequently no occasion for negroes, they traded ouly for gold, elephants' teeth, and Guinea pepper: This trude was carried on at the hazard of losing their 
ships and cargoes, if they had fallen into the hands of the Portugnese, who claimed an exclusive right of trade there. In 15.53 captain Thomas Windham traded along the coast with one hundred and forty men in three ships, and sailed as far as Benin to take in a load of pepper. Next year John Locke traded along the coast as far as D'Elmina, when he brought away considerable quantities of gold and ivory. He speaks well of the natives, and says, that- " whoever will deal with them must behave civilly, for they will not traffic if ill-used." In 1555 William Towerson traded in a peaceable manner with the natives, who complained to him of the Portuguese at D'Elmina, saying, "They were bad men, who made them slaves if they could take them, putting irons on their legs."

This bad example of the Portuguese was soon followed by some Englishmen, for captain Towerson says, that " in the course of his voyage he perceived the natives near D'Elmina unwilling to come to him, and that he was at last attacked by them, which he understood was done in revenge for the wrong done them the year before by one captain Ganch, who had taken away the negro captain's son, and three others, with their gold, \&c. This caused them to join the Portuguese, notwithstanding their hatred of then, against the English. Next year captain Towerson brought these men back again; whereupon the negroes shewed him much kindness. Soon after this, another instance occurred, in the case of captain George Fenner, who, being on the coast with thrce vessels, was attacked by the negroes, who wounded several of his people, and violently carried three of his men to their town. The captain sent a messenger, offering any thing that they desired for the ransom of his men : but they refused to deliver them, letting him know, that "three weeks, before, an English ship which came in the roads, had carried off three of their people; and that till they were brought back again, they would not restore his men, even though they should give their three ships to release them." It was probably the bad conduct of these and several other Englishmen, which occasioned what is mentioned in Hill's Naval History, viz. that "when captain Hawkins returned from his first voyage to Africa, queen Elizabeth sent for him, when she expressed her concern lest any of the African negroes should be carried off without their free consent, which she declared would be detestable, and would call down the vengeance of Heaven upon the undertakers." Hawkins made great promises, but did not perform them; for his next voyage to the coast seems principally to procure negro slaves, and sell them to the Spaniards in the West Indies, upon which the same author has these remarkable words: "Here began the horrid work of forcing the Africans into slavery: an injustice and barbarity, which, so sure as there is vengeance in Heaven for the worst of crimes, will some time be the destruction of all who act, or who encourage it."

This captain Hawkins, afterwards sir John Hawkins, seems to have been the firsi Englishman who gave public countenance to this wicked traffic; for Anderson says, that " in 1562, captain Hawkins, assisted by subscriptions of certain gentlemen, now fitted out three ships; and having learnt that negroes were a very good commodity in Hispaniola, he sailed to the coast of Guinea, took in negroes, and sailed with them, for 
Hispaniola, where he sold them and his English commodities, and loaded his three vessels with hides, sugar, ginger; \&c. with which he returned home, in 1562, making a prosperous voyage." As it proved lucrative, the trace was continued both by Hawkius and others, as appears from the Naval Chronicle, p. 55 ; where it is said, that " on the eighteenth of Uctober, 1564, captain John Hawkins, with two ships, of seven hundred, and one hundred and forty tons, sailed for Africa; that on the eighth of December, they anchored south of Cape Verd, while the captain manned the boat, and sent eighty men in armour into the country, to see if they could take some negroes; but the natives flying fron them, they returned to their ships, and proceeded farther down the coast. Here they staid certain days, sending their men on shore, in order," as the author says, "to burn and spoil their towns, and take the inhabitants. The land they observed to be well cultivated, there being plenty of grain and fruit of several sorts, and the towns prettily laid out."

On the twenty-fifth, being informed by the Portuguese of a town of negroes called Bymba, where there was not only a quantity of gold, but one hundred and forty inhabitants, they resolved to attack it, having the Portuguese for their guides; but by mismanagement they took but ten negroes, having seven of their own men killed and twenty= seven wounded. They then went farther down the coast, when having procured a number of negroes, they proceeded to the West Indies, where they sold them to the Spaniards." It is added, that " in 1567, Francis Drake, before performing his voyage round the world, went with sir John Hawkins on his expedition to the coast of Guinea, where, taking in a cargo of slaves, they determined to steer for the Caribbee islands."

How queen Elizabeth suffered so grievous an infringement of the rights of mankind to be perpetrated by her subjects, and how she was persuaded, about the thirtieth year of her reign, to grant patents for carrying on a trade from the north part of the Senegal to one hundred leagues beyond Sierra Leone, is hard to account for, otherwise than that it arose from a misrepresentation made to her of the situation of the negroes, and of the advantages it was pretended they would reap from their being made acquainted with the Christian religion. This was the case of Louis XII. of France; who, Labat, in his Account of the Isles of America, tells us, "was extremely uneasy at a law by which the negroes of his colonies were to be made slaves; but it being strongly urged to him as the readiest means of their conversion to Christianity, he acquiesced therewith." Nevertheless, some of the Christian powers did not so easily ryive way in this matter; for we find, that "cardinal Cilio, one of the pope's principal ministers of state, wrote a letter, on behalf of the college of cardiuals, to the missionaries in Congo, complaining that the pernicious and abominable abuse of selling slaves was yet continued, requiring them to remedy the same, if possible; but this the missionaries saw little hopes of accomplishing, by reason that the trade of the coutry lay wholly in slaves and ivory."

It has been urged, in justification of this trade, that by purchasing the captives taken in battle, they save the lives of so many 
human creatures, who otherwise would be sacrificed to the implacable revenge of the victors. But this pretence has been refuted by an appeal to reason and fact: for if the negroes apprehended they should be cruelly put to death if they were not sent away, why, it is asked, do they manifest such reluctance and dread as they do, at being brought from their native country? Smith, in his account p. 28, says, "The Gambians abhor slavery, and will attempt every thing, though ever so desperate, to avoid it. And Thomas Phillips, in his account of a voyage he performed to the coast of Guinea, writes, "They, the negroes, are so loth to leave their own country, that they have often leaped nut of the canoe, boat, or ship, into the sea, and kept under water till they were drowned, to avoid being taken up." But had the effect even been otherwise, the above plea is urged with an extremely bad grace, when it is notorious that the very wars, said to be productive of such cruelty, were fomented by the infamous art of the Europeans.

\section{True Story of Abelard and Eloisa.}

THE following is extracted from a work recently published in Paris, entitled Melanges d'Histoire ei de Literature.-The first piece in the volume relates to Abelard and Eloisa.

The common story of Abelard being employed as a tutor to Eloisa, and his being punished as soon as her uncle knew of her dishonour, is exceedingly remote from the truth. It is well known that Abelard was a person of the very highest eminence in philosophy and all the literature of his age ; that he became enamoured of Eloisa, and tempted the avarice of the old canon Hubert, with whom she lived, by offering him a large board, on condition of his taking him in to the house; that the canon added to the bargain the further obligation of instructing his niece : and that upon her proving with child, they both made their escape-she lying-in at his sister's; and he soon after returning, apparently without any loss of respect, to prosecute his studies, and continue his school of philosophy.

Our author fixes the date of her delivery in the year 1118, when she was eighteen, and he thirty-eight years old. He soon found means to appease Hubert, by promising marriage; but Eloisa, (as we know from one of those exquisite letters which Pope has initated,) in a fit of romantic attachment, refused to be any thing more or less than his mistress-and would not listen to a project which, according to the custom of the age, would have put an end to the principal occupation of his life. A secret marriage was then agreed upon, to satisfy the uncle, with whom she continued to reside; while the lover pursued his ordinary avocations--seeing her very seldom. At length some worthy nuns began to gossip, and to complain of the reverend canon's complaisance. He assured them of the marriage, which the lovers denied; and this produced a quarrel with Hubert, and a second elopement of his niece. Our author judiciously suggests, that the extreme unwillingness of Abelard to terminate all their difficulties by a public marriage, and his suffering Eloisa to sacrifice herself for his advantage, may.. shew that (as not unfrequently happens in such 
attachments) there was more love on her side than on his. The catastrophe followed, in all probability, soon after the second elopement; and five persons were engaged in it, besides Hubert, and a treacherous servant of Abelards. Of these only one and the servant were taken ; they suffered by the lex talionis, and had their eyes put out besides; and Hubert's goods were contiscated to the church.

Abelard, resolving new to retire from the world, made his unfortunate mistress do the same-though she seems not to have finally made up her mind for two years. She took the veil in 1122, at Argenteuil, after the usual noviciate of a year-and he soon after professed at St. Denis. Being of a turbulent, austere, and even quarrelsome dispesition, he could not remain long in this fraternity, but retired to a wild forest near Nogent-sur-Seine, where he founded the Paraclete, some time between 1128 and 1130 . Although, at first, he had only a loghouse for a chapel, and a few miserable huts for habitations, his great fame attracted scholars, who flocked around him, and led the life of hermits, to receive his instructions. In this situation he was chosen abbot of St. Gildas de Ruyr, whither he immediately repaired. Meantime Eloisa's couvent was dissolved, by the appropriation of its lands to another house, and Abelard invited lier to become abbess of the Paraclete, where she established herself with some other refugees, among whom were two of his nieces. At St. Gildas, to which he returned as soon as he had put Eloisa in possession of the Paraclete, he, as usual, quarrelled with his monks; his misfortunes, indeed, seem to have soured his temper, naturally irritable. Peter of Cluni afforded him a retreat; and he died in that monastery, of a cutaneous disease, in April 1142, at the age of sixty-three. Eloisa survived him twenty years, and died at the same age.' Their only child, who, from his extraordinary beauty, was named Astrolabe, took orders, obtained a canonry through the interest of the good abbot of Cluni, and survived his father, but has left no further traces of himself in history. Some of Eloisa's letters speak of her anxiety for his advancement in the chirch, with her characteristic earnestness and warm th of atfection.

The remains of Abelard were transported to the Paraclete by Eloisa's desire, and she was herself buried in the sane coffin. Their bodies were afterwards separated, but, in the year 1779 , they were again united; and, on opening the coffins, it was then observed that Abelard's bones were reduced to dust; except the scull, which was of an extraordinary thickness; that Eloisa's were much better preserved, and her skull was also peculiarly thick, and the teeth of a beautiful whiteness. These remains were, during the Revolution, carried to Paris, and were, till lately, in the Museum of Ancient Monuments; but the piety of the restored government has consigned them to a consecrated place in the cemetery of Pere La Chaise.

The tradition of the Paraclete is not very favourable to the amenity of Eloisa's temper and inanners in her retreat, however exalted a notion it may give of the charms of her conversation-charms, to which all accounts bear witness; and, indeed, the remains of her correspondence themselves impress us with an extraordinary sense of her merits. "Tlie best judges have given to her style the breference over that of her 
friend and master, for purity and natural grace. Her temper, like his, was in all likelihood affected by their calamities.

History of the Capture of Calcutta in the East Indig.and an Account of the horkid Catastrophe at THe Black Hole Prison.

BEFORE the war of 1755 , Calcutta was commonly garrisoned by three hundred Europeans, who were frequently employed in conveying the company's vessels from Patua, loaded with saltpetre, piece-goods, opium, and raw silk. The trarle of Bengal alone supplied rich cargoes for fifty or sixty ships annually, besides what was carried on in vessels to the adjacent countries. This flomishing state of Calcutta probably was one motive for the nabob Surajah Dowlah to attack it in 1756, when he marched against it with all his forces, amounting to seventy thousand horse and foot, with four hunored elephants, and invested the place on the 15 th of Jume. Previous to any hostilities, lowever, he wrote a letter to Mr. Drake the governor, offering to withlraw his troops, on condition that he would pay him his duty on the trade for fifteen years past, defray the expense of his amy, and deliver up the black merchants who were in the forts. 'This being refused, he attacked one of the redoubts at the entrance of the town; but was repulsed with great slaughter. On the l6th he attacked another advanced post, but was likewise repulsed with great loss. He renewed the attempt, however, on the $18 \mathrm{th}$, when the troops abandoned those posts, and retreated into the fort; on which the nabob's troops entered the town, and plundered it for twenty-four hours. An order was then given for attacking the fort: for which purpose a small breastwork was thrown mp, and two twelve-pounders mounted upon it, without firing oftener than two or three times an hour. The governor, calling a council of war, was informed that there was not ammunition in the fort to serve three days, in consequence of which the principal ladies were sent on board the ships lying before the fort. They were followed by the governor, who declared himself a Quaker, and left the place to be defended by Mr. John Zephaniah Holwell, the second in council. Besides the governor, four of the council, eight gentlemen in the company's service, forty officers, and one hundred soldiers, with fifty-two free merchants, captains of ships, \&c. escaped on board the ships, where were also fifty-nine ladies, with thirtythree children.

The whole number left in the fort amounted to two hundred and fifty effective men, with $\mathrm{Mr}$. Holwell, four captains, five lieutenants, six ensigns, and five sergeants ; also fourtcen sea captains, and twentynine gentlemen of the factory. Mr. Holwell then having held a council of war, divided three chests of treasure among the discontented soldiers; making them large promises also, if they behaved with great courage and fidelity; after which he boldly stood on the defence of the place, notwithstanding the immense force which opposed him. The attack was very vigorous : the enemy having got possession of the houses, galled the English from thence, and drove them from the bastions; but they themselves were several times dislodged by the 
fire from the fort, which made dreadful havock among their troops, while the English lost only five soldiers the first day. The attack, however, was continued till the afternoon of the 20th, when many of the garrison being killed and wounded, and their ammunition alniost exhausted, a Hag of truce was hung out. Mr. Holwell intended to have availed himself of this opportunity to niake his escape on board the ships, but they had fallen several miles down from the fort, without leaving a single boat to facilitate the escape of those who remained. In the mean time, the back gate was betrayed by the Dutch guard, and the enemy, entering the fort, killed all they first met, and took the rest prisoners. The fort was taken before nine in the evening; and, in an hour after, Mr. Holwell had three audiences of the nabob, the last being in the durbar or council. In all of these the governor made the most positive assurauces that no harm should happen to any of their prisoners : but the nabob was surprised and enraged at finding only 50001. in the fort, instead of the immense treasures he expected; and to this, as well as perhaps to the resentment of the jemidaars or officers, of whom many were killed in the siege, we may impute the shocking catastrophe that followed.

As soon as it was dark, the English prisoners, to the number of one hundred and forty-six, were directed, by the jemidaars who guarded them, to collect themselves into one body, and sit down quietly under the arched veranda, or piazza, to the westward of the Black Hole prison. Another guard was placed at the south end of this veranda, to prevent the escape of any of them. About five hundred gunmen with lighted matches were drawn up on the parade and sooil after, the factory was in flames to the right and left of the prisoners, who had various conjectures on this appearance. The fire advanced with rapidity on both sides; and the English began to suspect that they were to be suffocated between the two fires. On this, they soon came to a resolution of rushing upon the guard, seizing their scimitars, and attacking the troops upon the parade, rather than be thus tamely roasted to death; but Mr. Holwell advanced, and found the Moors were only searching for a place to confine them in. At this time Mr. Holwell might have made his escape, by the assistance of Mr. Leech, the company's snith, who had escaped when the Moors entered the fort, and returned as it was dark, to tell Mr. Holwell he had provided a boat, and would insure his escape, if he would follow him through a passage few were acquainted with, and by which he then entered. This might easily have been accomplished, as the guard took little notice of it; but Mr. Holwell told Mr. Leech he was resolved to share the fate of the gentlemen of the garrison; to which Mr. Leech gallantly replied, that "then he was resolved to share Mr. Holwell's fate, and would not leave him." The guard on the parade advauced, and ordered them all to go into the barracks. Then, with their muskets presented, they ordered them to go into the Black Hole prison, while others, with clubs and scimitars, pressed on them so strongly, that they were obliged to give way and enter; the rest following like a torrent.

Few among them, the soldiers excepted, had the least idea of the dimensions of the place, else they would at all events have rushed upon 
the guard had been cut to pieces, as the lesser evil. It was about eight o'clock when these unhappy people, exhausted by continual action and fatigue, were thus crammed together in a close sultry night, into a dungeon about eighteen feet square, shut $u p$ to the east and south, the only quarters where air could reach them, by dead walls, and by a wall and door to the north, open only to the west by two windows strongly barred with iron, from which they could scarce receive any circulation of fresh air.

They had been but a few minutes confined before every one fell into a perspiration so profuse, that no idea can be formed of it. This brought on a raging thirst, which increased as the body was drained of its moisture. Various expedients were thought of, to give more air. Every man was stripped, and every hat put in motion; they several times sat down on their hams, but each time several fell, and were instantly suffocated or trod to death. Before nine their thirst grew intolerable, and respiration difficult. Efforts were again made to force the door ; but still in vain. "Water! water!" became the general cry. Some water was brought; but these supplies, like water sprinkled on fire, only served to raise and feed the flanies. The confusion became general and horrid, from the cries and cravings for water. This scene of misery proved entertaininent to the brutal wretches without, who supplied them with the water, that they might have the satisfaction of seeing them fight for it, as they termed it; and held up lights to the bars, that they might lose no part of the inhuman diversion.

Before eleven o'clock one-third of the whole were dead, Thirst grew intolerable; but Mr. Holwell kept his mouth moist by sucking the perspiration out of his shirt sleeves, and catching the drops as they fell from his head and face. By half an hour after eleven, most of the living were in an outrageous delirium. They found that water heightened their uneasiness: "Air! air!" was the general cry. Every insult that could be devised against the guard, all the opprobrious names that the viceroy and his officers could be loaded with, were repeated, to provoke the guard to fire upon them. Every man had eager hopes of meeting the first shot. Then a general praver was offered to Heaven, to hasten the approach of the flames to the right and left of them, and put a period to their misery. Some expired upon others, while a steam arose from the living as well as the dead, which was very offensive.

About two in the morning they crowded so much to the windows, that many died standing, being so pressed all round, that they could not fall down. When the day broke, the stench arising from the dead bodies was intolerable. At that juncture, the Soubah, who had received an account of the havoc death bad made among them, seit one of his officers to inquire if the chief survived. Mr. Holwell was shewn to him, and a little before six o'clock an order came for their release. - Thus they had remained in this infernal prison from eight at night until six in the morning, when the poor remains of one hundred and forty six souls, (only twenty-three,) came out barely alive, and most of them in a high putrid fever. The dead bodies were dragged out of the hole by the soldiers, and thrown promiscuously 
into the ditch of an unfinished ravelin, which was afterwards filled with earth.

\section{Commonifealth of Babina.}

ThIs was the namie of a society founded in Poland in the reign of Sigismund-Aingustus, in the sixteenth century. It took its rise from a set of gentlemen, iuhabitants of Lublin, who had agreed to meet at Babina merely for the purpose of mirth and jollity. In time their number increased, and they formed themselves into a government, under the presidency of a king, senate, and chief magistrates. The magistrates were elected from something which appeared ridiculous in the character or conduct of any of the members. For instance, if any person was merdling or oflicious, he was immediately created an archbishop; a blundering or disputatious member was promoted to the speaker's chair; a boaster of his own courage was honoured with the commission of generalissimo, which was presented him with great ceremony by the subordinate heroes. Those who declined the office for which they were declared qualified, were persecuted with hissings, and abandoned by the society. Thus every vice and every foible was attacked with ridicule; and Babina became in a short time the terror, the admiration, and the reformer of the Polish nation; genius flourished, wit was cultivated, and the abuses which had crept into government and society were corrected by the judicious application of good-humoured satire. Never did any institution of this nature become so general and so useful; but at length it degenerated into a set of buffoons, and banterers of every thing, sacred or profane. For several years it was patronized by the kings of Poland, and Sigismund himself became a nember; the starosta of Babina telling him jocularly, that his majesty had certain qualities which entitled him to the first dignity of the commonwealth. Not the least remnant of this society now remains, though it was honoured with extraoidinary privileges by kings and emperors.

\section{Numeral Figures.}

THE learned, after many contests, have at length agreed that the numeral figures $1,2,3,4,5,6,7,8,9$, usually called Arabic, are of Indian origin. The Arabians do not pretend to have been the inventors of them, but borrowed them from the Indian nations. The numeral characters of the Bramins, the Persians, and Arabians, and other eastem nations, are similar. They appear afterwards to have been introduced into several European nations, by their respective travellers, who returued from the East. They were admitted into calendars and chronicles but they were not introduced into charters, says $\mathrm{Mr}$. Astle, before the sixteenth century. 'The Spaniards, no doubt, derived their use from the Moors who invaded thent. In 1240, the Alphonsean astronomical tables were made by the order of Alphonsus the Tenth, by a Jew and an Arabian; they used these numerals, from whence the Spaniards contend that they were first introduced by them.

They were not generally used in Germany until the beginning of the fourteenth century; but in general the forms of the ciphers were 
not permanently fixed there till after the year 1531. The Russians were strangers to them before Peter the Great had finistred his travels in the beginning of the last century.

The origin of these useful characters with the Indians and Arabiaus is attributed to their great skill in the arts of astronomy and arithmetic, which required more convenient characters than alphabetic letters, for the expressing of numbers.

Before the introduction into Europe of these Arabic numerals, they used alphabetical characters, or Roman numerals. The learned authors of the Nouveau Traité Diplomatique, the most valuable work on every thing concerning the arts and progress of writing, have given some curious notices on the origin of the Roman numerals. They say, that originally men counted by their fingers: thus, to mark the first four numbers they used a I, which naturally represents them; to make the fifth they chose a $\mathrm{V}$, which is made out by bending inwards the three middle fingers, and stretching out only the thumb and the little finger; and for the tenth they used an X, which is a double V, one placed topsyturvy under the other. From this the progression of these numbers is always from one to five, and from five to ten. The hundred was signified by the capital letter of the word in Latin C-centum. The other letters D for 500, and $M$ for 1000, were afterwards added. They subsequently abbreviated their characters by placing one of these figures before another; and the figure of less value before a higher number, denotes that so much may be deducted from the greater number; for instance IV signifies five less one, that is, four; $\mathbb{1 X}$, ten less one, that is, nine; but these abbreviations are not found amongst the most ancient monuments. These numerical letters are still continned by us, in recording accounts in our exchequer.

The men counted originally by their fingers, is no improbable supposition; it is still naturally practised by the vulgar of the most enlightened nations. In more uncivilized states, small stones have been used, and the etymologists derive the words calculate and calculation from calculus, which is the Latin term for a pebble-stone, and by which they denominate their counters used for arithmetical computations.

Professor Ward, in a learned dissertation on this subject in the Philosophical Transactions, concludes, that it is easier to falsify the Arabic ciphers that the Roman alphabetic numerals: when 1375 is dated in Arabic ciphers, if the 3 is only changed, three centuries are taken away; if the 3 is made into a 9 and take away the 1 , four hundred years are added. Such accidents have assuredly produced much confusion among our ancient manuscripts, and still do in our printed books; which is the reason that Dr. Robinson in his histories, has always preferred writing his dates in words, rather than confide them to the care of a negligent printer. Gibbon observes, that some remarkable mistakes have happened by the word mil, in manuscripts, which is an abbrevation for soldiers, or thousands; and to this blunder he attributes the incredible number of martyrdoms, which cannot otherwise be accounted for by historical records. 


\section{Dreadful Famine in Bengal.}

THE principal grain cultivated in Bengal is rice, which is exported into other countries. By various accidents, however, the crop of rice sometimes fails, and a famine is produced, and of this there have been many instances in Bengal, as well as in other parts of Hindoostan. One of the most deplorable of this kind happened in 1770. The nabob and several great men of the country distributed rice gratis to the poor, until their stocks began to fail, when those donations were of consequence withdrawn. Vast multitudes then came down to Calcutta, the capital English settlement in the province, in hopes of meeting with relief at that place. The granaries of the Company, however, being quite empty, none could be afforded; so that when the famine had prevailed a fortnight, many thousands fell down in the streets and fields; whose bodies, mangled by the dogs and vultures, corrupting in the air, seemed to threaten a plague as the consequence of the famine. An hundred people were daily employed on the Company's account, with doolys, sledges, and bearers, to throw them into the river. At this time the fish could not be eaten, the river being so full of carcases; and many of those who ventured to feed upon them died suddenly. Hogs, ducks, and geese also fed mostly on carnage, so that the only meat that could be procured was mutton; and this, from the dryness of the season, was so small, that a quarter of it would scarcely weigh one pound and half. This dreadful famine was occasioned ly a preternatural drought. In this country they have two harvests, one in April, called the little harvest, which consists of the smaller grain; the second called the grand harvest, is only of rice. But by a drought which happened in 1769 , the great harvest of that year failed, as did also the little one of 1870 , which produced the dreadful conseruences already mentioned.

\section{The Spanish Armada.}

THE armada which attempted to invade England in the reign of queen Elizabeth, is famous in history. This armada, to which the Spaniards, in confidence of success, gave the name of Invincible, consisted of one hundred and fifty ships, most of which were greatly superior in strength and size to any that had been seen before. It had on board near twenty thousand soldiers and eight thousand sailors, besides two thousand rolunteers of the most distinguished families in Spain. It carried two thousand six hundred and fifty great guns, was victualled for half a year, and contained such a quantity of military stores, as only the Spanish monarch, enriched by the treasures of the Indies and America, could supply. The troops on board were to be joined by thirty-four thousand more, which the duke of Parma had assembled in the neighbourhood of Nieuport and Dunkirk.

For transporting these, he had, with incredible labour, provided a great number of flat-buttomed boats, and had brought sailors to navigate them from the towns in the Baltic. Most of these vessels had been built at Antwerp, and as he durst not venture to bring them by sea to Nieuport, lest they should have been intercepted by the Dutch, 
he was obliged to send them along the Scheidt to Ghent, from Ghent to Bruges by the canal which joins these towns, and from Bruges to Nieuport by a new canal which he dug on purpose. This laborious undertaking was already finished, and the duke now waited for the arrival of the Spanish fleet, hoping, that as soon as it should approach, the Dutch and English ships which cruised upon the coast would retire.

When the news reached England, terror and consternation seized the inhabitants. A fleet of uot above thirty ships of war, and those very small in comparison, was all that was to oppose it by sea. All the commercial towns of Eugland, however, were required to furnish ships for reinforcing this small nary. The citizens of London, instead of tifteen vessels, which they were commanded to equip, voluntarily fitted out double the number; and the gentry and nobility equipped forty-three ships at their own charge. Lord Howard of Effingham was admiral; and under him served Drake, Hawkins, and Frobisher, all renowned seamen of courage and capacity. The principal fleet was stationed at Plymouth. A smaller squadron, consisting of forty vessels, English and Flemish, was commanded by Lord Seymour, second son of protector Somerset, and lay off Dunkirk, in order to intercept the duke of Parma.

The land-forces of England were more numerous than those of the enemy, but inferior in discipline and experience. An army of twenty thousand men was disposed in different bodies along the south coast, with orders to retire backwards and waste the country, if they could not prevent the Spaniards from landing; twenty-two thousand foot and one thousand horse, under the command of the earl of Leicester, was stationed at Tilbury, in order to defend the capital; and the principal army, consisting of thirty-four thousand foot and two thousand horse, commanded by lord Hunsdon, was reserved for guarding the Queen's person, and appointed to march whithersoever the enem y should appear. These armies, though all the Spanish forces had been able to land, would possibly have been sufficient to have protected the liberties of their country.

But as the fate of England, in that event, much depended on the issue of a single battle, all men of reflection entertained the most serious apprehensions from the shock of at least fifty thousand veterans, commanded by so consummate a general as the duke of Parma. The queen alone was undaunted. She issued all her orders with tranquillity, aninated her people to a steady resistance, and employed every resource which either her domestic situation or her foreign alliances could afford. She even appeared on horseback in the camp at Tilbury; and riding through the lines, discovered a cheerful and animated countenance, exhorted the soldiers to remember their dity to their country and their religion, and professed her intention, though a woman, to lead them herself into the field against the enemy, and rather perish in battle than survive the ruin and slavery of her people. "I know," said she, intrepidly, "I have but the weak and feeble arm of a woman; but I have the heart of a king, and a king of England too!" The heroic spirit of Elizabeth communicated itself to the army, and every man resolved to die rather than desert his station. 
The Spanish armada was ready in the beginning of May, but its sailing was retarded by the deaths of the admiral and vice-admiral. The command of the expedition was then given to the duke of Medina Sidonia, a man entirely unexperienced in sea affairs. This promotion in some measure served to frustrate the design. which was also rendered less successfol by other accidents. Next day after leaving the port of Lisbon, the armada met with a violent tempest, which sunk some of the smallest of their shipping, and obliged the. fleet to put back into the harbour. After some time spent in refitting, they put again to sea. Being descried by Fleming, a Scotch pirate, he immediately informed the English admiral of their approach. Effingham had just time to get out of port, when he saw the Spanish armada coming full sail towards him, disposed in the form of a crescent, and stretching to the distance of seven miles from the extremity of one division to that of the other.

The English admiral considering that the Spaniards would be much superior to him in close tight; by the size of their ships and the number of their troops, wisely resolved to content himself with harassing them in their voyage, and watching attentively all the advantages which might be derived from storms, cross winds, and such like fortuitous accidents. He soon discerned a favourable opportunity for attacking the vice-admiral Ricaldo. This he did in person, and displayed so much dexterity in working his ship, and in loading and firing his guns, as greatly alarmed the Spaniards for Ricaldo's fate. From that time they kept much closer to one another, notwithstanding which the English on the same day attacked one of their largest galleasses. Other Spanish ships came up to her relief, but in their hurry, one of the principal galleons, which had a great part of their treasure on board, ran foul of another ship, and had one of her masts broken. In consequence of this misfortune she feil behind, and was taken by Sir Francis Drake; who, on the same day, took another capital ship, which had been accidentally set on fire. Several other rencounters happened, in all of which the English proved victorious, through the great advantage which they derived from the lightness of their ships, and the dexterity of their sailors. The Spaniards did not sufficiently understand rautical mechanics, to avail themselves of the unusual magnitude of their ships. The English sailed round them, approached, and retired, with a velocity that amazed them, and did inmense execution with their cannon, for while every shot of theirs proved effectual, their ships suffered very little damage from the enemy, whose guns being planted too high, generally spent their force in the air.

The Spaniards, however, still continued to advance until they came opposite to Calais, where the duke de Medina, having ordered them to cast anchor, sent information to the duke of Parma of his arrival, and entreated him to hasten the embarkation of his forces. Farnese accordingly began to put his troops on board; but at the same time inforned Medina, that the vessels which he had prepared were proper only for transporting the troops, but were utterly unfit for fighting; and for this reason, till the armada was brought still nearer, and the coast cleared of the Dutch ships which had blocked up 
Nieuport and Dunkirk, he could not stir, without exposing his army to certain ruin, the consequence of which would probably be the entire loss of the Netherlands. In compliance with this request the armada was ordered to advance, and it had arrived within sight of Dunkirk, between the English fleet on the one hand, and the Dutch on the other, when a sudden calm put a stop to all its motions. In this becalmed situation, the three fleets remained for one whole day.

About the middle of the night a breeze sprung up, and lord Howard had recourse to an expedient, which had been happily devised on the day before. Having filled eight ships with pitch, sulphur, and other combustible materials, he set them on fire, and sent them before the wind among the different divisions of the Spanish fleet. When the Spaniards beheld these ships in flames approaching towards them, it brought to their remembrance the havock which had been made by the fire-ships employed against the duke of Parma's bridge at the siege of Antwerp. The darkness of the night increased the terror with which their imaginations were overwhelmed, and the panic flew from one end of the fleet to the other. Each crew, anxious only for their own preservation, thought of nothing but how to escape the present danger. Some of them took time to weigh their anchors, but others cut their, cables, and suffered their ships to drive with blind precipitation, without considering whether they did not thereby expose themselves to a greater danger than that which they were so solicitous to avoid. In this confusion the ships ran foul of one another; the shock was dreadful, and several of them received so much damage as to be rendered unfit for future use. When daylight returned, lord Howard had the satisfaction to perceive that his stratagem had fully produced the desired effect. The enemy were still in extreme disorder, and their ships widely separated and dispersed.

His fleet, on the contrary, had lately received a great augmentation in the ships fitted out by the nobility and gentry, and by those under lord Seymour, who had left Justin de Nassau, as alone sufficient to guard the coast of Flanders. Being bravely seconded by sir Francis Drake, and all the other officers, he made haste to improve the advantage which was now presented to him, and attacked the enemy in different quarters at the same time, with the utmost impetuosity and ardour. The engagement began at four in the morning, and lasted till six at night. The Spaniards displayed in every rencounter the most intrepid bravery, but, from the causes already mentioned, they did very little execution against the English; while many of their own ships were greatly damaged, and twelve of the largest were either run aground, sunk, or compelled to surrender.

It was now evident that the purpose of the armada was entirely frustrated. The Spanish admiral, after many unsuccessful rencounters, prepared therefore to make his way home, but as the winds were contrary to his return through the channel, he resolved to take the circuit of the island. The English fleet followed him for some time, and, had not their ammunition fallen short, they had obliged the armada to surrender at discretion. Such a conclusion of that vain-glorious enterprise would have been truly illustrious to the English, but the 
event was scarcely less fatal to the Spaniards. The armada was attacked by a violent storm in passing the Orkneys; and the ships, having already lost their anchurs, were obliged to keep at sea, while the mariners, unaccustomed to hardships, and unable to manage such unwieldy vessels, allowed them to drive on the Western Isles of Scotland, or on the coast of Ireland, where they were miserably wrecked. - Not one balf of the fleet returned to Spain, and a still smaller proportion of the soldiers and seamen. Queen Elizabeth ordered medals to be struck on the occasion with this motto.- "Affavit Deus, et dissipantur."

\section{Dreadful Pestilence, and Fire, of London.}

IN the reign of Charles II, in 1665, London was ravaged by the most violent Plague ever known in Britain. The whole summer had been remarkably still and warm, so that the weather was sometimes suffocating even to persons in perfect health, and by this unusual heat and sultry atmosphere, people were undoubtedly prepared for receiving the infection, which appeared with virulence in July, August, and September. A violent plague had raged in Holland in 1663 ; on which account the importation of merchandise from that country was prohibited by the British legislature in 1664. The infection, however, had actually been imported, for in the close of 1664, two or three persons died suddenly in Westminster, with marks of the plague on their bodies. Some of their neighbours, terrified at the danger, removed into the city, and communicated the infection to so many others, that it became impossible to extinguish it by separating those that were infected from those that were not. It was confined, however, through a hard frosty winter, till February, when it appeared in St. Giles's parish, to which it had been originally brought, and, after another interval, shewed its malignant force afresh in April. At first it took off one here and there, without any certain proof of their having infected each other, and houses were shut up to prevent its spreading. But it was now too late; the infection gained ground every day, and the shutting up of houses only made the disease spread wider. People, afraid of being shut up, concealed their illness, while numbers either escaped from their places of confinement, or expired in the greatest torments, destitute of every assistance; and many died, both of the plague and other diseases, who would in all probability have recovered, had they been allowed their liberty, with proper exercise and air.

A house was shut up on account of a maid servant, who had only spots, and not the gangrenous blotches upon her, so that her distemper was probably a petechial fever. She recovered; but the people of the house obtained no liberty to stir, for forty days. The bad air, fear, anger, and vexation, attending this injurious treatment, cast the mistress of the family into a fever. The visitors, appointed to search the houses, said it was the plague, though the physicians were of a different opinion: the family, however, were obliged to begin their quarantine anew, though it had now almost expired; and this second confinement affected them so much, that most of them fell 
sick of one distemper or another. Every illness that appeared in the family produced a fresh prolongation of their confinement, till at length the plagure was actually brought in by those who came to inquire into the health of the family; and almost every person of the house died. Many examples of a similar kind happened, and this was one of the fatal consequences of shutting up houses. All means of stopping the infection proved ineffectual. Multitudes fled into the country; many merchants, owners of ships, $\&$ c. shut themselves up on board their vessels, being supplied with provisions from Greenwich, Woolwich, and farm-houses on the Kentish side, where they were safe; for the infection never reached below Deptford, though the people went often ashore to buy fresh provisions. As the violence of the plague increased, the ships which had families on board removed farther off; some went quite out to sea, and put in to such harbours as they could get at.

In the mean time the deaths increased rapidly in the city. In the last week of July, the number of burials amounted to 2010 ; in the first week of August it rose to 3817 ; then to 3880 ; then to 4237 ; the next week to 6102 ; and at last to 7000 and 8000 weekly. In the last week of September, however, the fury of the disease began to abate: though vast numbers were sick, yet the number of burials decreased from 7155 to 5538 ; next week to 4929 ; then to 4327 ; next to 2665 ; then to 1421 ; and the next week to 1031 .

All this while the poor people had been reduced to the greatest distresses by the stagnation of trade, and the sicknesses occasioned by their manner of living. The rich, however, contributed to their subsistence in the most liberal manner. The sums collected, on this occasion, are indeed almost incredible; being said to have amounted to 100,0001 . per week. The king contributed 10001 . weekly; and in the parish of Cripplegate alone, 17,0001 . was distributed weekly among the poor inhabitants. By the vigilance also of the magistrates, provisions continued remarkably cheap throughout the whole time of this dreadful calamity, so that all riots on that account were prevented; and at last, on the cessation of the disease, in winter 1665 , the inhabitants who had fled returned, and London, to all appearance, became as populous as ever, though it was conputed that 100,000 persons lad been carried off by the plague.

The city was scarcely recovered from this desolation, when it was almost totally laid in ashes by a most dreadful Fire, which broke out in a baker's shop in Pudding-lane, on Saturday night, September 2, 1666. In a few hours Billingsgate was entirely burnt down; and before morning the fire had crossed Thames-street, and destroyed the church of St. Magnus. Thence it proceeded to the bridge, and consumed a great pile of buildings there; but was stopped by the want of any thing more to destroy. The flames, however, being driven by a strong east wind, continued their devastations in other quarters. All efforts to stop their progress proved unsuccessful throughout Sunday, when it proceeded up as far as Garlic-hithe, and destroying Canon-street, invaded Cornhill and the Exchange. On Monday, the flames having proceeded eastward against the wind through Thames-street, invaded 'lower-street, Gracechurch-street, Fenchurch-street, Dowgate, Old 
Fish-street, Watling-street, Threadneedle-street, and several others, from all which it broke at once into Cheapside, which in a few hours was all in flames, the fire having reached it from so many places at once.

The fire then continuing its course from the river on ore side, and from Cheapside on the other, surrounded the cathedral of St:Paul's. This building stood by itself, far from any houses, yet, such was the violence of the flames, and the heat of the atmosphere, that the cathedral took fire at top. The great beams and massy stones broke through in to Faitl-church underneath, which was quickly burnt, after which the flames invaded Paternoster-row, Newgate-street, the Old Bailey, Ludgate-hill, Fleet-street, Ironmonger-lane, Old Jewry, Lawrencelane, Milk-street, Wood-street, Gutter-lane, Foster-lane, Lothbury, Cateaton street ; and having destroyed Christ's church, burnt furiously through St. Martin's-le-grand toward Aldersgate. The fire had now attained its greatest extent, and was several miles in compass. The vast clouds of smoke obscured the sun, so that he either could not be seen, or appeared as red as blood. : The flames ascended an inconceivable height in the air, and their reflection from the smoke, which seemed also like flame, made the appearance still more terrible. The atmosphere was illuminated to a great extent; and this illumination is said to have been visible as far as Jedburgh in Scotland. Sume of the light ashes are also said to have been carried to the distance of sixteen miles.

Guildhall exhibited a singular appearance. 'The oak with which it was built was so solid that it wonld not flame, but burnt like charcoal, so that the building appeared for several hours like an enchanted palace of gold. At last, on Wednesday morning, when every one expected the suburbs were to have been burnt, the fire began to abate, the wind having ceased. It was checked by the great building in Leadenhall-street, and in other streets by blowing up several houses with gunpowder; and on 'Thursday the flames were quite extinguished.

By this extraordinary conflagration, there were destroyed, 13,200 houses, 87 churches, 6 chapels, 52 public halls, the royal exchange, the custom house, 3 city gates, the jail of Newgate, 14 stone bridges, the sessions house Guildhall, with its courts and offices, Blackwellhall, Bridewell, Poultry compter, and St. Paul's church ; which with wares, household furniture, money, goods, books, wine, sugar, tobacco, \&c. have been estiniated to ainount to no less than $£ 10,689,000$ sterling.

It was never certainly known whether this fire was accidental or designed. A suspicion fell upon the Papists; and this gained such credit, that it is asserted for a truth on the Monument erected to commemorate the conflagration. Though there was no sufficient proof of this, it had the effect of making the Papists more violently suspected and abhorred by the Protestants.

\section{Parisian or St Bartpolomew Massacre.}

THE most atrocious instance of inhuman massacre upon record, is that called the Parisian massacre, or massacre of St. Bartholoniew's 
day, which was carried on with such detestable perfidy and bloody cruelty, as would surpass all belief, were it not attested by the most undeniable evidence.

Bloody as the French revolution has been in some periods of it, and ferocious as the Maratists and Septembrisers were, it affords no instance, in its whole course, of such accumulated treachery, cruelty, barbarity, and perfidy, as this, which was planned, carried on, and executed from a spirit of religious fanaticism, under the royal authority of the king of France.

In 1572, in the reign of Charles IX. many of the principal Protestants were invited to Paris, with a solemn oath of safety, upon occasion of the marriage of the king of Navarre with the French king's sister. The queen dowager of Navarre, a zealous Protestant, was poisoned by a pair of gloves before the marriage was solemnized; and on the 24th of August, being Bartholomew's day, about daybreak, upon the toll of the bell of the church of St. Germain, the butchery began. The admiral of France was basely murdered in his own house. After this, the murderers ravaged the whole city of Paris, and butchered in three days ten thousand lords, gentlemen, presidents, and people of all ranks. "A horrible scene of things," says Thuanus, "followed. The very streets and passages resounded with the noise of those that met together for murder and plunder; the groans of those who were dying, and the shrieks of such as were going to be butchered, were every where heard; the bodies of the slain were thrown out of the windows; the courts and chambers of the houses were filled with them; the dead bodies of others dragged through the streets their blood running down the channels in torrents into the river; and in a word, an innumerable multitude of men, women, maidens, children, and women with child, were all involved in one common destruction; and the gates and entrances of the ling's palaces were all besmeared with their blood."

From Paris the massacre spread almost throughout the whole kingdom. In the city of Meaux they threw above two hundred into jail; and after they had ravished and killed a great number of women, and plundered the houses of the Protestants at large, they executed their fury on those they had imprisoned. In Orleans they murdered above five hundred men, women, and children, and enriched themselves with their spoils. The same cruelties were practised at Angers, Troyes, Bourges, Charente, and especially at Lyons, where they destroyed above eight hundred Protestants, (among whom were children hanging on their parents' necks, and parents embracing their chil. dren) putting ropes about their necks, dragging them through the streets, and throwing them, mangled, torn, and half dead, into the river. It would be endless to mention the butcheries committed at Valence, Roniaine, Rouell, \&c. According to Thuanus, above thirty-thousand Protestants were destroyed in this massacre, or, as others with greater probability affirm, above oue hundred thousand ! And yet, as if it had been a most heroic transaction, and could have procured immortal glory to the authors of it, medals were struck at Paris in honour of it. Thuanus adds, "And when the news came to Rome, it was wonderful to see how they exulted for joy." 
On the sixth of September, when the letters of the pope's legate were read in the assembly of the cardinals, by which he assured the pope that all was transacted by the express will and command of the king, it was immediately decreed that the cardinals should march to the church of St. Mark, and give thanks to God for so great a blessing conferred on the see of Rome; that on the Monday after, solemn mass should be celebrated in the church of Minerva, (at which the pope, Gregory XIII. and cardinals were present; and that a jubilee should be published, to return thanks to God for the extirpation of the enemies of the truth and church, in France. In the evening, the can. non of St. Angelo were fired; the whole city was illuminated; and no sign of rejoicing omitted, that was usually made for the greatest victories obtained in favour of the Roman church.

\section{Battle of The Granicus.}

Granicus is a small river near the Hellespont, in Lesser Asia, remarkable for the first victory gained by Alexander the great over the armies of Darius.-Authors disagree about the number of the Persians, though all admit that they were vastly more numerous than the Greeks. Justin and Orosius tell us, that the Persian army consisted of 600,000 foot and 20,000 horse; Arrian makes the foot amount to $200 ; 000$; but Diodorus tells us that they were only 100,000 foot and 10,000 horse. The Macedonian army did not exceed 30,000 foot and 5000 horse. The Persian cavalry ined the banks of the Granicus, in order to oppose Alexander wherever he should attempt a passage; and the foot were posted behind the cavalry on an easy ascent, Parmenio would have had Alexander to allow his troops some time to refresh themselves; but he replied, that, after crossing the Hellespont, it would be a disgrace to him and his troops to be stopped by a rivulet.

Accordingly a proper place for crossing the river was no sooner found, than he commanded a strong detachment of horse to enter; he himself followed with the right wing, which he commanded in person, the trumpets in the mean time sounding, and loud shouts of joy being heard through the whole army. The Persians, on their approach, let fly such showers of arrows against this detachment of Macedonian horse, as caused some confusion, several of their horses being killed or wounded. As they drew near the bank, a most bloody engagement ensued; the Macedonians attempting to land, and the Persians pushing them back into the river. Alexander, who observed the confusion they were in, took the command of them himself, and, landing in spite of all opposition, obliged the Persian cavalry, after an obstinate resistance, to give ground.

However, Spithrobates, governor of Ionia; and son-in-law to Darius, still maintained his ground, and did all that lay in his power to bring them back to the charge. Alexander advanced against him full gallop, and both were slightly wounded at the first encounter. Spithrobates having thrown his javelin without effect, advanced sword in hand to meet his antagonist, who ran him through with his pike as he raised his arm to discharge a blow with his scimitar. But Rosaces, 
brother to Spithrobates, at the same time gave Alexander such a furious blow on the head with his battle-axe, that he beat off his plume, and slightly wounded him through the helmet. As he was ready to repeat the blow, Clitus, with one stroke of his scimitar, cut off Rosaces' head, and thus, in all probability, saved the life of his sovereign. The Macedonians then, animated liy the example of their king, attacked the Persians with new vigour, who sonn after betook themselves to flight: Alexander immediately charged the enemy's foot with all his forces, who had now passed the river. The Persians, dishcartened at the defeat of their cavalry, made no great resistance. The Greek mercenaries retired in good order to a neighbouring hill, whence they seni deputies to Alexander, desiring leave to march off unmolested. But he, instead of coming to a parley with them, rushed furiously into the middle of this small body; where his horse was killed under him, and he was in great danger of being cut to pieces. The Greeks, defended themselves with incredible valour for a long time, but were at last almost entirely cut off. In this battle the Persians are said to have lost 20,000 foot and 25,100 horse, and the Macedonians only 55 foot and 60 horse.

\section{BatTLE OF BLENHEIM.}

BLENHEIM is a village of Germany, and is memorable for the famons battle fought there in 1704, in which the French and Bavarians were defeated by the English and their allies under prince Eugene and the duke of Marlborough. The French army amounted to 60,000 veterans, who had shared in the conquests of their grand monarque, and were now conmanded by two generals, the most distinguished at that time in France, - marshal Tallard and the duke of Bavaria. The former had established his reputation by many victories. He was active and penetrating, but his ardour of ten rose to impetuosity; alid he was so short-sighted as to be incapable of seeing objects at a very small distance. The duke of Bavaria was equally experienced in the field, and had stronger motives for activity. His country was ravaged before his eyes, and nothing remained of his possessions but the army which he commanded. The allied army, commanded by Eugene and Marlborough, amounted to above 52,000 troops, that had long been familiar with victory, and had seen the French, the Turks, and the Russians fly before them.

Both armies, after many marches and counter-marches, approached each other. The French were posted on a hill near Hochstet; their right covered by the Danube and Blenheim, their left by the village of Lutzengen, and their front by a rivulet, the banks of which were sleep and the bottom marsly. The right wing of the French was commanded by marshal Tallard, their left by the duke of Bavaria, and under him general Marsin, an experienced Frenchman. Their position being advantageous, they were willing to await the enemy rather than offer battle. On the other hand, Marlborough and Eugene were stimulated to engage them at all events, in consequence of an intercepted letter from Villeroy, intimating that he was preparing to cut off all communication between the Rhine and the allied army. The 
dispositions therefore being made for the atlack, and the orders communicated to the general officers, the allied forces advanced into the plain, and were ranged in order of battle.

The cannonading began about nine in the morning, and continued till about half after twelve. The troops then advanced to the attack; the right under the direction of prince Eugene, the left headed by Marlborough, and opposed to marshal Tallard. Marlborough, at the head of the English troops, having passed the rivulet, attacked the cavalry of Tallard with great bravery. This general being then reviewing the disposition of his troops to the left, his cavalry fought for some time without their commander. Prince Eugene had not yet attacked the forces of the elector, and it was near an hour before he could bring up his troops to the engagement. Tallard was no sooner informed that his right was attacked by the duke, than he flew to its head, where he found a furious encounter already begun, his cavalry being thrice driven back, and rallying as often. He had posted a large body of forces in Blenheim, and he made an attempt to bring them to the charge. They were attacked by a detachment of Marlborough's troops so vigorously, that instead of assisting the main body, they could hardly maintain their ground. All the French cavalry being thus attacked in flank, was totally defeated. The English army now penetrated between the two bodies of the French commanded by the marshal and elector, while the forces in Blenheim were separated by another detachment. In this distressed situation Tallard flew to rally some squadrons; but from his short-sightedness, mistaking a detachment of the enemy for his own, he was taken prisoner by the Hessian troops who were in the allied army. Meanwhile prince Eugene, after having been thrice repulsed, at last put the enemy into confusion. The rout then became geveral, and the flight precipitate. The consternation of the French soldiers was such, that they threw themselves into the Danube, without knowing whither they fled.

The allies being now masters of the field of battle, surrounded the village of Blenheim, where a body of 13,000 nien had been posted in the beginning of the action, and still maintained their ground. These troops, seeing themselves cut off from all communication with the rest of the army, and despairing of forcing their way though the allies, threw down their arms, and surrendered prisoners of war. Thus ended the battle of Blenheim, one of the most complete victories that ever was obtained, 12,000 French and Bavarians being slain in the fiell or drowned in the Danube, and 13,000 niade prisoners of war ; besides 100 pieces of cannon, 22 mortars, upwards of 100 pairs of colours, 200 standards, 17 pairs of kettledrums, upwards of 3000 tents, 34 coaches, 300 loaded mules, 2 bridges of boats, and all the French baggage taken, with their military chest. Next day, when the duke of Marlborough visited his prisoner the marshal, the latter assured him that he had overcome the best troops in the world. "I hope, sir," replied the duke, you will except the troops by whom they were conquered." The allies, in consequence of this victory, becane masters of a country 100 leagues in extent. 


\section{Battle of Austerlitz.?}

ThIs ever-memorable battle was fought on December 2 , $180 \%$, the anniversary of Bonaparte's coronation, between the French under him, and the united forces of Austria and Russia, headed by their respective emperors. The armies were nearly equal, about 70,000 men each. Bonaparte, by feigning a retreat, had drawn the allies to a spot which he had selected as most advantageous for giving battle. He bivouacked on the field, after having spent most of the night in giving orders and visiting his posts. The battle began with the dawn. The allied right and centre, after a cannonade of several hours, was routed; and their left, which had been more successful in the outset, was compelled to give way in the general confusion. The defeat was signal; but the approach of night prevented any vigorous pursuit. The state of the roads compelled the allies to abandon most of theirartillery; forty standards, all their baggage and ammunition, and one hundred and twenty pieces of cannon, remained in the hands of the French. The loss in men was never fully acknowledged by either side; but the carnage was by both admitted to have been most dreadful. Reports have stated that of the French at 13,000, in killed and wounded; that of the Austro-Russians at three times the number. It is certain that so many wounded were left on the field by the allies, that they could not all be dressed until two days after the battle.

An armistice was immediately proposed by the emperor of Austria, and an interview tonk place between him and Bonaparte, in a mill by the road side, near the village of Nasedlowitz.

The preliminaries of an humiliating peace were here agreed to. The emperor Alexander refused to become a party to its conditions, and succeeded, though under very distressing circumstances, to effect his retreat from the Austrian states.

\section{Instances of Gratitude.}

Francis Frescobatd, a Florentine mérchant, had gained a plentiful fortune, of which he was liberal to all in necessity. One day a young stranger applied to him for charity. Frescobald asked him "what he was, and of what country?" " $\mathbb{I}$ am," answered he, "a native of England; my name is Thomas Cromwell, and my father-inlaw is a poor shearman. I left my country to seek my fortune; came with the French arny that was routed at Gatylion, where I was a page to a fuotman, and carried his pike and bayonet." Frescobald commiserating his necessities, clothed him genteelly, took him into his house till he had recovered strength by better diet, and at his taking leave, mounted him upon a good horse, with sixteen ducats of gold in his pocket. Cromwell returned to England, where he got into the service of Cardinal Wolsey, and, after his death, he worked himself so effectually into the favour of Henry VII. that he made him a baron, viscount earl of Essex, and at last lord high chancellor.

Meantime Frescobald by repíeated losses was reduced to poverty; and some English merchants being indebted to him in the sum of 
15,000 ducats, he came to London to procure payment. In pursuit of this affair, he fortunately met with the lord chancellor as he was riding to court, who immediately alighted, embraced him, and asked him if it was not signior Francis Frescobald? "Yes, sir," said he, "and your most humble servant." "My servant!" said the chancellor; "no, you are my special friend, that relieved me in my wants, laid the foundation of my greatness, - and as such I receive you; and since the affairs of my sovereign will not now permit a longer conference, I beg you will oblige me this day with your company at my house to dinner with me." Frescobald was astonished who this great man could be who acknowledged such obligations, but recollecting his voice, his mien, and lis carriage, he concluded it to be Cromwell, and therefore went to his house.

His lordship came soon after, and, taking his friend by the hand, turned to the lord high admiral and other noblemen, saying, "This is the gentleman who first contributed to my advancement." He thei told them the whole story; led him into the dining-room, and placed him next to himself at table. The company being gone, the chancellor asked what affair had brought him to England? Frescobald gave him the true state of his circumstances; to which Cromwell replied, "I am sorry for your misfortunes, and $\mathbb{I}$ will make them as easy to you as I can; but as men ought to be just before they are kind, it is fit I should repay the debt $\mathbb{I}$ owe you." "Then leading him into his closet, he first took out sixteen ducats, and, delivering them to Frescobald, said, "My friend, here is the money you lent me at Fiorence, with ten pieces you laid out in my apparel, and ten more for my horse; but as you made advantage of this money in trade, take these four bags, in each of which is four hundred ducats." He next caused him to give him the name of his debtors, and the sums they owed; which he transmitted to one of his servants, with a charge to find out the men, and oblige them to pay him in fifteen days, under the penalty of his displeasure, - and thus in a short tine the entire sum was paid. All this time signior Frescobald was entertained in the chancellor's house, who proposed to him to continue in England, and offered him the loan of sixty thousand ducats for four years, if he would lrade here; but he desired to return to Florence, which he did, with extraordinary favours from lord Cromwell.

\section{AsPHYXiA, or SUSPENDED ANIMATION.}

THE following most extraordinary case of Asphyxia, is related by Dr. Cheyne, in his English Malady, p. $30 \%$.

"Case of the Honourable Colonel Townshend.Colonel Townshend, a gentleman of excellent natural parts, and of great honour and integrity, had for many years been afficted with a nephritic complaint, attended with constant vomitings, which had made his life painful and miserable. During the whole time of his illness he had observed the strictest regimen, living on the softest vegetables and lightest animal foods, drinking ass's milk daily even in the camp, and for conmon drink Bristol water, which the summer before his death he had drank on the spot; but his illness increasing, and his streigth 
decaying, he came from Bristol to Bath in a litter, in autumn, and lay at the Bell inn.

"Dr. Baynard, who is since dead, and I, were called to him, and attended him twice a day for about the space of a week, but his vomitings continuing still incessant, and obstinate against all remedies, we despaired of his recovery. While lie was in this condition, he sent for us early one morning : we waited on him, with Mr. Skrine his apothecary, since dead also; we found his senses clear and his mind calm; his nurse and several servants being abcut him. He had made his will, and settled his affairs. He told us he had sent for us to give him some account of an odd sensation he had for some time observed and felt within himself; which'was, that, composing himself, he could die or expire when he pleased, and yet, by an effort, or some how, he could come to life again; which it seems he had sometimes tried before he had sent for us.

"We heard this with surprise, but as it was not to be accounted for from common principles, we could hardly believe the fact as he related it, much less give any account of it, unless he should please to make the experiment before us, which we were unwilling he should do, lest in his weal condition he might carry it too far.

"He continued to talk very distinctly and sensibly above a quarter of an hour about this surprising sensation, and insisted so much on our seeing the trial made, that we were at last forced to comply. We all three felt his pulse first; it was distinct, though small and thready, and his heart had its usual beating. He composed himself on his back, and lay in a still position; while I held his right hand, Di. Baynard laid his hand on his heart, and Dr. Skrine held a clear looking-glass to-his mouth. I found his pulse sink gradually, till I could not feel any by the most exact and nice touch. Dr. Baynard could not observe the least motion in his heart, nor $\mathrm{Mr}$. Skrine the least soil of breath on the bright mirror he held to his mouth; then each of us by turns examined his arm, heart, and breast, but could not by the nicest scrutiny discover the least symptom of life in him. "We reasoned a long time about this odd appearance, as well as we could; and all of us judging it inexplicable and unaccountable, and finding he still continued in that condition, we began to conclude that he had indeed carried the experiment too far, and at last were satisfied he was actually dead, and were just ready to leave him. This continued about half an hour, at nine o'clock in the morning, in autumn. As we were going away, we observed some motion about the body, and, upon examination, found his pulse and the motion of his heart gradually returning; he began to breathe gently, and speak softly; we were all astonished to the last degree at this unexpected change, and after some further conversation with him, and among ourselves, went away fully satisfied as to all the particulars of this fact, but confounded and puzzled, and not able to form any rational scheme that inight account for it. He afterwards called for his attorney, added a codicil to his will, settled legacies on his servants, jeceived the sacrament, and calmly and composedly expired about six o'clock that evening.

"Next day he was opened, but his body was the soundest and best 
made I häd ever seen; his lungs were fair, large, and sound, his heart big and strong, and his intestines sweet and clean; his stomach was of a due proportion, the coats sound and thick, and the villous membrane quite entire; but when we came to examine the kidneys, though the left was perfectly sound and of a just size, the right was about four times as big, distended like a blown bladder, and yielding, as if full of pap; he having often passed $a$ : wheyish liquor, after his wine, during his illness. Upon opening this kidney, we found it quite full of a white chalky matter, like plaster of Paris, and all the fleshy substance dissolved and worn away, by what I called nephritic cancer. This had been the source of all his miseries; and the symptomatic vomitings from the irritation of the consentient nerves, had quite starved and worn him down. I have narrated the facts as I saw and observed them, deliberately and distinctly, and shall leave the philosophical reader to make what inferences he thinks fit. 'The truth of the material circumstances I will warrant."-It is to be regretted that Dr. Cheyne did not inquire, or neglected to record, the patient's own sensations, if he had any, during this singular state of suspended animation.

\section{Periodical Dumbiess.}

IN the Ephemerides of the Curions, we have an account of a periodical dumbness, which had continued formore than tifteen years, and had not gone off at the time the account was written. The person was son to an inn-keeper at Jessing, in the duchy of Wirtemberg. He was one night taken so ill after supper, that he covld neither stand nor sit, and continued for about an hour oppressed with sickness to such a degree as to be in danger of suffocation. At the expiration of this time be grew better, but during three months he was much dejected, melaucholy, and at times fearful. He was then suddenly struck dumb, and became unable to pronounce the least word, or form the least sound, though he could speak very articulately before. The loss of speech was at first instantaneous, and continued only a few minutes; but the duration of it began to lengthen every day, so that it soon amounted to half an hour, two hours, three hours, yet without any order. At last the return of speech kept so constant and regular an order, that for fourteen years together he could not speak except from noon, during the space of one entire hour, to the precise moment of one o'clock. Every time he lost his speech, he felt something rise from his stomach to his throat. Excepting this loss of speech, he was afflicted with no other disorder of any animal function. Both his internal and external senses continued sound; he heard always perfectly well, and answered the questions proposed to him by gestures or writing. All suspicion of deceit was removed by his keeping exactly the same hour, though he had no access to any instruments by which time can be measured.

\section{Sirigular Cases of DEAFNesS.}

In the Philosophical Transactions, No. 312, we have an account by M. Waller, F. R. S. of a man and his sister, each about fifty years old, 
born in the same town with Mr. Waller, who had neither of them the least sense of hearing; yet both of them knew, by the motion of the lins only, whatever was said to them, and would answer pertinently to the questions proposed. It seems they could both hear and speak when children, but lost this sense afterwards, although they retained their speech, which, though uncouth, was yet intelligible.

Such another instance is that of Mr. Goddy's daughter, minister of St. Gavar's in Geneva, related by Bishop Burnet. "At two years old they perceived she bad lost her hearing; and ever since, though she heard great noises, yet she hears nothing of what is said to her ; but by observing the motions of the mouth and lips of others, she has acquired so many words, that out of these she has formed a sort of jargon, in which she can hold conversation whole days with those that can speak her language. She knows nothing that is said to her, unless she sees the motion of their mouths that speak to her. One thing will appear the strangest part of the whole narration: she has a sister, with whom she has practised her language more than with any body else; and in the night, by laying her head on her sister's mouth, she can understand what she says, and so can discourse with her in the dark."

Is is obscrvable that deaf persons, and several other persons dull of hearing, hear better and more easily if a loud noise be raised at the time when one speaks to them; which is owing, no doubt, to the greater tension of the ear-drum on that occasion. Dr. Wallis mentions a deaf woman, who, if a drum were beat in the room, could hear any thing very clearly: so that her husband hired a drummer for a servant, that by this means le might hold conversation with his wife. The same author mentions another, who, living near a steeple, could always hear very well if there was a ringing of three or four bells, but never otherwise.

\section{Extraordinary Case of a Blind Lady.}

THIs lady had been afflicted with the confluent small-pox. "In the course of this disease," says the narrator, "during which she had been attended by the late Sir Hans Sloane, several threatening symptoms appeared, which, however, wore off at length; and the patient being thought out of danger, took several doses of such purgative medicines as are usually administered in the decline of the disease, without any bad consequence. But in the evening of the day in which she had taken the last dose that was intended to be given her, she was suddenly seized with pains and convulsions in the bowels; the pains and other symptoms became gradually less violent as the force of the medicine abated; and by such remedies as were thought best adapted to the case, they seemed at length to be entirely subdued. They were, however, subdued only in appearance; for at eleven o'clock A. M. the next day, they returned with great violence, and continued some hours; when they went off, they left the muscles of the lower jaw so much relaxed, that it fell down, and the chin was supported on her breast. The strength of the patient was so much exhausted during this paroxysm, that she lay nearly two hours with no other signs of life than a very feeble respiration, which was often so diff- 
cult to be discerned, that those about her concluded she was dead. From this time the fits returned periodically every day, at about the same hour.

"At first they seemed to affect her nearly in the same degree, but. at length all the symptoms were aggravated, the convulsions became more general, and her arms were sometimes convulsed alternately; it also frequently happened that the arm which was last convulsed remained extended and inflexible some hours after the struggoles were over. Her neck was often twisted with such violence, that the face looked directly backward, and the back part of the head was over the breast; the muscles of the countenance were also so contracted and writhed by the spasms, that the features were totally changed, and it was impossible to find any resemblance of her natural aspect by which she could be known. Her feet were not less distorted than her head ; for they were twisted almost to dislocation at the instep, so that she could not walk but upon her aukles.

"To remove or mitigate those deplorable symptoms, many remedies were tried, and, among the rest, the cold bath; but either by the natural effect of the bath, or by some mismanagement in the bathing, the unhappy patient first became blind, and soon afterwards boith deaf and dumb.

"It is not easy to conceive what could increase the misery of deafness, dumbness, blindiness, and frequent paroxysms of excruciating pain; yet a very considerable aggravation was added, for the loss of her sight, her hearing, and her speech, was followed by such a stricture of the muscles of her throat, that she could swallow no kind of aliment, either solid or liquid. It might reasonably be supposed that this circumstance, though it added to the degree of her misery, would have shortened its duration, yet in this condition she continued near three-quarters of a year; and during that time was supported by chewing her food, which having been turned often, and kept long in her mouth, she was obliged at last to spit ont. Liquors were likewise gargled about in her mouth for some time, and then returned in the same inanner; no part of them having passed the throat by an act of deglutition, so that whatever was conveyed into the stomach, either of the juices of the solid food, or the liquids, was either gradually imbibed by the sponginess of the parts which they moistened, or trickled down in a very small quantity along the sides of the vessels. But there were other peculiarivies in the case of this lady, yet more extraordinary.

"During the privation of her sight and hearing, her touch and her smell became so exquisite, that we could distinguish the different colours of silk and flowers, and was sensible when any stranger: was in the room with her. After she became blind, and deaf and dumb, it was not easy to contrive any method by which a question could be asked her, and an answer received. This, however, was at lasteffected by talking with the fingers, at which slie was uncommonly ready. But those who conversed with her in this manner were obliged to express themselves by touching her hands and fingers instead of their own. A lady who was nearly related to her, having: an apron on, that was embroidered with silk of different colours, 
asked her, in the manner which has been described, if she could tell what colour it was? and after applying her fingers attentively to the figures of the embroidery, she replied, that it was red, and blue, and green; which was true. The same lady having a pink-colsured ribbon on her head, and being willing still further to satisfy her curiosity and her doubts, asked her what colour that was? Her cousin, after feeling some time, answered that it was pink colour; this answer was yet more astonishing, because it shewed not only a power of distinguishing different colours, but different kinds of the same colour; the ribbon was not only discovered to be red, but the red was discovered to be of the pale kind called a pink. This unhappy lady, conscious of her own uncommon infirmities, was extremely unwiling to be seen by strangers, and generally retired to her chamber, where none but those of the family were likely to come.

"The same relation, who had by the experiment of the apron and ribbon discovered the exquisite sensibility of her touch, was soon after convinced by an accident, that her power of smelling was acute and refined in the same highly astonishing degree. Being one day visiting the family, she went up to her cousin's chamber, and after making herself known, she entreated her to go down, and sit with her among the rest of the family, assuring her that there was no other person present; to this she at length consented, and went down to the parlour door, but the moment the door was opened, she turned back, and retired to her own chamber much displeased; alleging, that there were strangers in the room, and that an attempt had been made to deceive her. It happened indeed that there were strangers in the room, but they had come in while the lady was above stairs, so that she did not know they were there. When she had convinced her cousin of this particular, she was satisfied; and being afterwards asked how she knew there were strangers in the room, she answered, By the smell. But though she could by this sense distinguish in general between persons with whom she was well acquainted from strangers, yet she could not so easily distinguish one of her acquaintances from another without other assistance. She generally distinguished her friends by feeling their hands; and when they came in, they used to present their hanrs to her, as a means of making them known: the make and warmth of the hand produced in general the differences that she distinguished; but sometimes she used to span the wrist and measure the fingers. A lady, with whom she was very well acquainted, coming in one very hot day, after having walked a mile, presented her hand as usual; she felt it longer than ordinary, and seemed to doubt whose it was; but after spanning the wrist, and measuring the fingers, she said, "It is Mrs. M. but she is warmer to-day than ever I felt her before."

"To amuse herself in the mournful and perpetual solitude and darkness to which her disorder had reduced her, she used to work much at her needle; and it is remarkable, that her needle-work was uncommonly neat and exact: among many other species of her work that are preserved in the family, is a pincushion, which can scarcely be equalled. She also used sometimes to write, and her writing was yet more extraordinary than her needle-work; it was executed with the 
same regularity and exactness, the characters were very pretty, the lines were all even, and the letter's placed at equal distauces from cach other; but the most astonishing particular of all, with respect to ler writing, is, that she could by some means discover when a letter had by mistake been omitted, and would place it over that word where it should have been inserted, with a caret under it. She used to sit up in bed at any hour in the night, either to write or to work, when her pain or any other cause kept her awake. These circumstances were so extraordinary, that it was long doubted whether she had not some faint remains both of hearing and sight, and many experiments were made to ascertain the fact; some of these experiments she accidentally discovered, and the discovery always threw lier into violent convulsions. The thought of being suspected of insincerity, or supposed capable of acting so wicked a part as to feign infirmities that were not inflicted, was an addition to her miseries which she could not bear, and which never failed to produce an agony of mind not less visible than those of her body.

"A clergyman who found her one evening at work at a table with a candle upon it, put his hat between her eyes and the candle, in such a manner that it was impossible she could receive any benefit from the light of it, if she had had her sight. She continued still at her work with great tranquillity, till, putting up her hand suddenly, to rub her forehead, she struck it against the hat, and discovered what was doing; upon which she was thrown into violent convulsions, and was not without great diffculty recovered. The family were by these experiments, and by several accidental circumstances, fully convinced that she was totally deaf and blind, particularly by sitting unconcerned at her work during a dreadful storm of thunder and lightning, though she was then facing the window, and always used to be much terrified in such circumstances.

"But Sir Hans Sloane, her physician, being still doubtful of the truth of facts which were scarcely less than miraculous, was permitted to satisfy himself by such experiments and observations as he thought proper; the issue of which was, that he pronounced her to be absolutely deaf and blind. She was at length sent to Bath, where she was in some measure relieved, her convulsions being less frequent, and her pains less acute; but she never recovered her speech, her sight, or her hearing, in the least degree. Many of her letters, dated at Bath, in which there are some instances of interlineations with a caret, the writer of this narrative has seen, and they are now in the custody of the widow of one of her brothers, who, with many other persons, can support the facts here related, however wonderful, with such evidence as it would not only be injustice, but folly, to disbelieve."

\section{ON Human Horns.}

\section{By Sir Everard Home, Bart. F. R. S.}

HoRNy excrescences arising from the human head have not only occurred in this country, but have been met with in several other parts of Europe : and the horns themselves have been deposited as 
valuable curiosities in the first collections in Europe. In giving the history of a disease so rare in its occurrence, and in its effects so remarkable as almost to exceed belief, it might be thought right to take some pains in bringing proofs to ascertain that such a disease does really exist. I consider the doing so, less necessary at present, there being two women now, 1791, alive, and residing in Eugland, who are affected by the complaint. I shall however, in the course of this paper, bring other evidence from the testimony of the most respectable authors who have considered this subject.

The two following cases contain a very accurate and distinct history of the progress of the disease through its different stages, and make any further detail of the symptoms entirely unnecessary.

Mrs. Lonsuale, a woman fifty-six years ago, a native of Horncastle in Linconshire, fourteen years ago observed a moveable tumor on the left side of her head, about two inches above the upper arch of the left ear, which gradually increased in the course of four or five years to the size of a pullet's egg, when it burst, and for a week continued to discharge a thick gritty fluid. In the centre of the tumor, after the fluid was discharged, she perceived a small soft substance, of the size of a pea, and of a reddish colour, on the top, which at that time she took for proud flesh. It gradually increased in length and thickness, and continued pliable for about three months, when it first began to put on a horny appearance. In two years and three months from its first formation, made desperate by the increased violence of the pain, she attempted to tear it from her head; and with much difficulty, and many efforts, at length broke it in the middle, and afterwards tore the root from her head, leaving a considerable depression, which still remains, in the part where it grew. Its length altogether is about five inches, and its circumference at the two ends about one inch, but in the middle rather less. It is curled like a ram's horn contorted, and in colour much reserbling isinglass.

From the lower edge of the depression another horn is now growing, of the same colour with the former, in length about three inches, and nearly the thickness of a small goosequill; it is less contorted, and lies close upon the head.

A third horn, situated about the upper part of the lambdoidal suture, is much curved, above an inch in length, and more in circumference at its root; its direction is backwards, with some elevation fron the head. At this place, two or three successive horns have been produced, which she has constantly torn away; but, as fresh ones have speedily followed, she leaves the present one unmolested, in hopes of its dropping off.

Besides these horny excrescences, there are two tumors, each of the size of a large cockle; one upon the upper part, the other about the niddle of the left side of the head; both of them admit of considerable motion, and seem to contain fluids of unequal consistence; the upper one affording an obscure fluctuation, the other a very evident one.

The four horns were all preceded by the same kind of incisted tumors, and the fluid in all of them was gritty; the openings from which the matter issued were very small, the cists collapsed and dried 
up, leaving the substance from which the horn proceeded distinguishable at the bottom. The cists gave little pain till the horus began to shoot, and then became very distressing, and continued with short intervals till they were removed. This case is drawn up by the surgeon who attended the woman for many years, which gave him frequent opportunities of seeing the disease in its different stages, and acquiring ain accurate history of its symptoms.

Mrs. Allen, a middle-aged woman, resident in Leicestershire, lad an incisted tumor upon her head, immediately under the scalp, very moveable, and evidently containing a fuid. It gave no pain unless pressed upon, and grew to the size of a small hen's egg. A few years ago it burst, and discharged a fluid; this diminished in quantity, and in a short time a horny excrescence, similar to those above-mentioned, grew out from the orifice, which has contilued to increase in size; and in the month of November, 1790, the time $I$ saw it, it was about five inches long, and a little more than an inch in circumference at its base. It was a good deal contorted, and the surface very irregular, having a laminated appearance. It moved readily with the scalp, and seemed to give no pain upon motion; but, when much handiled, the surrounding skin became inflamed. This woman came to London, and exhibited herself as a show, for money; and it is highly probable, that so rare an occurrence would have sutficiently excited the public attention to have made it answer her expectations in point of emolument, had not the circumstance been made known to her neighbours in the country, who were much dissatisfied with the measure, and by their importunity obliged her husband to take her into the country.

That the cases which I have related may not be considered as pecu. liar instances, from which no conclusion can be drawil, it may not be aniss to take notice of some of the most remarkable histories of this kind, mentioned by authors, and see how far they agree with those I have stated, in the general characters, that are sufficiently obvious to strike a common observer; for the vague and indefnite terms in which authors express themselves on this subject, shew plainly that they did not understand the nature of the disease.

In the Ephemerides Academize Natura Curiosorum, there are two cases of horns growing from the human body. One of these instances was a German woman, who had several swellings or ganglions upon different parts of her head, from one of which a horn grew. The other was a nobleman, who had a small tumor, about the size of a a nut, growing upon the parts covering the two last or lowermost, vertebrze of the back. It continued for ten years without undergoing any apparent change; but afterwards enlarged in size, and a horny excrescence grew out from it.

In the History of the Royal Society of Medicine, there is an account of a woman, ninety-seven years old, who had several tumors on her head, whis had been fourteen years in growing to the state they were in at that time; she had also a horn which had originated from a similar tumor. The horn was very moveable, being attaclied to the scalp, without any adhesion to the skull. It was sawn off, but grew again, and although the operation was repeated several times, the horn always returned. 
Bartholine, in his Epistles, takes notice of a woman who bad a tumor under the scalp covering the temporal muscle. This gradually enlarged, and a horn grew from it, which had become twelve inches long in the year 1646, the time he saw it. He gives us a representation of it, which bears a very accurate resemblance to that which I have mentioned to have seen in November 1790. The tumor or swelling is expressed in the figure; but the horn is coning directly. out from the surface of the skin.

In the Natural History of Cheshire, a woman is mentioned to have lived in the year 1668, who had a tumor or wen upon her head for thirty-two years, which afterwards enlarged, and two horus grew out of $i t$; she was then seventy-two years old.

There is a horny excrescence in the British Museum, which is eleven inches long, and two inches and a half in circumference at the base, or thickest part. The following account of this horn, I have been favoured with by Dr. Gray, taken from the records of the Museum. A woman, named French, who lived near Tenterden, had a tumor.or wen upon her head, which increased to the size of a walnut; and in the forty-eighth year of her age this horn began to grow, and in four years arrived to its present size.

There are many similar histories of these horny excrescences in the author's I have quoted, and in many others; but those mentioned above are the most accurate and particular with respect to their growth, and in all of them we find the origin was from a tumor, as in the two cases I have related; and although the nature of the tumor is not particularly mentioned, there can be no doubt of its being of the incisted kind, since in its progress it exactly resembled them, remaining stationary for a long time, and then coming forwards to the skin; and the horn being nuch smaller than the tumor, previously to the formation of the horn, is a proof that the tumor must have burst, and discharged its contents.

From the foregoing account it must appear evident that these homy excrescences are not to be ranked among the appearances called lisus naturce; nor are they altogether the product of disease, although undoubtedly the result of certain operations in the part, for its own restoration; but the actions of the animal cconomy being unable to bring them back to their original state, this species of excrescence is formed as a substitute for the natural cuticular covering.-Philosophical Transactions, vol. 81.

\section{Abstinence prom Food.}

OF the effects of a spare diet, many physicians have spoken in the highest terns. The noble Venetian, Cornaro, after his life was despaired of at the age of forty, recovered by mere abstinence, and lived to near one hundred. 'The early Christians of the East, who retired from persecution into the deserts of Arabia and Egypt, lived in health and cheerfulness on very slender food. St. Anthony lived one hundied and five years; James the Hernit, one hundred and four; Arseniiss, tutor of the emperor Arcadius, one hundred and twenty; St. Epiphanius, one hundred and fifteen; Simeon the Stylite, one 
hundred and twelve; and Romauld, one hundred and twenty. Buchanan mentions one Lawrence, who attained the age of one hundred and forty by temperance and labour; and Spottiswood speaks of another person, named Kentigern, afterwards called St. Mongah or Mungo, who lived to one hundred and eighty-five by the same means. According to Dr. Cheyne, most of the chronic diseases, the infirmities of old age, and the short lives of Englishmen, are owing to repletion; and may be either cured, prevented, or remedied by abstinence. But a want of due care may prove extremely detrimental to the constitution; for many hase undoubtedly done themselves irreparable injury by fasting too long.

Among animals, the serpent can endure an extraordinary degree of abstinence. Rattlesnakes have lived many months without any food, still retaining their vigour and fierceness. Dr. Shaw spealis of a couple of cerastes, a sort of Egyptian serpents, which had been kept five years in a bottle closely corked, without any food, unless a small quantity of sand, in which they coiled themselves up, may be reckoned as such. When he saw them, they were as brisk and lively as if just taken. Many species pass four, five, or six months every year, without either eating or drinking, as the tortoise, bear, dormouse, serpent, \&c. and are as fat and fleshy afterwards as before. Several species of birds, and almost the whole tribe of insects, subsist through the winter in a state of torpor, without food.

In most instances of extraordinary human abstinence related by naturalists, there were apparent marks of a texture of blood and humours like that of the animals above mentioned. There are substances of all kinds, animal, vegetable, \&c. floating in the atmosphere, which must be continually taken in by respiration; and that an animal body may be nourished by them, is evident in the instance of vipers, which if taken when first brought forth, and kept from every thing but air, will grow considerably in a few days. The eggs of lizards are observed to increase in bulk after they are produced, though there be nothing but air, as the eggs or spawn of fishes are nourished with the water.

Pliny says, a person may live seven days without any food whatever, and that many people have continned more than eleven days without either food or drink. Hist. Nat, lib. ii. c. 54.-Petrus d'Abono says, there was in his time in Normandy, a woman thirty years of age, who had lived without food for eighteen years. Exposit. Ull. prob. $x$. Alexander Benedictus mentions a person at Venice who lived forty-six years without food. Tract. lib. xii. c. 11.-Joubertus relates that a woman lived in very good health for three years without food or drink, and that he saw another who had lived to her tenth year without either food or drink, - Clausius, et Garcia ab Horto, mention that some of the more rigid Banians in India abstain from food frequently for twenty days together. Hist. Arom. lib. i.-Albertus Krantzius says, that a hermit in the mountains, in the canton of Schwitz, lived twenty years without food. Hist. Eccles. lib. xii. c. 21. Guaguinus says, that Louis the Pious, emperor and king of France, who died in 840 , existed the last forty days of his life without food or drink. Ilist. Francor. lib, v.-Citois gives the history of a girl ai 
Confoulens in Poitou, who lived three years without food. Abstin. Confolentan.-Albertus Magnus says, he saw a woman at Cologne who often lived twenty, and sometimes thirty days withont food, and that he saw a hypochondriacal man, who lived without food for seven weeks, drinking only a draught of water every other day. De Animalibus, lib. vii.-Hildanus relates the case of a girl who lived many years without food or drink. This subject, he says, had the abdomen wasted and retracted towards the spine, but without any hardness. She did not void any thing by the bowels. Cent. V. Obs. Chirurg. 33.- Sylvius says, there was a young woman in Spain, aged twenty-two years, who never ate any food, but lived entirely on water, and that there-was a girl in Narbonne, and another in Germany, who lived three years in good health, without any kind of food or drink. Consil. Adver. Farnem. - It is said that Democritus lived to the age of one hundred and nine years, and that in the latter part of his life he subsisted almost entirely, for forty days at one time, according to some writers, on smelling honey and hot bread.

To these testimonies it may afford some amusement to the reader, and at the same time furnish some curious data for the study of physiology, if we subjoin a few facts more in detail. -

"In a former visit to this place, (Barmouth, July 18, 1770,) my curiosity," says Pennant, " was excited to examine into the truth of a surprising relation of a woman, in the parish of Clynian, who had fasted a most supernatural length of time. I took boat, and had a most pleasant passage up the harbour, charmed witl the beauty of the shores, intermixed with woods, verdant pastures, and corn-fields. I landed, and, after a short walk, found in a farm called Tydden Bach, the object of my excursion, Mary Thomas, who lodged here, and was kept with great humanity and neatness. She was of the age of forty-seven, of a good countenance, very pale, thin, but not so much emaciated as might be expected from the strangeness of the circum. stances I am going to relate. Her eyes weak, her voice low, deprived of the use of her lower extremities, and quite bed-ridden; her pulse rather strong; her intellect clear and sensible.

"On examining her, she informed me, that at the age of seven, she had some eruptions like the measles, which grew confluent and universal; and she became so sore that she could not bear the least touch. She received some ease by the application of a sheep's-skin, just taken from the aninal; after this she was seized at spring and fall with swellings and inflammations, during which time she was confined to her bed; but in the intervals could walk about, and once went to Holy-well in hopes of cure.

"When she was about twenty-seven years of age she was attacked with the same complaint, but in a more violent manner; and during two years and a half rentained insensible, and took no manner of nourishment, notwithstanding her friends forced open her mouth with aspoon, to get something down; but the moment the spoon was takell away, her teeth met, and closed with snapping and violence; during that time she flung up vast quantities of blood.

"She well remembers the return of her senses, and her knowledge of every body about her., She thought she had slept but a night, and 
asked her mother whether she had given her any thing the day before, for she found herself very hungry. Meat was brought to her, but so far from being able to take any thing solid, she could scarcely swallow a spoonful of thin whey. From this time she continued seven years and a half without any food or liquid, excepting sufficient of the latter to moisten her lips. At the end of this period she again found herself hungry, and desired an egg, of which she got down to the quantity of a nut-kernel. About this time she requested to receive the sacrament; which she did, by having a crumb of bread steeped in the wine. She at this time, for her daily subsistence, eats a bit of bread weighing about two pennyweights seven grains, and drinks a wine glass of water, sometimes a spoonful of wine; but frequently abstains whole days from food and liquids." She sleeps very indifferently; the ordinary functions of nature are very small, and very seldom performed. Her attendant told me, that her disposition of mind was mild, her temper even; that she was very religious, and very fervent in prayer-the natural effect of the state of her body, long unembarrassed with the grossness of food, and a constant alienation of thought from all worldly affairs."--Journey to Snowden, vol. ii. p. $105-10 \%$.

"Gilbert Jackson, of Carse-Grange, Scotland, about fifteen years of age, in February $\mathbf{1 7 1 6}$ was seized with a violent fever, which returned in April for three weeks, and again on June 10; he then lost his speech, his appetite, and the use of his limbs, and could not be persuaded to eat or drink any thing. May 26, 1\%17, his fever left him; but he was still deprived of speech and the use of his limbs, and took no food whatever. June 30 , he was seized with a fever again, and the next day recovered his speech, but without eating or drinking, or the use of his limbs. On October 11, he recovered his liealth, with the use of one of his legs, but neither ate nor drank, only sometimes washed his mouth with water. On June 18, 1718, the fever returned, and lasted till September; he then recovered, and continued in pretty good health, and was fresh-coloured, but took no kind of meat or drink. On June 6, 1719, he was again seized with a very severe fever. On the 10 th, at night, his father prevailed on him to take a spoonful of milk boiled with oatmeal; it stuck so'long in his throat, that his friends feared he had been choked; but ever since that time he took food, though so little that a halfpenny loaf served him for eight davs. All the time he fasted, he had no evacuation; and it was fourteen days after he begail to eat, before he had any, he still continuing in pretty good health."

"In the year 1724, John Ferguson, of Kilmelfoord, in Argyleshire, overheated himself in the pursuit of cattle on the mountains ; then draik largely of cold water, and fell asleep. He slept for four-andtwenty hours, and waked in a high fever; ever since, his stomach loathed food, and could retain no kind of aliment but water. A neighbouring gentleman, Mr. Campbell, to whom his father was tenant, locked him up for twenty days, supplying him daily with water, and taking care that he should have no other food, but it made no difference either in his look or strength; at the age of thirty-six, when the account was sent to the Philosophical Society, he was of a fresh com- 
plexion, and was as strong as any common man." Plit. Trans. $1 \mathbf{7 4 2}$, vol. xlii. page 240 .

"A very curious instance of nearly two years' abstinence from all food and drink, is related in two numbers of Hufeland's Practical Journal, vol. viii. and ix, No. 2 ; and a pamphlet has since been published respecting this fact, by $\mathrm{Dr}$. Schmidtmann of Melle, in the bishopric of Osnabruck.

"A comtry girl, sixteen years old, in a village near Osnabruck, had enjoyed a good state of health during her childhood, but at about ten years of age she was seized with epileptic fits, against which a number of remedies were employed. After that time she was mostly confined to her bed, particularly in winter; but in summer she found herself a little better. From February 1\%98, the alvine and other secretions began to cease, though she took now and then a little nourishment, but from the beginning of the April, of the same year, she abstained entirely from all food and drink, falling into an uninterrupted slumber, almost senseless, from which she only awoke from time to time for a few hours. Her sensibility was during this time so great, that the slightest touch on any part of the body brought on partial convulsive motions. In this state she had continued for nearly ten months, when Dr. Schmidtmann saw her first, in March 1799. Though she had not taken the least nourishment during all this time, Dr. S. found her, to his utmost astonishment, fresh and blooming. For the last two months only, the intervals of sleep began to be longer ; her senses of sight and hearing were in perfect order, but her feeling she seemed to have quite lost, as she could suffer pinching of the arms and legs without pain ; her gums bled frequently, and the pulse was scarcely perceptible in the arms, but beat strong and full in the carotids, about one hundred and twenty in a minute. Dr. S. attempted to make her drink a little milk, but she protested she could not swallow it. The common excretions had quite ceased at this time.

"Although there conld hardly be a suspicion of any kind of imposition, the parents being honest people, yet, to remove all doubt, six sworn men were appointed from diferent places in the neighbourhood, to watch her day and night, and instructions given to them accordingly. This being continued for a fortnight, the men were dismissed, having given evidence upon oath, that the patient had never taken any food or drink whatever during that time, nor had she had any excretion. She had been once very ill, and nearly dying, seized with convulsions, feverish fits, and sometimes in a great sweat, which had the extraordinary property of turning water black. When Dr.S. saw her again, he found her quite recovered, not in the least emaciated, but rather looking lustier; her gums, however, still frequently bled, and her feeling was not yet returned; but her memory was not impaired, and she amused herself sometimes with reading and writing. No excretion had taken place. Sometimes she was attacked by a sudden weakness, particularly after having bled from the month. During the last severe winter, she could not endure the heat of the stove, because she feit then faint and oppressed."

Dr. Schmidtmann then enters into an inquiry by what means 
the patient in this case was nourished and maintained in that state in which she was found; and having discussed the matter at large, he is of opinion that sle drew, by resorption, such alimentary particles from the atmosphere as were sufficient for the nutrition of the body, and that the excretions were likewise replaced by the skin.

"However incredible and miraculous this fact may seem, yet we find similar instances recorded by several authors, viz. by Haller, Prichter, Swieten, Hufeland, \&c. In the Loudon Magazine for August, 1796, there is likewise an account of a young woman, twenty-four years of age, who had fasted for two years, and whose excretions were also entirely suppressed."-London Medical and Physical Iournal, vol iv. p. $8 \%$.

"A French officer of infantry, who had retired from service, and become deranged, took it in his head to refuse food, and continued in that determination from December 25 till February 9, drinking only a pint and a half of water daily, with a few drops of aniseedliquor in each glass, till the thirty-ninth day, from which time till the forty-seventh day he took nothing whatever. Till the thirtyeighth day, too, he remained out of bed; but weakness at length obliged him to lie down. The return to food was followed by a temporary cure of his insanity."-Hist. de l'Academie des Sciences, 1969, p. 45.

In the Philosophical Transactions we have an account of four colliers, who were confined twenty-four days in a coal-pit, at Herstol, near Liege, with nothing to support them but water; and in the Medical Commentaries (Dec. vol. iv. p. 360.) there is a history of a girl who had lost her way, and remained eighteen days on a baren moor, in the island of Lewis, where she could not possibly have had any other kind of sustenance: Mr. Miller, who relates the case, saw her two hours after she was found, and describes her as much emaciated.In fact, proofs abound as to the possibility of maintaining life for a considerable time, and under the most unfavourable circumstances; on small quantities of water or other liquids. Jejuni magis sitiunt, quam esuriunt. - The feeling of hunger, if not appeased by food, often ceases altogether; but the feeling of thirst becomes constantly more urgent, and, if the body be at the same time under the influence of heat, it produces the most aggravated distress.

\section{A Fine Feliow.}

Mr. CREECH in his second letter to Sir T. Sinclair, annexed to his Statistical Account of Edinburgh, has drawn the following striking contrast between the fine fellow of 1763 and of 1783 :- In 1763 , a young man was termed a fine fellow, who to a well-informed and accomplished mind, added elegance of manners and a conduct guided by principle; one who would not have injured the rights of the meanest individual; who contracted no debts that he could not pay, and thought every breach of morality unbecoming the character of $a$. gentleman; who "studied to be useful so far as his opportunity or abilities enabled him.-In 1783 , the term fine fellow was applied to one who conld drink three bottles, who discharged all debts of honour,

$$
3 \mathrm{x}
$$


or game debts, or tavern bills, and evaded payment of every other; who swore immoderately, and before ladies, and talked of his word of honour; who ridiculed religion and morality as folly and hypocrisy, but without argument; who was very jolly at the table of his friend, and would lose no opportuniy of seducing his wife, or daughter, if she was handsome; but, on such a thing being attempted on his own connexions, would have cut the throat, or blown out the brains, of his dearest companion; who was forward in all the fashionable follies of the times; who disregarded the welfare of society, or the good of mankind, if they interfered with his own vicious pursuits and. pleasures.

\section{Cla $\mathrm{NS}$.}

ThIs term in history, and particularly in that of Scotland, means a tribe of people of the same race, and often of the same name. The nations which overran Europe were originally divided into many tribes, and when they came to parcel out the lands which they had conquered, it was natural for every chieftain to bestow a portion in the tirst place upon those of his own race or family. These all held their land of him, and as the safety of each individual depended on the general union, these small societies clung together, and were distinguished by some common appellation, eithei patronymical or local, long before the introduction of surnames or ensigns armorial : but when these became common, the descendants and relations of every chieftain assumed the same name and arms with him; other: vassals were proud to imitate their example, and by degrees they were communicated to all who held of the same superior. Thus clanships were formed, and, in a generatiun or two, that consanguinity which was at first in a great measure imaginary, was believed to be real. An artificial union was converted into a natural one : men willingly followed a leader, whom they regarded as the superior of their lands: and the chief of their blood, and served him not only with the fidelity: of vassals, but the affection of friends. In the other feudal kingdoms we may observe such unions as we have described, imperfectly formed, but in Scotland, whether they were the production of chance, or the effect of policy, or strengthened by their preserving their genealogies both genuine and fabulous, clanships were universal. Such a confederacy might be overcome, it could not be broken; and no change of "manners or government has been able, in some parts of the kingdom, completely to dissolve associations which are founded upon prejudices so natural to the human mind. How formidable were nobles at the head of followers, who, counting that cause just and honourable which their chief approved, were ever ready to take the field at his command, and to sacrifice their lives in defence of his person or his fame. Against such men, a king coutended with great disadvantage; and that cold service, which money purchases or authority extorts, was not an equal match for ardour and zeal. The foregoing observations will receive considerable confirmation from what Sir John Dalrymple remarks of the Highland clans in his Memoirs of Great Britain. ${ }^{6}$ The castle of the chieftain was a kind of palace, to which 
crery man of his tribe was made welcome, and where he was entertained according to his station in time of peace, and to which all flocked at the sound of war. Thus the meanest of the clan, considering himself to be as well boin as the head of it, revered in his chieftain his own honour; loved in his clan his own blood; complained not of the difference of station into which fortune had thrown him, and respected himself : the chieftain in return bestowed a protection, founded equally on gratitude and the consciousness of his own interest. Hence the Highlanders, whom some account savage, carried, in the expression of their manners, the politeness of courts without their vices, and in their bosoms the high points of honour without its follies. In countries where the surface is rugged, and the climate uncertain, there is little room for the use of the plough; and where no coal is to be found, and few provisions can be raised, there is still less for that of the anvil and shuttle. As the Highlanders were, upon these accounts, excluded from extensive agriculture and manufacture alike, every fanily raised as much grain, and made as much raiment, as sufficed for itself; and nature, which art cannot force, destincel them to the life of shepherds. Hence they had not that excess of industry, which reduces man to a machine; nor that want of it, which sinks him into a rank of animals below his own. They lived in villages built in valleys and by the side of rivers. At two seasons of the year they were busy; the one in the end of spring and begiuning of summer, when they put the plough into the little land they had, capable of receiving it, then sowed their grain, and prepared their provision of turf for next winter's fuel; the other just before winter, when they reaped their harvest: the rest of the year was all their own, for amusement or for war. If not engaged in war, they indulged themselves in summer in the most delicious pleasure to men in a cold and a romantic country, - the enjoyment of the sun, and of the summer views of nature, never in the house during the day, even sleeping often at night in the open air, among the mountains and woods. They spent the winter in the chase, while the sun was up; and in the evening, assembling round a common fire, they entertained themiselves with the song, the tale, and the dance: but they were ignorant of sitting days and nights at games of skill or of hazard, amusements which keep the body indolent, and the mind in a state of vicious activity." The want of a good, and even a fine ear for music, was almost unknown among them, because it was kept in continual practice-among the multitude from passion; but by the wiser few, because they knew the love of music both heightened the courage and softened the temper of their people. Their vocal music was plaintive, even to the depth of melancholy; their instrumental, either lively for brisk dances, or martial for the battle. Some of their tunes even contained the great but natural idea of a history described in music, the joys of a mar. riage, the noise of a quarrel, the sounding to arms, the rage of a battle, the broken disorder of a flight,- the whole concluding with the solemil dirge and lamentation for the slain. By the loudness and artificial jarring of their war instrument, the bag-pipe, which played continually during the action, their spirits were exalted to a frenzy of courage in battle. They joined the pleasure of thistory and poetry 
to those of music, and the love of classical learning to both. For, in order to cherish high sentiments in the minds of all, every considerable family had an historian who recounted, and a bard who sung, the deeds of his clan, and of its chieftain; and all, even the lowest in station, were sent to school in their youth, partly because they had nothing else to do at that age, and partly because literature was thought the distinction, not the want of it the mark of good birth. The severity of their climate, the height of their mountains, the distance of their villages from each other, their love of the chase and of war, with their desire to visit and be visited, forced them to great bodily exertions: The vastness of the objects which surrounded them-lakes, mountains, rocks, cataracts-extended and elevated their minds; for they were not in the state of men who only know the way from one town to another. Their want of regular occupations led them, like the ancient Spartans, to contemplation, and the powers of conversation ; powers which they exerted in striking out the original thoughts which nature had suggested, not in languidly repeating those which they had learned from other people. They valued theniselves, without undervaluing other nations. They loved to quit their own country, to see and to hear, adopted easily the manners of others, and were attentive and insinuating wherever they went. When strangers came amongst them, they received them not with a ceremony which forbids a second visit, not with a coldness which causes a repentance of a first, not with an embarrassment which leaves both the landlord and his guest in equal misery, but with the most pleasing of all politeness, the simplicity and cordiality of affection; proud to give that hospitality which they had not received, and to humble the persons who had thought of them with contempt, by shewing how little they deserved it. Having been driven from the low countries of Scotland by invasion, they, from time immemorial, thought themselves entitled to make reprisals on the property of their invaders; but they touched not that of each other: so that in the same men there appeared, to those who did not look into the causes of things, a strange mixture of vice and of virtue; for what we term theft and rapine, they termed right and justice. But from the practice of these reprisals, they acquired the habits of being enterprising, artful, and bold. Hence the Highlander's were in the habitual practice of war, and hence their attachment to their chieftain, and to each other, was founded upon the two most active principles of human nature, love of their friends, and resentment against their enemies. But the frequency of war tempered its ferocity. They bound up the wounds of their prisoners, while they neglected their own; and in the person of an enemy, respected and pitied the stranger. They went always completely armed, a fashion which, by accustoming them to the instruments of death, removed the fear of death itself, and which, from the danger of provocation, made the common people as polite, and as guarded in their behaviour, as the gentry of other countries. From these combined circumstances, the higher rauks and the lower ranks of the Highlanders, joined that refinement of sentiment, which in all other nations is peculiar to the former, to that strength and hardiness of body which in other counties is possessed only by the latter. To be modest as well as brave, to be con- 
tented with the few things which nature requires; to act and to suffer without complaining; to be as much ashamed of doing any thing insolent or injurious to others, as of bearing it when done to themselves; and to die with pleasure, to revenge the affronts offered to their clan or their country: these they considered their highest accomplishments. In religion, every man followed, with indifference of sentiment, the mude which his chieftain had assumed. Their dress, which was the last remains of the Roman habit in Europe, was well suited to the nature of their country, and still better to the necessities of war. It consisted of a roll of light woollen called a plaid, six yards in length and two in breadth, wrapped loosely round the body, the upper lappet of which rested on the left shoulder, leaving the right arm at full liberty; a jacket of thick cloth fitted tightly to the body; and a loose short garment of light woollen, which went round the waist and covered the thigh. In rain they formed the plaid into folds, and, laying it on their shoulders, were covered as witl a roof. When they were obliged to lie abroad on the hills, in their hunting parties, or tending their cattle, or in war, the plaid served them both for bed and for covering, for, when three men slept together, they could spread three folds of cloth below, and six above them. The garters of their stockings were tied under their knee, with a view to give more freedom to the limb; and they wore no breeches, that they might climb mountains with the greater ease. The lightness and looseness of their dress, the custom they had of always going on foot, never on horseback, their love of long journeys, but, above all, that patience of hunger and hardships, which carried their bodies forward even after their spirits were exhausted, made them exceed all other European nations in speed and perseverance of march. In encampments, they were expert at forming beds in a moment by tying together bunches of heath, and fixing them upright in the ground; an art which, as the beds were both soft and dry, preserved their health in the field when other soldiers lost theirs. Their arms were a broadsword, a dagger called a dirk, a target, a musket, and two pistols; so that they carried the long sword of the Celtes, the pugio of the Romans, the shields of the ancients, and both kinds of modern firearnis, all together. In battle they threw away the plaid and under garment, and fought in their jackets; thus making their movements quicker and their strokes more forcible. The advance to battle was rapid, like the charge of dragoons; when near the enemy, they stopped a little to draw breath, and discharged the inusket, which they then dropped on the ground; advancing, they fired their pistols; which they threw almost at the same instant against the heads of their: opponents, and then rushed into their ranks with the broadsword, threatening and shaking their sword as they ran on, so as to conquer the enemy's eye while his body was yet unhurt. They fought, "not in long and regular lines, but in separate bands, like wedges, condensed and frm; the army being raised according to the clans which composed it, and each according to its families, so that there arose $a$ competition in valuur, of clan with clan, of family with family, of brother with brother. To make an opening in regular troops, and to conquer, they reckoned the same ting, becaus, in close engagenents, 
and in broken ranks, no regular troops could withstand them. They received the bayonet in the target which they carried on their left arm; then turning it aside, or twisting it in the target, they attack with the broadsword, the enemy encumbered and defenceless; and where they could not wield the broadsword, they stabbed with the diik. The indissolubility of these associations has been already noticed; and it may now be added, that though the abolition of the feudal system effected a greater. alteration in the character of those people, by inspiring them with sentiments and views of independence, during the last century, than a thousand years before had effected, yet the sensibility of their nature, the hardiness of their constitution, their warlike disposition, and their general hospitality to strangers, remain undiminished. And though emancipated now from the feudal yoke, they still shew a voluntary reverence to their chiefs, as well as affection to those of their own tribe and kindred; qualities which are not only very a miable and engaging in themselves, but which are connected with that character of alacrity and inviolable fidelity and resolution which their exertions in the field have justly obtained in the world.

\section{and \\ Part. IV. \\ ECCENTRIC.SECTS, \&c.}

\section{EsSEnians.}

AN ancient Jewish sect. Some suppose they originated from that dispersion of their nation which took place after the Babylonish captivity. They allowed a future state, but denied the resurrection of the dead, and they maintained that rewards and punishments extended to the soul only, considering the body as a mass of malignant matter, and the prison of the immortal spirit. The greater part of them considered the law of Moses as an allegorical system of spiritual and mysterious truth, and renounced all regard to the outward letter, in its explanation. They baid the highest respect to the moral precepts of the law but neglected the ceremoniai, excepting what regarded personal cleanliness, the observation of the sabbath, and making an annual present to the temple at Jerusalem.

Their way of life was very singular; they did not marry, but adopted the children of others, whom they bred up to the institutions of their sect; they despised riches, and had all things in common, and never changed their clothes till they were entirely worn out. When initiated, they were strictly bound to communicate the mysteries of their sect to others; and if any of their members were found guilty of enormous crimes, they were expelled. 
Pliny tells us, that they dwelt on the west side of Asphaltites, and that they were a solitary kind of men, without women or money, and feeding upon the fruit of the palm-tree; he adds, that they were constantly recruited by new comers, whom the surges of ill fortune had made weary of the world; in which manner the community was kept: up for several thousands of years, without any being born among them.

Philo mentions two classes of Essenes, one of which followed a practical institution; the other, who were called Therapeutæ, placed their whole felicity in the contemplation of the divine nature. Detaching thenselves entirely from secular affairs, they transferred their property to their relations and friends, and retired to solitary places, where they devoted themselves to a holy life. The principal society of this kind was formed near Alexandria, where they lived not far from each other, in separate cottages, each of which had its own sacred apartments, to which the inhabitants retired for the purpose of devotion.

\section{MAGI, OR MAGIANS.}

An ancient religious sect in Persia, and other eastern countries, who maintained that there were two principles, one the cause of all good, and the other the cause of all evil: and, abominating the adoration of images, they worshipped God only by fire, which they looked upon as the brightest and most glorious symbol of Arimanius, or the evil god. This religion was reformed by Zoroaster, who maintained that there, was one supreme independent Being, and under him two principles, or angels, one the angel of goodness and light, the other of evil and darkness; that there is a perpetual struggle between them, which shall last to the end of the world; that then the angel of darkness and his disciples shall go into a world of their own, where they shall suffer in everlasting darkness.

The priests of the Magi were the most skilful mathematicians and philosophers of the age in which they lived, insomuch that a learned mai, and a Magian, became equivalent terms. The vulgar looked on their knowlenge as supernatural; and hence those who practised wicked and mischievous arts, taking upon themselves the name of magians, drew upon it that bad signification which the word Magician now bears among us. This sect still subsists under the denomination of Gaurs, or Gares, Gabres, in Persia, where they watch the sacred fire with the greatest care, and never suffer it to be extinguished.

\section{Arimanius.}

THIS is the name of the evil god of the ancient Persians. The Persian Magi held two principles : a good dæmon or god, and an evil one; the first the author of all good, and the other of all evil: the former they supposed to be represented by light, and the latter by darkiess, as their truest symbols. 'The good principle they named Yezad or Yezdan, and Omoyd or Hormizda, which the Greeks wrote Oromasdes, and the evil dximon they called Abriman, and the Greeks Arimanius. Some of the Magiais held both these principles to have 
been from all eternity; but this sect was reputed heterodox, the original doctrine being, that the good principle only was eternal, and the other created.:

Plutarch gives the following account of the Magian traditions in relation to these gods, and the introduction of evil into the world, viz. that Oromazes consister of most pure light, and Arimanius of darkness, and that they were at war with each other; that Oromazes created six gods : first, the author of benevolence; second, of justice; third; of truth; fourth, of contentment; fifth, of pleasure; and sixth, of riches; and that Arimanius made as many, who were the authors of the opposite evils or vices; that then Oromazes, triplicating himself, removed as far from the sun as the sun is from the earth, and adorned the heavens with stars, appointing the dog-star for their leader; that he also created twenty-four other gods, and enclosed them in an egg, by which means evil and good became mixed together. However, the fatal time will come, when Arimanius, the introducer of plagues and famine, must of necessity be utterly destroyed by the former, and annihilated; then the earth being made plain and even, mankind shall live in a happy state, in the same society, and using one and the same language. Theopompus writes, that, according to the Magians, the said two gods, during the space of three thousand years, alternately conquer and are conquered, that for other three thousand years they will wage mutual war, fight and destroy the works of each other, till at last Hades, or the evil spirit, shall perish, and men become peifectly happy, their bodies needing no food, nor casting any shadow, i. e. being perfectly transparent.

\section{Garres or Gaurs.}

A RELIGIous sect in Persia and India, called also Gaurs. Those of this sect are dispersed through the country, and said to be the remains of the ancient Persians, or followers of Zoroaster, being worshippers of fire. They have a suburb at Ispahan, called Gaurabad; or the town of the Gaurs, where they are einployed in the meanest drudgery; sone of them are dispersed through other parts of Persia; but they principally abound in Kerman, the most barren province in the whole country, where the Mahometans allow them liberty for the exercise of their religion. Several of them fled many ages ago into India, and settled about Surat, where their posterity still remain. There is also a colony of them at Bombay. They are an ignorant, inoffensive people, extrenely superstitious, zealous for their rights, rigorous in their morals, and honest in their dealings. They believe a resurrection and a future judgment, and worship only one God. Although they perform their worship before fire, and direct their devotion towards the rising sun, for which they have an extraordinary veneration, yet they strenuously maintain that they worship neither; but that, as these are the most expressive symbols of the Deity, they turn towards them in their devotional services. Some have supposed that these are persons formerly converted to Christianity, who being afterwards left to themselves, mingled their ancient superstitions with the truths and practices of Christianity, and so formed for themselves 
a religion apart; and they allege that thronghout the whole of their system of doctrine and practice, we may discern traces of Christianity, though much defaced; such as the annunciation, the magi, the massacre of the infants, our Saviour's miracles, his persecution, aseension, \&c.

\section{Grmnosopinstis.}

THESE were a sect of Indian philosophers, famous in antiquity, so called from their going naked. They, however, did not absolutely go naked, but only clothed themselves no farther than modesty required. There were some of these sages in Africa, but the most celebrated of them were in India. 'In general the Gymnosophists were wise and learned men; their manners and discourses, - recorded by historians, do not savour of a barbarous education, but are the result of great sense and deep thought. They kept up the dignity of their character to so high a degree, that it was never their custom to wait upon any body, not even upon princes. They believed the immortality and transmigration of the soul; they placed the chief happiness of man in contempt of the goods of fortune, and the pleasures of sense ; and gloried in having given faithful and disinterested councils even to their princes and magistrates. It is said that when they became old and infirm, they threw themselves into a pile of burning wood, in order to prevent the miseries of an advanced age. One of them, named Calaney, thus burnt himself in the presence of Alexander the Great.

Apuleius describes the Gymnosnphists thus: "They are all devoted to the study of wisdom, both the elder masters and the younger pupils; and what to me appears the most amiable thing in their character is, that they have an utter aversion to idleness and indolence; accordingly, as soon as the table is spread, before a bit of victuals be brought, the youths are all called together from their several places and offices, and the masters examine them what good they have done since the sun-rise : here one relates something he has discovered by meditation; another has learned something by demonstration; and as for those who have nothing to allege why they should dine, they are turued out to work fasting." The great leader of the Gymnosophists, according to Jerome, was one Buddas or Butta, who is ranked by Suidas among the Brachmans. He makes Buddas the preceptor of Manes the Persian, the founder of the Gymnosophists.

\section{BONzes OF CHINA.}

THESE are the priests of the Fohists, or sect of Fohi. It is one of their established tenets that great rewards are allotted for the righteous, and punishments for the wicked, in the next world; and that there are various mansions in which the souls of men will reside, according to their different degrees of merit. But in order to deserve the favour of heaven, the Bonzes instruct the people to treat the priests with respect and reverence, to support and maintain them, and to erect temples and monasteries for them. They tell them, that unless 
they comply with their injunctions, they will be cruelly tormented after death, and pass through a variety of transmigrations; that they will be changed into mules, asses, rats, nice, $\& \mathrm{c}$.

The Chinese Bonzes, according to $F$. le Compte, are a gang of dissolute idle fellows. All their aim is to excite people to commiserate their abject condition; to which end they have recourse to various impostures. When the common arts of address fail them, they try what public penance will do. Some of them drag heavy chains, thirty feet long, after them; some sit in the highway, knocking their heads against flint stones; others set particular drugs on fire upon their hears; all these are several ways of drawing the attention and exciting the contpassion of the people, and they seldom fail of success.

F. Navarette tells us that the Bonzes are obliged to chastity, and that, on the 6th of April, 1667, a petty king of Cauton had condemned eleven of them to be burnt alive for incontinence. He adds, that it was reported of an empress of the last reigning family; who had a particular kindness for the Bonzes, that she granted them a dispensation for three days. The Bonzes of China, according to the same author, are computed at fifty thousand. It has been observed, that there is so strong a likeness between the apparent worship of many of the priests of Fo, and that which is exhibited in churches of the Roman faith, that a Chinese conveyed into one of the latter might inagine the votaries he saw there were adoring the deities of their own country. On the altar of a Chinese temple, behind a screen, is frequently a representation which might serve for the Virgin Mary, in the person of "Shinmoo," or the Sacred Mother, sitting on an alcove, with a child in her arms, and rays proceeding from a circle which are called Glory, round her head, with tapers burning constantly before her. The long loose gowns of the ho-shangs, or priests of $\mathrm{Fo}_{\mathrm{o}}$, bound with cords round the waist, might almost equally suit the friars of the order of St. Francis ; the formerlive, like the latter, in a state of celibacy, reside together in monasteries, and impose occasionally upon themselves voluntary penauce, and rigorous abstinence.

\section{Superstitions observed in Bombat.}

Mr. Ives had once an opportunity of observing the Persees perform their devotions to fire. A large brass pan was placed in the middle of the floor, with fire in it; two men were kneeling at their devotions, pronouncing their prayers with great rapidity. He was afterwards informed that one of them was a priest, at that time on a visit to another priest in a fit of sickness. He was likewise told that the Persees have such a veneration for fire, that they never put it out, or even breathe upon it; and he observed, that while the two priests were at their prayers over the pan of coals, they had a little white bib over their mouth, as he supposed, to prevent their breath from approaching their favourite element. The prayers, however, from the sinilarity of the sounds, appeared to him only to be a repetition of the same set of words. The visiting priest used many gestures with his hands over the fire, and afterwards stroked down the face of the sick person, which Mr. Ives considered the final benediction, as the cerenony ended immediately. 
As the Gentoos burn their dead, one would imagine that the Persees, who have such a veneration for fire, would be desirous of having: their bodies consumed by that element; but instead of this, they expose their dead bodies to be devoured by birds of prey, because, say they, as a living man is composed of all the elements, it is but reasonable, after he is dead, that every element should receive its own again. On the top of Malabar-hill, abont two miles from the town of Bombay, there are two round buildings for receiving the dead bodies of the Persees, which remain there till the bones are clean picked by: the birds. This is certainly an abominable custom, and affords shocking'spectacles; however, a guard is always placed at a little distance, to prevent people from prying too narrowly, into those matters, or, as Mr. Ives says, to ensure the vultures of their repast without any disturbance.

Mr. Grose says, that on his going to look into one of these repositories, a Persee advised him in a friendly manner to let it alone, as no person, who was not a party concerned, would long survive such curiosity. He tells also, that the person appointed to look after the dead, carefully observes which eye is first picked out by the birds, and thence judges of the situation of the soul of the deceased, a state of happiness being indicated by the right eye being first picked out. Mr. Ives observes, that by reason of the heat of the sun, much less noxious vapour is emitted by these bodies than night be expected, the flesh being soon shrivelled up, and the bones turned quite blask. At the extreme point of Malabar-hill there is a rock on the descent to the sea, flat on the top, in which there is a natural crevice, which communicates with a hollow terminating at an interior opening to the sea. This place is used by the Gentoos as a purifier from their sins. This purification is effected by their going in at the opening, and coming through the crevice, though it seems too small for people of any corpulence to pass.

\section{A BRACADABRA.}

THIs was the name of a god worshipped by the Syrians, and was recommended by Serenus Samonicus, as a magical antidote against agues and several other diseases. It was to be written upon a piece of paper as many times as it contains letters, omitting the last letter of the former every time, thus :

A b r a c a d a b r a

$A$ b r a c a d a b r

A b r a ca d a b

A b r a c a d a

A b r a c a d

A b r a c a

A b r a c

A b r a

A b r

A b

A

This was to be repeated in the same order, and then suspended about the neck by a linen thread. This was considered as a continual invo- 
cation of the deity's aid, and, though equally insignificant, was not more irrational, than the superstitious practices of some who called thenselves Christians, of wearing variuus things in the hope of their operating by sympathy.

\section{Fakirs.}

THEse are Indian monks, or friars. They outdo the severity and mortification of the ancient Anchorets. Some of them make a vow of continuing all their life in one posture, and keep it effectually. Others never lié down, but contiuue in a standing posture all their lives, supported only by a stick, or rope under their arm-pits. Some mangle their bodies with scourges and knives. They pretend to have conquered every passion, and triumphed over the world; and accord ingly scruple not, as if in a state of innocence, to appear entirely naked in public. The people of the East are persuaded of the virtue of the Fakirs; notwithstanding which, they are accused of committing the most enormous crimes in private.

There is also another lind of Fakirs, who do not practise such severities; these flock together, and go from village to village, prophesying and telling fortunes. They are wicked villains, and it is dangerous to meet them in a solitary place; nevertheless, the Indiain idolaters have then in the utmost veneration. They make use of drums, trumpets, and other musical instruments, to work themselves up to an artificial ecstasy, the better to publish their pretended prophecies. The most sober Indians consult them in the most preposterous attitude; and their female votaries converse with them a considerable time with the nost indecent freedom. The fire they burn is made of cow's dung dried in the sun. When they are disposed to sleep, they repose themselves on the same material, and sometimes on ordure itself. They are so indulgent towards every living creature, that they suffer themselves to be over-run with vermin, or stung by insects, without the least reluctancy or complaint. It is more than probable these Indian friars have some secret art to lull their senses asleep, in order to render themselves in a great measure insensible of the excessive torments they seem voluntarily to undergo.

Ovington assures us, that "as he was one" day in an assembly of Fakirs, he observed that they drank opiates infused in water; the intoxicating virtue whereof was enough to turn their brain." The garment of the chief Fakirs consists of three or four yards of orangecoloured linen, which they tie round them, and a tiger's skin, which hangs over their shoulders. Their hair is woven in tresses, and forms a lind of turban. The superior of the Falirs is distinguished from the rest by having a greater number of pieces in his garment, and by a chain of iron two yards long tied to his leg. When he designs to ,rest in any place, a garment is spread upon the ground, on which he sits and gives audience, whilst his disciples publish his virtne. Some persons of quality in India have become Fakirs ; among others five great lords belonging to the court of Chagehan, the Mogul of the Indies. It is said by some writers, that there are about two millions of Fakirs in the East Iudies. 
THESE were a celebrated order of religious persons, who generally passer their whole lives in cells, from which they never removed. 'These habitations were in many instances entirely secluded from all other abodes of men; sometimes in the deptlis of wildernesses, in pits, or in caverns; at other times we find several of these individuals fixing their habitations in the neighbourhood of each other, when their cells were called by the collective name of laura; but they always lived personally separate, and generally in cells at some distance from each olver. Thus the laura was distinguished from the conobium, or convents, where the monks form themselves into a society, and subsist on a common stock; and the Anchoret differed from a hermit, though his abode was frequently called a hermitage, in which the latter ranged about at liberty, while the former rarely, and in many instances never, quitted his cell. But a convent would sometimes be surrounded by a laura, to which the more devout or the more idle of the monks would ultimately retire. To Paul the hermit, the distinction is assigned of having devoted himself to this kind of solitude.?

The order of Anchorets, in Egypt and in Syria, comprehended, in the first instance, all those hermits who abandoned the ordinary abodes of mankind, and wandered among the rocks and haunts of wild beasts, nourishing themselves with roots and herbs that grew spontaneously, and reposing wherever they were overtaken by night: $f$

Amongst those early Anchorets, Simeon Stylites, who lived at the close of the fourth century, will ever occupy a wretched immortality. Having passed a long and severe noviciate in a monastery, which he entered at the age of thirteen, this devotee contrived, within the space nf a small circular enclosure of stones, to which he was confined by a heavy chain, to ascend a column, gradually raised from nine to sixty feet in height, on the top of which he passed thirty years of his life, and died of an ulcer in his thigh, without descending from it. Crowds of pilgrims from Gaul to India are said to have been proud to supply his necessities.

In succeeding ages the order of Anchorets assumed a more entire distinction from that of hermits and other religious, and was regnlated by its own rules. Early in the seventh century the councils began to notice and to modify this kind of life. "Those who affect to be Anchorets," say the Tuscan Canons, "shall first for three years be confined to a cell in a monastery; and if, after this, they profess that they persist, let them be examined by the bishop or abbot; let them live one year at large; and if they still approve of their first choice, let them be confined to their cell, and not be permitted to go out of it, but by consent and benediction of the bishop, in case of great necessity."

Frequently at this period would the monks of various abbeys select from among them a brother who was thought to be most exemplary in his profession, and devote him to this entire seclusion, as an honour, and to give him the greater opportunity of indulging his religious contemplations. A similar custom also obtained in the convents, and there are even many instances of men who became Ancho- 
rets in nunneries, and of women in the abbeys of monks. The bishops, in the eighth and ninth centuries, generally presided at the ceremony of seclusion, which was as follows: "The Anchorite was to be advised by the bishop, or some other priest, to examine his conscience, whether he acted from piety, sincere or feigned; and if the answer was favourable, the priest was, by order of the bishop, to shut him up. Provision was first to be made for his confession, and that, on the day preceding the ceremony, he received the refection of bread and water. On the night following, he passed devout vigils in the church nearest the hermitage. On the morrow, after an exhortation to the people and the Anchoret, the priest began a responsory; and, upon the conclusion of it, prostrated himself, with his ministers, before the step of the altar, and said certain psalms. After these, the mass was celebrated in the neighbouring church, and an especial prayer said for the Anchoret. Afte the Gospel, he offered a taper, which was to burn upon the altar at the mass. The Anchoret then read the schedule of his profession, which consisted only of the vows of obedience, chastity, and steadfastness, at the step of the altar; and, if he was a layman, the priest read it for him. He then made a sign of his intention, and offered it upon the altar, kneeling. The priest consecrated the habit, and sprinkled that and the Anchoret with holy water. Then followed mass and litany; after which they went in procession to the herinitage. The priest took him by the right hand, and led him to the house, which was then blessed, and shut from witlout.. The priest, with the assistants, retired, leaving the Anchoret within, and advised the standers-by to pray for him."-Fosbrooke's Monachism, 4to. 1817 .

These cells, according to some rules, were to be only twelve feet square, of stone, and with three windows. The door was locked upon the Anchoret, and often walled up. One of the windows, when they were attached, as they now frequently were, to the building of an abbey or monastery, generally formed the choir, and through it the sacrament was received; another was devoted to the reception of food; and the third for lights, being made of horll or glass. Thus affixed, they were called anchor-hotels, anchor-houses, and destina, as that which is said to have been occupied by St. Dunstan at Glastonbury, and which, according to Osborn in his life of that monk, was not more than five feet long, two feet and a half broad, and barely the height of a man. Here it became a merit to invent ingenious selftorture. The recluse would in some cases vow eternal silence, and never see any individual of his own-species, except the monk who brought him his food; he would wear old corslets of mail, chains, and heavy bracelets, and collars of iron round his neck, and immerge, himself (as in the instance of the "holy and solitary" Wulfrie of Hasselborough, mentioned by Matthew Paris,) in a tub of cold water, at night, to say the psalter.

\section{JEZIDES.}

THIs term, among the Mahometans, is of similar import with heretics among Christians. The Jezides are a numerous sect inhabiting Tur- 
key and Persia, so called from their head Jezid, an Arabian prince, who slew the sons of Ali, Mahomet's father-in-law, for which reason he is reckoned a parricide; and his followers heretics. There are about twenty thousand Jezides both in Turkey and Persia; who are of two sorts, black and white. The white are clad like Turks, and distinguished only by their shirts, which are not slit at the neck like those of others, but have a round hole to thrust their heads through. This is in memory of a golden ring or circle of light, which descended from lieaven upon the neck of their chief, the head of their religion, after his undergoing a fast of forty days. "The black Jezides, though married, are the monks of the religious order; and these are called Fakirs. The Turks exact excessive taxes from the Jezides, who treat the Turks as their mortal enemies; and when, in their wrath, they curse any creature, they call it Mussulman; but they are great lovers of the Christians, being more fond of Jesus Christ than of Mahomet, and are never circumcised but when they are forced to it. They are extremely ignorant, yet profess to believe both the Bible and the Koran, without reading either of them. They make vows and pilgrimages, but have no places of religious worship. All the adoration they pay to God consists of some songs in honour of Jesus Christ, the Virgin, Moses, and sometimes Mahomet ; and it is a principal point of their religion never to speak ill of the Devil, lest he should resent the injury if ever he should come to be in favour with God again, which they think possible ; whenever they speak of him, they call him Angel Peacock. They bury their dead in the first place they come at, rejoicing as at a festival, and celebrating the entry of the deceased into heaven. They go in companies, like the Arabians, and change their habitations every fifteen days. When they get wine, they drink it to excess ; and it is said that they sometimes do this for a religious purpose, calling it the blood of Christ. They buy their wives, and the market price is two hundred crowns for all women, handsome or not, without distinction.

\section{Religion of the Armenians.}

THE religion of the inhabitants of Armenia, a country of Asia, is the Christian, which is said to have been planted among them by St. Bartholomew. They are in general of the Eutychian sect, that is, they own but one nature in Jesus Christ; and when they speak of the hypostatical union, say that he is perfect God and perfect man without mixture. They have a high esteem for a book they call the Little Gospel, which treats of the infancy of Jesus. The Armenian clergy consist of patriarchs, with bishops, doctors, secular priests, and monks. The secular priests are not allowed to marry a second time, and therefore they take care to choose young healthy wives; they maintain themselves and families by some occupation, insomuch that they have hardly time to perform their ecclesiastical functions: they lie in the churches on the vigils of those days they are obliged to officiate. The Armenian monks are of the order of St Basil; and every Wednesday and Friday they eat neither fish, eggs, oil, nor any thing made of milk; and during Lent they live upon nothing but 
roots, they are allowed wine only on the Saturday in Holy-week, and meat on Easter Sunday. Besides the great Lent, they have four others of eight days each, which are instituted to prepare for the four great festivals of the Nativity, the Ascension, the Annunciation, and of St. George: in which times they must lot so much as speak of eggs, fisl, oil, or butter. The Armenians abstain at all times from eating of blood and things strangled. They have seven sacraments, - baptism, confirmation, penance, the eucharist, extreme un ${ }^{-}$ tion, orders, and matrimony. In baptism, the child is plunged three times into the water, and the same form of words that is used with us is repeated every time; the priest then puts a small cord, made with silk and cotton, on the neck of the infant; and aroints his forehead, chin, stomach, arm-pits, hands, and feet, making the sign of the cross, on each part. When the child is baptized, he is carried home by the godfather with sounds of drums and trumpets. The women do not go to church till forty days after their delivery, and they observe many Jewish customs.

At the communion, to which infants of two or three months old are admitted, the priest gives a piece of the consecrated host soaked in the consecrated wine. The elements are covered with a great veil, and placed in a cupboard near the altar, by the side of the Gospels. When the priest talies the chalice and patin, he is followed by his deacons and subdeacons, with flambeaux, and plates of copper furnished witl bells. In this manner, with a censer before him, he goes in procession round the sanctuary; he then sets them on the altar, pronounces the words of consecration, and turns himself to the people, who fall down, kiss the earth, and beat their breasts : then, after taking it himself, he distributes the host in wine to the people. They consecrate holy-water but once a year, at which time every one fills a pot, and carries it honie. This brings in a considerable revenue to the church. The Armenians seem to place the chief part of their religion in fastings and abstinences: and among the clergy, the higher their degree, the lower they must live; insomuch that it is said the archbishops live on nothing but pulse. Temperance is doubtless a virtue, but it is astonishing to what an absurd extreme it has been carried under the name of religion, and how much priests of all religions have persuaded mankind that they would recommend themselves to the favour of the Almighty, by abstaining from even a moderate use of his benefits. The worst of it is, that these artificial duties and factitious virtues uniformly eradicate the essence of all religion, morality, by leading those who perform them to place great merit in things of no value.

SEEKS.

THIs is the name of a religious sect settled at Patna, and so called from a word contained in one of the commandments of their founder, which signifies "Learn thou." In books giving an account of Oriental sects and customs, we find mention made both of Seeks and Seiks : and some think that the same tribe is meant by both names. If so, different authors write very differently of their principles and manners. 
In he Asiatic Researches, Mr. Williams gives an amiable account of the Seeks.

"The Seeks," he says, "are a sect disting uished both frowithe Mussulmans and the worshippers of Brahma. Otir autlior asked leave to enter iuto their chapel. They said it was a place of worship open to all men, but intimated that he should take of his shoes. He was then politely conducted into the hall, and seated upon a carpet in the midst of the assembly. The whole building forms a square of about forty feet. The hall is in the centre, divided from four other apartments by wooden arches upon wooden pillars. The walls above the arches are hung with European looking-glasses in gilt frames, and will pictures: on the left hand is the chancel, which is furnished with an altar covered with cloth of gold. About it were several flowerpots and rose-water bottles, and three urns to réceive charity. On a low desk, near the altar, stood a great book, of folio size, from which some portions were daily read in the divine service. At noon, the congregation arranged themselves upon the carpet. The great book and desk were brought from the altar, and placed on the opposite extremity. An old silver-haired man kneeled down before the desk, with his face towards the altar, and by him sat a man with a drum, and two or three with cymbals. The bock was now opened, and the old man began to chant to the tune of the instruments, and at the conclusion of every verse most of the congregation joined cliorus in a response, with countenances exhibiting joy. Their tones were not harsh, the tune was quick, and Mr. Wilkins learned that the subject was a hymn in praise of the unity, omnipresence, and omnipotency of the Deity.

"The hymn being concluded, the whole company got up, and presented their faces, with joined hands, towards the altar, in the attitude of prayer. The prayer was a sort of litany, pronounced by a young man in a loud and distinct voice ; the people joining, at certain periods, in a general response. The prayer was followed by a short blessing from the old man, and an invitation to the assembily to partake of a friendly feast. A share was offered to Mr. Wilkins. It was a kind of sweetmeat composed of sugar and flower, mixed up with clarified butter. They were next served with a few sugar-plums : thus ended the feast and ceremony.

"The founder of this sect was Naneek Sah, who lived about four hundred years ago, and left be hind him a book composed by himself inverse, containing the doctrines he had established; this book teaches that there is but one God, filling all space, and pervading all matter, and that there will be a day of retribution, when virtie will be rewarded, and vice punished. It forbids murder, theft, and other crimes, and inculcates the practice of all the virtues, but particularly a universal philanthropy, and hospitality to strangers and travellers. It not only commands universal toleration, but forbids disputes with those of another persuasion. If any shew a sincere inclination to be adnitted among them, any five or more Seeks being assembled in any place, even on the highway, they send to the first shop where sweetmeats are sold, and procure a very small quantity of a particular kind called batasa, which having diluted in pure water, they sprinkle some 
of it on the body and eyes of the proselyte, whilst one of the best instructed repeats to him the chief canons of their faith, and exacts from him a solemn promise to abide by them the rest of his life. They offered to admit Mr. Willins into their society; but he declined the honour, contenting himself with the alphabet, which they told him to guard as the apple of his eye, as it was a sacred character. The Janguage is a mixture of Persian, Arabic, and Shanscrit, gratted upon the provincial dialect of Pumjab, which is a kind of Hindoowe, or, as we commouly call it, Moorish.

\section{Carthusians.}

A RELigious order, founded A. D. 1080, by one Brudo; so called from the desert of Chartreuse, the place of their institution. Their rule is extremely severe; they must not go out of their cells, except to church, without leave of their superior, nor speak, to any person without leave. They must not keep any meat or drink till next day; their beds are of straw, covered with a felt; their clothing, two haircloths, two cowls, two pair of hose, and a cloak-all coarse. In the refectory, they must keep their eyes on the dish, their hands on the table, their attention on the reader, and their hearts fixed on God. Women must not come into their churches. It is computed that there are one hundred and seventy-two houses of Carthusians, whereof five are of nuns, who practise the same austerities as the monks. They are divided into sixteen provinces, each of which has two visitors; there have been several canonized saints of this order, four cardinals, seventy archbishops and bishops, and many learned authors.

\section{BEGUINES.}

THESE were a congregation of nuns founded either by St. Begghe, or by Lambert le Begue. They were established first at Liege, and afterwards at Neville, in $120 \%$; and from this last settlement isprang the great number of Beguines which were spread all over Flanders, and which have passed from Flanders into Germany. In the latter country, some of those religious fell into extravagant errors, persuading themselves that it was impossible, in the present life, to arrive at the highest perfection, even to impeccability, and a clear view of God -in short, to so eminent a degree of contemplation, that there was no necessity, after this, to submit to the laws of mortal men, civil or ecclesiastical.

The council of Vienna, in 1113 , condemned those errors, and abolished the order of Beguines, permitting, nevertheless, those among them who continued in the true faith, to live in chastity and penitence, either with or without vows. It was by favour of this latter clause that there still subsist, or at least subsisted till lately, so many communities of Beguines in Flanders; who, since the council of Vienna, have conducted themselves with so much wisdom and piety, that John XXII. by his decretal, which explains that of his predecessor marle in the council of Vienua, tnok them under his protection; and Boniface VIII in another, exempted them from the secular tribunal, 
and pat them under the jurisdiction of the bishops. There was scarcely a town in the Low Countries, in which there was und a society of Beguines, and even at Amsterdam there was a flourishing one.

These societies consisted of several houses placed in one enclosure, with one or more churches, according to the number of Beguises. There was in every house a prioress or mistress, without whose leave they durst not stir out. "They made a sort of vow in the followng terins:" I promise to be obedient and chaste as long as I continue in this Beguinage." They observed a three years' noviciate, before they took the habit. The rector of the parish is superior of the Beguinage; and he does nothing without the advice of eight Beguines. They were formerly habited in different manners, some in gray, others in blue; but of late they all wore black. When they went abroad in Anster. dam, they put on a black veil. Formerly they had as many difierent statues as there were societies. In the visitations of the yen 1600 and 1601, by the archbishop Matthias Hovius, they were forbidder, under the penalty of a fine, to have lap-dogs.

\section{Carmelites}

A TRIBE of mendicant friars, so named from mount Carmel. They pretend to descend in an uninterrupted succession from Elijah, Elisha, and the sons of the prophets. The manner in which they make out their antiquity is too ridiculous to be rehearsed. Some pretend they are descendants of Jesus Christ; others make Pythagoras a Carme lite, and the ancient Druids regular branches of their order.

Thocas, a Greek monk, speaks the most reasonably. He says, that in his time (1185) Elias's cave was still extant on the mountain; near which were the remains of a building, which intimated that there had been anciently a monastery ; that some years before, all old monk, a priest of Calabria, by revelation, as he pretended, from the prophet Elias, fixed there, and assembled ten brothers. In 1909, Albert, patriarch of Jerusalem, gave these solitaires a rigid ruie, which Papeleroch has since printed. In $121 \%$, or, according to others, 1226 , pope Honorius III. approved and confirmed it. This rule contained sixteen articles. These confined them to their cells, enjoined them to continue day and night in prayer; prohibited their having any property; enjoined fasting from the feast of the Holy Cross till Easter, except on Sundays; abstinence at all times from flesh; obliged them to manual labour; imposed a strict silence on them from vespers till the tierce the next day, \&c.

The peace concluded by the emperor Frederic II. with the Saracens, in 1229, occasioned the Carmelites to quit the Holy Land, under Alan V.general of the order. He first sent some of the religious to Cyprus, who landed there in 1238, and founded a monastery in the forest of Fontania. Some Sicilians at the same time leaving mount Carmel, returued to their own country, where they founded a monastery in the suburbs of Messina. Some English nonks departed out of Syria, in 1240, to found others in England. Others of Provence, in 1244, founded a monastery in the sesert of Aignalates, a league 
from Marseilles ; and thus, the number of their monasteries increasing, they held their European general chapter in 1245, at their monastery of Aylesford, in England. This order is so much increased, that it has at present thirty-eight provinces, besides the congregation of Mantua, in which are fifty-four monasteries, under a vicar general; and the congregation of Barefooted Carmelites in Italy and Spain, which have their peculiar generals.

After the establishment of the Carmelites in Europe, their rule was in some respects altered; the first time by pope Innocent IV. Who added to the first article a precept of chastity, and relaxed the eleventh, which enjoins abstinence at all times from flesh,-permitting them, when they travelled, to eat boiled flesh. He likewise allowed them to eat in a common refectory, and to keep asses and mules for their use. The rule was again mitigated by the popes Eugenius IV. and Pius II. Hence the order is divided into two branches, viz. the Carmelites of the ancient observance, called the Morlerate, or Mitigated; and those of the strict observance, who are the Barefooted Carmelites. A reform was set on foot in 1540 , by $S$. Theresa, a nun of the convent of Avila, in Castile; these last are divided into two congregations, - that of Spain, and that of Italy.

The habit of the Carmelites was at first white, and the cloak laced at the bottom with several other lists. But pope Honorius IV.commanded them to change it for that of the Minims. Their scapulary is a small woollen habit of a brown colour, thrown over their shoulders. They wear no linen shirts, but instead of them linsey-woolsey, which they change twice a week in the summer, and once a week in the winter. If a monk of this order violates his vow of cliastity, he is prohibited saying mass for three or four years, is declared infamous, and obliged to discipline himself publicly once a week. If he is again guilty of the sarne fault, his penance is doubled; and if a third time, he is expelled the order.

\section{Celestins.}

A RELIGious order, so called from their founder, pope Celestin $V$. After the death of this pope, his order made great progiess in Italy and France, whither the then general, Peter of Tivoli, sent twelve religious, at the request of Philip the Fair, who gave them two monasteries; one in the forest of Orleans, and the other in that of Compeigne. This order likewise passed into several provinces of Germany. They had about ninety-six convents in Italy, and twenty-one in France, under the title of priories, before the late revolution. The Celestins rise two hours after midnight, to say matins. They eat no flesh, excepi when sick. They fast every. Wedneslay and Friday, from Easter to the feast of Exaltation of the Holy Cross, and from the feast to Easter every day. Their habit consists of a white gown, a capuche, and a black scapulary. In the choir, and when they go out of the monastery, they wear a black cowl with the capuche ; their shirts are of serge. 
Adamites.

THIs is the name of a sect of ancient heretics, that sprung up anout the end of the second century, supposed to have been a branch of the Basilidians and Carpocrations. Epiphanius tells us, that they were called Adamites from their pretending to be re-established in the state of innocence, such as Adam was at the moment of his creation, whence they thought to imitate him in going naked. They detested marriage, maintaining that the conjugal union would never have taken place upon earth, had sin been unknown. This obscure and ridiculous sect did not at first continue long; but it was revived, with additional absurdities, in the twelfh century, by one Tandamus, since known by the name of Tanchelin, who propagated his errors at Antwerp, in the reign of the emperor Henry $V$. He maintained, that there ought to be no distirction between priests and laynen, and that fornication and aduliery were meritorious actions. Tanchelin had a great number of followers, and was constantly attended by those profligates, in arms. His sect did not, however, continue long after his death; but another appeared, under the name of Turlupins, in Savoy and Dauphiny, where they conmitted the most brutal excesses in open day. About the beginning of the fifteenth century, one Picard, a native of Flanders, spread those errors in Germany and Bohemia, particularly in the army of the famous Ziska, notwithstanding the severe discipline he maintained. Picard pretended that he was sent in to the world as a new Adam, to re-establish the law of nature; which, according to him, consisted in concealing no part of the body. This sect found also some partisans in Poland, Holland, and England: they assembled in the night, and one of the fundamental niaxims of their society was contained in the following verse :

$$
\text { "Jura, perjura, secretum prodere noli." }
$$

\section{OpIITES.}

$9 \mathrm{mil}$

These were Christian heretics, so called from the veneration they bad for the serpent that.tempted Eve, and the worship they paid to a real serpent. They pretended, that the serpent was Jesus Christ, and that he taught men the knowledge of good and evil. They distinguished between Jesus and Christ. Jesus, they said, was born of the Virgin, but Christ came down from heaven to be united with him. Jesus was crucified, but Christ had left him to return to heaven. They distinguished the God of the Jews, whom they called Jaldabaoth, from the supreme God; to the former they ascribed the bodies, to the latter the souls of men. They had a live serpent which they kept in a kind of cage; at certain times they opened the cage door, and called the serpent : the animal came out, and, mounting the table, twined itself about some loaves of bread; this bread they broke; and distributed to the company, who all kissed the serpent: this they called their Eucharist.

Mystics.

THESE are a kind of religious sect; distinguished by their professing pure, sublime, and perfect devotion, with an entire disinterested love 
of God, frce from all selfish considerations. The Mystics, to excuse their fanatic ecstasies and amorous extravagancies, allege that passage of St. Paul, "The Spirit itself maketh intercession for us, with groanings that cannot be uttered." "Now if the Spirit," say they, "s reign in us, we must resign ourselves to its motions, and be swaved and guided by its impulse, by remaining in a state of mere inaction." Passive contemplation is that state of perfection to which the Mystics all aspire.

This mystic science sprung up towards the close of the third cen. tury. The authors are not known, but the principles proceeded from the known doctrine of the Platonic school, which was also adopted by Origen and his disciples, namely, that the divine nature was diffused through all human souls, and that the faculty of reason, from which proceed the health and vigour of the mind, was an emanation from God into the soul, and comprehended in it the principles and elements of all truth, human and divine. The Mystics denied that by study men could excite this celestial flane in their breasts; and therefore they disapproved highly of the attempts of those who, by definitions, abstract theorems, and profound speculations, endeavoured to form distinct notions of truth. They maintained that silence, tranquillity, repose, and solitude, accompanied with such acts as tend to extenuate and exhaust the body, were the means by which the hidden and internal word was excited to produce its latent virtues, and to. instruct men in the knowledge of divine things. Those, say they, who behold with a noble contempt all human affairs, who turn away their eyes from terrestrial scenes, and shut all the avenues of the outward senses against the contagious influences of a material world, must necessarily return to God, when the spirit is thus disengaged from the impediments that prevented that happy union. And in this blessed frame they not only enjoy inexpressible raptures from their communion with the supreme Being, but also are invested with the inestimable privilege of contemplating truth undisguised and uncorrupted, in its native purity, while others behold it in a vitiated and delusive form.

The number of the Mystics increased in the fourth century, under the influence of the Grecian fanatic, who gave himself out for Dionysius the Areopagite; and by pretending to higher degrees of perfection than other Christians, and practising greater austerity, their cause gained ground, especially in the eastern provinces, in the fifth century. A copy of the pretended works of Dionysius was sent by Balbus to Lewis the Meek in 824, which kindled the flame of Mysticism in the western provinces, and filled the Latins with the most enthusiastic admiration of this new religion. In the twelfth century, the Mystics, by searching for mysteries and hidden meanings in the plainest expressions, forced the word of God into conformity with their visionary doctrines, their enthusiastic feelings, and the system of religion which they had drawn from the expaissicns of their irregular: fancies. In the thirteenth century they were the most formidable antagonists of the schoolmen; and towards the end of the fourteenth many of them resided, and propagated their tenets, in almost every part of Europe. They had, in the fifteenth century, many persons of 
distinguished merit in their number; and in the seventeenth, previous to the Reformation, if any sparks of real piety subsisted under the prevailing superstitions, they were to be found only among the Mystics. The principles of this sect were adopted by the Quietists in the seventeenth century, and, under different modifications, by the Quakers and Methodists of a later period.

\section{Manicheáns.}

A SECT of ancient heretics, who asserted two principles ; so called from their author, Manes. This heresy had its first rise about A.D.277; and spread principally in Arabia, Egypt, and Africa. St: Epiphanius treats of it at great length. It was a motley mixture of Christianity with the ancient philosophy of the Persians, in which Manes had been instructed during his youth. He combined these two systems, and applied and accommodated to Jesus Christ the characters and actions which the Persians attributed to the god Mithras.

He established two principles, a good and an evil one : the first, a subtle and pure matter, which he called light; did nothing but good; and the second, a gross and corrupted substance, which he called darkness, did nothing but evil. This philosoplyy is very ancient, and Plutarch treats of it at large in his Isis and Osiris. Our souls, according to Manes; were made by the good principle, and our bodies by the evil one ; these two principles being, according to him, co-eternal and independent of each other. Each of these is subject to the dominion of a superintendent being, whose existence is from all eternity. The being who exists over the light is called God; he that rules the land of darkuess, bears the title of hyle or demon. The ruler of the light is supremely happy, and in consequence thereof benevolent and gond; the prince of darkness is unhappy in himself, and desirous of rendering others partakers of his misery; and is evil and malignant. These two beings have produced an immense number of creatures resembling themselves, and distributed them through their respective provinces.

After a contest between the ruler of light and the prince of darkness, in which the latter was defeated, this prince of darkness produced the first parents of the human race. The beings engendered from this original stock, consist of a body formed out of the corrupt matter of the kingdom of darkness, and of two souls; one of which is sensitive and lustful, and owes its existence to the evil principle; the other rational and inmortal, a particle of that divine light which had been carried away in the contest by the army of darkness, and immersed into the mass of malignant matter. The earth was created by God out of this corrupt mass of matter, in order to be a dwelling for the human race, that their captive souls by degrees might be delivered from their corporeal prisons, and the celestial elements extended from the gross substance in which they were involved.

With this view God produced two beings from his own substance, viz. Jesus Christ and the Holy Ghost ; for the Manicheans held a consubstantial Trinity. Christ, or the glorious intelligence, called by the Persians, Mithras; subsisting in and by himself, and residing in the 
sun, appeared in due time among the Jews, clothed with the shadowy form of a human body, to disengage the rational soul from the corrupt body, and to conquer the violence of malignant matter. The Jeys, incited by the prince of darkiless, put him to an ignominious death, which he suffered, not in reality, but only in appearance, and according to the reality of men. When the purposes of Christ were aceomplished, he returned to his throne in the sun, appointing his apostles to propagate his religion, and leaving to his followers the promise of the Paraclete or Conforter, who is Manes the Persian. Those souls who believe Jesus Christ to be the Son of God, renounce the worship of the God of the Jerv, who is the prince of darkness, and obey the laws delivered by Christ, and illustrated by Manes the Comforter, are gradually purified from the contagion of matter, and their purification being completed, after having passed through the two states of trial, by fire and water, tirst in the moon and then in the sun, their bodies return to the original mass, (for the Manicheans denied the resurrection of bodies, and their souls ascend to the regions of light; but the souls of those who have neglected the salutary work of purification, pass after death into the bodies of other animals or natures, where they remain till they have accomplished their probation. Some, however, more perverse and obstinate, are assigned to a severe course of trial, being delivered over for a time to the power of malignant spirits, who torment them in various ways. After this, a fire shall break forih and consume the world; and the prince and powers of darkness shall return to their primitive seats of anguish and misery, in which they shall dwell for ever. These mansions shall be surrounded by an invincible guard, to prevent their ever renewing a war in the regions of light.

Manes borrowed many things from the ancient Gnostics; on which account many consider the Manicheans as a branch of the Gnostics. In truth the Manichean doctrine was a system of philosophy rather than of religion. They made use of amulets, in imitation of the Basilidians, and are said to lave made profession of astronomy and astrology. They denied that Jesus Christ, who was only God, assumed a true human body, and maintained that it was imaginary, and therefore they denied his incarnation, death, \&c. They pretended that the law of Moses did not come from God, or the good principle, but from the evil one; and that for this reason it was abrogated. They rejected almost all the sacred books, in which Christians look for the sublime truths of their holy religion. They affirmed that the old Testament was not the word of God, but of the prince of darkness, Who was constituted by the Jews in the place of the true God. They abstained entirely from eating the flesh of any aninal; following herein the doctrine of the ancient $P_{y}$ thagoreans: they also condemned marriages. The rest of their errors may be seen in St. Epiphanius and St. Augustine; which last having been of their sect, may be presumed to have been thoroughly acquainted with them.

Though the Manichees professed to receive the books of the New Testament, yet in effect they only took so much of them as suited with their own opinion. They first formed to themselves a certain idea or scheme of Christianity; and to this adjusted the writings 
of the apostles, pretending that whatever was inconsistent with this had been foisted into the New Testament by later writers, who were half Jews On the other hand, they nade fables and apocryphal books pass for a postolical writings, and are even suspected to have forged several others, the better to maintain their errors.

The rule of life and manners, which Manes prescribed to his followers was most extravagalliy rigrous and severe. However, he divided his disciples into two classes ; one of which comprehended the perfect Christians, under the name of the elect, and the other, the imperfect and feeble, under the title of auditors or hearers. The elect were obliged to a rigorous and entire abstinence from flesh, eggs, milk, fish, wine, all intoxicating drink, wedlock, and all gratifications; and to live in a state of the severest penury, nourishing their emaciated bodies with bread, herbs, pulse, and melons, and depriving themselves of all the comforts that arise from the moderate indulgence of natural passions, and also from a variety of innocent and agreeable pursuits. The auditors were allowed to possess housès, lands, and wealth, to feed on flesh, to enter into the bonds of conjugal tenderness, but this liberty was granted them with many limitations, and under the strictest conditions of moderation and temperance.

The general assembly of the Manicheans was headed by a president, who represented Jesus Christ. There were joined to him twelve rulers or masters, who were designed to represent the twelve apostles, and these were followed by seventy-two bishops, the images of the seventy-two disciples of our Lord. These bishops had presbyters or deacons under them; and all the members of these religious orders were chosen out of the class of the elect.

Their worship was simple and plain, and consisted of prayers, reading the scriptures, and hearing public discourses, at which both the auditors and elect were present. They observed baptism and the eucharist, and kept the Lord's day, observing it as a fast. They likewise kept Easter and Pentecost. Towards the fourth century the Manicheans concealed themselves under various names, which they successively adopted, and changed, in proportion as they were discovered by them. Thus they assumed the names of Encratites, Apotastics, Sacophori, Hydroparastates, Solitaires, and several others, under which they lay concealed for a certain time, but could not, however, long escape the vigilance of their enemies. About the close of the sixth centyry this sect gained a very considerable influence, particularly among the Persians.

In the twelfth century, this sect took a new face, on occasion of one Constantine, an Armenian, and an adherer to it, who took upon himself to suppress the reading of all other books besides the Evangelists, and the epistles of St. Paul, which he explained in such manner as to make them contain a new system of Manicheism. $\mathrm{He}$ entirely discarded all the writings of his predecessors, rejecting the chimeras of the Valentinians, and their thirty zeons; the fable of Manes with regard to the origin of rain; and other dreams, - but still retained the impurities of Barsilides. In this manner he reformed Manicheism insomuch that his followers made no scruple of anathematizing Scythian Buddas, called also Addas and Terebinth, the contemporaries 
and disciples, as some say, and, accorting to others, the predecessors and masters of Manes; and even Manes himself, Constantine being now their great apostle. After he had seduced an infinite number of people, he was at last stoned by order of the emperor. This sect prevailed in Bosuia and the adjacent provinces about the close of the fifteenth century, propagated their doctrines with confidence, and held their reiigious assemblies with impunity.

\section{Assassins, or Hassassing.}

THESE people were a sect of Mahometans, and appeared first about the year 890. Their earliest chief was a pretended proplet, named Karmal, who drew many followers by releasing them from all the restrictions common to the disciples of Mahomet, and promising unbounded enjoyment to such as implicitly obeyed his commands. In process of time these persons obtained possession of ten or twelve cities, and chose a leacler or king, to whom they gave the name of the Old Man of the Mountains, under whose direction they perpetrated the most savage yet secret massacres. "It being a part of their creed, for those to expect perfect happiness and every sensual enjoyment hereafter, who perished in the performance of their leader's commands; their devotion to the will of their chief may be easily imagined, and a singular instance is recorded by Ebn Amid in his History of the Saracens. In 1090, Malek, third sultan of the Seljukians of Iran, sent a messenger to Hassan, the Old Man of the Mountains, at this period, calling on him for obedience, and accompanying the demand with certain threats as the consequence of refusal. Hassan desired the ambassador might be admitted; and, having his troops assembled round him, commanded one of them to destroy himself: the man, without the slightest hesitation, stabbed himself to the heart, and fell dead at his sovereign's feet. He then commanded a second to precipitate himself from the nearest tower; and was instantaneously obeyed. "Go," said Hassan, "to the sultan your master, and inform him that I have no other reply to make him, excepting, that I have twenty thousand troops equally obedient with those you have this day witnessed." The sultan took the hint ; and, says the historian, having other matters on lis hands, thought it not advisable to prosecute a war against that prince.

The Assassins in 1192 assassinated Conrad; marquis of Montferrat, who had rendered hinself obnoxious to them by putting to death some of their companions. In 1231, they destroyed Lewis of Bavaria; and indeed the greatest and most powerful monarchs stood in awe of their displeasure, since no precaution was sufficient to guard any person against the effects of their revenge. They were destroyed, in 1257, by Haloen, the cham of Tartary, although a remnant, under the title of Ismaelians, existed so late as 1280, when they were finally extirpated by the Mamelukes.

\section{Alaror.}

THIS, in the Mabometan theology, is the partition wall that separates heaven from hell. Whe word is plural, and properly written 
Al araf. It is derived from the A rabic verb arafa, to distinguish. Al-araf Gives the denomination to the seventl chapter of the koran, wherein. unenion is made of this wall. Mahornet seems to have copied his Al-araf, either from the great gulf of separation mentioned in the New Testament, or from the Jewish writers, who also speak of a thin wall dividing heaven from hell. Mahometan writers differ extremely as to the persons who are to be found in Al-araf. Some take it for a sort of limbus for the patriarchs, prophets, \&c. others place here such whose good and evil works so exactly balance each other, that they deserve neither reward nor punishment., Others imagine this intermediate space to be possessed by those who, going to war without their parents' leave, and suffering martyrdom there, are excluded paradise for their disobedience, yet escape hell because they are maltyrs.

Eonians.

THESE were the followers of Eon, a wild fanatic of the province of Bretagne, in the 12 th century, whose brain was disordered. He concluded, from the resemblance between Eum, in the form for exorcising malignant spirits, viz. Per Eum, qui venturus est judicare vivos et mortuos, and his own name Eon, that he was the Son of God, and ordained to judge the quick and the dead. He was solemnly condemned by the council at Rheims, in 1148, at which pope Eugenius III. presided, and ended his days in a miserable prison. He left a number of followers, whom persecution could not persuade to abandon his cause, or to renounce an absurdity, which, says Moshein, one would think could never have gained credit but in Bedlam.

\section{Superstitious Adoration of THE Cross.}

THE adoration of the cross appears to have been practised in the ancient church, inasmuch as the heathens, particularly Julian, reproach the primitive Christians with it, and we do not find that their, apologists disclaimed the charge. Mornay, indeed, asserted that this had been done by St. Cyril, but conld not support his allegation at the conference of Fontainbleau. St. Helena is said to have reduced the adoration of the cross to its first principle, as she adored in the wood, not the wood itself, which would have been direct idolatry, but Him who had been nailed to this wood. With such modification, some Protestants have been induced to admit the adoration of the cross. John Huss. admitted of the phrase, provided it were expressly added, that the adoration was to the person of Christ.

But however Roman Catholics may seem. to triumph by such distinctions and mitigations, it is well known they have no great place in their own practice. Imbert, the good prior of Gascony, was severely prosecuted, in 1683 , for telling the people, that in the ceremony of adoring the cross, practised in that church on Good Friday, they were not to adore the wood, but Christ who was crucified on it. The curate of the parish told him the contrary:-it was the wood! the wood! they were to adore. Imbert replied, it was Christ, not the 
wood, for which he was cited before the archbishop of Bourdeaux, suspended from his functions, and even threatened with chains and perpetual imprisonment. It little availed him to cite the bishop of Meaux's distiuction; it was answered, that the church allowed it not.

\section{DragOONING.}

THis was one of the methods used by papists for converting refractory heretics. The following account of the dragooning of the French Protestants after the revocation of the edict of Nantes, under Louis XIV., is taken from a French piece translated in 1686. The troopers, soldiers, and dragoons went into the Protestants houses, where they marred and defaced their household stuff, broke their looking-glasses and other utensils and orlaments, let their wine run alout their cellars, and threw about their corn and spoiled it. Those things which they could not destroy in this manner, such as the furniture of beds, linens, wearing apparel, plate, \&c. they carried to the market-place, and sold them to the Jesuits and other Roman Caíholics. By these meails the Protestants, in Montauban alone, were in four or five days stripped of above a million of money. But this was not the worst. They turned the dining-rooms of gentlemen into stables for their horses, and treated the owners of the houses where they quartered with the highest indignity and cruelty, lashing them about from one to another day and night without intermission, not suffering them to eat or drink ; and when they began to sink under the fatigue and pains they had undergone, they laid them on a bed, and, when they thought them somewhat recovered, made them rise, and repeated the same tortures. When they saw the blood and sweat run down their faces and other parts of their bodies, they sluiced them with water, and, putting over their heads liettledrums turned upside down, they made a continual din upon them till these unhappy creatures lost their senses.

When one part of these tormentors were weary, they were relieved by another, who practised the same cruelties with fresh vigotir. At Negreplisse, a town near Montauban, they hung up Isaac Favin, a Protestant citizenn of that place, by his arm-pits, and tormented him a whole night by pinching and tearing off his flesh with pincers. They made a great fire round a boy about twelve years old, who, with hands and eyes lifted up to heaven, cried out, "My God, help me!" And when they found the youth resolved to die rather than renounce his religion, they snatched him from the fire just as he was on the point of being burit. In several places the soldiers applied red-hot irons to the hands and feet of men, and breasts of women. $A t$ Nantes they hung up several women and maids by their feet, and others by their arm-pits, and thus exposed them to public view stark naked. They bound to posts mothers that gave suck, and let tlieir sucking infants lie languishing in their sight for several days and nights, crying, mourning, and gasping for life. Some they bound before a great fire, and, being half roasted, let them go: a punishment worse than death.

Amidst a thousand hideous cries, and a thousand blasphemies, they hung up men and women by the hair, and some by the feet, on hooks 
in chimneys, smoking them with wisps of wet hay till they were suffocated. They tied some under the arms with ropes, and plunged them again and again into wells; they bound others like criminals, put them to the torture, and with a funnel filled them with wine, till the fumes of it took away their reason, when they made then say they consented to be Catholics. They stripped them naked, and, after a thousand indignities, stuck them with pins and needles from head to foot. They cut and slashed them with knives; and sometimes with red-hot pincers took hold of them by the nose and other parts. of the body, and dragged them about the rooms till they made them promise to be Catholics, or till the cries of these miserable wretches, calling upon God for help, forced them to let them go. They beat them with staves, and thus bruised, and with broken bones, dragged them to the church, where their forced presence was taken for an abjuration. In some places they tied fathers and husbands to their bed posts, and before their eyes ravished their wives and daughters with impunity. They blew up men and women with bellows till they burst them.

If any, to escape these barbarities, endeavoured to save themselves by flight, they pursued them into the fields and woods, where they shot at them like wild beasts, prohibiting them from departing the king. dom (a cruelty never practised by Nero or Dioclesian) upon pain of coufiscation of effects, the galleys, the lash, and perpetual imprison. ment, insomuch that the prisons of the sea-port towns were crammed with men, women, and children, who endeavoured to save themselves by fight from their dreadful persecution.

With these scenes of desolation and horror the popish clergy. feasted their eyes, and made them only a matter of laughter and sport. "Thongh my heart aches, says the writer of this tract, "whilst I am relating these barbarities, yet, for a perpetual nemorial of the infernal cruelty practised by these monsters, I beg the reader's patience, to lay before him two other instances, which, if he has a heart like mine, he will not be able to read without watering these sheets with his tears.

"The first is of a young woman, who being brought before the council, upon refusing to abjure her religion, was ordered to prison. There they shaved her head, singed off the hair from other parts of her body: and having stripped her stark naked, led her through the streets of the city, where many a blow was given her: then they set her up to the neck in a tub full of water, where after she had been for a while, they took her out, and put on her a shift dipped in wine, which, as it dried and stuck to her sore and bruised body, they snatched off again, and then had another, ready dipt in wine, to clap on her. This they repeated six times, thereby making her body exceeding raw and sore. When all these cruelties could not shake her constancy, they fastened her by the feet in a kind of gibbet, and let her hang in that posture, with her head downward, till she expired. - The other is of a man in whose house were quartered some of these missionary dragoons. One day, having drunk very plentifully of his wine, and broken their glasses at every health, they filled the floor with the fragments, and ofien walking over them, reduced them to very mall pieces. This 
done, in the insolence of their mirth, they resolved on a dance, and tuld their protestant host that he must be one of their company; but as he would not be of their religion, he must dance quite barefoot; and thus barefoot they drove him about the room, treading on the sharp points of the broken glasses. When he was no longer able to stand, they laid him on a bed, and in a short time stripped him stark naked, and rolled him from one end of the room to another, till every part of his body was full of the fragments of glass. After this they dragged him to his bed, and having sent for a surgeon, obliged him to cut out the pieces of glass with his instruments, thereby putting him to the most exquisite and horrible pains that can possibly be conceived.

"These, fellow Protestants, were the methods used by the most Christian king's apostolic dragoons to convert his heretical subjects to the Roman Catholic faith. These, and many other of the like nature, were the torments to which Lewis XIV. delivered them over, to bring them to his own church; and as popery is unchangeably the same, these are the tortures prepared for you, if ever that religion should be permitted to become settled amongst you ; the consideration of which inade Luther say of it, what every man who knows ally thing of Christianity must agree with him in, "If you had no other reason. to go out of the Roman church, this alone would suffice, that you see and hear how, contrary to the law of God, they shed innocent blood. This single circumstance shall, God willing, ever separate me from the papacy; and if I was now subject to it, and could blame nothing in any of their doctrines, yet for this crime of cruelty I would fly from her communion as from a den of thieves and murderers."

\section{Flagellantes.}

THESE were a sect of wild fanatics, who chastised and disciplined. themselves with whips in public. This sect arose in Italy in 1260: its author was one Railler a hermit; and it was propagated through almost all the countries of Europe. It was probably no more than the effect of an indiscreet zeal, founded on erroneous ideas of the Deity. A great number of persons of all ages and sexes made processions, walking two by two with their shoulders bare, which they whipped till the blood ran down, to obtain mercy from God, and appease his indignation against the wickedness of the age. They were then called the Devout; and having established a superior, he was called the general of the Devotion. Though the primitive Flagellantes were exemplary in point of morals, yet they were soon joined by a turbulent rabble, who were infected with the most ridiculous and iinpious opinions, so that the superiors and pontiffs thought proper. to put an end to this religious frenzy, by declaring all devout whipping contrary to the divine law, and prejudicial to the soul's eternal interest. However, this sect revived in Germany towards the middle of the fourteenth century, and, rambling through many provinces, occasioned great disturbances.

They held, among other things, that flagellation was of equal virtue with the sacraments; that the forgiveness of all sins was to be obtained by 
it from God, without the merits of Jesus Christ; that the old law of Christ was soon to be abolished, and that a new law, which enjoined the baptisin of blood to be administered by whipping, was to be substituted in its place: 'upon which Clement VII. by all injudicious policy, thundered out allathemas against the Flagellantes, who were burnt by the inquisitors in several places; but they appeared again in Thuringia and Lower Saxony in the fifteenth century, and rejected not only all the sacraments, but every branch of external worship, placing their only hopes of salvation in faith and flagellation, to which they added other strange doctrines concerning evil spirits. Their leader. Conıad Schmidt, and many others, were burnt by German inquisitors about $A$. D. 1414.

\section{Brethren and Sisters of the Free Spirit.}

THIs was an appellation assumed by a religious sect which sprung up towards the close of the thirteenth century, and gained many adherents in Italy, France, and Germany. They took their denomination from the words of St. Paul, Rom. viii. 2, 14. and inaintained that the true children of God were invested with perfect freedom from the jurisdiction of the law. They were enthusiasts to a degree of distraction, both in their principles and practice. They resembled the Beghards (by which name they were sometimes called) in their aspect, apparel, and manner of living. Some of their professed principles resembled those of the Pantheists; for they held that all things flowed by emanation from God; that rational souls were portions of the Deity; that the universe was God; that by the power of contemplation they were united to the Deity, and acquired hereby a glorious and sublime liberty, from both the sinful lusts and common instincts of nature; and hence they concluded, that the person who was thus absorbed in the abyss of the Deity, became a part of the Godhead, and was the son of God in the same sense and manner as Christ, and that he was freed from the obligation of all laws, human and divine. They treated with contempt all Christian ordinances, and all external acts of religion, as unsuitable to the state of perfection at which they were arrived. Some of them were honest but deluded enthusiasts, and they endured the torments inflicted on them by the inquisitors with astonishing heroism and triumph.

\section{WHITE BRETHREN.}

THESE were the followers of a priest from the Alps, about the beginning of the fourteenth century, who was arrayed in a white garment, and as they were also clothed in white linen, they were distinguished by this title. Their leader carried about a cross, like a standard, and his apparent sanctity and devotion drew together a number of followers. This enthusiast practised many acts of mortification and penance, endeavoured to persuade the European nations to renew the holy war, and pretended that he was favoured with divine visions. Boniface IX. ordered him to be appreliencled and commisted to the flames, upon which his followers dispersed. 


\section{RELIGIOUS FASTING.}

Recigrous fasting has been practised by most nations from the remotest antiquity. Some diviues even pretend its origin was in the terrestrial paradise, where our first parents were forbidden to eat of the tree of knowledge. But this seems carrying the matter too far; it is certain that the Jewish church has observed fasts ever since its first institution. Nor were the neighbouring heathens; viz. the Egyptians, Phœnicians, and Assyrians, without their fasts. The Egyptians, according to Herodotus, sacrificed a cow to Isis, after having prepared themselves by fasting and prayer; a custom which he likewise ascribes to the women of Cyrene. Porphyry affirms, that the Egyptians, before their stated sacrifices, always fasted many days, some times six weeks, and that the least behoved to be for seven days, during all which time the priests and devotees not only abstained from flesh, fish, wine, and oil, but even from bread, and some kinds of pulse. These austerities were communicated by them to the Greeks, who observed their fasts much in the same manner. The Athenians had the Eleusinian and Thesmoporian fasts, the observation of which was very rigorous, especially among the women, who spent one whole day sitting on the ground in a mournful dress, without taking any nourishment. In the island of Crete, the priests of Jupiter were obliged to abstain all their lives from fish, flesh, and baked meats. Apuleius informs us, that whoever had a mind to be initiated in the mysteries of Cybele, were obliged to prepare themselves by fasting ten days; and, in short, all the pagan deities, whether male or female, required this duty of those that desired to be initiated into their mysteries, - of their priests and priestesses that gave the oracles, and of those who came to consult them.

Among the heathens, fasting was also practised before some of their military enterprises. Aristotle informs us, that the Lacedemonians having resolved to succour a city of the allies, ordained a fast throughout the whole extent of their dominions, without excepting even the domestic animals; and this they, do for two ends, one to spare provisinns in favour of the besieged, the other to draw down the blessing of heaven upon their enterprise. The inhabitants of Tarentum, when besieged by the Romans, demanded succours from their neighbours of Rhegium, who immediately commanded a fast throughout their whole territories. Their enterprise having proved successful by their throwing a supply of provisions into the town, the Romans were obliged to raise the siege; and the Tarentines, in memory of this deliverance, instituted a perpetual fast.

Fasting has for ages been reckoned a particular duty among philosophers and religious people, sone of whom have carried their abstinence to an incredible length. At Rome it was practised by kings and emperors themselves. Numa Pompilius, Julius Casar, Augustus, Vespasian, \&c. had their stated fast-days; and Julian the Apostate was so exact in this observance as to outdo the priests themselves, and even the most rigid philosophers. The Pythagoreans kept a continual Lent; but with this difference, that they believed the use of fish to be equally unlawful to that of tlesh. Besides their constant temperance, they 
also frequently fasted rigidly for a very long time. In this respect, however, they were all outdone by their master Pythagoras, who conrinued his fasts for no less than forty days together. Even Pollonius Tyaneus, one of his must famous disciples, could never come up to him in the length of his fasts, though they greatly exceeded those of the ordinary $P$ ythagoreans.

The Gymnosophists, or brachmans of the East, are also very remarkable for their severe fastings, and the Chinese, according to Father le Conte, have also their stated fasts, with forms of prayer for preventing barrenness, inundations, earthquakes, \&ze. The Mahometans, too, who possess so large a part of Ásia, are very remarkable for tlie strict observance of their fasts, and the exactness of their dervises in this respect is extraordinary. Fasting was often used by the heathens for superstitious purposes; sometimes to procure the interpretation of dreams ; of others, to be an antidote against their pernicious consequences. A piece of superstition still prevails a mong the Jews, who, though expressly forbidden to fast on sabbath-days, think themselves at liberty to dispense with this duty when they have frightful and unlucky dreams the night preceding, that threaten them with great misfortunes. On these occasions, they observe a formal fast the whole day, and at night the patient, having invited three of his friends, ad: dresses himself to them seven times in a very solemn maner, saying, "May the dream I have had, prove a lucky one!" and his friends answer as many times, "Amen, may it be lucky, and God make it soly After which, in order to encourage him, they conclude the cerenony with these words of Ecclesiastes, "Go, eat thy bread with joy;" and then set themselves down to table. They have also added fasts not commanded in the law of Moses, particularly three, in memory of sore distresses their nation has suffered at different times.

7n The abstinence of the ancient Jews commonly lasted iwenty-seven or twenty-eight hours at a time, beginning before sunset, and not ending till some hours after sunset next day. On these days they were obliged to wear white robes, in token of grief and repentance; to cover themselves with sackcloth, or their worst clothes; to lie on ashes, to sprinkle them on their heads, \&c. Some spent the whole night, and the day following, in the temple or synagogue, in prayers and other devotions, barefooted, with a scourge in their hands, of which they sometimes made a good use, to raise their zeal. To complete their abstinence, at night they were to eat nothing but a little bread dipped in water, with some salt for seasoning; except they chose to add to their repast some bitter herbs and pulse.

$\rightarrow$ The ancients, both Jews and pagans, had also their fasts for purifying the body, particularly the priests, and such as were any way employed at the altars; for when noeturnal disorders happened to these, it was unlawful for them to approach all the next day, which they were bound to employ in purifying themselves. On this account, at great festivals, where their ministry could not be dispensed with, it was usual for them, on the eve thereof, not only to fast but also to abstain from sleep for the greater certainty: for this purpose the high-priest had under-ofhers to viake him, if overtaken with sleep, against which other preservatives were also made use of. 


\section{A Recluse.}

A RECLUSE, among the Papists, is a person shut up in a small cell of an hermitage or monastery, and cut off, not only from all conversation with the world, but even with the house. This is a kind of voluntary imprisonment, from a motive either of devotion or penance. The word is also applied to incontinent wives, whom their husbands procure to be thus kept in perpetual imprisonment in some religious house. Recluses were anciently very numerous. They took an oath never to stir out of their retreat, and, having entered it, the bishop set his seal upon the door; and the recluse had every thing necessary for the support of life conveyed through a window. If he was a priest, he was allowed a small oratory, with a window which looked into the church, through which he might make his offerings at the mass, hear the singing, and answer those who spoke to him; but this window had curtains before it, so that he could not be seen. He was allowed a little garden, adjoining to his cell, in which he might plant a few herbs, and breathe a little fiesh air. If he had disciples, their cells were contiguous to his, with only a window of communication, through which they conveyed necessaries to him, and received his instructions. If a recluse fell sick, his door might be opened for persons to come in and assist him, but he himself was not to stir out.

\section{ABDALS}

THE Abdals are a kind of saints, in the Eastern countries, supposed to be inspired to a degree of madness. This word comes, perhaps, from the Arabic Abdallah, the servant of God. The Persians call them, devaneh khodes, similar to the Latins' way of speaking of their prophets and sibyls, q. d. furentes deo, raging with the god. They are often carried by excess of zeal, especially in the Indies, to run about the streets, and kill all they meet of a different religion, of which travellers furnish many instances. The English call this "running a muck," from the name of the instrument, a sort of poniard, which they employ on these desperate occasions. If they are killed before they have done much mischief, they reckon it highly meritorious, and are esteemed by the vulgar, martyrs for their faith.

\section{Bridgetins.}

THESE were a religious order, denominated from their founder St. Bridget. The Bridgetins are sometimes also called, the Order of our Saviour; it being pretended that Christ himself dictated their rules and constitutions to St. Bridget. In the main, the rule is that of St. Augustine; only with additions pretended to have been revealed by Christ. The first monastery of the Bridgetins' order was erected by the foundress A. D. 1344 in the diocese of Lincopen, on the model of which all the rest were formed. The constitution of these houses was very singular: though the order was principally intended for nuns, who were to pay a special homage to the holy Virgin, there were also many friars of it, to minister to them spiritual assistance 
The number of nuns is fixed at sixty in each monastery, and that of friars to thirteen, answerable to the number of apostles, of whom St. Paul made the thirteenth; besides which there are four deacons, to represent the four doctors of the church, St. Ambrose, St. Augustine, St. Gregory and St. Jerome; and eight lay brother's, making;, together with the nuns, the number of seventy-two disciples.

The order being instituted in honour of the Virgin, the direction is committed to an abbess, who is superior both of the nuns and of the friars. Each house consists of two convents or monasteries, sepa: rately enclosed, but having one church in common; the nuns being placed above, and the friars on the ground. The Bridgetins profess great mortification, poverty, and self-denial, as well as devotion, and they are not to possess any thing they can call their own, not so much as a halfpenny, nor even to touch money on any account.

This order spread much throngh Sweden, Germany, the Netherlands, \&c. In England we read of but one monastery of Bridgetins, built by Henry $\mathrm{V}$. in 1415 , opposite to Richmond, now called Sionhouse; the ancient inhabitants of which, after the dissolution, settled at Lisbon. The revenues were rechoned at $1495 l$. per annum.

\section{Bangiorian Congtroversy.}

THIs celebrated controversy arose from a sermon preached before king George I. of England, by Dr. Hoadley, bishop of Bangor, on March 31, 1\%17. Mr. William Belsham, in his Memoirs, vol. i. p. 174, gives the following account of this controversy. "As the foundation of this famous discourse, the bishop chose the declaration of Christ to Pilate, "My kingdom is not of this world;" and the direct and undisguised object of it was to prove that the kingdom of Christ, and the sanctions by which it is supported, were of a llature wholly intellectual and spiritual; that the church, taking the term in its most unlimited signification, did not, and could not, possess the slightest degree of authority under any commission, or pretended commission, derived from man; that the church of England, and all other national churches, were merely civil or human institutions, established for the purpose of diffusing and perpetuating the knowledge and belief of Christianity, which contained a system of truths, not in their nature differing from other truths, except by their superior weight and importance, and which were to be inculcated in a manner analogous to other truths; demanding only, from their more interesting import, proportionally higher degrees of care, attention, and assiduity, in the promulgation of them.

It is scarcely to be imagined, in these times, with what a degree of false and malignant, rancour these plain, simple, and rational principles were attacked by the zealots and champions of the church. On the meeting of the couvocation, a committee was appointed to examine this famous publication, and a representation was quickly drawn up, in which a most heavy charge was passed upon it, as tending to subvert all goverument and discipline in the church of Christ, to reduce his lingdom to a state of anarchy and confusiou, to impugn and impeach the royal supremacy in matters ccclesiastical, and the 
authority of the legislation to enforce obedience in matters of religion by severe sanctions.

A sudden stop, however, was soon put to these disgraceful pro. ceedings, by royal prorogation; and from that period the convocation has never been convened, but as a matter of mere form, and for the purpose of being again prorogued. The controversy which then commenced was carried on for several years with great ability and animation on the part of the bishop, and by various excellent pensthough opposed by men whose learning and talents gave an artificial lustre to bigotry and absurdity. No controversy, upon the whole, ever more fully and completely answered the purpose intended by it. The obscurity in which this subject had been long involved, was dissipated; the public anind was enlightened and convinced; church authority (the chimera vormiting flames) was destroyed; and the name of Hoadley will be transmitted from generation to generation with increase of honotir, of esteem, and grateful veneration.

\section{Rosicrucians.}

THis name was assumed by a sect or cabal of hermetical philosophers, who arose, or were at least first taken notice of, in Gernany, in the beginning of the fourteenth century. They bound themselves together by a solemn secret, which they all swore inviolably to preserve; and obliged themselves, at their admissinn into the order, to a strict observance of several of the established rules. They pretended to know all sciences, and chiefly medicine; whereof they published themselves the restorers. They pretended to be masters of many important secrets, and, among others, of the philosopher's stone; all which they affrmed to have received by tradition from the ancient Egyptians, Chaideans, the Magi, and Gymnosophists. - They have been distinguished by several names; from the several branches of their doctrine. Because they pretend to protract the period of human life by means of certain nostrums, and even to restore youth, they were called Immortales; as they pretended to know all things, they have been called Illuminati; and because they have made no appearance for several years, they have been called the Invisible Brothers.' Their society is often signed by letters F. R. C. which some of them interpret, Fraties Roris Cocti; it being pretended, that the matter of the philosopher's stone is dew concocted, exhaled, \& $c$. Some make the present flourishing society of Freemasons, a branch of Rosicrucians, or rather the Rosicrucians themselves, under a new name, frame, of relation, viz. as retainers to building. It is certain there are some Freemasons who have all the characters of Rosicrucians; but the zera and original of masonry and that of Rosicrucianism, here fixed from Vaudreus, who has written expressly on the subject, are not cunsistent. The denomination appears to be derived from chemistry.

It is not compounded, says Mosheim, as many imagine, of the words rosa and crux, rose and cross, but of ros, dew, and crux. of all natural bodies, dew was deemed the most powerful solvent of gold; alid the cross, in the chemical language, is equivalent to light, because the figure of a cross exhibits at the same time three letters, of which 
the word uvx or light, is compounded. Hence a Rosicrucian philosopher is one who, by the assistance of the dew, seeks for light, or the philosophers stone. See Gassendi's Examen Philosophia Fluddana, sect. 15. tom. iii. p. 261, and Renaudot's Conferences Publiques, tom. iv. p. 87.

At the head of these fanatics were, Robert Fludd, an English physician, Jacob Behmen, a mystic writer, and Michael Mayer. The principles which servé as a kind of centre of union to the Rosicrucian society, are the following, They all maintain that the dissolution of budies by fire is the oily way by which men arrive at true wisdom, and come to discern the first principles of things. They all acknowledge a certain analogy and harmony between the powers of nature and the doctrines of religion, and believe that the Deity governs the kingdom of grace by the same laws with which he rules the kingdom of nature; and hence they use chemical denominations to express the truths of religion. They all holl that there is a sort of divine energy, or soul, diffused through the universe, which some call the archeus, others the universal spirit, \&c. They all talk in the most superstitious manner of what they call the signatures of things, of the powers of stars over all corporeal beings, and their particular influence upon the human race, of the efficacy of magic; and the various ranks and orders of demons. These demons they divide into two orders, sylplis and gnomes; from which system Pope borrowed his beautiful machinery for the Rape of the Locke. In fine, the Rosicrucians and all their fanatical followers agree in throwing out the most crude incomprehensible notions and ideas, in the most obscure, quaint, and mystical expressions.

\section{DANCERS.}

THe Dancers were a sect which sprung up about 13\%3, in Flanders, and places adjacent. It was their custom all of a sudden to fall a dancing, and, holding each other's hands, to continue thereat till, being nearly suffocated with violent exertions, they fell down breathless together. During these intervals of vehement agitation, they pretended to be favoured with wonderful visions. Like the Whippers, they wandered from place to place, bégging their victuals, holding their secret assemblies, and treating the priesthood and worship of the church with the utmost contempt. "Thus it appears," as Dr. Haweis observes, "that the French Convulsionists and the Welsh Jumpers, have had their predecessors of the same stamp. There is nothing new under the sun."

\section{HatTemists.}

THESE are a modern Dutch sect, so denominated from Pontian Van Hattem, a minister in Zealand, towards the close of the seventeenth century, who being addicted to the sentiments of Spinoza, was degraded from his pastoral office. The Verschousts and Hattemists resemble each other in their religious systems, though they never formed one communion. The founders of these sects deduced from the doctrine 
of absolute decrees a system of uncontrollable necessity; they denied the difference between moral good and evil, and the corruption of human nature, whence they concluded that mankind were under no. obligation to correct their manners, improve their minds, or obey the divine laws; that the whole of religion consisted, not in acting, but in suffering; and that all the precepts of Jesus Christ are reducible to this one, - that we bear with cheerfulness and patience the events that happen to us through the divine will, and make it our constant and only study to maintain a permanent tranquillity of mind.

Thus far they agreed; but the Hattemists farther affirmed, that Christ made no expiation for the sins of men by his death, but had only suggested to us, by his mediation, that there was nothing in us that could offend the Deity; this, they say, was Christ's manuer of justifying his servants, and presenting them blameless before the tribunal of God. It was one of their distinguishing tenets, that God does not punish men for their sins, but by their sins. These two sects, says Mosheim, still subsist, though they no longer bear the names of their founders.

\section{ILLUMINATI.}

THIs name was assumed by a secret society, founded on the first of May, 1776, by Adam Weishaupt, professor of canon law in the university of Ingoldstadt. The avowed object of this society was, " to diffuse from secret societies, as from so many centres, the light of science over the world; to propágate the purest principles of virtue; and to reinstate mankind in the happiness they possessed during the golden age fabled by the poets. Such a philanthropic object was doubtless well adapted to make a deep impression on the minds of ingenuous young men, and to such alone did Dr. Weishaupt first address himself. But " the real object," we are assured by Professor Robison and Abbe Barnel, "was, by clandestine arts, to overthrow. every government, and every religion; to bring the sciences of civil life into contempt; and to reduce mankind to that imaginary state of nature, when they lived independent of every other, on the spontaneous productions of the earth."

Freemasonry being in high reputation all over Europe when Weishaupt first formed the plan of his society, he availed himself of its secrecy, to introduce his new order, of which he constituted himself general, after initiating some of his pupils, whom he styled Areopagites, into its mysteries. And when report spread the news throughout Germany, of the institution of the order of Illuminees, it was generally considered as a mere college lodge, which could in terest the students no longer than during the period of their studies. Weishaupt's character too, which at that time was respectable for morality as well as erudition, prevented all suspicion of his harbouring any such dark designs as have since come to light: but it would far exceed the limits to which our work is restricted, to give even an outline of the nature and constitution of this extraordinary society; of its secrets and mysteries; of the deep dissimulation, consummate hypocrisy, and shocking impiety of its founder, and his associates; of his Jesuitical 
art in concealing their real objects, and their incredible industry and astonishing exertions in making converts; of the absolute despotism and complete system of espionage established throughout the order; of its diferent degrees of Novices, Minervals, Minor and Major Illuminees, Epopts or Priests, Regents, Magi, and Man-kings; of the Recruiters or Insinuators, with their various subtle methods of insinuating into all characters and companies; of the blind obedience exacted of the novices; and the absolute power of life and death assumed by the order, and conceded by the novices; of the dictionary, geography, kalendar, and cipher of the order; of the new names assumed by the members, such as Spartacus by Weishaupt, because he pretended to wage war against oppressors; Cato, by Zwack; Ajax, by Massenhausen, \&c.; of the Minerval academy and library; of the questions proposed to the candidates for degrees, and the various ceremonies of admission to each ; of the pretended morality, but real blasphemies and absolute atheism, of the founder and his tried friends. Such of our readers as wish to be fully informed of these matters; we must refer to Abbe Barruel's works, and to Professor Robison's Proof of a Conspiracy against all Religions and Governments of Europe.

But while we give full credit to the general facts related in these works, we cannot help expressing some doubts about the ultimate object of Dr. Weishaupt and his associates in this conspiracy. That men of their principles should secretly conspire to overthrow most of the religions and governments at present in Europe, is by no means incredible; that they should even prevail on many well-meaning philanthropists, who are no enemies to rational religion or good goverument, to join them, is very credible ; for it would be paying a poor compliment to our own constitution in church and state, were we not to acknowledge, that most of the other governments and religions in Europe are so full of despotism and superstition, that no true friend of mankind would regret their overthrow, could it be accomplished without bloodshed : but that a set of men of learning and abilities, such as Weishaupt and his associates are allowed to be, should form a conspiracy to overturn, and with more than gothic rage utterly abolish, the arts and sciences, and to restore the supposed original savage state of man, appears a phenomenon in the history of the human heart totally unaccountable. That "the heart of man is deceitful above all things, and desperately wicked," is a melancholy truth, which not scripture alone, but the history of mankind in all ages and nations affords full proof of, as well as the shocking history of the Illuminati ; but while pride and vanity have a place in the human heart, to say nothing of our other passions, which are more or less interested in the preservation "of the discoveries and the improvements in arts, sciences, and their inseparable concomitant luxury, we are persuaded no man, or body of men, who have enjoyed the sweets of civilized life, ever formed a serious wish for the total abolition of the arts and sciences, In the fury and rage of war, Goths, Vandals, and Turks may burn and destroy monuments of art and repositories of science; but when wars are over, instead of returning to the savage state, the barbarous conqueror, mix and amalgamate with the conquered, and become themselves more or less civilized. 
Dr. Weishaupt is allowed to have been influenced by a high degree of vanity, as an evidence of which, he communicales, as the first secret, to his most fivoured adepts, that the mysteries of Illuminism, while passing through the inferior degrees, had been successively attri? buted to the most ancient patriarchs and philosophers, and even to Christ himself, owing its origin to no other than Adam Weishaupt, known in the order by the nane of Spartacus.

\section{Buchanites.}

A SECT of enthusiasts, who sprung up in the west of Scotland in 1783, and took their name from a Mrs. Buchan of Glasgow, who gave herself out to be the woman spoken of in the Revelation, and that all who believed in her should be taken up into heaven without tasting death, as the end of the world was near. Mr. White, minis. ter of the Relief Church at Irvine, whom she styled the " man-child brought forth by the woman," with the town-clerk and some others, were among the principal people who were so infatuated as to listen to her ravings, and to join her followers. From the folly of some bigots, the Buchanites had their share of persecution. At Irvine, the house in which they met was assaulted, and the furniture and windows broken; in December, 1784, similar outrages were committed against them in Dumfries-shire, in consequence whereof, twenty-one of the rioters were fined by the sherift. Their party, however, never increased much, and the death of their leader, within a year or two afterwards, occasioned their dispersion, by putting an end their hopes of reaching the New Jerusalem without death.

\section{Cainites.}

THESE were a sect of heretics who sprang up in the second century, A: D. They believed Cain to have been produced by some greater power than Abel, for which reason he prevailed over his brother, and slew him. On the same principle they honoured those persons who are recorded in scripture as the worst of mankind, such as Korah, Dathan, and Abiram ; and particularly the traitor Judas, who, they say, knowing that the salvation of mankind was to be procured by the death of Jesus Christ, delivered him to his enemies to be executed, notwithstanding the resistance of certain powers, who, being ill-wishers to our happiness, would have prevented him. The Cainites adopted whatever was most impure and ignominious among the Gnostics and other heretics.

[When we cast a transient glance on the absurdities which liave been embraced urider the character of religion, it is melancholy to reflect on the degeneracy of the human intellect. ". The sects that have been enumerated in the preceding pages form but a small specimen of what might be produced. But amidst the diversified sentiments of conflicting parties, of this we may rest assured, that no principles which lead to persecution and inmorality can ever have come from God.] 
A Mong the numerous Hindoo deities, those whose images and worship are most strongly marked with impurity are Shivu, the Bacchus or Vulcan of the Hindoos; Krishnoo, resembling A pollo, and Juggernaut, which is a form of the annexed powerful divinity,

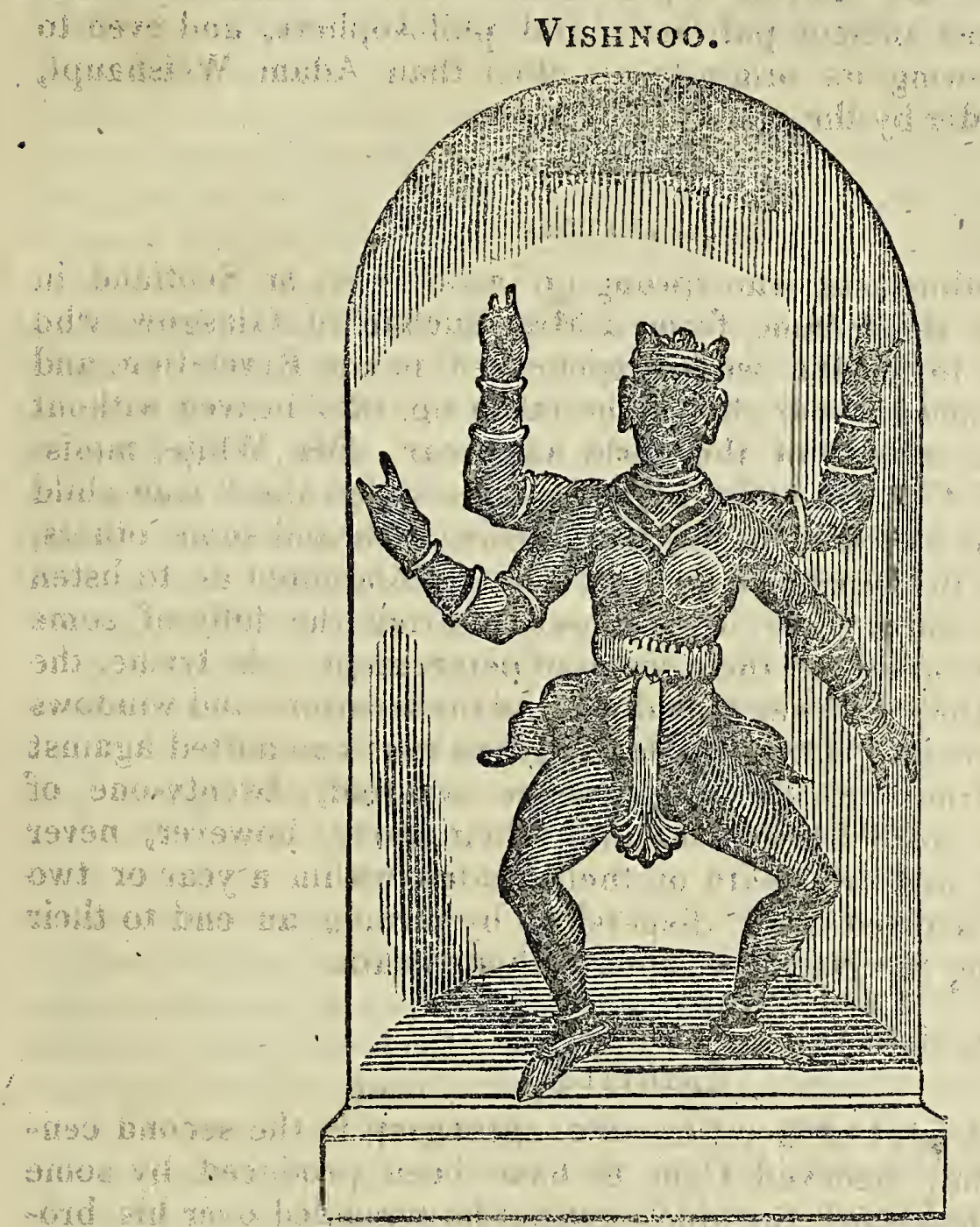

The services offered to Shivu resemble in many particulars the rites of Bacchus, and are of a nature ton abominable to be described. During the festival of Krishnu, the utmost licentiousness prevails; and his service principally consists in the celebration of amorous intrigues that are ascribed to him. Obscenity and blood are the attendants on Juggernaut. The daily services of their gods tend only to lewdness and cruelty. The effect of such a religion on the minds of the people is too obvious to require detail. Hence chastity is a virtue unknown in Hindoostan. The scenes that are constantly presented to the multitude in the ordinary course of their worship, so debase and pollute their minds, that the grossest sensualities are their delight in this world, and a more perfect gratification of them is all they hope for in a future state of being. Future happiness is declared to: consist entirely of sensual enjoyment. To feast on delicious viands, to dwell in palaces of gold, ornamented with precious stones, to rest on magnificent beds, and to gratify every sensual desire, are things, in the enjoyment of which a Hindoo concentrates the chief happiness of his heaven. 


\section{Part V.}

\section{SINGULAR INVENTIONS,}

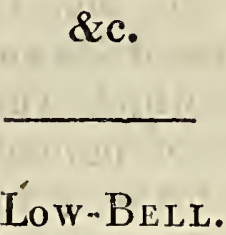

TuIs name is given to a bell, by means of which they take birds in the night in open champaign countries, and among stubble in October. The method is, to go out about nine o'clock in a still evening, when the air is mild, and the moon does not shine. The low-bell should be of a deep and hollow sound, and of such a size that a man may conveniently carry it in one hand. The person who carries it is to make it toll all the way he goes, as nearly as possible in that manner in which the bell on the neck of a sheep tolls as it goes on and feeds. There must also be a box made like a large lantern, about a foot square, and lined with tin, but with one side open. Two or three great lights are to be set in this, and the box is to be fixed to the person's breast with the open side forwards, so that the light may be cast forward to a great distance. It will spread as it goes out of the box, and will distinctly shew to the person that carries it, whatever there is in the large space of ground over which it extends, and consequently all the birds that roost upon the ground. Two persons must follow him, who carries the box and bell, one on each side, so as not to be within the reach of the light to shew themselves. Each of these is to have a hand-net of about three or four feet square, fastened to a long pole; and on whichever side any bird is seen at roost, the person who is nearest is to lay his net over it, and take it with as little noise as possible. When the net is over the bird, the person who. laid it is not to be in a hurry to take the bird, but must stay till he who carries the light is got beyond it, that the motions may not be discovered. The blaze of the light, and the noise of the bell, terrify and amaze the birds in such a manner that they remain still, to be taken; but the people who are about the work must keep the greatest quiet and stillness in their power. Some people go on this scheme alone. The person then fixes the light-box to his breast, and carries the bell in one hand and the net in the other ; the net in this case may be somewhat smaller, and the handle shorter.

\section{Dr. Long's curious Astronomical Machine.}

THIS machine is thus described by the Doctor himself. "I have, in a room lately built in Pembroke Hall, erected a sphere of eighteen feet diameter, wherein above thirty persons may sit conveniently : the entrance into it is over the south pole, by six steps; the frame of the sphere consists of a number of iron meridians, not complete semicircles, the northern ends of which are screwed to a large round 
plate of brass, with a hole in the centre of it; through this hole, from a bean in the ceiling, comes the north pole, a round iron rod about three inches long, and supports the upper parts of the sphere to its proper elevation for the latitude of Cambridge; the lower part of the sphere, so much of it as is invisible in England, is cut off; and the lower or southern ends of the meridians, or truncated semicircles, terminate over, and are screwed down to, a strong circle of oak, of about thirteen feet diameter, which when our sphere is put into motion, runs upon large rollers of lignum vitæ, in the manner that the tops of some windmills are made to turn round. Upon the iron meridians is fixed a zodiac of tin, painted blue, whereupon the ecliptic and heliocentric orbits of the planets are drawn, and the constellations and stars traced: the Great and Little Bear, and Draco, were the first painted, in their places round the north pole; the rest of the constellations were afterwards added ; the whole is turned round with a small winch, with no more labour than it takes to wind up a jack, though the weight of the iron, tin, and wooden circle, is about $1000 \mathrm{lb}$. When made use of, a planetarium will be placed in the middle. The whole, with the floor, is well supported with a frame of large timber." -This curious piece of mechanism has been since improved; all the constellations and stars of the northern hemisphere, visible at Cambridge, are painted in their proper places, upon plates of iron joined together, which form one concave surface.

\section{Ancrent Crowns.}

THE first were no more than a bandelet drawn round the head, and tied behind, as we still see it represented in medals round the heads of Jupiter, the Ptolemies, and the kings of Syria. Afterwards they consisted of two bandelets; by degrees they took branches of trees of various kinds; at length they added flowers, insomuch that Claudius Saturninus says, there was not any plant whereof crowns had not been made. The woods and groves were searched to find different crowns for the several deities; and they were used not only in the statues and images of the gods by the priests in sacrificing, and by kings and emperors, but also on altars, temples, doors of houses, sacred vessels, victims, ships, \&c. In scripture there is frequent mention of crowns, and the use of them seems to have been very common among the Hebrews. The high-priest wore a crown, which was a fillet of gold, placed upon the forehead, and tied with a ribbon, of hyacinth colour or azure blue. It seems that private priests, and even common Israelites, wore also a sort of crowns, since God commanded Ezekiel not to take off his crown, nor assume the marks of one in mourning. This crown was only a ribbon or fillet, with which the Jews, and several penple in the East, girt their heads.

The Roman emperors had four kinds of crowns, still seen on medals, viz. a crown of laurel, a radial or radiating crown, a crown adorned with pearls and precious 'stones, and the fourth a bonnet or kind of cap, something like the mortier. The Romans had also various kinds of crowns, which they distributed as rewards of merit; which were considered as marks of nobility to the wearers, 
and, upon competitions with rivals for rank and dignities, often determined the preference in their favour.

\section{Ancient Arms}

ARMS of stone, and even of brass, appear to have been used before men made use of iron and steel. Josephus assures us, that the patriarch Joseph first brought the use of iron arms into Egypt, arming the troops of Pharaoh with a casque and buckler. What contributed most to render the Romans masters of the world, was, that having successively warred against all nations, they constantly renounced their own methods, arms, \&cc. whenever they met with a better. Thus Romulus, during his war with the Sabines, a bold and warlike nation, adopted their broad buckler in lieu of the small Argian buckler which he had used till that time. The principal arms of the ancient Britons were liatchets, scythes, lances, swords, and bucklers; the Saxons, \&c. however, brought in the halbert, bows, arrows, arbalets, \&c. By the ancient laws of England, every man was obliged to bear arms, except the judges and clergy. By act 23, Hen. VIII. it was expressly enjoined, that all persons should be regularly instructed, even from tender years, in the exercise of the arms then in use, viz. the Iong bow and arrows; to be provided with a certain number of them. The ancient arms of our Scots Highlanders are, the broadsword, target, poniard and whinyar, or dirk.

\section{BATTERING RAM.}

THIS was an ancient military engine, used to batter and beat down the walls of places besieged. It is said tohave been invented by Artemanes of Clazomene, a Greek architect, who flourished B. c. 441. It is thus described by Josephus. A vast beam like the mast of a ship, strengthened at the one end with a head of iron, resembling that of a ram, whence it took its name, was hung by the middle with ropes to another beam, which lay across two posts ; and hanging thus equally balanced, it was by a great number of men drawn backwards and pushed forwards, striking the wall with its iron head. But this engine did most execution when it was mounted on wheels, which is said to have been. first done at the siege of Byzantium by Philip of Macedon. Plutarch informs us, that Marc Antony, in the Parthian war, made use of a ram eighty feet long; and Vitruvius tells us that they were sometimes one hundred and six, and sometimes one hundred and twenty feet in Jength; and to this, perhaps, the force and strength of the engine was in a great measure owing. The ram was managed by one hundred soldiers at a time, and when they were exhausted they were relieved by another century: so that it played constantly without intermission.

\section{TaBle Forks.}

THESE instruments, according to Voltaire, Hist Generale, vol. ii. p. 169. edit 175\%, were in use on the continent in the thirteenth and fourteenth centuries; but that they were a novelty to England in the 
reign of Elizabeth, is evident from the following passage it the first part of Eynes Morison's Itinerary', p. 208, where, speaking of his bargain with the patron of the vessel which conveyed him from Venice to Constantinople, he says, "We agreed with the master himself, who, for seven gold crowns by the month, paid by each of us, did courteously admit us to his table, and gave us good diet, serving each man with his knife, and spoone, and his forke to hold the meat while he cuts it, for they hold it ill manners that one should touch the meat with his hand; he also has a glass or cup to drink in peculiar to himself." Still farther, Thomas Croyate, who travelled in 1608, after describing with no small solemnity the manner of using forks, "s in all parts of Italy ;" adds, "Hereupon I-myself thought good to imitate the Italian fashion by this forked cutting of meat, not only while I was in Italy, but also in Germany, and oftentimes in .England since I came home." Thus they seem to have been introduced into Britain.

\section{OrGans.}

THAT organs are the invention of remote antiquity, is generally allowed; but the particular time and country in which the discovery was made, are uncertain. In ancient authors there are various passages where mention is made of the organ, but it was probably an instrument vary different from that which now goes by this name. It appcass indeed to have been borrowed by the Latins from the Greeks, but not to have been in general use till the eighth century. Vitruvius describes an organ in his 10th book, and St. Jerome mentions one with twelve pair of bellows, which night be heard 1000 paces, or a mile, off, and another at Jerusalem, which might be heard at the Mount of Olives. It has been affirmed, that in France it was not known till the time of Lewis I. A. D. 815, when an Italian priest taught the use and construction of it, which he had learned at Constantinople. By some, however, it has been carried as far back as Charlemagne, and by others as far as Pepin. Bellarmine says that the organ began to be used in the service of the church about A. D. 660 . Ammonius thinks, however, that this was after A. D. 820 , in the time of Lewis the Pious. The learned Bingham, in his Origines Sacræ; affirms that organs were not used till after the time of Thonas Aquinas, and he adds these words: "Our church does not use musical instruments, as harps and psalteries, to praise God withal, that she may not seem to Judaize". Hence it has been concluded by the learned Gregory, that they were not used in churches in his time, about A. D. 1250.

It appears; however, from the testimony of Gervas, the monk of Canterbury, who flourished A. D. 1200, that organs were introduced upwards of 100 years even before that time. If Gervas's authority be held good, it will countenance a pretty general opinion, that, in Italy, Germany, and England, they became frequent about the tenth century. But it is very certain that the use of the organ was very common in the latter ages of the church, and the propriety of it was undisputed. In the seventeenth century, however, during the civil wars; organs were removed from the churches in England, and 
so generally reprobated, that, at the Restoration, there could scarce be found either organists, organ-builders, or singers.

Organs have never yet been used in the establishment of Scotland, since it became presbyterian; but they are used in Holland, where that form of church government also obtains. The organs in Germany, (says Dr. Burney,) in magnitude, and the organists in abilities, seem unrivalled in any other part of Europe, particularly in the use of pedals. In Marpurg's Essays, vol. iii. there is a minute account of a variety of organs in Germany; of all which the longest pipe of the manuals is sixteen feet, and of the pedals thirty-two, One of the largest organs in Germany is at Gorlitz, in Upper Lusatia. The uncommon merit of Handel as an organist is well known. The organ in the cathedral church at Ulm, in Germany, is ninety-three feet high and twenty-eight broad: its largest pipe is thirteen inches diameter, and it has sixteen pair of bellows.

\section{BEDS.}

Mr. WhitTakeR, in his History of Manchester, observes, that it was universally the practice in the first ages, to sleep upon skins of beasts. It was originally the custom of the Greeks and Romans. It was particularly the custom of the ancient Britons before the Roman invasion, and these skins were spread on the floors of their apartments. Afterwards they were changed for loose rushes and leather, and the Welsh a few years ago lay on the former, and many of the Highlanders of Scotland sleep on the latter to this day. In process of time, the Romans suggested to the interior Britons the use, and the introduction of agriculture supplied them with the means and convenience, of straw beds. The beds of the Roman gentry at this period were generally filled with feathers, and those of the inns with the soft down of reeds; but, for many ages the beds of the Italians had been constantly composed of straw, as it still formed those of the soldiers and officers at the conquest of Lancashire, and from both our countrymen learnt their use. It, however, appears to have been taken up only by the gentlemen, as the common Welsh had their beds thinly stuffed with rushes as late as the conclusion of the twelfth century; and with the gentlemen it continued many ages afterwards. Straw was used, even in the royal chambers of England, as late as the close of the fifteenth century. Most of the peasants about Manchester lie on chaff at present, as do likewise the poorer class of people in Scotland. In the Highlands heath is also very generally used as bedding even by the gentry, and the repose on a heath-bed has been celebrated by traveliers as a peculiar luxury, superior to that yielded by down. In France and Italy, straw beds remain general to this day.

But after the above period; beds were no longer suffered to rest upon the ground. The better mode, that had anciently prevailed in the East, and had long before been introduced into Italy, was adopted in Britain; and they were now mounted on pedestals; this, however was equally confined to the higher ranks. The bed still continued on the floor, annong the common people; and the gross custom, that had prevailed from the beginning, was retained by the lower Britons 
to the last, and these ground beds were laid along their houses, and formed one common dormitory for all the members of the family. The fashion continued universally among the inferior ranks of the Welsh within these four or five ages, and with the uncivilized part of the Highlanders down to our own times. And even at no great distance from Manchester, in Buxton, within these sixty or seventy years, the people that repaired to the bath are all said to have slept in a long chamber together; the upper part being allotted to the ladies, and the lower to the gentlemen, and only partitioned from each other by a curtain.

\section{Incombustible Cloth.}

THIs cloth is made of asbestos.-. "It is an old tradition," says Cronstedt, "that in former ages they made cloth of the fibres of asbesti, which is said to be composed of the wood byssus; but it is not very probable, since, if one may conclude from some trifles now made of it, such as bags, ribbons, and other things, such a dress could neither have an agreeable appearance, nor be of any conveniency or advantage. It is more probable that the Scythians dressed their dead bodies which were to be burned, in a cloth manufactured of this stone; and this, perhaps, has occasioned the above fable." M. Magellan confirms this opinion of Cronstedt, and informs as that some of the Romans also enclosed dead bodies in cloth of this kind.

In 1756, or 1757, he tells us that he saw a large piece of asbestos cloth, found in a stone tomb with the ashes of a Roman, as appeared by the epitaph، It was kept, with the tomb also, if our author rightly remembers, in the right-hand wing of the Vatican library at Rome. The under-librariar, to shew that it was incombustible, lighted a candle, and let some drops of wax fall upon the cloth, which he set on fire with a candle in his presence, without any detriment to the cloth. Its texture was coarse, but much softer than he could have expected.

\section{CoRK JACKET.}

THIs was an invention of one Mr. Dubourg, a gentleman very fond of swimming, but subject to the cramp, which led him to consider of some method by which he might enjoy his favourite diversion with safety. The waistcoat is composed of four pieces of cork, two for the breasts and two for the back, each pretty near in length and breadth to the quarters of a waistcoat without flaps; the whole is covered with coarse canvass, with two holes to put the arms through ; there is a space left behind the two back pieces, and the same between each back and breast piece, that they may fit the easier to the body. Thus the waistcoat is only open before, and may be fastened on the wearer with strings, or, if it should be thought more secure, with buckles and leather straps. It does not weigh above twelve ounces, and may be made up for about six shillings. Mr. Dubourg tried his waistcoat in the Thames, and found that it not only supported him on the water, but that two men could not sink him, though they used their utmost 
efforts for that purpose. If those who use the sea occasionally, and those who are obliged to be almost constantly there, were to have these waistcoats, it would be next to impossible that they should be drowned. It would also be of vast service to those who for the sake of health bathe in the sea; and even the most delicate and timorous young lady might, by the help of one of those jackets, venture into a rough sea. Dr. Wilkinson of Woodford has improved this jacket, and rendered it much more accommodating to the motions of the body in swimming, by cutting the corks into small pieces, and quilting them between two waistcoats of canvass. A cork spencer has lately been invented, to save from drowning, in cases of shipwreck; which consists of a belt containing refuse pieces of cork, or old bottle corks, enclosed in a kind of light stuff, and fastened round the body with tapes. The use of the cork jacket has of late been revived in Liverpool, and the newspapers of that large commercial town teem with eulogiums on its utility. We are not aware that the reviver of this preservative from drowning, claims what he recommends as an original invention, but we have no recollection that lie acknowledges any obligation to predecessors. In some subordinate particulars, these cork jackets differ from each other, but in their essential principles, and the object they have in view, they bear so strong a resemblance as to suggest an idea approximating to identity.

\section{Brank.}

THIS is an instrument formerly used in Staffordshire for correcting scolding women. It is a sort of head-piece, which opens and encloses the head of the scold, while an iron, sharp as a chisel, opens the mouth, and subdues the more dreadful weapon within. Thus harnessed, the offender is led in triumph through the streets.

Dr. Plott, in his History of Staffordshire, gives a minute description and figure of the instrument, which is there called a scoldingbridle; and tells us, he looks upon it as much to be preferred to the ducking-stool, which not only endangers the health of the party, but also gives the tongue liberty betwixt every dip,-to neither of whicli this is at all liable.

But with all due deference to Dr. Plott, we would equally disapprove of both. The morals of the people will never be amended by hardening their feelings against the sufferings of others, however guilty or worthless. A good education will do more to reform the inferior classes, than all the ducking-stools and scolding-bridles, (we might add, bridewells and halters,) that ever were invented.

\section{A remarkable Forge.}

THE specimens of art produced by the Bahamans discover a degree of perfection little to be expected from the rude simplicity of their tools. Their looms are the most awkward machines imaginable, yet they manufacture very pretty and durable cloths of cotton, which are held in great estimation among themselves, and are often purchased by the Europeans for counterpanes; at a high price. Their dyes stand 
washing very well, especially their blues, which are infenior to none. The implements of their forges are very simple. The bellows consists of two bags of rough goat's skin, with a stick of about three feet in leinth, fixed perpendicularly to each, and also a horizontal tube (an old gun-barrel) to convey the air from the bag, through a litlle clay party-wall, to the fre. While the smith is at work, a boy holds a stick in each hand, blowing the fire with alternate puffs, so that the air is expelled and drawn in by turns through the two pipes, there being no other communication with the bags. In this way they contrive to make a welding heat, and fabricate not only the necessarv inplements of husbandry, but carpenter's tools, cutlasses, spears, and other weapons. The anvil is of stone, or an old iron caunon; and the hanmer is a thick piece of rounded iron, of about a foot in length, which they hold by one end. Besides blacksmiths, there are a sort of braziers or silversmiths, who make manillas or bracelets, handles to cutlasses, rings for the fingers, and other trinkets of brass or silver, which they melt in crucibles of their own making.

\section{INVENTION OF CLOCKS.}

THE invention of clocks with wheels is ascribed to Pacificus, archdeacon of Verona, who lived in the time of Lewis the Debonnair, on the credit of an epitaph quoted by Ughelli, and berrowed by him from Pauvinius. They were at first called hocturnal dials, to distinguish them from sun-dials, which shewed the hour by the sun's shadow. Others ascribe the invention to Boethius, about A. D. 510. M. Denham makes clock-work of a much older standing; and ranks Archimedes" sphere mentioned by Claudian, and that of Posidonius" mentioned by Cicero, among the machines of this kind: not that either their form or use was the same with those of ours; but that they had their notion from some hidden weights or springs, their wheels or pulleys, or some such clock-work principle. But be this as it may, it is certain the art of making clocks, such as are now used, was either first invented, or at least revived, in Germany, about two hundred years ago.

The clepsydra, or water-clocks, and sun-dials, have a much better claim to antiquity. The French annals mention one of the former kind sent by Aaron, khalif of Persia, to Charlemagne, about A. D.807, which seemed to bear some resemblance to modern clocks. It was of brass, and shewed the hours by twelve little balls of the sane metal, which fell at the end of each hour, and in falling struck a bell and made it sound. There were also figures of twelve cavaliers, which at the end of each hour came forth at certain apertures or windows in the sides of the clock, and shut them again, \&c.

The invention of pendulum clocks is owing to the happy industry of the last age; the honour of it is disputed by Huygens and Galileo. The former, who has written a volume on the subject, declares it was first put in practice in $165 \%$, and the description thereof printed in 1658. Becher, de Nova Temporis Dimetiendi Theoria, A. D. 1680; contends for Galileo, and relates, though at second-hand, the whole history of the invention; adding, that one Tresler, clock-maker to the 
then father of the grand duke of Tuscany, made the first pentulum clock at Florence, by direction of Galileo Galilei, a pattern of which was brought into Holland. The Academy de'l Cimento says expressly, that the application of the pendulum to the movement of a clock was first proposed by Galileo, and first put in practice by his son Vincenzo Galilei, in 1649. Be the inventor who he may, the invention never Hourished till it came into Huygens' hands, who insists, that if ever Galileo thought of such a thing, he never brought it to perfection.

The first pendulum clock made in England was in 1662, by $\mathrm{Mr}$. Fromentil, a Dutchman. Before the invention of the pendulum, a balance was used, resembling the fly of a jack.

Another account of clocks is the following.

The first clock ever known in France, was erected in the fifth century, in the cathedral church at Lyons. Gondebart, or Gombart III. king of Burgundy, having been informed that Theodoric, king of the Goths, who resided at that time in Ravenna, had machines which marked the order of the time according to the movements of the heavenly bodies, wrote to him to have one. It was accordingly executed by Boccius, a celebrated mechanic, and presented to Gondebart.

Clock-makers were first introduced into England in 1368; when Edward III. granted a license for three artists to come over from Delft, in Holland, and practise their occupation in this country. The oldest English clock of note is in a turret of the royal palace, Hampton, constructed in the year 1540 , which was in the reign of Henry VIII. by a maker whose initials are $\mathbb{N}$. O. To the time of queen Elizabeth, clocks were often denominated orloges or horoloyes. Among the modern clocks, those of Strasburg and Lyons are very eminent for the richness of their furniture, and the variety of their motions and figures. In the former, a cnck claps his wings, and proclainis the hour; the angel opens the door, and salutes the Virgin; and the holy Spirit descends on her, \&c. In the latter, two horsemen encounter, and beat the hour upon each other; a door opens, and there appears on the theatre the Virgin, with Jesus Christ in her arms; the magi, with the retinue, marching in onder; and presenting their gifts; two trumpets sounding all the while, to proclaim the procession. These, however, are far excelled by two that have been made by English artists, as a present from the East India Company to the emperor of China. These two clocks are in the form of chariots, in each of which a lady is placed, in a fine attitude, leaning her right hand upon part of the chariot, under which appears a clock of curious workmanship, little larger than a shilling, that strikes and repeats, and goes for eight days. Upon the lady's finger sits a bird, finely modelled, and set with diamonds and rubies, with its wings expanded in a fying posture, and actually fiutters for a considerable time, on touching a diamond button below it; the body of the bird, in which are contained part of the wheels, that animate it as it were, is less than the sixteenth part of an inch. The lady holds in her left hand a golden tube, little thicker than a large pin, on the top of which is fixed a circular ornament not larger than a sixpence, set with diamonds, which goes round in near three hours in a constant regular motion. Over the lady's head is a double umbrella, supported by a small fluted 
pillid, wint thicker than a quill, and under the large: of which a beil is tixed at a considerable distance from the clock, with which it seems. not to have any connexion, but from which a communication is secretly conveyed a hammer, that regularly strikes the hour, and repeats the same at pleasure by touching a diamond button fixcd to the clock below. At the feet of the lady is a golden dog; betore which, from the point of the chariot, are two birds fixed on syiral springs, the wings and feathers of which are set with stones of various colours, and they appear as if flying away with the chariot, which, from another secret motion, is contrived to run in any direction, either straight or circular, \&c. whilst a boy, that lays hold of the chariot behind, seems also to push it forwarts. Above the umbrella are flowers and ornaments of precious stones; and it temin ates with a flying dragon, set in the same manner. The whole is of go'd, nost curiously executer, and enbellished with rulies and pear's.

Boat for Ascending Rapids in Rivers.
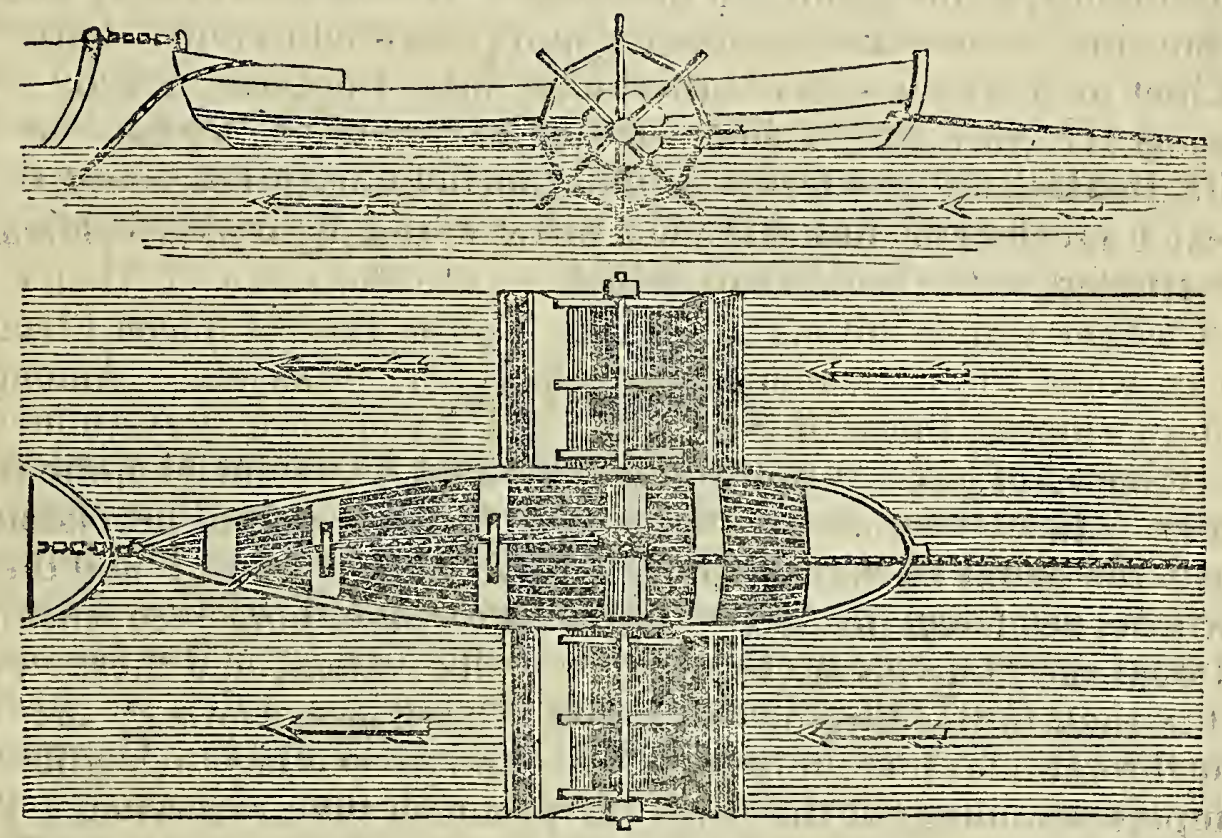

The American papers contain some remarkable accounts of a curiously constructed boat, which has been brought into operation on the rapids of the Delaware. It ascends against the stream, and tows up boats heavily laden with it. The plan seems to be this: An anchor is dropped at the head of the rapid to be passed, to which is mads fast a rope extending to the opposite extremity of the rapid. Here a boat is provided, crossed by a shaft, to which are attached wheels with floats or paddles like those of a steam-boat, but of a willh proportioned to the power required. On this shaft is a windlass or drum, around which the rope is passed, and thence over the stern of the boat into the water. These preparations being made, the bot is pushed into the current, which, acting with all its force upon the floats, and they presenting to the stream a much greater surface or resistance? to the water than the prow of the boat, the wheels are tinmed by the current, which, winding up the mpe, draws the boat irresistibly to the 
anchor at the head of the rapid. - These boats have been found to ascend one-half faster than the current flows down, and to be capable of towing up whatever may offer itself.

The boat having performed its voyage, its appendages are disengaged, when it descends with the current, and is again ready for another trip up the rapid. A correspondent of the New York Evening Post says, "I had the pleasure a few weeks since of witnessing the first experiment of the boat, opposite Trenton, on the Delaware, and was much surprised that an invention of such utility had not before been thought of, and brought into operation. There can be no doubt as to the practicability of the plan, and the competency of the power to be acquired, for propelling heavily laden boats against rapids; for in the experiment $\mathbb{I}$ witnessed, there were towed up at the same time, a large Durham boat, two batteaux, and twelve persons. The Durhain boat was old and leaky, and drew as much water as if loaded with three or four tons. The ascent seemed to be as speedy as if the paddie boat had no encumbrance. Many of our valuable rivers have not heretofore been navigated, on account of the obstructions in them by rapids, which have hitherto been thought insurmountable; but by the invention of Colonel Clarke such difficulties no longer exist. Much credit is certainly due to him for the invention, as it promises to be of the greatest utility to this country in the navigation of our rivers; and it is presumed, that this plan will ere long be brought into general use throughout the United States."

\section{Harpoon Gun.}

THIS is a kind of fire-arm for discharging harpoons at whales, and thereby killing them more easily and expeditiously than formerly. Though this method was projected many years ago; it has but lately come into use ; and premiums have been offered by the society for encouraging arts, \&c. to the persons who first struck a fisli in this manner. In the Transactions of that society for. 1786, we have an account of the first fish struck in this manner in 1784. The gun was of the blunderbuss construction, loaded with four tobacco pipes full of glazed powder : the fish was shot at the distance of ten fathoms, the harpoon going into her back up to the ring, and she was killed in about an hour. In 1785, three whales were killed in this manner, four in 1786, and three in 178\%. Since that time the gun harpoon lias come more into use, and will probably supersede the otlier method entirely.

In the Philosophical Transactions for 1789, we have accounts of a number of whales killed in this manner. The instrument appears to be extremely useful in calm weather, as the whale, though a timorous creature, will frequently allow a boat to approach it within twenty, fifteen, or ten fathoms, all of which distances are within reach of the gun harpoon, though not within reach of that thrown by the hand. The greatest inconvenience was in case of rain or snow, by which the lock was apt to get wet. To remedy this, a case of leather was made to fit round the gun, and over the lock, lined with tin, and big enough to fire the gun when it was on. The fish struck with an harpoon 
discharged in this manner, are soon killed, by reason of its penetrating their bodies to the depth of five or six feet, which no man's strength would be able to accomplish.

In the volume just quoted, we have an account of one which was shot through the tail. The harpoon broke in the slit, but five fathoms of line went through the tail. The fish was killed in eight hours, which is perhaps the only instance of a fish struck in that part being. caught. In another, the harpoon carried six feet of line, into his body: the creature died in ten minutes. Others were killed in fifteen minutes or half an hour, and one had a rib broken by the violence of the stroke. In the Transactions of the Society for 1790 , there are other accounts similar to the foregoing, and all agrecing as to the great usefiulness of the instrument, both for striking the fish at a considerable distance, and for killing them in a very short time.

\section{Hats.}

HATs are said to have been first used by men, about A. D. 1400 , for country wear, riding, \&c. But the hatters have a tradition a mong them, that the origin of their art, or at least of that branch of it called felting, is much more ancient. The tradition is, that while St. Clement, the fourth bishop of Rome, was flying from his persecutors, his feet became blistered, in consequence of which he was induced to put wool between the soles of his feet and the sandals which he wore. The consequence was, that in continuing his journey, the wool by the sweat and motion of his feet became completely felted, as if wrought on purpose. When he afterwards settled in Rome, he improved the discovery; and hence the origin of felting and hat making. The hatters in Ireland, as well as in several Catholic countries, still hold a festival on St. Clement's day.

Whatever truth may be in the above tradition, F. Daniel relates, that when Charles II. made his public entry into Rouen, in 1449, he had on a hat lined with red velvet, and surmounted with a plume or tuft of feathers: he adds, that it is from this entry, or at least under this reign, that the use of hats and caps is to be dated; which henceforward began to take place of the chaperons and hoods that had been worn before. In process of tine, from the laity, the clergy also took this part of the habit; but it was looked upon as a great abuse, and several regulations were published, forbidding any priest or religious person to appear abroad in a hat without coronets, and enjoining them to keep to the use of chaperons made of black cloth, with decent coronets; if they were poor, they were at least to have coronets fastened. to their hats, and this upon penalty of suspension and excommunication. Indeed, the use of hats is said to have been of a longer standing among the ecclesiastics of Brittany, by two hundred years, and especially among the canons; but these were only a kind of caps, and from hence arose the square caps worn in colleges, \&8. Lobineau observes, that a bishop of Dol, in the twelfth century, zealous for good order, allowed the canons alone to wear such hats, enjoining that if any other person came with them to church, divine service should imnediately be suspended. 
Stockings.

STOCKINGS were anciently made of cloth, o: of milled stuft sewed together, but since the iuvention of knitting and weaving stockings of silk, wool, cotton, thread, \&c. the use of cloth stockings is given up. Dr. Howell, in his History of the World, vol. ii. p. 222, relates, that queen Elizabeth, in 1601 , was presented with a pair of black knit silk stockings by her silk woman, and thenceforth never wore cloth ones. He adds, that Henry VIII. ordinarily wore cloth hose, except there came from Spain a pair of silk stoclings. Edward VI. was presented with a pair of sill stockings by sir Thomas Gresham, and the present was then much taken notice of. Hence it is said, that the invention of knit silk stockings originally came from Spain.

Others relate that one William Rider, an apprentice on London bridge, seeing at the house of an Italian merchant a pair of knit worsted stockings from Mantua, took the hint, and made a pair exactly like them, which he presented to William earl of Pembroke, and that they were the first of that kind worn in England, in 1564 . The modern stockings, woven or knit, are formed of an infinite inumber of little knots, called stitches, loops, or meshes, interningled. Knit stockings are wrought with needles made of polished iron or brass wire, which interweave the threads, and form the meshes of which the stockings consist.

Woven stockings are gencrally very fine; they are manufactured in a machine made of polished iron, the structure of which it is needless to describe, as it may be seen in almost every considerable town in Great Britain.

The invention of this machine is, by $\mathrm{Mr}$. Anderson, attributed to William Lee, M. A. of St. John's college, Cambridge, at a period so early as 1589. Others give the credit of it to a student at Oxford at a much later period, who, it is said by Aaron Hill, was driven to it by dire necessity. "This young man falling in love with an in:kecper's daughter, married her, though she had not a penny, and he by his marriage lost a fellowship. They soon fell into extreme poverty, and their marriage produced the consequences naturally'to be expected from it. They became miserable, not so much on account of their sufferings, as from the melancholy dread of what would become of their yet unborn infant. Their only means of support was the knitting of stockings, at which the woman was very expert. But sitting constantly together from morning to night, and the scholar often fixing his eyes with stedfast observation on the motion of his wife's fingers in the dexterous management of her needles, he took it into his imagination, that it was not impossible to contrive a little loom which might do the work with much more expedition. This thought he communicated to his wife, and, joining his head to her hands, the endeavour succeeded to their utmost wish. Thus the ingenious stocking loom, which is so common now, was first invented; by which he not only made himself and his family happy, but has left his nation: indebted to him for a benefit which enables us to export silk stockings in vast quantities, and to a great advantage, to those very countries from whence before we used to bring them at a considerable loss in balance of traffic." 


\section{Calumet.}

THe Calumet is a symbolical instrument of great importance among the American Indians. It is a pipe, whose bowl is generally marle of a soft red marble; the tube, of a very long reed, ornamented with wings and feathers of birds. No affair of consequence is transacted without the calumet. It appears in meetings of commerce or exchange, in congresses for determining peace or war, and even in the very fury of battle. The acceptance of the calumet is a mark of concurrence with the terms proposed; as the refusal is a certain mark of rejection. Even in the rage of a conflict, this pipe is sometimes offered; and if accepted, the weapons of destruction instantly dep from their hands, and a truce ensues. It seems the sacrament of savages, for no compact is ever violated which is confirmed by a whiff from this holy reed.

When they-treat of war, the pipe and all its ornaments are usually red, or sometimes red only on one side. The size and decorations of the calumet are for the most part proportioned to the quality of the persons to whom they are presented, and to the importance of the occasion. The calumet of peace is different from that of war. They make use of the former to seal their alliances and treaties, to travel with safety, and to receive strangers; but of the latter, to proclaim war: The calumet of peace consists of a red stone, like marble, formed into a cavity resembling the head of a tobacco pipe, and fixed to a hollow reed. They adorn it with feathers of various colours; and name it the calumet of the sun, to which luminary they present it, in expectation of thereby obtaining a change of weather as often as they desire.

From the winged ornaments of the calumet, and its conciliating uses, writers compare it to the caduceus of Mercury, which was carried by the caduceatores of peace; with terms to the hostile states. It is singular, that the most remote nations, and the most opposite in their other customs and manners, should in some things have, as it were, a certain consent of thought. The Greeks and the Americans had the same idea, in the invention of the caduceus and the calumet.

\section{Artificial Halos.}

HALOs may be produced by placing a lighted candle in the midst of steam in cold water. If a glass window be breathed upon, and the flame of a candle be placed some feet from it, while the spectator is also at a distance from some other part of the window, the flame will be surrounded with a coloured halo.' And if a candle be placed behind a glass receiver, when air is admitted into the vacuum within it at a certain degree of density, the vapour with which it is loaded will make a coloured balo round the flame. This was observed by Otto Guericke.

In Dec.1756, M. Muschenbroeck observed, that when the glass windows of his room were covered with a thin plate of ice on the uside, the moon appearing through it was surrounded with a variously 
coloured halo, and, opening the windows, he found that it arose entirely from that thin plate of ice, for none was seen except through it. Dr. Kotelnihow having, like Dr. Halley, made very accurate observations to determine the number of possible rainbows, considers the coloured halo which appears about a candle, as the same thing with one of those bows which is formed near the body of the sun, but which is not visible on account of his excessive splendour.

\section{The Circulation of the Blood.}

So important a subject as the circulation of the blood cannot fail of being interesting to our general readers; we shall therefore lay before them a brief account of it, divested of that complication which renders it only intelligible to anatomists.

The heart, by the contraction of which the blood is circulated, has arising out of it two great blood-vessels, whose branches extend to all parts of the body, accompanying each other throughout; the one is the great artery, the aorta, and the other the great vein, or vena cava. The heart has always two other great vessels arising from its other side; one called the great artery of the lungs, or pulmonary artery, the other the great vein of the lungs, or pulmonary vein. Let us therefore keep in view that the heart has four large trunks, communicating with it, and that, at the junction of each with the heart, there are placed valves, most beautifully perfect, which act in such a manner as to admit the tide of blood through its own proper channel, in passing and repassing the heart and lungs, and immediately to fy up and prevent its improper return, likeflood-gates. . Arteries a re always accompanied by veins closely connected together, the arteries carrying the blood from the heart-the veins carrying it back to it. An artery is elastic, and can contract and dilate-a vein is an inactive flaccid tube. An artery has no valve in its whole course to the extremities of the body-a vein has valves placed at very short distances. These valves are to support the upper column of blood as it ascends from below back to the heart, flying up and acting as a floor to that portion of blood which is above it, and between the next valve. and itself; thus every motion of our limbs moves the blood in their veins, and that motion can be no other than upwards, on account of those valves; while the motion of the blood in the arteries is directly from the contraction of the heart, and it has a free current to the extreme parts of the body. With this general view in mind, let us proceed to describe the circulation.

The blood is sent out at one gush, or pulsation, throughout the whole body, into the most minute branches of the arteries; those arteries make a turn, and, losing their elasticity, become veins, which grow large in proportion as they go towards the heart, and lie-exactly in the course of their corresponding arteries. Into these veins the blood is therefore forced, after having supplied the various secretions: of the body. This blood is thus brought back by the great vein, or vena cava, and at its junction with the left jugular ard subclavian vein, it receives by a little tube the white chyle or essence of the food brought by that tube from the stomach. The blood is then unfit for 
the artecies, and therefore is carried into one little cavity of the hear, and at one pulsation is driven by the pulmonary artery into the lungs, where, coming in contact with the air through their membranes, it absorbs oxygen from the air breathed, which changes its colour from dark to bright red. The blood, thus prepared for supporting life, is taken back by the pulmonary veins into the other side of the heart. which communicates with the aorta, and by one pulsation is sent to all parts of the body, returning again, as before, through the veins; and this course takes place at every pulsation of that great and beautiful machine-the heart.

\section{Experiments to ascertain the Force of the Blood in the Heart and Arieries.}

Physiologrsts and anatomists have from time to time attempted to make estimates of the force of the blood in the heart and arteries; but have differed as widely from each other, as they have from the truth, for want of sufficient data. This set the ingenious Dr. Hales upon making various experiments to ascertain the force of the blood in the veins and arteries of several animals. If, according to Dr. Koil's estimate, the left verticle of a man's heart throws out in each systole an ounce, or 1.638 cubic inches of the blood, and the area of the orifice of the anrta be $\mathbf{0 . 4 1 8 7}$, then dividing the former by this, the quotient 3.9 is the length of the cylinder of blood which is formed in passing through the aorta in each systole of the ventricle; and in the 75 pulses of a minute, a cylinder of 292.5 inches in length will pass; this is at the rate of $\mathbf{1 4 6 2}$ feet in an hour. But the systole of the heart being performed in one-third of the time, the velocity of the blood in that instant will be thrice as much, viz. at the rate of 4386 feet in an hour, or 73 feet in a minute. And if the ventricle throws out one ounce in a pulse, then in the 75 pulses of a minte, the quantity of blood will be equal to $4 \mathrm{lb} .11 \mathrm{oz}$. hence in thirty-four minutes, a quantity equal to the weight of a middle-sized man, viz. 159lb. will pass through the heart.

But if, with Dr. Harvey and others, we suppose 2 ounces of blood, that is, 3.276 cubic inches, to be thrown ont at. each systole of the ventricle, then the velocity of the blood in entering the orifice of the aorta will be double the former, viz. at the rate of 1.46 feet in a minute, and the quantity of blood will be equal to the weight of a man's body in half the time, viz. 17 minutes. If we suppose, what is probable, that the blood will rise $7+\frac{1}{2}$ feet high in a tube fixed to the carotid artery of a man, and that the inward area of the left ventricle of his heart is equal to 15 square inches, these multiplied in $7+\frac{1}{2}$ feet give 1350 cubic inches of blood, which presses on that ventricle, wher it first begins to contract, with a weight equal to is slbs.

What Dr. Hales thus calculated from supposition, with regard to mankind, he actually experimented upon horses, dogs, fallow deer, \&c. so that by fixing tubes in orifices opened in their veins and arteries: by observing the several heights to which the blood rose in those tubes as they lay on the ground; and by measuring the capacities of the ventricles in the heart, and orifices of the arleries me obtained the most satisfactory results. 


\section{Transfusion of Blood.}

THIS is an operation by which the blood of one animal is conveyed into the veins of another, and by which it was some time ago imagined the age of animals would be renewed, and a demi-immortality conferred on those who had undergone it. In the Philosephical Transactions we have an account of the success of various transfusions practised at London, Paris, Italy, \&c. Sir. Edmund King transferred forty-nine ounces of the blood sut of a calf into a sheep; the sheep, after the operation, appearing as well and as strong as formerly. M. Denis transfused the blood of three calves into three dogs, which all continued brisk, and ate as well as before. The same person transferred the blood of four wethers into a horse twenty-six years old, which thence received much strength, and a more than ordinary appetite. Soon after this operation was introduced al Paris, viz. in 1667 and 1668, M. Denis performed it on five human subjects, two of whom recovered of disorders under which they laboured: one, being iil perfect health, suffered no inconvenience from it, but two persons who were ill, and submitted to the operation, died; in consequence of which the magistrates issued a mandate, prohibiting the transfusion of blood into human bodies, under pain of imprisonment.

Mr. John Hunter made many ingenious experiments to determine the effects of transfusing blood, some of which are sufficient to attract. attention.

Of late years the attempt has been renewed in thig country, and, according to the accounts that have been published, the operations have been attended with considerable success.

\section{THE HAND.}

THE mechanism of the human hand is excellently fitted for the various uses and occasions we have for it, and the great numbers of arts and manufactures it is to be employed in. It consists of a compages of nerves and little bones joined into each other, which give it a great degree of strength, and at the same time an unusual flexibility, to enable it to handle adjacent bodies, laying hold of them, and grasping them, either to draw them towards or to thrust them off. Anaxagoras is said to have maintained that man owes all his wisdom, knowledge, and superiority over other animals, to the use of his hands; but Galen more justly remarks, that man is not the wisest creature because he has hands, but he had hands given him because he was the wisest creature, for it was not our hands that taught us arts, but our reason:

The hands are the organs of reason, \&c. In scripture, the word hand is variously applied. To pour water on any one's hand, signifies to serve him. To wash the hands, was a ceremony to denote innocence from murder or manslaughtes. To kiss the hand, was an act of adoration. To fill the hand, signified taking possession of the priesthood, and performing its functions. To lean upon any one's hand, was a marls of familiarity and supeiriority. To give the hand, signifies to grant peace, swear friendship, promise security, or make alliance. 
The right haud was the place of honour and respect. Among the Greeks and Romans it was customary for inferiors to walk on the left havd, that the right hand might be ready to afford protection to their left side, which was, on account of the awkwarduess of the left hand, more exposed to danger.

\section{AMBIDEXTERITY.}

BY this term we designate the quality of being able equally to use both hands. Various instances occur in history, where the left hand has been exercised preferably to the right. By the laws of the ancient Scythians, people were enjoined to exercise both hands alike ; and Plato enjoins ambidexterity to be observed and encouraged in his republic. In the German armies, the more distinguished soldiers, their pikemen and halberdiers, as well as those who formed the first line of the battalions, were trained to be able to fight equally with the left hand or the right. We find it mentioned in scripture, too, that on an extraordinary occasion, the single tribe of Gad produced seven hundred brave men who fought with their left hands as well as the right; and the Roman historians assure us, that they had gladiators who were trained up to the same exercise. An ingenious French writer is surprised, that among all the modern refinements in the art of war, none have thought of restoring the ancient practice, of training ambidexters, who undoubtedly might be of great service, especially in cases of stratagem.

\section{Post for the Conveyance of Letters or Despatches}

Posts of one kind or another appear to have been pretty early established among civilized nations. Without taking into account the different means of carrying on correspondence, said to have been attempted, by pigeons and other animals, we can at least trace with certainty the invention of something like regular posts as far back as the ancient Persians. Xenophon says, that they were invented by Cyrus on his Scythian expedition, about five hundred years before Christ; that the houses of the several stations were sumptuously built, and large enough to contain a number of men and horses; and that every courier, on his arrival, was obliged to communicate his despatches to the postmaster, by whom they were immediately forwarded. From the shore of the Ecan sea, to Susa the capital, there were, according to Herodotus, regular stages for posts, each a day's journey distant from the preceding.

In what manner posts were conducted among the Greeks, does not clearly appear, but, from their extensive commerce and frequent correspondence, some regular modes of conveyance must have been established.

Though posts were well known among the Romans, yet it is difficult to trace with certainty the period of their introduction. Some writers carry it back to the times of the republic; posts, and post-offices, under the name of statores and stutiones, having been then, it is said, established by the senate. Be that as it may, Suetonius assures us, 
that Augustus instituted posts along all the great roads of the empire. Ai first the despatches were conveyed from post to post by young men, who ran on foot, and delivered the despatch to others at the next stage. Augustus substituted, in room of these, horses and charints, both for conveyance of despatches and the convenience of travelling. His successors continued the same establishment; to the maintenance of which, every subject of the empire was obliged to contribute. Post-horses are mentioned in the Theodorian code De Cursu Publico; but these were only the public horses appointed to be kept there for the use of public messengers, who before this institution seized any that came in their way. At each post station, according to Procopius, ten horses, and as many postilions, were kept, and the usual rate of travelling was from five to eight stations a day. All these establishments of posts, however, in ancient times, were formed as much, if not more, for travelling stations, than for the mere conveyance of letters and despatches, though this was also secured.

The, earliest institution of posts that occurs in modern history is about the year 807 , by the emperor Charlemagne, who having reduced under his dominion Italy, Germany, and a part of Spain, established three posts at the public expense, to carry on the communication with these three provinces. The establishment of posts, however, like many other institutions of that emperor, dropped at his death; and for a considerable time afterwards, no traces of any such establishment are to be found. We cannot indeed discover its renewal with certainty sooner than 1464 , when that restless and suspicious prince Lewis XI. established posts in France, that he might be the sooner advertised of all that passed in his own or neighbouring kingdoms. He employed in this service two hundred and thirty couriers, who delivered the letters at the difierent stations, and in the various towns through which they passed in their course. Succeeding monarchs created at different times certain offices, for the express purpose of superintending the posts; but the frequent changes to which these ofices were exposed, prevented for a long time the establishment of any regular system of posts in that kingdom; insomuch that, in 1619 , the author of the Life of the duke d'Epergnon says, the packet or letter office was not yet set up in France. Former establishments, it is probable, were solely for the use of the court, not for the general good of the nation.

From France the institution gradually spread through several other parts of Europe. In Germany, Lewis Hornig assures us, they were first introduced by Count Taxis, who settled them at his own expense, in acknowledgment for which, the emperor Mathias, in 1616, gave, as a fief, the office of post-master to him and his descendants.

In Fngland, the establishment of posts, iu some form or other, appears as early as the reig $n$ of Edward III; lut the notices concerning them are very obscure and indistinct. In the reign of Edward VI. however, some species of posis must have been set up, as an act of parliament passed in 1548, fixing the rate of posthorses at one peuny per mile. The post-horses here referred to were, it is probable, chiefly for travelling, and the carriage of letters or packets only an occasional service. In 1581, we find, in Camden's Annals, mention made of a 
chief post-master for England before appointed. King James 1. originally erected'a post-office, under the coutrol of one Matthew de Quester, or del'Equesier, for the conveyance of letters to and from foreign parts, which office was afterwards claimed by lord Stanhope, but was confirmed and continued to William Frizel and Thomas Witherings, by king Charles I. in 1632. Previous to this time it would appear that private persons were used to convey letters to and from foreign parts; all such interference with the post-master's office is therefore expressly prohibited. King Charles, in 1635 , erected a letter-office for England and Scotland, under the direction of the above Thomas Witherings ; who, however, was superseded for abuses in 1640. The rates of postage then established was two-pence from eighty to one hundred and forty miles. The allowance to the post-masters on the road, for horses employed in these posts, was fixed at two-pence halfpenny per mile, for every single horse. All private inland posts were discharged at this time; and in $\mathbf{1 6 3 7}$ all private foreign posts were in like manner prohibited. The posts thus established, however, extended only to a few of the principal roads; and the times of transmission were not in every case so certain as they ought to liave been.

\section{Eastern Mode of Conveying Letters.}

Sanballat appears to have sent his letter to Nehemiah (chap. vi. 3. ) open, $i$. e. unenclosed, in contempt, as the Turks do to this day when they write to mean or common persons; but when they ivrite to their superiors, they enclose their letters in a handsome bag, with a paper tied to it, directed and sealed. Niebuhr asserts, in his Travels, that the Turks send their letters to their equals in long purses of silk. The Aiabs roll up their letters, and then flatten them to the breadth of an inch, and paste up the end instead of sealing them. The Persians make up their letters in a roll, about six inches long, and a bit of paper is fastened round it with gum, and sealed with an impression of ink which resembles printers ink, but not so thick. The Mexicans conveyed intelligence from place to place by small portions of cotton, coloured, and tied in a peculiar manner which was well understood. These demi-hieroglyphics were conveyed with great rapidity by persons purposely stationed at given distances from each other.

\section{Origin of the Materials of Writing.}

From the "Literary History of France," by the learned Benedictines, Mr. D'Israeli collected the chief materials of the present article.

It is curious to observe the various substitutes for paper before its discovery. When men had not yet discovered the art of recording: events by writing, they planted trees, erected rude altars, or heaps of stone, as remembrances of past events. Hercules probably could not write when he fixed his famous pillars. The most ancient mode of writing was on bricks, tyles, and oyster-shells, and on tables of stone; afterwards on plates of various materials, on ivory, on bark of trees, on leaves of trees, \&c. Engraving memorable exents on hard 
substances, it has been prettily observed, was giving as it were sifeech to rocks and metals. In the book of Job mention is made of writing on stone, on rocks, and on sheets of lead. It was on tables of stone that Moses received the law, written by the finger of God himself. Hesiod's worlis were written on leaden tables; lead was used for writing, and rolled up like a cylinder, as Pliny states. Montfaucon notices a very ancient hook of eight leaden leaves, which on the back had rings fastened by a sinall leaden rod, to keep them together. They afterwards engraved on bronze: the laws of the Cretans were on bronze tables: the Romans etched their public records on brass; the speech of Claudius, engraved on plates of bronze, is yet preserved in the town-hall of Lyons, in France. Several bronze tables with Etruscan characters have been dug up in Tuscany. The treaties between the Romans, Spartans; and the Jews, were written on brass; and conveyances of estates, for better security, were written on this enduring metal. In many cabinets may be found the discharges of soldiers, written on copper plates.

This custom has been discovered in India: a bill of feoffrnent on copper has been dug up near Bengal, dated a century before the birth of Christ.

Among these early inventions, many were singular, rude, and miserable substitutes for a better material. In the shepherd state, they wrote their songs with thorns and awls on straps of leather, which they wound round their crooks. The Icelanders appear to have scratched their runes, a kind of hieroglyphics, on walls : and Olof, according to one of the Sagas, built a large house, on the balks and spars of which he had engraved the history of his own and more ancient times; whilst another northern hero appears to have had nothing better than his own chair and bed on which to perpetuate his own heroic acts. At the town-hall in Hanover are kept twelve wooden boards, overlaid with bees-wax, on which are written the names of owners of houses. These wooden manuscripts must bave existed before 1423 , when Hanover was first divided into streets. Such manuscripts may be found in public collections. This exhibits a very curious, and the rudest state of society. The same means were used among the ancient Arabs, who, according to the history of Mahomet, seem to have taken the shoulder bones of sheep, on which they carved remarkable events with a knife, and, after tying them with a string, hung these chronicles up in their cabinets.

The laws of the twelve tables, which the Romans chiefly copied from the Grecian code, were, after they had been approved by the people, engraved on brass; they were melted by lightning, which struck, the capitol, and consumed other laws: a loss highly regretted by Angustus. This manner of writing we still retain, for inscriptions, epitaphs, and other memorials designed to reach posterity.

These early inventions led to the discovery of tables of wood; and as cedar has an antiseptic quality from its bitterness; they chose this wood for cases or chests to preserve their most important writings. The well-known expressions of the ancients, when they meant to give the highest eulogium of an excellent work, et cedro digna locuti, (that it was worthy to be written on cedar,) alludes to the oil of cedar, with 
which valuable sheets of parchment were anointed, to preserve them from corruption and moths. Perseus illustrates this, in the excellent version of Mr. Gifford :-

Who would not leave posterity such rhymes, As cedar oil might keep to latest times.

\section{Porousness and Durability of Charcont.}

CHARCOAL consists of wood half burnt, and is chiefly used where a cleal strong fire, without smoke, is required; the humidity of the wood being mostly dissipated in the fire wherein it is prepared. The microscope discovers a surprising number of pores in charcoal; they are disposed in order, and traverse it lengthwise; so that there is no piece of charcoal, how long soever, but may be easily blown through. If a piece be broken pretty short, it may be seen through with a microscope. In a range, the eighteeenth part of an inch long, Dr. Hook reckoned one bundred and fifty pores; whence he concludes, that in a charcoal of an inch diameter; there are not less than five million seven hundred and twenty-four thousand pores! It is to this prodigious number of pores, that the blackness of charcoal is owing; for the rays of light striking on the charcoal, are absorbed in its pores, instead of being reflected, whence the body must of necessity: appear black.

Charcoal was anciently used to distinguish the bounds of estates and inheritances ; as being incorruptible, when let very deep within ground. In fact, it lasts so long, that there are many pieces found entire in the ancient tombs of the northern nations. M. Dodart says there is charcoal made of corn, probably as old as the days of Cresar : he adds, that it has kept so well, that the wheat may be still distinguished from the rye; which he looks on as a proof of its incorruptibility.

\section{CHAOS.}

CHAOs is represented by the ancients as the first principle, orum, or seed, of nature and the world. All the sophists, sages, naturalists, philosophers, theologians, and poets, held that chaos was the eldest and first principle. The Phonicians, Egyptians, Persians, \&c. all refer the origin of the world to a rude, mixed, confused mass of matter. The Greeks, Orpheus, Hesiod, Menander, Aristophants, Euripides, and the writers of the Cyclic Poems, all speak of the first chaos. The Ionic and Platonic philosophers build the world out of it. The Stoics hold, that as the world was first made of the chaos, it shall at last be reduced to a chaos; and that its periods and revolutions in the mean time are only transitions from one chaos to another. Lastly, the Latins, as Ennius, Varro, Ovid, Lucretius, Statius, \&zc. are all of the same opinion. Nor is there any nation or sect whatever, that does not derive the structure of the world from a chaos.

Dr. Burnet observes,"that besides A ristotle, and a few other pseudoPythagoreans, nobody every asserted that our world was always from eternity; of the same nature, form, and structure as at present; but that it had been the standing opinion of the wise men of all ages, that 
what we now call the terrestrial globe was originally an unformed, indigested mass of heterogeneous matter, called chaos, and only the rudinents and materials of the present world. It does not appear who first broached the notion of a chaos. Moss, the earliest of all writers, derives the origin of this world from a confusion of matter, dark, void, deep, without form, which he calls Tohu-Bohu; which is exactly the chaos of the Greeks and Barbarian philosophers. Moses goes no farther than the chaos, nor tells us whence it took its origin or confused state; and where Moses stops, there precisely do all the rest.

Dr. Burnet endeavours to shew, that as the ancient philosophers, \&c. who wrote of the cosmogony, acknowledged a chaos for the principle of their world; so the divines and writers of the theogony, derive the origin or generation of their fabled gods from the same principle.

Mr. Whiston supposes the ancient chaos, the origin of our earth, to have been the atmosphere of a comet; which, all things considered, is not the most improbable opinion. He endeavours to make it out by many arguments, drawn from the agreement which appears to be between them. According to him, every planet is a comet, formed into a regular constitution, and placed at a proper distance from the sun, revolving in a nearly circular orbit; and a comet is a planet, either beginning to be destroyed or re-made; that is, a chaos or planet unformed, or in its prineval state, and placed as yet in an orbit very eccentric.

\section{Artificial Hatching.}

THE art of hatching chickens by means of ovens has long been practised in Egypt, chiefly in a village called Berme, and its environs. About the beginning of autumn; the natives scatter themselves all over the country, where each undertakes the management of an oven. The orens are of different sizes, but in general they contain from forty to eighty thousand eggs. The number of ovens is about three hundred and eighty-six, and they usually keep them working for about six months : as, therefore, each brood takes up in an oven, as under a hen, only twenty-one days, it is easy in every one of them to hatch eight different broods of chickens. Every Bermean is under the obligation of delivering to the person who trusts him with an oven, only two-thirds of as many chickens as there have been eggs put under his care; and he is a gainer by this bargain, as more than two-thirds of the eggs usually produce chickens. In calculating the number of chickens thus annually hatched in Egypt, it appears that the ovens of Egypt give life yearly to at least ninety-two million six hundred and forty thousand of these animals.

This useful and advantageous method of hatching eggs was discovered in France by the ingenious $\mathrm{Mr}$. Reaunur, who, by a number of experiments, reduced the art to fixed principles. He found that the heat necessary for this purpose is nearly the same with that marked thirty-two on his barometer, or ninety-six on Fahrenheit's. 'This degree of heat is nearly that of the skin of a hen, and all other domes- 
tic fonls, and probably of all other kinds of birds. The degree of lieat, which brings about the development of the chick, the gosling, and the turkey pout, is the same as that which hatches the canary songster, and in all probability the smallest humming bird ; the difference is only in the time this heat ought to be communicated to the eggs of different birds. It will bring the canary bird to perfection in eleven or twelve days, while the turkey pout will require twenty-seven or twenty-eight. After many experiments, $\mathrm{Mr}$. Reaumur found, that stoves heated by a baker's oven succeeded better than those made hot by layers of dung: and the furnaces of glass-houses, and those of the melters of metals, by means of pipes to convey heat into a roon, might, no doubt, be made to answer the same purpose. As to the form of the stoves, no great nicety is required. A chamber over an oven will do very well. Nothing more is necessary to know when you have obtained the degree of heat, than by melting a lump of butter, of the size of a walnut, with half as much tallow, and putting it into a phial. This serves to indicate the heat with sufficient exactriess, for when it is too great, this mixture will become as liquici as oil ; and when the heat is too small, it will remain fixed in a lump; but it will whew like a thick syrup, upon inclining the bottle, if the stove be of a right temperature. Great attention, therefore, should be given to keep the heat always at this degree, by letting in fresh air if it be too great, or shutting the stove more closely if it be too small; and that all the eggs in the store may equally share the irregularity of the heat, it will be necessary to shift them from the sides to the centre; and thus to imitate the hens, which are often seen to make use of their bills to push to the outer parts those eggs that were nearest to the middle of their nest, and to bring into the middle such as lay nearest the sides.

Mr. Reaumur has invented a sort of low boxes, without bottoms, and lined with furs. These, which he calls Artificial Parents, not only shelter the chickens from the injury of the air, but afford a kindly warmth, so that they take the benefit of their shelter as readily as they would have done under the wings of a hen. After hatching, it will be necessary to keep the chickens in a room artificially beated, and furnished with these boxes; but afterwards they may be safely exposed to the air in the court yard, in which it may not be amiss to place one of these artificial parents to shelter them, if there should be occasion for it. They are generally a whole day after being hatched, before they take any food at all. A few crumbs of bread may then be given them for a day or two, after which they will pick up insects and grass for themselves. But to save the trouble of attending them, capons may be taught to watch them in the same manner as hens do. Mr. Reaumur says he had seen above two hundred chickens at once, all led about and defended by three or four capons only. Nay, cocks may be taught to perform the same office, which they, as well as the capons, will continue to do all their lives after.

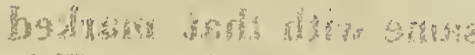




\section{Part VI.}

\section{NATURAL CURIOSITIES,}

\&c.

ABsorption of the Earti.

KIRCHER, and other geolngists, use this phrase to denote the swallowing up of great portions of land by eartiquakes, and other subterraneous convulsions or accidents. Several instances of these alarming commotions have occurred in various countries. "The mountain of Cymbotus, and the town of Curites seated on its declivity; the city of Tantalis, in Magnesia; the nountain Sypilus; Galanis and Garnates, two Phœuician towns; the promontory of Phegium, in Eihiopia; the mountain Picus, and several others-are mentioned as having sunk into the earth at different times. Later instances have occurred in China, France, and Switzerland.

4 mountain belonging to the chain of the Cevennes, in the "south of France, was precipitated, with an awful crash, into the valley below, on June 23, 1727; one block of stone, ninety feet long, and twenty-six in diameter, sunk vertically; and the village of Pradines, situated on the declivity, being overwhelmed by the rocky fragments, its inhabitants were oniy saved from destruction in consequence of having gone to some distance to celebrate Midsummer-eve.

To these and other instances of absorption, which might be mentioned, may be subjoined a circumstance which occurred on September 3, 1806, at Schweitz, a canton in Switzerland. Between the lakes of Zug and Lowertz, and the mountains of Rosenberg and Rossi, lay a beantiful valley, overspread with several pleasant villages. About five o'clock in the evening of September 3, the Spitzberg; or northeast projection of the mountain Rosenberg, fell into the valley, from the height of two thousand feet, and overwhelmed the villages of Goldau, Busingen, and Rathlen, and a part of Lowertz and of Oberart. The earth and stones rushed like lava into the valley, and covered more than three square miles of a fertile vicinity; filling up, at the same time, nearly a fifth of the lake Lowertz. The immense swell of the water which immediately tock place, submerged two inhâbited islands; and the village of Leven on the northern extreinity; by which accident, between fifteen hundred and two thousand inhàbitants perished. The most probable cause to be assigned of this dreadful calamity, was the sinking in of the earth which supporterl the base of the Spitzberg.

Moving Earti.

IN July, 1823, at the Waen Wem lime rocks, near Llanymyitech, the inhabitants of the neighbourhood were surprised to find that, dur- 


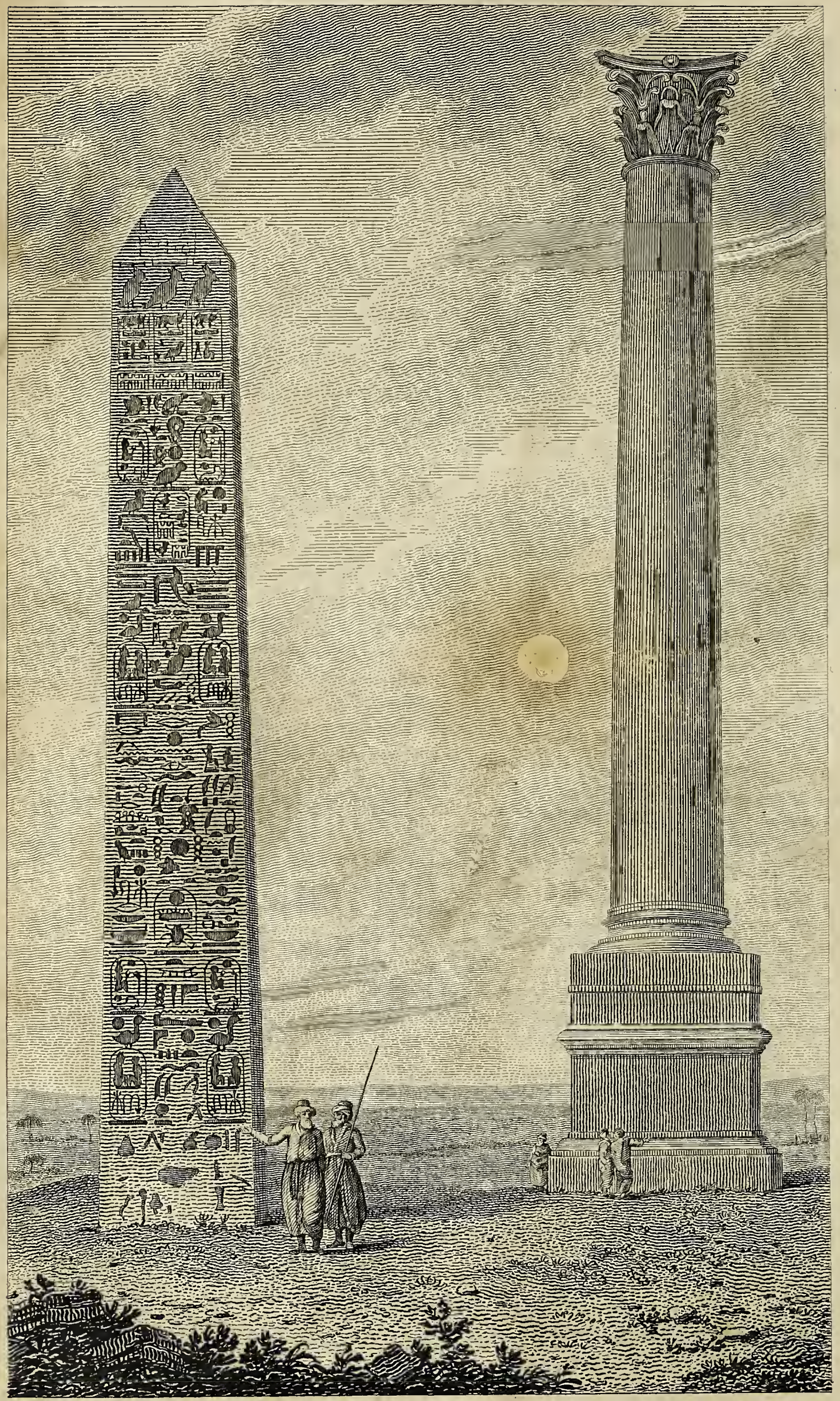

CILEOPATIRA'S NEETILE。

POMLPEX:S PIISLAR . 
mg the preceding night, several thousand tons of limestone had parted en masse from the main rock, and moved four or five yards forwards, pushing the earth before it with tremendous force, and leaving a horrid chasm behind. This seems the more extraordinary, as there appears no adequate cause for such an effect. The rocks had not been worked for several years, and as the weather was perfectly dry at the time, it would seem that nothing but an earthquake could have produced the separation. In many similar situations, near the spot in question, the cottagers have erected their'dwellings, in the full confidence that they could not have a surer foundation; and nothing extraordinary had happened during the night in question, to warrant the supposition that an earthquake was the cause. The matter must therefore remain at present a mystery, until some geologist shall be able to give a satisfactory reason for so unlooked-for an event; which created no little alarm among the cottagers in the neighbourhood, who had flattered themselves on the perfect security of the foundations of their humble dwellings.

\section{Cleopatra's Needle, and Pompey's Piliar.}

Cleopatra's Needles.-In ancient architecture, these are known as two obelisks, which stood towards the eastern part of the palace of Alexandria in Egypt. They were constructed of Thebaic stone, and covered over with hieroglyphics, of which the meaning is now unintelligible. One of these is overturned, broken, and lying buried among the surrounding sands. The other is still entire, and exhibits an appearance as represented in the engraving. Each of these obelisks was of a single stone, about sixty feet high, by seven feet square at the base, Of this that stands, the workmanship and sculpture are superbly exquisite, and it is to be regretted that the numerous and diversified characters with which it is covered should remain com. paratively unknown.

Pompey's Pillar.-Pompey's pillar is a famous monument of antiquity, copstructed of red granite, and situated on a rock, about a mile without the walls of Alexandria in Egypt. By the mensuration of Edward. Wortley Montagu, esq. the capital of the pillar, which is Corinthian, with palm leaves, and not indented, is nine feet seven inches high; the shaft sixty-six feet one and a quarter inch; the base,five feet nine and three quarter inches; the pedestal ten feet five and a half inches; the height from the ground ninety-two feet: though Dr. Pococke, by the shadow, determined the whole height to be one hundred and fourteen feet; and its diameter nine feet and an inch. It is perfectly well polished, and only, a little shivered on the eastern side. Nothing can equal the majesty of this monument; seen from a distance, it overtops the town, anci serves as a signal for vessels. Approaching it near, it produces, says Savary, an astonishment mixed with awe. One can never be tired with admiring the beauty of the capital, the length of the shaft, nor the extraordinary simplicity of the peclestal. This prodigions mass stands, as on a pivot, on a reversed obelisk; and was erected, as many have supposed, either by Pompey, or to his honour. But as no mention is made of 
it by Strabo, Diodorus Siculus, or any other ancient writers, Mr. Monlagu concludes that it was not known before the time of Vespasian, and that it was erected to his honour. In proof of this opiuion, he found within the circumference of the pillar a medal of Vespasiain in fise order.

Savary, on the authority of Abulfeda, who calls it "the pillar of Severus," ascribes it to this emperor; alleging that he visited Egypt, gave a senate to Alexandria, and deserved well of its inhabitants. Accordingly, it is said that this column was a mark of their gratitude. The Greek inscription, half effaced, which is visible on the west side when the sun shines upon it, was legible, without doubt, in the time of Abulfeda, and preserved the name of Severus. Nor is this the only monument erected to him by the gratitude of the Alexandrians. In the midst of the ruins of Antinoe, built by Adrian, is seen a magnificent pillar, the inscription on which is still remaining, dedicated to Alexander Severus.

Denon has given a drawing of this pillar, with the marked dimensions of its various parts; he makes its whole height a fraction more than 92 feet, and the height of the shaft, which is of a single piece, 63 feet 1.3. It acquired, as this author says, the name of Pompey's pillar, in the fifteenth century. A monument, as he supposes, had been raised by Pompey at Alexandria, but it had disappeared, and was thought to be recovered in this pillar or column, which has since been converted into a trophy erected to the memory of Septimius Severus. It is, however, placed on the ruins of the ancient city; and in the time of Septimius Severus, the city of the Ptolemies was not in a ruinous state. To support this column by a solid foundation, an obelisk has been sunk ia the earth, on which is placed a very clumsy pedestal, having a fine shaft, and surmounted by a Corinthiai: capital of bad workmanship. If the shaft of this column, continues Denon, separating it from the pedestal and the capital, once belonged to an ancient edifice, it is an evidence of its magnificence, and of the skill with which it was executed. It ought therefore to be said that what is called Pompey's pillar is a fine column, and not a fine monument; and that a column is not a monument. The earth about the foundation of this pillar luving been cleared away by time, two fragments of an obelisk of white marble, the only monument of that substance seen by Denon in Egypt, have been added to the original base, to render it more solid. After having observed that the column entitled Pompey's pillar, is very chaste both in style and execution; that the pedestal and capital are not forned of the same granite as the shaft; that their workmanship is heavy, and appears to be merely a rough draught; and that the foundations, made up of fragments, indi. cate a modern construction; it may be concluded, says our author, that this monument is not antique ; and that it may. have been erected either in the time of the Greek emperors, or of the caliphs; since if the capital and pedestal are well enough wrought to belong to the former of these periods, they are not so perfect but that art may have reached so far in the latter. See Pocock's Descr. of the East, vol. i. p. 8. and Phil. Trans. vol. lvii. art. 42. Savary's Letters on Egypt, vol. i. Denon's Travels in Egypt, vol. i. 
LABYRINTH OF EGYPT.

AcCordING to Pliny, this was the oldest of all the known labyrinths, and was subsisting in his time, after having stood three thousand six hundred years. He says it was built by king Petemsus, or Tithoes, but Herodotus makes it the work of several kings. It stood on the banks of the lake Mœris, and consisted of twelve large contiguous palaces; containing three thousand chambers, one thousand five hundred of which were under ground. Strabo, Diodorus Siculus, Pliny, and Mela, speak of this monument with the same admiration as Herodotus; but not one of them says it was constructed to bewilder those who went into it, though it is manifest that, without a guide, they would be in danger of losing their way. It was this danger, no doubt, that introduced a new term into the Greek language.

\section{Labyrinti of Crete.}

Tuls is the most faned labyrinth in history or fable; having been rendered particularly remarkable by the story of the monster Minotaur, and of Theseus, who found his way through all its windings by Airad ne's clew. Diodorus Siculus relates as a conjecture, and Pliny as a certain fact, that Dredalus ccustructed this labyrinth on a model of that of Egypt, though on a smaller scale. They add, that it was formed by the command of Minos, who kept the Minotaur shut up in it; but that in their time it no longer existed. Diodorus and Pliny, therefore, considered this labyrinth as a large edifice, while other writers represent it sinply as a cavern hollowed in the rock, and full of winding passages. But if this labyrinth had been constructed by Dredalus under Minos, it is surprising that we find no mention of it either in Homer, who more than once speaks of Minos and Crete, or in Herodotus, who describes that of Egypt, (after having said that the monuments of the Egyptians are much superior to those of the Greeks,) or in the more ancient geographers, or in any of the writers of the ages when Greece flourished.

Diodorus and Pliny suppose, that in their time no trace of the labyrinth existed in Crete, and that even the date of its destruction had been forgotten. : Yet it is said to have been visited by the disciples of Apollonius of Tyana, who was contenuporary with these two authors. The Cretans therefore believed that they possessed the labyrinth. "I would request the reader," says Abbé Barthelemi, "to attend to the following passage in Strabo: At Napulia, near the ancient Argos, says that judicious writer, are still to be seen vast caverns, in which are constructed labyrinths, that are believed to be the work of the Cyclops. The meaning of which is, that the labours of men had opened in the rock passages that crossed and returned upon themselves, as is done in quarries. Such is the idea we form of the labyrinth of Crete. Were there several labyrinths in that island? Ancient authors speak only of one, which the greater part place at Ciossus, and some at Gortyna. Belon aid Tournefort have given us the description of a cavern at the foot of mount of Ida, on the south side of the mountain, at a small distance from Gortyna. This was 
only a quarry, according to the former ; and the ancient labyrinth, according to the latter, whose opinion I have followed."

\section{Curious Subterranean Vaults of Maestricht.}

By Colonel Bory de, Saint-Vincent.

Petersberg, or the Hill of St. Peter, is situated between the Jaar and Meuse, and extends along the distance of nearly a league. The earth which is contained in the cavities in the interior of the hill furuishes materials for building, but principally for manure; and for this double purpose it has been excavated from the most remote ages of antiquity. In the synmetrical galleries of Petersberg, the Roman. pickaxe has imprinted a kind of monumental character, and the feudal spade has left its Gothic traces. Workmen have from time immemorial been employed in excavating the bowels of the earth, to fertilize its surface. For ages the pickaxe and wheelbarrow have worked passages in every direction, and the traveller in this subterrancous labyrinth is happy, if, with the aid of his torches, he can return the way he entered. Streets, squares, and cross roads appear on every side; in short, the vaults of Petorsberg present the appearance of a town, in which there are only wanting houses, inhabitants, theatres, carriages, and gas lamps: M. Bory de Saint-Vincent draws the following picture of this gloomy region :- "If any thing," he says, "can add to the horror of the perfect darkness, it is the total silence which reigns in these dismal vaults. The voice of man is scarcely sufficient to disturb it; sound is, as it were, deadened by the thickness of the gloom. Echo itself, which the bewildered traveller may interrogate in the desert, dwells not in these silent cavities."

It may naturally be conjectured that superstition has peopled these subterraneous vanlts with demons and hobgoblins. Tradition has even allotted a hell and a paradise to the cavities of Petersberg. The huge pieces of coal, which an equal temperature has protected from the ravages of time, imagination has converted into monsters with claws, loug tails, and horns. In various places, names, inscriptions, and remote dates, record the history of the origin of the excavations, and relate numerous adventures and unfortunate deaths of which Petersberg has been the theatre. In one part of the vaults a workman, whose torch became extinguished, perished amidst the pangs of hunger and the horrors of darkness; his hat and some fragments of his clothes still remain, to attest his melancholy fate. In another part the walls present the history of four friars, who proposed to erect a chapel at the remotest point of the cavities. The thread by which they were to trace back their way to the opening of the vaults, broke; the unfortunate men perished, and their bodies were subsequently found at the distance of a few paces from each other. However, catastrophes of this terrible kind presented fewer horrors to the conscripts of the Lower Meuse than the pursuits of the gendarmerie, and, according to the testimony of the author, many preferred these dismal retreats to the laurels of Wagram and Jena.

The interior of the hill of St. Peter has given rise to anecdotes worth collecting; the Austrians, having possession of the for of 
Petersberg, discovered a secret communication with the vaults of the hill, of which the French troops guarded some of the entries. With toreh in hand, and fixed bayonets, the Austrians attempted to surprise the French; but the latter, warned by the subterrancous lights, rushed upon the enemy, who were dazzled by their own torches, and a conflict ensued, which resembled a combat of the infernal deities.

The following story is of a less serious nature. Maestricht had fallen into the power of the French, and long continuepd a most formidable garrison. A portion of the Austrian population fled to the vaults beneath the hill of St. Peter. They took their cattle with them, and in the subterraneous cavities they hastily constructed rooms and stables. The French were unable to account for the miraculous disappearance of a portion of the conquered inhabitants, when a pig, which had escaped from its sty, rushed along the subterraneous galleries, squeaking tremendously. It was heard by the French sentinels, and this circumstance led them to suspect the retreat of the Austrians. They adopted means to make the pig squeak still louder, in the hope of attracting the fugitives, when, to the great surprise of the French soldiers, several pig's rushed out, to answer the summons of the imprudent deserter. In ancient times the Roman capital was saved by geese, and on this occasion a pig caused the destruction of the little republic of Petersberg. The Austrians were routed from: their retreat, and their cattle and pigs, as may well be supposed, were speedily roasted and devoured.

\section{Cavirn of Antiparos.}

THE island of Antiparos is remarkable for a subterraneous cavern, or grotto, accounted one of the greatest natural curiosities in the world. It was first discovered in the eighteenth century, by one Magni, an Italian traveller, who has given us the following account. "Having been informed," says he, "by the natives of Paros, that, in the little island of Antiparos, which lies about two miles from the former, a gigantic statue was to be seen at the mouth of the cavern in that place, it was resolved that we the French consul and himself) should pay it a visit. In pursuance of this resolution, after we had landed on the island, and walked about four miles through the midst of beautiful planes and sloping woodlands, we at length came to a little hill, on the side of which yawned a most horrid cavern, that with its gloom at first struck us with terror, and almost repressed curiosity. Recovering the first surprise, however, we entered boldly, and liad not proceeded above twenty paces, when the supposed statue of the giant presented itself to our view. We quickly perceived that what the ignorant natives had been terrified at as a giant, was nothing more than a sparry concretion, formed by the water drop. ping from the roof of the cave, and by degrees hardening into a figure that their fears had formed into a monster.

"Incited by this extraordinary appearance, we were induced to proceed still farther in quest of new adventures in this subterranean abode As we advanced, new wonders offered themselves: the spars, forried into trees, presented a kind of petrified grove; some white, 
some green, and all recelling in due perspective They struck ons with the more anazenent, as we knew them to be the mere productions of nature, which, hitherto in solitude, had in her playful moments dressed the scene as for her own amusement. But we had as yet seen only a few of the wonders of the place; and we were introduced as yet only into the portico of this amazing temple. In one corner of this half-illuminated recess, there appeared an opening of about three feet wide, which seemed to lead to a place totally dark, and that, one of the natives assured us, contained nothing more than a reservoir of water. Upon this we tried; and by throwing down some stones, which rumbling along the sides of the descent for some time, the sound seemed at last quashed in a bed of water. In order, however, to be more certain, we sent in a Levantine mariner, who, by the promise of a great reward, with a flambeau in his hand, ventured into this narrow aperture. After continuing within it for about a quarter of an hour, he returned, bringing some beautiful pieces of white spar in his land, which art could neither imitate nor equal: Upon being iuformed by him that the place was full of these beautiful incrustations, $I$ ventured in with him, for about fifty paces, anxiously and cautiously descending by a stecp and dangerous way: finding, however, that we came to a precipice that led into a spacious amphitheatre, if I may so call it, still deeper than any other part, we returned; and being provided with a ladder, flambeau, and other things to expedite our descent, our whole compary, man by nan, ventured into the same opening, and, descending one after another, we at last saw ourselves all together in the most magnificent part of the carern. Our candles being now all lighted up, and the place completely illuminated, never could the eye be presented with a more glittering oi magnificent scene-the room all hung with solid icicles; transparent as glass, yet solicl as marble; the eye could scarcely reach the noble and lofty ceiling; the sides were regularly formed with spars; and the whole presented the idea of a magnificent theatre, illuminated with an immense profusion of lights. The floor consisted of solid marble; and in several places magnificent columins, thrones, altars, and other objects, appeared, as if nature had designed to mock the pretensions of art; our voices, upon speaking or singing were redoubled to an astonishing loudness, and, upon the firing of a gun, the noise and reverberations were almost deafening.

"In the midst of this grand amphitheatre rose a concretion of about fifteen feet high, that in some measure resembled an altar, from which, taking the hint, we caused mass to be celebrated there. The beautiful columns, that shot up round the altar, appeared like candlesticks; and many other natural objects represented the customary ornaments of this sacrainent. Below this spacious grotto there seemed even another cavern, dowil which I ventured with my former mariner, and descénded about fifty paces by means of a rope. I at last arrived at a small spot of level ground, where the bottom appeared different from that of the amphitheatre, being composed of soft clay, yielding to the pressure, and in which $I$-thrust a stick to about six feet deep. In this, however, as above; numbers of the most beautiful crystals were formed, one of which particularly resembled 
atables Upon an egress from this amazing cavern, we perceived a Greek inscription upon a rock situated at the mouth; but so obliterated by time, that we could not read it. It seemed to import, that one Antipater, in the time of Alexander, had come thither; but whether he penetrated into the depths of the cavern, he does not think fit to inforn us."

From this account Mr. Tournefort's differs considerab y. Mr: Magni mentions only one descent or precipice from the entry of the cave to the grotto, or most magnificent part: Mr. Tournefort says that there were many very dangerous precipices and rugged ways, through-which they were obliged to pass, sometimes on their back and sometimes on their belly, but gives no particular account of his journey until he comes to the grand cavern. This indeed he describes very pompously; but as by it he evidently wants to support a favourite hypothesis, namely, the vegetation of stones, perhaps. the particulars are not altogether to be depended upon. He informs us, that at the entry into the grand cavern, they met with a Greek inscription, almost defaced, containing a number of proper names; and that there was a tradition among the inhabitants, that these were the names of those who had conspired against Alexander the Great, and, having missed their aim, had taken refuge in this grotto.

\section{Dropping Cave, or the White Cave of Slains.}

THIS is a remarkable cave in Aberdeenshire, which the Rev. Mr. Farquhar thus describes;- "It is visited by most strangers, being justly esteemed a rarity. The sea reaches to the mouth of it at high water. Upon entering, one sees the water oozing through a spungy porous rock on the top and sides; it falls down in pretty large drops, like a very moderate shower. These drops are of a remarkably petrifying nature; they gradually and imperceptibly line the cave with curious stalactical incrustations, in very different and strange forms. A great deal of these was taken out some years ago, and turned into lime. It is again petrified all over, and has the look of white marble."

\section{Zaney's Cave.}

ThIs is an extraordinary cavern of Virginia, in the North mountain, Frederick county. The entrance is from the top of the exten.sive ridge. The descent is 40 feet down into a deep pit, from the bottom of which the cave extends horizontally 400 feet, preserving a breadth of from twenty to fifty feet. After entering this cave, the mercury in Fahrenheit's thermometer, which in the open air is at $10^{\circ}$, rises to $57^{\circ}$.

\section{Ruthand Cavern.}

THIs cavern, which is the largest in this kingdom, is with in the mountains of Abraham's Heights, Watlock Bath.

The Rutland cavern is an object of general curiosity, and the tervific grandeur of the immense natural cavities, far exceeds the wildest 
pictures of romance, or the fearful scenes of enchantment, and gives a most interesting and perfectly new subject for the mind: From the finest terrace, comnanding all the beauties of Matlock, you enter the rock by a dry, roomy, and even mountainous archway, perfectly safe and pleasant for the most timid female. The external surface of the Heights of Abraham abounds in rare botanical plants, and from the Serpentine and Moon Battery Walks, sliaded by fine and loity cedars, the most sublime scenery is taken, rich and roniantic as the imagination can conceive. The pure air of this delightful region, and the extraordinary instances and facts of the lengthened periods of existence of its inhabitants, proclaim this to be really the seat of health.

The principal objects of general observation within the cavern, are the rocky mountain archway, inbedding marine shells; the druses, or grottos; fish-ponds; Ossian's Hall; an arcade to the Hall of Enchantment in the Castle of Otranto, of indescribable gralldeur; the den of lions; a grand cave, with the extraordinary distant glimmering of daylight; a fine arcade to Jacob's well and fountain; the waters of life; the ascent by one hundred steps to the ancient miine worked by the Romans; other fish-ponds, with fish living in perpetual darkness; the dark and gloomy cave of black stone; the encmy of miners; the den of wolves and bears; a romantic bridge; a fine rocky scene. These recesses lead to the most fantastic, grotesque, and whimsical distributions of rocks, imbedding the most rare and delicate fossils, grottos, and druses, that defy all attempts at description or relation.

\section{Falls of Foyers.}

Foyers is a river in Scotland. Dr. Ganett, in his Tour, vol. i. p. 322, gives the following accurate and elegant description of the Falls of Foyers. "Haviing left our horses at General's Hut, we were conducted by our landlord to the Falls. We first visited the upper one, which is about a nile and a half from the house, and nearly half a nile above the lower Fall. IJere the river Foyers being confined on each side by steep rocks, precipitates itself with great velocity, forming a very fine cataract. A little below the Fall, a bridge has been thrown over by the proprietor, Frazer or Foyers, from which the Fall is seen; but in order to obtain a proper view of it, we with some difficulty scrambled down the steep banks to the rock below, from whence we beheld this romantic scene in perfection. The bridge and rocks form a very fine frame or fore ground, behind which, at the distance of perhaps twenty yards, appeared the first part of the Fall; the second and most important break was a few yards nearer, and the lowest almost under the arch. Our guide was present when very accurate measurements were taken of these Falls. The following particulars are therefore put down from the information obtained on this interesting occasion.

From the arch of the bridge to the surface of the water, after the lowest part of the Fall, 200 feet.-Height of the Fall, 70 feet.-The bridge was built, says the Dr. in 1798 , before which time the only 
passage over this torrent was a rude alpine contrivance, consistinglof some sticks thrown over the rocks, and covered with turt. It was crossed by the peasantry on foot, but it must certainly liave turned giddy the steadiest heads unaccustomed to such scenes. About three vears before the present bridge was built, a neighbouring farmer, on his way home from Inverness, had called at the General's Hut, to shelter himself from the inclemency of the storm, and drive out the iuvading cold by reinforcing the garrison in the stomach. Here lie met with some old acquaintance, with whom he conversed of former times, without observing the frequency of the circulating glass. The snow continued to fall in thick flakes, and they were sitting by a comfortable fire : at last, when the fumes of the whiskey had taken possession of his brain, and raised his spirits to no ordinary pitch, he determined to go hone. When he came to this place, having been accustomed to cross the bridge on foot, he habitually took his road, and forced his horse over it. Next morning he had some faint recollection of the circumstance, though the seeming impossibility of the thing made him suspect that it was a dream: but, as the ground was covered with snow, it was easy to convince himself; he accordingly went, and on perceiving the tracks of his horse's feet across the bridge, he fell ill and died shortly afterwards. In our way to the lower Fall, our guide shewed a cave of considerable size, near the river, where the freebooters used to shelter themselves in turbulent times. There was a way of escape towards the water, should the main entry be discovered.-Our next object was the lower Fall. When we came to the rude pillars before mentioned, we left the road, and went down the side of the hill. The descent to the point of view is difficult, but we were amply repaid for our trouble. The following particulars were communicated by our guide.

From the top of the rocks to the surface of the water, 470 feet.Height of the Fall in one continued stream, $20 \mathrm{~g}$ feet.-From the surface of the smooth water above, to the beginning of the uninterrupted Fall, 5 feet :- so that the lieight of the Fall may properly be called 212 feet.-Down this precipice the river rushes with a noise like thunder into the alyss below, forming an unbroken stream as white as snow. From the violent agitation arises a spray which envelops the spectator, and spreads to a considerable distance. The following beautiful description of this Fall was written by Burns as he was standing by it:

"Among the beathy hills and ragged woods,

The roaring Foyers pours his noisy floods,

Till full he dashes on the rocky mounds,

Where through a shapeless beach his stream resounds.

As high in air the bursting torrents flow,

As deep recoiling surges foam below,

Prone down the rock the whitening sheet descends,

And viewless Echo's ear astonish'd rends :

Dim seen, through rising mists and careless showers,

The hoary cavern wide surrounding lowrs;

Still through the gap the struggling river toils,

And still below the horrid caldron buils." 
"This is undoubledly one of the highest Falls in the world," continues Dr. Garnell, "and the quantity of water is sufficient to give it consequence. The scene is awful and grand, and I suppose that any person who has once beheld it, will readily agree, that it is worth while to travel from Fort William to this place to see the Fall. Though an immense body of water falls down the cascade at Niagara in North America, yet its height is not much more than half the height of this, being only one hundred atid forty feet."

\section{Petrified Ponds in Persia.}

"This natural curiosity is near the lake Ourmia, and consists of several ponds or marshes, the waters of which are in a state of com: plete stagnation. By degrees they congeal, and by a slow and regular process petrify, and form the beautiful transparent stone, commonly called Tabriz marble, often seen in the Persian burying grounds, and which forms one of the principal ornaments of all public edifices in that country. These ponds, which are very near each other, occupy the space of half a mile: Their situation is known by a heap of stones; that accumulate round these excarations. I saw nothing in Persia more worthy of the attention of a naturalist; and I much regretted not being learned enough to explain this phenomenon. I will, however, endeavour to convey an idea of it, as I was, perhaps, the only European who had penetrated so far. When near the place where these ponds are, the earth gives out a hollow noise under one's step. The soil is barren and calcined, and a strong mineral smell issues from the surface of the waters. The progress of the petrifaction may be easily followed from its beginning to the end.

"In its natural state the water is clear, it afterwards becomes thick and stagnant, and then all at once black, and, when arrived at the last stage of congelation, it looks like white frost. A petritied pond resembles a pond covered with ice; if a stone is thrown upon it before the operation is terminated, it breaks the adhesion, and the black water at the bottom appears directly. If the congelation is finished, a stone thrown on the surface leaves no mark, and persons may walk without wetting their feet. In the places where there are holes, the progress of the concretion may be seen; it appears like leaves of large paper placed one over the other. This water has such a decided tendency to transform itself into stone, that the drops, which issue boiling from the earth, petrify, and retain the same form as if they had been converted into marble by a magic wand.

"This singular substance is brittle, transparent, and sometimes richly veined with green, red, and copper colour. It may be carried away in blocks, and is very easily polished. The princes of the present reigning family build but few edifices, and have not used much of this stone, but there are still round the pond enormous pieces that Nadir Shah caused to be cut out, designing them for public embellishments:

"The remarkable formation of this marble or stony concretion causes it to be looked upon in the East as an object of luxury, exclusively reserved to the king and his sons. The excavation of it is only 
allowed to those persons who have obtained a special firman; and pride is so much stronger than avarice, that the idea of making over this property to the highest bidder, never entered the inagination of its present possessors."-Morier.

\section{Moving Bog.}

THE following is a copy of a report relative to the moving bog of Kilmaleady, in the King's county, Ireland, made by order of the Royal Dublin Society, by Richard Griflith, mining engineer:

"The bog of Kilmaleady, from whence the eruption broke out, situated about two miles to the north of the village of Clara, in the King's county, is of considerable extent; it may probably contain about five hundred acres : in many parts it is forty feet in depth, and it is considered to be the wettest bog in the country. It is bounded on all sides, except the south, by steep ridges of high land, which are composed at the top of limestone gravel, and beneath of cavernous limestone rock, containing subterinean streams; but the southern face of the bog is open to a moory valley, about a quarter of a mile in breadth, which, for nearly half a nile in length, takes a southern direction in the lands of Lisanisky, and then turns at right angles to the west; and continues gradually widening for upwards of two miles. Through the centre of this valley flows a stream about twelve feet in breadth, which serves as a discharge for the waters from the bog and the surrounding country, and finally joins the river Brusna above the bridge of Ballycumber.

"The bog of Kilmaleady, like all other deep and wet bogs, is composed, for the first eight or ten feet from the surface downwards, of a reddish-brown spongy mass, formed of the still undecomposed fibres of the bog-moss, sphagnum palustre, which, by capillary attraction, absorbs water in great quantity. Beneath this fibrons mass, the bog gradually becomes pulpy, till, at length, towards the bottom, it assuines the appearance, and, when examined, the consistence, of a black mud, rather heavier than water.

"The surface of the bog of Kilmaleady was elevated upwards of twenty feet above the level of the valley, from which it rose at a very steep angle, and its external face, owing to the uucommon dryness of the season, being much firmer than usual, the inhabitants of the vicinity were enabled to sink their turf-holes, and cut turf at the depth of at least ten feet beneath the surface of the valley, and, in fact, until they reached the blue clay which forms the substratum of the bog. Thus the faces of many of the turf banks reached the unusual height of thirty feet perpendicular; when, at length, the lower pulpy or muddy part of the bog, which possessed little coliesion, being unable to resist the great pressure of water from behind, gave way, and being once set in motion, floated the upper part of the boig, and continued to move with astonishing velocity along the valley to the southward, forcing before it not only the clumps of turf on the edge of the bog, but even patches of the moory meadows, to the depth of several feet, the grass surface of which heaved and turned over almost like the waves of the ocean; so that in a very short space of 
time the whole valley, for the breadth of about a quarter of mile between the bog-edge and the base of the hill of Lisanisky, was covered with bog to the depth of from eight to ten feet, and appeared every where studded with green patches of moory mearlow.

"The hill of Lisanisky retarded the progress of the bog for some time; at length it began to flow at right angles in its first course along the valley where it turns to the west, and continued with unabated rapidity till it reached the bog road of Kilbride, (which runs directly across the valley, and is elevated five or six feet above it,) and choaked up the bridge through which the waters of the stream pass. This barrier retarded the progress of the bog for five days; at the end of that time; the accumulation was such, from the still moving bog and the waters of the stream, that it flowed over the road, and covered the valley to the south of it for about half a mile, flowing with varied velocity, till it was again stopped for a few hours, as I understand, by a second road across the valley, leading from Clara to Woodfield. Having also overcome this obstacle, it proceeded slowly westward; and if its progress had not been checked by the very judicious means that have been employed, the whole extent of the valuable meadows, which compose the valley where it expands to the westward, must long since liave been covered. But, when the bog had passed over the road of Kilbride, and the consternation in the country became general, at the desire of the lords justices, Mr. Gregory employed Mr. Killaly, engineer to the directors-geueral of inland narigation, to carry into execution any works that could be devised to arrest the progress of the bog. Mr. Killaly at once perceived, that the only feasible remedy was to draw off the water that had accumulated; and to acconıplish this end, he employed a uumber of labourers to open the course of the stream where it was choked up, and also the drains through the valley that could be directed in to the stream. By this means the head of water was soon lowered, and in consequence the bog ceased to flow-and all the loose masses which floated on the river were broken to pieces by labourers placed at intervals throughout its course.

"Such was the situation of afiairs on my arrival at the bog, early in the morning. During the course of the day I exerted myself to carry into execution the well-advised plan which had previously been commenced by Mr. Killaly. 'Towards evening, the floating masses which came down the river, began to lessen considerably both in size and number; and finding every thing proceeded with regularity and certainty, I thought it useless to remain longer.

"At present I entertain no apprehension of further devastation from the bog, except in the event of a very great fall of rain during the present week. Slight rains would be of service to increase the current of water, and facilitate the removal of a considerable deposit of heavy, black, bog mud, which at present fills the bottom of the stream. The general current has, however, been much increased, by the breaking down of weirs on the river Brusna, below the junction of the bog-river.

I shall now describe the present appearance and state of the hog and moory valley. 
In the centre of the bog, for the space of about a mile and a half in length, and a quarter of a mile in breadth, a valley has been formed, sloping at the bottom from the original surface of the bog, to the depth of thirty feet; where the eruption first took place. In this valley, or gulf, there are numberless concentric cuts, or fissures, filled with water nearly to the top. The valley between the edge of the bog and the road of Kilbride, for the length of half a mile, and an extent of between sixty and eighty acres, may be considered as totally destroyed. It is covered by tolerably firm bog, from six to ten feet in depth, consisting at the surface of numberless green islands, composed of detached parts of the moory meadows, and of small rounded patches of the original heathy surface of the bog, varying from two to ten feet in diameter, which are separated from each other by brown pulpy bog, and the bed of the original stream is elevated to about eight or ten feet above its former course, so as to flow over the road. Beyond the road to Kilbride, the bog has flowed for one mile westward, and covered from fifty to seventy acres: in this part, the heathy patches of bog generally lessen in quantity; the green islands disappear, and nothing is observed but a thin deposit, consisting of a granulated black bog-mud, varying from one to three feet in thickness. This, though destructive fcr the present year, may, when dry, be burnt, and removed for manure to the neighbouring uplands, or left on the spot to fertilize the valley. Thus the whole distance which the bog has flowed is about three miles in length, namely, one mile and a half in the bog, and the same distance over the moory valley; and the extent covered, amounts to about one hundred and ffty acres."

\section{Disappearing of Rivers.}

In a memoir of the Academy of Sciences, lately published, we have some curicus ubservations and conjectures concerning: the disappearing of rivers, by the Abbe Guettard. "It is very surprising," he observes, "that a river in its course, which is often very extensive, should not meet with spongy soils to swallow up its waters, or gulfs, in which they are lost; nevertheless, as there has been hitherto known but a small number of rivers whose waters thus disappear, this phenomenon has been accounted very extraordinary, both by the ancients and moderns. Pliny speaks of it with an energy familiar to him, and Seneca mentions it in his Questiones Naturales; he even distinguishes these rivers into two sorts, - those that are lost by degrees, and those which are swallowed up all at once, or ingulphed.

M. Guettard has undertaken to remove part of the obscurity attendant on this subject; by describing what he has observed in several rivers of Normandy, which are lost, and afterwards appear again; these are the Rille, the Tthone, the Aure, the Sap-Andre, and the Drome. The three first disappear gradually, and then come in sight again; the fourth loses itself entirely by degrees, but afterwards reappears; the fifth loses some of its waters in its course, and ends by precipitating itself into a cavity, whence it is never seen to rise again. What seems to occasion the loss of the Rille, the Ithone, and 
the Aure, is the nature of the soil through which they pass. M. Guettard has observed, that it is in general porous, and composed of a thick sand, the grains of which are not well compacted together: it sinks suddenly down by its own weight in some places, and there forms great holes; and when the water overflows the meadows, it frequently makes many cavities in several parts of them. If we therefore suppose inequalities in the channels of these rivers, and that there are certain places in which the water stagnates longer than in others, it must there dilute the ground, if we may use that expression, and having carried away the parts which united the grains of sand together, those grains will become afterwards no other than a kind of sieve, through which the waters will filtrate themselves, pro. vided nevertheless that they find passage under-ground, through which they may run. This conjecture appears to be so well founded, that each of these three rivers loses itself nearly in the same manner, that is, through cavities which the people of the country call Betoirs, and which swallow up more or less, according to their largeness.

M. Guettard, who has carefully examined them, remarks, that these betoirs are holes in the form of a tunnel, whose diameter and aperture are at least two feet, and sometimes they-exceed four; and whose depth varies in like manner from one and two feet, to five, six, and even twenty. The water generally gets into these cavities when the river is not very high, making a gurgling noise, and turning round in an eddy. A proof that waters are there filtered and absorbed among the grains of the sharp diluted sand, is, that frequently in a betoir two or three feet deep, and through which a great deal of water is lost, one cannot thrust a stick further than the surface of its bottom. Wherefore, as these betoirs so frequently occur in the bed and banks of the Rille, the Ithone, and the Aure, it is not surprising that these rivers should be thus lost. The Rille, during the summer season, loses almost all its water in the space of two short leagues; the Ithone does very near the same. But M. Guettard observes something curious concerning this river, to wit, that formerly it was not lost, but kept its course without any interruption, as appears by the history of the country; very likely the mud, which had been collected together in several parts of its channel, might have occasioned the waters remaining in others, and thereby caused many betoirs. This is the more probable, as the mud having been collected together in the bed of the river Aure, it appears that, in consequence thereof, the cavities were greatly increased, which makes it lose itself nuch sooner than formerly; however, it has been resolved to cleanse its channel, to remove this inconvenience : besides, possibly an earthquake happening in the country might have caused several subterraneous canals, through which the water of the Ithone has forced its way. In effect, it appeais that a soil's being porous is not sufficient to cause the loss of the river, for if it were, then it would occasion many fens round about, nor would it renew its course after having disappeared a certain time.

M. Guettard supposes that there are in these parts subterranenus cavities, through which the waters may flow; and in consequence of this he reports a number of facts, all tending to prove that there 
must be hollow quarries serving for strainers to these waters. He then enters into a discussion of this question: Are there any subterraneous rivers, and is the proposition of some persons in favour of this particular, well founded? He makes it apparent, by several instances which be quotes, and by many reasons which he urges; that there are at least strong presumptions in favour of this opinion. A fact that is observed in the betoirs of the rivers, and particularly of the Rille, proves in some measure that there are considerable lakes of water in the mountains which limit its course: :this fact is, that in winter the greatest part of their betoirs become springs, which supply anew the river's channel with as much water as they had absoibed from it during the summer. Now, whence can that water come, unless from the reservoirs or lakes that are enclosed in the mountains, which being lower than the river in summer, absorbits water, and being higher in winter by occasion of the rain theyreceive, send it back again in their turn? Mr. Guettard remaiks, that this alternate effect of the betoirs swallowing up the water, and restoring it again, causes, perhaps, an invincible obstacle to the restraining of the water within the channel of the river. It has indeed been several times attempted to stop these cavities; but the water returns with such violence in winter, that it generally carries away the materials with which they were stopped. The Sap-Andre is lost in part, like the Ithone and the Rille, but there is something more remarkable in it than in these rivers; viz. that at the extremity of its course, where there is no perceptible cavity, it is ingulfed, without any fall; the water passes between the pebbles, and it is impossible to force a stick into that placé any farther than into the betoirs. What makes this river take that subterraneous direction, is an impediment which its stream meets with in that place; it is there stopped by a rising ground, six or seven feet high, whose bottom it has very likely undermined, to gain a free passage, not having been able to make its way over it. At some distance it appears again; but in winter, as there is a greater quantity of water, it passes over that eminence, and keeps an uninterrupted course. The Drome, after having lost some of its water in its course, vanishes near the pit of Soucy in that place; it meets with a sort of subterraneous cavity, nearly twenty-five feet wide, and more than fifteen deep, where the river is in a manner stopped, and into which it enters, though without any perceptible motion, and never appears again: M. Guettard observes, that in a part of Lorraine, which likewise is not very extensive, five other rivers lose themselves in the same manner. Mr. Guettard finishes this memoir with some observations upon the Terre. This river is lost in the same manner as the Rille; and though it is very near Paris, this singularity is unknown to almost every body : were it not for the account of the Abbe le Bouf, M. Guettard would have been ignorant of it.

We may add to these phenomena, that we have in Surrey the river Mole, which rises in Dorking hundred, and, after a considerable course, passes by Witchill, near Dorking; a little beyond which, this river hides itself, or is swallowed up, in a cavern at the foot of the hill, whence Camden says it is called the Swallow; he also takes 
notice of its running under ground for about two miles, and rising again, and spreading ${ }^{*}$ itself into a wide stream. It is also affirmed that there are several of these dipping rivers in Wales, and others in the southern counties of England.

\section{Subterranean Lakes.}

IN the canton of Bresse, in Burgundy, there are two subter ranean lakes, which often overflow in times of the greatest drought, and lay a large tract of ground under water. One of them has no apparent spring or opening, and yet in a dry season it throws out water enough to overflow the meadow-land near it. The grottoes or caves of Arcy are seated about eighteen miles from Auxerre, and over them is soil about ten feet deep. The entrance into these caves is two hundred paces long, but narrow. There are arches which form several vaults, from whence drops clear water, which turns into a brilliant hard stone. Twenty paces from the entrance is a lake which seems to be formed by that part of the water that will not petrify. The highest of the vaults is not above eight feet. About eighty paces from the entrance there is a kind of hall, with a coffee-coloured ceiling, wherein there are a thousand odd figures, which have a very agreeable effect.

\section{Snake Stones, or Ammonille.}

In the old mineralogy, these were a large genus of fossil shells, very few if any of which are yet known in their recent state, or living either in our own or any other shores; so that it seems wonderful whence so vast a number and variety of them should be brought into our subterranean regions. They seem indeed dispersed in great plenty throughout the world, but nowhere are found in greater numbers, beauty, and variety, than in our own inslands. Mr. Harenberg found prodigious numbers of them on the banks of a river in Germany. He traced this river through its several windings for many miles, and, among a great variety of belemnita, cornua-ammonis, and cochlitr, of various kinds, lie found also great quantities of wood of recent petrifaction, which still preserved plain marks of the axe by which it had been cut from the trees then growing on the shore. The water of this river he found in dry seasons, when its natural springs were. not diluted with rains, to be considerably heavier than common water; and many experiments shewed him that it contained ferruginous, as well as stony particles, in great quantity, whence the petrifactions in it appeared the less wonderful, though many of them are of recent date.

Of the cornua-ammonis, or serpent-stones, he there observed more than thirty different species. They lie immersed in a bluish fossil stone, of a soft texture and fatty appearance, in prodigious numbers, and of a great variety of sizes, from the larger known sorts down to such as could not be seen without very accurate inspection, or the assistance of a microscope. Such as lie in the softest of these stones, are soft like their matrix, and easily crumble to pieces; others are 
harder. In a piece of this stone, of the size of a finger, it is common to find thirty or more of these fossils; and often they are seen in form of white specks, so minute that their figure cannot be distinguished till examined by the microscope. They all consist of several voluta, which are different in the different species,-and their stria also are extremely various; some very deep, with very high ridges between them, others very slight; some straight, others crooked, others undulated; and some terminating in dots, tubercles, or cavities, towards the back, and others having tubercles in two or three places. They are composed of a great number of chambers or cells, in the manner of the nautilus Gracorum, each having a communication with the others by means of a pipe or siphunculus.

There is a small white shell-fish of Barbarloes, which seems truly a recent animal of this genus ; and, in the East Indies, there is another also, small and greyish; but the large and beautifully marked ones are found only fossil. They are composed of various fossil bodies, often of quarry stone, sometimes of the matter of the common pyrites, and of a great variety of other substances; and though they appear usually mere stones, yet in some the early part of the original shell is perserved in all its beauty. Sometimes also, while the outer substance is of the matter of the pyrites, or other coarse, stony, or mineral matter, the inner cavity is filled with a pure white spar of the common plated texture. 'This gives a great beauty to the specimen. The cornua-anmonis, or snake stones; are found in many parts of England, particularly in Yorkshire, where they are very plentiful in the alum rocks, of several sizes.

\section{Etites, or Eagle Stone.}

THIs is a curiosity in natural history, which was formerly in repute for several extraordinary magical as well as medical powers; such as preventing abortion, discovering thieves, and other ridiculous properties. The popular tradition is, that it is found in the eagle's nest, whither it is supposed to be carried while the female sits, to prevent her eggs from being rotten. These stones are found in several parts : near Trevoux in France, one can scarce dig a few feet deep, without. finding considerable strata, of a coarse or ferruginous kind. They are originally soft, and of the colour of yellow ochre. But the finest and most. valued of all the eagle-stones, are accidental states of one or other of our common pebbles. These are so far from being a peculiar species of fossil, though usually accounted such, that they are not determinately of any one species of pebble. Those, however, which most usually furnish them, are the brown centered pebbles, with whitish, bluish, and brown crists.

The plain history of this remarkable fossil is this : the central nucleus of many species of pebbles, particularly of this, is coarser than the rest of the stone, that is, it is made up of more earth and less crystal; the natural eonsequence of which must be, that being of a more loose and rare texture, it is in drying more apt to shrink than such masses as are composed-of a harder and purer matter. The central nucleus ii this species is also surrounded with a whitish crust, of a more loose 
texture, and more subject to shrink in drying, than even the nucleus itself; and being composed of more earth and less crystal, is also more friable and soft. The outer circles of this stone are of a much harder substance. When the earthy matter in the nucleus and first crust of this pebble exceeds its just proportion, the consequence will be, that the stone will become an retites; or the nucleus, contracting itself to a small size, on the evaporation of its fluid matter, must separate from its first crust, and that also shrinking must be drawn backward towards the other crusts; when the cavity will become larger between that and the nucleus, and consequently the nucleus will rattle in it when the stone is shaken. The pebble in this state having been afterwards rolled away by the waters, the nucleus has by rolling broken to pieces all the inner crust, and it is usually found in the hollow of the stone, buried in a large quantity of whitish powder. These eagle-stones are not uncommon in our gravel pits. The atites is also known by the names of eutocium, echites; lapis aquilæ, aquileus, and lapis pregnans.

\section{BeLEMNITES.}

THESE are stones which are vulgarly called thunder-bolts, or thunder-stone. They are composed of several crusts of stone, encircling each other, of a conical form, and various sizes; usually a little liollow, and somewhat transparent, formed of sereral stria radiating from the axis to the surface of the stone, and when burnt, or rubbed against one another, or scraped with a knife, yield an odour like rasped horn. Their size is various, from a quarter of an inch to eight inches; their colour and shape differ. They are supposed to be originally either a part of some sea production, or a stone formed in the cavity of some worm shell, which being of a tender and brittle nature, las perished, after giving its form to the stone. They are very frequently found in many parts of England, and the country people have a notion, that they are always to be met with after a storm. They are often enclosed in, or adhere to, other stones, and are most frequent among gravel, or in clay. They abound in Gloucestershire; and are found near Deddington in Oxfordshire, where they sometimes contain the silver marcasite.

\section{Logan, or Rocking Stone.}

THIS is a stone of a prodigious size, so exactly poised, that it would rock or shake with the smallest force. Of these stones the ancients give us some account. Pliny says, that at Harpasa, a town of Asia, there was a rock of such a wonderful nature, that if touched with a finger it would shake, but could not be moved from its place with the whole force of the body. Ptolemy Hephastion mentions a gygonian stone near the ocean, which was agitated when struck by the stalk of an asphodel, but could not be removed by a great exertion of force. The word gygonius seems to be Celtic; for duringog signifies motion,-the rocking stone. Many rocking stones are to be 
found in different parts of this island, some natural, some artificial, or placed in their position by human art.

In the parish of St. Leven, Cornwall, there is a promontory called Castle Treryn: On the western side of the middle group, near the top, lies a very large stone, so evenly poised, that any hand may move it from one side to another; yet it is so fixed on its base, that it was thought no lever; nor any mechanical force, could remove it from its situation.

To triumph over this prevailing belief, a naval officer and his men some few years since made the attempt, and succeeded in partially dislodging it. This, however, gave so much offence to the neighbouring inhabitants, that with incredible labour and great expense, he got it replaced, but it is not so easily moved as it was originally. It is called the Logan stone, and is at such a height from the ground, that no person can scarcely believe it was raised to its present position by art. But there are other rocking stones, which are so shaped and so situated, that there can be no doubt they were erected by human strength. Of this kind Porlese thinks the great Quoit, or Karnlehau, in the parish of Tywednek, to be. It is thirty-nine feet in circumference, and four feet thick at, a medium, and stands on a single pedestal. There is also a remarkable stone of the same kind in the island of St. Agues, in Sicily. The under rock is ten feet six inches high, forty-seven feet round the middle, and touches the ground with no more than half its base. The upper rock rests on one point only, and is so nicely balanced, that two or three men with a pole can move it. It is eight feet six inches high, and forty-seven in circumference. On the top there is a bason hollowed out, three feet eleven inches in diameter at a medium, but wider at the brim, and three feet deep. From the globular shape of this upper stone, it is highly probable that it was rounded by human art, and perhaps even placed on its pedestal by human strength. In Stithney parish, near Helston in Cornwall, stood the famous Logan or rocking stone, commonly called MenAmber, $q . d$. Men-an-Bar, or the Topstore. It was eleven feet by six, and four high, and so nicely poised another stone, that a little child could move it, and all travellers who came this way desired to see it. But Shrubsal, Cromwell's governor of Pendennis, with much ado caused it to be undermined, to the great grief of the country. There are some marks of the tool on it, and, by its quadrangular shape, it was probably dedicated to Mercury. There is a rocking stone in Perthshire, near Balvaird castle, in. the Ochil hills, on the estate of Mr. Murray of Couland.

That the rocking stones are monuments erected by the Druids cannot be doubted; but tradition has not informed us for what purpose they were intended. Mr. Toland thinks that the Druids made the people believe that they alone could move them, and that by a miracle they condemned or acquitted the accused, and brought criminals to confess what could not otherwise be extorted from them. How far this conjecture is right, we shall leave to those who are deeply versed in the knowledge of antiquities to determine. 


\section{Lee-Penny, or Lee-STone.}

THis is a curious stone of antiquity, belonging to the family of Lee in Scotland: of which an account was published in the Gent. Mag. for December 178\%, which savours very much of the marvellous. It is a stone of a dark-red colour and triangular shape; its size is about half an inch each side. It is set in a piece of silver coin, which though much defaced, is supposed, by some letters still remaining, to be a shilling of Edward $I$. It has been, according to tradition, in the Lee family ever since the year 1320, that is, a little after the death of king Robert Bruce, who having ordered his beart to be carried to the Holy Land, one of the noble family of Douglas was sent with it, and got the crowned heart in his arms from that circumstance. But the person who actually carried the heart was Simon Locard of Lee, who, from his carrying it locked up in a box, changed his name to Lock-heart, and got a heart within a lock for part of his arms, with the motto, "Corda serrata fero." This Simon Lockhart, having taken prisoner a Saracen chief, his wife came to ransom him; and on counting out the money or jewels, this stone fell out of her purse, which she hastily snatched up. Lockhart observing this, insisted on having it, or else le would not give up his .prisoner. - Upon this the lady gave it him, and told him its many virtues, viz. that it cured all diseases in cattle, and the bite of a mad dog both in man and beast.

It is used by dipping the stone in water, which is given to the diseased animal to drink; and the person who has been bit, and the wound or part infected,-is washed with the water. No words are used in the dipping of the stone, nor any money is allowed to be taken by the servants. Many cures are said to have been performed by it, and people used to come from all parts of Scotland, and even from Yorkshire, to get the water in which the stone is dipt, to give their cattle, when ill of the murrain and black-leg. It is even said to have cured the plague at Newcastle, during the seventeenth century. Lady Bird of Sanchtonhall, near Edinburgh, having been bit by a mad dog, was seized with hydrophobia; upon which, having sent to beg the Lee-penny, she used it some weeks, drinking and bathing in the water it was dipped in, and was quite recovered. This happened about one hundred years ago, and is said to be very well attested. But it would require fresh attestation, and the most incontestable proofs, to persuade people in the present age to believe in such miracles, performed by a Saracenic talisman.

\section{Extraordinary Stzes and Value of Diamonds.}

TнE greatest diamond ever known in the world belongs to the king of Portugal, and was found in Brasil. It is still uncut, and Mr. Magellan informs us, that it was of a larger size, but a piece was broken off by the ignorant countryman who chanced to find this great gem, and tried its hardness by the stroke of a large hammer upon an anvil. This prodigious diamond weighs 1680 carats; and, although it is uncut; Mr. Rome de l'Isle says, that it is valued at 224 millions ster- 
ling, which gives the estimation of :79.36, or abvut $£ 30$ sterling for each carat; viz. for the multiplicand of the square of its whole weight. But even in. case of any error of the press in this valuation, if we employ the general rule above mentioned, this great gem must be worth at least $5,644,8001$. sterling, which are the product of 1680 by two pounds, viz. much above three millions and a half sterling.

The famous diamond which adorns the imperial sceptre of Russia, under the eagle at the top of it, weighs 79 carats, and is worth at least 4,854,\%281. sterling, although it hardly cost 135,417 guineas. This diamond was one of the eyes of a Malabarian idol, named Scheringham. A French grenadier, who had deserted from the Indian service, contrived to become one of the priests of that idol, from which he had the opportunity to steal one of its eyes; he then ran away to the English at Trichinapenty, and thence to Madras. A ship's captain bought it for twenty thousand rupees; afterwards a Jew gave seventeen or eighteen thousand pounds sterling for it; at last a Greek merchant, named Gregory Luf bras, offered it for sale at Amsterdam in 1766; and the late prince Orloff purchased it, as he himself told Mr. Magellan in London, for the empress Catherine II. The figure and size of this diamond may be seen in the British $\mathrm{Mu}$. seum in London, it is not of a regular form.

The diamond of the great Mogul is cut in rose; weighs 279 carats 9-16ths; and is worth 380,000 guineas. This diamond has a small. flaw underneath, near the botttom; and Tavernier, page 389, who examineủ it; valued the carat at 150 French lives. Before this diamond was cut, it weighed 793 carats 56 ths, according to Rome de l'lle; but Tavernier, page 839 of his second volume, says, that it weighed 900 carats before it was cut. If this is the very same diamond, its loss by being cut was very extraordinary. Another diamond of the king of Portugal, which weighs 215 carats, is extremely fine; and is worth at least 369,800 guineas 5 -7ths.

The diamond of the emperor of Germany weighs $139 \frac{1}{2}$ carats; and is worth at least 109,520 guineas. Tavernier says, that this diamond has a tinge of citron colour; and he valued it at 135 livres Tournois the carat. Robert de Berguen, the grandson of Lewis, says that this diamond was cut into two; that the grand Turk had another of the same size; and that there were at Bisnagar two large diamonds, one of 150 , and another of 140 carats.

The diamond of the late king of France, called the Pitt or Regent, weighs $136^{3}$ carats; this gem is worth at least 208,333 guineas, although it did not cost above the half of this value.

The other diamond of the same monarch, called the Sancy, weighs 55 carats; it cost 25,000 guineas, and M. Duteus says, that it is worth much above that price.

\section{Brasilian Stone.}

THIs is a species, of stone found in Brasil, which is flexible. "No quality," says Dr. James Hutton, in his description of one of these stones, "is more inconsistent with the character of a stone than flexibility. A flexible stone, therefore, presents an idea which natu- 
rally strikes us with surprise. For though, among mineral bodies, we find flexible substances of the stony kind, such as mica, mountain, leather, and amianthus, these minerals owe their flexibility either to their thinness, or to the fibrous structure of their parts. Theiefore, when a stone of any considerable thickness is said to have flexibility, we are led to think that there is something very extraordinary, and we wish to know upon what depends that quality, nowise proper to a stone. Such, however, is the stone from Brasil, of which the Baron de Dietrich read a description in the Royal Academy of Sciences, in Jan. 1784. There is a specinien of a stone which corresponds with that description, inserted in the Journal de Physique for 1784, at present in the museum of $\mathrm{Mr}$. Weix, which belonged to the late Lord Gardenstone. The length of the stone, which I have examined, is twelve inches, the breadth about five, and the thickness half an inch. When this stone is supported by the two ends in a horizontal position, the middle part bends, by its own weight, more than a quarter of an inch from the straight line. This species of fexibility may certainly be made a proper object of scientific investigation."

The doctor adds, "that the stone has a certain flexibility, to which neither the terms ductile nor elastic will properly apply. The flexibility of this stone is so easy, compared with the rigidity of its substance, and its elasticity so small compared with its flexibility, that there must be in this body some mechanical structure, by which this unnatural degree of flexibility is produced, i. e. a flexibility, which is not inherent in the general substance of the body. Now, the substance of this stone being chiefly quartz, the most rigid and inflexible of all materials, and the stone at the same time bending. in such an easy manner, there is reason to conclude that this arises from no principle of flexibility in the general substance of the stone, but from some species of articulation in the structure of it, or among its constituent parts, which, while it preserves the component particles in one entire mass, suffers the parts to move a certain space in relation to each other."

Dr. Hutton then gives an account of different examinations he made by the microscope, by splitting and by the blow-pipe: from which he concludes, "that the particles of quartz, which have little cohesion, are bound together by thin plates of transparent mica; and these connecting plates being flexible, this allows a certain motion of the rigid particles among themselves, without the fracture or general separation of the stone."

\section{BACON Fossil.}

THIS name is given to a remarkable fossil substance discovered on a rising ground belonging to Chapel-farm, in the parish of Cnuwys Monchard, near Tiverton in Devonshire. The estate formerly belonged to a monastery of Augustine friars which was built upon it. In sinking a pond, when the workmen had got to a depth of ten feet from the surface, they stuck upon a spongy substance, which appeared to be a very thick cuticle of a brown colour; they soon found pieces 
of bone and fat of the same hue. With some little trouble, at length the entire body of a hog was extricated, reduced to the colour and substance of an Egyptian mummy; the Hesh was six inches thick, and the hair upon it very long and elastic. On proceeding in the work, a considerable number of hogs, of various sizes, were found in different positions; in some places two or three together, in others singly; the bodies, when exposed to the air, still retained their consistency; the stratum continued for twelve feet, after which the pond, being sufficiently deep, was filled with water. The ground was never known to have been broken up before; the family which preceded the then present possessor had a journal of all remarkable events which had occurred in the parish during three centuries, but there was no entry in it which could lead to a solution of the phenomenon.

Mr. Polwhele, who obtained a specimen, mentions, in his History of Devon, that the bed in which the fossils lay was of stiff clay. He describes the piece in his possession to be very light, somewhat spongy, mottled like mottled soap; and evidently of a sebaceous nature. On a slight chemical analysis, it was mostly soluble in spirits of wine while hot, but separated into white flakes in cooling. In this it resembles spermaceti. On being boiled in a fixed-alkaline lixivium; it was easily convertible into soap.

\section{Sarcophagus.}

IN the natural history of the ancients, this was a stone much used among the Greeks in their sepulchres; it is recorded to have always perfectly consumed the flesh of human bodies buried in it, in forty days. For this property it was much famed, and all the ancient naturalists mention it. There was another very singular quality also in it, that is, its turning into stone any thing that was put into vessels made of it. This is recorded only by Mutianus and Theophrastus except that Pliny had copied it from these authors, and some of the later writers from him. The account Mutianus gives of it is, that it converted into stone the shoes of persons buried in it, and the utensils which were customary in some places to bury with the dead. The utensils this author mentions, are such as must have been made of different materials, and hence it appears that its petrifying quality extended to substances of very different kinds. Whether it really possessed this last quality, has been much doubted. Its taking the place of substances of very different kinds and textures, is no real objection; the account has probably some truth in it. Petrifactions in those early days might not be distinguished from incrustations of sparry and stony matter on the surfaces of bodies only, as we find, even to this day, the incrustations of spar or mosses, \&cc. in springs, are still called by many persons, petrified moss, \&c. Incrustations like these might easily be formed on substances enclosed in vessels made of this stone, by water passing through its pores, dislodging from its conmon mass, and carrying with it, particles of such spar as it contained; and afterwards falling in repeated drops on whateve lay in its way, it might again deposit them on such substances in forn of incrustations. Thus things made of different matter, which hap 
pened to be enclosed, and in the way of the passage of the water, would be equally incrusted with, and in appearance turned into, stone. The place from whence the ancients tell us they had this stone was Assos, a city of Lycia, in the neighbourhood of which it was dug; and Debout informs us, that in that country, and in some parts of the East, there are also stones of this kind, which, if tied to the bodies of living persons, would in the same manner consume their flesh.

\section{SinaI, or Sina.}

THIS is a famous mountain of Arabia Petraea, upon which God gave the law to Moses. It stands in a kind of peninsula, formed by the two arms of the Red Sea, one of which stretches out towards the north, and is called the gulf of Colsum; the other extends towards the east, called the gulf of Elan; or the Elanitish sea. At this day the Arabians call Mount Sinai by the name of Tor, i. e. the Mountain, by way of eminence; or, Gibel or Jibel Mousa, the Mountain of Moses. It is two hundred and sixty miles from Cairo, and generally it requires a journey of ten days to travel thither. The wilderness of Sinai, where the Israelites continued encamped for almost a year, and where Moses erected a tabernacle of the covenant, is considerably elevated above the rest of the country; and the ascent to it is by a very craggy way, the greatest part of which is cut out of the rock. The traveller then comes to a large space of ground, which is a plain surrounded on all sides by rocks and eminences, whose length is nearly twelve miles. Towards the extremity of this plain on the north side, two high mountains shew themselves, the highest of which is called Sinai, and the other Horeb. The tops of Horeb and Sinai have a very steep ascent; and do not stand upon much ground, in comparison to their extraordinary height; that of Sinai is at least one third part higher than the other, and its ascent is more upright and difficult. Two German miles and a half up the mountain, stands the convent of St. Catherine. The body of this monastery is a building of one hundred and twenty feet in length, and almost as many in breadth. Before it stands another small building, in which is the only gate of the convent, which remains always shut, except when the bishop is here. At other times, whatever is introduced within the convent; whether men or provisions, is drawn up in a basket, and with a cord and pulley. The whole building is of hewn stone, which in such a desert must have cost a prodigious sum. Near to this chapel issues a fountain of very good fresh water. Five or six paces from it, they shew a stone, the height of which is four or five feet, and breadth about three, which, they say, is the stone whence Moses caused the water to gush out. Its colour is of a spotted gray, and it is as it were set in a kind of earth, where no other rock appears. This stone has twelve holes or channels, which are about a foot wide, whence it is thought the water came forth for the Israelites to drink.

Much has been said of the writings to be seen at Sinai, and in the plain about it: and hopes were entertained of discoveries respecting the wanderings of the Israelites, from these writings. But the accurate Danish traveller, Niebuhr, found no writings there, but the 
names of persons who had visited the place from curiosity, and of Egyptians who had chosen to be buried in that region.

\section{Scylla and Charybis.}

SCYLLA is a rock near the coast of Italy, dangerous to shipping, opposite to Charybdis, a whirlpool on the coast of Sicily. These objects, so famous in the poems of Homer and Virgil, were examined with minute attention by that accurate observer of nature, the Abbe Spallanzani, who thus describes Scylla:

"It is a lofty rock, twelve miles from-Messina, which rises almost perpendicularly from the sea, on the shore of Calabria, and beyond which is the small city of the same name. Though there was scarcely any wind, I began to hear, two miles before I came to the rock, a murraur and noise like a confused barking of dogs, and on a nearer approach readily discovered the cause. This rock, in its lower parts, contains a number of caverns, one of the largest of which is called by the people there, Dragora. The waves, when in the least agitated, rush into these caverns, break, dash, throw frothy bubbles, and thus occasion these various and multiplied sounds. I then perceived with how much truth and resemblance of nature, Homer and Virgil, in their personifications of Scylla, had portrayed this scene, by describing the monster they drew, as lurking in the darkness of a vast cavern, surrounded by ravenous barking mastiffs, together with wolves, to increase the horror. Such is the situation and appearance of Scylia; let us now consider the danger it occasions to mariners, Though the tide is almost imperceptible in the open parts of the Mediterranean, it is very strong in the strait of Messina, in consequence of the narrowness of the channel, and is regulated, as in other places, by the periodical elevation and depression of the water. Where the flow or current is accompanied by a wind blowing the same way, vessels have nothing to fear, since they do not either enter the strait, both the wind and the stream opposing them, but cast anchor at the entrance; or, if both are favourable, enter on full sail, and pass through with such rapidity that they seem to fy over the water. But when the current runs from $S$. to $N$. and the $N$. wind blows hard at the same time, the ship; which expected easily to pass the strait with the wind in its stern, on its entering the channel is resisted by the opposite current, and, impelled by two forces in contrary directions, is at length dashed on the rock of Scylla, or driven on the neighbouring sands; unless the pilot shall apply for the succour necessary for his preservation : for, to give assistance in case of such accidents, twenty-four of the strongest, boldest, and most experienced sailors, well acquainted with the place, are stationed night' and day along the shore of Messina; who, at the report of guns fired as signals of distress from any vessel, hasten to its assistance, and tow it with one of their light boats. The current, where it is strongest, does not extend over the whole strait, but winds through it in intricate meanders, with the course of which these men are perfectly acquainted, and are thus able to guide the ship in such a manner as to avoid it. Should the pilot, however, confiding in his 
own skill, contemn or neglect this assistance, however great his ability or experience, he would run the most imminent risk of being shipwrecked.

"In this agitation and conflict of the waters, forced one way by the current, and driven in a contrary direction by the wind, it is useless to throw the line to discover the depth of the bottom, the violence of the current frequently carrying the lead almost on the surface of the water. The strongest cables, though some feet in circumference, bieak like small cords. Should two or three anchors be thrown out, the bottom is so rocky that they either take no hold, or, if they should, are soon loosened by the violence of the waves. Every expedient afforded by the art of navigation, though it might succeed in navigating a ship in other parts of the Mediterranean, or even the tremendous ocean, is useless here. The only means of avoiding being dashed against the rooks, or driven upon the sands, in the midst of this furious contest of the winds and waves, is to have recourse to the skill and courage of the Mesinese seamen."

"Charybdis is situated within the strait, in that part of the sea which lies between a projection of land named Punta Secca, and another projection on which stands the tower called Lanterna, or the Light-house, a light being placed at its top to guide vessels which may enter the harbour by night. Every writer who has hitherto described Charybdis, has supposed it to be a whirlpool; but this is a mistake, as Spallanzani has completely proved. Charybdis is distant from the shore of Messina about seven hundred and fifty feet, and is called by the people of the country Calofaro; not from the agitation of the waves, as some have supposed, but from the beautiful tower, and from the light-house erected near for the guidance of vessels. The phenomenon of the Calofaro is observable when the current is descending; for when the current sets in from the north, the pilots call it the descending rema, or current; and when it runs from the south, the ascending rema. The current ascends or descends at the rising or setting of the moon, and continues for six hours. In the interval between ascent and descent, there is a calm which lasts at least a quarter of an hour, but no longer than an hour. Afterwards, at the rising or. setting of the moon, the current enters from the north, making various incidents with the shore, and at length reaches the Calofaro. This delay sometimes continues two hours; sometimes it immediately falls into the Calofaro, and then experience has taught that it is a certain token of bad weather."

When our author observed Charybdis from the shore, it appeared like a group of tumultuous waters; which group, as he approached. becane more extensive and more agitated. He was carried to the erige, where he stopped some time to make the requisite observations; and was then convinced, beyond the shadow of a doubt, that what he saw was by no means a vortex or whirlpool. Hydrologists teach us, that by a whirlpool in a running water, we are to understand that circular course which takes in a certain circumference, and that this course of revolution generates in the middle a hollow inverted cone; of a greater or less depth, the internal sides of which have a spiral motion. But Spallanzani perceived nothing of this kind in the Calo. 
varo. Its revolving motion was circumscribed to a circle of almost one hundred feet in diameter; within which linits there was no incurvation of any kind, nor vertiginous motion, but an incessant undulation of agitated waves, which rose, fell, beat, and dashed on each other. Yet those irregular motions were so far placid, that nothing was to be feared in passing over the spot; which he did, though their little bark rocked very much from the continual agitation, so that they were obliged constantly to make use of their oars, to prevent its being driven out of the Calofaro. Our author threw substances of diferent kinds into the stream. Such as were specifically heavier than the water, sunk, and appeared no more; those which were lighter remained on the surface, but were soon driven out of the revolving circle by the agitation of the water. Though from these observations, he was convinced that there was no gulf under the Calofaro, as otherwise there would have been a whirlpool, which would have carried down into it the floating substances; he determined to sound the bottom with the plummet, and found its greatest depth did not exceed five hundred feet. He was likewise informed, to his no small surprise, that beyond the Calofaro, towards the middle of the strait, the depth was double.

"When the current and wind are contrary to each other, and both in their greatest violence, especially when the sirocco, or south wind, blows, the swelling and dashing of the waves within the Calofaro are much stronger, more impetuous, and more extensive. It then contains three or four small whirlpools, or even more, according to the greatness of its extent and violence. If at this time small vessels are driven into the Calofaro by the current or the wind, they are seen to whirl round, rock, and plunge, but are never drawn down into the vortex. They only sink when filled with water, by the waves beating over them.. When vessels of a lasger size are forced into it, whatever wind they have, they cannot extricate themselves; their sails are useless; and after having been for some time tossed about by the waves, if they are not assisted by the pilots of the country, who know low to bring them out of the course of the current, they are furiously driven upon the neighbouring shore of the Lanterna, where they are wrecked, and the greater part of their crew perish in the waves.

"From these facts, the classical reader will perceive, that the ancient description of Charybdis is by no means so accurate as that of Scylla. The saying, however, became proverbial among the ancients, viz. that "he who endeavours to avoid Charybdis, dashes upon Scylla," is in a great measure true. If a ship be extricated from the fury of Charybdis, and carried by a strong southerly wind along the strait toward the northern entrance, it will indeed pass out safely; but should it meet with a wind in a nearly opposite direction, it would become the sport of both these winds, and, unable to advance or recede, be driven in a middle course between their two directions, that is to say, full upon the rock of Scylla, if it be not immediately assisted by the pilots. It is likewise observed, that in these hurricanes a land wind frequently rises, which descends from a narrow pass in Calabria, and increases the force with which the ship is impelled towards the rock." 
Aormas.

THIS is a high rock of India, which had its name from its extraordinary height, as being above the flight of a bird. - Its circuit was about two miles, its height eleven furlongs, and the way leading up to the top artificial and narrow. At the bottom, on one side ran the river Indus; ; and on its top was a fine plain, part of which was covered with a thick wood, the rest arable land, with a fountain furnishing abundance of excell ent water. This rock was taken by Alexander the Great, in whose time there was a report that Hercules had attempted it in vain; however, according to Arrian, this report was without foundation. It is probable, indeed, that it was raised after the place was taken, in order to magnify Alexander's exploits.

While the Macedonian monarch was preparing all things necessary for the siege, an old man, with his sons, who had long lived in a cave near the summit, came, and offered to shew him a private way of ascending. This being readily accepted, Ptolemy, with a considerable body of light-armed troops, was despatched with them, with orders, in case they succeeded, to entrench themselves strongly upon the rock in the wood, to which the old man was to direct them, before they ventured to attack the Indians. Ptolemy exactly executed his orders; and gave notice, by a lighted torch set upon a pole, that he had got safely up. Upon this, Alexander gave immediate orders for a body of troops to attempt the passage by which the rock was commonly ascended; but they were repulsed with great slaughter. He then sent an Indian, with letters to Ptolemy, desiring him, the next time an attack was made by the common way, to fall upon the enemy behind. But, in the mean time, those who defended the rock attacked Ptolemy with great vigour, but were at last repulsed; though with much difficulty; but the next day, when Alexander renewed the attack, though Ptolemy attacked the Indians in the rear; the Macedonians were repulsed on both sides. At last, the king, perceiving that the strength of the Indians lay in the straitness and declivity of the way by which they were attacked, caused a great quantity of trees to be felled, and with them filled the cavities between the plain on which the Indians were encamped, and the highest of his own advanced posts. The Indians at first derided his undertaking: but at length, perceiving the ardour with which the work was carried on, and having felt the effects of the missile weapons of the Macedonians, they sent deputies to propose terms of capitulation. Alexander, suspecting that their design was only to amuse him till they made their escape, withdrew his guards from the avenues. As soon as he knew the Indians were descended, he, with seven hundred of Ptolemy's light-armed foot, took possession of the deserted rock, and then made a signal for his forces to fall upon the flying Indians. They setting up a loud shout, so terrified the fugitives, that numbers of them fell from the rocks and precipices, and were dashed to pieces, while the greater part of the remainder were cut off in the roads.

The Rock of Aultgrande.

AULTGRANDE is a river in Scotland, in the parish of Kiltearn, in Ross-shire, which takes its name from Loch Glass, and, after rumiug 
six miles, falls into the sea. Its course for two of these miles is through a deep chasm of an extensive and rugged precipice, called Craig Grande, or the Ugly Rock, of which the Rev. Mr. Robertson, in his statistical account of the parish, gives the following description. "This is a deep chasm or abyss, formed by two opposite precipices, that rise perpendicularly to a great height, through which the Aultgrande runs for the space of two miles. It begins at the distance of four miles from the sea, by a bold projection into the channel of the river, which it diminishes in breadth by at least one half. The river continues to run with rapidity for about three-quarters of a mile, when it is confined by a sudden jutting out of the rock. There the sideview from the summit is very striking. The course of the stream being thus impeded, it whirls, and foams, and beats with violence against the opposing rock, till, collecting strength, it shoots up perpendicularly with great fury, and, forcing its way, darts, with the swiftness of an arrow, through the winding passage on the other side. After passing the obstruction, it becomes in many places invisible, owing partly to the increasing depth and narrowness of the chasm, and partly to the view being intercepted by the numerous branches of trees which grow on each side of the precipice:

About a quarter of a mile farther down, the country people have thrown a slight bridge, composed of trunks of trees covered with turf, over the rock, where the chasm is about sixteen feet wide. Here the observer, if he has intrepidity enough to venture himself on such a tottering support, and can look down the gulf below without any uneasy seinsations, will be gratified with a view equally awful and astonishing. The wildness of the steep and rugged rocks; the gloony horror of the cliffs and caverns, inaccessible by mortals, and where the genial rays of the sun never yet penetrated; the water-falls, which are heard pouring down in different parts of the precipice, and sound various in proportion to their distance; the hoarse and hollow murmuring of the river, which runs at the depth of near one hundred and thirty feet below the surface of the earth; fine groves of pines, which majestically climb the sides of a beautiful eminence, that rises immediately from the brink of the chasm; all these objects cannot be contemplated without exciting emotions of wonder and admiration in the mind of every beholder.

\section{BEN-NEVIS, OR BENEVIS.}

THIs is a lofty mountain of Scotland, in Inverness-shire, 4370 feet above the level of the sea. The summit of this mountain affords one of the most extensive prospects in Scotland. One sees at once across the island eastward to the German ocean, and westward to the Atlantic. The extent of view on the horizon of sea is about eighty miles, and from the Murray Frith on the north-east, to the island of Colonsay on the south-west, it reaches one hundred and seventy miles. Mr. Fraser, minister of Kilmalei, has given a most beautiful description of all the various prospects it affords, for which we must refer the reader to Sir J.Sinclair's Statistical Account, vol. viii.p. 414-418, and content ourselves with quoting his conclusion. "In a word, (says he, 
the number, the extent, and the variety of the several prospects, the irregular wildness of the hills, of the rocks, and of the precipices; the noise of rivulets and of torrents breaking and foaming among the stones, in such a diversity of shapes and colours, the shining smoothness of the seas and of the lakes, the rapidity and rumbling of the rivers, falling from shelf to shelf, and forcing their streams through a multitude of obstructions; the serenity of the azure skies, and the splendour of the glorious sun riding in the brightness of his majestyhave something so charmingly wild and romantic, and so congenial to. the contemplative mind, as surpasses all description, and presents a scene, of which the most fervid imagination can scarcely form an idea."

Mr. Williams, in his Natural History of the Mineral Kingdom, mentions, that "A great part of the hill of Benevis is composed of porphyry. It is a remarkably fine, beautiful, and elegant stone, of a reddish cast, in which the pale rose, the bluish, and yellowish white colours, are finely blended and shaded through the body of the stone, which is of a jelly-like texture, and is undoubtedly one of the finest and most elegant stones in the world. About three-fourths of the way. up this hill, about the north-west side, there is found a porphyry of a greenish colour, with a tinge of brownish red. This stone is smooth; compact, hard, and heavy; of a close uniform texture, but of no brightness when broken. It is spotted with angular specks, of a white quartzy substance. The elegant reddish granite of Benevis is perbaps the best and most beautiful in the world; and there is enough of it to serve all the kingdoms in the universe, though they were all as fond of granite as ancient Egypt.

The Alps.

THE Alps are a range of high mountains separating Italy from Gaul and Germany, in the form of a crescent. They take their rise from the Vada Sabatia, or Savona, and reach to the Sinus Flanaticus, now Golfo di Carnato, of the Adriatic, and the springs of the river Colapis, now the Kulpe; extending, according to Livy, two thousand stadia in length, or two hundred and fifty miles. They are divided into several parts, and accordingly have different names. From Savoua to the springs of the Varus, where the Alps lie against the sea of Genoa, they were called Maritimæ, now Le Montagne di Tenda; these extend from south to north, between Gaul to the west, and Genoa to the east; beginning at Monaca on the Mediterranean, then running out through the east of the county of Nice, and between that and the marquisate of Saluzzo, terminate at length at mount Viso, between Dauphine and Piedmont. Hence to Susa run the Alpes Cottia or Cottanx, mountains extremely high, separating Dauphine from Piedmont, and extending from mount Viso to mount Cenis, between the Alpes Maritimz to the south, and the (iraix to the north. The Alpes Graix, so called from the passage of Hercules, begin from mount Cenis, where the Cottize terminate, and run between Savoy and the Tarantese to the west, and Piedmont and the duchy of Aosta to the east, quite to the great St. Bernard, where the Alpes Pennina begin. They are also called by some 
Graciz Alpes, and Graciis Montes, (by 'Tacitus ;) which extend from west to east, between St. Pernard and the Adula, or St. Gothard; and thus they run out between the Valese to the north, and the Milanese to the south. With these are continued the Alpes Rhretica to the head of the river Piave; a part of which are the Alpes Tridentina, to the north of Trent. To these join the Alpes Norica, reaching to Dolbach in Tyrol, to the north of the river Tajamento: thence begin the Alpes Carnicæ, or of Carninica, extending to the springs of the Save: and the last, called Alpes Pannonicæ and Julia, extend to the springs of the Kulpe. Some, however, extend the Alps to the north of Dalmatia, others again to Thrace and the Euxine, but their termination at the Kulpe, as above, is more generally received. They were formerly called Albia Alpionia.

Through these mountains Hannibal forced his passage into Italy by pouring vinegar, it has been said, on the rock, heated by burning large piles of wood on them, by which means they became crumbled; but it is more certain that the French army under Bonaparte effected a passage into Piedmont over the Great St. Bernard, previous to the defeat of the Austrian army near Marengo, on the June 14, 1300.

The Alps are covered with perpetual snow : they are the highest mountains in Europe, being, according to some geometricians, about two miles in perpendicular height. They begin at the Mediterranean, and, stretching northward, separate Piedmont and Savoy from the adjacent countries; whence directing their course to the east, they form the boundary between Switzerland and Italy, and terminate near the extremity of the Adriatic sea, north-east of Venice. It was over the western parts of these mountains, towards Piedmont, that Hannibal forced his passage. The prospect from many parts of this enormous range of mountains is extremely romantic, especially towards the north-west. One of the nost celebrated is the grand Chartreuse, where is a monastery founded by St. Bruno about the year 1084. From Echelles, a little village in the mountains of Savoy, to the top of the Chartreuse, the distance is six miles. Along this course, the road runs winding up, for the most part not six feet broad. On one hand is the wood, with pine-trees hanging over head; on the other, a prodigious precipice almost perpendicular, at the bottom of which rolls a torrent, that, sometimes tumbling among the fragments of stone which have fallen from on high, and sometimes precipitating itself from vast descents with a noise like thunder, rendered yet more tremendous by the echo from the mountains on each side, concurs to form one of the most romantic and astonishing scenes in nature.

On the top of the mountain is the convent of St. Bruno, which is the superior of the whole order. The iuhabitants consist of one hundred fathers, with three hundred servants, who grind their corn, press their wine, and perform every domestic office, even to the making of their clothes. In the Album of the fathers is an admired Alcaic ode, written by the late ingenious Mr. Gray when he visited the Chartreuse, and which has since been published among his works. The glaciers of Savoy are also justly reckoned amongst the most stupendous works of nature. These are immense masses of ice, lodged upon the gentler declivities amidst the Alps, and exhibiting represen. 
tations beyond conception fantastic and picturesque. In the extraordinary narrative of Mr. Bourrit's journey hither, we meet with the following account of the Prieure, in the valley of Chamouni.

"We had, says he, the magnificent prospect of a chain of mountains, equally inaccessible, and covered with ice, and above the rest that of Mont Blane, whose tops seemed to reach, and even pierce the highest region of the clouds. The chain, upon which the mountain looks down like a giant, is composed of masses of rocks, which terminate in pikes or spires, called the Needles, and which are ranged like tents in a camp. Their sides appear lighter and more airy, from the ornaments of several hollow breaks and furrows fretted in the rock itself, as well as from the different streaks and panes of ice and snow, which, without changing the general character of their form, or the majesty of their appearance, give them a picturesque variety. Lower down, the eye surveys with ravishment the fields of ice, and the several glaciers, extending almost into the plain, whilst this appears like an artificial garden, embellished with the mixture of a variety of colours. We have a picturesque opposition to this chain, which is formed by innumerable mountains at the distance of near fifty leagues, between whose tops we have a glimpse of those several plains which they environ."

"M. de Saussure, who had visited these mountains about two months before M. Bourrit, felt himself naturally electrified in this place. This extraordinary sensation seems not to have been experienced by the latter or his company, but they heard a long continued rumbling noise, like that of thunder, which was rendered more awful by the silence of the place where they stood. This noise proceeded from the subsequent causes, viz. the avalanches of snow, which separated from the tops of the mountain, and rolled down to the bottom; considerable fragments of the rock which followed them, overturning others in their fall, and massy blocks of ice, precipitated from the summit. The valley of Montanvert appears to be particularly romantic. Here, says M. Bourrit, we beheld a spacious icy plain, entirely level, upon this rose a mountain all of ice, with steps ascending to the top, which seemed the throne of some divinity. It likewise took the form of a grand cascade, whose figure was beyond conception beautiful; and the sui, which shone upon it, gave a sparkling brilliancy to the whole. The valley on our right hand was ornamented with prodigious glaciers, that, shooting up to an immeasurable height between the mountains, blend their colours with the skies, which they appear to reach."

Volcano in Hawair, or OWhyHeE, one of THE SaNDWich

For the engraving which represents this terrible phenomenon, and also for the account which follows, we are indebted to the Tour of the Rev. William Ellis, who was for several years a missionary in these distant regions of the globe, and was an eye-witness to the eruptive scenery which he thus describes.-

'Refreshed by a comfortable night's sleep, we arose efore day-light on the morning of the first of August, and after stirring up the em- 


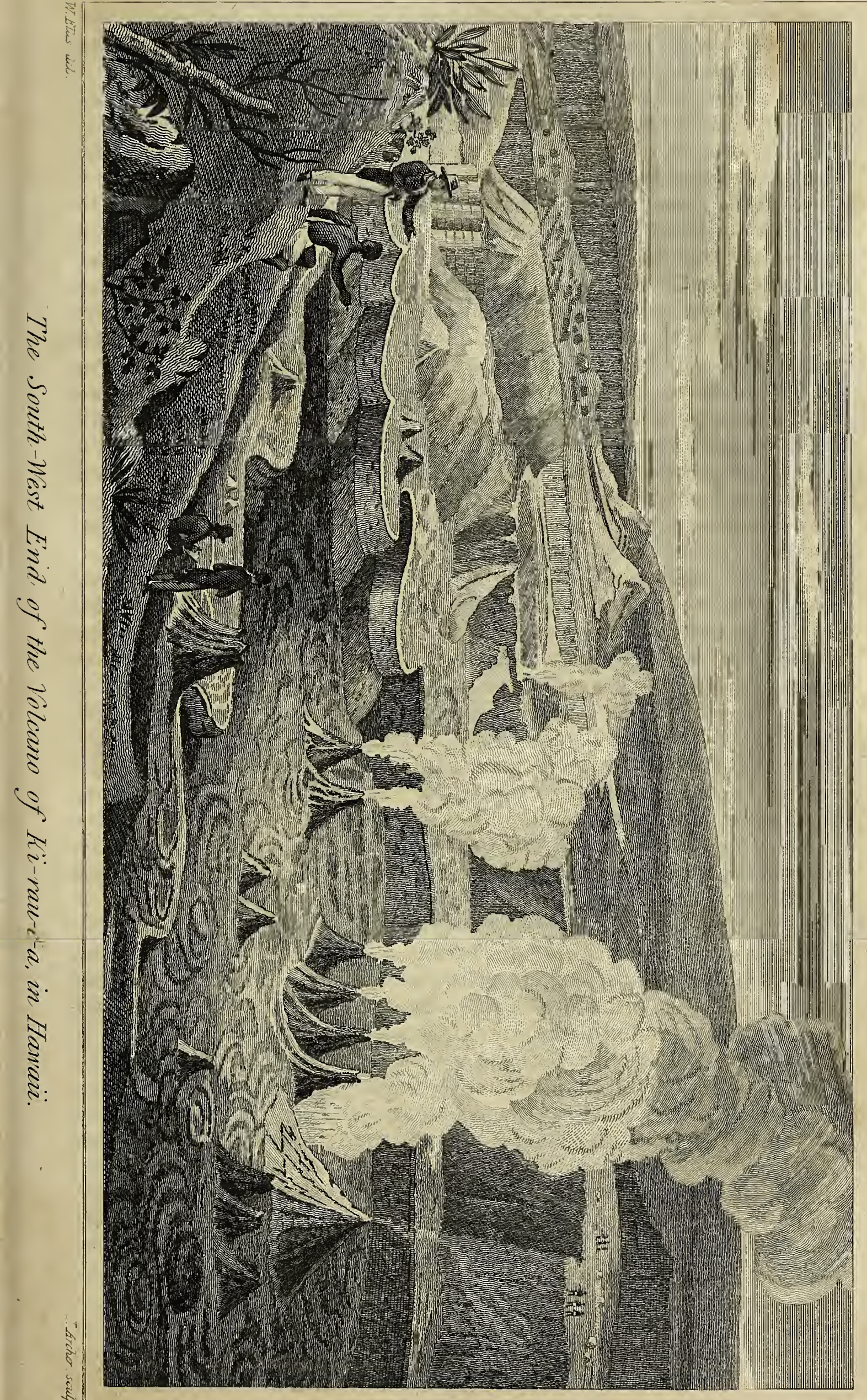



bers of our fire, rendered, with grateful hearts, our morning tribute of praise to our almighty Preserver.

"As the day began to dawn, we tied on our sandals, ascended from the subterraneous dormitory, and pursued our journey, directing our course towards the column of smoke, which bore E. N. E. from the cavern where we slept.

"The path for several miles lay through a most fertile tract of country, covered with bushes, or tall grass and fern, frequently from three to five feet high, and so heavily laden with dew, that before we had passed it, we were as completely wet as if we had walked through a river:: The morning air was cool, the singing of birds enlivened the woods, and we travelled along in Indian file nearly four miles an hour, although most of the natives carried heavy burdens, which were tied on their backs with small bands over their shoulders, in the same manner that a soldier fastens on his knapsack. Having also ourselves a small leather bag, containing a bible, inkstand, note-book, compass, \&c. suspended from one shoulder, a canteen of water from the other, or sometimes a light portfolio, or papers, with. specimens of plants besides; our whole party appeared, in this respect at least, somewhat en militaire.

"After travelling a short distance over the open country, we came to a small wood, into which we had not penetrated far, before all traces of a path entirely disappeared. We kept on some time, but were soon brought to a stand by a deep chasm, over which we saw no means of passing. Here the natives ran about in every direction, searching for marks of footsteps, just as a dog runs to and fro when he has lost the track of his master.

"After searching about half an hour, they discovered a path, which led some distance to the southward, in order to avoid the deep chasm in the lava. Near the place where we crossed over, there was an extensive cavern. The natives sat down on the top of the arch by which it was formed, and began eating their sugar-cane, a portable kind of provision usually carried on their journeys, while we explored the cavern in hopes of finding fresh water. In several places drops of water, beautifully clear, constantly filtered through the vaulted arch, and fell into calabashes placed underneath to receive it. Unfortunately for us, these were all nearly empty. Probably some thirsty traveller had been there but a short time before.

"Leaving the wood, we entered a waste of dry sand, about four miles across. The travelling over it was extremely fatiguing, as we sunk up to our ancles at every step. The sand was of a dark olive colour, fine and sparkling, parts of it adhering readily to the magnet, and, being raised up in heaps in every direction, presented a surface, resembling, colour excepted, that of drifted snow.

"It was undoubtedly volcanic; but whether thrown out of any of the adjacent craters in its present form, or made up of small particles of decomposed lava, and the crystalline olivin we had observed so abundant on the lava of the southern shore, and drifted, by the constant trade wind, from the vast tract of lava to the eastward, we could not determine.

"When we had nearly passed through it, we sat down on a heap of 
lava to rest and refresh ourselves, having taken nothing since the preceding noon. About ten o'clock, Messrs. Bishop and Goodrich jeached the place where we were sitting. They had heard by some travellers, that two or three days would elapse before Makoa would overtake them, and deeming it inexpedient to wait so long, had procured a guide, and early this morning set out from Kapapala to follow the rest of the party.

"Having refreshed ourselves, we resumed our journey, taking a northerly direction toward the columns of smoke, which we could now distinctly perceive. Our way lay over a wide waste of ancient lava, of a black colour, compact and heavy, with a shining vitreous surface, sometimes entirely covered with obsidian, and frequently thrown up, by the expansive force of vapour, or heated air, into conical mounds, from six to twelve feet high, which were, probably, by the same power rent into a number of pieces, from the apex to the base. The hollows between the mounds and long ridges were filled with volcanic sand, and fine particles of olivin or decomposed lava.

"This vast tract of lava resembled in appearance an inland sea, bounded by distant mountains. Once it had certainly been in a fuid state, but appeared as if it had become suddenly petrified, or turned into a glassy stone, while its agitated billows were rolling to and fro. Not only were the large swells and hollows distinctly marked, but in many places the surface of these billows was covered by a smaller ripple, like that observed on the surface of the sea at the first springing up of a breeze, or the passing currents of air which produce what the sailors call a cat's-paw. The billows may have been raised by the force which elevated the mounds or hills, but they look as if the whole mass, extending several miles, had, when in a state of perfect fusion, been agitated with a violent undulating or heaving motion.

"The sun had now risen in his strength, and his bright rays, reflected from the sparkling sand, and undulated surface of the vitreous lava, dazzled our sight, and caused considerable pain, particularly as the trade-wind blew fresh in our faces, and continually drove into our eyes particles of sand. This part of our-journey was unusually laborious, not only from the heat of the sun, and the reflection from the lava, but also from the unevenness of its surface, which obliged us constantly to tread on an inclined plane, in some places as smooth and almost as slippery as glass, where the greatest caution was necessary to avoid a fall. Frequently we chose to walk along on the sidge of a billow of lava, though considerably circuitous, rather than pass up and down its polished sides. Taking the trough, or hollow between the waves, was found safer, but much more fatiguing, as we sunk every step ancle-deep into the sand.' The natives ran along the ridges, stepping like goats from one ridge to another. They, however, occasionally descended into the hollows, and make several marks with their feet in the sand at short distances, for the direction of two or three native boys with our provisions, and some of their companions, who had fallen behind early in the morning, not being able to keep up with the foremost party.

63 Between eleven and twelve we passed a number of conical hills on our right, which the natives informed us were craters. A quantity of 
sand was collected round their base, but whether thrown onit by them, or drifted thither by the wind, they could not inform us. In their vicinity we also passed several deep chasms, from which, in a number of places, small columns of vapour arose, at frequent and irregular intervals. They appeared to proceed from Kirauea, the great volcano, and extended towards the sea in a south-east direction. Probably they are connected with Ponahohoa, and may mark the course of a vast subterraneous channel leading from the volcano to the shore. The surface of the lava on both sides was heated, and the, vapour had a strong sulphureous smell.

"We continued our way beneath the scorching rays of a vertical sun till about noon, when we reached a solitary tree growing in a bed of sand, spreading its roots among the crevices of the rocks, and casting its grateful shade on the barren lava. Here we threw ourselves down on the sand and fragments of lava, stretched out our weary limbs, and drank the little water left in our canteens.

"In every direction we observed a number of pieces of spumous lava, of an olive colour, extremely cellular, and as light as sponge. They appeared to have been drifted by the wind into the hollows which they occupied. The high bluff rocks on the north-west side of the volcano were distinctly seen; the smoke and vapours driven past us, and the scent of the fumes of sulphur, which, as we approached from the leeward, we had perceived ever since the wind sprung up, becoming very strong, indicated our proximity to Kirauea.

su." Impatient to view it, we arose, after resting about half an hour, and pursued our journey. In the way we saw a number of low bushes, bearing beautiful red and yellow berries in clusters, each berry being about the size and shape of a large currant. The bushes, on which they grew were generally low, seldom reaching two feet in height; the branches small and clear, leaves alternate, obtuse with a point, and serrated; the flower was monopetalous, and, on being exanined, determined the plant to belong to the class decandria, and order monogynia. The native name of the plant is ohelo. The beries looked tempting to persons experiencing both hunger and thirst, and we eagerly plucked and ate all that came in our way. They are juicy, but rather insipid to the taste. As soon as the natives perceived us eating them, they called out aloud, and begged us to desist, saying we were now within the precincts of Pélés dominions, (the godess of the volcano,) to whom they belouged, and by whom they were rahuiia, (prohibited,) until some had been offered to her, and permission to eat them asked. We told them we were sorry they shouid feel uneasy on this account, - that we acknowledged Jehovah as the only divine proprietor of the fruits of the earth, and felt thankful to him for them, especially in our present circumstances. Some of them then said, "We are afraid. We shall be overtaken by some calamity before we leave this place.' We advised them to dismiss their fears, and eat with us, as we knew they were thirsty and faint. They shook their heads, and, perceiving us determined to disregard their entreaties, walked along in silence."

We travelled on, regretting that the natives sliould indulge notions (no superstitious, but clearing every ohelo bush that grew near our 
path, till about two P. M. when the Crater of Kirauea suddenly burst upon our view. We expected to have seen a mountain with a broad base and rough indented sides, composed of loose slags or hardened streams of lava, and whose summit would have presented a rugged wall of scoria, forming the rim of a mighty caldron. But instead of this, we found ourselves on the edge of a steep precipice, with a vast plain before us, fifteen or sixteen miles in circumference, and sunk from two hundred to four hundred feet below its original level. The surface of this plain was uneven, and strewed over with large stones and volcanic rocks, and in the centre of it was the great crater, at the distance of a mile and a half from the precipice on which we were standing. Our guides led us round towards the north end of the ridge, in order to find a place by which we might descend to the plain below. As we passed along, we observed the natives, who had hitherto refused to touch any of the ohelo berries, now gather several bunches, and, after offering a part to Pélé, eat them very freely. They did not use much ceremony in their acknowledgment; but when they had plucked a branch, containing several clusters of berries; they turned their faces towards the place whence the greatest quantity of smoke and vapour issued, and, breaking the branch they held in their hand in two, they threw one part down the precipice, saying at the same time, 'E Pèlè, eia ka ohelo'au; e taumaha aku wau ia oe, e ai hoi au tetahi.' 'Pélé, here are your ohelos: I offer sonte to you, some I also eat.' Several of them told us, as they turned round from the crater, that after such acknowledgments they might eat the fruit with security. We answered, we were sorry to see them offering to an imaginary deity the gifts of the true God; but hoped they would soon know better, and acknowledge Jehovah alone in all the benefits they received.

"We walked on to the north end of the ridge, where, the precipice being less steep, a descent to the plain below seemed practicable. It required, lowever, the greatest caution, as the stones and fragments of rock frequently gave way under our feet, and rolled down from above; but with all our care, we did not reach the bottom without several falls and slight bruises.

"The steep which we had descended was formed of volcanic matter, apparently a light red and gray kind of lava, vesicular, and lying in horizontal strata, varying in thickness from one to forty feet. In a small number of places the different strata of lava were also rent in perpendicular or oblique directions, from the top to the bottom, either by earthquakes, or other violent convulsions of the ground connected with the action of the adjacent volcano. After walking some distance over the sunken plain, which in several places sounded hollow under our feet, we at length came to the edge of the great crater, where a spectacle, sublime and even appalling, presented itself before us -

$$
\text { "We stopped, and trembled." }
$$

"Astonishment and awe for some moments rendered us mute, and, like statues, we stood fixed to the spot, with our eyes riveted on the abyss below. Immediately before us yawned an inmense gulf, in the 
form of alcrescent, about two miles in length, from north-east to south-west, nearly a mile in width, and apparently eight hundred feet deep. The bottom was covered with lava, and the south-west and northern parts of it were one vast flood of burning matter, in a state of terrific ebullition, rolling to and fro its "fiery surge" and flaming billows. Fifty-one conical islands, of varied form and size, containing so many craters, rose either round the edge or from the surface of the burning lake. Twenty-two constantly emitted columns of gray smoke, or pyramids of brilliant flame; and several of these at the same time vomited from their ignited mouths streams of lava, which rolled in blazing torrents down their black indented sides into the boiling mass below.

"The existence of these conical craters led us to conclude, that the boiling caldron of lava before us did not form the focus of the volcano; that this mass of melted lava was comparatively shallow: and that the basin in which it was contained was separated, by a stratum of solid matter, from the great volcanic abyss, which constantly poured out its melted contents through these numerous craters into this upper reservoir. We were further inclined to this opinion, from the vast columns of vapour continually ascending from the chasms in the vicinity of the sulphur banks and pools of water, for they must have been produced by other fire than that which caused the ebullition in the lava at the bottom of the great crater, and also by noticing a number of small craters in vigorous action, situated high up the sides of the great gulf, and apparently quite detached from it. The streams of lava which they emitted rolled down into the lake, and mingled with the melted mass there, which, though thrown up by different apertures, had perhaps been originally fused in one vast furnace.

"The sides of the gulf before us; although composed of different strata of ancient lava, were perpendicular for about four hundred feet, and rose from a wide horizontal ledge of solid black lava of irregular breadth, but extending completely round. Beneath this ledge the sides sloped gradually towards the burning lake, which was, as nearly as we could judge, three hundred or four hundred feet lower. It was evident that the large crater had been recently filled with liquid lava up to this black ledge, and had, by some subterranean canal, emptied itself into the sea, or upon the low land on the shore; and in all probability this evacuation had caused the inundation of the Kapapala coast, which took place, as we afterwards learned, about three weeks prior to our visit. The gray, and in some places apparently calcined sides of the great crater before us : the fissures which intersected the surface of the plain on which we were standing; the long banks of sulphur on the opposite side of the abyss; the vigorous action of the numerous small craters on its borders; the dense columns of vapour and smoke that rose at the north and south end of the plain; together with the ridge of steep rocks by which it was surrounded, rising probably in some places three hundred or four hundred feet in perpendicular height, presented an immense volcanic panorama, the effect of which was greatly augmented by the constant roaring of the vast furnaces below. 
"After the first feelings of astonishment had subsided, we remained a considerable time contemplating a scene, which it is impossible to describe, and which filled us with wonder and admiration at the almost overwhelming manifestation it affords of the power of that dread Being who created the world, and who has declared that by fire he will one day destroy it. We then walked along the west side of the crater, and in half an lour reached the north end.

"While walking over the plain, which was covered with a thin layer of what appeared like indurated sand, but which we afterwards found to be decomposed lava, the natives requested us not to kaha, a heru $k a$ one, strike, scratch, or dig the sand, assuring us it would displease Pélé, and be followed by an irruption of lava, or other expression of vengeance from this goddess of the volcano, of whose power and displeasure they had manifested the greatest apprehensions ever since our approach to Kirauea.

"At the north end of the crater we left the few provisions and little baggage that we had, and went in search of water, which we had been informed was to be found in the neighbourhood of a number of columns of vapour, which we saw rising in a northerly direction. About half a mile distant, we found two or three small pools of perfectly sweet, fresh water; a luxury which, notwitlstanding the reports of the natives, we did not expect to meet with in these regions of fire. It proved a most grateful refreshment to us, after travelling not less than twenty miles over a barren thirsty desert.

“ These pools appeared great natural curiosities. The surface of the ground in the vicinity was perceptibly warm, and rent by several deep irregular chasms, from which steam and thick vapours continually arose. In some places these chasms were two feet wide, and fiom them a volume of steam ascended, which was immediately condensed by the cool mountain air, and driven, like drizzling rain, into hollows in the compact lava on the leeward side of the chasms. The pools, which were six or eight feet from the chasms, were surrounded and covered by Aags, rushes, and tall grass. Nourished by the moisture of the vapours, these plants flourished luxuriantly; and, in their turn, sheltered the pools from the heat of the sun, and prevented evaporation. We expected to find the water warm, but in this we were also agreeably disappointed. When we had quenched our thirst with water thus distilled by nature, we directed the natives to build a hut in which we might pass the night, in such a situation as to command a view of the burning lava; and while they were thus employed, we prepared to examine the many interesting objects around us. $\mathrm{Mr}$. Bishop returned, with a canteen of water, to meet $\mathrm{Mr}$. Harwood, who had not yet come up.

"Mr. Thurston visited the eastern side of the great crater, and I went witl Mr. Goodrich to examine some extensive beds of sulphur at the north-east end. After walking about three-quarters of a mile over a tract of decomposed lava, covered with ohelo bushes and ferns, we came to a bank about a hundred and-fifty yards long, and in some places upwards of thirty feet high, formed of sulphur, with a small proportion of red clay or ochre." The ground was very hot; its surface rent by fissures; and we were solnetimes completely enveloped 
in the thick vapours that continually ascended from these cracks. A number of apertures were visible along the whole extent of the bank of sulphur; smoke and vapours arose from these fissures also; and the heat of the sulphur around them was more intense than in any other part. Their edges were fringed with tine crystals, in various combinations, like what are called fowers of sulphur. We climbed about half way up the bank, and endeavoured to break off some paris of the crust, but soon found it too hot to be handled. However, by means of our walking sticlis, we detached some curious specimens. Those procured near the surface were crystallized in beautiful acicular prisms, of a light yellow colour; while those found three or four inches deep in the bank, were of an orange yellow, generally in single or double tetrahedral pyramids, and full an inch in length. A singular hissing and cracking noise was heard among the crystals, whenever the outside crust of the sulphur was broken and the atmospheric air admitted. The same noise was produced among the fragments broken off, until they were quite cold. The adjacent stones and pieces of clay were frequently incrusted, either with sulphate of ammonia, or volcanic sal ammoniac. Considerable quantities were also found in the crevices of some of the neighbouring rocks, which were much more pungent than that exposed to the air. Along the bottom of the sulphur bank we found a number of pieces of tufa, or claystone, which appeared to have been fused, extremely light and cellular. It seemed as if sulphur, or some other inflammable substance, had formerly occupied the cells in these stones. A thick fog now came over, which being followed by a shower of rain, obliged us to leave this interesting laboratory of nature, and return to our companions. On the eastern side of the crater, we saw banks of sulphur less pure, but apparently more extensive, than those we had visited; but their distance from us, and the unfavourable state of the weather, prevented our examining them. On our way to the sulphur banks, we saw two flocks of wild geese, which came down from the mountains, and settled among the ohelo bushes, near the pools of water. They were smaller than the common goose, had brown necks, and their wings were tipped with the same colour. The natives informed us there were vast flocks in the interior, although they were never seen near the sea.

"Just as the sun was setting we reached the place where we had left our baggage; and found Messrs. Bishop and Harwood sitting near the spot, where the natives, with a few green branches of trees, some fern leaves; and rushes, had erected a hut. We were none of us pleased with the site which they had chosen. It was at the northeast end of the crater, on a pile of rocks overhanging the abyss below and actually within four feet of the precipice. When we expressed our disapprobation, they said it was the only place where we might expect to pass the night undisturbed by Péte, and secure from earthquake and other calanity, being the place in which alone Pélé allowed travellers to build a hut. We told them it was unnecessarily near; and, being also unsafe, we wished to remove. They answered, that as it was within the limits prescribed by Pélé for safe lodging, they should be unwilling to sleep any where else, and had not time to build another hut for us. 
We then directed them to collect a quantity of firewood, as we expected the night would be cold, although the thermometer then stood at $690^{\circ}$. We were the more anxious to have the fuel collected before the shades of night should close upon us, as travelling in some places was extremely dangerous. The ground sounded hollow in every direction, frequently cracked, and, in two instances, actually gave way while we were passing over it. Mr. Bishop was approaching the hut, when the lava suddenly broke under him. He iistantly threw himself forward, and fell flat on his face over a part that was more solid. A boy, who followed me with a basket to the sulphur banks, and walked about a yard behind Mr. Goodrich and myself, also fell in. There was no crack in the surface of the lava over which he was walking, neither did it bend under his weight, but broke suddenly, when he sunk in up to his middle. His legs and thighs were considerably bruised, but providentially he escaped without any other injury. The lava in both places was about two inclies in thickness, and broke short, leaving the aperture regular and defined, without even cracking the adjoining parts. On looking into the holes, we could see no bottom, but on both sides, at a short distance from the apertnre, the lava was solid, and they appeared to have fallen into a narrow chasm, covered over by a thin crust of lava, already in a state of decomposition."

When night came on we kindled a fire, and prepared our frugal supper. We then spread our mat on the ground, but as it rained severely, against which our hut furnished but an indifferent shelter, we preferred to sit or stand round the fire, rather than to lie down on the ground. Between nine and ten the dark clouds and heavy fogs, that since the setting sun had hung over the volcano, gradually cleared away, and the fires of Kirauea, darting their fierce light athwart the midnight gloom, unfolded a sight terrible and sublime, beyond any that we had yet seen.

"The agitated mass of liquid lava, like a flood of melted metal, raged with a tumultuous whirl. The lively flame that danced over its unduJating surface, tinged with sulphureous blue, or glowing with mineral red, cast a broad glare of dazzling light on the indented sides of the insulated craters, whose roaring mouths, amidst the rising flames and eddying streams of fire, shot up at frequent intervals, with very loud detonations, spherical masses of fusing lava, or bright ignited stones.

We sat gazing at the magnificent phenomena for several hours, when we laid ourselves down on our mats, in order to observe more leisurely their varying aspect; for although we had travelled upwards of twenty miles since the morning, and were both weary and cold, we felt but little disposition to sleep.

The natives, who probably viewed the scene with thoughts and feelings somewhat different from ours, seemed, however, equally interested. They sat most of the night talking of the achievements of Pélé, and regarding with a superstitious fear the brilliant exhibition. They considered it as the primeval abode of their volcanic deities. The conical craters, they said, were their houses, where they frequently amused themselves by playing at Konane, a game resem- 
bling drafts; the roaring of the furnaces, and the crackling of the flames, were the music of their dance, and the red flaming surge was the surf wherein they played, sportively swimming on the rolling wave. The history which they gave of these gods was wild, marvellous, romantic, and superstitious, but from the narration an allegory might easily be extracted, which requires no great share of ingenuity to reconcile with fact.

"The volcano of Kirauea, the largest of which we have any account, and which was, until visited by us, unknown to the civilized parts of the world, is situated in the district of Kapapala, about twenty miles from the sea shore. We could form no correct estimate of its elevation above the level of the sea. The only means we had of judging being the difference of temperature in the air, as shewn by our thermometer, which on the shore was usually at sunrise $71^{\circ}$, but which in the neighbourhood of the volcano, was, at the same hour, no higher than $46^{\circ}$. The upper edge of the crater being measured with a line; was found to be seven miles and a half in circumference. We then descended, and measured the side of the ledge, and satisfied ourselves that at the depth of five hundred or six hundred feet the circuniference is at least five miles and a half. We did not get the exact depth, but judge it to be not less than one thousand feet. We threw down some large stones from the place near our hut, which after several seconds struck on the sides, and then bounded down to the bottom where they were lost in the lava. When they reached the bottom they appeared like pebbles, and we were obliged to watch their course to perceive them at all.

"But the magnificent fires of Kirauea which we had viewed with such admiration, appeared to dwindle into insignificance, when we thought of the probable subterranean fires immediately beneath us. The whole island of Hawaii, covering a space of four thousand square miles, from the summits of its lofty mountains, perhaps sixteen thousand feet above the level of the sea, down to the beach, is, according to every observation we could make, one complete mass of lava, or other volcanic matter, in different stages of decomposition. Perforated with innumerable apertures in the shape of craters, the island forms a hollow cone over one vast furnace, situated in the heart of a stupendous submarine mountain, rising from the bottom of the sea; or possibly the fires may rage with augmented force beneath the bed of the ocean, rearing, through the superincumbent weight of water, the base of Hawaii, and at the same time forming a pyramidical funnel from the furnace to the atmosphere."

\section{ETNA.}

THIs burning mountain of Sicily was represented, in the heathen mythology, as the place where Vulcan superintended the forges of the Cyclops, who were continually engaged in making thunderbolts for Jupiter.

"On their eternal anvils there be found,

The brethren beating, and the blows go round." 
The prospective view from the summit of this mountain is one of the most enchanting. The following is the description of Brydone.

"In about an hour's climbing we arrived at a place where there was no snow, and where a warm and comfortable vapour issued from the mountain, which induced us to make another halt. Here I found the mercury at $19^{\circ} 6_{2}^{1}$. The thermometer was fallen three degrees below the point of congelation; and before we left the summit of Etna, it fell two degrees more, namely, to twenty-seven. From this spot it was only about three liundred yards to the highest summit of the mountain, where we arrived in time to see the most wonderful and most sublime sight in nature.

"But here description must ever fall short; for no imagination has dared to form an idea of so glorious and so magnificent a scene; neither is there, on the surface of this globe, any one point that unites so many awful and sublime objects: The immense elevation from the surface of the earth, drawn as it were to a single point, without any neighbouring mountain for the senses and imagination to rest upon, and recover from their astonishment in their way down to the world; this point or pinnacle, raised on the brink of a bottomless gulf, as old as the world, often discharging rivers of fire, and throwing out burning rocks, with a noise that shakes the whole island. Add to this, the unbounded extent of the prospect, comprehending the greatest diversity, and the most beautiful scenery in nature, with the rising sun advancing in the east to illumine the wondrous scene.

"The whole atmosphere by degrees kindled up, and shewed dimly and faintly the boundless prospect around. Both sea and land looked dark and confused, as if only emerging from their original chaos, and light and darkness seemed little undivided, till the morning by degrees advancing completed the separation. The stars are extinguished, and the shades disappear. The forests, that till now seemed black and bottomless gulfs, from whence no ray was reflected to shew their form or colours, appear a new creation, rising to sight, catching life and beauty from every increasing beam. The scene still enlarges, and the horizon seems to widen and expand itself on all sides; till the sun, like the great Creator, appears in the east, and, with his plastic ray, completes the mighty scene. All appears enchantment, and it is with difficulty we can believe we are still on earth. The senses, unaccustomed to the sublimity of such a scene, are bewildered and confounded; and it is not till after some time that they are capable of separating, and judging of, the objects that compose it. The body of the sun is seen rising from the ocean, immense tracts both of sea and land intervening; the islands of Lipari, Panari, Alicudi, Stromboli, and Volcano, with their smoking summits, appear under your feet; and you look down on the whole of Sicily as on a map, and can trace every river through all its windings from its source to its mouth. The view is absolutely boundless on every side, nor is there any one object within the circle of vision to interrupt it; so that the sight is every where lost in the immensity; and $I$ am persuaded it is only from the imperfection of our organs, that the coasts of Africa, and even of Greece, are not discovered, as they are certainly above the horizon. 
"The circumference of the visible horizon on the top of Atua cannot be less than 2000 miles. At Malta, which is near 200 miles: distant, they perceive all the eruptions from the second region, and that island is often discovered from about one half the elevation of the mountain; so that at the whole elevation the horizon must extend to near double that distance, or 400 miles, which makes 800 miles for the diameter of the circle, and 2400 for the circumference. But this is by much too vast for our senses, not intended to grasp so boundless a scene. But the most beautiful part of the scene is certainly the mountain itself, the island of Sicily, and the numerous islands lying round it. All these, by a kind of magic in vision that I am at a loss to account for, seem as if they were brought close round the skirts of Etna; the distances appearing reduced to nothing. Perhaps this singular effect is produced by the rays of light passing from a rarer medium into a denser, which, from a well-known law in optics, to an observer in the rare nedium appears to lift up objects that are at the bottom of the dense one, as a piece of money placed in a bason appears lifted up as socn as the bason is filled with water.

"The Regione Deserta, or the frigid zone of HEna, is the first object that calls your attention. It is marked out by a circle of snow and ice, which extends on all sides to the distance of about eight miles. In the centre of this circle, the great crater of the mountain rears its burning head, and the regions of intense cold and intense heat seem for ever to be united in the same point. The Regione Deserta is immediately succeeded by the Sylvosa, or the woody region, which forms a circle or girdle of the most beautiful green, which surrounds the mountain on all sides, and is certainly one of the most delightful spots on earth. This presents a remarkable contrast with the desert region. It is not smooth and even like the greatest part of the latter, but is finely variegated by an infinite number of those beautiful little mountains that have been formed by the different eruptions of Etna. All these have now acquired a wonderful degree of fertility, except newly formed. We looked down into the craters of these, and attempted, but in vain, to number them.

"The zone is every where succeeded by the vineyards, orchards, and corn-fields, that compose the Regione Culta, or the fertile region. This zone makes a delightful contrast with the other regions. It is bounded by the sea to the south and south-east, and on all its other sides by the rivers Semetus and Alcantara, which run almost round it. The whole course of these rivers is seen at once, and all their beautiful windings through these fertile valleys, looked upon as the favourite possession of Ceres herself, and the very scene of the rape of her daughter Proserpine.

"Cast your eyes a little further, and you embrace the whole island, all its cities, rivers, and mountains, delineated in the great chart of nature; all the adjacent islands, the whole coast of Italy, as far as your eye can reach; for it is no where bounded, but every where lost in space. On the sun's first rising, the shadow of the mountain extends across the whole island, and makes a large track visible even in the sea and in the air. By degrees this is shortened, and in a litile time is confined only to the neighbourhood of Etna." 
The ancient poets have exercised their descriptive powers in representing the eruptions of $\mathbb{E}$ tna. Thus Virgil :

"By turns a pitchy cloud she rolls on high, By turns liot embers from her entrails fly, And flakes of mounting flames that lick the sky. Oft from her bowels massy rocks are thrown, And, shivered by fiery force, come piecemeal down. Oft liquid lakes of burning sulphur flow, Fed from the fiery springs that boil below."

\section{Dryden's Translation.}

The following lines from Ovid are sufficiently curious and amusing:

"Nor Etna vomiting sulphureous fire

Will ever belch ; for sulphur will expire,

The veins exhausted of the liquid store:

Time was she cast no flames; in time will cast no more.

For whether earth's an animal, and air Imbibes, her lungs with coolness to repair, And what she sucks remits; she still requires Inlets for air, and outlets for her fires :

When tortur'd with convulsive fits she shakes, That motion chokes the vent, till other vent slie makes :

Or when the winds in hollow caves are clos'd, And subtle spirits find that way oppos'd, They toss up flints in air; the flints that hide The seeds of fire, thus toss'd in air, collide, Kindling the sulphur, till the fuel spent The cave is cool'd, and the fierce winds relent. Or whether sulphur catching fire, feeds on Its unctuous parts, till, all the matter gone, The flames no more ascend : for earth supplies The fat that feeds them; and when earth denies That food, by length of time consum'd, the fire, Famish'd for want of fuel, must expire."

\section{Garth's Translation.}

A fine description occurs in the first Pythian ode of Pindar :

"Now, under sulph'rous Cuma's sea-bound coast And vast Sicilia lies his shaggy breast, By snowy Ætna, nurse of endless frost, The pillar'd prop of heaven, for ever press'd; Forth from those nitrous caverns issuing rise Pure liquid fountains of tempestuous fire, And veil in ruddy mists the noonday skies, While wrapt in smoke the eddying flames aspire; Or gleaming through the night with hideous roar Far o'er the redd'ning main huge rocky fragments pour.

West's Translation. 
Some of our modern British poets have also inspirited their productions by happy allusions to the phenomena of $\mathbb{E t n a}$ and Vesuvius :-

Thus in thy world material, mighty Mind!

Not that alone which solaces and shines;

The rough and gloomy challenges our praise.

The winter is as needful as the spring,

The thunder as the sun; a stagnate mass

Of vapours breeds a pestilential air :

No more propitious the favonian breeze

To nature's health, than purifying storms.

The dread volcano ministers to good;

Its smothered flames might undermine the world.

Loud Etnas fulminate in love to man." Young.

Another of our devotional poets has heightened the effect of his striking description of the descent of the God of Israel upon Mount Sinai, by a similar allusion:

"Nor shall the burning hills of old

With Sinai be compar'd,

Etna shall be named no more;

Etna, the torch of Sicily;

Not half so high

Her lightnings fly,

Not half so loud her thunders roar

Cross the Sicanian sea, to fright the Italian shore.

Behold the sacred hill" Watts's Lyrics.

Diodorus Siculus has recorded an account of the first eruption to which he can attach any authenticity. He has neglected to mention the precise date when it occurred, but informs us that the Sicani, who at that time inhabited Sicily, were compelled by it to abandon the eastern side of the island, which was at a subsequent period inhabited by the Sicilians from Italy, and to settle on the southern side.

Thucydides mentions three different eruptions, which happened between the year B. c. 733, the third of the eleventh Olympiad, and B. C. 425, the third of the eighty-eighth Olympiad; but he does not specify the exact dates of their respective occurrence.

The first of the three, which is the second eruption, is said by Eusebius to have taken place B. C. 565, in the time of Phalaris.

The second irruption mentioned by Thucydides, which is the third in the order of authentic memorials, is assigned to the year B. c. 476, the second year of the seventy-fifth Olympiad, when Phædon was archon at Athens, and when Mardonius, the general of Xerxes, was defeated by the Athenians at Platra. The volcanic eruption, and the victory referred to, are both specified in an ancient inscription on the Oxford marble, which however mentions the first and not the second year of the Olympiad, when Xantippus was the Athenian archon. Strabo, Silicus Italicus, Valerius Maximus, Elian, and other ancient authors, record a very singular act of heroism during this eruption, and which is exhibited on an ancient medal. Two Sicilian 
youths, Amphinomus and Anapis, rushed into the midst of the flames, and rescued their aged parents, at the imminent hazard of their own lives : a deed of filial piety and genuine heroism, which the Catanians rewarded by the consecration of a temple to their memory.

The third eruption, mentioned by Thucydides, or the fourth in the series of authentic history, occurred B. c. 425 , in the eighty-eighth Olympiad, and desolated part of the Catanian territory.

The fifth eruption occurred in the consulship of Sergius Fulvus Flaccus and Quintus Calpurnius Piso, nearly 133 years before the Christian era. It is to be regretted that Julius Obsequius and Orosius, by whom it is recorded, have not transnitied any details respecting it.

In the consulship of Lucius Emilius $\mathbb{E}$ epidus, and Lucius Aurelius Orestes, about B. C. 125, Etna poured forth such a torrent of fire, that the adjoining sea is represented as absolutely hot, and imnense numbers of fishes were destroyed. One historian declares, that the inhabitants of the isles of Lipari ate so many of those fishes as to occasion a distemper, which proved generally fatal.

Orosius states, that four years after the preceding eruption, the city of Catania was desolated by another equally tremendous; the roofs of the houses were demolished by the burning ashes, and so dreadful was the desolation, that the Romans exempted the inhabitants from all taxes for the space of ten years, to afford them an opportunity for repairing the damages they had sustained.

Livy mentions an eruption of Ritna just previous to the death of Cæsar, in the forty-third year before Christ. It was not very considerable in itself, but acquired importance from being afterwards cousidered as an omen of Cæesar's death.

An eruption happened in the year 40 of the Christian era, on the night in which the emperor fled from Messina, where he was at the time. This is mentioned by Suetonius, in the Life of Caligula.

According to Carrera, there was an eruption of Mount Etna, A. D. 253. The same author records another in the year 420 .

Jeoffrey of Viterbo, in his Chronicle, mentions an eruption in $\mathbf{8 1 2}$, in the reign of Charlemagne.

The next was of a more tremendous nature, and of more disastrous consequences. It occurred on the fourth of February, in the year 1169. About day-break there was an earthquake in Sicily, which was felt on the opposite side of the strait, as far as Reggio. The ridge of the mountains on the side nearest to Torvasino was obviously desolated, Catania was reduced to ruins, and upwards of fifteen thousand of its inhabitants perished. The roof of the churcl of St. Agatha fell in, and the bishop was killed; several castles were destroyed; new rivers burst forth, and ancient ones disappeared. The clear spring of Arethusa, whose waters were, so celebrated, became muddy and brackish; and the fountain of Ajo, after ceasing for two hours, gushed out more copiously than before; its waters assuming a blood colour, which they retained for an hour. A remarkable phenomenon took place at Messina, where the sea retired to a considerable distance beyond its ordinary limits, but returning, it soon after advanced to the city walls, and rushed into the streets. Multi- 
tudes who had sough the shore, weie swallowed up by the waves, the vines, corn, and trees of every description, were burnt up, and the fields rendered unfit for cultivation by being covered with stones.

In 1181 an eruption broke forth on the eastern side, on which occasion streams of lava ran down the nountain, and encircled the church of St. Stephen, without doing it any damage.

1 On the twenty-third of June 1329, another of those catastrophes occurred, of which Nicholas Specioli has recorded some particulars. About the hour of vespers, Etua was agitated by commotions, accompanied with terrific sounds, so much so that the utmost alarm spread throughout the whole island of Sicily. A blaze of fire, enveloped in smoke, suddenly issuing from the southern summit, spread snow over the rocks of Mozona. As the evening advanced, the flames seemed to touch the clouds, spreading themselves with furious impetuosity, and reducing every builling to ruins that obstructed their course; many rocks on the shore of Mascoli were dashed into the- sea, and springs and streams of water were annihilated. On the southern side of the church of St. John, called Il Paparinceca, fire issued with great violence from an opening or fissure made in the ground; the sun was eclipsed from morning to evening with clouds of smoke and ashes, Our historian, on approaching the newly opened crater, perceived the earth totter under his feet, and saw red-hot stones issue successively in a very short space, with a thundering noise.

A few days were sufficient to convert the neighbourhood into a scene of desolation. From showers of fire, ashes, and stones, which continued to descend, every species of animals, with multitudes of the feathered creation, perished in great numbers; the fishes also died in the rivers and the adjacent sea. It is even stated, that many persons died of fear, at which no one will be much astonished who reads the terrible account of Nicholas Specioli. He declares, that neither Babylon nor Sodom suffered so tremendous a visitation. The north winds, which blew at the time, carried the ashes as far as Malta. Successive calamities followed each other till the fifteenth of July.

In $133 \%$, only four years afterwards, another eruption took place, which poured forth large volleys of stones.

On the twenty-fifth of August 1381, the territory of Catania was again desolated, the olive yards in the neighbourhood of the city being burnt up by another \&tnean visitation.

Sixty-three years afterwarls, a similar torrent of destruction issued forth, and ran towards Catania; the shocks were so violent, that huge masses of rock were torn from its summit, and hurled into the abyss below, and for eighteen months the mountain was almost incessantly agitated.

On the twenty-fifth of September, 1446, an hour after sun-set, an eruption issued from the place called La Pietra di Mazani, which, however, was of short continuance.

In Septenber the following year, another occurred, which was likewise of short duration, but accompanied with a considerable confagration.

A period of nearly a century elapsed, during which no explosion taking place, the inhabitants of the vicinity began to think themselves 
secure from further molestations, and ventured into every part of the mountain. But this long season of tranquillity was succeeted by a new and terrible visitation in April, 15:6. On the twenty-fith of that month a strong westerly wind arose, and a thick cloud appeared at the summit of the mountain, of a red colour; a large quantity of fire issued from the abyss, and proceeded with great rapidity along the eastern side of the mountain, breaking down the rucks, and destroying everv living thing in its course. From the same crater another and more dreadful fiery stream ran in the same manner towards the west, over Bronte, Adano, and Castelli. The church of St. Leon was demolished by the shock accompanying the eartbquake, and its ruins afterwards consumed by the sulphureous torrent. Chasms were opened in the sides of the mountain, whence fire and burning stones darted into the air with a uoise like that of the discharge of artillery. This eruption was attended by one most melancholy disaster, namely the death of Francis Negro de Piazza, a celebrated physicisn of Lentini, who being desirous of obtaining a near view of the exuptions, to make some observations which might conduce to the interests of science, was burnt to ashes by a volley of the ignited stones.

In the months of April and May the year following, 153\%, Ema again appeared in a state of commotion, and was rent in several places, from which torrents of fire issued forth with destructive fury. The gardens, vineyards, and monastery of St. Nicholas d'Arena were destroyed, as well as mounts Pellieri and Fallica, with their vineyards, and the greatest proportion of the inhabitants. The river Simeto, overfowing the adjacent plains, swept away the country people and their cattle; the whole vicinity of Paterno, the castles, and more than five hundred houses, suffered by this calamitous inundation. Violent gusts of wind tore up the trees in every direction. As soon as the violence of the eruption abated, the summit of the mountain sunk in with a noise so terrific, that the people in the island believed that the last day had arrived, and prepared for their final exit, by repairing to the rite prescribed in the Catholic church. These disturbances continued through the whole year, and in July and August especially, all Sicily was in mourning. Filotes affirms, that many of the Sicilians were struck deaf by the noise. The castle of Carleone, thongh more than twenty-five leagues distant from the voleano, is said to have been demolished.

Thirty years after the preceding, the country adjacent to Rtua was again covered with ashes, and the volsanic production of a new eruption. In 1599 desolation again orerspread the country from a similar cause, which was rencwed with increasing violence iwenty, five years afterwards, in the month of June, 1603. Other instances of destructive ebullition occurred in $160 \%, 1609,1614$, and many following years ; indeed, Carrera declares that the mountain continued to emit flames, with some variations and transient intermissions, for thirty-three years. Torrents of lava flowed fơr three entire months, in particular streams, in $160 \%$, destroying part of the forest of Del Pino, and of the wood Sciambuta, with numerous vineyards. The year 1650 was also remarkable for an eruption which laid waste the northern side of the mountain. 
Carréra, before referred to, relates that he was personally witness to a dreadful eruption, which commenced on the tenth of Derember, 1.664, and centinued to blaze incessantly, though with some occasioual abatements of violence, till the end of the month of May, 169 ?

But the most formidable conflagration was that of 1669 , which has been minutely described in the Philosophical Transactions, (No. 51,) Abridg. vol. ii. For eighteen days previous to the eventful crisis, the sky was covered with dark clouds, and the aimosphere agitated by thunder and lightning. Many of the houses were overturied by earthquakes in the village of Nicolosi, and the rest abandoned by their inhabitants. The crater on the summit exhibited, for a long time, extraordinary signs of commotion: and the islands of Stromboli and Volcano indicated the approaching catastrophe. On the $84 h$ of March, the atmosphere dadkened orep the village of La Pedara and its vicinity. On the $11 \mathrm{th}$, a chasm of some miles in length, and five or six feet wide, was opened on the eastern side of the wountain, about twenty miles distant from the old mouth, and tein miles from Catania. On the following night a new chasm was formed on the very spot where Monte Russo now stands. Several other chasns also appeared in different places at a considerable distance, four of them fowards the southward side; and from all of them issued immense quantities of smoke, accompanied with trementous thunder; and alaming earthquakes. From the principal clasm, fakes of a dark earth-coloured spongy matter proceeded, and a vast stream of lava, which flowed towards the labe La Hordia, six miles from Montpellieri, desolating fields and villages in its progress. On the following day it proceeded to the teritory called Mal Passo, and in twenty hours depopulated and wasted it. After this it advanced in a new direction upon Montpellieri, committing similar ravages. In some places this tremendous stroam of burning lava acquired the breadth of two miles, and extended to Mazzalucia. A new and intense opening appeared on the $23 \mathrm{~d}$ of the month, which produced a hill of stones, sand, and ashes, with two summiss, two miles in circumference, and a hurrlred and fifty paces in height. This new mountain continued to pour for h ashes for three nonths, covering the adjacent country to the distance of fifteen miles. Some of these ashes are said to have been borne along by the wind as far as Messina, Calabria, and other places. Early in the morning of the 25th of March, the whole mointain of Zitra was agitated by an earthquake; the highest crater fell into the focus of the volcano, and on the spot where it previously appeared, nothing was to be seen but a wide and deep gulf, upwards of a mile in extent, from which large masses of stones and ashes were continually discharged, and amongst these the? celebrated block of lava on Mount Trumento. The torrent of lava now flowed towarls Catania with renewed force and noise, accompanied by earthquakes and other alarming symptoms. The walls were overfowed, and the gardens belonging to the Benedictine convens utterly desolated. From this spot it rivided into several streams, and passed into the ocean, to the distance, according to the carl of Winchelsea's account, trausmitted to the English conrt, of six husdred yards, and to the extent of a mile in breatho. In the same 
communication it is stated, that the stream of lava destroyed in forty days, the habitations of twenty-seven thousand persens; and of wenty thousand inhabitants of Catania, three thousand only survived. In its progress it filled up a lake four fathoms deep, and four miles in circuit, and not only so, but raised the cavity into $a_{0}$ mountain.

The earl further mentions, that at night he ascended two towers in different places, and could plainly see, at the distance of ten miles, the fire beginning to run from the mountain in a direct line, and the flames rise as high and as large as the loftiest steeples in the British dominions, throwing up great stones into the air. He could discern this fiery river descending down the mountain, having stones of a paler red swimming in it, some of them of the size of an ordinary table. The fire moved in several other places, and all the country was covered with it; the flames ascending from different places, and smoking like a violent furnace of melted iron, uttering a loud noise, especially when large masses fell into the sea. The English merchants state, in the Philosophical Transactions, that the lava proceeded slowly on till it came to the sea, when a most extraordinary conflict ensued between the two adverse elements. The noise was more dreadful than the loudest thunder, being heard through the whole country tc an immense distance; the water seemed to diminish and retire before the lava, while clouds of vapour darkened the sun. The fish on the coast were destroyed, the colour of the sea itself changed, and the transparency of its waters lost for a considerable period. They revresent the fire as spreading three miles in breadih, and seventeen in length. In attempting to approach it, they durst not venture nearer than about a furlong, apprehensive of an immense pillar of ashes, in their view, twice the magnitude of St. Paul's church in London, and far higher. A continued noise issued from the mouth of the opening or cleft, like the beating of the waves of the sea against a rock, or like distant thunder, which at times conld be heard sixty, and even a hundred miles; to which distance ashes were also carried. The mouth whence this tremendous inundation proceeded was only about ten feet in diameter. According to the testimony of Bor elli, burning rocks; sixty palms in length, were thrown a mile, and stones of inferior dimensions three miles; the sun did not make its appearance for many weeks, and the day assumed the darkness of the night? Four months elapsed before this terrible scene was altered. Borelli expresses his deep regret at the destruction of many valuable remains of antiquity ; among the rest, an amphitheatre, the Circus Maximus, the Naumachia, and some temples.

A curious circumstance cccurred during this eruption, which, Brydone says, nay be depended upon as of undoubted authenticity. A vineyard belonging to a convent of Jesuits lay directly in the way of the lava. This vineyard was formed on ancient lava, probably a thin one, with a number of caverns and crevices under it? The liquid lava entering into these caverns, soon filled them up, and by degrees bore up the vineyard; and the Jesuits, who every monent expected to see it buried, beheld with anazenent the whole field beginning to move off. It was carried on the surface of the lava to a considerable 
distance; and though the greatest part was destroyed, some of it remains to this day.

A new burning gulf was opened on the top of the mountain in December, 1632, which diffused its lava over the hill Mazarra.

In the evening of the twenty-fourth of May, 1686, an eruption took place, which consumed woods, vineyards, and corn-fields to the extent of four leagues, till its course was arrested by a large valley near the castle of Mascali; but unhappily several people, impelled by curiosity, having ascended a hill in the neighbourhood near the wood of Catania, were buried alive by its sinking inwards.

In 1755 the eruptions of Fina were renewed after a long interval, when a vast quantity of boiling water issued forth from the great crater, preceded by smoke, flames, subterraneous commotions, and other usual signs of an approaching catastrophe. The torrent at length descended in cataracts from rock to rock till it reached the plains, which it overspread with desolation for many miles, and fivally discharged itself into the sea. Although the water was not emitted for more than half an hour, its effects were extremely calamitous, and two new chasms were subsequently opened, from which lava issued. The water proceeded from the bowels of the mountain, and in its progress from the summit gained considerably from the melted snow. It destroyed forest trees of large size, tearing them up by the roots as it rushed along. The main torrent divided into four streams, which reuniting afterwards, formed islands and rivers nine hundred feet in width. In the descent the channel sometimes dilated, and at others contracted; in some places it was found to be fifteen hundred feet wide. Lava and pieces of rock were driven about by the violence of the current, and valleys filled up by the sand which was conveyed, A few days afterwards an explosion happened of stones and black sand ; the former of which was carried as far as the hills of Mascali, and the latter to Messina, and even to Reggio on the opposite coast. Two days only elapsed, when the mountain opened again, and discharged a torrent of lava for six days, which was observed to proceed towards the plain happily at the rate of only a mile per day.

In 176:3 an eruption happened, which lasted, with some intermission, for three months, and was attended with very interesting and novel circumstances: The flame which issued from the crater assumed a pyramidical form, and ascended to a prodigious height in the atmosphere, resembling an artificial fire-work of great beauty, and accompanied by explosions which shook the very ground where the spectators ventured to assemble. Sometimes the clouds of smoke were of a silver colour, and at other times, when it caught the sun's rays, it exhibited a purple hue. The lava afforded a very beautiful light as it ran down the sides of the mountain, and continued in a heated state, exhaling smoke for two years. It was remarked, that for five years afterwards snow did not re-appear on the summit.

In 1766 a new crater was opened at the grotto of Paterno, from which lava issued in quantisies sufficient to form a hill, which, four years afterwards, gave decisive indications, by smoke and noise, of its volcanic powers. During all this period the lava did not becone cool, nor the fire extinct. 
Several new craters were formed in the year 1830 , one of them almost two miles below the opening of 1763 ; and from February to May continual convulsions occurred, and quantities of pumice stones and sand were discharged. The most considerable crater was formed on the twenty-third of the last-mentined month, on Mount Fumento, on the summit of Etna; a stream of lava was ejected on this occasion, which spread at the rate of a mile in a day through the valley of Landunza. The lava issuing from two other openings, diffused itself to the distance of seven miles in six days. From another crater, produced on the twenty-fifth, red-hot stones were projected to a great distance, and a stream of fire ran over a tract of country, two miles in extent, in a very short space of time.

Gioeni has given an accurate account of another eruption, which happened in the month of July, $178 \%$, which was preceded for sixteen or seventeen days by the ordinary indications. On the seventeenth, after several slight shocks of earthquake, lava began-to flow from the back part of one of the two hills which form the double head of Fina. On the following day, after some hours of tranquillity, the subterraneous commotions increased, the smoke thickened, till at length there fell a shower of fine brilliant black sand; on the eastern side, a quantity of stones were thrown out, and flashes of fire, accompanied with a flond of scoriz and lava, were observed at the foot of the mountain. About sun-set conical flames issued from the volcano in different directions, alternately rising and falling; and at thee o'clock in the morning, the mountain had the appearance of being cleft, while the upper part seemed one burning mass. Two of the flames were of vast extent, and the intermediate space was nccupied by another, composed of several minor flames, ascending, from a base of a mile and a half in diameter, to the height of two miles. A phenomenon, hitherto unobserved in former conflagrations, was there exhibited. The cone was covered with a very thick smoke, which was pervaded with brilliant flashes of lightning, and sounds were frequently heard resembling the explosion of large cannon. A jet of faming volcanic substances was thrown from the cone, as from a foumain, to the distance of six or seven miles; and so thick a smoke issued from the base of the cone, as to obscure considerable portions of the flame when the lava was discharged. This beantiful scene lasted threequarters of an hour ; it began again, and with greater force, the next night, but was then of much shorter duration; flames, smoke, and ignited matter, in showers, were projected during the intervals. After the eruption, the summit of the mountain, on the western side, was overspread with hardened lava, scorix, stones, and smoke; mephitic vapours, showers of sand, and intense heat, continued their annoying operations. The lava on the west separated into two branches; the one of which proceeded towards Libeccio, the other in the direction of Bronte and the plain of Lago. It had evidently been in a state of fusion; and the fume of sulphur was enitted from one of the spiracules. The breadth of the lava was nearly from fourteen to twentyone feet, its depth thrteen feet and thee-quarters, and its extent two miles.

In October of the same year, another cruntion occumed, which 
has been described by Spallanzani. The stream of lava, on this occasion, from the great crater, was three miles long, with differing breadth, in some places a quarter of a mile, in others one-third, or even more, varying also in depth from six to eighteen feet. Its course was westerly, and its effervescence violent.

The most recent eruption took place in the month of March, 1809. A very interesting and minute account was transmitted at the time in a letter from a British officer in Sicily, to his friends in Scotland; which our readers will no doubt deem worthy of insertion. It is dated Messina, April 25th, 1309, and proceeds thus:-

"On the morning of the $2 \%$ th of March, 1809, about seven o'clock", advices of an eruption of Atna were conveyed hither, (Messina,) by a very swift courser, a cloud of black ashes from the mountain-top, which is fifty miles distant in a straight line. These ashes, borne on a hard gale of wind, showered into the town in such quantities, that even cart loads might have been collected from the streets and housetops. They resembled gunpowder; so much, indeed, that an Irish soldier in the citadel called out, "Blood and turf! the wind has forced open the magazine doors, and there's all the powder blowing about the barracks!"

"Soon after day-light, an awful bellowing and horizontal shaking of the mountain excited a general alarm among the inhabitants of its vast regions. Uncertain where the calamity might fall, many deserted their houses. This shock was immediately succeeded by a furious eruption of ashes from the great crater, which formed immense clouds, and covered an amazing extent of country. So violent was the discharge, - that, in spite of the gale, a vast quantity overspread the country many miles to windward of the spot whence they issued.

"On the evening of the same day, an eruption of lava took place at a short distance below, whose terrible streams flowed down the mountain about three miles, and then divided into two branches. This volcano soon ceased burning, and another broke out next day with greater fury than the former, about five miles lower down, at a place called Monte Negro. This one displayed three vast columns of flame and smoke, and its lava extended, in a few days, across the woody region, to the distance of three or four leagues. Hitherto we have heard of no guide bold enough to conduct the curious traveller as far as either of these eruptions, because of the vast and deceitful heaps of snow and ashes scattered about the two upper regions of the mountain; nor has any person, I believe, been yet so rash as to ascend higher than one which broke out two hours after the first alarm, about twelve miles below Monte Negro, and eight west of Lingua Grossa, a town on the north-east side, near the foot of Rina. This eruption has opened a row of craters, within a space of about two miles, forming with the other an irregular line running in a north-east direction from the top of the mountain.

"From the dark bosom of a wood of tall firs and huge oaks, spread over steep craggy hills and close valleys, conceive twelve craters or mouths, two unceasingly, and the rest at intervals, with a noise like a tremendous chorus of several thousand cannons, muskets, and sky-rockets, discharging flame, and showers of burning rocks of 
various forms and all magnitudes, from several vards in diameter, down to the smallest pebble, which, according to their weight and bulk, ascend from two hundred to one thousand feet. The two forementioned craters, or ratier double crater, the lowest of the row down the mountain, formed the principal object of this awful and magnificent scene-they were the only craters which did not seem to labour. Their joint emissions had encompassed them with a black oblong hill of ashes and lava stones; thirty yards above the top of which, their mingling flames furiously ascended, in one inmense blaze, which seemed one hundred yards in breadth. Amidst this blaze, vast showers of rocks, rising and falling, were continually passing each other. About the middle of the whole line of craters was situated one, which laboured the most, and made the loudest, the heaviest, the lighest, and the most dangerous discharges; from the rocks of which, our party twice narrowly escaped, one or two of very considerable size falling within a pace of us;-I think the lava flowed only from a few of the chief craters, particularly the double one. Duing the emissions of rock and flame, the boiling matter was seen in slow undulating waves, issuing through the sides, close to the bottom of the black hills of ashes. The double crater appeared, completely isolated by the lava of others. Just below this, all the lavas uniting, formed one grand stream of various breadths, from half a nile to fifty yards, which, leaving the fir-wood, pursued its destructive course down a rocky part of the mountain, interspersed with oaks; until, about five miles below the double crater, it entered some vineyards, after dividing into two branches, the principal one of which, advancing a mile farther, directly threatened the house of baron Corri. Within two hundred yards of this house, it entered a hollow way, which it was hoped would turn its course; but, going on, according to the direction of the impelling fluid behind, its loose rocks rolling off the main body, soon filled up the small ravine, and formed a causeway for itself to pass. The other branch took the direction of Lingua Grossa, and arrived very near the baron Cagnone's house, whose inhabitants, as well as those of the town, were trembling for their property, when the eruption ceased.

"The stream sometimes branched off and joined again, forming islands as it flowed along. Sometimes its banks were formed by the sides of ravines; but where the country was open, it formed its own, which from the porous nature of the lava imbibed the cool air, and soon hardened into black and lofty banks of many feet in thickness. It gradually thickened in advancing, until about four niles from the crater, when it began to assume the appearance of a vast rugged mound of black rocks, or stones and cinders, moving almost imperceptibly along. By daylight, the general appearance of this anazing stream, or moving mound, was black, and night be compared to a long tract of ploughed ground, moving and smoking along, raised on banks from fifteen to forty feet high. The end of it, however, presented a bold front of vivid fire, about fifteen or sixteen feet high, and eighty paces in extent. While it moved forward in -a body, the loose stones and cinders presenting less resistance to the stream behind, impelled in a continual succession to the top, rolled cracking down its rough 
shimg siles and front, arvancing hefore the main body, and buming the ghiss, the weeds, and grape vines, like light troops skimishing on the front and flanks of an army marching in solid column.

w I never saw a painting which gave any thing like a correct idea of lava, yet it appears no difficult task. I could discern nothing of the fluid part of the stream; yet, until somewhat cooled by flowing several miles, it must be liquid immediately underneath the thin light crusted surface. Just after issuing from the crater, I should think it flowed at the rate of four miles an hour; half way down the stream, (whose whole extent, when the eruption ceased, was about six miles,) a mile and a half an hour; and so on, gradually decreasing in velocity to the most advanced part, where its progress was a few hundred yards a day.

3 " The night-view of the eruption and stream of lava was truly grand and terrific. The rocks emitted from the craters displayed a white heat, and the flames an intense red. When the adjacent lills and valleys were covered by a shower of rocks, they appeared for a time beautifully spangled with stars, whose silver brightness, as well as that of the burning trees, formed a no less admirable contrast to the flames of the crater, than did the evening songs of the birds to the bellowing; of the mountain. The lava was a fancied infernal fire, streaked black and red, presenting a horrid contrast to the dark surrounding seenery. Here, down to the rocky slopes, it rolled a cataract of fire ; there, it displayed floating mounts, crowned with imagined fortresses. Trees were seen, as if growing from the fire, whose parched branches and burning trunks exhibited the idea of desolation in all its horrors. The country abont Lingua Grossa, Pie Monte, and other places on that side of the mountain, now lits covered with ashes three on four inches in depth. Though some lands have sufiered by lava? many have been manured by ashes, and the whole island is freed from the dread of earthquakes, for some time to come. Thus we find,

\section{"All partial evil universal good."}

"Except the inhabitants likely to suffer, little concern or curiosity was expressed by the Sicilians. Even the baron Corri, whose house was so much in danger, with superstitious obstinacy rejected for a long time every proposal of the British officers for removing his property. "No, no," he always replied, "let it be as God wills it:" At length, however, self-interest prevailed, and solitary walls alone remained. But when the lava had arrived within two hundred yards of this deserted habitation, the eruption ceased, to the great joy of the natives, who attributed this mercy to the merits and interference of their patron saints, whose images were daily brought from Castiglione; a distance of three miles, in procession, during the progress of this calamity, and placed, while mass was performed, amidst the tears of a wretched multitude, a few yards in the front of the slowly advancing fire This procession was composed of the miserable and ragged natives, of both sexes and all ages, crying and sobbing, beating their breasts, tearing their hair, and Hogging their backs in penance, while heir priests were calling on all their saints to assist them. On their way to the lavá, they stopped at the baron's bouse, from the balcony 
of which, the chief priest, with the most violent gestures of grief, defivered a short sprnon, in which he told them the eruption was a judgment upon their sins, and recommended them to mend their lives, and pray to all the saints to intercede for them. Every pause of this discourse was filled with a general burst of tears, beating of breasts, tearing of hair; and flogging of backs. I was never more affected by any scene of public distress.

"What mortal can dare to think he breathes a single moment without divine assistance? How feeble, how insignificant does he feel, who stands within two hundred yards of these furious volcanoes. What must be the pangs of his heart, who beholds his earthly property, his native fields; in a few hours overwhelmed. Transitory, compared with this, are all the other scourges of the earth. The fertility swept away by floods and tempests, by war and pestilence, is shortly succeeded by smiling plenty. The fields of Austerlitz and Jena already revive from their late desolation. Even Spain may, perhaps, smile ere long; but many successive generations, with hopeless sighs, must view the black and barren rocks which have buried the native lands of their unhappy forefathers."

\section{Volcanoes and Eruptions in Iceland.}

ICELAND is noted for its volcanoes, which seem to be more furious than any others yet discovered. Indeed, from the latest accounts, it would seem that this miserable country was one continued volcano. Mount Hecla has been supposed to be the only burning mountain, or at least the principal one, in the island. It has indeed been more taken notice of than many others of as great extent, partly from its having had more frequent eruptions than any other, and partly from its situation, which exposes it to the sight of ships sailing to Greenland and North America. But in a list of eruptions published in the Appendix to Pennant's Arctic Zoology, it appears that out of fifty-one remarkable ones, only one-third have proceeded from Hecla, the other mountains being no less active in the work of destruction than this. These eruptions take place in the mountains covered with ice, which the inhabitants call Jokuls. Some of these, as appears from a large map of Frederick V. (1734,) have been swallowed up. The great lakes in this country have been occasioned by the sinking of such mountains, as similar instances are seen in other places. The great Icelandic lake, called Myratu, seems to have been one. Its bottom is entirely formed of lava, divided by deep cracks, which shelter, during winter, a great quantity of trouts. It is now only thirty feet deep, but originally was much deeper, having been nearly filled up in 1728 by an eruption of the great mountain Krafle: the fiery stream took its course towards Myratu, and ran into it with a horrid noise, which continued till 1730.

"The mountains of Iceland," says Mr. Pennant, are of two kinds, primitive and posterior. The former consist of strata usually regular, but sometimes confused. They are formed of different sorts of stone, without the least appearance of fire. : Some are composed of sand and free-stone, petrosilex or chirt, slaty or fissile stone, and various hinds of earth or bole, and steatitæ, different sorts of breccia or con- 
glutinated stones; jaspers of different kinds, Iceland crystal; the common rhomboid spathum; chalcedonies stratified and botryoid; zeolites of the most elegant kinds ; crystals, and various other substances that have 110 , relation to volcanoes. The primitive mountains are those called Jokuls, and are higher than the others. One of them, called Esian or Rias, is six thousand feet high. It seems to be composed of great and irregular rocks of a dark gray colour, piled on each other. Another, called Enneberg, is about three thousand feet high : the Sncefield Jokul, two thousand two hundred and eighty-seven yards ; the Snofieldnas, or promontory of Snofield, from chree hundred to four hundred fathoms. The rocks of Drango are seven in number, of a pyramidical figure, rising out of the sea, at a small distance from the cliffs, four of which are of a vast height, and have a most magnificent appearance. Eastward from the Snofield begius the Eisberge, soaring to a vast height, many parts of which hare felt the effects of fire, and in some of the melted rocks are large cavities.

"Budda-1ekkur, a rock at one end of this mountain, is also volcanic, and has in it a great cavern, hung with stalactitæ. The name of Solvahamar is given to a tremendous range of volcanic rocks, composed entirely of slags, and covered in the season with sea-fowl. It would be endless, however, to mention all the places which bear the marks of fire in various forms, either by having been vitrified, changed into a fiery colour, ragged and black, or exhibit indications of having run for miles in a sloping course towards the sea.

"These volcanoes, though so dreadful in their effects, seldom begin to throw out fre without giving warning. A subterraneous rumbling woise, heard at a considerable distance, precedes the eruption for several days, with a roaring and cracking in the place from whence the fire is about to burst forth; many fiery meteors are observed, but generally unattended with any violent concussion of the earth, though sometimes earthquakes, of which several instances are recorded, have accompanied these dreadful conflagrations. The drying "up of small lakes, streams, and rivulets, is also considered as a sign of an impending eruption; and it is thought to hasten the eruption, when a mountain is so covered with ice, that the holes are stopped up, through which the exhalations formerly found a free passage. "The immediate sign is the bursting of the mass of ice with a loud noise, flames then issue from the earth, and lightning and fire-balls from the smoke; stones, ashes, \&c. are thrown out to vast distances."

Olafsen relates, that, in an eruption of Kattelgiaa in 1755, a stone weighing $290 \mathrm{lbs}$. was thrown to the distance of twenty-four English miles. A quantity of white pumice-stone is thrown out by the boiling waters, and it is conjectured, with great probability, that the latter proceeds from the sea, as a quantity of salt, sufficient to load several horses, has frequently been found after the mountain has ceased to burn, Among the numberless ravages of so many dreadful volcanoes, which from time immemorial has contributed to render this country still less inhabitable than it is from the climate, we shall only give an acconut of that which happened in 1783 , and which from its violence seems to be unparalleled in history. 
Its first signs were observed on the first of June, by a trembling of the earth in the western part of the province of Shapterfial. It increased gradually to the 11 th, and became at last so great that the inlabitants quitted their houses, and lay at nights in tents on the ground. A continual smoke was seen rising out of the earth, in the northern and uninhabited parts of the country. Three fire-spouts, as they were called, broke out in different-places: one in Alfarsdal, a little east of the Skapta; the other two were a little west of the IIwerfisfliot. The Skapta rises in the north-east, and running first west, and then south, falls into the sea in a south-east direction. Part of its channel is confined for about twenty-four English miles, and is in some parts two hundred fathoms deep, in others one hundred or one liundred and fifty, and its breadih in some places one hundred, fifty, or forty fathoms. Along the whole of this part of its course the river is very rapid, though there are no considerable cataracts or falls. There are several other such confined channels, but this is the most considerable. The three fire-spouts, or streams of lava, which had broken out, united into one, after having risen a considerable height into the air, arriving at last at such an a mazing altitude, as to be seen at the distance of more than two hundred English miles; the whole country, double that distance, being covered with a smoke hardly to be described.

On the 8th of June this fire was first visible. Vast quantities of sand, ashes, and other volcanic matters, were ejected, and scattered over the country with the wind. The atmosphere was filled with sand, brimstone, and ashes, in such a manner as to occasion continual darkness, and considerable damage was done by the pumicestones, which fell red-hot in great quantities. Along with these, a tenacious substance, like pitch, fell in vast quantities; sometimes rolled up like balls, at other times like rings or garlands, which proved no less destructive to vegetation than the other. This shower having continued for three days, the fire became very visible, and at last arrived at the amazing height above mentioned. Sometimes it appeared in a continual stream, at others in flashes or flames, seen at the distance of thirty or forty Danish miles, (one hundred and eighty or two bundred and forty English,) with a continual noise like thunder, which lasted the whole summer. The same day that the fire broke out, there fell a vast quantity of rain, which running in streams on the hot ground, tore it up in large quantities, and brought it down on the lower lands. This rain water was much impregnated with acid and other salts, so as to be highly corrosive, and to occasion a painful sensation when it fell on the hands or face. At a greater distance from the fire, the air was excessively cold. Snow lay upon the ground three feet deep in some places, and in others there fell great quantities of hail, which did very great damage to the cattle and every thing without doors. Thus the grass and every kind of vegetable in those places nearest the fre was destroyed, being covered with a thick crust of sulphureous and sooty matter. Such a quantity of vapour was raised by the contest of the two adverse elements, that the sun was darkened, and appeared like blood, the whole face of nature seeming to be changed; and this obscurity seems to have reached as 
far as Great Britain, for, during the whole summer of 1783 , an obscurity reigned throughout all parts of this island, the atmosphere being clouded with a continual haze, which prevented the sun from appearing with his usual splendour. The dreadful scene alove described lasted in Iceland for several days; the whole country was laid waste, and the inhabitants fled every where to the most remote jarts of their country, to seek for saiety from the fury of this unparaileled tempest.

On the first breaking out of the fire, the Skapta was considerably augmented, on the east side of which one of the fire-spouts was situated; and a similar overflow of water was observed in the great river Piorsa, which runs into the sea a little east of a-town called Urebek ka, and into which another river called Tuna, falls, after having ruin throngh a large tract of barren and uncultivated land: but on the 1th of June, the watcrs of the Skapta were lessened, and in less than twenty-four hours totally dried up. 'The day following, a prodigious stream of liquid and red-hot lava, which the fire-spout had discharged, ran down the channel of the river. This burning torrent not only filled up the channel, but, overtlowing the bauks, spread itself over the whole valley, covering all the low grominds in its neighbourhood; and not having any suficient outlet to empty iiself by, it rose to a vast height, sn that the whole adjacent country was overflowed, and some of the lower hills covered. The hills are not continued in a long chain, but detached, and between them run little rivulets, so that, besides filling up the whole valley in which the Skapta ran, the fiery stream spread itself for a considerable distance on each side, getting vent between the hills, and laying all the neighbouring country under fire. The spouts still continuing to supply fresh quantities of inflamed matter, the lava took ias course up the channel of the river, overflowing all the grounds above, as it had done those below the place whence it issued. The river was dried up before it, until at last it was stopped by the hill whence the Skapta rises.

Having now no proper outlet, it rose to a prodigious height, and overflowed the village. of Buland, consuming the houses, church, and every thing that stood in its way, though the high ground on which this village stood, seemed to ensure it from any danger. The fiery lake still increasing, spread itself out in length and breadth for thirtysix English miles; and having converted this tract of land into a sea of fire, it stretched towards the south, and getting vent again by the Skapta, rushed down its channel with great impetuosity. It was still confined between the narrow banks of that river for about six English miles, but coming at last into a more open place, it poured forth in prodigious torrents, with amazing velocity and force; spreading itself now towards the south, tearing up the earth, and carrying on its surface flaming woods and whatsoever it met with. In its course it laid waste another large district of land. The ground where it carme was cracked, and sent forth great quantities of steam long before the fire reached it; and every thing near the lake was burnt up, or reduced to a fluid state.

In this situation matters remained from the 12 th of June to the 13 ih 
of August, after whicl the fiery lake no longer spread itself, though it continued to burn; and when any part of the surface acquired a crust by cooling, it was quickly broken by the fire below, and thus tumbling down among the melted substances, was tossed about with prodigious noise; and in many parts of its surface, small spouts; or at least ebullitions, were formed, which continued for some length of time.

In other directions this dreadful inundation proved no less destructive. Having run through the narrow part of the channel of Skapta as early as the twelfth of June, it stretched out towards the west and south-west, overtlowing all the flat country; its edge being no less than seventy fathoms high at the time it got out of the channel of the river. Continuing its destructive conrse, it overflowed a number of villages, running in every direction where it could find a vent. In one place it came to a great cataract in the Skapta, about fourteen fathoms high, over which it was precipitated witl tremendous noise, and thrown in great quantities to a very considerable distance. In another place it stopped up the channel of a large river, filled a great valley, and destroyed two villages by approaching only within one hundred fathoms of them. Others were overflowed by inundations of water procceding from the river, which had been obstructed in their course, until at last all the passages on the south-east and west being stopped, and the spouts still sending up incredible quantities of fresh lava, it burst out to the north and north-east, spreading over a tract of land forty-eight miles long and thirty-six broad. Here it dried up the rivers Tuna and Abasyrdi; but even this vast effusion being iusufficient to exliaust the subterraneous liquid fire, a new branch took its course for about eight miles down the channel of the Ilwersisfliot, when, coming again to an open country, it formed what $\mathrm{Dr}$. Van Troil calls á small lake of fire, about twelve miles long and six broad. At last, however, this branch also stopped on the sixteenth of August, the fiery fountains ceased to pour forth new supplies, and this most astonishing eruption came to a period.

The whole extent of ground covered by this dreadful inundation was computed at ninety miles long and forty-two broad, the depth of the lava being from sixteen to twenty fathoms. Twelve rivers were dried up, twenty or twenty-one villages were destroyed, and two hundred and twenty-four people lost their lives. But this is only the extent on the south-east and west: for that towards the north, being thinly inlıabited land, where nobody cared to venture, was not exactly known. Some hills were covered by this lava, others were melted down by its heat, so that the whole had the appearance of a sea of red-hot melted metal. After this eruption, two new islands were thrown up from the bottom of the sea. One, about three miles in circumference and about one in height, made its appearance in 1784, where there were formerly one hundred fathoms of water; it was about one hundred miles south-west of Iceland, and forty eight from a cluster of snall islands called Gieofulga : it continued for some time to burn with great violence, sending forth prodigious quantities of pumice-stones, sand, \&c. like other volcanoes. The other lay to the north-west, between Iceland and Greenland; it burnt day and night 
without intermission for a considerable time, and was also very high, and larger than the former. $O$ e or both of these islands have since been swallowed up. All the time of this great eruption, and for a considerable time after, the whole atmosphere was loaded with smoke, steam, and sulphureous vapours. The sun was sometimes wholly invisible; and when it could be seen, was of a reddish colour. Most of the fisheries were destroyed; the banks where the fish used to resort being so changed, that the fishermen could not know them again, and the smoke was so thick that they could not go far out to sea. The rain-water, falling through this smoke and steam, was so impregnated with salt and sulphureous matter, that what had escaped the destructive effects of the fire became poisonous, so that the cattle died for want of food, or perished by eating those unwholesome vegetables. Nor were the inhabitants in a much better situation, many of them having lost their lives by the poisonous qualities of the smoke and steam with which the whole atmosphere was filled.

Before the fire broke out in Iceland, there is said to have been a very remarkable eruption in the uninhabited parts of Greenland, and that in the northern parts of Norway the fire was visible for a long time. A considerable quantity of ashes, sand, and other volcanic matters, fell at Fars, which covered the whole surface of the ground whenever the wind blew from Iceland, though the distance is not less than four hundred and eighty miles. Ships sailing betwixt Copenhagen and Norway were covered with ashes and sulphureous matter, which stuck to the masts, sails, and decks, besmearing them all over with a pitchy substance.

\section{BRINE SPRINGS.}

THESE are fountains which flow with salt water instead of fresh. Of these there are a great number in South Britain ; but though not peculiar to this island, they are far from being common on the continent. There is a remarkable one at East Chermock, in Somersetshire, about twenty miles from the sea. There is another at Leamington in Warwickshire; very near the river Learn ; which, however, is but weak. $A$ third runs into the river Cherwell in Oxfordshire; and there are several more in Westmoreland and Yorkshire; but as they are weak, and the fuel in most of those counties is scarce and dear, no salt is prepared from them. At Borrowdale, near Grange, seven miles from Keswick in Cumberland, a pretty strong spring rises in a level near a moss ; sixteen gallons of water of which, yield one of pure salt; which is remarkable, as the same quantity of salt cannot be obtained from less than twenty-two gallons of the waters of the German ocean. At Salt-water Haugh, in Durham, there are a multitude of salt springs which rise in the middle of the river Weare, for the space of about forty yards in length and ten in breadth; but particularly one out of a rock, which is so strong, that in a hot sumner's day the surface is covered with a pure white salt At Weston, in Staffordshire, there are brine springs which afford about a ninth part of very fine white salt. There are others at Enson, St. Thomas, and in the parish of Ingestre, ibut so weak that they are not wrought, though it is believed 
that by boring, stronger springs might be found in the neighbounhod. In Lancashire there are several salt springs, but, if we except those at Barton, which are as rich as the spring at Norwich, by no means so famous as those of Cheshire, called in general by the name of the Wiches. At Namptwich, situated on the river Weever, the brine is still richer, for six ounces of salt are obtained from sixteen of water. The inhabitants of Wales, who, before that country was incorporated with England, were supplied chiefy, if not solely, with that necessaiy commodity from these two towns, called the former Hellath Wen, and the latter Hellath Du; i. c. the white and black salt-pit.

In 1690 a rock of salt was discowered at a small distance from Norwich, which has been wrought to a great depth, and to a vast extent, so as to be justly esteemed one of the greatest curiosities in England; and it is highly probable that there is an immense body of fossil salt in the bowels of the earth, under this whole county, for, upon boring, brine pits have been found in many places on both sides of the Weever. This is the nore likely, siuce at Middlewich, which stands at the confuence of the Croke and the Dan, there are sait springs with a fresh brook runing between thein. The brines from these pits are of unequal strength, but when mixed, they commonly obtain four ounces of sait from a pound of brine. In these springs. the water is strongest near the bottom, richer in dry weather than it wet, and when long drawn than when first wrought. But there are no rules in respect to other salt springs, for in those of Franche Comte the brine is strongest in wet weather. There are several other bodies dissolved in those brines, besides salt : in some a sulphureous substance, which sublimes as the hine heats; a sort of dirty ochre, which discolours the brine, but, if suffered to stand, speediry subsides; and, in most brines, a calcareous, or rather selenitic carth, which settles to the botton of the pan.

\section{Shit Mines in Poland.}

THE salt mines of Vielicza, near Cracow in Poland, are very extraordinary caverns. Mr. Wraxall describes them thus, in his Memoirs of the Courts of Berlin, Dresden, Warsaw, and Vienna. "After being let down," says he, "by a rope to the depth of two hundred and thirty fect, our conductors led us through galleries, which for loftiness and breadth seemed rather to resemble the avenues to some subterranean palace, than passages cut in a mine. They were perfectly dry in every part, and terminated in two chapels, composed eutirely of salt, hewn out of the solid mass. The images which adorn the altars, as well as the pillars and ornaments, were all of the same transparent materials; the points and spars of which, held by the guides in their hands, produced an effect equally novel and beautiful. Descending lower into the earth by means of ladders, I found myself in an immense hall or cavern of salt, many hundred feet in height, length, and dimensions, the floor and sides of which were cut with exact regularity: one thousand persons might dine in it without inconvenience, and the eye in vain attempted to trace or define its limits. Nothing could be niore sublime than this vast subterranean apartment, illuminated by 
Pamucanx, which fainly discover its prodigions magnitude, leaving the imagination at liberty to enlarge it indefinitely. After renaining two and a hat hours under ground, I was drawn up again in three minutes with the greatest facility."

\section{LAKE Avernus.}

THIs is a lake of Campania, in Italy, near Baiz, famous among the ancients for its poisonous qualities. It is described by Strabo as lying within the Lucrine bay, deep and darksome, surrounded with steep banks that hang threatening over it, and only accessible by one narrow passage. Black, aged groves stretched their boughs over the watery abyss, and with impenetrable foliage excluded almost every ray of wholesome light; mephitic vapours ascending from the hot bowels of the earth, being denied free passage to the upper atmosphere, floated along the surface in poisonous mists, and killed even the birds that attempted to fly over it. These circumstances produced horrors fit for the gloomy votaries of the infernal deities. A colony of Cimmerians, as well suited to the rites as the place itself, cut Jwellings in the bosom of the surrounding hills, and officiated as priests of Tartarus. Superstition, always delighting in daik ideas, early and eagerly seized upon this spot; and represented a cavern near it, called the Sybil's cave, as the mouth of the infernal regions. Hither she led her trembling votaries, to celebrate her dismal orgies: here she evoked the manes of departed heroes, here she offered sacrifices to the gods of hell, and attempled to dive into the secrets of futurity. Poets enlarged upon the popular theme, and painted its awful scenery with the strongest colours of their art. Homer brings Ulysses to Avernus, as to the mouth of the infernal abodes; and in imitation of the Grecian bard, Virgil conducts his hero to the same ground. Whoever sailed thither, first did sacrifice, and encleavoured to propitiate the infernal powers, with the assistance of some priest who attended upon the place, and directed the mystic performance. Within, a fountain of pure water broke out just over the sea, but which nobody tasted, as it was fancied to be a vein of the river Styx; near this fountain was the oracle, and the hot waters frequent in these parts were supposed to be branches of the burning Phlegethon. The holiness of these shades remained unimpeached for many years. Hannibal marched his army, to offer incense at this altar; though it may be suspected he was led to this act of devotion rather by the hopes of surprising the garrison of Puteoli, than by his piety:

After a long reign of undisturbed gloom and celebrity, a sudden glare of light was let in upon Avernus : the horrors were dispelled, and with them vanished the sanctity of the lake; the axe of Agrippa brought its forest to the ground, disturbed its sleepy waters with ships, and gave vent for all its malignant êluvia to escape. The virulence of these exhalations, as described by ancient authors, has appeared so very extraordinary, that modern writers, who know the place in a cleared state only, charge these accounts with exaggeration: bit Mr. Swinburn thinks them entitled to more credit, for even now, he observes, the air is feverish and dangerous, as the jaundiced faces 
of the vine-dressers, who have succeeded the Sylils and the Cinmerians in the possession of the temple, most fully testify. Boccacio relates, that, furing his residence at the Neapolitan court, the surface of this lake was suddenly covered with dead fish, black and singed, as if killed by some subaqueous eruption of fire. At present this lake abounds with tench, the Lucrine with eels.

The changes of fortune in these lakes is singular. In the splendid days of imperial Rome, the Lucrine was the chosen spot for the brilliant parties of pleasure of a voluptuous court; now, a slimy bed of rushes covers the scattered pools of this once beautifil sheet of water, while the once dusky Avernus is clear and serene, offering a most alluring surface and charming scene for similar amusements. Opposite to the temple is a cave, usually styled the Sybil's grotto; but apparently more likely to have been the inouth of communication between Cuana and Avernus, than the abode of a prophetess, especially as the Sybil is positively said by historians to have dwelt iit a cavern under the Cuanean citadel.

\section{Lake Aspiatities.}

THIS is a lake of Judxa. Almost all the ancient geographer's have described this lake; Josephus, Julius Africanus, and Pausanias, notice it, after personal visits. Josepluus niakes it the northern boundary of Canaan, (Ant. ix.) and assigns its distance from Jerusalem to be three hundied stadia, (xv.9.) He speaks of its water as salt, and of its shores as barren; that heavy bodies would float upon the waters, and that men thrown into them, though bound, would swim. He believes the Pentapolis of Sodom and Gomorrah not to have been sunk beneath the site of this lake, but to have been overwhelmed by fire in the neighbourhood of it; and he mentions their shadows as yet visible. - De Bello, v.

Julius Africanus states, that all living bodies swim, and all dead bodies sink in this lake; that burning torches, in like manner, float, and when extinct fall to the bottom. Pausanias confirms the first of these assertions, and remarks, that the Dead Sea, as he calls it, is affected in every respect differently from other waters, (v. 7.)

The scriptural account of the overthrow of the offending cities, in no way leads to a belief of their submersion in water. On the contrary, every word in every passage of the Old or New Testament, allusive to this terrific event, speaks of fire as the agent. Yet Maundrell mentions persons of credibility, who told him that they had seen columns and ruins of buildings under the surface of the lake; and DHerbelot cites Daowra as one of the five cities, the remains of which are still visible.-Bibliotheque Orientale, ad verb.

The lake is at present called Almotanah and Bahret Lout by the Arabs, and Ula Deguisi by the Turks. Its water is much salter than that of the ocean,-and its specific gravity in 12.11, according to Malte Brun, that of fresh water being $\mathbf{1 0 0 0 . ~ I t s ~ f i g u r e ~ a p p r o a c h e s ~ t o ~}$ a semicircle, the convexity of which is to the west. It is said to be twenty-four leagues in length, and four or five in extreme breadth. Hitherto only one European has succeeded in making the circuit of it; and Nau, who in his travels has recorded this expedition of 
Daniel, abbot of St. Saba, states on his authority, that "the Dead Sea, at its extremity, is separated as it were into two parts, and that there is a way by which you may walk across it, being only mirlleg deep, at least in summer; that there the lake rises, and bounds another small lake of a circular or rather oval figure, surrounded with plains and mountaius, and that the neighbouring conntry is peopled by innumerable Arabs."

M. Seetzen, in the year 1805-6, passed round the southern extre mity of this lake; but a short account only of his route, (a quarto of forty-seven pages of correspondence with $\mathbf{M}$. de Zach, printed by the Palestine Association in 1810, has yet appeared. M. Burckhardt was unable to reach its borders. He was informed, in its neighbourhood, that no visible increase of its waters takes place during winter, as the greater part of the torrents which descend from the eastern mountains are lost in the sandy plain before they reach the lake. Some Arabs assured him that there were spots in a ford some miles north of Szaffye, the extreme southern point of the lake, in which the water is quite hot, and the bottom of red earth. This ford may be crossed in three hours and a half; the water here is generally not more than two feet deep, and it is probable there are hot springs in the bottom. It is so strongly impregnated with salt, that the skin peels off the legs of those who wade across it. Besides the river Jordan, the lake receives six lesser streams, and it has no visible ontlet; and as there is no apparent increase of its waters, it was long conjectured that a vent was found through subterrancous chanuels. But evaporation alone is sufficient to account for the phenomenon.

Most of the marvellous properties of this lake are now exploded. It was once considered an Avernus; but bird's are observed to fly over it uninjured. No living creature was supposed to exist in its waters; hut the exuvia of fish are often cast upon its shores. The apples of Sodom, which grew on its banks, have been wonderfully described both by Josephus and Tacitus, (History, v. 8.) Later writers have also mentioned them in similar terms, among whom we may cite the veracious Mandeville : "And there besydan growen trees, that baren fulle faire apples, and faire of colour to beholden, but whoso breketh them, or cuttethe them in two, he shalle fynde within them coles and cyndres." Milton has made a fine use of this legend, after the transformation of Satan and is bad angels into serpents, when they are tempted to eat the apples growing on trees resenibling the forbidden tree of knowledge :

Greedily they pluck'd

The fruitage fair to sight, like that which grew

Near that bituminous lake where Sndom flam'd;

This, more delusive, not the touch, but taste

Deceiv'd; they, fondly thinking to allay

Their appetite with gust, instead of fruit

Chew'd bitter ashes,

Paradise J.ost, book x. 1. 560 .

Reland, Neret, and Maundrell reject the whole account as a fable; but Hasselquist, the botanist, asserts the apples of Sodom to be the 
production of the solanum melongena of Linnaus. This is found in great abuudance round Jericho, and in the neighbourhood of the Dead Sea: The dust with which it is sometimesfilled, is the work of an insect, (teuthrede, which pulverizes the whole of the inside, leaving the rind entire, and unchanged in colour. M. Leetzen does not agree with this conjecture; he saw at Kerek a species of cotton, which he was told was produced from a fruit resembling a pomegranate, growing on the borders of the Dead Sea. It is this pulpless fruit which he is induced to think is the malum sodomeum. Viscount, Chateaubriand saw a third fruit growing on a thorny shrub, which, before it is ripe, is filled with a corrosive and saline juice, ain, when dried, yields blackish seeds resembling ashes, and tasting like bitter pepper.

The asphaltum or bitumen, produced by this lake, floats upon its surface, and is stated to rise from the bottom of the water in hige lumps, which explode as soon as they are affected by the external air. It abounds in the neighbouring mountains, and resembles black pitch, from which it is only to be distinguished by its fetid and sulphureous smell.

\section{ExiRAORDINARY CURRENT IN NORWAY.}

ABout six leagues from Hundholm is the celebrated current of Salten (Saltenstron,) which is even more dreaded than the Maelstrom, as all the inlabitants of Saltensfiord have to cross this dangerous passage, in which sereral persons annually perish.-There is (says the letter of a late visitor) really something wonderful in the violence of the current of the waters, when they are confined in this narrow passage, where the stream runs about seven French leagues in an hour, and forms, besides, a multitude of whirlpools, wherever it meets with any resistance from the sinuosities of its banks.

The Valley of Waipio, in Hawail or OWHyhee, one of the SANDWICH IsLaNDS.

OF this remarkable valley the representation and deseription are from Mr. Ellis's Tour.

"It was about, five n'clock in the afternoon of the 16th of August, 1823, when $\mathrm{Mr}$. Thurston and myself left Kapulena. Wishing to spend the Sabbath in the populous village of Waipio, we travelled fast along the narrow paths bordered with long grass, or through the pleasant, well-cultivated plantations of the natives. The Sandwich Islanders have no idea of constructing their roads or foot-path in a straight line. In many parts, where the country was level and open, the paths from one village to another were not more than a foot wide, and very crooked. We often had occasion to notice this, but never passed over any so completely serpentine as those we travelled this evening.

"The sun had set when we reached the high cliff that formed the southern boundary of Waipio. Steep rocks, not less than five hundred feet high, rose immediately opposite. Viewed from the great elevation at which we stood, the charning valley spread out bencath 


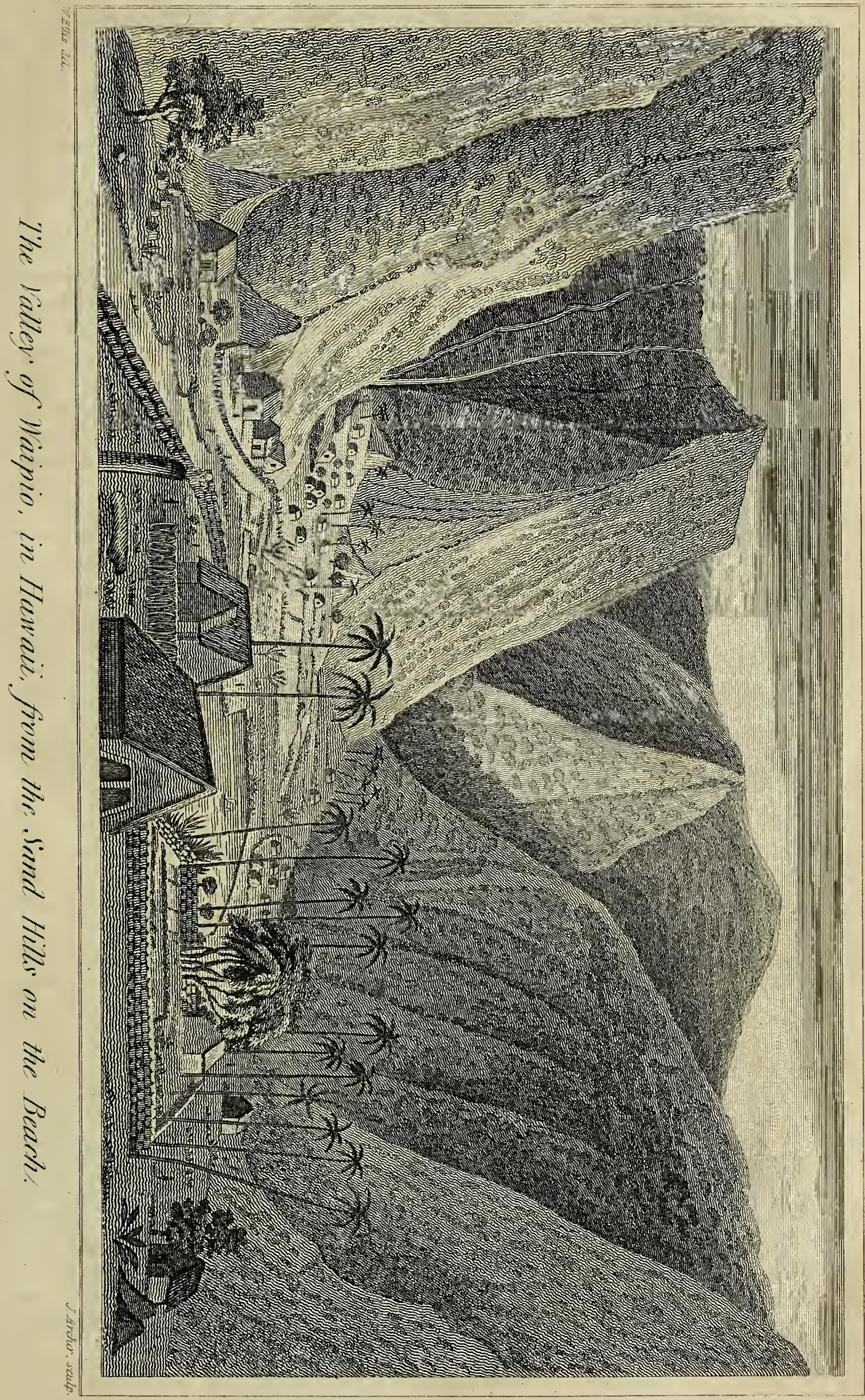



us like a map, (with its numerous imhabitants, cottages, plantations, tist-ponds, and meandering streams, on the surface of which the light canoe was moving to a fro, ) appeared in beautiful miniature. Makoa, our guide, led the way down the steep cliffs. The descent was difficult, and it was quite dark before we reached the bottom. A party of natives, returning from a fishing excursion, ferried us across the stream that ran along near the place where we descended, and we directed our steps towards the house of Haa, head-man of the village. He received us courteously, ordered a clean mat to be spread for us to recline on, and water for us to drink: some of his attendants also handed us a large wooden tobacco-pipe, which is usually passed round when strangers arrive; this last compliment, however, we begged leave to decline. Makoa seated himself by the side of the chief, and gave him a brief outline of our tour-our object, and the instructions given to the people. In the mean time fish was prepared for supper by a fire of sandal wood, which, instead of filling the house with disagreeable smoke, perfumed it with a fragrant odour. After family worship in the native language, we retired to rest.

"The next morning unveiled to view the extent and beauty of this romantic valley. Its entrance from the sea, which was blocked up with sand-hills fifty or sixty feet high, appeared to be a mile or a mile and a half wide. The summits of the hills, which bordered the valley, seemed six hundred feet above the level of the sea. They were nearly perpendicular, yet they were mostly clothed with grass, and low straggling shrubs were here and there seen amidst the jutting rocks. A number of winding paths led up their steep sides, and, in several parts, limpid streams flowed in beautiful cascades from the top to the bottom, forming a considerable stream, which, meandering along the valley, found a passage though the sand-hills, and emptied itself into the sea. The bottom of the valley was one continued garden, cultivated with taro, bananas, sugar-cane, and other productions of the islands, all growing luxuriantly. Several large ponds were also seen in different directions, well stocked with excellent fish. A number of small villages, containing from twenty to fifty houses each, stord along the foot of the mountains, at unequal distances on each side, and extencied up the valley till projecting hills obstructed the view."

\section{Colebrook Dale.}

THIS is a winding valley in the eastern side of Shropshire, on the banks of the Severn, between two vast mountains, which divide in various romantic forms, and are covered with beautiful hanging woods. In making a navigable canal to the Severn in 1787 , several springs of excellent native tar were discovered, which, though now much reduced, flowed' so copiously at first, as to afford from seventy to eighty gallons per day; so that barrels could hardly be got ready to secure it. A spring of brine was also discovered, as strong as most of those used for making salt. A work for obtaining mineral tar from the condensed sinoke of pit-coal has been erected, and the most exten- 
sive iron works in England are established in this dale, which, with the bridge of cast iron over the Severn, adds much to the natural romantic scenery of the place. The noise of the forges, mills, \&c." says Mr. Young, "with all their vast machinery; the flames bursting from the furnaces, with the burning of coal, and the smoking of the lime-kilns, are all together horribly sublime." The iron bridge was erected in 1779 ; the road over it, made of clay and iron slag a foot deep, is twenty-four feet wide; the span of the arch is one hundred feet six inches; and the height from the base to the centre forty feet. The weight of iron in all is one hundred anci eventy-eight tons and a half.

\section{AVALANCHES.}

THE immense masses of snow which are precipitated from the $\mathrm{Al}$ ps, and often overwhelm whole villages in their destructive course, are distinguished by this name. When the snow begins to melt by the heat of summer, the water which is produced, in its attenut to run off below, destroys the adhesion between the snow and the earth; and a new snow, falling upon the old and almost detached nass, increases the weight, and determines its fall.-In 1719 an avalanche from a neighbouring glacier overspread the greater part of the houses and baths at Lenk, and destroyed a considerable number of the inhabitants. In 1769-70 an avalanche, produced by the immense quantity of snow which had fallen during the winter, rolled down upon the pastures on the mountain of Sext in the Alps, when the impulse was so great, that it levelled with the ground a forest of beeches and firs which covered the declivity of the monntain; stopped the course of the river Gipre; which runs through the subjacent valley; and overthrew a number of trees and barns on the opposite shore of the stream. In August,. 1820, two gentlemen from Oxford-Mr. Dornford, fellow of Oriel, and Mr. Henderson, fellow of Brazen-nose, college-set ont, in company with Dr. Hamel and M. Sellique, (who abandoned the enterprise at the end of the same day,) attended by twelve guides, to ascend Mont Blanc. They encountered the greatest danger (indeed with destruction to three of the party) from an avalanche. When within four hundred yards of the summit of this interesting mountain, the snow suddenly gave way beneath them, and carried them all within a few paces of an immense crevasse. Our readers will like to read an account of this moment of danger in Mr. Dornford's ow'll words.

"The difficulty of breathing gradually increasing, and our thirst being incessant, I was obliged to stop half a minute to arrange my veil: in this interval my companion $H$. and three of the guides passed me, so that I was now the sixth in the line, and of course the centre man. He was next before me, and as it was the first time we had been so circumstanced during the whole morning, he remarked it, and said we ought to have one guide at least between us, in case of accident. This I overruled, by referring him to the absence of all appearance of danger at that part of our march; to which he assented. Idid not attempt to recover my place in front, though the wish more 
than once crossed my mind, finding perhaps that my present one was much more laborious. To this apparently trivial circumstance I was indebted for my life.

"A few minutes after the above conversation, my veil being still up, and my eyes turned at intervals towards the summit of the mountain, which was on the right, as we were crossing obliquely the long slope which was to conduct us to Mont Maudit, the snow suddenly gave way beneath our feet, beginning at the head of the line, and carried us down the slope to my left. I was thrown instantly off ny feet, but was still on my knees, and endeavouring to regain my footing, when, in a few seconds, the suow on our right, which was of course above us, rushed into the gap thus suddenly made, and completed the catastrophe, by burying us all at once in its mass, and hurrying us downwards towards two crevasses, about a fnrlong below us, and nearly parallel to the line of our march. The accumulation of snow instantly threw me backwards, and I was carried down in spite of all my struggles. In less than a minute I emerged, partly from my own exertions, and partly because the velocity of the sloping mass had subsided, from its own friction. I was obliged to resign my pole in the struggle; feeling it forced out of my hand; a short time afterwards I found it on the very brink of the crevasse. At the moment of my emerging, I was so far from being alive to the danger of our situation, that on seeing my two companions at some distance below me, up to the waist in snow, and sitting motionless and silent, a jest was rising to my lips, till a second glance shewed me, that, with the exception of Matthew Balmat, they were the only remnants of the party visible. Two more, however, being those in the interval between myself : and the rear of the party, having quickly re-appeared, I was still inclined to treat the affair rather as a perplexing, though ludicrous delay, (in having sent us down so many hundred feet lower, than in the light of a serious accident, when Matthew Balmat cried out that some of the party were Inst, and pointed to the crevasse, which had hitherto escaped our notice, into which he said they had fallen. A nearer view convinced us all of the sad truth. The three front guides, being where the slope was somewhat steeper, had been carried down with great rapidity, and to a greater distance, and had thus been hurried into the crevasse, with an immense mass of snow upon them, which rose nearly to the brink. Balmat, who was fourth in the line, being a man of great muscular strength, as well as presence of mind, had suddenly thrust his pole into the firm snow beneath, when he felt himself going, which certainly checked, in some measure, the force of his fall. Our two hindermost guides were also missing, but we were soon gladdened by seeing them make their appearance, and cheered them with loud and repeated huzzas. One of these had been carried into the crevasse where it was very narrow, and had been thrown with some violence against the opposite brink. He contrived to scramble out without assistance, at the expense of a trifling cut on the chin. The other had been dragged out by his companions quite senseless, and nearly. black from the weight of snow which had been upon him. In a short time, however, he recovered. It was inng before we could convince ourselves that the others were past hope, 
and we exhausted ourselves fruitlessly, for some time, in fathoming the loose snow with our poles. When the sad truth burst upon us, our feelings may perliaps be conceived, but cannot be expressed."-Such is Mr. Dornford's account of this calamitous adventure. The survivors did not pursue the attempt, but after every endeavour, although fruitless, to recover their lost companions, abandoned the enterprise, and returned to Chamounie.

Few years ever pass, in these elevated regions of desolation, without witnessing similar calamities, varying indeed in their local circumstances, but all partaking of one common character. But no disaster, how horrible soever in its nature, is sufficient to deter new adventurers from resorting to the same dangerous expedients, without any other stimulant to urge them to their enterprise, or reward them for their toil and danger, than what the gratification of curiosity can bestow. Many who escape the precipices and chasms in which others perish, lose their way, and are frozen to death with the cold; and among those who have the happiness to return unhurt, few have been able to boast that their recompense has been equal to their labour.

\section{ICE-HILL.}

This is a kind of structure common on the Neva at Petersburg, which affords a perpetual fund of amusement to the populace. They are constructed in the following manner. A scaffolding is raised upon the river, about thirty feet in height, with a landing-place at the top, the ascent to which is by a ladder. From the summit a sloping plain of boards, about four yards broad and thirty long, descends to the superficies of the river; it is supported by strong poles gradually decreasing in height, and its sides are defended by a parapet of planks. Upon these boards are laid square masses of ice, about four inches thick, which being first smoothed with the axe, and laid close to each other, are then sprinkled with water: by these means they coalesce, and, adhering to the boards, immediately form an inclined plain of pure ice., From the bottom of this plain the snow is cleared away for the length of two hundred yards, and the breadth of four, upon the level bed of the river; and the sides of this course, as well as the sides and top of the scaffolding, are ornamented with firs and pines. Each person being provided, with a sledge, mounts the ladder; and having attained the summit, he sets himself upon his sledge at the upper extremity of the inclined plain, down which he suffers it to glide with considerable rapidity, poising it as he goes down; when the velocity acquired by the descent, carries it more than one hundred yards above the level ice of the river. At the end of this course; there is usually a similar ice-hill, nearly parallel to the former, which begins where the other ends, so that he immediately mounts again, and in the same manner glides down the other inclined plain of ice. This diversion he repeats as often as he pleases. These ice-hills exhibit a pleasing appearance upon the river, from the trees with which they are ornamented, as well as from the moving objects which at particular times of the day are descending without intermission. 
\&c.

\section{NeCROMANCY.}

This is a superstitious and impious imposture; which appears to hase had its origin at a very early period in Egypt, and to have beels. thence propagated in every nation, with the manners of which history lias niade us acquainted. The conquests of Sesostris might have introduced it into India; the Israelites would naturally borrow it from the people among whom they sojourned four hundred years; and it would easily find its way into Phonicia, from the vicinity of that country to the land of its nativity. From the Egyptians and Phonicians it was adopted, with the other rites of paganism, by the Greeks; and it was imported into fome with Grecian literature and manners. It spread itself through all the modern nations of Europe, and took such deep root as to be long retained, even after those nations were converted to the Christian faith.

Of its early antiquity we have complete evidence in the writings of Moses, where it is severely condemied as abomination to the Lord: and though it appears to have spread even into Phœnicia, we may conclude its birth-place to have been Egypt, because, at their exodus, the Israelites were corrupted only by Egyptian superstitions, and because necroniancy was one of those whoredoms which Ezekiel says they brought with them from Egypt, and continued to practise till they were carried captives into Babylon. Profane authors not only affirm Egypt to have been the birth-place of necromancy, but in some degree account for the origin of so impious a delusion. From Diodorus the Sicilian we learn that the Grecian fables of Charon the ferryman of hell, of Styx, Cocytus, the Elysian fields, Tartarus, the judgment of Minos and Rliadamanthus; \&c. with the whole scenery of the inferior regions, were imported from Egypt into Greece. The ancient Egyptians, and indeed all the people of the East, made use of caves for burying-places, which were well suited to the solemu sadness of the surviving friends, and proper receptacles for those who were never more to behold the light. In Egypt, many of those subterraneous cavities being dug out of the natural rock, still remain, and command the admiration of travellers; and near to the pyramids, in particular, there are some apartments of a wonderful fabric, which though they extend in length four thousand four hundred feet, and are about thirty feet in depth, appear to have been, if not entirely dug, at least reduced to form, by the chisel or pickaxe.

Fron the practice of burying in such caverns, sprung the opinion of the infernal mansions; whence it was easy for the priests of Egypt 
to fabricate Erebus, Tartarus, the Elysian fields, and all those sceness which were displayed before the initiated, and by them described to the people. That the Israelites, notwithstanding the divine prohibition, continued to practise the art of necromancy, is apparent from Saul's transaction with the witch of Endor. From the same transaction it is likewise apparent, that the witches of Israel, and in all probability the necromancers of Egypt, pretended to raise the ghosts of the dead by a demon or familiar spirit, which they had at their command, to employ upon every emergency. This demon was called $O b$; and therefore Saul desires his servants to find him a woman who was mistress of an $\mathrm{Ob}$.

But though the Egyptian priests were undoubtedly the inventors of necromancy, and though it was from them imported into Greece by the Selli, or priests of Dodona, it does not appear that the Grecian necromancers pretended to be masters of Obs or familiar spirits. Mopsus, Orplieus, Linus, Eumolpus, \&c. who either travelled into Egypt in quest of linowledge, or were actually natives of that country, instructed the Greeks in this occult science; but whatever might be the practice of these apostles themselves, their disciples professed to do all the feats of magic by performing certain rites, by offering certain sacrifices, by muttering certain forms of words, by charms, spells, and exorcisms. By these they pretended to evocate the dead, as certainly as the Egyptians and Jews did by their faniliar spirits. The popular story of Orpheus and Eurydice was founded on one of those necromantic deceptions exhibited in a cave near Dodona, where the priests had a hades, or infernal mansion, in imitation of those with which some of them were well acquainted in Europe. Virgil makes one of his shepherds, by means of certain herbs, poisons, and senseless charms, raise up ghosts from the bottom of the graves; and Lucan, before the battle of Pharsalia, makes young Pompey travel by night to a Thessalian sorceress, and anxiously inquire of her the issue of the war. This female necromancer, by a tedious process of charms and incantations, conjures up the ghost of a soldier who had been lately slaiu. The phantom, after a long preamble, denounces a prediction much of the same kind with that which. Saul received from Samuel at Endor; and though nothing but the Spirit of God could have foreseen the inevitable destruction of Saul, his sons, and his army, it was very easy for a man of tolerable sagacity to foresee the defeat of Pompey's raw and undisciplined troops by the hardy veterans of the victorious Casar.

Not many years ago, some of the Highlanders relied implicitly unon certain oracular responses, called in their language Taglianin. This word seems to be compounded of $t a$, which in some parts of the Highlands is still used to denote a spirit or ghost, and ghanin, which signifies calling upon or invoking. Taghanin, therefore, in its original import, is necromancy, in the most proper sense of that word. There were very different kinds of taghanin, of which one was very lately practised in Skye. The diviner covered himself with a cow's hide, and repaired at night to some deep-sounding cave, whither the person who consulted him followed soon after, without any attendants. At the mouth of the cave he proposed, aloud, questions, of which he 
wanted solutions; and the man within pronounced the responses in ia tone of voice similar to that with which the Obs; or pretended demons of antiquity, gave from beneath the ground their oracular answers.

Another species, called Taglianin-an-uisge, or taglianing by water, was also practised in the isle of Skye, by a man named MCuidhean, whose ancestors had long been famous for the art. Helived near beattiful cascade on a small river, and when consulted on any matter of consequence, he covered his whole body with a cow's hide, and placed limseif between the water of the cascade and the rock over which it flowert. Then another man, with a heavy pole, gave repeated strokes to the water, the diviner behind it crying out now and then, in Gaelic, "Is this a stock of arn?" This operation was continued till M'Cuidhean was perceived to be frantic or furious, when he was considered as in a condition to answer the most important questions. He was frequently consulted about futurity; and though he could not, in the proper sense of the word, be called a necromancer, his responses were listened to as proceeding from something more than human. A degree of frenzy, either real or affected, seems to have accompanied the predictions of certain kinds of diviners in all ages, and we camm: help remarking the similarity between the madness of $\mathrm{M}^{\circ} \mathrm{Cu}$ idhern and that of the Sybil in the Feid, lib. vi. ver. 87-80. though we cannot suppose the former to have been borrowed from the latter. That all these pretences, whether ancient or modern, to the power of divination by means of familiar spirits, or by the art of necromancy, were groundless as well as impious, it is needless to offer any proof.

An exhibition was some time ago opened at the Lyceum in the Strand, London, which the proprietor denominated Phantasmagoria. With the common magic-lantern alone, varying the use of it by placing the spectators behind instead of before the screen, he imitated the imaginary forms of spectres, their unexpected appearance, their instantaneous vanishing, and all the other particulars, vulgarly said to belong to the department of ghosis, with the greatest success. His entertaining exhibitions demonstrated the simplicity of the means by which necromancers have achieved their most fearful exploits.

\section{$\wedge \mathrm{UGURY}$.}

AvGURY is the art of foretelling, presaging, or predicting, from observing the flight and actions of birds, or otherwise. Among the olf Romans, this art was distributed into five divisions. The first was from appearances in the heavens, as thunder and lightning, meteors, comets, \&c. Prosperous auguries of this kind were thunder on' lightning on the left, - because whatever comes to us from the skies on our left, is sent by the gods from their right. The Persians and the Greeks, on the contrary, looked on thunder from the right as favourable (Xen. Cyr. 111. ii. 353.) Again, fortunate signs were deduced by lightning shot from the east, and returning again, after a circuit of the sky, to the same quarter - a portent which is said to have occurred to the dictator Sylla; or if it struck the earth, and seened to rebound. 
Lightning in the day-time was attributed to Jupiter, in the night to Pluto; and such bolts only as Jupiter launched singly from himself, were esteemed fortunate in popular belief; those which were emitted during the sitting of a council of the gods, were: of ill omen, - but no rules are laid down, by which the difference between the two is to be determined. Thunder, with reports even in number, portended good fortune. Lightning from north to west was a forerunner of evil; so too was it, if accompanied with hail, or if it struck men or temples, or if it descended from a clear sky. Here again, on this last point, the Greeks thought differently. When Jove thundered to Ulysses from the cloudless serene sky, the hero, we are told, rejoiced in his heart. (Odyss. 103.)

The second division of Augury referred especially to the notes and the flights of birds. Such birds as gave augury by their chirping, were called oscines, (os, a mouth, cano, I sing,) such as the flying præpetes. The crow, the raven, and the owl, were anongst the former; the vulture among the latter: some, as the pye, belonged to both classes. Birds were also otherwise divided: 1st, Sinistra, which permitted an attempt to be made; but the oscines on the left, it is said, were always favourable; (Alex. Ab. Alex. v. 13.); though we know not how to reconcile this belief to the crow of Melibæus, (Virg. Ec. 1.) unless by remarking, once for all, that the whole art of augury appears to have been a juggle, and a mass of uncertainty and contradiction. 2nd, Funebres, ill-omened, which were called also arcula, arceo, I drive away ; clivia, clivus, a difficulty ; remoræ, remoror, I delay ; incbra, inhibeo, I stop; altera, if they interfered with a former good one; and volsgra, vello, I pluck, if by plucking their own feathers they portend ill.

An eagle from the right, particularly if it fiew with outstretched and changing wings, betokened prosperity. Homer in this agreed with the Romans. When Priam set forward to entreat Achilles for the body of Hector, this was the very omen for which, by the advice of Hecuba, he besonght Jupiter. An eagle on the right, uttering its note while sitting, was pronounced by an Ephesian augur to appertain to the fortunes of a man who should fill a public office, since it was a bird of command; the office was to be attended with danger, since other birds attack a sitting eagle; and it was not to be lucrative, since an eagle collected its prey while on the wing. The fate of Xenophon verified these predictions. (Anal. v. 9.) The eagle which took off the cap of the elder Tarquin, and placed it again on his head, portended to him his future sovereignty; while the young brood which was driven from its focd by vultures, and torn in pieces with its eyrie, equally foretold, to his proud descendant, his exile and dethronement. Before the abdication of the Syracusan Dionysius, it is said that an eagle had snatched a javelin from the hands of one of his body guards, and after bearing it aloft had dropped into the sea. Claudius and Vitellius each drew encouragement from an eagle; and a victory which Domitian had won over Antony, his rebellious lieutenant of Upper Germany, though the field of battle was 2500 miles distant, was announced at Rome, on the very day of the triumph itself, by an eagle which alighted on the conqueror's statue, and uttered cries of 
joy;-nay, some spectators, of warmer imagination, believed that the head of the traitor had been borne in the talons of this auspicisus bird. (Suet. Dom. 6.)

A concourse of crows, vultures, and eagles, hovered above the troops of Brutus and Cassius, as they took post at Philippi, (Dion. xlvii.) and the same birds spake a note of fearful preparation to Lepidus, by thronging the temples of the genius of Rorne and of Concord. Cranes, if they are diverted from their flight, and turned backward, had already snuffed the storm, and were a sign of wo to mariners. (Georg. i. $Z E n$. x.) The stork is believed by the commentaturs to have been an omen of concord; but the belief, perhaps, is founded on misapprehension of a passage in Juvenal. The falconsgentle, as the gamesters of the hood-and-bell would term it, betoken marriage and rich pastures. It was cited by the soothsayer Theoclymenus, as favourable to Telemachus, (Od. 525.) and the bard finds no better omen to which he can liken his hero, when he is rusliing to the destruction of Hector. (Il. x. 139.) A falcon too, (capis, in the Tuscan language,) gave its name to Capua. The pie, the nightingale, and the heron were prosperous if they flew towards each pole; but as Pliny (ii. 7.) confidently believed that the heron had but one eve, perhaps he was no better informed upon its celestial than upon its physical habits. Swallows were the precursors of misfortune; they sat on the tent of Pyrrhus, and on the mast of Antony. When the Syrian Antiochus was about to join battle with the Parthians, he disregarded the admonition of a swallow's nest in his pavilion, and paid for his incredulity, or tis carelessness, with no less than his life. The dove in company, was longed for; when single, it was despised. Sailors loved the swan, but she was naught to landmen. The evening crow of the cock struck joy into the ears of the listener; but evil were his stars who heard the hen attempt to emulate her mate. Of all birds the owl was the most hateful, if it screeched; not so, if it was merely seen.

Augury by the feeding of chickens, was the third division of the art. The pullarius, or feeder, had the charge of the cavea or coop. At the earliest break of dawn, the strictest silence being preserved, be threw grain to the birds. If they did not hurry from the coop, or if coming out they disregarded their food, or carelessly picked and scattered it, or cowered with their wings, or crowed and passed by it, the omen was of infinite terror; on the contrary, an eager haste to devour the grain, especially if from greediness it fell from their beaks and rebounded from the ground, making what was called the tripudium solis timum, terram vel solum pavire, i. e. ferire, shewed the especial favour of heaven. The profane jest of Publius Claudius, who drowned his chickens which refused to eat, bidding them at least to drink their fill, and his subsequent destruction, is recorded by Valerius Maximus, (i. 4.) and by Cicero, (Nat. Deor. ii. 3.) as a warning to all unbelieving generals. Any deceit practised by the pullarius reverted to his own head. Of this we have a memorable instance in the great battle between Papirius Cursor and the Samnites, in the year of Rome 459. So anxious were the troops for battle, that the pullarius dared to annourice to the consul a tripudium solis timum, although the chiekens refused to eat. Papirius unhesitatingly gave 
the signal for fight, when his son having discovered the false augury, lastened to communicate it to his father. "Do thy part well," was the reply, "and let the deceit of the augur fall on hinself. The tripudium has been announced to me, and no omen can be better for the Roman army and people!" As the troops advanced, a javelin, thrown at random, struck the pullarius dead. "The hand of heaven is in the battle," cried Papirius, " the guilty is punished!" and he advanced and conquered.

There were many signs to be derived from animais which came under the fourth division of Augury. A wolf running to the right with his mouth full, was an argument of great joy: Plut, viii. 22. A wolf in the capitol was an ill portent, and occasioned its lustration, Liv. iii. 29. The defeat of the Romans at the Ticinus was prognosticated by the entrance of a wolf into their camp, and his escape unhurt, after wounding his pursuers: Liv. xxi. 46. and still greater calamities of the second Punic war were announced, when a more daring animal of the sane breed carried away the sword of a centinel in Gaul: Id.62. A wolf once put a stop to a plan of colonization in Libya, by hungrily devouring the land-marks which had been assigned for the new settlement, (Plut. in Vita C. Gracchi,) but, to make amends for this act, on another occasion, by running away with a burnt sacrifice from the altar, an animal of the sane kind led his Samnite pursuers to the spot afterwards occupied, in commenoration of the chase, by the Hirpini, Festus, ix. A wolf running away with his slate, (tabula,) from Hiero, when a school-boy, was thought to pottend his future greatness.

Swarms of bees, if observed on any public place, as the forum of a temple, were carefully noted, and the ill omen which they were supposed to bring was averted with all diligence by repeated sacrifices. Scipio's tent was polluted by then before the battle of Ticinus. The speaking of oxen, an occurrence, (if we credit Livy, hy no means uncommon,) for he has recorded it eight or nine times, betokened some negligence towards the state, and demanded copious expiation. Now and then a cow dropped a foal instead of a calf, or ran up stairs into the second or third story of a house. Both of these acts were great sources of constemation. Locusts were formidable, not only from the natural devastation which they produced, but from the supernatural vengeance which they threatened. Even the nibbling of mice was not to be disregarded; and it was not only to the divine epics of the starving garreteer, (Juv. iii.) that the teeth of these little marauders were addressed; they sometimes looked for higher game, and indented the golden crown of the 'Thunderer himself: Liv. xxvii. '23. xxx. 2 . nay, their inauspicious squeak deprived Fabius Maximus of his dictatorship: Val. Max. i. He whose path, in stepping from his thresho!d, was crossed by a hare, or a pregnant fox, or a bitch, or a snake, or a weasel, would do well to refurn home; but if he were fortunate enongh to encounter a she-goat, let him proceed with a merry heart, and think upon Caranus: Justin, vii.

The fifth and last division of Augury had respect to Dire, a word which scarcely admits of a close translation, and which we must be content to render, vaguely, prodigies. Of these, livy will fumish the 
inquisitive with abundance. He may reac of lambs with pigs' heads, and pigs with human faces, (xxvii. 4.) a wonder which in our own time has been reversed; of weeping images, and bleeding springs, of perspiring gods, and triple-headed donkeys; of armed men and fleets in the skies; of showers of blood, or stones, or flesh, or milk, or chalk; of the mutual tranformation of cocks into hens, and hens into cocks; of the shouts of unborn infants foretelling victory from the womb; of double moons, and triple suns; of burning seas, and fish turned up by the. ploughshare; of hermaphrodites ; of children eyeless, noseless, single-. handed, or elephant-headed; of flying stones and sweating shields; of gore-dropping wheat-sheafs; of iuundations, storms, earthquakes, and eclipses. Each and all of these had its peculiar expiation, procuratio, and the skilful augur would forebode to a nicety what each portended.

A sneeze in the morning was ill-omened, and interrupted all the business of the day. At noon it was fortunate, and if it occurred: after dinner, a dish must be brought back and tasted, to avert misfortune, which otherwise was certain. The sneeze of Tolenachus was grateful to the ears of Penelope, and Xenophon owed his commission to a similar opportune interruption in one of his speeches. The sneeze of Cupid approved the love of Acme and Septimius; (Catullus, 42.) and it was only to Hippias, who lost both his native land his grinders, that a classical sneeze had been esteemed unlucky: Herod. vi. Flaminius fell from his loorse as he approached the banks of Thrasimenus. Augustus put on his left sandal awry on the very morning in which he nearly lost his life by a mutiny. Pompey accidentally threw a black cloak over his soldiers on the day of Pharsalia. Nero gave up his expedition to Alexandria, because his robe caught in the seat as he rose to set out. Caius Gracchus stumbled at his threshold on the morining in which he perished; and the son of Crassus, when he took the field against the Parthians, lost a toe by a similar accident.

These are some among the prophetical signs to which the attention of the Augur was directed. Many may be found in the course of classical reading; and all, we may assert without constradiction, of equal importance, and not less assured certainty.

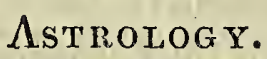

PTolemy, one of the greatest professors of the art of Astrology, who flourished in the reign of Adrian, gives the following definition of it. "It teaches the motions, configurations, and influences of the signs, stars, and celestial planets, to prognostieate of the natural effects and mutations, and their inferior and elementary bodies:" Quadripartite, i. In this earliest sense of the word, Astrology and Astronomy are the same; latterly, they were widely separated; Astrology being divided in to two parts, natural and judicial: by the first, sundry operations of nature, as changes of the weather, \&c. were predicted; by the second, moral events, and the destinies of nations and individuals, were just as confidently foretold.

The cultivators of judicial astrology boasted much of its antiquity. Adam, they said, received it directly from God, and by it foreknowing that the earth was twice to be destroyed, once by fire and once 
by water, and desirous to communicate this information to his pos. terity, he engraved characters declaratory of it upon two pillars, the one of brick, the other of stone. The brick pillar was destroyed by the flood; the pillar of stone, as Josephus relates, was still existing in his days in Syria. Seth learned this art from Adam; and he, as well as Abel, Cain, Enoch, Noah, and Nimrod, were all expert astrologers; the lives of the antediluvian patriarchs having been prolonged to a duration of many hundred years, purposely in order that they might have time to bring their knowledge of astrology to perfection. Abraham, in his migration from Chaldæa, brought the art with him into Egypt, and hence it flowed first to the Greeks, and afterwards to the Latins; although the Ethiopians, the Carians, the Magi, and the Arabs, all claim the merit of its propagation.

In imperial Rome, astrology was held in great repute, especially under the reign of Tiberius. "Do you wish," says Juvenal, in his sublimest Satire,

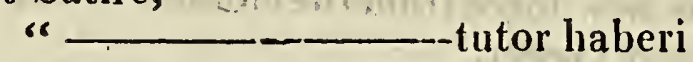

Principis angusta Caprearum in rupe sedentıs

Cum grege Chaldæo?"

It was from Thrasyllus, the origin of whose influence over his master is so finely related by Tacitus, (Annales, vii. 21.) that Tiberius acquired the knowledge which enabled him to foretell to Galba, when he was only consul, "Thou too, Galba, shalt some day taste the sweets of empire ;" thus alluding to his late and brief possession of sovereignty. When Claudius was dying from the effects of Locusta's poison, Agrippina cautiously dissembled his progressive illness; nor would she announce his decease till the very moment arrived which the astrologers had pronounced for the accession of Nero, although the ambitious mother had been warned from the same source, that her own death would be the consequence of her son's enthronement. "If he reigns," said the Chaldreans, "he shall kill his mother." "Let him kill me," was the reply, "so that he but reigns."

Augustus had discouraged this empty science, by banishing astrologers from Rome, but the favour of his successors recalled them; and though occasional edicts, in subsequent reigns, restrained, and even punished, all who divined by the stars-and though Vitellius and Domitian revived the edict of Augustus - the practices of the astrologers were secretly encouraged, and their predictions extensively believed. Domitian himself, in spite of his hostility, trembled at their denouncements. They prophesied the year, the hour, and the manner of his death; and agreed with his father in foretelling that he should perish, not by poison, but by the dagger. On the evening of his assassination he spoke of the entrance of the moon into Aquarius on the morrow. "Aquarius," said he, "shall no longer be a watery, but a bloody sign: for a deed shall there be done, which shall be the talk of all mankind." The dreaded hour of eleven approached ; his atterdants told him it was passed; and he admitted the conspirators, and fell: Suet. in Dom. 16.

Adrian was by turns a believer in, and a persecutor of, astrology. He is said to have kept an astrological diary, and to have prognosticated his own death with correctness; and in his days, and those of 
Marcus Antoninus, the art received great accessions fiom Pulumy, Uuder Gordian, Censorinus wrote his tract De Die Natali, which, though treatiug manily on astrology, is valuable for much collateral information afforded by it. Vossius is perhaps a partial witness, for hé himself was a philomath. "It is a little book of gold," he says in one place, (De Scient. Math. 34.): and in another, "It is a most learned work, and of the highest use and importance to chronologers, since it corrects, and deternines with great exactuess, some principal aras in pagan history."

In the eighth century, the venerable Bede and his distinguished scholar Alcuin, are said to have pursued this mystic study; in that immediately following, the Arabians revived and encouraged it; and under the patronage of Alcuainam, the Miramolin, in the year $82 \%$. Ptolemy's work was translated, under the title of Almagest, by Al Hazen ben Yusseph. Albumasar added, to this work, and the astral science continued to receive new force from the labours of Alpagarius, Ebemozophin, Alfaragius, and Geber.

The wise Alonzo of Castile has immortalized himself by his scien. tific researches'; and the Jewish and Christian doctor's, who arranged the tables which pass under his name, were convened from all the accessible parts of civilized Europe. Five years were employed in their discussion : and it has been said, that the enormous sum of 400,000 ducats was disbursed in the taverns of the alcazar of Galiana, in the adjustment and correction of Ptolemy's calculations. "Nor was it only the physical motions of the stars which occupied this grave assembly. The two cabalistic volumes, yet existing in cipher in the royal library of the king of Spain, and which tradition assigns to the hand of Alonzo himself, betoken a more visionary study; and in spite of the denunciations against his orthodoxy, which were thundered in his ears on the authority of Tertullian, Basil, and Bonaventure, the fearless monarch gave his sanction to such masters as practised truly the art of divination by the stars; and in one part of his code, enrolled astrology among the seven liberal sciences.

of the early progress of astrology in England; little is known. Bede and Alcuin we have already mentioned as addicted to this study. Roger Bacon could scarcely escape either the coutagion of the art, or the imputation of it, if in trath he was incredulous; and his imprisonment was owing to one or the other of these causes. It was the period of the Stuarts, which must be considered as the acmé of astrology among us: then Lilly drank the doctrine of the magical circle, and the invocation of spirits, from the Ars Notoria of Cornelius Agrippa, and used the form of prayer prescribed therein to the angel Salmonæus, and entertained among his familiar acquaintance the guardian spirits of England, Salinael and Malchidael: Merlin Anglicus, 164\%. His ill success with the divining rod induced him to surrender the pursuit of rhabdomancy, in which he first engaged; though he still persevered in asserting, and the assertion is not among the lowest proofs of his shrewdness, that the operation demanded secrecy, and intelligence of the agents, and, above all, a strong faith, and a competent knowledge of their work. - The Dean of Westminster had given him permission to search for treasure in the cloister of the 
abbey in the dead of the night. On the western side the rods turned over each other with inconceivable rapidity; yet, on digging, nothing but a coffin could be discovered. The man of art retired to the abbey, and then a storm arose which nearly destroyed the west end of the-church, extinguished all the candles but one, and this burned dimly, and made the rods immoveable. Lilly succeeded at length in charming away the demon, but no persuasion could induce him to make another experiment in that species of divination.

His first tutor, Evans, a debauched Welsh parson, had already initiated him in his astrology, and, after seven or eight weeks' study, he had been able to set a figure perfectly. Of this he had given a public specimen, by intimating that the king had chosein an unlucky horoscope for his coronation in Scotland in 1633. The library of a second Evans, who far exceeded the first, having accidentally come in to the possession of our astral tyro, determined his future leading study; and henceforth he became a professed astrologer.

Few disciples of Sidrophel have done more than Lilly to establish the justice of the hard words which the learned knight and physician, Sir Christopher Heydon, who flourished nearly at the same time, has oljected so much to, as used by his antagonist Mr. Chambers. Mr. Chambers says " all astrologers are damned, that they are worse than witches, waggling wits, giddy pates, juggling jacks, coggling figure flingers, paltry ignorant wizards, stable-keepers of Augeas, foul dungheaps, Babylonical jumblers, Balaam's asses, sons of ditch-drabs, and confederates of the Devil." He adds, with equal mildness, that "their mother was a Hittite, that the magistrate who-refuses to expel them is worse than an infidel, and that those are happy who shall bruise their bones and limbs against the stones." Lilly, it was clear, deserved as much of these reproaches as will fairly attach to one who has been well described as " a man who, by dint of plain, persevering, consistent, unblushing roguery, acquired a decent reputation, convinced himself that he was honest, put money into his pocket, and in due time was comfortably buried under a nice black marble stone, inscribed with a record of deceased virtue in English and Latin." His roguery consisted in maintaining the triple character of impostor, thief, and pimp. His reputation arose from prophesying alternately on the side of the king and the parliament, as the scale of each inclined. His money was made by interested marriages; by pensions for furnishing the existing government with artful intelligence; by presents, and by pupils. His first wife left him 1,000l. for six years conjugal service. His second wife brought him $500 \mathrm{l}$. but she was extravagant, and spent more than her portion. The parliament gave him occasional donations, and a pension of 100l. a year. The king of Sweden sent him a gold chain and medal worth fifty pounds, for the honourable mention which was made of his majesty in the Almanack for the year $165 \%$, and 1658 ; and after having lectured publicly on astrology for a few years, we find him expending nearly 40001 . in the purchase of estates. His funeral achievements were arranged by his sage admirer, Elias Ashmole, who procured a Latin and English elegy on his death, from the afterwards well-known bishop of Smalridge, at that timc a scholar of Westminster school. 
A single anecdote will amply illustrate Lilly's character. In his Almanack for 1653 , he asserted that the parliament stood on a tisklish foundation, and that the commonality and soldiery would join together against it. For this he was called upon by the House. Before his appearance, however, he contrived to have six copies of the Almanack printed, in which the offensive passages were omitted. These he produced from his pocket at the bar ; contending that they only were genuine, and that the others were surreptitiously circulated under his name by some enemy who sought to ruin him.

Lilly has furnished us with the portrait of some of his contemporary fellow students. Forman, Bredan, Bubb, Hart, and Pool. The first is notorious for his connexion with the detestable countess of Essex. The second, who was a clergyman, was distinguished for his love of tobacco and strong drink; insomuch, that "when he had no tobacco, he would cut up the bell-ropes and smoke them. The third was pilloried for certain knavish practices in the "conynge" art. The fourth escaped the same punishment by running away; and the fift avoided the elevation of the gallows for theft, by absconding in time. Yet these were the sort of men at whose annual festival the learned Ashmole condescended to officiate as steward. A few years before his death, Lilly adopted Henry Coley, a tailor, as his successor; this worthy had been his amanuensis, and traded in prophecy with success almost equal to that of his master.

At the revolution, astrology declined, and notwithstanding the lahours of the immortal Partridge then, and those of Ebenezer Sibley, which in our own days fill two quarto volumes, the art may now be considered as exploded. The gradual march of knowledge and civilization has every where, unless in the East, tended to extinguish this among other superstitions, by which the blind anxiety of men sought to penetrate futurity. There are few believers left arnong us, even in the more admissible solar and lunar influences; and as for the connexion of destiny with the stars, most even of the purchasers of Moore's almanacks would, if pressed hard, be ready to admit the justice of Cardinal Mazarine's dying remark. When that minister lay on his death-bed, a comet happened to appear; and there were not wanting flatterers to insinuate that it was in reference to his approaching end. He, answered with a manly pleasantry, "Messieurs, la comiète me fait trop d'honour."

A belief in judicial astrology can now only exist in the people who may be said to have no belief at all; for mere traditional sentiments can hardly be said to amount to a belief. But a faith in this ridiculous system in our own country is of late existence; it was a favourite superstition with the learned, and whenever an idea germinates in a learned head, it slioots with additional luxuriance.

When Charles the First was confined, Lilly the astrologer was consulted for the hour which would favour his escape.

The most respectable characters of the age, Sir William Dugdale, Elias Ashmole, Dr. Grew, and others, were members of an astrological club. Congreve's character of Foresight, in Love for Love, was then no uncommon person, though the humour now is scarcely intelligible. Dryden cast the nativities of his sons. 
It has been reponted of several famous for their astrologic skill, that they lave suffered a voluntary death, merely to verfy their own predictions; this has been said of Cardan, and of Burton the author of the Anatomy of Melancholy.

It is curious to observe the shifts to which astrologers are put when their predictions are not verified. Great winds were predicted by a famou's adept, about the year 1586. No unusual storms, however, happened. Bodin, to save the reputation of the art, applied it as a figure to some revolutions in the state; and of which there were instances enough at that moment. Among their lucky and unlucky days, astrologers pretend to give those of various illustrious persons and of families. One is very striking. - Thursday was the unlucky day of our Henry the Eighth. He, his son Edward the Sixth, queen Mary, and queen Elizabeth, all died on a Thursday.

The life of Lilly the astrologer, written by himself, is a curious wo:k. He is the Sidrophel of Butler in his Hudibras:

Astrology greatly flourished in the time of the civil wars. The royalists and the rebels had their astrologers, as well as their soldiers, and the predictions of the former had a great influence over the latter.

In 1670 the passion for horoscopes, and expounding the stars, prevailed in France among the first rank. The new-born child was usually presented naked to the astrologer, who read in its forehead, and the transverse lines in its hand, and thence wrote down its future destiny. Catherine de Medicis brought Henry the Fourth, then a child, to old Nostradamus, whom antiquaries esteem more for his Chronicle of Provence, than his vaticinating powers. The sight of the reverend seer, with a beard which "streamed like a meteor in the air," is said to have terrified the future hero. - Will it be credited, that one of these magicians having assured Charles the Ninth that he would live as many days as he could turn about upon his heels in an hour standing upon one leg, that his majesty every morning performed that solemn exercise for an hour? the principal officers of the court, the judges, the chancellors, and generals likewise, in compliment, standing on one leg, and turning round!

\section{WitCHCRAFT.}

THIs was a supernatural power, which persons were formally supposed to obtain the possession of, by entering into compact with the devil. They gave themselves up to him, body and soul; and he engaged that they should want for nothing, and that he would avenge them upon all their enemies. As soon as the bargain was concluded, the devil delivered to the witch an imp, or familiar spirit, to be ready at a call, and to do whatever it was directed. By the assistance of this imp of the devil, the witch, who was almost always an old woman, was enabled to transport herself in the air on a broomstick or a spit to distant places, to attend the meeting of the witches, at which the devil always presided. They were enabled also to transform themselves into various shapes, particularly to assume the form of cats and hares, in which they most delighted; to inflict diseases 
on whomsnever they thought proper; and to punish their enemies in a variety of ways.

The belief that certain persons were endowed with supernatural power, and that they were assisted by invisible spirits, is very ancient. The sages of the Romans seem rather to have been sorcerers than witches; indeed, the idea of a witch, as above described, could not have been prevalent till after the propagation of Christianity, as the heathens had no knowledge of the evil spirit, styled by Christians the devil. Witchcraft was universally believed in Europe till the sixteenth century, and even maintained its gronnd with tolerable firmness till the middle of the seventeenth. Vast numbers of reputed witches were convicted, and condemned to be burnt, every year. The methods of discovering them were various. One was, to weigh the supposed criminal against the church bible, which, if she was guilty, would preponderate; another, by making her attemut to say the Lord's prayerthis no witch was able to repeat entirely, but would omit some part or sentence thereof. It is remarkable, that all witclies did not hesitate at the same place; some leaving out one part, and some another. Teats, through which the imps sucked, were indubitable marks of a witch; these were always raw, and also insensible, and, if squeezed, sometimes yielded a drop of blood. A witch could not weep more than three tears, and that only out of the left eye. This want of tears was, by the witch-finders, and even by some judges, considered as a very substantial proof of guilt. Swinming a witclu, was another kind of popular ordeal generally practised; for this she was stripped naked, and cross bound, the right thumb to the left toe, and the left thumb to the right toe. Thus prepared, she was thrown into a pond or river, in which, if guilty, she could not sink; for having, by her compact with the devil, rebounced the benefit of the water of baptism, that element, in its refurn, renounced her, and refused to receive her into its bosom. Sir Robert Filmer mentions two others, by fire: the first, by burning the thatch of the house of the suspected witch; the other, burning any animal supposed to be bewitched by her, as a ling or ox: these, it was lield, would force a witch to confess. The trial by a stool, was another method used for the discovery of witches. It was thus managed. Having taken the suspected witch, she was placed in the middle of a room upon a stool or table, cross-legged, or in some uncasy posture, to which if she submitted not, she was then bound with cords; there she was watched, and kept without meat or sleep for the space of twenty-four hours, for they said, within that time they should see her imp come and suck. A little hole was likewise made in the door, for imps to come in at; and lest it should come in some less discernible shape, they that watched were taught to be ever and anon sweeping the room, and, if they saw any spiders or flies, to kill them ; if they could not kill them, then they might be sure they were imps.: If witches, under any examination or torture, would not confess, all their apparel was changed, and every hair of their body shaven off with a sharp razor, lest they should secrete magical charms to prevent their confessing. Witches were most apt to confess on Fridays. Py such trials as these, and by the accusation of children, old women, and fools, were thousands of unhappy women 
condemned for witchcraft, and burnt at the stake. It wauld be ridiculous to attempt a serious refutation of the existence of witches, and at present, luckily, the task is unnecessary. In this country, at least, the discouragement long given to all suspicion of witchcraft, and the repeal of the statutes against that crime, have very much weakened, though perhaps they have not entirely eradicated, the persuasion. On the continent, too, it is evidently on the decline; and notwithstanding the exertions of Dr. De Haen, and of the celebrated Lavater, we have little doubt that in a short time posterity will wonder at the credulity of their ancestors.

That there ever were witches, is an opinion that cannot for a mo. ment be believed by a thinking man. The actions imputed to then were either absurd or impossible; the witnesses, by whose evidence they were condemned, being either weak enthusiasts or downright villains; and the confessions ascribed to the witches themselves, the effects of a disordered imagination, procured by cruel treatment and excessive watchings. As to the nightly meetings, demonologists themselves have been obliged to confess that they were nothing else but uneasy dreams, often produced by soporific compositions. The facts which have been brought forward by the advocates for witchcraft bear in their front the most evident marks of trick and imposture; and this has constantly been found out, whenever these facts have been properly examined. The crime of witcheraft, which was punished capitally by the law of Moses, was justly punished under the Jewish Theocracy, as an act of rebellion against the Divine Majesty, in attempting to deceive the people by leading them to trust in demons and other imaginary beings.

\section{Sorcery, or Magic.}

THIs is the power which some persons were formerly supposed to possess, of commanding the devil and the infernal spirits, by skill in charms and invocations, and of soothing them by fumigation. Sorcery is therefore to be distinguished from witchcraft, it being an art which was supposed to be practised, not only by commanding evil spirits, but by compact with the devil. As an instance of the power of bad smells over demons or evil spirits, we may mention the flight of the evil spirit mentioned in Tobit, into the remote parts of Egypt, produced, it is said, by the smell of the burnt liver of a fish. Lilly informs us, that one Evans, having raised a spirit at the request of Lord Bothwell and Sir Kenelm Digby, and forgetting a fumigation, the spirit, vexed at the disappointment, pulled him without the circle, and carried him from his house in the Minories, into a field near Battersea Causeway. King James, in his Demonologia, has given a very full account of the art of sorcery.

"Two principal things (says he) cannot well in that errand be wanted; holy water, and some present of a living thing unto him. These things being all prepared, circles are made, triangular, quadrangular, round, double, or single, according to the form of the apparition they crave. When the conjured spirit appears, which will not be until after many ceremonies, Lord's prayers, and much muttering and inur- 
murings of the conjurors, if they have missed one jote of all their rites, or if any of their feet slyde over the circle, through terror of his fearful apparition, he paies himself at that time, of that due debt which they owed him, and otherwise would have delaied longer to have paied him. I mean, he carries them with him, body and soule."

How the conjurors made triangular or quadrangular circles, his majesty has not informed us, nor does he seem to imagine there was any difficulty in the matter. We therefore suppose that he learned his mathematics from the same system as Dr. Scheverell; who, in one of his sermons, made use of the following simile: "They concur like parallel lines, meeting in one common centre."

Another mode of consulting spirits was by the beryl, by means of a speculator or seer: who, to have a complete sight, ought to be a pure virgin, a youth who had not known woman, of at least a person of irreproachable life and purity of manners. The method of consultation is this: The conjuror having repeated the necessary charms and adjurations, with the litany or invocation peculiar to the spirits or angels he wishes to call, (for every one has his particular form, ) the seer looks into a crystal or beryl, wherein he will see the answer represented either by types or figures; and sometimes, though very rarely, will hear the angels or spirits speak articulately. Their pronunciation is, as Lilly says, like the Irish, much in the throat. Lilly describes one of these beryls or crystals. It was, he says, as large as an orange, set in silver, with a cross at the top, and round about engraved the names of the angels Raphael, Gabriel, and Uriel. A delineation of another is engraved in the frontispiece to Aubery's Miscellanies.

The sorcerers or magicians do not always employ their art to do mischief; but, on the contrary, frequently exert it to cure diseases inflicted by witches; to discover thieves; recover stolen goods; to foretell future events, and the state of absent friends. On this account they are frequently called white witches, Our ancestors had great faith in these fables, when they enacted, by stat. 33 Hen. VIII. c. 8. all witchcraft and sorcery to be felony without benefit of clergy; and again by statute 1 Jac. I. c. 12. that all persons invoking an evil spirit, or consulting, covenanting with, entertaining, employing, feeding, or rewarding, any evil spirit, or taking up dead bodies from their graves to be used in any witchcraft, sorcery, charms, or enchantment; or killing, or otherwise hurting, any person by such infernal arts; should be guilty of felony without benefit of clergy, and suffer death; and if any person should attempt by sorcery to discover hidden treasure, or to restore stolen goods, or to provoke unlawful love, or to hurt any man or beast, though the same were not effected, he or she should suffer imprisonment and pillory for the first offence, and death for the second. These acts continued long in force, to the terror of all ancient females in the kingdom; and many poor wretches were sacrificed thereby to the prejudice of their neighbours and their own illusions, not a few having by some means or other confessed the incredible facts at the gallows; but all executions for this dubious crime are now abolished. It is enacted by stat. 9 Geo. II. c. 5. that 
no prosecution shall for the furture be carried on against any person for conjuration, witcheraft, sorcery, or enchantmeut. But the misdemeanor of persuns pretending to use witcheraft, tell fortunes, or discover stolen goods, by skiil in the occult sciences, is still deservedly punished with a year's imprisonment, and standing four times in the pillory.

\section{Amulets.}

IN the customs of almost all the nations of antiquity, amulets were favourite and sometimes very important, instruments of superstition and empiricism. They were most frequently suspended from the neck, and contained the name or exploits of some deity, whose protection they were supposed to ensure, and of whose service they were the token or badge. They were formed of all sorts of materials, though precious stones were naturally preferred, and thus they often adjed to the elegance of dress, what was meant for the safety of the person. In their formation, or their being made into amulets, particular times were imagined to be very propitious, especially afier the reveries of the astrologers succeeded the early discoveries of astronomy. Various herbs and plants, gathered at these times, of which the full age of the moon was considered one of the most important, were presented as sovereign remedies for many fatal disorders, the bite of venomous reptiles, \&c. The Egyptians had a great variety of them, of which the most popular was the Abraxas, a Cabalistic word engraven on a stone, to which it gave name. The Jews had an early propensity to using them for similar purposes. (Compare-Deut. xviii. 10-12, with Jer. viii. 17. In later times the Mishna allowed an amulet to be worn, which had previously been three times successful in the cure of any disease.

The Chaldeans, Persians, and oriental nations, also held them in the highest estimation. Amongst the Greeks, parts of animals, minerals, and herbs, were used as amulets, especially in exciting and conquering the passion of love; and Pliny mentions many that were in use among the Romans. Ovid speaks of Mount Caucasus as celebrated for yielding the necessary plants,

\section{Lecta Promotheis dividit herba jugis,}

supposed to spring from the blood of Prometheus; and Colchis is mentioned by other poets as noted for similar productions. Amulets were also sometimes appended to the bodies of beasts, for medical and other purposes. They are still commonly worn in the East, and among the Turks, with whom magical words, numbers, and figures, sentences of the koran, prayers, \&c. inscribed on scrolls of paper or silk, are in great request in time of war.

Christianity, in the decline of the Romall empire, supplied numerous amulets to her nominal converts from Paganism, in crosses, agnus dei's, relics of the saints and martyrs, \&c. The pope is said still to claim a prerogative of creating them. Their connexion with ancient British customs is also important. Burton, prescribing some, 
while he deprecates the use of others, as cures for melancholy. - "I say with Renodeus, they are not altogetler to be rejected;" he adds"Peony doth cure epilepsie; pretious stones most diseases ; wolf's dung borne with one, helps the collic; a spider, an ague," \&c. The celebrated Mr. Bayle mentions the application of some amulets, as a proof of the poiver of external effluvia over the corporeal system; and states the fact of having cured himself of a tendency to bleeding at the nose by the application of moss from a dead man's skull. Several physicians have noticed similar phenomena; and it is well known, from the wearing of camphor and other substances, that the efluvia of various bodies is very powerful in preventing contagion. It may be some assistance to the readers of our. early poets, to subjoin a curious exiract from the scarce work of Regnald Scot, On the Discoverie of Witchcraft, with respect to what was then thought to be the specitic virtues of certain stones, worn as amulets in the "olden time."

"An agat," they saie, "hath virtue against the biting scorpions or serpents. It is written, but I will not stand to it, that it maketh eloquent, and procureth favour from princes; yea, that the fume thereof doth turn awaie tempests. Alectorius is a stone about the bigness of a bean, as clear as the christall, taken out of a cock's bellie, which has been gelt or made a capon foure years. If it be held in one's mouth, it assuageth thirst; it maketh the husband to love the wife, and the bearer invincible. Chelidonius is a stone taken out of a swallowe, which cureth melancholie, howbeit, some authors saie it is the herbe whereby the swallowes recover the sight of their young, even if their eies be picked out with an instrument. Garanites is taken out of a crane, and Draconites out of a dragon. But it is to be noted, that such stones must be taken out of the bellies of the serpents, beasts, or birds, wherein they are, while they live; otherwise, they vanish awaie with the life, and so they reteine not the virtues of those starres under which they are. Amethysus maketh a drunken man sober, and refresheth the wit. The coral preserves such as bear it from fascination or bewitching, and in this respect they are hanged about children's necks. But from whence that superstition is derived, and who invented the lie, I know not; but I see how redie people are to give credit therento, by the multitude of corals that waie employed. Heliotropius stancheth blood, driveth awaie poisons, preserveth health; yea, and some write that it provoketh raine, and darkeneth the sunne, suffering not him that beareth it to be abused. Hyacinthus doeth all that the other doeth, and also preserveth from lightening. Dinothera, hanged about the necke, collar, or yoke of any creature, tameth it presentlie. A topase healeth the lunatike person of his passion of lunacie. Aitites, if it be shaken, soundeth as if there were a little stone in the bellie thereof; it is good for the falling sicknesse, and to prevent untimelie birth. Chalcedonius maketh the bearer luckie in lawe, quickeneth the power of the bodie, and is of force also against the illusions of the divell, and phantastical cogitations arising of melancholie. Carneolus mitigateth the heat of the mind, and qualifieth malice; it also stancheth bloodie fluxes. Iris helpeth a woman to speedie deliverance, and maketh rainebows to appeare. $\AA$ 
sapphire helpeth agues and gowts, and suffereth not the bearer to be afraid; it hath virtue against venom, and staieth bleeding at the nose, being often put thereto. A smaragdine is good for the eye-sight, and maketh one rich and eloquent. Mephis, as Aaron and Hermes report out of Albertus Magnus, being broken into powder, and drank with water, maketh insensibilitie of torture. Heereby you may understand, that as God hath bestowed upon these stones, and such other like bodies, most excellent and wonderful vertues; so, according to the abundance of humane superstitions and follies, manie ascribe unto them either more vertues, or others then they have."

\section{Speli, or Charm.}

To explain this piece of superstition, an example or two may suffice. On St. Agnes's night, the twenty-first of January, take a row of pins, and pull out every one, one after another, saying a Pater-noster on sticking a pin in your sleeve, and you will dream of him or her you shall marry. Another method is to see a future spouse in a dream. The party inquiring must lie in a different county from that in which he conmonly resides, and on going to bed must knit the left garter about the right-legged stocking, letting the other garter and stocking alone; and as he rehearses the following verses, at every comma knit a knot:-This knot I knit,-To know the thing I know not yet,-That I may see,-The man [woman'] that shall my husband [wife] be,-How he goes and what he wears, - And what he does all days and years." And, if spells fail not, he will appear it a dream, with the insignia of his profession. To these rules we shall only add an anecdote, by way of caution to all who have any curiosity to try experiments of this kind. The chief danger arises from the impression made by this false faith on the imagination. About fifteen or twenty years ago, a young woinan, in the Mearns, went out upon St. Valentine's, or some other saint's night, to get a sight of her future husband. This she was to procure, upon going to a certain kilı at some distance, pronouncing some spell, and making a motion of weighing three times, while she had nothing to weigh. This she did accordingly. Her imagination being strongly impressed with the expectation of seeing sonething, she saw, or thought she saw, a coffin ascending in the smoke of the kiln. She went home in a panic, told what she had seen, took a fever, and died the fourth day after.

\section{On Apparitions.}

SEVERAL instances of apparitions occur in the Bible; that of Samuel, raised by the witch of Endor, has occasioned great disputes. We find great controversies ainong authors, in relation to the reality, the existence or $n \cap n$-existence, the possibility or impossibility, of apparitions. The Chaldeaus, the Jews, and other nations, have been the steady adherents of the belief of apparitions. The denial of spirits and apparitions, is by some made one of the marks of infidelity, if not of atheism.

Many of the apparitions that have been recorded, are, doubtless, 
mere delusions of the senses; many others are fictitious, contrived merely to amuse, or answer some deceptive purpose. Partal darkness, and obscurity, are the most powerful means by which the sight is deceived; night is therefore the proper season for apparitions. Indeed, the state of the mind, at that time, prepares it for the admission of these delusions of the imagination. The fear and caution which must. be observed in the night; the opportunity it affords for anbuscades and assassinations; depriving us of society, and cutting off many p easing trains of ideas, which objects in the light never fail to introduce, - are all circumstances of terror ; and perhaps, on the whole, so much of our happiness depends upon our senses, that the deprivation of any one may be attended with proportionable horror and uneasiness.

The notions entertained by the ancients respecting the soul, may receive some illustration from these principles. In darkness or twilight, the imagination frequently transforms an animated body into a luman figure, but, on approaching,' the same appearance is not to be found; lience they sometimes fancied they saw their ancestors, but, not finding the reality, they distiuguished these illusions by the name of sharles. Many of these fabulous narrations might originate from dreams. There are times of slumber, when we are not sensible of being asleep. On this principle, Hobbes has ingeniously accounted for the spectre which appeared to Brutus.

"We read," says he, "of M. Brutus, that at Philippi, the night before he gave battle to Augustus Casar, he saw a fearful apparition, which is commonly related by historians as a vision; but, considering the circumstances, one may easily judge it to have been but a short dream : for, sitting in his tent, pensive and troubled with the horror of his rash act, it was not hard for him, slumbering in the cold, to dream of that which most affrighted him; which fear, as by degrees it made him awake, so it must needs by degrees inake the apparition to vanish; and having no assurance that he slept, he could have no cause to think it a dream, or any thing but a vision."

The well-known story told by Clarendon of the apparition of the duke of Buckingham's father, will admit of a similar soluiion. There was no man in the kingdom so much the subject of conversation as the duke, and, for the corruptness of his character, he was very likely to fall a victin to the enthusiasm of the times. Sir George Villiers is said to have appeared to a man at midnight, therefore there is the greatest probability that the man was asleep; and the dream affrighting him, made a strong impression, and was likely to be repeated.

It must, however, be acknowledged, that these reasons against apparitions are far from being conclusive. In favour of them, many powerful arguments may be advanced; but we must wait for stronger evidence than we have yet seen, before we can decide either for or against apparitions.

\section{Superstitions respecting the Moon.}

THE following observations on this subject,-with some alterations, are extracted from Torster's Researches concerning Atmospheric Phenumena.- 
The superstitions respecting the Moon are without number. From noticing that the tides, and many important atmospheric changes, were regulated by her conjunction with and opposition to the sun, she became at different times an object of worship among the Egyptian nations; and among Christians at a later period, the same circumstances gave rise to endless superstitions. The ancient Irish used to utter a benediction on the New Moon; and in the Highlands of Scotland, at the present day, the girls get across a gate at the first sight of the Crescent, and say,

\section{"All hail to the moon, all hail to thee!} I pritheé, good Moon, come tell to me, This night, who my husband shall be."

Aubry, in his Miscellanies, actually declares, that he knew two maids who sung this, and then going to bed dreamed of the two men that they respectively married afterwards.

A popular song, in the Scottish dialect, of the date of king James, or earlier, represents the seeing what is called the New Moon in the Old Moon's horns as a very unlucky omen.

Not only the ancient Egyptians, Greeks, and Romans made sacrifices at the time of the nascent Moon, and had numerous superstitions respecting the Moon in general; but also the Druids, and all the early northern nations did sinnilar things, and entertained similar opinions which shews that they must have been founded on some general facts.

It is a curious fact, mentioned by Mungo Park, that the Mandingo nations of Africa have similar superstitions, and say a short prayer to the New Moon.

The ancient superstition of The Man in the Moon, is supposed to have taken rise from the passage in the book of Numbers, where a man is related to have been punished with death for gathering sticks on the Sabbath.

The various rustic operations to be begun on certain days of the moon are well known, and described by Hesiod, Virgil, and others; many of which are still retained in Europe even to this very time. People in Sussex cut their corns in the wane, that they may continue further to waste with the decrease of that heavenly body.

In some parts of Wiltshire, they say it is unlucky to look at the New Moon for the first time through a glass; and indeed showery weather about that time of the Moon, which might keep the spectator indoors, and make him see her crescent first through a window, may be a bad prognostic for the month. The ignorant run out of doors, and turn the money in their pockets, if they hear by chance of her first appearance. In Sussex they say a Saturday's Mioon is always a stormy one. Many people positively assert that Friday is always either the fairest or the worst day in the week. Hence this ancient adage,

\section{"Friday and the week Are seldom alike.}

In what this originated, unless it were some casual oceurrence of a succession of fine and of wet Fridays, cannot be ascertained. Some 
indeed have carried their views back to the crucifixion, which took place on this day; and hence, until lately, ships were rarely put to sea on this day, except on some particular emergency.

\section{Animal Maginetism.}

ThIs was a sympathy supposed by some persons to exist between the-maguet and the human body; by means of which, the former became capable of curing many diseases in an unknown way, something resembling the performances of the old magicians. The fanciful system, to call it by no worse name, of animal magnetism, appears to have originated, in $17 \% 4$, from a German philosopher named Father Kehl, who greatly recommended the use of the magnet in medicine. M. Mesmer, a physician of the same country, by adopting the principles of $\mathrm{Kehl}$, became the direct founder of the system ; but afterwards deviating from the tenets of his instructor, he lost his patronage, as well as that of Dr. Ingenhouz, which he had formerly enjoyed.

Mesmer had already distinguished himself by "A Dissertation on the Influence of the Stars upon the Human Body," which he publicly defended in a thesis before the university of Vienna; but he was so unable to stand before the opposition of Kehl and Ingeinouz, that his system fell almost instantly into disrepute. Mesmer appealed to the academy of sciences at Berlin; but they rejected his principles as destitute of foundation, and unworthy of the smallest attention. He then made a tour through Germany, publishing the great cures he performed by means of his animal magnetisn, while his opponents every where pursued him with detections of the falsehood of his assertions. Mesmer, still undaunted by so many defeats, returned to Vienna; but meeting there with no better success than before, he retired to Paris in the beginning of 1778.

Here he met with a very different reception. He was first patronized by the author of the Dictionnaire des Merveilles de la Nature, in which work a great number of his cures were published, Mesmer himself receiving likewise an ample testimony of his candour and solid reasoning. He soon collected patients, and in April, 17\%8, retired with them to Cretail, whence he in a short time returned with them perfectly cured. His success was now as great as his misfortunes had been before. Patients increased so rapidly, that he was soon obliged to take in pupils, to assist him in his operations. These pupils succeeded as well as Mesmer himself; and so well did they take care of their own emolument, that one of them, named M. Deslon, realized upwards of 100,0001 . sterling.

n 1779 Mesmer published a Memoir on Animal Magnetism, promising afterwards a complete work upon the subject, which should make as great a revolution in philosophy, as it had already done in medicine. The new system now gained ground daily, and soon became so fashionable, that the jealousy of the faculty was thoroughly awakened, and an application concerning it was made to government. In consequence of this, a committee was appointed to inquire into the matter, composed partly of members of the royal academy of sciences, 
with Dr. Benjamin Franklin at their head. This was a thunderstroke to the supporters of the new doctrine. Mesmer himself refused to have any communication with the committee; but his most celebrated pupil Deslon was less scrupulous, and explained the principles of his art in the following manner.

"1. Animal magnetism is an universal fluid, constituting an absolute plenum in nature, and the medium of all mutual influence between the celestial bodies, and betwixt the earth and animal bodies. 2. It is the most subtile fluid in nature, capable of a flux and reflux, and of receiving, propagating, and continuing all kinds of motion. 3 . The animal body is subjected to the influences of this fluid by means of the nerves, which are immediately affected by it. 4. The human body has poles and other properties analogous to the magnet. 5. The action and virtue of animal magnetism may be communicated from one body to another, whether animate or inanimate. 6. It operates at a great distance from the intervention of any body. $\%$. It is increased and reflected by mirrors; communicated, propagated, and increased by sound; and may be accumulated, concentrated, and transported. 8. Notwithstanding the universality of this fluid, all animal bodies are not equally affected by it; on the other hand, there are some, but few in number, the presence of which destroys all the effects of animal magnetism. 9. By means of this fluid, nervous disorders are cured immediately; and its virtues, in short, extend to the universal cure and preservation of mankind."-From this extraordinary theory, Mesmer or M. Deslon had fabricated a paper, in which he stated, that there was in nature but one disease and one cure, and that this cure was animal magnetism.

To ascertain the truth of these assertions, the committee attended M. Deslon in the room where his patients underwent his magnetical operations. The apparatus consisted of a circular platform, made of oak, one and a half feet high, with a number of holes at the bottom, in which were iron rods with moveable joints, for the purpose of applying them to any part of the body. The patients were placed in a circle around it, each touching one of these rods, and joined to one another by a cord passing round their bodies. Each of them held an iron rod in his hand, ten or twelve feet long, to concentrate the magnetism. M. Deslon also called in the aid of music from a pianoforte; on which some airs were played, accompanied with songs ; alleging that music is a conductor of animal magnetism, which is transmitted to the patients by the sounds. The internal part of the platform was said to concentrate the magnetism, and was the reservoir whence the virtue was diffused among the patients. The committee satisfied themselves, by means of a needle and electrometer, that neither common magnetism nor electricity was concerned. M. Deslon also communicated the magnetism by his finger, and a rod which he held in his hand, and which he carried about the face, head, or such part of the patient as was diseased. His principal application, however, by the pressure of his hands or fingers, was on the lower regions of the stomach. The effects of these operations upon his patients were very different. Some felt nothing, others spit, coughed, sweat, and felt, or pretended to feel, extraordinary heats in 
different parts of their body. Many women, but very few men, had convulsions, which Deslon ealled their crisis, \&c.

The commissioners, at last, finding they could cone to no satisfac. tory conclusion while they attended in this public way, determined to try the experiments themselves privately. Accordingly, they, 1. tried the effects of animal magnetism upon themselves, and felt nothing: 2. seven of Deslon's patients were magnetized at Dr. Franklin's house, four of whom felt nothing; three felt, or affected to feel, something: 3. several persons in a higher sphere of life were magnetized, and felt nothing. 4. The commissioners now, determined to discover what share imagination had in this business, blindfolded several of the common people, and made them sometimes think that they were magnetized; at other times they magnetized them without letting them know that they did so: the consequence was, that when they supposed themselves magnetized, they likewise thought they felt something, and vice versa. 5. A magnetized tree was said to produce convulsions; a young man, blindfolded, fell into convulsions when he thought himself near the tree, though he was at a great distance from it. Deslon accounted for this on the principle of all trees being magnetic; but in this case, every one susceptible of magnetism would be seized with convulsions when he approached a tree. The same influence of imagination was observed in a womait, who was accustomed to have convulsions when magnetized: they came on when nothing was done to her, on being told, when blindfolded, that she was magnetized. Other instances were given, from which it was evident, either that the patients were impostors, or in such a wretched state of debility, both of mind and body, that the most trifling effects of the former had the most powerful effects on the latter. The commissioners, therefore, entirely disapproved of the whole. The touch, imitation, and inagination, they concluded, were the great causes of the effects produced by Mr. Deslon's operations; and by means of these, they supposed that convulsions, which in themselves are a very violent disorder, might be spread much farther than could be wished, even through a whole city. It was observed that the operator sometimes pressed closely, and for a long time, upon the hypochondria and pit of the stomach; and it is well known that a strong pressure on these parts will produce disagreeable sensations in those who enjoy perfect health. Mesmer complained of the report of the commissioners, petitioned parliament, and was by them commanded to discover the mysteries of his doctrine; which is now universally exploded.- The conclusion of the academicians concerning it was, that it is not only entirely useless to philosophy, but that it affords one fact more to be added to the history of the errors and illusions of the human mind, and a signal instance of the power of imagination.

\section{SECOND SIGHT.}

THIs is the power of seeing things future, or things distant; which has been supposerl inherent in some of the Scottish islanders. It is described as an impression made either by the mind upon the eye, or by the eye upon the mind, by which things distant or future are per- 
ceived, and seen as if they were present. A man on a journey far from home falls from his horse; another, who is perhaps at work about the house, sees him bleeding on the ground, commonly with a landscape of the place where the accident befalls him. Another seer, driving home his cattle, or wandering in idleness, or musing in the sunshine, is suddenly surprised by the appearance of a bridal ceremony, or funeral procession, and counts the mourners or attendants, of whom, if he knows them, he relates the names; if he know's them not, he can describe the dresses. Things distant are seen at the instant when they happen.

Of things future, Johnson says that he knows no rule pretended to, for determining the time between the sight and the event; but we are informed by $\mathrm{Mr}$. Grose, that in general the time of accomplishment bears some relation to the time of the day in which the impressions are received. Thus visions seen early in the morning, which seldom happens, will be much sonner accomplished than those which appeared at noon ; and those seen at noon will take place in a much shorter time than those happening at night: sometimes the accomplishment of the last does not fall out within a year or more. These visions are not confined to solemn or important events ; nor is it true, as is commonly reported, that to the second-sight nothing is presented but phantoms of evil. The future visit of a mountebank or piper; a plentiful draught of fish; the arrival of common travellers; or, if possible, still more trifling matters than these, - are foreseen by the seers.

A gentleman told Dr. Johnson, that when he had once gone far from his own island, one of his labouring servants predicted his return, and described the livery of his attendants, which he had never worn at home, and which had been, without any previous design, occasionally given him.

By Dr. Beattie of Aberdeen it is thus accounted for. "The islands of Scotland are a picturesque, but a melancholy country. Long tracts of mountainous desart, covered with dark heath, and often obscure by misty weather, narrow valleys thinly inhabited, and bounded by precipices resonnding with the sound of torrents; a soil so rugged, and a climate so dreary, as in many parts to admit neither the amusements of pasturage nor the labours of agriculture; the mournful dashing of waves along the friths and lakes that intersect the country; the protentous noises which every change of the wind, and every increased diminution of the waters, is apt to raise, in a lonely region, full of echoes, and rocks, and caverns; the grotesque and ghastly appearance of such a landscape by the light of the moon; objects like these diffuse a gloom over the fancy, which may be compatible enough with occasional and social merriment, but cannot fail to tincture the thoughts of a native in the house of silence and solitude. If these people, notwithstanding their reformation in religion and more frequent intercourse with strangers, -do still retain many of their superstitions, we need not doubt that in former times they must have been more enslaved to the horrors of imagination, when beset with the bugbears of Popery and Paganism. Most of their superstitions are of a melancholy cast. That of second-sight, by which some are still supposed to be haunied, is considered by them as a misfortune, on account of the 
many dreadful images it obtrudes upon the fancy. It is said that in some of the alpine regions also, the inhabitants lay claim to a sort of second-sight. Nor is it wonderful that persons of a lively imagination, immured in deep solitude, and surrounded with the stupendous scenery of clouds, precipices, and torrents, should dream, even when they think themselves awake, of those few striking ideas with which their lonely lives are diversified-of corpses, funeral processions, and other subjects of terror; or of marriages, or the arrival of strangers, and such like matters of more agreeable curiosity. Let it be observed, also, that the ancient islanders of Scotland had hardly any other way of supporting themselves than by hunting, fishing, or war, professions that are continually exposed to fatal accidents. And hence, no doubt, additional horrors would often haunt their solitude, and a deecer gloom overshadow the imagination even of the hardiest among the natives.

"A sufficient evidence can hardly be found for the reality of the second-sight, or, at least, of what is commonly understood by that term. A treatise on the subject was published in the year $\mathbf{1 7 6 2}$, in which many tales were told, of persons whom the author believed to have been favoured or haunted with these illuminations; but most of the tales were trifling and ridiculous, and the whole work betrayed, on the part of the compiler, such extreme credulity, as could not fail to prejudice many readers against his system. That any of these visionaries are apt to be swayed in their declarations by sinister views, we will not say; but this may be said with confidence, that none but ignorant people pretend to be gifted in this way. And in them it may be nothing more, perhaps, than short hits of sudden sleep or drowsiness, attended with lively dreams, and arising from some bodily disorder, the effect of idleness, low spirits, or a gloomy imagination. For it is adnitted, even by the most credulous Highlanders, that as knowledge and industry are propagated in their country, the second-sight disappears in proportion; and nobody ever laid claim to the faculty, who was much employed in the intercourse of social life.

'Nor is it at all extraordinary that one should have the appearance of being awake, and should even think one's self so, during those fits of dozing; that they should come on suddenly, and while one is engaged in some business, The same thing happens to persons much fatigued, and long kept awake, who frequently fall asleep, for a moment or for a long space, while they are standing, or walking, or riding on horseback. Add but a lively dream to this slumber, and, which is the frequent effect of disease, taking away the consciousness of having been asleep, and a supertitious man may easily mistake his dream for a waking vision; which, however, is soon forgotten, when no subsequent occurrence recals it to his memory, but which, if it shall be thought to resemble any future event, exalts the poor dreamer into a Highland prophet. This conceit makes him more recluse and more melancholy than ever, and so feeds his discase and multiplies his visions: which, if they are not dissipated by business or society, may continue to haunt him as long as he lives; and which, in their progress through the neighbourhood, receive some 
new tinctures of the marvellous from every mouth that promotes theif circulation.

"As to the prophetical nature of this second-sight, it cannot be admitted at all, that the Deity should work a miracle in order to give an intimation of the frivolous things that these tales are made up of,-the arrival of a stranger, the nailing of a coffin, or the colour of a suit of clothes; that these intimations should be given for no end, and to those persons who are idle and solitary, who speak Gaelic, or who live among mountains and deserts, is like nothing in nature or providence that we are acquainted with, and must therefore, unless it were confirmed by satisfactory proof, which is not the case, be rejected as absurd and incredible. These visions, such as they are, may reasonably be ascribed to a distempered fancy. And that in them, as well as in ordinary dreams, certain appearances should, on some rare occasions, resemble certain events, is to be expected from the laws of chance; and seems to have in it nothing more marvellous or supernatural, than that the parrot, who deals out his civilities at ralldom, should sometimes happen to salute the passenger by his right appellation."

To the confidence of these objections Dr. Johnson replies, - " that by presuming to determine what is fit, and what is beneficial, presupposes more knowledge of the universal system than man has attained, and therefore, if we depend upon principles too complicated and extensire for our comprehension, there can be no security in the consequences, because the premises are not understood; that the secondsight is only wonderful because it is rare, for, considered in itself, it involves no more difficulty than dreams, or perhaps than the regular exercise of the cogitative faculty; that a general opinion of communicative impulses, or visionary representations, has prevailed in all ages and all nations; that particular instances have been given, with such evidence as neither Bacon nor Bayle have beeu able to resist; that sudden impressions, which the event has verified, have been felt by more than own or publish them; that the second-sight of the Hebrides implies only the local frequency of a power which is no where totally unknown; and that where we are unable to decide by antecedent reasons, we must be content to yield to the force of testimony. By pretension to second-sight, no profit was ever sought or gained. It is an involuntary affection, in which neither hope nor fear is known to have any part. Those who profess to have it, do not boast of it as a privilege, nor are they considered by others as advantageously distinguished. They have no temptation to feign, and their hearers have no motive to encourage, the imposture." Dr. Johnson also aftirms, that the islanders of all degrees, whether of rank or of understanding, universally admit it, except the ministers, who, according to him, reject it in consequence of a system, against conviction. He affirms, too, that in $\mathbf{1 7 7 3}$ there was in the Hebrides a second-sighted gentleman, who complained of the terrors to which he was exposed.

On a subject involved in so much obscurity, and bordering so much on the marvellous, it is natural to suppose that a diversity of opinions would be entertained; and as no decisive evidence can be adduced, 
either to disprove the existence of this strange faculty, or to establish it on a basis that shall command universal belief, the reader must exercise his own judginent; and either receive it as an inconprehensible fact, or discard it as an unaccountable fiction. It will perhaps be readily admitted by those who contend for its reality, that they cannot fairly, on rational principles, account either for its existence or mode of operation; but those who resolve it into the workings of imagination, must be well aware, that this concession can furnish no argument in favour of its non-existence. The faculties of our minds, and the manner in which they receive impressions from distant objects, are but imperfectly known; the process, therefore, admitting it to be a reality, may not in itself be more mysterious than that by which images are received through the organs of bodily vision; and if the faculty were as generally diffised and exercised in the former case as in the latter, we should look on both with equal indifference, as common events resulting from established causes.

The period may perhaps arrive, when the phenomena of the human mind may be much better understood than they are at present; and it may then be satisfactorily seen, why a surprising power of mental discernment should be incorporated in one constitution, while it is withheld from others of the same species. With the operation of natural causes, in all their variety and extent, we are but very imperfectly acquainted; our inability therefore to find an adequate agent within the empire of nature, will no more justify us in rejecting as fabulous, a phenomenon for which we can find no adequate cause, than it will sanction our appeals to supernatural agency when we wish to draw a veil over human iguorance.

BELOMANCY.

Turs signifies divination by arrows. Belonancy was practised in the East, but chiefly among the Arabians. It was performed in different manners. One was, to mark a parcel of arrows, and to put eleven or more of them into a bag; these were afterwards diawn out, and according as it was marked or not, they judged of future events. Another way was, to have three arrows, upon one of which was written, "God orders it me ;" upon another, "God forbids it me ;" and upon the third, nothing at all. 'These were put into a quiver, out of which, they drew one of the three at random: if it happened to be that with the first inscription, the thing they consulted about was to be done; if it chanced to be that with the second inscription, it was let alone; but if it proved that without any, they drew over again. Belomancy is an ancient practice, and probably that which Ezekiel mentions, chap. xxi. 21. At least, St. Jerome understands it so, and observes that the practice was frequent among the Assyrians and Babylonians. Something like it is also mentioned in Hosea, chap.iv. only that staves are mentioned instead of arrows, which is rather that of demancy than belomancy. Grotius, as well as Jerome, confounds the two together, and shews that it prevailed among the Magi, Chaldeans, and Scythians, whence it passed to the Sclavonians, and thence to the Germans, who, as Tacitus observes, made, use of it. 


\section{PART VIII.}

\section{EXTRAORDINARY BUILDINGS,}

\&ce.

\section{Pantheon.}

Tris is a beautiful edifice at Rome, anciently dedicated to alt the gods, but now converted into a church, and dedicated to the Virgin and all the martyrs. It has been generally supposed to have been built by Agrippa, son-in-law to Augustus, because it has the following inscription on the frieze of the portico: "M. Agrippa, L. F. Cos. Tertium fecit." Several antiquarians and artists, however, have supposed that the Pantheon existed in the times of the commonwealth; and that it was only embellished by Agrippa, who added the portico. Be this as it will, the Pantheon, when perfected by Agrippa, was an exceedingly magnificent building. The form of its body is round or cylindrical, and its roof or dome is spherical; it is one hundred and forty-four feet diameter within; and the height of it, from the pavement to the grand aperture on the top, through which it receives the light, is just as much. It is of the Corinthian order. The inner circumference is divided into seven grand niches, wrought in the thickness of the wall : six of these are flat at the top; but the seventh, opposite to the entrance, is arched. Before each niche are two columns of antique yellow marble, fluted, and of one entire block, making in all the finest in Rome. The whole wall of the temple, as high as the grand cornice inclusive, is cased with divers sorts of precious marble in compartments. The frieze is entirely of porphyry.

Above the grand cornice arises an attic, in which were wrought, at equal distances, fourteen oblong square niches. Between each niche were four marble pilasters, and between the pilasters marble tables of various kinds. This attic had a complete entablature, but the cornice projected less than that of the grand order below. Inmediately from the cornice spring the spherical roofs, divided by bands which cross each other like the meridians and parallels of an artificial terrestrial globe. The spaces between the bands increase in size as they approach the top of the roof; to which, however, they do not reach, there being a considerable plain space between them and the great opening. That so bold a roof might be as light as possible, the architect formed the substance of the spaces between the bands of nothing but lime and pumice stones. The walls below were decorated with lead and brass, and works of carved silver over them, and the roof was covered on the outside with" plates of gilded bronze. There was an ascent from the springing of the roof to the very summit, by a flight of seven stairs. The portico is composed of sixteen columns of granite, four feet in diameter, eight of which stand in 
front, with an equal columniation all along. The ascent to the portico is by eight or nine steps.

Such was the Pantheon, the richness of which induced Pliny to rank it among the wonders of the world. . The eruption of Vesuvius, in the reign of Tiberius, having damaged the Pantheon considerably, it was repaired by Domitian and Adrian. But the Pantheon is more indebted to Septimus Severus than to any one since its erection. Septimus bestowed essential reparation upon it, as appears from an inscription upon the architrave. This temple subsisted in all its grandeur till the incursion of Alaric. Zosymus relates, that the Romans having engaged to furnish this barbarian with $3000 \mathrm{lbs}$. of gold, and 5000lbs. of silver, upon condition that he should depart from their walls, and it being inıpossible to raise those sums, they stripped the temples of their statues and ornaments of gold and silver. Genseric king of the Vandals, thirty-nine years after, took away part of their marbles, and loaded one of his ships with statues. On this occasion the inestimable works of Diogenes became the prey of this barbarian.

The Christian emperors had issued orders for demolishing the Pagan temples; but the Romans spared the Pantheon, which suffered no damage from the zeal of the pontiffs, or the indignation of the saints, before the first siege of Rome by Alaric. It remained so rich till about A. D. 655, as to excite the avarice of Constantine II. who came from Constantinople, and pillaged the Pantheon of its brazen coverings, which he transported to Syracuse, where they soon fell into the hands of the Saracens.

About fifty years before this, pope Boniface IV. had obtained the Pantheon of the emperor Phocas, to make a church of it. The artists of these parts spoiled every thing they laid their hands upon. After the devastations committed by the barbarians, Rome was contracted within a narrow compass. The Pantheon standing at the entrance of the Campus Martius, was surrounded with houses, which spoiled the fine prospect of it; and some of them were built close to its walls. Pedlars' sheds were built within its portico, and the intercolumniations were bricked up, to the irreparable damage of the matchless pillars, of which some lost part of their capitals, and others were chiselled out six or seven inches deep, and as many feet high, to let in posts. This disorder continued till the pontificate of Eugene IV. who had all the houses cleared away, when the miserable barracks in the portico were knocked down. Benedict II. covered it with lead, which Nicholas $V$. renewed in a better style. Raphael Urban, who had no equal as a painter, and as an architect no superior, left a considerable sum for the reparation of the Pantheon, where his tomb is placed. La Vagua, Udino, Hannibal Caracci, Flamingo, Vacca, and Archangelo Corelli, did the same.

Pope Urban VIII. was a protector and practiser of the arts. He repaired it; but while he built up with one hand, he pulled down with the other. He caused two belfries, of a wretched taste, to be erected on the ancient front-work, and divested the portico of all the remains of its ancient grandeur, viz. the brazen coverture of the crossbeams, which amounted to a prodigious quantity. This pope, who 
was of the family of Barbarini, presented as much of this metal to his nephew as was sufficient for the decoration of his new palaces, on which occasion this pasquinade was stuck up :

\section{Quod non fecerunt Barbari fecere Barbarini.}

Alexander VII. did what Urban had neglected to do. He ordered search to be made for pillars to match those of the portico of the Pantheon, and some were found of the very same model. He also caused all the old houses before the portico to be pulled down, and the rubbish to be cleared away which covered the steps and the bases of the pillars. Clement IX. enclosed the portico with iron rails. Several later popes have added to its decorations, which were all in the taste of the times they were done in, and the body of the edifice and its architecture gained nothing from them.

\section{Antrquities of Benevento, in Italy.}

THE arch of Trajan, now called the Porta Aurea, forms one of the entrances to the city. This arch, though it appears to great disadvantage, from the walls and houses that hem it in on all sides, is in tolerable preservation, and is one of the most magnificent remains of Roman grandeur to be met with out of Rome. The architecture and sculpture are both singularly beautiful. This elegant monument was erected A. D. 114, about the commenccment of the Parthian war, and after the submission of Decebalus had entitled Trajan to the surname of Dacicus. The order is Composite; the materials, white marble; the height, sixty palms ; length, thirty-seven and a half; and depth, twenty-four. It consists of a single arch, the span of which is twenty palms, the height thirty-five. On each side of it, two fluted columns, upon a joint pedestal, support an entablement and an attic. The intercolumniations and frieze are covered with basso-relievos, representing the battles and triumphs of the Dacian war. In the attic is the inscription. As the sixth year of Trajan's consulate, marked on this, is also to be seen on all the different columns he erected along his new road to Brundusium, it is probable that the arch was built to commemorate so beneficial an undertaking. Except the old metropolis of the world, no city in Italy can boast of so many remains of ancient sculpture as Benevento. Scarce a wall is built of any thing but altars, tombs, columns, and remains of entablatures.

The cathedral is a clumsy edifice, in a style of Gothic, or rather Lombard architecture. The church, dedicated to the Virgin Mary, was built in the sixth century, enlarged in the eleventh, and altered cousiderably in the thirteenth, when archbishop Panger adorned it with a new front. To obtain a sufficient quantity of marble for this purpose, he spared neither sarcophagus, altar, nor inscription, but fixed them promiscuously and irregularly in the walls of his barbarous structure. Three doors, a type of the Trinity, according to the rules established by the mystical virtuosi of those ages, open in to this facade. That in the centre is of bronze, embossed with the life of Christ, and the effigies of the Beneventine metropolitan, with all his suffragan bishops. The inside offers nothing to the curious observer but 
columns, altars, and other decorations, executed in the most inelegant style that any of the church-building barbarians ever adopted. In the courtyard stands a small Egyptian obelisk, of red granite, crowded with hieroglyphics. In the adjoining square is a fountain, and a very indifferent statue of Benedict XIII. long archbishop of Benevento.

\section{Temple of Jupiter at Otympia.}

'lus temple was of the Doric order, sixty-eight feet high to the pediment, ninety-five wide, and two hundred and thirty long; the cell encompassed with the columns. It was erected with the country stone; the roof was not of earth baked, but of Pentelie marble, the slabs disposed as tiles; the way to it was up a winding staircase. The two pediments were enriched with sculpture, and one had over the centre a statue of Victory gilded, and underneath a votive buckler of gold. At each corner was a gilded vase. Above the columns were fixed 21 gilded bucklers, offered, at the conclusion of the Achean war, by the Roman general Mummius. The gates in the two fronts were of brass, and over them were carved the Labours of Hercules. Within the cell were double colonnades, between which was the approach to the image.

The Jupiter of Olympia inmortalized its maker, Phidias. It was of ivory and gold, the head crowned with olive. In the right hand was a statue of Victory; in the left a flowered sceptre, composed of various metals, on which was an eagle. The sandals were of gold, as also the vestment, which was curiously embossed with lilies and animals. The throne was gold inlaid with ebony and ivory, and studded with jewels, intermixed with paintings, and exquisite figures in relievo. The pillars between the feet contributed to its support. Before it were walls, serving as a fence, decorated principally with the exploits of Hercules. The portion opposite the door was of a blue colour. It was the office of a family descended from Phidias, called Phædruntæe, or the polisher, to keep the work bright and clean. The veil or curtain was cloth rich with the purple dye of Phœnicia, and with Assyrian embroidery, an offering to king Antiochus, and was let down from above by strings.

The image appeared higher and broader than it measured. Its magnitude was such, that though the temple was very large, the artist seemed to have erred in the proportions. The god, though sitting, nearly touched the ceiling with his head. A part of the pavement before it was of black marble, enclosed in a rim of Parian or white, where they poured oil to preserve the ivory.

The altar of Jupiter Olympius was of great antiquity, and covered with ashes from the thighs of the victims, which were carried up and consumed on the top with wood of the white poplar-tree. The ashes also of the Prytaneum, in which a perpetual fire was kept on a hearth, were removed annually on a fixed day, and spread on it, being first mingled with water from the Alpheus. The cement was made with that fluid only; and therefore this river was esteemed the most friendly of any to the god. On each side of the altar were stone steps. Its 
height was twenty-two feet. Girls and women were allowed to ascend the basement, which was one hundred and twerty-five feet in circumference. The people of Elis sacrificed daily, and private persons as often as they chose.

\section{ABYDUS.}

ABYDUs is a town in Egypt, famous for the palace of Memnon, and the temple of Osiris, and inhabited by a colony of Milesians. It was the only one in the country, into which the singers and dancers were forbidden to enter. This city, reduced to a village under the empire of Augustus, now presents to our view only a heap of ruins, without inhabitants; but to the west of these ruins is still found the celebrated tomb of Ismandes. The entrance is under a portico, sixty feet high, and supported by two rows of massy columns. The immoveable solidity of the edifice, the huge masses which compose it, the hieroglyphics it is loaded with, stamp it a work of the ancient Egyptians.

Beyond it is a temple three hundred feet long, and one hundred and fifty-five wide. Upon entering the monument, we meet with an immense hall, the roof of which is supported by twenty-eight columns, sixty feet high, and nineteen in circumference at the base; they are twelve feet distant from each other. The enormous stones that form the ceiling, perfectly joined and incrusted as if they were one, presented to the eye nothing but one solid platform of marble, one hundred and twenty-six feet long, and twenty-six feet wide. The walls are covered with hieroglyphics. One sees there a number of animals, birds, and human figures, with pointed caps on their heads, and a piece of stuff hanging down behind, and dressed in loose robes that come down only to the waist. The sculpture, however, is clumsy; the forms of the body, the attitudes and proportions of the members, ill observed. Amongst these we may distinguish some women suckling their children, and men presenting offerings to them. Here also we meet with the divinities of India.

Monsieur Chevalier, formerly governor of Chandenagore, who resided twenty years in that country, carefully visited the monument on his return from Bengal. He remarked here the gods Juggernaut, Gonez, and Vechnou or Wistnou, such as they are represented in the temples of Indostan. A great gate opens at the bottom of the first hall, which leads to an apartment forty-six feet long, by twenty-two wide. Six square pillars support the roof of it, and at the angles are the doors of four other chambers, but so choked up with rubbish, that they cannot now be entered. The last hall, sixtyfour feet long by twenty-four wide, has stairs by which one descends into the subterraneous apartments of this grand edifice. The Arabs, in searching after treasure, have piled up heaps of earth and rubbish. In the part we were able to penetrate, sculpture and hieroglyphics are discoverable, as in the upper story. The natives say that they correspond exactly with those above ground, and that the columns are as deep in the earth, as they are lofty above ground. It would be dangerous to go far into these vauits; for the air of them is soloaded 
with a mephitic vapour, that a candle can scarcely be kept burning in them. Six lions' heads, placed on the two sides of the temple, serve as spouts to carry away the water. The ascent to the top is by a staircase of a very singular structure. It is built with stones incrusted in the wall, and projecting six feet out ; so that being supported only at one end, they appear to be suspended in the air.

The walls, the roof, and the columns of this edifice, have suffered nothing from the injuries of time; and did not the hieroglyphics, by being corroded in some places, mark its antiquity, it would appear to have been newly built. The solidity is such, that unless people make a point of destroying it, the building must last for a number of ages. Except the colossal figures, whose heads serve as an ornament to the capitals of the columns, and which are sculptured in relievo, the rest of the hieroglyphics which cover the inside are carved in stone. To the left of this great building we meet with another, much smaller, at the bottom of which is a sort of altar. This was probably the sanctuary of the temple of Osiris.

\section{Curiosities of Bombay.}

Among the curiosities of Bombay, Mr. Ives mentions a very large terapin, or tortoise, kept at the governor's house, the age of which was upwards of two hundred years. Frogs, which abound every where through the East Indies, are very large at Bombay. Our author saw one that measured twenty-two inches from the extremities of the fore and hind feet when extended, and he supposes that its weight could not have been less than four or five pounds. On the sea shore, round the island, are a great variety of beautiful shells, particularly the sort called ventle-traps, or wentle-traps, held in great esteem among the ladies some time ago. Several pounds sterling are said to have been given by a virtuoso for one of these shells, when commodore Leslies' collection of shells was sold by anction.

$\mathrm{Mr}$. Ives enumerates the following kinds of snakes found in this island and other parts of the British empire in the East Indies. 1. The Cobra de Capella, which grows from four to eight or nine feet long. Their bite kills in fifteen minutes. 2. The Cobra Manilia is a small blueish snake, of the size of a man's little finger, and about a foot long, frequently seen about old walls. A species of these, found at Bombay, kill much sooner than even the former. 3. The Palæira, a very thin beautiful snake, of different colours; its head is like that of the common viper, but much thicker than the body. Our author saw one that was four feet long, and not much thicker than a swan's quill. "4. The Green Snake is of a very bright green colour, with a sharp head; towards the tail it is much smaller than in the middle. The largest part of it is no bigger than a tobacco-pipe. 5. The Sand Snake is small and short, but not less deadly than the others. 6 . The Cobra de Aurelia resembles an earth-worm, is about six inches long, and no bigger than a small crow-quill. It kills by getting in to the ear, causing madness, \&c. \%. The Manilia Bomba is a very beautiful snake, of about the same size throughout the whole length, except at the two ends, where it comes to a point. It is white in the 
belly, but finely rariegated on the back. It lives in the sand, and the sting which it inflicts with its tail, is said also to occasion contractions in the joints.

\section{Prison in Venice.}

When I was in Venice, says Moseley, I descended into the cells of the Prigoni Publiche, or Great Common Prison.-Here-even herethe soul of man clings to his body; and shews no more symptoms, or prescience, of immortality, than if that body were on a bed of down, canopied in a gorgeous palace.

In the morning, when I set out on this gloomy expedition, Dominico Zacchi, my Venetian servant, who had attended Lord St. Asaph, Sir George Beaumont, and several other English traveller's, during their residence at Venice, took his leave of ine. This was on the sixteenth of September, 178\%. Dominico thought that I would never return, or, if I did, I might "a tale unfold" that would endanger my safety at Venice. But he said, from what he had heard, he did not think it possible for me to survive the foul and pestilential air I had to encounter.

My design was to see the perfection-the far-farmed ultimatum of policy - the immured for life in solitary cells.

The late Mr. John Howard, F. R. S. was at the prison wlien he was in Venice; but he only heard something, and saw nothing, of this prison of prisons.

He had not bodily strength to bear the exertion required in such an undertaking; neither do I believe he would have been suffered to enter them. It was with some difficulty that I obtained permission from the inquisitors, which was granted me merely on account of my being an English physician; a character much respected at that time in Venice. I wished to have seen the Sotto Piombi, where the state prisoners were kept, but that was refused. Here, under the roof of the public buildings, they are confined; exposed to the rigour of winter's cold and summer's heat, and the vicissitudes of scorching days and chilling nights.

I was conducted through the prison by one of its inferior dependants. We had a torch with us, and crept along narrow passages as dark as pitch. In some of them two people could scarcely pass each other. The cells are made of massy marble; the architecture of the celebrated Sansovine.

The cells are not only dark and black as ink, but being surrounded and confined with huge walls, the smallest breath of air can scarcely find circulation in them; they are about nine feet square on the floor, arched at the top, and between six and seven high in the highest part. There is to each cell a round hole of eight inches diameter, through which the prisoner's daily allowance of twelve ounces of bread and a pot of water is delivered. There is a small iron door to the cell. The furniture of the cell is a little straw, and a small tub; nothing else. The straw is renewed, and the tub emptied, occasionally, through the iron door.

The diet is ingeniously contrived for perpetuating punishment. 


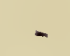




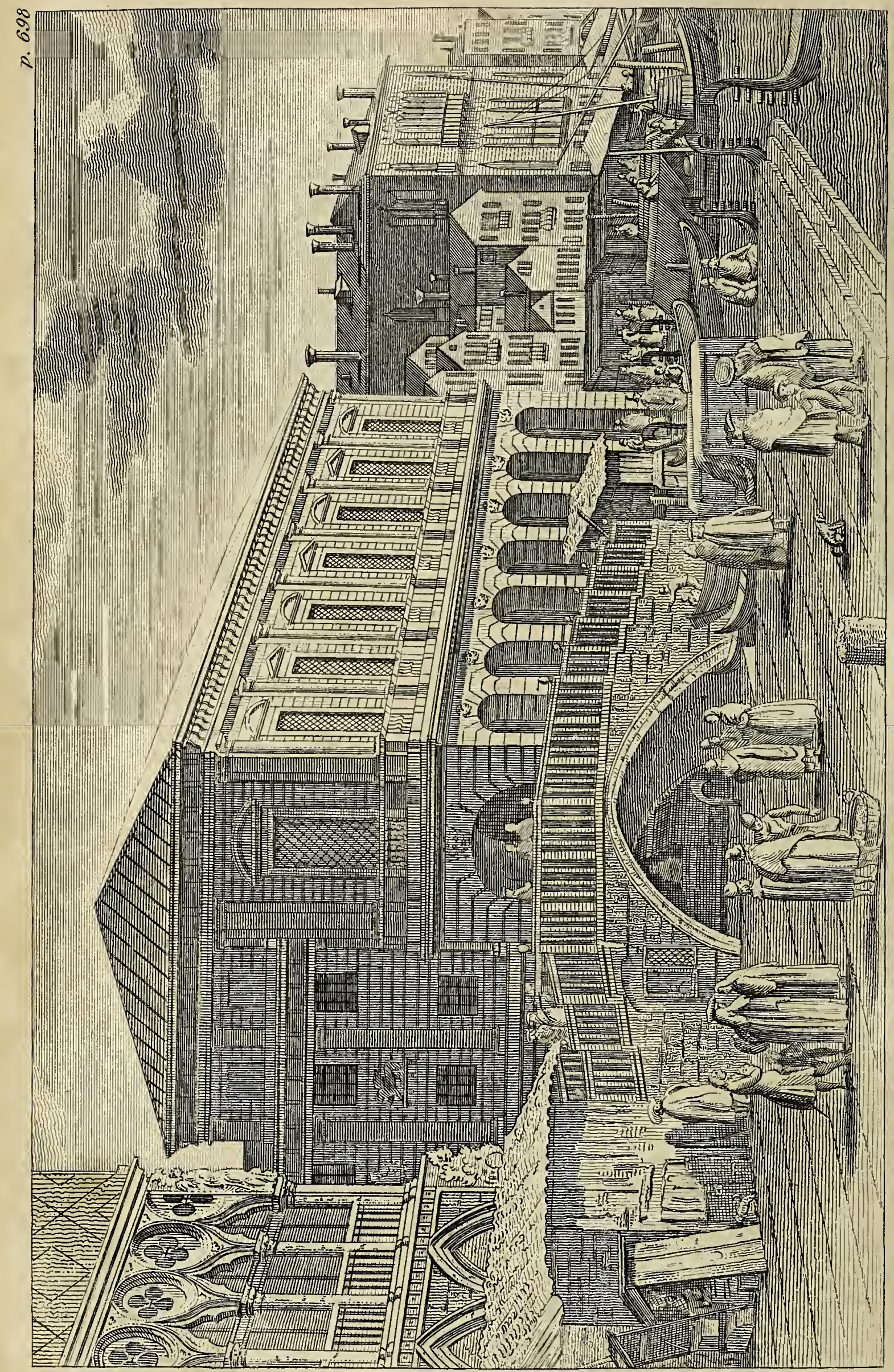


Animal food, or a cordial nutritions regimen, in such a situation, would bring on disease, and defeat the end of this Venetian justice. Neither can the soul, if so inclined, steal away, wrapt up in slumbering delusion, or sink to rest, from the admonition of her sad existence, afforded by the gaoler's daily return.

I saw one man who had been in a cell thirty years; two who had been twelve years; and several who had been eight and nine years in their respective cells.

By my taper's light I could discover the prisoners' horrid countenances. They were all naked. The man who had been there thirty years, in face and body was covered with long hair. He had lost the arrangement of words, and order of language. When I spoke to him, he made an unintelligible noise; and expressed fear and surprise, and, like some animals in deserts, which have suffered by the treachery of the human race, or have an instinctive abhorrence of it, he would lave fled like lightning from me, if he could.

One, whose faculties were not so obliterated, who still recollected the difference between day and night, whose eyes and ears, though long closed with a silent blank, still languished to perform their natural functions, implored in the most piercing manner that I would prevail on the gaoler to murder him, or to give him some instrument to destroy himself. I told him I had no power to serve him in this request. He then entreated I would use my endeavours with the itiquisitor's to get him hanged, or drowned in the canal d'Orfano. But even in this I could not serve him. Death was a favour I had not interest enough to procure for him. This kindness of death, however, was, during my, stay in Venice, granted to one man who had been "from the cheerful ways of men cut off" thirteen years.

Before he left his dungeon, I had some conversation with him; this was six days previous to his execution. His transport at the prospect of death was surprising. He longed for the happy moment. No saint ever exhibited more fervour in anticipating the joys of a future state, than this man did at the thoughts of being released from life, during the four days' mockery of his trial.

It is in the canal d'Orfano where vessels from Turkey and the Levant perform quarantine. This place is the watery grave of many who have committed political or personal offences against the state or senate; and of many who have committed no offences at all. They are carried only through the city in the middie of the night, tied up in a sack, with a large stone fastened to it, and thrown into the water. Fishermen are prohibited, on forfeiture of their lives, against fishing in this district. The pretence is the plague. This is the secret history of people being inst in Venice.

What I now uniold in regard to the prison in Venice is known but to a few people. liave reason to believe that no foreigner besides myself ever witnessed the scene I have related-the exploring of which nearly cost me my life. The heat and want of air in the passages so oppressed my strength and respiration, that I could scarcely walk or breathe when I left the prison. Sweat ran through every pore of my body-my clothes were, to my coat sleeves, wet through I staid too long there. I went to St. Mark's Place as soon as I could 
and, by the assistance of the trembling Dominico, waiting for my return - the blessed light of day, fresh air, and a few glasses of Maraschino, I was enabled to get to my lodgings at the Scudo di Francia, on the side of the great canal, near the Rialto, where I was for several hours extremely ill, and for several days much indisposed.-Moseley.

\section{Mount Michael.}

THIs is the name of one of the most celebrated state prisons of France, which lies about twenty miles from Granville. It is a rock, situated in the midle of the bay of Avranches, and is only accessible at low water. One side of it is completely fortified by its craggy and almost perpendicular descent, which renders it impracticable to climb it by any address or courage, however consummate. The other parts are surrounded by walls, fenced with semilunar towers after the Gothic manner, but sufficiently strong, together with the advantage of its situation, to render it impregnable to any attack. At the foot of the mountain begins a street or town, which winds round its base to a considerable height. Above are chambers where state prisoners are kept, and where there are other buildings intended for residence. On the summit is erected the abbey itself, occupying a prodigious space of ground, and of a strength and solidity equal to its enormous size; as it has for many centuries withstood all the injuries of the weather, to which it is so much exposed.

In an apartment, called the Sale de Chevalerie, the knights of St. Michael used to meet in solemn convocation on important occasions. They were the defenders and guardians of this mountain and abbey, as those of the Temple, and of St. John of Jerusalem, were of the holy sepulchre. The hall iu which they met is very spacious, but rude and barbarous. At one end is a painting of the archangel, the patron of their order; and in this hall Lewis XI. first instituted, and invested with the insignia of knighthood, the chevaliers of the cross of St. Michael. There is a miserable dark apartment, or rather dungeon, in which many eminent persons were formerly confined. In the middle of it is a cage, composed of prodigious bars of wood; and the wicket which gives entrance into it is ten or twelve inches in thickness. The inside of it comprises about twelve or fourteen feet square, and is nearly twenty in height. The subterraneous chambers in this mountain are said to be so numerous, that the gaolers themselves do not know them. There are certain dungeons called aubliettes, into which they were accustomed anciently to let down malefactors guilty of very heinous crimes: they provided them with a loaf of bread and a bottle of wine, and then they were totally forgotten, and left to perish by hunger in the dark vaults of the rock. This punishment, lowever, was not inflicted by any king during the two last centuries. There is also a remarkable chamber, in one corner of which is a kind of window; between this and the whole of the building is a very deep space of near one hundred feet perpendicular, to the bottom of which is another window npening to the sea. It is called the Hole of Montgomerie.

The church of Mount Michael is a great curiosity. It stands on 
nine pillars of most enormous dimensions, built on the solid rock. Each of them appears to be about twenty-tive feet in circumference; there are two others much inferior in size, on which the centre of the church rests, and over which is the tower. The following is the legendary account of the origin of this church:

In the reign of Childebert II. there was a bishop of Avranches, named St. Aubert. To this holy man the archangel Michael appeared one night, and ordered him to go to this rock to build a church. St. Aubert treated this as a dream, upon which the angel appeared a second time; and being still disobeyed, he returned a third time, when, by way of printing his command upon the saint's memory, he made a hole in his skull by touching it with his thumb. The skull is still preserved in the treasury of the church; it is enclosed in a little shrine of gold, and a crystal, which opens over the orifice, admits the gratification of curiosity by a minute examination of it. The saint immediately repaired to the rock, and constructed a small church.

Here, however, true history supplies the place of fable, and informs us that in $966 \mathrm{R}$ ichard II. duke of Normandy, began to build the abbey. It was completed about 1070 , under William the Conqueror, though many other additions were made by succeeding abbots. In the treasury of the cliurch are innumerable other relics, among which some few have a real and intrinsic value. There is a fine head of Charles VI. of France, cut in crysta!, and the representation of a cockle-shell in gold, weighing many pounds, given by Richard II. when he founded the abbey. There is an arm said to belong to St. Richard, king of England; but who this saint was, it must be very dificult to determine.

\section{TEMPLE OF HianNeN.}

HIANNEN is an island near the coast of China, and is celebrated for the magnificence of its principal pagod, consecrated to their deity Fo. This temple is situated on a plain, terminated on one side by the sea, and on the other by a lofty mountain. The front is one hundred and eighty feet long, and its gate is adorned with figures in relief. The entry is a vast porctio, with an altar in the middle, on which is placed a gigantic statue of gilt brass, representing the god Fo, sitting cross-legged. Four other statues are placed at the corners of this portico, each eighteen feet high, although they represent people sitting. Each of these is formed from a single block of stone. One holds a serpent in its hand, which is twisted round its body in several folds; the second has a bent bow and a quiver; the other two present, ene a battle-axe, and the other a kind of guitar. After crossing this portico, you enter a square outer court, payed with large gray stones, the least of which is ten feet long and four broad. At the four sides of this court are four pavilions, terminating in domes, and having communication with one another by a gallery that runs quite round it. One of these contains a bell ten feet in diameter. In the other is kept a drum of an enormous size, which the bonzes use to proclaim the day of new alid full moon. The clappers of the Chinese bells are 
on the outside, and made of wood in the form of a mallet. The two other pavilions contain the ornaments of the temple, and often serve to lodge travellers, whom the bonzes are obliged to receive.

In the middle of this court is a large tower, which terminates also by a dome, which you ascend by a beautiful stone stair-case, that winds round it. This dome contains a temple remarkably neat; the ceiling is ornamented with Mosaic work, and the walls are covered with stone figures in relief, representing animals and monsters. The pillars which support the roof of this edifice are of wood varnished, and on festivals are ornamented with small flags of different colours; the pavement of the temple is formed of little shells; and its differ ent compartments represent birds, butteiffies, flowers, \&c. The bonzes continually burn incense upon the altar, and keep the lamps lighted which hang upon the ceiling of the temple. At one extremity of the altar stands a brazen urn, which when struck sends forth a mournful sound; on the opposite side is a hollow machine of wood, of an oval form, used for the same purpose, which is to accompany with its sound their voices when they sing in praise of the tutelary illol of the pagod. The image of Poussa is placed on the middle of this altar, on a flower of gilt brass, which serves as a base, and holds a young child in its arms, several idols of subaltern deities are ranged around him, and shew their veneration by their attitudes. The bonzes have traced out on the walls of this temple several hieroglyphical characters in praise of Poussa. There is also to be seen an allegorical painting, in fresco, representing a burning lake, in which several men appear to be swimming, some carried by monsters, others surrounded by dragons. In the middle of the gulf rises a steep rock, on the top of which the god is seated, holding in his arms a child, who seems to call out-to those who are in the lake; but an old man, with hanging ears and horns on his head, prevents them from climbing to the summit of the rock, and threatens to drive them back with a large club. The bonzes are at a loss to explain this painting. Behind the altar is a library, containing books on the worship of idols.

On descending from this dome, you cross the court, and enter a kind of gallery, the walls of which are lined with boards ; it contains twenty-four statues of gilt brass, representing as many philosophers, ancient disciples of Confucius. At the end of this gallery is a large hall, which is the refectory of the bonzes; and after having traversed a spacious apartment, you at length enter the temple of Fo, to which there is an ascent by a large stone stair-case. It is oruamented with vases full of artificial flowers and musical instruments. The statue of the god is not to be seen but through a piece of black gauze, which forms a veil before the altar. The rest of the pagod consists of several large chambers, extremely neat, but badly disposed.

The gardens and pleasure grounds are on the declivity of the mountain, and a number of delightful grottos are cut out in the rock, which afford an agreeable shelter from the excessive heat of the sun. There are several other pagods in the island, among which is one called the Pagod of the. Ten Thousand Stones, because it is built on the brow of a mountain, where there is a number of little rocks, under which 
the bonzes have formed grottos and covered seats. A certain delightful rural simplicity reigns here. Strangers are received here by the bonzes with great politeness, anid may freely enter their temples; but they must not attempt to gratify their curiosity fully, nor to enter those apartments into which they are not introduced; for the bonzes, who are forbidden under severe penalties to have any intercourse with women, and who yet often keep them in private, might resent too impertinent a curiosity.

\section{Pagod, OR Pagoda.}

THE best account of these East Indian temples is a paper in the Asiatic Researches, containing the sculptures, \&c. at Mavalipuran, a few miles north of Sadras, and known to'seamen by the name of the Seven Pagodas. The monuments which Mr. Chambers, who communicated the information, describes, appear, he says, to be the ruins of some great city decayed many centuries ago. "They are situated close to the sea, between Covelong and Sadras, somewhat from the high road that leads to the different European settlements, and, when visited in 1776, there was still a native village adjoining to them, which retained the ancient name, and in which a number of branins resided, that seemed perfectly acquainted with the subjects of most of the sculptures to be seen there.

"Proceeding on by the foot of a hill on the side facing the sea, there is a pagoda rising out of the ground, of one solid stone, of about sixteen or eighteen feet high, which seems to have been cut upon the spot, out of a detached rock, that has been found of a proper size for that purpose. The top is arched, and the style of architecture, according to which it is formed, is different from any now used in those parts. Beyond this, a group of human tigures in bas relief, considerably larger than life, attract attention. They represent considerable persons, and their exploits, many of which are now very indistinct through the injuries of time, assisted by the corroding nature of the sea air; while others, protected from that element, are as fresh as when recently finished. The hill, which is at first of easy ascent, is in other parts rendered more so by very excellent steps cut out in several places, where the communication would be difficult or impracticable without them. A winding stair of this sort leads to a kind of temple cut out of the solid rock, with some figures of idols in high relief upon its walls, very well finished and perfectly fresh, as it faces the west, and is therefore sheltered from the sea air."

This temple, our author conjectures to have been a place of worship appertaining to a palace, some remains of which still exist, and to which there is a passage from the temple by another flight of steps. This finishes the objects "on that part of the upper surface of the hill, the ascent to which is on the north; but, on descending from thence, you are led round the hill to the opposite side, in which there are steps cut from the bottom to a place near the summit, where is an excavation that seems to have been intended for a place of worship, and contains various sculptures of Hindoo deities. The most remarkable of these is a gigantic figure of Vishnou asleep on a kind of bed, 
with a huge snake wound about in many coils by way of pillow for his head; and these figures, according to the manner of this place, are all of one piece, hewn from the body of the rock.

"These works, however, althongh they are unquestionably stupendous, are, in our author's opinion, surpassed by others about a mile and a half south of the hill. They consist of two pagodas of about thirty feet long by twenty feet wide, and about as many in height, cut out of the solid rock, and each consisting originally of one single stone. Near these also stand an elephant full as big as life, and a lion much larger than the natural size, but very well executed, each hewn also out of one stone. The great rock above described is at some distance from the sea, perhaps fifty or one hundred yards, and in that space the Hindoo village before mentioned stood in 1776. But close to the sea are the remains of a pagoda built of brick, and dedicated to Sib, the greatest part of which has evidently been swallowed up by that element, for the door of the innermost apartment, in which the idol is placed, and before which there are always two or three spacious courts surrounded with walls, is now washed by the waves, and the pillar, used to discover the meridian at the time of founding the pagoda, is seen standing at some distance in the sea.

"In the neighbourhood of this building there are some detached rocks, washed also by the waves, in which there appear sculptures, though now much worn and defaced. And the natives declared to the writer of this account, that the more aged people among them remembered to have seen the tops of several pagodas far out in the sea, which being covered with copper, probably gilt, were very visible at sun-rise, as their shining surface used then to reflect the sun's rays, but that now that effect was no longer produced, as the copper had since become incrusted with mould and verdigris."-From these circumstances it is probable that the magnificent city, of which these appear to be part of the ruins, has been destroyed partly by an earthquake, by which the rock was rent, and partly by a sudden inundation of the sea occasioned by this commotion of the earth.

\section{Ruins of Palmyra.}

THESE celebrated ruins consist of temples, porticoes, and palaces of Grecian architecture, and lie scattered over an extent of several miles. They were accidentally discovered by some English travellers from Aleppo about a century ago. The most remarkable of them is the temple of the Sun, of which the ruins are spread over a square of about two hundred and twenty yards. It was encompassed with a stately wall, built of large square stones, and adorned with pilasters within and without, to the number of sixty-two on a side. Within the court are the remains of two rows of noble marble pillars thirty-seven feet high, with their capitals of most exquisite workmanship. Of these only fifty-eight remain entire, but they appear to have gone round the whole court, and to have supported a double piazza. The walks opposite the castles appear to have been spacious. At each end of this line are two niches for statnes; at their pedestals, borders, supporters, and canopies are carved with the utmost propriety and elegance. 
The space within this enclosure seems to have been an open court, in the middle of which stood the temple encompassed wich another row of pillars of a different order, and much taller, being fifty high; but of these, sixteen only remain. The whole space contained within these pillars is fify -nine yards in length, and twenty-eight in breadth. The temple is thinty-three yards long, and thirteen or fourteen broad; is points morth and south, and exactly in the middle of the building, on the west side, is a most maguificent entry, on the remains of which are some vines and clusters of grapes, carved in the most masterly imitation of nature that can be conceived. Just over the door are discerned a pair of wings, which extends its whole breadth, but the body, whether of a eagle or an angel, is destroyed. The north end of this temple is adorned with the most curious fret-work and bas relief; and in the middle there is a dome or cupola about ten feet in diameter. North of this place is an obelisk, consisting of seven large stones, besides its capital. It is about fifty feet high, and just above the pelestal, twelve feet in circumfercnce. About a quarter of a mile from this pillar, to the east and west, are two others, besides the fragments of a third. About one hundred paces from mide mie obelisk is a magnificent entry to a piazza, which is forty feet broad, and more than half a mile long, enclosed with two rows of marble pillars twenty-six feet high, and eight or nine in compass. Of these there still remain one hundred and wenty-nine, but there must originally have been no less than five hundred and sixty. The upper end of the piaza was closed by a row of pillars.

T'o the left are the ruins of a stately banqueting house, built of better marble, and finished with yet greater elegance, than the piazza. The pillars which supported it were of one entive stone. It measures twenty-two feet in length, and in compass eight feet nine inches. In the west side of the piazza are several apertures for gates into the courts of the palace. Fach of these were adorued with four porphyry pillars, placed by couples in the front of the gate facing the palace, two on each sille: Two of these only remain entire. They are thirty feet long, and nine in circumference. On the east side of the piazza stands a great number of marble pillars, some perfect, but the greater part mutilated. At a little distance are the remains of a small temple without a roof. Before the entry, which looks to the south, is a piazza supported by six pillars, two on each side, and one at each end. The pedestals of those in front have been flled with inscriptions both in the Greel and Palmyrene languages, which are become totally illegible.

Among these ruins are many sepulchres; these are all square vowers, four or five sturies high. There is a wall across the whole building, and the space on each hand is subdivided into six partitions by thick walls. The space between the partitions is wide enoughto receive the largest corpse, and in these niches there are seven or eight piled one above another. Many inscriptions have been found at Palmyra, which have occupied much of the attention of the learned. See Barthelemy's Reflections on the Palmyrene Alphabet, published at Paris in 1754; An Explication of the Inscriptions at Palmyra hitherto published, by John Swinton, of Christ Church, Oxford: 
Philosophical Transactions, No. 217 and 218; Ancient Universal History, vol. i. ; and, above all, the Ruins of Palmyra, or Tadmor in the Desart, published by Mr. R. Wood, who, with M. Bouverie and Mr. Dawkins, travelled thither in 1751. The result of their observations was published in 1753 , in the form of an atlas. The ruins of this once nighty and celebrated city were celebrated in fiftyseven copper-plates, 16 by 12 inches, printed on imperial pàper, and are admirably executed.

Palmyra was visited by Mr. Bruce prior to his journey into Abyssinia. Before he came within sight of the ruins, he ascended a hill of white gritty stone, in a very narrow winding road, but on getting up to the top, he was struck with the most stupendous siglit which, he believes, ever mortal saw. The whole plain below, which is very extensive, was all covered with magnificent buildings, that seemed to touch one another. All of them are finely proportioned, and composed of white stones, which at that distance appeared like marble.

\section{JID D A.}

THis is the name of an Arabian town, situated, according to $\mathrm{Mr}$. Bruce, in a very unwholesome, barren, and desert part of the country. "There is no stirring out of the town," says Mr. Bruce, "even for a walk, unless for about half a mile on the south side of the sea, where there is a number of stinking pools of stagnant water, which contributes to make the town very unwholesome. From this disagreeable situation, it is probable it would have been long ago abandoned, had it not been for its vicinity to Mecca. The town itself receives but little advantage, for all the customs are immediately sent to the rapacious sheriff of Mecca. "The gold," says Mr. Bruce, " is returned in bags and boxes, and passes on as rapidly to the ships as the goods do to the market, and leaves as little profit behind. In the mean time provisions rise to a prodigious price, and this falls on the townsmen, while all the profit of the traffic is in the hands of strangers, most of whom, after the market is over, which does not last six weeks, retire to Yemen and the adjacent countries, which abound in every sort of provision."

The trade at Jidda is carried on in a very strange, or rather incredible, manner. "Nine ships," says Mr. Bruce, "were there from India;" one of them worth, I suppose, 200,000l. One merchant, a Turk, living at Mecca, thirty hours' journey off, where no Christian dares go, while the continent is open to the Turk for escape, offers to purchase the cargoes of four out of these nine ships himself; another of the same cast comes, and says he will buy none unless he has them all. The samples are shewn, and the cargoes of the whole nine ships are carried in to the wildest parts of Arabia, by men with whom one would not wish to trust himself alone in the field. This is not all ; two Indian brokers come into the room to settle the price, one on the part of the Indian captain, the other on that of the buyer, the Turk. They are neither Mahometans nor Christians, but have credit with both. They sit down on the carpet, and take an Indian shawl, which they carry on their shoulder like a napkin, and spread it over 
their hands. They ta!k in the mean time indiferent conversation, as if they were employed in no serious business whatever. After about twenty minutes spent in handling each others' fingers below the shawl, the bargain is concluded, say for nine ships, without one word ever having been spoken on the subject, or pen and ink used in any shape whatever. There never was an instance of a dispute happening in these sales. But this is not all, the money is yet to be paid. A private Moor, who has nothing to support hin but his character, becomes responsible for the payment of these cargoes. This man delivers a number of coarse hempen bags, full of what is supposed to be money. He marks the contents upon the bag, and puts his seal upon the string that ties the mouth of it. This is received for what is marked upon it, without any one ever having opened one of the bags; and in India it is current for the value marked upon it as long as the bag lasts." The port of Jidda is very extensive, and contains numberless shoals, small islands, and sunk rocks; but in the harbour itself, ships may ride secure, whatever wind blows. The only danger is in coming in or going out; but as the pilots are very skifful, accidents seldom happen.

\section{Kubesha in Egrpt.}

Colonel GaERBer, who wrote an account of these countries in 1728, gives the following description of this very curious place. " Kubesha is a large strong town, situated on a hill between high mountains. Its inhabitants call themselves Franki, Franks, or Europeans, and relate that their ancestors were brought there by some accident, the particulars of which are now forgotten. The conimon conjecture is that they were mariners cast away upon the coast; but those who pretend to be better versed in their history, tell the story in this way:-

The Greeks and Genoese say they carried on during several centuries a considerable trade, not only on the Black Sea, but likewise on the Caspian, and were certainly acquainted with the mines contained in these mountains, from which they drew, by their trade with the inhabitants, great quantities of silver, copper, and other metals. ro work this upon the spot, they sent hither a number of workmen; to establish manufactures, and instruct the inbabitants. The subsequent invasion of the Arabs, Turks, and Moguls, during which the mines were filled up, and the manufactures abandoned, prevented the strangers from effecting their return, so that they continued here, and erected themselves into a republic.

What renders this account the more probable is, that they are still excellent artists, and make very good fire-arms, as well rifled as plain, sabres, coats of mail, and several articles in gold and silver, for exportation. They have likewise, for their own defence, small copper can= nons, of three pounds calibre, cast by themselves. They coin Turkish and Persian silver money, and even rubles, which readily pass current, as they are of the full weight and value. In their valleys they have pastures and arable lands, as well as gardens, but they purchase the greatest part of their corn, trusting chiefly for support to the sale of their manufactures, which are much admired in Persia, and the 
Crimea. They are generally in good circumstances, are quiet and inofichsive, but high-spirited and independent. Their town is considered as a neutral spot, where the neighbouring princes can deposit their treasures with safety. They elect twelve yearly magistrates, to whom they pay the most unlimited obedience, and, as all the inhabitants are on a footing in perfect equality, each individual in his turn is sure to have a share in the government.

\section{ALEXAN DIAN LibRARY.}

THIS was a magnificent establishment, and repository of learning, founded in Alexandria about 304 years before Christ, by Ptolemy Soter, the father of the celebrated line of the Ptolemies. ' So early as the time of Piolemy Philadelphus, son of the founder, it possessed one hundred thousand volnmes; it was much increased by many succeeding monarchs, and at length contained from seven to eight hundred thousand volumes. In this library were deposited the original works of Sophocles, Euripides, and Eschylus; for Ptolemy Euerotes liaving borrowed them of the Atheniars, would only return copies of them to the Grecians, whom, however, he presented with fifteen talents, about three thousand pounds sterling, as a recompense for their loss.

The entire library was at first contained in that part of the city called the Bruchion, but the number of its volumes became so great, that it was necessary to erect another building in the Serapeum; called the Daughter Library, - a fortunate circumstance for the preservation of this latter portion of its treasures; for when Juliu's Casar, on besieging the city, set fire to the lleet which he found in the port of Alexandria, the flames spread to that quarter which contained the Iarger portion of the books, but those in the Serapeum remained safe. This portion Cleoputra en,iched with the two hundred thousand volumes presented to her by Marc Antony, comprising the Pergamaan library. It continued to be angmented from time to rime by the Romans, and, notwithstanding some partial spoliations, was richer at the period of its destruction than when all its early buildings were standing.

This disastrous event for all subsequent scholars took place A. D. 642 , upon the taking of this city by the Saracens. With more zeal, perhaps, than judgment, John Philoponus, sumamed the Grammarian, at that time resident at Alexandria, applied to Amrou, the Arabian general, for the inestimable gift of the library; and the general wrote to the sullain Omar, to urge the request. His reply was worthy of the superstition propagated by his sword. "If," said he, "these writings of the Greeks agree with the Koran, they are useless, and need not be preserved; if they disagree, they are pernicious, and inust be destroyed." The decree was issued, and the four thousand baths of the city are said to have been heated during six months by the most valuable productions of antiquity.

\section{ADRIAN'S WALL.}

TuIs work, though called by the Roman historians marus, which signifies a wall of stone, was only composed of earth covered with 
green turf. It was carried on from the Solway Frith; a little west of the village of Burgh on the Sands, in as direct a line as possible, to the river Tyne on the east, at the place where the town of Newcastle now stands: so that it must have been above sixty English, and near seventy Roman miles in length. It consists of four parts: 1 . The principal agger, mound of earth, or rampart, on the brink of the ditch. 2. The ditch on the north side of the rampart. $\%$. Another rampart on the south side of the principal one, about frve paces distant from it, 4. A large rampart on the north side of the ditch. This last was probably the military way to the line of forts on this worls: it was so to those formerly built by Agricula; and if it did not serve the same purpose in this, there must have been no military way attending it. The south rampart might serve for an inner defence, in case the enemy, should beat them from any part of the principal rampart, or it might: be designed to protect the solliers from any sudden aitack of the provincial Britons.

For many ages this work has been in so ruinous a condition, that it is impossible to discover its original dimensions with certainty. From its appearance, it seems probable that the principal rampart was at least ten or twelve feet hivh, and the south one not much less, but the north one was considerably lower. From the dimensions of the ditch, taken as it passes through a lime-stone quary near Harlow hill, it appears to have been nine feet deep, and eleven wide at the top, but somewhat narrower at the hottom. The north rampart was about twenty feet distant from the ditch.

\section{History of Ancient English Castles.}

CASTLES walled with stoue, and designed for residence as well as defence, are for the most part, according to Mr. Grosse, of no higher antiquity than the Conquest; for although the Saxons, Romans, and even, according to some writers on antiquity, the ancient Britons, had castles built with stone; yet these were both few in number, and at that period, through neglect or invasions, were either destroyed, or so much decayed that little more than their luins were remaining. This is asserted by nany of on historians and antiquaries, and assigned as a reason for the ease with which Willian made himself master of England.

This circumstance led him also, both with a view to guard against invasions from without, and to awe his newly acquired subjects, immediately to begin erecting castles all over the kingdom, and likewise to repair and augment the old ones; and as he bad parcelled out the lands of the English amongst his followers, they, to protect themselves from the resentment of those so despoiled, built strong-holds and castles on their estates. This likewise caused a considerable increase of these fortresses; and the turbulent and unsettled state of the kingdom in the succeding reigns, served to multiply them prodigiously, every baron, ox. leader of a party, builing castles, insomuch that towards the end of king Stephen's reign they amounted to the almost incredible number of 1115 .

As the feudal system gathered strength, these castles became the 
heads of baronies. Each castle was a manor; and its castellain, owner, or governor, the lord of it. Markets and fairs were directed to be held there, not only to prevent frauds in the king's duties, but also as they were esteemed places where the laws of the land were observed, and as such had very particular privileges. But this good order did not last long; for the lords of castles began to arrogate to themselves a royal power, not only within their castles, but likewise over its environs; exercising judicature, both civil and criminal, coining of money, and arbitrarily seizing forage and provision for the subsistence of their garrisons, which they afterwards demanded as a right. At length their insolence and oppression grew to such a pitch, that, according to William of Newbury, "there were in England as many kings, or rather tyrants, as lords of castles ;" and Matthew Paris styles them, very nests of devils, and dens of thieves.

Castles were not solely in the possession of the crown and the lay barons, but even bishops had their fortresses, though it seems to have been contrary to the canons, from a plea made use of in a general council, in favour of king Stephen, who had seized upon the strong castles of the bishops of Lincoln and Salisbury. This prohibition, if such existed, was, however, very little regarded; as in the following reigns many strong places were held, and even defended, by the ecclesiastics; neither was more obedience afterwards paid to a decree made by the pope at Viterbo, May 28, 1220, wherein it was ordained that no person in England should keep in his hands more than two of the king's castles. 'The licentious behaviour of the garrisons of these places becoming intolerable, in the treaty between king Stephen and Henry II. when only duke of Nornandy, it was agreed that all the castles built within a certain period should be demolished; in consequence many were actually razed, but not the number stipulated.

The few castles under the Saxon government were probably, on occasion of war or invasions, garrisoned by the national militia, and at other times slightly guarded by the domestics of the great personages who resided therein ; but after the Conquest, when all the estates were converted into baronies held by knight's service, castle-guard coming under that denomination, was among the duties to which particular tenants were liable. From these services the bishops and abbots, who till the times of the Normans had held their land in frank almoign, or free alms, were by this new regulation not exempted. They were not, however, like the laity, obliged to personal service, it being sufficient that they provided fit and able persons to officiate in their stead. This, however, was at first stoutly opposed by Anselm, archbishop of Canterbury, who being obliged to fird some knights to attend. William II. in his wars in Wales, complained of it as an innovation, and infringement of the rights and immunities of the church. It was no uncommon thing for the Conqueror, and the kings of those days, to grant estates to men of approved fidelity and valour, on condition that they should perform castle-guard in the royal castles with a certain number of men, for some specified time; and sometimes they were likewise bound by their tenures to keep in repair, and guard, some particular tower or bulwark, as was the case at Dover castle. 
In process of time these services were commuted for annual rents, sometimes styled ward-penny, and waytfee, but commonly castleguard rents, payable on fixed days, under prodigious penalties called sursizes. At Rochester, if a man failed in the payment of his rent and castle-guard on the feast of St. Andrew's, his debt was doubled every tide during the time for which the payment was delayed. These were afterwards restrained by an act of parliament passed in the reign of king Henry VIII. and finally annihilated, with the tenures by knight's service, in the time of Charles II. Such castles as were private property were guarded either by mercenary soldiers, or the tenants of the lord or owner.

Castles which belonged to the crown, or fell to it either by fofeiture or escheat, circumstances that frequently happened in the distracted reigns of the feudal times, were generally committed to the custody of some trusty person, who seems to have heen indifferently styled governor and constable. Sometimes also they were put into the possession of the sheriff of the county, who often converted them into prisons. That officer was then accountable, at the exchequer, for the farm or produce of the lands belonging to the place entrusted to his,care, as well as all other profits; he was likewise, in case of war or invasion, obliged to victual and furnish them with munition out of the issues of his county ; to which he was directed by writ of privy seal.

Extraordinary Phenomenon in Bengal.

IN August, 1770, a most alarming phenoménon appeared, of a large black cloud at some distance in the air, which sometimes obscured the sun, and seemed to extend a great way over and about Calcutta. The hotter the day proved, the lower this clond seemed to descend, and for three days it occasioned great speculation. The bramins pretended that this phenomenon, which was a cloud of insects, had been foretold by them; and if ever they descended to the earth, the country would be destroyed by some untimely nisfortune. They said, that, about fifty years before, there had been such another bad time, when the earth was parched for want of water; and this cloud of insects made its appearance, though it came much lower the second time than it had done before. On the third day, the weather being very hot and clouly, they descended so low that they could be plainly seen. They seemed to be about the size of a horse-stinger, with a long red body, large head and eyes, keeping close together like a swarm of bees, and to appearance flying quite on a line. None, however, were caught, the people being over much frightened by the prognostications of the bramins. Whilst it rained, they continued in one position for nearly a quarter of an hour, then they rose five or six feet at once, and in a little time descended as much, until a strong N.w. wind blew for two days successively. During its continuance they ascended and descended, but more precipitately than before; and next morning the air was quite clear. For some days before the cloud made its appearance, the frogs, toads, and insects, which during the rains made a continual noise through the night, disappeared, and were never heard nor seen, except in the river. 
THIS famous chapel, which is so much visited by pilgrims, was, according to the legend, originally a small house in Nazareth, inh lited by the Virgin Mary, in which she was saluted by the angel, and where she brought forth-our Saviour. After their death it was held in high veneration by all Christians, and at length metamorphosed into a chapel, and dedicated to the Virgin; upon which occasion, St. Luke, according to the Catholics, made that identical inage, which is still preserved here, and dignified with the name of our Lady of Loretto.

This sanctifed edifice was allowed to sojourn in Galilee as long as that district was inhabited by Christians; but when the infidels got possession of the country, a band of angels, to save it from pollution, took it in their arms, and conveyed it from Nazareth to a casthe in Dalmatia: but not having been entertained with suitable respect at this castle, the same indefatigable angel's are said to have carried it over the sea, and placed it in a field belonging to a noble lady called Lauretta, from whom the chapel takes its name. "This field happening to befrequented by highwaymen, the angels renoved it to the top of a hill belonging to two brothers; who, being equally enamoured of their new visitor, became jealous of each oiher, quarre!led, fought, and fell by mutual wounds.

After this catastrophe, the angels finally renoved the holy chapel to the place where it now stands, and has stood these four hundred years, having lost all relish for travelling, so that the arrival of the Frelich atheists could not stir it one foot. The sacred chapel stands die east and west, at the farther end of a large church, formed of the most durable stone of Istria, which has been built round it? The inside is of the choicest marble, after the plan of San Savino's, and ornamented with basso-relievos, the workmanship of the best sculptors which Italy could furnish in the reign of Leo X." "The subject of these basso-relievos are, the history of the blessed Virgin, and other parts of the Bible. The whole santa casa is about fifty feet in length, thirty in breadth, and thirty in height: but the real house itself is no more than thirty-two feet in length, fourteen in breadth, and, at the sides, about eighteen feet in height; the centre of the roof is four or five feet higher. The walls of this little holy chapel are composed of pieces of a reddish substance, of an oblong square shape, laid one upon another in the manner of brick. Before the late war, this chapel was the richest receptacle of the tributes of superstition, in Europe, and, to the devotees of the Roman Catholic persuasion, the most sublime olject of pilgrimage.

\section{JERUSALEM.}

JERUSALEM, the holy city, has become a desert. Though at this time rebuilt, and to the approaching traveller presenting the semblance of a populous and flourishing city, no sooner does he enter it, than the delusion ceases. Every step he takes echoes on his ear, a terrible silence prevails in every part: he meets with few persols in the 
streets, and those few regard him and each other with anxious suspicion. He may sometimes hear the plaintive bleating of a lamb, as it struggles under the hands of a pale meagre wretch who is slaughtering it. He meets with one, more suspicious and observant than the rest. Something is concealed under his garments. The man approaches; he is a Jew : the treasure he has so carefully concealed is a hard-earned meal, which he fears to call his own till he has eaten it. The travelier is surprised at the sound of horse-tramplings: a horseman flies past him, bearing a head newly severed from the body. It is a Turk with the head of an Arab. Such is now Jerusalem; and the traveller leaves it, deeply impressed with the awful veracity of divine truth.

Of this once favoured, but now devoted city, Mr. Carne, a traveller who has lately visited it, thus speaks.

"By moonlight next morning, we were on the way to the sacred city. For about three hours it led over the plain, and then ascending the hills, the road became very disagreeable, in some parts so narrow that one horse only could proceed at a time with safety, as the rains had made the rocky paths much worse than usual. At the end of nine hours, however, as we proceeded over the summit of a rugged hill, we beheld Jerusalem at a small distance before us. Its aspect certainly was not magnificent or inspiring, but sad and dreary.

"On reaching the gate of Bethlehem, we were speedily admitted, and after some time procured a lodging in the house of a native, not far from the walls, and near the tower of David. We had enough of convents, and a traveller will find himself much more agreeably situated, and more at ease, in living Orientally, than confined within the walls, and obliged to conform to the hours, of a monastery. I had my divan and coffee, excellent wine, and music in the evening, and wished only to remain in peace; but in a day or two repeated messages came from the superior of the convent, urging my entering into it, it being unusual for a traveller to lodge without, and in these times exceedingly unsafe. Arriving at the convent, they put me into a little cold cell, with a single chair and table in it, and a small flock-bed, as if I had come to perform a pilgrimage; and the pictures of saints and martyrs on the walls, were but poor consolations for the substantial comforts I bad lost.

"The morning after my arrival was a very lovely one, and, though it was in February, perfectly warm. I passed out of the gate of Bethlehem, and, traversing part of the ravine beneath, ascended the mount of Judgment on the south side of the city. How interesting was her aspect, beheld over the deep and rocky valley of Hinnom? her gloomy walls encompassing Mount Zion on every side, and as yet there was no sound to disturb the silence of the scene. The beautiful Mount of Olives was on the right, and at its feet the Valley of Jehoshaphat, amidst whose great rocks and trees stood the tomb of Zecharias, the last of the prophets that was slain : the only stream visible flowed from the fountain of Siloam, on the side of Zion opposite. It is true, the city beloved of God has disappeared, and with it all the hallowed spots once contained within its walls, and keen must be the faith that can now embrace their identity; yet the face of nature 
still endures: the rocks, the mountains, lakes, and valleys, are unchanged, save that Ioneliness and wildness are now, where once were luxury and every joy; and though their glory is departed, a high and mournful beauty still rests on many of these silent and romantic scenes. Anidst them a stranger will ever delight to wander, for there his imagination can seldom be at fault. The naked mountain, the untrodden plain, and the voiceless shore, will kindle into life around him, and his every step be filled with those deeds through which guilt and sorrow passed away, and 'life and immortality were brought to light.'

"This was the most desirable time of the year to be at Jerusalem, as the feast of Easter was about to commence, and many of the pilgrims had arrived. The streets of the city are narrow, and very ill paved, and the houses in general have a mean appearance. - The bazaar is a very ordinary one. The Armenian quarter is the only agreeable part of the city: the convent, which stands near the gate of Zion, is very spacious and handsome, with a large garden attached to it, and it can furnish accommodations for eight hundred pilgrims within its walls; the poorer part lodging in out-houses and offices in the courts, while the richer find every luxury and comfort, for all the apartments in this convent are furnished in the Oriental manner. The wealthy pilgrims never fail to leave a handsome present, to the amount sometimes of several lonndred pounds. If a pilgrim dies in the convent, all the property he has with him goes to the order.

"The lower division of the city towards the east, is chiefly occupied by the Jews: it is the dirtiest and most offensive of all. But few passengers in general are met with in the streets, which have the aspect of fortresses where the convents are situated, from the height and strength of the walls the monks have thought necessary for their defence. Handsomely dressed persons are seldom seen, as the Jew's and Christians rather study to preserve the appearance of poverty, that they may not excite the jealousy of the Turks.

"The population of Jerusalem has been variously stated; but it can hardly exceed twenty thousand: ten thousand of these are Jews, five thousand Christians, and the same number of Turks. The walls can with ease be walked round on the outside in forty-five minutes, as the extent is scarcely three miles."-Carne's Letters from the East, vol. i. p 296-302.

Of this once splendid and glorious, but now almost desolated city, the annexed engraving exhibits the appearance from a distance.

\section{Medina.}

THIs renowned Mahomedan city, of which the following engraving exhibits the celebrated Mosque, stands in Arabia Felix, in the province of Hedsjas, about a day's jaurney from Jambo on the Red sea. It is situated in a sandy plain, and is of moderate extent, and surrounded with indifferent walls. It belongs to the sheriffe of Mecca, but of late has been governed-by a sovereign of its own, of the family of Daric Berkad. Before the days of Mahomet it was called Jathreb, but was called Medined en Nebbi, the City of the Prophet, from the period at which Mahomet, upon his expulsion from Mecca by the Ioreishites, 


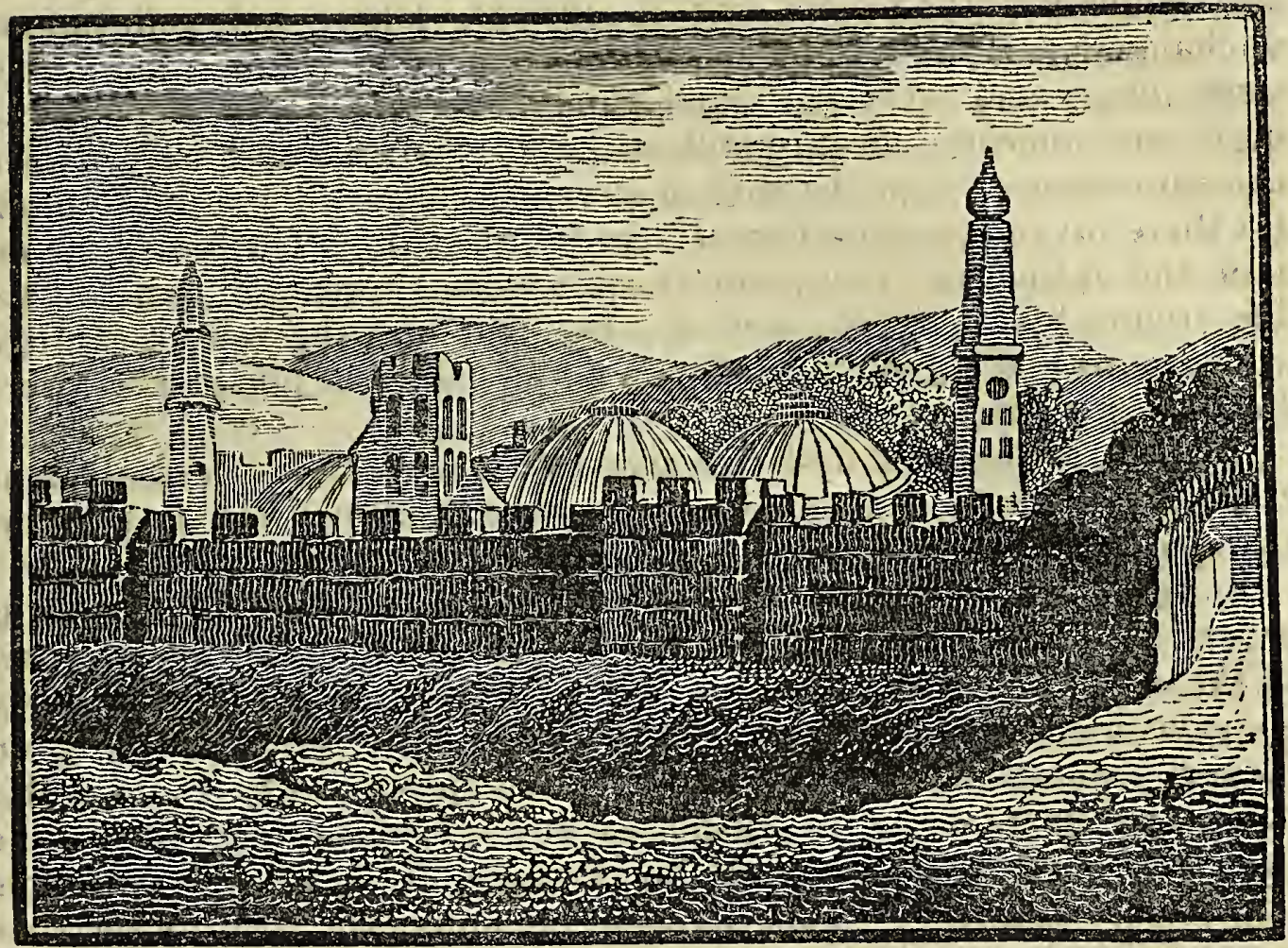

MOSQUE AT MEDINA.

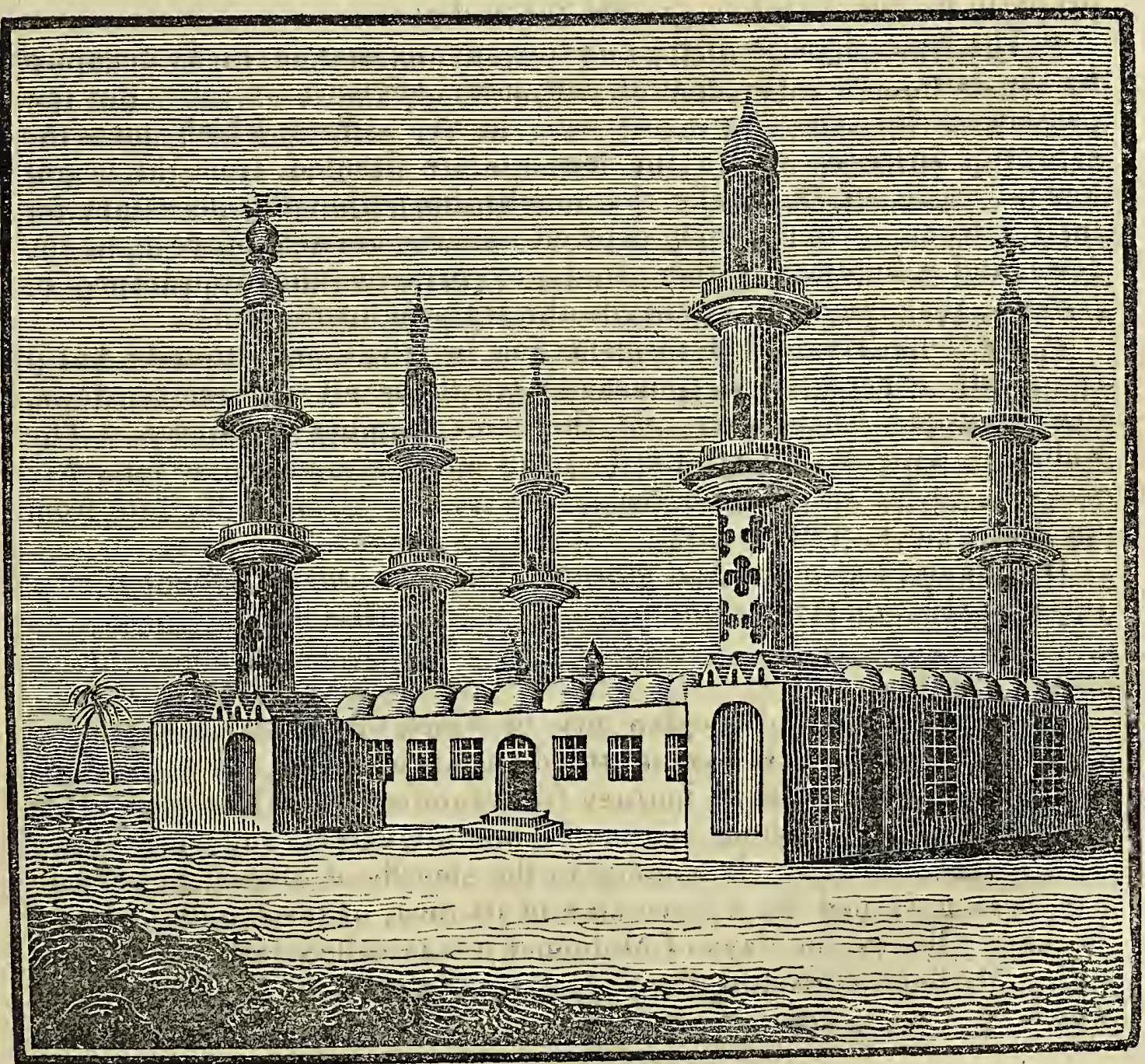


took refuge liere, and continued to make it the place of his residence for the remainder of his life. The tomb of Mahonet at Medina is held in high respect by the Mussulmans, yet they are not obliged to visit it in order to perform their devotional exercises, but, as the caravans pass near it from Syria in their returri to Mecca, they turn asire to view the prophet's sepulche. The tomb is situated in the corner of the great square; it is of plain mason-work, surrounded with iron rails, and is only to be seen by looking through them, and is placed between the two tombs in which are deposited the ashes of the two first caliphs. The story that has so long been circulated, and has obtained such general credit, that his coffin is of steel, and is suspended in air between two vast magnets, is an idle fiction, that has nothing but vulgar prejudice for its support.

Although it is not more magnificent than the tombs of the founders of other mosques, the building that covers it is hung with a piece of silk stuff embroidered with gold, which is renewed every seven years by the pacha of Damascus. This building is guarded by forty eunuchs, chiefly for the security of the treasure which is said to be kept in it. This treasure consists chiefly of precious stones, the offerings of rich Mussulmans; but the account given of it is blended with nuch fable.

\section{BAREL.}

ThIs is the name of a city and tower, undertaken to be built by the whole human race soon after the flood, and remarkable for the miraculous frustration of the attempt by the confusion of languages. As to the situation of ancient Babel, most authors are of opinion that it was exactly in the place where the celebrated city of Babylon afterwards stood. That it was in the same country, appears indisputably from Scripture ; but that it was exactly in the same place cannot be proved, nor is it a matter of any consequence.

Authors have been much divided as to the motive by which the whole race of mankind were induced to join in such an undertaking. Some have imagined that it was out of fear of another deluge ; otheirs, that, knowing beforehand they were to be dispersed over all the different countries of the world, they built this tower, in order to defeat the design of the Deity, because, having a tower of sucl vast height as they supposed, those who were at a distance could easily find their way back again. Had either of these been their design, however, it is probable they would have chosen an eminence rather than a plain, for the situation of their tower; or, indeed, they would have chosen some high mountain, such as Ararat, for their mark, rather than any tower at all ; for though it is said they designed the top of their tower to reach to heaven, we can scarcely suppose them to have been such fools as to imagine this possible in the literal sense of the word. But, indeed, when we consider their ignorance of the true figure and motions of the earth and celestial bodies, and reflect on the many absurdities in religion and science believed by the ancients, even this monstrous idea is not too gross to have been entertained by them. But it appears most rational to take the word, in the limited 
sense, in which it is often used by Moses and his countrymen, where they speak of cities walled up to heaven.

Others imagine that the top of this tower was not to reach up to heaven, but to be consecrated to the heavens, $i$. $e$. to the worship of the sun, moon, and stars, of the fire, air, \&c. and other natural powers, as deities; and therefore that the true Deity interposed, in order to prevent a total and irrecoverable defection. Certain it is, that the species of idolatry, which takes for the objects of its worship those natural agents, as it is the most ancient, so it is by far the most rational, and most difficult to be disproved. It is much more difficult, for instance, to prove that the sun, which by his enlivening beams gives vigour to the whole creation, is not a deity, than that a $\log$ of wood is not one; and hence, if such a system of religion became universally established among mankind, it would be almost impossible ever after to eradicate it. Indeed, that the scheme of Babel, whatever it was, could have been put in execution by man, seems evident from the interposition of the Deity on the occasion; for we cannot suppose that he would have wrought a miracle on purpose to defeat that which would have defeated itself, if it had let it alone.

Agreeably to this hypothesis, Dr. Tennison supposes that the tower was of a pyramidical form, in imitation of the spires of flame, and that it was erected in honour of the sun, as being the most probable cause of drying up the flood. The materials for building this tower, the Scripture informs us, were bricks and slime, or bitumen. According to an eastern tradition, three years were taken up in making the bricks, each of which was fifteen cubits long, ten broad, and five thick.

\section{BABEL.}

THIs tower was, at its base, a square of a furlong on each side, or a mile and a half in compass, and consisted of what appeared to be eight towers, built one above the other, the height of each being seventy-five feet, and that of the whole six hundred. The ascent was by stairs on the outside, which formed a sloping line from the bottom to the top, winding eight times round it. As these compartments or stories had mally rooms with arched roofs supported by pillars, they made parts of the temple, when the tower became consecrated to idolatrous purposes. Over the whole of the top of the tower there was, it is said, an observatory, by the advantages of which, the Babylonians extended their skill in astronomy beyond other nations: for when Alexander took Babylon, Callistheres the philosopher, who accompanied him thither, found they had astronomical observations for 1903 years prior to that time, which carried up the account as high as the fifteenth year after the flood, or within fifteen years after the tower of Babel was built, or to the year 2334 before Christ.

This tower or temple stood until the time of Xerxes, who, on his return from his Grecian expedition, about 422 year's B. C. plundered it of all its wealth, and then demolished the whole, leaving scarcely any thing but a heap of ruins.

During subsequent periods, these monuments of ancient ingenuity and grandeur have been visited by numerous travellers, all of whom 
concur in opinion, that the city, the tower, and the surrounding comtry, exhibit nothing but a scene of desolation, fulfilling with terrible exactness the following prediction delivered by the prophet:

"And Babylon, the glory of kingdoms, the beauty of the Chaldees' excellency, shall be as when God overthrew Sodom and Gomorrah. It shail never be inhabited, neither shall it be dwelt in from generation to generation; neither shall the Arabian pitch tent there, neither shall the shepherds make their fold there. But wild beasts of the desert shall lie there, and their houses shall be full of doleful creatures; and owls shall dwell there, aud satyrs shall dance there; and the wild beasts of the islands shall cry in their desolate houses, and dragons in their pleasant palaces; and her time is near to come, and her days shall not be prolonged." Isaiah xiii. 19, \&c.

\section{AranjuEz.}

THIs is the name of a beautiful palace belonging to the kings of Spain, situated on an island formed by the 'Tagus, the Xarama, and a canal, in the province of Toledo, six and a half Spanish leagues from Madrid. The country on which it stands is one of the most delightful in Spain. The ground was appropriated to the purpose by Charles I. and the foundation laid by his son Philip II. Succeeding monarchs, in particular Ferdinand VI. and Charles III., contributed their share to its enlargement and embellishment. This palace is remarkable, not for its magnitude, but for combining various claims to admiration, on the score of beauty and interest. It contains an excellent collection of paintings, of ancient and modern busts, marble staircases, superis mirrors from the manufactory of St. Ildefonzo, and an apartnent filled with beautiful specimens of porcelain from the works at Madrid. But even these are exceeded in interest by the gardens, which are in the form of a star, and excite the admiration of every observer. The eln-tree alleys are particularly fine, being so wide that four carriages can go abreast, while between each double row there flow's a small canal. The main alley is between six and seven hundred paces long, and twelve feet broad, and is enclosed with a lofty hedge. At every seventy or eighty paces are resting places in the form of squares or hexagons, while fountains and jets-d'eau play heautifully in every corner. The water is brought by an aqueduct from the small lake called Mar de Ontigola, about a mile distant. Near this lake is the village of Ontigola, the usual residence of foreign ministers, when the court is at Aranjuez. The common practice is for the court to come here a little after Easter, and remain till the end of June. In July and August the air becomes unwholesome, and engenders violent fevers.

The adjoining town of Aranjuez was at first an inconsiderable village, and is indebted for its enlargement and present importance to Ferdinand VI. It is built somewhat in the Dutch style, and in conformity to a model laid down by government, who make over lots of ground to those who undertake to build according to the prescribed plan. Broad and parallel streets, with fine pavements, here intersect each other at right angles. The houses are built in the simplest form 
two stories high, painted white, with green doors and window-shutters, and double rows of trees planted before them. The principal church stands in the great square, along with the Franciscan monas. tery, and covered market place." The inhabitants are comfortable, and even opulent, deriving handsome incomes from the expenses of the court, and from letting part of their houses. The high road from Aranjuez to Madrid is constructed on the model of the ancient Roman roarls, and each mile is said to have cost three millions of reals, 33,2501 . sterling. It was begun under Ferdinand VI. The population of the town, during the residence of the court, is about ten thousand.

\section{BARgarRoN.}

THrs is the name of a village famous for being the first place in Scotland where fine thread was manufactured. Miss Christiana Shaw, daughter of John Shaw, esq. of Bargarron, who, when a girl of eleven years of age, was supposed to have been bewitched, and on whose account four men and three women were executed for the supposed crime, at Parsley, in 1696-\%, had the merit of introducing this manufacture. Mr. Walter Young, minister of the parish, gives the following account of its commencement.

"Having acquired a remarkable dexterity in spinning fine yarn, she conceived the idea of manufacturing it into thread. Her first attempts in this way were necessarily on a small sale. She executed almost every part of the process with her own hands, and bleached her materials on a large slate placed on one of the windows of the house. She succeeded, however, so well in these essays, as to have sufficient encouragement to go on, and to take the assistance of her younger sisters and neighbours. The then lady Blantyre carried a parcel of her thread to Bath, and disposed of it advantageously to some manufacturers of lace, and this was probably the first thread made in Scotland, that had crossed the Tweed. About this time a person who was acquainted with the family, happening to be in Holland, found means to learn the secrets of the thread nanufacture, which was then carried on to a great extent in that country, particularly the art of sorting and numbering the threads of different sizes, and packing them up for sale, and the management of the twisting: and twining machines. This knowledge he communicated on his return to his friends in Bargarron, and by means of it they, were enabled to conduct theif manufacture with more regularity, and to a greater extent The young women in the neighbourhood were taught to spin fine yarn, several twining mils were erected, correspondences for promoting the consumption of it were established, and a profitable business was carried on. Bargarron thread became extensively known, and, being ascertained by a stamp, bore a good price. From the instructions of the family of Bargarron, a few families in the neighbourhood engaged in the same business, and continued in it for a number of years. It was not to be expected, however, that a manufactory of this kind could be confined to so small a district, or could be allowed to remain in so few hands for a great length of time. 
The secrets of the business were gradually divulged by apprentices and assistants. A Mr. Polloch in Paisley availed himself of these communications, and laid the foundation of the well-established and extensive manufacture of thread, which has ever since been carried ou in that town. From that time the women in this neighbourhood nave continued to practise the spinning of fine yarn, which they dispose of to the Paisley manufacturers."”

\section{John o'Groat's House.}

THIs is an ancient house, situated in Caithness-shire, seated on Dunges-bay, or Duncan's Bay Head, and remarkable for being the most northerly point in Great Britain, on which account it has been often visited by travellers. But if it has acquired fame from its peculiar lncal situation, it merits no less celebrity on account of its origin, which is not so well known, but is thus related by Dr. Morison, in his Statistical Account of the Parish of Canisbay.

"In the reign of James IV. Malcolm, Gavin, and John de Gront, supposed to have been brothers, and originally from Holland, arrived in Caithness from the south of Scotland, bringing with them a letter, written in Latin by that prince, recommending them to the countenance and protection of his loving subjects in the county of Caithness. They purchased or got possession of the lands of Warse and Dungis Bay, in the parish of Canisbay, on the Peutland Frith; and each of them obtained an equal share of the property they acquired. In process of time their families increased, and there came to be eight different proprietors of the name of Groat. These eight families having lived comfortably in their possessions, for many years, established an annual meeting, to celebrate the anniversary of the arrival of their ancestors on that coast. In the course of their festivity on one of these occasions, a question arose respecting the right of taking the door, and sitting at the head of the table, and such like points of precedency, each contending for the seniority and chieftainship of the clan, which increased to such a height as would probably have proved fatal to some, if not to all of them, had not John de Groat, who was proprietor. of the ferry, interposed it. He having procured silence, expatiated on the happiness they had hitherto enjoyed, owing to the harmony that had subsisted among them. He assured them, that as soon as they began to quarrel among themselves, their neighbours would fall upon them, take-their property, and expel them from the country. He therefore conjured them by the ties of blood and mutual safety, to return quietly that night to their homes, and pledged himself that he would satisfy them all with respect to precedency, and prevent the possibility of such disputes at their future anniversary meetings. They all acquiesced, and departed in peace. In due time John de Groat built a room, distinct by itself, of an octagon shape, with eight doors and windows in it, and having placed in the middle a table of oak, of the same shape, he desired each of them to enter at his own door, and sit at the head of the table, he himself taking the seat that was left unoccupied. By this ingenious contrivance, any dispute in regard to rank was pre- 
vented, as they all found themselves on a footing of equality, and their former good humour and harmony was restored. That building was then called John o'Groat's house, and though the house is totally gone, the place where it stood still retains the name, and deserves to be remembered as long as good intentions and good sense are estimable in a country. The particulars above mentioned were communicated to John Sutherland, esq. of Wexter, above fifty years ago, by his futher, who had seen the letter written by James IV. in the possession of George Groat of Warse. The remains of the oak table have been seen by many now living, who have inscribed their names upon it."

\section{The Dring Gladiator.}

THIs is a most valuable monument of ancient sculpture, long preserved in the palace of Chigi, but carried to Paris with the Lacoon, \&c. in 1796. This gladiator having received the mortal stroke, appears particularly careful ut procumbat honeste, "that he might fall honourably." : " He is seated in a reclining posture on the ground, and seems to have just strength sufficient to raise himself on his right arm; and in his expiring moments he does not abandon himself to grief and dejection, but is solicitous to attain that firmness of aspect and attitude which the gladiators valued themselves on preserving in this last scene of distress. He betrays no tokens of fear by his countenance, nor sheds one tear, although he appears, notwithstanding his remaining strength, to have but a few moments to live. Thus the ancients knew how to animate marble, and to give it almost every expression of life.

\section{NATURAL BRIDGES.}

The Rev. Mr. Aukle, in his account of the parish of Castletown, in Roxburghshire, gives the following description of a natural bridge in that parish. "One of the greatest curiosities," says he, "to be seen in this county, or perhaps in Scotland, is a bridge of stone over the river Blackhurn. It stretches across the stream, and joins the hills on each side. It is fifty-five feet long, ten feet wide, and the thickness of the arch is two feet of solid stone. It is not composed of one entire rock, but consists of many stones, about a foot and a half square, set neatly together. The bridge slopes a little downwards, and the water rushes under the arch through an open.ing of thirty-one feet.

Mr. Jefferson, of the United Siates of America, gives a particular description of a most wonderful work of this kind in the state of Virginia. It is on the ascent of a hill, which seems to have been cloven throngh its length by some great convulsion of nature. The fissure just at the bridge is, by some admeasurements, two hundred and seventy feet deep, by others only two hundred and fifty. It it is about forty-five feet wide at the bottom, and ninety feet at the top ; this, of course, determines the length of the bridge, and its height from the water. Its breadth in the middle is about 
sixty feet, but more at the ends, and the mass at the summit of the arch about forty feet. A part of this thickness is constituted by a coat of earth, which gives growth to many large trees. 'The residue, with the hill on both sides, is one solid rock of limestone. The arch approaches the semi-elliptical form; but the larger axis of that ellipsis, which would be the end of the arch, is much longer than the transverse. Though the sides of this bridge are provided in some parts with a parapet of tixed rock, yet few men have resolution to walk to them, and look over into the abyss. One involuntary falls on his hands and feet, creeps to the parapet, and peeps over it. Looking down from this height about a minute, gave Mr. Jefferson a violent headache. If the view from the top be painful and intolerable, that from below must be delightful in an equal extreme. It is impossible for the emotions arising from the sublime to be felt beyond what they are here; so beautif:l an arch, so elevated, so light, and springing as it were up to heaven, the rapture of the spectator really is indescribable. This fissure continuing deep, narrow, and straight, for a considerable distance above and below the bridge, opens a short but very pleasing view of the North mountain on one side, and the Blue ridge on the other, at the distance of about five miles each. This bridge is in the county of Rockbridge, to which it has given name, and affords a public and commodious passage over a valley, which cannot be crossed elsewhere for a considerable distance. The strean passing under it is called Cedar Creek. It is a water of James's river, and sufficient in the driest season to turn a gristmill, though its fountain is not more than two miles above.

Don Ulloa mentions a break similar to this in the province of Agaraez in Sonth America. It is from sixteen to twenty-two feet wide, one hundred and eleven feet deep, and of one hundred and thirteen miles continuance, English measure. Its breadth at top is not sensibly greater than at bottom. Don Ulloa inclines to the opinion, that this channel bas been effected by the wearing of the water which russ through it, rather than that the mountain should have broken open by any convulsion of nature. But if it had been worn by the running of water, would not the rocks which form the sides have been plain? or if, meeting in some parts with veins of harder stone, the water had left prominences on one side, would not the same cause have sometimes, or perhaps generally, occasioned prominences on the other side also? Yet Don Ulloa tells us, that on the other side there are always corresponding cavities, and that these tally with the prominences so perfectly, that, were the two sides to come together, they would fit in all their indentures, wilhout leaving any void. In fact; this does not resemble the effect of yuning water, but looks ratheras if the two sides had been parted asunder.

The sides of the break, over which is the natural bridge of Virginia, consisting of a veiny rock which yields to time, the correspondence between the salient and re-entering qualities, if they existed at all, have, now disappeared. This break has the advantage of the one described by Don Ulloa in its finest circumstance; no portion, in that instance, having held together during the separation of the other parts, so as to form a bridge over the abyss. 


\section{BRIDGES OF BOATS.}

THESE are either made of copper or wooden boats, made fast with stakes or anchors, and laid over with planks. One of the most notable exploits of Julius Cæsar was his expeditiously making a bridge of boats over the Rhine. Modern armies carjy copper or tin boats, named pontoons; to be in readiness for making bridges; several of these being joined side by side until they reach across the river, and planks laid over them, make a plain for the men to march on. There are five bridges of boats at Beaucaire and Rouen, which rise and fall with the water; and that of Seville is said to exceed them both. The bridge of boats in Rouen, built instead of the state stone-bridge erected there by the Romans, is represented by a modern writer as the wonder of the present age. It always floats, and rises and falls with the tide, or as the land waters fill the river. It is near three hundred yards long, and is paved with stone like the streets; can iages with the greatest burdens go over it with ease, and men and horses with safety, though there are no rails on either hand. The boats are very firm, and well moored with strong chains, and the whole well looked after, and constantly repaired, though now very old.

\section{Pendent Bridges.}

THEsE bridges are not supported either by posts or pillars, but hung at large in the air, only supported at the two ends or butments. Iristances of such bridges are given by Palladia and others. Dr. Wallace gives the design of a timber bridge seventy feet long, without any pillars, which may be useful in some places where pillars cannot be conveniently erected. Dr. Plot assures us, that there was formerly a large bridge over the castle-ditch at Tilbury in Staffordshire, made of pieces of timber, none much above a yard long, and yet not supported underneath either with pillars or archwork, or any sort of prop whatever.

\section{RUSHeN AN D OTHER BRIDGes.}

RusHEN bridges are made of large sheaves of rushes, growing in marshy grounds, which they cover with boards or planks: they serve for crossing ground that is boggy, miry, or rotten. The Romans had also a sort of subitaneous bridges, made by the soldiers, of boats, or sometimes of casks, leathern bottles, or bags, or even of bullocks' bladders blown up and fastened together, called Ascogafic. $\mathrm{Mr}$. Couplet gives the figure of a portable bridge, two hundred feet long, easily taken asunder and put together again, and which forty men may carry. Frazier speaks of a wonderful kind of bridge at Apurima in Lima, made of ropes formed of the bark of a tree.

\section{The Great Canal of Scotrand.}

Turs is a navigable canal between the Forth and Clyde, dividing the kingdom into two parts; it was first thought of by Charles II. for 
transports, and small ships of war; the expense of which was to have been five hundred thousand pounds, a sum far beyond the abilities of his reign. It was again projected in 1722, and a survey made: but nothing more was done till 1761, when the then Lord Napier, at his own expense, caused to be made a survey, plan, and estimate, on a small scale. In 1\%64, the trustees for fisheries \&c. in Scotland, caused to be made another survey, plan, and estimate, of a canal tive feet deep, which was to cost seventy-nine thousand pounds. In 1766, a subscription was obtained by a number of the most respectable merchants in Glasgow, to form a canal four feet deep, and twentyfour feet in breadth; but when the bill was nearly obtained in parliament, it was given up, on account of the smalluess of the scale, and a new subscription set on foot for a canal seven feet deep, estimated at one hundred and fifty thousand pounds. This obtained the sanction of parliament, and the work was begun in 1768 by Mr. Smeaton the engineer.

The extreme length of the canal from the Forth to the Clyde is thirty-five miles, beginning at the mouth of the Carron, and ending at Dalmure Burnfoot on the Clyde, six miles below Glasgow, rising and falling one hundred and sixty feet by means of thirty-nine locks, twenty on the east side of the sunmit, and nineteen on the west, as the tide does not ebb so low in the Clyde as in the Forth, by nine feet. Vessels drawing eight feet water, and not exceeding nineteen feet beam, and seventy-three feet in length, pass with ease, the canal having been afterwards deepened to more than eight feet. The carrying the canal through moss, quicksand, gravel, and rocks, up precipices, and over valleys, was attended with inconceivable difficulties. There are eighteen drawbridges, and fifteen aqueduct bridges of note, besides small ones and tunnels. In the first three miles there are only six locks; but in the fourth mile there are no less than ten locks, and a very fine aqueduct bridge over the great road west of Falkirk. In the next six miles there are only four locks, which carry on to the summit. The canal then runs' eighteen miles on a level, and terminates about a mile from Glasgow. In this course, for a considerable way the ground is banked about twenty-five feet high, and the water is sixteen feet deep, and two miles of it are made through a deep moss. At Kirkinhillock the canal is carried over the water of Logie, on an aqueduct arch of ninety feet broad. This arch was thrown over in three stretches, having only a centre of thirty feet, which was shifted on small rollers from one stretch to another: a thing new, and never attempted before with an arch of this size, yet the joinings are as failly equal as any other part, and admired as a very fine piece of masonry. On each side there is a very considerable banking over the valley. The work was carried on till within six miles of its junction with the Clyde; when the subscription and a subsequent loan being exhausted, it was stopped in 1795. The city of Glasgow, however, by means of a collateral branch, opened a communication with the Forth, which has produced a revenue of about six thousand pounds annually; and, in order to finish the remaining six miles, government, in 1784, gave fifty thousand pounds out of the forfeited estates, the dividends arising from this sum to be applied to making and repairing roads 
the Highlands. Accordingly, the work was resumed in July, 1786, and completely finished within four years after; the navigation being opened between the British sea and Atlantic ocean on the 28th of July, 1790.

The aqueduct bridge over the Kelvin, supposed to be the greatest of the kind in the world, consists of four arches, and carries the canal over a valley sixty-three feet high, and four hundred and twenty in length, exhibiting a very singular effort of human ingenuity and labour. To supply this canal with water, was of itself a very great work. There is one capacious reservoir, of fifty acres, twenty-four feet deep, into which many rivers and springs terminate, which it is thought will afford a sufficient supply of water at all times. This whole undertaking has cost about two hundred thousand pounds. It is the greatest of the kind in Britain, and must prove of immense national utility, as it shortens the nautical distance from eight hundred to one thousand miles, and affords a safe and speedy navigation, at all seasons, to Ireland, and the western parts of Britain, without any danger of shipivreck.

\section{DECOY.}

AMONG fowlers, this is a place made for catching wild fowl. A decoy is generally made where there is a large pond, surrounded with wood, and beyond that a marshy and uncultivated country; if the piece of water is not thus surrounded, it will be attended with noise and other accidents, which may be expected to frighten the wild fowl from a quiet haunt, where they mean to sleep during the day in security. If these noises or disturbances are wilful, an action will lie against the disturber. As soon as the evening sets in, the decoy rises, as they term it, and the wild fowl feeds during the night. If the evening is still, the noise of their wings during their flight is heard at a very great distance, and is a pleasing though melancholy sound. This rising of the decoy in the evening, is in Somersetshire called radding. The decoy ducks are fed with hempseed, which is thrown over the skreens in small quantities, to bring them forwards into the pipes or canals, and to allure the wild fowl to follow as the seed floats. There are several pipes, as they are called; which lead up a narrow ditch, that closes at last with a funnel net. Over these pipes, which grow narrower from their first entrance, is a continued arch of netting suspended on hoops. It is necessary to have a pipe or ditch for almost every wind that can blow, as upon this circumstance it depends. which pipe the fowl will take to ; and the decoy-man always keeps on the leeward side of the ducks, to prevent his effuvia reaching their sagacious nostrils.

All along each pipe at certain intervals are placed skreens made of reeds, so situated that it is impossible the wild fowl should see the decoy-man before they have passed on towards the end of the pipe, where the purse-net is placed. The inducement of the wild fowl to go up one of these pipes is, because the decoy-ducks, trained to this, Jead the way, either after hearing the whistle of the decoy-man, or enticed by the hempseed : the decoy-ducks will dive under water, whilst 
the wild fowl Ay on, and are taken in the purse-net. It often happens, however, that the wild fowl are in such a state of sleepiness and dozing, that they will not follow the decoy-duck; use is then generally inade of a dog, which is taught his lesson: he passes backwards and forwards between the reed skreen, in which are little holes both for the decoy-man to see, and the little dog to pass through; this attracts the eye of the wild fowl, who, not choosing to be interrupted, advance towards the small and contemptible animal, that they may drive him away. The dog all the time, by the direction of the decoy-man, plays among the skreens of reeds, nearer and nearer the purse-net; till at last, perhaps, the decoy-man appears behind a skreen, and the wild fowl, not daring to pass by him in return, nor being able to escape upwards on account of the net-covering, rush on into the purse-net. Sometimes the dog will not attract their attention, unless a red handkerchief, or something very singular, is put about him.

The general season for catching fowls in decoy is from the end of October till February; the taking of them earlier is prohibited by an act 10 Geo. 1I. c. 32 , which forbids it from June 1 st to October 1st, under the penalty of five shillings for each bird destroyed within that space. The Lincolnshire decoys are generally let at a certain annual rent, from five pounds to twenty pounds a year; and there is one-in Somersetshire that pays thirty pounds. The former contribute principally to supply the markets in London.

A mazing numbers of ducks, wilgeons, and teal are thus every year taken. A few winters past, in one season, and in only ten decoys, in the neighbourhood of Wainfleet, the number amounted to thirty-one thou. sand two hundred, in which were included several other species of ducks. These quantities make them so cheap on the spot, that the decoy-men would be content to contract for years to deliver their ducks at Boston for ten-pence per couple. It was customary formerly to have in the fens an animal to drive on the young ducks, before they took wing. Numbers of people assembled, who beat a vast tract, and forced the birds into a net placed at the spot where the sport was to terminate: one hundred and fifty dozens have been taken at once; hut this practice being supposed to be detrimental, has been abolished by act of parliament.

\section{AnCIENT BRICKS.}

BRICKS are of great antiquity, as appears by the sacred writings, the tower and the walls of Babylon being built with them." The Greeks generally used three kinds of bricks. The dimensions of the brick chiefly used by the Romans, were a foot and a half long, and a foot broad; which measures agree with those of several Roman bricks in England, which are about seventeen inches long and eleven broad, of our measure. Sir Henry Wotton speaks of a sort of bricks at Venice, of which stately columns were built; they were first formed in a circular mould, and cut, before they were burnt, in four or more quarters or sides; afterwards, in laying, they were jointed so close, and the points concentered so exactly, that the pillars appeared one entire piece. 
WONDERTUL ANIMALS, INSECTS, TR E E S, \&c.

\section{ELephants.}

THE elephant is not only the most tractable, but the most intelligent of quadrupeds, although his brain is small in proportion to his bulk. He is sensible of benefits, resentful of injuries, and endowed even with a sense of glory. In India, elephants were formerly employed in launching of ships: one being directed to force a very large vessel into the water, and the work proving superior to his strength, his master, with a sarcastic tone, bid the keeper take away this lazy beast, and bring another; the poor animal instantly repeated his efforts, fractured his skull, and died on the spot.

In Delhi, an elephant passing through the streets, put his trunk into a tailor's shop, where several people were at work: one of them pricked the end with his needle; the beast passed on, but filled his trunk in the next dirty puddle with water, returned to the shop, and spurting every drop among-the people who had offended him, spoiled their work.

An elephant in Adsmeer, which often passed through the market, as he went by a certain herb woman, always received from her a mouthful of greens : at length he was seized with one of his periodical fits of rage, broke his fetters, and running through the market, put the crowd to flight; among others was this woman, who in haste forgot a little child she had brought with her. The animal recollecting the spot where his benefactress was wont to sit, took up the infant gently in his trunk, and placed it in safety on a stall before a neighbouring house.

Another in his madness killed his cornac, or keeper; the wife seeing the misfortune, took their two children, and flung them before the elephant, saying, "Now you have destroyed their father, you may as well put an end to their lives and mine." It instantly stopped, relented, took the largest of the children, placed him on his neck, adopted him for his cornac, and never afterwards would permit any body else to mount it.

A soldier at Pondicherry, who was accustomed, whenever he received the portion of drink that came to his share, to carry a certain quantity of it to one of these animals, having one day drank too freely, and finding himself pursued by the guards, who were going to take him to prison, took refuge under the elephant's body, and fell asleep. In vain did the guard try to force him from this asylum, as the elephant protected him. The next morning, the soldier, recovering from 
his drunken fit, shuddered with horror to find himself stretched under the belly of this huge animal. The elephant perceived the man's embarrassment, and caressed him with his trunk, to inspire him with courage, and make him understand that he might now depart in safety.

A painter was desirous of drawing the elephant which was kept in the menagerie at Versailles in an uncommon attitude, which was that of holding his trunk raised up in the air with his mouth open. 'The painter's boy, in order to keep the animal in this posture, threw fruit into his mouth; but as he had frequently deceived lim, and made an offer only of throwing him the fruit, he grew angry; and, as if he had known that the painter's intention of drawing him was the cause of the affront, instead of revenging himself on the lad, he turned his resentment on the master, and taking up a quantity of water into his trunk, threw it on the paper on which the painter was drawing, and spoiled it.

At the Cape of Good Hope, it is customary to hunt and kill these animals for the sake of their teeth. When a chase commences, three horsemen, well mounted, and armed with lances, attack the elephant alternately, each relieving the others as they see their companion pressed, till the beast is subdued. Three Dutchmen. brotlers, who had made large fortunes by this business, determined to retire to Europe, and enjoy the fruits of their labours, but resolved, before they went, to have a last chase by way of amusement. They met with their game, and began the attack in the usual manner; but unfortunately one of their horses fell, and flung his rider : the en raged animal instantly seized the unhappy man with his trunk, flung him up to a vast height in the air, and received him on one of his tusks; then turning towards the two other brothers, a's if with an aspect of revenge and insult, held out to them the impaled wretch writhing on the bloody tooth.

From the earliest account in history, the eastern nations have employed elephants in war. Alexander the Great was the first European who ever mounted an elephant. He carried a number of them into Greece, which Pyrrhus some years after directed against the Romans at the battle of Tarentum. Both the Greeks and Romans soon learnt to get the better of those monstrous animals; they opened their ranks, and allowed them to pass through; neither did they attempt to hurt them, but threw darts, \&xc. at their guides. Now that fire-arms are the principal instruments of war, elephants, which are terrified at the noise and flame, instead of being useful, would only embarrass and confuse an army: however, in Cochin and other parts of Malabar, and in Tonquin, Siam, and Pegu, where fire-arms are little understood, they are still used in battle. The guide sits astride upon the neck, and the combatants sit or stand upon the other parts of the body.

They are also extremely serviceable in fording rivers, and carrying over baggage on their backs. Aftel the keepers have loaded them with several hundred weight, they fasten ropes to thern; of which the soldiers taking hold, either swim or are drawn across the river. In time of action, they now and then fix a heavy iron chain to the end of their trunks, which they whirl round with such agility, as to make 
it impossible for an enemy to approach them at that time. Another use they still have for this creature in war, is, to force open the gates of a city or garrison which is closely besieged. This he does by setting his hinder parts against them, wriggling backwards and forwards with his whole weight, till he has burst the bars, and forced an entrance, to prevent which, most of the garrisons in this country have large spikes stuck in their gates, that project to a considerable distance. After all, those prodigious animals are kept more for show aud grandeur than for use, and their keeping is attended with a very great expeuse; for they devour vast quantities of provision, and must sornetimes be regaled with a plentiful repast of cinnamon, of which they are excessively fond. It is said to be no uncommon thing with a nabob, if he has a mind to ruin a private gentleman, to make him a present of an elephant, which he is ever afterwards obliged to maintain, at a greater expense than he can afford: by parting with it, he would certainly fall under the displeasure of the grandee, besides forfeiting all the honour which his countrymen think is conferred upon him by so respectable a present.

\section{Hippopotamus, or River Horse.}

THE head of this animal is of an enormous size, and the month vastly wide. The ears are small and pointed, and lined within very thickly with short fine hairs. The eyes and nostrils are small in proportion to the bulk of the animal. On the lips are some strong hairs, scattered, in patches here and there. The hair on the body is very thin, of a whitish colour, and scarce discernible at first sight. There is no mane on the neck, as some writers assert, only the hairs on that part are rather thicker. The skin is very thick and strong, and of a dusky colour. The tail is about a foot long, taper, compressed, and naked. The hoofs are divided into four parts. The legs are short and thick. In bulk it is second only to the elephant. The male has been found to be seventeen feet long, the circumference of the body fifteen, the height near seven, the legs nearly three, the head above three and a half, and the girt near nine. The mouth, when open, is above two feet wide, and furnishcd with forty-four teeth of different figures, including the cutting teeth and the canine. The cutting, and particularly the canine teeth of the lower jaw, are very long, and so hard and strong that they strike fire with steel. This circumstance, it is probable, gave rise to the fable of the ancients, that the hippopotamus vomited fire from lis mouth. The substance of the canine teeth is so white, so fine, and so hard, that it is preferable to ivory for making artificial teeth. The cutting teeth, especially those of the lower jaw, are very long, cylindrical, and chamfered. The canine teeth are also long, crooked, prismatic, and sharp, like the tusks of the wild boar. The grinders are square and oblong, like those of a man, and so large, that a single one sometimes weighs three pounds. The tusks, according to Dr. Sparrman, are twentyseven inches long.

With such powerful arms, and such a prodigious strength of body, the hippopotamus might render himself formidable to every other 
animal. But he is naturally of a mild disposition, and is only formidable when provoked. His bulk is so great, that twelve oxen have been found necessary to draw one ashore, which had been shot in a river above the Cape; and Hasselquist says, its hide is a load for a camel.

Though he delights in the water, and lives as freely in it as on land, yet he has not, like the beaver or otter, membranes between his toes. The great size of his belly renders his specific gravity nearly equal to that of the water, and makes him swim with ease. These animals inhabit the rivers of Africa, from the Niger to Berg river, many miles north of the Cape of Good Hope. They formerly abounded in the rivers nearer the Cape, but are now almost extirpated: and to preserve the few that are in Berg river, the governor absolutely prohibited the shooting of them without particular permission. They are not found in any of the African rivers that run into the Mediterranean, except the Nile, and even there only in Upper Egypt, and in the fens and lakes of Ethiopia, which that river passes through.

From the unwieldiness of his body, and the shortness of his legs, the hippopotamus is not able to move fast upon land, and is then extremely timid. When pursued, he takes to the water, plunges in, sinks to the bottom, and is seen walking there at full ease; he cannot, however, often continue long there without rising to the surface; and in the day-time is so fearful of being discovered, that when he takes in fresh air, the place is hardly perceptible, for he does not venture even to put his nose out of the water. In rivers unfrequented by mankind, he is less cautious, and puts his whole head out of the water. If wounded, he will rise and attack boats and canoes with great fury, and often sink them by biting large pieces out of the sides: and frequently pesple are drowned by these animals, for they are as bold in water as they are timid upon land. It is reported that at one bite they will sever a man in two.

In shallow rivers the hippopotamus makes deep holes in the bottom, in order to conceal his great bulk. When he quits the water, he usually puts out half his body at once, and smells and looks around, but sometimes rushes out with great impetuosity, and tramples down every thing in his way. During the night, he leaves the river in order to pasture; when he eats sugar-canes, rushes, millet, rice, \&c. consuming great quantities, and doing much damage in the cultivated fields. But as he is so timid on land, it is not difficult to drive him off. The Egyptians, Mr. Hasselquist informs us, have a curious method of freeing themselves from this destructive animal. - They mark the place he frequents most, and there lay a great quantity of pease; when the beast comes on store, hungry and voracious, he falls to eating what is nearest him, and, filling his belly with the pease, they occasion an insupportable thirst; he then returns immediately to the river, and drinks upon these pease large draughts of water, - which suddenly causes his death, for the pease soon begin to swell with the water, and not long after, the Egyptians find him dead on the shore, blown up, as if killed with the strongest poison. 3. The river horse also feeds on roots of trees, which he loosens from the earth with his great teeth; but never eats fish, as is asserted by 
Dampier. It was reported to M. Hasselquist, that he is an inveterate enemy to the crocodile, and lills it whenever he meets it, and that this, with some other causes, contributes much to the extirpation of the crocodile, which otherwise, considering the many eggs they lay, would utterly destroy Egypt. But Mr. Pennant treats the alleged: enmity of the hippopotamus and crocodile as a vulgar error; an eyewitness declaring he had seen then swimming together without any disagreement. The hippopotami sleep in the reedy islands in the middle of the stream, and on these they bring forth their young. A herd of females has but a single male; they bring one young at a time, and that on the land, but suckle it in the water. They are capable of being tamed. Belon says, he had seen one so gentle as to be let loose out of its stable, and to be fed by its keeper, without attempting to injure any one. They are generally taken in pitfalls, and the poor people eat the flesh. In some places the natives place boards full of sharp irons in the corn grounds; which these beasts strike into their feet, and so become an easy prey. Sometimes they are struck in the water with harpoons fastened to cords, and ten or twelve canoes are employed in the chase.

The hippopotamus was known to the Romans. Scaurus treated the people with the sight of five crocodiles and one hippopotamus, during his redileship, and exhibited them in a temporary lake. Augustus produced one at his triumph over Cleopatra. This animal is the behemoth of Job; who admirably describes its manners; its food; and its haunts, chap. x. verse 15-24. Ver. fifteen, the learned Bochart olserves, implies the locality of its situation; being an inhabitant of the Nile, in the neighbourhood of $\mathrm{Uz}$, the land of Jub. The sixteenth describes its great strength, and the eighteenth the peculiar hardness of its bones. The twenty-first and twenty-second indicate its residence amidst the Nile and other African rivers, shadowed with thick forests : the twenty-third, the characteristic wideness of its mouth, which is hyperbolically described as large enough to exhaust the Jordan. An entertaining account of the hippopotamus is given in Sparrman's Voyage to the Cape of Good Hope, where these animals are called sea-cows. After giving a particular narrative of a hunting expedition for two days, upon which he and $\mathrm{Mr}$. Immeluian had set out, on the twenty-fourth of January, 17\%6, accompanied by other three Europeans and two Hottentots, and wherein he himself was once in imminent danger of his life from one of these animals, Mr. Sparrman proceeds as follows :-

"The same night, the twenty-sixth, we betook ourselves again to our posts, and at half after eight, it being already very dark, a seacow began at intervals to put its head above the water, and utter a sharp, piercing, and very angry cry, which seemed to be between grunting and neighing. Perhaps this cry may be best expressed in the words, hurkh---hurkh, huch-luch : the two first being uttered slowly in a hoarse but sharp and tremulous cry, resembling the grunting of other animals; while the third, or compound word, is sounded extremely quick, and is not unlike the neighing of a horse. It is true, it is impossible to express these inarticulate sounds in writing, but perhaps one may make nearer approaches to it than to the gutturo- 
palatial sounds of the Hottentat language. At eleven oclock came the same or some other hippopotamus, and visited the posts we occupied. He did not, however, dare to cone up, though we heard him rustle the boughs which hung over the surface of the water, as well as a little grass and a few low shrubs which grew on the inside of the river banks. We were, however, in hopes that this way of living would not long suffice animals one of which only requires almost a larger portion than a whole team of oxen. Thus far at least is certain, that if one should calculate the consumption of provisions made by a sea-cow from the size of its fauces, and from that of its body ard belly, which hangs almost down to the ground, together with the quantity of grass which I have obseryed at different times to have been consumed by one of them, in spots whither it has come overnight to graze, the amount would appear almost incredible: We passed the following night at the same posts, the sea-cows acting much as before.

"On the twenty-eighth, after sun-rise, just as we were thinking of going home to our waggons, there comes a female hippopotamus, with her calf, from some other pit or river, to take up her quarters in that which we were then blockading. While she was waiting at a rather steep part of the river's banks, and looking back after her calf, which was lame, and came on but slowly, she received a shot in hei side, upon which she immediately plunged into the river, but was not mortally wounded, for Flip, the farmer's son, the drowsiest of all sublunary beings, who had shot her, and at that instant could hardly be awakened by two Hottentots, was still half asleep when he fired his piece. And happy was it for him, that the enormous beast did not make towards his hiding or rather sleeping place, and send him into the other world to sleep for ever. In the mean while, his shot was so far of service, that one of my Hottentots ventured to seize the calf, and hold it fast by its legs till the rest of the hunting party came to his assistance; upon which the calf was fast bound, and with the greatest joy borne to our waggons, though, while they were taking it over a shallow near the river, the Hottentots were very much alarmed, lest the wounded mother, and the other sea-cows, induced by the cries of the calf, should come to its rescue; the creature, as long as it was bound, making a noise a great deal like a hog that is going to be killed, or has got fast between two posts. The sound, however, proceeding from the hippopotamus calf was more shrill and harsh. It shewed likewise a considerable share of strength in the attempt it made to get loose, and was quite unmanageable and unwieldy; the length of it being three and $a$ half feet, and the height two feet, though the Hottentots supposed it to be no more than a fortnight, or at most three weeks, old. When at last it was turned loose, it ceased crying; and when the Hottentots had passed their hands several times over its nose, in order to accustom it to their effluvia, it began directly to take to them. While the calf was yet alive, adds he, I made a drawing of it, a copy of which may be seen in the Swedish Transactions for 1793. After this it was killed, dissected, and eaten, in less than three hours time. The reason of this quick despatch was partly the warmiti of the weather, 
and partly our being in absolute want of any other fresh provisions. We found the fat and flesh of this calf as slabby as one might have expected from its want of age, and consequently not nearly so good as that of the old sea-cows; of which I found the flesh tender, and the fat of a taste like marrow, or at least not so greasy and strong as other fat. It is for this reason likewise that the colonists look upon the flesh and fat of the sea-cow as the wholesomest meat that can be eaten; the gelatinous parts in particular, when properly dressed, being accounted a great delicacy. The dried tongues of these animals are also considered, even at the Cape, as a rare and savoury dish.

'On my return to Sweden, I had the honour to furnish his majesty's table with a dried sea-cow's tongue, two feet and eight inches long. With respect to form, the tongue of a full-grown hippopotamus is very blunt at the tip, and is in fact broadest at that part; at the same time it is slanted of towards one side, and marked with lobes, as I was informed it is ; this circumstance may perhaps proceed from the friction it suffers against the teeth, towards the side on. which the animal chiefly chews; at least some traces of this oblique form were discoverable on the dried tongue $I$ am speaking of. The hide of the adult hippopotamus bears a great resemblance to that of the rhinoceros, but is rather thicker. Whips likewise made of this hide are stronger, and, after being used some time, are more pliable, than those made of the hide of the rhinoceros usually are, though they are not so transparent as those latter are when new.

"The food of the hippopotamus consists entirely of herbs and grass; a circumstance of which we are informed by Father Lobo, and which may partly be inferred from what $I$ have already said on the subject, as well as the figure of the stomach belonging to the fotus of a hippopotamus, given in Messrs. de Buffon and Daubenton's elegant work. I therefore do not look upon it as very probable that these animals, agreeably to the assertion of $M$. de Buffon, p. 93, or of Dampier in his Voyage, should hunt after fish by way of preying upon them: especially, as in some of the rivers of the southern part of Africa, where the sea-cows are seen daily and in great abundance, there is not a fish to be seen ; and in others, only a few bastard springers, as they are called, cyprinus gonorynchus, which are scarcely as big as a common herring. It is said, a small species of carp is still more ra rely to be met with here. It is true, that the sea-cows sometimes frequent the mouths of the rivers here, which are full of sea-fish, and even sometimes the sea itself; we know, therefore that these huge quadrupeds are, notwithstanding this, obliged to go from theuce upon dry land in quest of food. Neither is it probable that they can drink the sea water; as an instance was related to me of the contrary, in a hippopotamus, which having been disturbed in the rivers, had taken refuge in the sea, and yet was obliged to go ashore every night, and drink fresh water from a well in the neighbourhood, till at last it was shot by some people that lay in wait for it there.

"That the hippopotamus lives in salt water, I have seen evident proofs at the mouths both of Cromme and Cantour rivers, particulary in the latter, on my jurney homeward; where many of these 
animals blowed themselves in broad daylight, and thrust their heads up above the water; and one of them, in particular, which had been wounded by an ill-directed shot on the nose, neighed from anger and resentment.

"In Krakikamma I saw on the beach manifest traces of a hippopotamus which had come out of the sea, but liad retired thither again directly. That very attentive navigator, Captain Burzz, informed me that he had frequently seen, on the eastern coast of Africa, sea-horses, meaning probably the hippopotamus, raise their heads above the surface of the water, in order to blow themselves, and neigh. I have been induced to be rather circumstantial on this subject, as M. Adamson had taken it into his head, in his Voyage au senegal, to limit the abode of the hippopotamus to fresh-water rivers only, in Africa; and $M$. de Buffon has taken upon him to support this opinion, and to render Holbe's testimony to the contrary liable to suspicion.

"The method of catching the hippopotamus consists, besides shooting it, in making pits for it in those parts which the animal passes in his way to and from the river; but this method is peculiar. to the Hottentots, and is only practised by them in the rainy season, as the ground in summer is too hard for that purpose. It is said that they have never succeeded in killing this huge aquatic animal with poisoned darts, though this way of lilling game is practised with advantage by the Hottentots, for the destruction both of the elephant and rhinoceros. The colonists likewise were not entirely unacquainted with the method used by M. Hasselquist, as being common in Egypt, viz. to strew on the ground as many pease and beans as the animal can possibly eat, by which means it bursts its belly, and dies. But as this method is very expensive, and they can generally have this animal for a single charge of powder, and a tin ball shot in a proper direction, they chiefiy, and almost solely, have recourse to this cheaper expedient.

"The hippopotamus is not so quick in its pace on land, as the generality of the larger quadrupeds, though it is not so slow and heavy as M. de Buffon describes it to be, for both the colonists and Hottentots look upon it as dangerous to meet a hippopotamus out of the water; especially as, according to report, they had a recent instance of one of these animals having for several hours pursued a Hottentot, who found it very difficult to make his escape. The people of the country did not entertain that opinion of the medicinal virtues of the hippopotamus, which they did of certain parts of the elephant and rhinoceros, except one colonist, who imagined he had found the os petrosum of this animal, reduced to powder, and taken in the quantity that would lie on the point of a knife, excellent for convalsions in children. That the flesh is reckoned very wholesome food, I have already mentioned.

"Having exceeded the limits. I prescribed to myself, I do not intend to dwell here on the anatomy of the hippopotamus we caught; particularly as the internal conformation of the calves is somewhat different from that of the adult animal. I shall therefore only briefly mention the following particulars:- the stomachs were four in number, and consequently one more than in the fotus examined by 
M. Daubenton, which was kept in spirits. Compare Buffon, tom xii. tab. iv. fig. 2.

"This huge animal has doubtless obtained its present name merely in consequence of the neighing sound it makes, as otherwise in its form it bears not the least resemblance to a horse, but rather to a hog. Neither does it in the least resemble the ox; so it could be only the different stomachs of this animal which could occasion it to be called sea-cow at the Cape: and perhaps it is for the same reason that the Hottentots call it the t'gao, which nearly approaches to t'kau, the name by which the buffalo is known amongst these people.

"From the account given by Bellonius of the tame hippopotanus, which he describes as a beast of a very mild and gentle nature, as well as from the disposition of the calf we had just caught, I am persuaded that this animal might easily be brought over to Europe, where, report says, it has been exhibited at two different times in the public spectacles at Rome. For this purpose, the capture might easier be made at Konap's-river, where these animals, according to the accounts given me by the Caffres, reside in great abundance, and milch cows might be kept ready at hand, in order to rear the calf, in case it should be a suckling. Indeed, I am apt to suppose that one a little older than this would not be very nice in his food, as that which we caught was induced by hunger, as soon as it was let loose from the waggon, to put up with something which had been just dropped from one of our oxen. This perhaps may appear very extraordinary, in an animal with four stomachs; but there have been instances of this kind known in common cattle, which in Herjedal are partly fed with horse-dung. See Halpher's Description of Norway, p. 27 to $8 \%$ I have been likewise assured, that this method of feeding cattle has been practised with great advantage in Uplandia, when there has been a scarcity of fodder; and that afterwards these same cattle, when they have not been in want of proper forlder, have taken to this food on their own accord, and eaten it without any thing else being mixed with it."

\section{SEA-Dragon.}

THrs is a monster of a very singular nature. In the Gentleman's Magazine for 1149 , we have the account of a sea-dragon, which was said to be taken between Orford and South Would, on the coast of Suffolk, and afterwards carried round the country as a curiosity by the fishermen who caught it. "Its head and tail," says the writer, "resemble those of an alligator; it has two large fins, which serve it both to swim and to fly; and though they were so dried that I could not extend them, yet they appear, by the folds, to be shaped like those which painters have given to dragons and other winged monsters, that seive as supporters to coats of arms. Its body is. covered with impenetrable scales; its legs have two joints, and its feet are hoofed like those of an ass; it has five rows of very white and sharp teeth in each jaw, and is in length about four feet, though it was longer when alive, it having shrunk as it became dry. It was caught in a net with mackerel; and being brought on shore, was 
knocked down with a stretcher or boat-hook. The net being opened, it suddenly sprung up, and flew above fifty yards; the man who first seized it, had several of his fingers bitten off; and the wound mortifying, he died. It afterwards fastened on the man's arm who shews it, and lacerated it so mueh, that the muscles are shrunk; and the hands and fingers distorted; the wound is not yet healed, and is thought to be incurable. It is said by some to have been described by naturalists under the name of a sea-dragon."

\section{Agouti.}

THE Agouti is an American animal, much resembling the guineapig, having the characters of the rat kind, with the voice and liair of the hog. The hairs are very hard, thick, and glossy, and are of a mixed colour, of a reddish and brown, with more or less black; those on the belly, however, are yellowish; its head and whiskers are like those of the rabbit kind, but that the nose is sharper, and the upper chop longer than the under one, as in the hog kind: the upper lip is split as in the hare, and the legs are naked, or have at the utmost only a few hairs on them; the fore feet have four toes, and the hinder ones six, and these are much longer than the fore legs; its tail is very short, its eyes very prominent, and its voice altogether resembles the grunting of a hog. It is a very voracious animal, devouring its food with extreme eagerness, and using its fore feet for hands in the manner of the squirrel. It rums very swiftly, and is very expert at digging, so that it soon buries itself in the earth. When provoked, it raises all the hair of its back upright, and strikes the earth with its hinder feet.

\section{Tre Mud-Iguana.}

THIS is a very singular animal. It was first observed by Dr, Garden of Charleston, and afterwards described by Mr. Ellis in his Philosophical Transactions for 1766. It has gills, fins, and two feet, and is in length from thirty-one to forty inches. They inhabit South Carolina, where they are found in marshy and muddy places, by the side of pools, and under the trunks of old trees that hang over the water. They feed on serpents. The feet appear like little arms and hands, each furnished with four fingers, and each finger with a claw. The head is something like an eel's, but more compressed; the eyes are small, and placed as those of the eel are. This smallness of the eye best suits an animal that lives so much in mud. The nostrils are very plainly to be distinguished; these, with the gills, and remarkable length of the lungs, shew it to be a true amphibious animal. The mouth is small in proportion to the length of the body; but its palate, and inside of the lower jaw, are well provided with many rows of pointed teeth; and with this, added to the sharp exterior bony edges of both the upper and under jaw, the animal seems capable of biting and grinding the hardest kind of food: The skin, which is black, and full of small scales, resembles shagreen. These scales are of different sizes and shapes, according to their situation, but all 
appear sunk in its'gelatinous surface; those along the back and belly are of an oblong oval form, and close set together; and in other parts they are round and more distinct. Both the parts are mottled witli small white spots, and have two distinct lines composed of small white streaks, continued along from the feet to the tail. The fin of the tail has no rays, and is no more than an adipose membrane like that of the eel.

Dr. Garden, in a letter to Mr. Ellis, mentions a remarkable property of this animal; viz. that his servant endeavouring to kill one of those by dashing it against the stones, it broke into three or four pieces. Linnæus, from the description sent to him, made it a new genus called Siren, of a new order Meantes, of the class Amphibia. But from this class, both the order.Meantes, and that of Nantes, have been lately expunged, and Gmelin had reduced the Siren to a species of Muræna. Its place here, however, seems still of doubtful propriety, as Gmelin himself acknowledges in the preface to his Systema Natire; for, Campfer, having dissected the Siren, discovered that on each side of the head it is furnished with three true gills, separated from each other by membrawes having teeth-like append ages, that the mouth is armed with strong and firmly planted teeth; that the heart has only one ventricle; and that the abdomen is filled with very long and capacious intestines : from all these circumstances, he concludes that this animal ought to be considered as a fish of the order of Branchiostegi; while in other respects it is more nearly allied to the genus Murrena, of the order Apodes; although it differs materially from the other species of that genus, by having only three notched bones in the gills, and from the pectoral fins being each divided into four finger-like appendages.

\section{Can A Dian Jerboa.}

This animal is thus described by general Davis. "As I conceive there are very few persons, however conversant in natural history, who may have seen or known that there was an animal existing in the coldest parts of Canada, of the same genus with the jerboa, hitherto confined to the warmest climates of Africa, I take the liberty of stating the following particulars. With respect to the food, or mode of feeding, of this animal, I have it not in my power to speak with any degree of certainty, as I could by no means procure any kind of sustenance that could induce it to eat; therefore, when caught it lived only a day and a half. The first I was so fortunate as to catch, was taken in a large field near the fall of Montmorena, and by its having strayed too far from the skirts of the wood, allowed myself, assisted by three other gentlemen; to surround it, and after an hour's hard chase to get it unhurt, though not before it was thoroughly fatigued, which might in a great measure accelerate its death. (2) During the time the animal remained in its usual vigour, its agility was incredible for so small a creature. It always took progressive leaps of from thiee to four, and sometimes of five yards, although seldom above twelve or fourteen inches from the surface of the grass ; but I have frequently observed others, in shrubby places, and in the 
woods, among plants, where they chiefly reside, leap considerably higher. When found in such places, it is impossible to take them, from their wonderful agility, and their evading all pursuit by bounding into the thickest part of the covert they can find.

"With respect to the figure given of it in its dormant state, I have to observe, that the specimen was found by some workmen, in digging the foundation for a summer-house in a gentleman's gardell, about two miles from Quebec, in the latter end of May, 178\%. It was discovered enclosed in a ball of clay, about the size of a cricket. ball, nearly an inch in thickness, perfectly smooth within, and about twenty inches under ground. The man who first discovered it, not knowing what it was, struck the ball with his spade, by which means it was broken to pieces, or the ball would have been presented to me. How long it had been under ground, it is impossible to say; but as I never could observe these animals in any part of the country after the beginning of September, I conceive they lay themselves up for some time in that month, or beginning of October, when the frost becones sharp. Nor did I ever see them again before the last week in May, or beginning of June. From their being enveloped in balls of clay, without any appearance of food, I conceive they sleep during the winter, and remain for that term without sustenance. As soon as I conveyed this specimen to my house, I deposited it, as it was, in a small chip box in some cotton, waiting with great anxiety for its waking, but that not taking place at the season they generally appear, I kept it until we found it begin to smell; I then stuffed it, and preserved it in its torpid position. I am led to believe its not recovering from nicely dried, that state arose from the heat of my room during the time it was in the box, a fire having been constantly burning in the stove, and which in all probability was too great for its respiration."

\section{The Mountain Hare, or Alpine Rabitt.}

THIs species of hare is first seen in the Altaic chain, and extends to lake Baikal, - thence to Kamschatka, - and is found in the Fox Islands : they inhabit always the middle regions of the snowy mountains, in the rudest places, wooded, and abounding with herbs and moisture. They sometimes form burrows between the rocks, and often lodge in the crevices. They are generally found in pairs, but in cloudy weather they collect together, and lie on the rocks, and give a keen whistle like that of a sparrow. On the report of a gun, they run into their holes, but soon come out again. By wonderful instinct, they provide against the rigorous season. A company of them, towards autunin, collect together vast heaps of herbs and grasses, newly dried, which they place either beneath the overhanging rocks, or between the chasms, or round the trunks of trees. In many places the herbs appear scattered as if to be dried in the sun.

The heaps are formed of round or conoid ricks, and are of various sizes, according to the number of the society employed in forming them. They are sometimes of a man's height, and many feet in diameter, but usually about three feet. Without this provision of winter's stock they would perish during the storms of snow. They 
select the best of vegetables, and crop them when in the fullest vigour, which they make into excellent hay by drying it. These ricks occasion fertility among the rocks, for the relics, mixed with the dung of the animal, rot in the barren chasms, and form a soil productive of vegetables. These ricks are also of great service to people who hunt sables; for their horses would often perish, if they had not the provision of these little industrious animals to support them; which is easily to be discovered by their height and form, even when covered with snow. The people of Jakutz feed both their horses and cattle with the relics of the winter stocks of the hares. These animals are neglected as a food by mankind, but are the prey of sables and the Siberian weasels. They are likewise greatly infested with a sort of gad-fly, which lodges its egg in their skin in August and September, which often proves destructive to them.

\section{Black Hares.}

Mr. Muller says, he once saw two black hares in Siberia, of $\dot{a}$ wonderful fine gloss; and as full a black as jet. Near Casan was taken another, in the middle of winter 1763. In the south and west provinces of Russia is a nixed breed of hares, between this and the common species. It sustains, during winter only, a partial loss of colour; the sides and more exposed parts of the ears and legs in that season becoming white, the other parts retaining their colours. This variety is unknown beyond the Uralian chain. They are called by the Russians, Russacks; they take them in great numbers in snares, and export their skins to England and other places. The Russians and Tartars, like the ancient Britons, esteem the flesh of hares as impure.

\section{The Land Crab.}

Tuis creature inhabits the Bahama islands, as well as most lands between the tropics, and feeds upon vegetables. These animals live not only in a kind of orderly society in the retreats of the mountains, but regularly once a year march down to the sea-side in a body of some millions at a time. As they multiply in great numbers, they choose the month of April or May to begin their expedition, and then sally out by thousands from the stumps of hollow trees, from the clefts of rocks, and from the holes which they dig for themselves under the surface of the earth. At that time the whole ground is covered with this band of adventurers; there is no setting down one's foot without treading upon them. The sea is their place of destination, and to that they direct their march with, right-lined precision. No geometrieian could send them to their destination by a shorter course ; they never turn to the right or left, whatever obstacles intervene, if they are at all surmountable; and if they even meet with a house, they will attempt to scale the walls, to keep the unbroken tenor of their way.

But though this be the general order of their route, they, upon other occasions, are obliged to conform to the face of the country; 
and if it is intersected with rivers, they are then observed to wind along the course of the stream. The procession sets forward from the mountains with the regularity of an army under an able commander. They are commonly divided into three battalions; of which the first consists of the strongest and boldest males, that, like pioneers, march forward to clear the route, and face the greatest dangers. They are often obliged to halt for want of rain, and to go into the most convenient encampment till the weather changes.

The main body of the army is composed of females, which never leave the mountains till the rain is set in for some time; they then descend in regular battalions, being formed into columns of fifty paces broad, and three miles deep, and so close that they almost cover the ground. The rear-guard follows, three or four days after, like a straggling undisciplmed tribe, consisting of males and females, but not so vigorous as the former. The night is their chief time of proceeding, although, if it rains by day, they do not fail to profit by the occasion, but continue to move forward in their slow uniform manner. When the sun shines, and is hot upon the surface of the ground, they make a universal halt, and wait till the cool of the evening. When they are terrified, they march back in a slow disorderly way, holding up their nippers, with which they sometimes tear off a piece of the skin, and leave the weapon where they inflicted the wound. They even try to intinidate their enemies, for they often clatter their nippers together, as if to threaten those that disturb them.

But though they thus strive to be formidable to man, they are much more so to each other ; for they are possessed of one most unsocial property, which is, that if any one of them by accirlent is maimed in such a mainer as to be incapable of proceeding, the rest fall upon it, and devour it on the spot, and then pursue their journey.

When, after a fatiguing march, and escaping a thousand dangers, for they are sometimes three months in getting to the shore, they have arrived at their destined port, they prepare to cast their spawn. In order to this, the creature has no sooner reached the shore, than it goes to the edge of the water, and lets the water wash over its body two or three times. This seems only a preparation for bringing the spawn to maturity, for, without farther delay, they withdraw, to seek a lodging upon land. In the mean time the spawn grows larger, is excluded out of the body, and sticks to the barbs which are situated under the tail. This bunch is seen as big as a hen's egg, and exactly resembling the roes of herrings. In this state they once more seek the shore for the last time; and shaking off the spawn into the water, leave accident to bring it to maturity.

At this time numerous shoals of hungry fish are at the shores, in expectation of this annual supply; the sea to a great distance seems black with them; and about two-thirds of the crab's eggs are immediately devoured by these rapacious invaders. The eggs that escape are hatched under the sand; and, soon after, millions at a time of these little crabs are seen quitting the shore, and slowly travelling up to the mountains.

The old ones, however, are not so active to return; they have become so fecble and lean, that they can hardly ereep along, and the 
Alesh at that time changes its colour. Most of them, however, are obliged to continue in the flat parts of the country till they recover, making holes in the earth, which they cover at the mouth with leaves and dirt, that no air may enter. There they throw off their old shells, which they leave quite whole, the place where they opened on the belly being unseen. "At that time they are quite naked, and almost without motion for six days together, when they become so fat as to be delicious food. They have then under their stomachs four large white stones, which gradually decrease in proportion as the shell hardens, and when they come to perfection they are not to be found. It is at that time that the animal is seen slowly making its way back, which is commonly performed in six weeks; but when possessed of its retreats in the mountains, its fortresses:are impreguable; for, only subsisting upon vegetables, it seldom ventures out; and its habitation being in the most inaccessible parts, it remains for a great part of the season in perfect security. It is only when impelled by the desire of bringing forth its young, that it descends into the flat countries, and is taken.

At that time the natives wait for its descent in eager expectation, and destroy thousands; but, disregarding their bodies, they only seek for that small spawn which lies on each side of the stomach within the shell, of about the thickness of a man's thumb. They are much more valuable upon their return after they have cast their shells, for, being covered with a skin resembling soft parchment, almost every part except the stomach may be eaten. They are taken in their holes by feeling for them with an instrument; they are sought after by night, when on their journey, by Hambeaux. The instant the animal feels itself attacked, it throws itself on its back, and with its claws pinches most terribly whatever it happens to fasten or. But the derterous crab-catcher takes them by the hinder legs in such a manner that the nippers cannot touch him, and thus he throws them into his bag. Sometimes also they are caught when they take refuge in the bottoms of holes, in rocks by the sea-side, by covering the mouth of the hole to prevent their getting out; and soon after this, the tide coming, enters the hole, and the animal is found, upon its elbing, drowned in his retreat.

These crabs are of various sizes, the largest about six inches wide; they walk sideways, like the sea-crab, and are shaped like them; some are black, some yellow, some red, and others variegated with red, white, and yellow mixed. Some of these are poisonous; and some people have died by eating them, particularly the black kind. The light-coloured are reckoned best; and when full in flesh, are very, well tasted. In some of the sugar islands they are eaten without danger, and are no small help to the negro slaves, who, on many of these islands, would fare very hard without them.

\section{HEDGE-HOG.}

THE hedge-hog being possessed of little strength or agility, does not attempt to flee from or assail his enemies; but erects his bristes, and rolls himself up like a ball, exposing no part of the body 
that is not furnished with large weapons of defence. He will not unfold himself unless thrown into water; the more he is frightened or harassed, the closer he shuts himself up, and frequently discharges his urine, which has a very filthy and loathsome smell. While in this state, most dogs, instead of biting him, stand off and bark, not daring to seize him; or if they attempt it once, their mouths are so hurt by his bristles, that they will not attempt it a second time. Both the male and fenale are covered with bristles from the head to the ail.

The females bring forth their young, in the beginning of summer. They commonly produce three or four, and sometimes five, at a time. The young ones are of a whitish colour, and only the points of the bristles appear above the skin. Some zoologists say it is impossible to tame them, ard that the mother and her young have been confined together, and furnished with plenty of provisions, but instead of nourishing them, she has devoured them one after another. $\mathbf{M r}$. Kerr, however, says, that, "by the Caimucs, this animal is domesticated, and kept in their huts, instead of cats." Hedge-hogs feed upon fallen fruits, some roots, and insects: they are very fond of flesh, either raw or ronsted. They frequent woods, and live under the trunks of trees, in the clefts of rocks, or under large stones. Some naturalists allege that they go into gardens, mount the trees, and come down with pears, apples, or plums, stuck upon their bristles. But this is a mistake; although kept in a garden, they never attempt to climb trees, or stick even fallen fruit upon their bristles, but lay hold of their food with their mouth. They never come'out of their holes in the day, but go in quest of food during the night. They eat little, and can live very long without nourishment. They do not lay in any store of provisions in harvest; such an instinct would be useless, as they sleep all the winter. The lie under the unmerited reproach of sucking cows, and hurting their udders, but the small. ness of their mouth renders that impossible.

\section{BLood-Hound.}

THis was a dog of great use, and in high esteem, with our ancestors its employ was to recover any game that had escaped wounded from the hunter, or been killed, and stolen out of the forest. It was remarkable for the acuteness of its smell, tracing the lost beast by the blood it had spilt; from whence the name is derived. This species could by the utmost certainty discover the thief, by following his footsteps, let the distance be ever so far, and through the most secret and thickest coverts; nor would it cease its pursuit till it had taken the felon. They were likewise used by Wallace and Bruce during the civil wars. The poetical historians of the two heroes frequently relate curious passages on the subject of the service these dogs did to their masters, and the escape they had from those of the enemy. The blood-hound was in great request on the confines of England and Scotland, where the borderers were continually preying on the herds and flocks of their neighbonrs. The true blood-hound was large, muscular, broad-breasted, of a stern countenance, of 
deep tan-colour, and generally marled with a black spot above each eye.

In some of the West India Islands, blood-hounds have been trained to hunt runaway negroes, and in Porto Rico these ferocious animals are an article of traffic. During the Maroon war, a troop was introduced into Jamaica, but through the humanity of the commanding officer they were kept in the rear of the army, and were never called into action. The dishonour, however, which attended the measure accompanies the record in which an account of the detestable expedient is preserved. It has thrown a shade on the history of Britain, that never can be effaced.

The method of training the young blood-hounds to bunt negroes is thus stated by Rainsford in his history of Hayti. When taken from their dams, these young dogs are kept in a kind of cage, and are never fed until they are exceedingly hungry: Their food is then carried to them in skins or bladders generally coloured black. After some time, having been accustomed to tear open these skins, to devour the blood and entrails which they contain, they no sooner see them approaching, than they become clamorous to seize their prey. In process of time the skins assume a new form, making some approximation to a negro. On these the dogs seize with avidity, ripping open its belly, and devouring its contents. At length the artificial negro is arrayed like a living one, and he appears to walk towards the cages in which the dogs are waiting for their prey. The artificial negro seems then to shun the dogs, but this only makes them more ferocious, and they are finally rewarded with being permitted to bring him to the ground, and to tear open his bowels.

When thus trained, they are always kept in confinement, except when called out on the detestable hunting expeditions, which furnishes white men with joy at hearing the shrieks and groans of the unfortunate blacks that are overtaken in the woods by these ferocious animals. Were not these dogs confined, no negro could live among them. They are, however, reserved as instruments of terror, and contribute by their character to rivet the chains which the sons of Africa seem destined to wear. That Jamaica should have imported one lundred of these dogs, under the direction of some Spanish huntsmen, to pursue the Maroons, covers her with a degree of infamy which no apology can palliate, which no advocate can ever fairly excuse.

\section{Sea-Serpent.}

THIs is a monstrous animal, said to inhabit the northern seas about Greenland and the coasts of Norway. The following marvellous account of this monster is given by Guthrie. In 1756, one of them was shot by a master of a ship; its head resembling that of a horse; the mouth was large and black, as were the eyes; it had a white mane hanging from its neck; it floated on the surface of the water, and held its head at least two feet out of the sea. Between the head and neck were seven or eight folds, which were very thick; and the length of this suake was more than one hundred yards; some say fathoms. They have a remarkable aversion to the smell of castor; 
for which reason, ship, boat, and bark masters provide themselves with quantities of that drug, to prevent being overset; the serpent's olfactory nerves being remarkably exquisite. The particularities related of this animal would be incredible, were they not attested upon oath.

Egede, a very reputable author, says, that on the sixth day of July, 1734 , a large and frightful sea-monster raised itself so high out of the water, that its head reached above the main-top-mast of the ship; that it had a long sharp snout, broad paws, and spouted water like a whale; that the body seemed to be covered with scales; the skin was uneven and wrinkled, and the lower part was formed like a snake. The body of this monster is said to be as thick as a hogshead; his skin is variegated like a tortoise-shell; and his excrement, which floated upon the surface of the water, is corrosive."

Notwithstanding the belief of Guthrie, and the testimony which he produces, many have doubted the existence of the sea-serpent. Its bulk is said to be so disproportionate to all the known animals of our globe, that it requires more than ordinary evidence to render it credible; while the evidence offered is so very feeble and unsatisfactory, that no man of sound judgment would think it sufficient to establish the truth of an extraordinary fact.

But although former accounts of the sea-serpent have been discredited, of late years the attestations of modern voyagers have in some measure revived the belief of its existence. In 1819 one of these monsters, of incredible dimensions, was said to have been seen by many persons in the Norwegian seas. That of which the following cut gives some representation, was seen by several witnesses off the coast of America in 1826.

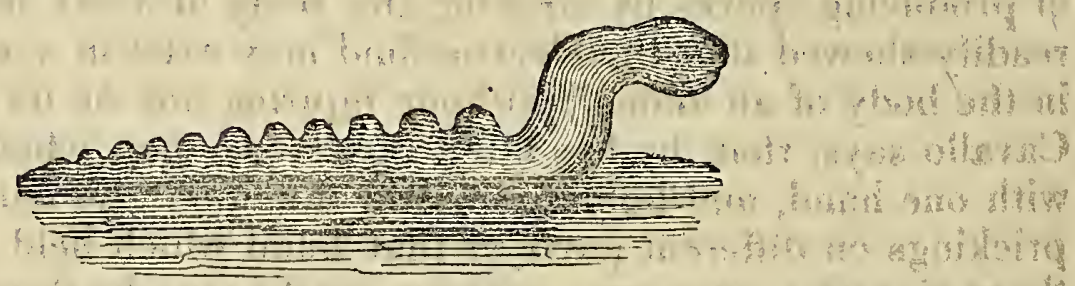

Since the above period, other accounts have been circulatea respecting the actual existence of these monsters of the deep, so that even the most sceptical appear to be staggered, and all would rejoice if one of these creatures could be taken and brought on shore.

\section{OAK Pucerons.}

THIs is a name given by naturalists to a very remarkable species of animal of the Puceron kind. They bury themselves in the cleft of the oak and some other trees, and getting into the crevices, where the bark is a little separated from the wood, they live and feed without being exposed to their enemies. They are larger than the other pucerons, the winged ones being nearly as large as a common housefy; those without wings are also larger than any other species of the same genus: The winged ones are black, and the others of a coffee colour. Their trunk is twice the length of their bodies, and, when 
walking, it is carried straight along the belly, trailing behind it with the point up. When this creature is disposed to suck a part of a tree that is just before it, it draws up, and shorteus the trunk, till it brings it to a proper length and direction; but when it sucks in the common way, it crawls upon the inner surface of the bark, and the turned-up end of the trunk, which resembles a tail, fixes itself against the wood that is behind it, or contiguous to its back, and sucks there. The extremity of this trunk holds so fast by the wood, that when it is pulled away, it frequently brings a small piece of the wood away with it.

The ants are as fond of these as the other species of pucerons, and that for the same reason; not feeding upon them, but on their excrement, which is a liquid matter of a sweet taste, and is the natural juice of the tree, very little altered. These creatures are the surest guides where to find this species of puceron, for if we at any time see a number of these ants crawling up an oak, and creeping into the clefts of the bark, we may be assured that in that place there are quantities of these oak pucerons.

\section{Anjmals Which are endued witi uncommon Electrical}

\section{Propertites.}

Not long after the discovery of the electrical shock, and the method of augmenting the power of electricity, it naturally became an object with electricians to investigate the effects of it upon animal bodies. These were quickly found to be entirely similar to such as are produced upon any other conducting substances, viz. an emission of sparks, aitraction, repulsion, \&c. By degrees it was found, that very strong signs of electricity were exhibited by some animals, even without the application of any artificial apparatus. 'The experiment of producing sparks by stroking the body of a cat in frosty weather, readily shewed that the electric fluid may exist in a very active state in the body of an animal, without injuring any of its functions. Mr. Cavallo says, that he has often observed, that, when stroking a cat with one hand, and holding it with the other, he felt frequent smart prickings on different parts of that hand which held the animal. In these circumstances very pungent sparks may be drawn from the tips of the ears of the cat." He also mentions, " that by using a metal button fastened with a stick of sealing-wax, he can obtain such strong sparks from the back of a cat, a hare's skin, a rabbit's skin, \&c. that he can presently charge a coated phial with either of these, and so strongly as to pierce a hole through a card with its discharge."

From animals of the inferior kind, a transition was made to the human species; and powers of electricity were discovered in them, where it had not been suspected before. Some persons have been remarkable for an extreme lustre of their eyes; and others have been so much electrified naturally, as to give evident signs of it when a sensible electrometer had been applied to them. Others have manifested an extreme sensibility of even the smallest degrees of electricity, insomuch that they would be affected by a flash of lightning, though so renote that the thunder could not be heard; all this shewing; that the subtle fluid treated of, bears a very active part in the animal economy, led to more important researches on the subject. 
One of the first discoveries was, that some creatures are so strongly electrified naturally, as to have it in their power to give a strong shock at pleasure, capable of destroying any small animal that comes near them. Of these, however, only four, and those of the aquatic kind, have yet been observed, viz. the gymnotus electricus, the torpedo, the silurus elcctricus, and a fish found on the coast of the Comoro islands.

The gymnotus has the astonishing property of giving the electric shock to any person, or number of persons, either by the immediate touch with the hand, or by the mediation of any metalic conductor; and a person who kept some of them told Mr. Garden, that they had this property much stronger when first caught than afterwards.

"The person," says he, "who is to receive the shock, must take the fish with both hands, at some considerable distance asunder, so as to form the communication, otherwise he will not receive it; at least, I never saw any one shocked from taking hold of it with one hand only, though some have assured us that they were shocked by laying one hand on it. I myself have taken hold of the largest with one hand often, without receiving a shock; but I never touched it with both hands at a little distance asunder, without feeling a smart shock. I have often remarked, that when it is taken hold of with one hand, aind the other is put into the water over its body without touching it, the person received a smart shock; and I bave observed the same effect follow when a number joined hands, the person at one extremity of the circle taking hold of, or touching the fisli, and the person at the other extremity putting his hand into the water over the body of the fish. The shock was communicated through the whole circle as smartly as if both the extreme persons had touched the fish. In this it seems to differ widely from the torpedo, or else we are much misinformed of the manner in which the benumbing effect of that fish is communicated. The shock which the gymnotus gives, seems to be wholly electrical, and all the phenomena or properties of it exactly resemble those of the electrica aurea of our atmosphere, when collected, as far as they are discoverable, from the several trials made on this fish. This stroke is communicated by the same conductors, and intercepted by the interposition of the same original electrics, or electrics per se, as they used to be called. The keeper of this fish informed me, that he caught several of the species in Surinam river, a great way up, beyond where the salt water reaches, and that they are a fresh-water fish only. He says that they are eaten, and by some people esteemed a great delicacy. They live on fish, worms, or any animal food, if it is cut small so that they can swallow it. When small fishes are thrown into the water, they first give them a shock, which kills or stupifies them; they can then swallow them easily, and without any trouble. If one of these small fishes, after it is shocked, and to all appearance dead, be taken out of the vessel where the electrical fish is, and put into other water, it will soon revive again. If a large fish, that they can swallow, be thrown into the water when they are hungry, they give him some smart shocks till he is apparently dead, and then try to swallow or suck him in; but, after several attempts, finding he is too large, 
they quit him. Upon the most careful inspection of such fish, I could never see any mark of teeth, or the least wound or scratch, on them. When the electrical fish are hungry, they are pretty keen after their food; but they are soon satisfied, not being able to contain much at one time. An electrical fish, of three feet and upwards in length, cannot swallow a small fish above two, or at most three inches and a half long. I have been told that some of these have been found in Surinam river upwards of twenty-two feet long, whose stroke or shock proves instant death to any person that unluckily receives sit."

Mr. Firmin, in his Natural History of Surinam, published in 1765, tells us, that one cannot touch this electric fish with the hands, or even with a stick, without feeling a horrible numbness in the arms up to the shoulders; and he further relates, that, making fourteen persons grasp each other by the hands, while he grasped the hands of the last with one of his, and with the other tonched the eel with a stick, the whole number felt so violent a shock, that he could not prevail on them to repeat the experiment.

Mr. Vanderbott, in two letters from Essequibo, written in the year 1761, mentions two species; the black and the reddish; though he acknowledges that, excepting the difference of colour and degree of strength, they are not materially different. In most experiments with these animals, he remarked a surprising resemblance between them and an electrical apparatus; nay, he observed, that the shock was given to the finger of a person held at some distance from the bubble of the air formed by the fish when it came to the surface of the water to breathe, and he concluded that at such times the elec. trical matter was discharged from its lungs. He mentions another characterizing circumstance, which is, that though metals in general were conductors of its electric property, yet some were found to be sensibly better than others for that purpose of this property $\mathrm{Dr}$. Priestley takes notice, and says that a gold ring is preferable to any thing else. The same is likewise observed by Linnans. Dr. Priestley adds, that the sensation is strongest when the fish is motion, and is transmitted to a great distance; so, if persons in a ship happen to dip their fingers or feet in the sea, when the fish is swimming at the distance of fifteen feet from them, they are affected by it. He also tells us, that the gymnotus itself, notwithstanding all its electric powers, is killed by the lobster.

The astonishing property of the torpedo in giving a violent shock to the person who takes it in his hands, or who treads upon it, was long an object of wonder. For some time it was in general reckuned to be entirely fabulous ; but at last the matter of fact being ascertained beyoud a donbt, philosophers endeavoured to find out the cause. M. Reaumur accounted for it by the action of a vast number of minute muscles, which by their accumulated force gave a sudden and violent stroke to the person who touched it. But solutions of this kind were quite unsatisfactory, because the stroke was found to be communicated through water, iron, wood, \&c.

When the phenomena of electricity began to be better known, it was then suspected that the shock of the torpedo was occasioned by 
a certain action of the electric fluid; but as not the least spark of fire, or noise, could ever be perceived, this too seemed insufficient. Subsequently, however, Mr. Walsh, with indefatigable pains, not only explained this surprising phenomenon on the known principles of electricity, but gave a demonstration of his beng in the right, by constructing an artificial torpedo, by which a shock resembling that of the natural one can be given. The electric organs of the torpedo consist of two sets of very small cylinders lying under the skin, one of which is electrified positively, and the other negatively, seemingly at the pleasure of the fish. When a communication is made between a set of cylinders positively electritied, and those which are negatively so, a discharge and shock ensue, like what happens in the case of the Leyden phial.

The only difficulty now is, to account for the total absence of a spark, which in the case of the torpedo never exists even in the smallest degree, and the impossibility of conducting the shock through the smallest interval of air. But this also is explained in a satisfactory manner by $\mathrm{Mr}$. Walsh, and shewn to be nothing else than what every day takes place in our electrical experiments.

It is well known, that a small charge of electricity, if put into a little phial, will occasion a bright spark and loud noise when discharged; but if the same charge is put into a phial much larger, the spark and noise will be less in proportion: neither will the spark break through near such a space of air in the latter case as in the former, though the shock would in both cases be the same to a person who received it through his body. If, instead of a large phial, we suppose the charge to be diffused all over a large battery; the shork would still be the same, and yet the spark and noise attending it would be almost imperceptible. The case is the same with the torpedo: each of the electric organs is a battery composed of innumerable small cylinders, which discharging themselves all at once, produce a formidable shock : but by reason of the smalluess of the charge of each, the spark is imperceptible.

The truth of this was exemplified by Mr. Walsh's artificial torpedo, which though it would give a very considerable shock through a conductor totally unintercupted, yet on the least breach therein, even for the breadth of a hair, no shock was felt. In every other respect the electricity of the torpedo agrees with that exhibited by the common electrical machines. An insulated person cannot receive a shock by touching one of the organs of the fish; but a violent stroke is given to the person, whether insulated or not, who lays one hand on the positive and the other on the negative organ. The fish, as is reasonable to imagine, seems to have this electric property in its own power; and appears sensible of it, for when giving the shock, it is accompanied by a kind of winking of the eyes.

The ancients considered the shocks given by the torpedo as capable of curing disorders; and a modern philosopher will scarcely hesitate to believe their assertions, now that electricity has been found to be a remedy for many diseases.

The third fish, which is known to have the power of giving the shock, is found in the rivers of Africa, but.we have a yery imperfect 
,

3 


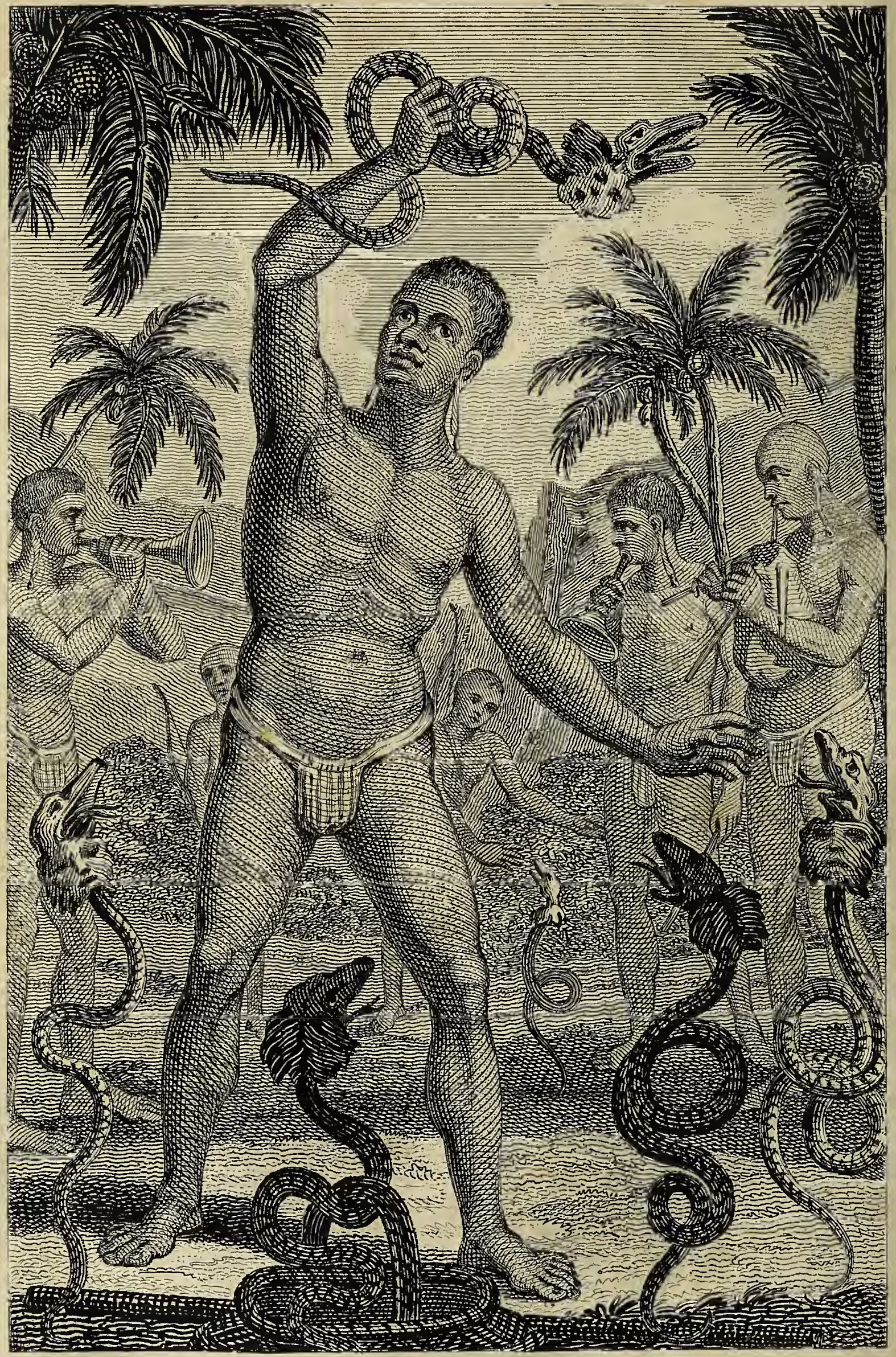

I) ANC CING SERPEIYTS 
account of its properties. Mess. Adanson and Forskal make a short mention of it, and M. Broussonnet describes it under the French name of Le Trembleur, in the Hist. de l'Academie Royal des Seiences, for the year 1782. This animal belongs to the order called, in Willoughby's system, silurus : hence it is commonly called silurus electricus. Some of these fishes have been seen even above twenty inches long. The body of the silurus electricus is oblong, smooth, and without scales; being rather large; and flattened towards its anterior parts. The eyes are of a middle size, and covered by the skin which envelops the whole head. Each jaw is armed with a great number of small teeth. About the mouth it has six flamentous appendices, viz. four from the under lip, and two from the upper; the two external ones, or farthermost from the mouth on the upper lip, are the longest. The colour of the body is grayish, and towards the tail it has some blackish spots. The electric organ seems to be towards the tail, where the skin is thicker than on the rest of the body; and a whitish fibrous substance, which is probably the electric organ, has been distinguished under it. It is said that the silurus electricus has the property of giving a shock, or benumbing sensation, like the torpedo, and that this shock is communicated through substances that are conductors of electricity.

A fourth electrical fish was discovered on the coast of Joanna, the chief of the Comoro islands, in lat. $12^{\circ} 13^{\prime}, \mathrm{S}$. by lieutenant William Paterson. An imperfect account of it was published in the Phil. Trans. vol. 76 . This fish is described to be seven inches long, and two and a half inches broad; it has a long projecting mouth, and seems of the genus Tetrodon. The back of the fish is of a dark brown colour, the belly part of sea-green, the sides yellow, and the fins and tail of a sandy green. The body is interspersed with red, green, and white spots, the white one particularly bright; the eyes large, the iris red, its outer edge tinged with yellow." Mr. Cavallo adds to this description, that, while this fish is living, strong electrical shocks are felt by a person who attempts to hold it between his hands. Three persons are nentioned, in the account, to have experienced this property of one of these fishes; but the want of opportunity prevented further experiments."

Besides those animals which nanifest their electric power evidently by giving a strong shock, there are others in which the fluid seems to act by the emission of light.: This indeed has not been proved by actual experiment, though it would certainly be well worth while to try whether by insulating a number of them, any nore evident signs of electricity could be obtained. These creatures are of the insect tribe; some of them furnished with wings, as the shining flies in the warm countries; whilst others, as the glow-worm, crawl perpetually on the earth. It is most probable also, that the sparkling of sea-water is owing to the electricity of the insects in it.

Tricks PERForMED WITH SERPENTS.

CASAUBON says, that he knew a man who could at any time summon one hundred serpents together, and draw them into the 
fire. Upon a certain occasion, when one of them, bigger than the rest, would not be bronght in, he only repeated his charm, and it came forward, like the rest, and subinited to the flames. Many other feats have been often practised upon these animals by artful men, who had first prepared the serpents for their exercise, and then exhibited them as adventitiously assembled at their call. In India there is nothing so common as dancing serpents, which are carried about in a broad flat vessel, somewhat resembling a sieve. They erect, and put themselves in motion, at the word of command. When their keeper sings a slow tune, they seem by their heads to keep time; and when he sings a quicker measure, they appear to move in a more brisk and lively manner. All animals have a certain degree of docility, and serpents can be brought to move at the voice of their master. From this trick, successfully practised before the ignorant, it is most probable has arisen most of the boasted pretensions which some have made to the charming of serpents; an art to which the native Americans pretend at this very day. We are also assured by Mr. Hasselquist, that it is practised amongst the native Egyptians, and we know that numerous individuals iii our own country triumph in the exercise of some very extraordinary powers over the serpent tribes.

\section{The Salamander.}

THIs animal has been said, and eren in the Philosophical Transactions, to have lived in the fire; but this is a mistake. It is found in the southern countries of Europe. The following account of this species is extracted from the Count de Lacepede's Natural History of Serpents:- Whilst the hardest bodies cannot resist the violence of fire, the world have endeavoured to make us believe, that a small lizard can not only withstand the flames, but even extinguish them. As agreeable fables readily gain belief, every one has been eager to adopt that of a small animal so highly privileged, so superior to the most powerful agent in nature, and which could furnish so many objects of comparison to poetry, so many pretty emblems to love, and so many brilliant devices to valour. The ancients believed this property of the salamander; and wishing that its origin might be as surprising as its power, and desirous of realizing the fictions of the poets, they pretended that it owed its existence to the purest of elements, which cannot consume it, and they called it the daughter of fire, giving it, lowever, a body of ice. The moderns have followed the ridiculous tales of the ancients; and some have gone so far as to think that the most violent fire could be extinguished by the land salamander. Quacks sold this small lizard, affirming that when thrown into the greatest conflagration, it would check its progress. It was necessary that the philosopliers should have proved by facts what reason demonstrated, but it was not till the light of science was diffused abroad, that the world gave over believing in this wonderful property of the salamander. This lizard, which is found in so many countries of the ancient world, and eveu in very high latitudes, has been very little noticed, because it is seldom seen out of its hole, and because for a 
long time it has inspired much terror. Even Aristotle speaks of it as of an animal with which he was scarcely acquainted.

One of the largest of this species, preserved in the late French king's cabinet, is seven inches five lines in length, from the end of the muzzle to the root of the tail, which is three inches eight lines: The skin does not appear to be covered with scales, but it is furnished with a number of excrescences like teats, containing many holes, several of which may be very plainly distinguished by the naked eye, and through which a kind of milk oozes, that generally spreads itself in such a manner as to form a transparent coat of varnish above the skin of this oviparous quadruped, which is naturally dry. The eyes are placed in the upper part of the head, which is a little flattened.

The colour of this species is very dark : upon the belly it has a bluish cast, intermixed with pretty large irregular yellow spots, which extend over the whole body, and even to the feet and eyelid: some of these spots are besprinkled with small black specks; and those which are upon the back often touch without interruption, and form two long yellow bands. The colour must, however, be various; and some salamanders are found in the marshy forests of Germany, which are quite black above, and yellow below. To this variety we must: refer the black salamander, found by M. Laurenti in the Alps, which he considered as a distinct species.

The salamander has no ribs; neither have frogs, to which it has a great resemblance in the general form of the anterior part of its body. When touched, it suddenly covers itself with that kind of coat of which we have spoken, and can also very rapidly change its skin from a state of humidity to a state of dryness. The milk which issues from the small holes in its surface is very acrid; when put upon the tongue, one feels as it were a kind of sear at the part which is touched. This milk, which is considered as an excellent substance for taking off the hair, has some resemblance to that which distils from the esula and euphorbium. When the salamander is crushed, or when it is only pressed, it exhales a peculiarly bad smell. Salamanders are fond of cold damp places, thick shades, tufted woods, high mountains, and the bauks of streams that run through meadows; they sonlimes retire in great numbers to hollow trees, hedges, and below old rotten stumps; and they occasionally pass the winter, in places of high latitude, in a kind of burrow, where they are found joined and twisted together.

The salamander being destitute of claws, having only four toes on each of the four feet, and no advantage of conformation to make up its deficiencies, its manner of living nust be very different from that of other lizards. It walks very slowly, and though able to climb trees with rapidity, it often appears to drag itself with great difficulty along the surface of the earth. It seldom goes far from its place of shelter: it passes its life under the earth, often at the bottom of old walls, during the summer; it dreads the heat of the sun, which would dry it, and it is only when rain is about to fall, that it comes forth from its asylum to bathe itself, and to imbibe an element to which it is analogous. Perhaps it finds then with 
greatest facility those insects upon which it feeds. It lives upon flies, beetles, snails, and earth-worms. When it reposes, it rolls up its body in several folds like serpents; it can remain some time in the water without danger, and it casts a very thin pellicle of a greenish gray colour. Salamanders have even been kept more than six months in water without food; care only was taken to change the water often. Every time a salamander is plunged into the water, it attempts to raise its nostrils above the surface of it, to seek for air, which is a new proof of the need that all oviparous quadrupeds have to breathe during the time they are not in a state of torpor. The salamander has apparently no ears, and in this it resembles serpents. It has even been said that it does not hear, and on this account it has got a suitable name in some provinces of France. This is very probable, as it has never been heard to utter any cry, and silence in general is coupled with deafness. Having then, perhaps, one sense less than other aninials, and being deprived of the faculty of communicating its sensations to those of the same species, even by imperfeet sounds; it must be reduced to a much inferior degree of instinet; it is therefore very stupid, and not bold, as has been reported; it does not brave danger, for it does not seem to perceive it. Whatever gestures one makes to frighten it, it always advances without turning aside; however, as no animal is deprived of that sensation necessary for its preservation, it suddenly compresses its skin when tormented, and spurts forth, upon those who attack it, that corrosive milk which is under it. If beaten, it begins to raise its tail ; afterwards it becomes motionless, as if stunned by a kind of paralytic stroke, for we must not, with some naturalists, ascribe to an animal so devoid of instinct, so much art and cunning, as to suppose that it can countefeit death. In short, it is difficult to kill it, but when dipped in vinegar, or surrounded with salt reduced to powder, it expires in convulsions, as is the case with several other lizards and worms.

The ancients, and even Pliny, have affirmed that the poison of the salamander is the most dangerou's of all, and that it might even cause the destruction of whole nations. The moderns also for a long time believed the salamander to be very poisonous; but they have at length had recourse to observation, with which they ought to have begun." The famous Bacon wished naturalists would endeavour to ascertain the truth respecting the poison of the salamander. Gesner proved by experiment that it did not bite, whatever means were used to irritate it, and Wurfbainus shewed that it might-safely be touched, and that one might without danger drink the wates of those wells which it inhabited?

M. de Maupertuis studied also the nature of this lizard. In making researches to discover what might be its pretended poison, he demonstrated experimentally that fire acted upon the salamander in the same manner as upon all other animals. He remarked that it was scarcely on the fre, when it appeared to be covered with the drops of its niilk, which, rarefied by the heat, issued through all the pores of the skin, but in greater quantity from the head and dugs, and that it immediately became hard. It is needless to say, that this milk is not sufficiently abundant to extinguish even the smallest 
fire. M. de Maupertuis, in the course of his experiments, in vain irritated several of these salamanders : none of them even opened their mouths; he was obliged to open them by force. As the teeth of this lizard are very small, it was very difficult to find an animal with a skin sufficiently fine to be penetrated by them: he tried without success to force them into the flesh of a chicken stript of its feathers; he in vain pressed them against the skin; they were displaced, but could not enter. He, however, made a salamander bite the thigh of a chicken, after he had taken off a small part of the skin. He made also salamanders, newly caught, bite the tongue and lips of a dog, as well as the tongue of a turkey; but none of these animals received the smallest injury.

M. de Maupertuis made a dog and a turkey swallow salamanders whole, or cut in pieces, and yet neither of them appeared sensible of the least uneasiness. M. Laurenti since made experiments with the same view; he forced gray lizards to swallow the milk proceeding from the salamander, and they died very suddenly. The milk therefore of the salamander, taken internally, may hurt, and even be fatal to certain animals, especially those that are small, but it does not appear to be hurtful to large animals.

It was long believed that the salamander was of ore sex, and that each individual had the power of engendering its like, as several species of worms. This is not the most absurd fable which has been imagined with respect to the salamander; but if the manner in which they come into the world is not so marvellous as has been reported, it is remarkable in this, that it differs from that in which most other lizards are brought forth, as it is analogous to that in which the chaleide and the seps, as well as vipers and several kinds of serpents, are produced. On this account the salamander merits the attention of naturalists much more than on that of the false and brilliant reputation it has so long enjoyed.

M. de Maupertuis having opened some salamanders, found eggs in them, and some young perfectly formed; the eggs were divided into two long bunches like grapes, and the young were enclosed in two transparent bags; they were equally well formed as the old ones, and much more active. The salamander therefore brings forth young from an egg hatched within its belly, as the viper; and her fecundity is very great : naturalists have long said that she has forty or fifty at once; and M. de Maupertuis found forty-two eggs in the body of one female salamander, and fifty-four in another. The young salamanders are generally black, almost without spots; and this colour they preserve sometimes during their whole lives, in certain countries, where they have been taken for a distinct species.

Mr. Thunberg has given, in the Memoirs of the Academy of Sweden, the description of a lizard, which he calls the Japanese lizard, and which appears not to differ from our salamander, but in the arrangement of its colours. This animal is almost back, with several whitish and irregular spots, both on the upper part of the body and below the paws; on the back there is a stripe of dirty white, which becomes narrow to the point of the tail. This whitish stripe is interspersed with very small specks, which form the distinguishing charac- 
teristic of our land salamander. We therefore must consider this Japanese lizard, as a variety of our land salamander, modified a little by the climate of Japan. It is found in Niphon, the largest island of that empire, inhabiting mountains and rocky places. The Japanese consider it as a very powerful stimulant, and a very active remedy in some disorders. In the neighbourhood of Jedo, a number of these Japanese salamanders may be seen dried, hanging from the ceiling of the shops.

\section{Field Crickets.}

IN White's Natural History of Selbourne, a very pleasing account is given of the manners and economy of these insects, which, however, are so sly and cautious, that it is no easy matter to get a sight of them, for, feeling a person's footsteps as he advances, they stop short in the midst of their song, and step nimbly into their burrows, where they lurk till all suspicion of danger is over. At first it was attempter to dig them out with a spade, but without any great success, for either the bottom of the hole was inaccessible by its terminating under a great stone, or, in breaking up the ground, the poor insect was inadvertently crushed to death. Out of one so bruised a multitude of eggs were taken, which were long and narrow, of a yellow colour, and covered with a very tough skin. Gentle means were then used, and proved successful: a pliant stalk of grass, gently insinuated into the caverns, will probe ther windings to the bottom, and quickly bring out the inhabitant, and this the humane inquirer may gratify his curiosity without injuring the object of it. It is remarkable, that though these insects are furnished with long legs behind, and brawny thighs for leaping, like grasshoppers, yet when driven from their holes, they shew no activity, but crawl along in a shiftless manner, so as easily to be taken; and again, though provided with a curious apparatus of wings, yet they never exert them when there seems to be the greatest occasion. The males only make that trilling noise, perhaps out of rivalry and emulation, as is the case with many animals, which exert some sprightly note during their breeding-time: it is raised by a brisk friction of one wing against the other. They are solitary beings, living singly, male or female, but there must be a time when they have some intercourse, and then the wings may perhaps be useful during the night.

When the males meet, they fight fiercely, as our author found by some which he put into the crevices of a dry stone-wall, where he wanted to have marie them settle. For though they seemed distressed by being taken out of their native habitations, yet the first which got possession of the chinks would seize on any that obtruded upon them with a vast row of serrated claws.

With their strong claws, toothed like the shears of a lobster's claw, they perforate and round their curious regular cells; having no fore claws to dig; like the mole cricket. When taken in the hand, they never offered to defend themselves, though armed with such formidable weapons of such herbs as grow before the mouth of their burrows, they eat indiscriminately; and on a little platform, which 
they make just by, they drop their ordure, and never in the daytime seem to stir above two or three inches from home.

Sitting in the entrance all night as well as day, from the middle of May to the middle of July, in hot weather, when they are most vigorous, they make the hills echo; and in the stiller hours of darkness, they may be heard at a considerable distance. In the beginning of the season, their notes are more faint and inward, but they become louder as the summer advances, and so die away again by degrees. The chirping of the field-cricket, though sharp and stridulous, yet delights some hearers, filling their minds with ideas of every thing that is rural and joyous. About the tenth of March the crickets appear at the months of their cells, which they then open, and shape very elegantly. All that ever I have seen at this season were in their pupa state, and had only the rudiments of wings, lying under a skin or coat, which must be cast before the insect can arrive at its perfect state, from whence I should suppose that the old ones of last year do not always survive the winter. In August their holes begin to be obliterated, and the insects are seen no more till spring: Not many summers ago, I endeavoured to transplant a colony to the terrace of ny garden, by boring deep holes in the sloping turf. The new iuhabitants staid some time, and fed and sung, but wandered away by degrees, and were heard at a farther distance every norning; so that it appears that in this emergency they made use of their wings in attempting to return to the spot from whence they were taken. One of these crickets, when confined in a paper cage, set in the sun, and supplied with plants moistened with water, will feed and thrive, and become so merry and loud as to be troublesome in the same room where a person is sitting; ; the plants are not wetted, it will die.

\section{Domestic, or Hearti Cricket.}

THIS insect delights in new-built houses; being, like the spider, pleased with the moisture of the walls. The softness of the mortar enables them to burrow and mine between the joints of the bricks or stone, and to open communications from one room to another. They are particularly fond of kitchens and bakers' ovens, on account of their perpetual warmth. "Fender insects," says Mr. White, "that live abroad, either enjoy only the short period of one summer, or else doze away the cold uncomfortable months in profound slumbers; but these, residing as it were in a torrid zone, are always alert and merry: a good Christmas fire is to them like the heat of the dog-days. Though they are frequently heard in the day, yet is their natural time of motion only in the night. As soon as it grows dusk, the chirping increases, and they come running forth, and are from the size of a flea to that of their full stature. As one should suppose from the burning atmosphere they inhabit, they are a thirsty race, and shew a great propensity for liquids, being found frequently drowned in pans of water, milk, broth, or the like. Whatever is moist, they affect; and therefore often gnaw holes in wet woollen stockings and aprons that are hung to the fire. These crickets are not only very 
thirsty, but very voracious, for they will eat the scummings of pots, yeast, salt, and crumbs of bread, and any kitchen offals and sweepings. In the summer we have observed them to fly, when it became dusk, out of the windows, and over the neighbouring roofs. "This feat of activity accounts for the sudden manner in which they often leave their haunts, as it does for the method by which they come to houses where they were not known before. It is remarkable, that many sorts of insects seem never to use their wings but when they have a mind to shift their quarters and settle new colonies. When in the air, they move up and down in waves or curves, like woodpeckers, opening and shutting their wings at every stroke, and so are always rising or sinking.

"When they increase to a great degree, as they did once in the house where I am now writing, they hecome noisome pests, fying into the candle, and dashing againsi people's faces; but they may be blasted by gunpowder discharged into their crevices and crannies. In families, at such times, they are like Pharaoh's plague of frogs, in their bed-chambers, and upon their beds, and in their ovens, and in their kneading troughs. Their sharp shrill noise is occasioned by a brisk attrition of their wings. Cats catch hearth-crickets, and, playing with them as they do with mice, devour them. Crickets may be destroyed like wasps, with phials half filled with beer, or any liquid, and set in their haunts; for always being eager to drink; they will crowd in till the bottles are full. A popular prejudice, however, frequently prevents their being driven away and destroyed; as some people imagine that their presence brings a kind of good luck to the house while they are in it, and think it would be hazardous to destroy them."

\section{Mole Cricket.}

THIS insect haunts moist meadows, and frequents the sides of ponds and banks of streams, performing all its functions in a swampy wet soil. With a pair of fore feet curiously adapted to the purpose, it burrows and works under ground like the mole, raising a ridge as it proceeds, but seldom throwing up hillocks. As mole-crickets often infest gardens by the sides of canals, they are unwelcome guests to the gardener, raising up ridges in their subterraneous progress, and rendering the walks unsightly. If they take to the kitchen-quarters, they occasion great damage among the plants and roots, by destroying whole leds of cabbages, young legumes, and flowers. When dug out, they seem very slow and helpless, and make no use of their wings by day; but at night they come abroad, and make long excursions. In fine weather, about the middle of April, at the close of the day they begin to solace themselves with a low dull jarring note, continued for a long time without interruption, and not unlike the chattering of the fern-owl or goat-sucker, but more inward. About the beginning of May they lay their eggs, as Mr. Whyte informs us, who was once an eye-witness; "for a gardener, at a house where he was on a visit, happening to he mowing on the sixth of that month by the side of a canal, his scythe struck too deep, pared off a piece of turf, and laid 
open a curious scene of domestic economy. There were many caverus and winding passages leading to a kind of chamber, neatly smoothed and rounded, and about the size of a moderate snuff-box. Within this secret nursery were deposited nearly one hundred eggs, of a dirty yellow colour, and enveloped in a tough skin, but too lately excluded to contain any rudiments of young, being full of a viscous substance.

The eggs lay but shallow, and within the influence of the sun, just under a heap of fresh-mowed mould, like that which is raised by ants. When mole-crickets fiy, they move in undulations, rising and falling in curves, like other species mentioned before. In different parts of this kingdom people call them fen-crickets, churr-worms, and evechurrs, all very apposite names."

\section{Centipede Worims.}

HHESE worms have a great many feet, though the number does not amount to one hundred, as the term imports. M. Maloet mentions a nian, who for three years had a violent pain in the lower part of his forehead, near the root of the nose; at length he felt an itching, and afterwards something moving within his nostril, which he brought away with his finger. It was a worm of the centipede kind, an inch and a half long, which ran swiftly. It lived five or six days among tobacco. The patient was free of his pain ever after. Mr. Littre mentions a somewhat similar case in 1708 , of a larger centipede roided at the nose, after it had thrown the woman, in whose fron. tal sinus it was, into convulsions, and had almost deprived her of her reason.

\section{Microscopic Animals.}

ON this subject the following observations from Mr. Adams are peculiarly interesting.

"How many kinds of these invisibles there may be, is yet unknown, as they are discerned of all sizes, from those which are barely invisible to the naked eye, to such as resist the force of the microscope, as the fixed stars do that of the telescope, and, with the greatest powers hitherto invented, appear only as so many moving points. The smallest living creatures our instruments can shew, are those which inhabit the waters; for though animalcules equally minute may fly in the air, or creep upon the earth, it is scarcely possible to get a view of them; but as water is transparent, by confining the creatures within, we can easily observe them by applying a drop of it to the glasses. Animalcules in general are observed to move in all directions with equal ease and rapidity; sometimes obliquely, sometimes straight forward; sometimes moving in a circular direction, or rolling upon one another, running backwards and forwards, through the whole extent of the drop, as if diverting themselves; at other times greedily attacking the little parcels of matter they meet with. Notwithstanding their extreme minuteness, they know how to avoid obstacles, or to prevent any interference with one another in their notions: sometimes they will suddenly change the direction in which 
they move and take an opposite one; and by inclining the glass on which the drop of water is, as it can be made to move in any direction, so the animalcules appear to move as easily against the stream as with it. When the water begins to evaporate, they flock towards the place where the fluid is, and shew a great anxiety and uncommon agitation of the organs with which they draw in the water. These motions grow languid as the water fails, and at last cease altogether, without a possibility of renewal, if they be left dry for a short time. They sustain a great degree of cold, as well as insects, and will perish in much the same degree of heat that destroys insects. Some animalcules are produced in water at the freezing point, and some insects live in snow. By nixing the least drop of wine with the water in which they swim, they instantly fall into convulsions and die. The same rule seems to hold good in those minute creatures, which is observable in the larger animals, viz. that the larger kinds are less numerous than such as are smaller, while the smallest of all are found in such multitudes, that there seem to be myriads for one of the others. They increase in size like other animals, from their birth until they have attained their full growth; and when deprized of proper nourishment, they in like manner grow thin and perish."

The modes of propagation among these animalcules are various, and the observation of them is extremely curious. Some multiply by a transverse division; and it is remarkable, that though in general they avoid one another, it is not uncommon, when one is nearly divided, to see another push itself in upon the small neck which joins the two bodies, in order to accelerate the separation. Others, when about to multiply, fix themselves to the bottom of the water; then becoming first oblong, and afterwards round, turn rapidly as on a centre, but perpetually varying the direction of their rotary motion. In a little time, two lines forming across are perceived; after which the spherule divides into four, which grow, and are again divided as before. A third kind multiply by a longitudinal division, which in some begins in the fore part, in others in the lind part; and from others a small fragment detaches itself, which in a short time assumes the shape of the parent animalcule. Lastly, others propagate in the same manner as the more perfect animals.

Some doubts have arisen whether those minute bodies really do enjoy animal life; or whether they are not in many cases to be accounted only inanimate and exceedingly minute points of matter, actuated by the internal motion of the fluid. But to all hypotheses of this kind, Mr. Adams makes the following reply. "From what has been said it clearly appears, that their motions are not purely mechanical, but are produced by an internal spontaneous principle; and that they must therefore be placed among the class of living animals, for they possess the strongest marks of the most decided characters of animation; and consequently; that there is no foundation for the supposition of a chaotic and neutral kingdom, which can only have derived its origin from very transient and superficial views of these animalcules? 
THIs creature sometimes grows to the length of eight feet, and weighs between eight and nine pounds. The colour of the head is brown, and the eye red; the upper part of the body of a yellowish brown colour, transversely marked with irregular broad black lists. The rattle is of a brown colour, composed of several horny membranous cells, of an undulated pyramidical figure. These are articulated within one another in such a manner, that the point of the first cell reaches as far as the basis of the protuberant ring of the third, and so on; which articulation being very loose, gives liberty to the parts of the cells that are enclosed within the outward ring, to strike against the sides of them, and so to cause the rattling noise which is heard when the snake shakes its tail. This is the most inactive and slow-moving of all the snakes, and is never the aggressor, except in what it preys upon. Mr. Catesby is of opition that no remedy is yet discovered for the bite of this animal. He had frequent opportunities of seeing Indians who had been bitten by it, and always thought that those who recovered were cured more through the force of nature, or by reason of the slightness of the bite, than by the remedies used. He says, the Ludians know their destiny the moment they are bitten; and if the bite happens to be on any of the large veins, they apply no remedies, knowing them to be entirely useless. He believes the report of the fascinating power of this serpent, though he never had an opportunity of seeing it.

\section{Mermaid or Merman.}

THIS is a sea-creature, frequently talked of, supposed to be half human, and half a fish. Though naturalists doubt of the reality of mermen or mermaids, there are many testimonies of their existence given by historians. In 1187, as Laray informs us, a mermaid was fished up on the coast of Suffolk, and kept by the governor six month's, It bore so near a conformity with man, that nothing seemed wanting but speech. One day it made its escape, and, plunging into the sea, was never more heard of. In 1480, after a huge tempest, which broke down the dikes in Holland, and made way for the sea into the meadows, \&c. some girls of the town of Edam, in West Freezeland, going in a boat to milk their cows, perceived a mermaid embarrassed in the mud with a very little water. They took it into their boat, and brought it with them to Edam, dressed it in women's apparel, and taught it to spin. It fed like them, but never attempted any thing like speech. Some time afterwards it was brought to Haerlem, where it lived for some years, though still shewing an inclination to the water. Parival relates, that they had given it some notion of a Deity, and that it made its reverences very devoutly whenever it passed by a crucifix. Dalices de Hollande. In 1560, near the island of Manar, on the west coast of Ceylon, some fishermen brought up, at one draught of a net, seven mermen and mermaids, of which several Jesuits, and among the rest, F. Hen. Henriques and Dimas Bosquez, physicians to the viceroy of Goa, were witnesses. The physician, who examined them with a great deal of care, and made a dissection of one, asserts that all the parts, both internal and external, were perfectiy confor- 
mable to those of men. Another mermaid was caught in the Baltic in 1531, and sent as a present to Sigismund king of Poland, with whom it lived three days, and was seen by all the court. Another very young one was taken near Rocca de Sinbra, as related by Damian Goes. In Pontopidan's Natural History of Norway, also, we have an account of mermaids, but not more remarkable, or better attested, than the above.

So late as the year 1822 , something, said to be a mermaid, of which the following representation is a tolerable likeness, was exhibited in London.

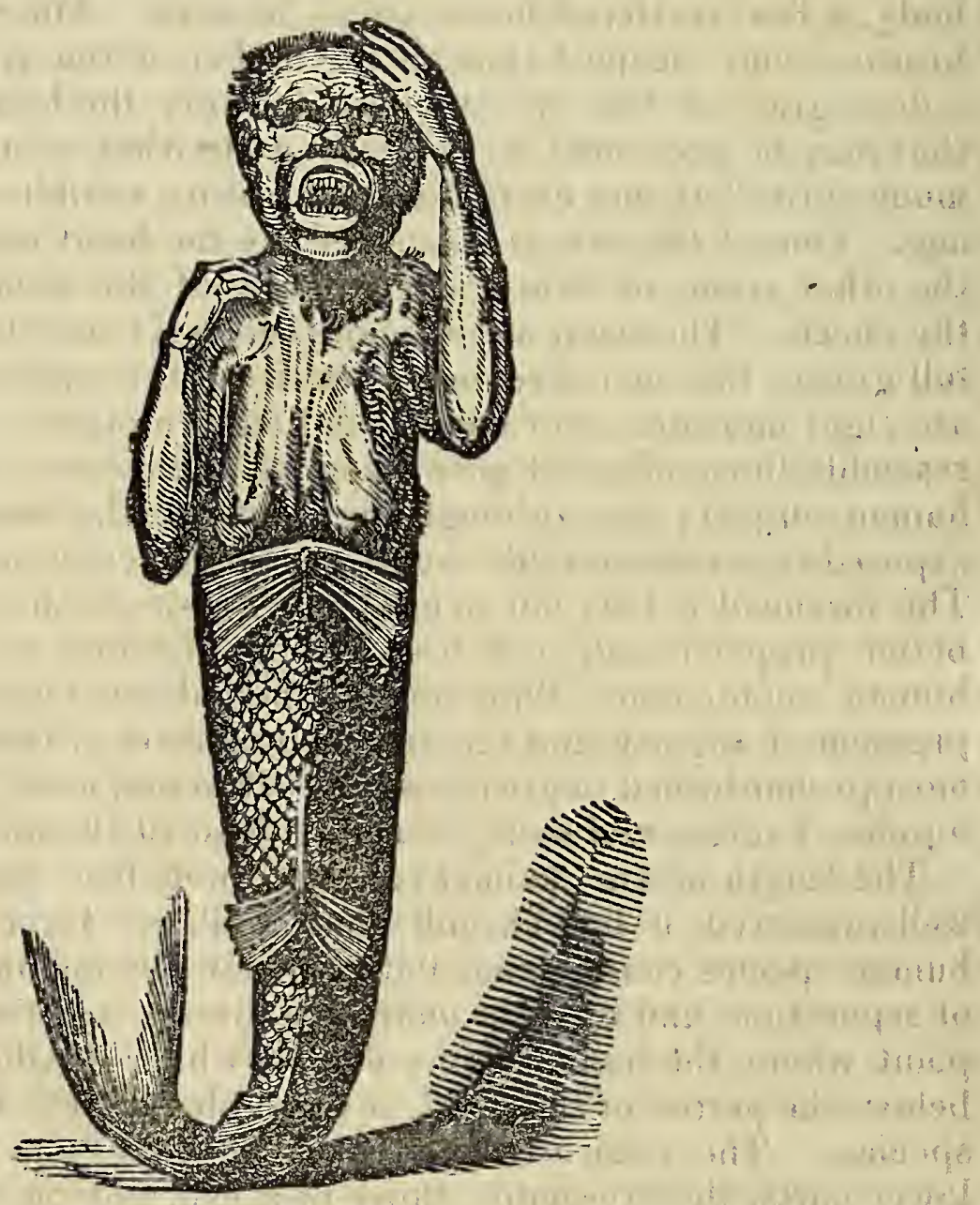

The history of this strange creature is briefly as follows. It was caught on the north of China by a tisherman, who sold it for a trifle. From China it was brought to Batavia, where it was purchased by a captain Eades of Boston, in America, for five thousand Spanish dollars. From Batavia it was carried to the Cape of Good Hope, and from thence it found its way to London, where it was, seen by many thousands during a period of several months.

As the creature actually appeared on its arrival in London, the features of the human countenance were exhibited in frightful distortion; and how disgusting soever the figure which accompanies these observations may appear, the artist has availed himself of the privilege of his profession, and given a flattering likeness.

The head is disproportionably large, resembling that of a baboon; 
and, fromits minn with the neck, is projected considerably forward. Whe face is mich elevated : the lips have nearly disappeared; and the cheek-bones are extended almost equal with the projection of the rhose: From the entremity of the chin to the throat the distance is tovery great, bearing in this part a stronger resemblance to the feline than to the human species. At the commencement of the vertebre, just behind the head, there is a singular projection, exhibiting such a mark of deformity as a dislocation might be supposed to produce. The head is thinly covered with long black hair, not inchined to frizzle. On the shoulders, on the arms, and on most of the upper parts of the body, a few scattered hairs are to be seen. The skin is of a dirty brown colour, deepest towards the nether extremity, but turning into a dirty gray as the eye wanders towards the head. In every part that may be presumed to coincile with what is human, ihe skin is much shrivelled, and every limb and feature exhibits signs of advanced age. One of the ears is concealed by the hand that is elevated, and the other seems to form a continuation of the wriukles leading from the cheek. The teeth afford sufficient evidence that the creature is full grown, the incisores being worn on the upper surface. There are eight incisores, four canine, and eight molares. Whe canine teeth resemble those of a full-grown dog, all the others resemble those of a human subject; but although the cavity of the mouth is sufficiently exposed to a considerable extent, no tongue could be distinctly traced. The forehead is low, but in most other respects the features are much better proportioned, and bear a more decided resemblance to the human countenance than any of the baboon tribes. From the expression of anguish and terror which appears in the face, the creature most probably died in great agonies. The ears, nose, lips, chin, breasts, nipples, fingers, and nails, resenthe those of the human figure.

The length of the animal is abont three feet, but not having been well preserved, it had shrumk considerably. Its resemblance to the human species ceases immediately under the mamma. On the line of separation, and directly under the breast, are two fins. From the point where the human figure ceases, which is about ivelve inches below the vertex of the head, it resembles a large ish of the salmon species. The creature is covered all over with scales. On the lower parts, they resemble those of a fish, but on the parts that correspond, with the human they are much less; and in some places they are scarcely perceptible, except on a very close inspection. On the lower part of the body it has six fins; one dorsal, two ventral, two pectoral, and the tail. This latter resembles what has usully been given in the representation of mermaids.

Whether this creature had ever existed in any way corresponding to the form in which it was exhibited, was a point much debated among those by whom it was inspected. Some few contended for its realify, but the greater number denounced it to be an imposition on the Inglish credulity. It was readily admitted by the latter party, that all the substances were completely animal, but that the upper part was that of a baboon, carefully presenved, and ingeniously joined to the tail of a fish by some Chinese artist; and in this decision public ophion appeased generally to concul. 
On the whole, it may, however, be plainly observed, that nothing but dissection can satisfy every inquiry, and remove every doubt; and if on investigation it should be proved to be an imposition, the observer, though convinced of the fraud, would be half tempted to forget the author of the deception, in his admiration of the excellence of its execution.

\section{The Noctilucous Nereis.}

THIs is a kind of worm, which inhabits almost every sea, and is one of the causes of the liminousness of the water. These creatures shine like glow-worms, but with a brighter splendour, so as at uight to make the element appear as if on fire all around. Their bodies are so minute as to elude examination by the naked eye. They are seen upon all kinds of marine plants, but they often leave them, and are found upon the surface of the water. They are frequent at all seasous, but especially in summer before stormy weather, when they are more agitated and more luminous. Their numbers and wonderful agility, added to their pellucid and shining quality, do not a little contribute to their illuminating the sea, for myriads of those animalcules may be contained in the portion of a cup of sea-water. Innumerable quantities of them lodge in the cavities of the scales of fishes, and to them, probably, do the fishes owe their noctilucous quality.

"I have observed with great attention," says Barbut, "a fish just caught out of the sea, whose borly was covered with them, and have examined them in the dark; they twist and curl themselves with wonderful agility, but sonn retire out of our contracted siglit; probably their glittering numbers dazzle the eye, and their extreme minuteness eludes our researches. It is to be observed, that when the unctuous moisture that covers the scales of fishes is exhausted by the air, these animals are not to be seen, nor are the fishes then noctilucous; that matter being perhaps their nourishment when living, as they themselves afford food for many marine aninals. They do not shine in the day-time, because the solar rays are too powerful for their light, however aggregate or immense their number." Their appearance is particularly brilliant when the wind is in the east and southeast points, and in the winter nights preceded by a warm day. If water containing these animalcules be kept warm, they retain their light two whole days after they are dead, but in cold water lose it in eight hours: motion and warmth which, increase their vivacity and strength, increase their light also.

\section{The SEa TuRtie.}

TuIs creature is found in the island of Ascension, and also in other places in the South Sea. The shell is so very strong, that it can carry more than six hundred pounds on its back, or, as many men as can stand on it loaded. It digs round holes in the sand, in which it lays a vast number of eggs yearly, to the amount of one thousand, it is said. It broods on them during the night. Its flesh is of a 
greenish colour, makes excellent food, and is the favourite dish of sailors, as well as of epicures. It lives on cuttle and shell fish, and grows to a prodigious size, some having been found to weigh four hundrèd and eighty pounds. The Americans find so good account in catching turtle, that they have made themselves very expert at it : they watch them from their nests on shore, in moon-light nights; and, before they reach the sea, turn them on their backs, and leave them till morning; when they are sure to find them, since they are utterly unable to recover their former posture: at other times they hunt them in boats with a peculiar kind of spear, striking them with it through the shell; and as there is a cord fastened to the spear, they are taken much in the same manner as whales.

\section{Golden Fish.}

These fish are domesticated by the Chinese, and generally kept for ornament by great people in their courts and gardens. They breed them in small ponds made for the purpose, in basons, and even in porcelain ressels. This fish is no larger than our pilchard or herring. The male is of a bright red colour from the top of the head to the middle of the body ; the rest is of a gold colour ; but it is so bright and splendid, that the finest gilding, according to Fole Comte, cannot approach it. The female is white, but its tail and half its body resemble the lustre of silver. F. du Halde, however, observes, that a red and white colour are not always the distinguishing marks of the nale and female, but that the females are known by several white spots which are seen round the orifices that serve them a's organs of hearing, and the males by having these spots much brighter. Gold fish are light and lively, they love to sport on the surface of the water, soon become familiarized, and may even be accustomed to come and receive their food on somoling a little rattle. Great care is necessary to preserve them, for they are extremely delicate, and sensible of theleastinjuries of the air; a loud noise, such as that of thunder or cannons, a strong smell, a violent shaking of the vessel, or a single touch, will oft-times destroy them.

These fish live with little nourishment; those small worms which are engendered in the water, or the earthy particles that are mixed with it, are suficient for their food. The Chinese, however, take care to throw into the basons and reservoirs where they are kept, small balls of paste, which they are very fond of when dissolved; they give them also lean pork, dried in the sun, and reduced to a fine and delicate powder, and sometimes snails. The slime which these insects leave at the bottom of the vessel is a great delicacy for them, and they eagerly hasten to feed upon it. In winter they are removed from the court to a warm chamber, where they are kept generally shut up in a porcelain vessel. During that season they receive no nourishment. However, in spring, when they are carried back to their former buson, they sport and play with the same strength and liveliness that they did the preceding year.

In warm countries these fish multiply fast, provided care be taken to collect their spawn, which floats on the water, and which they 
almost entirely devour. This spawn is put into a particular vessel, exposed to the sun, and preseryed there until vivified by the heat; gold fish, however, seldom multiply when they are kept in close vases, because they are then too much confined. In order to revider them fruitful, they must be put into reservoirs of considerable depth, in some places at least, and which are constantly surplied with fresh water.

At a certain time of the year, a prodigious number of barks may be seen in the great river Yang-Tse-Kiang, which go thither to purchase the spawn of these fish. Towards the month of May, the neighbouring inhabitants shut up the river in several places with mats and hurdles, which occupy an extent of almost nine or ten leagues, and they leave only a space in the middle sufficient for the passage of barks. The spawn of the fish, which the Chinese can distinguish at first sight, although a stranger could perceive no traces of it in the water, is stopped by these hurdles. The water mixed with spawn is then drawn up, and, after it has been put into large vessels, is sold to merchants, who transport it afterwards to every part of the empire. This water is sold by measure, and purchased by those who are desirous of stocking their ponds and reservoirs with fish.

Notwithstanding the tenderness of these fish, even in their native climates, they are now naturalized in Britain, where they even breed. They were first introduced into England aboist A. D. 1691; but were not generally known till 1928 , when a great number were lirought over, and presented to Sir Mathew Dekker, and by him circulated round the neighbourhood of London, from whence they have been distributed to most parts of the conntry. Nothing can be more amusing than a glass bowl containing these fishes: the double refractions of the glass and water represent them when moving in a mose beautiful variety of dimensions, shades, and colours; while the two mediums, assisted by the concavo-convex shape of the vessel, magnify and distort them vastly; not to mention that the introduction of another element, and its inhabitants, into our parlours, engages the fancy in a very agreeable manner.

\section{ICINEUMON WASP, OR SAVAGE.}

Trine are ninety-seven species of this insect. The manner of living is diferent in the varions species, and so is the general form of the body, and their hauns: but though the rachod of life be utterly dherent, yet the same manners appear innate and inherent in all. mey agree in bong the fiercest of all lies; they will atack insects much larger than themselves, and this whether they be defenceless or armed, as they are provided with a sting. The strength in all this savage kind is great: their jaws are hard and sharp, and their sting is so poisonous as to be suddenly fatal to the creatures with which they engage. The savage seizes strongly on the anmal he attachs, and gives a stroke of anazing force; after which he falls down as if hinself were killed, but it is to rest from his fatigue, and enjoy his. vichry. He keeps a steady eye on the creature he has struck, tillit dies, What buplens in a few mouses, and then drags it to the nest to feed 
the young. The number of other insects they destroy is scarcely to. be conceived; the mouth of their cave is, like that of a giant in the days of yore, strewed with the remains of prey. The eyes, that filament which serves as a brain, and a small part of the contents of the body, are all the savage eats, and he will kill fifty for a meal.

\section{GNats}

THEsE insects, too well known by the severe puncture they inflict, and the itchings thence arising, aford a most interesting history. Before they turn to flying insects; they have been in some manner fishes, under two different forms. One may observe in stagnating waters, from the beginning of May till winter, small grubs, with their heads downwards, and their hinder parts on the surface of the water; from which part arises sideways a kind of vent-hole, or small hollow funnel, and this is the organ of respiration. The head is armed with hooks that serve to seize on insects and bits of grass, on which it feeds: On the sides are placed four small fins, by the help of which the insect swims about, and dives to the bottom. The larva retain their form during a fortnight or three weeks, after which period they turn. to chrysalids. All the parts of the winged insect are distinguishable through the outward robe that shrouds them. The chrysalids are rolled up into spirals. The situation and shape of the windpipe are then altered; it consists of two tubes near the head, which occupy the place of the stigmata, through which the winged insect is one day to breathe. These chrysalids, constantly on the surface of the water in order to draw breath, abstain now from eating; but upon the least motion are seen to roll thenselves up, and plunge to the bottom, by means of little paddles sitnated at their binder parts.

After three or four days' fasting they pass to the state of gats. A moment before, water was the guat's element; but now, become an aerial insect, he can no longer exist in it. He swells his head, and bursts its enclosure. The robe he lately wore turns to a ship, of which the insect is the mast and sail. If, at the instant the gnat displays his wings, there arises a breeze, it proves to him a dreadful hurricane; the water gets into the ship, and the insect, which is not yet loosened from it, sinks and is lost. But in calm weather the gnat forsakes his slongh, dries himself, fies into the air, and seeks to pump the alimentarv juice of leaves, or the blood of man or beast.

The sting which our naked eye discovers, is but a tube, containing five or six spicula, of exquisite minuteness; some dentated at their extremity like the head of an arrow, others sharp like razors. These spicula, introduced into the veins, act as pump-suckers, into which the blood ascends by reason of the smallness of the capilary tubes. The insect ejects a small quanity of liquor into the wound, by which the blood becomes more fuid, and is seen by the microscope passing through those spicula: the animal then swells, yrows red, and does not quit its hold till it has gorged itself. The liquor it has ejected causes by its fermenting that disagreeable itching which we experence, and which may be removed by volatile alkali, or by scratching the part newly stung, aud washing it instantly with cold water; for if negleded, 
the venom ferments, and the tumour and the itching are only increased by friction. Rubbing one's self at night with fuller's earth and water, lessens the pain and iufammation.

The female deposis her eggs in the water, by the help of her moveable hind part and her legs, placing them one by the side of another in the form of a little boat. This vessel, containing two or three hundred eggs, swims on the water for two or three days, after which they are hatcher. If a storm arises, the boats are sunk. Every month there is a fiesh progeny of these insects. Were they not devoured by swallows and other birds, as well as by several carnivorous insects, the air would be darkened by them.

\section{Recenthy discovened Insects.}

SEVERAL nondescript little animals were discovered by La Marniere the riaturalist, when he accompanied the celebrated but unfortunate Perouse in his voyage of discovery. These he ranked among insects, and to some of them gave particular names, but without arranging them agreeable to the Linnan system of zoology. He describes them as follows.- "This insect inhabits a small prismatic triangular cell, pointed at the two extremities, of the consistence and colour of clear Lrittle ice. The body of the insect is of a green colour, spotted with small bluish points, among which are some of a golden tinge. It is fixed by a ligament to the lower part of its small habitation. Its neck is terminated by a small blackish head, composed of three converging scales, in the form of a hat, and enclosed between three fins, two of them large and channelled in the upper part, and one small and semicircular. When it is distended, it immediately withdraws its head and its fins into its cell, and gradually sinks into the water by its own specific gravity. The movement carried on by the two larger fins, which are of a sofish cartilaginous substance, may be compared to that which would be produced by two hands joined together in the state of pronation, and forming alternately two inclined planes, and one horizontal plane; it is by means of this that it supports itself on the top of the water, where it probably feeds on fat and oily substances on the surface of the sea."

Our authol found it near Nootka, on the north-west coast of America, during a calti. At the same time he saw a collection of insects, consisting of oval bodies, similar to a soap-bubble, arranged in parties of three, five, six, and nine; among them were also some solitary ones. These collections of globules, being put into a glass filled with sea-water described a rapid circle round the glass by a common movemeit, to which each individual contributed by a simple compression of the side of its body, probably the effect of the re-action of the air with which they were flled. It is not, however, easy to conceive how these distinct animals, for they may be readily separated without deranging their economy, are capable of concurring in a common motion.

"These considerations, says our author, together with the form of the animal, recalled to my mind, with much satisfaction, the ingenious system of $M$. de Bufon; and $\mathbb{l}$ endeavoured to persuade myself that 
I was about to be witness to one of the most wonderful phenomena of nature, supposing that these molecules, which were now increasing or diminishing their number, or performing their revolutions in the glass, would soon assume the form of a new animal, of which they were the living materials. My impatience led me to detach two from the most numerous group, inagining that this number might perhaps be more favourable to the expected metamorphosis. I was, however, mistaken. These I exanined with more attention than the rest, and the following account is of their proceedings alone.-Like two strong and active wrestlers, they immediately rushed together, and attacked each other side by side: sometnes one would dive, leaving its adversary at the surface of the water; one would describe a circular movement, while the ofher remained at rest in the centre: their motions at length became so rapid, as no longer to allow me to distinguish one from the other. Having quitted them for a short time, on my return I found them reunited as before, and amicably moving round the edge of their glass by their common exertions."

The same author has also given an account of a singular animal, which has a considerable resenblance to a litue lizard; its body is of a firm gelatinons consisience; its head is furnished on each side with two small gelatinous horns, of which the two hindermost are situated the farthest inward; its body is provided with four open fan-like paws, and some appendages near the insertion of the tail, and terminates like that of a lizard; the ridge of the back is divided the whole way down by a band of deep blue; the rest of its body, as well as the inside of its paws, is of a bright silvery white. It appears to be very sluggish in its motions; and when disturbed by the finger, merely turned its belly upwards, soon afterwards resuming its former position. Martiniere caught it during a calm at the landing-place on the Bashee Islands.

\section{Ant's' EGgs.}

THESE are a kind of little white balls, found in the nests of ants, ordinarily supposed to be the ova of this insect. Later naturalists have observed, that these are not properly the ants' eggs, but the young brood themselves in their first state; they are so many little vermiculi, wrapped in a film or skin, composed of a sort of silk, which they spin out of themselves, as silk worms and caterpillar's do. At first they are hardly observed to stir; but after a few days' continuance, they exhibit a feeble motion of flexion and extension, and begin to look yellowish and hairy, shaped like small maggots, in which shape they grow up till they are almost as large as ants. When they pass their metamorphosis, and appear in their proper shape, they have a small black speck on them, close to the anus of the included ant, which M. Leuwenhoek, probably enough imagines to be the feces voided by it.

Sir Edward King, M. D. opened several of these vulgarly reputed eggs; in some of which he found only a maggot, in the circumstances above described; while in another the maggot had begun to put on the shape of an ant about the head, having two little yellow specks 
where the cyes were to be. In others a further pregress was obsersed, the inchded naggots being furnished with every thing to complete the shape of an ant, but wholly transparent, the eyes onlvexcented, which were as black as bugles. Lastly, in others he took out ants every way periect and complete, which immediately crept about among the rest. These supposed ants' eggs are brought up every moming in summer, near the top of the nest, where they are lodged all the warm lat of the day, within reach of the sun's infuence. At night, or if it be cool or like to rain, they carry then down to a great depth; so that you may dir a foot deep ere you come at them. The true ant-eggs are the white substance which, upon opening thein lanks, appear to the eye like the scatterings of tine white sugar or salt, but very soft and tender. Examined by a microscope, it is foumd to consist of several pure white appearances, in distinct membranes, all figured like the lesser sorts of bird's eggs, and as clear as the bladder of a fish. The same substance is found in the hodies of the auts themselves. On this spawn, when emitted, they lie? in multfudes, to brood, till it is turned into little vernicules as small as nites, commonly called unts' eggs.

\section{Methods of DESTROYING ANT-HIILS.}

ANT-HILLS do great mischief to dry pastures, not only by wasting so much land as they cover, but by hindering the scythe in mowing the grass, and yielding a poor hungry food pernicious to cattle. The manner of destroying them is, to cut them into four parts from the top, and then dig into them so deep as to take out the core below, so that when the turf is laid down again, it may be somewhat lower than the level of the land; and this will prevent the ants from returning to the same place, which otherwise they would certainly: do: The earth that is taken out, must be scattered to as great a distance every way as may be, otherwise they will collect it together, and make another hill just ly. The proper time for doing this is winter ; and if the places be left open, the frost and rains of that time of the year will destroy the rest; but in this case care must be taken that they are covered up early enough in the spring, otherwise they will be less fertile in grass than the other places. In Hertfordshire they use a particular kind of spade for this pupose; it is very sharp, and formed at the top into the shape of a crescent, so that the whole edge makes up more than three-fourths of a circle; this acts in every part, and does the business very quickly and effectually. Others use the same instruments that they do for mole-hills. Human soil is a better remedy than all those, as is proved by experiment; for it will kill great numbers of them, and drive all the rest away, if only a small quantity of it be put upon their hills. Unslacked lime has also been used successfully.

\section{SPONGE.}

So early as the days of Aristotle, sponges were supposed to possess animal life; the persons employed in collecting them, having 
observed them shrink when torn from the rocks, thus exhibiting symptoms of sensation. The same opinion prevailed in the time of Pliny. But no attention was paid to this subject, till Marsigli examined them, and declared them vegetables. Dr. Peysonell, in a paper which he sent to the Royal Society in the year 1752, and in a second in $175 \%$, aftirmed they were not vegetables, but the production of animals, and described the process which they performed in making the sponges.' Mr. Ellis, in the year 1762, was at great pains to. discover these animals. For this purpose he dissected the spongia urens, and was 'surprised to find a great number of small worms of the genus nereis, or sea scolopendra, which had pierced their way through the first substance of the sponge, in quest of a safe retreat. That this was really the case, he was fully assured of, by inspecting a number of specimens of the same sort of sponge, just fresh from the sea. He put them into a glass filled with sea-water; and then; instead of seeing any of the little animals which Dr. Peysonell described, he observed the papilla, or small holes with which the papilla are surrounded, contract and dilate themselves. He examined another variety of the same species of sponge, and plainly perceived the small tubes inspire and expire the water. He therefore concluded that the sponge is an animal, and that the ends or openings of the branched tubes are the mouths by which it receives its nourishment, and discharges its excrements.

\section{The SWIFT.}

THE swift is a species of swallow, and is a summer inhabitant of these kingdoms. It comes the latest, and departs the soonest, of any of the tribe, not always staying to the middle of August, and often not arriving before the beginning of May. A pair of these birds.were found adhering by their claws, and in a torpid state, in Feb. 1766, under the roof of Longnor chapel, in Shropshire; on being: brought to a fire, they revived, and moved about the room. "The fabulous history of the Manucodiata, or bird of paradise," says Mr. Pennant, "is, in the history of this species, in a great measiure verified: that was believed to have no feet; to live upon the celestial dew; to foat perpetually on the atmosphere ; and to perform all its functions in that element. The swift actually performs what has been in these enlightened times disproved of the former : except the small time it takes in -sleeping, and what it devotes to incubation, every other action is done on the wing. The materials of its nest are collected either as they are carried abont by the wind, or it pulls them up from the surface in its sweening fight; its food is undeniably the insects that fill the air; its drink is taken in sips from the water's surface.

The swift is a most alert bird, rising very early, and retiring, to roost very late; and is on the wing, in the nidst of summer, at least sixteen lours. In the longest days it does not retire to rest till a quarter before nine at night, being the latest of all day-birds. Just before they retire, whole groups of them assemble high in the air, and squeak, and shoot about with wonderful rapidity. But this bird is

$$
5 \text { E }
$$


never so much alive as in sultry thundery weather, when it expresses great alacrity, and calls forth all its powers. In hot mornings, several, getting together in little parties, dash round the steeples and churches, squeaking as they go, in a very clamorous manner. These, by nice observation, are supposed to be males serenading their sitting-hens; and not without reason, for they seldom squeak till they come close to the walls or eaves, and since those within utter at the same time a little inward note of complacency. When the hen has been sitting all day, she rushes forth just as it is dark, and stretches and relieves her weary limbs, snatches a scanty meal for a few minutes, and theis returns to her duty of incubation.

Swifts, when wantonly and cruelly shot while they have young, discover a little lump of insects in their mouths, which they pouch, and hold under their tongue. In general, as already observed, fed in a much higher district than the other species, they also range to vast distances; since locomotion is no labour to them, they being endowed with such wonderful powers of wing. At some certain times in the summer, however, they have been observed hawking very. low, for hours together, over pools and streams; and on inquiring in to the object of their pursuit, that induced them to descend so much below their usual range, it has been found that they were taking phryganeæ, ephemeræ, and libellulæ, cadeu-flies, may-flies, and dragon-fies, that were just emerged out of their aurelia state. It appeared then no longer a wonder that they should be so willing to stoop for a prey that afforded them such plentiful and succulent nourishment. Swifts sometimes pursue and strike at hawks that come in their way, but not with that vehemence and fury which swallows express on the same occasion. They are out all day long, even though wet, feeding, and disregarding the rain: from whence two things may be gathered; first, that many insects abide high in the air, even in rain; and next, that the feathers of these birds must be well preened, to resist so much wet. Windy weather, and especially with heavy showers, they dislike; and on such days withdraw, and are scarcely ever seen.

There is a circumstance respecting the colour of swifts, Mr. White remarks, which seems not to be unworthy our attention. When they arrive in the spring, they are all over of a glossy dark soot-colour, except their chins, which are white; but, by being all day long in the sun and air, they become quite weather-beaten and bleached before they depart, and yet they return glossy again in the spring. Now, if they pursue the sun in lower latitudes, as some suppose, in order to enjoy a perpetual summer, why do they not return bleached? Do they not rather retire to rest for a season, and at that juncture moult and change their feathers, since all other birds are known to moult soon after the season of breeding? Swifts are very anomalous in many particulars, dissenting from all their congeners, not only in the number of their young, but in breeding once a summer; whereas all the other British hirundines breed invariably twice. It is past all doubt that swifts can breed but once, since they withdraw in a short time after the flight of their young, and snme time beiore their congeners bring out their second broods. We may here remark, that as swifts breed once in a summer, and only two at a time, and the other hirun- 
dines twice; the latter, which lay from four to six eggs, increase at an average five times as fast as the former.

But in nothing are swifts more singular than in their early retreat. They retire, as to the main body of them, by the tenth of August, and sometimes a few days sooner; and every straggler invariably withdraws by the twentieth, though their congeners all of them stay till the beginning of October, many through all that month, and some occasionally to the beginning of November. This early retreat is mysterious and woudertinl, since that time is often the sweetest season in the year. But, what is more extraordinary, they begin to retire still earlier in the most southerly parts of Andalusia, where they can be no ways influenced by any defect of heat, or, as one might suppose, defect of food. Are they regulated in their motions with us by a defect of food, or by a propensity to moulting, or by a disposition to rest after so rapid a flight, or by what? This is one of those incidents in natural history which not only baffle our researches, but almost eludes our guesses!" Swifts never perch on trees or roofs, and so never congregate with their congeners. They are fearless while haunting their nesting places, are not to be frightened away with a gun, and are often beaten down with poles and cudgels as they stoop to go under the eaves. Mr. White informs us, that having untiled part of a roof over the nest of a swift, the dam notwithstanding sat in the nest: so strongly was she affected by natural love for her brood, which she supposed to be in danger, that, regardless of her own safety, she would not stir, but lay sullenly by them, permitting herself to be taken in the hand.

Swifts are much infested with those pests to the genus called hippobosca hirundinus, and often wriggle and scratch themselves in their flight; to get rid of that clinging annoyance; and young ones, overrun with these insects, are sometimes found under their nests, fallen to the ground, the number of vermin rendering their abode insupportable. Swifts have only one harsh screaming note; yet there are ears to which it is not displeasing, from an agreeable asso.ciation of ideas, since that note never occurs but in the most lovely summer weather. They never settle on the ground but through accident; neither can they walk, but only crawl; but they have a strong grasp with their feet, by which they cling to walls. Their bodies being flat, they can enter a very narrow crevice; and where they cannot pass on their bellies, they will turn up edgeways. In London, a party of swifts frequents the Tower, playing and feeding over the mire just below the bridge; others haunt some of the churches of the Borough next the fields, but do not venture, like the house-marten, into the close crowded part of the town.

The Swedes have bestowed a very pertinent name on this swallow, calling it ring-swallow, from the perpetual rings or circles that it takes round the scene of its nidification. As these birds are apt to catch at every thing on the wing, many have taken them by the bait of a cockshafer tied to a thread, which they have swallowed as freely as a fish swallows a baited hook. In the isle of Zante, the boys are said to get on an elevated place, and, merely with a hook baited with a feather, have caught five or six dozen of them in a day. Besides 
our island, the swift is known to inhabit the whole of the European continent; and has also been noticed at the Cape of Good Hope, and the Carolinas in North America. Hence, most likely, it is a general inhabitant of both the old and new continent.

\section{Power of Reason IN a Crow.}

IT is well known that crows feed upon several kinds of shell-fish, when within their reach, and that they contrive to break the shell by raising the shell-fish to a great height, and letting it drop upon a stone or rock This may perhaps be considered as pure instinct, directing the animal to the proper means of acquiring its food. But what is to be thought of the following fact, which was communicated to the editors of the Eucyclopedia Britannica, by a gentleman whose veracity, they say, is unquestionable, and who, being totally unacquainted with the theory of philosophers, has, of course, no favourite hypothesis to support?

In the spring of 1791, a pair of cows made their nest in a tree, of which there are several planted round his garden, and in his morning walks he had often been amused by witnessing furious combats between them and a cat. One morning the battle raged more fiercely than usual, till at last the cat gave way, and took shelter under a hedge, as if to wait a more favourable opportunity of retreating to the house. The crows continued for a short time to niake a threatening noise; but perceiving that on the ground they could do nothing more than threaten, one of them lifted a stone from the middle of the garden, and perched with it on a tree planted in the hedge, where she sat watching the motions of the enemy of lier young. As she crept along under the hedge, the crow accompanied her by flying from branch to branch and from tree to tree; and when at last puss veutured to quit her hiding place, the crow, leaving the tree, and hovering over her in the air, let the stone drop from on high on lier back. That the crow on this occasion reasoned, is self-evident; and it seems to be little less evident that the ideas employed in her reasoning were enlarged beyond those which she had received from her senses. By her senses she may have perceived that the shell of a fish is broken by a fall; but could her senses inform her that a cat would be wounded or driven off the field by the fall of a stone? No; from the effect of the one fall, preserved in her memory, she must have inferred the other by her power of reasoning.

\section{Cock-Crowing.}

THERE is this remarkable circumstance about the crowing of cocks : at several different times in the course of a night, a general crowing may be heard from all quarters where there are cocks, - the first that begins, apparently setting all the rest off; and this fact is remarkably striking in all places where numbers of cocks are bred for the purpose of fighting. As far as I can observe, except at the dawn of the day, these crowing matches happen at very irregular and uncertain periods. The ancients, however, seem to have regarded 
them as taking place at marked intervals of time, which appear to bave caused their division of the night-watches by the first, second, aved third cock-crowings, as mentioned by St. John.

\section{The Partridge.}

THE affection of the partridge for her young is peculiarly strong and lively. She is greatly assisted in the care of rearing them by her mate; they lead them out in common, call them together, point out to them their proper food, and assist them in finding it by scratching the ground, with their feet; they frequently sit close to eacb other, by covering the chickens with their wings like the hen. In this situation they are not easily fiushed; and the sportsman, who is attentive to the preservation of his game, will carefully avoid giving any disturbance to a scene so truly interesting. Should the pointer, however, come too near, or unfortunately run in upon them, there are few who are ignorant of the confusion that follows. The male first gives the signal of alarm by a peculiar cry of distress, throwing himself, at the same moment, more immediately into the way of danger, in order to deceive or mislead the enemy; he flies, or rather runs along the ground, hanging his wings, and exhibiting every symptom of debility, in order to decoy the dog to a distance from the covey; the fenale flies off in a contrary direction, and to a greater distance, but returuing soon after by secret ways, she, finds her scattered brood closely squatted among the grass, and, collecting them in haste, she leads them from the danger before the $\mathrm{dog}$ has had time to return from his pursuit.

\section{SEA-APE.}

STELLEN gave this name to a marine animal which he saw on the coast of America, and thus describes in his history of Kamtschatka, p. 136. "The head appeared like that of a dog, with sharp and upright ears, large eyes, and with both lips bearded; the body round, and conoid, the thickest part near the head; the tail forked, the upper lobe the longest; the body covered with thick hair, gray on the back, reddish on the belly. It seemed destitute of feet. It was extremely wanton; and played a number of monkey tricks. It sometimes swam on one side, sometimes on the other side of the ship, and gazed at it with great admiration. It made so near an approach to the vessel, as almost to be touched with a pole; but if any body noved, it instantly retired. It would often stand erect for a considerable space, with one-third of its body above water, then dart beneath the ship, and appear on the other side, and repeat the same thirty times together. It would frequently arise with a sea-plant, not unlike the bottle-gourd, toss it up, and catch it in its mouth, playing with it numberless fantastic tricks."

\section{Curjous Facts in Natural History.}

IT has been generally considered, on the authority of $\mathrm{Mr}$. Pennalit, that toads live on insects and worms, but it appears, from 
undoubted authority, that they also destroy mice. A gentleman residing at Keswick has published a letter in the Sporting Magazine, in which he says, that one evening, in the latter end of July he observed a rusiling in the strawberry bed in his garden, and found that a toad had just seized a field-mouse, which had got upon the toad's back, scratching and biting to get released, but in vain. The toad kept his hold, and, as the strength of the mouse failed, he gradually drew the unfortunate little animal into his mouth, and gorged him. Another correspondent in the same magazine, relates a wonderful instance of the voracity of stoats : some workmen, on removing a pile of faggots near some coppice, where it had lain about five months, found sixty-three rabbit skins, and twenty-five hare skins, all perfectly whole, besides fragments of skins; on removing a few more bundles, they found six stoats, four of which were killed, the other two escaped. It is generally thought that stoats merely suck the blood of these animals, but this fact proves that the opinion is erroneous.

\section{Poison Tree of Java.}

THIS is a tree which has often been described by naturalists; but its existence has been very generally doubted, and the descriptions given of it, containing much of the marvellous, have been often treated as idle fictions. N. P. Foersch, however, in an account of it, written in Dutch, asserts that it does exist; and tells us, that he once doubted it as much as any person, but, determined not to trust general opinions; he made the most particular inquiries possible; the'result of which was, that he found it was situated in the island of Java, about twenty-seven leagues from Batavia, fourteen froin Soura Charta, the emperor's seat, and about nineteen from Tinkjoe, the residence of the sultan of Java. It is surrounded on all sides by hills and mountains, and the adjacent country for twelve miles round the tree is totally barren. Our author says, he has gone round the spot at about eighteen miles from the centre, and on all sides he found the country equally dreary, which he ascribes to its noxious efllivia. The poison procured from it is a gum issuing from between the bark and the tree; and it is brought by malefactors who have been condemned to death, but were allowed by this alternative to have a chance for their lives.

An old ecclesiastic, our author informs us, dwelt on the outside of the surrounding hills, whose business it was to prepare the criminals for their fate, if death slould be the consequence of their expedition. And indeed, so fatal is its effuvia, that he acknowledged scarcely two out of twenty returned, from above seven hundred whom he had dismissed. Mr. Foersch adds, that he had seen several of the criminals who had returned, and who told him, that the tree stands on the borders of a rivulet, is of a middling size, and that five or six young ones of the same kind stand close to it. They could not, however, see any other plant or shrub near it, and the ground was of brownish sand, full of stones and dead bodies, and difficult to pass. No animal whatever is ever seen there alive; and such as get there by any 
means never return, but have been brought out dead by such of the criminals as have themselves escaped death.

But all these accounts, and many other anecdotes reported by Foersch, are denied by Lambert Nolst, M. D. fellow of the Batavian Experimental Society at Rotterdam; who says, that the assertions and pretended facts of Foersch have no collateral evidence; and every thing which we gather from the account of others, or from the history of the people, invalidates them. For these and other reasons Dr. Nolst concludes that very little credit is due to the representations of Foersch, and that the island of Java produces no such tree, which, if it really grew there, would be the most remarkable of all trees."-Gent. Mag. 1794, p. 433.

\section{Gareinia Mangostana.}

THIS is the name of a tree of great elegance, and producing the most pleasant fruit of any yet known. This tree has been very accurately described by Dr. Garein, in honour of whom Linuæus gave it the name, in the 36 th volume of the Phil. Trans. It grows, he informs us, to seventeen or eighteen feet high, with a straight taper stem like a fir, having a regular tuft, in form of an oblong cone, composed of many branches and twigs, spreading out equally on all sides, without leaving any hollow. Its leaves are oblong, pointed at both ends, entire, smooth, of a shining green on the upper side, and of an olive on the back. Its flower is composed of four petals almost round, or a little pointed like that of a rose, only deeper and less lively. The calyx of this flower is of one piece, expanded, and cut into four lobes: the two upper ones are something larger than the lower ones; they are greenish on the outside, and of a fine deep red, within; the red of the upper ones is more lively than that of the lower ones. This calyx encloses all the parts of the flower; it is supported by a pedicle, which is green, and constantly comes out at the end of a twig above the last pair of leaves.

The fruit is round, of the size of a small orange, from an inch and a half to two inches diameter. The body of this fruit is a capsule of one cavity, composed of a thick rind, a little like that of a prmegranate, but softer, thicker, and fuller of juice. Its thickness is commonly of a quarter of an inch. Its outer colour is a dark brown purple, mixed with a little gray and dark green. The inside of the peel is a rose-colour, and its juice is a purple: this skin is of a styptic or astringent taste, like that of a pomegranate, nor does it stick to the fruit it contains. The inside of this fruit is a furrowed globe, divided into segments like those of an orange, but equal in size, and not adhering to each other. The number of these segments is always equal to that of the rays of the top which covers the fruit. The fewer there are of these segments, the bigger they are; there are often, in the same fruit, segments as big again as any of those that are on the side of them. These segments are white, a little transparent, fleshy; membranous, full of juice like cherries or raspberries, and of the taste of strawberries and grapes together. Each of the segments encloses a seed of the figure and size of an almond stripped of its shell, having a protuberance on one of its sides. These seeds are covered 
with two small skins, the outermost of which serves for a basis to the filaments and membranes of which the pulp is composed. The substance of those seeds come very near to that of chesunts, as to their consistency, colour, and astringent quality.

"This tree," says Dr. Garein, "continually grows in the Molucca Islands, where it is called Mangostan, but has been transplanted from thence to the island of Java and Malacca, at which last place it thrives very well. Its tuft is so fine, so regular, so equal, and the appearance of its leaves so beautiful, that it is at present looked upon at Batavia as the most proper for adorning a garden, and affording an agreeable shade. There are few seeds, however, to be met with in this fruit, that are good for planting, most part of them being abortive." He adds, that one may eat a great deal of this fruit without any scruple. Other writers concur in their praises of this fruit. Rumphius observes, that the mangostan is universally observed to be the best and wholesomest fruit that grows in India ; that its flesh is juicy, white; almost trans: parent, and of as delicate and agreeable a flavour as the richest grapes; the taste and smell being so grateful, that it is scarcely possible to be cloyed with eating it. He adds, that when sick people have no relish for any other food, they generally eat this with great delight; but should they refuse it, their recovery is no longer expected. "It is remarkable," says he, "that the mangostan is giren with safety in almost every disorder. The dried bark is used with success in the dysentery and tenesmus; and an infusion of it is esteemed a good gorge for a sore mouth, or ulcers in the throat. The Chinese dyers use this bark for the basis of a black colour, to fix it the firmer.

Captain Cook, in his Voyage round the World, vol. p. 737, says this tree is peculiar to the East Indies. The fruit is about the size of a crab-apple, and of a deep red-wine colour. On the top of it is the figure of five or six triangles joined in a circle; and at the bottom several hollow green leaves, which are remains of the blossom. When they are to be eaten, the skin, or ratler flesh, must be taken off, under which are found six or seven white kernels, placed in a circular order; and the pulp with which these are enveloped is the fruit, than which nothing can be more delicious. It is a happy mixture of the tart and the sweet, which is no less wholesome thau pleasant, and, like the sweet orange, is allowed in any quantity to those who are aflicted with putrid or inflammatory fevers.

\section{ROYAL OAK.}

THIS is a fair-spreading tree at Boscubel, in the parish of Donnington in Staffordshire, the boughs whereof was once covered with ivy ; in the thickness of which, king Charles II. sat in the dav-time with Colonel Careless, and in the night lodged in Boscobel house : so that they are mistaken who speak of it as an old hollow oak; it being then a gay flourishing tree, surrounded with many more. The renains thereof are now fenced in with a handsome wall, with this inscription in gold letters. "Felicissimam arborem, quam in asylum potentissimi regis Caroli II. Deus op. max. per quam reges regnant, hio crescere voluit," \&ce 
Tне following circumstance which happened at Baddesley, a small village in Hampshire, is given in the words of Mr. Gilpin.

"A cottager, who lived near the centre of the village, heard frequently a strange noise behind his house, like that of a person in extreme agony. Soon after, it caught the attention of his wife, who was then confined to her bed. She was a tiniorous woman, and, being greatly alarined, her husband endeavoured to persuade her that the noise she heard was only the bellowing of the stags in the forest. By degrees, however; the neighbours on all sides heard it; and the circumstance began to be much talked of. It was by this time plainly discovered that the groaning noise proceeded from an elm which grew at the bottom of the garcien. It was a young vigorous tree, and to all appearance perfectly sound. In a few weeks the fame of the groaning tree was spread far and wide; and people from all parts flocked to hear it. Among others, it attracted the curiosity of the late Prince and Princess of Wales, who resided at that time, for the advantage of a sea-bath, at Pilewell, within a quarter of a mile of the groaning-tree.

"Though the country people assigned many superstitious causes for this strange phenomenon, the naturalist was unable to assign it physical one that was in any degree satisfactory. Some thought it was owing to the twisting and friction of the roots; others thought that it proceeded from water which had collected in the body of the tree, or perliaps from pent air; but no cause that was alleged, appeared equal to the effect. In the mean time the tree did not always groan, sometimes disappointing its visitarits; yet no cause could be assigned for its temporary cessations, either from seasons or weather. If any difference was observed, it was thought to groan' least when the weather was wet, and most when it was clear and frosty; but the sound at all times seemed to come from the roots.

"Thus the groaning-tree continued an object of astonishment, during the space of eighteen or twenty months, to all the country round; and, for the information of distant parts, a pamphlet was drawn up, containing a particular account of all the circumstances relating to it. At length the owner of it, a gentleman of the name of Forbes, making too rash an experiment to discover the cause, bored a hole in its trunk. After this it never groaned. It was then rooted up, with a further view to make a discovery; but nothing appeared which led to any elucidation of the cause. It was necessarily believed, however, that there was wo trick in the affair ; but that some natural cause really existed, though it was never understood." - $R e$ marks on Forest Scenery, vol. i. p. 163, 164.

\section{Age of Trees.}

TREEs, after a certain age, waste: An oak at one hundred years old ceases to grow. The usual rule for judging of the age of wood, is by the number of circles that appeat in the substance of a trunk or stock cut horizontally, each circle being supposed the growth of a 
year; though some reject this method as precarious, alleging, that a single circle is sometimes the produce of several years ; besides that, after a certain age, no new circles are found.

Major Rooke, in his "Sketch of the Forest of Sherwood" has some curious particulars respecting the age of oaks. In cutting down some timber, he found letters stamped on the body of the trees, denoting the king's reign in which they were respectively marked. It appears that the bark had been stripped off when the letters were cut on the timber, which were covered by the next year's growth of wood. Some are of James the First; others, of William and Mary; and one was marked in the reign of King John. This tree is supposed to have been upwards of seven hundred years old. It was cut down in 1791, and the letters were found about eighteen inches within the surface, and about a foot from the centre of the tree.

\section{The Walnut Tree.}

THIs tree is originally a native of Persia, and attains, in this country, the height of from fifty to sixty feet; having a beautiful erect trunk, that branches out into a large spreading crown, which is furnished with pinnated leaves. No place of equal extent is supposed to possess so many valuable walnut-trees as Norbury Park in Surrey, which, about a century ago, was said to contain nearly forty thousand.-It is remarked as a proof of the uncertainty of their produce, that, in some years, six hundred pounds' worth of walnuts have been gathered from the trees in this park, whereas in others they have yielded scarcely a single bushel. Croydon fair is remarkable for its profusion of walnuts. The fruit, when fresh, is very grateful : it contains much oil. The juice of the green coat of the walnut will die the skin of a tawny liue; an expedient resorted to by the Gipsies, not only to give themselves a dingy appearance, but to disguise any child whom they may have enticed from its parents.

\section{Shea, or Butter Tree.}

THrs is a tree, from the fruit of which the negroes, in the interior of Africa, between the tropics, prepare a kind of vegetable butter. These trees are not planted by the natives, but are found growing naturally in the woods; and in clearing woodland for cultivation, every tree is cut down but the shea. The tree itself very much resembles the American oak; and the fruit, from the kernel of which, being first dried in the sun, the butter is prepared by boiling the kernel in water, has somewhat the appearance of a Spanish olive. The kernel is enveloped in a sweet pulp, under a thin green rind; and the butter produced from it, besides the advantage of its keeping the whole year without salt, whiter, firmer, and Mr. Park says, (to his palate,) of richer flavour than the best butter which lie had tasted imade from cow's milk. The growth and preparation of this commodity seem to be among the first objects of African industry in this and the neighbouring states; and it constitutes a main article of their inland commerce. In some places they dry the fruit in kilns, containing each 
about half a cart-load of fruit, under which is kept a clear wood fire. Our author, who saw the fruit in one of these kilns, was. informed, that in three days the fruit would be ready for pounding and boiling; and that the butter thus manufactired is preferable to that which is prepared from fruit dried in the sun; especially in the rainy season, when the process by insolation is always tedious, and oftentimes ineffectual. Might it not be worth while, if practicable, to cultivate shea trees in some of our West India islands?

\section{The VEGETABLE. LAMB.}

WhoEver has perused the accounts of early travellers, must recollect the stories that have been copied into our Herbals, of Tartarian sheep growing upon stems in the earth, and thence devouring all the vegetables that come within their reach. A tale of this kind could not fail to attract the attention of the immortal fathers of modern botany, who took considerable pains to investigate it, and from his and wan the following particulars.

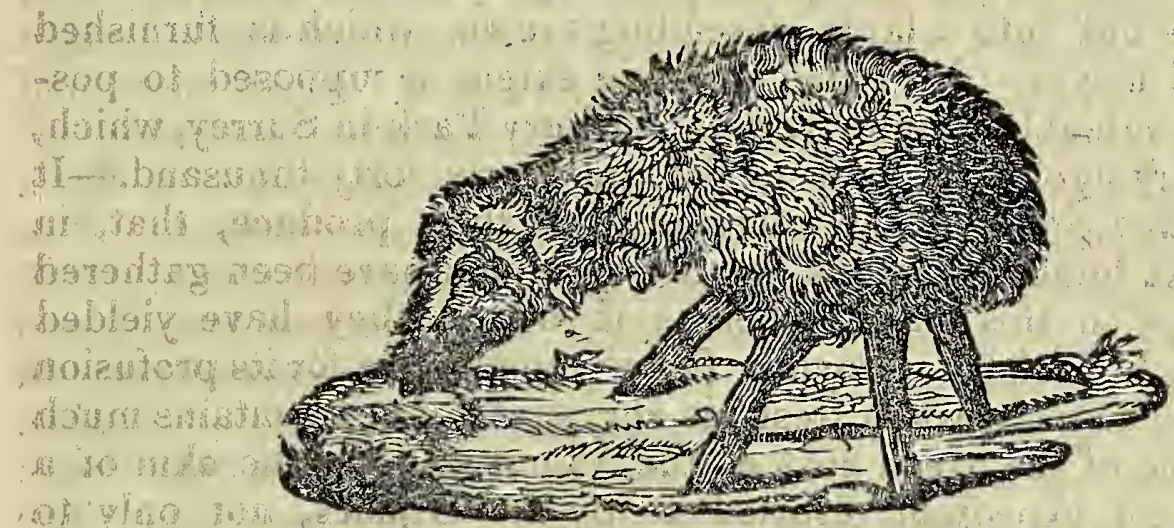

In the eastern part of Chinese Tartary, there is a species of fern, called the Baronetz, or Tartarian Lamb. It is furnished with thick tubers, which being surrounded on all sides with yellow wool, and thin chaffy scales, are often raised so high above the ground, that the roots beneath bear some resemblance to legs fixed in the soil. The genus of this fern has not yet been ascertained, but it is known that the roots spread round to a considerable extent; and perhaps this circumstance prevents all other plants from growing near it. This fact, connected with the figure which is prefixed, has induced the ignorant and superstitious to transform this curious vegetable into a voracious sheep, which Dr. Darwin has celebrated in some appropriate and characteristic lines.

\section{Wonderfit Plant of Sombrero.}

TH Is is a strange kind of sensitive plant, growing in the East Indies, in sandy bays, and in shallow water. It appears like a slender straight stick; but when you attempt to touch it, it immediately withdrawg itself into the sand. Mr. Miller gives an account of it in his description of Sumatra. $\mathrm{He}$ says, the Malays call it lalan-lout, that is, seer grass. He never could observe any tentacula; but, after many 
unsuceessful attempts, drew out a broken piece about a foot long. It was perfectly straight and uniform, and resembled a worm draw aver a knitting needle. When dry, it appears like a coral.

\section{Extraurdinary Increase of Potatoes.}

THE following facts are recorded in a Memoir by John Howard, Esq. of Cardington, in Bedfordshire, an a new kind of potato, remarkable for its prolitickness. "In 1765, (says he,) being at Clifton near Bristol, I was informed that a person had brought from America a particular sort of potato; and with some trouble I procured half a dozen roots of it, as the greatest part of those brought over were already planted. That autunn I planted three of them, and in the following spring the other three, in my garden at Cardington, in Bedfordshire, setting them in hillocks about six feet asuinder. The strength of the stems, and largeness of the blossoms and apples, gave the pleasing prospect of great increase ; and accordingly when took them up in the autumn of 1766 , I found they had increased far beyond any of the common sort, which for some years I had encouraged our cottagers to cultivate. The produce from each cutting was in weight from twenty-six to twenty-seven pounds and a half. I sent for two of the Bedford gardeners who serve the market, to see them taken up, and they were surprised at the great increase. I gave some of them to these gardeners, and others to almost all our own cottagers. The increase continued to appear the same in the succeding year (1767) as in the last; only as many of the single potatoes had been found to weigh four or five pounds each, I had now planted most of them in drills three feet asunder, to procure a greater number and a less size. Their produce now was from twenty-two to thirty pounds from each cutting; and the potatoes were most sizable for common use. The vegetation was not so lixuriant as in those I before planted in hillocks, but the increase of these was, allowing the cuttings to weigh an ource, full four hundred fold. Having last year upwards of a waggon load of these potatoes, I with pleasure ordered it to be made publicly known, that every person who chose to cultivate them were welcome to have a quantity for planting. In consequence of this, numbers applied in our own and the adjacent counties. In my plautations, as well as those of other persons, the increase has been still greater this year; for the season having proved very favourable, I have had from some hillocks, forty one pounds and a lialf, allowing for dirt."

\section{Propagatyon of Plants.}

THE number of vegetables that may be propagated from an individual is ceny remarkable, especially in the most minute parts. aniual product of one seed, even of the common mallow, has been found to be no less than two hundred thousand; but it has been since proved, by a strict examination into the more minute parts of the vegetable world, that so despised a plant as the common wall-moss produces a nuch more numerous offspring. In one of the little 
heads of this plant there have been counted thirteen thousand eight hundred and twenty-four seeds. Now alotting to a root of this plant eight hranches, and to each branch six heads, which appears to have been a very moderate coniputation, the produce of one seed is $6 \times 13824=82044$, and $8 \times 82944$, gives 663,552 seers, as the annual produce of one seed, and that so small, that thirteen thousand eight: hundred and twenty four of them are contained in a capsule, whose length is but one ninth of an inch, its diameter but one twenty-third of an inch, and its weight but the thirteenth part of a grain.

\section{TOBACCo.}

THFRE is nothing more astonishing in the history of the human mind, than that unaccountable sort of prejudice which some penple evince at the introduction of any thing to which they have not been accustomed, be the thing ever so good or advantageous. This kind of feeling occasioned it to be debated, on first adopting the use of 1)tatnes, whether they were really fit for food, or were not rather a tegetable poison; it occasioned the resistance of small-pox inoculation, yearsago, and of the vaccine in the present day, "as flying in the face of God," to adopt a phrase of some old ladies, as great fatalists in these matters as the Turks, but it is in no instance more strikingly exhihited than in that of the first bringing of tobacco into this country. Who would have thought that a king of England, two centuries lyack, and that one of the poorest and neediest of our monarchs, would have written a book in the bitterest style of invective, expressly to hinder the use of a commodity, the duties on which now yield to the state more than the amount of his whole revenue, Not but we believe, could bis majesty bave been sensible of what it might have been made to produce such was his love or want of money, he would have spoken of it in more moderate terms than he has done in the following extract. She king we allude to is James I. who in his Counter-blast to Tobacco," says, -

wThat it is not only a common herbe, which, though under divers names, is almost every where, but was first found out by the barbarous Indians;" and asks his good countrymen to consider what honours or policy can move then to imitate the manners of such wild, godlesse, and slavish people? He proceeds :- It is not long since the first entiy of this abuse amongst us here, as this present age can very well remember bath the tirst author and forms of its introduction, and now many in this kingdome have had such a continual use of this unsavourie smoke, that they are not able to forveare the same, no more than an old drunkard can abide to be long sober. How several are by this eustome disabled in their goods, let the gentrie of this land bear witnesse; some of whom bestow 300 ! some $400 l_{\text {. a }}$ year on this precious stinke And is it not great vanitie and uncleannesse, that at the table, a place of respect, men should sit tossing of tobacco pipes, and smoking of tobacco, one to another, making the filthy stinke theref to exhale across the dishes, and infect the wine; but no other tive no action is exempted from the public use of this uncivil trielse-for a man cannot hardly welcome his friends at his home, 
but straight they must in hand with tobacco; yea, the mistresse cannot in more mannerly kind entertaine her servant than by giving him out of her faine hand a pipe of tobacco;"- " a weed," he adds, "the smcking whercof is loathsone to the eye, hateful to the nose, harmful to the braine, dangerous to the lungs, and in the blacke stinking fume thereof nearest resembles the Stigian smoke of the pit that is bottomlesse."

He is still more bitter in his witty apophthayms, in which he avers that tobacco is the lively image and pattern of hell, for that it has by allusion in it all the parts and vices of the world, whereby hell may be gained. For, first, it is a smoke, so are all the vanities of the world. Secondly, it delighteth them that take it; so do all the pleasures of the world Thirdly, it maketh men drunken and light in the head: so do all the vanities of this world. Fourthly, he that taketh tobacco saith he cannot leave it, it doth bewitch him; even so the pleasures of the world make men loath to leave them : arid further, besides all this, it is like hell in the very substaice of it ; for it is a stinking loathsome thing, and so is hell." And further his majesty professed, that, were he to invite the devil to a dinner, he should have three dishes:-first a pig; second a poll of ling and mustard; and third, a pipe of tobacco for digesture.

The king's aversion was adopted by his courtiers as a matter of courtesy, who all preterided a great horror of smoking. The people generally, however, paid no attention to this, or all the other methods which were used to discountenance it, and in some respects even carried it to a greater excess than at present, particularly by smoking tobacco in the theatres. Malone, (History of the English Stage,) mentioning the custom, in Shakspeare's time, of spectators being allowed to sit on the stage during performances, says, they were attended by pages, who furnished them with pipes and tobacco, which were smoked there, as well as in other parts of the house:

"When young Roger goes to see a play,

His pleasure is, you place him on the stage,

The better to demonstrate his array,

And how he sits, attended by his page,

That only serves to fill those pipes with smoke,

For which he pawned hath his riding cloak."

Springs to Catch Woodcocks.-1613.

But Hentzner's account, at this same period, 1598, which Mr. Ma lone lias onitted to quote, as to the custom mentioned is far more explicit and amusing. Speaking of the London playhouse then, he says, "Here, and every where else, the English are constantly smoking of tobacco, and in this manner: they have pipes on purpose made of clay, into the further end of which they put the herb, so dry that it may be rubbed into powder, and, putting fire to it, they draw the smoke into their mouths, which they puff out again through their nostrils, like funnels, alóng with it plenty of phlegm and defluxion of the bead."-Paul Hentzner's Journey into England, 1598.

Sir Walter Raleigh is well known to have first introduced the use of tobacco into England, and is the nerson king James hints at, 
when he speaks of the first author and introduction of it being then well remembered; and is said to have been so partial to it, that he took, says a nearly contemporary writer, "a pipe of tobacco a little before he went to the scaffold, which some formal persons were scandalized at; but I think," he adds, "twas well and properly done, to setcle his spirits." And the same author adds the following curious anecdotes on this subject. "In my part of North Wilts, (Malmsbury hundred,) it were brought into fashion by Sir. Walter Long. They had at first silver pipes, the ordinary sort made use of a walnut shell and a straw. I lave heard my grandfather Lyte say, that one pipe was handed from man to man round the table. Sir Walter Raleigh, standing at a stand, at Sir Robert Poyntz parke, at Acton, took a pipe of tobacco, which made the ladies quit it till he had done. Within these thirty-five years," he adds, (about 1630,) it was then sold for its weight in silver. Some of our old yeone neighbours say, that when they went to Malms bury or Chippenham market, they culled out their biggest shillings, to lay in the scales against the tobacco. Now, the customs of it are the greatest his majesty Charles Il. hath.

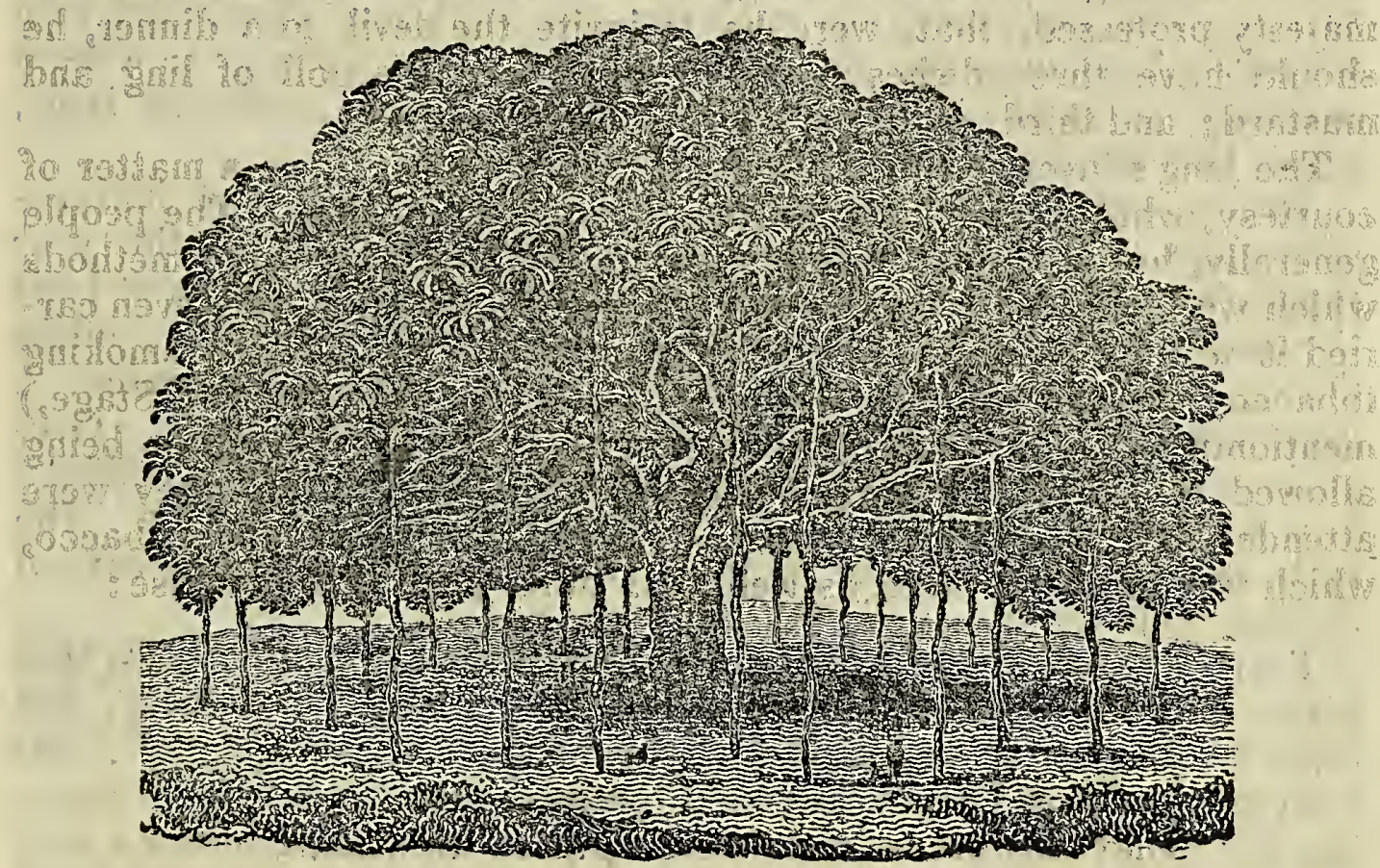

THE Banian TreE.

THE above tree, which is also called the Burr tree, or the Indian fig, is one of the most curious and beautiful of nature's productions, in the genial climate of India, where she sports with the greatest variety and profusion. Each tree is in itself a grove; and some of them are of an amaing size and extent, and, contrary to most. other animal and vegetable productions, seem to be exempted from decay. Every branch from the main body, throws out its own roots; at first, in small tender fibres, several yards from the ground; these continually grow thicker, until by a gradual descent they reach the surface, and there striking in, they increase to large trunks, and become parent trees, shooting out new branches from the tops. $A$ banian tree, with many trunks, forms the most beautiful walks, vistas, and cool recesses, that can be imagined. 


\section{Part X.}

\section{MISCELLANEOUS ARTICLES OF C UR IOS ITY.}

\section{Pairing.}

THE instinct of pairing is bestowed on every species of animals to which it is necessary for rearing their young, and on no other species.

All wild birds pair, but with a remarkable difference between such as place their nests on trees, and such as place them on the ground. The young of the former, being hatched blind, and without feathers, require the nursing care of both parents till they are able to $\mathrm{Aly}$. The male feeds his mate on the nest, and cheers her with a song. As soon as the young are hatched, singing yields to a more necessary occupation, that of providing food for a numerous issue, a task that employs both parents.

Eagles and other birds of prey build on trees, or on other inaccessible spots. They not only pair, but continue in pairs all the year round, and the same pair procreates year after year: this is at least the case of the eagles. The male and females hunt together, unless during incubation, at which time the female is fed by the male. A greater number than a single pair are never seen in company. Gregarious birds pair, probably to prevent discord in a society confined to a narrow space: this is the case of pigeons and ronks. The male and female sit on the eggs alternately, and divide the care of feeding their young.

Partridges, pheasants, plovers, sea-fowl, grouse, and other kinds that place their nests on the ground, have the instinct of pairing, but differ from such as build on trees in the following particular: that after the female is impregnated, she completes her task without needing any help from her mate. Retiring from him, she chooses a safe spot for her nest, where she can find plenty of worms and grass-seed at hand; and her young, when hatched, take foot, and seek food for themselves. The only remaining incumbent duty on the dam is, to lead them to proper places for food, and to call them together when danger impends. Some males, provoked at the desertion of their mates, break the eggs if they stumble on them.

Eider ducks pair like other birds that build their nests on the ground; and the female finishes her nest with down plucked from her own breast. If the nest be destroyed for the down, which is remarkably warm and elastic, she makes another nest as before. If she is robbed a second time, she makes a third nest, but the male furnishes the down. The black game never pair ; in spring, the cock, on an eminence, crows and claps his wings, and all the females within hearing instantly resort to him. Pairing birds, excepting those of 
prey, flock together in February to choose their mates. They soon disperse, and are not seen afterwards, but in pairs.

Pairing is unknown to quadrupeds that feed on grass. To such it would be useless, as the female gives suck to her young while.she is feeding. If $\mathbb{M}$. Buffon deserves credit, the roe-deer are an exception. They pair, though they feed on grass, and have but one litter in a year. Beasts of prey, such as lions, tigers, wolves, pair not. The female is left to shift for herself and her young; ' which is a laborious task, and often so unsuccèssful as to shorten the life of many of them. Pairing is essential to birds of prey, because incubation leaves the female no sufficient time to hunt for food. Pairing is not necessary to beasts of prey, because their young can bear a long fast. Add another reason, that they would multiply so fast by pairing, as to prove troublesome neighbours to the human race. Among animals that pair not, males fight desperately about a female. Nor is it unusual for seven or eight lions to wage bloody war for a single female.

The same reason that makes pairing necessary for gregarious birds, obtains with respect to gregarious quadrupeds, those especially who store up food for winter, and during that season live in common. Discord among such would be attended with worse consequences than even among lions and bulis, which are not confined to one place. The beavers, with respect to pairing, resemble birds that place their nests on the ground. As soon as the young are produced, the males abandon the stock of food to their mates, and live at large, but return frequently to visit them while they are suckling their young. Hedgehogs pair, as well as several of the monkey kind. We are not well acquainted with the natural history of these animals; but it would appear that the young require the nursing care of both parents. Seals have a singular economy. Polygamy seems to be a law of nature among them, as a male associates with several females. The 6ea-turtles have no occasion to pair, as the female performs her task at once by laying her eggs in the sand. The young are hatched by the sun, and immediately crawl to the sea.

\section{Astonishing Properties of Giass.}

1. Glass is one of the most elastic bodies in nature. If the force with which glass balls strike each other, be reckoned 16 , that whereswith they recede by virtue of their elasticity will be nearly 15.2. When glass is suddenly cooled, it becomes exceedingly brittle; and this brittleness is sometimes attended with very surprising phenomena. Hollow balls, made of annealed glass, with a small hole in them, will fly to pieces by the heat of the hand only, if the hole by which the interual and external air communicate be stopped with a finger. Lately, however, some vessels made of such annealed glass have been discovered, which have the remarkable property of resisting very hard strokes given from without, though they shiver to pieces by shocks received from the fall of very light and minute bodies dropped into their cavities. These glasses may be made of any shape, but their bottoms must always be thicker than their sides. The thicker the bottom is, 
the easier does the glasses break. One whose bottom is at least three fiigers' breadth in thickness, flies with as much ease as the thinnest lass. Some of these vessels have been tried with the strokes of a mallet sufficient to drive a nail into wood tolerably hard, and have lield good without breaking. They have also resisted the shock of several heavy bodies, let fall into their cavities from the height of two or three feet; as, musket balls, pieces of iron or other metals, pyrites, jasper, wood, bone, \&c. But this is not surprising, as other glasses of similar shape and size will do the same; but the wonder is, that taking a shiver of flint, of the size of a small pea, and letting it fall into the glass only from the height of three inches, in about two seconds the glass flies, and sometimes at the very moment of the shock; nay, a bit of fint no larger than a grain, dropped into several glasses successively, though it did not immediately break them, yet when set by, they all flew in less than three quarters of an hour. Some other bodies, produce the same effect, as sapphire, diamond, porcelain, hard-tempered steel, marble bowls, and pearls. These experiments were marle before the Royal Society, and the effects were the same whether the glasses were held in the hand, put in water, filled with water, or rested on a pillar. The glasses also broke, upon rubbing their bottoms slightly with the finger, within half an hour after rubbing : but when made uniformly very thin, they did not break. Hollow cups made of green-bottle glass, three inclies thick at bottom, were instantly broken by a shiver of flint weighing about two grains, though they had resisted the shock of a musket-ball from the height of three feet.

2. Various but unsatisfactory reasons have been assigned for these phenomena, by Euler and otliers. The effects are evidently occasioned by putting in motion some subtile fluid, from which the substance of the glass is filled; and the motions of this fluid, when once excited in a particular part of the glass, are soon propagated through the whole or greatest part of it, and thus the colesive power becomes at last too weak to resist them. There can be little doubt that this fluid is that of electricify. It is known to exist in glass in a very great quantity; and to be capable of breaking glasses even when annealed with the greatest care, if put into too violent a motion. Probably the cooling of the glass hastily may make it more electric than is consistent with its cohesive power, so that it is broken by the least increase of motion in the electric fluid by friction or otherwise. This is evidently the case when it is broken by rubbing with the finger; but why it should also break by the mere contact of fint, and other bodies above mentioned, has not yet been satisfactorily accounted for.

3. A most remarkable phenomenon is produced in glass tubes placed in certain circrimstances. When these are laid before a fire in an horizontal position, having their extremities properly supported, they acquire a rotatory motion round their axes, and even a progressive inotion towards the fire. When the progressive motion towards the fire is stopped by any obstacle, their rotation still continues.? When the tubes are placed in an upright posture, leaning to the right hand, the motion will be from $L$. to $W$. but if they lean to the left hand, their motion will be from $w$. to $E$, and the nearer they are placed to 
the upright posture, the less will the motion he, either way. If the tube is placed horizontally on a glass plane, the fragment, for instance of coach-window glass, instead of moving towards the fire, will move from it, and about its axis, in a contrary direction to what it had done before; nay, it will recede from the fire, and move a little upward, when the place inclines towards the fire. These experiments are recorded in the Philos. Trans. No.476. "They succeeded best with tubes about twenty or twenty two inches long, which had in each end a pretty strong pin fixed in cork for an axis. The causes of this phenomenon have not yet been discovered.

4. Glass is less dilatable by heat than metalline substances, and solid glass sticks are less dilatable than tubes. This was first discovered by Colnnel Roy, in making experiments to reduce barometers to a greater degree of exactness than has hitherto been found practicable; and since his experiments were made, one of the tubes, eighteen inches long, being compared with a solid glass rod of the same length, the former was found by a pyrometer to expand four times as much as the other, in a heat approaching to that of boiling oil. On account of the quality which glass has of expanding less than metal, M. de Luc recommends it to be used in pendulums ; and he says, that its expansions are always equable, and proportioned to the degrees of heat it quality which is not to be found in any other substance yet known. Glass is also more fit, from the condensation of vapours, than metallic substances. An open glass filled with water, in summer, will gather dew on the outside, just as far as the water in the inside reaches: and a person's breath blown on it, manifestly moistens it. Glass also becomes moist with dew, when metals do not. A drinking glass, parlly filled with water, and rubbed on the brim with a wet finger, yields musical notes, higher or lower as the glass is more or less full, and makes the liquor leap. Glass is possessed of very great electrical virtues.

\section{Earth Bread.}

IN the German Ephemerides for 1764, we have the following account of a kind of bread made of earth. In the lordship of Moscow, in the Upper Lusatia, a sort of white earth is found, of which the poor, urged by the calamities of the wars which raged in those parts, make bread. It is taken out of a hill where they formerly worked for saltpetre. When the sun has somewhat warmed this earth, it cracks, and several small white globules proceed from it, resembling meal; it does not ferment alone, but only when mixed with meal. M. Sarlitz, a Saxon gentleman, informed us, that he had seen persons who in a great measure lived upou it for some time. He assures us that he procured bread to be made of this earth alone, and of different mixtures of earth and meals, and that he even kept some of this bread by him upwards of six years; he further says, a Spaniard told him, that this earth is also found in Gerone in Catalonia. It would appear from hence, that we are not yet fully acquainted with all the modes, which nutrition can assume; and it would be remarkable if the curse of war should lead men to provide against the horrors of famine. 


\section{Phenix.}

THIs is a fabulous bird of antiquity. The ancients speak of it as being single, or that there is only one of this kind alive at once in the world; they describe it as of the size of an eagle, its head finely pressed with a beautiful plumage, its neck covered with feathers of a gold colour, and the rest of its body purple, only the tail white, and the eyes sparkling like stars. They say, that it lives about five hundred years in the wilderness; that when thus advanced in age, it builds itself a pile of sweet wood and aromatic gums, and fires it with the wafting of its wings, and thus burns itelf, and that from its ashes arises a worm, which in time grows up to be a phcenix. Hence the Phonicians gave the name of phonix to the palm-tree; because, when burnt down to the root, it rises again fairer than ever.

In the sixth book of the Annals of Tacitus, sect. 28, it is observed that, in the year of Rome 787 , the phnix revisited Egypt; which occasioned among the learned much speculation. This bird is sacred to the sun. Of its longevity, the accounts are various. The common persuasion is, that it lives five hundred years; though by some the period is extended to one thousand four hundred and sixty-one, and Ausonius makes it no less than 69,984 years.

The several eras when the phœnix has been seen are fixed by tradition. The first was in the reign of Sesostris; the second in that of Amasis; and, in the period when Ptolemy III. was on the throne of Egypt, another phonix directed its fight towards Heliopolis. When to these circumstances are added the brilliant appearance of the phonix, and the tale that it makes frequent excursions witha load on its back, and that when, by having made the experiment through a loug tract of air, it gains sufficient confidence in its own vigour, it takes up the body of its father, and flies with it to the altar of the sun, to be there consumed; it cannot but appear probable, that the learned of Egypt had enveloped, under this allegnry, the philosophy of comets.

\section{Comparative Force of Men and Horses.}

THere are several curious as well as useful observations in Desagulier's Experimental Philosophy, concerning the comparative force of men and horses, and the best way of applying trem.-A horse draws with the greatest advantage, when the line of direction is level with his breast; in such a sitnation, he is able to draw two hundred pounds eight hours a day, walking about two miles and a half au hour. And if the same horse is made to draw two hundred and forty pounds, he can work but six hours a day, and cannot go quite so fast: On a carriage, indeed, where friction alone is to be overcome, a middling horse will draw a thousand pounds. But the best way to try a horse's force, is by making him draw up out of a well, over a single pulley or roller; and in such a case one horse will draw two hundred pounds. Five men are found to be equal in strength to one horse, and can with as much ease push round the horizontal beam of a mill, in a walk forty feet wide. 
The worst way of applying the force of a horse is to make him carry or draw up hill; for if the hill be steep, three men will do more than a horse, each man climbing up faster with a burden of one hundred pounds weight, than a horse that is loaded with three hundred pounds; a difference which is owing to the position of the parts of the human body, being better in climbing than those of a horse. On the other hand, the best way of applying the force of a horse, is in a horizontal direction, wherein a man can exert least force; thus a man weighing one hundred and forty pounds, and drawing a boat along by means of a rope coming over his shoulders, cannot draw above twenty-seven pounds, or exert above one-seventh part of the force of a horse employed to the same purpose. The very best and most effectual posture in a man, is that of rowing : wherein he not only acts with more muscles at once, for overcoming the resistance, than in any other position; but as he pulls back wards, the weight of his body assists by way of lever.-See Desaguliers, Exp. Phil. vol. i. p. 241, where we have several other-observations relative to force acquired by certain positions of the body, from which that author accounts for most feats of strength and activity.

\section{FAiries.}

THese fabled beings were most usually imagined to be women of an order superior to human nature, yet subject to wants, passions, accidents, and even reath; sprightly and benevolent while young and handsome,-morose, peevish, and malignant, if ugly, or in the decline of their beauty; fond of appearing in white, whence, they are often called the white ladies. Jervaise of Tilbury, marslial of the kingdom of Arles, who lived in the beginning of the thirteenth century, writes thus concerning them, in a work inscribed to the emperor Otho IV. "It has been asserted by persons of unexceptionable credit, that fairies used to choose themselves gallants from among men, and rewarded their attachment with affluence of worldly goods; but if they married, or boasted of a fairy's favours, they as severely smarted for such indiscretion." The like tales still go current in the ci-devant province of Languedoc, where there is not a village without some ancient seat or cavern which had the honour of being a fairy's residence, or some spring where a fairy used to bathe.

This idea of fairies has a near anitity with that of the Greeks and Romans concerning the nymphs of the woods, mountains, rivers, and springs; and an ancient scholiast on Theocritus says, "The nymphs are demons which appear on the mountains in the figure of women." The Arabs and other orientals have also their grim and neri, of whom they entertain the like notions.

But fairies have been likewise described as of both sexes, and generally as of minute stature, though capable of assuming various forms and dimensions. The most charming representation of these children of romantic fancy, is in the Midsummer Night's, Dream of Shakspeare, and in a work recently published by Thomas Hood, entitled The Plea of the Midsummer Fairies. Spenser's Fairy Queen is an epic poem, under the characters of fairies. This sort of poetry raises a 
pleasing kind of horror in the mind of the reader, and amuses his imagination with the strangeness and novelty of the persons represented in it; but, as a vehicle of instruction, the judicious object to it, as not having probability enough to make any moral impression. The belief of fairies still subsists in many parts of our own country. The "Swart fairy of the mine," is scarce yet believed to have quitted our subterraneous works. Puck, or Robin Goodfellow, is still sup. posed to haunt many of our villages. And in the Highlands of ScotScotland, new-born children are watched till the christening is over, lest they should be stolen or changed by some of these imaginary. beings.

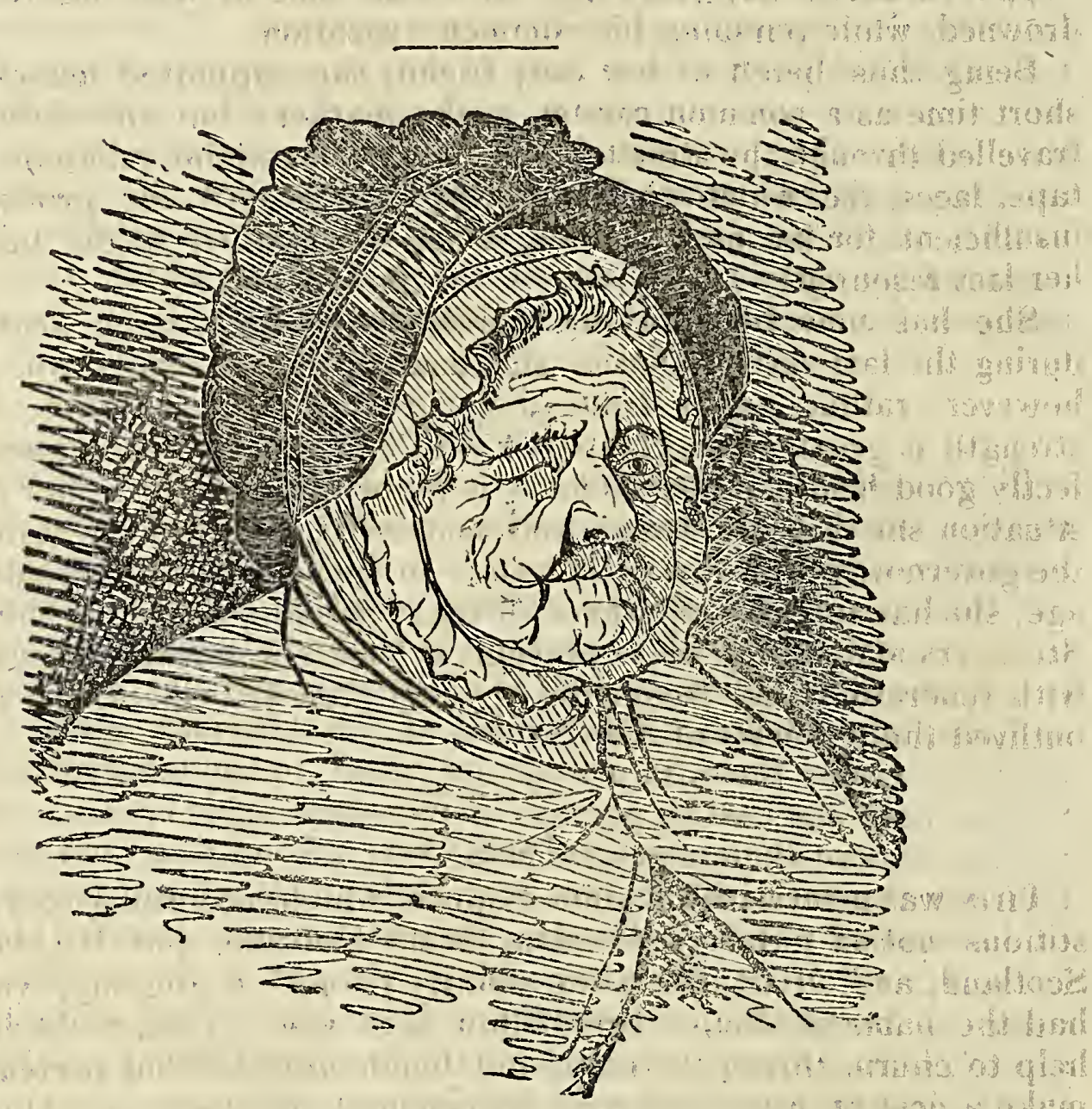

Elime Tate, aged 110.

Written in 1822.

IT is a characteristic of civilized nations, to venerate age, and of none more so than the English, whether the individuals

"Flaunt in rags, or flutter in brocade."

On this account we hope the following instance of longevity will not prove unacceptable to our readers.

Eilen Tate, now an inhabitant of the work-house in Liverpool, was born in the parish of Killede, in the county of Antrim, Ireland. Her maiden name was Craig; but of her family, her connexions, and early life, very little is known, and of that little, scarcely any thing: 
can be considered as interesting to the public. Having attained a state of maturity, she was married to a schoolmaster, whose nanie was Tate, by whom she had four children, two of whom died at an early age.

Of the two that survived, one frequented the seas; and in the course of events, sailing regularly from Liverpool, he considered that place as his home. His mother at this time being left a widow, he took a house in this town, and sending for her to inspect and manage his affairs, she bade a final adieu to Ireland, and fixed her abode in Liverpool. In this situation she remained until his death, which happened about fifty years ago, at which time he was unfortunately drowned, while pursuing his common avocation.

Being thus bereft of her only friend, she supported herself for a short time as a common carrier in the market; but this failing, she travelled through the streets with a basket, containing religious tracts, tape, laces, \&c. which she continued to sell, 'until the profits were insufficient for her maintenance, when she applied to the parish as her last resource.

She has now been in the workhouse about sixteen years, but during the last seven months she has not visited the town. This, however, rather arises from disinclination than inability, as her strength is great, when compared with her age, and she enjoys perfectly good health. Her memory is highly retentive. In her present situation she is quite happy and contented, and is a favourite with the governor, who is a worthy man. In consequence of her advanced age, she has an extra allowance of tea, some ale, and other comforts. Strangers and gentry who occasionally visit the workhouse, view her with veneration, and frequently give her money. She seems to have outlived the tempests of life.

\section{Brown Y.}

THIS was a serviceable kind of sprite, which, according to a superstitious notion fornerly prevalent in the Hebrides and Highlands of Scotland, as well as anong the country people in Englaud; where he had the name of Robin Goodfellow, was wont to clean the houses, help to churn, thresh the corn, and belaboured all that pretended to make a jest of him. He was represented as stout and blooming, had fine long flowing hair, and went about, with a wand in his hand. He was the very counterpart of Milton's Lubber Fiend.

Short Account of Henry Jening, of Ellerton on Swale, YoRKSHIRE.

THE annexed engraving of this extraordinary man, who lived to the astonishing age of one hundred and sixty-nine years, was taken from an original painting done by Walker.-Henry Jenkins has nothing inemorable in his life, to recominend him to public notice, but his great age, his poverty, and retentive memory. As his age exceeded that of Old Parr by sixteen years, there was a time when his name excited much attention. Among the instances of longevity, which 
are given in our Chronologies and Cyclopredias, Henry Jenkins is generally introduced to grace the list. In the Philosophical Transactions, number 221, we have an account of his death, which is said to have takell piace on the eighth of December, 1670 . The following particulars of this wonderful man were drawn up by Mrs. Anne Seville, to whom Henry Jenkins was personally known.

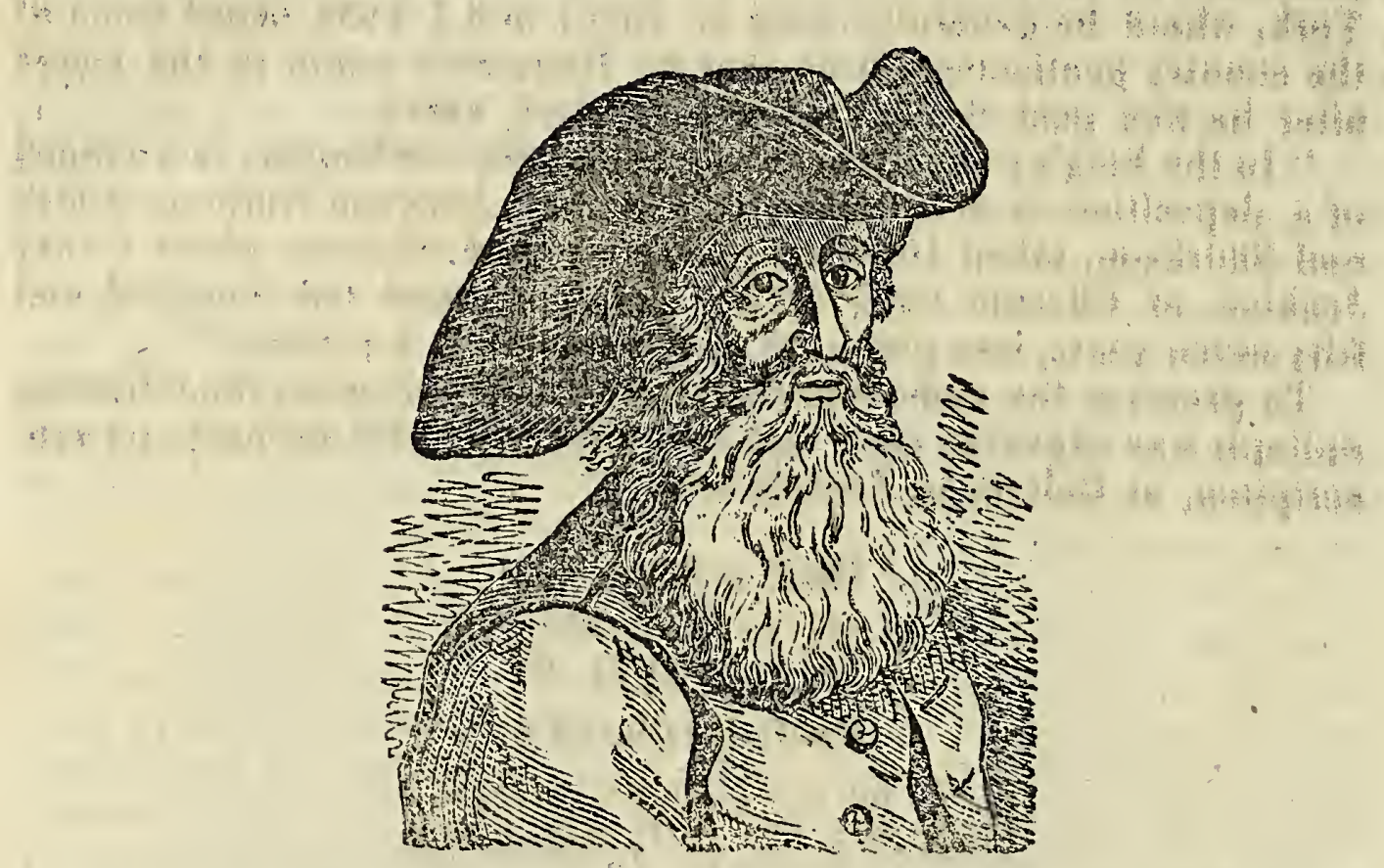

"When I came first to live at Bolton, (says this lady,) I was tuld seve ral particulars of the great age of Henry Jenkins, but I believed little of the story for many years, till one day he coming to beg an alms, 1 desired him to tell me truly how old he was. He paused a little, and then said, that, to the best of his remembrance, he was about 162 or 3 . I then asked what kings he remembered ? He said, Henry the Eighth.' I asked what public thing he could longest remeinber? He said Flowden Field. I asked whether the king was there? He said, no, he was in France, and the earl of Surry was general. I asked him how old he might be then? He said, I believe I might be between 10 and 12 ; for, says he, I was sent to Northallerton with a horse-load of arrows, but they sent a bigger boy from thence to the army with them. All this agreed with the history at that time, for bows and arrows were then used; the earl he named was general, and king Henry the Eighth was then at Tournay. It is observable that Jenkins could neither write nor read. There were also four or five in the same parish, that were reputed all of them to be 100 years old, or within two or three years of it, and they all said he was an elderly nan ever since they knew him, for he was born in another parish, and before any registers were kept in churches, as it is said. He told me then, too, that he was butler to the lord Conyers, and remembered the Abbot of Fountain's Abbey very well, before the dissolution of the monasteries. Henry Jenkins departed this life Dec. 16\%, at Ellerton upon Swale, in Yorkshire.

"The battle of Flowden Field was fought Sept. 9, 1513, and he was about 12 years old when Flowden Field was fought. So that 
this Henry Jenkins lived one hundred and sixty-nine years, viz. sixteen longer than Old Parr. In the last century of his life he was a fisherman, and used to wade in the streams: his diet was coarse and sour, but towards the latter end of his days he begged up and down. He hath sworn in Chancery, and other courts, to above one hundred and forty years' memory, and was often at the assizes at York; where he generally went on foot; and I have heard some of the country gentlemen affirm, that he fiequently swam in the rivers after he was past the age of one hundred years.

"In the king's remembrancer's office in the exchequer, is a record of a deposition in a cause by English bill, between Anthony Clark and Smirkson, taken 1655, at Kettering, in Yorkshire, where Henry Jenkins, of Ellerton upon Swale, Jabourer, aged one hundred and fifty-seven years, was produced, and deposed as a witness."

To preserve the name and age of this venerable man, the following epitaph was engraven on a monument erected to his memory, by subscription, at Bolton, in Yorkshire.

Blush not, marble,

To rescue from oblivion The Memory of

Henry Jenkins.

A person obscure in birth,

But of a life truly memorable:

For

He was enriched

With the goods of nature,

If not of fortune, And happy

In the duration,

If not variety,

of his enjoyments ;

And

Tho' the partial world

Despised and disregarded

His low and humble state,

The equal eye of Providence

Beheld and blessed it

With a Patriarch's health and length of days;

To teach mistaken man,

These blessings are entailed on temperance,

A life of labour, and a mind at ease.

He lived to the amazing age of

169 ,

Was interr'd here, December-

1670 ,

And had this justice done to his memory,

1743. 
IDOL OF HawaIt, on OWHYUEE, ONE OF THE SANDWICH ISLANDS.

ADJACENT to the governor's house stand the ruins of Ahuena, an ancient heiau, where the war-god was often kept, and human sacrifices were offered. Since the abolition of idolatry, the governor has converted it into a fort, has widened the stone wall, and placed upon it a number of cannon. The idols are all destroyed excepting three, which are planted on the wall, one at each end, and the other in the centre, where they stand li e centinels amidst the guns, as if desigued by their frightful ippearance to terrify an enemy.

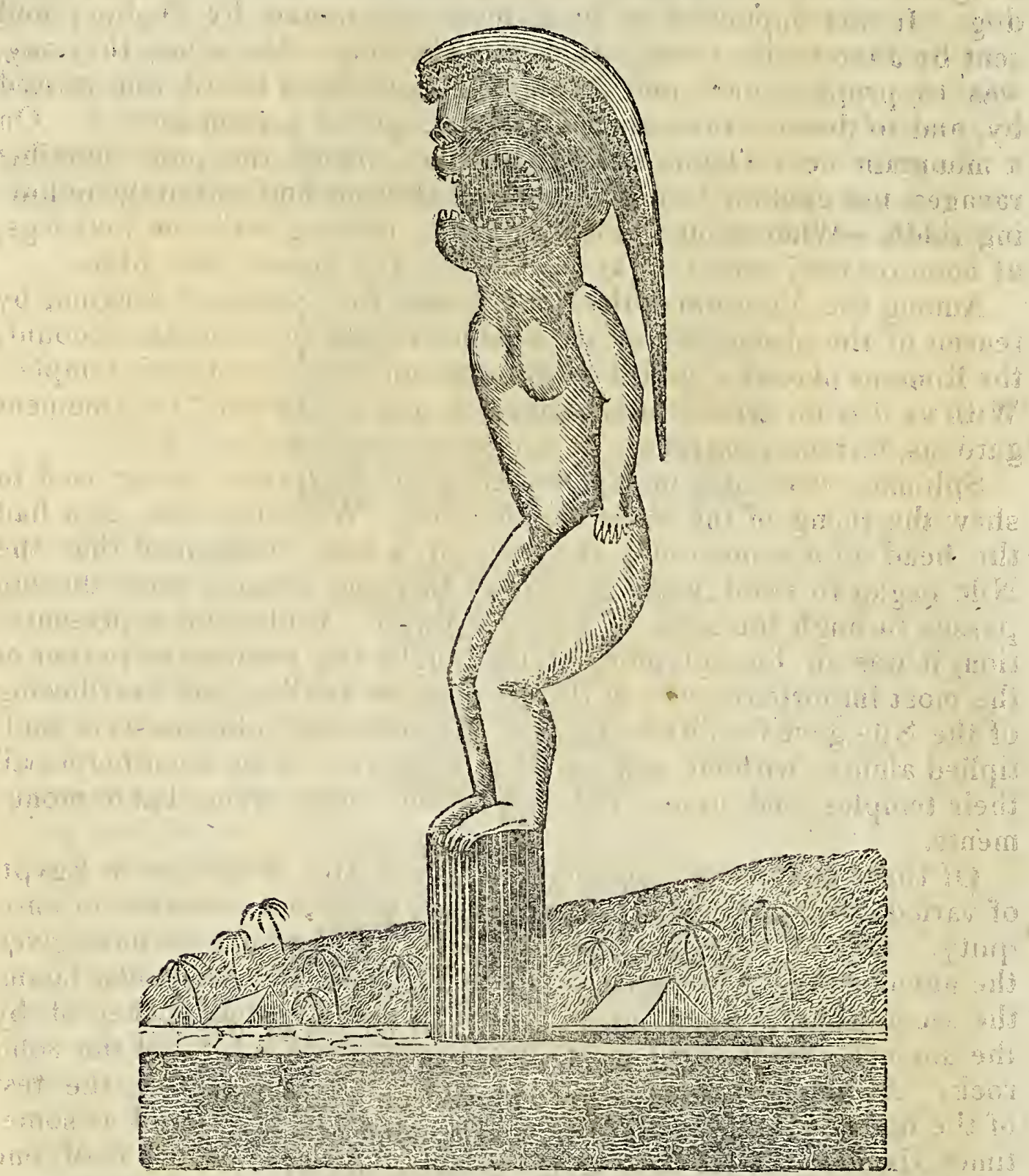

On the 29th of August, 1823, I visited the ruins, and took the above sketch of one of the idols, which stood sixteen feet above the wall, it was ulwards of three feet in breadth, and had been carved ont of a single tree.

Whis monster may be considered as a tolerable specimen of the greater part of the Hawaian idols, The head has generally the most homid appentance, the mouth being large, and usually extended wide, exhibiting a row of large teeth, resembling in no small degree the 


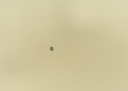




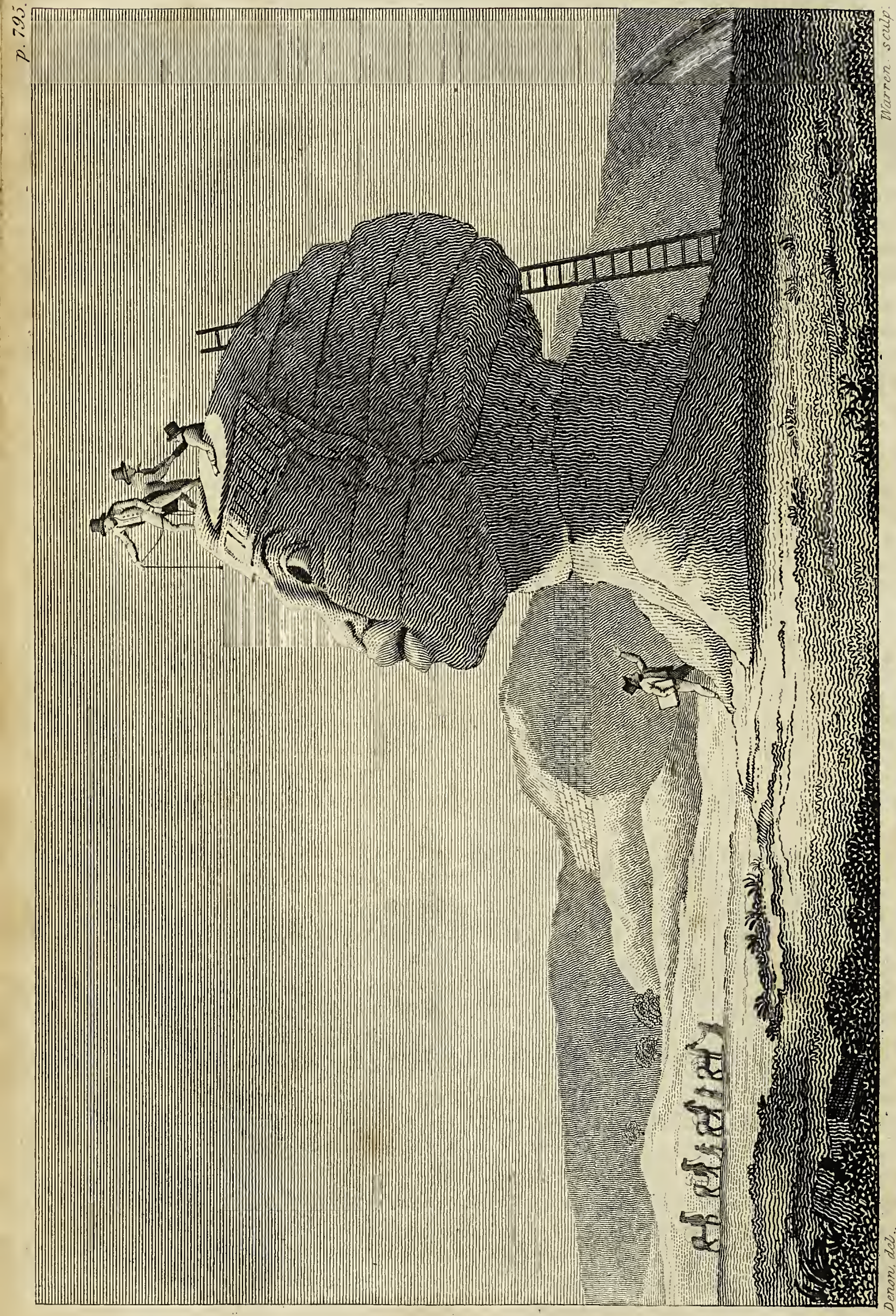


eogs in the wheel of an engine, and adapted to excite terror rather than inspire confidence in the beholder. Some of their idols were of stone, and many were constructed of a kind of wicker-work covered with red feathers. - Ellis's Tour.

\section{SPIINX,}

THIS is a monster that was of great fame among the ancients. It was represented as having the head and breasts of a woman, the wings of a bird, the claws of a lion, and the rest of the body like a dog. It was supposed to have been engenderer by Typhon, and sent by Juno to be revenged on the Thebans. Its office, they say, was to propose llark and enigmatical questions to all who passed by, and to devour them if they falled to give a correct answer. On a mountain near Thebes it was said to commit the most horrible ravages, nor could it be destroyed until OEdipus had solved the following riddle - What animal is it that in the morning walks on four legs, at noon on two, and at night on three? The answer was, Man.

Among the Egyptians, the sphinx was the symbol of religion, by reason of the obscurities of its mysteries; and on a similar account, the Romans placed a sphinx in the pronaos or porch of their temples. With us it is an article of sculpture, and is chiefly used to ornament gardens, terraces, entrances at doors and porticoes, \&c. \&c.

Sphinxes were also in repute among the Egyptians, being used to shew the rising of the water in the Nile. With this view, as it had the head of a woman and the body of a lion, it signified that the Nile began to swell in the months of July and August, when the sun passes through the signs of Leo and Virgo. Under this representation, it was an hieroglyphic, which taught the people the period of the most important event in the year, as the swelling and overflowing of the Nile gave fertility to Egypt. Accordingly, sphinxes were multiplied almost without eud, si) that they were to be seen before all their temples, and associated with all their more remarkable monuments.

Of these imaginary monsters several are still to be seen in Egypt, of varied dimensions, and connected with various remnants of antiquity. One of the most remarkable is that of which we have given the accompanying engraving. It stands near the pyramids, facing the second pyramid on the eastern side, aud is much spoken of by the ancients, as being of a prodigious size, and cut out of the solid rock. Al present, nothing but the head and neck appear, the rest of the body being hidden in the sand. The top of its back is some times visible: this is one hundred feet long. The whole is of one solid stone, making part of the rock, on which the pyramids are placerl. The head rises about twenty-nine feet above the sand. This head, according to Thevenot, is twenty-six feet high, and fifteen feet from the ear to the chin; but Pliny assures us that the head was no less than one huidred and wo feet in circumference, and sixtytwo feet high from the belly, and that the body was one hundred and forty-three feetlong, and was thought to be the sepulchre of Amasis. Some have suggested that the well of the great pyramid led to this 
nonster by a subterranean passage, and that the priests resorted thither at certain times to pronounce their oracles, alleging that $a$ hole, placed at the top of the sphinx's head, answered their purpose. It has, however, been found on examination, that this hole is only five feet deep, and communicates neither with the mouth, nor with the interior of the monster.

The Arabs, inspired by Mahomet with a horror for all representations of men and animals, have disfigured its face with arrows and lances. Some have urged, from the appearance of the countenance, that the Egyptians were black ; and that from the face of the sphinx resembling that of the negro, the similitude of the Egyptians may be inferred. The reasons, however, on which this opinion rests, are insufficient to support the conclusion. The statues of the Nile, it is said, were nade of black marble, in allusion to that river's coming from Ethiopia. If this opinion be correct, perhaps the negro face might have been given to the sphinx for the same reason. It would hardly have been thought necessary to explain why the figure of the Nile was black, if the complexion of the natives had been generally acknowledged of the same tinge.

The small statues of Isis, \&c. frequently found among the ruins of Egypt, are far from resembling those of the negro. Similar observations will apply to figures in alto-relievo and basso-relievo, on the walls of Thebes, and in the caverns of Gebel-el-Silsili. Of the colossal statues at Thebes, the features are too much damaged to be adduced in proof on either side.

The learned Mr. Bryant, (Ancient Mythology vol. iii. p. 532,) observes, that the sphinx seems to have been originally a vast rock of different strata; which, from a shapeless mass, the Egyptians fashioned into an object of beauty and veneration. The Egyptians first used this figure in their buildings; from them it passed to the Greeks, and other nations, who afterwards improved it into an elegant ornament.

Corrupted Appellations.

NoTH ING can be more foreign to the original meaning of many words and proper names, than their present appellations, frequently owing to the history of those things been forgotten, or an ignorance of the language in which they are expressed. Who, for instance, would suppose that the head of the French coast, near Calais, called by our sea-men Blackness, could be so entitled from its French name of Blanc Nez, or tle White Headland? Henry VIII having taken the town of Boulogne, in France, the gates of which he brought to Hardes in Kent, where they are still remaining, the flatterers of that reign highly magnified this action, which, like Porto-Bello, became a popular subject for signs; and the port or harbour of Boulogne, called Boulogne Mouth, was accordingly set up at a noted in in Holborn; the name of the inn outliving the sign and fame of the conquest, an ignorant painter, employed by a no less ignorant landlord to paint a new one, represented it by a bull and a large gaping human mouth, answering to the vulgar pronunciation of Bull-andMouth. The same piece of history gave being to the Bull-and-Gate, 
originally meant for Boulogne Gate, and represented by an embattled gate or entrance into a fortified town.

The Barber's Pole has been the subject of many conjectures; some conceiving it to have originated from the word pole or head, with several other conceits as far-stretched and unmeaning : but the true intention of that party-coloured staff was, was to shew that the mas? ter of the shop practised surgery, and could breathe a vein as well as mow a beard; such a staff being to this day, by every village practitioner, put into the hand of a patient undergoing the operation of phlebotomy. The white band which accompanies the liand was meant to represent the fillet, thus elegantly twined about it.

3 Nor were the Chequers, at this time a common sign of a public house, less expressive, being the representation of a kind of a draughtboard, called Tables, and shewed that here this game might be played. From their colour. which was red, and their similarity to a lattice, it was corruptly called the red lettuce, which word was frequently used by ancient writers to signify an ale-house.

The Spectator has explained the sign of the Bell Savage inn plausibly enough, in supposing it to have been originally the figure of a beautiful female found in the woods, called in the French La Belle Sauvage. But another reason has since been assigned for this appellation, namely, that the inn was once the property of Lady Arabella Savage, and familiarly called Bell Savage's Inn, probably represented by a bell and a savage, or wild man, which was a rebus for her name; rebusses being much in fashion in the 16th century.

The Three Blue Balls prefixed to the doors and windows of pawn. brokers shops; by the vulgar humorously enough said that it is two to one that the things pledged are never redeemed, were in reality the arms of a set of merchants from Lombardy, who were the first that publicly tent money on pledges. They dwelt together in a street, from them named Lombard-street, in London, and they also gave their name to another at Paris. The appellation of Lombard was formerly all over Europe considered as synonymous to that of usurer.

At the institution of Yeomen of the Guards, they used to wait at table on all great solemnities; and were ranged near the buffets; this procured them the name of Buffeteers, not very unlike in sound to the jocular appellation of Beef-eaters, now given them; though probably it was rather the voluntary misnomer of some wicked wit, than an accidental corruption arising from ignorance of the French lang uage.

The opprobrious title of Bum-Bailiff, so constantly bestowed on the sheriff's officers, is, according to judge Blackstone, only the corruption of bound bailiff, every sheriff's officer being obliged to enter into bonds, and to give security for his good behaviour, previous to his ap pointment.

A Cordwainer seems to have no relation to the occupation it is meant to express, which is that of a shoemalser. But cordonier, originally spelt cordaunier, is the French word for that trade; the best leather ised for shoes, coming originally from Cordova in Spain. Spanish leather shoes were once famous in England.

Of a piece with these corrupted appellations, is that of the usual 
proclamation of "O yes, O yes !"in our courts of law, commanding silence; which is a corruptiou of the Erench word, Oyez, Listen; and has been retained ever since the pleadings were held in that language.

\section{DOOMSDAY, OR DOMESDAY BOOK.}

THIS is a very ancient record, made in the time of William $I$. and containing a survey of all the lauds of England. It consists of two volumes. The first is a large folio, written in thirty-eight double pages of vellum, in a small, but plain character; each page having a double column. Some of the capital letters and principal passages are touched with red ink; and some have strokes of red ink run across them, as if scratched out. This volume contains the description of thirty-one counties. The other is in quarto, written upon four hundred and fifty double pages of vellum, but in a single column, and in a large but very fair charactur. It contains the counties of Essex, Norfolk, Suffolk, part of the county of Rutland, included in that of Northampton, and part of Lancashire in the county of York, and Chester.

This work, according to the red book in the exchequer, was begun by order of William the Conqueror, with the advice of his parliament, in the year of our Lord 1080, and completed in 1086. The reason given for taking this survey, as assigned by several ancien records and historians, was, that every man should be satisfied with his own right, and not usurp with impunity what belonged to another. But besides this, it is said by others, that now all those who possessed landed estates became vassals to the king, and paid him so much inoney by way of homage, in proportion to the lands they held. This appears very probable, as there was at that time extant, a general survey of the whole kingdom, made by order of king Alfred.

For the execution of the survey recorded in Domesday book, commissioners were sent to every county and shiré, and juries sum- $_{\text {in }}$ moned in each hundred, out of all orders of freenen, from barons down to the lowest farmers. The commissioners were to be informed by the inhabitants, upon oath, of the name of each manor and that of its owner; also by whom it was held in the time of Edward the Confessor; the number of hides, the quantity of wood, of pasture, and of meadow land; how many ploughs were in the demesne, and how many in the tenanted part of it; how many mills, how many fishponds or fisheries, belonged to it; with the value of the whole together in the time of king Edward, as well as when granted by king William, and at the time of this survey; also, whether it was capable of inprovement, or of being advanced in its value. They were likewise directed to return the tenants of every degree, the quantity of lands then and formerly held by each of them, what was the number of villains or slaves, and also the number and kinds of their cattie and live stock. These inquisitions being first methodized in the country, were afterwards sent up to the king's exchequer.

This survey, at the time it was made, gave great offence to the people; and occasioned a jealousy that it was intended for some new imposition. But notwithstanding all the precaution taken by the 
Conqueror, to have this survey faithfully and impartially executed, it appears, from indisputable authority, that a false return was given in by some of the commissioners; and that, as it is said, out of a pious motive. This was particularly the case with the abbey of Croyland in Lincolnshire, the possessions of which were greatly under-rated, both with regard to quantity and value. Perhaps more of those pious frauds were discovered, as it is said Ralph Flambard, minister to William Rufus; proposed the making a fresh and more rigorous inquisition; but this was never executed. Notwithstanding this proof of its falsehood in sume instances, which must throw a suspicion on all others, the authority of Domesday book was never permitted to be called in question; and always, when it has been necessary to distinguish whether lands were held in ancient demesne or in any other manner, recourse was had to that only, to deternine the doubt.

From this definitive authority, from which, as from the sentence pronounced at domesday, or the day of judgment, there conld be no appeal, the name of the book is said to have been derived. But Stowe assigns another reason for the appellation; namely, that Domesday book is a corruption of Domes Dei book; a title given it because heretofore deposited in the king's treasury, in a place of the church of Westminster, or Winchester, called Domus Dei. From the great care formerly taken for the preservation of this survey, we may learn the estimation in which its importance was held. The dialogue de Scaccaris says, "Liberille Domesday, Sigille regis contes est individuas in thesauro."

Until lately it has been kept under three different locks and keys; one in the custody of the treasurer, and the others in that of the two chamberlains of the exchequer. It is now deposited in the chapter-house at Westminster, where it may be consulted on paying to the proper offers a fee of $\%$ s. $8 \mathrm{~d}$. for a search, and four-pence per line for a transcript.

Besides the two volumes above mentioned, there is also a third mate by order of the same king; and which differs from others in form nore than matter. There is also a fourth called Donesday, which is kept in the exchequer, which, though a very large volume, is unly an abridgment of the others, In the remembrancer's office in the exchequer is kept a fifh book, likewise called Domesday, which is the same with the fourth book already mentioned. King. Alfred had a roll which was called Domesday; and the Domesday book made by William the Conqueror referred to the time of Edward the Confessor, as that of king Alfred did to the time of Ethelred. The fourth book of Domesday having many pictures and gilt letfers in the begining relating to the time of king Edward the Confessor, has led some to a false opinion that Domesday book was composed in the reign of king Edward.

\section{Combinations of Alphabetical Chamacters.}

THE learned author of Hermes informs is, that to about twenty plain elementary sounds, we owe that variety of articulate words which 
have been sufficient to explain the sentiments of such an innumerable multitude, as well as the past and present generations of men Mr. Slieridan says, that the number of simple sounds in our tongue are twenty-eight; while Dr. Kenrick says, that we have only eleven distinct species of articulate sounds, which, even by contraction, prolongation, and composition, are increased only to the number of sixteen; every syllable or articulate sound in our language being one of the number. Bishop Wilkins and Dr. William Holder speak of thirty-three distinct sounds.

After the analysis or decomposition of language into the elementary sounds, the next, towards the notation of it by alphabetical character, would be the delineation of a separate mark or-letter to represent each sound; which marks, though few in number, would admit of such a variety of arrangements and combinations as might be capable of producing that infinity of articulate sounds which compose language. The ingenious Wachters, in his "Natura et Scriptura Concordia," p. 64, endeavours to shew that ten marks or characters are sufficient for this purpose. If this is the case, the most simple alphabet, which consisted only of thirteen letters, must have been sufficient to answer all the purposes of mankind, and much of our alphabet may appear superfluous. From a calculation made by Mi. Prestet, it appears that, allowing only twenty-four letters to an alphabet, the different words that may be made out of those letters, take them first one by one, and then two by two, three by three, \&c. would amount to the following number $1,391,724,288,88 \%, 252$, $999,425,128,493,402.200$ ! And that able mathematician, Taequet, has calculated the various possible combinations of twenty-four letters, even without any repetition, to amount to no fewer than $620,448,401,733,2: 39,439,360,000$; while Cluvius makes them only $5,852,616,738,497,664,000$. The smallest of these numbers, however, is infinite to the human conceptions, and much more than sufficient to express all the sounds that ever were articulated by man.

Of all known languages, the Greek is looked upon as one of the most copious, the radices only of which are esteemed about 3244, but then it abounds so exceedingly in compounds and derivatives, that Wilkins thinks they may be moderately computed at 10,000 . Hermannus Hugo asserts, that no language has so few as 100,000 words; and Varro is frequently quoted by learned men, as having affirmed that there are in the Latin no fewer than 5,000,000, reckoning all the variations of nouns and verbs by composition, conjugation, de. clension, and inflection.

\section{Dieu et MON Droit.}

THESE words are French, and signify in English, "God and my Right." They form the motto of the arms first assumed by Richard I. to intimate that he did not hold his empire in vassalage of any mortal. It was afterwards taken up by Edward III. and was continued without interruption to the time of king William. III, who used the motto "Je mainten dray," though the former was still retained on the great 
seal. After him, gueen Anne used the motto "Semper eadem," which had been before used by qucen Elizabeth; but ever since queen Anne, “Dieu et mon Droit?has been the royal motto; which is the more surprising, as the illustrious house of Hanover never claimed or pretended to hold the crown as Richard I: and the house of Stewart did, jure divino.

Antidotes against Book Worms.

THE nixture of the juice of worinwood and other bitter ingredients in the paste, which is an expedient used by bookbinders, is no security to books against book-worms. The best security is from mineral salts, which all insects hate. For this purpose, bookbinders ought to mix with the paste employed in binding, the salt called arcantum duplicatum, alum, and vitriol. With this precaution, books may be preserved from all injury by this mischievous little creature. Mr. Prediger, in his instructions to German bookbinders, Leipsic, 1741, reconmends making paste of starch instead of flour, and advises to powder slightly the books, their covers, and the shelves on which they stand, with a mixture of powder of alum and fine pepper, and in the months of March, July, and September, to rub the books with a piece of woollen cloth, steeped in powdered alum.

\section{Gog and MagOG.}

THese two names are generally joined together in scripture. Ezek. xxxviii. 2, 3, \&c. xxxix. 1, 2, \&c. Rev. xx. 8. Moses speaks of Magog the son of Japhet, but says nothing of Gog, Gen. x. 2. 1 Chron. i. 5. Gog was prince of Magog according to Ezekiel, Magog being the naine of the country or people. The generality of the ancients made Magog the father of the Scythians and the Tartars; and several interpreters discovered many footsteps of their name in the provinces of Great Tartary. Others supposed that the Persians were the descendants of Magog. Some have imagined that the Goths were descended from Gog and Magog, and that the wars describerl by Ezekiel, and undertaken by Gog against the saints, are those which the Goths carried on against the Roman empire, in the fifth century. "Bochart has placed Gog in the country of Caucasus: he derives the name of this celebrated mountain from the Hebrew Gogchasan, "the fortress of Gog." He maintains that Prometheus, said to be chained to Caucasus by Jupiter, is Gog, and no other. There is a province in Iberia, called the Gogarene. Most commelltators think that Gog and Magog, mentioned in Ezekiel and the Revelation, are to be taken in an allegorical seuse, for such princes as were enemies to the church and saints. Thus, many by Gog, in Ezekiel, understand Antiochus Epiphanes, and the persecutors of those Jews who were found true to their religion; and by those persons of the same name, in the Revelation, they suppose Antichrist to be meant, the great enemy of the church and faithful. Some have endeavoured to prove that Gog, spoken of in Ezekiel, means Cambyses king of Persia. Others, with more plausibility, think that Gog and 
Magog, in the Revelations, fenote all the enemies of the church, who whould be persecutors of it, to the consummation of ases.

Of the antique figures of Grog and Magog in the Guilthall, Lonnon, no account that con be deemed anthentic has been preserved. Tradition has handed to us many legendary tales, not one of which is entitled to any credit.

\section{ZEND, OR RENDAVESTA.}

THIS is a book ascribed to Zoroaster, and contains his pretended revelations; which the ancient Magicinns, or nudern Persces, called also Gaurs, observe and reverence in the same manner as the Christians do the Bible, and the Nahometans the Koran, making it the sole rule both of their faith and manners. The word, it says, originally signifies an instrument for kindling fire, and is applied to this book, to denote its aptitude for kindling the flame of religion in the hearts of those who read it. The Zend contains a reformed system of Marianism; teaching that there is a sup:ene Being, external, self-existent, and independent, who created both light and darkness, out of which he made all other things; that these are in a state of conflict, which will continue till the cod of the world ; and then there shail be a general resurrection and indencint; and that just respibution shali be rendered $1 n$ to men accoming to their works; that the angel of darkness, with his followers, sha!l be consigned to a place of everlasting darkiess and punishment, and the andel of light with his disciples, introduced into a state of everisting light and hapuiners; after which, light and dartuess shall iso more interfere with each other.

The Zend also enjoins the constan maintenance of sacred fires, and fre-temples for religions worship; the distinction of clean and unclean beasts; the paynent of tithes to priests who are to be of one family or tribe; a mulitude ol wathings and puritications, resembling those of the Jewish law, and a variety of rules and exhortations for the exercise of benevolence and charity. In this book there are many passages evidently taken ont of the Scriptures of the Old Tes. tament, particularty out of the Psalms of Davis. The author represents Adam and Eve as the first parenis of all maukind, gives in substance the same account of the creation and deluge with Moses, differing indeed with ronard to the former, by converting the six davs of the Mostic account into six times, comprehending in the whole three bundred and sivty-five days; and speaks also of Abraham, Joseph, Moses, and Solomon.

Moreover, Mr. Baumgarten asserts, that this work contains doctrines, opinions, and facts, actually borrowed from the Jews, Christians, and Mahometans; whence, and from other circninstances, he concludes that both the history and wrings of this prophet were probably invented in the later ages, when the fire-worshippers under the Mahometan government thought fit to vindicate their religion from the suspicion of idolatry. At whatever period the Zend may have been written, we are assured by $\mathrm{Dr}$. Hyde, that it is in the pure oid Persian language, and in the character called Peplavi. Some parts 
of it contain the original text, and others Zoroaster's second thoughts subjoined, for explaining more fully his doctriue. These were occastoncd by the opposition of adversaries, and unforeseen circumstonces which occurred during the fubrication of the imposture.

About three huadred years ago, when the old Persian laiguage had become antiquated and little understowd, one of the destours, or ligh priests anong the Persees, composed the Sadda, which is a compendium, in the vulgar or modern Persic tongue, of those parts of the Zend that relate to religion, or a lind of code of canous and precepts drawn from the theological writings of Zoroaster, seiving as an authoritative rule of faith and practice for his followers. This Sadda is written in a low kind of Persic verse, and, as Dr. Hyde informs is, it is honorum ef malorm farrago, having many good and pious things, and others very superstitious and trifing.

\section{Coniet.}

A heavenly body, in the planctary region, appearing suddenly, and again disappeariog; and, during the time of its appearance, moving through its proper orbit like a planet. The orbits of comets are ellipses, having one of their foci in the centre of the sun; and being very long and eccentric, they becone invisible when in that part most remote from the sun. Comets, popularly called blazing stars, are distinguished from otherstars by a long train or tail of lighe, always opposite to the sun; hence arises a popular division of conets into three kinds, bearded, tailed, and haired comets; though the division rather relates to the different circumstances of the same comet, than tw the phenomena of several. Thus when the comet is eastward of the sun, and moves from it, the comet is said to be bearded, barbahos, because the light marches before it. When the light is westward of the smin, the comet is said to be taled, because the train follows. When the comet and the sun are diametrically opposite, the earth being between them, the train is hid behind the body of the comet, excepting a litle that npears around it, in form of a border of hair, hence called crinitus.

According to Sir Isac Newton, the tail of a comet is a very thin vapour, emited by the lread or nucleus of the comet ignited by its neighbourhood to the sun, and this vapour is furnished by the atmosphere of the comet. The vapours of comets being thus dilated, rarefied, and diffused, may probably, by means of their own gravity, be attracted down to the planets, and become intermingled with their atmospheres. For the conservation of the water and moisture of the planets, comets seem absolutely requisite, from whose condensed vapours and exhalations all that moisture which is spent in vegetation and putrefaction, and turned into dry earth, may be resupplied and recruited; for all vegetables increase wholly from fuids, and turn by putrefaction into earth. Hence the quantity of dry earth must continully increase, and the moisture of the glohe decrease, and at last be quite evaporated, if it have not a continual supply. And I suspect, adds Sir Isaac, that the spirit which makes he finest, shlit lest, and best part of our air, and which is absolutcly requisice for the life and being of all things, comes principally from the conets. 
The same great author has computed that the sun's heat, in the comet of 1680 , was to his heat with us at midsummer, as 28,000 to one; and that the heat of the body of the comet was near 2000 times as great as that of red-hot iron. He also calculates, that a globe of red-hot iron, of the dimensions of our earth, would scarcely be cool in 50,000 years. If then the comet be supposed to cool 100 times as fast as red-hot iron, yet since its heat was one thousand times gieater, supposing it of the bigness of the eart!, it would nut be cool in a million of years.

\section{Changes of the Weather.}

THE following curious observations are principally extracted from Forster's Researches about atmospheric phenomena.

1. Rain may be expected when the swallow flies low, and skims backward and forward over the surface of the earth and waters, frequently dipping the tips of her wings into the latter.

2. When bees do not range abroad as usual, but keep in or ne 1 r their hives, or when ducks, geese, and other water-fowl are usual y clamorous, we may also expect wet.

3. Before rain, swine, as well as poultry, appear very uneasy, and rub in the dust.

4. Before and during rain, ducks, geese, and other fowls, wash and dive in the waters more than usual. Pigeons also wash before rain; and cats wash their faces; they have been observed also before rain to scratch the bark of the trees. In autumn flies sting and become unusually troublesome, on the approach of rain.

5. Dogs, and other domestic' animals, likewise express "signs of uneasiness, and are very sleepy and dull before rain and stow. Dogs are said to dig great holes in the ground in rainy weather.

6. If we happen to be abroad when, after long continued dry weather, the sky is thickening, and rain approaching, we may frequently observe the cattle stretching out their neck, and snuffing in the air with dis. tended nostrils; and often, before storms, assembled in a corner of the field, with their heads to the leeward.

7. The loud and continued croaking of frogs heard from the pool, the squalling of the pintado and the peacock, the appearance of spiders crawling on the walls more than ordinary, and the coming forth of worms, have also been considered as signs of rain. When cocks crow at uncommon hours, and clap their wings a great deal, it is said to be a sign of rain, as is the appearance of the redbreast near houses.

8. Sparrows chirp particulariy loud during rain, and often begin before it falls, affording thereby for some time a prognostic of its coining.

9. If toads come from their holes in great numbers; if moles throw up the ear h more than usual; if bats squeak or enter the houses; if asses shake their ears, and bray much; if hogs shake and destroy the corn stalks; if oxen lick their forefeet, or lie on their right side; or if mice contend together or squeak much, -according to manv authors, we may expect rain. Sheep or other cattle gamboling or running about, and appearing very uneasy, also portend the same. 
10 Sometimes, previnns to rain, sheep and goats seem more desirons to graze, and quit their pastures with reluctance.

11. Anong other things, the activity of ants in carrying about their eggs, the voice of the solitary crow, and frequent immersion of many water-fowl, have been considered as indications of rain.

12. The garrulity of crows, ravens, rooks, and other birds of this sort, is indeed well known; "Corvus aquat," is a proverb cited by Erasmus: But we must distinguish between the voice of the raven before rain, perched solitarily on a tree, and uttering a harsh cry, from his deep and peculiarly modulated voice, when sailing round and round high in the air, before and during serene weather. The raven, as well as nther birds, often soars at an elevation much beyond what we are apt to imagine. When at the top of Cader Idris, near Dolgelly, I observed these birds fying considerably above the summit of that mountain on which I sat

13. The hooting and screeching of owls often indicates a change of weather. They hoot in fact during variable weather ; when fair is about to be changed for wet, or wet for fair, a similar disturbance of their feelings, from atmospherical causes, probably takes place, which makes them hont.

14. The misletoe thrush, turdus viscivorus, frequently sings particularly loud and long before rain.

15. Mariners at sea expect a storm when the stormy petrels, procelaria pelagice, shelter themselves in numbers under the wake of the vessel.

16. Pennant observes, that on the island of St. Kilda, the fulmar, procellaria glacialis, is very useful in foreboding the direction of the wind. When these birds return to the land in numbers, there will be no west wind for a long time; when, on the contrary, they return to the ocean, a zephyr is experted.

17. Magpies before and during wind fly abcut in companies, and make a fluttering noise.

18. When the sea-gulls come in numbers to shore, and make a noise about the coast; or when, at sea, they alight on ships; the sailors consider it a sure foreboding of a storm. Before storms, too, the porpoise, dolphin, and grampus, come to the shore in large bodies.

19. When dolphins play about the surface of a calm sea, Pliny observes, wind may be expected from that quarter whence they have come.

20. Chickweed has been said to be an excellent weather guide: when the flower expands freely, no rain will fall for many hours; if is so continues open, 10 rain for a long time need be feared. In showery days the flower appears half concealed, and this state may be regarded as indicative of showery weather; when it is entirely shut we may expect a rainy day.

21. If the flowers of the Siberian sowthistle remain open all night, we may expect rain the next day.

22. Before a shower, the trefoil contracts its leaves, as does the convolvulus and many other plants. Lord Bacon observes, that the trefoil has its stalk inore erect against rain. 
23. The same nobleman mentions a small red fower growing in stuboble fells, called by the country people Wincopipe, probably the aragallis arvensis, which if it opens in the morning ensures us a fine day.

The Ruins of Balbec, from a Recent Inspection.

"ON the summit of the mountains we stopped to take a farewel view of the celebrated plain at our feet, and then advanced over : barren tract, till we came to a spot watered by one or two rivers, anc shaded with trees. These luxurious retreats are often resorted to by the inhabitants of the city. The road afterwards wound through wild and rocky defiles in the mountains, and by the steep side of a rapid forrent that flowed over its course beneath, till, towards evening, we came into a plain, and passed the night in the cottage of a peasant. The next day was uncommonly fine, and we pursued our way in good spirits. The aspect of the country was more agreeable than on the preceding day, and the cottages were more numerously scattered.

"Soon after sunset we came to Zibolane, a large village finely situated, and surrounded with groves; and a river rau through the middle of it. The habitation of one of the villagers was again our home: they spread their best mat on the floor, in the midst of which the fire buried bright and cheerfully, and preparch a good supper of fowls and eggs, foliowed by coffee and the chibouque ; and we fond the luxuvies of Damascus had not spoiled our relish of this simple and friendly reception.

"Demetrie, the servant of Mr. G. was a bigoted Greek, and true to his country, though not a little of a rogue. and a great gourmand. Every evening he said his prayers to the Virgin, accompanied with crossings, which, after the Greek fashion, were drawn from his chin to his middle; and the constant subject of his prayers was, that the Virgin would give him plenty to eat and drink, and send him home safe to his family.

"On the third day we came to the ruins of Babec, which, being approached from Damascus, are not sen th you are almost cluse on them. The village adjoining is very mean, and contains a few hundred inhabitants; it has a mosque and minaret. This place was situeted just between the limis of the rival pachas, and was under the juristiction of neither. We made our way to the wretched residence of a Greek priest, who looked the picture of squalidness and poverty, and resides in this lonely spot to minister to two or three score of Christians. He drew a key out of his pocket, and unlocked with great care a waste and dark aparment a few yards from bis own.

"We soon sallied ont to visit the temple, but were encountered about half way by the governor or stieik of the village, who, with much clamour, refised to allow us to proceed till he understoon who we were. We accordingly walked back, and in a short tine he made his appeamee at the priest's accompanied by an armed soldier, and a number of the vilhogers gathered round. The sheik temanded money for pemission to see the ruins; and after mul alereation, and 
vident threats on his side, the sum was reduced to twenty-seven piastres; on receiving whil he went away, and troubled us no more.

"The sun had set on the vast temple, and the mountains around it, with indescribable grandeur: the clain of Anti-Libanus in front was covered with snow; and the phin, wild and beautiful, stretched at its feet farther than the eye could reach. The pigeons, of manycoloured plumage, fiew in clusters around the runed walls, at whose feet were a variety of trees and flowers, amilst which a clear and rapid stream. The outer wall that encloses the great area of the building to the nowh, is immensely high, and about six hundred feet long; the western wall is lower, being more broken; and mirl-way of its height are the three enormous stones, abont sixty fect long and twelve wide. The temple itself is near one hundred and eighty feet. in length, and half that in width, and is surrounded by a single row of pillars, forty-four in number, nearly sixty feet high, and twenty-six leet in circumference : they are, as well as the temple, of a fine granite of a light red colour; their capitals are of the Corinthian order, of exquisite workmanship, and are very little defaced: indeed, the entireness and preservation of the decorations of this superb temple are surprising. The architrave and comice are beatifully carred; three or four of these columus, separated from the roof, recline against the wall of the temple; and, on the snuth side, one noble pillar has sunk from its position into the clear and beatiful pool formed by the fountain beveath the temple, aganst the body of which half its length and rich capital still support themselwes.

"The magnificence of this covidor can scarcely be imagined. Its western aspect is towards the plain; and at your feet lie masses of broken pillars, capitals, and friezes, over which you must rass to approach the temple. From the north you look down on the vast area within the walls, the sides of which are lined with rumed chambers, elegantly carved and adomed, and numerous wiches for stritues; now, however, empty. The south hangs over the fountain and sheet of water below, in whose bosom it is clearly refected. The interio of the building is above a hundred and twenty feet long, but is narrow in proportion to its length. In the sides of the walls is a double row of pilasters, and between these are numerous niches, where statues formerly stood. In many parts of the temple, around the place of entrance, and on the roof of the corridor, are sculptured in an exquisite manner figures of the heathen deities, of the cagle with outspread wings, \&c. The roof of the interior is entirely gone.

"The hands of the natives have, no dount, committed many ravages here. Faccardine, prince of the Druses, destroyed or injured several parts of these ruins; but when he afterwards visited Italy, and contracted a taste for its architecture, he bitterly lamented the sacrilege he had committed at Balbec. The Turks have, without doubt, used it as a fortification, as they have made additions to some parts of the walls, and left many vestiges of their barbarian architecture blended with the colossal remains of the temple.

"About a hundred feet from this edifice is a row of Corinthian pillars, much loftier and more slender than those of the great corridor; 
they stand alone on an elevated site, and their rich capitals and architrave are still entire. Six only now remain, and their appearance is peculiarly elegant. On them the setting sun lingers the last of all the ruin; and their slender and dark red shafts, bebeld at some distance in the purple light, as they stand high and aloof, have a solemn and shadowy appearance, - as if they stood on the tomb of former greatness.

"On the south-east side, nearer to the village, is a small circular building of marble, richly ornamented with sculpture, and supported by pillars. It is in a rather ruinous condition, but appears quite unconnected with the mass of buildings adjoining. Its roof, in the form of a dome, though shattered, is still standing.

"About a mile down the plain is the quarry, from which the enormous stones used in the construction of Balbec were hewn. One still remains, the chief part smoothed and prepared with great labour for building, but adhering by one of its sides to the native rock; it is of a coarse granite, and its dimensions are much superior to either of the three great stones in the middle of the wall. The labour of removing such enormous masses, and then of elevating then to su great a height, must have been immense; how the latter could have been achieved is marvellous. A few of the smaller pillars appear to be of a solid piece of coarse marble ; but the large columns are composed of three or four pieces of the native material.

"Covered galleries, several hundred feet in length, the walls of pro. digious thickness, are hollowed beneath the temple. The interior of the temple was divided into three aisles, but most of the pillars which fornied them are destroyed; at the upper end, a few steps lead to the altar or sacred place; but the idol formerly adored here is gone from its place, which, however, is adorned with a variety of beautiful sculpture. Exposed as this roofless temple has been for so many agges to every storm, it is surprising the decorative parts of it have not suffered more; but the shafts of many of the pillars without, which face the north-east, have been rent and hollowed in some parts. Carne's Letters from the East, vol. ii. p. 99-10\%. 





of

A

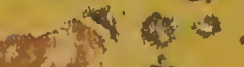

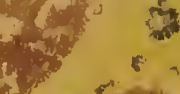

- $6 \log ^{\circ}$

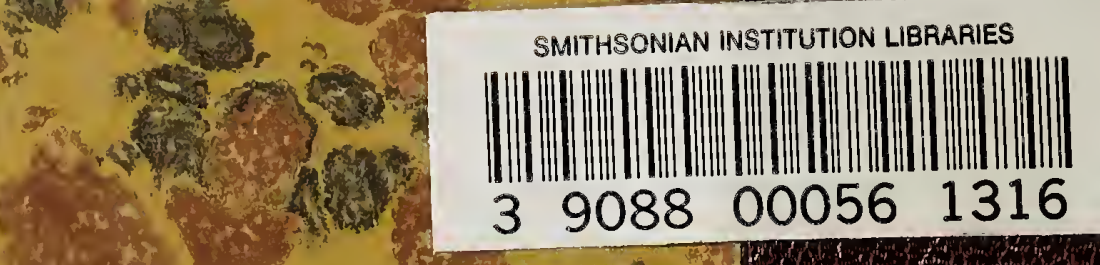

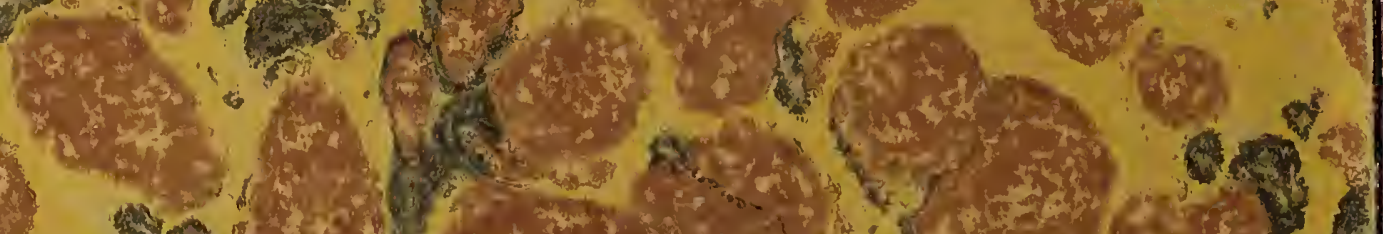

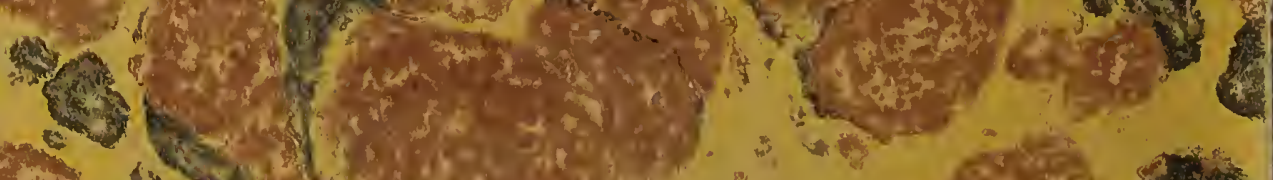
W. $-50 \%$

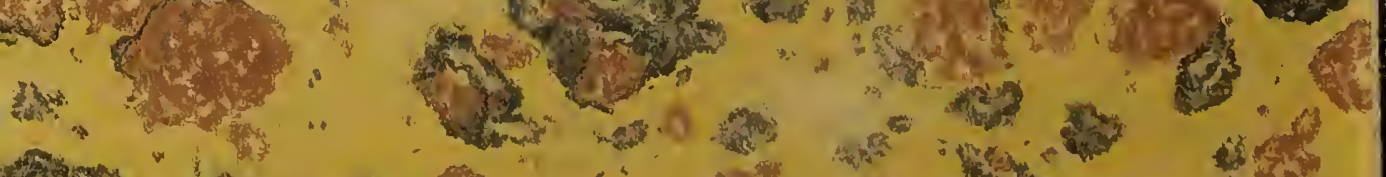
(4) 00

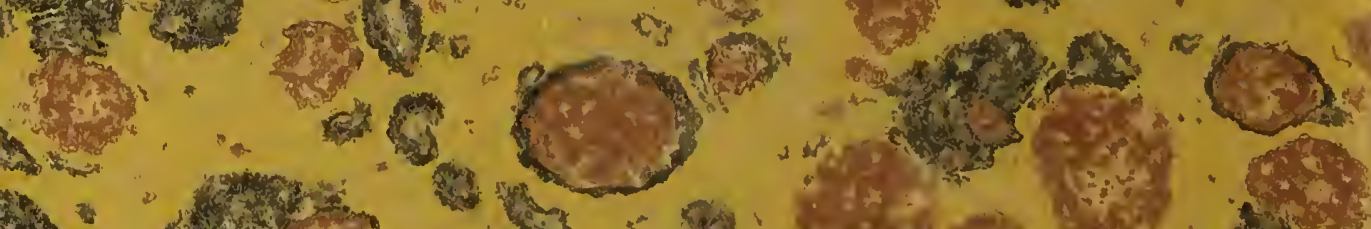

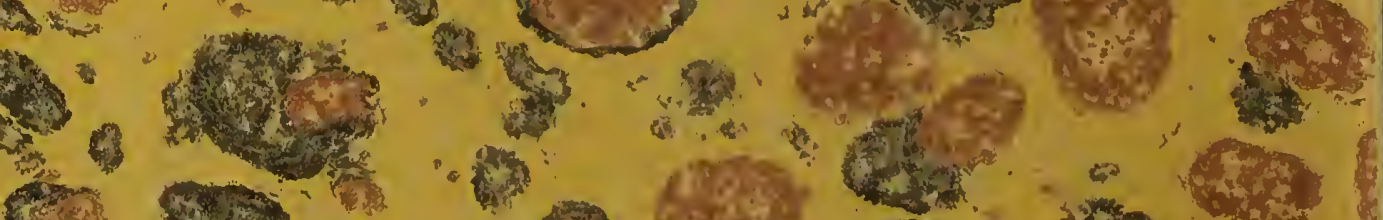

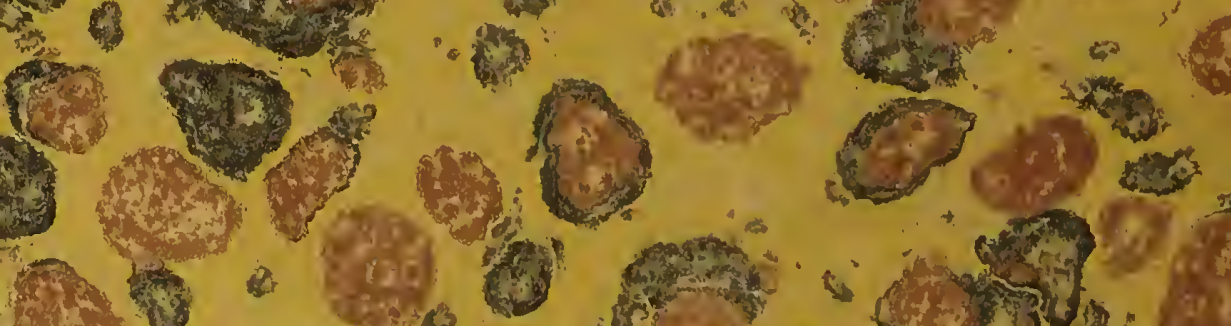

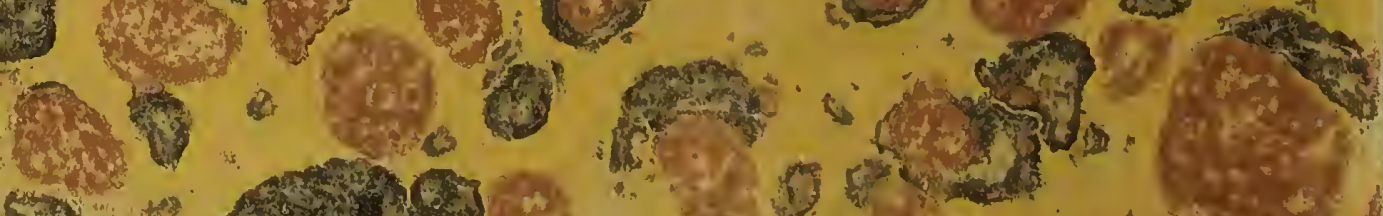
- 38 . 40.50

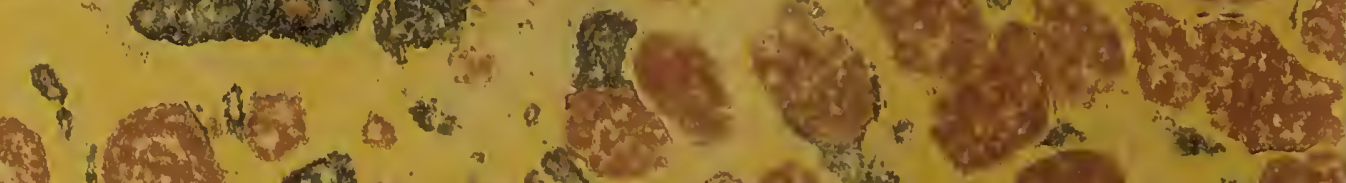
a 4 os (1) (2)

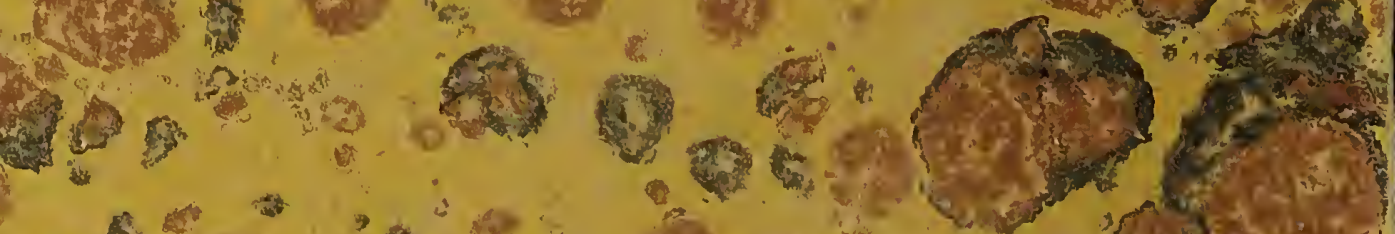

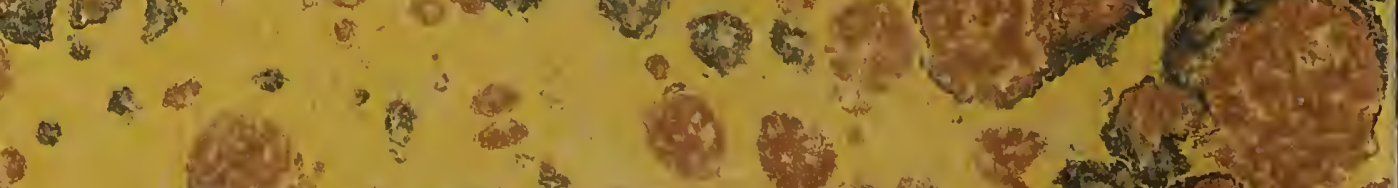

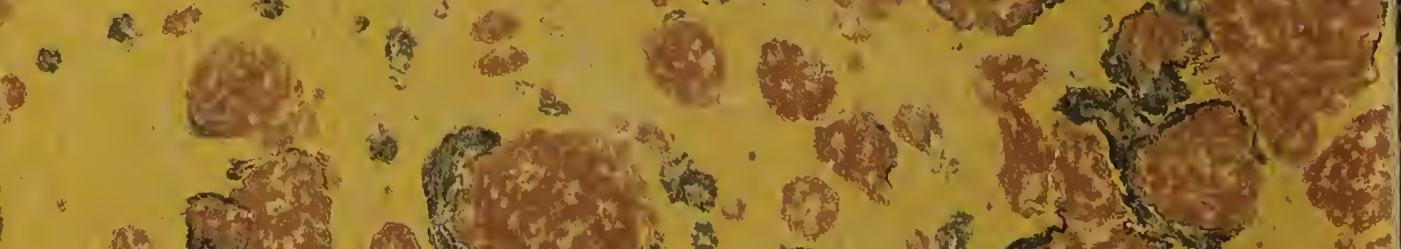
\%

or a 20

- "Es (1.5. Q 